
Traur R. Hiclie

ICac-1910

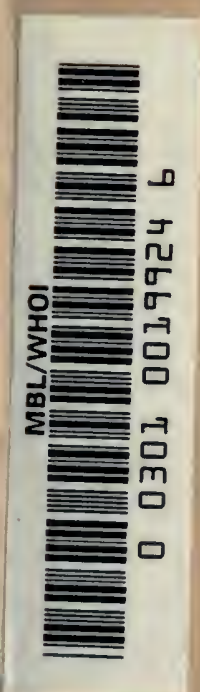





\section{THE \\ PHYSIOLOGY OF REPRODUCTION}





\title{
THE PHYSIOLOGY OF REPRODUCTION
}

\author{
BY \\ FRANCIS H. A. MARSHALL \\ M.A. (CaNtab.), D.Sc. (EdiN.) \\ FELLOW OF CHRIST'S COLLEGE, CAMBRIDGE, AND UNIVERSITY LECTCRER \\ IX AGRICULTURAL PHYSIOLOGY
}

WITH A PREFACE BY

Profkssor E. A. SCHÄFER, Sc.D., LL.D., F.R.S.

AND CONTRIBUTIONS BY

WILLIAM CRAMER, Pн.D., D.Sc.

AND

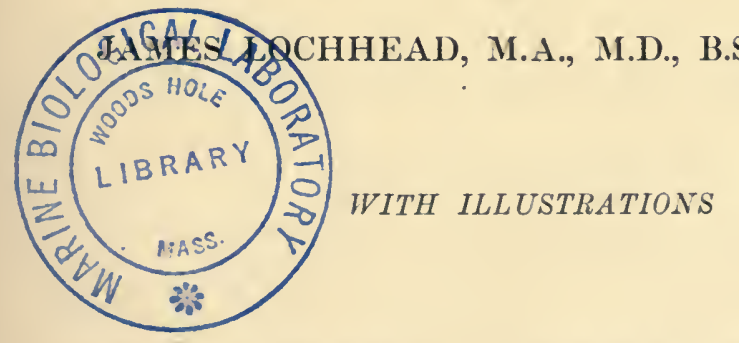

L O N M A N S, GREEN A ND CO.

39 PATERNOSTER ROW, LONDON

NEW YORK, BOMBAY, AND CALCUTYA

1910

All rights reserved 

WAI'IER HEAPE, Esq., M.A., F.R.S. 



\section{PREFACE}

THIs is the first time that the Physiology of the Organs of Reproduction has been presented in a complete form, and many who desire to obtain more precise knowledge regarding the problems with which it deals, than is to be found in text-books of Physiology, will welcome the appearance of Dr. Marshall's book. The importance of such knowledge to the community in general is now becoming recognised, and the interest which the subject awakens is no longer confined to members of the medical profession and to breeders of animals. Especially will the work furnish a much needed introduction to the science of Eugenics, whilst the multiplicity of facts which are set forth, and the manner in which questions of difficulty are discussed, will have the effect at once of satisfying and of stimulating inquiry in a most important, if hitherto somewhat neglected, branch of Physiology.

\section{E. A. SCH ÄFER.}

Uxiversity, Edxburgh, June 1910. 



\section{CONTEN'TS}

INTRODUCTION

CHAPTER I

THE BREEDING SEASON

Protozoa-Cœlenterata-Nemertea, \&c.-Annelida-Arthropoda - Mollusca - Echinodermata - Cephalochordata - PiscesAmphibia - Reptilia - Aves - Mammalia-Periodicity of Breeding, \&c.

CHAPTER II

THE GESTROUS CYCLE IN THE MAMMALIA

Monotremata-Marsupialia-Rodentia-Ungulata-CetaceaCarnivora-Insectivora-Cheiroptera-Primates.

\section{CHAPTER III}

THE CHANGES THAT GCCUR IN THE NON-PREGNANT UTERUS DURING

The Cycle in Man-Monkeys-Lemurs-Insectivora-Carnivores -Ũngulates.

\section{CHAPTER IV}

CHANGES IN THE OVARY-OÖGENESIS-GROWTH OF FOLLICLESOVULATION-FORMATION OF CORP'RA LUTEA AND ATRETIC FOLEICLES-THE SIGNIFICANCE OF THE PROCESTROUS CHANGES IN THE UTERUS

Dev lopment of Ovary and Oògenesis-Maturation and Ovulation - The Formation of the Corpus Luteum-The Atretic Follicle - Superfœtation-Formation of Ova-The Significance of the Proœstrous Changes.

\section{CHAPTER V}

SPERMATOGENESIS-INSEMINATIO

Structure of Spermatozoa-Seminal Fluid-Movements of Sper. matozoa-Insemination. 
FERTILISATION

The Hereditary Effects of Fertilisation-Telegony-On Gametic Selection and the Conditions Favourable for the Occurrence of Fertilisation-Conjugation in the Protozoa-The Supposed Chemotactic Properties of Spermatozoa and their Relation to the Phenomena of Fertilisation-Artificial Aids to Fertilisation-Artificial Parthenogenesis.

\section{CHAPTER VII}

THE ACCESSORY REPRODUCTIVE ORGANS OF THE MALE AND THE MECHANISMS CONCERNED IN INSEMINATION . . . .

The Vesiculæ Seminales-The Prostate Gland-Cowper's Glands -The Copulatory Organ-The Mechanisms of Erection, Ejaculation, and Retraction.

\section{CHAPTER VIII}

THE BIOCHEMISTRY OF THE SEXUAL ORGANS . . . . .

The Female Generative Organs: Mammals, Birds, Invertebrates -The Male Generative Organs : The Semen-The Chemistry of the Spermatozoön.

\section{CHAPTER IX}

THE TESTICLE AND THE OVARY AS ORGANS OF INTERNAL SECRETION .

The Correlation between the Testis and the other Male Organs and

Characters-The Correlation between the Ovary and the other Female Organs and Characters-The Factors which determine the Occurrence of Heat and Menstruation-The Function of the Corpus Luteum-The Supposed Internal Secretion of the Uterus-The Correlation between the Generative Organs and the Ductless Glands-General Conclusions regarding the Internal Secretions of the Ovary and the Testis-The Effects of Castration upon the General Metabolism.

\section{CHAPTER $\mathrm{X}$}

Foetal Nutrition : the placenta .

Part I. The Placenta as an Organ of Nutrition-i. Historical Survey-ii. Structure and Functions of the Epithelial Investment of the Villi-iii. The Decidua.

Part II. The First Stages of Pregnancy : Placental Classification -i. The Ovarian Ovum.-ii. The Fertilised Ovum and its Coverings.-iii. The Uterine Mucosa.-iv. Placental Classification.

Part III. The Foetal Membranes, the Yolk-sac, and the Placenta --i. General Anatomy of the Fnetal Membranes.-ii. The Nutritive Importance of the Yolk-sac (Marsupialia, Ungulata, Carnivora, Proboscidea and Hyrax, Rodentia, Insectivora, 
Primates).-iii. The Placenta in Indeciduata (Ungulata, Lemuroidea, Cetacea, Edentata, and Sirenia).-iv. The Placenta in Deciduata (Carnivora, Proboscidea, Hyrax, Rodentia, Insectivora, Cheiroptera, Primates).-v. General Considerations of Fœtal Nutrition and the Placenta: $A$. The Plan of Placental Formation. B. The Nature of the Tropho. blastic Activity.

\section{CHAPTER XI}

THE CHANGES IN THE MATERNAL ORGANISM DURING PREgNANCY .

I. The Stimulus for the Maternal Changes during Pregnancy.II. Change in the Metabolism of the Mother during Pregnancy : $A$. The Source of the Materials transferred to the New Organism. B. The Body-Weight during Pregnancy. $C$. The Protein Metabolism in Pregnancy. D. The Carbohydrate Metabolism in Pregnancy. $\boldsymbol{H}^{\prime}$. The Metabolism of Fats in Pregnancy. $F$. The Metabolism of Metals and Salts in Pregnancy. $G$. Respiratory Exchange during Pregnancy.III. The Changes in the Maternal Tissues during Pregnancy.

\section{CHAPTER XII}

THE INNERVATION OF THE FEMALE GENERATIVE ORGANS-UTERINE CONTRACTION-PARTURITION-THE PUERPERAL STATE

The Innervation of the External Generative Organs-The Innervation of the Ovaries-The Innervation of the Uterus and Vagina and the Mechanism of Uterine Contraction-The Normal Course of Parturition in the Human FemaleParturition in other Mammalia-The Nervous Mechanism of Parturition-Changes in the Maternal Organism-The Cause of Birth-Prolonged Gestation-The Puerperium.

\section{CHAPTER XIII}

LACTATION

Structure of the Mammary Glands-The Composition and Properties of Milk-The Influence of Diet and other Factors on the Composition and Yield of Milk-The Duration of Lactation-The Discharge of Milk-The Formation of the Organic Constituents of Milk-The Normal Growth of the Mammary Glands-The Factors which are concerned in the Process of Mammary Growth-The Factors which are concerned in the Commencement of Mammary Secretion-Criticisms.

\section{CHAPTER XIV}

Effect of Age-Effects of Environment and Nutrition-Effect of Prolonged Lactation-Effect of Drugs-Effects of In-Breeding and Cross-Breeding-Inheritance of Fertility-Certain Causes of Sterility-Artificial Insemination as a Means of overcoming Sterility-Abortion-The Increase of Fertility, a Problem of Practical Breeding-The Birth-Rate in Man. 


\section{CHAPTER XV}

THE FACTORS WHICH DETERMINE SEX

i. Theories which assume that Sex-determination takes place subsequently to Fertilisation.-ii. Theories which assume that Sex-determination takes place at the time of Fertilisation or previously to Fertilisation.-iii. Theories which limit Sexdetermination to no particular period of development, or which assert that Sex may be established at different periodsHermaphroditism and Sexual Latency-General Conclusions.

\section{CHAPTER XVI}

PHASES IN THE LUE OF THE INDIVIDUAL-THE DURATION OF LIFE AND THE CAUSE OF DEATH . . . . . . .

Growth of the Body before Birth-Growth of the Body after Birth-Puberty - The Menopause-Senescence-The Duration of Life and the Cause of Death. 


\section{ILLUS'TRA'TIONS}

FIG.

1. Diagram illustrating the "Wellenbewegung" hypothesis

2. Transverse section through Fallopian tube showing folded epithelium and muscular coat . . . . . . 76

3. Se stion of a cornu of a rabbit's uterus . . . . . $\quad$. 77

4. Cross-section through cervical canal of human uterus . $\quad 78$

5. Section through wall of vagina of monkey (upper part) . $\quad 79$

6. Section through wall of vagina of monkey (lower part) . 81

7. Se tion through mucosa of human uterus showing pre-menstrual

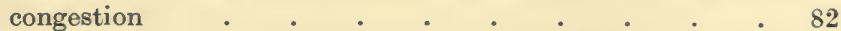

8. Section through mucosa of human uterus showing extravasation of blood . . . . . . . . . . . 84

9. Section through mucosa of human uterus showing sub-epithelial hæmatomata . . . . . . . . . 86

10. Section through mucosa of human uterus showing bleeding into the cavity during menstruation . . . . . 87

11. Section through mucosa of human uterus during the recupera-

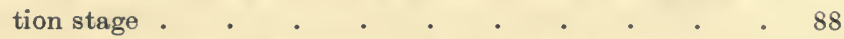

12, 13. Sections through procstrous uterine mucosa of dog . 100-101

14. Section through edge of mucosa of dog during an early stage

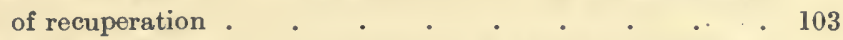

15. Section through portion of mucosa of dog during recuperation period . . . . . . . . .

16. Section through portion of mucosa of dog during lat ${ }^{3}$ stage of recuperation . . . . . . . .

17. Section through portion of proœstrous uterine mucosa of rabbit showing glandular activity . . . . .

18. Section through portion of uterine mucosa of sheep, showing black pigment formed from extravasated blood a $\quad .109$

19. Section through ovary of cat . . . . . . . 114

20. Section through ovary of adult dog . . . . . . 115

21. Section through ovary of pig embryo . . . . . 116

22. Cortex of pig embryo showing germinal epithelium, \&c. . $\quad 117$

23. Various stages in the development of the Graafian follicle (rabbit) • $\cdot$. 
24 to 27. Developing ova from ovary . . . . . 120-121

28. Ovary at birth, showing primordial follicles . . . . 123

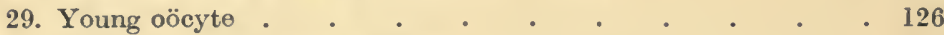

30. Young human Graafian follicle . . . . . 127

31. Human ovum at termination of growth period . . . 128

32. Human ovum examined fresh in the liquor folliculi . . $\quad 129$

33. Recently ruptured follicle of mouse . . . . . . 144

34. Early stage in formation of corpus luteum of mouse _ . 145

35. Late stage in formation of corpus luteum of mouse . . $\quad 146$

36. Corpus luteum of mouse fully formed . . . $\quad 147$

37. Section through old corpus luteum . • . . . . 153

38. Section through follicle in early stage of degeneration . . 155

39. Section through follicle in late stage $\quad . \quad . \quad . \quad 157$

40. Section through human testis and epididymis . . . . 166

41. Section through testis of monkey . . . . . . 167

42. Section through portion of two seminiferous tubules in testis

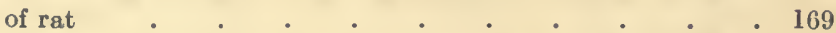

43. A cell of Sertoli with which the spermatids are beginning to be connected (human) . . . . . . . . 170

44. Diagram illustrating the cycle of phases in spermatogenesis . $i b$.

45. Scheme of spermatogenesis and oögenesis . . . . . . 171

46. Human spermatozoa on the flat and in profile . . . . 173

47. Human Spermatozoa . . . . . . . 174

48. Different forms of spermatozoa from different species of animals . . . . . . . . . . . 175

49. Diagram illustrating wave-like movement of swimming sperma-

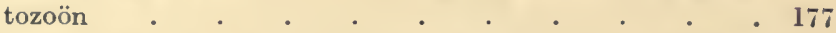

50. Successive stages in the fertilisation of an ovum of Echinus esculentus, showing the entrance of the spermatozoön.

51. Three stages in the conjugation of male and female nucleus

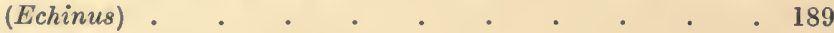

52. Fertilisation process in bat's ovum . . . . . . 190

53. Passage of convoluted seminiferous tubules into straight tubules, \&c. . . . . . . . . . . . . 228

54. Transverse section through the tube of the epididymis . $\quad 229$

55. Transverse section through commencement of vas deferens $\quad .230$

56. Section through part of human prostate . . . . . 235

57. Section through prostate gland of monkey $\quad . \quad$. . $\quad .237$

58. Transverse section through adult human penis . . . 243

59. Section through erectile tissue . . . . . . . 244

60. Part of transverse section through penis of monkey . . . 245

61. Distal end of ram's penis, showing glans and filiform appendage 247

62. Transverse section through filiform appendage of ram . $\quad 248$ 
FiG.

63. Transverse section through middle of glans penis of ram .

64. Distal end of bull's penis showing glans, \&c. . . . . 250

65. End-bulb in prostate . . . . . . . . 259

66. Diagram illustrating innervation of genital organs of male at at 261

67. Transverse section through rabbit's uterus after ovariotomy . 318

68. Transverse section through bitch's uterus $9 \frac{1}{2}$ months after

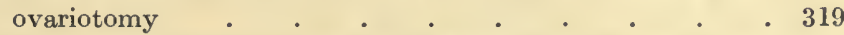

69. Section through ovary of rat after transplantation on to peritoneum . . . . . . . . .

70. Section through ovary of rat after transplantat on on to peritoneum . . . . . . . . . 322

71. Transverse section through normal uterus of rat . . . 323

72. Transverse section through uterus of rat after ovariotomy $\quad 324$

73. Transverse section through uterus after ovarian transplantation 325

74. Section through rat's kidney into the tissue of which an ovary had been transplanted . . . . . . . 327

75. Part of an early human chorionic villus . . . . . 362

76. Early blastocyst of rabbit . . . . . . . 372

77. Diagram to illustrate the three parts of the wall of the yolksac (rabbit) . . . . . . . . . . . . 381

78. Diagram of an opossum embryo and its appendages _ . $\quad 382$

79. Diagram showing the arrangement of fœetal membranes in Dasyurus . . . . . . . . .

80. Diagram showing the arrangement of fœtal membranes in Perameles. . . . . . . . . 385

81. Elongated blastocyst of sheep at thirteenth day of pregnancy 386

82. Transverse section through blastocyst of sheep at twentyfifth day . . . . . . . . . . . . . 387

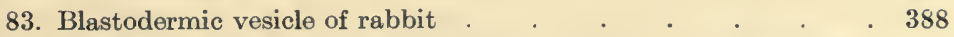

84. Diagram of blastodermic vesicle of rabbit in longitudinal section

85. Diagram to illustrate fotal membranes of Erinaceus _ . 391

86. Hypothetical section of human ovum imbedded in decidua . 393

87 Portion of injected chorion of pig . . . . . . . . 394

88. Section through wall of uterus and blastocyst of pig at twentieth day of pregnancy . . . . . .

89. Diagram representing a stage in the formation of the placenta (pig)

90. Section through uterine and embryonic parts of a cotyledon of sheep at twentieth day of pregnancy . . . . 398

91. Section through base of fotal villus, \&c. (sheep) . . . 399

92. Columnar trophoblast-cells from the base of fœtal villus at third month of pregnancy (cow) to show phagocytosis 
93. First stage of cellular secretion in placenta of cow

94. Ingestion and disintegration of red blood corpuscles by trophoblast of sheep . . . . . . . . . 408

95. Absorption of "Stäbchen" by trophoblast of shecp . . 409

96. The uterine mucosa of dog at about twenty-third day of pregnancy

97. Ovum with zonary band of villi

9९. The angioplasmode of dog at thirtieth day of pregnancy . .

99. The labyrinth and green border of placenta of dog at fortieth day of pregnancy $\quad . \quad$. . . . . . . . 417

100. Transverse section of a four days' gestation sac of rabbit $\quad 421$

101. Transverse section of a seven days' gestation sac of rabbit . 422

102. Thickened ectoderm in rabbit, attached to placental lobe . . 424

103. Iron granules in placenta of rabbit at eighteenth day of pregnancy . . . . . . . . .

104. Glycogenic areas of rabbit's placenta at twelfth day of

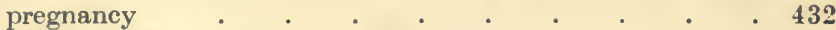

105. Inversion of germinal layers in blastodermic vesicle of mouse .

106. Longitudinal sections of implantation cavity of field-mouse about eighth day of pregnancy . . . . . .

107. Longitudinal section of uterus and implantation cavity of guinca-pig

108. Blastodermic vesicle of guinea-pig showing inversion of germinal layers

109. Implantation cavity of guinea-pig . . . . . . . 445

110. Implantation cavity of guinea-pig . . . . . . . 446

111. Allantoidean diplo-trophoblast of Erinaceus . . . . . . 448

112. Section in situ of ovum of Erinaceus _ . . . . . 450

113. The extension of yolk-sac against lacunar trophoblast in Erinaceus . . . . . . . . .

114. Transverse section through uterus of Sorex at a stage when the blastocysts are still in the oviducts . . . . 452

115. Part of the anto-mesometrial wall of the uterus of Sorex . . 453

116. Uterus and embryo of Sorex . . . . . . . 455

117. Orifice of uterine gland of mole with trophoblastic dome . $\quad 457$

118. Replacement of omphaloidean by allantoidean placenta . $\quad 459$

119. Placenta of bat . . . . . . . . . . 461

120. Median longitudinal section of an early human ovum, $0.4 \mathrm{~mm}$. in length . . . . . . . . . . . 464

121. Diagram of the earliest human ovum hitherto described . . 468 122. Section through the wall of the uterus in the early part of

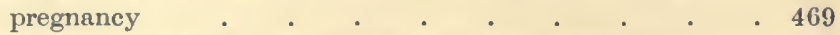

123. Section of a portion of the wall of the human blastocyst . $\quad 470$ 
FIG.

124. Section of a partion of the necrotic zone of the decidua, \&c. . 471

125. Section through embryonic region of ovum . . . 442

126. Condition of the glands at the beginning of pregnancy in Man 473

127. Median longitudinal section of embryo of $2 \mathrm{~mm}$. . . $\quad 475$

128. Diagram of stage in development of human placenta . . 476

129. Fat in a villus of human placenta . . . . . . 479

130. Iron granules in a villus of the placenta in Man . . 480

131. The first stage in the revolution of the equine fœtus . . 535

132. The foal in the normal position for delivery . . . . $\quad$. 536

133. Virginal external os (human) . . . . . . . 550

134. Parous external os (human) . . . . . . ib.

135. Section of mammary gland of woman a c • . $\quad$ • 556

136. Section of mammary gland (human) during lactation $\quad . \quad$. 557

137. Section of mammary gland (human) in full activity . . 558

13. Section through an alveolus with fat drops in cells . . . $\quad 559$

139. Section of developing mammary gland of horse $\quad . \quad$. 574

140. Section of mammary gland (human) showing doveloping alveoli . . . . . . . . . . . . 575

141 to 147. Diagrams from Minot's Problem of Age, Growth,

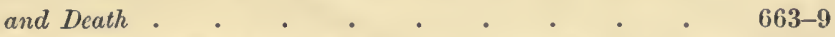

148. Section through ovary of woman of fifty-six showing degenera-

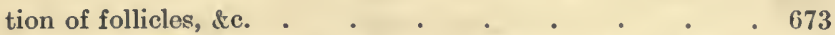

149. Section through uterine mucous membrane of woman of sixty . 674

150. Section through vaginal mucous membrane of woman of sixty-one . . . . . . . . . .

151. Group of nerve cells from the first cervical ganglion of a child at birth . . . . . . . . . . .

152. Group of nerve cells from the first cervical ganglion of a man of ninety-two $\quad . \quad$. $\quad . \quad$. . . . .

153. Land tortoise aged at least eighty-six belonging to M. Élie Metchnikoff

154. Lonk sheep aged eighteen years, with her last lamb . 


\section{ERRATA}

P. 51, footnote 1 , instead of "prjewalsky" read "prjewalskii."

P. 306, 1. 12, instead of "castration. ${ }^{2}$ " read "castration.1" (that is, see footnote ${ }^{1}$ instead of footnote ${ }^{2}$ ).

P. 306, 1. 13, instead of "about horned cattle" read "about many horned cattle."

P. 306, l. 9 from bottom, instead of "males. " read "males." (that is, see footnote ${ }^{2}$ instead of footnote ${ }^{1}$ ).

P. 316, 1. 16, before "Ruicilla" read "a specimen of."

P. 355, 1. 3 from bottom, instead of "Priestley" read " Pembrey." 


\section{THE}

\section{PHYSIOLOGY OF REPRODUC'TION}

\section{INTRODUC'TION}

Since the time when physiology first became an organised science many volumes have been written on the digestive, excretory, nervous, and other systems of the body, but no attempt has yet been made to supply those interested in the reproductive processes with a comprehensive treatise dealing with this branch of knowledge. Indeed, in most text-books on physiology now commonly in use either the section devoted to the reproductive organs is restricted to a few final pages seldom free from error, or else the subject is entirely omitted. Yet generative physiology forms the basis of gynæcological science, and must ever bear a close relation to the study of animal breeding. In writing the present volume, therefore, I have been actuated by the desire to supply what appears to me to be a real deficiency; and in doing so I have attempted, however inadequately, to co-ordinate or give a connected account of various groups of ascertained facts which hitherto have not been brought into relation. For this purpose I have had occasion to refer to many books and memoirs dealing with subjects that at first sight might have been supposed to differ considerably. Thus, works on zoology and anatomy, obstetrics and gynæcology, physiology and agriculture, anthropology and statistics, have been consulted for such observations and records as seemed to have a bearing on the problems of reproduction.

My sources of information are duly acknowledged in the footnotes, but I am glad to take this opportunity of mentioning the following works from which I have obtained special help : "The Evolution of Sex," by Professors Geddes and Thomson, "Obstetrics," by Professor Whitridge Williams, the sections on 
the male and female reproductive organs, by Professor Nagel and Dr. Sellheim, in Professor Nagel's " Handbuch der Physiologie des Menchen," "Experimental Zoology," by Professor T. H. Morgan, and the writings of Mr. Walter Heape.

The present volume is addressed primarily to the trained biologist, but it is hoped that it may be of interest also to medical men engaged in gynæcological practice, as well as to veterinarians and breeders of animals. As a general rule, I have confined myself to the physiology of generation among the higher forms, and more particularly the Mammalia, but I have not hesitated to discuss the reproductive processes in the Invertebrata in cases where they seemed likely to elucidate the more complex phenomena displayed by the higher animals. The all-important questions of heredity and variation, although intimately connected with the study of reproduction, are not here touched upon, excepting for the merest reference, since these subjects have been dealt with in various recent works, and any attempt to include them would have involved the writing of a far larger book. Similarly, the subject matter of cytology, as treated in such works as Professor Wilson's volume on the cell, is also for the most part excluded.

It may be objected that, for a book on physiology, too much space is devoted to the morphological side of the subject. This has been done purposely, since it seemed impossible to deal adequately with the physiological significance of the various sexual processes without describing the anatomical changes which these processes involve.

In preparing this work I have been assisted by many friends. I have been fortunate in securing the co-operation of Dr. William Cramer and Dr. James Lochhead, of the University of Edinburgh. Dr. Cramer has contributed the section on the biochemistry of the sexual organs, while Dr. Lochhead has written the chapters on fotal nutrition and the metabolism of pregnancy, a labour of no inconsiderable magnitude in view of the complexity of the subject. I take this opportunity of recording my indebtedness to Mr. Walter Heape, through whose influence I was first led to realise the importance of generative physiology both in its purely scientific and in its practical aspects. I am under no light obligation to Professor 
Schäfer for valuable and ready help at all stages in the preparation of this volume. Professor Schäfer has kindly looked through the manuscript of the chapter on "The Testicle and Ovary as Organs of Internal Secretion," besides giving helpful advice and criticism on various points connected with publication. Indeed, it is not too much to say that had it not been for him, the book would scarcely have been written. Dr. H. K. Anderson and Professor Sutherland Simpson have read the manuscript or proofs of the chapter dealing with "The Accessory Male Organs." Mr. E. S. Carmichael, of the Royal Infirmary, Edinburgh, has read the section dealing with parturition. Dr. J. H. Ashworth has looked through the chapter on "Fertilisation"; and Dr. F. G. Hopkins has done the same for Dr. Cramer's biochemical chapter. Dr. Anderson and Dr. Ashworth have also given me the benefit of their special knowledge in other parts of the work. To all these I am under obligations. I wish also to tender my thanks to those authors and publishers who have kindly allowed me to reproduce illustrations from their respective works, as well as to record my indebtedness to the following, who have been of service by giving me information, important references, or assistance in other ways:-Dr. Nelson Annandale, Superintendent of the Indian Museum, Calcutta, Dr. W. Blair Bell, of Liverpool, Mr. Eagle Clarke, Superintendent of the Scottish National Museum, Professor J. C. Ewart, of the University of Edinburgh, Professor J. P. Hill, of University College, London, Dr. A. C. Haddon, of Christ's College, Dr. W. A. Jolly, of the University of Edinburgh, Dr. Janet E. Lane-Claypon, of London, Mr. D. G. Lillie, of St. John's College, Mr. K. J. J. Mackenzie, of Christ's College, Mr. F. A. Potts, of Trinity Hall, Dr. C. G. Seligmann, of London, and Mr. A. E. Shipley, of Christ's College. Lastly, I wish to acknowledge the assistance of Mr. C. H. Crawshaw, of Christ's College, in the correction of the proofs, as well as to express my obligations to Mrs. Hingston Quiggin for the willing labour she has expended in preparing the index and finally revising the text, and to Mr. Richard Muir for the skilful manner in which he has executed those drawings which are new. 


\section{CHAP'TER I}

\section{THE BREEDING SEASON}

"To everything there is a season, and a time to every purpose under the heaven."-Ecclesiastes iii. 1.

"IT is well known that almost all animals, except Man, have a stated season for the propagation of their species. Thus the female cat receives the male in September, January, and May. The she-wolf and fox in January; the doe in September and October. The spring and summer are the seasons appointed for the amours of birds, and many species of fishes. The immense tribe of insects have likewise a determinate time for perpetuating their kind; this is the fine part of the year, and particularly in autumn and spring. The last-mentioned class of beings is subject to a variation that is not observed in the others. Unusual warmth or cold does not retard or forward the conjunction of birds or quadrupeds; but a late spring delays the amours of insects, and an early one forwards them. Thus it is observed that, in the same country, the insects on the mountains are later than in the plains."

The foregoing quotation from Spallanzani's "Dissertations," 1 although not strictly accurate in all its statements, contains a clear recognition of two fundamental facts which indeed have been realised from the earliest times; firstly, that the periods of reproductive activity among the great majority of animals (not to mention plants) occur rhythmically, the rhythm having a close connection with the changes of the seasons ; and secondly, that the reproductive rhythm is liable, to a greater or less extent, to be disturbed or altered by climatic or other environmental influences. And while there may be a basis of truth for the statement that the periodicity of the breeding season

- Spallanzani, Dissertations relative to the Natural History of Animuls and Vegetables. Translated from the Italian, vol. ii., London, 1784. 
in the higher animals is less liable to modification than is the case with certain of the lower forms of life, there is abundant evidence that among the former no less than among insects the sexual functions are affected by external conditions and food supply.

Darwin remarks that any sort of change in the habits of life of an animal, provided it be great enough, tends in some way to affect the powers of reproduction. "The result depends more on the constitution of the species than on the nature of the change ; for certain whole groups are affected more than others ; but exceptions always occur, for some species in the most fertile groups refuse to breed, and some in the most sterile groups breed freely." "Sufficient evidence has now been advanced to prove that animals when first confined are eminently liable to suffer in their reproductive systems. We feel at first naturally inclined to attribute the result to loss of health, or at least to loss of vigour; but this view can hardly be admitted when we reflect how healthy, long-lived, and vigorous many animals are under captivity, such as parrots and hawks when used for hunting, chetahs when used for hunting, and elephants. The reproductive organs themselves are not diseased; and the diseases, from which animals in menageries usually perish, are not those which in any way affect their fertility."' 1

It would seem probable that failure to breed among animals in a strange environment is due not, as has been suggested, to any toxic influence on the organs of generation, but to the same causes as those which restrict breeding in a state of nature to certain particular seasons, and that the sexual instinct can only be called into play in response to definite stimuli, the existence of which depends to a large extent upon appropriate seasonal and climatic changes. ${ }^{2}$

There are at present no sufficient data for a comparative account of the physiology of breeding among the lower animals; and in the present chapter, which is preliminary in character, I shall content myself with stating a few general facts about

- Darwin, Variation of Animals and Plants, Popular Edition, vol. ii., London, 1905.

${ }^{2}$ See especially page 20 , where Bles's observations on the breeding habits of Amphibia are referred to. 
the breeding season, giving illustrations, taken from various groups of Vertebrates and Invertebrates, of its seasonal recurrence, and the manner in which this varies under altered conditions of life.

\section{ProtozoA}

Among the Protozoa the organisms pass through successive phases of vitality, which are comparable to the different ageperiods of the Metazoa. In such simple forms of life, fission or division into two parts is the usual method of reproduction, ${ }^{1}$ and the frequency of its occurrence appears to depend more upon the phase which has been reached in the life-cycle, than upon the influences of the environment. Thus, there is a period of extreme vigour of cell-multiplication, corresponding to the youth of a metazoön; secondly, there is a period of maturity, characterised by changes in the chemical and physical properties of the cell, and leading to the formation of conjugating individuals; and finally, in forms which do not conjugate, there is a period of senescence which ends in death. It is interesting to note, however, that the rapidity of fission is affected by the temperature and the food; for example, an individual of the Ciliate Infusiorian, Stylonychia pustulata, if well supplied with food, divides once in twenty-four hours in a temperature of from $5^{\circ}$ to $10^{\circ} \mathrm{C}$, and once in twelve hours in a temperature of from $10^{\circ}$ to $15^{\circ} \mathrm{C}^{2}$ Again, Flagellate Infusoria of different kinds have been induced to conjugate by changing the temperature or increasing the density in the surrounding medium. ${ }^{3}$ Furthermore, the life-cycle of Paramocium may be renewed without the occurrence of conjugation, that is to say, fission can be made to continue and senescence can be avoided, by introducing a change in the

1 In this process no material is lost, and two simple nucleated organisms result. During the period of maturity referred to in the text, multiplication is often preceded by union (either temporary or complete) of two individuals, and this process is called conjugation (see p. 211, Chap. VI.).

2 Sedgwick, Student's Text-Book of Zoology, vol. i., London, 1898.

${ }^{3}$ Calkins points out that the same experiment is performed by mosquitoes and other insects on certain parasitic Protozoa, as when a parasite is with. drawn from the hot environment of the Mammalian blood into the comparatively cold region of the mosquito's alimentary tract. ("The Protozoan Life-Cycle," Biol. Bull., vol. xi., 1E06.) 
composition of the medium surrounding the culture. ${ }^{1}$ (See p. 213.)

Moreover, there is evidence that in the case of Colpoda steini at least the occurrence of conjugation is detarmined entirely by the conditions of the surrounding medium.

\section{Ceglenterata}

With the majority of the Metazoa, as already indicated, there is a more or less definitely restricted season to which the occurrence of the chief reproductive processes is confined.

Thus in the common hydra of Bengal (Hydra orientalis, Annandale), which, like most other Cœlenterates, reproduces by budding as well as by the sexual method, ${ }^{2}$ the former process occurs chiefly during winter, the buds developing into new individuals. Towards the beginning of the hot weather budding becomes less active, and in some individuals ceases altogether, while the same thing happens during periods of tenıporary warmth in winter. A rise in temperature induces a proportion of the individuals present in an aquarium or pond to develop testes or male reproductive glands; if the rise is considerable it may cause a few of the remaining individuals to produce ova. On the other hand, no individual living in its natural environment has been known to exhibit any sign of sex after the rise in temperature had become steady. The conditions most favourable to the production of ova appear to be a period of comparatively low temperature and abundant nutrition followed by a sudden but not excessive rise of temperature. ${ }^{3}$

1 Calkins, loc. cit.

${ }^{2}$ Asexual reproduction is of very common occurrence among the majority of the lower animals and plants. It may take the form of simple binary fission (in unicellular organisms), of spore formation, or of germination or budding. Sexual reproduction consists essentially of the union two cells and their subsequent division to give rise to the new individual. In the multicellular organisms (Metazoa and Metaphyta) there are two kinds of conjugating cells, or gametes, which are specialised for the purpose. These are produced by the male and female respectively, and are known as spermatozoa and ova. Thus, sexual reproduction in the Metazoa is a modification of conjugation in the Protozoa. (See Chap. VI.)

"Annandale, "The Common Hydra of Bengal," Memoirs of the Asiatic Society of Bengal, vol. i., 1906. Cf. Whitney, "The Influence of External Factors in causing the Development of the Sexual Organs in Iydra viridis," 
Some of the marine hydroids show an alternation of generations which does not appear at first sight to be in any way related to change in the environment. In such cases the fertilised ovum develops into a polyp which gives rise to a colony of polyps by a process of sexual reproduction. After the colony has reached a certain size, a new kind of bud is formed, and this becomes a jelly-fish. The latter, after leading an independent existence, produces eggs, and these in turn become fertilised, giving rise to a new generation of polyps. Morgan points out that as the polyp colony goes on increasing in size, its relation to its surroundings must undergo change, and that, very possibly, it is this change which determines the development of jelly-fish in place of polyps. If this interpretation is correct the breeding season among marine hydroids is controlled by environmental conditions, just as it is among most other animals. ${ }^{1}$

Some interesting observations have been recorded by Ashworth and Annandale ${ }^{2}$ about the breeding habits of seaanemones. The species Sagartia troglodytes and Actinia mesembryanthemum, which are very prolific in captivity, have been noticed to breed regularly in the early spring. Actinia commences to produce young in the beginning of February, and Sagartia about a month later. As a rule the young are extruded in the early morning, and one individual may repeat Arch. f. Entwick.-Mechunik, vol. xxiv., 1907. Whitney says that in Hydra viridis an abundance of food following a low temperature causes a suppression of the formation of testes and ova.

${ }^{1}$ Morgan, Experimentul Zoology, New York, 1907. Morgan shows that the same point is illustrated by certain recent experiments of Klebs on flowering plants. These at first produce only leaves and branches. When they reach a certain size they produce flowers. Klebs regards the development of the flowers as beiug due to a relation that becomes established between the plant (when it has reached a certain stage of growth) and the environment. He shows also that by altering the environment a shoot may be induced to go on growing vegetatively, when it would ordinarily develop into a flowering branch. The flowering of the plant, therefore, is not merely the culmination of its form, as most botanists regard it. For much valuable and suggestive information on the factors which control breeding in plants G. Klebs' work should be consulted. (Willkïrliche Entwickelungsänderungen bei Pflanzen, 1903.)

2 Ashworth and Annandale, "Observations on some Aged Specimens of Sagartia troglodytes, and on the Duration of Life in Cœelenterates," Proc. Roy. Soc. Edin., vol. xxv., 1904. 
the process every morning for a number of weeks, when the breeding season comes to an end. In one season, when the aquaria were somewhat neglected, the specimens of Sagartia produced fewer young than usual, and these were not extruded until the beginning of April. Specimens of Actinia living in the same aquaria were more prolific, but their breeding season was also somewhat retarded. In the month of August two anemones of the species Sagartia troglodytes were brought from Thorshavn in the Færoës, and placed in the aquaria. In the following October both of these produced several young; while in April of the next year one of them again gave birth, but only to a single anemone. It seems probable that in this case the change of temperature or environment had induced the anemones to breed at an unusual season; for it is unlikely that October is the normal period for reproduction in the Færoës, as by this time the sea has already begun to run high, and there would be a great risk of the young anemones becoming destroyed, being unable to attach themselves.

Ashworth has pointed out ${ }^{1}$ that in the coral Xenia hicksoni, which lives in the tropics, there is every evidence that spermatozoa are discharged over a very considerable period, if not practically throughout the whole year, whereas in the related form Alcyonium digitatum, of Northern Europe, the period during which the spermatozoa are discharged is limited to about a month in the winter. Ashworth remarks that the difference is probably due to the fact that Xenia, living on reefs in the shallow waters of tropical seas, is not subject to great variations in temperature and food-supply, while with Alcyonium, such variations are no doubt considerable. In a similar way Miss Pratt, ${ }^{2}$ who has studied the process of oögenesis in Sarcophytum, Holophytum, and Sclerophytum, concludes that the sexually mature condition in these tropical genera extends over a considerably longer period than in the case of corals inhabiting temperate waters.

It may also be noted that, whereas in the Ctenophora of the Mediterranean the breeding season extends throughout the

1 Ashworth, "Structure of Xenia hicksoni," Quar. Jour. Micr. Scicnce, vol. xlii.

2 Pratt, "On Some Alcyonidæ," Herdman's Ceylon Reports, vol. iii. 
year, in members of the same class in northern seas it only lasts through the summer. ${ }^{1}$

\section{Nemertea, \&c.}

The breeding season and its relation to the environment have formed the subject of a careful investigation by Child ${ }^{2}$ in the case of a small Nemertean, Stychostemma asensoriatum, which is found very abundantly in one of the park lagoons of Chicago. The season extends from May to November or December, according to the temperature of the water. Egglaying can occur freely in the laboratory, the eggs being deposited always during the night, or in darkness, when the animals move about freely. Although breeding in the natural statc is restricted to the warmer part of the year, eggs can be obtained in the laboratory at practically any time, by simply regulating the temperature. Thus egg-laying can be induced in the winter at ordinary room-temperature, even though the worms are kept without food. "In animals which contained only a few small oöcytes when taken, and which are kept in clean water without food, the growth of the oöcytes will continue, and within a week or two eggs may be laid." "The body of the animal may even decrease somewhat in size during the growth of the oöcytes." It is clear, therefore, that in Stychostemma the limits of the breeding season are determined chiefly by the temperature of the water, and that food is a factor of secondary importance.

Similarly, in the case of the parasitic Trematode, Diplozoön paradoxum, which ordinarily produces eggs only in the summer, it has been found that the formation of eggs could be artificially prolonged throughout the winter, if the fishes on whose gills the animal lives are kept in an aquarium at summer heat. ${ }^{3}$

\section{ANNELida}

Certain species of Polychæt Annelids, known as the Palolo worms, exhibit a quite remarkable regularity in the periodicity of their breeding habits. During their immaturity all the Palolos

1 Bourne, "The Ctenophora," Treatise on Zoology, vol. ii., London, 1900.

${ }^{2}$ Child, "The Habits and Natural History of Stychostemma," American Naturalist, vol. xxxv., 1901.

3 Semper, Animal Life, London, 1881. 
live in burrows at the bottom of the water. With the attainment of sexual maturity, and under certain peculiar conditions, they swarm out for purposes of breeding. In the Atlantic Palolo (Eunice fucata) and the South Pacific Palolo (Eunice viridis) the process invariably takes place twice, upon or near the day of the last quarter of the moon; but with the former species it occurs in June and July, and with the latter in October and November. In the Japanese Palolo (Ceratocephale osawai) the swarming takes place on nights closely following the new and full moons (i.e. when the spring tides occur), in October and November, the worms swimming out regularly four times a year. Each swarming-period lasts from one to four days. It has been noted further that the swarm is greater after the new moon (when the spring tide is highest) than after the full moon (when the tide is not so high), that each swarming takes place invariably just after the flood in the evening, that it continues for from one to two hours, and is generally larger on warm, cloudy nights than on clear, chilly nights. It would appear also that no individual worm takes part in more than one swarming in the year. ${ }^{1}$

\section{ARthropoda}

Innumerable instances of the periodicity of breeding and its relation to seasonal and environmental changes might be adduced from the great group of Arthropods, but the reason for the variations which occur is not always obvious. Thus, in the common crayfish (Astacus fluviatilis), in France the males are said to approach the females in November, December, and January, whereas in England they begin to breed as early as the commencement of October, if not earlier. ${ }^{2}$ Also, in the Cape species of Peripatus ( $P$. capensis) birth takes place in a fixed season (during April and May), whereas, in the South American species, births are said to occur probably throughout the entire year. ${ }^{3}$

In the case of the hemipterous insect known as the plantlouse (Aphis), we have evidence that the mode of reproduction

1 Izuka, "Observations on the Japanese Palolo," Jour. of the College of Science, University of T'okyo, vol. xvii., 1903.

2 Huxley, The Crayfish, London, 1880.

3 Sedgwick, "Peripatus," Camb. Nat. Hist., vol. xii., London, 1901. 
is dependent upon temperature. In a favourable summer the females of this animal may produce as many as fourteen consecutive generations of young by parthenogenesis, the ova undergoing development without being fertilised by the male. At the beginning of the winter male plant-lice make their appearance and fertilise the eggs, which develop in the succeeding spring. Réaumur, however, by artificially maintaining a constant summer temperature, succeeded in producing more than fifty parthenogenetic generations of plant-lice, all descended from a single mother. ${ }^{1}$

Morgan, however, describes some observations which seem to indicate that the change is not merely due to temperature. He shows, for example, that the sexual forms of Aphis may appear in the autumn before the onset of the cold weather, and conversely that many individuals may continue to reproduce parthenogenetically, until finally they perish from the cold. Morgan suggests that the alternation in the mode of reproduction may depend upon changes which take place in the food-plant in the autumn, instead of being solely a temperature effect. He shows also that there is evidence for the conclusion that in the genus Chermes, in which the alternation of generations occurs between the fir-tree and the larch, the conditions existing on the larch are those that call forth the sexual forms. ${ }^{2}$

It has been supposed that the change in the environment is also responsible for determining the sexes in aphids. Miss Stevens, however, has recently shown that what appears to be a change in sex should rather be regarded as a change from the parthenogenetic to the sexual mode of reproduction. ${ }^{3}$ According to this view the sex of each individual is determined by the character of the gamete or gametes by which it is developed. The supposed influence of food and external conditions upon sex-determination in various kinds of insects, and other animals, is discussed at some length in a future chapter of this work (Chapter XV.).

Semper pointed out long ago that the occurrence of reproduction (or of the particular mode of reproduction), with

1 Semper, loc. cit.

2 Morgan, loc. cit.

${ }^{3}$ Stevens, "Studies in the Germ-Cells of Aphids," Carnegie Institution Report, Washington, 1906. 
insects as with other animals, depends, among other things, upon the nature of the diet, upon the chemical conditions of the surrounding medium, upon the moisture of the air, or upon other circumstances which are often unknown. Thus, failure to breed in a new environment is experienced by many Lepidoptera. For example, Death's-Head hawk moths, which are commonly blown over to this country from the Continent, but do not breed here, deposit their eggs on young potato plants, and these develop into moths which emerge in the autumn. The eggs, however, are quite infertile, so that, as a result, the Death's-Head has never established a footing in Britain, though stray specimens are often captured. ${ }^{1}$ In the case of other insects, such as the mosquito (Anopheles), there is direct evidence that food is an important factor in egg-formation. Thus it was found that mosquitoes fed on bananas refused to breed, but when fed on human blood they invariably laid eggs after two or three days. ${ }^{2}$ It is interesting to note also that in the mosquitoes and other Culicidæ, the males are generally unable to suck blood, this habit being apparently correlated with the function of oviposition. Dr. Gordon Hewitt informs me that among the Empidæ, which are carnivorous, the females, during the nuptial flights, are always fed by the males on small insects, and that they seem incapable of discharging their sexual functions unless they are fed in this way. ${ }^{3}$

In some insects oviposition takes place long after the death of the males. Thus, Lefroy and Howlett state that in the mango weevil (Cryptorhynchus gravis) the males die in August while the females live until the following March to lay eggs. ${ }^{4}$

\section{Mollusca}

Among the marine Mollusca, in curious contrast to so many forms of life, winter is the usual time for the deposition of the

1 Conntry Side, October 27, 1906.

2 "Report of Malaria Expedition to Nigeria," Liverpool, Trop. Med. Memoir, IV. See also Ross (Nature, vol. lxxx., 1909), who says that females of Culex and Stegomya apparently only desire to suck blood after fertilisation.

3 Howlett, "Coupling of Empis," Ent. Mag., vol. xliii., 1907.

4 Lefroy and Howlett, Indian Insect Life, Calcutta, 1909. 
eggs. ${ }^{1} \quad$ On our own coasts Nudibranchs come to shore to lay their eggs from January to April. Patella spawns from October until the end of the year. Purpura lapillus is said to be most active during the same season, but it breeds to some extent throughout the year. Buccinum undatum breeds from October until May, whereas Littorina breeds all the year round. ${ }^{2}$

Among the land-Mollusca there is a more marked periodicity in the breeding season than among the marine forms. In temperate climates breeding is restricted to the summer. In the tropics the occurrence of the breeding season is generally determined by the alternations of wet and dry seasons. In other cases, where there are no great seasonal changes, the land-Mollusca may breed all the year round. ${ }^{3}$ The snails of the Mediterranean area, according to Semper, arrive at sexual maturity when they are six months old, and before they are fully grown. Those individuals which reach this age in the spring deposit eggs a second time after the heat of the suminer is over, and so experience two breeding seasons in the year, with an interval of a few months between them during the hot weather. Semper shows, further, that individuals of the same genera, or perhaps even of the very same species, in the damper and colder climates of the north, do not lay eggs till development is complete; while in the dry, warm region of the Medilerranean, they have produced two lots of eggs before they are fully grown. This is because completion of growth and sexual maturity do not necessarily coincide. In a similar way, in the pond-snail (Limnoea) the minimum of temperature which admits of the assimilation of food, and so of growth, is much above the winter temperature of egg-deposition.

In tropical climates, where the variation in temperature throughout the year is reduced to a minimum, the periodicity in the breeding habits of animals is to a considerable extent obliterated, at least in so far as it is dependent upon tempera-

1 Lo Bianco, "Notizie biologische riguardanti specialmente il periodo di maturità sessuale degli animali del golfo di Napoli." Mitth. Zool. Stat. Neapol., vols. viii. and xiii. Much valuable information concerning the breeding habits of Mollusca and other animals, inhabiting the Bay of Naples, is given in these papers.

2 Cook, "Mollusca," Camb. Nat. Hist., vol. iii , London, 1895.

${ }^{3}$ Semper, loc. cit. 
ture. Semper ${ }^{1}$ says that few things impressed him more in the Philippine Islands than the absence of all true periodicity in the breeding habits not only of the land-molluses, but also of the insects and other land-animals. "I could at all times find eggs, larvæ, and propagating individuals, in winter as well as in summer. It is true that drought occasions a certain periodicity, which is chiefly perceptible by the reduced number of individuals in the dry months, and the greater number in the wet ones; it would seem that a much smaller number of eggs are hatched under great drought than when the air is very moist. Even in January, the coldest and driest month, I found land-snails which require much moisture, and at every stage of their development, but only in shady spots, in woods, or by the banks of streams. But what was far more striking in these islands was the total absence of all periodicity in the life of the sea-animals, particularly the invertebrata; and among these I could not detect a single species of which I could not at all seasons find fully grown specimens, young ones, and freshly deposited eggs." . Semper goes on to remark that even in some cold seas periodicity is far more often eliminated than is commonly supposed, and mentions that the eggs of the seamollusc, Tergipes, have been found at all seasons, like those of Littorina on our own coasts.

\section{ECHINODERMATA}

Sea-urchins and starfish, and other Echinodermata, appear generally to have a regularly recurrent breeding season, at which the genital organs swell up to an enormous size. In the sea-urchin, Echinus esculentus, these organs grow into huge tree-like structures with branched tubes, lined by the sexual cells. These are sold for food by the fishermen in Naples, who call them "frutta di mare." It is said that a single female $E$. esculentus will produce as many as $20,000,000$ eggs in a breeding seasion. At other times of the year the generative organs are so reduced as to be scarcely recognisable. E. esculentus at Port Erin, in the Isle of Man, spawns in June. ${ }^{2}$ At Dunbar, in

1 Semper, loc. cit.

2 Chadwick, Liverpool Marine Biological Committee Memoirs, vol. iii., Echinus, Liverpool, 1900. 
Scotland, it has been observed to spawn at the same time. The sea-urchins at Naples spawn at the end of the year (E. acutus being mature in November and December, and E.microtuberculatus from September onwards). ${ }^{1}$

\section{Cephalochordata}

In the lancelet (Amphioxus lanceolatus) of the Mediterranean the breeding season extends from spring until autumn, the glands becoming so large by the ripening of ova and spermatozoa that the atrium is used up to its utmost capacity. Spawning, when it occurs, invariably takes place about sun-down (i.e. between 5 and 7 P.M.), and never, so far as known, at any other time. ${ }^{2}$

\section{Pisces}

Among fishes the duration of the breeding season varies considerably according to the group to which they belong. The ova of Elasmobranchs are deposited singly or in pairs at varying intervals throughout a great part of the year. In Teleosts, on the other hand, the breeding season is limited as a rule to the spring and summer in temperate climates. In a single individual spawning may last no longer than a few weeks or even days. ${ }^{3}$ The enormous number of eggs produced by most Teleosts must be connected with the absence of internal fertilisation; involving a large wastage of ova which never come in contact with male cells or spermatozoa.

The cod, off our own coasts, has a spawning season extending from January to June, but the majority of individuals spawn in March. It has been found, however, that in some parts of the North Sea the cod may spawn in the autumn. In the whiting the spawning period lasts from early March until the third week in August. ${ }^{4}$ The investigations of the Marine

${ }^{1}$ Lo Bianco, loc. cit. The spawning times of most of the Naples Echinoderms are given in these memoirs. 1894.

${ }^{2}$ Willey, Amphioxus and the Ancestry of the Vertebrates, New York,

3 Bridge, "Fishes," Camb. Nat. Hist., vol, vii., London, 1905.

"Masterman, "A Contribution to the Life-Histories of the Cod and Whiting," Trans. Roy. Soc. Edin., vol. xl., 1900. 
Biological Association have shown that in the plaice of the South Devon bays the maximum spawning period is between the third week of January and the second week of February. This period in the North Sea and Irish Sea would appear to be slightly later. Herdman ${ }^{1}$ records that, in the year 1904, the plaice in the open-air ponds at the Port Erin Biological Station started spawning on March 3, and those at the Peel (Lancashire) Sea Fish Hatchery (under cover) on March 1.

In the Holostean fish, Lepidosteus, which lives in the fresh waters of North America, the breeding season recurs with a wonderful regularity about May. At this time the fish resort in large numbers to shallower water, where the temperature is higher. Here the ova and spermatozoa are emitted during recurrent periods of sexual excitement. ${ }^{2}$ The related fish, Amia, of Central and Southern North America, spawns usually in May, the exact season depending somewhat upon the temperature of the water. The fish make their way from deep water to the shallow spawning place, which is generally at the end of a swampy lake. ${ }^{3}$

In the Crossopterygian fish, Polypterus bichea, the ova ripen in the summer months from June to September, the breeding season depending upon the period of inundation, as in most of the Nile fishes. ${ }^{4}$ The other species of Polypterus ( $P$. senegalis and $P$. laprodei), which inhabit the river-basins of tropical Africa, spawn also in the wet season in July and August. ${ }^{5}$

In the Dipnoan, Ceratodus, of Australia the principal time for spawning is September and October, at the end of the dry

1 Herdman, "Spawning of the Plaice," Nature, vol. lxix., 1904. See also Wallace (W.), same volume. For information concerning the spawning seasons of different species of fish, The Jonrnal of the Ifarine Biological Association, the publications of the English and Scottish Fishery Boards, and the International Council for Fishery Investigation, should be consulted. These reports show that the migratory and reproductive periods of fishes are affected by the temperature, salinity, \&c., of the sea.

2 Agassiz, "The Development of Lepidosteus," Proc. Amer:Acad. Arts and Science, vol. xiv., 1878.

3 Bashford Dean, "The Farly Development of Amia," Quar. Jour. Micr. Science, vol. xxxviii., 1895.

"Harrington, "The Life-Habits of Polypterus," Amcrican Naturalist, vol. xxxiii, , 1899 .

5 Budgett, "On the Breeding Habits of Some West African Fishes," Trans. Zool. Soc., vol. xvi., 1901. 
season. ${ }^{1}$ In the other two Dipnoans, Lepidosiren of South America and Protopterus of Africa, spawning occurs shortly after the emergence of the fish from their summer sleep. Kerr, writing of the former, says that the exact time for breeding varies greatly from year to year in correlation with the extreme variability of the climate, the swamps, which the mud-fish inhabit, sometimes remaining dry for prolonged periods. ${ }^{2}$

Many fishes migrate, before the commencement of the breeding season, to localities suitable for the deposition of their eggs. Thus, certain marine fishes like the salmon, the shad, and the sturgeon ascend rivers for long distances before spawning; others merely migrate to shallower water nearer shore. The eel, on the other hand, is a fresh-water fish which migrates to the sea for breeding, and deposits its eggs in deep water.

Jacobi ${ }^{3}$ showed that the migration of the eel is not determined by the growth of the genital organs, for these do not begin to develop until the fish have reached the sea. He concluded, therefore, that eels need salt water before the genital organs can develop. Similarly, Noel Paton ${ }^{4}$ has pointed out that salmon, with their genitalia in all stages of development, are ascending the rivers throughout the whole year.

Miescher, ${ }^{5}$ too, has shown that salmon go practically without food so long as they are in fresh water, being nourished by the large store of material which they accumulated while they were in the sea. This observation has been confirmed by Noel Paton. Miescher and Paton have shown, further, that the gain in solid material (proteins, \&c.), by the genitalia, ${ }^{6}$ as the fish pass up the rivers, is met by a loss in solid material in the muscles. This transference is not brought about by anything of the nature of a degeneration taking place in the muscles; but the latter appear simply to excrete or give out the material which has been

1 Semon, In the Australian Bush, London, 1899.

${ }^{2}$ Kerr, "The External Features in the Development of Lepidosiren paradoxa," Phil. Trans. B., vol. cxcii., 1900.

${ }^{3}$ Jacobi, Die Aalfrage, Berlin, 1880.

- Paton, Fishery Bourd Report of Investigations on the Life Ilistory of the Silmon, Glasgow, 1898.

- Miescher, Histochemische und Physiologische Arbeitcn, vol. ii., Leipzig, 1897.

- 7 The gain in the genitalia is due largely to the formation of comparatively simple proteins (protamines, histones, \&c.). See Chapter VIII. 
accumulated in them. It should be noted, however, "that the gain of solids by the genitalia is small as compared with the loss of solids by the muscle, that in fact the greater part of the solids lost from the muscles are used up for some other purpose than the building up of the genitalia." 1 Paton concludes that the state of nutrition is the main factor determining migration towards the river, and that, when the salmon has accumulated a sufficiently large store of material, it returns to the rivers which were its original habitat. It does not seem possible, however, to maintain that nutrition is a determining influence in the growth of the genital glands, since these are undeveloped when the fish begin to migrate and enter upon their period of starvation.

Wiltshire ${ }^{2}$ states that in some fishes, at the period of oviposition, the lips of the genital orifice swell and become congested. This condition he regards as comparable to that which occurs during the " heat" period of a mammal.

\section{Amphibia}

The intimate connection between sexual periodicity and climatic variation exhibited by many Amphibia and Reptilia, especially in temperate climates, was commented on by Spallanzani. $^{3}$ This close dependence upon environmental conditions is evidently due largely to the habits of life of these animals, many of which hibernate or show great sluggishness in cold weather; while among Amphibia it must be associated with the further fact that, whereas most members of the group live to a great extent upon land, it is necessary for them to deposit their eggs in water. Spallanzani concludes that the reason why Amphibia are subject to a variation which is not observable in birds and Mammals is because the former, like insects, are cold-blooded, and have a comparatively small supply of internal heat to

'Paton, loc. cit. Milroy ("Chemical Changes in the Muscles of the Herring during Reproductive Activity," Seventh International Congress of Physiologists, Heidelberg, 1907; abstract in Zeit. f. Phys., vol. xxi., 1907; and Biochem. Jour., vol. iii., 1908) has recently shown that similar changes take place in the herring, in which, however, the starvation period is briefer.

2 Wiltshire, "The Comparative Physiology of Menstruation," Brit. Med. Jour., 1883.

3 Spallanzani, Dissertations, vol. ii., London, 1784. 
animate them when it is cold. "As therefore the exercise of their functions depends on the heat of the atmosphere, their amours will also depend upon this cause, and will, of course, be later in cold than in hot climates, and in both will vary with the season."

Spallanzani illustrates the truth of this fact by pointing out that various species of frogs and toads begin to propagate earlier in Italy than in Germany or Switzerland. ${ }^{1}$ On the other hand he records the observation that the tree-frog and the fetid terrestrial toad were copulating in the ponds and reservoirs of Geneva in March, at a time when in Lombardy they had not yet quitted their subterranean abodes.

It is interesting to note that in the frog and other Amphibia the ova are produced in winter, when the animals eat little or nothing, just as the genital organs of the salmon develop during the period of migration, when the fish have practically ceased to feed.

Bles ${ }^{2}$ has discussed at some length the conditions under which it is possible to induce various species of Amphibia to breed in captivity. He states that the most necessary condition is that the animals should be allowed to hibernate at the proper season, and in order to accomplish this they must be in thoroughly good health when the winter sets in, having passed the summer in the best circumstances in regard to light, heat, and supply of food. Bles's observations relate more especially to the African frog, Xenopus larvis, but he believes his conclusions to apply in a large degree to many other species of Amphibia.

The frogs in question were kept in a "tropical aquarium" (that is to say, an aquarium which could be kept at a tropical temperature by regulating a heating apparatus). In the summer the temperature was inaintained at about $25^{\circ} \mathrm{C}$. ; in December

1 In the common frog (Rana temporaria) the usual time for spawning in Middle Europe is March, earlier in warm, later in cold seasons; in southern countries, January or February, but in Norway not until May. Vide Gadow, Cambridge Nutural History, vol. viii., London, 1901. This book contains a quantity of valuable information concerning the breeding habits of many Amphibia and reptiles.

2 Bles, "The Life-History of Xenopus lavis," Trans. Roy. Soc. Edin., vol. xli., 1905. 
it was allowed to drop to $15^{\circ}-16^{\circ} \mathrm{C}$. during the day, and $5^{\circ}-8^{\circ} \mathrm{C}$. during the night. The bottom of the aquarium was covered with earth and stones, on which the weed Vallisneria thrived. The water in the aquarium was never changed. The frogs were fed daily upon small worms, or strips of liver, until they would eat no more. During winter they became lethargic, taking very little food. When the temperature rose in the spring and the days became brighter, the frogs became more active, especially the males. At this time breeding could be induced by a certain method of procedure which Bles describes as follows:" "First, the temperature of the aquarium is raised to $22^{\circ} \mathrm{C}$.; and secondly, when it has become constant, a certain amount of water, say two gallons, is drawn off morning and evening, allowed to cool for twelve hours, and then run in slowly in the following manner, in order to simulate the fall of rain. The cooling vessel is raised above the level of the aquarium, and a syphon is used to run off the water. The lower end of the syphon is drawn out to a fine point, and turned up in such a way that the water rises up like from a fountain, and falls as spray into the aquarium. . . By carrying out such measures I obtained from one female, between April and July 1903, more than fifteen thousand eggs."

The abdomen of the female Xenopus is stated to become very much distended during the winter by the enormously enlarged ovaries. "The three flaps surrounding the cloacal aperture are flaccid until the spring, when they become swollen and turgid, and more highly vascularised." (Cf. the changes in the female genital organs of Mammals during the "heat" periods, described in the next chapters.) The male Xenopus is said to assume its nuptial characters two days after the temperature is raised to $22^{\circ} \mathrm{C}$, and a very little later it becomes vocal, the voice strengthening from day to day. Copulation takes place only at night, and spawning may commence an hour afterwards; but this does not occur unless the water is changed in the manner above described.

According to Leslie ${ }^{1}$ it would appear that Xenopus, in its native country, breeds only in August, i.e. in the South African

1 Leslie, "Notes on the Habits and Oviposition of Xenopus lavis," Proc. - Zool. Soc., 1890. 
spring. Bles, however, is disposed to think that Xenopus, like Discoglossus in the wild state, may breed several times during the spring and summer, since the frogs in confinement in some years spawned three times.

Semper ${ }^{1}$ has shown that if axolotls are kept crowded together in small aquaria, without plants or seed, individuals which are sexually mature will not deposit ova even though the water be changed and abundant food supplied. But if they be suddenly transferred to aquaria stocked with plants, and with stones and sand on the bottom and running water, they can be induced to spawn within a few days, and may do so as often as three or four times a year. Bles states that he is able to confirm Semper's observations upon axolotls, and that he obtained similar results by treating individuals of Triton waltlii and of Discoglossus in the same way.

Annandale ${ }^{2}$ states that in the Malay Peninsula Rhacophorus leucomystax and Rana limnocharis appear to breed only after a heavy fall of rain, and he concludes that the stimulus set up by falling water is necessary before the sexual impulse can be induced.

Thus there appears to be abundant evidence that breeding in mature Amphibians does not occur cyclically merely, but it takes place only in response to certain definite external stimuli. Bles remarks that if this view is correct, and assuming it to apply to other groups besides the Amphibia, it helps to explain why many animals fail to breed in captivity ; and also how it is that others (e.g. insects), in a state of nature, appear in large numbers in one year and are much less numerous in another. ${ }^{3}$

It is interesting to note that among frogs and other coldblooded Vertebrates there is a periodicity in the occurrence of their reflex responses. ${ }^{4}$ It has been shown that if the region

1 Semper, "Ueber eine Methode Axolotl-Fier jederzeit zu erzeugen," Zool. Anz., vol. i., 1878. See also Animal Life.

2 Annandale, F'usciculi Mulayınses, Zool., Part J. 1904.

- See page 5, Chapter I.

- The sexual posture of frogs in the act of copulation is maintained as a spinal reflex. The tortoise is similar. The reflex is inhibited by excitation of the optical lobes. (Spallanzani, loc. cit. ; Goltz, Zeut. f. deutsch. med. Wiss., 1865-66 ; Tarchanoff, Pfügcr's Arch., vol. xl., 1887 ; Albertoni, Arch. Ital. dc Biol., vol. ix., 1887). 
of the shoulder-girdle bearing the four limbs, together with the connected skin and muscles, and the three upper segments of the spinal cord, are cut out from the male frog during the breeding season (but not at other times), the irritation of the skin will cause a reflex, clasping movement, similar to that characteristic of the normal male at this period. In spring and early summer, after reviving from their winter sleep, frogs tend to be irregular in certain other of their reflex responses. MacLean has shown that in the heart of the frog, newt, and salamander, and also the eel, vagus inhibition is absent or markedly diminished at certain periods corresponding roughly to the seasons of sexual activity, ${ }^{1}$ but the significance of the changes is not very apparent.

\section{RePTILIA}

Reptiles which hibernate usually begin to breed shortly after the commencement of the warm weather which terminates the hibernating period, just as in the case of Amphibia. Other reptiles, which live in warm or tropical climates, also have regularly recurrent breeding seasons, in some cases extending over many months, generally in the spring and summer. ${ }^{2}$ It would seem that in reptiles also, breeding only occurs in response to certain external stimuli, and that temperature is the main factor, as supposed by Spallanzani.

\section{Aves}

It would appear almost superfluous to cite examples of sexual periodicity from among birds. That spring and summer are the seasons when most birds pair, build their nests, and incubate their eggs, and that these processes are wont to vary slightly with the character of the season, are facts that are familiar to all. Bird-fanciers know also that the capacity of certain birds for egg-laying may be influenced by diet, and that this capacity can sometimes be increased (e.g. in the common fowl ${ }^{3}$ ) by the supply of suitable food.

1 MacLean, "The Action of Muscarin and Pilocarpin on the Heart of certain Vertebrates, with Observations on Sexual Changes," Biochem. Journal, vol. iii., 1908.

2 See Gadow, loc. cit.

3 Wright, The New Book of Poultry, London, 1902. 
With the approach of the breeding season the genital organs grow enormously until the whole oviduct reaches a state of hypertrophic turgescence. Gadow states that in the common fowl the oviduct at the period of rest is only six or seven inches long and scarcely a line wide, but that at the time of egg-laying it becomes more than two feet in length and nearly half an inch in width, thus increasing the volume about fifty times. This remarkable growth occurs annually. Gadow remarks also that the testes of the house-sparrow increase from the size of a mustard-seed to that of a small cherry, and in so doing temporarily displace the usual arrangement of the viscera in the body-cavity. ${ }^{1}$

A very large number of birds seasonally migrate, and this habit, as in the case of the migratory fish already referred to, is closely associated with the function of breeding. ${ }^{2}$ Jenner ${ }^{3}$ stated long ago that migration was invariably associated with an increase in size of the ovaries and testes, and that when these begin to shrink, after discharging their functions, the birds take their departure. Thus the ovaries of the cuckoo are stated to be almost atrophied in July. It would seem quite possible that the annual development of the sexual organs is the immediate stimulus which, in the individual, fixes the time for the spring migration, for it is known that in birds passing northward the ovaries and testes are well developed. (But $c f$. fishes, p. 18.) Thus wading birds, such as the sanderling shot by Mr. Eagle Clarke at Spurn Head, in May, were found by him to have their sexual organs in a very advanced state of growth. These birds were probably on their way to Greenland or Siberia.

Schäfer ${ }^{4}$ has suggested that the migratory impulse is deter-

1 Gadow, Article on "Reproductive Organs," in Newton's Dictionary of Birds, London, 1893-96. Disselhorst also ("Gewichts- und Volumszunahmen der männlichen Kєimdrüsen," Anat. Anz., vol. xxxii., 1908) has called attention to the enormous increase in size and weight of the testicles and ovaries in many birds (and also in some Mammals) in the breeding season. Thus, in Pringilla, the testicles may increase three-hundred-fold.

2 For much of the information given here regarding migration, I am indebted to Mr. Eagle Clarke.

3 Jenner, "Some Observations on the Migration of Birds," Phil. Trans., Part I.. 1824.

4 Schäfer, "On the Incidence of Daylight as a Determining Factor in Bird Migration," Nature, November 7, 1907. 
mined by the relation of daylight to darkness, having been brought into being through the agency of natural selection, in consequence of the necessity to most birds of daylight for the procuring of food. This hypothesis explains both the northerly migration in spring and the southerly migration in autumn, since at both times the birds are travelling in the direction of increased light (or, if they start before the equinox, towards regions where they will enjoy longer daylight later in the season). The suggestion that the time of the spring migration is determined in each individual by a stimulus set up by the growing genital organs is in no way opposed to Schäfer's theory, which provides an explanation of the general fact of migration.

It has been noted that the northerly spring migration is far more hurried than the somewhat leisurely autumn migration in the reverse direction. Furthermore, although the north-south migratory movements are as a rule extraordinarily regular, it has been observed that the birds do not all set out together, and that the times of departure and arrival for each species may vary in any one year by several weeks. Moreover, golden plover are found migrating across Britain on their way northward (perhaps to Iceland) at a time when other individuals of the same species are rearing young in Britain. (The breeding season in Iceland is about a month or six weeks later than in Britain.) In view of these facts it is evident that the occurrence of the migratory movement is dependent not merely upon external or environmental influences, but also upon internal or individual ones, and, as already stated, it is not improbable that one of the factors involved is the state of development of the organs of generation.

Many birds are double-brooded, having young ones not only in spring, but also in autumn before the close of the mild weather (in temperate climates). Swifts are stated to have a second brood in Southern Europe after leaving Britain in August, and the same is said to be the case with nightingales. Wiltshire ${ }^{1}$ mentions that a pair of swifts that stayed behind the others, had a brood in September, which migrated with the parent birds in October. Whether birds are single- or double-brooded probably depends to a large extent upon the duration of the 1 Wiltshire, loc. cit. 
period of incubation. This period in wading birds and sea-birds is approximately double that of passerine birds ; but, within the limits of the group to which they belong, it is closely related to the size of the birds. Thus the incubation-period of the stormy petrel is thirty days; that of the starling is fifteen or sixteen days; while that of the raven (the largest passerine bird) is about nineteen days. The starling is, as a rule, almost certainly double-brooded, while the petrel and the raven are singlebrooded. ${ }^{1}$ Other birds, such as the sparrow, are probably often treble-brooded. It is, of course, well known that domestication tends to increase the number of broods which a bird may produce (e.g. in pigeons and poultry).

\section{Mammalia}

The breeding season in the Mammalia, and the variations in its periodicity, are discussed at some length in the next chapter. Here it will suffice to point out that whereas the occurrence of breeding in any one country or locality is closely connected with the climatic conditions and the periodicity of the seasons in that country, this rule does not hold invariably. For while the sheep in South Africa breeds in April and May (the South African autumn), thus following the seasons (since sheep breed ordinarily in autumn in this country), the camels in the Zoological Gardens in London experience rut in early spring, or at approximately the same time as the breeding season of the wild camels in Mongolia. ${ }^{2}$ It has been already noted that some Mammals refuse to breed in captivity, while in many others the occurrence of breeding can be regulated to some extent by such factors as accommodation, heating, and feeding. Also in certain domestic animals, such as the sheep, the condition of "heat" can be induced more readily by the supply of additional or special kinds of food. ${ }^{3}$.

1 I am indebted to Mr. Eagle Clarke for certain of this information.

2 Heape, "The Sexual Season of Mammals," Quar. Jour. Micr. Science, vol. xliv., 1900. The black swans in the Zoological Gardens breed at the same time as those in Australia. (Cf. also Timor pony, p. 51.)

${ }^{3} C f$. birds, p. 23, and insects, p. 13. This point is referred to more fully in Chapter XIV., where the causes which influence fertility are discussed. 
The approach of the breeding season in many animals, if not in most, is marked by a display of greater vitality, as nıanifested by an increased activity, which relates not merely to the sexual organs but to the whole metabolism of the body. This enhanced vitality is, as a rule, maintained throughout the breeding season. Thus male birds at the time of pairing are in a state of the most perfect development, and possess an enormous store of superabundant energy. Under the influence of sexual excitement they perform strange antics or rapid flights which, as Wallace remarks, probably result as much from an internal impulse to exertion as from any desire to please their mates. Such, for example, are the rapid descent of the snipe, the soaring and singing of the lark, the strange love-antics of the albatross, and the dances of the cock-of-the-rock, and of many other birds. ${ }^{1}$ The migratory impulse, which, as already mentioned, is closely associated with the periodic growth of the sexual organs, may also very possibly be regarded as affording evidence of increased vitality at the approach of the breeding season. Moreover, many of the secondary sexual characters, both those of the embellishing kind and others as well, are developed during only a part of the year, which is almost invariably the period of breeding.

A familiar example of this correspondence between the development of secondary sexual characters and the activity of the reproductive organs is supplied by the growth of the antlers in stags. At the time of rut, which in the red-deer (Cervus elaphus) begins in September or October (see p. 48), the antlers, or branched outgrowths from the frontal bones, are completely developed, having shed their "velvet" or covering of vascular skin. The animals during this season are in a state of constant sexual excitement, and fight one another with their antlers for the possession of the hinds. ${ }^{2}$ By the end of the year the fighting and excitement have ceased, and the stags begin once more to herd together peaceably, and apart from the females. Shortly afterwards the antlers are shed. In most parts of Britain this occurs about April; but a Highland stag has been

1 Wallace (A. R.), Darwinism, London, 1890.

2 The larynx also is said to enlarge at this season, when the stag is wont to utter a loud bellowing noise. 
known to drop his antlers as soon after the rutting season as December, while, on the other hand, some immature animals in the Lake District are said to earry them until May. After the shedding of the antlers new ones begin to grow from the pedicles, the growth taking place chiefly in July and August. When the new antlers have reached their full development the "velvet" is shed (about the beginning of September). The size of the antlers, and the number of branches or " points," go on increasing every year throughout the reproductive period of the stag's life and until he begins to decline with old age. ${ }^{1}$

In the American prongbuck (Antilocapra americana), which is unique among hollow-horned ruminants in shedding the horns every year, the shedding follows the rutting season more closely than in the stag. The rutting in this species begins in September, and lasts about six weeks. In old bucks the horns are shed in October, while the new growth is not completed until July or August in the following year. ${ }^{2}$

A secondary sexual character of a comparable kind occurs in the male salmon, in which the tip of the lower jaw, during the breeding season, is turned up and enlarged, as if to protect the fish in fighting when charged by another male. ${ }^{3}$

In Polypterus, during the breeding season, the oval fin of the male becomes greatly enlarged and thickened, and has its surface thrown into folds between the fin-rays. The object of this modification is not known. ${ }^{4}$

The papillæ on the hind limbs of the breeding male Lepidosiren are structures which seem to possess a special significance, since Kerr ${ }^{5}$ has shown that they probably serve as accessory organs of respiration. During the greater part of the year they are relatively inconspicuous; but as soon as the animal is set free at the beginning of the wet season, they begin to grow with remarkable rapidity, forming slender filaments two or three inches in length and blood-red in colour from their intense vascularity. After the breeding season is over the filaments commence to atrophy, and eventually shrink to their

1 Cunningham (J. T.), Sexual Dimorphism, London, 1900.

2 Cunningham (J. T.), loc. cit.

3 Darwin, Descent of Man, Popular Edition, London, 1901.

- Budgett, loc, cit.

5 Kerr, loc. cit. 
former size, but still present for some time a distinctive appearance owing to their being crowded with black pigment-cells. Whatever may be the precise purpose of this curious modification it is certain that its development is associated with reproductive activity, and so may be regarded as an expression of the intense vitality which the organism exhibits at this period.

Some animals exhibit in the breeding season a particularly vivid coloration which is absent from them at other times. The case of the male dragonet (Callionymus lyra), which becomes a brilliant blue-and-yellow colour, has been discussed at some length by Cunningham, ${ }^{1}$ who concludes that the production of the guanin and pigment that give rise to the colour is to be connected with the intense nervous excitement which affects the fish at the time of courtship. "Physiological processes are known to be governed largely by nervous impulses, and not merely the circulation, but the excretory activity of the skin, are known to be influenced by nervous action. Pigment and guanin are produced in the skin by the secretory or excretory activity of the living cells." 2 Whatever be the precise explanation of this particular instance of intenser coloration, there can be no doubt that it is an indication of a more active metabolism.

The brilliant colours of the male lump-sucker (Cyclopterus lumpus), and of other fish ${ }^{3}$ at the time of breeding, are probably due to the same causes as in the dragonet. ${ }^{4}$

1 Cunningham (J. T.), loc. cit.

2 Cunningham (J. T.), loc. cit.

${ }^{3}$ Numerous instances are given by Darwin, loc. cit., both for fishes and Amphibians.

4 The nuptial changes which occur in fishes are not necessarily in the direction of increased brilliance of coloration. Miss Newbigin describes these changes in the salmon as follows: "When the fish comes from the sea the skin is of a bright silvery hue, wlile the flesh has the familiar strong pink colour. The small ovaries are of a yellow-brown colour. As the reproductive organs develop during the passage up the river, certain definite colour-changes occur. The skin loses its bright silvery colour, and, more especially in the male, becomes a ruddy-brown hue. At the same time the flesh becomes paler and paler, and in the female the rapidly growing ovaries acquire a fine orange-red colour. The testes in the male remain a creamy whitc. Aftcr spawning the skin tends, in both sexes, to lose its ruddy colour and to regain the bright silvery tint; the flesh, however, remains pale until the kelt has revisited the sea" (Report of Scottish Fishery Board, 1898).

Barrett-Hamilton (Proc. Canb. Phil. Soc., vol. x., 1900, and Annals and 
The tail of the lyre-bird, which is shed at the end of the breeding season, not to be renewed again in the same form until the following summer, the brilliant plumage of the breeding drake, the more intense colouring of the phalarope, and many other birds during the season of courtship, are familiar instances of the same kind of phenomena. ${ }^{1}$ The remarkable plate of horn which is developed in the upper mandible of the pelican in the breeding season, and bodily shed at the end of it, and the "gular pouch" in the throat of the breeding bustard, are examples of a more special kind, the existence of which, however, must be connected, either directly or indirectly, with the contemporaneous increase of sexual activity and the enhanced vitality which accompanies it.

In some animals certain glandular organs, apart from those concerned in the reproductive processes, show a special activity at the breeding season. For example, in the swiftlets (Collocalia) the salivary glands become peculiarly active, and secrete a substance which is allied to mucin, and is employed in building the edible birds'-nests of Chinese epicures. ${ }^{2}$

$\Lambda$ somewhat similar peculiarity exists in the inale of the sea-stickleback (Gusterosteus spinachia), which binds together the weeds forming its nest by means of a whitish thread, secreted by the kidneys, and produced only during the breeding season. According to Möbius, as quoted by Geddes and Thomson, ${ }^{3}$ the

Mag. of Nat. Ilist., vol. ix., 1902) draws attention to many such sexual phenomena, and more especially to those occurring in the spawning season in certain salmonoid fisbes of the genus Onchorhynchus. The fish undergo extraordinary changes in colour and shape, and, since they die when spawning is accomplished, it is argued that the changes cannot have any asthetic significance, but represent a pathological condition in which the fish become continually more feeble and eventually succumb.

1 Beebe ("Preliminary Report on an Investigation of the Seasonal Cbanges of Colour in Birds," Amer. Nat., vol. xlii., 1908) describes an experiment in which certain tanagers and bobolinks, which had been prevented from breeding, were kept througlout the winter in a darkened chamber with a somewliat increased food-supply. As a consequence the nuptial plumage was retainerl until the spring, when the birds were returned to normal conditions. They shortly afterwards moulted. The breeding plumage was then renewed, so that in this case the dull winter plumage was never acquired.

2 Geddes and Thomson, Evolution of Sex, Revised Edition, London, 1901.

${ }^{3}$ Geddes and Thomson, lac. cit. 
secretion is semi-pathological in nature, being caused by the mechanical pressure of the enlarged testes upon the kidneys. The male gets rid of the thread-like secretion by rubbing itself against objects, and thus, by an almost mechanical process, the weaving habit is supposed to have become evolved.

During the breeding season the anal scent-glands of snakes are said to be actively functional, but not at other times. A similar fact is stated about the submaxillary glands of crocodiles, and the cloacal gland; of tortoises and other reptiles. ${ }^{1}$ The secretions of these glands, like the musk glands of Mammals, no doubt serve the purpose of enabling the sexes to detect one another's presence more easily. (See p. 241.)

The periodicity which is such a marked feature of animal life in temperate climates has been discussed at some length by Semper. ${ }^{2}$ This author concludes that the phenomenon in question is dependent on the severe extremes of summer and winter temperature to which the animals are exposed. "Every individual requires a certain duration of life to achieve its individual development from the egg to sexual maturity and full growth; the length of time requisite for this is very various, and, above all, bears no proportion to the size attained. . . . This length of time, which we may generally designate as the period of individual growth, is not alike even for all the individuals of the same species; on the contrary, it depends on the co-operation of so many different factors that it must necessarily vary considerably. Now, if from any cause the period of individual growth, say of the salmon, became changed in consequence of the slower development of the embryo in the egg or of the young larvæ, most or all the young salmon thus affected would die in our climate, because the greater heat of spring is injurious to them at that stage." In a similar way it may be argued that the periodicity of the breeding season, no less than the rate of growth, is governed by the necessities of the young. No doubt this is true to a large extent, yet at the same time it is equally evident, as has been shown above in numerous instances, that this periodicity is greatly affected by

1 Owen, Anatony of Vertebrates, vol. i., London, 1866. Laycock, Nerrous Diseases of Women, London, 1840.

${ }^{2}$ Semper, Animal Life, London. 1881 
climatic and environmental changes, and even by stimuli of a more particular nature ( $c f$. frogs, p. 20). But this power, which all animals in some degree possess, of responding to altered conditions, may none the less have arisen primarily to meet the requirements of the next generation; or, to speak more accurately, that those animals which breed at a certain particular season (or in response to certain conditions which prevail at that season) have the advantage in being able to produce a new generation to which this capacity to respond similarly will be transmitted. In other words, the restriction of the breeding habit to certain seasons may have been brought about under the influence of natural selection to meet the necessities of the offspring.

Heape, however, has raised the objection ${ }^{1}$ that this view is inapplicable to the Mammalia, in which there is a period of gestation of greatly varying length in the different species. If the theory were correct, why, he asks, do some bats experience a breeding season in the autumn, and not produce young until the following June, although only two months are required for the development of the embryo in these animals; why do roedeer in Germany breed in autumn, while the embryo does not develop beyond the segmentation stage until the following spring; and why does the seal take eleven or twelve months for gestation when a large dog requires only nine weeks? Heape believes that the recurrence of the breeding season is governed directly by climatic, individual, and maternal influences, ${ }^{2}$ and that "variation in the rate of development of the embryo, in the length of gestation, and in the powers of nursing, are quite sufficient to provide for the launching of the young at a favourable time of the year."

I cannot altogether concur in Heape's view of this question. For it seems to me by no means improbable that whereas the necessities of the offspring, under changed environmental conditions, may sometimes have been provided for by modifications

1 Heape, "The Sexual Season of Mammals," Quar. Jour. Micr. Science, vol. xliv., 1900.

2 Under the heading of "individual influences" Heape includes special nervous, vascular, and secretory peculiarities of the individual and its habits of life. The length of the gestation and lactation periods he calls "maternal influences." 
in the rate of development or length of gestation, yet in other cases a similar result may have been effected by alterations in the season of breeding. The mere fact that breeding in any one species occurs, as a rule, periodically at a time which is on the whole well suited to the requirements of perpetuating the race, is itself presumptive evidence that the periodicity of the breeding season is controlled (through natural selection) by the needs of the next generation. Further, the breeding season having been fixed at one period in the history of the species, the same season would probably be retained (in the absence of disturbing factors) by the descendants of that species under the directive influence of heredity. This view is in no way opposed to the doctrine that the sexual capacity is developed in the individual in response to definite stimuli, which are largely environmental and often seasonal.

The occurrence of a succession of "heat" periods within the limits of a single breeding season no doubt arose in consequence of the increased opportunity afforded thereby for successful copulation. The number and frequency of the "heat" periods under these circumstances are affected by the conditions under which an animal lives in just the same kind of way as the periodicity of the breeding season is affected, as will be shown in the succeeding chapter on the œestrous cycle in the Mammalia. Concerning the immediate cause of "heat," and the nature of the mechanism by which it is brought about, something will be said later (Chapter IX.).

The origin of the breeding season is a wider question. For its complete solution, as pointed out by Heape, a comparative study of the sexual phenomena in the lower animals is essential, while, as already remarked, sufficient data for a comprehensive treatment of this subject do not at present exist.

That the breeding season occurs in some animals "as the result of a stimulus which may be effected through the alimentary canal is demonstrated by the effect upon ewes of certain stimulating foods."

"That it is associated with a stimulus which is manifested by exceptional vigour and exceptional bodily 'condition' is demonstrated by the pugnacity of the males at such times, by the restless activity of the females, by the brilliant colouring of 
such widely divergent animals as, for instance, annelids, amphibia, birds, and mammals, by the condition of the plumage of birds, and of the pelage or skin of mammals."

"That it is [frequently] associated with nutrition, and that it is a stimulus gradually collected is indicated by the increased frequency of the [breeding] season among domesticated mammals as compared with nearly allied species in the wild state.

"That it is manifested by hypertrophy and by congestion of the mucous tissue of the generative organs, and of various other organs, such as the wattles and combs of birds, the crest of the newt, and by the activity of special glands, the affection of all of which may be exceedingly severe, is true.

"These, and many other similar facts, are well known, but they do not assist in the elucidation of the origin of the function.

"The most they do is to show that the sexual instinct is seasonal, and that nutrition, whether affected by external or internal factors, plays an important part in its manifestation." 1

The last proposition may be expressed even more generally in the statement, already formulated, that generative activity in animals occurs only as a result of definite stimuli, which are partly external and partly internal; while the precise nature of the necessary stimuli varies considerably in the different kinds of animals, according to the species, and still more according to the group to which the species belong.

1 Heape, loc. cit. It should be remembered, however, that many animals, such as the salmon, have their breeding season after prolonged fasts. See above. (Cf. also the fur-seal, p. 60.) 


\section{CHAP'TER II}

\section{THE CESTROUS CYCLE IN THE MAMMALIA}

"Omne adeo genus in terris hominumque ferarumque

Et genus æquoreum, pecudes, pictæque volucres

In furias ignemque ruunt: amor omnibus idem."

-Virgil, Georg. iii.

Is describing the sexual processes of the Mammalia, and the variations in the periodicity of breeding which occur in the different groups, I have employed the terminology originally proposed by Heape, ${ }^{1}$ and afterwards adopted by me, ${ }^{2}$ in giving an account of these phenomena in the sheep and other animals. The terms used may now be defined.

The term sexual season is used by Heape to designate the particular time or times of the year at which the sexual organs exhibit a special activity. It is, in fact, employed in practically the same sense as that in which the expression "breeding season" is used in the previous chapter. Heape suggests that it is better to adopt the latter term to denote "the whole of that consecutive period during which any male or female mammal is concerned in the production of the young," since the expression is often used to include the period of pregnancy or even the period of lactation. The sexual season is the season during which copulation takes place, but this only occurs at certain still more restricted times, the periods of " œestrus" (defined below). The male sexual season, when there is one, is called the rutting season; but in many species the male animals

1 Heape, "The Sexual Season," Quar. Jour. Micr. Science, vol. xliv., 1900.

2 Marshall, "The CEstrous Cycle and the Formation of the Corpus Luteum in the Sheep," Phil. Trans. B., vol. cxcvi., 1903. "The CEstrous Cycle in the Common Ferret," Quar. Jour. Micr. Science, vol. xlviii., 1904. See also Marshall and Jolly, "Contributions to the Physiology of Mammalian Reproduction: Part I. The CEstrous Cycle in the Dog," Phil. Trans. B., vol. cxcviii., 1905 . 
are capable of copulating at any time, whereas in the females this function is restricted to definite periods.

The non-breeding season or period of rest in a female Mammal, when the generative organs are quiescent (at least relatively) and the uterus is normal and comparatively anæmic, and the animal shows no disposition to seek out a mate, is called by Heape the Ar.ostrous period or simply the Arøstrum. This period is generally considerably prolonged, and in many Mammals occupies the greater part of the year. Its close marks the beginning of the sexual season.

The first part of the sexual season is occupied by the Prooestrum. This period is characterised by marked changes in the generative organs, the uterus becoming congested, while in the later stages there is often a flow of blood from the external opening of the vagina. The proœstrum is the period often referred to by breeders as the time when an animal is "coming on heat," or " coming in season."

The next period, Estrus, or Estrum (as it is sometimes called), "marks the climax of the process; it is the special period of desire in the female; it is during ostrus, and only at that time, that the female is willing to receive the male, and fruitful coition rendered possible in most, if not in all, Mammals." 1

The periods of proœstrum and œestrus are commonly referred to together as the " heat" or " brunst" period, and sometimes as the period of "rut," 2 and no attempt is then made to distinguish the time occupied by "coming in season," and the time at which the female is ready to receive the male. This failure to distinguish the two periods (proœstrum and œstrus) has led to much confusion, especially in regard to the nature of the relation between "heat" in the lower Mammals and menstruation in the human female. As was first pointed out by Heape, it is the proœstrum alone, and not the entire "heat" period which is the physiological homologue of menstruation. This is a point which will be dealt with more fully in the next chapter of this book.

If conception takes place as a result of coition during œstrus,

1 Heape, loc. cit.

2 "The term "rut" is used by Heape in the case of the male only, the "rutting season," as stated above, being the male sexual season. 
this period is followed by gestation $;^{1}$ gestation in its turn, after a short puerperium or period of recovery, is followed by nursing or lactation, and the latter is succeeded by another anœstrum at the close of the breeding season. ${ }^{2}$

If, on the other hand, conception does not occur during œstrus, the latter is succeeded by a short Metœstrum, during which the activity of the generative system subsides and the organs gradually resume the normal condition.

In some animals, such as the dog, the metcestrous period is followed by a prolonged period of rest or anœstrum. In others, such as the rat or the rabbit, the metœstrum may be succeeded by only a short interval of quiescence. This short interval, which sometimes lasts for only a few days, is called the Dioestrum. This in turn is followed by another proøstrous period, and so the cycle is repeated until the sexual season is over. Such a cycle (consisting of a succession of the four periods, proœstrum, œstrus, metœstrum, and diœstrum) is known as the Diœstrous cycle. The number of diœstrous cycles in one sexual season depends upon the occurrence or non-occurrence of successful coition during œstrus. Thus, if conception takes place during the first œstrous period of the season, there can be no repetition of the cycle, at any rate until after parturition. The cycle may then be repeated. If conception does not occur at any cestrus during the sexual season, the final metcstrous period is succeeded by a prolonged anœstrous or non-breeding period. This is eventually followed by another procstrum, marking the commencement of a new sexual season. The complete cycle of events is called the Estrous cycle.

The number of diœstrous cycles which can occur in a female Mammal in the absence of the male, or in the absence of successful coition, depends upon specific and individual differences. Thus in some animals, such as the Scotch black-faced sheep in the

1 There is evidence that "heat" may occur abnormally during gestation. This phenomenon has been observed in dogs, cows, horses, and other animals (see p. 51). Coition during pregnancy may result in superfotation (see p. 159), and may tend to occur periodically at times corresponding to what would have been the regular beat periods if the animal had remained non-pregnant.

2 In some animals parturition is followed almost immediately by another proœstrum and œstrus, in spite of lactation. 
Highlands, this number is usually limited to two. In many Rodents, on the otler hand, there may be six or seven, or even more recurrences of the cycle within the limits of a single sexual season.

Animals in which the ostrus does not recur during the sexual season, Heape has called Monœestrous animals. Those in which there is a recurrence of the diœstrous cycle during a single season, have been designated Polyostrous animals. The polyœstrous condition may be regarded as a device (using teleological language) to increase the reproductive powers by providing more frequent opportunities for successful coition. But as to what factors are actually involved in bringing about the rhythmic recurrence of the cycle is a question which must at present be left open.

The differences in sexual periodicity in both monœstrous and polyostrous Mammals, the differences in the duration of the sexual season in polyœstrous Mammals, the great variation which occurs even in closely allied forms or even within the limits of a single species, and the effects of domestication and climate upon sexual and reproductive capacity are points which will be considered in describing the various types of breeding phenomena which exist in the different groups.

As Heape says, "the complication into which an otherwise simple story is thrown is due . . to variation in the quiescent period." The two varieties of the quiescent period (anœstrum and diœstrum) "are homologous, the one is a modification of the other;" and the modification is no doubt related to an increased or decreased power of reproduction. At the same time, for the purposes of the present chapter, "the difference between them [must be regarded as] essential, for their relation to the sexual season renders it necessary to discriminate clearly. between them."

\section{Monotremata}

Little is known concerning the breeding habits of the platypus and the echidna, which represent this order, the lowest of the Mammalia. Semon ${ }^{1}$ states that they breed only once a year,

1 Semon, In the Australian Bush, English Edition, London, 1899. See also Sixta, "Wie junge Ornithorhynchi die Milch ihrer Mutter saugen," Zool. Anz., vol. xxii., 1899. 
and that in Echidna, as a general rule, only a single egg is impregnated and developed at a time. After the egg is laid (for Monotremes, as is well known, differ from all other Mammals in being oviparous) the mother stows it away in her pouch. This is always well developed at the sexual season, after which it disappears, not to appear again until the approach of the next sexual season. Semon states that, although the pouch is first visible in the embryo, it is thereafter lost to sight until the beginning of the first procstrum.

\section{Marsupialia}

It would appear probable that most Marsupials breed once annually, but some are said to do so more frequently. Semon ${ }^{1}$ says that in the native Australian "bear" (Phascolarctus cinereus), on the Burnett, the sexual season begins at the end of October. Since he failed to find pregnant females until the middle or end of November, it would seem that the sexual season probably extends for three or four weeks. The males at this time experience a rutting season, during which they cry loudly, more frequently in the evening and night, but also during the day. The gestation, as in all Marsupials, is extremely short, the young being transferred at a very early stage of development to the mother's pouch, as in the case of Echidna. ${ }^{2}$

The kangaroos in the Zoological Society's Gardens in London are stated to display sexual excitement in September, and also in April. At such times a slight flow of mucus, which may be tinged with a little blood, has been observed passing from the aperture of the vagina. ${ }^{3}$ It would appear, therefore, that kangaroos may breed twice a year. Unfortunately, there is no positive information available as to whether ostrus recurs during the same sexual season.

1 Semon, loc. cit.

2 In the bandicoot (Perameles) the joung are nourished by an allantoic placenta as in the higher Mammals. (See p. 384.) This is exceptional among Marsupials.

3 Wiltshire, "The Comparative Physiology of Menstruation," Brit. Med. Jour., 1883. 


\section{Rodentia}

There can be little doubt that the great majority of Rodents are polyostrous. Most of them, so far as is known, have one annual breeding season, which may, under favourable conditions, extend over several months. Thus the rat (Mus decumanus) and mouse (M. musculus) are known to experience a recurrence of the diostrous cycle in the absence of the male, while, if pregnancy occurs, a new "heat" period very rapidly succeeds parturition. In a state of semi-domestication $\boldsymbol{M}$. rattus and $M$. decumanus have, in my experience, a fairly regular breeding season from about the end of January until the end of May. During this period the majority of mature females are either pregnant or suckling their young (that is, of course, among females which have been allowed to run freely with males). Pregnancy may-occur at other times of the year, but is not nearly so common. The duration of the diœstrous cycle in the rat is said to be about ten days ${ }^{1}$ the period of gestation is approximately three weeks. Heape states that $\boldsymbol{M}$. minutus and M. sylvaticus are also probably polyœstrous. The bank vole (Arvicola glareolus) is almost certainly polyœstrous, since it can become pregnant immediately after parturition at certain tinies of the year. The same condition no doubt exists in the field vole (A. agrestis), which breeds in Britain from January to October. ${ }^{2}$ Acccrding to Lataste, ${ }^{3}$ Eliomys quercinus, Gerbillus hertipes, Dipodillus campestris, D. simoni, Meriones shawi, and M. longifrons are also polyœestrous. The length of the dicstrous cycle in all these animals, as observed by the same investigator, is usually about ten days, as in the common rat.

In the wild condition in Britain, according to Heape, recurrent diœstrous cycles last " about three months, probably, in Arvicola agrestis; from four to six months, probably, in Mus minutus; about nine months in Mus rattus; and even longer, perhaps, in Mus musculus and M. decumanus." From my own experience with the two latter species in captivity, I am disposed

1 Heape, loc. cit.

2 Millais, British Mammals, vol. ii., London, 1905.

${ }^{3}$ Lataste, Recherches de Zooéthique sur les Mammiféres de l'ordre des Rongeurs, Bordeaux, 1887. 
to believe that Heape has overstated the duration of the sexual season in these animals in a state of nature.

The breeding season in the wild rabbit (Lepus cuniculus) in this country generally lasts from about February to May, but may be continued for longer. In the domesticated breeds it sometimes lasts nearly the whole year if the circumstances be favourable in regard to warmth and food supply. Heape says that five or six months only is the usual duration of the period during which diœstrous cycles recur in the domestic rabbit, and that if ostrus is experienced in winter it may occur independently of the possibility of pregnancy.

The duration of the dicstrous cycle varies considerably. "While some individuals exhibit œstrus every three weeks fairly regularly, others do so every ten days; on the whole, I think ten to fifteen days is the usual length of their diœstrous cycle." 1 In Lepus variabilis recurrent diœstrous cycles are probably continued for about two months.

The squirrel (Sciurus vulgaris) in Britain, according to Heape, is probably moncestrous; but this animal, in Southern Europe and Algiers, according to Lataste, is apparently polyœstrous. In Britain squirrels breed early in the year, and sometimes have a second litter in August.

It is difficult to determine the length of the proœstrum and œstrus in Rodents, since the external changes which characterise these conditions are comparatively slight. Heape says that the procstrum in the rabbit lasts, probably, from one to four days. At this time the vulva tends to become swollen and purple in colour, but there is no external bleeding. The same may be said of the rat and the guinea-pig; but, in the experience of the writer, it is generally impossible to detect the proœstrous condition in either of these animals with absolute certainty. CEstrus probably lasts for about a day. Lataste ${ }^{2}$ states that external bleeding occurs during the "heat" periods of Pachyuromys duprasi, Dipodillus simoni, and Meriones shawi.

The guinea-pig (Cavia porcellus) in captivity can become pregnant at any season, but more frequently in the summer than in the winter. "Heat" rapidly succeeds parturition, as 
in the case of so many other Rodents. ${ }^{1}$ The period of gestation is about sixty-two days, an unusually long time for so small an animal, being more than twice as long as the gestation period of the rabbit. As a result the newly born guinea-pig is well advanced in development, and able to feed for itself, instead of being dependent on its mother's milk.

In most male Rodents the testes undergo a periodic increase in size and descend into the sessile scrotum at the beginning of the season of rut, after which they become smaller again, and are withdrawn into the peritoneal cavity. In the Leporida, however, and in some other species, the testes are not so retracted, but remain throughout the year in the scrotal sacs. ${ }^{2}$

\section{UNGULATA}

This order contains several examples of animals which are almost certainly monœstrous in a state of nature, but are polyœstrous in captivity or under domestication. In the latter case the increase in sexual capacity appears to be due partly to the inherited effects of domestication, and partly to the direct influence of a more favourable environment.

For example, the sheep presents a complete gradation from the apparently monœestrous condition of some wild species to the extreme degree of polyœstrum, which is reached by certain of the more domesticated breeds. ${ }^{3}$

The Barbary wild sheep (Ovis tragelaphus) in the Zoological Society's Gardens is monœstrous, breeding only once annually. ${ }^{4}$ The same is stated to be the case with the Burrhel sheep $(O$. burrhel), although the moufflon $(O$. musimon) in captivity may experience two or more recurrent diøstrous cycles in an annual sexual season. ${ }^{5}$ It would seem, however, from the account given by Lydekker ${ }^{6}$ of the breeding habits of $O$. musimon, as

1 Sobotta, "Über die Bildung des Corpus Luteum beim Meerschweinchen," Anat. Hefte, vol. xxxii., 1906.

2 Owen, On the Anatomy of Vertebrates, vol. iii., London, 1868.

3 Marshall, "The Estrous Cycle, \&c., in the Sheep," Phil. Irans. B., vol. cxcvi., 1903.

4 Heape, loc. cit.

5 I am indebted to Mr. F. E. Beddard, Prosector of the Zoological Society, for this information.

${ }^{6}$ Lydekker, Wild Oxen, Sheep, and Giats of All Lands, London, 18?8. 
well as $O$. vignei, $O$. ammon, and $O$. canadensis, that these sheep in their wild condition are probably monœstrous, for their annual sexual season is of short duration, and occurs with great regularity. Similarly it may be inferred from Prjewalsky's statements ${ }^{1}$ that $O$. poli, $O$. burrhel, and $O$. argali are monœstrous and breed once a year. Among wild sheep generally the sexual season occurs as a rule in autumn, but it may vary with the locality or climate. Thus with $O$. vignei in the Punjab, the sheep begin to breed in September, whereas, with the same species in Astor, the sexual season must be considerably later, since the young in the latter district are produced about the beginning of June. ${ }^{2}$

Scotch black-faced sheep in the Highlands experience two dioestrous cycles, each of three weeks' duration, so that the annual sexual season for these animals lasts six weeks. In the Lowlands the sheep of this breed may have at least three recurrent diøstrous cycles in the absence of the ram, while flockmasters inform me that, under unusually favourable conditions, there may be as many as five or six, the duration of each cycle varying from about thirteen to eighteen days. It can hardly be doubted that of the two conditions of the Scotch blackfaced sheep that of the Highland ewes is the more natural, for sheep, in their wild state, are essentially mountain animals, being almost entirely confined to mountain districts in the Holarctic region, their range only just extending across the border into the far warmer Oriental region. "The immense mountain ranges of Central Asia, the Pamir, and Thian-Shan of Turkestan may be looked upon as the centre of their habitat." 3

The sexual season in hill sheep in Great Britain is ordinarily from about the middle of November until the end of the year. Under exceptional circumstances individuals may experience œestrus at other seasons, such as in April after an early abortion in the winter. In other British breeds the sexual season is earlier. Thus Hampshire Down sheep are often "tupped" in

' Prjewalsky, Mongolia, the Tangut Country, and the Solitudes of Northern Tibet (Morgan's Translation), London, 1876.

2 Lydekker, loc. cit.

${ }^{3}$ Flower and Lydekker, Mammals Living and Extinct, London, 1891. 
the summer, but they do not, as a rule, breed more than once a year. The Limestone sheep of Westmorland and Derbyshire, and the Dorset Horn sheep of the South of England, are the only British sheep which are ordinarily capable of breeding more than once annually. With the former the general lambing season is from the middle of February to the middle of March, but lambs are often born earlier. The ewes sometimes receive the ram very early when suckling the lambs, so that a second crop of lambs is born in August. This increase in the sexual capacity is especially noteworthy in view of the fact that Limestone sheep are classed as a mountain breed which thrives best on dry heaths or bare hill pastures. In Dorset Horn sheep lambs are frequently produced twice a year, but the practice is discouraged as it is said to deteriorate the ewes. With this breed œstrus may continue to recur (in the absence of the ram) from the autumn sexual season (when the sheep are ordinarily tupped) onwards until the following spring.

With many foreign breeds lambs are born twice yearly. Thus Mr. Annandale informs me that the horned sheep which run half wild in Patani, in the Malay Peninsula, normally have lambs twice a year. It would appear also that among the indigenous sheep of India, which are scarcely ever supplied with any artificial or other food, green or dry, beyond what they can pick up at the pasture ground, lambs may be born three times in two years, and that there are no definite seasons for lambing. ${ }^{1}$

Among the Merino sheep in Cape Colony the sexual season is April (the autumn month, corresponding to October in this country), but some sheep come "in season" earlier. At high altitudes, however, where the sheep subsist entirely upon the natural produce of the veldt, the sexual season is May, or a month later than the usual time in Cape Colony. On the other hand, in the low country below the second range of mountains, there are two seasons for "tupping," and lambs are produced twice a year. Among the Merinos in Argentina there are also two breeding seasons within the year.

Probably the maximum amount of sexual activity experi-

1 Shortt, A Manual of Indian Cattle and Shecp, 3rd Edition, Madras, 1889 . 
enced by any sheep is that reached by certain Australian Merinos which are described as being able to breed all the year round, a fact which implies, in the absence of gestation, an unbroken series of dicstrous cycles. The report of the Chief Inspector of Stock for New South Wales divides the time of lambing into six periods which embrace the entire year. ${ }^{1}$

That the great variability in sexual activity which the sheep exhibits is dependent largely upon differences in food supply and climate cannot be doubted, for the black-faced sheep in Scotland, and the Merinos in Cape Colony afford direct evidence that this is the case. Indeed, the effect of the environment on the recurrence of breeding was noted long ago by Aristotle, ${ }^{2}$ who observes that "in some places where the weather is warm and fine, and food is abundant," sheep may have lambs twice a year. The result of flushing (or the practice of stimulating the generative system by supplying extra food or better pasture, and thereby hastening the approach of the sexual season and increasing the fertility) is further evidence of the effect of good nourishment upon the sexual and reproductive powers. On the other hand, there can be no question that the varying degrees of breeding activity are in part racial characteristics, as is shown, for example, by the Dorset Horn sheep in the south of England, and still more evidently by the Limestone sheep of Westmorland and Derbyshire. But that an increase in the duration (or more frequent recurrence) of the sexual season is not necessarily a highly artificial condition or the result of special attention in regard to food supply, \&c., on the part of the flock-master, is shown by such a condition occurring among the indigenous sheep of India and the half-wild sheep of Patani.

The duration of the diœstrous cycle in black-faced sheep, as already mentioned, is from about thirteen to twenty-one days, the variation appearing to depend partly upon the nature of the country in which they live. In other breeds the cycle may be said to vary within approximately the same limits. Ellen-

${ }_{1}$ Wallace (R.), Farming Industries of Cape Colony, London, 1876 ; The Rural Economy and Agriculture of Australia and New Zculand, London, 1891; Argentine Shows and Live Stock, Edinburgh, 1904.

${ }^{2}$ Aristotle, History of Animals (Crosswell's Translation), Bohn's Library, London, 1862. 
berger, ${ }^{1}$ however, gives from twenty to thirty days as the length of this interval. The proœstrum and œstrus together do not as a rule occupy more than two or three days, and ostrus alone may last for only a few hours. The external signs of the procstrum are comparatively slight in sheep. The vulva is usually somewhat congested, and there is often a flow of mucus from the external generative aperture, but blood is seldom seen. Owing to the extreme shortness of the " heat " period the mucous flow may continue during the œstrous and metœstrous periods. The internal changes are briefly described in the succeeding chapter. The only external indication of ostrus is that afforded by the behaviour of the ewes. At this time they tend to follow the ram, and display a general restlessness of demeanour. The period of gestation is twenty-one or twentytwo weeks. Nathusius' observations show that it is fairly constant within the limits of particular breeds. ${ }^{2}$

The ostrous cycle in the sheep, and its great variability, have been discussed at some length, since this animal is probably typical of most Ungulata in the way in which its generative system is affected by different conditions of life, while the facts about other Ungulates are not so perfectly known. The effect of changed conditions upon the sheep's fertility, i.e. upon its capacity to bear young (as distinguished from mere sexual capacity), is a subject which is dealt with more fully in a future chapter (Chapter XIV.).

The wild goat, like the wild sheep, has a very restricted sexual season, ${ }^{3}$ while, according to Low, the domesticated goat experiences œestrus at very frequent periods. ${ }^{4}$

A similar statement may be made about cattle, for Heape ${ }^{5}$ says that, whereas wild cattle in captivity are capable of reproduction at any time of the year, and experience a remarkable increase in the recurrence of their diøstrous cycles, we are led to infer from the limited calving season among

- Ellenberger, Vergleichende Physiologie der Haussaügethiere, vol. ii. Berlin, 1892.

2 Nathusius, "Ueber einen auffallenden Racenunterschied in der'Trächtigkeitsdauer der Schafe," Zool. Garten, Jahrg. 3, 1862.

${ }^{3}$ Lydekker, loc. cit.

4 Low, The Domesticated Animals, Lonion, 1845.

Heape, loc. eit. 
similar animals in the wild state that the sexual periods are likewise restricted. Raciborsky ${ }^{1}$ says that in the more domestic types of cattle the cows receive the bull more frequently than in the wilder breeds. Ellenberger ${ }^{2}$ states that among domestic cattle the diœstrous cycle varies from about two to four weeks, but Schmidt ${ }^{3}$ has shown that the differences may be much greater. Wallace ${ }^{4}$ says that oestrus recurs in summer every nineteenth day, but in winter it may not recur oftener than every twentieth or every twenty-first day. Usually the cow seeks the bull again four or five weeks after calving. Shortt, ${ }^{5}$ however, states that in India this does not occur until after six or nine months. Blood is not infrequent in the external proœstrous discharge of cows and heifers. Emrys-Roberts ${ }^{6}$ has described the internal generative organs of a proœstrous cow as containing a watery secretion tinged with blood. The secretion was found to contain far less mucin than during the anœstrous period.?

The period of gestation in cattle is about nine months, but it is slightly variable.

According to Heape, who has collected evidence from various authorities, the ibex, markhor, barasingha, and Hemitragus jerulaicus in Cashmir, as well as the American bison, blacktailed deer in Montana, red-deer, fallow-deer, and roe-deer, ${ }^{8}$ and

1 Raciborsky, Traité de Menstruation, Paris.

2 Ellenberger, loc. cit.

3 Schmidt, "Beiträge zur Physiologie der Brunst beim Rinde," Dissertation, Zürich, München, 1902.

4 Wallace (R.), loc. cit. 1889.

5 Shortt, A Manual of Indian Cattle and Sheep, 3rd Edition, Madras,

6 Emrys-Roberts, "A Further Note on the Nutrition of the Farly Embryo, \&c.," Proc. Roy. Soc. B., vol. lxxx., 1908.

7 According to Emrys-Roberts, the profuse mucinous secretion during the procestrum in the Mammalia is derived, not from the body of the uterus, but from the cervix and vagina.

8 There has been some controversy regarding the breeding season and period of gestation in roe-deer. According to Bischoff (Entwicklungsgeschichte des Rehcs, Giessen, 1854) rut occurs in early autumn, but the embryo is not developed beyond the stage of segmentation in the following spring. Grohmann (Sport in the Alps, Edinturgh, 1904) says that rut is experienced in July and the beginning of August, but that there is a "false rut" in November. Observations on roe-deer in Vienna showed that the period of gestation is ten months; for seven females which were served by one 
several antelopes are all probably monœstrous in the wild state. This is rendered not unlikely from the limited sexual and calving seasons which these animals are known to experience, but it is by no means certain. "The American bison experiences a sexual season from some time in July until some time in August. [Catlin says August and September are the months when they breed; see below.] In the Cashmir ibex it persists during parts of November and December. In the markhor and Hemitragus jerulaicus in Cashmir it occurs in December, while in the barasingha in that country, from September 20th to November 20 th, it has been observed. . . . In Scotland the reddeer's sexual season lasts three weeks, during September and October, according to Cameron $;^{1}$ while in this country [England] September is the sexual month for the fallow-deer, ${ }^{2}$ and July and August the time when the roe-deer will receive the male.

"In all these cases there can be little over three weeks during which copulation takes place, and the extremely limited period during which parturition occurs strongly corroborates the view that this is the extent of the usual time during which sexual intercourse is possible. The fact that in captivity three weeks is the usual period which intervenes between two ostri in such animals, and the extreme probability that individual females do not experience œstrus at exactly the same time, predispose one to believe that they are monœstrous in the wild buck in July 1862, gave birth each to two young in the following May. It would appear probable, therefore, that the ovum lies dormant during the early months of gestation. Grohmann suggests that the "false rut" in November may have a quickening influence on the ovum, and so cause it to develop.

${ }_{1}$ Millais says (vol. iii. 1906) that the actual time of rut depends much on the season. September 28 , in Scotland, is called "the day of roaring." Sir S. M. Wilson (Fiell, October 8, 1904), however, reports a case of a stag which roared during the whole summer in Kinveachy Forest, Boat of Garten, in 1904. Stags eat little or nothing during the rutting season, and lose weight rapidly. During the first days of roaring they are said to suck up a mixture of peat and water (Millais, loc. cit.).

2 Millais says (loc. cit) that the fallow-deer in England ruts in October. The necks of the big bucks swell greatly during the first week, and the animals become more and more unsettled until about the 25th, when the first calls are heard. The actual rut is short as a rule. The doe drops her calf about the beginning of June, and rarely two or three are born at a time. Sometimes, however, the females may come in season at irregular times, and drop calves in any of the months after June and even as late as November. 
state; but, if the limit of time for coition is three weeks, there is still just time for the females to undergo two diøestrous cycles, and it is this possibility which prevents positive assertion on the matter.

"Among captive animals, not more than two diœstrous cycles have been observed in the gnu during one sexual season. Gazella dorcas has two or three; the giraffe about three; while the eland, nylghau, and water-buck have a series of diœstrous cycles, each lasting three weeks, during May, June, and July each year.

"The gayal and bison, the axis and wapiti deer, on the other hand, experience a continuous series of diøestrous cycles all the year round, at intervals of about three weeks." 1

Heape states also that with red-deer in the Zoological Gardens there is a very extensive series of diœstrous cycles, and that with wapiti deer in captivity the possibility of pregnancy at any season is only prevented by the fact that the male does not rut during the casting and growth of the antlers.

The males of many of the other species referred to experience a definite rutting season, like the stag in Britain.

As already mentioned, the male camels in the Zoological Gardens in London experience rut in early spring, or at the same time as the sexual season of the female camels in Mongolia. The period of gestation in the camel is thirteen months, so that in this animal, as in the walrus among carnivores, the recurrence of the sexual season is delayed by pregnancy, and conception cannot take place oftener than once in two years. ${ }^{2}$ The same is the case with the wild yak in the deserts of Tibet, ${ }^{3}$ and also, in all probability, with the musk-ox in Greenland. ${ }^{4}$

The sexual season in many Ruminants is a period of intense excitement, especially in those cases in which the males experience a definite rut. (See above, p. 27, in Chapter I.) Thus, Catlin, ${ }^{5}$ referring to the American bisons, says: "The running season, which is in August and September, is the time

1 Heape, loc. cit.

2 Swayne, Seventeen Trips through Somaliland, London, 1895.

${ }^{3}$ Prjewalsky, loc. cil.

4 Lydekker, loc. cit.

5 Catlin, North American Indians, vol. i., 2nd Edition, London, 1841. 
when they congregate into such masses in some places as literally to blacken the prairies for miles together. It is no uncommon thing at this season, at these gatherings, to see several thousands in a mass, eddying and wheeling about under a cloud of dust, which is raised by the bulls as they are pawing in the dirt or engaged in desperate combats, as they constantly are, plunging and butting at each other in the most furious manner. In these scenes, the males are continually following the females, and the whole mass are in a constant motion; and all bellowing (or ' roaring') in deep and hollow sounds which, mingled together, seem, at the distance of a mile or two, like the noise of distant thunder."

That the antlers are the fighting weapons in stags, and that their growth is associated with the advent of the sexual season, after which time they are cast off, are facts which have been already referred to. The effects of castration upon the growth of the antlers are described in a later chapter (p. 305).

Passing to the non-ruminating Ungulata, we find that the wild sow has only one annual sexual season. It is not certain whether this consists of more than a single œstrous cycle. Under domestication, however, the sow is polyœstrous, and may take the boar five weeks after parturition. The duration of the diœestrous cycle is from two to four weeks, according to Fleming. ${ }^{1}$ The period of gestation is about four months. Litters are usually produced only in spring and autumn; but by weaning the young early (or partially weaning them), and feeding the mother liberally, it is possible to get five litters in two years. A sanguineo-mucous flow has been observed issuing from the genital aperture during the procstrum. At the same time the vulva is distinctly swollen.

Wiltshire $^{2}$ states that in the hippopotamus in captivity a condition of cestrus may be experienced at regular monthly intervals. This animal has been known to breed in Zoological Gardens.

The mare is polyœstrous, the normal diœstrous cycle being abont three weeks and the ostrous period a week, though its

1 Fleming, Veterinary Obstetrics, London, 1878.

2 Wiltshire, loc. cit. See also Ellenberger, loc. cit., and Wallace (R.), Farm Live-Stock of Great Britain, 4th Edition London. 1907. 
actual length may vary by three or four days. ${ }^{1}$ The sexual season in the absence of the stallion extends throughout the spring and early summer months, and is generally longest in the more domesticated breeds. Professor Ewart informs me that in a pony imported from Timor, which is in the Southern Hemisphere, œstrus was experienced in the autumn, or at the same time as the spring in Timor (cf. camels, p. 49). The period of gestation in the mare is eleven months, and "heat" recurs eleven days after parturition. This is called the "foal heat." Certain mares are irregular in the recurrence of the " heat" periods, and, in some, "foal heat" does not occur until seventeen days after parturition instead of the usual eleven days. In exceptional cases a mare, like a cow, may conceive at the "foal heat" and yet take the horse three weeks later, just as though she had failed to become pregnant." Heape states that, very exceptionally, mares are monœstrous. Blood has been observed in the mare's proøstrous discharge, but it is not generally present. The genitalia, however, are always swollen and congested, and a glutinous secretion is generally emitted from them. The clitoris and vulva often undergo a succession of spasmodic movements, preceded by the discharge of small quantities of urine. Suckling mares tend to fail in their milk supply, and the quality of the milk appears to undergo some kind of change, as it is frequently the case that foals during the heat periods of their dams suffer from relaxation of the bowels or even acute diarrhœa. In mares which are not suckling the mammary gland becomes congested and increases in size during the heat. At the same time some mares develop great excitability, and kick arid squeal, becoming dangerous to approach and impossible to drive. There is, however, great variation, for other animals may pass through the "heat" period without exhibiting any well-marked signs of their condition, which in a few instances can only be determined by the behaviour of the mare towards the stallion. ${ }^{3}$

1 Ewart found that in Equus prjewalsky, cestrus lasted a week.

2 Wallace, loc. cit. Professor Ewart informs me that pregnant mares do not necessarily abort as a result of taking the horse at the third, sixth, or even ninth week of gestation.

3 Wortley Axe, "I'he Mare and the Foal," Jour. of the Rongal Agric. Soc.. 3rd Series vol. ix., 1898. Ewart ("The Development of the Horse," to be 
The elephant in captivity is said to be polyostrous, but I can find no record of the duration of the diøstrous cycle. Since pregnancy is very prolonged (twenty months), the sexual season cannot occur more than once in two years; that is, if the animals breed. The elephant in the Zoological Gardens in London is stated to have persistent oestrus probably for three or four days.

\section{Cetacen}

Little is definitely known about the periodicity of breeding in Cetacea. According to Millais, ${ }^{1}$ the right whale brings forth in March in every other year, the young being suckled for about twelve months. The humpbacked whales, blue whales, and sperm whales appear to have no regular time for breeding, but Millais says the young of the humpbacked whales are generally born sometime during the summer. Haldane's records, ${ }^{2}$ which appear to refer to several different whales, show that fotuses varying in length from six inches to sixteen feet were found in animals captured at the Scottish whaling stations in the summer of 1904 . This great variation seems to imply that there is no regular season at which whales copulate, and that very possibly these animals are polyostrous. Lillie ${ }^{3}$ states that two specimens of Balcmoptera musculus were taken off the west of Ireland on July 31, 1909, and that one contained a fotus of one foot in length, while the other had a foetus of five and a half feet in length. Lillie says also that several female rorquals having foetuses of different sizes were captured within a short time of

published in Quar. Jour. Micr. Science, says that the period of ostrus in mares tends to be shorter the later in the season, and when the food becomes less plentiful and less nutritious all external signs of oestrus disappear. Under favourable conditions, however, mares may become pregnant in winter. Ewart gives the following as the periods of gestation in various Equida:Asses and zebras, 358 to 385 days; Prjewalsky's lorse, 356 to 359 days; Celtic pony, 334 to 338 days. In coarse-headed types of horse it is about the same as in Prjewalsky's horse, but in the finer breeds the period is the same as in the Celtic pony. In abnormal cases pregnancy may be unduly prolonged in mares as in other animals, a mare occasionally going twelve months in foal instead of eleven.

1 Millais, The Mammals of Great Britain, vol, iii., London, 1906.

2 Haldane, "Whaling," \&c., Annals of Scottish Nat. Hist., April, 1905.

${ }^{3}$ Lillie, "Observations on the Anatomy and General Biology of some Members of the larger Cetacea," MS. still unpublished. 
one another. These observations, therefore, are in a general way confirmatory of those of Haldane.

According to Guldberg and Nansen, ${ }^{1}$ the porpoise copulates at any time between June and October, the period of gestation being ten months or longer. The white-sided dolphin is said to copulate in late summer, pregnancy being about ten months, and the white-beaked dolphin is thought to be similar. ${ }^{2}$

Humpbacked whales and other Cetacea have been described as indulging in amorous antics at the breeding time, rubbing against one another and patting one another with their long fins. $^{3}$

\section{Carnivora}

In the female of the dog the average duration of the complete œstrous cycle is six months, there being two annual "heat" periods, typically in the spring and in the autumn. It follows, therefore, that the bitch is monœestrous. Bitches belonging to the smaller breeds tend to come "on heat" more frequently than those of the larger varieties. Thus, in Irish terriers, the cycle may recur after four months, though in this breed six months is the more ordinary time. ${ }^{4}$ On the other hand, in Great Danes the duration of the œstrous cycle is often as much as eight months. It would appear that in those cases where "heat" recurs as often as every four months, this is only when pregnancy is prevented, for more than two litters of pups are seldom if ever produced in a year. Stonehenge ${ }^{5}$ says that there is much individual variability in the periodicity of the cycle, and that "heat" may recur at any interval from four up to eleven months, but that six, five, and four months are the most usual periods. Each bitch as a rule has her own peculiar period to which she remains constant, unless systematically prevented from breeding, in which case the periods tend to recur irregularly or even cease altogether. ${ }^{6}$ It has been observed also that the recurrence of the sexual season tends to

1 Guldberg and Nansen, "On the Structure and Development of the Whale," Bergen, 1904.

2 Millais, loc. cit.

${ }^{3}$ Ibid.

- Marshall and Jolly, loc. cit.

5 Stonehenge, The Dog in Health and Discase, 4th Edition, London, 1887.

${ }^{6}$ Heape, loc. cil. 
become irregular with advancing age, and this irrespectively of whether or not the animal is permitted to become pregnant. The periodicity depends also to some extent upon climate, for in Danish Greenland the dogs usually breed only once a year. ${ }^{1}$

The pronstrum in the bitch is characterised externally by the vulva being swollen and moistened with mucus, and by the existence, usually, but not absolutely invariably, of a flow of blood from the aperture of the vagina. The length of the proøstrum is about ten days. The sanguineous discharge generally ceases at the commencement of œestrus, which may last for another week or ten days.

Heape states that the winter œstrus in some breeds does not last so long as the summer cestrus. In certain individuals a relatively slight mucous or sanguineo-mucous flow takes place during the period of cestrus, and may even be continued beyond it, but this is exceptional. Stonehenge states that a bitch will not, as a rule, receive the dog until external bleeding has subsided, and that the most favourable time for successful coition is about the eleventh day of "heat" (in other words, at the beginning of the period of cestrus). This statement is fully borne out by dog-breeders.

The external changes which occur during "heat" are accompanied by changes in the metabolism, for Potthast, ${ }^{2}$ working on the nitrogen metabolism of the bitch, records a slight retention of nitrogen during the "heat" period. A similar result was obtained by Hagemann, ${ }^{3}$ who states that the retention is followed by a loss of nitrogen after copulation. These results should be compared with those recorded for menstruating women (see p. 68).

The histological changes which take place in the uterus during the ostrous cycle are described in the next chapter.

The period of gestation in the dog varies from fifty-nine to sixty-three days. With dogs belonging to the smaller breeds the period is often somewhat less than with large dogs. The

1 Rink, Danish Greenland, London, 1877.

2 Potthast, "Kenntniss des Eiweissumsatzes," Dissertation, Leipzig, 1887.

3 Hagemann, "Eiweissumsatz im tierisch Organismus," Dissertation, Erlangen, 1891. C $C$. also Schörndorff, “Einfluss der Schilddrüse auf den Stoffwechsel," Pflïger's Arch., vol. 1xvii., 1897. 
period of lactation is very variable in duration, and may extend until the commencement of the next procestrum.

The wild dog of South America (Canis azarce), according to Rengger, ${ }^{1}$ breeds only in winter, and therefore but once a year. The same is said to be the case with the wolf and the fox in their wild state; but these animals, in the Zoological Gardens in London, experience two annual "heat" periods like the dog. ${ }^{2}$ The wolves in the Dublin Gardens, however, are stated to have only one annual sexual season when permitted to breed; otherwise they come "in heat" more frequently, but are always monœstrous. ${ }^{3}$ The period of gestation in the wolf and fox is approximately the same as in the dog, i.e. about two calendar months.

Bischoff ${ }^{4}$ refers to the fact that the sexual season of the fox is affected by the nature of the country which it inhabits, foxes which live at high altitudes breeding later than those residing on the plains. Millais ${ }^{5}$ says that fox-cubs in most parts of Britain are not born until the end of March or beginning of April, whereas, in the south of England, they are often produced as early as January.

The Cape hunting-dog (Lycaon pictus) has been known to have bred in captivity on several occasions, and notably in the Gardens at Dublin, where six litters were produced from a single pair between January 1896 and January 1900. The first three litters were born in January, the fourth in November 1898, the fifth in May 1899, and the sixth in January 1900. Cunningham writes: "It is not easy to offer a satisfactory explanation of the irregularity of the fourth and fifth litters. I am inclined to believe, however, in the absence of definite information on this point obtained from the animals in a state of nature, that the lycaon breeds only once a year, and that the irregularity noticeable in the fourth and fifth litters is due

${ }^{1}$ Rengger, Naturgcschichte d. Saügcthiere von Paraguay, Basel, 1830.

2 Heape, loc. cit.

${ }^{3}$ For the information regarding the breeding of the animals in the Royal Zoological Society's Gardens, Dublin, I am indebted to the late Professor D. J. Cunningham and Dr. R. F. Scharf. (See Marshall and Jolly, loc. cit.)

4 Bischoff, "Ueber die Rauhzeit des Fuchses und die erste Entwicklung seines Eies" Sitz. der Math.-phys., Wien, Classe vom 13 Juni, vol. ii., 1863.

s Millais, loc. cit. 
to a tendency on the part of the Dublin specimens to adapt themselves to the climatic conditions of Ireland. At the same time it should be mentioned that certain indications were observed in connection with the demeanour of the parents towards each other which seemed to indicate that the sexual instinct was excited at more than one period of the year." The period of gestation was ascertained to be about eighty days, or nearly three weeks longer than in the domestic dog. "As might be expected, the young when they are born are more lusty and more advanced in development than new-born puppies of the dog." On one occasion, when the litter produced was unusually large, the gestation period was lengthened to eighty-six days. ${ }^{1}$

The female of the domestic cat generally breeds two or three times a year. According to Spallanzani ${ }^{2}$ the "heat" periods occur in February, June, and October, but there can be no doubt that many individuals breed at other times, and that there is great variation. ${ }^{3}$ Heape ${ }^{4}$ says that there may be no less than four sexual seasons within a year, but this can only be when the cats are not allowed to become pregnant. The usual number of litters, in my experience, is two, in typical cases in spring and autumn as in the dog. Heape states also that feral cats breed only once a year. The domestic cat is polyœestrous, and may experience a long succession of diœstrous cycles in one sexual season, each diœstrous cycle lasting about fourteen days and sometimes less. ${ }^{5}$ The period of gestation is about nine weeks.

Millais ${ }^{6}$ says it is uncertain whether the wild cat has one

1 Cunningham (D. J.), "Cape Hunting Dogs (Lycaon pictus) in the Gardens of the Royal Zoological Society of Ireland," Proc. Roy. Soc. Edin., vol. xxv., 1905.

2 Spallanzani, Dissertations, vol. ii., London, 1784.

3 Marshall and Jolly, loc. cit. I have known a cat experience œstrus regularly at intervals of about a fortnight from December until the following August, but such a long succession of diœestrous cycles is probably unusual.

Heape, loc. cit.

5 Heape, lnc. cit. Mr. W. O. Backhouse informs me that in his experience with Siamese cats the females, if the kittens are destroyed or birth is premature, come on heat regularly about eight days after parturition. This probably occurs in other breeds, at any rate in spring and summer.

- I am much indebted to Mr. A. H. Cocks for supplying me with interesting information concerning various Carnivora in captivity. 
or two annual breeding seasons. The probability is that there is only one (in March), the young being born in May; but Millais records that he has seen young wild cats, which could not have been more than forty days old, killed in Scotland in October. Cocks, in a letter quoted by Millais, says that he has received wild cats which, judging from their size, were probably born in August or September, and that in captivity he has observed a female experience " heat" during the summer. " Many years, when owing to the death of the young, or the fact that the pair had not bred together in the spring, I have kept male and female together all summer, but they showed no inclination to breed." In a more recent letter to the author Mr. Cocks states that the old female wild cat in his possession came " in season" and received the male in the autumn of 1904, after the death of the kittens which were born earlier in the same year. The animal, however, failed to become pregnant. In the experience of this observer the commonest month for wild kittens is May, but the range of dates in his collection varies from April 20 to July 22. The period of gestation was ascertained to be sixty-eight days. The period of cestrus was observed to last for five days, or about the same time as in the domestic cat.

The male wild cat has a definite season of rut (like the stag), and calls loudly and incessantly, making far more noise than the female cat. ${ }^{1}$ This information is interesting, since the males of most Carnivora, so far as is known, do not experience anything of the nature of a recurrent rutting season, although many individuals show indication of increased sexual activity at some times more than at others. So far as I am aware, nothing of the nature of a rutting season is ever known in the males of the domestic cat, dog, or ferret, all of which seem to be capable of coition at any period of the year. On the other hand, the males of certain seals appear to possess a season of rut at the same time as the sexual season in the females.

Little is known definitely regarding the breeding habits of the larger Felidæ in their wild state, beyond the fact that they probably agree in having a single annual sexual season. In captivity certain of them, at any rate, are polyœstrous. Thus,

${ }^{1}$ I am indebted to Mr. Cocks for information regarding the breeding habits of the wild cat. 
in the lioness oestrus has been known to recur at intervals of three weeks until the animal became pregnant, while the period of oestrus may itself last a week. ${ }^{1}$ Further, the lioness may experience three or four sexual seasons in the year, as in the domestic cat, this having been observed to occur in the lioness in the Dublin Zoological Gardens when copulation had not been successful, or when the animals were not permitted to breed. If allowed to become pregnant the lioness at Dublin may still experience two sexual seasons, and have two litters of cubs within the year. The puma in the Dublin Gardens is stated to have one sexual season annually if breeding, or two if there is no gestation. The larger Felidæ as a rule breed comparatively freely in confinement, some places, such as the Dublin Gardens, being famous for successful lion breeding. The period of gestation in the lioness is from fifteen to sixteen weeks; that of the tigress is about twenty-two weeks; while the puma goes with young for fifteen weeks.

Most species of bears, both in their wild state and in confinement, are monœstrous and have one annual sexual season. The grizzly bear, however, according to Somerset, ${ }^{2}$ bears young only once in two years. The bears in the Zoological Gardens at Dublin, on the other hand, may experience more than one annual sexual season if pregnancy does not occur. The period of gestation in the brown bear is seven months; in the grizzly bear it is probably longer. Heape states that with the bears in the Zoological Gardens in London œstrus may be experienced for two or three months continuously ; but this condition, as he points out, is unnatural and probably an effect of confinement, for though coition can occur, it does not, as a rule, result in pregnancy.

The ferret, which is a domesticated variety of the polecat, is monoestrous, but may have as many as three annual sexual seasons ${ }^{3}$ which, however, instead of being distributed at regular intervals throughout the year, occur only in the spring and summer, the autumn and winter being occupied usually by a prolonged anostrous period. This tendency towards a con-

1 See Marshall and Jolly, loc. cit.

2 Somerset. Quoted by Heape, loc, cit.

3 Carnegie, Ferrets and Ferreting, London. 
centration of sexual seasons during one part of the year may be considered as an approach to a condition of polyœstrum; for, if the œstrous periods were to recur at still shorter intervals than is actually the case, they could be regarded as forming so many diœstrous cycles in one sexual season. So far as I am aware, the ferret does not experience oestrus more than twice annually if allowed to breed.

The polecat is also monœstrous, but breeds only once a year. Mr. Cocks informs me that in captivity the young of this animal are generally born in the first half of June, and that the gestation period, as in the ferret, is about forty days.

The stoat, weasel, and pine-marten, in their wild state, are almost certainly monœstrous and breed once a year. In the last-mentioned animal Cocks ${ }^{1}$ found that a single oestrus may last a fortnight. The stoat and weasel do not appear to have been bred in captivity. The otter in a state of nature breeds only once a twelvemonth (in winter, as a rule, but young may be born at any season according to Cocks). In captivity, however, œstrus may recur at regular monthly intervals all the year round. ${ }^{2}$

The various species of seals are in all probability monœstrous, and have one litter of young annually. Some species show an almost perfect rhythmic regularity in the recurrence of their breeding season. Thus, in the case of the harp seal in the northeast of Newfoundland, and also in Greenland, according to Millais, ${ }^{3}$ the pups are born each year between March 8 th and 10 th.

1 Cocks, "Note on the Gestation of the Pine-Marten," Proc. Zool. Soc., 1900.

2 Cocks, "Note on the Breeding of the Otter," Proc. Zool. Soc., 1881. Mr. Cocks' subsequent experience concerning which he has been kind enough to write to me, confirms the conclusion that there is no anostrous period in the otter in captivity. There has been some controversy regarding the breeding of the badger. According to Meale-Waldo the period of gestation is between four and five months ("The Badger: its Period of Gestation," Zoologist, 1894), but according to Cocks ("The Gestation of the Badger," Zoologist, 1903, 1904), this period may be anything between under five and over fifteen months, for although the sexual season may apparently occur at any time of the year, the young are invariably born within a period limited to six weeks. This extraordinary conclusion is based on a number of observations. Fries ("Über die Fortpflanzung von Meles taxus," Zool. Anz., vol. iii., 1880) describes the badger's ovum as undergoing a resting stage during which development is at a standstill ( $c f$. roe-deer, p. 47).

${ }^{3}$ Millais, loc. cit. 
Farther north, however, at Jan Mayen, they are not born until about March 23rd or 24th. Turner's notes ${ }^{1}$ on the breeding habits of seals also point to the conclusion that the sexual season with these animals is restricted to regular periods of comparatively short duration, so that it may probably be assumed that seals are monœstrous. The males of seals, as already remarked, experience rut at the time of the female sexual season. Whether the male generative organs are functional (e.g. whether the testes produce sperms) at other times does not appear to be known. It is of interest to note that in many species the rut is experienced during a period of complete fasting. Thus it is stated that the male fur seal, after coming to land, may live for over a hundred days without taking food, and that during this period he is colstantly engaged in struggles with Qther males, finally leaving the shore in a state of extreme emaciation.

The walrus affords an example of a Mammal which bears young only once in three years. Parturition takes place about May or June, and the sexual season recurs about two years subsequently. Thus the nursing or lactation period extends for nearly two years, while gestation lasts about one year. ${ }^{2}$

\section{INSECTIVORA}

The majority of the animals in this order are almost certainly polyœstrous, but comparatively little is known concerning their breeding habits. The shrew in this country may be found breeding in any month from April until November, so that it is practically certain that this animal is polyœstrous, and may liave two litters, if not three litters in a year. It is extremely probable also that the water-shrew breeds twice a year. In the hedgehog in this country, litters are born at the end of May or June, and in August or September. ${ }^{3}$ In Germany it is said that the breeding season extends from March until July. ${ }^{4}$

1 Turner, "On the Placentation of Seals," Trans. Roy. Soc. Edin., vol. xxvii., 1875.

2 Millais, loc, cit.

Millais, The Mammals of Great Britain and Ireland, vol. i., London, 1904.

"Van Herwerden, "Beitrag zur Kenntniss des menstruellen Cyklus," Monatsschr.f. Geburtshülfe und Gynäk., vol. xxiv., 1906. 
The period of gestation in the hedgehog is not more than one month. The Malayan hedgehogs Gymnura and Hylomys are stated to experience an uninterrupted polyœstrum.

In the mole a great development of the male generative organs begins to take place at the end of January, culminating at the end of March. Previous to the end of January it is a matter of great difficulty to distinguish the males from the females without having recourse to dissection. The testicles lie on each side of the urinary bladder within the peritoneal cavity. In March they are protruded into sacs, which look like a continuation of the peritoneal cavity beneath the base of the tail. Meanwhile the seminiferous tubules within the testicles undergo enlargement, and cells are proliferated, which give origin to the spermatozoa. The prostatic glands, which begin to increase in size in February, acquire enormous dimensions, and conceal the urinary bladder at the end of March ${ }^{1}$ ( $c f$. hedgehog, p. 238). At the beginning of the breeding season the male moles fight one another with great ferocity, and one is often killed. Pairing takes place at the end of March, or in April, or sometimes as late as early May. A second litter of moles may be born later in the year, but this fact has not been definitely proved. ${ }^{2}$

It would appear that in some Insectivores the proœstrum may be comparatively severe, for in Tupaia javanica Stratz $^{3}$ has described a "menstrual" blood-clot which contained pieces of desquamated epithelium.

\section{Chiroptera}

As will be explained more fully in a future chapter, some species of bats appear to be exceptional in that the season of estrus does not synchronise with the period of

'Owen, loc. cit. The same authority states that in the Cape mole (Chrysochloris) he found the testes near the kidneys, but that the vasa deferentia had a convoluted course, which showed that they underwent periodic movements. Owen also describes the vesiculæ seminales in the hedgehog as growing to an enormous size at the season of rut.

2 Millais, loc. cit. See also Adams, "A Contribution to our Knowledge of the Mole," Manchester Lit. and Phil. Soc. Mem., 1902.

${ }^{3}$ Stratz, Der geschlechtsreife Saügethiereierstock, Haag, 1898. 
ovulation. It has been shown by Benecke, ${ }^{1}$ Eimer, ${ }^{2}$ van Beneden, ${ }^{3}$ and Salvi, that whereas copulation may occur in the autumn, the ova are not fertilised until after the winter hibernation, the spermatozoa in the meantime lying dormant. Salvi, however, describes the bats in the Grotta dell' Inferno, near Sassari, as copulating also in the spring, but it is suggested that coition at this season may only take place among those females which have failed to become inseminated effectively in the previous autumn. ${ }^{5}$ It does not appear to be known whether the polyœstrous condition ever occurs in bats.

It is stated that a "menstrual" (procestrous) flow has been observed in the flying fox (Pteropus). ${ }^{6}$

\section{Primates}

Lemurs.-Among Lemuroids, Stratz $^{7}$ has shown that in Tarsius spectrum there is a sanguineous procstrous discharge almost as concentrated as in monkeys. This is presumably followed by an cstrous period. It is stated also that Tarsius experiences an uninterrupted series of diœstrous cycles (i.e. a condition of continuous polyœstrum); but that, whereas conception is possible at any time of the year, breeding occurs more frequently in October and November than at other seasons. ${ }^{8}$

Monkeys.-The essential similarity between the proøstrum in the lower Mammalia and menstruation in monkeys will be made clear in the next chapter, when the histological changes which occur in the uterus are described. The consideration of the subject, however, is somewhat complicated by the fact pointed out by Heape ${ }^{9}$ that, whereas monkeys may have a continuous series

1 Benecke, "Ueber Reifung und Befruclitung des Eies bei den Fledermaüsen," Zool. Anz., vol. ii., 1879.

${ }^{2}$ Eimer, "Ueber die Fortpflanzung der Fledermaüse," Zool. Anz, vol. ii. 1879.

"Van Beneden, "Observations sur la Maturation, la Fécondation, et la Segmentation de l'œuf chez les Cheiroptères, Arch. de Biol., vol. i., 1880.

"Salvi, "Osservazioni sopra l'Accoppiamento dei Chirotteri nostrani," Atti della Societd Toscana di Scienze N'aturali. vol. xii., 1901.

"Duval, "Etudes sur l'Embryologie des Cheiroptères." Première Partie, Paris, 1899.

- Wiltshire, loc, cil.

8 Van Herwerden, loc. cit.

7 Stratz, loc. cit.

- Heape, loc. cit. 
of diœestrous cycles usually at regular monthly intervals, they are not necessarily capable of breeding at every heat period. Thus there is evidence that in the gorilla and chimpanzee in West Africa there is a special sexual season, ${ }^{1}$ and Heape ${ }^{2}$ has shown that the same can be said of Semnopithecus entellus and Macacus rhesus in India, but that the exact time for breeding varies in the different localities. Thus in Simla Macacus rhesus copulates about October, and gives birth to young about August or September in the following year, whereas on the plains around Muttra it seems probable that March is the usual month when young are born. However, Mr. Sányál, the Superintendent of the Zoological Gardens in Calcutta, expressed the opinion that $M$. rhesus can breed at all times of the year. On the other hand, it has been shown by van Herwerden ${ }^{3}$ that Cercocebus in the Island of Banha breeds only, as a rule, in the late summer or early autumn.

Heape ${ }^{4}$ states that in the Moor maco in the Gardens in London there is definite œestrus which always occurs after the cessation of the menstrual discharge, and persists for two or three days, and Ellis ${ }^{5}$ has shown that this is also probably the case with the orang utan as well as with various monkeys.

Pocock ${ }^{6}$ has given some interesting details concerning the phenomena which attend the menstrual process in various monkeys and baboons in the Zoological Society's Gardens. He states that the females of many species at about the time of menstruation exhibit extreme inflammation of the naked area surrounding the genital and anal orifices. An inflammatory swelling was noticed in various species of Cercocebus, and Papio and in Macacus nemestrinus, ${ }^{7}$ but not in Cercopithecus, or in

1 Winwood Reade, Savage Africa, London. Mohrike, Das Ausland, 1872. Garner, Gorillas and Chimpanzees, 1896.

" Heape, "The Menstruation of Semnopithecus entellus," Phil. Trans. B., vol. clxxxv., 1894. "The Menstruation and Ovulation of Macacus rhesus." Phil. Trans. B., vol. clxxxviii., 1897.

3 Van Herwerden, loc, cit.

"Heape, "The Sexual Season," \&c.

5 Havelock Ellis, Psychology of Sex, vol. ii., Philadelphia, 1900.

- Pocock, "Notes upon Menstruation, Gestation, and Parturition of some Monkeys that have lived in the Society's Gardens," Proc. Zool. Soc., 1906.

7 Similar observations had been previously described in Cercopithecus, Papio, and other species by certain of the older naturalists. See St. Hilaire and Cuvier, Hist. Nat. des Mammiferes, 1819-35. 
certain other species of Macacus including M. rhesus. Heape, however, states that in menstruating specimens of $M$. rhesus observed by him, and $M$. cynomolgus, the skin of the buttocks became swollen and red or purple in colour, as well as the skin of the abdomen, the inside of the thighs, and the under surface of the tail, while the skin of the face tended to become flushed or blotched with red; at the same time the nipples and vulva were congested. Menstrual hæmorrhage has been recorded in many monkeys and baboons, but there appears to be considerable variability in its extent. Pocock says: "In baboons it may or may not take place, and may be great or little in amount. It has been noticed to occur in some profusion in a female of Macacus sinicus, and not to occur appreciably in a female of the closely allied species, M. fascicularis. Obviously, therefore, it cannot be associated with the inflammatory swelling of the genito-anal region [since no swelling was apparent in either of these two species]; and it is hardly likely to have a specific value in taxonomy. Perhaps the nearest guess that can at present be made is the surmise that it is dependent on the constitution or health of the individual."

Heape noticed that in $M$. rhesus the menstrual discharge lasted for from three to five days. Pocock records that in a Chacma baboon (Papio porcarius) hæmorrhage continued for about four days. In both animals the phenomenon was truly " menstrual" (i.e. of monthly occurrence).

Pocock records the interesting fact that whereas the swelling of the inflammatory area commences at about the same time as the hæmorrhage, it does not reach its full size until several days after the discharge is over. It soon afterwards begins to shrink, and in about another two weeks has disappeared, so that the female at a distance is indistinguishable from the male. After a few days' rest inflammation again sets in, and the process is repeated. Pocock suggests that this sub-caudal swelling may serve the purpose of apprising the male (at a distance) as to when the female is " on heat," and it is to be noted that it is at its maximum after menstruation is over (as just mentioned), and so presumably therefore during a definite period of cestrus.

The question as to the correspondence in time between the 
processes of menstruation and ovulation is discussed in a later chapter.

Little is definitely known concerning the length of the gestation period in the various apes and monkeys. Pocock's observations show that in Macacus nemestrinus this period is between six and seven months. Blandford ${ }^{1}$ states his belief that about seven months is the usual period for the genus Macacus. Sányál, according to information recorded by Sclater, ${ }^{2}$ found that a female of Cercopithecus cynosurus in the Zoological Gardens, Calcutta, carried her young for seven months.

Gestation in the Quadrumana is dealt with at some length by Breschet, ${ }^{3}$ who cites many of the older observations. He shows that the question as to the duration of the period is complicated by the fact that monkeys, unlike the majority of Mammals, may copulate at other times than the breeding season, and that they are said occasionally to experience menstruation during pregnancy.

Man.-As is well known, menstruation recurs normally in the non-pregnant human female at intervals of from twenty-eight to thirty days. The exceptions to this general rule are, however, very numerous, and have often been noticed. Thus the interval may be extended to five weeks, or be abbreviated to two weeks without any derangement to the general health. "In one hundred women, sixty-one [were found] to menstruate every month, twenty-eight every three weeks, ten at uncertain intervals, and one, a healthy woman aged twenty-three years, every fortnight." 4 The duration and amount of the discharge may also vary considerably both in different women and in the same woman at different times.

It is stated, also, that the periodicity of menstruation depends partly on the climatic conditions, and that women in Lapland

1 Blandford, The Fauna of British India, vol. i., London, 1888.

2 Sclater, Mammals of South Africa, London.

3 Breschet, "Recherches anatomiques et physiologiques sur la Gestation des Quadrumanes," Memoires de l'Acad. des Sciences, vol. xix., 1845.

"Laycock, loc. cit., and Havelock Ellis, loc. cit. There is in some cases a tendency for the cycle to become divided up into two cycles, separated by the so-called "Mittelschmerz," or inter-menstrual pain, which is occasionally accompanied by a sanguineous discharge. (Halliday Croom, "Mittelschmerz," Trans. Edin. Obstet. Soc., vol, xxi., 1896). 
and Greenland menstruate less frequently, whereas in certain low and hot countries the catamenia may recur every three weeks. ${ }^{1}$

Further, the regularity with which the menstrual periods occur is liable to be disturbed by environmental changes. Thus, it is stated that change of residence, or foreign travel, without otherwise affecting the health, may bring about amenorrhœea or a temporary cessation of menstruation..$^{2}$ Such an effect is, no doubt, comparable to the well-known influence of captivity or change of environment in arresting the sexual functions of many animals.

The commonest time for the continuance of the menstrual flow is said to be about three or four days in this country, but it may last for as long as eight days, or, on the other hand, for only a few hours without disturbance of health. It usually begins gradually, becoming most profuse about the second or third day, and then diminishes. ${ }^{3}$ The total amount of blood lost has been variously estimated at from two to four ounces. In hot climates the quantity is greater than in cold; and it is said to be increased by luxurious living, and also by abnormal mental stimulation. The character of the menstrual discharge and its source of origin can best be considered in describing the histology of the uterus during the cestrous and menstrual cycles (see Chapter III.).

The monthly development of the uterine mucous membrane which precedes the menstrual discharge is often accompanied by a fulness of the breasts which begins to disappear after the commencement of the flow. Swelling of the thyroid and parotid glands, and tonsils, as well as congestion of the skin and a tendency towards the formation of pigment, are also

1 Matthews Duncan, "Sterility in Women," Brit. Mell. Jour., 1883 ; and Laycock, loc. cit.

2 Wiltshire, loc. cit.

${ }^{3}$ Galabin, A Mranual of Midwifery, 6th Edition, London, 1904. The age at which menstruation begins varies in different countries, being earlier in warm climates than in cold ones. In our own country the first menstruation does not usually occur before the age of fourteen or fifteen, while the menopause (or period when menstruation ceases) begins about the age of forty-five. (See p. 672.) Kennedy (Elin. Alal. Jour., vol. xxvii., 1882), however, has reported a case of a woman who continued to menstruate after giving birth to a child at the age of sixty-three. 
known to occur. ${ }^{1}$ The voice also is liable to be affected at the menstrual periods, and the skin and breath sometimes have a peculiar odour. Mental depression may exist, and be accompanied by nervous pathological phenomena.

According to the upholders of the "Wellenbewegung" hypothesis ${ }^{2}$ the reproductive life of the human female consists of a succession of wave-like periods which follow the monthly cycle. Thus, according to Stevenson, ${ }^{3}$ the curve of temperature

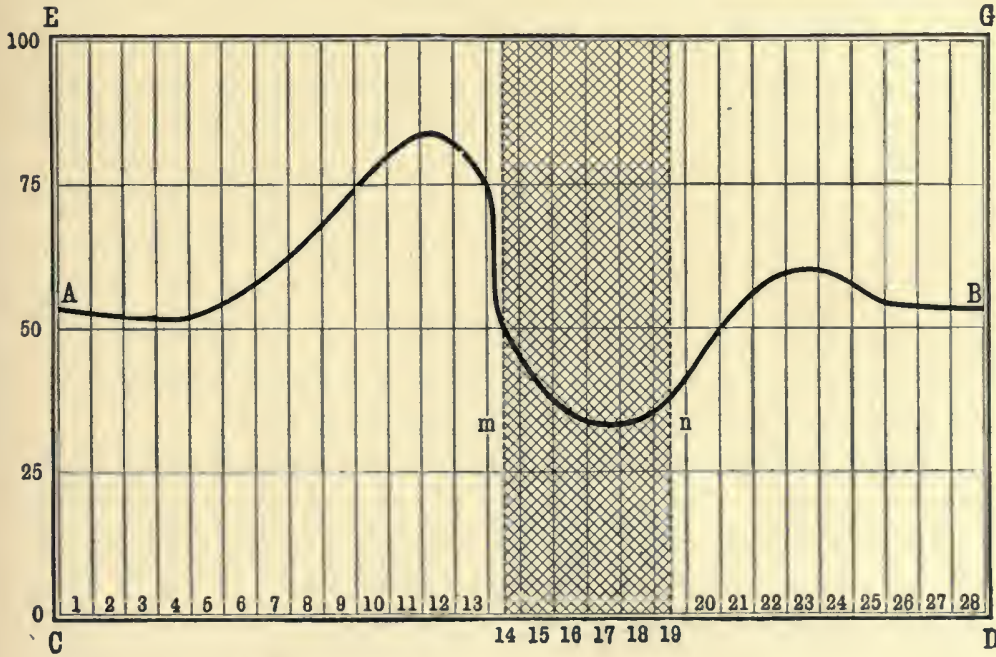

FIG 1.-Diagram illustrating the "Wellenbewegung" hypothesis. The curve $A B$ represents the varying intensity of the vital processes during the twenty-eight days of the menstrual cycle. The numbers between $m$ and $n$ represent the days occupied by menstruation. (From Sellheim.)

is above the mean line for about half the month, when it rises to half a degree above the mean. It falls below the mean line just before the onset of menstruation, during which it remains about half a degree below. Similar results were obtained by

1 See p. 350, Chapter IX.

${ }^{2}$ Godman, "The Cyclical Theory of Menstruation," Amer. Jour. Obstet., vol. xi , 1878. Reinl, "Die Wellenbewegung des Lebensprozesses des Weibes," Volkmann's Sammlung klin. Vorträge, No. 273. Ott, "Les lois de la périodicité de la fonction physiologique dans l'organisme féminine," Nouvelles Arch. d'Obstet. et de Gynéc., 1890.

3 Stevenson, "On the Menstrual Wave," Amer. Jour. Obstet., vol. xv., 1882. 
Reinl, Ott, and Giles, ${ }^{1}$ but Vicarelli ${ }^{2}$ and certain other authors have recorded an increased temperature during menstruation. ${ }^{3}$ Zuntz, ${ }^{4}$ however, as a result of more recent experiments, says that there is a regular lowering of the temperature throughout the menstrual period, after which it rises to the normal.

Stevenson states also that the curve of urea excretion follows a similar course to the temperature curve, and that, speaking generally, there is an increase in metabolism coincident with the time of development of the uterine mucosa. There is, however, no doubt much truth in von Noorden's criticism ${ }^{5}$ that the "menstrual wave" hypothesis has given occasion to many premature conclusions regarding the behaviour of the metabolism. Schroder, ${ }^{6}$ who investigated the nitrogen metabolism, found a retention of nitrogen immediately before and during menstruation ( $c f$. ., Potthast, \&c., for dogs, p. 54), but other investigators have obtained somewhat different results. ${ }^{7}$ Zuntz has shown from numerous experiments that, contrary to the conclusions of other authors, there is no evidence of a constant variation in the respiratory exchange during the menstrual cycle.

Mosher ${ }^{8}$ states that there is a fall of blood pressure at the time of menstruation. Zuntz ${ }^{9}$ records a diminution in the pulse rate.

Sfameni ${ }^{10}$ states that there is a decrease in the quantity of hæmoglobin in the blood during menstruation. He says also that the number of blood corpuscles increases in the days immediately preceding the hæmorrhage, but is diminished during it. ${ }^{11}$

' Giles, "The Cyclical or Wave Theory," \& c., Trans. Obstet. Soc., London, vol. xxxix., 1897.

${ }^{2}$ Vicarelli, "La température de l'utérus dans ses diverses conditions physiologiques," Arch. Ital. de Biol., vol. xxxii.. 1899.

${ }^{3}$ Sfameni, "Influence de la menstruation sur la quantité d'hémoglobine." Arch. Ital. de Biol., vol. xxxii., 1899.

- Zuntz (L.), " Einfluss der Ovarien auf den Stoff wechsel," Arch.f. Gynäk., vol, Ixxviii., 1906.

${ }^{5}$ Von Noorden, Metabolism and Practical Medicine (English Translation), vol. i., Iondon, 1907.

- Schroder, "Untersuchungen uiber den Stoff wechsel während der Menstruation," Zeitschr.f. klin. Medicin, vol. xxv., 1894.

${ }^{7}$ See von Noorden, loc. eit.

${ }^{8}$ Mosher, "Blood-pressure during Menstruation," Jolins Hopkins IIospital Bulletin, 1901.

9 Zuntz, loc. cit.

10 Sfameni, loc. cit.

${ }^{11} \mathrm{Cf}$. Carnot and Deflandre, "Variations du nombre des Hématies chez la Femme pendant la période menstruelle," $C$. $R$. de la Soc. de Biol, vol. lxvi., 1909 . 
Birnbaum and Osten ${ }^{1}$ state that in the blood of menstruating women coagulation is retarded. This statement is based on experiments made by adding fibrinogen to menstrual blood serum.

Blair Bell ${ }^{2}$ states that in connection with menstruation there is a marked drop in the calcium content of the systemic blood, and that this is most marked just before bleeding begins. This is correlated with an excretion of calcium salts in the menstrual discharge, an examination of which revealed the presence of a considerable quantity of calcium, both free and within the leucocytes (see p. 87). This excretion of calcium during menstruation is regarded by Blair Bell as connected phylogenetically with the process of egg-formation by birds and other lower Vertebrates.

According to Martin, ${ }^{3}$ and certain other writers, the human female often experiences a distinct post-menstrual œstrus, at which sexual desire is greater than at other times; so that, although conception can occur throughout the inter-menstrual periods, it would seem probable that originally coition was restricted to definite periods of cestrus following menstrual or proœstrous periods in women as in the females of other Mammalia. On this point Heape writes as follows:- "This special time for oestrus in the human female has very frequently been denied, and, no doubt, modern civilisation and modem social life do much to check the natural sexual instinct where there is undue strain on the constitution, or to stimulate it at other times where extreme vigour is the result. For these reasons a definite period of cestrus may readily be interfered with, but the instinct is, I am convinced, still marked." 4

Heape has also given a brief résumé of the evidence that primitive Man resembled the lower Primates in having a definite sexual season. The evidence is based largely upon the works of

1 Birnbaum and Osten, "Untersuchungen iber die Gerinnung des Blutes während der Menstruation,” Arch.f. Gynäk., vol. lxxx., 1906.

${ }^{2}$ Blair Bell, "Menstruation and its Relation to the Calcium Metabolism." Proc. Roy. Soc. Med., July 1908.

${ }^{3}$ Martin, "The Physiology and Histology of Ovulation, Menstruation, and Fertilisation," Hirst's System of Obstetrics, vol. i., London, 1888.

"Heape, loc. cit. 
Ploss ${ }^{1}$ and Westermarck, ${ }^{2}$ the latter of whom goes somewhat fully into the subject in a chapter on "A Human Pairing Season in Primitive Times," to which the reader is referred for further references on this subject. ${ }^{3}$

It has been shown that there is a more or less restricted season for breeding among certain of the North American Indians, among certain tribes in Hindustan, among many of the native Australians, among the Esquimaux, among the natives of the Andaman Islands, as well as among certain other of the more primitive races of mankind. The season seems generally to occur in the spring, but this is not invariably so. Annandale and Robinson ${ }^{4}$ state that among the Semang or aboriginal tribes of the Siamese State of Jalor, children are generally born only in March, or immediately after the wet season, a fact which appears to imply that there is a regular sexual season in June.

Further evidence of the existence of a primitive sexual season in Man is furnished by the records of the annual feasts which the ancients indulged in-usually in the spring-and which Frazer ${ }^{5}$ has shown to be represented in modern European countries by the May-queen festivals, and other similar customs that have survived into our own time. It is well known that the ancient festivals among the civilised peoples of the past were times of great sexual licence, and so in all probability were similar in origin to the licentious feasts and dances of various savage races at the present day. Their anthropological significance and the intimate association between them and the idea of reproduction are discussed at great length by Frazer in his book entitled The Golden Bough.

There is, moreover, evidence of a human pairing season in the higher birth-rate which occurs at certain seasons in various countries at the present day. Ploss has collected statistics illustrating this fact in Russia, France, Italy, and Germany,

1 Ploss, Das Weib, Leipzig, 1895.

2 Westermarck, The IIistory of IIuman Marriage, London, 1891.

3 See also Havelock Ellis, loc. cit.

+ Annandale and Robinson, Fasciculi Malayenses: Anthropology, Part I., 1903.

5 Frazer, The Golden Bough, 2nd Edition, London, 1900. 
and Haycraft ${ }^{1}$ has shown that there are indications of a similar condition existing in Scotland. On this subject Mayo-Smith ${ }^{2}$ writes as follows: "The largest number [of births] almost always falls in the month of February . . . corresponding to conceptions in May and June. . . Observations tend to show the largest number of conceptions in Sweden falling in June; in Holland and France, in May-June; in Spain, Austria, and Italy, in May; in Greece, in April. That is, the farther south, the earlier the spring and the earlier the conceptions." Other facts of a like kind are recorded by Westermarck, who concludes that primitive Man had an innate tendency towards increased powers of reproduction at the end of spring or beginning of summer, and that this tendency became variously modified under the influence of natural selection in the different human races which subsequently arose. ${ }^{3}$

Finally, it may be pointed out that Westermarck's conclusion - which seems a very probable one in view of the evidence which he and others have collected -is in no way invalidated by the fact that the human female experiences normally an uninterrupted succession of dinestrous (i.e. menstrual) cycles; for, as already shown, a similar condition is known to exist in several at least of the lower Primates, with which there is also evidence that in a state of nature the breeding functions are restricted to particular seasons of the year. ${ }^{4}$

1 Haycraft, "On some Physiological Results of Temperature Variations," Trans. Roy. Soc. Edin., vol. xxix., 1880.

${ }^{2}$ Majo-Smith, Statistics and Sociology, vol. i., New York, 1895. Cf. also van Herwerden, loc. cit.

${ }^{3}$ Mayo-Smith (loc. cit.) points out that sexual periodicity in civilised Man is much obscured by social influences. "One great social influence is the time of marriage. Marriage tends to accumulate about the social festivities of Christmas time, and in Catholic countries especially in the period just before Lent." He suggests that in agricultural districts the concentration about Christmas is due to the leisure following the labours of the autumn. "In cities the births are more evenly distributed, showing that artificial life has overcome the influence of seasons and particular occupations."

- That is to say that, whereas menstruation goes on at regular intervals all the year round, the procestrous or menstrual periods are only followed during the breeding season by cestri at which it is possible for conception to occur. There are some indications that the sexual instinct among males is also periodic, both in the lower Primates and in the human subject, but the periodicity is not so marked as among females. Havelock Ellis (loc. cit.) has 
Whether the monostrous or the polyostrous condition is the more primitive is a question which cannot at present be decided. The fact that polyœstrum is secondarily acquired among many animals may perhaps be regarded as evidence that monœstrum is the more primitive of the two conditions ; for, as already shown, there are numerous instances of Mammals which are almost certainly monœstrous in their wild state, but which have independently assumed a condition of polyœstrum under the more luxurious influences of domestication. Thus, while the sheep, the sow, and the cat are almost certainly monœstrous in a state of nature, the domesticated breeds of these animals show a varying degree of polyœestrum which appears to depend largely upon the extent to which domestication has been carried as well as upon food and the influences of the surroundings. On the other hand, the existence of the continuous polyœstrum in tropical climates among such primitive Mammals as the Insectivores, and the common occurrence of varying degrees of polyœstrum among the Rodents, not only in captivity but also in the wild state, point to the possibility that polyœstrum may in reality be the more primitive condition, and one which can easily be reverted to under the influence of a favourable environment.

The main purpose of polyœstrum (to use teleological language) is no doubt, as already remarked, to provide increased opportunity for coition, and so to promote the fecundity of the race. But it must be remembered that ostrus is not necessarily associated with ovulation, and consequently the explanation just given of the polyœestrous habit is not of universal application. This is a point which will be referred to again in dealing with ovulation. It is of course possible, however, that the polyœstrous condition, having once been acquired, might in certain circumstances be perpetuated in spite of its inutility.

Before concluding the present chapter it remains for me to allude briefly to the effect of maternal influences on the cestrous cycle. These, as pointed out by Heape, may or may not com-

discussed this question at some length, adducing evidence of a sexual rhythm in men. See especially appendix to Ellis's work by Perry-Coste, who shows that there may be a tendency towards rhythmic regularity in the sexual functions as manifested especially in the recurrence of seminal emissions. 
pletely disorganise the recurrence of the sexual season. In such animals as the dog they do not do so, because the dog is moncestrous, and has, as a rule, only two sexual seasons annually, so that the anostrous period considerably exceeds in length the period of gestation. In large animals such as the camel, on the other hand, where the gestation period extends for thirteen months, the recurrence of the sexual season is postponed by pregnancy for a whole year. Again, in small animals like the rat, gestation only prevents the recurrence of nestrus, reducing the number of diœstrous cycles, but not interfering with the recurrence of the sexual season. "But whenever gestation occurs it encroaches upon, if it does not entirely absorb, the anœstrum; that is to say, it reduces the period during which the generative organs would lie fallow if the sexual season were a barren one. Thus in the case of a mare, a barren sexual season may consist of a series of diœstrous cycles lasting for as long as six months, in which case the anœstrum lasts six months also, after which another sexual season begins. A reproductive sexual season, however, results in a period of eleven months' gestation, interfering not only with the diostrous cycles which would have recurred if conception had not taken place, but also absorbing practically the whole of the anœstrum." 1

The duration of the gestation period is intimately connected not only with the size of the body, but also with the stage of development at which the young are born. ${ }^{2}$ It is longest in the large terrestrial and gigantic aquatic Mammals (Ungulata and Cetacea), which live amid favourable conditions of nourishment. With these animals the young are so far advanced in development at the time of birth that they are able to follow the mother about, and to a certain extent shift for themselves. In Carnivores and Rodents the period of pregnancy is relatively shorter, and the young are often born naked, and with unopened eyes, and consequently are absolutely helpless for a considerable time after birth. The gestation period is shortest in the aplacental Mammals (Monotremata and Marsupialia), in which the young are born at a very early stage and transferred to a pouch

1 Heape, loc. cit.

2 Sedgwick, Student's Text-book of Zoology, vol. ii., London, 1905. 
formed by cutaneous folds in the vaginal region. In Monotremes the young are hatched from eggs which, after being laid, are deposited in the pouch.

The question as to what are the precise factors which determine the length of the gestation period has already been referred to in the first chapter, where it was pointed out that both the duration of pregnancy and the time of the year at which breeding occurs are necessarily controlled by natural selection, acting in the interests of the next generation.

The effects of lactation upon the recurrence of œstrus vary widely, and are often different among individuals belonging to the same species. Thus, although the mare as a general rule is capable of becoming pregnant while suckling, in some individuals the sexual season is postponed, the mares only becoming pregnant once in two years.

The return of menstruation during lactation in women has been dealt with recently by Heil, ${ }^{1}$ and Dingwall Fordyce. ${ }^{2}$ Heil, who had studied the conditions of two hundred nursing mothers, expresses the belief that the occurrence of menstruation and not the condition of amenorrhœa is the normal state during lactation, but that menstruation is not so frequent in the later lactations as during the earlier ones. Fordyce has reached similar conclusions, finding that menstruation occurred during lactation in forty per cent. of the cases in which suckling was performed, while in ninety-two per cent. of the cases its return was within nine months of parturition, and that menstruation during lactation was commoner with the earlier than with the later lactations, showing that age is an important factor.

The histological changes which occur in the internal generative organs of various Mammalia during the ostrous cycle are described at some length in the succeeding chapters.

1 Heil, "Laktation und Menstruation," Monatsschr.f. Gcburtsh. u. Gynäk., vol. xxiv., 1906.

2 Fordyce, "An Investigation into the Complications and Disabilities of prolonged Iactation." Being an extension of papers published in The Lancet, Part I., 1906, The Brit. Med. Jour., Part I., 1906, and The Brit. Jour. of Children's Diseases, 1906. Gellborn ("Abnormal Mammary Secretion," Jour. Amer. Mcd. Assoc., Nov. 21, 1908) mentions a case of an ape (Cercopithccus) in which menstruation always disappeared during profuse lactation, but reappeared as soon as the mammary secretion ceased or became markedly decreased. 


\section{CHAP'TER III}

\section{THE CHANGES THAT OCCUR IN THE NON-PREGNANT UTERUS DURING THE ESTROUS CYCLE}

"Menstruation is like the red flag outside an auction sale; it shows that something is going on inside."-MATTHEWS DUNCAN.

For full descriptions of the morphology of the uterus in the different mammalian orders, reference may be made to the text-books on human, comparative, and veterinary anatomy. But before passing on to describe the changes which occur in the histology of the uterus during the menstrual cycle, it may not be out of place to remind the reader of the general structural relations of the generative organs in the human female.

The two ovaries, the structure of which is described in the next chapter, are situated one on each side of the pelvis, and are connected with the posterior layer of the broad ligament of the uterus. In connection with each ovary is a Fallopian tube or oviduct, which opens into the peritoneal cavity about an inch from the ovary. ${ }^{1}$ Surrounding the orifice is a fringe of irregular processes or fimbriæ, which, when expanded, assist in directing the ovum in its passage into the tube. The tubes are about four inches long, and terminate at the superior angles of the uterus, with the cavity of which they are in continuation. They are surrounded by an external serous coat derived from the peritoneum, a muscular coat containing both longitudinal and circular fibres, and an internal mucous membrane, which is highly vascular and is lined within by a ciliated epithelium.

1 A vestigial structure lying transversely between the ovary and the Fallopian tube on either side is called the parovarium or epoöphoron, or organ of Rosenmiiller, or sometimes the duct of Gartner. It consists of a few scattered tubules, with no aperture. It is the homologue of the epididymis of the male. Vestiges of structure corresponding to the organ of Giraldès are also sometimes found in the vicinity of the parovarium, but nearer to the uterus. These have been called the paroöphoron. 
The human uterus consists of two parts, the corpus or body of the uterus, and the cervix or neck, which opens into the vagina. The body of the uterus contains the following layers, which correspond with those of the Fallopian tubes: (1) A serous layer; (2) a thick muscular layer, consisting of three more or less blended sub-layers; and (3) a still thicker layer, known as the mucous membrane or mucosa (sometimes called the endo-

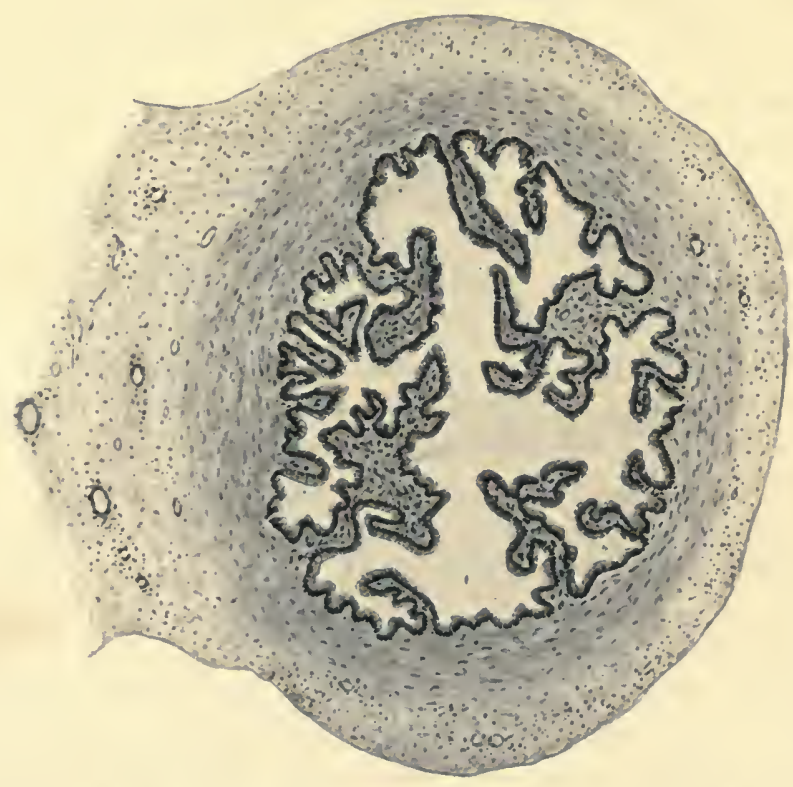

FIG. 2.-Transverse section through Fallopian tube, showing folded epithelium and muscular coat.

metrium), which is composed of a connective tissue containing spindle-shaped cells, and is lined by a ciliated epithelium bounding the uterine cavity. The mucosa contains numerous tubular glands, which open out into the cavity of the uterus and are covered by an epithelial layer, these being continuous with the epithelium of the surface. The sub-epithelial mucosa, which is sometimes called the uterine stroma, contains also a number of blood-vessels and lymph spaces. The vessels are branches of the ovarian and uterine arteries and veins. The 
uterus is also supplied by nerves which are referred to in a future chapter (p. 527).

In many of the lower Mammals the uterus is represented by two tubes, called the horns of the uterus or uterine cornua, which may unite posteriorly to form the corpus, or may, on the other hand, open separately into the vagina. The arrangement

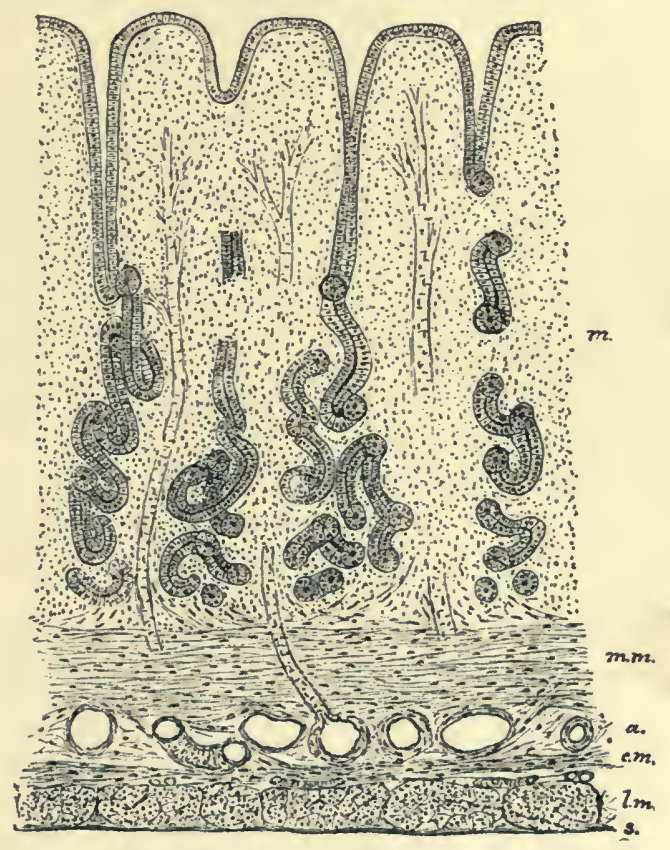

FIG. 3.-Section of a cornu of a rabbit's uterus.

$s$, Serous layer; $l m$, longitudinal muscle fibres; $\mathrm{cm}$, circular muscle fibres; $a$, areolar tissue with large blood-vessels; $m m$, muscularis mucosæ; $m$, mucosa. (From Schäfer.)

of the different layers in each of the cornua is essentially similar to that presented by the corpus uteri in the human species.

The neck or cervix uteri, which is narrower than the rest of the organ, opens into the vagina by a transverse aperture known as the os. The vagina is the broad passage from the uterus to the exterior. Its walls contain both longitudinally and circularly arranged muscle fibres. Internally it is lined 
by a stratified scaly epithelium, surrounded by erectile tissue. The entrance to the vagina from the exterior is guarded by a thin fold of mucous membrane, which usually becomes perforated at the first coition. This structure, which is called the hymen, is peculiar to the human race. ${ }^{1}$

The vulva comprises the female generative organs which are visible externally. These include the mons veneris, the

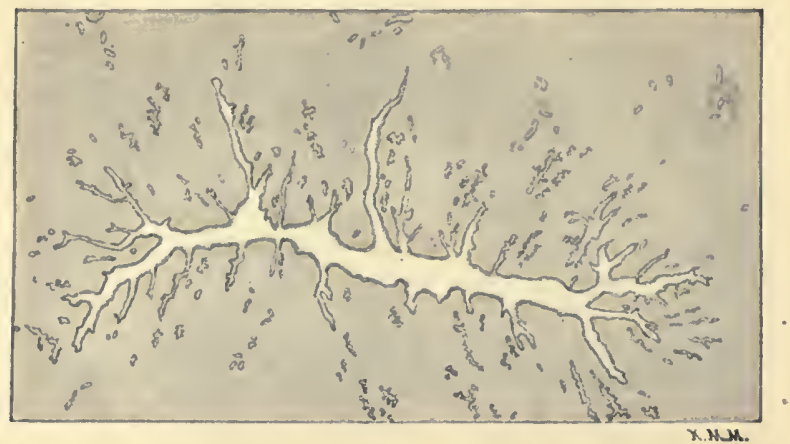

FIG. 4.-Cross-section through cervical canal of human uterus. (From Williams' Obstetrics. Appleton \& Co.)

labia majora and minora, and the clitoris. The last-mentioned structure is a small erectile organ, which is homologous with the penis. ${ }^{2}$

\section{The Cycle in Man}

In giving an account of the changes which take place in the uterus during the menstrual cycle of the human female, it will be convenient to adopt the scheme of classification employed by Milnes Marshall ${ }^{3}$ in his work on Vertebrate

1 The significance or function of the hymen is not certainly known. Metchnikoff (The Nature of Man, English Edition, London, 1903) suggests that it may have been useful in the earlier history of the race, when sexual intercourse probably occurred at an early age, before the reproductive organs were mature. Under such circumstances the hymen, instead of being a barrier, may have facilitated successful coitus. Metchnikoff supposes the aperture to have become gradually dilated by repeated intercourse without being torn, until it admitted of the entrance of the adult male organ.

2 The outer part of the vagina into which the female uretbra opens is often called the vestibule or urogenital sinus.

3 Milnes Marshall, Vertebrate Émbryology, Loudon, 1893. 
Embryology. This classification, as will be seen later, is identical with that adopted by Heape ${ }^{1}$ in describing the menstrual

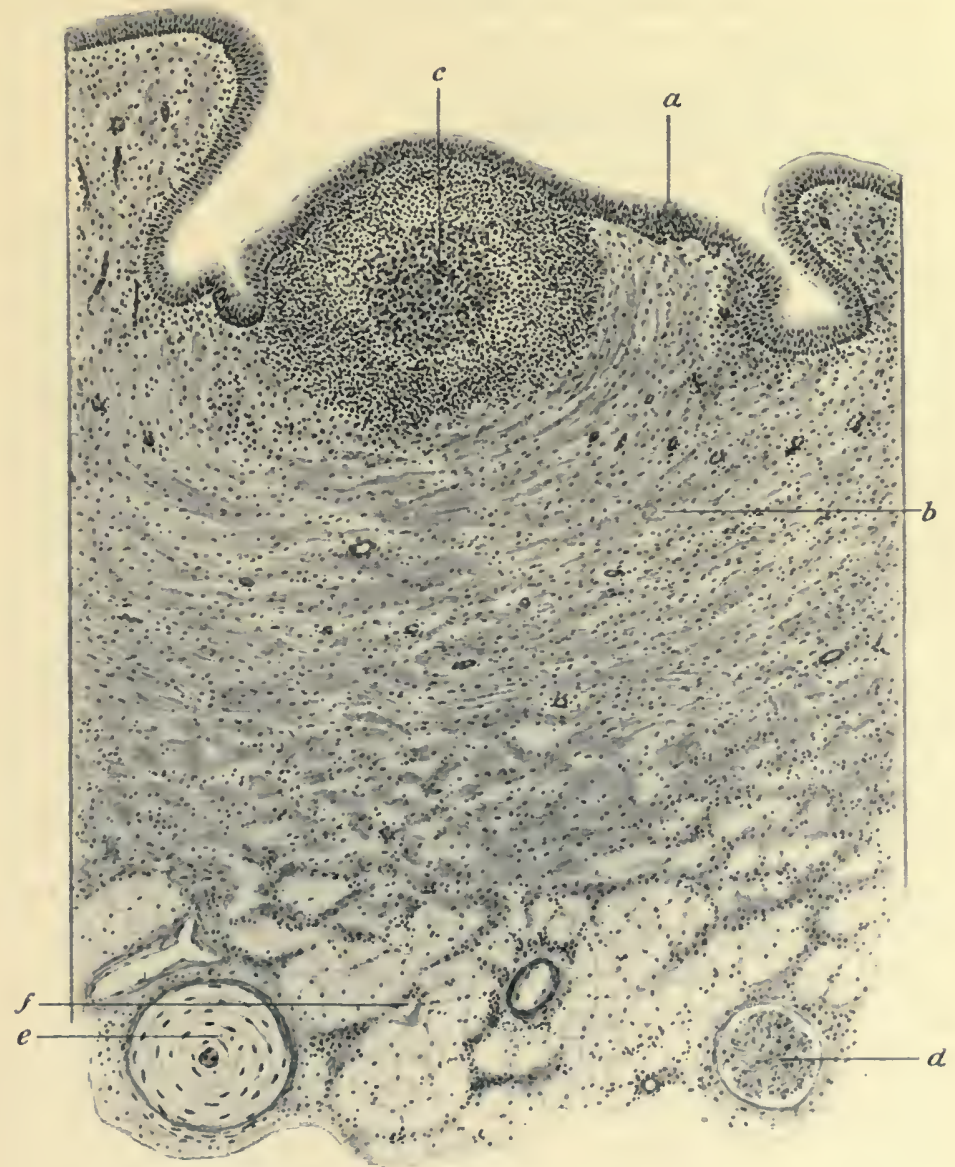

Fig. 5. - Section through wall of vagina (upper part) of monkey. $a$, epithelium; $b$, sub-mucous layer; $c$, lymphatic gland; $d$, nerve; $e$, Pacinian body ; $f$, fat cells.

"Heape, "The Menstruation of Semnopithecus," \&c., Phil. Trans., B., vol. clxxxv., 1894, and vol. clxxxviii., 1897. A similar classification has been adopted by Minot (Human Embryology, 1892), who divides the menstrual process into (1) Tumefaction; (2) Menstruation; and (3) Restoration of the mucosa. 
changes of monkeys. The cycle is divided into four stages, as follows :-

(1) The Constructive Stage.

(2) The Destructive Stage.

(3) The Stage of Repair.

(4) The Stage of Quiescence.

The last stage may conveniently be considered first.

The Stage of Quiescence.-The normal condition of the human endometrium has been described by Webster, ${ }^{1}$ to whose account the reader is referred. This author calls special attention to the following points: (1) The thickness of the mucosa is not uniform, but varies considerably. (2) The epithelial cells which line the nutcosa, and also those which line the glands, show differences in shape and size, and in the position of the nuclei. (3) The epithelial cells lining the glands are, as a rule, larger than the superficial cells. (4) The interglandular connective tissue or stroma is mainly embryonic in nature, and consists of a nucleated protoplasmic reticulum, containing every stage of transformation into the more differentiated spindle-shaped cells. (5) The stroma nearest the surface is for the most part arranged parallel to it, the cells immediately below the epithelium forming a kind of basement-membrane. (6) The superficial portion of the mucosa is supplied only by capillaries. (7) The line of junction of mucosa and muscle-wall is irregular, and there is no special muscularis mucosæ.

The Constructive Stage.-During this stage the stroma of the uterus undergoes a process of growtl. This is brought about partly by cell division, partly (according to Engelmann ${ }^{2}$ ) by an increase in intercellular substance, and partly by an enlargement of the glands and blood-vessels. According to Lipes, ${ }^{3}$ this stage commences as soon as the process of regeneration (following the preceding menstrual period) is completed, which is about eighteen days after the cessation of the previous flow. "During the stage of regeneration the cells of the stroma

1 Webster, Uuman Placentation, Chicago, 1901.

${ }^{2}$ Engelmann, "The Mucous Membrane of the Uterus," \&c., Amer. Jour. Obstet., vol. viii., 1875.

${ }^{3}$ Lipes, "A Study of the Changes occurring in the Endometrium during the Menstrual Cycle," Albany Medical Annals, vol. xxv. 1904. 
lay over each other rather thickly, but now become pressed apart, particularly in the outer third of the mucosa. The protoplasm of these cells becomes compressed, and the pro-

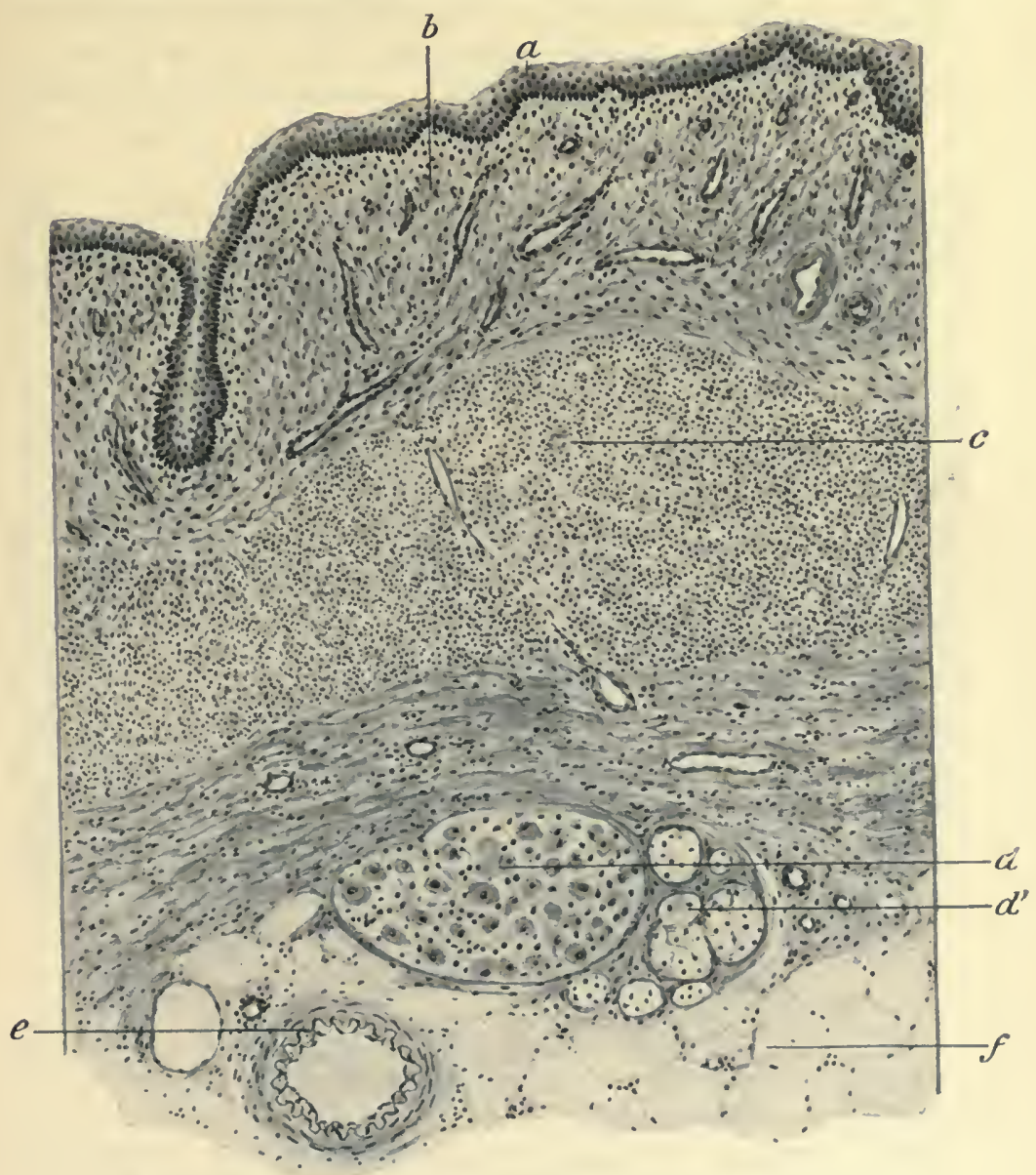

FiG. 6.-Section through wall of vagina (lower part) of monkey.

$a$, epithelium lining cavity; $b$, sub-mucous layer; $c$, muscular layer; $d, d^{\prime}$, nerve ganglia; $e$, artery ; $f$, fat cells.

jections by which they are bound together are either greatly lengthened or completely separated." The capillaries of the mucous membrane become congested (Fig. 7), and a serous or 
sanguineo-serous exudate infiltrates into the stroma. The enlargement of the vessels continues, but does not become very pronounced until shortly before the stage of destruction which may be said to mark the beginning of menstruation proper.

Lipes also describes an increase in the size of the glands of the mucous membrane, which he supposes to be due to the collection of the secretion of the gland-cells. This mucus-like

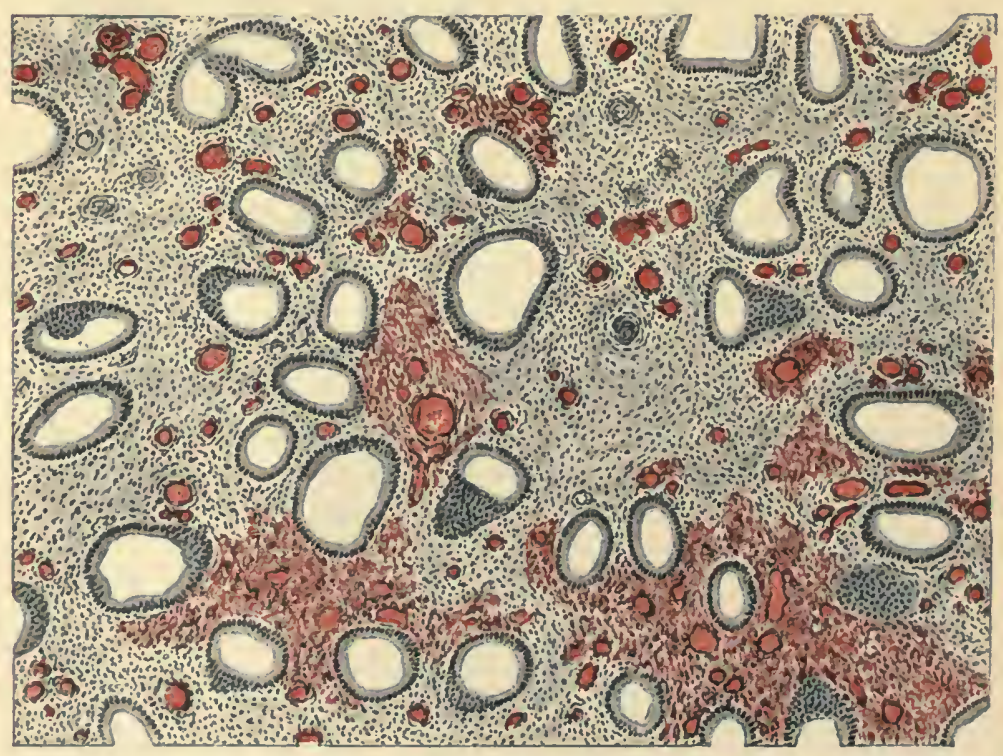

FIG. 7.-Section through mucosa of human uterus showing pre-menstrual congestion. (From Sellheim.)

product of the gland-cells is said to give them a distinctly granular appearance. "The gland-cells become uniformly swollen and take stains more evenly, and their nuclei are more widely separated as a result of the increase in the volune of the protoplasm, and are uniformly more round in comparison with the oval nuclei, which are seen in the regeneration period." Westphalen ${ }^{1}$ has pointed out that the nuclei, which are situated near the base of the cell as a rule, appear in the middle of the cell at the beginning of the stage of pre-menstrual swelling.

1 Westphalen, "Zur Physiologie des Menstruation," Arch. f. Gynäk, vol. lii., 1896 . 
As a consequence of these changes the mucosa becomes considerably increased in thickness. Thus, if a woman who had been menstruating regularly dies shortly before the expected approach of a menstrual period, the thickness of the mucous membrane is often as much as one-sixth of an inch at its thickest part, as compared with a thickness of from one-tenth to onetwentieth of an inch in wornen who died within ten days after the cessation of the flow. ${ }^{1}$ Leopold ${ }^{2}$ has described a growth so considerable that the uterine cavity, prior to the stage of bleeding, becomes almost completely obliterated.

It should be mentioned, however, that according to some authors the amount of pre-menstrual growth in the uterine mucosa is very slight, while Oliver ${ }^{3}$ seems to be doubtful whether any growth occurs at all, stating that he has made an examination of uteri at various pre-menstrual and menstrual stages, and has failed to find any evidence of changes in the mucosa tissue apart from those directly associated with the phenomena of bleeding. Westphalen's view appears to be similar; for, according to this observer, there is no multiplication of nuclei during this stage, the pre-menstrual swelling being brought about entirely by the serous saturation of the stroma.

The Destructive Stage.-At the close of the constructive period the blood leaves the capillaries and becomes extravasated freely in the stroma, but there has been some dispute as to how this process is effected. It has been suggested that the blood transudes through the walls of unruptured capillaries under the influence of congestion, or that permanent openings exist from the vessels into the uterine glands, these being closed normally by muscular contraction ; ${ }^{4}$ but the belief now generally held is that, whereas the walls of many of the congested vessels break down under pressure, and so freely admit of the exit of the blood corpuscles into the mucosa tissue, hæmorrhage also takes place partly by diapedesis. Engelmann, ${ }^{5}$ Williams, ${ }^{6}$ and

1 Galabin, A Manual of Midwifery, 6th Edition, London, 1904.

${ }^{2}$ Leopold, "Untersuchungen iiber Menstruation und Ovulation," Arch. f. Cynäk., vol. xxi., 1883.

3 Oliver, "Menstruation: its Nerve Origin," Jour. Anat. and Phys. vol. xxi., 1887.

4 Galabin, loc. cit.

- Engelmann, loc cit.

- Williams (Sir J.), "The Mucous Membrane of the Body of the Uterus," Obstet. Jour. Gt. Britain vols, iii. and v., $1875187 \%$. 
others have ascribed the breaking down of the vessel-walls to fatty degeneration, but this has been denied by Möricke, ${ }^{1}$ and more recently by Findley, ${ }^{2}$ while Leopold has described the appearance of the fatty degeneration as a result rather than a cause of hæmorrhage.

After the extravasation of blood, the corpuscles tend to become aggregated in lacunæ which lie beneath the superficial

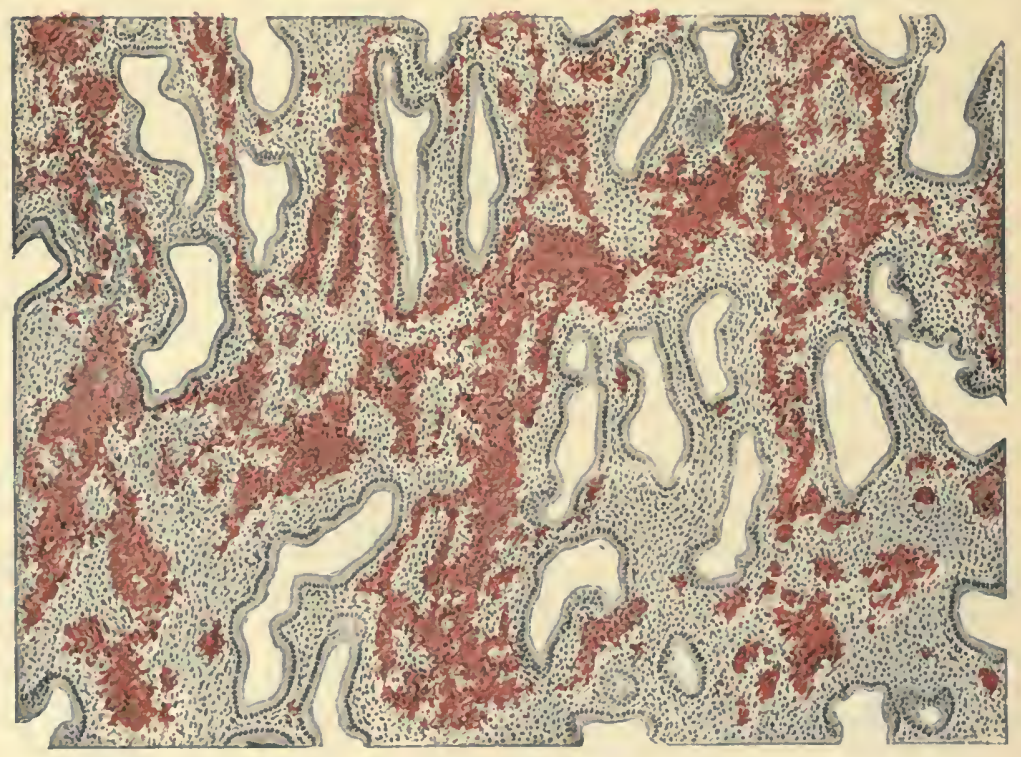

Fig. 8.- Section through mucosa of human uterus showing extravasation of blood. (From Sellheim.)

epithelium. These lacunæ are the sub-epithelial hæmatomata of Gebhard, ${ }^{3}$ according to whom the epithelium becomes lifted almost bodily from its bed, the space between it and the stroma being filled with blood. Gebhard concludes that the blood eventually reaches the uterine cavity by being forced between

1 Möricke, "Die Uterusschleimhaut in der verschietenen Altersperioden und zur Zeit der Menstruation "Zeitsch. f. Geburtshülfe u. Giymük., vol. vii., 1882.

2 Findley, "Anatomy of the Menstruating Uterus," Amer. Jour. Obstel., vol. xlv., 1902.

${ }^{3}$ Gebhard, "Ueber das Verhalten der Uterusschleimhaut bei der Menstruation," Verhand d. Gesells. f. Geb. u. Gyn. zu Berlin, Zeitsch.f. Geb. u. Gym., vol. xxxii., 189 . 
the epithelial cells, or that a larger exit is provided by certain of the cells being carried bodily away. Gebhard also believes that bleeding may take place into the lumina of the glands. Christ ${ }^{1}$ states that when the menstrual flow is very profuse there is a considerable loss of surface epithelium, but that in other cases the removal of epithelium is slight. This author has also described bleeding into the glands. (Fig. 9.)

Very contradictory statements have been made regarding the extent to which denudation takes place during menstruation. Williams (Sir J.), von Kahlden, ${ }^{2}$ and others among the older writers, expressed the belief that a large part, if not the whole, of the uterine mucous membrane was destroyed. This view, as will be seen later, has been partially confirmed for monkeys by Heape. It has been pointed out, however, by Whitridge Williams, ${ }^{3}$ that the older writers made their observations upon uteri which had undergone post-mortem changes. The preponderance of recent opinion appears to be that destruction of the mucous membrane is, as a rule, confined to the epithelium, and that this is only partially removed. Among those who have accumulated evidence in support of this conclusion are Gebhard, Strassmann, ${ }^{4}$ Westphalen, Findley, Whitridge Williams, and Lipes. De Sinety, ${ }^{5}$ Möricke, and Oliver appear to uphold the opinion that even the superficial epithelium remains practically intact. Mandl, ${ }^{6}$ Maerdervort, ${ }^{7}$ and also Champneys ${ }^{8}$ have made the exceedingly likely suggestion that the extent to which the mucosa is destroyed varies within wide limits in different individuals or even in the same individuals at different periods of life.

1 Christ, "Das Verhalten der Uterusschleimlaut während der Menstruation," Inorg. Dissert., Giessen, 1892.

2 Von Kahlden, "Ueber das Verhalten der Uterusschleimhaut während und nach der Menstruation," Hegar's Festschrift, Stuttgart, 1889.

3 Whitridge Williams, Obstetrics, London and New York, 1904.

4 Strassmann, "Beitrïge zur Lehre von der Ovulation, Menstruation, und Conception," Arch.f. Gynäk, vol. lii., 1896.

5 De Sinety, "Recherches sur la muqueuse utérine pendant la menstruation," Annales de Gynce., 1881.

- Mandl, "Beitrag zur Frage des Verhalteıs der Uterusmucosa withrend der Menstruation," Arch.f. Gynük., vol. lii.. 1896.

" Maerdervort, "Die normale und menstruirende Gebärmut terschleimhaut," Inorg. Dissert., Freiburg, 1895.

8 Champneys, "On Painful Menstruation," Harreian Lectures, 1890. 
Minot, ${ }^{1}$ and Martin, ${ }^{2}$ agree in supposing that the superficial layers of the mucosa degenerate after the blood has passed out, so that the bleeding is in no sense the eonsequenee of the destruetion. Aceording to Martin, fatty degeneration plays a distinct part in eausing the destruction.

Lipes has shown that the amount of destruction is related to the character of the hæmorrhage. If the congestion is rapid and the amount of extravasated blood large, the denudation

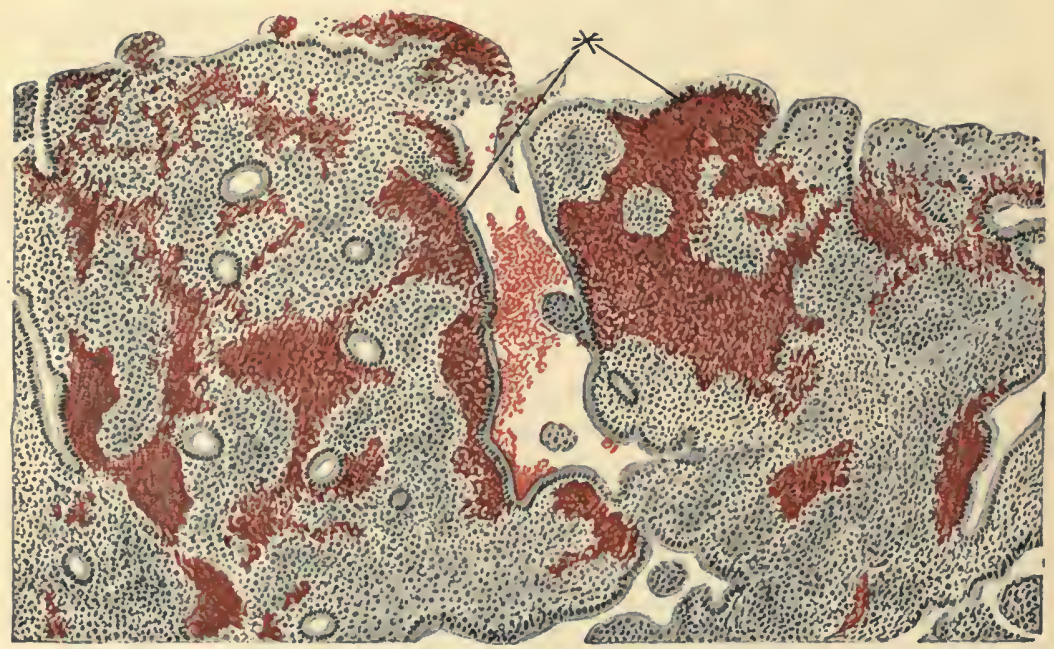

FIG. 9 -Section through mucosa of human uterus showing sub-epithelial hæmatomata*. (From Sellheim.)

is eomparatively extensive ; but if the hæmorrhage is slight, and takes place chiefly by diapedesis, then the loss of tissue is praetically nil. Lipes adds that in none of the cases examined by him were there enough epithelial eells in the discharge to suggest a complete loss of epithelium.

Galabin states that in addition to uterine and vaginal epithelial eells being found in the diseharge, shreds of tissue can frequently be deteeted showing the strueture of uterine stroma. Heape ${ }^{3}$

1 Minot, loc. cit.

2 Martin, "The Physiology of Ovulation, Menstruation, and Fertilisation," Hirst's Obstetrics, vol. i. 1888.

${ }^{3}$ Heape, "The Menstruation and Ovulation of Monkeys and the Human Female," Trans. Obstet. Soc., vol. xl., 1899. 
also has detected stroma tissue in the menstrual discharge of the human female. This clearly shows that destruction is not always confined to the cpithelial layer.

The blood poured out into the uterine cavity, and thence to the exterior, does not usually clot, unless the amount be excessive. This is due to the fact that the blood is considerably diluted with mucus derived from the uterine glands. The glandular activity is accompanied by an emigration of leucocytes which, according to Blair Bell, ${ }^{1}$ are engaged in secreting calcium compounds (sec p. 69). The relative proportion of blood to mucus

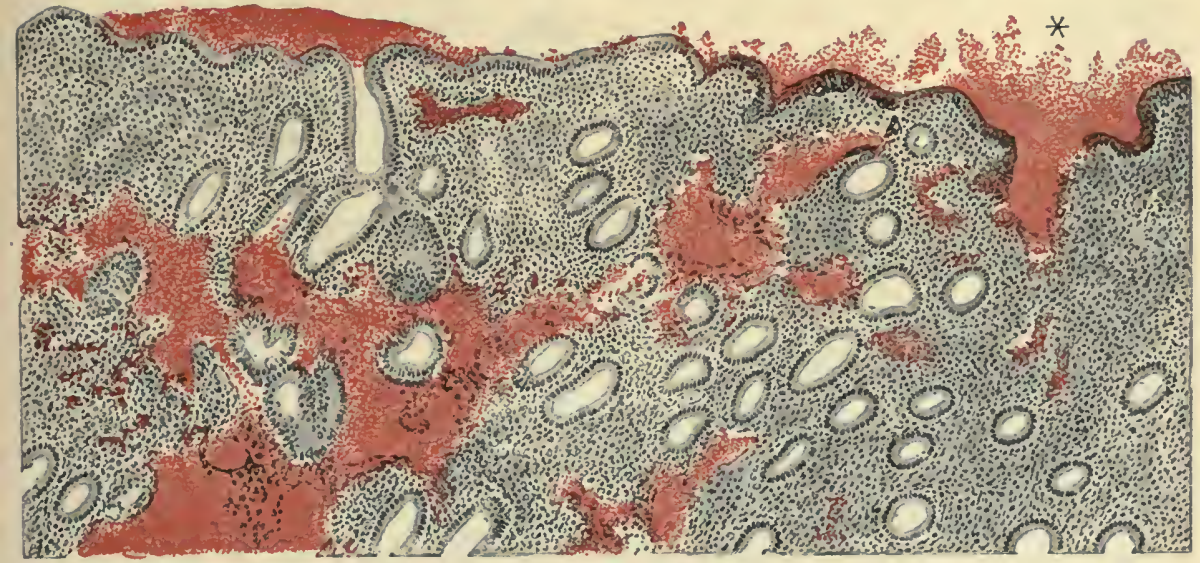

FIG. 10.-Section through mucosa of menstruating human uterus showing bleeding into the cavity *. (From Sellheim.)

in the fluid is usually said to increase from the commencement of menstruation, until the discharge reaches its maximum, after which it goes on diminishing until the flow ceases.

The Stage of Repair.-This corresponds to Gcbhard's period of post-menstrual involution. After the flow has ceased, or even a short time before it has quite ccased, regencration of the uterine mucosa begins. According to Westphalen, ${ }^{2}$ profuse karyokincsis takes place in the tissue of the mucosa, which once more increases in thickness, whereas Heape, as will be scen later, describes a shrinkage as occurring in the regenerative

1 Blair Bell, "Menstruation and its Relation to the Calcium Metabolism," Proc. Roy. Soc. Med., July 1908.

2 Westphalen, loc. cit. 
stage in monkeys. Wyder, ${ }^{1}$ who believed in the partial destruction of the uterine stroma, concluded that this was restored by a hyperplasia of cells in the interglandular tissue of the deeper layers of the mucous membrane, and that the lost epithelium was regenerated from the epithelium of the glands: Similar views have been held by other writers.

Those authorities who hold that the destruction is practically confined to the epithelium believe that the lost cells are

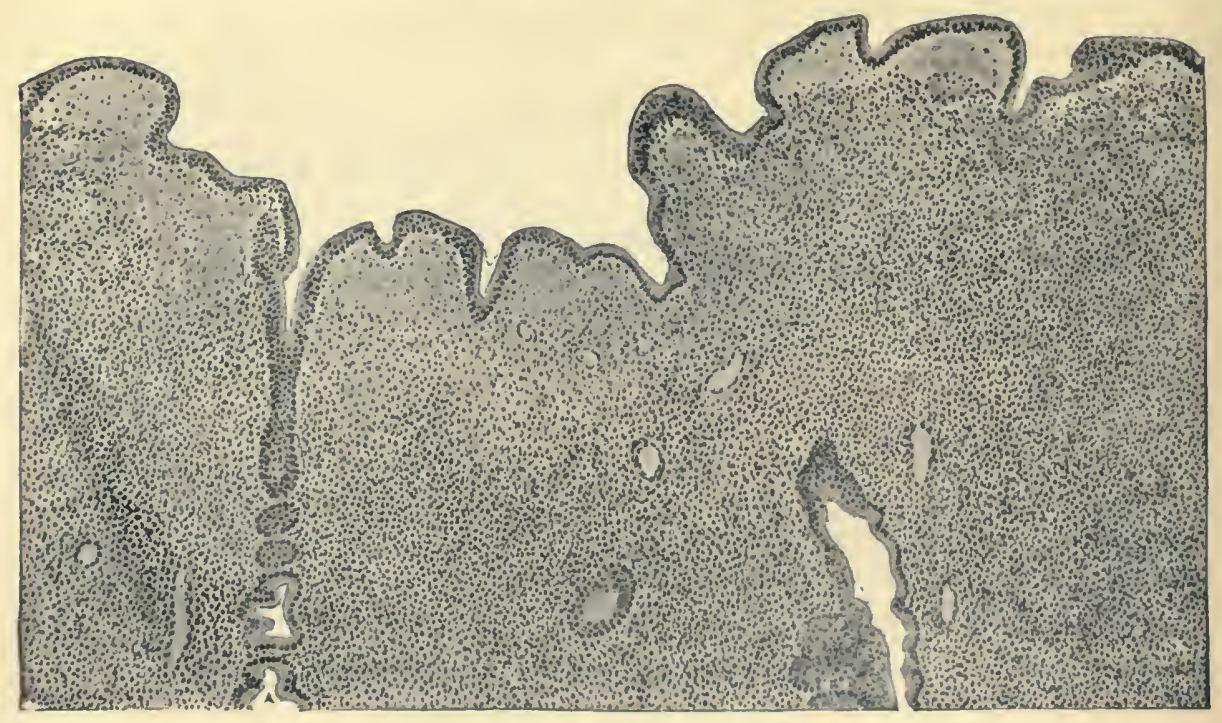

FIG. 11.-Section through the human uterus during the recuperation stage. (From Sellheim.)

replaced by multiplication of the remaining cells. Mandl, for example, describes various stages of mitotic division in the cells of the epithelium at this stage. But this autlior is of opinion that the epithelia of the glands assist in the process of renewal. Gebhard describes the epithelium, which had been lifted from its bed by the blood in the liamatomata, as sinking back to its former position, such cells as were lost being regenerated by multiplication of the others.

The restoration of the mucosa is accompanied by a decrease

1 Whitridge Williams, loc, cit. 
in the size of the blood-vessels, and an absorption of the blood which remains extravasated in the stroma. As to how the blood is absorbed has not been determined in the human female. This is a question which will be discussed in considering the regeneration stage in monkeys and in the lower Mammals. It is stated that new capillaries are formed after the close of the destruction.

The average length of the normal menstrual cycle, as already mentioned, is twenty-eight days. Of these about five are occupied by the pre-menstrual swelling, four by menstruation, and probably about seven by the regeneration process, leaving not more than twelve days for the period of quiescence. ${ }^{1}$ There can be no doubt, however, that the length of the respective stages must vary according to the extent of the destruction and the amount of tissue which it is necessary to replace. According to Westphalen, ${ }^{2}$ the regenerative process may last for as long as eighteen days, or until the commencement of the succeeding pre-menstrual swelling. ${ }^{3}$

\section{The Cycle in Monkeys}

The histology of the menstrual cycle in Sernnopithecus entellus and Macacus rhesus has been very fully studied by Heape. ${ }^{4}$ Previously to Heape's work, Bland Sutton ${ }^{5}$ had paid some attention to the histology of the menstrual process in Macacus rhesus, but without entering into great detail. More recently van Herwerden ${ }^{6}$ has given an account of the cyclical changes of the uterus in Cercocebus cynomolgus.

1 Whitridge Williams, loc, cit.

2 Westphalen, loc. cit.

${ }^{3}$ For further references to the subject of menstruation in the human female the following authors may be consulted: Steinhaus, "Menstruation und Ovulation." Leipzig, 1890; Heape, Phil. Trans. B., vols. clxxxv. and clxxxviii., 1894 and 1897 ; Gebhard, "Dic Menstruation," V'eit's IIandbuch der Gyniik., vol. iii., 1898. For an account of the various pathological changes which are known to occur in the human uterus, see Macgregor, A Contribution to the Patholog!y of the Endometrium, Edinburgh 1905.'

4 Heape, loc. cit. 1880.

5 Bland Sutton, "Menstruation in Monkeys," Brit. Gyncec. Jour., vol, ii.,

- Van Herwerden, "Bijdrage tot de Kennis von den Menstrueelen Cyclus," Tijelschrift d. Ned. Dierk. Vereen., vol. x., 1906. 
Heape has divided the cycle into the following four periods and eight stages :-
A. Period of Rest.
B. Period of Growth.

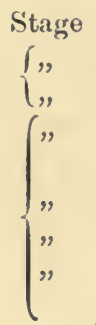
I. The Resting Stage.
II. The Growth of Stroma.
III. The Increase of Vessels.
IV. The Breaking Down of Vessels.
C. Period of Degeneration.
D. Period of Recuperation.
V. The Formation of Lacune.
VI. The Rupture of Lacunæe.
VII. The Formation of the Menstrual Clot.

Heape's account may now be briefly summarised.

I. The Resting Stage.-The epithelial layer of the uterine mucosa consists of a single row of cubical or columnar cells. The outer border is clearly defined, but on the inner side the protoplasm of the epithelium is continuous with that of the sub-epithelial mucosa or stroma tissue. The surface epithelium is continuous with that of the glands, but the latter rest on a basement-membrane which separates them from the interglandular stroma. The stroma contains round nuclei embedded in a network of protoplasm, with fine, delicate processes in which granules may be seen. In Semnopithecus fibrils running fan-wise were observed in the deeper parts of the stroma, but these were not seen in Macacus. Multiplication of cells was not noticed at this stage, either in the epithelium or in the stroma. The vessels in the mucosa are small. A few arteries occur in the deeper portion, but only thin-walled capillaries in the more superficial part; the latter, however, are fairly numerous.

II. The Growth of Stroma.-The nuclei of the more superficial part of the stroma undergo a great increase, the division being amitotic in character, at least so far as could be seen. Is a consequence the inucosa in its upper third becomes considerably swelled (hyperplasia), but in the deeper portion there is no change in the tissue. Owing to the effects of pressure the nuclei become elongated or fusiform. Division occurs either by fragmentation or by the nucleus simply splitting into two. The growth in the upper part of the stroma is associated with an increase in the size of the blood-vessels in the deeper part. 
The superficial epithelium, and also the epithelium of the glands, remain practically unchanged.

III. The Increase of Vessels.-Owing to the continued swelling of the stroma the nuclei in the superficial portion are packed less densely, the lining epithelium becoming simultaneously stretched. The glands tend to become wider. Hyperplasia of the vessels occurs below the epithelium, the surface of the mucosa appearing flushed. At the same time leucocytes become more numerous within the vessels. There is no change in the constitution of the deeper portion of the stroma.

IV. The Breaking Down of Vessels.-The whole of the mucosa, including the epithelium, stroma, and vessel-walls, undergoes pronounced hypertrophy, and in the superficial region the congested capillaries break down and their contents become extravasated through the stroma. Fatty degeneration was not observed by Heape, who is disposed to think that the degeneration is of the amyloid or hyaline type. The leucocytes were noticed to be increased decidedly in number, but they were only detected outside of the blood-vessels in the superficial stroma, where the vessel-walls had given way. Diapedesis of corpuseles was nowhere observed. The nuclei of the stroma become larger and more rounded, and exhibit a nuclear network and deeply staining nucleoli. The glands increase in size, becoming longer; their lumina are wide, and an active process of secretion is taking place. Superficially the mucosa appears very markedly flushed.

V. The Formation of Lacunce.-At this stage the extravasated blood corpuscles collect in lacunæ which are situated in the loose stroma tissue which lies below the epithelium. These lacunæ are clearly identical with the sub-epithelial hæmatomata of Gebhard. The dense stroma tissue, characteristic of an early stage, still persists in places, but is now of rare occurrence. All the superficial vessels have by this time broken down, but those in the deeper tissue remain intact. Neither leucocytes nor red corpuscles are to be found free in the deeper tissue of the stroma. The condition of the glands is the same as in the preceding stage, but there is evidence of degenerative changes in certain of the stroma nuclei, and also in some of the free leucocytes.

VI. The Rupture of Lacuna.-The superficial stroma and 
epithelium shrivel up at this stage, and, as a consequence, the blood contained in the lacunæ is poured into the uterine cavity. The lacunæ are very often close to the glands, so that when a lacuna ruptures, a whole gland may be carried away in the blood stream. The lacunæ have no regular inner wall, but in some places the processes of the stroma were observed to combine together to form a kind of wall which appeared to resist the further encroachment of blood corpuscles in the stroma tissue. Leucocytes are very numerous (usually in the close neighbourhood of the ruptured vessels), some of them being described as mononuclear, and some as having two, three, or four nuclei (products of division). The proportion of leucocytes to red corpuscles was found to be 2 per cent. of the former to 98 per cent. of the latter in unruptured vessels full of blood, while in ruptured vessels, from which blood had escaped, the percentage of leucocytes was noted to be as high as 18.75. Heape does not state, however, that basophil or eosinophil cells occur, such as have been described in the uterus of the dog at a corresponding stage in the cycle. Degenerative changes were noted in many of the epithelial cells, and also in some of the stroma cells, certain of which were seen scattered beneath the remains of the epithelial lining. The stroma below the lacunæ was observed to contain normal as well as shrivelled tissue, but the deeper parts appeared to undergo very little alteration.

VII. The Formation of the Menstrual Clot.-At this stage Heape describes " a severe, devastating, periodic action:" The entire superficial epithelium, portions of the glands or even a whole gland, and a part of the stroma, with broken-down bloodvessels and corpuscles, are torn bodily away, "leaving behind a ragged wreck of tissue, torn glands, ruptured vessels, jagged edges of stroma, and masses of blood corpuscles, which it would seem hardly possible to heal satisfactorily without the aid of surgical treatment." Heape is in no doubt as to the extent of the denudation, differing thus from those writers referred to above, who believe that the destructive process in the human female does not extend beyond certain portions of the superficial epithelium. The cast-off mucous membrane is termed by Heape the mucosa menstrualis. The deeper tissue undergoes no change, the blood-vessels therein being still possessed of com- 
plete walls, but these are larger and more numerous than before. There is no extravasated blood in this region. The proportion of leucocytes in the vessels was observed to be about three per cent. of the corpuscles present, while those on the surface were estimated to comprise about 2.5 per cent. of the total number of corpuscles. Heape ascribes this comparative equalisation to the fact that the ruptured vessels to which the leucocytes adhered in the earlier stages, are themselves cast off, and their contents mingled with the extravasated blood. The supply of leucocytes in the vessels, however, is well maintained.

The menstrual discharge is described as consisting of (1) a viscid, stringy, opaque white fluid derived partly from the blood serum and partly from the secretion of the uterine glands, containing numerous small granules which have their origin in the broken-down plasmodium of the uterine mucosa; (2) red blood corpuscles; (3) masses of stroma tissue and epithelium, both from the lining of the uterine cavity and from the glands, and squamous epithelium from the vagina; and (4) leucocytes together with isolated nuclei of broken-down epithelial and stroma cells. The menstrual clot is composed very similarly, containing a mass of corpuscles together with fragments of uterine tissue. It is expelled at the end of menstruation after remaining some time in the uterine cavity.

VIII. The Recuperation Stage.-The changes which occur during this stage are described by Heape as consisting of five processes, as follows :-

(1) The re-formation of the epithelium.

(2) The reduction of the blood supply.

(3) The formation of new and recuperation of old blood-vessels.

(4) The changes which take place in the stroma.

(5) The behaviour of the leucocytes.

(1) The new epithelium is formed, according to Heape, partly from the epithelium of the glands, but partly from the underlying stroma. The latter is described as a tissue of very primitive characteristics, and the re-formation of the epithelium is regarded as a specialisation of cells belonging to a layer which, in the embryo, gave rise in the same way to similar epithelial 


\section{4 'THE PHYSIOLOGY OF REPRODUCTION}

cells (that is to say, on this view, what takes place after menstruation is merely a repetition of a process which occurs in the embryo). The new epithelial cells, which are at first flattened, gradually become cubical. Heape's account is thus completely at variance with the descriptions of those authors who hold that in the human female the epithelium is renewed entirely from the torn edges of the old epithelium. Heape states that the process of re-formation commences before the expulsion of the menstrual clot, and even before the cessation of the flow of blood into the uterine cavity.

(2) There is still an escape of blood as long as the menstrual clot lies within the uterine cavity, but after its expulsion the flow is checked. Heape suggests that the contractions of the uterus which serve to expel the clot may assist in stopping the escape of blood. Probably, also, the growth of the new epithelium helps to stop the hæmorrhage. After the growth of the new vessels the flow of blood entirely ceases.

(3) At the commencement of this stage many of the extravasated blood corpuscles are seen lying in intercellular spaces in the stroma. These corpuscles, according to Heape, are drawn again into the circulatory system by becoming enclosed within newly formed capillaries. Heape describes the process as follows: "The protoplasm of the cells bounding these [bloodcontaining] spaces flattens out, the nuclei of the cells becoming also flattened and elongated, and numerous fine capillary vessels are thus formed, continuous with the deeper parts of the mucosa with large pre-existing capillaries, and so with the circulatory system.

"These fine capillaries exist only temporarily. When the blood corpuscles are again drawn into the circulation, and when the mucosa has shrunk again into its resting condition, the fine capillaries are no longer seen; but during the time in which the reclaiming process goes on they exist in very large numbers." It shculd be added that this description of the formation of vessels in the uterine mucosa of Semnopithecus and Macacus is in opposition to the usual view regarding the growth of new vessels, which are ordinarily supposed to be only capable of developing as off-shoots from pre-existing ones.

it Heape also describes a recuperation of the old blood-vessels. 
The nuclei which were hypertrophied become reduced in size, and the swollen protoplasm becomes contracted. In this way the vessels are reduced once more to their normal size.

(4) The changes in the cells of the stroma are described as being similar to those in the cells which form the walls of the hypertrophied vessels, the large nuclei and swollen protoplasm giving place to compact nuclei and fine thread-like processes of protoplasm. The multiplication of the stroma nuclei still goes on to a limited extent, but is not nearly so frequent. The tissue is very open during the early stages of recuperation, but gradually becomes drawn together. As a result the whole stroma is reduced considerably in bulk.

(5) The extravasated leucocytes, like the red corpuscles, are said to be returned into the circulatory system by means of the newly formed vessels. Heape says that isolated wandering leucocytes are very rare indeed at this stage, and he makes no mention of basophil or eosinophil cells, such as have recently been described in the uterus of the dog. The actual proportion of leucocytes within the vessels is said to be greater than at any other period in the cycle, as many as fifty per cent. having been observed in certain of the vessels. With regard to the function of the leucocytes Heape suggests that in cases of suppressed menstruation they might play an inportant part, but that in normal menstruation "they seem to have been induced to appear on the scene in such numbers, unnecessarily ; the casting away of the menstrual mucosa, together with all noxious material, and the clean healing of the womded surface, rendering their protective presence unnecessary." At the same time Heape points out that the presence of the leucocytes in the vessels is evidence of the existence therein of a noxious substance which is not present in the surrounding tissue, and he supposes tliat this irritant may be got rid of completely in the flow of blood.

Menstruation in Macacus has also been studied by Bland Sutton, ${ }^{1}$ according to whom the sanguineous discharge is slight. Sutton found no evidence of destruction of the uterine mucosa, not even of the epithelium, but the uterus was distinctly congested, and there was an escape of blood into the cavity. It 1880.

'Bland Sutton, "Menstruation in Monkeys," Brit. Gyncec. Jour., vol. ii. 
should be noted, however, that Sutton's investigation was upon monkeys in this country, whereas Heape's observations relate to Indian animals, and that in Pocock's experience, ${ }^{1}$ menstruation does not, as a rule, occur in Macacus rhesus in the Zoological Gardens. But it would appear also from this author's observations that the severity of the menstrual process in monkeys may vary within as wide limits as it is said to do in the human female.

The changes which occur throughout the menstrual cycle in Cercocebus cynomolgus have been studied in some detail by van Herwerden, ${ }^{2}$ who begins by classifying the material in two groups. In group A are included those animals in which, at the time of killing, the uterus was relatively small and menstruation was correspondingly slight. In group B are placed those monkeys which, on being killed, showed comparatively large well-developed uteri, and in which the menstrual process was characterised by some degree of severity. Van Herwerden is of opinion that the individuals included in the first category were animals killed during the non-breeding season, while those belonging to group B were specimens killed at the breeding season, when the generative organs were in a state of greater activity.

The complete menstrual cycle in Cercocebus is divided into the following periods and stages :-

I. Inter-menstrual period.

II. Pre-menstrual period .

\{1. Increase of superficial stroma elements.

2. Slight swelling of mucosa.

(1. Increasing hyperæmia.

2. Rupture of capillaries.

3. Formation of lacunce.

III. Menstrual period

IV. Post-menstrual period.

4. Degeneration of epitlielium and stroma elements.

5. Rupture of lacunre and tearing off of degenerate tissue.

6. Begrinning of regeneration.

It will be seen from this scheme of classification that the changes recorded by van Herwerden as occurring in the menstrual cycle of Cercocebus are very similar to those described

1 Pocock, "Notes upon Menstruation," \&c., Proc. Zool. Soc., 1906.

2 Van Herwerden, loc. cit. 
by Heape in Semnopithecus and Macacus. Both authors agree in stating that the superficial portion of the mucosa is denuded during the destruction period, differing thus from Bland Sutton and those writers on human menstruation (referred to above) who maintain that the denudation only involves certain portions of the superficial epithelium. Van Herwerden states that the menstrual changes are less marked in the region of the fundus uteri.

The chief differences between van Herwerden's account and that of Heape are as follows:-

According to the former the stroma cells increase mitotically, and not by simple division or fragmentation as supposed by Heape.

The epithelium is described as being renewed from the glandular epithelium in Cercocebus, and not in part from the subjacent stroma, as it is said to do in Semnopithecus and Macacus.

Van Herwerden says that, so far as was observed, the walls of new vessels were not formed during recuperation from stroma cells, as has been described by Heape.

Van Herwerden states that Cercocebus may experience œstrus after menstruation is over. Presumably, therefore, œestrus occurs contemporaneously with the recuperation process in the uterus.

\section{The Cycle in Lemurs}

As already mentioned, Stratz ${ }^{1}$ has called attention to the pronestrous changes which take place in the uterus of Tarsius spectrum, but the process has been studied more closely by van Herwerden. ${ }^{2}$ This author describes the following changes :-

(1) There is a swelling of the glands which is closely followed by mitotic division among a large number of the epithelial cells. Hyperæmia then sets in; but the congestion is localised to certain places, and is not diffused over the entire mucous membrane. Afterwards blood becomes extravasated in the stroma tissue, the corpuscles being aggregated in the more superficial parts - that is to say, in the vicinity of the epithelium. It was

1 Stratz, Der yeschlechtsrcife Saügethiereierstock, Haag, 1898.

2 Van Herwerden, loc. cit. 
noticed that certain corpuscles were taken up by leucocytes, and transported to the uterine cavity. Others were carried along in close association with epithelial cells, both from the superficial layer and from the glands.

It would appear that destruction of the epitlielium does not occur to any extent, and that the bleeding is not severe. This would seem to constitute the chief difference between the procestrous changes in Tarsius, and the corresponding changes in monkeys.

The periodicity of the sexual phenomena in Tarsius spectrum has already been referred to.

\section{The Cycle in Insectivora}

The changes which occur in the internal generative organs during the cycle in Tupaia javanica, and in the aberrant Insectivore, Galeopithecus volans, have received some slight attention.

Stratz ${ }^{1}$ has described the existence of a blood-clot and a "menstrual" flow in Tupaia, and records the presence of desquamated epithelial cells in the blood-clot. Van Herwerden, ${ }^{2}$ however, states that the individuals which Stratz examined were in the puerperal stage, and that, although Tupaia can experience "heat" and become pregnant at this time, trustworthy conclusions regarding the severity of the procestrous changes cannot be drawn from such specimens. That there was considerable bleeding van Herwerden admits. Nothing is known about the periodicity of the clianges in Tupaia.

In Galeopithecus van Herwerden describes uterine hyperæmia during the procestrum. In the superficial mucosa numerous highly congested capillaries were noticed. In the later stages blood was found extravasated in the stroma, some of it being collected in spaces which were probably comparable to the sub-epithelial hæmatomata described by Gebhard in the menstruating human female. In the superficial epithelium spots were detected where a few of the cells had been removed. Bleeding did not appear to be localised to any particular area in the uterus. 
Van Herwerden is certain that the changes observed could not be ascribed to a puerperal condition, as in the case of Tupaia, but must have been the result of a normal proøstrum. The periodicity of the changes is unknown.

\section{The Cycle in Carnivores}

The histological changes in the non-pregnant uterus have been studied in the $\operatorname{dog}^{1}$ and in the ferret. ${ }^{2}$ The periods into which the uterine cycle is divided are identical with those adopted by Heape for the monkey :-

(1) Period of rest

Ancestrum.

(2) Period of growth and congestion

(3) Period of destruction

(4) Period of recuperation

$\left\{\begin{array}{l}\text { Ancestrum. } \\ \text { Procestrum. } \\ \text { Estrus. } \\ \text { Metcestrum. }\end{array}\right.$

It is seen that cestrus, or the time of desire, begins normally about the close of the period of destruction. With the ferret it may be very prolonged, extending until the end of the recuperation period, or even considerably beyond it. Consequently there may be no metœstrum (strictly speaking) with the ferret, since the period during which copulation can occur is liable to persist until the uterus has reached the resting stage.

(1) Period of Rest.-The uterine mucosa in both the dog and the ferret is bounded at the surface by an epithelium consisting of a single row of coluninar or cubical cells, and is continuous with that of the glands. The stroma is a connective tissue, confaining numerous fusiform cells. Blood-vessels of small size are fairly common. Leucocytes do not appear to occur in the mucosa outside of the vessels. Pigment is not present at this stage, at least ordinarily.

(2) Period of Growth and Congestion.-The mucosa at this period becomes slightly thickened, and tends to be more compact. This is effected by cell divisions, but mitoses have not been

Marshall, and Jolly, "Contributions to the Physiology of Mammalian Reproduction: Part I. The CEstrous Cycle in the Dog," Phil. Trans., B, vol. cxeviii., 1905.

2 Marshall, "The OEstrous Cycle in the Common Ferret," Quar. Jour. Micr. Sei. vol. xlviii., 1904. 
observed. Retterer, ${ }^{1}$ who has contributed a short account of the changes in the bitch's uterus, describes the mucosa as growing to three or four times its normal thickness, but this observation has not been confirmed. The growth is accompanied by enlargement and congestion of the capillaries, which at the same time become more numerous. ${ }^{2}$ The vessels in the surrounding muscular tissue also tend to enlarge. The epithelium undergoes

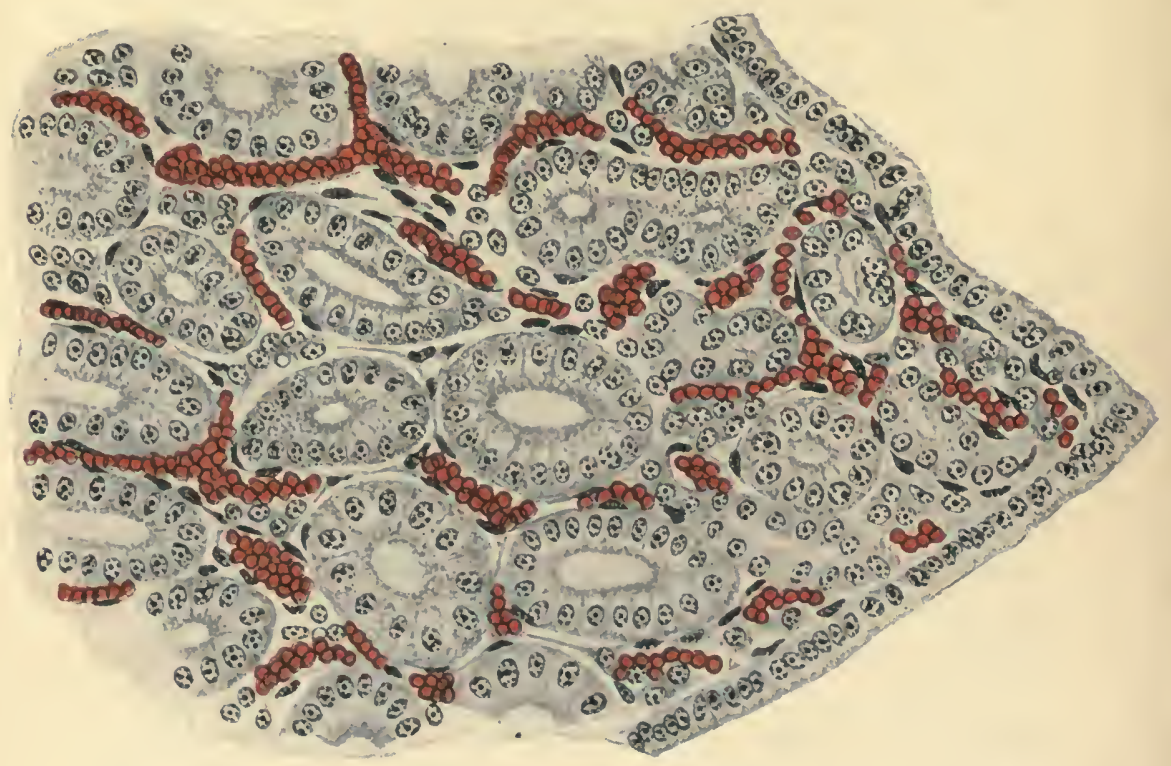

FIG. 12.-Section through procestrous uterine mucosa of dog, showing congested vessels between the glands. (From Marshall and Jolly.).

no material change so far as seen. In the case of the ferret the uterine cavity is described as becoming markedly reduced in size, while the glands are stated to undergo an appreciable swelling accompanied by an increased secretory activity.

(3) Period of Destruction.-The walls of the stretched bloodvessels break down, and red corpuscles, accompanied by

1 Retterer, "Sur les Modifications de la Muquense Utérine ì l'Epoque du Rut," C. R. de la Soc. de Biol., vol. iv., 1892.

${ }^{2}$ Cf. Retterer, loc. cit.; also Keiffer, "La Formation Glandulaire de l'Uterus," Annales de la Soc. Medico-Chirurg. de Brabant. 1899; and Bonnet, "Beiträge zur Embryologie des Huudes," Anat. Ilefte, vol. xx., 1902. 
lencocytes, become extravasated throughout the stroma. Some of the vessels, however, remain intact. The breaking down of vessels appears to occur fairly uniformly throughout the stroma instead of being restricted to any particular portion. The extravasated blood for the most part collects immediately below the superficial epithelium, but it is not aggregited in large lacuna-like spaces, such as Heape has described in the monkey.

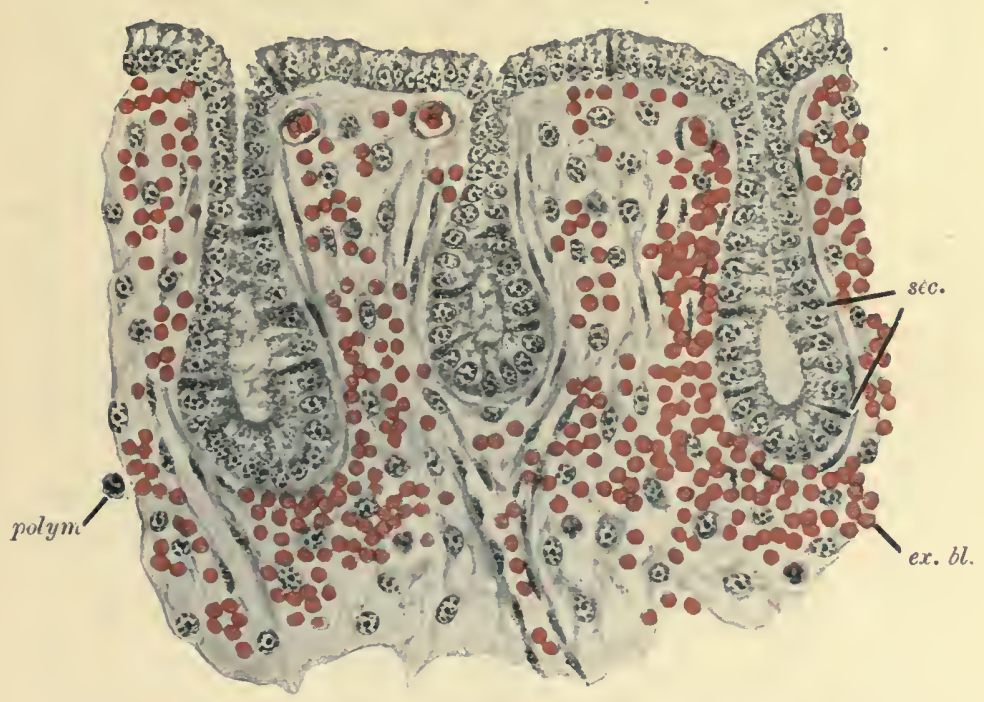

F1G. 13.- Section through procestrous uterine mucosa of dog. (From Marshall and Jolly.)

ex. bl., Extravasated blood corpuscles ; polymı., polymorph ; scc., cells probably indicating secretory activity.

These "sub-epithelial hæmatomata" have been noticed especially in the procstrous bitch. The walls of the vessels in the muscular layers do not give way.

Eventually the extravasated blood corpuscles (or, at any rate, the majority of them) make their way into the cavity of the uterus, and thence to the vagina, where external bleeding is observed. This is especially noticeable in the case of the bitch, with which, as already mentioned, external bleeding may last for as long as ten days. The bleeding is accompanied by an increase in the mucous secretion. At about the same stage 
goblet-shaped cells are frequently observable in the glandular epithelium, and it is suggested that these are in some way connected with the secretory activity of the glands.

It is probable that destruction of the superficial epithelium occurs normally to a greater or less extent both in the bitch and in the ferret: Epithelial cells have been observed lying free in the uterine cavity, while, in some sections, places have been noticed where the stroma presented a raw edge, having been stripped of its epithelial covering. In the bitch a layer of flattened stroma cells may sometimes be seen in close attachment to the epithelium during the process of denudation. In the ferret it would appear that the destruction may occasionally be severer, but it is thought that this is exceptional. It has been pointed out, however, that a comparison between the thickness of the uterine wall (and conversely the size of the uterine cavity) in ferrets killed at the commencement of the recuperation period and during the period of rest, is very suggestive of a definite removal of stroma as well as of epithelium in the process of destruction.

Polymorph leucocytes have been observed in abundance at this stage in the bitch's uterus, both in the stroma and also in the cavity, and large mononuclear leucocytes (hyaline corpuscles), containing pigment derived doubtless from the extravasated blood, have also been seen to occur. Large cells, with faintly staining nuclei of very considerable size and conspicuous nucleoli, have been noticed at rare intervals lying in spaces in the stroma tissue of the proœstrous bitch. The origin and significance of these cells are not known.

There is no blood-clot formed in the uterus, either in the bitch or in the ferret.

(4) Period of Reciperation.-The new epithelium in the bitch is first seen as a layer of flattened cells which bear a resemblance to the cells of the stroma. Its manner of formation is an open question, but it would seem probable that it is derived mainly, if not entirely, from the remaining cells of the old epithelium, or from those of the glands. It is just possible, however, that in certain places the epithelium may be renewed from the underlying stroma tissue, as is said by Heape (but not by van Herwerden) to be the case in the monkey. 
During the earlier stages of recuperation a variable, and often a large, number of red blood corpuscles remain scattered in the stroma, chiefly in the part nearest the surface. At a later stage extravasated corpuscles are no longer seen in any quantity, while numerous new vessels appear to have been formed, presumably from pre-existing vessels.

Polymorphs are no longer common in the bitch's mucosa tissue, but leucocytes of other varieties are a characteristic

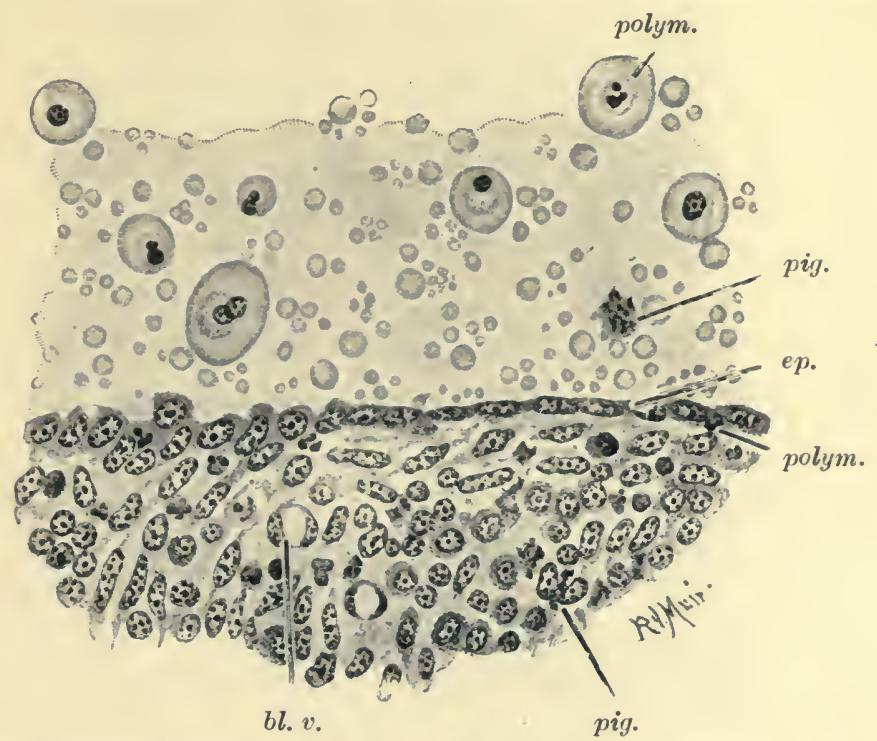

Fig. 14-Section through edge of mucosa of dog during an early stage of recuperation. (From Marshall and Jolly.)

$b l . v$, blood-vessel ; ep., epithelium in process of renewal ; pig., pigment; polym., polymorph.

feature. The following kinds have been observed: (1) Coarsely granular eosinophil cells, with lobed nuclei. These occur in the blood in cases of trichinosis, bronchial asthma, sarcoma, osteomalacia, skin diseases, and other affections, but are rare under ordinary conditions. (2) Basophil cells, with simple nuclei and containing coarse granules, but never any pigment. The number of granules varies, and in some of the cells is very small. These basophil cells are evidently similar to the mast cells of Ehrlich, and the plasma cells of Unna. Mast 


\section{4}

THE PHYSIOLOGY OF REPRODUC'TION

cells are said to be often found in inflammatory areas, and are described as occurring in the stroma tissue of tumours in association with plasma cells, and also in the peripheral circulation in cases of lymphatic and myeloid leucæmia. They are especially numerous during the recuperation period of the bitch's uterus, and it is suggested that they must in some unknown way be functionally connected with that process.

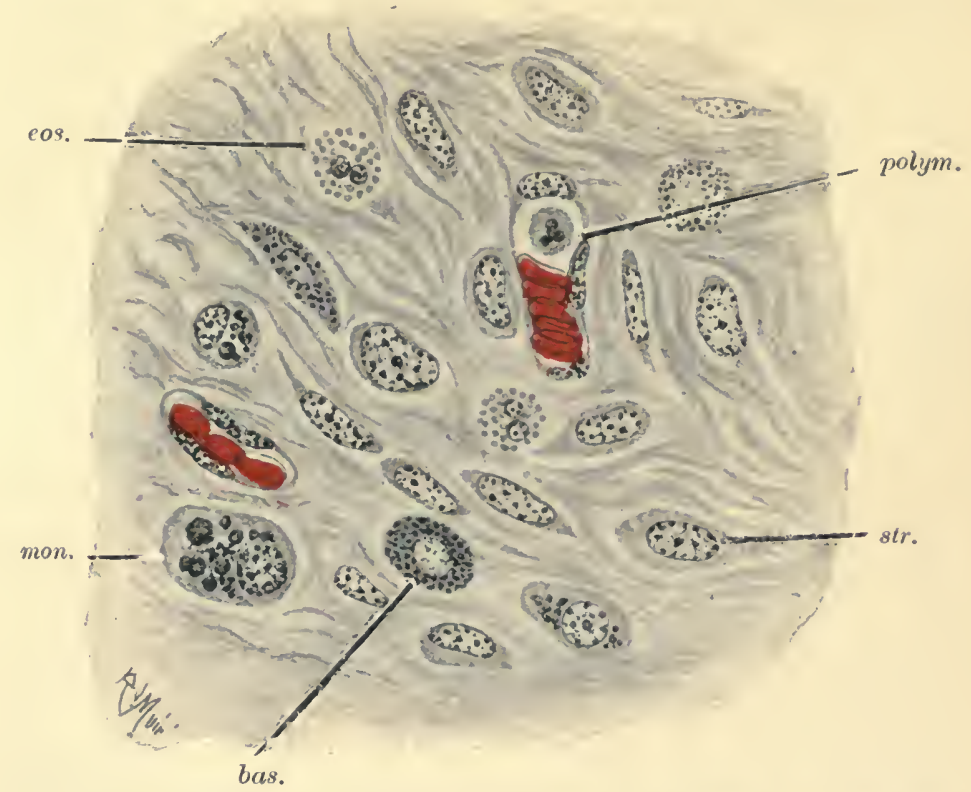

FIG. 15.-Section through portion of mucosa of dog during the recuperation period. (From Marshall and Jolly.)

bas., basophil cell ; cos., eosinophil cell ; mon., mononuclear leucocyte ; polym., polymorphs ; str., stroma cell.

(3) Large mononuclear leucocytes (hyaline corpuscles or macrocytes), containing blood-pigment which gives the Prussian-blue reaction. Since pigment formation and ingestion by leucocytes are of frequent occurrence in the bitch's uterus at about this stage, it is probable that this is the fate of the great majority of the extravasated red corpuscles. It is possible, however, as suggested in the paper from which this account is taken, that a relatively small proportion may make their way 
into the lymphatics, and so re-enter the circulation. Pigment formation has not been observed in the ferret.

At a late stage in recuperation the stroma tissue tends to become denser, and also to increase in thickness (ferret), until the whole uterus once more acquires its normal condition.

If copulation has taken place, spermatozoa in great numbers

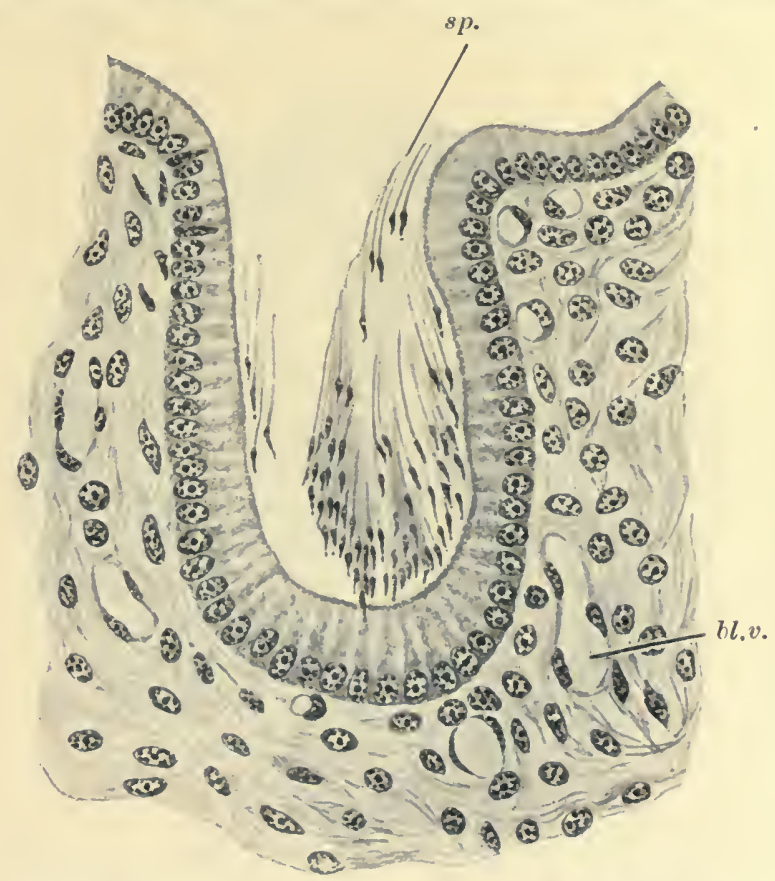

FIG. 16.-Section through mucosa of dog during a late stage of recuperation. (From Marshall and Jolly.)

ul. $v$., blood-vessel ; sp., spermatozoa in cavity of gland.

may be observed in the deeper portions of the uterine glands, as well as along the edges of the uterine cavity.

\section{The Cycle in Rodents}

Comparatively little attention has been paid to the uterine changes in Rodents. In the rabbit it has been noticed that the uterus is swollen and congested during "heat," and the same observation has been made in the marmot 
(Spermophilus citillus). ${ }^{1} \quad$ Lataste $^{2}$ has described procstrous growth and congestion in the uterus of several Muridx, and this is stated to be followed by a sanguineous discharge from the original opening. Lataste has also described desquamation of the uterine epithelium, but.he appears to regard this process as taking place independently of " heat."

More recently Königstein ${ }^{3}$ has recorded cyclical changes in

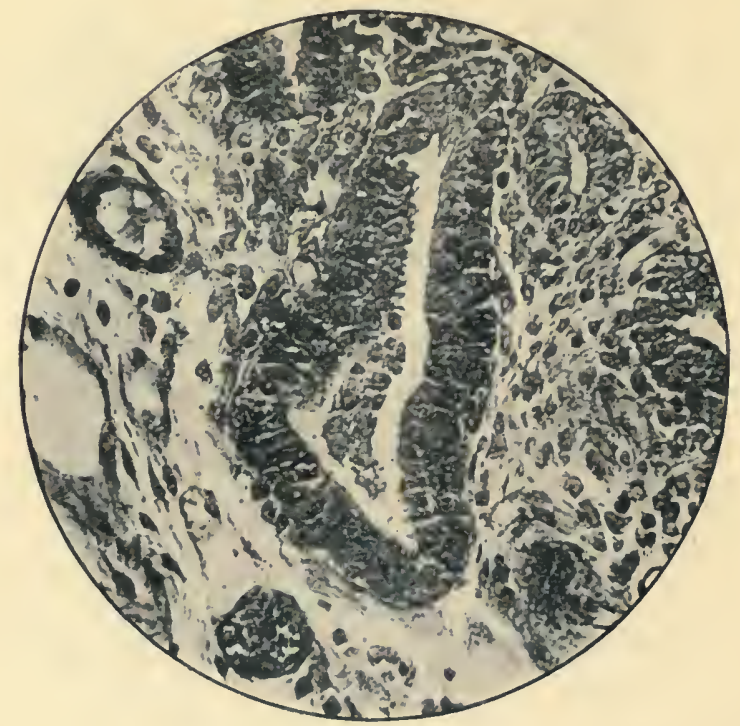

FiG. 17.-Section through portion of proœstrous uterine mueosa of rabbit showing glandular activity. (From Blair Bell, in Proc. Roy. Soc. Medicine.)

several Rodents (rat, guinea-pig, \&c.), and has described proostrous desquamation of the uterine epithelium, followed by recuperation. The degenerative clianges are accompanied

1 Rejsek, "Anheftung (Implantation) des Säugethieres an die Uteruswand, insbesondere des Eies von Spermophilus eitillus," Areh. f. Mikr. Anat., vol. 1xiii., 1904.

2 Isataste, Recherches de Zoéthique sur les Mammifères de l'ordre des Rongeurs, Bordeaux, 1887.

${ }^{3}$ Königstein, "Die Veränderungen der Genitalsehleimhaut während der Gravidität und Brunst bei einigen Nagern," Pfüger's A rch., vol. exix., 1907. 
by a secretion of mucus, and there is a marked leucocytosis over the entire generative tract. Desquamation of epithelium also occurs in the vagina. Furthermore, emigration of leucocytes between the epithelium of the glands, accompanied by great glandular activity, has been observed by Blair Bell ${ }^{1}$ in the procstrous uterus of the rabbit.

\section{The Cycle in Ungulates}

The uterine changes have been worked out most fully in the case of the sheep. ${ }^{2}$ They relate chiefly to the blood-vessels, and are grouped according to four periods as in the case of the monkey, the dog, and the ferret, referred to above.

(1) Period of Rest.-The histological characters of the uterus during this period are those of an organ in a state of quiescence. Protoplasmic processes can be seen passing from certain of the stroma nuclei, but these, though denser in some places than in others, show little evidence of division. Dark brown or black pigment may be present in considerable quantities, especially in the region subjacent to the epithelium, both in the cotyledonary papillæ and (more frequently) between them and round their bases. Such pigment has not been observed in yearling sheep (i.e. in sheep less than a year old); neither does it appear to occur, as a rule, during the anostrum, but only during the diøestrous interval.

(2) Period of Growth.-The nuclei in the stroma multiply, and the mucosa increases slightly in thickness. The epithelium, however, appears to remain unaffected. The blood-vessels increase both in size and number, producing uterine congestion. These changes occur both in the cotyledonary papilla and in the intervening tissue around the bases of the papillæ.

(3) Period of Destruction.-The congestion is followed in most cases by the breaking down of some of the vessels. Very frequently the first extravasation takes place from vessels situated immediately below certain parts of the stroma where the nuclei are most thickly distributed. Leucocytes are extravasated

1 Blair Bell, loc, cit.

2 Marshall, "The Estrous Cycle and the Formation of the Corpus Luteum in the Sheep," Phil. Trans., B., vol. cxcvi., 1903. 
along with the red corpuscles, but there is no evidence of the existence of wandering cells apart from those which are derived apparently from the broken-down vessels. The blood tends to collect below the epithelium. Bleeding into the uterine cavity may occur, but is not invariable. A few epithelial cells are sometimes torn off (presumably in places where blood is poured out into the cavity), but destruction even to this extent does not necessarily take place. Denudation of the stroma has never been observed. It would seem that the severity of the proastrous process tends to diminish with each successive dioestrous cycle in the breeding season, and that sometimes in a late procestrum the period of destruction is never reached, the congested vessels subsiding without undergoing rupture. Bleeding, when it does occur, appears to be more frequent in the cotyledonary papillæ than between them, and is commoner in the large papillæ than in the smaller ones.

Kazzander ${ }^{1}$ appears to have been the first to detect extravasated blood in the sheep's mucosa. Subsequently Bonnet ${ }^{2}$ has noted uterine bleeding in various Ruminants, as well as in the mare and sow, and Kolster ${ }^{3}$ has made similar observations (cf. also Emrys-Roberts, see p. 47). Ewart also has described proøstrous extravasation and the presence of hæmatoidin crystals in the uterus of the mare. Glandular activity during heat was also noted. ${ }^{4}$

(4) Period of recuperation.-The sheep's procstrum may be said to end with the period of destruction, the entire process probably lasting for not longer than one or two days, its exact duration depending upon its severity. Estrus itself, which occurs during the beginning of the period of recuperation, sometimes occupies only a few hours.

In those places where bleeding into the cavity took place in the preceding period the epithelium is renewed, apparently

"Kazzander, "Uber die Pigmentation der Uterinschleimhaut des Schafes," Arch. f. Mikr. Anat., vol. xxxvi., 1890.

2 Bonnet, article in Ellenberger's Vergleichende Physiologic des Haussäugethicre, vol. ii., Berlin, 1892. Cf. also Ellenberger's article in same volume.

${ }^{3}$ Kolster, "Weitere Beiträge zur Kenntniss der Embryotrophe bei Indecidunten," Anat. Ilefte, vol. xx., 1902.

- Ewart, "The Developwent of the Horse," Quar. Jour. Micr. Science, (not yet published). 
from the edges of the adjoining epithelium which had not suffered destruction. In this way the re-formation of the epithelium is sufficiently accounted for, since, as already remarked, only a very inconsiderable number of cells is removed during the sheep's proøstrum.

Congestion of the stroma gradually diminishes, and the

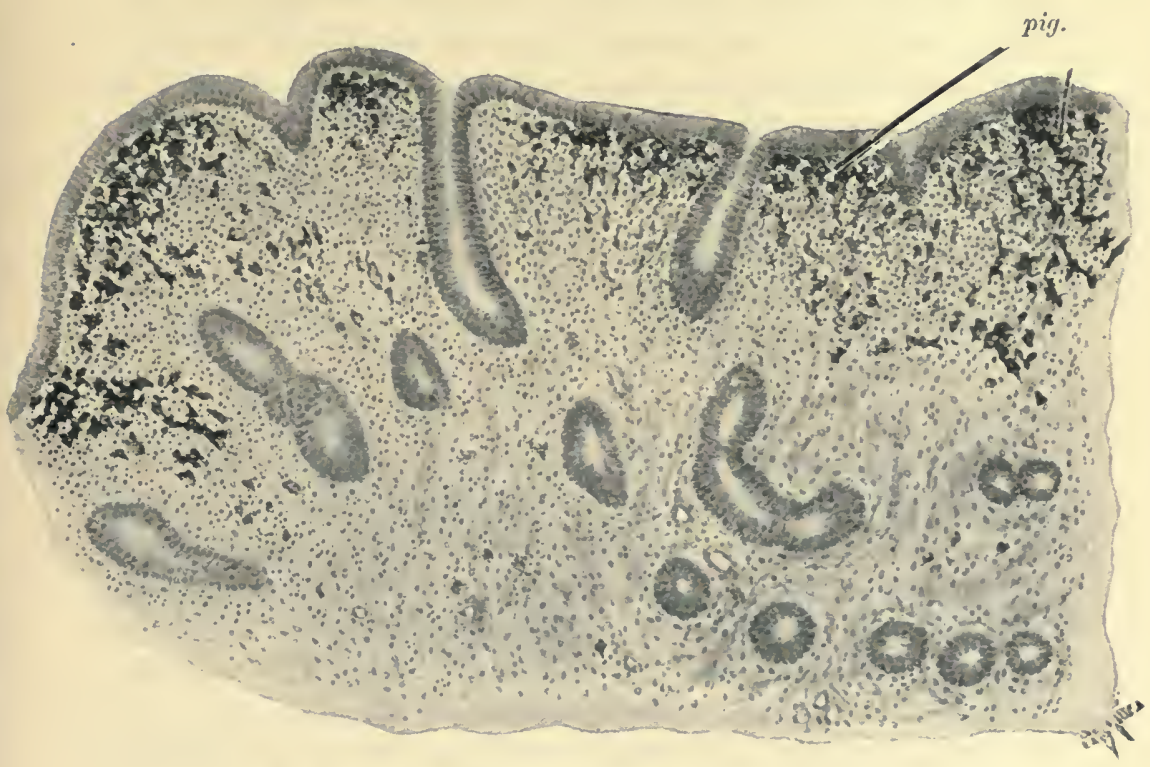

FIG. 18.-Section through portion of uterine mucosa of sheep showing black pigment ( $p i g$. ) formed from extravasated blood.

mucosa as a whole undergoes a slight shrinkage. It would appear that a few new capillaries are formed, but there is no evidence that any of the extravasated corpuscles are gathered up afresh into the circulatory system. On the other hand, there are ample indications that all those corpuscles which remain in the tissue become transformed into pigment, as originally concluded by Bonnet. ${ }^{1}$ According to this investigator, the extravasation takes place in the deeper mucosa, and the

1 Bonnet, “Ueber Melanose der Uterinschleimhaut," \&c., Deutche Zeitsch. f. Thiermedizin, vol. v., 1880, and vol. vii., 1882. "Beiträge zum Embryologie der Wiederkauer," \&c., Arch. f. Anat. u. Phys., Anut. Abth., 1884. 
derivatives of the corpuscles are carried in the form of pigment to the more superficial area by wandering cells. Kazzander, ${ }^{1}$ however, does not admit the agency of leucocytes; but the most recent observations support Bonnet's conclusions, excepting that (as previously stated) the extravasation which takes place during the destruction period is in the superficial mucosa rather than in the deeper tissue. Thus, although leucocytes are probably involved in the process of pigment formation, there is no need to assume that they carry the extravasated corpuscles to the region where pigment is most abundant. Sometimes the interior of the uterus appears superficially to be perfectly black with pigment, but in such cases the pigment is, no doubt, derived from blood which had been extravasated during a series of procstrous periods, and not merely during the most recent one. Assheton ${ }^{2}$ states that the pigment so formed is subsequently disposed of.

A consideration of the facts set forth in this cliapter should leave one in no doubt regarding the essential similarity between the menstrual cycle in the Primates, and the astrous cycle in the lower Mammalia. Those who have denied that there is any correspondence between "heat" and menstruation ${ }^{3}$ have laid stress upon the assertion that whereas "heat" in the lower animals is the time for coition, this act, as a general rule, is not performed during menstruation. But, as was first pointed out by Heape, it is the proøstrum alone and not the entire " heat period" (a term used generally to include both procstrum and œstrus) which is the physiological homologue of menstruation; and, moreover, the latter process in many of the Primates is succeeded by a regular post-menstrual œestrus.

The physiological identity of the proøstrum with menstruation should always be kept in view in considering the cause and nature of the phenomena, since, as will be seen later, many strange errors have been committed, and wrong conclusions

1 Kazzander, loc, cit.

2 Assheton, "The Morphology of the Ungulate Placenta," Phil. Trans. B., vol, cxcviii., 1906.

${ }^{3}$ Beard, in The Span of Gestution and the Cause of Birth (Jena, 1897), says, "very little is required in disproof" of this correspondence. 
arrived at, through failure to realise the unity of the two processes.

It has been shown further that although the changes which occur in the uterus during the cycle present a striking similarity in the various mammalian types in which they have been studied, yet there is a considerable amount of variation in the severity and duration of the proøstrous phenomena. The extent of the congestion, and the destruction which usually succeeds it, are greatest, as a rule, in the highest Mammals, and comparatively slight in the Rodentia and Ungulata. The histology of the cycle in the lowest Mammals has never been worked out, but, as already mentioned in the preceding chapter, vaginal bleeding has been noticed in Marsupials.

The purpose or meaning of the procstrum, and the factors which contribute to its occurrence, will be considered as fully as the present knowledge of the subject permits, after the changes which take place in the ovaries have been dealt with, in a future chapter of this work. It may be at once stated, however, that most authorities are now agreed that the menstrual process is in some sense a preparation for the attachment of an ovum to the wall of the uterus, but opinions differ as to the precise nature of the preparation. On the other hand, it is evident that the changes involved in menstruation are not absolutely essential, since there arc records of pregnancy occurring in individuals who had never experienced menstruation. Moreover, there is evidence that the procstrous discharge may be not only of no utility to the organism, but may even become injurious, as in the morc severe cases of menstruation among women.

In view of these facts it may be called in question whether the procstrous changes in the uterus should not be regarded merely as the result of a wave of disturbance which ushers in the period of desire, and is of the nature of a consequence rather than a purpose. This is in accord with Metchnikoff's suggestion, ${ }^{1}$ that the catamenia in women is essentially a "disharmony" of organisation, which has been brought about as the result of modifications acquired recently in the history of the species. If this is so, a similar explanation must be adopted in the case of 1903.

1 Metchnikoff, The Nature of Man, Mitchell's Translation, London 


\section{2 'THE PHYSIOLOGY OF REPRODUCTION}

those animals which experience an especially severe proœstrum. According to such a view as this the phenomena of menstruation must be looked upon as belonging to the borderland of pathology. In this connection the large number of leucocytes which attend the menstrual process, some of them clearly phagocytic in function, is not altogether unsuggestive. 


\section{CHAPTER IV}

CHANGES IN THE OVARY-OÖGENESIS-GROWTH OF FOLLICLES-OVULA'TION-FORMATION OF CORPORA LUTEA AND ATRE'TIC FOLLICLES-THE SIGNIFICANCE OF THE PROCESTROUS CHANGES IN THE UTERUS

"The newest freak of the Fallopian tubes and their fimbrix, and the very latest news from the ovisac and the corpora lutea."-JоHN BRows, Hora Subseciva.

\section{Development of Ovary and Oögenesis}

TuF animal egg is a large spheroidal cell consisting of external protoplasm or cytoplasm, a nucleus or germinal vesicle, and a nucleolus or germinal spot. ${ }^{1}$ Within the cytoplasm is a mass of food material or yolk (sometimes known as deutoplasm), the quantity of which varies slightly in different Mammalia, and is very considerable in birds and certain other animals. The unfertilised ovum differs from the male germ-cell or spermatozoön in its devoting itself mainly to the storage of food-substance and accumulation of potential energy, for it is incapable of active movement. The metabolic processes of the ovum, therefore, are almost entirely constructive, while those of the spermatozoön are largely destructive. The function of the ovum is to conjugate with the spermatozoön, and subsequently, by a lengthy process of cell division, to give rise to a new individual.

The mammalian ovary, ${ }^{2}$ or organ in which the ova are produced, is composed of a stroma of fibrous connective tissue, which contains some plain muscular fibres (especially in the neighbourhood of the attachment to the broad ligament) as well as numerous blood-vessels. The surface is lined by a layer of columnar epithelial cells. Within are a number of

1 A centrosome has been described as present in the ova of some animals. For a detailed description of the ovum in different forms see Wilson, The Cell in Development and Inheritance, 2nd Edition. New York, 1900.

2 See also Stratz, Der geschlechtsreife Säugethiercierstock, Haag, 1898. 


\section{THE PHYSIOLOGY OF REPRODUC'IION}

vesicles of various sizes, each with an ovum, surrounded by an epithelium. These are called Graafian follicles. Certain other structures, consisting of very large yellow-coloured cells enclosed by a branching network of connective tissue, are also often found. These are the corpora lutea or discharged follicles to be described more fullv later. The stroma contains, further, a varying number of epitheloid interstitial cells.

In order to gain a proper understanding of the structural

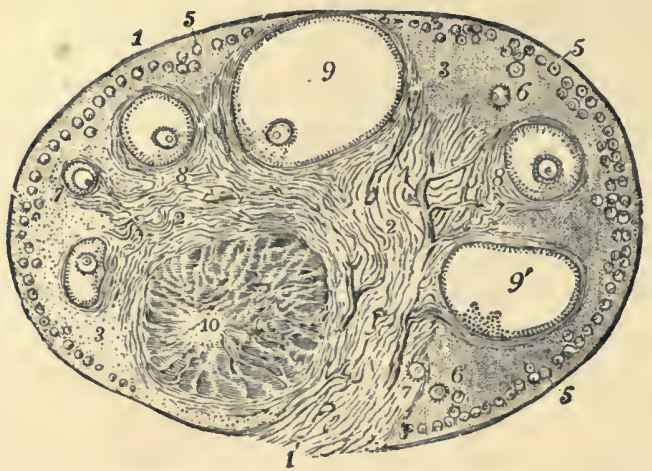

FIG. 19.-Section through ovary of cat. (From Schrön.)

1, Outer surface; $1^{\prime}$, attached border; 2 , fibrous central stroma ; 3 , peripheral stroma; 4, blood-vessels; 5 , young follicles; $6,7,8,9$, and $9^{\prime}$, larger developing follicles; 10, corpus luteum.

and functional relations of the different parts of the ovary, it is necessary to make some study of its developmental history.

Pfliiger ${ }^{1}$ appears to have been the first to regard the ova ${ }^{2}$ and epithelial cells of the Graafian follicles as originating either in the form of ingrowths simulating tubular glands, or as solid columns of cells from that embryonic layer which Waldeyer afterwards designated the germinal epithelium. The tubular ingrowths had already been noticed by Valentin, ${ }^{3}$ who, however,

1 Pfliger, Ueber die Eierstöcke der Säugethiere und des Menschen, Leipzig, 1867.

2 The mammalian ovum was discovered by von Baer (Ueber Entwickelungsgeschichte der Thiere-Beobachtung und Reflexion, vol. i., Königsberg, 1828). In 1861 Gegenbaur showed that the vertebrate ovum was a single cell.

s Valentin, "Ueber die Entwickelung der Follikel in dem Eierstocke der Säugethiere," Müller's Arch., 1838. 


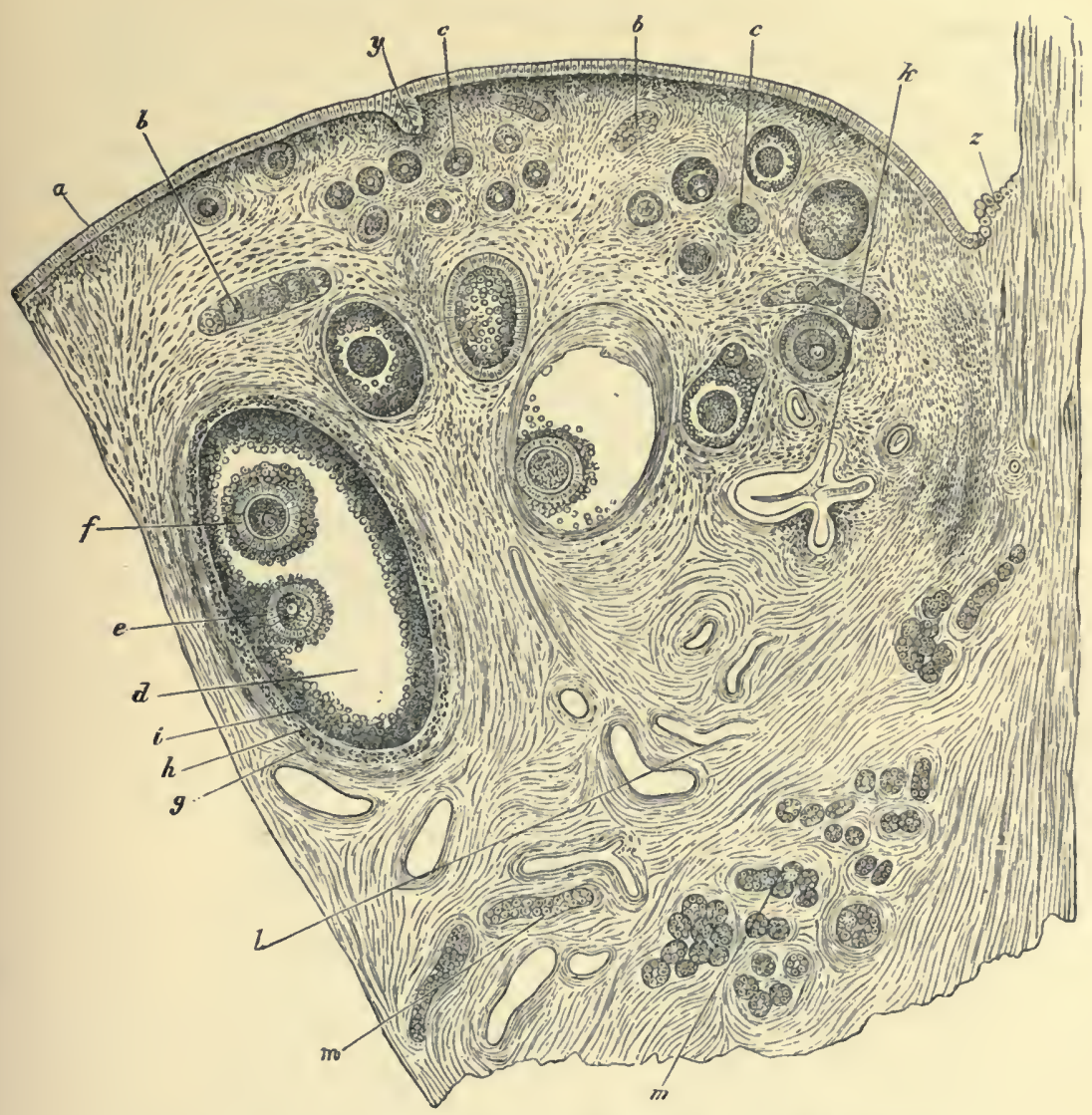

F1G. 20. - Section through ovary of adult dog. (From Waldeyer.)

$a$, germinal epithelium ; $b$, remains of egg tubes; $c$, small follicles ; $d$, more advanced follicle ; $e$, discus proligerus and ovum ; $f$, second ovum (a rare occurrence); $g$, theca externa of follicle; $h$, theca interna ; $i$, membrana granulosa; $k$, degenerate follicle; $l$, blood-vessels; $m$, tubes of parovarium; $y$, involuted germinal epithelium; $z$, transition from germinal to peritoneal epithelium.

failed to recognise their connection with the germinal epithelium. Later observers, however, did not confirm the tubular origin of the ovary.

To Waldeyer belongs the credit of first recognising the true nature and significance of the process of egg formation, an 


\section{6 'IHE PHYSIOLOGY OF REPRODUC'TION}

account of which was published in his famous monograph Eierstock und $E i{ }^{1}$ He found that in the chick, on the fourth day of development, the cœlomic epithelium which covers the inner surface of the Wolffian body became differentiated from the tissue surrounding it, the cells being relatively large and cuboidal in shape. A little later he observed that the cells had multiplied to such an extent as to give rise to a distinct elevation. In this way the germinal epithelium was formed, and this marked the site of the future ovary. The mesoblast underlying the germinal epithelium is described as growing upwards among the cells of the latter, and so giving rise to the

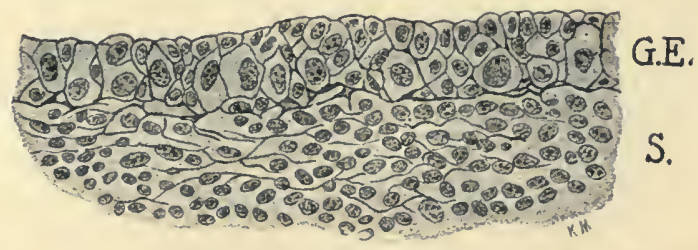

FIG. 21.-Section through ovary of pig embryo. (From Williams' Obstetrics, Appleton \& Co.)

G.E., germinal epithelium; S., stroma.

appearance of those germinal ingrowths or "egg-tubes," which were described by Pflüger.

The cells of the germinal epithelium are thus divided by mesoblast into clusters of "egg-nests" which contain the primordial ova, as Waldeyer has shown. As a result of this process two zones of tissue are formed in the future ovary. The outer or cortical zone consists of clusters of cells derived from the germinal epithelium, with mesoblastic processes in between them. The inner or medullary zone is composed at first entirely of mesoblast, which gives rise to the vascular tissue and stroma of the ovary.

The majority of investigators, including Balfour, ${ }^{2}$ Schäfer, ${ }^{3}$

1 Waldeyer, Eierstock und Ei, Leipzig, 1870.

2 Balfour, "Structure and Development of the Vertebrate Ovary," Quar. Jour. Micr. Science, vol. xviii., 1878.

3 Schäfer, "On the Structure of the Immature Ovarian Ovum," \&c., Proc. Roy. Soc., vol. xxx., 1880. 
Nagel, ${ }^{1}$ and van Winiwarter, ${ }^{2}$ have followed Waldeyer in supposing that the follicular epithelial cells (which form the innermost layer of the wall of the Graafian follicle) are derived like the ova from the germinal epithelium. Schäfer described appearances indicating the possibility of the innermost layer of follicular

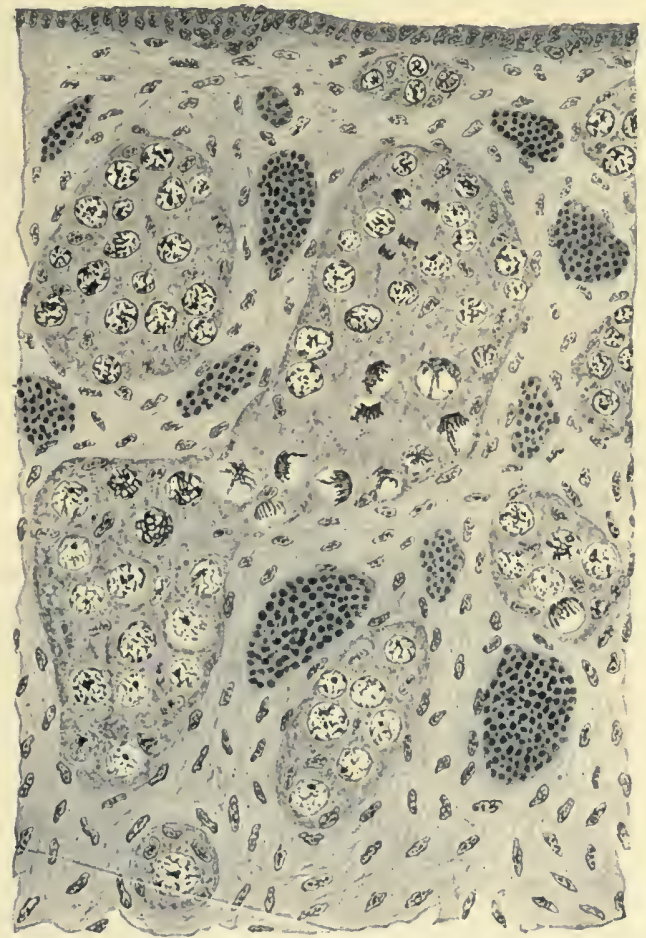

FIG. 22.-Cortex of pig embryo, showing germinal epithelium, Pfluger's tubes with ova in various stages of development. (From Williams' Obstetrics, Appleton \& Co.)

epithelium being derived from the ovum itself ; but, as he himself pointed out, this view does not involve any morphological absurdity if the ova and follicle-cells have a common origin. Balfour described protoplasmic masses of embryonic ova in which the cells appeared to be united together in such a way as to suggest

1 Nagel, "Das menschliche Ei," Arch. f. Mikr. Anat., vol. xxxi., 1888.

2 Van Winiwarter, "Recherches sur l'Ovogenèse," \&c., Arch. de Biol, vol. xvii., 1901. 
that one ovum might undergo development at the expense of the others. Somewhat similar appearances have been observed in the bat's ovary by van Beneden, ${ }^{1}$ who regarded them as syncitia from which both ova and follicular epithelial cells took origin.

On the other hand, Kölliker believed that the follicle-cells arose from the epithelium of the Wolffian body, while Foulis, ${ }^{2}$ Schrön, ${ }^{3}$ Wendeler, ${ }^{4}$ and Clark, ${ }^{5}$ expressing the opinion that the follicle-cells are derived from the mesoblast, have also dissented from this the more usual view. Clark, in support of his theory, has pointed out that the cells which immediately surround the primordal follicles are often spindle-shaped and similar in appearance to many of the stroma cells, and further, that the primordal ova in the early. stages of development are often apparently in direct contact with connective tissue which obviously had been derived from the embryonic mesoblast.

Most authorities, however (inchuding the more recent investigators), are of opinion that the follicular epithelial cells, in common with the ova, are derived from the germinal epithelium. Further, Miss Lane-Claypon ${ }^{6}$ has recently shown that the epithelioid interstitial cells ${ }^{7}$ which (in addition to the connective tissue and plain muscle-fibres) are contained in the ovarian stroma in all probability arise also from the original germinal epithelium.

The changes involved in the production of ova have been fully investigated by van Winiwarter ${ }^{8}$ in the rabbit. These

1 Van Beneden and Julin, "Observations sur la Maturation." \&c., Arch. de Biol., vol. i., 1880.

${ }^{2}$ Foulis, "The Development of the Ova," \&c., Jour. Anat. and Phys., vol. xiii., 1876.

${ }^{3}$ Schrön, "Beitrag zur Kenntniss der Anatomic und Physiologie des Eierstocks der Säugethiere," Zeitsch.f. wissensch. Zool., vol. xii., 1863.

4 Wendeler, " Entwickelungsgeschichte und Physiologie der Eierstöcke," Martin's Die Krankheiten des Eierstocks und Nebeneierstocks, Leipzig. 1899.

5 Clark, "The Origin, Growth, and Fate of the Corpus Luteum," Johns IIopkins Ilospital Reports, vol. vii.. 1898.

- Lane-Claypon, "On the Origin and Life History of the Interstitial Cells of the Ovary of the Rabbit," Proc. Roy. Soc., B., vol. Ixxvii., 1905.

7 For a comparative account of the interstitial substance in the ovaries of various mammals, with references to the literature, see Frænkel, "Vergleichende Histologische Untersuchungen über das Vorkommen driisiger Formationen im Interstitiellen Eierstocksgewebe," Arch. f. Gynäk., vol. Ixxv., 1906.

8 Van Winiwarter, "Recherches sur l'Ovogenèse de l'Organogenèse de l'Ovaire des Mammifères," Arch. de Biol., vol. xvii., 1900. 
changes which chiefly concern the chromatin of the nucleus may be summarised as follows :-

I. Early changes: $(a)$ Protobroque cells, Variety $a$.--The

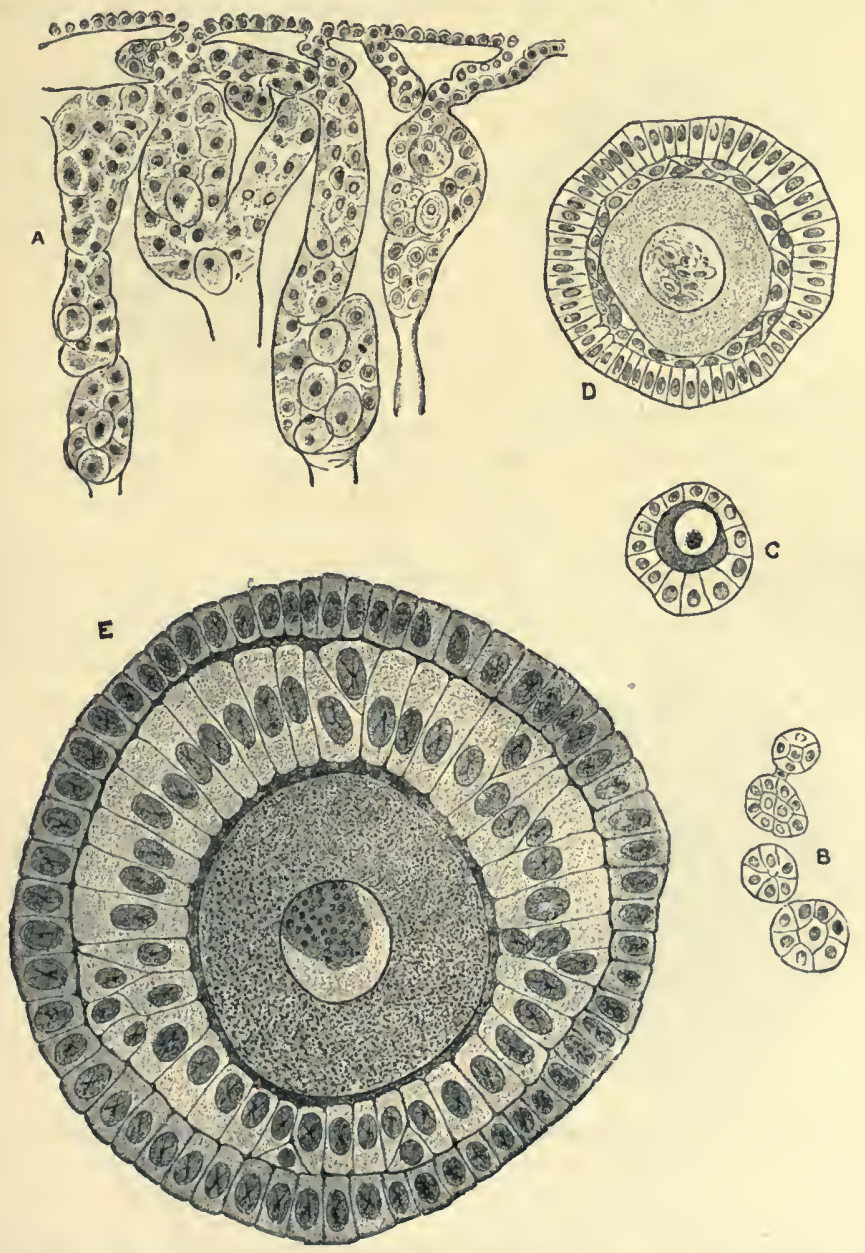

FIG. 23. - Various stages in the development of the Graafian follicle of the rabbit. (From Scbäfer.)

A, from young rabbit showing Pflüger's egg-tubes; B, C, D, E, successive later stages.

nuclei are granular in appearance, the chromatin is arranged irregularly, and there is no reticulum. These are the original 
germinal epithelial nuclei. (b) Protobroque cells, Variety b.The cells belonging to Variety $a$ divide, and give rise to more cells of the same kind, as well as to protobroque cells of the $b$ variety. In the latter the nuclei are less granular, and contain

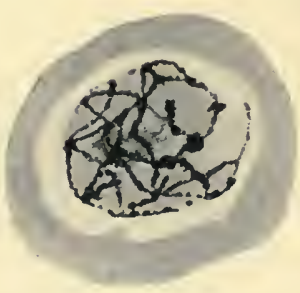

Early ovogenetic stage.

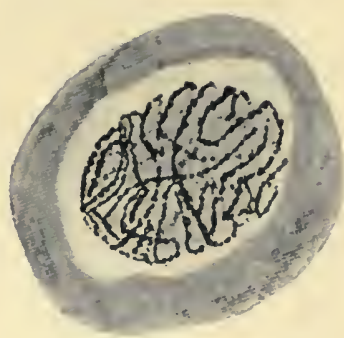

Leptotenic stage.

FIG. 24.-Developing ova from ovary two days before birth. (After Lane-Claypon.)

a certain number of fine chromatin filaments. (c) Deutobroque cells.-The protobroque cells of the $b$ variety likewise divide, and give rise to more protobroque cells, similar to themselves, and also to deutobroque cells. These latter are larger in size,

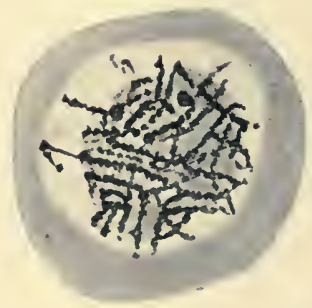

Early.

Synaptenic stage.

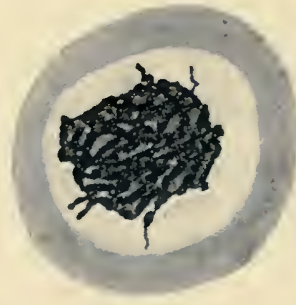

Late.

FIG. 25.-Developing ova from ovary about one day before birth. (After Lane-Claypon.)

and contain nuclei with the chromatin arranged in the form of a reticulum.

II. Later changes: (a) Leptotenic stage.-Certain of the deutobroque nuclei become gradually differentiated, the chromatin during the leptotenic stage passing through a process in which it breaks up into fine filaments; these are distributed 
over the nuclear region. (b) Synaptenic stage.-The filaments become congregated together in the form of a lump, or dark mass, heaped up at one side of the nuclear region. (c) Pachytenic
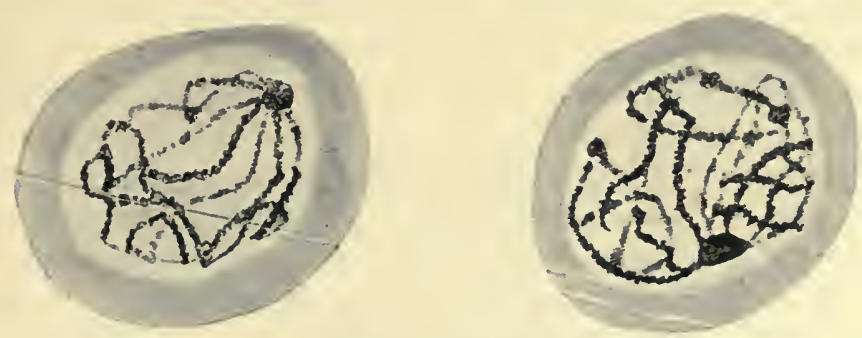

Pachytenic stage.

FIG. 26. - Developing ova from ovary one day after birth. (After Lane-Claypon.)

stage.-The nuclear filaments again become unwound, and spread themselves out over the whole nuclear region; they are, however, considerably coarser than in the earlier stages. (d) Diplotenic stage.-The chromatin strands split along their

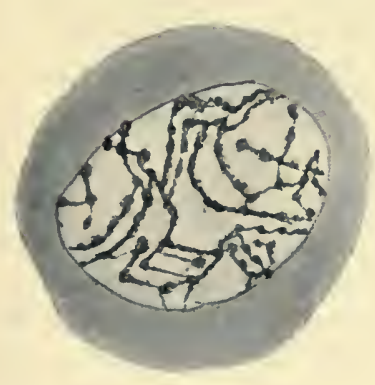

Diplotenic nucleus three days after birth.

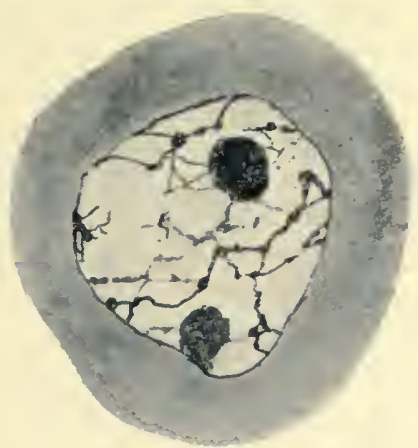

Dictyate nucleus seven days after birth.

Fig. 27.-Developing ova. (After Lane-Claypon.)

whole length, and the two halves of each strand at first lie in pairs near to one another. (e) Dictyate stage.-The split strands pass away from one another, and the chromatin generally becomes distributed once more throughnut the nuclear region in the form of a reticulum. 
The nucleus or germinal vesicle of the primordial ovum thus produced then enters upon a long period of rest, the changes involved in oögenesis having been complcted. ${ }^{1}$

Somc of the deutobroquc cells, instead of passing through the transformations above described, rest for a timc and subsequently undergo retrogressive changes, bccoming converted, according to Miss Lane-Claypon, either into follicular epithelial cells or into interstitial cells. "Every cell of the gerninal epithelium is probably a potential ovum, relatively very few remaining in the protobroque state, although some may still be seen at the periphery in ovaries of the eightecnth day [of gestation in the rabbit]. Incomparably the greater part pass into the deutobroque state, preparatory, doubtless, to the formation of ova. All cannot become ova, for the other forms of cell are necessary for the maintenance of the ovarian functions; possibly, therefore, only the most robust cells, and those which are most conveniently situated for obtaining nourishment, undergo the ovogenetic changes. This suggestion would seem to be borne out by the fact that many more of the central cells, which are nearer the food supply, undergo ovogenesis, than of the peripheral ones. The rest of the cclls which are not able, for one cause or another, to undergo these changes, appear to remain quiescent for a while, until finally they regress, and pass into a condition of subserviency to the nceds of those which have become ova. Both follicle-cells and interstitial cells are, however, still potential ova. They have passed through the initial stages, and only need enlargement and nuclear transformations in order to become ova should the appropriate stimulus be given (as will be described below, p. 160). This chance is not given to the follicle-cells. $\Lambda \mathrm{s}$ soon as the follicle begins to grow they multiply rapidly, and

1 For an account of the minute structure of the Mammalian egg, together with a résumé of the literature, see van der Stricht, "La Structure de l'CEuf des Mammifères," Part I., Arch. de Biol., vol. xxi., 1904; Part II., Bull. de l'Acad. Royale de Médecine de Belgique, Bruxelles, 1905; Part III., Bruxelles, 1909. For a general account of the egg and the plenomena of oögenesis in the different groups of animals, both Vertebrate and Invertebrate, with a complete bibliography, see Waldeyer, "Die Geschlechtszellen," in Hertwig's Handbuch der Entwicklungslehre der Wirbelticre, vol. i., Jena, 1903; also Wilson, The Cell in Development and Inheritance, 2nd Edition, New York, 1900. 
probably provide, by their [partial] disintegration, the follicular secretion upon which the ovum feeds and grows." 1

The description given above of the origin of the follicle and interstitial cells applies especially to the rabbit. Miss LaneClaypon has also investigated their developmental history in the rat, ${ }^{2}$ and expresses belief that in this animal also they are

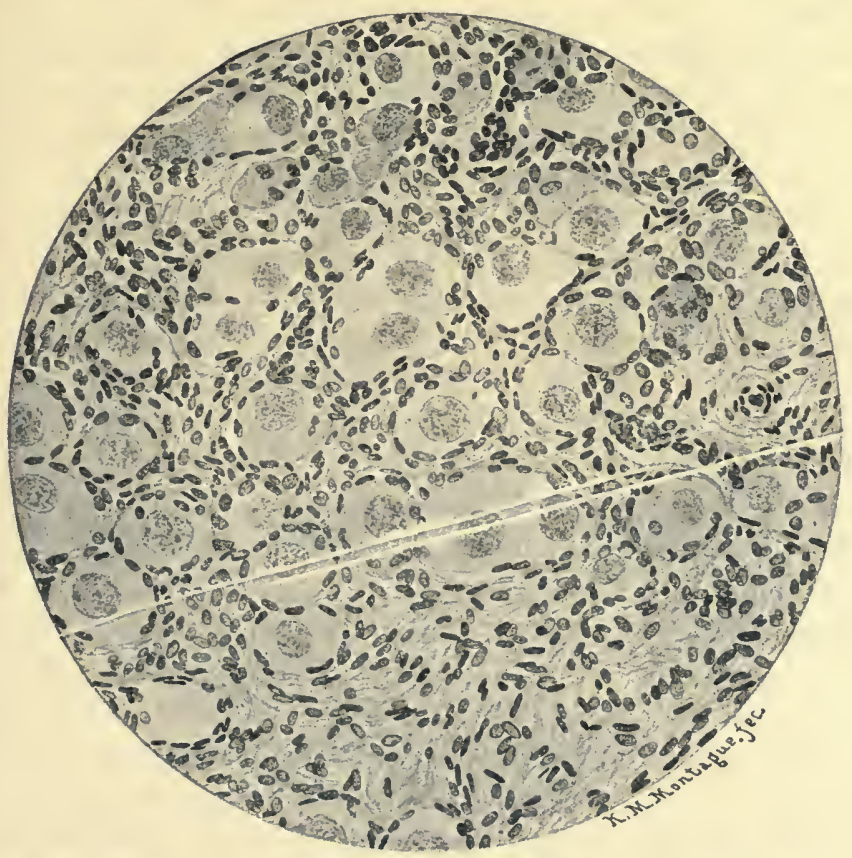

F1. 28.-Ovary at birth, showing primordial follicles. $\times 300$. (From Williams' Obstetrics, Appleton \& Co.)

derived from the germinal epithelium by a similar process of differentiation. Both follicular epithelial cells and interstitial cells are stated to pass through identically the same stages, but the latter are said to remain grouped together in the spaces between the follicles instead of arranging themselves around the diplotenic nuclei of the developing ova.

1 Lane-Claypon, loc. cit.

2 Lane-Claypon, "On Ovogenesis and the Formation of the Interstitial Cells of the Ovary," Jour. Obstet. and Gyncec., vol. xi.. 1907. 
Thus it appears that the ova, the follicular epithelial cells, and most probably also the interstitial cells, are all derived from the germinal epithelium by processes involving changes in the nuclear chromatin; but that, whereas these changes are similar in the case of the follicle and interstitial cells, those undergone by the developing ova are more extensive and show a greater complexity.

The significance of the common origin of these different ovarian elements will be more apparent when we consider the views which are held regarding the further development and the probable functional importance of these cells.

It should be mentioned, however, that Allen ${ }^{1}$ and Sainmont, ${ }^{2}$ working on the organogenesis of the ovary in the rabbit and the cat respectively, have come to the conclusion that the ovarian interstitial cells have a connective tissue origin, but these investigators do not appear to have traced the successive stages of cellular development with the same completeness as Miss LaneClaypon. Sainmont is of opinion that they have a trophic function, a suggestion which was first made by Pflüger. ${ }^{3}$

There would seem to be no doubt that the developing ova in the immature ovary subsist and grow at the expense of the surrounding tissue. Thus protoplasmic masses, formed by the aggregation of very young ova, have been described by Balfour, ${ }^{4}$ who made the suggestion that one ovum may develop at the cost of the others. These aggregations of ova were noticed in the ovary of the foetal rabbit at about the sixteenth day of pregnancy. A day or two previously the ova were observed to be separate. Miss Lane-Claypon, who confirms the observation, is of opinion that Balfour's suggestion was right, and that the ova which disappear serve ultimately as food-stuff for the

${ }^{1}$ Allen, "The Embryenic Development of the Ovary and Testis of the Mammals," Amer. Jour. of Anat. vol. iii., 1904. Allen describes the interstitial cells in a three-months-old rabbit as being derived from certain cells in the thecx internx of degenerate follicles. The cells are said to lose their walls, become irregular in shape, and undergo a rapid process of amitotic division, after which they become transformed into typical interstitial cells.

2 Sainmont, 'Recherches relatives à l'organogenèse du Testicule et l'Ovaire chez le Chat" Arch. de Biol. vol. xxii., 190 5.

${ }^{3}$ Pflïger, Ueber die Eicrstöcke der Süugethiere und des Menschen, Leipzig. 1863.

4 Balfour, loc. eit. 
one ovum whose condition happens to be the most vigorous. "This cannibalism on the part of the young ovum is not surprising, if the life of an ovum be considered. It is really but the normal condition of the cell at all its stages of development; it grows and fattens at the expense of other cells. In the young ovary, it is starting its first stage of growth and must devour other cells; later on, during the growth of the follicle, it lives upon the follicle-cells, and later still, when, after fertilisation, the [term] ovum in its extended sense refers to the young fœtus, [this latter] lives on the material provided by the cells of the maternal organism." 1

\section{Maturation and Ovulation}

The youngest and smallest Graafian follicles lie near the surface of the ovary, but pass inwards as they increase in size. The large, mature follicles, however, come to lie just below the surface from which they begin to protrude visibly at the approach of the breeding season. During the proœstrum one or more follicles (the number varying in different animals, according to the size of the litter) may generally be seen showing a very considerable protrusion, while in some animals, such as the sow, the appearance of the ovary at this time is not dissimilar to a bunch of grapes.

A large Graafian follicle in a mature ovary contains the following parts: Forming the outermost part of the wall and in continuity with the ovarian stroma is the theca externa, which is a layer of somewhat fibrous connective tissue. Within this is the theca interna, which is less fibrous. The two thecæ are only slightly modified ovarian stroma. Within the theca interna is the epithelial wall, which, in the very young follicles, consists of a single layer of cells immediately surrounding the ovum. These, as already mentioned, multiply rapidly (by mitotic division) and give rise to a layer many cells deep, which, as the follicle increases in size, becomes divided into two layers,

1 Lane-Claypon, “On Ovogenesis," \&c., loc. cit. That one ovum may develop at the expense of others is particularly well shown in Hydra, Tubularia, and certain other Colenterates. The nuclei of the ingested ova continue to be easily recognisable even during the early segmentation stages of the developing egg. 
the membrana granulosa lining the follicle, and the discus proligerus surrounding the ovum. The innermost cells of the discus rest upon a thick, transparent, radially striated membrane with a granular outer border. This is the zona radiata or zona pellucida. The striated appearance is due to the presence of fine canals. Within the zona, and immediately enclosing the ovum, another very thin membrane can sometimes be made out. This is the vitelline membrane. The membrana granulosa and discus proligerus are united by one or more strands of follicular epithelial cells. A viscid fluid, containing protein matter, collects

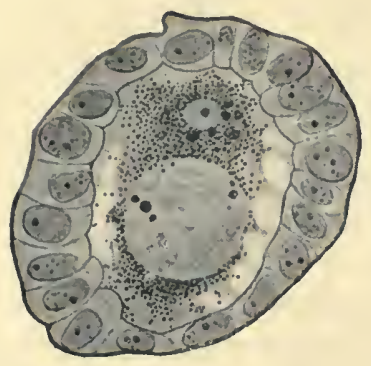

FIG. 29.-Young oöcyte or egg surrounded by a single layer of follicular epithelial cells. (From van der Stricht.) between them and becomes gradually increased in quantity as the follicle continues to grow. ${ }^{1}$

The liquor folliculi begins to form in the developing rat's ovary at about the ninth day of pregnancy. ${ }^{2}$ Miss Lane-Claypon suggests that the karyolytic changes which occur in the nuclei of the follicular epithelial cells may have some connection with the origin of the liquor. She states, however, that in the process of formation of the liquor folliculi in the adult ovary, the follicle cells appear simply to disintegrate and dissolve without showing the phenomena of karyolysis. On the other hand Honore, ${ }^{3}$ who has investigated the subject in the case of the rabbit, concludes that the liquor folliculi is secreted by the follicle cells, without their undergoing destruction (or that, if this occur, it is immaterial to the process of liquor formation), in the same way as the urine is secreted by the epithelium of the renal

1 Occasionally a Graafian follicle may contain more than one ovum, but this is abnormal. Such follicles have been described as occurring in the rabbit's ovary by Honoré ("Recherches sur l'Ovarie du Lapin," Arch. de Biol., vol. xvii. 1901), and in the dog's ovary by Smytl ("An Unusual Graafian Follicle," Biol. Bull., vol. xiv., 1908). The latter writer states that one follicle contained seven ova. He slows that the tendency to produce multiple ova may be hereditary, and that it is apparently correlated with a high fertility.

2 Lane-Claypon, loc. cit.

3 Honoré, "Recherches sur l'Ovarie du Lapin," Arch. de Biol., vol. xvi., 1900. 
tubules. In support of this view Honoré points out that there are no indications of degeneration or destruction of the follicular epithelial cells of the ripe follicles during ostrus, and moreover, that these cells are retained in the follicle at the time of ovulation, giving rise subsequently to the luteal cells of the corpus luteum. It would appear possible, however, that the liquor folliculi is formed partly by the secretory activity, and partly

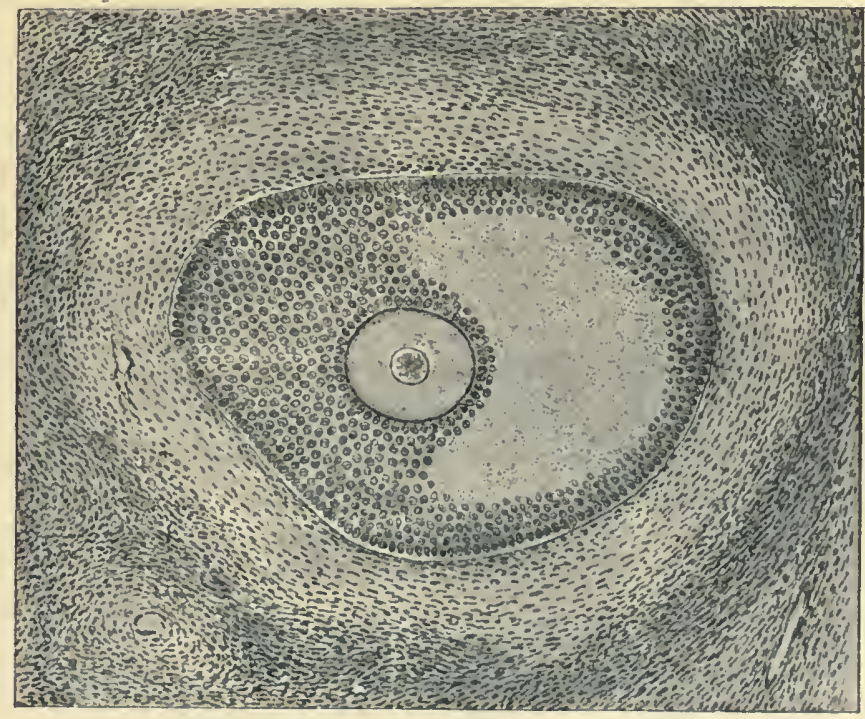

FIG. 30.-Young human Graafian follicle. The cavity contains the liquor folliculi. (From Sellheim.)

by destruction of the follicle cells, just as, according to one view, milk is derived from both the secretion and the disintegration of the cells of the mammary gland (see p. 560).

Heape ${ }^{1}$ states that during the growth of the ovum nourishment is supplied to it by the aid of the discus proligerus, for fine protoplasmic processes may be seen passing from the cells of this layer and projecting into radiating canals in the zona which encloses the ovum, being in contact with the vitelline membrane.

1 Heape, "The Development of the Mole," Quar. Jour. Micr. Science, vol. xxvi., 1886. 
Immediately after copulation, and therefore during cestrus, the cells of the discus proligerus (in the rabbit) ${ }^{1}$ begin to withdraw radially, and eventually remain attached to the zona radiata by the extremely thin strands just referred to. At the same time the ovum itself withdraws somewhat from the zona, leaving a narrow circular space. These processes occupy some

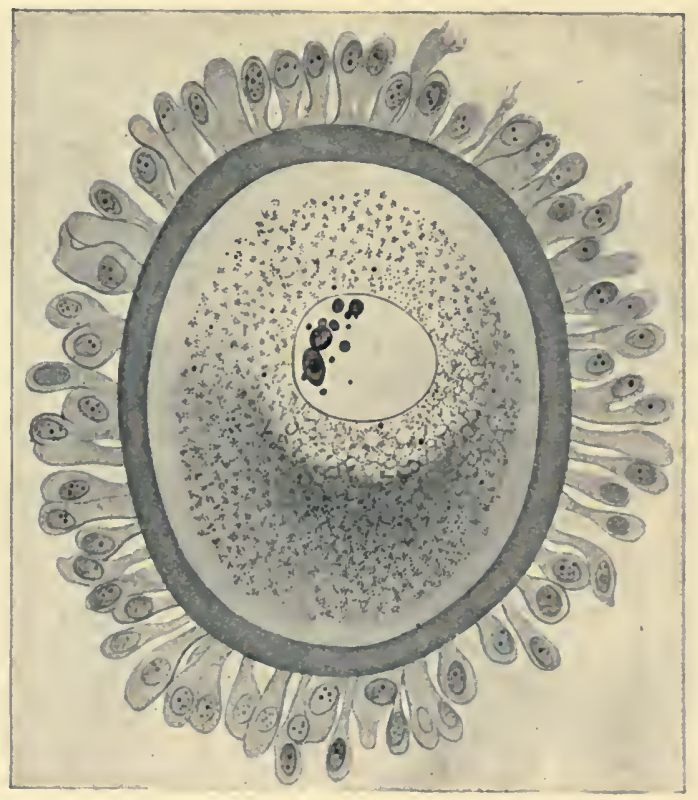

F1G. 31.- Human ovum at termination of growth period. (After van der Stricht.) Yolk granules, vacuoles, and fat drops are seen.

hours. About nine hours after copulation, when the supply of nourishment has been entirely cut off, the two polar bodies are formed, and the ovum becomes mature.

The essential facts about the maturation process were first ascertained by van Beneden ${ }^{2}$ in Ascaris, and were afterwards

1 Heape, "Ovulation and Degeneration of Ova in the Rabbit," Proc. Roy. Soc., B., vol, lxxvi., 1905.

2 Van Beneden, "Recherches sur la Maturation de l'Euf," Arch. de Biol., vol. iv., 1883 . 
studied more fully by Boveri. ${ }^{1}$ In recent years Montgomery ${ }^{2}$ has elucidated the process still further by showing that prior to the formation of the first polar body the chromatin filaments

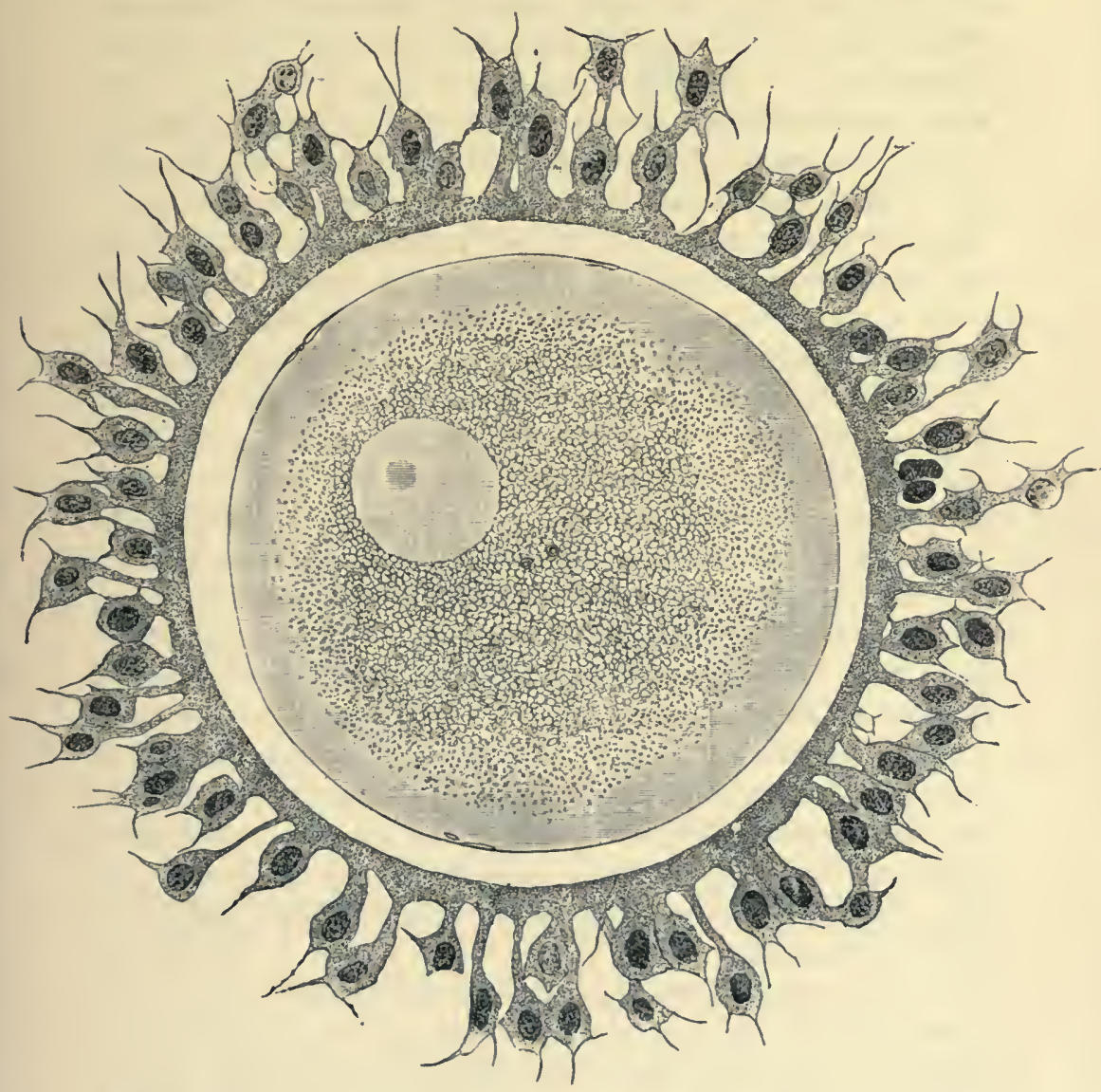

FIG. 32.-Human ovum examined fresh in the liquor folliculi. (From Waldeyer.) The ovum shows yolk granules in the centre surrounding the nucleus (with its nucleolus) and a clearer veriplieral portion. It is enclosed by follicular epithelial cells.

1 Boveri, "Zellenstudien," Jenaische Zeitsch., vol. xxi., 1887.

2 Montgomery, "Some Observations and Considerations upon the Matura. tion Phenomena of the Germ Cells," Biol. Bull., vol, vi., 1904. The references to Montgomery's earlier memoirs dealing with the same subject are given in this paper. 
or chromosomes of the cell nucleus conjugate together in pairs, and that in all probability one member of each pair is a descendant of a chromosome derived from the father, while the other member is descended from a corresponding maternal chromosome. ${ }^{1}$ The possible significance of this conjugation of chromosomes is referred to on a later page (p. 196). In the subsequent maturation division the chromosomes again separate. ${ }^{2}$

The changes involved in the formation of the first polar body are in most respects similar to those of ordinary cell division. The centrosome, which lies in the cytoplasm, divides, and the two daughter centrosomes thus produced travel to opposite sides of the nucleus. In the meantime, the latter forms a spindle composed of the chromosomes, the nuclear membrane having disappeared. Each centrosome becomes surrounded by a system of rays, and in this way the attraction spheres are formed. The chromosomes next arrange themselves equatorially between the attraction spheres, each one having now split into two parts. Half of these migrate towards each centrosome, and the nucleus becomes divided. One of the daughter nuclei, together with a thin investment of protoplasm, is extruded from the ovum. 'This is the first polar body, which is therefore a product of unequal cell division. Subsequently to extrusion it sometimes divides into two. After the formation of the first polar body, the ovum again divides in the same unequal fashion, and the second polar body is formed and extruded. The polar bodies undergo degeneration. Meanwhile the nucleus of the ovum once more becomes surrounded by a membrane and enters upon a resting stage.

The process of formation of the second polar body differs from that of the first in that the chromosomes do not undergo splitting. Consequently the nucleus of the mature ovum con-

1 The observations of this author, together with those of Sutton, McClnng, Wilson, \&c., point to the conclusion that all the nuclei in the somatic cells contain two parallel series of chromosomes (paternal and maternal).

2 In the reduction process each pair of fused cliromosomes becomes divided into a group of four bodies united by linin threads. These are the tetrads or "vierergruppen." It follows that the number of tetrads in any particular species is always one-half the number of somatic chromosomes. Thus, if the somatic cells contain sixteen chromosomes, the number of tetrads formed is eight, while, as shown in the text, the number of chromosomes in the mature germ cells (after reduction) is also eight. 
tains only half the original number of chromosomes. This number varies in the different species, but is constant in each. ${ }^{1}$ In Man it is twenty-four, so that in the mature human ovum there are only twelve chromosomes. ${ }^{2}$ As will be shown in the next chapter, the spermatozoa, or male germ cells, undergo a similar process of maturation, the conjugating cells containing only half the number of chromosomes characteristic of the species, just as in the case of the conjugating ova. It has been supposed, therefore, that the reduction in the number of chromosomes is a preparation on the part of the germ cells for their subsequent union, and a means by which the number of chromosomes is held constant in each species.

The discovery that the nuclei of the conjugating cells contain only half the number of chromosomes possessed by the soma or body cells was made originally by van Beneden. It has since been extended to so many animals and plants that it may probably be regarded as a general law of development. ${ }^{3}$

It is commonly believed that the chromatin material is the substance which has the potentialities of development, and which plays the principal part in perpetuating the hereditary structure and qualities of the particular animal or plant, but there is no real proof that this is the case (see p. 199 below).

The maturation phenomena may take place within the ovary prior to the discharge of the egg, or they may be postponed until after ovulation has occurred. In the rabbit, as has been

1 Van Winiwarter, however, states that in the rabbit the number varies from thirty-six to eighty, but is generally about forty-two (Arch. de Biol., vol. xvi., 1900).

2 Duesberg, "Sur le Nombre chromosomes chez l'Homme," Anat. Anz., vol. xxviii., 1906.

${ }^{3}$ For details of the process in various forms of life see Wilson, The Cell, 2nd Fdition, New York, 1900. See also Doncaster, "On the Maturation of the Unfertilised Fgg, \&c., in the Tenthredinidx," Quar. Jour. Micr. Science, vol. xlix., 1906 ; "Gametogenesis, \&c.," Quar. Jour. Micr. Science, vol. li., 1907. Doncaster shows that in the sawflies there are two types of maturation process, in one of which there is no reduction. It is probable that only the reduced eggs are capable of fertilisation. In other cases, however, the ova are able to undergo parthenogenetic reproduction without forming polar bodies. See Hewitt, "The Cytological Aspect of Parthenogenesis in Insects," Manchester Memoirs, vol. lx., 1906 ; Doncaster, "Animal Parthenogenesis," Sciencc Progress, vol. iii. (July) 1908. 'These papers contain further references. 
shown already, ${ }^{1}$ the polar bodies are formed while the ovum is still in the ovary, but not until after the occurrence of copulation.

In the case of the mouse, Sobotta ${ }^{2}$ came to the conclusion that the first polar spindle is suppressed, and that the second polar body might be formed during the passage of the ovum down the Fallopian tube. Gerlach ${ }^{3}$ describes the second polar body as being in some instances suppressed after the entry of the spermatozoön in fertilisation, the second polar spindle degenerating within the egg. Kirkham, ${ }^{4}$ however, states that the maturation of the mouse's ovum is in no way exceptional, the process involving the formation of two polar bodies as in most other animals. The first polar body is extruded in the ovary, while the second is given off in the Fallopian tube immediately after fertilisation by a spermatozoön. ${ }^{5}$ Rubaschkin ${ }^{6}$ has shown that the maturation processes in the guinea-pig are similar. In both the guinea-pig and the mouse, ova which are retained in the ovary, and also those which are discharged and fail to become fertilised, undergo degeneration with the second polar spindle within them.

The maturation phenomena in the bat (Vesperugo noctula) have been investigated by van der Stricht, who has published a

1 Heape, loc. cit.

2 Sobotta, "Die Befruchtung und Furchung des Eies der Maus," Arch. f. Mikr. Anat., vol. xlv., 1895.

${ }^{3}$ Gerlach, Veber die Bildung der Richtungshörper bei Mus musculus, Wiesbaden, 1906.

"Kirkham, "The Maturation of the Mouse Egg," Biol. Bull., vol. xii., 1907 ; and "The Maturation of the Egg of the Wbite Mouse," Truns. Con. neeticut Acad. Arts and Sciences, vol. xiii., 1907.

5 Sobotta ("Die Bildung der Richtungskörper bei der Maus," Anat. Hefte, vol. $x \times x v ., 1907$ ), in a further paper, expresses himself doubtful as to whether two polar bodies are really discharged in all cases in the maturation process of the mouse's ovum. His own observations lead him to conclude that two polar bodies are discharged in not more than one-fifth of the total number of maturations, only one polar body being formed in the great majority of cases. Lams and Doorme ("Nourelles Recherches sur la Maturation et la Fécondation de l'Guf des Mammifères," Arch. de Biol., vol. xxiii., 1907) state that they found two polar bodies expelled in forty-four cases out of forty-eight, the first being always smaller than the second.

'Rubaschkin, "Ueber die Reifungs- und Befruchtungsprocesse des Meerschweincheneies," Anat. Hefte, vol. xxix., 1905. 
series of papers on the subject. ${ }^{1}$ This observer states that there are always two polar bodies formed. The first is extruded in the ovary. The second spindle is formed at about the ovulating stage, and the second polar body is discharged in the interior of the Fallopian tube. The first body is formed in February or March, or sometimes later, according to the temperature. ${ }^{2}$

It would seem that in the case of the mole the two polar bodies are discharged while the ovum is still retained within the ovary. ${ }^{3}$

In the pigeon it has been shown that the polar bodies are given off while the ovum is passing down the glandular portion of the oviduct and after the entrance of the spermatozoön. The first polar spindle, however, is formed in the ovarian egg; but it is not definitely known at what stage fertilisation occurs, excepting that it is previous to the time when the egg is clasped by the oviducal funnel.

In the frog the polar bodies are extruded after ovulation has taken place, but the egg is not set free until it has reached a certain stage of maturation, which is preparatory to the discharge of the first polar body. The nucleus undergoes a change, and, in place of being large and watery, consists of a small mass of chromatic substance lying in the protoplasm. An achromatic spindle is developed, and the chromatin becomes arranged in the form of granules at the equator of the spindle. The nuclear membrane disappears with the large watery nucleus. The ova in this condition pass into the oviducts. ${ }^{4}$

In certain Invertebrates (Nematodes, Annelids, and Gasteropods) it has been noticed that the occurrence of the maturation

1 Van der Stricht, "La Ponte ovarique," \&c., Bull. de l'Acad. Roy. de Méd. de Belgique, 1901. Une Anomalie trìs interessante concernant le Développement d'un (Euf de Mammifère, Gand, 1904. "Les Mitoses de Maturation de l'Euf de Chauve-Souris," Mémoire prísenté au VIII Congrès de l'Assoc. des Anatomistes, Nancy, 1906.

2 Van der Stricht says (La Structure de l'Euf des Mammiferes, Bruxelles, 1909) that he has seen twenty-two ova at the stage of the second polar spindle within the ovary and twenty-seven at the same stage outside of the ovary, the dates varying in each case from the end of February to the end of April. 1886.

${ }^{3}$ Heape, "The Development of the-Mole,"Quar.Jour. Micr. Science, vol. xxvi.,

4 Morgan, The Development of the Frog's Egg, New York, 1897. 
phenomena depends upon the act of fertilisation. For example, in the Japanese Palolo-worm, a marine Polychæt Annelid, Izuka ${ }^{1}$ has shown that the first polar body is discharged (after certain preparatory changes) one hour after fertilisation by a spermatozoön, and that the second polar body is extruded fifteen or twenty minutes later. In other animals (e.g. Amphioxus), one maturation process takes place before, the other during the entrance of the spermatozoön. ${ }^{2}$

It would appear from these facts that the maturation processes in many animals only take place as a result of a specific stimulus which may be induced by the act of copulation, or may be caused only by the entry of the spermatozoon into the protoplasm of the ovum. It would seem, on the other hand, that in some animals maturation takes place independently of any stimulus at such time as the follicle has attained to a sufficient degree of ripeness or after it has discharged its ovum. ${ }^{3}$

It has already been shown incidentally that the processes of maturation and ovulation are intimately associated, and that the latter, like the former, is in many animals dependent for its occurrence upon a definite physiological stimulus. The Graafian follicle may rupture when the egg has reached a certain degree of maturity, or it may require the additional stimulus of sexual intercourse before ovulation can be induced.

In the rabbit ovulation takes place about ten hours after coition. ${ }^{4}$ The ovum, which is entirely free from follicular epithelial cells, is discharged into the infundibulum which at this time closely invests the ovary. The discharged ovum is incapable of assimilating nutriment unless it becomes fertilised,

1 Izuka, "Observations on the Japanese Palolo," Jour. of the Coll. of Scienee, University of Tokyo, vol. xvii., 1903.

2 See Przibram, Embryogeny, English Translation, Cambridge, 1908.

3 The ehemistry of the maturation proeess is discussed by Mathews ("A Contribution to the Chemistry of Cell Division, Maturation and Fertilisation," Amer. Jour. of Phys., vol. xviii., 1907). This author deseribes the maturation of the egg of Asterias as being inaugurated by the dissolution of the nuelear membrane. If oxygen is withheld the mature egg soon dies. It is believed that an "oxidase" escapes from the nueleus into the eytoplasm on the rupture of the nucleus. The astral radiations disappear if oxygen is witldrawn, but reappear if oxygen is readmitted. It is eoneluded that the astral figures are the produet of three substanees: (1) eentriole substanee; (2) oxidase; and (3) oxyger.

4 Heape, loc. cit. 
and if fertilisation is not effected it undergoes degeneration. Heape found that ovulation could not be induced by artificial insemination, nor by any means other than sexual intercourse, and moreover, that intercourse was a sufficient stimulus, even when the progress of the spermatozoa from the vagina into the uterus was artificially stopped, provided that there was no interference with the vascular supply to the ovaries.

It is stated by Weil ${ }^{1}$ that ovulation may take place independently of coition in rabbits which have given birth to young just previously, and Iwanoff, ${ }^{2}$ in confirmation of this statement, records experiments in which pregnancy was induced in rabbits by the artificial injection of seminal fluid shortly after parturition.

In the mouse, ${ }^{3}$ the rat, ${ }^{4}$ and the guinea-pig, ${ }^{5}$ ovulation occurs spontaneously during "heat," and generally, if not invariably, during œestrus.

In the dog ovulation takes place independently of coition after external bleeding has been going on for some days, or when it is almost or quite over ; in other words, it occurs during œstrus and not during the proœstrum, or at any rate not during the early stages of the procstrum. ${ }^{6}$ It is probable that the sow also ovulates during œestrus and not during the proœstrum, since it is stated that sows are most successfully served on the second or third day of " heat." Coition, if it occurs earlier, is frequently not followed by conception. ${ }^{7}$ From Hausmann's description it would seem that ovulation does not take place prior to coition, but this statement has not been confirmed. ${ }^{8}$

1 Weil, "Beiträge zur Kenntniss der Befruchtung und Entwickelung des Kanincheneies," Wien Med. Jahrbuch, 1873.

2 Iwanoff, "La Fonction des Vésicles séminales et de la Glande prostatique," Jour. de Phys. et de Path. Gén., vol. ii., 1900.

3 Sobotta, loc. eit.

- 'Tafani, "La Fécondation et la Segmentation studieés dans les Wufs des Rattes," Arch. Ital. de Biol., vol. ii., 1889.

"Rubaschkin, loc. cit.

- Marshall and Jolly, "Contributions to the Physiology of Mammalian Reproduction: Part I. The Estrous Cycle in the Dog," Phil. T'rans,, B., vol. cxeviii., 1905.

7 Wallace (R.), Farm Live Stock of Great Britain, 4th Edition, London, 1907.

${ }^{8}$ Hausmann, Ueber die Zeugung und Entstehung des wahren weillichen Eies, \&c., Hanover, 1840. 
In the ferret ovulation occurs during ostrus, but postponement of coition may bring about the degeneration of the ripe follicles, since they do not always discharge spontaneously. ${ }^{1}$

Artificial insemination, followed by pregnancy, has been successfully performed on mares, donkeys, and cows. ${ }^{2}$ Consequently it may be concluded that these animals ovulate independently of coition. According to Ewart, ${ }^{3}$ ovulation in the mare very often does not occur until near the end of the œstrous period.

It has been shown also that the sheep ovulates spontaneously at each of the earlier heat periods of the sexual season, but that there are reasons for believing that during the later periods the stimulating power at the disposal of the ewes may be so reduced that without coition it is incapable of causing ovulation. There is also evidence that when coition occurs at the beginning of an œestrous period, it may provide a stimulus inducing ovulation to take place a few hours earlier than it otherwise would; in other words, that if ovulation has not already occurred during an œstrus, the stimulus set up by coition may hasten the rupture of the follicle. ${ }^{4}$ Recently Iwanoff has succeeded in inducing pregnancy in sheep by artificial insemination. (See p. 183.)

There can be little doubt that in the great majority of Mammals ovulation, as a general rule, occurs regularly during œstrus. In certain bats, however, copulation is performed during the autumn, whereas ovulation is postponed until the following spring, the animals in the meantime hibernating, while the spermatozoa are stored up in the uterus (see p. 177). ${ }^{5}$ The ovary in the winter months (during the hibernating period) is said to be in a state of quiescence, and the exact time for

1 Marshall, "The Estrous Cycle in the Common Ferret," Quar. Jour. Micr. Sci., vol. xlviii., 1904.

2 Heape, "The Artificial Insemination of Mammals," Proc. Roy. Soc., vol. $1 \times i ., 1897$.

3 Ewart, "The Development of the Horse," MS.

"Marshall, "The Estrous Cycle and the Formation of the Corpus Luteum in the Sheep," Phil. Trans., B., vol. cxcvi., 1903.

"Benecke, "Ueber Reifung und Befruchtung des Eies bei den Fledermäusen," Zool. Anz., vol. ii., 1879. Eimer, "Ueber die Fortpflanzung der Fledermäuse," Zool. A nz., vol. ii., 1879. Van leneden and Julin, "Observations sur la Maturation, la F'érondation, et la Segmentation de l'Euf chez les Cheiropteres," Arch. de Biol., vol. i., 1880. 
maturation and ovulation depend upon the temperature of the early months of the year, occurring generally in February or March, but sometimes as late as April. ${ }^{1}$ Ovulation takes place some days or even weeks after the formation of the first polar body. It would appear, then, that in bats the follicles can discharge spontaneously under the influence of appropriate seasonal stimuli, and without even the occurrence of œstrus. ${ }^{2}$

There has been a considerable amount of controversy regarding the periods at which ovulation occurs in the Primates, the question being discussed at some length in three papers by Heape. ${ }^{3}$ This author has shown that ovulation and menstruation are not associated in monkeys (at any rate not necessarily), and that whereas, in both monkeys and the human species, menstruation may occur periodically all the year round, in monkeys there is a limited season for conception and ovulation; while in civilised woman this period is not limited to any particular time of the year, although there is evidence that primitively man agreed with the lower Primates in having a definite sexual season (during which ovulation occurred). (See p. 71.) Van Herwerden ${ }^{4}$ has adduced further evidence which shows that there is no apparent connection between ovulation and menstruation, either in monkeys or in the aberrant lemur, Tarsius spectrum. It would seem probable, however, in view of Pocock's observations ${ }^{5}$ upon the occurrence of a pronounced post-menstrual oestrus in certain monkeys in the Zoological Gardens, that ovulation may take place at this period (that is, at the close of menstruation).

In the case of the human female there is still a great divergence of opinion in regard to the usual time for the discharge

1 Van der Stricht, "L'Atrésie ovulaire," \&c., Verhand d. Anat. Gesell. in Bonn, 1901. "Les Mitoses de Maturation," \&c., Nancy, 1906.

2 In some Invertebrata which undergo cyclical changes it has been shown that ovulation occurs only at certain intervals depending upon the general condition of the organism. Thus in the females of certain Crustacea ovulation regularly fullows the moult and cannot precede it.-Science (New Series), vol. xxv. (Feb. 1907).

${ }^{3}$ Heape, Phil. T'rans., B., vol. clxxxv., 1894, and vol. clxxxviii., 1897. Truns. Obstct. Soc., vol. xl., 1898.

"Van Herwerden, "Bijdrage tot de Kennis van den Menstruellen Cyclus," Tijdschr. d. Ned. Dierk. Vereen, vol. x., 1906.

5 Pocock, "Notes upon Menstruation," \&c., Proc. Zool. Soc., 1906. 
of the ova. Some authors express the belief that ovulation occurs before menstruation, others that it takes place during that process, and others again that it follows menstruation. Hergesell ${ }^{\mathbf{1}}$ has lately adduced evidence which, in his opinion, points to the conclusion that ovulation precedes menstruation, but the occurrence of corpora lutea of uncertain age in the ovary cannot be regarded as supplying definite proof. There are reasons, on the other hand, for concluding that, primitively at any rate, the most usual period for ovulation in the human female was during a definite œstrus following a proœstrum, as in many of the lower Mammals; for the period of most acute sexual feeling is generally just after the close of the menstrual period (see p. 69), while, according to Raciborsky, this is also the commonest season for fertile coition. ${ }^{2}$ Moreover, the facts narrated by Bryce and Teacher, in a recent memoir on the early development and embedding of the human ovum, render it extremely probable that the ovum described had been discharged shortly after the cessation of the last menstruation. $^{3}$

With regard to the question as to whether any special stimulus is necessary to induce ovulation in women, Oliver ${ }^{4}$ is of opinion that whereas it sometimes may occur spontaneously, it is more than probable that it " may be and often is accelerated by coitus," since at this time there is " an increased determination of blood to the whole genital tract." 5

1 Hergesell, "Das zeitliche Verlalten der Ovulation zur Menstruation," Inaug. Diss., Leipzig, 1905.

2 Raciborsky, Traité de Menstruation, Paris.

${ }^{3}$ Bryce and Teacher, Contribution to the Study of the Early Development and Embedding of the Human Ovum, Glasgow, 1908.

"Oliver, "A Study of Fertilisation with Reference to the Occurrence of Ectopic Pregnancy," Edin. Med. Jour., vol. liv., 1902.

5 Pregnancy, and therefore ovulation, have been known to take place before the onset of menstruation. I'regnancy may also occur during amenorrhoea (e.g. at the commencement of the menopause) and during the lactation period, when menstruation is often in abeyance. Again, it is stated that ovulation has been noted during infancy, before any of the otler indications of puberty have been observed (Webster, "The Biological Basis of Menstruation," Montreal Melical Journal, April 1897). Further, it will be shown below (p. 348) that the ovaries can maintain their normal functions after the removal of the uterus. It would seem, therefore, that ovulation may occur spontaneously in women, and is not necessurily connected with either men- 
This suggestion receives some support from an experiment by Clark, ${ }^{1}$ who caused the rupture of a Graafian follicle artificially in a freshly removed ovary by injecting carmine gelatine into the vessels and so raising the ovarian blood pressure.

The causes which determine the rupture of the Graafian follicle are also discussed by Heape, ${ }^{2}$ who is of opinion that this is brought about in the rabbit by the stimulation of erectile tissue, and not simply as the result of internal pressure arising from increased vascularity or a greater quantity of liquor folliculi. ${ }^{3}$ In this animal the process must be due to a nervous reflex, induced by the act of copulation. As has been shown above, in those animals in which the ova are discharged spontaneously, this usually occurs during œstrus, and not during the proœstrum when the congestion of the generative tract is at its height.

Harper's experiments ${ }^{4}$ on the fertilisation of the pigeon's egg elucidate the question somewhat further. This author writes as follows: "When a pair [of pigeons] ready for mating is put together, egg-laying ordinarily ensues at the end of a rather definite period, at the least eight days. The female functions are held in abeyance till the proper stimulus is received from a mate. ${ }^{5}$ The maturing of the egg is so exclusively a female function that it seems odd at first thought that an apparent exception should occur to the rule. Of course, we know that struation, œstrus, or coitus. On the other hand, there is evidence that ovulation is intimately associated with the occurrence of the sexual orgasm in certain instances. Thus Galabin records a case of a woman who married under the age of twenty, and lived in married life with two husbands in succession, and who, when she had passed the age of forty, experienced the sexual orgasm in coitus for the first time, and from that day dated her first and only pregnancy (Manual of Midwifery, 6th Edition, London, 1904). The orgasm (which is characterised by the erection of the clitoris, accompanied by certain sensations) is not necessary for conception, for pregnancy often occurs in women who are "impotent."

1 Clark, "The Origin, Development, and Degeneration of the Blood-Vessels of the Human Ovary, "Johns IIopkins IIospital Reports, vol. ix., 1900.

2 Heape, “Ovulation," \&c., Proc. Roy. Soc., B., vol. lxxvi., 1905.

${ }^{3}$ It has been suggested that the follicle may rupture as a result of the breaking down of the blood-vessels in its wall, and the consequently increased pressure due to the bleeding into the cavity. See Heape.

4 Harper, "The Fertilisation and Early Development of the Pigeon's Egg," Amer. Jour. of Anat., vol. iii., 1904.

5 In the common fowl, and probably in most other birds, ovulation takes place independently of the male. 
the final maturation of the egg, or the giving off of the polar bodies, awaits in most animals the act of fertilisation. But here the effect is produced upon the egg by the entrance of sperms. How mating and the act of copulation [which is repeated at frequent intervals every day at this time] could influence the ripening of the egg in the ovary is another problem. In this connection the curious fact must be mentioned that two female pigeons placed in confinement may both take to laying eggs. The function of ovulation is in a state of tension, so to speak, that requires only a slight stimulus, 'mental' apparently in this case, to set the mechanism to working. At any rate, it is impossible to regard the presence of sperm in the oviduct as an essential element of the stimulus to ovulation, although it may have an important influence in the normal case. Our attention is directed to the various and complex instincts of the male which come under the head of courtship, both before and after mating is effected, as furnishing a part of the stimulus to the female reproductive organs." Harper proceeds to describe a curious habit which is common among pigeons before copulating. The male bird regurgitates some secretion in its throat, and this is taken up by the bill of the female in much the same manner as the young take their food. "It is easy to see that here may be one of the sources of indirect stimulation to the female reproductive organs."

Spallanzani ${ }^{1}$ found that whereas the female fire-bellied toad could lay its eggs in the absence of the male, the female fetid toad, if isolated, retained its eggs in the ovaries. The common frog is capable of spontaneous oviposition, at least in some cases. $^{2}$

The exact nature of the mechanism by means of which the discharged ova in the human female are made to pass into the aperture of the oviduct is not certainly known. Rouget ${ }^{3}$ believed that the fimbriated end of the Fallopian tube erected and partially enclosed the ovary. Kehrer ${ }^{4}$ suggested that the

3 Spallanzani, Dissertutions, Fnglish Translation, London, 1784.

${ }^{2}$ Morgan, The Development of the Frog's Eyg, New York, 1897.

3 Rouget, "Recherches sur les Organes Erectiles de la Femme," Jour. de la Phys., vol. i., 1858.

"Kehrer, "Die Zusammenziehungen des Weiblichen Genitalcanals," Beiträge zur Vergleich. und Exper. Geburtskunde, 1864. 
ovum was shot into the open fimbrix in the act of ejaculation. The motion of the cilia, which line the fimbriated end as well as the interior of the tube, no doubt serve to set up a current which assists in directing the ova. Gerhardt, ${ }^{1}$ who has paid some attention to the question, concludes that in Man and many other Primates a number of factors co-operate to secure the entry of the discharged ovum into the tube. These factors include the erectibility of the fimbriæ, the muscular movements of the same, the ciliary currents on the fimbriæ and tube, and the configuration of the ovarian surface. In other orders of Mammals the process is brought about in various ways. In Monotremes, Marsupials, and Cetaceans the entrance to the tube is relatively large as compared with the size of the ovary. In certain other animals a portion of the peritoneum is used as a common envelope for the ovary and the end of the tube. Thus in the dog and ferret the ovary is enclosed in a sac communicating with the cavity of the tube, so that the discharged ova can scarcely fail to effect an entrance into the uterus. There can be little doubt, however, that in the majority of animals ciliary movement plays an important part in directing the course of the expelled ova.

Nussbaum $^{2}$ has described the eggs of the frog as being carried into the mouths of the oviducts by the motion of the cilia of the cœlomic epithelium. These cilia are said to drive in a forward direction any small bodies lying free in the cœlom. Harper ${ }^{3}$ states that in the pigeon the egg is clasped by the oviduct, which at this time displays active peristaltic contractions, as if in the act of swallowing the egg.

There is evidence, however, that ova which are discharged from one ovary do not always pass into the oviduct on the corresponding side. For example, instances have been known of animals with a bicornuate uterus becoming pregnant in the uterine horn on the side opposite to that on which the ovary had discharged (as indicated by the presence of a newly

1 Gerhardt, "Studien über den Geschlechtsapparat der Weiblichen Säugethiere: I. Die Ueberleitung des Eies in die Tuben," Jenaische Zeitschr., vol. xxxix., 1905.

2 Nussbaum, "Zur Mechanik der Eiablage bei Rana fusca," Arch. f. Mikr. Anat., vol. xlvi., 1895.

${ }^{3}$ Harper, loc. cit. 
formed corpus luteum). Moreover, it has been recorded that animals from which one ovary had been removed have become pregnant in both horns of the uterus, an observation which clearly shows that the ova which are discharged from one ovary may travel across the peritoneal cavity and enter into the Fallopian tube on the other side of the body.

In certain abnormal cases the ovum escapes altogether into the peritoneal cavity, and never finds its way into either oviduct. If the ovum becomes fertilised, as sometimes happens, the condition known as ectopic or extra-uterine gestation may result; that is to say, the embryo which is formed may become attached to some part of the wall of the body cavity and there undergo development. Ectopic or extra-uterine pregnancy has been known to occur in the domestic animals as well as in the human subject. ${ }^{1}$ Thus Gofton ${ }^{2}$ has recently described a case of a cat which was pregnant with six kittens, one in the normal position in the uterus, and the other five in the abdominal cavity. The foetal envelopes of the abdominal embryos were attached by a sort of placenta to the parietal peritoneum and to the omentum, and one lad also an extensive attachinent to the fundus of the stomach. All the embryos were well developed and apparently normal. Moreover, Dr. Blair Bell has informed me of a case of primary abdoninal pregnancy in a rabbit owned by him. There were four well-developed fœtuses.

\section{The Formation of the Corpus Luteum}

After the discharge of the ovum from the ovary the ruptured Graafian follicle undergoes a series of changes which result in the formation of the structure known as the corpus luteum.

The fully formed corpus luteum consists of large cells containing a yellow pigment, the luteal cells, separated from one another by an anastomosis of connective tissue which is seen to branch inwards from the surrounding ovarian stroma, and

1 See the text-books on Midwifery, and for further details, The Journal of Obstctrics and Gynacology, vol. x., December 1906, which number is entirely devoted to the subject of extra-uterine pregnancy. Ovarian pregnancies, in which the spermatozoa have entered newly ruptured follicles, are also known.

2 Gofton, "Ectopic Gestation in a Cat," Royal Dick Coll. Mag., vol. i., 1906. 
to form a central plug in which there are no luteal cells. This connective tissue contains numerous blood-vessels, so that the fully developed corpus luteum is a highly vascular structure.

Three hypotheses have been put forward regarding the manner of formation of the corpus luteum. That of Paterson, ${ }^{1}$ who supposed it to be derived from the blood coagulum left in the cavity of the Graafian follicle after its discharge, gaincd few or no adherents. The other two theories, those of von Baer ${ }^{2}$ and Bischoff, ${ }^{3}$ on the other hand, have each received considerablc support.

Von Baer regarded the corpus luteum as an entirely connective tissue structure, in the origin of which the follicular epithelium had no share; while Bischoff concluded that the luteal cells were formed by the hypertrophy of the epithelial cells of the undischarged Graafian follicle. Among the principal supporters of Von Baer's view appear the names of Leuckart, His, Kölliker, Slavjansky, Gegenbaur, Benckiser, Schottländer, and Minot. Those who have adopted the alternative theory of Bischoff include Pflüger, Waldeyer, $C_{1} l l$ and Exner, Beigel and Schulin. ${ }^{4}$

To Sobotta ${ }^{5}$ bclongs the credit of being the first to deal systematically with the question, and, with the publication of his papers on the corpus luteum in the mouse, the controversy entered. upon a new phase. In Sobotta's investigation the material employed was collected upon a definite plan, the animals being killed at known intervals after coition, in reference to the occurrence of which the period of ovulation had been previously determined. In this way there was obtained a large series of corpora lutea represcnting successive stages of development. The investigation resultcd in confirming Bischoff's

1 Paterson, "Observations on Corpora Lutea," Edinburgh Med. and Surg. Jour., 1840.

${ }^{3}$ Von Baer, De Ori Mammalium et Hominis Genesi Epistola, Lipsiæ, 1827.

${ }^{3}$ Bischoff, Entwickelungsgeschichte des Kanincheneies, Braunschweig, 1842.

+ For an account of the older literature of the subject see Sobotta, "Über die Entstehung des Corpus Luteum der Säugethiere," Merkel and Bonnet's Ergebnisse dor Anat. u. Entwick., vol. viii., 1899.

5 Sobotta, "Über die Bildung des Corpus Luteum bei der Maus," Anat. Anz., vol. x., 1895; and Arch. f. Mikr. Anat., vol. xlvii., 1896. 


\section{4 'THE: PHYSIOLOGY OF' REPRODUC'IION}

view that the luteal cells are the much hypertrophied epithelial cells of the undischarged follicle, the connective tissue network being derived from the inner layer of the theca. Sobotta describes the outer theca as taking no share in the ingrowth, while the theca interna is stated to become entirely spent in the formation of the inter-epithelial anastomosis. The hypertrophy of the epithelial cells is said to be of the nature of a simple enlargement, unaccompanied by division.

Sobotta's conclusions in regard to the development of the corpus luteum in the mouse were subsequently confirmed by

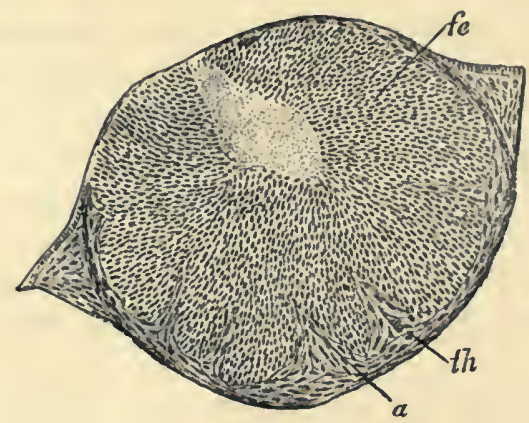

FI(r. 33.-Recently ruptured follicle of mouse. (From Sobotta.)

$f e$, follicular epithelium or membrana granulosa (somewhat hypertrophied); th, theca interna; $a$, ingrowth from same.

him in a further investigation carried out on similar lines on the corpus luteum in the rabbit. ${ }^{1}$ Moreover, Stratz ${ }^{2}$ published descriptions of certain stages of corpus luteum formation in Tarsius, Tupaia, and Sorex, and these agree in essential particulars with those given by Sobotta; while Honore ${ }^{3}$ also working on the rabbit, differed only in concluding that the inter-epithelial network is derived in part from the theca externa, and not exclusively from the theca interna, and that the latter is not entirely exhausted by the ingrowth, some part of it still

1 Sobotta, "Über die Bildung des Corpus Luteum beim Kaninchen." A nat. Hefte, vol. viii., 1897.

${ }^{2}$ Stratz, Der Geschlcchtsrcife Säuycthiceicrstock, Haag, 1898.

3 Honoré, "Recherches sur l'Ovaire du Lapin," Arch. de Biol., vol. xvi., 1900 . 
remaining to form a layer within the outer theca in the fully formed corpus luteum.

On the other hand, several investigators have expressed doubts regarding Sobotta's conclusions, and some have adopted the theory originally formulated by von Baer that the luteal cells arise from the connective tissue sheath of the follicle, the follicular epithelium being either entirely discharged along with the ovum or else being partially discharged and partially degenerating in situ. Amongst those who have adopted this view are Nagel, ${ }^{1}$ who investigated the human corpus luteum;

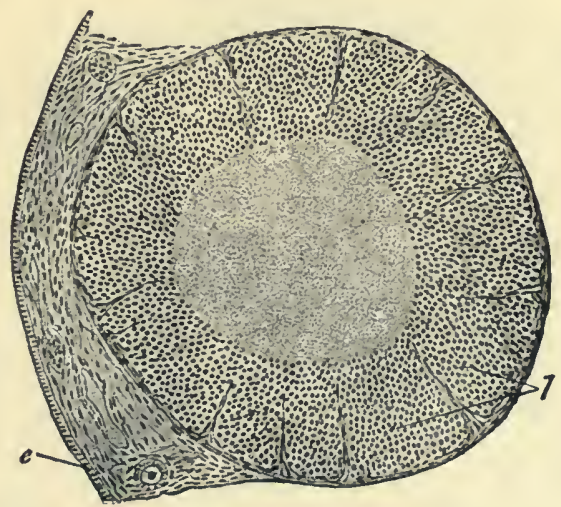

FIG. 34.-Early stage in formation of corpus luteum of mouse. (From

Sobotta.)

$l$, developing luteal cells; $e$, germinal epithelium.

Clark, ${ }^{2}$ who contributed an account of the formation of the corpus luteum in the sow and in the human subject; Doering, ${ }^{3}$ who also worked upon the sow, and claimed to have confirmed Clark's account; and Bühler, ${ }^{4}$ Wendeler, ${ }^{5}$

1 Nagel, " Die Weiblichen Geschlechtsorgane," Bardeleben's Handbuch der Anatomie des Menschen, vol. vii., Jena, 1896. "Uber neuere Arbeiten auf dem Gebiete der Anatomie der weiblichen Geschlechtsorgane," Merkel and Bonnet's Ergelnisse d. Anat. u. Entwick, vol. viii., 1899.

2 Clark, "Ursprung, Wachstum, und Ende des Corpus Luteum," Arch. $f$. Anat. u. Phys., A nat. Abth., 1898; Johns Hopkins Hospital Reports, vol.vii., 1899.

3 Doering, "Beitrag zur Streitfrage iber die Bildung des Corpus Luteum," Anat. Anz, vol. xvi., 1899.

4 Biibler, "Entwickelungsstadien Menschlichen Corpora Lutea," Verhand. d. Anat. Cresell., in Pavia, 1900.

- Wendeler, Martin's Die Krankheiten der Eierstocke und Nebeneierstocke. 
and Stöckel, ${ }^{1}$ who have examined and described developing human corpora lutea. Moreover, His, ${ }^{2}$ Kölliker, ${ }^{3}$ and Paladino ${ }^{4}$ have reiterated their adherence to von Baer's hypothesis since the publication of Sobotta's work.

It is remarkable, however, that none of the supporters of this hypothesis appear to have examined the growing corpus luteum in all its stages of development, while in the case of several of the accounts it is not clear whether the structures described were not in reality atretic. follicles-that is to say,

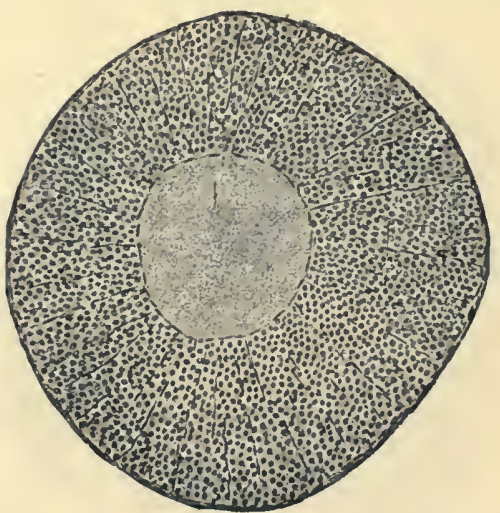

Fig. 35.-Late stage in formation of corpus luteum of mouse. (From Sobotta.) Thecal ingrowths are numerous. The cavity of the follicle is not yet filled in.

follicles which had undergone degenerative changes without ever being discharged. Thus, the words used in a description given by Clark seem to indicate that this author was dealing with the degenerative epithelial cells of an atretic follicle. It seems not impossible also that the young human "corpus luteum" described by Doering was a degenerate follicle; while Kölliker's opinion that the corpus luteum is an entirely connective tissue structure appears to have been founded on the assumption that

I Stöckel, " Ueber die Cystiche Degeneration der Ovarien bei Blasenmole," Sep. Abdruck aus der Festschrift für Pritsch.

2 His, Discussion, Verhand. d. Anat. Gesell., in Tiibingen, 1899.

${ }^{3}$ Kölliker, "Ueber Corpora Lutea Atretica bei Säugethieren," Verhand. d. Anat. Gesell., in Kiel, 1898.

- Paladino, "Per la Dibuttata Questione sulla Esenza del Corpo Luteo," Anat. Anz., vol. xviii., 1900. 
the changes exhibited by discharged follicles and retrogressive undischarged follicles are identical in character. It is to be noted further that in the investigations of all those writers who have upheld the connective tissue hypothesis, the ages of the developing corpora lutea were unknown, the material having been collected in no case by Sobotta's method of killing the animals at successive intervals after coition.

In 1901, after the publication of the papers referred to above,

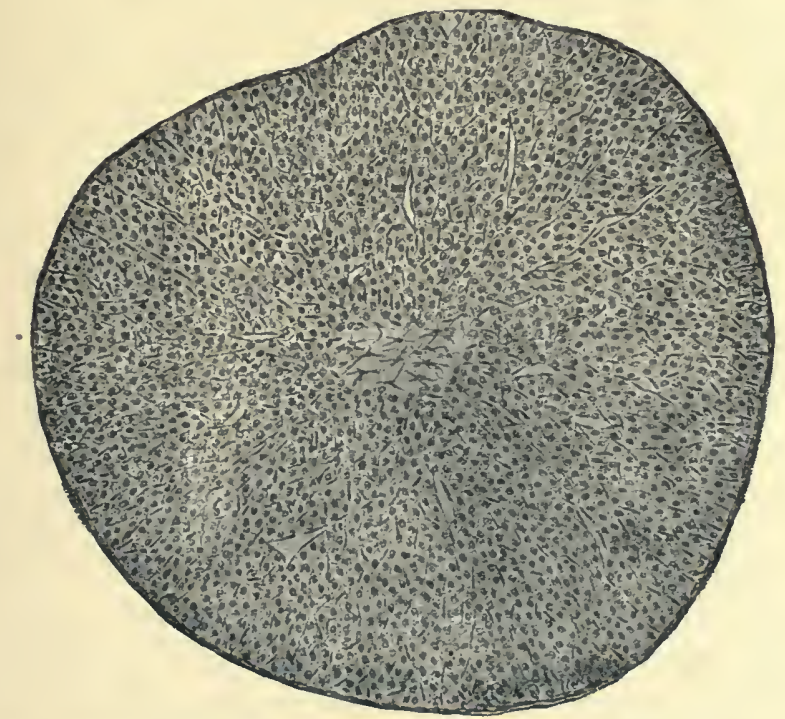

FIG. 36.-Corpus luteum of mouse fully formed. (From Sobotta.) The luteal tissue is vascularised and the central cavity filled in with connective tissue.

the present writer issued a preliminary account ${ }^{1}$ of an experimental inquiry upon the formation of the corpus luteum in the sheep. In this inquiry the animals were killed at successive intervals after coition, or (in cases where coition did not or was not known to occur) after oestrus was observed. The result of this investigation was to confirm Bischoff's hypothesis in all

1 Marshall, "Preliminary Communication on the Estrous Cycle and the Formation of the Corpus Luteum in the Sheep," Proc. Roy. Soc., vol. lxviii., 1901. The full paper was afterwards published in the Phil. Truns., B., vol. cxcvi., 1903. 
essential particulars. The sheep, however, was found to present some differences from the mouse (as investigated by Sobotta) in regard to the origin of the connective tissue network of the corpus luteum, this being discovered to originate partly from the theca externa, and not merely from the theca interna. It was found also that the cells of the follicular epithelium continued to undergo mitotic division after the rupture of the follicle, but not with the same frequency as previously. The theca interna was stated to become entirely spent in the growth of the connective tissue network. Four days after œstrus the discharged follicle was found to have acquired all the characteristics of the fully developed corpus luteum, the luteal cells, as seen in section, being at least six times as large as the original epithelial cells.

In the same year as the publication of the paper referred to above, on the sheep's corpus luteum, van der Stricht ${ }^{1}$ gave an account of the discharged follicle in bats belonging to the genera Vesperugo, Vespertilio, and Placotus. This was also confirmatory of the conclusion that the follicle cells hypertrophy and give rise to luteal cells, but mitotic division among these cells was also seen to occur. Van der Stricht calls attention to the appearance of fatty particles at a very early stage in the history of the luteal cells. A point of greater importance is that van der Stricht found that, whereas the majority of the luteal cells are derived from the follicular epithelium, a certain relatively small proportion of them are developed out of interstitial cells in the inner theca of the connective tissue sheath. This observation lends additional interest to Miss Lane-Claypon's statement that the follicle and interstitial cells have an identical origin, since both are derived from the germinal epithelium, and pass through a similar series of changes. ${ }^{2}$

The structure of the ovary, and the cyclical changes which it

1 Van der Stricht, "La Rupture du Follicule Ovarique et l'Histogénèse du Corps Jaune," C. R. de l'A ssoc. des A natomistes, 3rd Session, Lyon, 1901. “La Ponte Ovarique," \&c., Bull. de l'Acad. Roy. de Médecine Belgique, 1901.

" Marshall, "'The Development of the Corpus Luteum : a Review," Quar. Jour. Mier. Science, vol. xlix., 1905. Miss Lane-Claypon's discovery that the follicular epithelial and interstitial cells are probably equipotential may perhaps belp to elucidate some of the discrepancies between the accounts by various authors of the formation of the corpus luteum. 
undergoes in the case of the "marsupial cat" (Dasyurus viverrinus), have been investigated by Sandes, ${ }^{1}$ who shows that the mode of formation of the corpus luteum in Marsupials is essentially similar to what it is in the Eutheria. The theca interna folliculi is shown to be rudimentary in Dasyurus, a circumstance which rendered it especially easy to follow the subsequent changes undergone by this layer. Sandes describes the follicular epithelium as undergoing so great an hypertrophy prior to the thecal ingrowth as sometimes almost to fill the cavity of the discharged follicle, so that there could be no possibility of confusing the epithelial with the connective tissue cells. ${ }^{2}$

The formation of the corpus luteum in the rabbit has been further studied by Cohn, ${ }^{3}$ while the same process in the marmot has formed the subject of an investigation by Völker. ${ }^{4}$ Both authors agree in supporting Bischoff. Völker finds that the theca externa takes a share in the connective tissue ingrowth, while the theca interna does not become exhausted in the process.

Jankowski, ${ }^{5}$ however, has arrjved at totally different conclusions, and adopts the view that the luteal cells are modified connective tissue cells. The material employed in this research appears to have consisted of a miscellaneous collection of sows' and guinea-pigs' ovaries obtained without any attempt at syste-

1 Sandes, "The Corpus Luteum of Dasyurus Viverrinus," Proc. Linncan Soc., New South Wales, rol, xxviii., 1903.

2 Through the kindness of Professor J. P. Hill I have been permitted to examine sections in his possession of the corpus luteum of the Monotreme Ornithorhynchus paradoxus. These sections show much hypertrophied and apparently fully developed luteal cells, but no trace of any ingrowth from the connective tissue wall of the corpus luteum.

${ }^{3}$ Cohn, "Zur Histologie und Histogenesis des Corpus Luteum und des Interstitiellen Ovarialgewebes," Arch.f. Mikr. Anat., vol. Ixii., 1903.

"Völker, "Über die Histogenese Corporis Lutei bei den Ziesel (Spermophilus citillus)," Bull. Internat. Acad. Sci. (Médicine), Prague, 1904.

5 Jankowski, "Beitrag zur Entstehung des Corpus Luteum der Säugethiere," Arch. f. Mikr. Amut., vol. xliv., 1904. Williams (Obstetric8, New York, 1904) takes up the same position as Jankowski, partly on the ground that "the membrana granulosa presents extensive degenerative changes, and is usually cast off in great part at the time of rupture," and partly because certain cells of the theca interna come to resemble luteal cells prior to ovula. tion. The former statement is far from proved, and the latter cannot be regarded as conclusive (see text). Cf. also Seitz, "Die Fullikelatresie," Arch. f. Gynäk., vol. Ixxvii., 1906. 
matic investigation, so that the ages of the corpora lutea were unknown. Jankowski bases his opinion largely on the appearance of cells resembling luteal cells in the theca interna of the undischarged follicle. It would seem possible that these were interstitial cells, and so probably potentially equivalent to follicle cells (as supposed on independent grounds by van der Stricht and Miss Lane-Claypon).

Sobotta, ${ }^{1}$ however, and also Loeb, ${ }^{2}$ have subsequently investigated the formation of the corpus luteum in the guinea-pig, and find that it is substantially the same as in the mouse, the rabbit, and the sheep.

The results of those investigators who agree in adopting Bischoff's theory of the mode of formation of the corpus luteum may be summarised as follows :-The luteal cells represent the epithelial cells of the undischarged Graafian follicle. These, after rupture, undergo a great hypertrophy, which may be accompanied in the earlier stages by mitotic division, but only to a relatively slight extent (Ovis, Vesperugo, \&c.). Meanwhile the thickness of the wall of the discharged follicle is further increased by an ingrowth of connective tissue, which eventually forms an anastomosis of cells, generally fusiform in shape, between the hypertrophying follicular epithelial cells. This connective tissue ingrowth is either derived from the theca interna alone (Mus, Cavia, Tarsius, Tupaia, Sorex, Dasyurus, Vesperugo, $\& c$.$) , or it may arise from both the theca interna and the theca$ externa (Lepus, Ovis, Spermophilus). The theca interna may become entirely spent in this process (Mus, Cavia, Tarsius, Tupaia, Sorex, Ovis, Dasyurus), or certain strands of this layer may still remain and line the outside edge of the follicle after it has become transformed into a fully developed corpus luteum (Lepus, Spermophilus, Vesperugo). In some animals the interstitial cells of the theca interna may develop into luteal cells in just the same manner as the follicular epithelial cells (Vesperugo, \&c.). The cavity of the discharged follicle becomes filled in eventually by the further ingrowth of connective tissue, which forms a central plug.

1 Sobotta, “Über die Bildung des Corpus Luteum beim Meerschweinchen," Anat. Hefte, vol. xxxii., 1906.

2 Loeb (L.), "Über die Entwicklung des Corpus Lateum beim Meerschweinchen," Anat. Anz., vol. xxviii., 1906. 
The changes undergone by the discharged follicle have also been studied in certain of the lower Vertebrates. Giacomini, ${ }^{1}$ who has investigated the subject in birds, amphibians, and, more particularly, Elasmobranch fishes, describes an hypertrophy of the follicular epithelium consequent upon ovulation. The discharged follicle of Myliobatis is described and figured as a glandular body in which the enlarged epithelium is penetrated by an extensive ingrowth of connective tissue and bloodvessels. Wallace ${ }^{2}$ gives a somewhat similar account of the spent follicles in the fishes Zoarces and Spinax. In the latter especially there is a pronounced hypertrophic enlargement of the follicle cells, associated with thecal ingrowths arrayed in a radial manner. Lucien ${ }^{3}$ has described corpora lutea in the reptiles Anguis and Seps, in which there is a simple hypertrophy of the follicular epithelium unaccompanied by mitotic division. Similar structures in reptiles have also been observed by Mingazzini, ${ }^{4}$ who believes them to be identical with mammalian corpora lutea. On the other hand Bühler, ${ }^{5}$ who investigated the ovaries of Cyclostomes and certain Teleosteans, was unable to find any hypertrophy of the wall of the spent follicle, and Cunningham, ${ }^{6}$ also writing on Teleosteans, arrived at the same result as Bühler. However, it is evident that the epithelial theory of the origin of the corpus luteum receives confirmation from those members of the lower Vertebrata in which there is a follicular enlargement following ovulation.

The mammalian corpus luteum may contain a central clot composed of blood derived from the vessels of the follicular wall which gave way at the time of ovulation. In this case the blood-clot becomes gradually absorbed along with the remainder

1 Giacomini, "Contributo all 'Istologia dell' Ovario dei Selaci," Ricerca Lab. di Anat. Normale della Roy. Univ. di Roma, vol. v., 1896.

"Wallace (W.), "Observations on Ovarian Ova, \&c.," Quar. Jour. Micr. Science, vol. xlvii., 1903.

${ }^{3}$ Lucien, "Note préliminaire sur les premières Phases de la Formation des Corps Jaune chez certains Reptiles," C. R. dc Soc. de Biol., vol. lv., 1903.

4 Mingazzini, "Corpi Lutei verie falsi da Rettili," Ricerca Lab. di Anat. Normale della Roy. Univ. di Roma, vol. iii., 1893.

5 Biihler, "Rückbildung der Eifollikel bei Wirbelthieren," Morph. Jahr., vol. xxx., 1902.

- Cunningham (J. T.), "On the Histology of the Ovary and of the Ovarian Ova in certain Marine Fishes," Quar. Jour. Micr. Science, vol. xl., 1897. 
of the liquor folliculi. On the other hand, there may be practically no hæmorrhage, or the discharged blood may be expelled to the exterior of the ovary (with the greater part of the liquor), remaining as a small clot upon the surface. ${ }^{1}$ It would seem probable that the vessels burst as an effect of the released tension consequent upon the rupture of the follicle; but, as already mentioned, it has been suggested that possibly the latter process may itself vccur as the result of the pouring out of blood into the cavity. During the early stages of formation of the sheep's corpus luteum leucocytes of the polymorph variety have been observed in great abundance, but in the later stages they disappear, some of them undergoing degeneration. These leucocytes are not extravasated, but wander inwards with the growing strands of connective tissue. ${ }^{2}$ Their occurrence should probably be associated with the necessity to dispose of the blood-clot when such is present.

The ingrowth of connective tissue commences a very short time after ovulation, and in the sheep may be seen very distinctly as early as in the seven-hour stage of development. Blood-vessels are carried inwards with the connective tissue, and these undergo multiplication, so that the corpus luteum is a highly vascular structure.

If the discharged ovum fails to become fertilised the corpus goes on growing for a short time and then degenerates, so that, in the case of the human female, two months after ovulation it is reduced to the condition of an insignificant cicatrix. In the smaller animals it disappears after a considerably shorter time. If, on the other hand, conception succeeds ovulation, the corpus luteum continues to increase in size until almost the middle of pregnancy, and in the human female attains to a diameter of nearly an inch in length.

The large size of the completely developed corpus luteum is the more remarkable in that it results to so large an extent from the simple hypertrophy of certain of its constituent cells.

1 It is sometimes stated that the hamoglobin of the blood-clot is transformed into the yellow pigment (known as lutein) whicl gives the luteal cells their characteristic colour; but this is obviously incorrect, since there may be no blood-clot in the follicle, whereas the luteal cells always contain lutein.

¿ Marshall, Phil. Trans, loc. cit. 
The wonderful property which these cells possess of enlarging within a very short time of ovulation is seemingly without a parallel in the physiology of the Vertebrata, and it becomes additionally interesting in view of the almost certain fact that the cells, from which the luteal cells develop, are derived, like the ova, from the original germinal epithelium.

During the later part of pregnancy the corpus luteum becomes

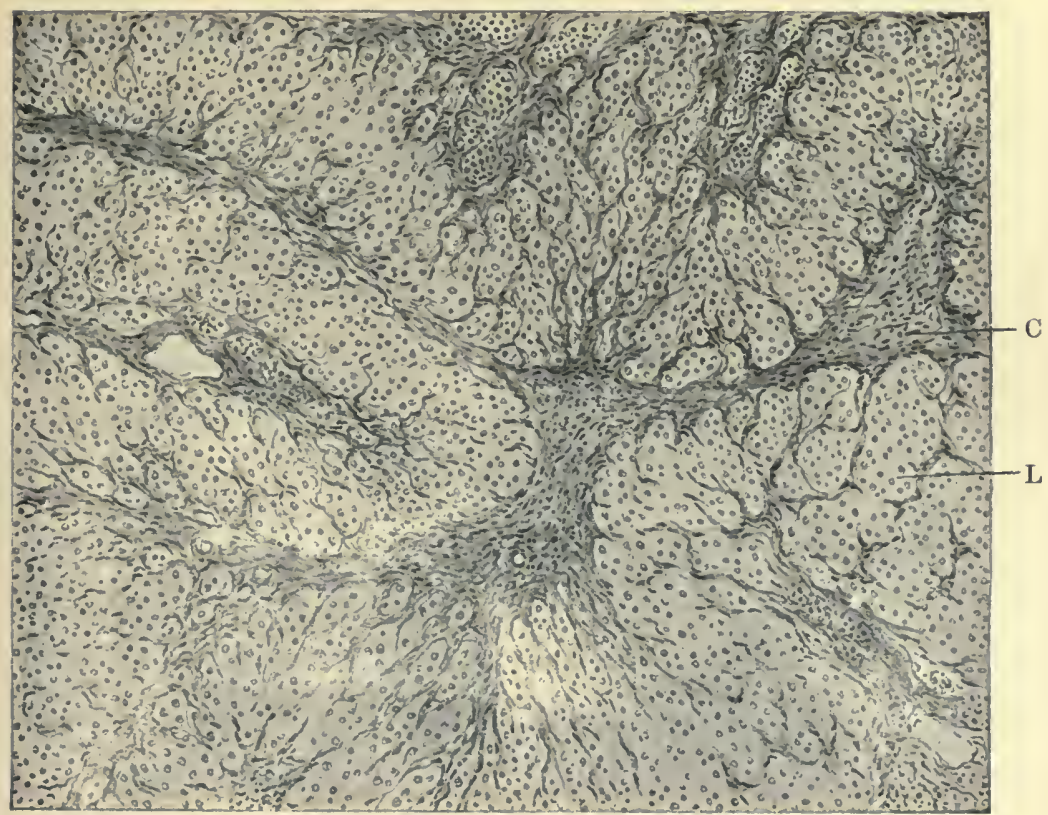

FiG. 37.-Section through old corpus luteum. (From Sellheim.)

C, connective tissue ; L, luteal tissue.

reduced in size, the luteal cells degenerating, losing their yellow colour, and eventually (at least in some cases) appearing to become transformed into cells resembling, if not identical with, the ovarian interstitial cells referred to above (see p. 148). ${ }^{1}$ At the end of pregnancy the human corpus luteum has a diameter not exceeding half-an-inch in length.

1 Schäfer, Essentials of Histology, 7th Edition, London, 1907. The similarity between the luteal and interstitial cells has also been remarked upon by Allen, loc. cit. 
The corpus luteum of pregnancy is sometimes distinguished from the structure formed when pregnancy does not supervene after ovulation, the latter being called the false corpus luteum, ${ }^{1}$ or corpus luteum of menstruation; but it is obvious that the two bodies are identical in the early stages, and otherwise essentially similar. $^{2}$ Moreover, according to Ancel and Bouin, ${ }^{3}$ in animals like the rabbit, which do not ovulate spontaneously during œstrus, these two kinds of corpora lutea are identical throughout. In such animals interstitial cells are believed to replace functionally the "periodic corpus luteum."

The hypotheses which have been put forward regarding the function of the corpus luteum, and the possible part which this organ plays in the metabolism of pregnancy, will be discussed at some length in a future chapter. (For chemistry of corpus luteum see p. 263.)

\section{The Atretic Follicle}

It has been already mentioned that the rabbit, the ferret, and certain other animals do not necessarily ovulate during cestrus in the absence of the male. The follicles, instead of bursting, undergo degeneration (atresia) with their contained ova. Heape ${ }^{4}$ has shown that the congested vessels in the wall of the follicle may rupture and pour blood into the cavity, where it forms a clot surrounding the degenerating ovum. The brilliant, suffused red appearance of many of the rabbit's follicles during the early stages of degeneration is said to result from internal bleeding. The first rush of blood into the cavity washes away the epithelium from the wall of the follicle, at the same time disintegrating the theca interna. Bleeding, however, does not necessarily occur at all. In section the cavity of the degenerate follicle appears, during the early stages, to be bounded by the theca externa, while the ovum may be seen as a shrunken object no longer enclosed by $\dot{a}$ discus proligerus. $^{5}$ Heape $^{6}$

1 Or corpus luteum spurium.

2 The retrogressive changes are similar in both kinds of corpora lutea.

"Ancel and Bouin, "Sur les Homologies et la Significance des Glandes à Sécrétion interne de l'Ovaire," C. $R$. de la Soc. de Biol., vol. lxvi., 1909.

- Heape, "Ovulation, \&c.," Proc. Roy. Soc., B., vol. Ixxvi., 1905.

5 Marshall, "The Estrous Cycle in the Common Ferret," Quar. Jour. Mier. Science, vol. xlviii., 1904.

- Heape, loc. cit. 
states that the contents of the follicle are gradually absorbed through the agency of ingrowing parenchyma cells and leucocytes. The cavity is eventually filled in by the ingrowth of normal ovarian tissue.

The following characteristics serve to distinguish the degenerate or atretic follicle (sometimes called the corpus luteum atreticum) from the true corpus luteum: (1) There is no indication of any rupture to the exterior. (2) The ovum, being retained in the follicle, loses its regularly circular shape, becomes

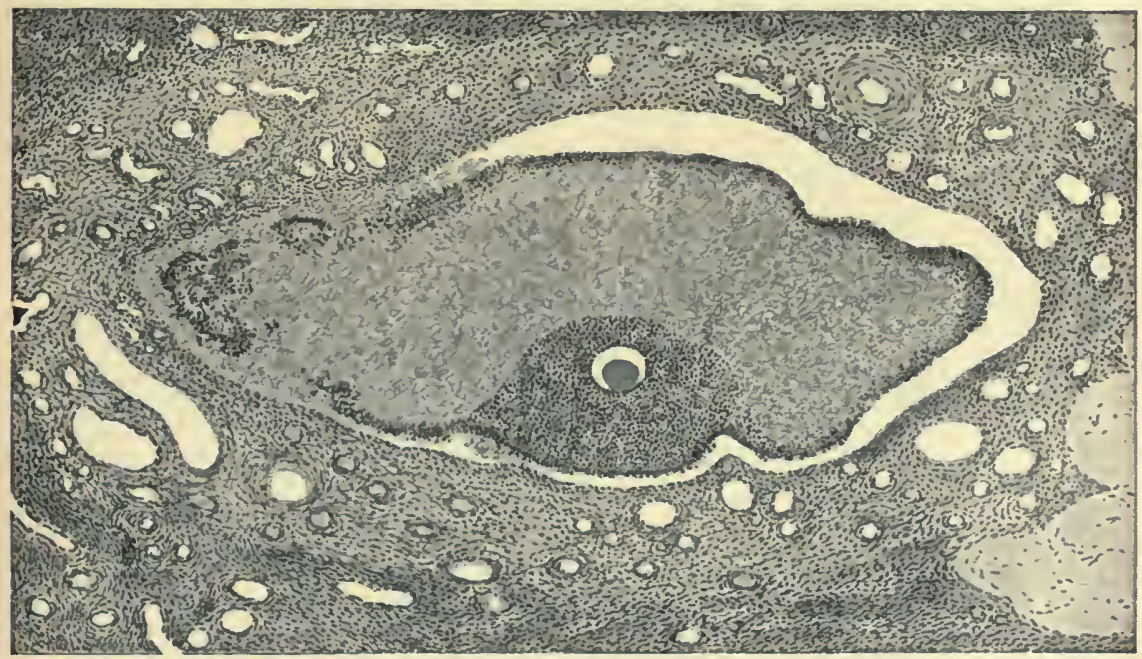

FIG. 38.-Section through follicle in early stage of degeneration. (From Sellheim.) The ovum and follicular epithelium are in process of atrophy.

shrivelled, and gradually disappears altogether. (3) The follicular epithelium, instead of hypertrophying, degenerates, the chromatic substance at one stage often appearing in the form of fine points in the cytoplasm, and much smaller than nuclei. Subsequently the remains of the cells become unrecognisable, finally disappearing altogether. (4) The connective-tissue wall does not proliferate to form a network among the epithelial cells, and there is generally no ingrowth from the thecæ until the epithelial cells are in an advanced state of degeneration or have altogether disappeared. The earliest indication of atretic change is usually 
seen in the clrromatolytic changes in the epithelium. Afterwards the theca interna degenerates, and then the ovun and zona pellucida.

It should be mentioned, however, that the presence of a degenerate ovum cannot, by itself, be regarded as an absolute indication of follicular atresia, since Sobotta ${ }^{1}$ has recorded instances of rupture in the mouse and in the rabbit in which the ova were accidentally retained within the cavity of the follicle, the latter nevertheless forming an otherwise typical corpus luteum; and van der Stricht ${ }^{2}$ has described a similar case of retention in Vesperugo, in which part of the follicle was degenerate while another part possessed the characteristic structure of a corpus luteum.

Degeneration may set in at all stages in the development of a follicle, and not merely in the fully formed follicle which has failed to rupture. Loeb ${ }^{3}$ has described follicular atresia as being common in guinea-pigs of less than six months old.

The degenerative changes which such follicles pass througl have been studied in various Mammalia (chiefly rabbits, cavies, and other Rodents) by Schulin, ${ }^{4}$ Flemming, ${ }^{5}$ Schottländer, ${ }^{6}$ Henneguy, ${ }^{7}$ Janosik, ${ }^{8}$ Kölliker, ${ }^{9}$ van der Stricht, ${ }^{10}$ Seitz, ${ }^{11}$ Loeb,

1 Sobotta. loc. cit.

${ }^{2}$ Van der Stricht, Une Anomalie intércssante de Formation de Corps Jaune, Gand, 1901.

${ }^{3}$ Loeb (L.), " Über liypertrophisehe Vorgiinge bei der Follikelatresie," A rch. f. Mikr. A uat., vol. lxv., 1905. 1881 .

"Sehulin, "Zur Morphologie des Ovariums," A reh.f. Mikr. Anat., vol. xix.,

5 Flemming, "Ueber die Bildung von Riehtungsfiguren in Säugethieren beim Untergang Graafselien Follikel," A rch.f. A nat. u. Phys., A nat. Abth., 1885.

6 Schottlinder, "Beitrag zur Kenntniss der Follikelatresie," \&e., Arch. f. Mikr. A nat., vol. xxxvii., 1891. "Ueber den Graafschen Follikel," \&c., Arch. f. Mikr. Anut., vol. xli., 1893.

7 Henneguy, "Recherches sur l'Atrésie des Follicules de Graaf," \&c., Jour. de l'Anat. et de la Phys., vol. xxx., 1894.

"Janosik, "I)ie Atrophic der Follikel," Arch. f. Mikr. A nat., vol. xlviii., 1896.

'Kölliker, “ Über Corpora Lutea $\Lambda$ tretiea bei S̈̈ugethieren," Verhund. $d$. Anat. Gesell., in Kiel, 1898.

10 Van der Stricht, "L'Atrésie Ovulaire," \&c., Verhand. d. Anat. Gescll, in Boun, 1901.

1 Seitz, "Die Follikelatresie wihrend der Sehwangerschaft," \&e., Arch. f. Gynäk., vol. Ixxvii., 1906. 
and certain other writers, whose results are for the most part in general agreement.

Schulin, and also Janosik, appear to regard the follicular epithelial cells as being converted into leucocytes, which they undoubtedly resemble when undergoing degeneration. Flemming, on the other hand, denies the existence of leucocytes, pointing out

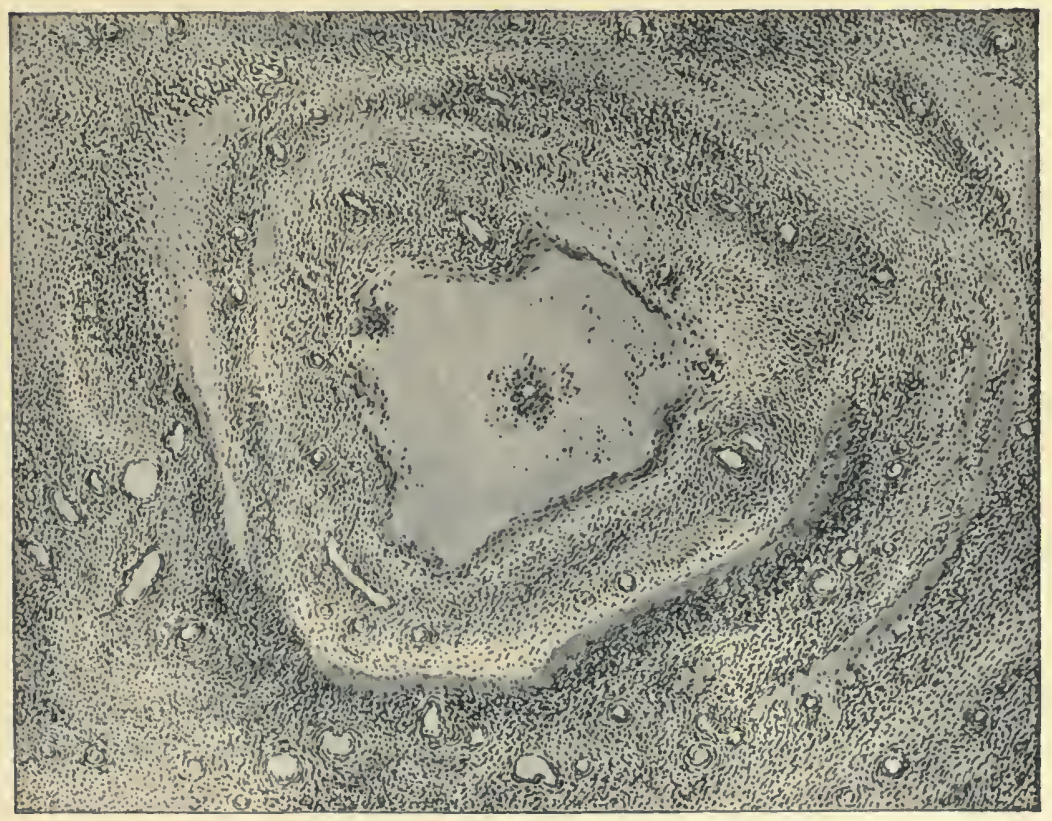

FIG. 39.-Section through follicle in late stage of degeneration. (From Sellheim.) The cavity is in process of being filled by an ingrowth of tissue from the wall. The ovum has disappeared.

that none exist in the theca, and Schottländer clearly distintinguishes degenerating epithelial cells from leucocytes.

More recently, however, Dubuisson ${ }^{1}$ has stated that in the sparrow the follicle cells may multiply and act as phagocytes to the yolk of the degenerating ovum, which becomes filled with them. Afterwards they are said to migrate, leaving nothing but connective tissue which fills in the cavity of the follicle. A

1 Dubuisson, "Contribution à l'Étude du Vitellus," Arch. de Zool. Expér., vol. v., 5th series, 1906. 
similar process is described as occurring in certain reptiles. Pere ${ }^{1}$ also has recorded the phagocytic absorption of ova by follicle cells in the ovary of the fasting newt.

Schottländer states that atresia can occur by fatty degeneration as well as by chromatolysis.

Flemming and others have described nuclear spindles in the ova of follicles in an early stage of atresia, thus showing that these had reached maturity before degeneration set in.

Atretic follicles may shrivel up rapidly, or continue for a time in a cystic condition. In the latter case the cavity remains filled with fluid. Kölliker has shown that certain of the cells in the theca interna of cystic follicles may undergo a process of hypertrophy; and the same fact has been noticed by Seitz, who calls these cells " theca lutein cells" owing to their resemblance to the cells of the corpus luteum. Seitz found these cells only during pregnancy.

Heape ${ }^{2}$ has shown that in the rabbit two kinds of degeneration prevail. In the one kind the changes first affect the follicle and then the ovum, as described above. In the other the ovum is first affected and the follicle afterwards. Heape interprets the latter change as evidence that the ovum is not capable of assimilating the nourishment supplied to it.

Atresia is commonly stated to occur most frequently during pregnancy, but it may occur at other times. ${ }^{3}$ Thus Sandes ${ }^{4}$ has shown that in Dasyurus, as soon as the corpus luteum is formed, the surrounding follicles which were previously in various stages of active development begin to undergo atrophy. The process begins in the follicles in closest proximity to the newly formed corpus luteum, and is continued during pregnancy in the other follicles in ever-widening circles. Sandes suggests that this occurs as a result of mechanical pressure due to the growth of the corpus luteum, or is in some way effected by the internal secretion which the latter organ is supposed to elaborate. Heape ${ }^{5}$ states that in the case of the rabbit, if the buck is with-

3 Perez, "Sur la Résorption phagocytaire des Ovules," \&c., ProcèsVerbaux de la Soc. des Sciences de Bordeaux, 1903.

2 Heape, loc. cit.

"Marshall, "The Estrous Cycle, \&c., in the Sheep," Phil. Trans., B., vol. cxcvi., 1903.

4 Sandes, loc. cit.

${ }^{5}$ Heape, loc. cit. 
held from a doe during several consecutive oestrous periods, not merely the majority of the older follicles degenerate, but also many of the younger ones, so that the animal is liable to become sterile during the remainder of the breeding season. ${ }^{1}$

There can be little doubt that the more usual cause of degeneration in immature follicles is lack of sufficient nutriment, or of nutriment of the requisite kind. It is usually to be observed in under-fed animals, or in animals living under unsuitable conditions, but it also occurs in very fat animals. Ewart states that follicular degeneration tends to occur in mares leading a semi-wild life in winter. ${ }^{2}$ Probably it is least cornmon in animals which are in a good thriving condition, but further investigation is urgently needed before these points can be decided.

\section{Superfatation}

In the majority of Mammals, as in Dasyurus, there can be little doubt that the presence of the corpus luteum tends to produce follicular degeneration, or at any rate to inhibit maturation. In the mare, however, Ewart has shown that degeneration does not generally take place during early pregnancy, so that if a mare aborts (a common occurrence with this animal) ripe ova are available for fertilisation, and pregnancy can be started anew without delay. ${ }^{3}$

If ovulation takes place during pregnancy, and if, owing to the occurrence of coition (see p. 51) the ova become fertilised, the phenomenon of superfotation may take place-that is to say, fœetuses of different ages may be present in the same uterus -but this condition is of course abnormal, though it has been known to occur in several animals. Thus, Mr. W. O. Backhouse has informed me of a case of a cat which experienced heat and underwent coition after being pregnant for six weeks, and three weeks later produced five kittens, four of which were of the normal size and were obviously born at full time (dating from the heat period prior to the beginning of pregnancy), whereas

${ }^{1} C f$. Dubreuil and Regaud (C. R. de la Soc. de Biol., vol. Ixvii., 1909), who say that absence of sexual intercourse causes hremorrhage in the follicles.

${ }^{2}$ Ewart, loc. cit.

Ibid. 
the other kitten was very sinall, and apparently about three weeks developed.

\section{Formation of Ova}

It is usually stated that all the ova which are to be developed in the ovary exist in it at the time of birth, and that a considerable proportion of these undergo atrophy before puberty. Thus, the number of ova in the ovary at birth has been estimated at 100,000 , of which it is supposed that not more than 30,000 remain at puberty. ${ }^{1}$

Miss Lane-Claypon, ${ }^{2}$ however, has described the formation of ova, resembling primordial ova, from interstitial cells during adult life. These cells are shown to increase markedly in size, their length being often almost doubled. In addition to their becoming enlarged, certain of the interstitial cells near the periphery undergo further changes during the later stages of pregnancy. The cells appear to pass outwards and become cut off by connective tissue, and in many cases almost reach the surface of the ovary. This process begins in the rabbit at about the twentieth day of pregnancy. A little later some of the cells appear to be multi-nucleated, and it is suggested that these are formed by the fusion of the same number of interstitial cells as there are nuclei. The nuclei then degenerate with the exception of one, and the inference is drawn that the latter lives and grows at the expense of the others in just the same way as Balfour concluded that one developing ovum in the immature ovary might be nourished by the surrounding ova which were undergoing degeneration.

In the ovary of a rabbit whose time of parturition had nearly arrived, the interstitial cells were observed to have undergone further changes identical with those taking place in the deutobroque cells of a young ovary during the period of oögenesis (see above, p. 120). The leptotenic stage is rapidly passed through and the nucleus enters upon the synaptenic condition, which

1 Galabin, A Munual of Midwifery, 6th Edition, London, 1904. According to another calculation the human ovary at the age of seventeen contains 17,600 ova (Heyse, Arch. f. Gynäk., vol. liii., 1893), of which only 400 become mature (Henle, Handbuch der Anatomie, 1873).

" Lane-Claypon, "On the Origin and Life-History of the Interstitial Cells in the Ovary in the Rabbit," Proc. Roy. Soc., B., vol. Ixxvii., 1905. 
extends over a somewhat longer time. The massing of the chromatin into a lump having been completed, it again becomes spread out and rearranged, and the pachytenic stage is entered upon. The chromatin filaments during this stage are markedly thicker and more bulky. It is followed by a not very typical diplotenic stage, in which the duality of the filaments is said to be not well shown. In the next stage-the dictyate stagethe nucleolus becomes very definite, and the chromatin is arranged more or less over the entire nuclear area, which is now of considerable dimensions. "There can be ... not much doubt that the changes taking place are identical with those seen in the young ovary, which lead to ovogenesis, and therefore it would appear that ovogenesis also takes place in the adult animal during pregnancy." 1

Thus it would seem that the interstitial cells, which, like the ova, are almost certainly derived from the germinal epithelium, are actually potential ova, being capable of developing into true ova when the appropriate stimulus is given. This stimulus is provided by pregnancy, at which period they undergo enlargement so as to exceed the size of a primordial ovum, and in addition pass through the same series of nuclear transformations as those which characterise embryonic oögenesis. ${ }^{2}$

\section{The Significance of the Procestrous Changes}

Having discussed the conditions under which the Graafian follicles ripen and discharge in various species of the class Mammalia, we are now in a position to consider more fully the significance of the uterine changes with which ovulation is frequently associated.

Many obstetricians have adopted the view that the degeneration stage of menstruation in the human female is of the nature of an undoing of a preparation (represented by the

1 Lane-Claypon, loc. cit.

${ }^{2}$ For an account of the interstitial tissue of the ovary in various animals, see Fraenkel. See also Cesa-Bianchi, who states that the interstitial ovarian gland in hibernating animals undergoes a great development in spring and summer, but is much reduced in winter. He also comments on the close resemblance between luteal and interstitial cells. ("Vergleichende histologische Untersuchungen über das Vorkommen drüsiger Formationen im interstitiellen Eierstockgewebe," Arch. f. Gynäk., vol. l×8v., 1906.) 
previous growth stage) for an ovum which failed to become fertilised (or even to be released from the ovary). This theory was originally put forward by Sigismund, ${ }^{1}$ and was subsequently accepted by His. ${ }^{2}$ It has been summarised in the well-known dictum that " women menstruate because they do not conceive." It has been shown above, however, that menstruation in the Primates is the physiological homologue of the procstrum in the lower Mammalia, and that ovulation in the latter occurs usually, so far as is known, during œstrus, or at any rate not until after the commencement of the destruction stage of the proœstrum. Consequently Sigismund's theory becomes untenable.

Loewenthal ${ }^{3}$ advanced the somewhat similar theory that the monthly bleeding is actually brought about by the death of the ovum in the uterus, the "decidua" of menstruation being produced by the embedding therein of the unfertilised egg. No evidence has been adduced in support of this view, which is evidently open to the same objection as Sigismund's hypothesis.

A further modification of the same theory has been advanced by Beard, ${ }^{4}$ who expresses the belief that the process of menstruation is of the nature of an "abortion of something prepared for an egg given off at or after the close of the preceding menstruation, and [that] it takes place because this egg has escaped fertilisation." "Prior to the appearance of the menses the uterus has formed a decidua, which is regarded as equivalent to that which would arise when a fertilised egg became affixed to the uterus." This theory also, if it is to be entertained at all, necessitates the assumption that there is no correspondence between the procstrum in the lower Mammalia and menstruation in the Primates, since the degeneration stage of the proœstrum in the dog or ferret, for instance, can hardly be of the nature of an abortion of something prepared for an ovum which was discharged at the preceding "heat period" many months before. The difficulty is further increased for those animals which experience œstrus only once a year, or even

1 Sigismund, "Ideen über das Wesen der Menstruation," Berliner Klin. Wochenschr., 1871.

2 His, Anutomie Menschlicher Embryonen, 1880.

3 Loewenthal, "Eine neue Deutung des Menstruationsprocesses," Arch. $f$. Gyniik., vol. xxiv., 1884.

- Beard, The Span of Gestation and the Cause of Birth, Jena, 1897. 
less often, for it is improbable that they ovulate more frequently than they come "on heat." Beard, however, denies that there is any correspondence between " the heat or rut of Mammals" and menstruation in the higher forms, saying that very little is required in disproof of the supposed relation.

The theory that the whole procstrous process, including both the degeneration and the recuperation stages, is of the nature of a preparation ${ }^{1}$ on the part of the uterus for the reception of a fertilised ovum is not opposed to any of the known facts. The process is sometimes viewed as a kind of surgical " freshening " of the uterus, whereby the ovum can be safely attached to the mucosa during the healing stage. It is possible, however, that the changing of the uterine tissue is not the least important part of the process.

Emrys-Roberts ${ }^{2}$ has made the further suggestion that the secretion of the uterine glands, together with the blood and other products of procestrous destruction, may serve to provide a rich pabulum on which to nourish the embryo during the earliest days of pregnancy.

In opposition to these theories it may be urged that pregnancy has been known to take place in women who have never menstruated, and that it may occur during periods of amenorrhœea, or during the lactation period, when menstruation is sometimes in abeyance. Such cases, however, are the exception, and it must not be inferred that because the procstrous function can occasionally be dispensed with without inducing a condition of sterility, it normally plays no part in the physiology of generation.

It has been pointed out, however, that the severity of the menstrual process in women is occasionally so great as to be positively injurious, and that such cases evidently belong to the category of constitutional disharmonies which Metchnikoff ${ }^{3}$

1 Kundrat and Engelmann, "Untersuchungen über die Uterusscbleimhaut," Stricker's Med. Jahr., 1873. Lawson Tait, Discases of Homen, 1889. For a further discussion of some of the theories regarding the purpose of menstruation see Heape, "The Menstruation of Semnopithecus entellus," Phil. Trans. B., vol. clxxxv., 1894.

2 Emrys-Roberts, "A Preliminary Note upon the Question of the Nutri. tion of the Early Embryo," Proc. Roy. Soc. B., vol. lxxvi., 1905.

3 Metchnikoff, The Nature of Man, London, 1903. 


\section{THE PHYSIOLOGY OF REPRODUC'TION}

has shown to be so common in the organs and functions of the generative system.

Geddes and Thomson ${ }^{1}$ also have called attention to the pathological character of menstruation, as evidenced not only by the pain which frequently accompanies the process, and the local and constitutional disorders by which it is often attended, but by the general systemic disturbance which always occurs synchronously with it. These authors interpret the discharge as a means of disposing of the anabolic surplus which is consumed during pregnancy by the developing embryo. A similar view is adopted by Webster, ${ }^{2}$ who associates the introduction of menstruation (as distinguished from the procstrum of the lower animals) with a diminished fertility.

Reference has already been made to the "Wellenbewegung" or "wave" hypothesis regarding the nature of menstruation (see p. 67).

The physiological cause of the procstrum, and the probable part played by the ovaries in this connection, will be discussed at some length in a later chapter.

1 Geddes and Thomson, The Erolution of Sex, Revised Edition, London, 1901.

2 Webster, "The Biological Basis of Menstruation," Montreal Med. Jour, April 1897. 


\section{CHAP'TER V}

\section{SPERMATOGENESIS-INSEMINATION}

“Denique per maria ac montis fluviosque rapacis

Frondiferasque domos avium camposque virentis, Omnibus incutiens blandum per pectora amorem Efficis ut cupide generatim sæcla propagent."

-LuCretius.

The spermatozoa, or reproductive cells of the male, were observed as far back as the year 1677, when Hamm, who was a pupil of Leeuwenhoek, directed the latter's attention to them. Leeuwenhoek, however, did not understand the significance of what he saw.

Spallanzani ${ }^{1}$ was the first to show that the presence of spermatozoa in the semen was an essential factor in fertilisation, since the filtered fluid was found to be impotent. Subsequently Kölliker ${ }^{2}$ discovered that the sperms arise from the cells of the testis, and Barry ${ }^{3}$ observed the conjugation of sperm and ovum in the rabbit.

Van Beneden's discovery that the nuclei of the conjugating cells-both ova and spermatozoa-contain only half the number of chromosomes that they had originally has been referred to in the preceding chapter, where the maturation phenomena in the ovum have been briefly outlined ${ }^{4}$ (p. 130). The four products of division formed at the completion of reduction in the male differ from those in the female in that each of them is a functional conjugating cell. Before describing the reduction process in detail it will be well to give a short account of the structure of the testis. ${ }^{5}$

1 Spallanzani, Dissertations, English Tıanslation, vol. ii., London, 1784.

2 Kölliker, Beiträge zur Kenntniss der Geschlechtsverhältnisse, \&c., Berlin, 1841.

3 Barry (M.), "Spermatozoa observed within the Mammiferous Ovum," Phil. Trans., 1843.

* For accounts of the history of the chief discoveries relating to the spermatozoa, fertilisation, \&c., see Thomson, The Science of Life, London, 1899, and Geddes and Thomson, The Evolution of Sex, 2nd Edition, London, 1901.

5 See Barry (D. T.), "The Morphology of the Testis," Jour. of Anat. and Phys., vol. xliv., 1910. 
This organ is enclosed within a fibrous capsule, the tunica albuginea, which is very rich in lymphatics. It is covered by a layer of serous epithelium reflected from the tunica vaginalis. Posteriorly the capsule is prolonged into the interior of the testis in the form of a mass of fibrous tissue (the mediastinum testis). Certain other fibrous processes or trabeculæ also pro-

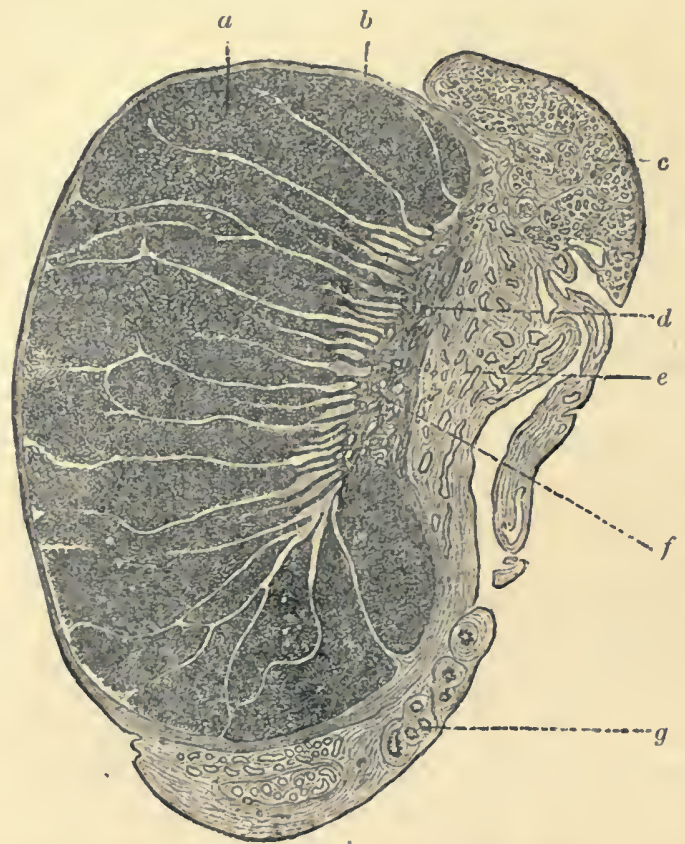

FIG. 40.-Section through human testis and epididymis. (After Böhm and von Davidoff, from Schäfer.)

$a$, glandular substance divided into lobules by septa of connective tissue ;

$b$, tunica albuginea; $c$, part of epididymis ; $l$, rete testis; $e$, body of epididymis ; $f$, mediastinum; $g$, sections through commencing portion of vas deferens.

ject inwards from the capsule, and divide the glandular substance into lobules. The efferent ducts of the testis (vasa efferentia) open into a single convoluted tube situated at the posterior margin of the organ and attached to the mediastinum. This is the epididymis. Its lower extremity is prolonged into a thick-walled muscular tube (the vas deferens) which is the 
passage of exit for the seminal fluid or sperm-containing secretion. The glandular substance of the testis is composed of the con-

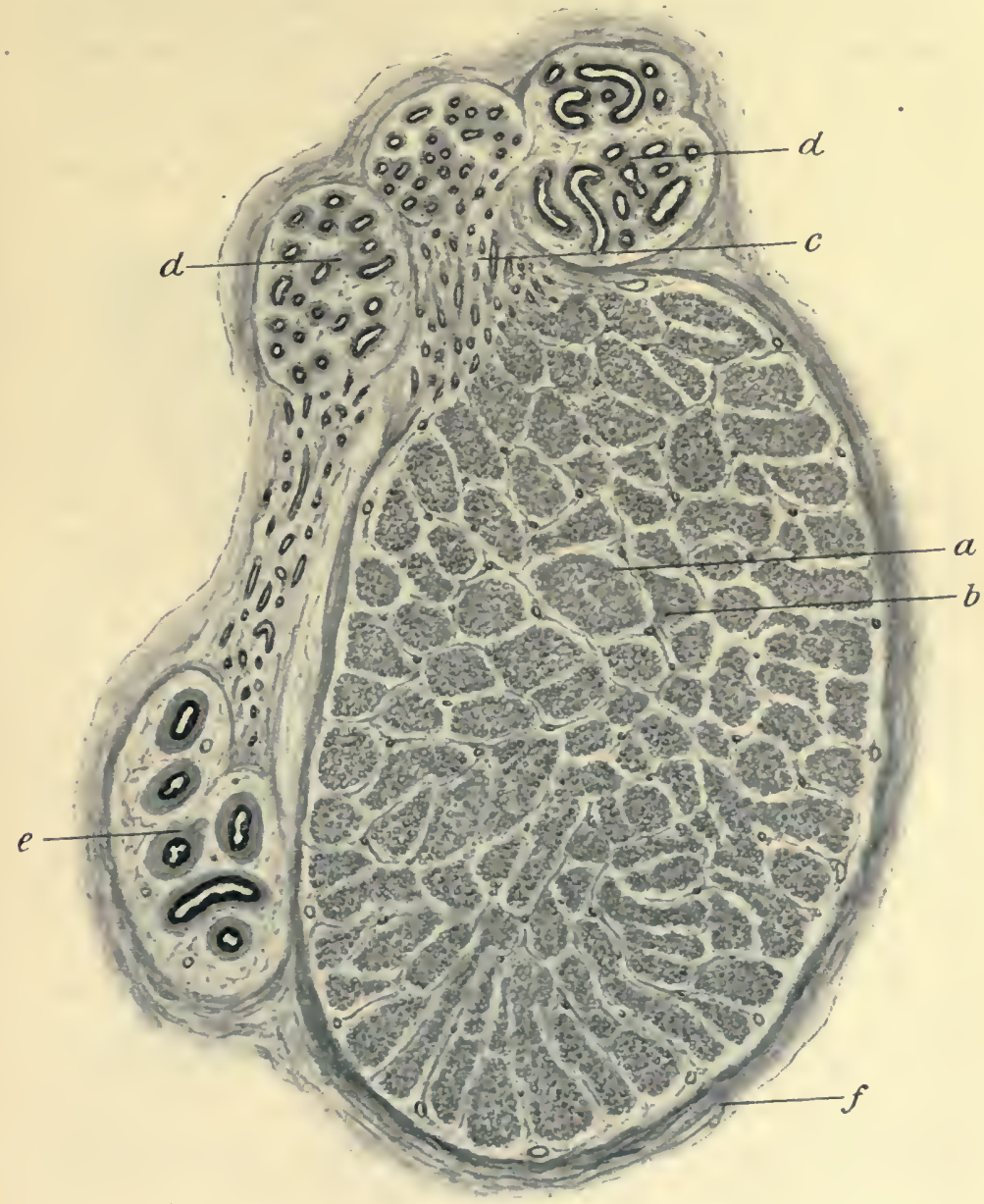

FiG. 41.-Section through testis of monkey.

$a$, seminiferous tubules; $b$, interstitial tissue ; $c$, rete testis ; $d$, vasa efferentia ; $e$, vas deferens ; $f$, tunica albuginea.

voluted seminiferous tubules, two or three of which join together to form a straight tubule which passes into the body of the mediastinum. The straight tubules within the mediastinum 
unite in their turn, giving rise to a network of vessels called the rete testis. From the rete the vasa efferentia are given off. Between the tubules is a loose connective tissue containing a number of yellow epithelioid interstitial cells. The connective tissue also contains numerous lymphaties and blood-vessels (branches of the spermatic artery). The nerves of the testis are derived from the sympathetic system, but a few filaments come from the hypogastric plexus.

In embryonic development the tubules arise from the primitive germinal epithelium. According to Allen ${ }^{1}$ the interstitial cells are derived from connective tissue.

The straight tubules, and the tubules of the rete, are lined by a single layer of cubical or flattened epithelium without a basement membrane. The seminiferous tubules, on the other hand, contain several layers of epithelial cells supported by a thick basement membrane. The layer nearest the membrane consists of clear cubical cells, a few of which show evidence of division. These are the spermatogonia. Certain of the epithelial cells between the spermatogonia are enlarged, and project among the more internal cells in association with developing sperms. These are the cells of Sertoli. On the inside of the spermatogonia are certain larger cells, known as spermatocytes. These are products of division of spermatogonia, each of which on dividing into two gives rise to a cell like itself, and another cell, which grows larger, passes into the second layer, and becomes a spermatocyte.

The spermatids, which in some seminiferous tubules lie on the inside of the spermatocytes, are the double products of division of the latter. The spermatids so formed may be seen as small cells with spherical nuclei, and forming irregular clumps on the inner surface of the tubule. Often, however, the spermatids are elongated, being partially converted into spermatozoa. As this process of transformation proceeds, the developing sperms become arranged in little groups. Associated with each group is a foot-cell, or a cell of Sertoli, which probably serves as a

1 Allen, "The Embryonic Development of the Ovary and Testis," Amer. Jour. of Anut., vol. iii., 1904. As already mentioned, Allen regards the interstitial cells of the ovary as being developed from connective tissue, thus differing from Miss Lane-Claypon. 
support and as a means of conveying nourishment to the growing spermatozoa. ${ }^{1}$ The tails of the latter at this stage project freely.into the cavity of the tubule, and a little later the spermatozoa shift bodily forward and become completely liberated.

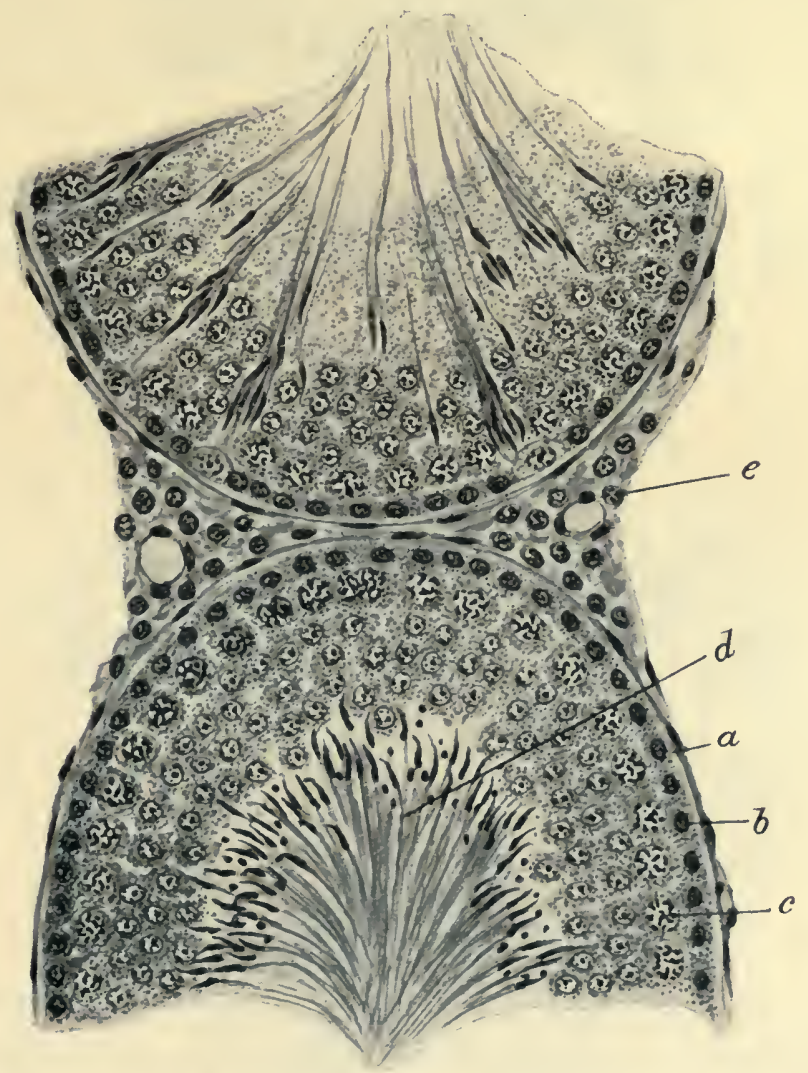

FIG. 42.--Section through portion of two seminiferous tubules in testis of rat.

$a$, basement membrane ; $b$, spermatogonium ; $c$, spermatocyte ; $d$, spermatozoa in cavity of tubule; $e$, interstitial tissue containing vessels.

'Merkel, "Die Stützellen des Menschlichen Hodens," Müller's Archiv, 1871. Brown, "On Spermatogenesis in the Rat," Qual. Jour. Micr. Science, vol. xxv., 1885. Bende, "Untersuchungen über den Bau den Funktioniren den Samenkanälchens einiger Sïugethiere," Arch. f. Mik $\%$. Anat., vol. xxx., 1887. 
According to Loisel, ${ }^{1}$ the orientation of the sperms in the testis is due to a secretion from the cells of Sertoli, together with

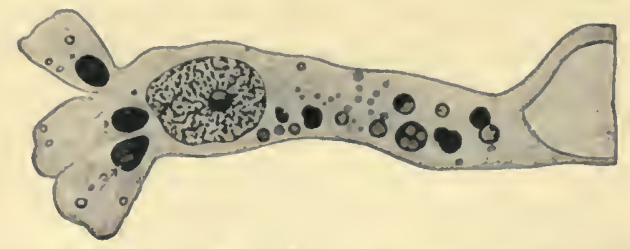

F1G. 43.-A cell of Sertoli with which the spermatids (three of which are slıown) are beginning to be connected-human. (After Bramman, from Schäfer.) The cell contains globules of nutritive substance and similar smaller globules are seen in the spermatids.

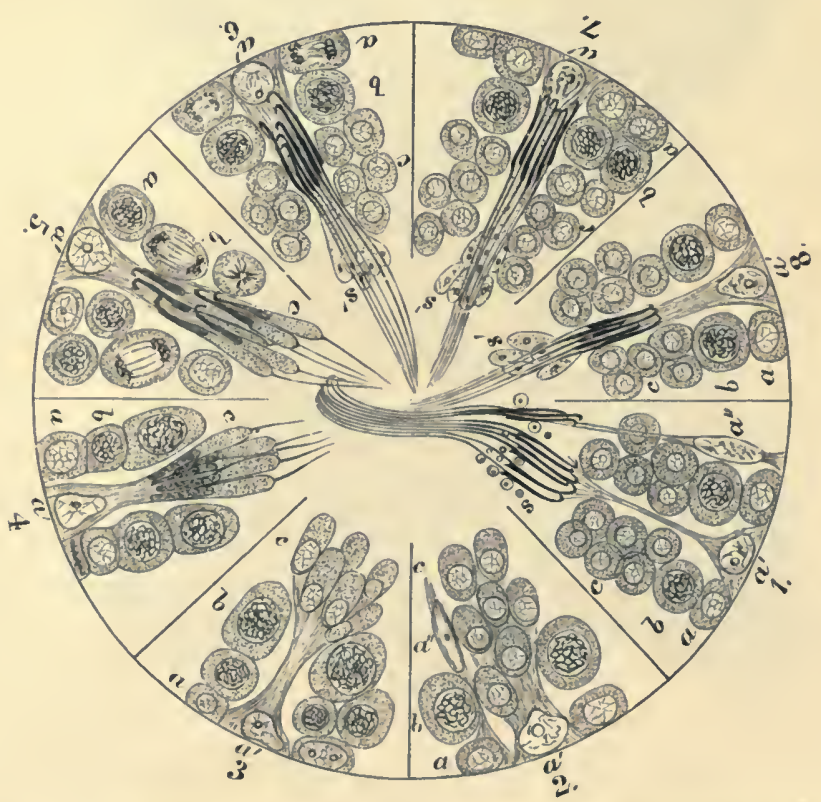

FIG. 44.-Diagram illustrating the cycle of phases in spermatogenesis. (From Schäfer.)

$a$, spermatogonia (seen dividing at 6$) ; a^{\prime}, a^{\prime \prime}$, Sertoli cells; $b$, spermatocytes (seen dividing at 5); $c$, spermatids; $s^{\prime}$, parts of spermatids which disappear when spermatozoa are fully formed; s, scminal granules.

1 Loisel, "Facteurs de la Forme et de la Fasciculisation des Spermies dans les Testicules," Jour. de l'Anat. et de la Phys., vol, xlii., 1906. 
certain of the other cells in the parietal layer of the seminiferous epithelium.

In male animals which have a rutting season spermatogenesis occurs only at this time. At other seasons of the year the testes remain in a quiescent condition. ${ }^{1}$ The periodic activity of the testis is usually correlated with a great increase in the size of that organ (see pp. 24 and 61).

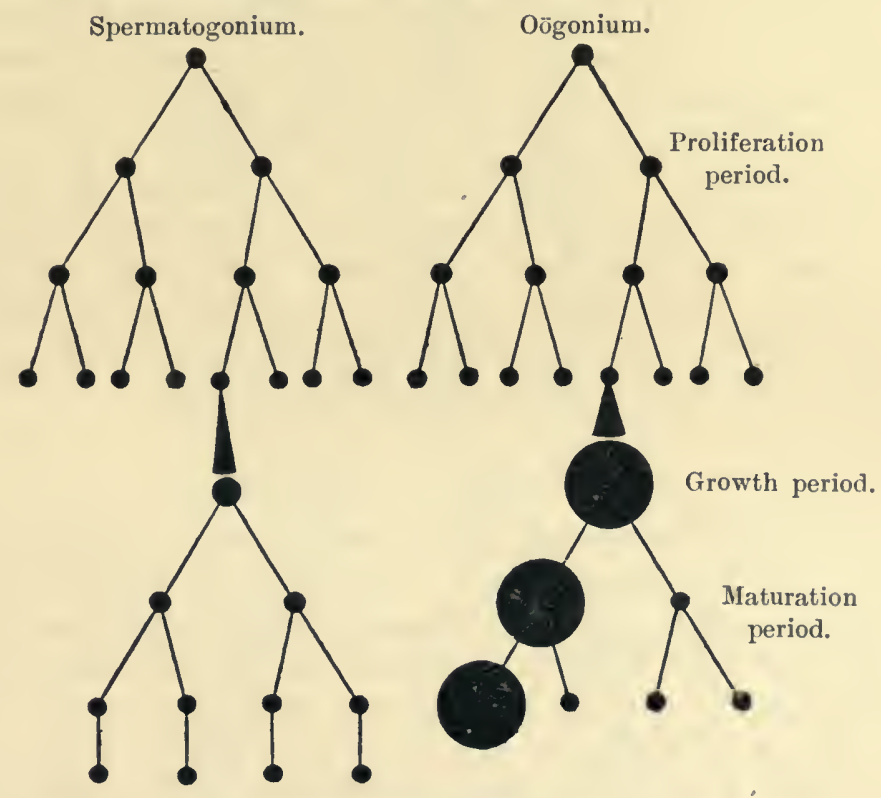

FIG. 45.-Scheme of spermatogenesis and ooggenesis. (After Boveri.)

The changes which occur in spermatogenesis may be summarised as follows: (1) A spermatogonium divides into two, one product of division passing into the second layer of the seminal epithelium and becoming a spermatocyte.

(2) A

1 In some animals the renewal of activity in the testes is associated with the descent of these organs from their position in the abdominal cavity through the inguinal canal and into a cutaneous fold. This is transformed into the scrotum, which lies behind the penis (except in Marsupials, where it is in front). In many Mammals the descent takes place at an early age and is permanent. In others (most Rodents, Insectivores, and bats) the testes are withdrawn into the abdominal cavity after the breeding season is over. This is effected by the cremaster muscle. 
spermatocyte, or mother-cell, divides. (3) A product of division of a spermatocyte divides, giving rise to a spcrmatid, the number of chromosomes becoming reduced during this process to onehalf the previous number. Subsequently the spermatid elongates, the nucleus becomes shifted to one end, and the spermatozoön which is formed in this way is set free. The process is continually going on in the seminiferous tubules of the testis, successive crops of spermatozoa being from time to time produced. The various stages of development may generally be observed in the same testis, or even within the limits of a single tubule.

It is supposed that the reduction in the number of the chromosomes is a preparation of the conjugating cells for their subsequent union in fertilisation, and is a means by which this number is held constant in the species (see p. 131). ${ }^{1}$ In those animals in which reproduction is normally effected without the intervention of a spermatozoön (parthenogenesis) the ovum may discharge only one polar body instead of two.

\section{Structure of Spermatozoa}

A fully developed human spermatozoön consists of a flattened egg-shaped head, a short cylindrical body or middlepiece, and a long delicate vibratile tail. Lying anterior to the head is a small apical body, or achrosome, which in some animals bears a little barb-like projection by means of which the spcrmatozoön bores its way into the ovum. The tail of the sperm consists of an axial filament surrounded by a protoplasmic envelope, which becomes very thin or disappears altogether at the extremity, leaving a short naked end-piece. The axial filament passes anteriorly through the middle-piece, and ends in a small knob (the end-knob) at the base of the head. Ballowitz ${ }^{2}$ has shown that the axial filament is composed of a number of parallel fibrillæ, like a muscular fibre.

1 For an account of the process of spermatogenesis in different animals and plants, and a discussion of the phenomena described, see Wilson, The Cell in Development and Inheritance, 2nd Edition, London, 1900. In this work the theories of Weismann and others are dealt with, and a full account of the literature is given.

2 Ballowitz, "Untersuchungen uiber die Struktur der Spermatozoen," Arch. f. Mikr. Anat., vol. xxxii., 1888, and vol. xxxvi., 1890; Zcitschr. f. wiss Zool., vol. 1x., 1890, and vol. lii., 1891. 


\section{SPERMATOGENESIS_INSEMINA'TION}

Schweigger-Seidel ${ }^{1}$ and La Valette St. George ${ }^{2}$ were the first to prove, independently but almost simultaneously, that the

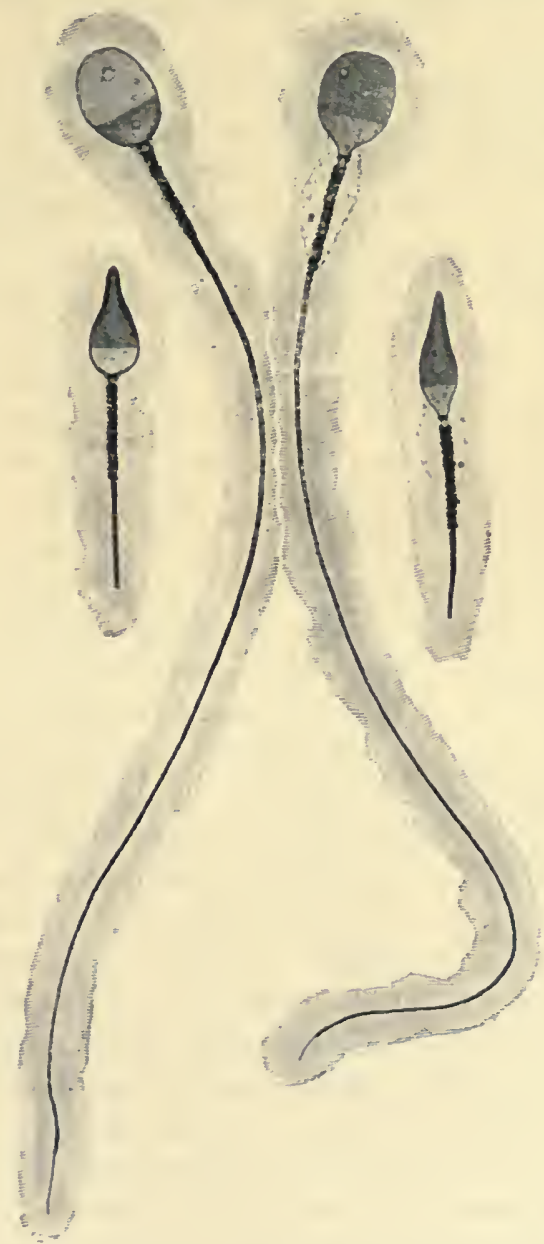

Frg. 46.-Human spermatozoa on the flat and in profile. (After Bramman, from Schäfer.) $\times 2500$. Those on the right have adhering protoplasm. The tail is only partly shown in the two seen in profile.

1 Schweigger-Seidel, “ Über die Samenkörperchen und ihre Entwickelung," Arch. f. Mikr. Anat., vol. i., 1865.

${ }^{2}$ La Valette St. George, "Über die Genese der Samenkörper," Arch. $f$. Mikr. Anat., vol. i., 1865. 
spermatozoön has the essential characteristics of a complete cell. The head contains the nuclear material, which is surrounded by a thin layer of cytoplasm. The end-knob is said to represent the centrosome.

Spermatozoa, conforming with more or less closeness to the type described above, occur in the greater majority of multicellular animals from the Cœlenterata up to Mammals. In

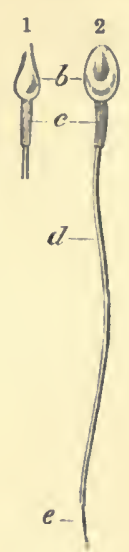

FiG.47.-Human spermatozoa $(\times 1000)$. (After Retzius, from Schäfer.)

1 , in profile; 2 , view on the flat; $b$, head; $c$, middle-piece; $d$, tail; $e$, end-piece of tail, described as a distinct part by Retzius. Pisces, and also in Echinoderms, the general resemblance is very distinct, but in other forms of life there is more diversity in the form assumed by the spermatozoa. "The head (nucleus) may be spherical, lance-shaped, rod-shaped, spirally twisted, hook-shaped, hoodshaped, or drawn out into a long filament; and it is often divided into an anterior or a posterior piece of different staining capacity, as is the case with many birds and Mammals. The achrosome sometimes appears to be wanting, e.g. in some fishes. When present, it is sometimes a minute rounded knob, sometimes a sharp stylet, and in some cases terminates in a sharp barb-spur by which the spermatozoön appears to penetrate the ovum (Triton)." 1 The middle-piece also shows considerable variability. It may be spherical, cylindrical, or flattened against the nucleus; sometimes it is of great length, and sometimes it passes insensibly into the flagellum or tail. The latter, in some insects and tishes, gives attachment to a membranous fin. The end of the axial filament, as already mentioned, is sometimes left naked, giving rise to the end-piece.

The tadpole-like shape is not an essential characteristic of the spermatozoön, for in certain Arthropods and Nematodes there is no flagellum, and the sperms are consequently incapable of spontaneous movement. In the daphnid Polyphemus the 
sperms are said to be amoboid. In some crustacean spermatozoa there are a number of radiating spine-like processes which seem to take the place of the flagellum.

! In other animals, and notably in the gasteropod mollusc Paludina, there are two kinds of spermatozoa. In this animal one is of the usual type, whereas the other is larger and wormshaped, with a tuft of cilia at one end. The smaller variety alone is said to be functional. ${ }^{1}$

The size of the sperm varies greatly in different animals. In Man its length is about 05 millimetres or a 300 th of an inch,

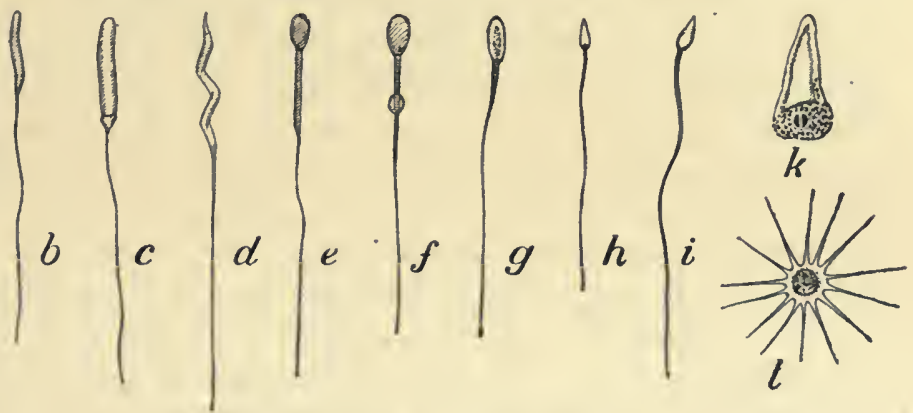

Fig. 49.-Different forms of spermatozoa from different species of animals, as follows :-

$a$, bat; $b \& c$, frog; $d$, finch; $e$, ram ; $f \& g$, boar; $h$, jelly-fish; $i$, monkey; $k$, round worm; $l$, crab. (From Verworn.)

the head and the middle-piece being each about 005 millimetres long.

It is obvious that the sperm contributes comparatively little material to the fertilised ovum, being provided with only sufficient protoplasmic substance to form a locomotive apparatus by means of which it gains access to the ovum. The predominantly destructive metabolism of the spermatozoön as contrasted with the ovum has been strongly emphasised by Geddes and Thomson, ${ }^{2}$ who believe it to exemplify those katabolic

1 For further details of the structure of various kinds of sperms see Wilson, loc. cit.; also Ballowitz's papers just referred to, and Retzius' Biologische lintersuchungen, vols. xi., xii., and xiii., Stockholm and Jena. The latter contains numerous large plates with figures of spermatozoa.

2 Geddes and Thomson, The Evolution of Sex, Revised Edition, London, 1901 . 
phenomena which, according to their view, are usually associated with the male sex.

\section{Seminal Fluid}

The semen serves as the mechanical medium in which the spermatozoa move. It is possible also that it has a nutritive function. It is secreted by the seminifcrous tubules. It is milky in appearance, and has a characteristic smell. When ejected the seminal fluid is mixed with the secretions of the accessory glands (prostate, \&c.), which render it still more milky. On standing it tends to become gelatinous. According to Lode, ${ }^{1}$ the specific gravity of semen is between 1.027 and 1.046.

The number of spermatozoa which exist in normal human semen is subject to much variation. Lode ${ }^{2}$ has shown that it diminishes almost to zero after a number of successive emissions, but increases again after an interval of several days. The average number is given as 60,000 per cubic centimetre. The number of sperms present in the ejected seminal fluid of the dog was also found to be greater at the end of an interval in which there were no emissions, but it did not continue to increase after more than eight or ten days. In a normal emission of semen (Man) Lode calculates that there are about $226,000,000$ spermatozoa, but that the number may vary from zero to $551,000,000$.

The spermatozoa which are not ejaculated degenerate. The tails break off, and undergo a gradual liquefaction. The end products are ultimately absorbed by the epithelial cells of the seminal vesicles, and perhaps by the cells of the vasa deferentia or of the testis itself. According to Pere $z,{ }^{3}$ the spermatozoa of male newts which are kept apart from females are absorbed by phagocytes."

\section{Movements of Spermatozon}

When the spcrmatozoa are in the testis they are inactive, but they begin to move rapidly as soon as they are ejected in the

1 Lode, "Untersuchungen über die Zahlen- und Regenerationsverhältnisse der Spermatozoiden bei Hund und Mensch," Pfü̈ger's Arch., vol. 1., 1891.

2 Lode calculates that about $339,385,500,000$ spermatozoa must be produced in man between the ages of twenty-five and fifty-five.

'Perez, "Résorption phagocytaire des Spermatozoïdes," Proces-Verbaux de la Soc. des Sciences de Bordcaux, 1904.

+ The chemistry of the spermatozöon and semen is dealt with in Chapter VIII. 
seminal fluid. The rate at which they progress has been estimated at 3.6 millimetres per minute. ${ }^{1}$ Bischoff $^{2}$ found spermatozoa at the top of the oviduct in the rabbit nine or ten hours after coition.

It is probable that the ejected spermatozoa continue to undergo movement, as a general rule, so long as they retain their vitality, the rate of movement becoming gradually diminished and ceasing altogether shortly before death. In bats, however, during the period of hibernation the sperms become quiescent without dying, their vigour being restored in the spring when they conjugate with the ova. ${ }^{3}$ It is exceedingly probable also that in the spotted viviparous salamander and the other animals referred to below (p. 186), in

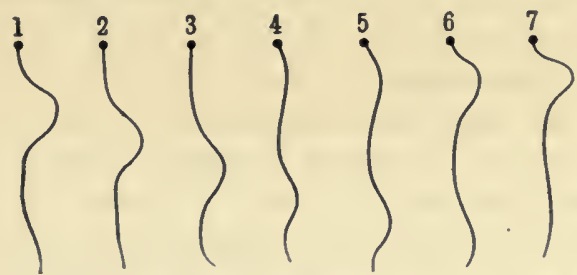

FIG. 49.-Diagram illustrating wave-like movement of swimming spermatozoön. (From Nagel.)

which the male cells retain their vitality for long periods, these must at such times remain quiescent, for otherwise their store of energy would soon become exhausted.

The spermatozoa swim by means of their tails. The movement is represented in the accompanying figure (taken from Nagel), ${ }^{4}$ which shows the successive positions assumed by the sperm in a state of locomotion. A wave of movement first makes its appearance in the forepart of the tail, and then rapidly travels backwards to the end, to be succeeded by a fresh wave which follows the same course. It would seem that the driving

1 Lott, Anatomie und Physioloyie des Cervix Lteri, Erlangen, 1871. According to Adolphi ("Ueber das Verhalten von Schlungenspermien in strömender Flussigkeiten," Anat. Anz., vol. xxix., 1906), the spermatozoa of the adder swim at the rate of $50 \mu$. to $80 \mu$. per second.

${ }^{2}$ Bischoff, Die Entwickelung des Kaninchen-Eies, Giessen, 1842

3 See p. 136.

- Nagel, Handbuch der Physiologie des Menschen, vol. ii., Braunschweig, 1906 . 
force is located a little behind the head. The head itself does not appear to be concerned in the movements of locomotion.

The movements of spermatozoa have probably been studied most closely in Insecta and Echinodermata. Buller ${ }^{1}$ says that the sperms of the Echinoidea in a drop of sea-water (or the medium in which they are normally discharged) swim spirally, so long as they do not come into contact with the surface. The spirals may be so steep that the sperms appear to move almost in a straight line, in which case progression across the field of the microscope is relatively rapid. In other cases the incline of the spiral is so slight that the spermatozoa swim almost in circles, and consequently move forward across the microscopic field with great slowness. Every gradation between these two extremes was observed, but the more active sperms generally swam in the steeper spirals.

Dewitz ${ }^{2}$ has shown that when the spermatozoa of the cockroach are put into 0.6 per cent. solution of sodium chloride, and placed between two surfaces, such as those of a slide and a cover-glass, they collect after a short time, partly upon the upper surface of the slide and partly upon the lower surface of the cover-glass. In these positions they describe circles with their tails, the rotation being invariably counter-clockwise. The bulk of the liquid remains free from spermatozoa, the latter adhering to the glass surfaces after having once reached them. If a ball be placed in the fluid, its surface is soon sought by the spermatozoa. ${ }^{3}$ Verworn has described this phenomenon under the name of "barotaxis," and states that it is caused by pressure acting unequally on different sides of the spermatozoön. It is said to be of great importance in the process of fertilisation, and probably assists the spermatozoön in entering the micropyle

1 Buller, "Is Chemotaxis a Factor in the Fertilisation of the Eggs of Animals?" Quar. Jour. Micr. Science, vol. xlvi., 1902.

2 Dewitz, "Ueber Gesetzmässigkeit in der Ortsveränderung der Spermatozoen," \&c., Pflüger's A rchiv, vol. xxxviii., 1886. Rotation by spermatozoa seems to have been recorded first by Eimer, "Untersuchungen über den Bau und die Bewegung der Samenfäden," Verhand d. Phys. Med. Gesel. zur Würzburg, vol. vi., 1874.

3 Ballowitz, "Untersucbungen iiber die Struktur der Spermatozoen," \&c., Zeitschr. f. Zool., vol. i., 1890. 
of the ovum. ${ }^{1}$ Dewitz's observations were subsequently confirmed by Ballowitz. ${ }^{2}$

Counter-clockwise rotation upon surfaces was first recorded for the spermatozoa of Echinoderms by Dungern, ${ }^{3}$ who discovered the phenomenon in Sphorechinus and Arbacia. About the same time Buller, ${ }^{4}$ who has described the manner of rotation more fully, observed its occurrence in the sperms of various other Echinoderms, and particularly in those of Echinus: "When a spermatozoön comes in contact with a glass surface, unless it becomes immediately fixed to the glass [it] begins to make characteristic circular revolutions upon it. If the coverglass be supported by pieces of another cover-glass, and the upper surface of the drop in contact with it be carefully focussed, it is seen that all the spermatozoa which are not attached by their heads, but are moving there, are revolving from the observer's point of view in clock-wise direction. If the lower surface of the drop in contact with the slide be examined, a reverse rotation-the counter-clockwise-is seen to be the rule. In both cases, therefore, if the surfaces be regarded from the point of view of the spermatozoa, the rotation is always in one direction-namely, the counter-clockwise."

The head is the only visible part of the rotating spermatozoön. This moves rapidly round in a circle, which in the case of Echinus is slightly less than 0.05 millimetres (or the length of a spermatozoön) in diameter. A normally rotating sperm of Sphcerechinus was observed to make 109 circles around one point in ninety seconds. The rate of movement of the head is calculated to be about $0 \cdot 12$ millimetres per second, or $7 \cdot 2$ millimetres per minute.

The characteristic rotation may likewise take place upon surfaces which are bounded by air (instead of glass), and it has been observed also upon the outer surface of the gelatinous layer of the ova of Echinus. Buller concludes, therefore, that the nature of the surface is not an important factor in the process.

1 Verworn, General Physiology, Lee's Translation from the second German Edition, London, 1899.

2 Ballowitz, loc. cit.

${ }^{3}$ Dungern, "Die Ursachen der Specietät bei der Befruchtung," Zentralbl. f. Physiol, vol. xv., 1901.

- Dungern, loc cit. 
Ballowitz expresses the opinion that the circles described by insects' sperms are simply the modified spirals made by the free-swimming cells. Buller thinks that this view, which provides a purely mechanical explanation, is also probably correct for the spermatozoa of Echinoderms.

Since counter-clockwise rotation upon surfaces has been observed in the spermatozoa of two groups as widely separate as the Insecta and the Echinodermata, it would seem probable, as Buller remarks, that it will be found to occur in other animals.

The spermatozoa of Mammals, in traversing the female passages after copulation, make their way upward towards the ovaries in opposition to downward currents set up by the cilia of the lining epithelia. Kraft ${ }^{1}$ has shown that when rabbits' spermatozoa, in a state of feeble motion, are placed upon the inner wall of the oviduct, their movements become more vigorous and they swim against the current which the cilia produce. Roth ${ }^{2}$ also has succeeded in experimentally illustrating the same fact.

It is commonly stated that in Man the passage of the spermatozoa from the vagina inwards is assisted by a contraction of the muscular wall of the uterus, which compresses the cavity of that organ into which the sperms are drawn when relaxation takes place. ${ }^{3}$ The contraction of the uterus is said to be a reflex action resulting from copulation. It has also been suggested that, during copulation, a mucous plug which is ordinarily contained in the cervix may be temporarily and partially expelled into the vagina and afterwards withdrawn with the spermatozoa adhering to it. ${ }^{4}$

So also Heape ${ }^{5}$ has shown that in the rabbit the passage of the spermatozoa into the uterus is probably assisted by a sucking

"Kraft, "Zur Physiologie des Flimmerepithels bei Wirbelthieren." Pflüger's Archiv, vol. xlvii., 1890.

2 lloth, "Ueber das Verlalten beweglicher Mikroorganismen in strömender Fliissigkeit," Deutsche med. Wochenschrift, vol. xix., 1893. Verworn (loc. cit.) describes this property of spermatozoa under the name of rheotaxis, which, he says, is a special kind of barotaxis. See also Adolphi, "Die Spermatozoen der Säugethiere schwimmen gegen den Strom," Anut. Anz., vol. xхvi., 1905.

3 See Beck, "llow Do the Spermatozoa enter the Uterus?" Amer. Jour. of Olstet., vol. viii., 1875.

- See Williams, Obstctrics, New York, 1904.

B Heape, "The Artificial Insemination of Mares," Veterinarian, 1898. 
action on the part of the latter organ. The os uteri, which is situated above the ventral wall of the vagina, was observed to dip down into the seminal fluid at the bottom of the vagina, and then to be withdrawn again in conjunction with a peristaltic contraction of the uterus. These movements were repeated at intervals. Morcover, it was found that the sucking action could bc induced artificially by stimulating the erectile tissue of the vulva. It is probable, however, that the spermatozoa, after once cntering the uterus, proceed to their destination unassistcd, and that the direction of their movement is determined by the capacity they possess to respond to the stimuli set up by opposing currents. Moreover, pregnancy has been known to follow imperfect coition in Man, so that thcre can be no doubt that under certain circumstances the spermatozoa are capable of passing inward by their own unaided efforts.

\section{INSEMINATION}

The act of copulation results in the introduction of seminal fluid through the generative aperture of the female. The mechanism by which this is effected in the higher animals is described in a future chapter, where the functions of the accessory male organs are dealt with. The introduction of the fluid into the female generative passagcs is known as insemination (as distinguished from impregnation, which is the term used in reference to the female when fertilisation takes place ${ }^{1}$ ).

It is obvious that in those animals which ovulate spontaneously during the ostrus periods it should be possiblc to induce pregnancy at such times by the artificial introduction of spermatozoa into the vagina or into the uterus. That this could actually be effected was probably first demonstrated by Spallanzani, ${ }^{2}$ though there is evidence that the practice of artificial inscmination was not unknown to the Arabs many centuries ago. ${ }^{3}$ The following is a description of Spallanzani's

1 That is to say, the animal is inseminated when the spermatozoa are introduced, and it is impregnated when the ovum becomes fertilised by a sperm. See Heape, "The Artificial Insemination of Mammals," Proc. Roy. Soc., vol. lxi., 1897.

"Spallanzani, Disscrtations, vol. ii., London, 1784.

${ }^{3}$ Gautier, Le Fécondution artificielle, \&c., Paris, 1889. 
original experiment, as quoted from a contemporary English translation :-

"I chose a bitch spaniel of moderate size which had before had whelps. Suspecting, from certain appearances, that she would soon be in heat, I confined her in an apartment, where she continued a long time, as will be seen below. For greater security, that she might never be let loose, I fed her myself, and kept the key the whole time. On the thirteenth day she began to show evident signs of being in heat; the external parts of generation were tumid, and a thin stream of blood flowed from them. On the twenty-third day she seemed fit for the admission of the male, and I attempted to fecundate her artificially in the following manner. A young dog of the same breed furnished me, by a spontaneous emission, with nineteen grains of seed, which were immediately injected into the matrix, by means of a small syringe introduced into the vagina. As the natural heat of the seed of animals of warm blood may be a condition necessary to render fecundation efficacious, I had taken care to give the syringe the degree of heat which man and dogs are found to possess, which is about $30^{\circ}$ [or between $99^{\circ}$ and $100^{\circ}$ Fahrenheit]. Two days after the injection, the bitch went off her heat, and in twenty days her belly appeared swollen, which induced me to set her at liberty on the twenty-sixth. Meanwhile the swelling of the belly increased; and sixty-two days after the injection of the seed, the bitch brought forth three lively whelps, two male and one female, resembling in colour and shape not the bitch only, but the dog also from which the seed had been taken. Thus did I succeed in fecundating this quadruped; and I can truly say, that I never received greater pleasure upon any occasion, since I first cultivated experimental philosophy."

Spallanzani also records a similar experiment by Pierre Rossi, in which a dog was impregnated by artificial means.

Considerable success has been obtained in recent years in experiments on the artificial insemination of dogs. Gautier ${ }^{1}$ refers to a case in which pregnancy was induced by this means. Albrecht ${ }^{2}$

1 Gauticr, loc, cit.

2 Albrecht, "Künstliche Befruchtung," Wochenschr. f. Thierheilkunde und Viehaucht, Jahrg. xxxix. 
and Plönnis ${ }^{1}$ have also described experiments in which they successfully inseminated dogs by artificial methods (see p. 611). Heape ${ }^{2}$ has recorded a series of experiments carried out by Sir Everett Millais on the artificial insemination of Basset hounds. The present writer has succeeded in inducing pregnancy by this method in a Dandie Dinmont terrier. Moreover, there are numerous cases on record in which dogs have been successfully inseminated artificially as a means of overcoming certain forms of barrenness (see p. 611). The method adopted in all these experiments was substantially the same as that employed by Spallanzani.

Artificial insemination is now also practised on mares, donkeys, and cows, and usually with the object of remedying sterility. In thoroughbred mares especially it has proved of great service, having been the means of preserving for breeding purposes many valuable animals which otherwise would have been discarded. ${ }^{3}$

Iwanoff ${ }^{4}$ has described experiments in which pregnancy was induced in rabbits and guinea-pigs by the artificial injection of testicular fluid into the female generative passages. The same investigator states that he induced hybridisation between a male rat and a female mouse by artificially inseminating the latter (see p. 611, Chapter XIV.).

He has shown, further, that the spermatozoa retain their vitality sufficiently long to admit of their being employed successfully in artificial insemination if they are kept in solutions of various salts (sodium chloride, sodium carbonate, \&c.) or in serum instead of in the secretions of the accessory generative glands. Hunter appears to have been the first to practise arti-

1 Plönnis, “Künstliche Befruchtung einer Hünden," \&c., Inaug. Disscrt., Rostock, 1876.

2 Heape, loe. cit.

${ }^{3}$ For references to particular experiments see Heape, "The Artificial Insemination of Mares," l'etcrinarian, 1898; also a booklet published by Huish (The Cause and Remedy of Sterility in Mares, Cours, and Bitches, London, 4th Edition, 1899), in which a large number of cases are described in which artificial insemination was successfully carried out; also I wanoff, “De la Fécondation Artificielle chez les Mammifères," Arch. des Seienees Biologiques, vol. xii., 1907. The last-mentioned paper contains an account of a very large series of experiments on horses, cows, and sheep, with a full description of the practical methods employed, and a very complete account of the literature of the subject.

“ Iwanoff, “La Fonction des Vésicules séminales," \&.c., Jour. de Phys. et de Path. gen., vol. ii., 1900. 
ficial insemination upon a woman (previously sterile), ${ }^{1}$ but it has since been successfully adopted by various medical men, the method being to inject the spermatozoa through the os into the cavity of the uterus (see p. 609).

With thosc animals whose ova arc normally fertilised outside the body, artificial inscmination is a still simpler proccss. Spallanzani was the first to show that the eggs of various species of Amphibia could be fertilised by the application of fluid obtained from the testes or seminal vesicles of the male, and that the frogs and newts which were generated by this means in no way differed from those produced in naturc. Spallanzani was also successful in artificially fecundating the eggrs of the silk-worm moth.

Artificial impregnation of fish ova was first employed by Jacobi, ${ }^{2}$ and the method which he adopted is practically the same as that habitually practised at the present day for stocking water-courses with fish.

The vitality of the spermatozoön appears to vary widely in the different species of animals.

Leeuwenhoek, ${ }^{3}$ and subsequently Prévost and. Dumas, ${ }^{3}$ state that they found moving sperms in the internal genital organs of femalc rabbits and dogs eight days after coition. Bonnet ${ }^{4}$ says that he observed motionless sperms, which, therefore, were probably dead, but had not yet undergonc disintegration, in a bitch seventeen and a half days after coition. In a series of expcriments upon the longevity of the spermatozoön in the rabbit, it was found that these cells can survive in the vasa deferentia for at least ten days after the removal of the testes, but that they die before the end of thirteen days. ${ }^{5}$

Spallanzani ${ }^{6}$ cites the fact that a hen can lay fertilised eggs twenty days after impregnation by a cock.

1 Home, "An Account of the Dissection of an Hermaphrodite Dog," Phil. Trans., 1799.

${ }^{2}$ See Güther, Introduction to the Study of Fishes, Edinburgh, 1880.

${ }^{3}$ See Waldeyer's article in Hertwig's Handbuch der Entwicklungslehre, Jena, 1903.

"Bonnet, "Giebt es bei Wirbelthieren Parthenogenesis," Merkel und Bonnet's Ergebniese d. Anat. u. Entwick, vol. ix., 1900.

s Marshall and Jolly, "Contributions to the Physiology of Mammalian Reproduction: The (Estrous Cycle in the Dog," Phil. Trans. B., vol. cxcviii., 1905.

6 Spallanzani, loc. cit. 
Strassmann ${ }^{1}$ has recorded a case in which human spermatozoa survived in the female generative passages for a week after coition. Bossi ${ }^{2}$ refers to a similar instance where the sperms lived for over twelve days. In another rase described by Dührssen, ${ }^{3}$ living spermatozoa were found in a woman who stated that coition had not been experienced for three and a half weeks.

In many species of bats, as already mentioned, copulation takes place in autumn and ovulation in the following spring, so that the spermatozoa retain their vitality while stored up in the uterus during the hibernating period. Sperms obtained from the females at this time are dormant, but regain their vitality on the application of warmth. ${ }^{4}$

The spermatozoa of some warm-blooded animals will stand considerable variation in temperature and still retain their vitality. Thus they have been known to live for many hours at ordinary room temperature; but, undoubtedly, ejected sperms tend to survive longest if kept at body temperature. Heape ${ }^{5}$ states that some seminal fluid of a dog was sent to him by post in a glass tube, and on being examined eighteen hours after it was obtained, fully half the spermatozoa were found to be active and vigorous, while increased warmth stimulated to activity those which showed signs of sluggishness but did not revive the remainder.

In the experience of the writer, horses' spermatozoa die more easily if exposed to cold. Chelchowski, ${ }^{6}$ in describing the methods adopted in the artificial insemination of mares, lays stress upon the necessity of keeping the seminal fluid warm, and states that, if this is done, it is possible to keep the sperms alive for twenty hours.

The case of bats, which has been referred to above, has a parallel in certain cold-blooded animals. Thus, according to

' Strassmann, Lehr3uch der gerichtlichen Mediz $n, 1895$.

2 Bossi, "Etude Clinique et Expérimentale de l'Époque la plus favorable à la Fécondition de la Femme," Rivista di O.stet. e Ginecol., 1891.

3 Duhrssen, "Lebendige Spermatozoen in der Tube," Central! $l$. f. Gynäk., 1893.

- See Eimer and other references given on page 136.

${ }^{5}$ Heape, loc. $c$ t .

${ }^{6}$ Chelchowski, Die Ster.lität des Pferdes, Wien, 1894. 
Rollinat, ${ }^{1}$ in snakes belonging to the species Tropidonotus viperinus the females are usually inseminated in the autumn, whereas the eggs are not laid until the beginning of the following summer. Also in the case of the spotted viviparous salamander (Salamander maculosa), after the birth of the young, which occurs about the month of May, a new batch of ova pass into the oviducts and are fertilised (prior to the commencement of the sexual season) by spermatozoa which were introduced in the July of the previous year, and thereafter stored in the uterus. ${ }^{2}$ It is obvious that in both these cases the spermatozoa retain their vitality in the female for periods of many months.

In animals like the earthworm, in which the spermatozoa are stored in special reservoirs known as spermathecæ, it is probable that they retain their vitality for long periods. Lang ${ }^{3}$ has shown that the sperms may live for three years in the vesiculæ seminales of snails.

The extreme longevity possessed by the male cells of some insects is still more remarkable. Von Siebold ${ }^{4}$ states that the spermatozoa of bees may survive for four or five years. Moreover, queen ants have been known to lay fertile ova thirteen years after the last intercourse with a male.

1 Rollinat, "Sur l'Accouplement des Ophidiens a la Fin de l'Été et au Commencement de l'Automne," Bull. Zool. Soc. France, vol. xxiii., 1898.

2 Sedgwick, Student's Text-Book of Zoology, vol. ii., London, 1905.

${ }^{3}$ Lang, "Über Vorversuche zu Untersuchungen über die Varietätenbildungen von Helix hortensis Müller and Helix nemoralis L.," Festschr. zum siebz'Gsten Geburtstage von Ernst Haeckel, Jena, 1904.

- Von Siebold, "Fernere Beobachtungen iiber die spermatozoen Wirbel. loser Tiere," Müller's Archiv, 1837. 


\section{CH A P'TER V I}

\section{FERTILISATION}

"Although it be a known thing subscribed by all, that the fœlus assumes its origin and birth from the male and female, and consequently that the egge is produced by the cock and henne, and the chicken out of the egge, yet neither the schools of physicians nor Aristotle's discerning brain have disclosed the manner how the cock and its seed doth mint and coine the chicken out of the egge."-HARvEY.

Although much progress has been effected, and many new facts have been discovered, since Harvey wrote his famous dissertation on "The Efficient Cause of the Chicken," the actual nature of the process whereby the ovum, after being discharged from the ovary, is endowed with a new vitality through union with a spermatozcön, is a problem the solution of which is still far from complete.

In 1843 Martin Barry, ${ }^{1}$ as already mentioned, first observed the union of the spermatozoön and ovum in the rabbit, and a little later Newport ${ }^{2}$ recorded its occurrence in the frog; but it was not until the last quarter of the nineteenth century that the significance of the process was realised. It was largely through the work of Hertwig, Strasburger, and van Beneden that most biologists came to believe that the union of the nuclei of the gametes was the essential act in the process of conjugation. The more recent investigations of Boveri and others do not, however, entirely support this conclusion.

As already described, the head of the spermatozoön represents the nucleus, and contains the chromatin material. When the sperm penetrates into the substance of the ovum the tail becomes absorbed, but the head remains as the male pronucleus. The matured nucleus of the ovum, or female pronucleus (the two polar bodies having been discharged), passes towards the

1 Barry, "Spermatozoa Observed within the Mammiferous Ovum," Phil. Trans., 1843.

2 Newport, "On the Impregnation of the Ovum in the Amphibia," Phil. Trans., 1851. 
centre of the cell, where it unites with the male pronucleus which generally becomes somewhat enlarged. The middlepiece of the spermatozoon also enters the egg, and, according to Boveri, ${ }^{1}$ induces the formation of a centrosome, which, after the completion of fertilisation, initiates the process of cell division.
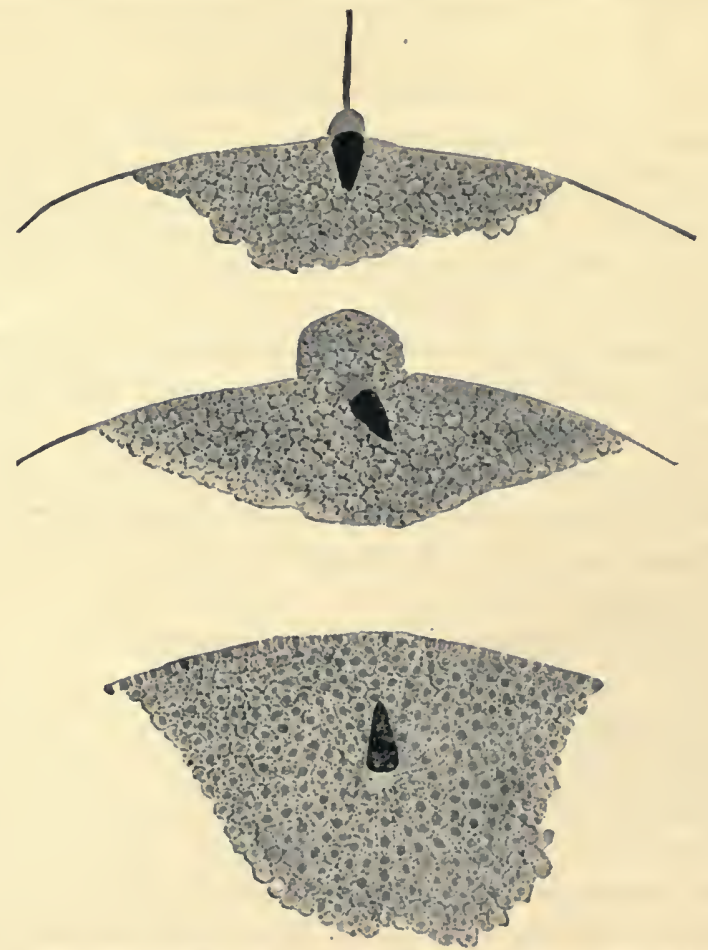

Fig. 50.-Successive stages in the fertilisation of an ovum of Echinus esculentus, showing the entrance of the spernatozoon. (From Bryce.)

Cytoplasmic filaments arrange themselves around the centrosome in the form of a star, the sperm-aster, which accompanies the male pronucleus, and afterwards comes to lie alongside of

-1 Boveri, Zellen Studien IV., Ueber die Natur der Centrosomen, Jena, 1901. Jenkinson, "Observations on the Maturation and Fertilisation of the Egg of the Axolotl," Quar. Jour. Micr. Science, vol. xlviii., 1904, has recently stated that the middle-piece of the spermatozoön, after forming the centre of the sperm-sphere and sperm-aster, completely disappears, and that the centrosome is forned from the sperm-nucleus at a later stage. (The sperm-sphere is the clear area which forms in the ovum round the head and middle-piece of the spermatozoön shortly after its entrance.) 
the segmentation nucleus (as the nucleus formed by the union of the two pronuclei is called). In the segmentation nucleus the normal number of chromosomes characteristic of the species is once more restored. The oösperm, or zygote, produced in this way is the starting-point of a long series of cell divisions which culminate in the formation of a new, completely developed individual.

Jenkinson, who has carried out a series of experiments intended to elucidate the physical processes occurring in fertilisation, draws the conclusion that the structures which appear in the ovum are produced under the influence of the middle-piece
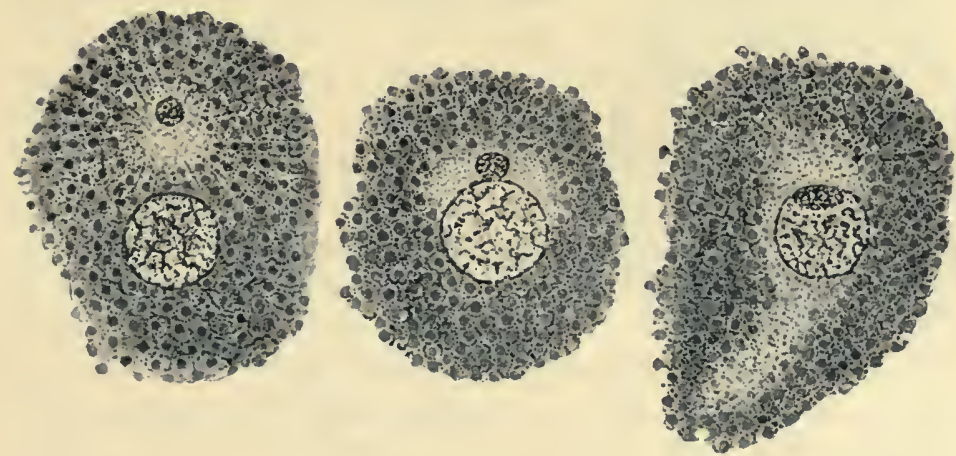

FIG. 51:-Three stages in the conjugation of male and female nucleus in the fertilisation process of Echinus. (From Bryce.)

and centrosome. He supposes these bodies to possess the power of withdrawing water from the cytoplasm, of swelling up and dissolving in the water so absorbed, and then giving off radial outgrowths which precipitate the proteins of the cell, and so produce the fertilisation spindle. Jenkinson lays some stress on the fact that a watery fluid collects in vacuoles in the centre of the sperm-sphere of the axolotl, and regards the presence of this fluid as evidence that the sperm introduces a hydroscopic substance into the ovum. In confirmation of this the experiments show that a hydroscopic particle is capable of giving rise to an astral structure in a colloid solution. ${ }^{1}$

Boveri and others have proved experimentally that portions of unfertilised Echinoderm ova, without egg nuclei, may develop

1 Jenkinson, loc. cit. Further references are given in this paper. 
normally after the addition of spermatozoa, while Driesch has shown that if such ova are deprived of their envelopes by shaking, and are then divided into fragments some of which contain no nuclei, the latter are capable of being fertilised a second time. It is clear, therefore, that in such cases the union of nuclei is not essential for the development of the ovum. ${ }^{1}$

In those ova which are surrounded by a membrane it is probable that the fertilising spermatozoön bores its way through

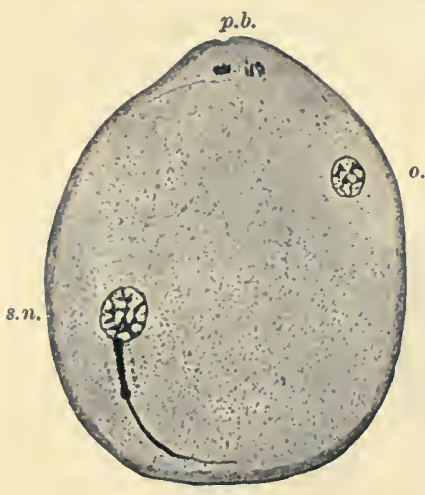

FIG. 52.-Fertilisation process in bat's ovum. (After van der Stricht.)

p. $b$., polar bodies; $0 . n .$, nucleus of ovum : 8. n., nucleus of spermatozoön. at any point (Mammals and Amphibians). In other cases there is a small aperture in the wall of the ovum; this is called the micropyle (some Pisces and Insecta). Some eggs, however, are naked, so that the sperms may effect an entrance anywhere on the surface (some Echinoderms and Coelenterates), or there may be funnel-shaped depressions on the egg's periphery (certain hydromedusæ). ${ }^{2}$

In the majority of animals only one spermatozoön normally enters the ovum, but in some (certain insects, elasmobranch fishes, reptiles, earthworm, lamprey, axolotl, ${ }^{3}$ \&c.), several may effect an entrance. The latter condition is called Polyspermy. Only one spermnucleus conjugates with the ovum-nucleus; the others as a general rule undergo degeneration, but in a few cases (elasmobranchs and reptiles) they are said to divide, forming accessory nuclei whose ultimate fate is unknown. In those animals in which only one sperm normally enters the egg, pathological polyspermy may occasionally occur. In such cases each sperm centrosome may give rise to a sperm-aster. The

1 For references to the original papers, which are somewhat numerous, see Przibram, Embryogeny, English Translation, Cambridge, 1908.

${ }^{2}$ Wilson, The Cell, \&c., 2nd Edition, New York, 1900.

3 Jenkinson, loc. cit. Further references are given in this paper. 
eggs which are fertilised in this way either do not divide at all or go on dividing irregularly for a short time and then perish. ${ }^{1}$

It is supposed that the entrance of supernumerary sperms is prevented normally either by some mechanical means, such as the development of a membrane formed after the penetration of the first sperm, or else by a change in the chemical constitution of the ovum, occurring as the immediate result of fertilisation. ${ }^{2}$ Thus, the brothers Hertwig ${ }^{3}$ showed that in the case of eggs the vitality of which had been reduced artificially (e.g. by poisons), the vitelline membrane was formed so slowly after the entrance of the first spermatozoön that others also were able to make their way into the egg cytoplasm. On the other hand, the ova of many animals in which no membrane is formed seem to possess the capacity of resisting the entry of supernumerary spermatozoa, and the same is apparently the case with those ova which have a membrane before fertilisation, this membrane being penetrated by only a single sperm. Loeb ${ }^{4}$ has recently suggested that polyspermy may be prevented by an alteration in the surface tension of the egg after the entrance of the spermatozoön.

In the Mammalia fertilisation takes place usually in the upper part of the Fallopian tube.

\section{The Hereditary Effects of Fertilisation}

The attempts that have been made to interpret the nature and essence of sexual reproduction may be ranged under two heads, representing the two chief theories that have been elaborated (with some modifications by their respective adherents) to explain the observed phenomena. ${ }^{5}$ According to

${ }^{1}$ Wilson, loc. cit.

2 Farmer, "On the Structural Constituents of the Nucleus," \&c., Croonian Lect'rre, Proc. Roy. Soc. B., vol. Ixxix., 1907.

${ }^{3}$ Hertwig, O. and R., "Beiträge zur Kenntniss der Bildung, Befruchtung und Teilung des tierischen Eies," Morph. Jahr., vols. ii. and iii., 1887:

" Loeb, T'he Dynamics of Living Matter, New York, 1906.

${ }_{5}^{5}$ For accounts of the various theories which have been put forward concerning the nature of fertilisation, see Wilson, loc. cit., Geddes and Thomson, The Evolution of Sex, 2nd Edition, London, 1901 ; Weismann, The Evolution Theory, English Translation, London, 1904; and Lock, Variation, \&c., London, 1906. Further references are given in these works. 
one hypothesis, conjugation of the gametes results in a rejuvenescence which is essential for the perpetuation of the race (see p. 212). According to the second theory, which is not necessarily antagonistic to the first, gametic union is a source of variation. ${ }^{1}$ The latter theory may now be briefly considered. A full discussion of the hereditary effects of fertilisation is, however, beyond the scope of the present work.

The doctrine that conjugation is a source of variation was first promulgated at the beginning of the last century by Treviranus. Subsequently Brooks ${ }^{2}$ adopted the same idea, and Weismann made it the basis of his famous theory of heredity. ${ }^{3}$ "Sexual reproduction is well known to consist in the fusion of two contrasted reproductive cells, or perhaps even in the fusion of their nuclei alone. These reproductive cells contain the germinal material or germ-plasm, and this again, in its specific molecular structure, is the bearer of the hereditary tendencies of the organisms from which the reproductive cells originate. Thus, in sexual reproduction, two hereditary tendencies are in a sense intermingled. In this mingling I see the cause of the hereditary individual characteristics; and in the production of these characters, the task of sexual reproduction. It has to supply the material for the individual differences from which selection produces new species."

Weismann supposes the nuclear chromatin of the cell to consist of a large number of self-propagating vital units which he calls biophors. These biophors he believes to be grouped

1 A third theory, which has never obtained any great support among biologists, suggests that the purpose of sexual reproduction may be to prevent variation, and so preserve specific uniformity. According to this view the sexual process, although continually creating new variations, is also constantly obliterating them by tending to produce individuals possessing the mean of their parents' characters. 'This theory, which is the converse of the second theory referred to in the text, has received the support of the Hertwigs. In this connection it may be remarked that variability is quite as great among non-sexual parthenogenetic animals as among those which are reproduced sexually. This fact is difticult to explain if we adopt the theory that the purpose of gametic union is to induce variability. Moreover, Enriques ("La Coniugazione e il differenziamento sessuale negli Infusori," Arch. f. Protisten. kunde, vol. ix., 1907), as a result of a series of experiments upon conjugation in Infusoria, has adopted a similar view to that of the Hertwigs.

2 Brooks, The Law of Heredity, Baltimore, 1883.

3 Weismann, The Germ Masm, English Translation, London, 1893. 
together to form more complex units, named determinants, which represent the separate parts of the organism. The determinants are supposed to be aggregated together to comprise units of a still higher order, known as ids. These are identified with the chromatin granules. Every part of the organism (or every character that it possesses) is believed to be represented in an id. Moreover, Weismann assumes that the ids vary slightly in related individuals, the differences in the ids corresponding with the variations in the species. Lastly, the ids are said to be arrayed in linear series so as to form idants. Weismann identifies these with the chromosomes. It follows, therefore, that each chromosome represents a particular group of slightly differing germ-plasms. The purpose of variation, as expressed in the terms of this theory, is to produce new combinations of heritable variations by the mixture of different ids. And since the number of chromosomes, and consequently the number of ids, is doubled as a result of the conjugating process, the complexity of the chromatin would become indefinitely increased if there were no periodic reduction. But this, according to Weismann, is provided against in the maturation process of the gametes, when the quantity of chromatin in the cells becomes reduced by one-half, as described in the preceding chapters.

The reduced number of chromosomes is supposed to contain all the primary constituents of each of the two parents. And what is more, according to this theory, every gamete contains ids which are derived, not only from both the parents, but also from the ancestors, all the immediate ancestors being represented.

Weismann's theory of the nature of fertilisation was accepted by many biologists as a working hypothesis, until the disinterment of Mendel's discovery about ten years ago. The confirmation of this discovery by numerous workers in different fields has led to a revision of many of Weismann's conceptions.

The original experiments of Mendel ${ }^{1}$ were upon hybridisation

1 Mendel, "Versuche uber Pflanzen Hybriden," Verh. natur. f. Ver., in Briinn, vol. iv., 1865. Reprinted in English in Mendel's Principles of Heredity (Bategon), Cambridge, 1909. Mendel's work was rediscovered and confirmed by de Vries, Correns, and 'Tchermak in 1900, and subsequently 
in peas, the two parent varieties initially selected differing from each other in one particular character. The hybrids produced by crossing were all similar superficially, and resembled one of the parents in the character in question, which was therefore called the dominant character, the other character being known as recessive. When the hybrids were crossed among themselves, approximately one half of the offspring were found to be identical with their hybrid parents (dominant hybrids), one quarter resembled one of the original varieties (the grandparent with the dominant character), while the remaining quarter were like the other pure variety (the grandparent with the recessive character). Consequently the pure dominants and the dominant hybrids resembled one another outwardly, but they differed in their capacity to transmit the characteristics in question, since the pure dominants alone were capable of always breeding true. The recessives also invariably bred true. Mendel drew the conclusion that in the hybrid the gametes (both male and female) were of two kinds, which were respectively identical with the two kinds represented by the gametes of the original pure varieties. The differentiation of gametes carrying different characters is the essential principle in Mendel's theory, the existence of dominant and recessive characters, though often observable, being by no means universal.

Another example, taken from the work of Bateson and Punnett, will be sufficient to elucidate further the Mendelian conception of gametic differentiation. Breeders of blue Andalusian fowls have always recognised the practical impossibility of obtaining a pure strain of this breed. However carefully the birds are selected they invariably produce two sorts of "wasters," some being pure black, and some white with irregular black marks or splashes. Bateson and Punnett were the first to supply the explanation. They found that, on breeding from a large number of blue Andalusian fowls, on an average half of the offspring were blue like the parents, a quarter were black, and a quarter were "splashed-white." They conse-

by Bateson and a large number of other workers. For a general account of the Mendelian theory, and numerous references to the literature of the subject, see Bateson, loc. cit.; also Bateson, Saunders, Punnett, and Hurst, \&c., in Reports to the Erolution Committee of the Royal Society, Patts I., II., III., 1V. and V., 1〔02, 1905, 1〔06, and 1909 . 
quently drew the conclusion that the mechanism of inheritance in the Andalusian fowl is comparable to what Mendel supposed to exist in his hybrid peas. The gametes of the breed, according to this hypothesis, instead of being all similar and carrying the blue character (as one would suppose on Weismann's theory), are of two different kinds, those of the one kind being bearers of the black character, and those of the other being bearers of the splashed-white character. Such gametes, uniting by chance when the fowls mate together, give rise to three kinds of offspring, one black-white (becoming blue, actually, like the parents), one black-black, and one white-white, these appearing (on an average) in the proportion of $2: 1: 1$ according to the law of probability. In this particular case of Mendelian inheritance, neither of the two alternative parent characters (i.e. neither black nor splashed-white) is dominant and neither is recessive. Why black-bearing gametes uniting with whitebearing gametes should give rise to blue individuals the Mendelian theory does not attempt to explain.

The importance of Mendel's discovery lies in the fact that it forms the basis of a theory whereby variability can be discussed in terms of the conjugating cells themselves, and not merely in terms of the resulting zygotes. Moreover, it is a theory which has been found to be applicable to a very wide class of facts. There are reasons for supposing that sex is a Mendelian phenomenon; that is to say, that the ova and spermatozoa are themselves sexual entities prior to conjugation (see p. 633). It still remains to be proved, however, that the principles underlying Mendel's theory are applicable to all forms of inheritance. ${ }^{1}$

It has been mentioned that on Weismann's hypothesis every gamete contains ids representing both its parents and all its immediate ancestors. On the other hand, according to the Mendelian theory, although all the essential characters of the organism are represented in each germ cell, the Mendelian characters, or allelomorphs as they are called, are each represented by paternal or maternal ids only, and not by both, while the immediate ancestors have no representation at all.

'Cf. Darbishire, "Recent Advances in Animal Breeding," Royal Horticultural Society's Report of the Conference on Genetics, London, 1907. 
It has been supposed that the chromatin granules (which Weismann identified with the ids) are the carriers of the Mendelian allelomorphs, and that when these fuse together during the conjugation of the chromosomes which precedes the process of reduction (see p. 130), there is an exchange of allelomorphs between the chromosomes. If this interpretation is correct, it is simply a matter of chance whether an allelomorph remains in the chromosome which originally contained it, or becomes transferred to the other chromosome of the conjugating pair. And since each of the two chromosomes passes into a different product of cell division, the allelomorphs would become distributed in precisely the kind of way that the Mendelian theory postulates. ${ }^{1}$

The Mendelian investigators have shown that by experimental breeding it is apparently possible to superimpose certain characters belonging originally to one kind of individual, upon different characters belonging to another kind, thus creating new combinations of characters. Thus it is claimed that by starting with two individuals, each possessing two unit or allelomorphic characters, which we may call $\mathrm{A}$ and $\mathrm{X}$ (associated together in one individual) and $B$ and $Y$ (associated in the other), it is possible in two generations to produce new individuals in which the combinations are interchanged, $\mathrm{A}$ being associated with $\mathrm{Y}$, and $\mathrm{B}$ with $\mathrm{X}$. It has been claimed also, that, in spite of the new combinations, each of the original separate unit characters can be preserved in a state of complete purity, and without in any way affecting, or being affected by, the characters upon which they have been superimposed. By resorting to such methods, it has been thought possible to build up, little by little, entirely fresh types of organisms, possessing new combinations of pure characters, which previously existed only in different individuals.

It remains to be considered how far this conception of an organism as an individual capable of description in terms of unit characters (each of which can be transmitted pure) is in harmony with modern physiological theory, or justified by experimental investigation.

In the first place, it may be pointed out that the entire 3 Lock, loc. cit. 
trend of physiological research in recent years has been to show that the correlation that exists even between remote parts of the body is often extraordinarily close, and that in all probability there is not an organ or structure that is not dependent in its growth and activity upon chemical substances, elaborated by other and sometimes distant parts of the body, and carried thence in the circulating blood. Thus a change in the whole metabolism, producing palpable modification in whole groups of characters, may be induced experimentally in the individual, by interfering with or removing one particular organ. This is well shown in the various kinds of correlation existing between the organs of internal secretion. Again, a change in the environment may directly affect the metabolism, and so influence all the characters of the body. To the physiologist, therefore, a so-called unit character cannot readily be regarded as something represented by a substance located originally in a chromosome or chromomere. Such a view, as Verworn ${ }^{1}$ remarks, is "too morphologically conceived." It is more in keeping with the physiological view of life to regard the characters of the individual as manifestations of a particular kind of metabolism, which is itself partly the outcome of environmental influences, and partly the developmental result of the sort of metabolism that existed in the germ cells from which the organism was derived. According to this view, it is clear that the presence of any one characteristic may exert an influence upon many, if not upon all, the other characteristics, and that, even in heredity, one camiot hope to alter any single organ or structure without affecting, in some slight degree at any rate, all, or nearly all, the other parts of the body. It may be argued, therefore, in criticism of the Mendelian conception of unit characters, that it takes little or no account of the netabolism of the organism as a whole. Thus it has been shown that in the case of presence or absence of hair pigment (which las been regarded as a simple example of alternate characters, such as can be superimposed experimentally upon other characters in the course of two generations), there is a pronounced correlation between albinism and other characteristics of the body, these characteristics depending for their existence upon a common metabolism.

\footnotetext{
1 Verworn, loc. cit.
} 
Moreover, the difficulty experienced by Wood $^{1}$ in superimposing the complete hornlessness of Suffolk sheep upon the white face of the Dorset horns, is probably another example of the physiological correlation subsisting between different, and apparently unconnected, structures. Originally, this case was regarded as one of simple superposition, and Bateson ${ }^{2}$ describes the hornless character as having been transmitted " pure," but subsequently many of the so-called hornless sheep were found to have grown scurs. The explanation which I tentatively suggest is, that the character of pure hornlessness was somehow or other incompatible with the pure white-faced character, these two characters being ordinarily indications of two sorts of metabolism, in just the same kind of way as the beef-producing quality and the milk-producing quality seem to be to some extent incompatible in cattle. I am inclined to go further, and to suspect that many of the other Mendelian cases, when examined more critically, will show that no one character can be superimposed upon another, in experimental breeding, without altering, though perhaps only very slightly, the character upon which it has been superimposed.

It is only when the amount of alteration is minimal that the transmission of pure characters is apparent, according to Mendelian expectation; but experimental evidence has shown that there are considerable numbers of such cases. It is a legitimate field of work for the biometrical school of biology to determine by statistical methods the extent to which variation occurs as a result of attempted superposition of characters which in their "pure" state are physiologically incompatible. Furthermore, a latent character may be regarded as one, the outward manifestation of which is incompatible with the existing kind of metabolism, but which is capable of reappearance as soon as the conditions become favourable. But because it is helpful to assume that latent characters are present in some

1 Woor, "The Inheritance of Horns and Face-Colour in Sheep," Jour. Agric. Science, vol. iii., 1909.

${ }^{2}$ Bateson, Mcndel's Principles of Hercdity, Cambridge, 1909. No doubt, however, it is arguable that the scurs themselves represent unit characters, and that if the scurs are of different kinds, these also represent unit characters (which have hitherto somehow remained "latent"), and that if they occur with different degrees of development, these again are unit characters. And so on. 
manner in the animal organisation, it is not legitimate to suppose that they are definitely located in the nuclei of germ cells or in any other definite parts or structures. ${ }^{1}$

Moceover, it should be remembered that there is no experimental proof that the chromosomes of the gametes are the physical basis of inheritance. The only definite evidence in support of this supposition appears to be Boveri's experiment, in which he fertilised a non-nucleated ovum of one species of sea-urchin with the spermatozoön of another species. ${ }^{2}$ The resulting pluteus or larva was purely paternal in its characters. Boveri concluded, therefore, that this result was due to the introduced nucleus, the maternal cytoplasm having no determining effect upon the offspring, but merely supplying the material upon which the sperm operated. ${ }^{3}$ Seeliger, ${ }^{4}$ Morgan, ${ }^{5}$ and others have objected to Boveri's conclusion on the ground that larvæ arising from cross-fertilisation show an unusually wide range of variation. Moreover, Godlewsky ${ }^{6}$ has recently carried out an experiment in which he fertilised a non-nucleated portion of a sea-urchin's egg with the spermatozoön of a crinoid, and obtained, as a result, a larva of the maternal type. This experiment seems to nullify Boveri's conclusion.

Hickson has remarked that if it be true that the chromosomes are the sole carriers of heredity it seems to be necessary to believe in the individuality of the chromosomes; that is to say,

1 The attempt to locate latent characters of organisms in particular parts of the germ cells should perhaps be regarded as a survival from a time when all kinds of qualities, abstract or otherwise, were supposed to reside in definitely restricted positions. "Compare Phenology. The centres in the nervous system are not comparable, since these are to be regarded as parts of mechanisms for controlling different functions. The centres preside over the respective functions, but the functions themselves are not located in the centres."

2 Boveri, "Ein Geschlechtlich erzeugter Organismus ohne Mütterliche Eigenschaften," S. B.d. Ges.f. Morph. u. Phys., München, vol. v., 1889.

3 The nuclei of such larvæ have been shown to possess only half the normal number of chromosomes; see Morgan, "The Fertilisation of Nonnucleated Fragments of Echinoderm Eggs," Arch. f. Entwick.-Mechanik, vol. ii., 1895.

4 Seeliger, "Giebt es Geschlechtlicherzeugte Organismen ohne Muitterliche Eigenschaften?" Arch.f. Entwick.-Mechanik, vol. i., 1894.

- Morgan, loc. cit. See also Wilson, loc. cit.

- Godlewsky, "Untersuchungen über die Bastardierung der Echiniden und Crinoiden-Familie," Arch.f. Entwick.-Mechanik, vol. xx., 1906. 
that the chromosomes seen at the poles of the spindle at the termination of mitosis are individually identical with those seen at the equator of the spindle at the next mitosis. He points out, further, that there is distinct evidence that this is not the case in certain Protozoa and Cœlenterata. Again, Hickson has called attention to the long duration of the period of conjugation in Infusoria (Heterokaryota), remarking that this is difficult to explain if we accept the view that the cytoplasm of the conjugating cells is not concerned with the transmission of hereditary characters. ${ }^{1}$

Verworn, in the criticism referred to above, las objected on more general but scarcely less substantial grounds to the doctrine that the hereditary transmission of parental characteristics is mediated by the transference of nuclear substance only. "The physiological mode of thought will hardly be able to adapt itself to the idea of a single hereditary substance, which is localised somewhere in the cell, and transferred in reproduction. A substance that is to convey the characteristics of a cell to its descendants, before all else must be capable of life, i.e. must have a metabolism, and this is impossible without a connection with other substances necessary to cell-metabolism, i.e. without the integrity of all essential cell-constituents. The designation of a single cell-constituent as the specially differentiated bearer of heredity is wholly unjustified; the cell protoplasm is of exactly the same value in this respect as the nucleus, and we must constantly return to the fact that in all living nature no instance is known in which a complete cell possessing nucleus and protoplasm does not always mediate hereditary transmission. The character of every cell is determined by its peculiar metabolism. Hence, if the peculiarities of a cell are to be transmitted, its characteristic metabolism must be transmitted; this is only conceivable when nuclear substance and protoplasm, with their metabolic relations, are transferred to the daughter-cells. This is true of the sexual reproduction of the higher animals, as well as of the asexual

2 Hickson, "The Physical Basis of Inberitance," British As8oc. Reports, Leicester Meeting, 1907, and Trans. Manchester Micr. Soc., 1907. See also Fick. "Vererbungsfragen Reduktions und Chromosomen hypothesen Bastard. regeln," Merkel und Bonnet's Ergeb.f. Anat. u. Phys., vol. xvi., 1906. 
reproduction of unicellular organisms ; in the former, however, the metabolism of one cell, the spermatozoon, is by the process of fertilisation combined with that of another cell, the ovum, into a single resultant, the metabolism of the offspring that arises from the fertilised ovum; the offspring hence possesses the characters of the two parents." 1

In view of the considerations set forth above it must be admitted that the question as to the respective parts played by the nucleus and the cytoplasm in hereditary transmission remains as yet unsolved.

\section{TELEgONY}

It used to be supposed that the spermatozoa of an animal on being introduced into a female of the same kind, besides fertilising the ripe ova and producing young, were capable of exercising a permanent influence over the mother, and so transmitting certain of their characters, not only to their own immediate offspring, but to the future offspring of the mother by another sire. This phenomenon, ${ }^{2}$ in which many practical breeders still believe, was called Telegony or Infection, and the female was said to be " infected" by the previous sire.

The classical example, and one in which Darwin ${ }^{3}$ himself believed, of the supposed influence of a previous sire upon the future offspring, is the case of Lord Morton's quagga, which was stated to have infected an Arab mare, so that she subsequently produced two striped colts by a black Arab horse. In recent years Ewart ${ }^{4}$ has repeated the experiment, employing a

1 Verworn, loc, cit. Cf. Farmer (loc, cit.), who regards the chromo. somes of the nucleus as representing primordia, which are responsible for the appearance of the hereditary characters, but need to be supplemented by specific exciting substances which determine what particular potential character shall actually develop.

2 The phenomenon was explained by supposing that the young, while still in utero, in some way affected the mother, and this influence was further transmitted to the subsequent offspring. It will be seen that this explanation assumes the possibility of the inheritance of acquired characters of which there is little or no evidence. For recent reviews of this ques. tion see Morgan, Experimental Zoology, New York, 1907; and Thomson, Heredity, London, 1907.

${ }^{3}$ Darwin, The Variation of Animals and Plants under Domestication, Popular Edition, vol. i., London, 1905.

- Ewart, The Penycuik Experiments, London, 1899. 
Burchell's zebra and a number of different mares. These experiments were supplemented by others in which animals of various kinds were used. As a result of his investigations he has come to the conclusion that there is no evidence for the existence of Telegony. A microscopic examination of the structure of the hairs of the subsequent foals bred by Professor Ewart provided further negative evidence. ${ }^{1}$ Minot, ${ }^{2}$ also, in a series of experiments upon guinea-pigs, found no indication of any telegonic influence. Moreover, Karl Pearson, ${ }^{3}$ as a result of an extensive statistical inquiry, was unable to discover any evidence of telegony in Man.

\section{On Gametic Selection and the Conditions favourable for the OCCURRence of Fertilisation}

It is a well-known fact in biology that, as a general rule, conjugation occurs most readily between gametes belonging to the same kind of organism. There are innumerable cases, however, in which the spermatozoa of one species are capable of fertilising the ova of another, and so initiating development. The resulting embryo in such cases may grow into a mature hybrid offspring which is not infrequently sterile (a fact which will be referred to again later), or, on the other hand, owing to some mutual incompatibility in the respective modes of growth inherited from the two parent forms, the embryo may survive for a short time and then perish.

Cross-fertilisation can usually be induced most easily among closely related species or among varieties belonging to the same species. Thus, the different varieties of the frog, Rana fusca, intercross as readily with one another as each variety fertilises its own ova. On the other hand, the gametes of two species as widely separate as the frog, Rana fusca, and the salamander, Triton alpestris, have been known to conjugate, but the fertilised eggs so produced divided irregularly and consequently 1901

1 Marshall, "On Hair in the Equida," Proc. Roy. Soc. Edin., vol. xxiii.,

2 Minot, "An Experiment with Telegony," British Assoc. Reporls, Cambridge Meeting, 1904.

Pearson, The Grammar of Science, 2nd Edition, London, 1900. 
failed to develop. ${ }^{1}$ In some cases (e.g. the two species of frogs, $R$. fusca and $R$. arvalis) cross-fertilisation can take place in one direction, but not in the reverse. Pflüger explained this result by supposing it to be due to peculiarities in the shape or structure of the spermatozoa, those which have the thinnest or most pointed heads being described as more successful in inducing cross-fertilisation than those with large stout heads. ${ }^{2}$ This explanation, while seeming to account for certain individual instances, cannot be applied to all cases of cross-sterility.

Bataillon ${ }^{3}$ has described experiments in which he fertilised the eggs of Pelodytes and Bufo with the spermatozoa of Triton alpestris, and obtained some degree of success, for the eggs in each case underwent an irregular segmentation before they perished. The spermatozoa underwent degeneration after conjugating, so that the chromatin of the fertilised ova was derived entirely from the female pronucleus. The experiments, therefore, afford additional proof that spermatozoa in conjugating with ova perform a function altogether apart from amphimixis (or the introduction of fresh chromatin substance as a source of variation), and that this function is the initiation of development.

Among the Mammalia, as is well known, cross-fertilisation between nearly allied species commonly occurs. The resulting hybrid may be either sterile (e.g. the mule) or fertile (e.g. the hybrid offspring of the bull and American bison). There is no evidence that more widely separated species of Mammals can be induced to have hybrid offspring. Spallanzani, ${ }^{4}$ by artificially inseminating an œstrous bitch with the spermatozoa of a cat, attempted such an experiment, but without a positive result.

A number of investigators have effected cross-fertilisation between various kinds of Echinoderms. Vernon, ${ }^{5}$ who experi-

1 Pfluiger, "Die Bastardzeugung bei den Batrachiern," Pfiüger's Arch., vol. xxix., 1882.

" Pflüger and Smith, "Untersuchungen über Bastardierung der Anuren Batrachier," \&c., Pflügır's Archiv, vol. xxxii., 1883.

3 Bataillon, "Impregnation et Fécondation," C. R. de l'Acad. des Sciences, vol. cxlii., 1906.

- Spallanzani, Dissertations, English Translation, vol. ii., London, 1784.

5 Vernon, "The Relation between the Hybrid and Parent Forms of Echinoid Larvæ," Phil. Trans. B., vol. cxc., 1898. 
mented with forty-nine different combinations, obtained results which were more or less successful in thirty-seven. In some of these, however, development did not proceed beyond the blastula stage. Vernon attempted to show that the capacity of the animal to transmit its characters to its hybrid offspring depended upon the condition of ripeness or staleness of its gametes at the time of fertilisation. Thus, the spermatozoa of the sea-urchin, Strongylocentrotus, were supposed to grow more and more " prepotent" as they became more and more mature. Doncaster, ${ }^{1}$ however, has described further experiments which seem to indicate that the variation in the form of the hybrids obtained by Vernon was really due to differences in the temperature of the water.

Loeb ${ }^{2}$ discovered that cross-fertilisation of the eggs of Strongylocentrotus by the spermatozoa of various species of starfish could be effected by adding sodium carbonate or sodium hydroxide to the sea-water in just sufficient quantity to render it slightly alkaline. Under these conditions as many as fifty per cent. of the Strongylocentrotus eggs could be fertilised by Asterias spermatozoa, whereas in normal sea-water crossfertilisation between these two Echinoderms only occurs very exceptionally. What the nature of the change is whereby the alkaline sea-water enables the sperm to fertilise the ova does not appear to be known. It has been observed that the addition of the alkali increases the motive-power of the sperms, but the same result is brought about by bicarbonate of sodium, without augmenting their capacity to cross-fertilise. Loeb suggests that the entrance of the spermatozoön into the interior of the egg-

1 Doncaster, "Experiments in Hybridisation," Phil. Trans. B., vol. cxcvi., 1903. MacBride ("Some Points in the Development of Ophiothrix fragilis," Proc. Roy. Soc. B., vol. Ixxix., 1907) has recently shown that the immature (ovarian) ova of the Ophiuroid, Ophiothrix, may be fertilised, but that the subsequent development is abnormal, segmentation resulting in a morula instead of a blastula, while at the stage at which the archenteron is formed, there is a tongue of cells projecting into its lumen. It appears, therefore, that the stage of maturity at which ova are fertilised may affect their embryonic development if not their hereditary characteristics.

"Loeb, "Ueber die Befruchtung von Seeigeleiern durch Seesternsamen," Pflüger's Archiv, vol. xcix., 1903. "Weitere Versuche uiber heterogene Hybridisation bei Echinodermen," Pfüger's Archiv, vol. civ., 1904. See also translation of the latter, as well as other papers, in the University of California Publications, Physiology, vols. i. and ii., 1902-4. 
protoplasm may be due to surface-tension forces, and that the conditions for this process may depend upon the surface tension between the spermatozoön and the sea-water becoming greater than the sum of the surface tensions between the sea-water and the egg, and the spermatozoön and the egg. Loeb remarks, further, that the fertilisation of Strongylocentrotus eggs by sperms of the same species can best be accomplished in normal sea-water, and with this observation he associates the fact that the mobility of the Strongylocentrotus sperms is diminished by the alkaline water. ${ }^{1}$

While suggesting that restrictions to the power of crossfertilisation may be due to differences in surface tension, Loeb admits that the evidence seems to show that the capacity to conjugate is to some extent at least specific. Attempts were made to fertilise the eggs of sea-urchins with the spermatozoa of Annelids and Molluses, but these experiments were without success. Very recently, however, Kupelweiser ${ }^{2}$ reports that he has been successful in fertilising Strongylocentrotus ova with the spermatozoa of the mussel (Mytilus), and that the products developed into gastrulæ.

Dr. A. T. Masterman tells me that, in certain cases, hybridisation among fishes may be induced more readily in the absence of opportunity for normal fertilisation, that is to say, for fertilisation of ova by spermatozoa of the same species. If such ova are present, the spermatozoa tend to conjugate with them rather than with ova belonging to a different but closely allied species. It would appear, therefore, that the spermatozoa exhibit an elective affinity for ova belonging to the same species as themselves. This has been shown especially in hybridisation experiments between brill and turbot. ${ }^{3}$

That assortative mating amongst gametes occurs generally as the result of a preferential tendency possessed by them towards conjugating with other gametes bearing similar characters to

1 Loeb, The Dynamics of Living Matter, New York, 1906.

2 Kupelweiser, "Versuche uiber Entwickelungserregung und Membranbildung bei Seeigeleiern durch Mollusksperma," Biol. Centrabl., vol. xxvi., 1906.

${ }^{3}$ M'Intosh and Masterman, Life History and Development of the Food Fishes, and articles in the Reports of the Scottish Fishery Boards, 9th Rep., Pt. III., 10th Rep., Pt. III., and 13th Rep., Pt. III. 
their own, and that the comparative scarcity of hybrids in a state of nature is very largely the result of this selective action, are facts with which many of the older naturalists were familiar. With reference to the various species of plants belonging to the family Compositæ, Darwin wrote as follows :-

"There can be no doubt that if the pollen of all these species could be simultaneously or successively placed on the stigma of any one species, this would elect with unerring certainty its own pollen. This elective capacity is all the more wonderful as it must have been acquired since the many species of this great group of plants branched off from a common progenitor."

Romanes, ${ }^{1}$ who quotes this passage, remarks that "Darwin is here speaking of 'elective affinity' in its fully developed form, as absolute cross-sterility between fully differentiated species. But we meet with all lower degrees of cross-infertility-sometimes between 'incipient species,' or permanent varieties, and at other times between closely allied species. It is then known as 'prepotency' 2 of the pollen belonging to the same variety or species over the pollen of another variety or species, when both sets of pollen are applied to the same stigma. Although in the absence of the prepotent pollen the less potent will fertilise the seed, yet, such is the appetency for the more appropriate pollen, that even if this be applied to the stigma some considerable time after the other, it will outstrip. or overcome the other in fertilising the ovules, and therefore produce the same result on the next generation as if it had been applied to the mother plant withont any admixture of the less potent pollen, although in some cases such incipient degrees of cross-infertility are further shown by the number or quality of the seeds being fewer or inferior."

It would appear, however, that when the aggregate vitality

'Romanes, Darwin and Afler Darwin, vol. iii., London, 1897. See also Darwin, Animals and Plants, London, 1875, and Cross-and Self-Fertilisation in Plants, Isondon, 1876.

2 The term "Prepotency" is here used in a different sense to that in which it is usually employed by zoologists, according to whom it means the greater capacity of one parent, as compared with the other, to transmit its characters to its offspring; thus, instead of both parents transmitting their characters equally, one may be "prepotent" over the other. (Cf. the Mendelian term "dominant," which has a more precise signification; see p. 194.) 
of the ova and spermatozoa is reduced below a certain point, assortative mating as a result of affinity between gametes bearing similar characters no longer occurs. It thus happens that a reduction of vitality is frequently correlated with an increased tendency towards cross-fertilisation, which, on this view, is a source of renewal of vitality. This theory was adopted to explain certain phenomena of cross-fertilisation occurring among plants, by Fritz Müller, who wrote as follows :-

" Every plant requires for the production of the strongest possible and most prolific progeny, a certain amount of difference between male and female elements which unite. Fertility is diminished as well when this degree is too low (in relatives too closely allied) as when it is too high (in those too little related)." And, further, "species which are wholly sterile with pollen of the same stock, and even with pollen of nearly allied stocks, will generally be fertilised very readily by the pollen of another species. The self-sterile species of the genus Abutilon, which are, on the other hand, so much inclined to hybridisation, afford a good example of this theory, which appears to be confirmed also by Lobelia, Passiflora, and Oncidium." 1

Castle ${ }^{2}$ found that the eggs of the hermaphrodite Ascidian, Cionaintestinalis, could not, as a rule, be fertilised by spermatozoa derived from the same individual, while they could be fertilised readily with the spermatozoa of another individual. This rule, however, was not without exceptions, for in some cases as many as fifty per cent. of the eggs of one Ciona could be fertilised with sperms of the same individual, although this was very unusual. Morgan, who confirmed Castle's observations, states that the failure to conjugate is due to the inability of the sperms to enter the eggs. If the sperm succeeds in entering, as in the exceptional cases, the fertilised egg develops normally. Morgan found, further, that if the sperms are stimulated to greater activity by alcohol, ether, ammonia, or certain salt solutions, self-fertilisation may in some cases be induced. In another Ascidian, Cynthia partita, Morgan observed that self-fertilisa-

1 Muiller, "Investigations respecting the Fertilisation of Abutilon," English 'Translation in American Natural 'st, vol. viii., 1874.

2 Castle, "The Early Embryology of Ciona intestinalis," Bull. Mus. Comp. Zool., vol. xxvii., 1896. 


\section{THE PHYSIOLOGY OF REPRODUCTION}

tion frequently occurs, but that the eggs in this species also are most usually fertilised by spermatozoa from another individual. ${ }^{1}$

It is well known that the fertility of animals which are much in-bred is often reduced, but this is by no means invariably the case. ${ }^{2}$ Thoroughbred horses are notoriously in-bred, and it is interesting to note that one of the earlier reports of the Royal Commission on Horse-breeding states that no less that forty per cent. of the thoroughbred mares in this country fail to have foals each year. This relatively large amount of sterility is probably due to a variety of causes, and not entirely to the results of in-breeding.

Low ${ }^{3}$ has recorded an experiment on the effect of in-breeding in fox-hounds. The particular strain is described as having perished completely. Low states also that similar experiments have been performed upon pigs, and, as a consequence, the litters became diminished in size and frequency, while difficulty was often experienced in rearing those which were produced.

Von Guaita, ${ }^{4}$ and Bos, ${ }^{5}$ in describing the effects of inbreeding in mice and rats respectively, have recorded a steady decrease of fertility in successive generations.

Castle-and his collaborators, ${ }^{6}$ as a result of an investigation upon the same question in the pumice-fly (Drosophila ampelophila), have come to the conclusion that in-breeding tends to reduce the fertility to a slight extent, whereas cross-breeding has a contrary effect.

The diminished fertility of in-bred animals may be due partly to a decrease in the supply of mature ova correlated with

1 Morgan, "Self-Fertilisation indueed by Artificial Means," Jour. of Exper. Zool., vol. i., 1904. "Some Further Experiments on Self-Fertilisation in Ciona," Biol. Bull., vol. viii., 1905.

2 The results of in-breeding are diseussed at some length by Darwin, Variation of Animals and Plants, vol. ii., Popular Edition, London, 1905. For a reeent review of the subject see Morgan, Experimental Zoology, New York, 1907.

${ }^{3}$ I.ow, The Domesticated Animals of Great Britain, London, 1845.

4 Von Guaita, "Versuche mit Kreuzungen von versehiedenen Rassen der Hausmaus," Ber. d. Naturf. Gesell., Freiburg, vol. x., 1898.

"Bos, "Untersuehungen ueber die Folgen der Zucht in engster Blutverwandtschaft," Biol. Centralbl., vol. xiv., 1894.

6astle, Carpenter, Clark, Mast, and Barrows, "The Effeets of In-breeding, \&e., upon the Fertility and Variability of Droscphila," Proc. Amer. Acad. of Arts and Sciences, vol. xli., 1906. 
a general want of vigour. It seems probable, however, that it also results from failure on the part of the gametes to conjugate, since the productiveness of in-bred animals can often be increased by cross-breeding with other varieties. (See p. 601.)

Heape ${ }^{1}$ states that Dorset Horn sheep, when served by rams of their own breed, show a greater tendency towards barrenness than when served by Hampshire Down rams. It is possible that what in this case appears to be barrenness is in reality very early abortion, the in-bred embryos tending to die at an early stage and to be absorbed in utero, thus escaping observation. It seems not unlikely, however, that, in the absence of cross-breeding, there is sometimes an insufficiency of vitality at the very outset, the elective affinity of the gametes being too feeble to induce conjugation.

Some years ago the writer carried out an experiment upon a bitch belonging to the Dandie Dinmont variety, which is known to be very in-bred. Seminal fluid was obtained from a pure-bred Dandie Dinmont dog, and also from an obviously mongrel terrier of unknown ancestry. The semen from the two dogs was examined microscopically, and in each case was found to be rich in sperms, which so far as seen were all moving and in a vigorous condition. Approximately equal quantities of each sample of semen were then mixed together in a glass tube. After a further examination of the mixture, when it was observed that all the sperms were still active, the fluid was injected into a pure-bred Dandie Dinmont bitch, which was distantly related to the Dandie Dinmont dog. Previously to the experiment the bitch had been kept apart from other dogs, and this restriction was continued so long as she showed signs of œestrus. Fifty-nine days after the injection the bitch littered four pups, which closely resembled one another. Of these one died early, but the other three grew into mongrels which somewhat resembled the terrier sire, so that there can be little doubt that all four pups were mongrels. No stress should be laid upon the result of a single experiment; but the evidence, such as it was, was indicative of a selective tendency, consequent upon a reduced vitality, on the part of the ova of the in-bred

1 Heape, "Abortion, Barrenness, and Fertility in Sheep," Jour. Royal Agric. Soc., vol. x., 1899. 
animal to conjugate with dissimilar rather than with related spermatozoa.

Professor Ewart has informed the writer of a case in which a Dandie Dinmont bitch in his possession copulated with a dog belonging to the same breed, and two days subsequently had intercourse with a Scotch terrier. In due time the bitch littered three pups, and of these only one was a pure-bred Dandie Dinmont, while the other two were half-bred Scotch terriers, in spite of the fact that the Dandie Dinmont dog copulated two days earlier than the Scotch terrier. This case may be regarded as to some extent confirmatory of the experiment described above. ${ }^{1}$

Doncaster, ${ }^{2}$ in describing his experiments on Echinoid hybridisation, states "that cross-fertilisation is assisted by conditions which tend to reduce the vitality of the eggs." This artificial reduction of vitality could be accomplished cither by warming the eggs, or by shaking them, or by keeping them for several hours, or by placing them for from one to two hours in diluted sea-water, the last method being the most uniformly conducive to the occurrence of cross-fertilisation. There is some evidence, therefore, that a reduction of vigour among the gametes, whether occurring naturally as a consequence of inbreeding or produced artificially as in Doncaster's experiments, nay lead to a similar result, since both conditions may bring about an increased tendency towards the union of dissimilar gametes. On another view, the tendency towards

1 Seeing that an assortative mating of gametes can probably occur between the ova of one individual and the spermatozoa derived from different individuals, whether as a result of gametic similarity or reduction of vitality, it is not improbable that gametic selection also sometimes takes place when various gametes of a single individual are bearers of different characters, in the manner postulated by the Mendelian theory. Such a preferential mating, if it exists, would of course obscure the evidence of that very gametic segregation, the probable existence of which, in other cases, is inferred from the numerical proportions in which the different sorts of zygotes or offspring are produced: for if there is an assortative mating among the gametes, it is obvious that the offspring would no longer be produced in definite Mendelian proportions, since these depend upon the chance unions of gametes. According to this view, prepotency may perhaps be interpreted as the tendency of the gametes of an individual to conjugate with other gametes bearing similar ber editary characters.

Doncaster, loc. cit. 
cross-fertilisation in Doncaster's experiments may be looked upon as evidence of a diminished power of resistance, on the part of the ova, to the entrance of foreign spermatozoa, consequent upon a reduced vitality in the ova. ${ }^{1}$

Further evidence upon this question is afforded by studying the Protozoa. (See also pp. 601-604.)

\section{Conjugation in the Protozoa}

The phenomenon of conjugation in the Protozoa possesses a special interest, inasmuch as it is undoubtedly the forerunner of fertilisation in the Metazoa. It is clear, therefore, that a complete understanding of the changes which attend the former process cannot fail to throw great light on the nature and significance of gametic union in multicellular organisms.

In the different groups of Protozoa all gradations are to be found between conjugation in the general sense (i.e., the union, either temporary or permanent, of two similar unicellular organisms), and a process identical with metazoan fertilisation. Thus, in the peritrichous Ciliata there is a pronounced sex differentiation in the size and activity of the gametes, which clearly correspond to ova and spermatozoa. Even the maturation phenomena, which play so important a part in the developmental history of the metazoan gametes, are represented in some sort by comparable processes which have been observed in certain Protozoa. ${ }^{2}$ There can be no doubt, therefore, as to the essential similarity of conjugation in unicellular organisms and fertilisation in multicellular ones.

Raymond Pearl, ${ }^{3}$ as a result of a biometrical study of the process of conjugation in Paramœinum caudatum, has arrived

1 It may be mentioned also that Loeb has shown that, whereas mature starfish eggs soon die if fertilisation is prevented, eggs in which maturation is artificially hindered through lack of oxygen or the addition of an acid to the sea-water, remain alive much longer than when allowed to become mature. (Loeb, "Maturation, Natural Death, and the Prolongation of the Life of Unfertilised Starfish Eggs," \&c., Biol. Bull., vol. iii., 1902) It would appear therefore that the mature eggs have suffered a loss of vitality which ordinarily can only be increased by the act of fertilisation.

${ }^{2}$ See Enriques, loc. cit.

3 Pearl, "A Biometrical Study of Conjugation in Paramacium," Biometreka, vol. v., 1907. 
at the conclusion that in this protozoön there is a definite tendency for like individuals to mate with like, since there is a considerable degree of homogamic correlation both between the lengths of the conjugant pairs and also between their breadths. Evidence is presented to show that the homogamic correlation arises through the necessity for the anterior ends and mouths of the two individuals to "fit" reasonably well in the act of successful conjugation. If this is so, the necessity for assortative mating in Paramcecium is purely mechanical, and the principle involved is not of general application to other gametic organisms. Pearl states, also, that there is no evidence that conjugation tends to produce increased variability in ex-conjugants. On the contrary, there are indications that conjugation tends to restrict the existing variability induced by environmental influences; or, in other words, to preserve a relative stability of type. This conclusion is antagonistic to Weismann's hypothesis referred to above. (See footnote 1, p. 192.)

As already mentioned, the reproductive processes in the Protozoa, like those in the Metazoa, tend to run in cycles, each cycle beginning and ending with an act of conjugation. Maupas' observations showed that in various genera of Infusoria (Paramocium, Stylonychia, \&c.) a long period, during which the animals multiply by simple cell division, is succeeded by a period when conjugation is of very common occurrence. This marks the commencement of a new cycle, being physiologically comparable to the period of sexual maturity in multicellular organisms. If conjugation were prevented from occurring, the individuals gradually ceased to divide and underwent changes which invariably led to death. As a result of these experiments, Maupas arrived at the conclusion that the purpose of conjugation is to counteract the tendency towards senile degeneration, and to bring about a rejuvenescence or renewal of vitality. ${ }^{1}$

Maupas' observations have been confirmed by Joukowsky ${ }^{2}$

1 Maupas, " Recherches expérimentales sur la Multiplication des Infusories Ciliés," Arch. de Zool. Exp. et Gen., vol. vi., 1888. "Le Régennissement Karyogamique chez les Ciliés," Arch. de Zool. Exp. el Gen., vol. vii., 1889.

2 Joukowsky, "Beiträge zur Frage nach den Bedingungen der Vermehrung und des Eintrittes der Konjugation bei den Ciliaten," Verh. Nat. Med. Ver., Heidelberg, vol. xxvi., 1898. 
and Simpson, ${ }^{1}$ and more particularly by Calkins. ${ }^{2}$ The last investigator found, further, that the periodic seasons of "depression" or loss of vitality which invariably occurred if conjugation were prevented, and which normally resulted in the cessation of cell division and ultimately in death, could be tided over and the race carried through further cycles of activity by having recourse to artificial stimuli in the medium surrounding the culture. In a series of experiments, which Calkins conducted for twenty-three months with a single race of Paramocium, it was found that periodic reductions of vitality occurred at intervals of about six months. At such times the race under cultivation would have died out entirely had it not been for the application of stimuli in the form of extracts of various food substances (beef, pancreas, brain, \&c.). With the assistance of these restoratives, on three separate occasions, this particular race of Paramœcium was carried through four cycles of activity and 742 generations without the occurrence of conjugation. It thus appears that a change in the environment may result in a rejuvenescence of the race.

As a consequence of these experiments, Calkins has suggested that the purpose of conjugation may be to bring about the union of individuals which have lived in different environments, and so to produce a renewal of vitality in the same kind of way as a change in the environment itself.

Calkins differs from Maupas in stating that diverse ancestry is not essential in order that conjugation may occur, since he obtained as large a percentage of successful endogamous as exogamous pairings, and carried one endogamous ex-conjugant through 379 generations. On the other hand, there is some evidence that conjugation does not result in rejuvenescence when both gametes have lived for a long time in the same medium, so that their chemical composition is too similar. ${ }^{3}$

1 Simpson (J. Y.), "Observations on Binary Fission in the Life-History of the Ciliata," Proc. Roy. Soc. Edin., vol. xxiii., 1901.

2 Calkins, "Studies on the Life-History of Protozoa,"IV., Jour. of Exp. Zool., vol. i., 1S04. (References to earlier papers are here given. See also Biol. Bull., vol. xi., 1906.)

3 Cull, "Rejuvenescence as a Result of Conjugation," Jour. of Exp. Zool., vol. iv., 1907. Blackman ("The Nature of Fertilisation," British Assoc. Reports, York Meeting, 1906) is of opinion that the rejuvenescence theory of fertilisation is difficult to apply generally in view of the large number of 
According to Enriques, ${ }^{\mathbf{1}}$ however, conjugation in Colpoda steini only takes place under certain envirommental conditions (e.g. if the layer of the water is not thicker than two millimetres) and does not occur at all if the conditions of life are stationary, the infusorians going on multiplying indefinitely and the number of divisions from the last conjugation making no difference. ${ }^{2}$ According to Woodruff, ${ }^{3}$ on the other hand, a varied environment seemed to obviate the necessity for conjugation in Paramocium.

It may seem a far cry from the Ciliate Infusorian to the British thoroughbred horse, yet there is evidence that here also an in-bred and relatively infertile race may be rejuvenated through access to new surroundings. Allison, referring to blood stock of British origin, born in Australia and New Zealand, writes as follows: "We can draw from these, not only strains of blood which we have lost, but horses and mares, born again, so to speak, and admirably suited to strengthen and regenerate our home stock." 4 The same result is said to have been achieved in the descendants of British horses (especially hackneys) imported into Argentina. ${ }^{5}$

The case of the Porto Santo rabbits and that of the goats of Juan Fernandez, which are cited by Huth ${ }^{6}$ as evidence that in-breeding is harmless, may perhaps be similarly explained.

\section{The supposed Chemotactic Properties of Spermatozoa and their Relation to the Phenomena of Fertilisation}

It has been suggested that the spermatozoön is attracted towards the ovum by a chemotactic action which the metabolic products of the latter are able to exert upon the former. plants in which the fusing cclls or nuclei arc closely related. The forcc of this objection must be admitted. If, however, the conjugating cells have been subjected to slightly different environmental influences, this near relationship is not necessarily a difficulty.

"Enriques, loc. cit.

${ }^{2}$ If water from a culture in which conjugation is "epidemic" be added to a normal culture, it is statcd to induce conjugation. Conversely, if water from a normal culture is added to a "conjugation culture," it inhibits it.

${ }^{3}$ Woodruff, "The Life Cycle of Paramœcium when Subjected in Varicd Environment," Jour. of Exp. Zool., vol. xlii., 1908.

- Allison, The British Thoroughbred Horse, London, 1901.

5 Wallace (R.), Argentine Shows and Livestock, Edinburgh, 1904. Cf. also Darwin, Animals and Plants, London, 1905.

- Huth, The Marriage of Near Kin, 2nd Edition, London, 1887. 
Pfeffer's experiments ${ }^{1}$ upon the spermatozoa of ferns are usually cited as evidence of this view.

Pfeffer observed that malic acid, when put into a capillary tube with one end open and placed in a drop of liquid containing fern spermatozoa, has a strong attractive influence upon these organisms, causing them to swim in large numbers into the opening of the tube. He concluded, therefore, that it is the malic acid in the archegonium of the fern's ovum which causes the approach of the spermatozoa.

According to Strasburger, ${ }^{2}$ the ova of the Fucacex also possess chemotactic properties, attracting the spermatozoa from a distance equal to about two diameters of an ovum. Bordet, ${ }^{3}$ however, who likewise experimented upon the Fucaceæ, obtained no evidence of chemotactic attraction, but he found, on the other hand, that the sperms were very sensitive to contact.

Jennings, ${ }^{4}$ in the course of his experiments on the behaviour of the Protozoa, has shown that these organisms will tend to collect in a drop of acid placed in water. This is due to the fact that, whereas no reaction takes place when the individuals pass from water to acid, there is a distinct reaction in passing in the reverse direction. All the organisms which enter the drop of acid remain there, and consequently they accumulate, but this is not due to any attractive influence on the part of the drop. It is of course possible that Pfeffer's observations on the supposed attraction possessed by malic acid for the spermatozoa of ferns is susceptible of a similar explanation.

Buller, ${ }^{5}$ who has discussed the question at some length and has performed numerous experiments, states that, so far as he is aware, not a single case is known where chemotaxis plays a part in the fertilisation of the ova of animals.

1 Pfeffer, "Locomotorische Richtungsbewegungen durch chemische Reize," Untersuchungen aus. d. Bot. Inst. zur Tübingen, vol. i., 1884.

2 Strasburger, Das botan. Prakticum, Berlin, 1887.

3 Bordet, "Contribution a l'Étude de l'Irritabilité des Spernıtozoïdes chez les Fuccacées," Bull. de l'Acad. Belgique, vol. xxxvii., 1894.

4 Jenninge, "Studies of Reactions to Stimuli in Unicellular Organisms, Amer. Jour. of Phys., vol. xxi., 1897.

5 Buller, "Is Chemotaxis a Factor in the Fertilisation of the Eggs of Animals?" Quar. Jour. Micr. Science, vol. xlvi., 1902. 


\section{Artificial Aids to Fertilisation}

It has been already recorded that cross-fertilisation between certain species of Echinoderms can be effected by having recourse to physico-chemical methods. It is not surprising, therefore, that fertilisation between individuals belonging to the same species can be assisted, or caused to take place more frequently, in the presence of certain substances artificially added.

Thus, according to Roux, frog's eggs can be fertilised more readily by adding saline solution to the water in which they are deposited. Wilson says that in the case of the molluse Patella, a larger number of eggs can be fertilised if potash solution is added. ${ }^{1}$ Dungern ${ }^{2}$ states that the activity of the spermatozoa in the sea-urchin can be increased in the presence of substances extracted from the ova. Similarly it is said that normal prostatic secretion has an exciting action on mammalian spermatozoa (p. 236). Furthermore, Torelle and Morgan ${ }^{3}$ have shown that the immature spermatozoa of starfish can be stimulated, and fertilisation can be induced, by adding ether and various salt solutions to the sea-water.

\section{Artificial Parthenogenesis}

The fact that the ova of various kinds of organisms are capable under certain circumstances of segmenting and developing into new individuals without the intervention of male germ-cells, has been already referred to. In such animals as the Aphidæ this method of reproduction appears to be called forth by certain conditions of temperature and moisture. In other forms of life the necessary factors for the occurrence of parthenogenesis are not so evident, but the fact of its existence has been known from early times. ${ }^{4}$

In many animals parthenogenesis has been observed to occur

1 For further information on this subject, with references to literature, see Przibram, Embryogeny, English Translation, Cambridge, 1908; and Jenkinson, Experimental Embryology, Oxford, 1909.

2 Dungern, "Neue Versuche zur Physiologie der Befruchtung," Zeitschr. f. allgem. Phys., vol. i., 1902.

3 Morgan, Experimental Zoology, New York, 1907.

- See footnote, p. 131. 
occasionally, although it may never have become a confirmed physiological habit. The silkworm moth (Bombyx mori) affords an example of this phenomenon. In the higher animals also it has been shown that unfertilised eggs may very abnormally start to segment without any obvious source of stimulus. Janosik ${ }^{1}$ has recorded segmentation in the ovarian ova of Mammals, but it is doubtful whether such cases should be regarded as truly parthenogenetic in nature.

Tichomiroff ${ }^{2}$ showed that the unfertilised eggs of the silkworm moth, which, as just mentioned, is occasionally parthenogenetic, can be caused to develop in greatly increased numbers by rubbing them lightly with a brush, or by dipping them for about two minutes in strong sulphuric acid, and then washing them. Pere ${ }^{3}$ subsequently made some similar observations, noting also that normal parthenogenetic development was commonest in those individuals which were most robust.

Richard Hertwig ${ }^{4}$ was the first to show that if the ova of various Echinoderms are treated with certain reagents, and then restored to normal sea-water, they will frequently display signs of segmentation. The particular reagent originally employed by Hertwig was a $0 \cdot 1$ per cent. solution of sulphate of strychnine. Not long afterwards Mead ${ }^{5}$ observed that the eggs of the marine Annelid, Chatopterus, which ordinarily become mature only after the entrance of the spermatozoa, could be induced to throw out their polar bodies by adding potassium chloride to the sea-water in which they were placed.

Morgan ${ }^{6}$ found that an addition of sodium chloride to seawater containing ova of sea-urchins caused these to form astrospheres, while, if the ova were afterwards transferred to ordinary

1 Janosik, "Die Atrophie der Follikel," \&c., Arch. f. Mikr. Anat, vol. xlviii., 1896.

2 Tichomiroff, "Die künstliche Parthenogenese bei Insekten," Arch. f. Anat. in Phys., Phys. Abth., Suppl., 1886.

${ }^{3}$ Perez, "Des Effets des Actions mécaniques sur le Développenent des Gufs non-fécondé," \&c., Procés-Verbaux de la Soc. des Scienees de Bordenux, $18.96-97$.

"Hertwig, "Ueber Befruchtung und Conjugation," Verhanll. der Deutsch. Zool. Gesellsch., 1892.

5 Mead, Lectures delivered at Wood's Holl, Boston, 1898.

- Morgan," "The Action of Salt Solutions on the Unfertilised and Fertilised Ova of Arbacia," \&c., Arch.f. Entuick.-Mech., vol. iii., 1896, and vol.viii., 1899. 
sea-water, they sometimes proceeded to segment. The latter process, however, was not normal, since the ova that had been subjected to this treatment became transformed into masses of ininute granules, and, instead of acquiring cilia and giving rise to embryonic individuals, they underwent a process of disintegration.

To Loeb belongs the credit of having done more than any other worker to elucidate the physico-chemical aspects of the phenomena of fertilisation. Loeb was the first definitely to succeed in producing plutei from the unfertilised eggs of the sea-urchin. His original method was to expose the eggs for about two hours to sea-water in which the degree of concentration had been raised by about forty or fifty per cent. This effect could be produced by the addition of sodium chloride, but it was found to be immaterial what particular substance was employed to raise the concentration, so long as it was one which did not act injuriously on the eggs. The ova were afterwards restored to normal sea-water, when they began to undergo segmentation and subsequently developed into normal plutei.

Loeb was able to show, further, that the parthenogenetic development of the ova in such cases was brought about by a loss of water. Thus, when the concentration of the sea-water was less than forty per cent., some of the ova of the sea-urchin Arbacia could be induced to develop, even though they were allowed to remain in the hypertonic solution. By adopting similar methods a like result could be effected for the other species of sea-urchin, and also in the case of the starfish Asterias jorbesii; but it was necessary, as a general rule, to restore the ova to norinal seawater, as the continuance of abnormal conditions, although it might not hinder segmentation, usually arrested the further course of development. ${ }^{1}$

It was found, however, that osmotic fertilisation differed in several respects from fertilisation by a spermatozoön. Firstly, the ova fertilised by the former method began to seg-

1 Loeb (J.), "On the Nature of the Process of Fertilization," \&c., Amer. Jour. of Phys., vol. iii., 1899. "On the Artificial Production of Normal I arva from the Unfertilised Eggs of the Sea-Urchin (Arbacia)," Amer. Jour. of Phys., vol. iii., 1900. "On Artificial Parthenogenesis in Sea-Urchins," Scicnce, vol. xi., 1900. "Further Experiments on Artificial Parthenogenesis," \&c., Amer. Jour. of Phys., vol. iv., 1900. These papers are reprinted in Loeb's Studics in General Physiology, vol. ii., Chicago, 1905. 
ment without developing a membrane such as is invariably formed in normal eggs shortly after the entrance of the spermatozoa. Secondly, the rate of development in the artificially fertilised eggs was considerably slower than in the eggs fertilised by spermatozoa. Thirdly, the larvæ arising from osmotic parthenogenesis, as soon as they began to swim, did so at the bottom of the dish in which they were placed, instead of rising to the surface of the water like normal larvæ. It was found also that the percentage of eggs which could be induced to develop by the osmotic process was invariably very much smaller than the percentage of normally fertilised eggs which underwent development. The consideration of these differences led Loeb to conclude that the spermatozoon in normal fertilisation carried into the ovum not one, but several substances or conditions, each of which was responsible for a part only of the normal characteristics of the process; and that, in order to imitate successfully the action of the sperm, it would be necessary to combine two or more artificial methods.

When the eggs of Strongylocentrotus purpuratus were put into 50 cubic centimetres of sea-water to which 3 c.c. of a decinormal solution of a fatty acid had been added, and were left in this water for about a minute, and were then transferred to ordinary sea-water, they were observed to form membranes. It was also noticed that the eggs underwent internal changes characteristic of nuclear division, but they were rarely seen to segment. Subsequently they began to disintegrate, and after twenty-four hours were nearly all dead. If, however, the ova, after they had formed a membrane, were deposited in seawater which had been rendered hypertonic by adding 15 c.c. of sodium chloride solution of two and a half times the normal concentration, to 100 c.c. of sea-water, all or nearly all the eggs could be induced to develop. Furthermore, the rate of development was practically the same as that of normally fertilised eggs, a large percentage of the blastulæ looked normal and rose to the surface of the water, and the plutei which developed showed the usual degree of vitality.

The brothers Hertwig ${ }^{1}$ had previously discovered that sea-

1 Hertwig (O. and R.), Untersuchungen zur Morphologie und Physiologie der Zelle, Jena, 1887. 
water saturated with chloroform induced the unfertilised eggs of the sea-urchin to develop membranes. Herbst ${ }^{1}$ more recently showed that benzol, toluol, creosote, or oil of cloves produced a similar effect. Loeb ${ }^{2}$ found that amylene and various other hydrocarbons and acids also called forth membrane formation, and that eggs which were subjected to these methods could be made to segment by subsequent treatment with hypertonic sea-water in the way described. The substances which called forth membrane formation can be divided into two groups, the first consisting of hydrocarbons and certain substitute products, and the second being comprised of certain acids. Loeb states also that the order in which the two agencies are employed is of vital consequence, for if the eggs are subjected to the membrane-forming solution after being placed in the hypertonic sea-water instead of before, they develop a membrane, but shortly afterwards disintegrate. As a result of this series of experiments he concludes that the process of membrane formation is an essential and not a secondary phenomenon. ${ }^{3}$ He makes the further suggestion that membrane formation is brought about by a kind of secretory process, due to the squeezing out under pressure of a liquid substance from the interior of the ovum ${ }^{4}$ ( $c f$. Jenkinson, p. 189). According to this view the excretion of the fluid is the essential feature, while the actual formation of the membrane is probably only a secondary mechanical effect of the sudden secretion.

In the case of the starfish it was found that the process of artificial membrane formation was alone sufficient to induce parthenogenetic development without any further treatment with hypertonic sea-water. This observation is connected by Loeb with the fact that starfish eggs are sometimes able to develop in the absence of any external cause or agency.

${ }^{1}$ Herbst, "Über die kuinstliche Hervorragung von Dottermembranen," \&c., Biol. Centralbl., vol. xiii., 1893.

${ }^{2}$ Loeb, The Dynamics of Living Mutter, New York, 1906. This work contains further references. "On an Improved Method of Parthenogenesis," Univ. of California Publications: Physiology, vol. ii., Berkeley, 1904.

${ }^{3}$ It was found, however, that in the case of the starfisl! a very small number of eggs could develop without first forming a membrane, and that this number could be increased by transitorily treating the eggs with acidulated sea-water. See below.

- Loeb, "Ueber die Natur der Lösungen," \&c., Pflüger's Arch., vol. ciii., 1904. 
Parthenogenetic development of starfish eggs has been produced also by mechanical agitation $;^{1}$ but it is possible, as Loeb observes, that the diffusion of carbonic dioxide, or some other gas, into or from the eggs may be the real exciting cause. ${ }^{2}$

Loeb found also that the unfertilised eggs of the Annelid, Chcetopterus, could be made to develop into swimming larvæ by adding a small quantity of a soluble potassium salt to the sea-water in which they were placed. ${ }^{3}$ The same result could be brought about by the addition of hydrochloric acid. The eggs appeared to undergo development, as far as the trochophore stage, but without segmenting.

Lillie, ${ }^{4}$ however, found that the nuclear divisions were abnormal, and that the apparent trochophore larvæ were not typical, being in reality merely "ciliated structures" which were far behind the real larvæ in organisation. But Bullot ${ }^{5}$ showed that in another Annelid, Ophelia, ova fertilised by hypertonic sea-water underwent a regular segmentation.

Loeb has shown that the ova of limpets (Acmoea and Lottia) could be artificially fertilised by the combined action of fatty acid and hypertonic sea-water. This method also had the effect of hastening maturation, since ova which could not be fertilised by spermatozoa could be made to develop into larvæ by the artificial treatment. It was found, further, that maturation could be induced by the action of alkaline sea-water, and that ova which were treated in this way could be fertilised by spermatozoa or artificially fertilised. ${ }^{6}$

Bataillon ${ }^{7}$ states that the unfertilised eggs of the lamprey, and also those of the frog, can be made to undergo segmentation

1 Mathews, "Artificial Parthenogenesis produced by Mechanical Agitation," Amer. Jour. of Phys., vol. vi., 1901.

2 Loeb, The Dynamics of Living Matter, New York, 1906.

${ }^{3}$ Loeb, "Experiments on Artificial Parthenogenesis in Annelids," \&c. Amer. Jour. of Phys., vol. iv., 1901.

4 Lillie, "Differentiation without Cleavage in the Egg of the Annelid, Chctopterus pergamentaceus," Arch. f. Entwick.-Mechanik, vol. xiv., 1902.

5 Bullot, "Artificial Parthenogenesis and Regular Segmentation in an Annelid (Ophelia)," Arch. f. Entwick.-Mcchanik, vol. xviii., 1904.

${ }^{6}$ Loeb, Univ. of California Publications: Physiology, Berkeley, vol. i., 1903, and vol. iii., 1905.

"Bataillon, "Nouveaux Essais de Parthénogénèse expérimentale chez les Vertèbrés inférieurs (Rana fusca et Petromyzon planeri"), Arch. f. Entwick.Mechanik, vol. xviii., 1904. 
as far as the morula stage by depositing them in a salt solution of such a concentration that they lose water. Sugar solutions were also found to be effective. ${ }^{1}$

Various experiments have been tried with the object of finding out whether ova could be fertilised by substances artificially extracted from spermatozoa, but so far without any positive result. ${ }^{2}$ Thus Gies attempted to obtain an enzyme from spermatozoa, with a view to seeing if such a substance would exert any influence on the unfertilised ovum, but his experiments lent no support to the idea. ${ }^{3}$ Pizon's ${ }^{4}$ experiments on the same question were also negative in result. (See p. 299.)

Loeb $^{5}$ has discussed at some length the question as to whether any idea can be formed regarding the nature of the action of the spermatozoön in causing the ovum to develop. He states his belief that "the essential effect of the spermatozoön consists in the transformation of part of the protoplasmic or reserve material in the egg into the specific nuclein or chromatin substance of the nucleus. In each nuclear division one half of the mass of each original chromosome goes into the nucleus of each of the two resulting cells. But during the resting period which elapses until these nuclei are ready to divide again, each chromosome grows to its original size, and then a new division occurs. It is quite possible that the oxygen which is required for the process of cell division is needed for the synthesis of nuclein or chromatin substance. The fact that the rate of development is influenced by temperature, in much the same way as are chemical reactions, supports the idea given above that the essential feature of fertilisation consists in the starting or the acceleration of a chemical reaction which is going on steadily in the egg. Loeb was disposed to conclude, therefore, that the spermatozoön acts as a positive catalyser, but further evidence has led him to reject this idea as improbable. He points out that, if it were correct, normal sea-

I Loeb, loc, cit.

2 See Loeb, The Dynamics of Living Matter, New York, 1906.

"Gies, "Do Spermatozoa contain Enzyme having the Power of causing Development of Mature Ova?" Amer. Jour. of Phys., vol. vi., 1901.

"Pizon, "Recherches sur une prétendue Ovulase des Spermatozoïdes," C. R. de l'Acad. des Scicnces, vol. cxli., 1905.

soeb (J.), loc. cit. 
urchin eggs should segment if kept for a sufficiently long period, and that it ought to be possible to induce segmentation by applying heat, since heat is known to accelerate chemical reactions, but neither of these results could be obtained.

He then suggests the possibility that the spermatozoön, in conjugating with the ovum, removes from the latter a negative catalyser or condition whose existence in the ovum somehow inhibits the process of development. This suggestion seems to provide an explanation of the secretory phenomena, which, on Loeb's hypothesis, are the cause of the membrane formation. "Finally, we may be able to understand a fact which [has been] observed in the eggs of a starfish, and which has not yet been mentioned, when the eggs of Asterina or Asterias are allowed to ripen, they will die within a few hours unless they develop either spontaneously or through the influence of sperms or some of the above-mentioned agencies. The disintegration which leads to the death of the non-developing egg is obviously due to an oxidation, since I found that the same eggs when kept in the absence of oxygen will not disintegrate. We know that oxygen is an absolute prerequisite for the development of the fertilised egg " [but this statement is disputed by Delage]. The fact that oxygen is a poison for the mature but nondeveloping egg shows that the chemical processes which occur in the unfertilised, non-developing egg must be altogether different from those which go on in the developing egg of the star-fish. ${ }^{1}$

1 Loeb, loc. cit. See also "The Toxicity of Atmospheric Oxygen for the Eggs of the Sea-Urrchin after the Process of Membrane Formation"; "On the Necessity of the Presence of Free Oxygen in the Hypertonic Sea-water for the Production of Artificial Parthenogenesis" ; "On the Counteraction of the 'Toxic Effect of Hypertonic Solutions upon the Fertilised and Unfertilised Egg of the Sea-Urchin by lack of Oxygen," Univ. of California Publ cations : Physiology, vol. iii., 1906. See also "Versuche über den Chemischen Charakter des Befruchtungsvorgangs," Biochem. Zeitschr., vol. i., 1906. "Weitere Beobachtungen über den Einfluss der Befruchtung und der Zahl der Zellkerne auf die Säurebilđung im Ei," Biochem. Zeitschr., vol, ii. 1906 ; "Über die Superposition von küntlichen Parthenogenese und Samenbefruchtung in derselber Ei," Arc々. f. Entwick.-Mechanik, vol. xxiii., 1907 ; "Über die allgemeinen Methoden der künstlichen Parthenogenese," Pfïjer's Arch., vol. cxviii., 1907 ; and other papers in the same volume. The following papers also deal with artificial partbenogenesis in various animals: Delage, C. R. de l'Acad. des Sciences, vol. cxxxv., 1902 (describing fertilisation by 
Loeb's general conclusion is that the phenomenon of fertilisation (as studied in the sea-urchin, the star-fish, Lottia, Polynoe and Sipunculids) consists essentially, firstly, in a liquefaction or hydrolysis (or both) of certain fatty compounds in the ovum, and secondly, in an initiation in the right direction of a new process of oxidation. ${ }^{1}$ These changes which occur in the fertilised egg lead to the synthesis of nuclein material from the protoplasm. According to this view, the process of astrosphere formation is not the direct effect of the act of fertilisation, but is a secondary consequence of the new chemical changes which are brought about by the entrance of the spermatozoön. ${ }^{2}$

Delage, ${ }^{3}$ however, has recently adduced experimental evidence, some of which is opposed to Loeb's interpretation of the observed phenomena. This investigator has shown that

anæsthetisation with carbon dioxide during maturation) : and $C . R$. de l'Acad. des Sciences, vol. cxli., 1906 (describing fertilisation with various salt solutions) ; Treadwell, "Notes on the Nature of Artificial Parthenogenesis in the Egg of Patella obscura, Biol. Bull., vol. iii., 1902 ; Scott, "Morphology of the Parthenogenetic Development of Amphitrite," Jour. of Exper. Zool., vol. iii., 1906 ; Lefevre, "Artificial Parthenogenesis in Thalassema mellita," Jour. of Exper. Zool., vol. iv., 1907 ; Kostanecki, "Zur Morphologie der kiinstlichen parthenogenetischen Entwicklung bei Mactra," Arch. f. Mikr. Anat., vol. Ixxii., 1908. See also Mathews, whose paper has been already referred to (Chapter IV. p. 134, "A Contribution to the Chemistry of Cell Division, Maturation, and Fertilisation," Amer. Jour. of Phys., vol. xviii., 1907). This author lays stress on the part played by the centriole, and suggests " that the various methods employed to produce artificial parthenogenesis do not do so by their direct physical action on the cell, but indirectly by producing in one way or another active centriole substance in the cell cytoplasm, or by causing its discharge from the nucleus."

1 Loeb, "The Chemical Character of the Process of Fertilisation and its bearing upon the Theory of Life Phenomena."-Address before the International Congress of Zoologists, Boston, 1907, Univ. of California Publications, vol. iii., 1907.

2 Since this was written, Loeb has elaborated his theory further in an important work recently published, in which full references are given (Dic chemische Entwicklungserregung des ticrischen Eies, Berlin, 1909). Membrane formation is regarded as an essential factor in normal fertilisation, and is of the nature of a cytolysis of the egg, for all cytolytic agents produce it. Normally the fertilisation membrane is brought about by a lysin carried in by the sperm, which also carries another substance that serves to counteract the evil effects of membrane formation. See p. 301, Chapter VIII., where the subject is discussed further.

3 Delage, "Les Vrais Facteurs de la Parthénogénèse Expérimentale," Arch. de Zool. Expér. et Gen., vol. vii., 1908. 
it is possible artificially to fertilise sea-urchins' eggs by treating them with solutions of tannin and ammonia. He had already formed the conception that the essential facts of cell division could be resolved into a succession of processes involving coagulation and liquefaction. The formation of the vitelline membrane is said to be essentially a coagulative process (and also possibly the formation of the centrosome and of the nuclear spindle), and the dissolution of the nuclear membrane and certain of the accompanying events are regarded as evidence of liquefaction. These considerations led Delage to employ tannin as an agent for inducing coagulation, and ammonia for causing liquefaction. Tannate of ammonia was found to produce a similar effect, but this is explained by Delage on the assumption that, since tannin is a feeble acid and ammonia is a feeble base, the ammonium tannate becomes dissociated, so that the acid function (which brings about coagulation) and the alkaline function (which causes liquefaction) may be supposed to co-exist in the solution, and so separately to exert an influence on different parts of the egg. By adopting the abovedescribed method, Delage succeeded in artificially fertilising ova, so that they developed into complete sea-urchins, but it is curious to note that the symmetry of these individuals was liable to be abnormal, one of them being hexameral instead of pentameral. Delage also obtained successful results by using carbon dioxide and other agents, and star-fishes' eggs as well as sea-urchins' were successfully fertilised. Furthermore, certain of the experiments seem to indicate that the presence of oxygen is not a necessary factor (as supposed by Loeb), since development could be induced after practically all the oxygen present had been eliminated.

It is, of course, obvious that Loeb's interpretation of the observed phenomena of fertilisation among the Metazoa is inapplicable to the process of gametic union in the Protozoa, in which the conjugating units are often apparently similar and equipotential, and the same objection may be offered to Delage's theory. It is possible, however, that conjugation in the Protozoa, while presenting an essential similarity to fertilisation in the. Metazoa, initiates a series of chemical processes of a relatively simpler kind. Moreover, the theory that the changes 
consequent upon gametic union are the result of a catalytic chemical reaction is in no way opposed to the vaguer physiological conception that the object of the process is to secure a rejuvenescence of vital substance without which the race cannot be perpetuated.

The cytological changes which occur in artificially fertilised ova have been dealt with at considerable length by Wilson, to whose paper ${ }^{1}$ the reader is referred. It is shown that the ovum of the sea-urchin, under an appropriate stimulus, is able to construct the complete mechanism of mitotic cell division without the importation of a sperm-centrosome, but beyond this a multitude of aberrations are exhibited. The number of chromosomes is one-half that occurring in normally fertilised eggs, being in the sea-urchin eighteen instead of thirty-six. The centrosomes are primarily formed de novo. According to Delage, ${ }^{2}$ however, the number of chromosomes in artificially fertilised sea-urchins becomes eventually restored to the normal by a process of auto-regulation.

1 Wilson, "Experimental Studies in Cytology: I. A Cytological Study of Artificial Parthenogenesis in Sea-Urchin Eggs," Arch. f. Entwick.-Mechanik, vol. xii., 1901. For an account of the cytological phenomena in normal parthenogenetic eggs, especially in insects, see Hewitt, "Cytological Aspects of Parthenogenesis in Insects," Memoirs and Proc. Manchester Literary and Philosophical Soc., vol. 1., 1906.

2 Delage, "Études expérimentales sur la Maturation Cytoplasmique chez les Ėchinodermes," Arch. de Zool. Expér. et. Gén., vol. ix., 1901. Cf. also Tennent and Hogue, "Studies on the Development of the Starfish Egg," Jour. of Exp. Zool., vol. iii., 1906. 


\section{CHAPTER VII}

THE ACCESSORY REPRODUCTIVE ORGANS OF THE MALE AND THE MECHANISMS CONCERNED IN INSEMINATION

"Mais, par ce moyen de propagation seminale, demeure es enfans ce qu'estoit de perdu es parens et es nepveux ce que dépérissoit es enfans, et ainsi successivement."-RABELAIS.

A BRIEF description of the mammalian testis has already been given in a chapter on the physiology of the spermatozoön (p. 166). It remains, however, to state what is known regarding the functional relations of the accessory male organs, and to refer incidentally to the homologous structures in the female.

After traversing the tubules of the rete testis the spermatozoa, swimming in the seminal fluid, make their way into the vasa efferentia, which open into the canal of the epididymis. The vasa efferentia in Man are about twenty in number. Before passing into the epididymis they become convoluted, forming the coni vasculosi. Both the vasa efferentia and the tube of the epididymis contain smooth muscular fibres in their walls. They are lined internally by columnar epithelial cells provided with long cilia, which assist the muscles in expelling the semen.

Passing away from the epididymis, and in continuation with its canal, is the vas deferens, which is nearly two feet long in the human subject, and has an average diameter of about onetenth of an inch. It possesses a plain muscular wall, consisting of an outer layer of longitudinal, a middle of circular, and an inner of longitudinal muscles. On the inside of the muscles there is a mucous coat lined by a columnar epithelium, which is not ciliated. ${ }^{1}$

1 Arising from the lower part of the epididymis, or from the vas deferens close to its commencement, is a long narrow diverticulum which ends blindly. This is the vas aberrans. It is probably a vestigial structure. A few small convoluted tubes, situated near the head of the epididymis and representing vestiges of part of the Wolftian body, are called the paradidymis or organ of Giraldès. The innervation of the vas deferens is described below in dealing with the process of ejaculation. 


\section{THE PHYSIOLOGY OF REPRODUC'TION}

A branch from one of the vesical arteries accompanies the vas deferens, and eventually enters the testis, where it anastomoses with the spermatic artery. The vas deferens, near its termination, becomes sacculated, and in this region is known as the ampulla of Henle. In the walls of the ampulla there are

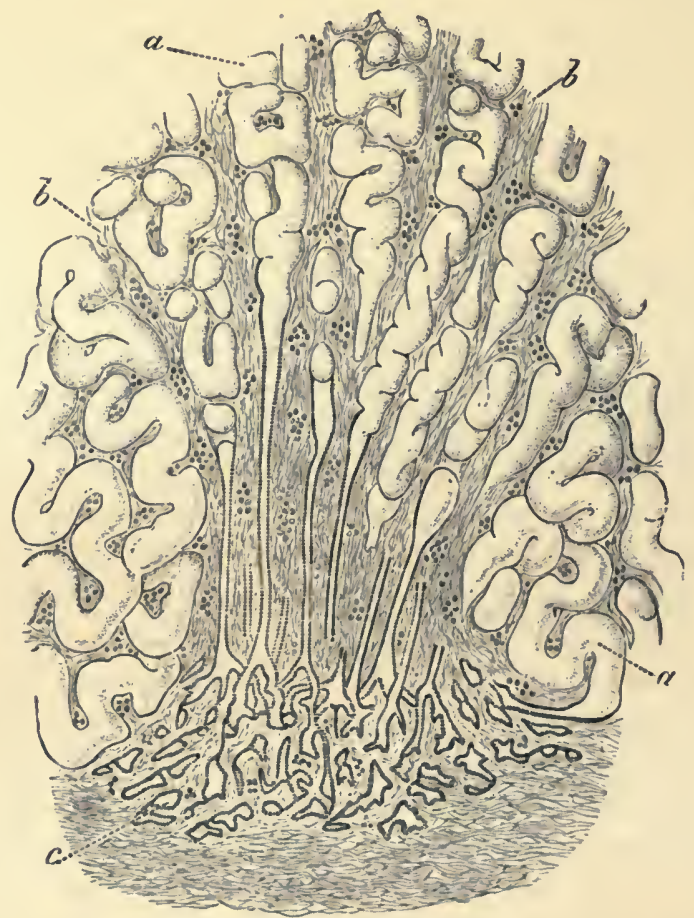

FIG. 53.-Passage of convolnted seminiferous tubules $(a)$ into straight tubules, and of these into rete testis $(c)$, (after Mihalkowicz, from Schäfer); $b$, fibrous stroma continued from mediastinum.

a number of small tubular glands, which doubtless supply some portion of the ejected fluid.

Disselhorst ${ }^{1}$ believes that the ampulla acts as a seminal reservoir (a function which has also been assigned to the vesiculæ seminales, as described below), and states that he has

1 Disselhorst, "Ausfiulurapparat und Anlangsdrüsen der Mannlichen Geschlechtsorgane," Oppel's Lehrbuch der V.rgleichenden Mikroscopischen Anatomie der Wirbeltiere, vol. iv., Jena, 1904. 
found spermatozoa stored up in little pockets in the walls of this structure in animals during the rutting time. He suggests, further, that there is a relation between the state of development of the ampulla and the time occupied by copulation. When the organ is small or absent, as in dogs, cats, and boars, the coition is a slow process, but when the ampulla is large and

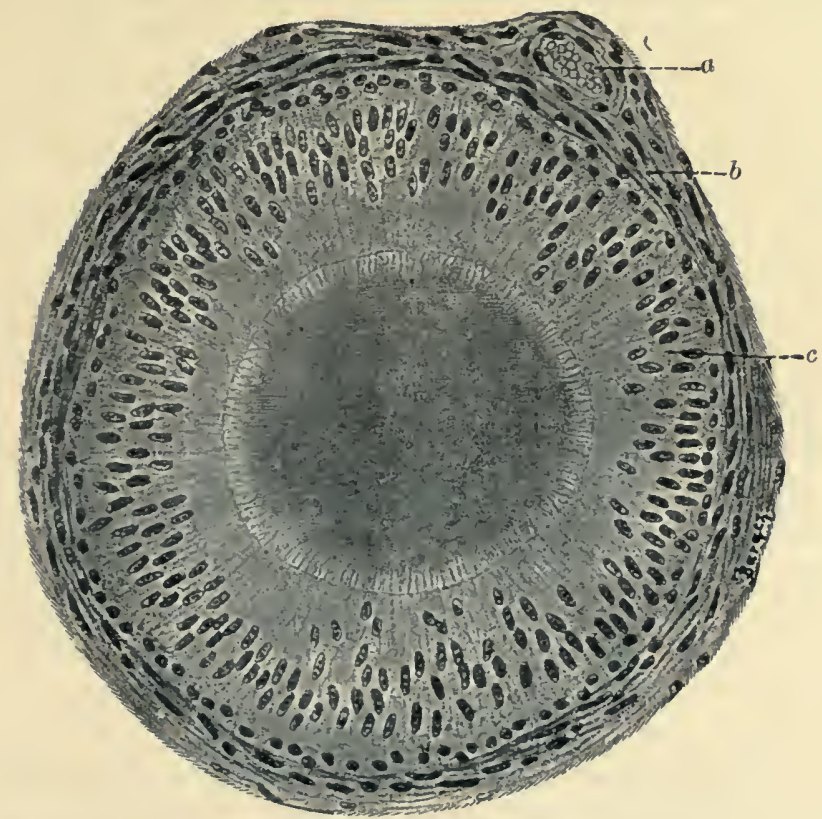

FIG. 54.-Transverse section through the tube of the epididymis. (After Szymonowicz, from Schäfer.)

$a$, blood-vessel; $b$, circular muscle fibres; $c$, epithelium.

well-developed, as in horses and sheep, the coitus occupies a relatively short time.

The vas deferens on either side unites with the terminating portion of the corresponding seminal vesicle to form the ejaculatory duct. 'Lhe two ejaculatory ducts, after traversing the prostate, open into the floor of the urethra by small slit-like apertures. Their function is to convey to the urethra the fluid contained in the seminal vesicles and in the vasa deferentia. 
The coats of the ejaculatory ducts are relatively thin. The lining epithelium is similar to that of the vas deferens.

The urethra, which serves as the common channel for both urine and seminal fluid, is lined by a columnar epithelium resting on a vascular corium. The latter is surrounded by submucous tissue containing two layers of muscular fibres, the inner being arranged longitudinally, and the outer circularly. The

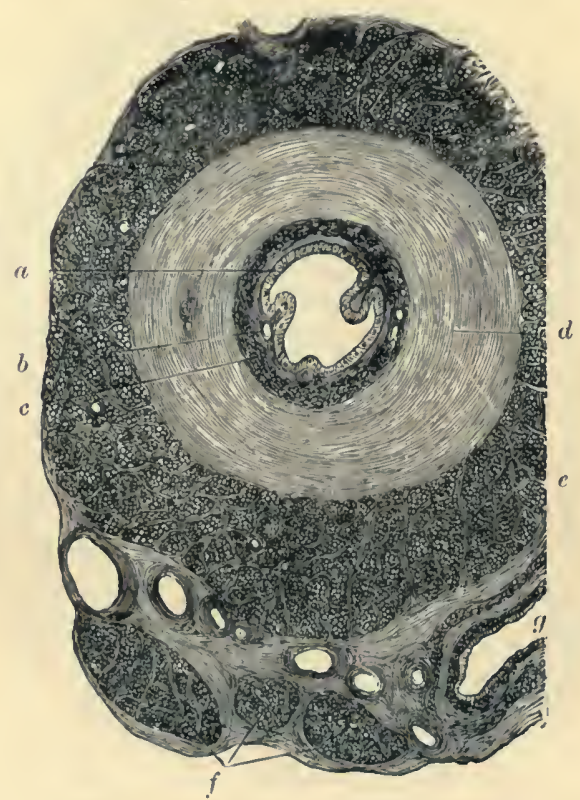

FIG. 55.-Transverse section through commencement of vas deferens. (After Klein, from Schäfer.)

$a$, epithelium ; $b$, mucous nembrane; $c, d, e$, inner, middle, and outer lajers of muscular coat ; $f$, internal cremaster muscle; $y$, blood-vessel.

urethra in man is usually described as consisting of three divisions, the prostatic, the membranous, and the spongy portions. Of these the membranous portion comprises that part of the urethra between the apex of the prostate and the bulb of the corpus spongiosum, to be described below. Opening medially into the prostatic portion of the urethra, between the two ejaculatory ducts, is the aperture of the uterus masculinus, or organ of Weber, which is the homologue of the vagina and 
uterus in the female. This vesicle, which is a small cul-de-sac, and in Man lies hidden by the prostate, is probably almost or quite functionless, but it has a few very small glands which open into its cavity. In some animals-such as the goat, for example-it is of comparatively large dimensions, the upper part being divided into two horns. In connection with it is a structure corresponding to the hymen of the female. On the floor of the prostatic portion of the urethra is an elevation of the mucous membrane and underlying tissue, known as the crista urethra or caput gallinaginis. This eminence (which contains erectile tissue) serves when distended with blood to prevent the semen from passing backwards to the bladder, and mingling with the urine in the process of emission. It is assisted in this function by the contraction of the sphincter of the bladder.

The urethra in the female corresponds to that part of the male urethra which is anterior to the openings of the ejaculatory ducts. It is lined with a stratified scaly epithelium, like that of the vagina into which it opens. Communicating with the female urethra are two complex tubular glands known as the glands of Skene. Their ducts open very close to the urethral aperture.

\section{The Vesicule Seminales}

The seminal vesicles are offshoots from the lower ends of the vasa deferentia. They consist in Man of coiled tubes, about five inches long, into which several diverticula sometimes open. The structure of the vesicles is similar to that of the sacculated part of the vas deferens, but the muscular layers are relatively thinner.

There has been some dispute as to the chief function of the seminal vesicles. According to one view, they serve mainly as receptacles for the spermatozoa before ejaculation. Most authorities, however, are disposed to lay greatest stress upon their secretory function.

Rehfisch ${ }^{1}$ has shown that if fluids are injected into the

1 Rehfisch, "Neuere Untersuchungen über die Physiologie der Samenblasen," Deutsche med. Wochenschr., vol. xxij., 1896. 
testicular end of the vas deferens, they first enter the seminal vesicle and afterwards pass out through the urethra. He concludes that the vesiculæ serve the double purpose of secretory glands and reservoirs for the semen. Misuraca ${ }^{1}$ states that in dogs and cats, which have no seminal vesicles, ${ }^{2}$ the spermatozoa disappear from the male passages from five to seven days after castration, whereas in guinea-pigs, in which the vesicles are well developed, sperms may be found alive as long as twenty days after the removal of the testes. This is regarded as evidence that the seminal vesicles function as receptacles for the spermatozoa. Moreover, Meckel ${ }^{3}$ stated that he found sperms in the vesiculæ of the mole in the month of February (i.e. during the breeding season); and Seubert ${ }^{4}$ recorded a similar observation about the hedgehog in August (also in the breeding season) ( $c f$. p. 60). Disselhorst, ${ }^{5}$ however, throws some doubt on these observations. That the vesiculæ may undergo periodic enlargement in animals which have a rutting season is, however, an unquestionable fact.

As evidence that the vesiculæ seminales are undoubtedly secretory glands, Lode ${ }^{6}$ showed that in young animals, in which one of the testes had been removed, the corresponding vesicula continued to grow, and became filled with its characteristic fluid. It was evident, therefore, that the fluid must have been secreted in the vesicula in question, since it could not have been derived from the testis of the other side. (The effects of complete castration on the growth and activity of the vesiculæ seminales are briefly referred to below.) Stilling " and

1 Misuraca, "Sopra un importante questione relativa alla castrazione," Rivista sperimentale di Freniatria, vol. xv., 1890.

${ }^{2}$ Seminal vesicles are absent not only in dogs and cats, but in many other Carnivora, and also in Cetacea and Ruminantia. They are also wanting in rabbits, but are present in the vast majority of Rodentia (Owen, Comparative Anatomy, vol. iii., London, 1868).

${ }^{3}$ Meckel, Beiträge zur Vergleichende Anatomie: I. Ueber die Männlichen Zeschlechtsteile des Maulwurfs, 1809.

"Seubert, "Symbolum ad Erinacei europxi anatomen," Inaug. Dissert., Bonil, 1841.

'Disselhorst, loc. cit.

- Lode, "Experimentelle Beitriige zur Physiologie der Samenblasen," Sitzungsber, d. kais. Acad. d. Wissenschaft in Wien, vol. civ., 1895.

" Stilling, "Beobachtungen iber die Functionen der Prostata und über die Entstehungen prostatischer Concremente," Virchow's Archiv, vol. xcviii., 1884. 
Akutsu ${ }^{1}$ state that the epithelial cells of the vesiculæ seminales change their character according to whether they are in a state of rest or activity. In the former condition they are larger and contain more plasma substance. Kolster ${ }^{2}$ has described desquamation of epithelial cells in the seminal vesicles of the elk (Cervus alces).

The secretion is formed apparently in considerable quantity. Its character and composition vary somewhat in different Mammals. In Man it is gelatinous, and consists chiefly of globulins. ${ }^{3}$ It has been investigated in Rodents by Sobotta, ${ }^{4}$ Rauther, ${ }^{5}$ and others, who describe it as a white or yellowishwhite gelatinous fluid, which becomes almost solid after ejaculation. This capacity to clot is supposed by Landwehr ${ }^{6}$ to be due to the presence of fibrinogen, 27 per cent. of which was found to be present. Calcium, however, could not be discovered. Camus and Gley ${ }^{7}$ state the clotting is brought about by a specific ferment (which they call vesiculase) in the prostatic secretion. (See p. 237.)

The clotting of the fluid, after its entrance into the female passages in Rodents, prevents the escape of the spermatozoa and so helps to ensure fertilisation. This fact was first discovered by Lataste, ${ }^{8}$ who speaks of the "bouchon vaginal" formed by the solidified secretion of the vesiculæ. Similar observations have been made by Leuckart ${ }^{9}$ and others. The

1 Akutsu, "Mikroscopische Untersuchung der Secretionsvorgänge in den Samenblasen," Pflüger's Archiv, vol. xcvi., 1903. Further references are given in this paper.

${ }^{2}$ Kolster, "Ueber einen eigenartigen Prozess in den Samenblasen von Cervus alces," Arch.f. Mikr. Anat., vol. 1x., 1902.

3 Fürbringer, "Die Störungen des Geschlechtsfunktion des Menschen," Nothnagel's P'athologie und Therapie, vol. xix., 1895.

"Sobotta, "Die Befruchtung und Furchung des Eies der Maus," Arch. f. Mikr. Anat., vol. xlv., 1895.

5 Rauther, "Ueber den Genitalapparat einiger Nager und Insektivoren," \&c., Jenaische Zeitsch. $f$. Naturwissenschaft, vol. xxxvii., 1903.

"Landwehr, "Ueber den Eiweisskörper (fibrinogene substanz) der Vesicula seminalis der Meerschweinchen," Pflüger's Archiv, vol. xxiii., 1880.

7 Camus and Gley, "Note sur quelques faits relatifs a l'énzyme prostatique (vésiculase) et sur la fonction des glandes vésiculaires," C.R. de Soc. de Biol., vol. iv. (10th series), 1897.

${ }^{8}$ Lataste, "Sur le bouchon vaginal des Rongeurs," Zool. Anz., vol. vi., 1883.

- Leuckart, Zur Morphologie und Anatomie der Geschlechtsorgane, Göttingen, 1847. 
"bouchon vaginal" is said to remain in situ for several hours, and then to become softened and fall out.

Tarchanoff ${ }^{1}$ has suggested that in the frog the filling of the seminal vesicles serves to excite-sexual feeling in the male during the breeding season, but certain other observations have been made which seem to disprove this (or at any rate to show that it is not universally true). Thus, in some animals, it is known that sexual desire exists before the seminal vesicles become full. Moreover, Steinach ${ }^{2}$ found. that rats, whose seminal vesicles had been removed, still retained their desire for copulation although their fertility was diminished.

That the spermatozoa possess complete functional activity before they can be in any way influenced by the secretion of seminal vesicles has been conclusively shown by Iwanoff, ${ }^{3}$ who induced pregnancy artificially in rabbits, guinea-pigs, and other animals, by injecting into the female passages fluid obtained directly from the epididymis, and mixed with a 5 per cent. solution of sodium carbonate. The diminished fertility in Steinach's rats, after the removal of the vesiculæ, was probably due to the absence of formation of the "bouchon vaginal," as has been suggested by Rauther. ${ }^{4}$

It would seem probable that, in the majority of animals which possess vesiculæ seminales, the secretion of these glands serves to dilute the semen, and so assists in providing a fluid medium for the transference of the spermatozoa.

Exner ${ }^{5}$ has suggested that the seminal vesicles may have the function of absorbing the seminal fluid which is not ejaculated, but there is little evidence that this is the case.

Lode ${ }^{6}$ found that in castrated bulls, horses, and guinea-pigs, the glandular epithelium of the vesicles atrophied, but the con-

1 Tarchanoff, "Zur Physiologie des Geschlechtsapparates des Frosches," PAlügr's Archiv, vol. xl., 1887.

2 Steinach, "Untersuchungen zur Vergleichenden Physiologie der Männ. lichen Geschlechtsorgane," \&c., Pfüger'\& Archiv, vol. lvi., 1894.

"Iwanoff, "La Fonction des Vésicles seminales et la Glande prostatique," Jour. de Phys. et de Path. Gen., vol. ii., 1900.

+ Rauther, loc. cit.

5 Exner, "Physiologie der Männlichen Geschlechtsfunktionen," Frisch and Zuckenhandl, Handbuch der Urologie, 1903.

${ }^{6}$ Lode, loc. cit. 
nective tissue underwent hyperplasia. Gruber ${ }^{1}$ and Pelikann ${ }^{2}$ observed that in castrated men the glands atrophied, but became filled with a kind of mucous liquid.

\section{The Prostate Gland}

The prostate in Man and other Mammals is a tubular gland which surrounds the urethra at the base of the bladder, and opens into it by a number of small ducts situated close to the

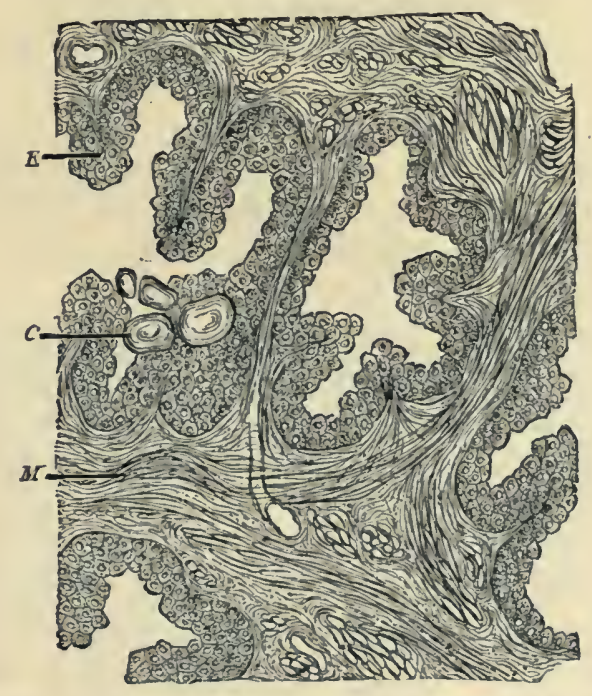

Fic. 56.-Section through part of human prostate. (After Heitzmann, from Schäfer.)

$C$, concreticns, often found in old subjects; $E$, epithelium ; $M$, muscular tissue.

apertures of the ejaculatory ducts. It is usually described as consisting of three lobes, two lateral and one median, the former comprising the chief mass of the organ. Associated with the glandular substance is a considerable quantity of plain muscular tissue. The prostate is provided with lymph-vessels and bloodvessels. The arteries arise from the vesical, hæmorrhoidal, and

1 Gruber, "Untersuchung einiger Organe eines Castraten," Müller's Archiv, 1847.

${ }^{2}$ Pelikann, Gerichtl.-mediz. Unters. über d. Slopz'ntum in Russland, Giessen, 1876. 
pudic arteries. The veins communicate with the dorsal vein of the penis and with the internal iliac vein. The innervation of the gland is described below in dealing with the mechanism of ejaculation (p. 258).

The prostatic secretion is a viscid, slightly acid liquid (sometimes neutral or even alkaline), containing proteins and salts. ${ }^{1}$ (See p. 287.) The characteristic smell of the ejected seminal fluid is said to be partly due to the prostate secretion, which also contributes to the formation of Böttcher's crystals described below (p. 285).

De Bonis ${ }^{2}$ describes the epithelial cells of the dog's prostate as containing a small number of granules. When these have been formed in sufficient quantity, so as almost to fill the cell, its wall ruptures and the granules pass out into the lumen of the gland. This occurs especially during coitus. After the discharge of the granules fresh ones are formed in the cells of the gland.

Little is definitely known regarding the function of the prostate beyond the fact that it contributes additional fluid to the semen. It may, perhaps, assist in providing the spermatozoa with nutriment. ${ }^{3}$ There is some evidence, however, that it exercises a stimulating influence upon the movements of the spermatozoa. Steinach observed that prostatic fluid, when added to normal saline solution, kept the spermatozoa in active movement for a longer period than saline solution alone. Steinach also found that rats in which the prostate gland, together with the seminal vesicles, was extirpated, were absolutely sterile, ${ }^{5}$ but this may have been due to failure to form a "bouchon vaginal" in the female. As already mentioned

1 Poehl, Die Physiol.-chem. Grundlage der Spermintheorie, St. Petersburg, 1898; Fürbringer, Die Störungen der Geschlechtsfunktion des Mannes, Wien, 1895 ; Berliner klin. Wochenschrift, vol. xxiii., 1886.

2 De Bonis, "Über die Sekretionserscheinungen in den Drüsenzellen der Prostata," Arch. f. Anat. u. Phys., Anat. Abth., 1907.

It has been suggested also that the prostate is a sphincter of the bladder, but this is rendered unlikely by its absence in the female. It is more probable that it serves to cleanse the urethra of urine before copulation.

4 Fürbringer, loc. cit. Kölliker, "Physiologisclıe Studien über die Samenflissigkeit," Zeitschr. f. wiss. Zool., vol, vii., 1856.

Bxtirpation of the vesiculæ seminales alone produced only partial sterility (see p. 234). 


\section{MALE ACCESSORY REPRODUCTIVE ORGANS 237}

(p. 233), the clotting which causes the formation of the "bouchon" in Rodents is believed by Camus and Gley ${ }^{1}$ to be due to a ferment ("vesiculase") which is present in the prostatic fluid. The removal of the prostate in Steinach's experiments had no effect in diminishing sexual desire.

Walker ${ }^{2}$ has also adduced experimental evidence pointing

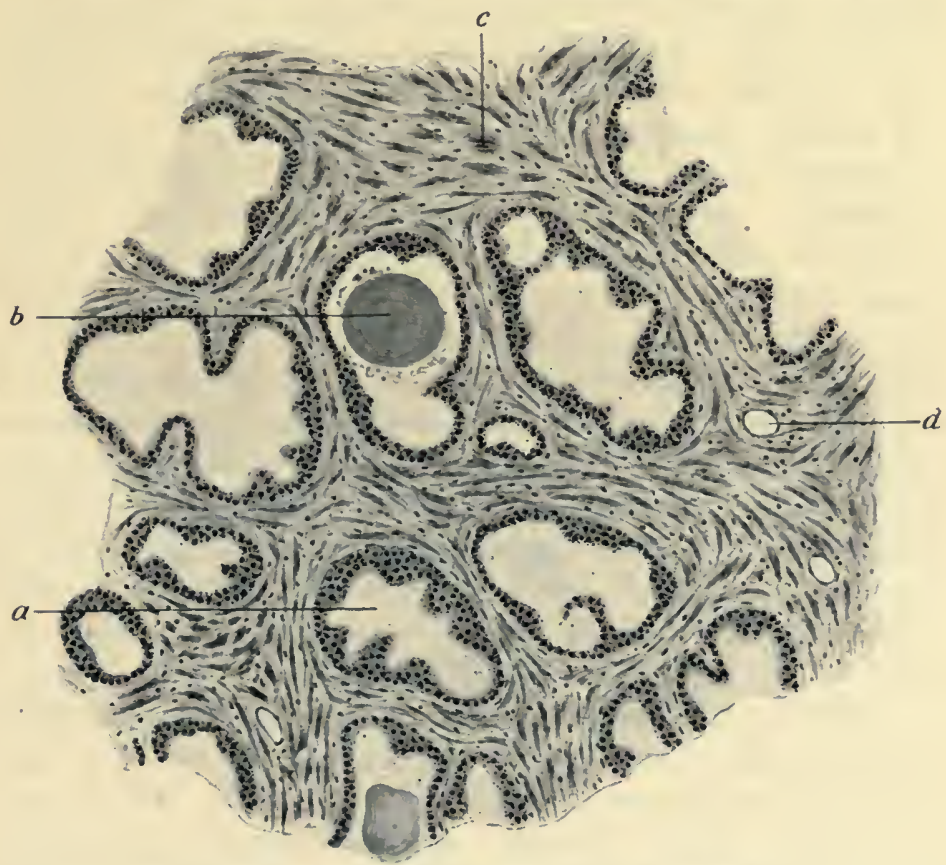

FiG. 57.-Section through prostate gland of monkey.

$a$, tubular alveolus lined with epithelium; $b$, alveolus containing concretion in lumen; $c$, bundle of muscular fibres in connective tissue; $d$, bloodvessels in stroma.

to the conclusion that the prostatic fluid of the dog stimulates the sperms to more active movement.

Iwanoff's experiments ${ }^{3}$ (see p. 234), however, show that spermatozoa which have never come into contact with prostatic

1 Camus and Gley, loc. cit.

2 Walker (G.). "Beitrag zur Kenntniss der Anatomie und Physiologie der Prostata beim Hunde," Arch.f. Anat. u. Phys., Anat. Abth., 1899.

${ }^{3}$ Iwanoff, loc, cit. 


\section{8}

secretion possess full functional activity, and are capable of fertilising ova successfully.

Serralach and Parès ${ }^{1}$ have adduced evidence indicating that the prostate is an internally secreting gland which controls the testicular functions, and regulates the process of ejaculation. It is stated that if the prostate is removed spermatozoa are no longer produced in the testis, and that the secretory activity of the accessory genital glands ceases. These changes, however, can be prevented by the administration of glycerine extracts of prostate gland. The experiments were upon dogs. The most obvious criticism of Serralach and Parès' view is that it is unlikely, on phylogenetic grounds, that the functional activity of the essential organ of reproduction should depend on the presence of an accessory gland of comparatively recent evolutionary development. On the other hand, it is arguable that the prostate may originally have formed part of the testis, and subsequently have become differentiated as a seyarate organ in the course of phylogeny. Reference may be made in this connection to the somewhat similar theory, which certain gynæcologists have held, that the ovarian functions are dependent on an internal secretion arising in the uterus, whereas the most recent experimental evidence proves clearly that this is not the case (see p. 345).

Griffiths ${ }^{2}$ has shown that the prostate glands in the hedgehog and the mole undergo definite cyclical changes which are correlated with changes in the functional activity of the testes ( $c f$. p. 232). In the quiescent state the prostate is composed of a few tubules lined by small, flattened, epithelial cells, which are at this time incapable of producing a secretion. With the approach of the breeding season the tubules grow much larger and the epithelial cells become columnar. During rut the prostate gland is a mass of tortuous tubules, and has grown to many times the size of the quiescent organ. The tubules are described as being filled with coagulated mucus, containing a number of small round cells resembling leucocytes; while the epithelial cells are said to show numerous mucigenous granules,

' Serralach and Parès, "Quelques données sur la Physiologie de la Prostate et du Testicule," C. R. de la Soc. Biol., vol. Ixiii., 1908.

${ }^{2}$ Griffiths, "Observations on the Function of the Prostate Gland in Man and the Lower Animals," Jour. of Anat. and Phys., vol. xxiv., 1890. 
especially in the inner or lumen half, but also, though less markedly, in the outer half of each cell ( $c f$. de Bonis' description of the dog's prostate referred to above). ${ }^{1}$

The prostatic secretion is expelled into the urethra during the sexual act by the contraction of the sheath of non-striped muscle which surrounds each tubule throughout its entire length.

It has been shown in both Man and animals that the growth of the prostate is dependent upon the growth of the testes, since it remains of small size until the time of puberty, when the generative system reaches its full development. In those abnormal cases in which testicular growth is arrested, the prostate remains in a condition of rudimentary development. Moreover, it has been shown that the prostate in Man normally undergoes atrophy in old age (see p. 676), or as a result of castration, becoming transformed after a few years into a mass of fibrous connective tissue containing a small number of scattered muscle fibres in a state of degeneration. It has been found also that the prostatic tubules disappear almost entirely in castrated animals, and what is left of the epithelium completely loses its secretory function ${ }^{2}$ (cf. p. 303). De Bonis' experiments, however, seem to show that the administration of prostatic extract to castrated dogs may lead to a renewal of activity and to the formation of fresh granules in the secretory cells, but this result could not be obtained by employing testicular extract.

\section{CowPER's GLands}

Cowper's glands are situated near the anterior end of the urethra. They are a pair of small tubulo-racemose glands, and communicate with the urethra by two ducts, apertures of which

1 See also Grifliths, "Observations on the Anatomy of the Prostate," Jour. of Anat. and Phye., vol. xxiii., 1889. For the comparative anatomy of the prostate, see Oudemans' Die Accessorischen Geschlechtsdrisen der Sïugethiere, Haarlem, 1892. According to this authority, the hedgehog lias two pairs of prostates. The homologies of these glands in Insectivores still seem to be obscure. See below, under Cowper's glands.

2 Grifliths, loc. cit. Cf. also Griffiths, "The Condition of the Testes and Prostate Gland in Eunuchoid Persons," Jour. of Anat. and Phys., vol. xxviii., 1893 ; Walker (G.), "Experimental Injection of Testicular Fluid to prevent the Atroplyy of the Prostate Gland after the Removal of the Testes," Johns Hopkins Hospital Bull., vol. xi., 1900; Wallace (Cuthbert), "Prostatic Enlargement," Loudon, 1907 ; de Bonis, loc. cit. 
(in the human subject) are about two inches below the openings of the vasa deferentia. The lobules of the glands are surrounded by a firm investing membrane which contains muscular tissue. They are lined internally by a secretory epithelium.

The significance of the viscous secretion which these glands produce is still unknown. It has been suggested that it serves to cleanse the urethra of urine or semen. Since it is poured out in considerable quantity during coitus, and appears sometimes to precede the ejaculation of the actual semen, it is not impossible that the secretion of these glands may possess the special function of ridding the urethra of all traces of urine preparatory to the passage of the spermatozoa. The glands of Littré or Morgagni, which beset the whole lining membrane of the urethra, except near the external orifice, probably serve the same purpose as Cowper's glands. ( $C f$. prostate, footnote ${ }^{3}$, p. 236.)

According to Nagel, ${ }^{1}$ Cowper's glands are of the normal dimensions in castrated men, and consequently should not be regarded as purely sexual organs. On the other hand, Schneidemühl, ${ }^{2}$ whom Nagel quotes, says that in animals they atrophy after castration. Griffiths ${ }^{3}$ describes these glands in the hedgehog and the mole as undergoing periodic changes similar to those of the prostate glands. In the hedgehog the secretion is abundant during the summer (i.e. in the breeding season), and possesses a disagreeable and penetrating odour. According to Gley, ${ }^{4}$ the secretion in this animal contains a ferment which causes the fluid of the vesiculæ seminales to clot, so that Cowper's glands in the hedgehog are the physiological equivalent of the prostate gland in the Rodentia."

1 Nagel, "Physiologie der Männlichen Geschlechtsorgane," Nagel's Handbuch der Physiologie des Menschen," vol. ii., Braunschweig, 1906.

2 Schneidemuihl, "Vergleichende Anatomische Untersuchungen über denfeineren Bau der Cowperschen Drüse," Deutsche Zeitschr. f. Tiermedizin, vol. vi., 1883.

${ }^{3}$ Griffiths, "Observations on the Function of the Prostate Gland," \&c., Jour. of Anat. and Phys., vol. xxiv., 1890.

" Gley, "Rôle les Glandes génitales accessoires dans la Reproduction," Nel primo Centenario dalla Morte di Iazzaro Spallanzani Acad. Sci. e Stranieri, 1899.

5 It should be mentioned that very considerable doubt has been thrown on the homology of what are often called Cowper's glands (those presumably referred to by Gley and Griffiths) in the hedgehog with the glands known by that name in other Mammals. According to Leydig ("Zur Anatomie der 
Furthermore, Stilling ${ }^{1}$ states that the epithelium of Cowper's glands undergoes definite histological changes which depend upon the occurrence of coitus. ${ }^{2}$

Corresponding to Cowper's glands in the male there are in the female a pair of small glands situated one on each side of the vagina. These are the glands of Bartholini or Duverney. Their ducts open out on to the vulva, on the sides of the vaginal orifice. These glands secrete a viscid fluid which helps to moisten and lubricate the surface of the vulva.

In addition to the accessory male glands described above, there are, in many animals, other glands (perineal, inguinal, and preputial) which are probably sexual, inasmuch as they are believed to serve as means of attraction between the sexes during the breeding season. ${ }^{3}$. Most of these glands emit secretions of a musky odour, which in the vast majority of cases is peculiar to the male, and very often to the male during the rutting season only. Amongst the animals in which this peculiarity occurs are the musk deer and other kinds of deer and antelopes, the musk rat, the hamster, and many other Rodentia

Männlichen Geschlechtsorgane und Analdrüsen der Säugethiere," Zeitschr.f. wiss. Zool., vol. ii., 1850), Cowper's glands in the hedgehog are in reality represented by a pair of glands embedded in the urethral muscle (ef. Oudemans, loc. cit.). The so called Cowper's glands, which, as mentioned above, undergo marked cyclical changes, are situated outside the pelvis close to the ischial tuberosity and the base of the penis (Linton, "A Contribution to the Histology of the so-called Cowper's Glands of the Hedgehog," Anat. Anz., vol. xxxi., 1907). In the absence of embryological evidence, Linton appears to regard these glands as sui generis. They are shown by this author to be composed of two distinct kinds of secreting acini, one lined by a single layer of columnar epithelial cells, and the other by many layers of polyhedral cells. Both kinds secrete a considerable quantity of fluid, containing circular bodies which are believed to be the nuclei of disintegrated cells, though no cells in process of disintegration could be found in the single-layered type of acinus.

'Stilling, "Über die Cowperschen Drüsen," Virchow's Arch., vol. c., 1885.

${ }^{2}$ For an exhaustive account of the minute anatomy of the accessory glands and ducts of the male reproductive system in the different groups of Vertebrata, with full references to the literature, see Dissellorst in Oppel's Lehrush, loc. cit.

3 Tiedemann, Comparative Physiology, English Translation, London, 1834 ; Grosz, " Beiträge zur Anatomie der Geschlechtsdrüsen der Insektivoren und Nager," Arch. f. Mikr. Anat., vol. 1xvi., 1905. See also description of prepuce (p. 242). 
and Insectivora. The temporal gland of the elephant is also stated to emit a sexual secretion, especially in the male during rut.

\section{The Copulatory Organ}

The penis is the intromittent organ of copulation. Besides serving to conduct the urine to the exterior through the chamnel of the urethra, it has the further function of conveying the semen into the genital passages of the female. This latter function is dependent upon its power of erection under the influence of sexual excitement.

The erectile tissue of the penis is contained chiefly in three tracts, the two corpora cavernosa, which are situated one on each side and are united in the middle line, and the smaller corpus spongiosum, which is placed inferiorly and surrounds the urethral passage. The corpora cavernosa are enclosed by an investment, containing plain muscle fibres, numerous well-developed elastic fibres, as well as bundles of white fibres. Trabeculæ pass inwards from the fibrous sheath and cross the cavities of the cavernous bodies, dividing them into interstices which are filled with venous blood, being, in fact, greatly enlarged vessels. The corpus spongiosum is similar in structure, but its fibrous framework is not so well developed. The canal of the urethra is surrounded by plain muscle fibres. Muscular tissue is also present in the external coat of the spongy body, and in the trabeculæ.

At their proximal ends the three corpora are enlarged into bulbs. Those of the cavernous bodies are covered by the ischio-cavernosi muscles (or erectores penis), while the bulb of the spongy body is surrounded by the bulbo-cavernosus muscle (or ejaculator urinæ). At its distal end the corpus spongiosum becomes enlarged, forming the glans penis, which is identical in structure with the rest of the body.

The integument of the penis in the region of the glans becomes doubled in a loose fold. This is the prepuce or foreskin. Numerous sebaceous glands are present near the free margin of the prepuce. These glands emit an odoriferous secretion which in some animals is especially marked during the season of rut. ${ }^{1}$

1 Courant, "Über die Präputialdrüsen des Kaninchens und über Veränderungen derselben in der Brunstzeit," Arch. f. Mikr. Anat., vol. lxii., 1903. 


\section{MALE ACCESSORY REPRODUCTIVE ORGANS 243}

The penis is very sensitive to external stimulation, its surface being beset with simple and compound end-bulbs and Pacinian corpuscles, especially in the region of the glans. Its innervation is described below.

The arteries of the penis are the internal pudic arteries and the dorsal artery. Some of the arterial branches project into the intertrabecular spaces of the corpora cavernosa, and

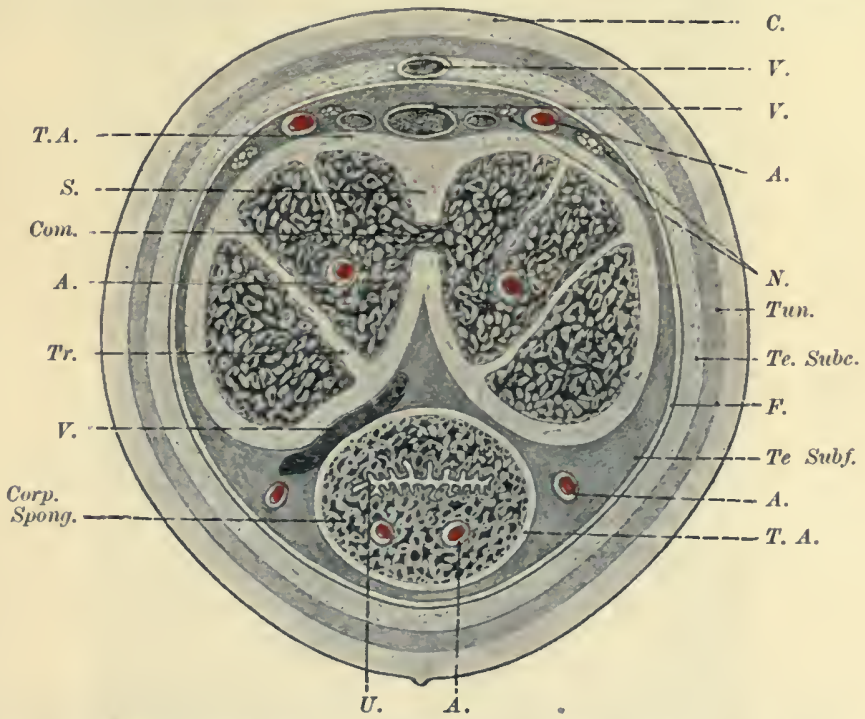

FIG. 58. - Transverse section through adult human penis. $\times 3$. (After Eberth, from Nagel.)

$A$., artery; $C$., cutis; Com., communication between the two corpora Cavernosa ; Corp. Spong., corpus sponglosum; $F$., fascia; $N$., nerves ; $S$. , septum; T. A., tunica albuginea; Te. Subc, tela subcutanea penis; Te. Subf., tela subfascialis; Tun, tunica dartos penis ; $T r_{.}$, trabecula of corpus cavernosum; $U$., urethra ; $V$., veins.

form coiled dilated vessels which are known as the helicine arteries. In most cases the arteries are said to open into the venous spaces, through the intervention of capillaries, but a few of the smaller arteries are stated to communicate directly with the cavernous veins. The blood is carried away by two sets of veins, the one set uniting to form the dorsal vein, and the other communicating with the prostatic plexus and the pudendal veins. 


\section{THE PHYSIOLOGY OF REPRODUCTION}

When the venous spaces in the erectile tissue are distended with blood the organ erects, becoming hard and rigid in condition. It is this power of erection which enables the penis to function as an intromittent organ during copulation.

The above description applies more especially to the copulatory organ in Man. In the other groups of Mammals it has essentially the same structure, but presents sundry modifications in the different orders. ${ }^{1}$ In the Monotremata,

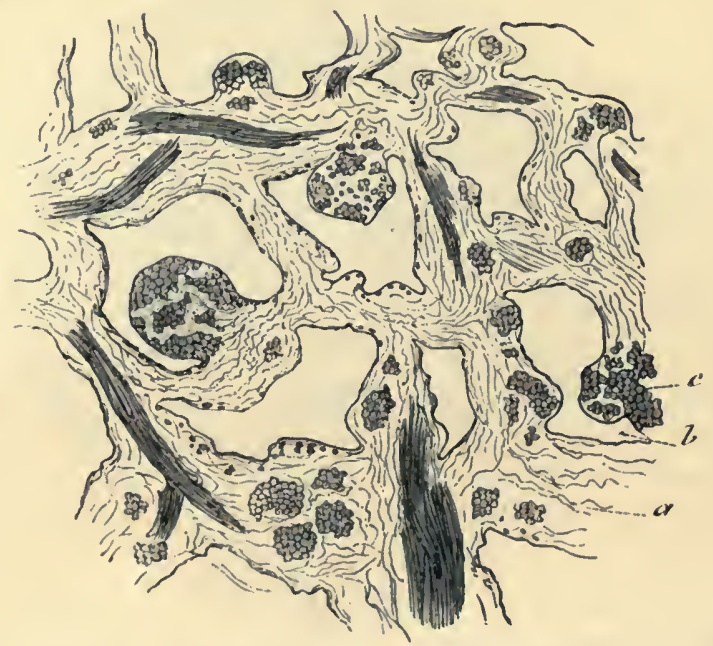

Fic. 59.-Section through erectile tissue. (After Cadiat, from Schäfer.) $a$, trabeculie ; $b$, venous spaces ; $c$, muscular fibres cut across.

however, there is no corpus spongiosum. ${ }^{2}$ In some Mammals (Carnivora and Rodentia) the penis is provided with a

1 For an account of the structure of the copulatory organ in the various groups of Vertebrates, with notes on the different modes of copulation and bibliography, see Gerhardt, "Morphologische und biologische Studien über die Kopulationsorgane der Säıgethiere," Jenaische Zeitschr. f. Naturwissenschaft, vol. xxxix., 1905.

2 The penis of the Monotreme is perforated by a canal, through which the semen passes but not the urine. When in a relaxed state the organ lies in a little pouch in the floor of the cloaca, from which it projects when erected. The cloaca is the single common chamber througl which the freces and urine pass to the exterior, as in birds and reptiles. In birds the penis is either altogether absent or else is "rudimentary (Crax, Cryptume, Lamellirostres, Ratitæ), Disselhorst, " Gewichts- und Volumszunahme der männlichen Keimdrüsen," \&c., Zool. Anz., vol. xxxii., 1908. 


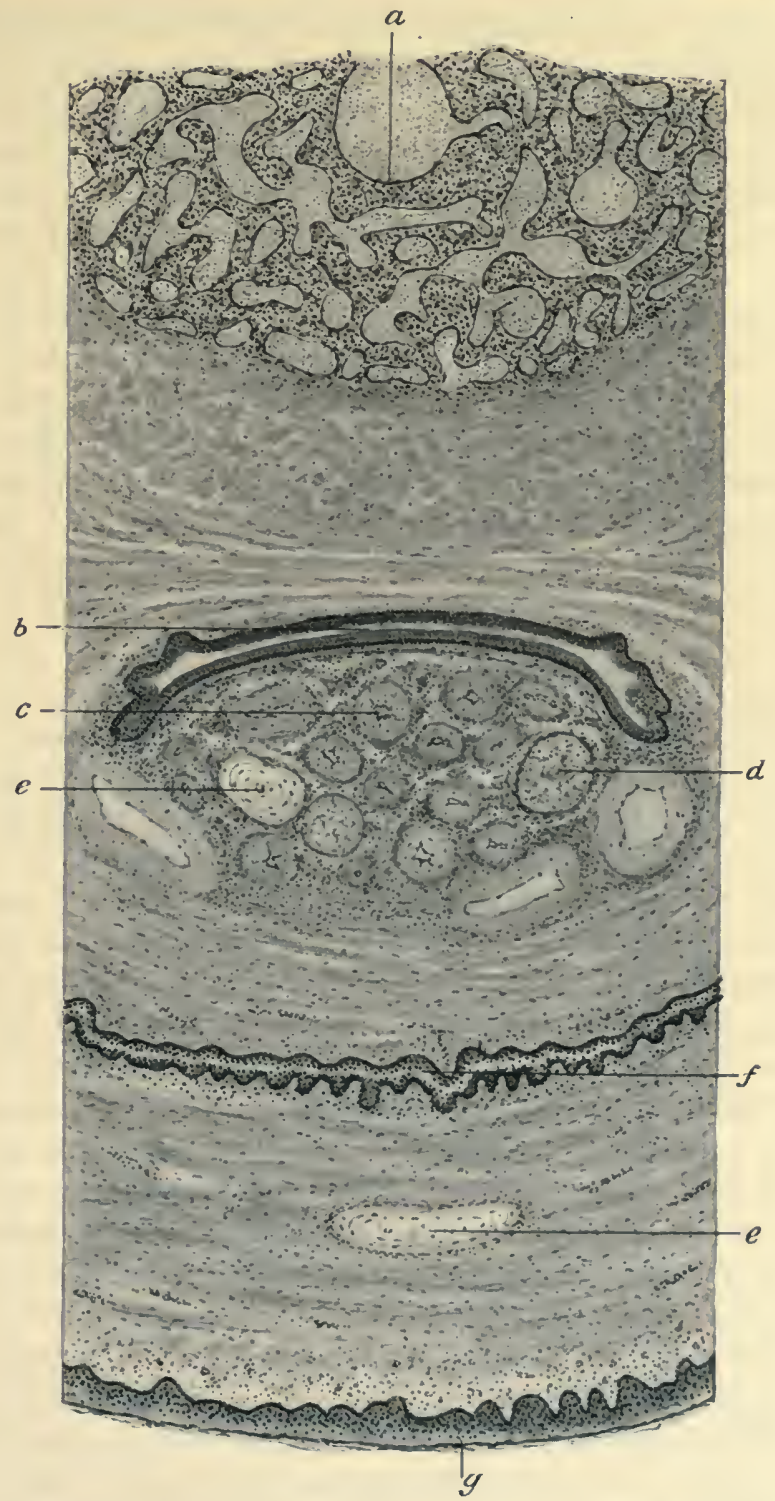

F1G. 60.-Part of transverse section through penis of monkey.

$a$, erectile tissue ; $b$, urethra ; $c$, artery ; $d$, nerve ; $e$, Pacinian body ; $f$, fold of epithelium; $g$, surface epithelium. 
cartilaginous or bony support, the os penis, which is developed especially in the region of the glans. It is particularly large in the walrus. In the Cetacea the penis is often of enormous size (six feet in length in some species), and terminates in a point, but is otherwise normal. It can be withdrawn into the body when not being used. In copulation, whales apply their ventral surfaces to one another.

In most Rodents and Marsupials the penis in the relaxed state is withdrawn within an eversible fold of skin which constitutes a dermal sac. When the penis is erected this sac is everted, and forms its outer integument. Cole has described the structure of the intromittent sac in the male guinea-pig, which appears to be typical of many other Rodents. ${ }^{1}$ Dorsal to the urethral aperture when the penis is withdrawn, and ventral to it when it is everted, is seen the entrance to the intromittent sac. Lying in the cavity of the sac are two horny styles. Two dorsal longitudinal folds are also noticeable. These are the backward prolongations of the lateral lips of the urethral aperture, the ventral lip consisting of corpus spongiosum and separating the aperture of the urethra from that of the sac. Attached to the base of the sac are two retractor organs which consist of elastic fibres and erectile tissue, and are connected at their other extremities with the integument of the penis. The eversion of the sac is brought about by the erection of the two longitudinal folds referred to above. The whole of the sac is composed largely of erectile tissue, but the tissue of the longitudinal folds is even more highly erectile than the rest of the sac. The entire structure is provided with a very rich nerve supply. When the penis is erect, and the sac everted, the two horny styles are protruded externally to a considerable length. Moreover, both the sac and the surface of the glans are covered with sharp spine-like structures, while in some species of Caviidre they are provided also with two sharp horny saws which are appended to the sides of the penis farther back. There can be little doubt that the purpose of this unique contrivance is to act as an exciting organ on the sexual structures of the female.

1 Cole, "On the Structure and Morphology of the Intromittent Sac of the Male Guinea-pig," Jour. of Anat. and Phys., vol. xxxii., 1898. 


\section{MALE ACCESSORY REPRODUC'IIVE ORGANS 247}

In another rodent, the marmot, according to Gilbert ${ }^{1}$ the skin which covers the os penis becomes torn away during the rutting season, so that the bone projects freely beyond the end of the glans and is then used as a stimulating organ.

Structures which project from the penis, and are probably employed as sexual irritants, are also found in the rhinoceros, the tapir, and certain other animals.

In the cat the glans is beset with callous retroverted papillæ, which no doubt serve the same function. They are present also in the lion and tiger, but are of smaller size. ${ }^{2}$

Perhaps the most curious modifications presented by the mammalian organ of copulation are those found in certain species of Ruminants. In the sheep, the gazelle, the giraffe, and a number of antelopes, there is a long filiform process

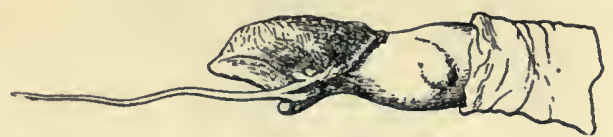

FIG. 61.-Distal end of ram's penis, as seen from the left side, showing glans and filiform appendage. The prepuce is folded back. Slightly reduced.

attached to the end of the organ and traversed by the urethral passage. In some forms the process arises medially (the penis being symmetrical); but in others, such as the sheep, it is attached to the left side of the organ, the distal end of which appears to have undergone some sort of torsion. ${ }^{3}$ The urethra opens to the exterior at the extreme end of the filiform appendage. This structure-which has been investigated, especially in the case of the sheep ${ }^{4}$-is composed largely of erectile tissue which surrounds the urethra, and may be regarded as an extension of the corpus spongiosum. Outside the erectile tissue is a well-marked muscular layer which lies next to the integument. The process is supported by a pair of fibro-cartilage bodies,

1 Gilbert, "Das Os priapi der Säugethiere," Morph. Jahrbuch, vol. xviii.

2 Owen, On the Anatomy of Vertebrates, vol. iii., London, 1868.

${ }^{3}$ Garrod, "Notes on the Osteology and Visceral Anatomy of Ruminants," Proc. Zool. Soc., vol. xlv., 1877.

4 Nicolas, "Sur l'Appareil Copulateur du Bélier," Jour. de l'Anat. et la Phys., vol. xxiii., 1887. Marshall, "The Copulatory Organ in the Sheep," Anat. Anz., vol. xx., 1901. 
placed one on each side of the urethra and extending throughout the whole length of the structure.

The fact that the filiform prolongation is an erectile organ points to the conclusion that its function is insertion into the os uteri during copulation. An examination of the uterus in the sheep shows that the os, when open, is fully large enough to admit of the entrance of the distal portion of the penis in the region of the glans. If the extreme distal end does so enter, the filiform process must extend into the cavity as far, or

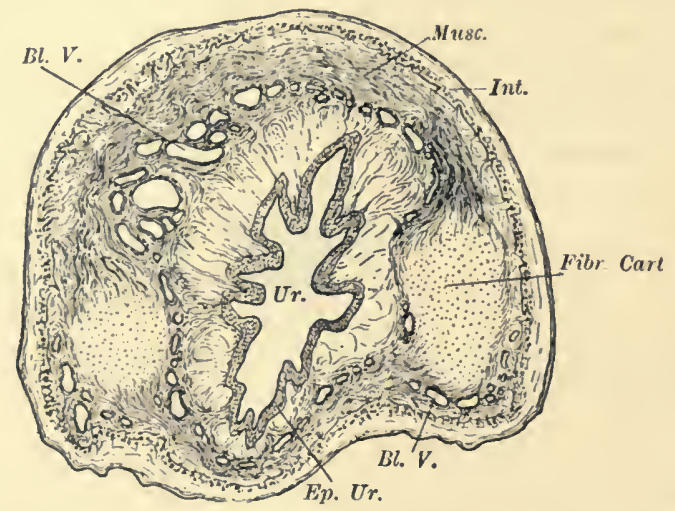

FIG. 62.-Transverse section through filiform appendage of ram, about a quarter its length from the tip. $\times 45$.

$B l$. V., blood-vessels; $E p$. Ur., epithelium surrounding urethral cavity; Fibr. Cart., fibro-cartilage; Int.. integument; Musc., muscular layer; Ur., urethra.

nearly as far, as the junction of the relatively short corpus uteri with the two cornua. That the appendage functions in the manner described seems additionally probable in view of the fact, to which sheep-breeders attest, that if the process is cut off the ram is rendered barren. Professor Robert Wallace informs me that it used to be a regular practice, for the protection of ewes while being driven south from the Highlands of Scotland, to cut off the filiform appendage from the rams to prevent them from impregnating the ewes on the way, this method of inducing sterility proving quite as effective as removal of the testicles. 


\section{MALE ACCESSORY REPRODUCTIVE: ORGANS 249}

In the bull, the musk ox, and some other Ruminants the filiform process is vestigial.

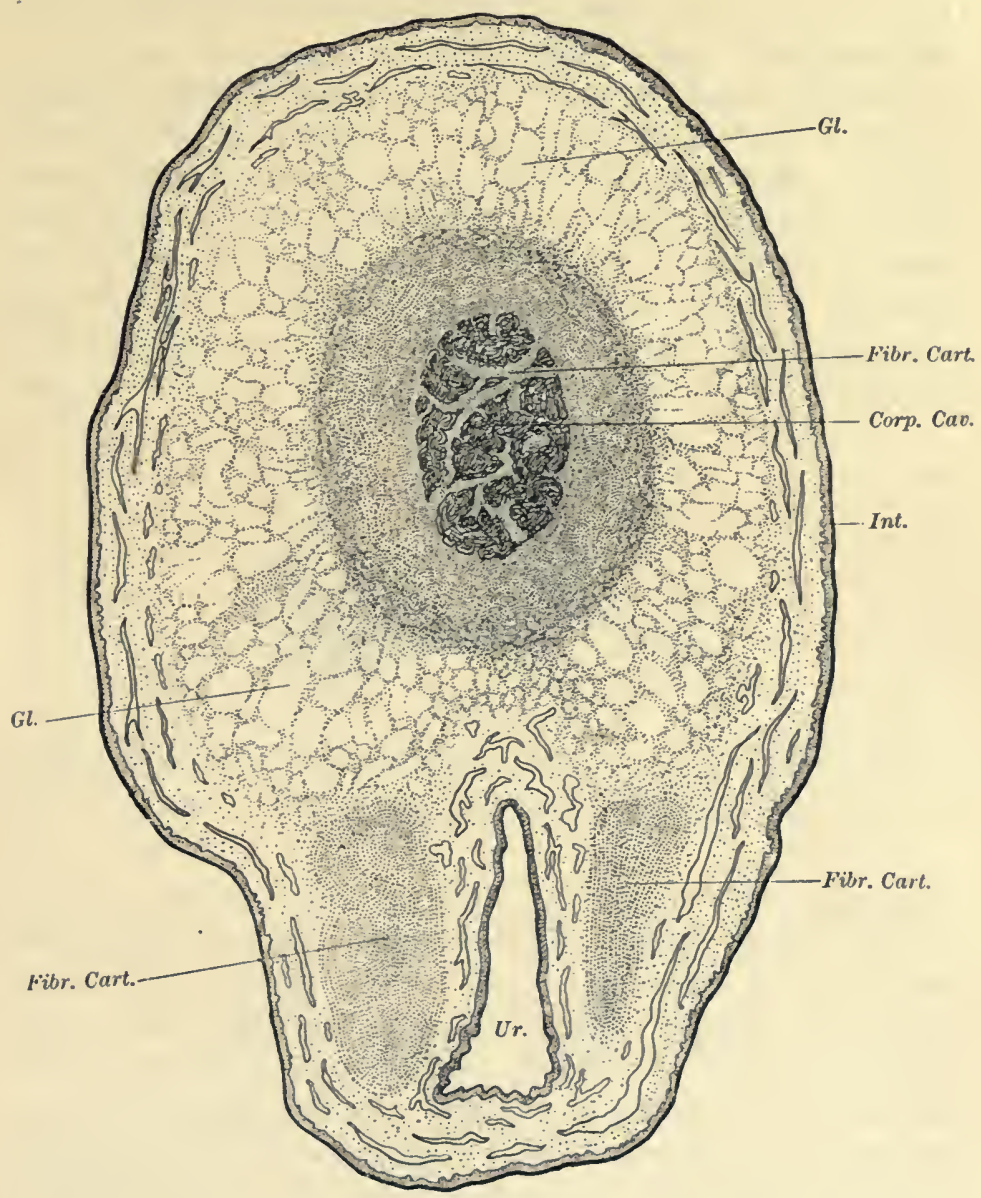

FIG. 63. - Transverse section through the middle of the glans penis of the ram. $\times 45$.

Corp. Cav., corpus cavernosum ; Fibr. Cart., fibro-cartilage; Gl., erectile tissue of glans; Int., integument ; Ur., urethra.

The penis in the male mammal is represented in the female by the diminutive clitoris. This organ, however, is not traversed by the urethra (at least in the majority of animals). 
On the other hand, the corpora cavernosa and the glans are represented by homologous structures. The clitoris, like the penis, contains very numerous sensory nerve endings ${ }^{1}$ and undergoes erection during sexual congress.

The relation between the clitoris and the uro-genital canal is closer in some Mammals than in others. In some species (e.g. the capybara among the Rodents, and Tupaia among Insectivores) the clitoris is of considerable size, and is grooved along its under surface in relation to the upper wall of the urethra. In other animals (e.g. Arvicola, Talpa, and Stenops) the groove on the under surface of the elongated clitoris is converted by the coalescence of its margins into a tube, which

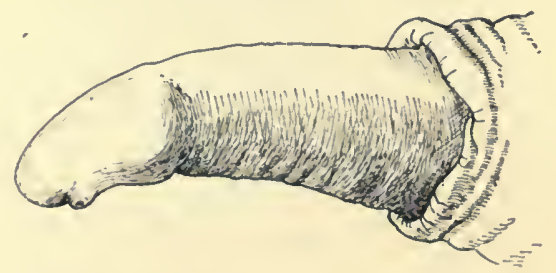

FIG. 64.-Distal end of bull's penis as seen from left side, showing glans and urethral papilla representing vestigial filiform appendage. The prepuce is folded back. About two-thirds natural size.

constitutes the urethral portion of the uro-genital canal. Further, in the female of the spotted hyena ( $H$. crocuta), the whole of the uro-genital canal, beyond the apertures of the ducts of Bartholini's glands, is prolonged forward to the extremity of the clitoris and terminates in a similar manner to that of the urethra of the male. In this animal, therefore, the vagina is completely absent, the os uteri opening directly into the uro-genital canal, which is elongated and tubular in form as in the male. A somewhat similar condition has been known to occur abnormally in the human female. ${ }^{2}$

1 Worthmann, "Beiträge zur Kenntniss der Nervenausbreitung in Clitoris und Vagina," Arch.f. Mikr. Anat., vol. Ixviii.

2 Watson (M.), "The Homology of the Sexual Organs illustrated by Comparative Anatomy and Pathology," Jour. of Anat. and Phys., vol. xiv., 1879. 


\section{The Mechanisms of Erection, Ejaculation, and Retraction.}

The erection of the penis is brought about mainly by the dilatation of its blood-vessels. First of all the bulbous (proximal) part of the organ increases in size, and then the swelling extends throughout the cavernous bodies, and eventually to the glans. If the penis is cut across when in a state of relaxation only a small quantity of venous blood exudes from the wound; but if the same operation is performed during erection, the blood flow is enormously increased, while simultaneously becoming bright and arterial in colour. ${ }^{1}$ François-Franck, ${ }^{2}$ observed a corresponding rise in the arterial and venous tension. $\mathrm{He}$ found also that the organ in the process of erection became very considerably swollen in size before the increase in the blood pressure had extended to the veins. Lovén ${ }^{3}$ showed that the veins in the penis are traversed by five times as much blood during erection as they are in a state of repose. The same investigator found that, whereas the ordinary arterial pressure in the penis is about half that of the carotid, during erection it rose to three-fifths that of the carotid. The increase in the amount of blood in the organ is accompanied by a rise of temperature. ${ }^{4}$

There can be no doubt that the erection of the penis is brought about partly through the contraction of the ischiocavernosus (or erector penis) and bulbo-cavernosus muscles, certain of the fibres of which pass over the efferent vessels, and so arrest the outward flow of blood. ${ }^{5}$ The result of this contraction

1 Eckhard, "Untersuchungen über d. Ercktion d. Pcnis beim Hunde," Beitr. zur Anat. und Phys., vol. iii., Giessen, 1863.

2 François-Franck, " Recherches sur l'Innervation Vaso-motrice du Pénis," Arch. de Phys., 1895.

${ }^{3}$ Lovén, Berichte über die Verhandlungen der Königl. Sächs. Gesell. zu Leipzig, vol. viii., 1866. Nikolsky, "Ein Beitrag zur Physiologie des Nervi erigentes," Arch. f. Anat. u. Phys., Phys. Abth., 1879.

"Rettcrer, Article on " Erection," in Richet's Dictionnaire de Physiologie, vol. v., 1902.

${ }^{5}$ De Graaf (Regner), De Virorum Organis Generationi Inservientibus, Geneva, 1785. Günther, Untersuchungen und Erfahrungen aus dem Gebiete der Anatomie, vol. i., Hanover, 1837. Kobelt, De l'Appareil du Sens Génital des Deux Sexes, Strasbourg, 1851. For further references, see Retterer, loc. cit. 
is, that whereas the blood can freely enter the dilated vascular spaces of the penis, its exit is retarded, while this leads to a further distension of the vessels, the venous outlets of which become still more compressed.

Although the muscular mechanism of the penis unquestionably assists in the erection of that organ, it is equally clear that it is incapable by itself of causing that phenomenon, since erection cannot be induced by ligaturing the efferent veins. Moreover, the penis can be made to erect in animals in which the muscular mechanism has been paralysed by the injection of curari, but the erection in such cases is incomplete.

It is stated also that the smooth or unstriated muscle fibres, which are scattered throughout the trabecular framework of the corpora, participate in the process of erection, but there has been some disagreement as to the precise part they play. Kölliker ${ }^{1}$ suggested that their action is temporarily inhibited, and that the relaxation of the trabeculæ, which consequently follows, permits the vascular spaces to distend. According to Valentin, ${ }^{2}$ these muscles contract, and in so doing cause a dilatation of the walls of the vessels, which thereby increase in volume. Langley and Anderson's observations, which support Kölliker's suggestion, are described below in giving an account of the nervous mechanisms of erection and retraction.

It is obvious, however, that in those cases in which the penis remains erected for a considerable time a constant circulation must be maintained through both the afferent and the efferent vessels of the organ.

In some animals (dog, cat, horse, hedgehog), but not in the rabbit or Man, the penis possesses an accessory muscle. This is called the retractor penis. It consists of a thin band of longitudinally arranged, unstriated fibres, inserted at the attachment of the prepuce, and continued backwards in the middle line over the ventral surface of the corpus spongiosum to the bulbous part of the urethra, where it divides into two halves which separate on either side of the anus. Some of the fibres are continuous with a portion of the bulbo-cavernosus of the same side, while others are connected with the wall of the urethra.

1 Kölliker, Verhandl. der Würzburger Phys. Med. Gesell., vol. ii., 1851.

2 Valentin, Lehrbuch der Physiologie, vol. ii., 1844. 
When it contracts it causes a marked dorsal curvature of the penis. ${ }^{1}$

Although the sexual orgasm is usually accompanied by a high degree of mental excitement, it is essentially a reflex action, and can take place when all connection with the brain is severed by transection of the spinal cord. It is generally believed that the centre for erection lies in the lumbo-sacral region of the cord. ${ }^{2}$ Numerous experiments have been recorded which prove conclusively that it is not situated in the upper part of the cord or in the brain. Thus, Goltz ${ }^{3}$ showed that transection of the spinal cord above the lumbar region did not destroy the reflex. Brachet ${ }^{4}$ also has recorded the occurrence of ejaculation under a similar condition. According to Müller, ${ }^{5}$ only the lower part of the cord need be retained in order to preserve the erection reflex, since this is still present after the complete destruction of the cord in the whole of the lumbar and the upper part of the sacral region. Müller was able to induce erection in a dog, which had undergone this operation, by rubbing the surface of the penis.

It is known, however, that erection (and even ejaculation)

1 Langley and Anderson, "The Innervation of the Pelvic and Adjoining Viscera: Part III. The External Generative Organs," Jour. of Phys., vol. xix., 1895. The retractor muscle is remarkable for its sensitiveness to changes of temperature, and at the same time for being unusually tenacious of life. It can be cut out of the body and preserved in blood serum, in a cool place, for days at a time, and afterwards, on warming, will relax and undergo spontaneous contractions. At a temperature of $40^{\circ} \mathrm{C}$. it is quite placid; but, on cooling slightly, it will shorten, and not infrequently enter into a series of slow rhythmic contractions. If cooled to $15^{\circ} \mathrm{C}$. it will contract to about one quarter of its original length. (Sertoli, "Contribution à la Physiologie Génèrale des Muscles lisses," Arch. Ital. de Biol., vol. iii., 1883; Gruenhagen, " Das Thermotonometer," Pflüger's Arch., vol. xxxiii., 1884. See also Fletcher, "Preliminary Note on the Motor and Inhibitory Nerve-Endings in Smooth Muscle," Proc. Phys. Soc., Jour. of Phys., vol. xxii., 1898.)

"See Onuf, "Notes on the Arrangement and Function of the Cell Groups in the Sacral Region of the Spinal Cord," Jour. of Nervous and Mental Diseases, 1899.

"Goltz, "Ueber das Centrum der Erectionsnerven," Pfüger's Arch., vol. vii., 1873. See also Goltz and Frensberg, "Ueber die Functionen des Lendenmarks des Hundes," Pflüger's Arch., vol. viii., 1874.

- Brachet, Recherches expérimentales sur les Fonctions du Système Nerveux Ganglionaire, Paris, 1839.

5 Müller, "Klinische und Experimentelle Studien über die Innervation der Blase," \&c., Deutsche Zeitschr. f. Nervenheilk., vol. xxi., 1902. 
can also be induced voluntarily by stimuli conveyed from the brain (i.e. by sexual emotion). It is interesting to note, therefore, that Budge ${ }^{1}$ and Eckhard ${ }^{2}$ were able to cause the penis to erect by electrical stimulation of the cervical cord, the pons, and the crura cerebri. The same result was obtained by Pussep by exciting a definite region in the cerebral cortex. In this case erection was followed by ejaculation. ${ }^{3}$

It is stated also that hanging and decapitation in Man are sometimes followed by erection. ${ }^{4}$ According to Spina, ${ }^{5}$ who experimented on the guinea-pig, section of the spinal cord, near the last costo-vertebral articulation, is invariably succeeded by erection and ejaculation.

There are certain facts which seem to show that the higher nerve centres exercise an inhibitory influence over the sexual processes. Thus, Retterer ${ }^{6}$ states that it is easier to induce erection by external irritation in a dog whose spinal cord has been cut through, than in a normal animal.

Eckhard ${ }^{7}$ was the first to show that the penis in the dog could be induced to erect experimentally by the stimulation of certain nerves which he called the nervi erigentes. These nerves, which are truly vaso-dilator, were found in the dog to arise from the 1st and 2nd sacral nerves, and in some cases from the 3rd sacral nerve also. Gaskell ${ }^{8}$ showed that in the rabbit the erector fibres leave the spinal cord by the anterior (and not by the posterior) roots of the 2 nd and 3 rd sacral nerves. Morat ${ }^{9}$ also

1 Budge, "Ueber das Centrum genitospinale des Nervus sympatheticus," Virchow's Archiv, vol. xv., 1858.

2 Eckhard, loc. cit.

"Pussep, "Ueber die Gehirnzentren der Peniserektion und des Samenergusses," Inaug.-Dissert., St. Petersburg, 1902. Abstract in Le Physiologiste Russe, vol. iii., 1904.

"Götz, "Über Erektion und Ejaculation bei Erhängten," Inaug.-Diss., Berlin, 1898.

B Spina, "Experimentelle Beiträge zu der Lehre von der Erektion und Ejaculation," Wiener Med. Blätter, 1897.

${ }^{6}$ Retterer, Article "Erection," in Richet's Dictionnaire de Physiologie, vol. v., Paris, 1902.

7 Eckhard, loc. cit.

${ }^{8}$ Gaskell, "On the Structure, Distribution, and Function of the Nerves which Innervate the Visceral and Vascular Systems," Jour. of Phys., vol. vii., 1886:

- Morat, "Les Nerfs Vaso-dilatateurs et la Loi de Majendie," Arch. de Phys., 1890. 
found that in the dog these fibres are contained only in the anterior roots of the 1st and 2nd sacral nerves.

The corresponding parts in the female are similarly innervated. Thus, Langley ${ }^{1}$ has described stimulation of the sacral nerves in the vertebral canal of the rabbit as producing dilatation and flushing of the vulva. These effects were most marked on exciting the 3 rd and 4 th sacral nerves. The stimulation of the 1st and 2nd sacral nerves, on the other hand, generally produced contraction and pallor. Langley obtained similar results in experiments on the male rabbit, the stimulation of the sacral nerves causing either protrusion and flushing of the penis, or else retraction and pallor.

Nikolski ${ }^{2}$ had previously stated that, on stimulating the anterior ramus of the nervus erigens (or the ramus from the 1st sacral) in the dog, he obtained a vaso-constrictor instead of a vaso-dilator effect, thus differing from Eckhard and other investigators.

Sherrington ${ }^{3}$ found that in the male monkey excitation of the 2nd and 3rd sacral nerves produced moderate erection, and that of the 1st sacral only slight erection. In the female monkey the effects of stimulating the 3rd sacral were usually greater than in the case of the 2nd, while the 1st sacral produced no certain effects. Similar results were observed in experimenting on the cat, but in this animal stimulation of the 1st sacral nerve appears to have had a more marked effect.

François-Franck ${ }^{4}$ found that the anterior ramus from the 1st sacral, was capable of causing both vaso-constriction and vaso-dilatation. This investigator noticed further that both effects could be produced by stimulating the hypogastric nerves, but that the vaso-dilator action was more pronounced.

Budge ${ }^{5}$ also described erector action from the hypogastrics in the rabbit. Langley and Anderson, ${ }^{6}$ however, were unable

1.Langley, "The Innervation of the Pelvic Viscera," Proc. Phys. Soc., Jour. of Phys., vol. xii., 1891.

${ }^{2}$ Nikolski, loc, cit.

s Sherrington. "Notes on the Arrangement of some Motor Fibres in the Lumbo-Sacral Plexus," Jour. of Phys., vol. xiii., 1892.

"François-Franck, loc. cit.

5 Budge, loc. cit.

- Langley and Anderson, "The Innervation of the Pelvic and Adjoining Viscera," Jour. of Phys., vol. xix., 1895. 
to confirm this statement, but they found that the hypogastrics sometimes contained constrictor fibres for the external generative organs.

They state that they could discover no satisfactory evidence of the presence of vaso-dilator fibres in any of the upper or lumbar set of nerves. It would appear, therefore, that the vaso-dilator function is probably confined to the lower or sacral set of nerves.

Following Langley and Anderson's description, the fibres from the sacral set of nerves may be divided into two groups or classes, the visceral and the somatic. Stimulation of the visceral fibres (which run in the nervi erigentes) produces dilator effects on the vessels of the penis (and vulva), as already described. It also causes inhibition of the unstriated muscles of the penis, the retractor muscle of the penis (when present), and the unstriped muscles of the vulva (in the female). The somatic sacral nerves send motor branches to the ischio-cavernosuis and bulbo-cavernosus muscles, as well as to the constrictor urethræ or deeper muscular stratum of the perineum. In the female they innervate the erector clitoridis, which represents the ischiocavernosus, and the sphincter vaginæ, which embraces the lower end of the vagina, and is the homologue of the bulbocavernosus. The sacral nerves, as far as Langley and Anderson ${ }^{1}$ were able to determine, send no visceral fibres by their somatic branches.

The same investigators found that stimulation of the upper or lumbar set of nerves produced strong contraction of the vessels of the penis, ${ }^{2}$ as well as contraction of the retractor muscle, and of the other unstriated muscles of the penis, prepuce, and scrotum (dog, cat, and rabbit). The penis underwent marked retraction as a result of the excitation. Stimulation of the 2nd lumbar nerves in the cat generally produced a slight but distinct action on the external generative organs. The 3rd, 4th, and 5th lumbar nerves in many cases had a strong action, but the 6 th had no action. The 1st lumbar and 13th thoracic were found to have a slight action. In the dog stimu-

1 Langley and Anderson, loc. cit.

2 Vaso-constrictor fibres for the penis were first found by Eckhard (loc. cit.) in the nervus dorsalis penis. 
lation of the 5 th lumbar nerve had no effect upon the generative organs, but the 1st lumbar was observed to have a distinct action, and also the 13th and 12 th thoracic. In the rabbit no effect was produced by stimulating the 1st lumbar nerve. The 2nd lumbar had a slight action occasionally, but the 3rd, 4th, and 5 th lumbar nerves always had an effect which was more or less pronounced.

The fibres from the lumbar nerves run in the white rami communicantes to the sympathetic chain, where they take two routes. (a) The majority of the fibres take the course of the pudic nerves (nervi pudendi). They follow the sympathetic chain to the sacral ganglia, from which fibres are given off, and these run in the grey rami communicantes to the sacral nerves. Their further course is by way of the pudic nerves (i.e. in the somatic branches), none apparently running in the nervi erigentes (i.e. to the visceral branches). (b) The second of the courses taken by the lumbar nerve fibres is that by the pelvic plexus. Only a relatively small number, however, take this route. Most of them run in the hypogastric nerves, but a few may join the plexus from the lower lumbar or upper sacral sympathetic chain, or from the aortic plexus. Of these latter, some may join the first root of the nervus erigens, and proceed with it to the pelvic plexus. ${ }^{1}$

It has already been mentioned that the clitoris in the female, like the penis, undergoes erection during coitus. The same is the case with the other parts of the vulva which contain erectile tissue. The friction which is set up between these structures and the glans of the penis causes a reflex discharge of motor impulses in both the female and the male. In the female the uterus undergoes a series of peristaltic contractions, by means of which the semen is sucked into its cavity (see p. 180). Moreover, Bartholini's glands show an increased activity and pour out a viscid secretion. In the male, the sexual impulses culminate in the emission of the semen. This is brought about by a series of muscular contractions, which probably begin in the walls of the vasa efferentia and pass to the canal of the epididymis, and thence along the vas deferens on either side. The vesiculæ seminales contract simultaneously, expelling their

1 Langley and Anderson, loc. cit. 
contents into the vasa, and the mixed fluid passes out through the ejaculatory ducts into the prostatic portion of the urethra. The prostatic muscles also contract, and probably assist in forcing the semen along the urethra, while at the same time expelling the secretion of the prostate glands. Entrance to the bladder is prevented by the erection of the crista urethræ, assisted by the contraction of the sphincter of the bladder, as already mentioned. The final discharge is brought about by the rhythmical contractions of the bulbo-cavernosus and ischiocavernosus muscles, which have the effect of emptying the canal from behind forwards, and so ejecting the semen, mixed with the various glandular secretions, into the vaginal passage of the female.

The innervation of the muscles of the penis has already been described.

The secretory cells of Cowper's glands receive branches from the pudic nerves.

The prostate is innervated by fibres coming both from the nervi erigentes and from the hypogastric nerves. The former are purely motor, whereas the latter are both motor and secretory. Eckhard ${ }^{1}$ found that stimulation of the nervi erigentes in the dog caused the expulsion of the prostatic secretion into the urethra. Loeb ${ }^{2}$ obtained contraction of the prostatic vesicles by excitation of the hypogastric nerves. Mislawsky and Bormann ${ }^{3}$ confirmed both these observations, and found also that stimulation of the hypogastrics, while inducing the muscles to contract, at the same time promoted secretory activity in the glandular cells, the secretion continuing so long as the stimulation was kept up. ${ }^{4}$ Fogge also states that he found hypogastric stimulation to produce contraction of the prostatic muscles. ${ }^{5}$

1 Eckhard, loc. cit.

2 Loeb (A.), "Beiträge zur Bewegung des Samenleiters," Inaug.-Dissert., Giessen, 1866.

${ }^{3}$ Mislawsky and Bormann, "Die Secretionsnerven der Prostata," Zentralbl. f. Phys., vol. xii., 1898.

- Timofeew has described end-bulbs in the prostate, testis, and other male genital organs. Some of these are of a peculiar kind, and are in connection with two nerve-fibres ("Zur Kenntnis der Nervenendigungen in den Männlichen Geschlechtsorganen der Säuger," Anat. Anz., vol. ix., 1894).

s Fogge, "On the Innervation of the Urinary Passage in the Dog." Jour. of Phys., vol. xxviii., 1902. 
Akutsu ${ }^{1}$ has shown that the vesiculæ seminales in the guineapig receive fibres (motor as well as secretory) by the hypogastric nerves. The fibres leave the spinal cord in the 2nd, 3rd, and 4th lumbar nerves.

Budge $^{2}$ showed that it was possible to induce contraction of the vasa deferentia by stimulating the spinal cord at the level of the 4th lumbar vertebra. He observed also that contraction could be caused by stimulating one of the sympathetic ganglia, apparently the inferior mesenteric. ${ }^{3}$

According to Rémy, ${ }^{4}$ stimulation of a small ganglion situated

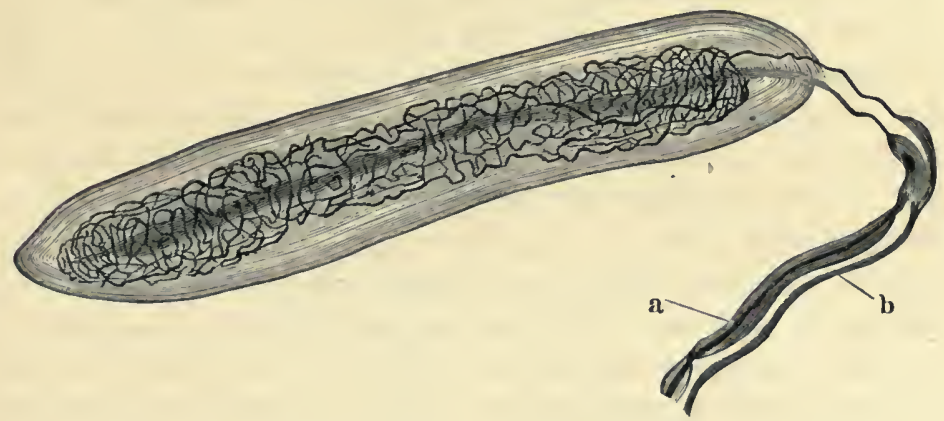

FIG. 65.-End-bulb in prostate. (After Timofeew, from Nagel.)

$a$, thick medullated nerve fibre; $b$, fine medullated nerve fibre.

on the inferior vena cava at the level of the renal veins in the guinea-pig produced a sudden ejaculation.

Loeb $^{5}$ states that he was able to induce contraction of the vasa deferentia by stimulating the hypogastric nerves.

Langley ${ }^{6}$ found that most of the efferent fibres for the vasa deferentia traversed the sympathetic in the region of the 4th, 5 th, and 6 th lumbar ganglia, so that presumably they chiefly arose from the $3 \mathrm{rd}, 4 \mathrm{th}$, and 5 th lumbar nerves. Sherrington? observed that in the macaque monkey (Macacus rhesus), the

1 Akutsu, "Beiträge zur Kenntniss der Innervation der Samenblase beim Meerschweinchen," Pfüger's Archiv, vol. xcvi., 1903.

2 Budge, loc. cit.

${ }^{3}$ Langley and Anderson, loc. cit.

4 Rémy, "Nerfs éjaculateurs," Jour. de l'Anat. et de la Phys., vol. xxii., 886

5 Loeb, loc, cit.

? Sherrington, loc. cit.

- Langley, loc. cit. 
2nd and 3rd lumbar nerves, and in the cat, the 3rd and 4th lumbars, contained motor fibres for the vasa deferentia. The fibres giving this result could be found outside the spinal cord in the genito-crural nerve. The contraction of the vasa was of a slow and peristaltic kind, and did not cease immediately the stimulus was withdrawn. ${ }^{1}$

Langley and Anderson, as a result of an extensive series of experiments, conclude that the internal generative organs of the cat and rabbit are supplied by fibres running out by the anterior roots of the $3 \mathrm{rd}, 4$ th, and 5 th lumbar nerves, and sometimes also the 2 nd. These fibres pass through the sympathetic to the inferior mesenteric ganglia, and continue their course by the hypogastric nerves. Stimulation of these fibres in the cat and the rabbit caused strong contraction of the whole musculature of the vasa deferentia and uterus masculinus (which Langley and Anderson regard as the physiological homologue of the vesiculæ seminales in these animals). The vas deferens in contracting was observed to become from one to three centimetres shorter, so that there could be no doubt that the longitudinal muscular coat took part in the process. The contraction was strong enough to cause emission of semen from the aperture of the penis. It would appear, therefore, that ejaculation occurred without erection. In the dog, in which the longitudinal muscle layer is not well developed, the contraction of the vas deferens, on excitation of the upper lumbar nerves, was not nearly so pronounced.

Langley and Anderson found that stimulation of the sacral nerves had no effect on the internal generative organs. These

1 There has been some disagreement as to whether the vas deferens undergoes true peristaltic movement. According to Budge (loc. cit.) this does occur in the rabbit and cat. Fick confirmed Budge for these animals " Ueber das Vas deferens," Müller's Archiv, 1856), but found no peristalsis in the dog (cf. Langley and Anderson for the dog). On the other hand, Loeb (loc. cit.) could discern no peristaltic movement in the vas deferens of the rabbit, but only a powerful contraction. Nagel, who bas more recently investigated the question, states that the vas deferens in the rabbit does not undergo a true peristaltic movement, but a simple quick contraction which suffices for the emptying the tube ("Contractilität und Rarzburkeit des Samenleiters," Verhandl. d. Phys. Gesell. zu Berlin; Arch.f. Anat. u. Phys., Phys. Abth., 1905. Suppl. See also Nagel, Handbuch der Phys, des Menschen, vol. ii., Braunschweig. 1906). 


\section{MALE ACCESSORY REPRODUC'TIVE ORGANS 261}

are innervated exclusively from the lumbar nerves, as above described. ${ }^{1}$

In view of the facts which have been related, it would appear that ejaculation is a reflex act of some complexity involving

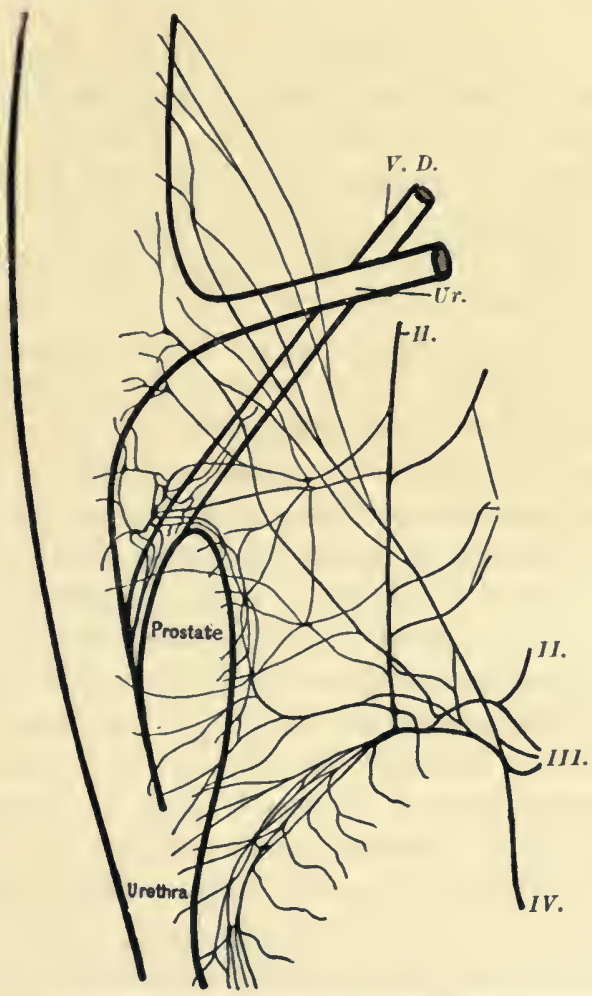

F1G. 66. -Diagram illustrating innervation of internal genital organs of male cat. (From Nagel.)

$H$., hypogastric nerve; Ur., ureter; V. D., vas deferens ; II. III. IV., branches arising from $2 \mathrm{nd}, 3 \mathrm{rd}$, and 4 th lumbar nerves.

more than one centre in the spinal cord. The centre for the final expulsion of the semen must be the same as that for erection, since the muscular mechanisms concerned are to a large extent identical in each case. The centre presiding over the internal generative organs is apparently in the lumbar spinal

1 Langley and Anderson, loc. cit. 
cord. As already mentioned, Brachet observed ejaculation after all connection with the higher centres had been cut off. The centripetal nerves for the ejaculatory reflex are the sensory nerves of the penis, the stimulation of the glans being particularly effective. ${ }^{1}$

Erection has been observed to occur in animals which were castrated late in life, sexual desire in such cases being to some extent retained. It has been shown, however, that erection cannot be induced experimentally in animals which have been castrated prior to puberty; or, at any rate, that it is far more difficult to cause erection in such animals. Thus, in three experiments carried out by the writer, in conjunction with Professor Sutherland Simpson, ${ }^{2}$ it was found impossible to induce erection by stimulating the nervi erigentes in three cats which were castrated when about half grown and afterwards allowed to reach their full size. It is possible, therefore, that in such animals the muscular apparatus of the penis fails to develop sufficiently to admit of erection occurring, but it would seem unlikely that the nervous mechanism is impaired. If erection is due mainly to an inhibition of the vaso-motors of the penis, as is ordinarily supposed, there would seem to be no theoretical reason why it should not be possible to bring about that process experimentally in castrated animals. It is conceivable, therefore, that the process of erection is after all a more complex phenomenon than is generally believed, but our experiments throw no further light on the mechanism of that process.

2 For further references to the literature of the nervous mechanism of erection and ejaculation, see Bechterew, Die Funktionen der Nervencentra, Weinberg's German Translation, vol. i., Jena, 1908.

2 Simpson and Marshall, "On the Effect of Stimulating the Nervi Erigentes in Castrated Animals," Quar. Jour. Exper. Phys., vol. i., 1908. 


\section{CHAP'TER VIII ${ }^{1}$}

\section{THE BIOCHEMISTRY OF THE SEXUAL ORGANS}

"Nous sommes dans un de ces châteaux des légendes allemandes où les murs sont formés de milliers de fioles qui contiennent les âmes des hommes qui vont naître. Nous sommes dans le séjour de la vie qui précède la vie."-Maeterlinck, La Vie des Abeilles.

\section{The Female Generative Organs}

\section{Mammals}

In Mammals very little is known concerning the chemistry of the female generative organs. The difficulty experienced in obtaining material has rendered impossible a chemical investigation of the ovum itself. The fluid contained in the Graafian follicles of the cow is stated to be of a serous nature. From the corpora lutea of the same animal amorphous and crystalline pigments have been isolated, both of which belong to the class of substances called lipochromes or luteins. ${ }^{2}$ These pigments are also found in other sites, e.g. in adipose tissue, in serum, in the retina, and in milk. Similar substances have been isolated from plants, e.g. the crystalline caroten which constitutes the colouring matter of carrots and tomatoes. The luteins are not related to blood pigment, and although hæmatoidin may be found in corpora lutea, especially when they are fresh, the existence of the luteins appears to be quite independent of the presence of blood pigments. The luteins contain carbon, hydrogen, and oxygen, and have a yellowish or reddish colour. Exposed to light they undergo oxidation. They are soluble in alcohol, ether, and chloroform, and in that respect resemble fats, from which they differ, however, in their resistance towards alkalies. With

${ }^{1}$ By William Cramer.

2 Piccolo and Lieben, "Studi nel corpo luteo della vacca," Giorn. $s c$. natur. ed econ., vol. ii., 1866. Kuibne and Ayres, "On the Stable Colours of the Retina," Journal of Physiology, vol. i., 1878. 
strong nitric acid and sulphuric acid they give a blue colour. Their solutions in alcohol, ether, or chloroform are further characterised by the absorption-spectrum, ${ }^{1}$ which shows two bands in the blue part of the spectrum (between the lines F and $\mathrm{G})$.

Observations concerning the chemistry of human ovaries have been made chiefly in certain pathological conditions of these organs. Various protein substances have been isolated from the fluid contents of ovarian cysts. In the case of cysts due to a dilatation of the Graafian follicles the contents were found to be identical with other serous liquids. From cystic tumours of the ovaries, the contents of which may be either watery or gelatinous, a number of protein compounds have been isolated, which, on hydrolysis, all yield a considerable quantity of a reducing substance-glucosamine-and therefore belong to the group of glycoproteins. Hammarsten ${ }^{2}$ isolated a substance, called by him Pseudomucin, which did not coagulate on heating and was not precipitated by acetic acid. On hydrolysis it yielded 30 per cent. glucosamine. Pfannenstiel ${ }^{3}$ isolated from ovarian colloid another mucoid substance, Pseudomucin $\beta$, a gelatinous mass which was insoluble in acetic acid and water, but was dissolved by dilute alkali. These substances are formed by the activity of the cells lining the cysts.

\section{Birds}

Our knowledge of the chemistry of the ovum is derived almost entirely from investigations on the hen's egg. The average weight of an egg is 40-60 grm., half of this being the weight of the white of the egg, while the yolk weighs 12-18 grm. and the shell 5-8 grm.

The egg-shell contains chiefly calcium carbonate. During development the egg-shell loses calcium, which goes to the building up of the structures of the developing embryo. ${ }^{4}$ In

1 Thudichum, "Über das Lutein und die Spektren gelbgefärbter organischer Substanzen," Centralblatt f. $d$. med. Wissenschaft, 1869, vol. vii.

2 Hammarsten, "Metalbumin und Paralbumin," Zeitschr. f. physiol. Chcmie, vol. vi., 1882.

3 Pfannenstiel, "Über die Pseudomucine der cystischen Ovariengeschwiilste," Arch. f. Gynokologie, vol. xxxviii.

4 Vaughan, "Estimation of Lime in the Shell and in the Interior of the Egg before and after Incubation," Journal of Physiology, vol. i., 1878. 
some species the shell is coloured by pigments, which are probably derivatives of the bile pigments. ${ }^{1}$

The shell membrane consists of a substance belonging to the group of the keratins. It is very rich in sulphur (about 4 per cent. S.), and, on hydrolysis, yields a relatively large amount of cystin (see p. 276).

The chief constituents of the white and the yolk of the egg are water, proteins, fats, and phosphorised fats, while carbohydrates as such are almost entirely absent.

The proportion in which these constituents are present in the white and in the yolk of the egg differs, as will be seen from the following table giving the total composition of both these parts.

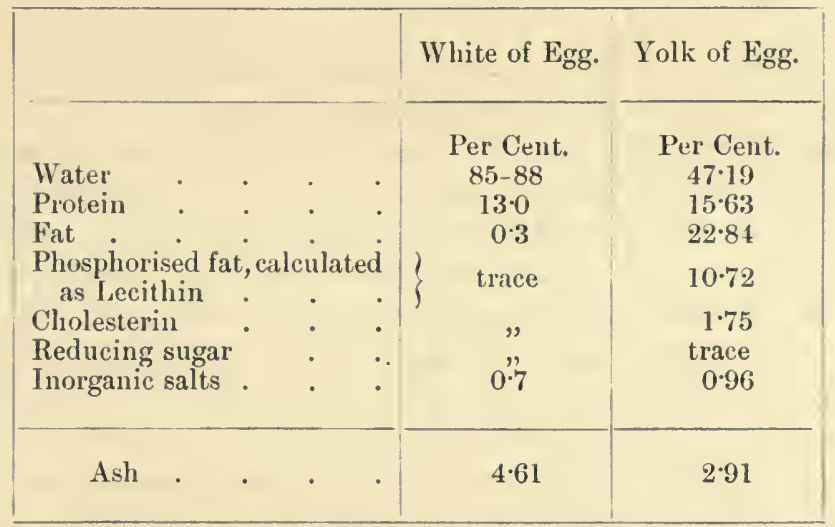

Another important difference in the composition of the white and the yolk of the egg is to be found in the relative quantities of the inorganic constituents as they are present in the dry residue, ${ }^{2}$ both as in organic salts and inorganic combination.

100 parts of Dry

Residue of $\quad \mathrm{K}_{2} \mathrm{O} . \quad \mathrm{Na}_{2} \mathrm{O} . \quad \mathrm{CaO}$. $\quad \mathrm{MgO} . \quad \mathrm{Fe}_{2} \mathrm{O}_{3} . \quad \mathrm{P}_{2} \mathrm{O}_{6} . \quad \mathrm{Cl}$.

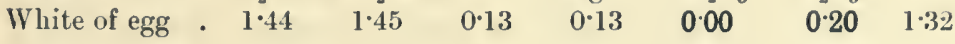

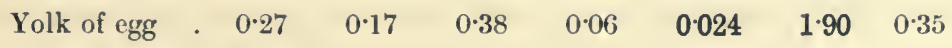

1 Krukenberg, "Farbstoffe der Vogeleierschalen," Verhandlungen $d$. Phys. Med. Gesellschaft, Würzburg, vol. xvii., 1883.

2 Bunge, "Der Kalk und Eisengehalt unserer Nahrung," Zeitschrift $f$. Biologie, vol. xlv., 1904, p. 532. 
It will be seen that the yolk is distinguished by the presence of iron which is almost completely absent in the white, and by its richness in phosphorus. Although the percentage of iron present in the yolk is very small, it is nevertheless greater than in almost any other animal or vegetable food-stuff.

As a rule the proportions in which the inorganic elements are present are given in terms of percentages of the ash. Such a table, ${ }^{1}$ which perhaps brings out more clearly the difference between the white and the yolk of the egg, may be given here :-

100 parts of the Ash of $\mathrm{K}_{2} \mathrm{O}$.

$\mathrm{Na}_{2} \mathrm{O}$.

Contain-

White of egg

$31 \cdot 41$

$31 \cdot 57$ $2 \cdot 78$

$\mathrm{MgO}$. $\mathrm{Fe}_{2} \mathrm{O}_{3}$. $\mathrm{P}_{2} \mathrm{O}_{5}$ $\mathrm{SiO}_{2}$. Cl. $\begin{array}{lllllllll}\text { Yolk of egg . } & 9 \cdot 29 & 5.87 & 13.04 & 2 \cdot 13 & 1 \cdot 65 & 65 \cdot 46 & 0.86 & 1.95\end{array}$

There are, of course, slight variations between different eggs in the amount of mineral constituents present in the ash. It is possible that there are such variations even in the eggs laid by one and the same bird at different periods. Systematic investigations on this point have been made only with reference to the iron. These observations show that more iron is present in eggs laid in spring than in eggs laid by the same bird in autumn, the amounts varying from 0.0129 per cent. $\mathrm{Fe}_{2} \mathrm{O}_{3}$ to 0.0086 per cent. $\mathrm{Fe}_{2} \mathrm{O}_{3}$, the maximum found being 0.0167 per cent. $\mathrm{Fe}_{2} \mathrm{O}_{3}$. (The percentage is calculated for the dried yolk.) This fact probably explains the very exaggerated statements which have been made concerning the production of eggs rich in iron by keeping hens on a diet rich in iron. The careful observations of Hartung ${ }^{2}$ show that there is indeed a distinct effect produced by such a diet, provided that it is given over a prolonged period - two months or more. But the effect of such a diet is limited, and does not go beyond the physiological maximum. The percentage of iron present in eggs laid under these conditions remains fairly constant, and is about equal to the maximum found under normal conditions, namely 0.0165 per cent. $\mathrm{Fe}_{2} \mathrm{O}_{3}$, so that the seasonal diminution which normally appears is prevented.

\footnotetext{
1 Albu and Neuberg, Physiologie und Pathologie des Mineralstoffwechsels Berlin, 1906, p. 241.

2 Hartung, "Der Eisengehalt des Hühnereies," Zeitschrift für Biologie, vol. xliii., 1902.
} 
The phosphoric acid constitutes more than half of the ash of the yolk, and it is interesting to note that both the phosphorus and the iron which are destined to enter into the composition of some of the most important constituents of the cell, such as nucleoproteins, hæmoglobin, lipoids, \&c., are already present in organic combination. The phosphorus is contained in the phosphorised fats, which constitute about 11 per cent. of the yolk, and partly in the phosphoprotein vitellin, which also contains iron.

The phosphorised fats are obtained by extracting the yolk, which has previously been freed from water, with cold ether, and precipitating the ethereal extracts with acetone. The precipitate contains the phosphorised fats, while the acetone solution contains the cholesterin which has been extracted together with the phosphorised fats. After all the ether-soluble phosphorised fats have been removed by the ether, further extraction with cold alcohol will remove other phosphorised fats from the yolk.

The precipitate obtained from the ethereal extract by acetone has often been called lecithin, the name given to the simplest and best-known phosphorised fat.. But the recent work of Erlandsen, ${ }^{1}$ and of Thierfelder and Stern, ${ }^{2}$ has shown, what in the case of nervous tissue had been recognised long ago by Gamgee and by Thudichum, that there are a great number of phosphorised fats very similar to lecithin and very difficult to separate from each other. These substances, accompanied always by cholesterin, are widely distributed through the organic world. In fact they are present in every cell, and in almost every animal fluid. This fact alone is sufficient to indicate that the phosphorised fats and cholesterin must fulfil an important function in the life of the cell.

What this function is has not yet been clearly recognised. We know that anæsthetics such as chloroform, and toxins such as snake-venom, exert their action on the cell by virtue of the power of the phosphorised fats to absorb these substances.

1 Erlandsen, "Untersuchungen über die lecithinartigen Substanzen des Herzmuskels," Zeitschrift f. physiol. Chemie, vol. li., 1906.

2 Thierfelder and Stern, "Über die Phosphatide des Eigelbs," Zeitschrift f. physiol. Chemie, vol. liii., 1907. 
One may therefore venture the suggestion that lecithin and its allies have a similar function with regard to other substances affecting the life of the cell under normal conditions. Some experiments of the writer, ${ }^{1}$ carried out in 1908 , suggest that these phosphorised fats may act as oxygen-carriers, and that they may thus fulfil an important function in cell-respiration. A similar view has been put forward recently on purely theoretical grounds by Mansfeld. ${ }^{2}$

However that may be, there can be little doubt that in the egg which contains an exceptionally large amount of phosphorised fats these substances have to fulfil a different function. Phosphorus enters into the composition of many cell constituents, for instance, the complex protein substances found in the nuclei of cells, the so-called nucleoproteins, so that the assimilation of phosphorus is an important factor in the growth of an organism. Feeding experiments on Man and on animals have made it probable that phosphorus in organic combinations is better assimilated than phosphorus which is given in the form of inorganic phosphates. In birds the yolk of the egg fulfils a function similar to that of the milk in Mammals; both supply the offspring with the material necessary for its growth. We thus find that both the yolk and the milk are not only rich in phosphorus, but that most of the phosphorus is present in organic combination, as casein and nuclein in the latter, and as vitellin and phosphorised fats in the former.

We also find that during incubation the vitellin disappears and the phosphorised fats diminish, so that, at the twentieth day, their quantity is reduced by one half. ${ }^{3}$ It is, of course,

1 Unpublished observations. It was found that watery emulsions of egglecithin absorbed mucl more oxygen than water alone or watery solutions of proteins, and that such a lecithin-emulsion sometimes greatly accelerated the oxidation of hydriodic acid by the oxygen of the air. The results obtained were, however, very variable.

2 Mansfeld, "Narkose und Sauerstoffmangel," Pfüger's Archiv, vol. cxxix., 1909.

${ }^{3}$ Merconitzki, "Die quantitativen Veränderungen des Lecithins im enstehenden Organismus," Russky Wratsch, 1907, quoted from Biochemisches Centralblatt, vol. vi., 1907. Plimmer and Scott, "The Transformations in the Phosphorus Compounds in the Hen's Egg during Development," Jour. of Physiology, vol. xxxviii., 1909. 
clear that the formation of nucleoproteins cannot account for this enormous consumption of phosphorised fats. Some of these substances reappear in the embryo. A proportion of them contributes to the formation of bones, which contain a considerable amount of inorganic phosphates. Part reappears in the foetal tissues as phosphorised fats, especially in the nervous tissue, which is very rich in these substances. That portion of the phosphorised fats which is transformed into inorganic phosphates, may at the same time fulfil another very important function by the oxidation of the fat group in their molecule. It will be shown below that the development of the embryo is intimately associated with, and perhaps dependent upon, the transformation of chemical energy into heat. This transformation is brought about by the oxidation of certain organic substances, which are different in the different classes of Vertebrates. It will be shown also that in birds the chemical energy is furnished by fats, and it is very probable that the phosphorised fats furnish at the same time material for the formation of the tissues of the embryo and fat as a source of chemical energy.

It is interesting to note that a similar double function has been assigned to glycogen in the case of the developing rabbit. ${ }^{1}$ Of the cholesterin about one-third disappears during incubation.

The phosphorus which enters into the composition of nucleoprotein is bound up therein in the form of phosphoric acid, combined with purine bases and pentoses (see p. 294). Neither nucleoprotein nor pentoses are present in the fresh egg, and purine bases are present only in very small amounts. The fact that during development these substances rapidly increase in amount, indicates therefore that a synthesis of nucleoprotein from the reserve material of the egg (proteins and phospliorised fats) takes place during development. The purine bases found in the embryo are essentially the same as those found in the adult organism. ${ }^{2}$

1 Lochhead and Cramer, "The Glycogenic Changes in the Placenta and Fœtus of the Pregnant Rabbit," Proc. Roy. Soc., Series B., vol. lxxx., 1908.

2 Kossel, "Weitere Beiträge zur Chemie des Zellkernes," Zeilschrift für Physiologische Chemie, vol. x., 1886. Mendel and Leavenworth, "Chemical Studies on Growth: VI.Changes in the Purine-Pentose- and Cholesterol-Content of the Developing Egg," American Journal of Physiology, vol. xxi., 1898. 
Of the phosphorised fats of the yolk, lecithin is the simplest and best-known representative. Like all fats, it is an ether compound of glycerine and fatty acids, such as stearic, palmitic, and oleic acid, and is, like all fats, soluble in alcohol and ether. With water it swells up and forms a colloidal solution. It is distinguished by the presence in its molecule of one molecule of phosphoric acid to which one molecule of an organic nitrogenous base, choline, is attached. If boiled with baryta water it is decomposed into glycerophosphoric acid, fatty acids, and choline. Lecithin forms loose compounds with proteins, the so-called lecithalbumins, of which vitellin is probably one.

Vitellin is an ill-defined compound between lecithin and a protein substance which itself contains about 1 per cent. phosphorus. It is insoluble in water, but soluble in dilute solutions of neutral salts, behaving in that respect like a globulin. On peptic digestion a pseudonuclein, rich in phosphorus, is formed from the protein part of vitellin. This pseudonuclein contains also a relatively large amount of iron in organic combination, and it is this substance which is responsible for the presence of iron in the yolk of the egg. According to Bunge, ${ }^{1}$ this substance plays an important part in the formation of hæmoglobin in the chick. It is the precursor of hæmoglobin, and has, therefore, been called by him hæmatogen. It contains $5 \cdot 19$ per cent. P., and 0.29 per cent. Fe. Recently Plimmer ${ }^{2}$ has isolated from egg-yolk another protein, livetin, soluble in water and containing 0.1 per cent. phosphorus.

Two different fats have been isolated from the yolk-the one solid, rich in palmitic acid; the other fluid, containing equal parts of palmitic and oleic acids. A small amount of stearic acid is also present in both fats. The composition of the fat is influenced by the food, the fat of the food passing into the yolk in the same kind of way as it passes into the fat deposits of the adult organism. ${ }^{3}$

The food has also an influence upon the colour of the yolk,

1 Bunge, "Über die Assimilation des Eisens," Zeitschr. f. physiolog Chemie, 1884, vol. ix. 1908

"Aders Plimmer, "The Proteins of Egg-Yolk," Journal Chemical Soc.,

${ }^{3}$ Henriques and Hansen, "Über den Übergang des Nahrungsfettes in das Huhnerei," Skandin. Arch. f. Physiologie, vol. xiv., 1903. 
which is due to luteins. Feeding with grains produces a light yellow yolk, a dark yellow yolk results if grass and herbs are given, while feeding with worms leads to the production of an even darker reddish yolk. What the changes are in the colouring matter of the yolk has not yet been ascertained. ${ }^{1}$

During the development of the chick a considerable portion of the fat disappears. In other words, a certain amount of chemical energy, which in the fresh egg is present in the form of fat, disappears. Liebermann ${ }^{2}$ has shown, for instance, that of $5 \cdot 4$ grm. of fat present in a fresh egg only $2 \cdot 7 \mathrm{grm}$. can be recovered when the chick is hatched. The fate of the chemical energy which has thus disappeared has been accounted for completely by the observations of Bohr and Hasselbalch, ${ }^{3}$ which are the most exact and comprehensive investigations on the subject of the metabolism of the embryo.

They showed that the respiratory quotient of the developing egg-that is, the ratio of the amount of $\mathrm{CO}_{2}$ excreted to the amount of $\mathrm{O}_{2}$ absorbed-is 0.71 . Such a quotient indicates the oxidation of fat. From the amount of $\mathrm{CO}_{2}$ excreted during a given period it is possible to calculate the amount of fat oxidised during that period. Under ordinary conditions the oxidation of fat produces heat which can be determined experimentally. By calculating from the amount of fat oxidised during development the amount of heat which would be generated under ordinary conditions, and by actually determining at the same time the amount of heat given off by the developing egg, Bohr and Hasselbalch found during a period of twelve days :-

The amount of heat calculated from the amount of fat oxidised . $.12 \cdot 11 \mathrm{Cal}$.

The amount of heat actually given off $\quad . \quad .12 \cdot 16 \mathrm{Cal}$.

This remarkable agreement in so complicated an experiment - which is a triumph of the experimental skill of the observers

1 For the morphological distribution of the constituents of the yolk, see Waldeyer, "Die Geschlechtszellen," in Hertwig's Handbuch der Entwicklungslehre der Wirbeltiere, vol. i., Jena, 1903.

2 Liebermann, "Embryochemische Untersuchungen," Pflüger's Archiv, vol. xliii., 1888 .

3 Bohr and Hasselbalch, " Über die W:irmeproduktion und den Stoff wechsel des Embryo," Skandinavisches Arch. f. Physiologie, vol. xiv., 1903. 
- shows clearly that fat is the almost exclusive source of the chemical energy which is used up during development. Another very important conclusion can be drawn from these observations, namely, that all the chemical energy which disappears during development reappears in the form of heat. None is transformed in an unknown way into energy of a different kind, or transferred to the developing embryo.

The intensity of the metabolic changes which take place during development, and which can be expressed by the amount of $\mathrm{CO}_{2}$ excreted, is very great. ${ }^{1}$ Calculated for the same unit of weight of the animal, it is as great in the embryo as it is in the adult animal, and may even exceed it. This is the case not only in birds, but also in Mammals. These changes are intimately bound up with the development of the embryo. Exposure to cold, which delays development, also diminishes the excretion of carbonic acid. ${ }^{2}$ Experiments on the eggs of cold-blooded animals ${ }^{3}$ show that those conditions which favour development, such as high temperature, also lead to an increase in the $\mathrm{CO}_{2}$ excretion.

The same problem has been attacked in a different way by Tangl. ${ }^{4}$ He determined, by means of a calorimeter, the heat produced by the combustion of eggs at different stages of their development. There is a gradual diminution of the caloric value as development goes on, indicating that chemical energy is used up in the process of development. In the case of the chick the difference between the caloric value of the fresh egg and that of the developed chicken is 16 calories. These 16 calories represent the chemical energy which has been used up for what Tangl calls the "work of development."

But since Bohr's work has shown that the chemical energy which disappears during development is completely transformed into heat, it would be better to replace the

1 Bohr and Hasselbalch, "Über die Kohlensäureproduktion des Hühnerembryos," Skandinav. Arch. f. Physiologie, vol. x., 1900.

2 Pembrey, "On the Response of the Chick, before and after Hatching, to Changes in External Temperature," Journal of Physiology, vol. xxvii., 1894.

${ }^{3}$ Bohr, "Über den respiratorischen Stoff wechsel beim Embryo kaltblitiger Tiere," Skandinav. Arch. f. Physiologie, vol. xv., 1904.

4 Tangl, "Beiträge zar Energetik der Ontogenese : I. Die Entwicklungsarbeit im Vogelei," Pfüger's Archiv, vol. xeiii., 1903; vol. cxi., 1908. 
term "work of development" by the term "energy of development.

The nature of the substances which by their oxidation furnish the "energy of development" is different in the different classes of animals. In birds it is furnished, as we have seen, by the oxidation of fats, and possibly also of the fat group of phosphorised fats. In Mammals in which development proceeds in utero, and there is a constant exchange of material between the mother and the fœtus, the investigation of these problems is more difficult, owing to the complexity of the conditions. Investigations on the respiratory quotient of the embryo in pregnant guinea-pigs and rabbits ${ }^{1}$ indicate that there is an oxidation of carbohydrate material, and systematic chemical investigations of the placenta and fotus of pregnant rabbits $^{2}$ have shown that there is a constant and regular disappearance of glycogen from the placenta, which reappears only partly as such in the embryonic tissues. It can therefore be concluded that in these animals glycogen furnishes at least part of the "energy of development." But it is doubtful whether this conclusion can be applied to all the Mammals, since, in the case of the cow and of the sheep, for instance, very little glycogen is found in the placenta.

In reptiles ${ }^{3}$ also the chemical energy used up during development is furnished mainly by carbohydrates.

Similar observations have been made on the eggs of fishes, ${ }^{4}$ where the energy of development was found to be very small.

In all these cases the chemical energy used up in the process of development has been found to be furnished either by fats or by carbohydrates. No conclusive evidence has as yet been obtained that the store of nitrogenous substances is used for that purpose.

1 Bohr, "Der respiratorische Stoff wechsel des Säugethierembryos," Skandinav. Arch.f. Physiologie, vol. x., 1900.

${ }^{2}$ Lochhead and Cramer, "The Glycogenic Changes in the Placenta and Fœtus of the Pregnant Rabbit," Proc. Roy. Soc., Series B., vol. 1xxx., 1908, p. 263.

3 Bohr, " Über den respiratorischen Stoff wechsel beim Embryo kaltblütiger Tiere," loc. cit.

4 Tangl and Farkas, "Beiträge zur Kenntniss der Ontogenese : IV. Über den Stoff u. Energieumsatz im bebrüteten Forellenei," Pfüger's Archiv, vol. civ., 1904. 
Liebermann records a loss of nitrogenous substances in liis analysis of hens' eggs at various stages of development; but as Hasselbalch ${ }^{1}$ pointed out, this loss is accounted for by the eggmembrane, which is left behind when the chick is hatched, and which was not included in Liebermann's analysis.

Reference has already been made to nitrogenous constituents of the yolk: the two phosphoproteins vitellin and livetin. The other protein substances of the white of the egg can be distinguished according to their reactions as albumens, globulins, and a substance behaving like a peptone in so far as it is not coagulated by heat and not precipitated by ammonium sulphate or by hydrochloric and acetic acids. According to the investigations of Mörner, ${ }^{2}$ this substance is a true glucoprotein and belongs to the mucoid substances. It has, therefore, received the name Ovomucoid. On boiling with hydrochloric acid it yields 34 per cent. of glucosamine. ${ }^{3}$ The amount of ovomucoid present in the white of the egg is about 10 per cent. of the proteins ; 6 per cent. of the proteins belong to the globulin group, the remainder being the albumens. All the proteins of the white of the egg, not only the ovomucoid, are exceptionally rich in the carbohydrate radicle, and on boiling with dilute hydrochloric acid yield considerable quantities of glucosamine. The albumens and globulins contain about 10 per cent. of glucosamine. This explains perhaps the almost complete absence of carbohydrates in the egg. It acquires further significance from the fact that the developing tissues of the embryo are very rich in mucin, a protein containing considerable quantities of glucosamine.

The globulin fraction of the egg-white has not yet been studied in detail. It is probable that it is a mixture of several globulins.

The investigation of the albumen fraction has been greatly facilitated by the work of Hofmeister ${ }^{4}$ and Hopkins, ${ }^{5}$ which

1 Hasselbalch, "Über den respiratorischen Stoffwechsel des Hühnerembryos," Skandinav. Arch. f. Physiologie, vol. x., 1900.

2 Mörner, "Über die im Hühnereiweiss in reichlicher Menge vorkommende Mucinsubstanz," Zeitschr. f. physiol. Chemie, vol. xviii.

${ }^{3}$ Quoted from Ergebnisse der Physiologie, vol. i., Part I.

" Hofmeister, "Ửber Krystallisation des Eialbumins," Zeitschrift für physiolog. Chemie, vol. xiv., 1890, and vol. xvi., 1892.

s Hopkins and Pinkus, "Observations on the Crystallisation of Proteids," Journal of Physiology, vol. xxiii., 1898. 
has made it possible to obtain part of the albumen fraction in a crystallised form. In this way Osborne and Campbell ${ }^{1}$ have isolated two different albumens, the crystallisable "ovalbumen" and the non-crystallisable "conalbumen." Possibly even these two substances are mixtures of albumens, for Bondzinski and Zoja ${ }^{2}$ claim to have isolated from the crystallisable ovalbumen several albumens by means of fractionate crystallisation. Crystalline egg albumen contains $0 \cdot 13$ per cent. phosphorus, ${ }^{3}$ and is therefore another source of phosphorus in organic combination.

The white of the eggs of some Insessores has the peculiar property of forming a transparent fluorescent jelly when it is coagulated by heat." The name "Tata-eggwhite," has been given to this substance. This phenomenon is probably due to the presence of a relatively large amount of basic salts in the white of the egg, since the white of a hen's egg will also coagulate to a transparent jelly if the egg has been kept for a few days in 10 per cent. caustic potash.

Further insight into the composition of some of the proteins of the egg has been gained by means of the methods devised within recent years by E. Fischer and by Kossel, for the study of the constitution of the protein substances. By boiling with hydrochloric acid the proteins are split into the constituent amino acids and diamino acids, which are then determined as nearly quantitatively as possible. ${ }^{5}$

In the results given in tabular form on p. 276 , the figures represent percentages, those under "total" indicating the percentage recovered in the form of amino acids or diamino acids. The absence of any one constituent is indicated by 0 , the presence without quantitative estimation by + , while - indicates that

1 Osborne and Campbell, Journ. Americ. Chem. Soc., vol. xxii., 1900.

${ }^{2}$ Bondzinski and Zoja, "Über die fraktionierte Krystallisation des Eieralbumins," Zeitschrift f. phys. Chemie, vol. xix., 1894.

3 Willcock and Hardy, "Preliminary Note upon the Presence of Phosphorus in Crystalline Egg Albumin," Proc. Cambridge Philosophical Soc., 1907.

4 Tarchanoff, "Über die Verschiedenheiten des Eiereiweisses bei befiedert geborenen (Nestflüchten) und bei nakt geborenen (Nesthocker) Vögeln," Pflüger's Archiv, vol. xxxi., 1883. Tarchanoff, "Über Hühnereier mit durchsichtigem Eiweiss," Pflüger's Archiv, vol. xxxix., 1883.

${ }^{5}$ For fuller reference see Plimmer, The Chemical Constitution of the Proteins, London, 1908, in the series of Monographs on Biochemistry; and Abderhalden, Lehrbuch der Physiologischen Chemie, 2 Anflage, 1909. 
investigations as to the presence or absence of a particular constituent have not been made.

\begin{tabular}{|c|c|c|c|}
\hline & $\begin{array}{l}\text { Egg Albumen } \\
\text { (Abderhalden } \\
\text { and Pregl). }\end{array}$ & $\begin{array}{c}\text { Vitellin } \\
\text { (Hughounenq). }\end{array}$ & $\begin{array}{l}\text { Keratin from } \\
\text { Egg Membrane } \\
\text { (Abderhalden } \\
\text { and Ebstein). }\end{array}$ \\
\hline 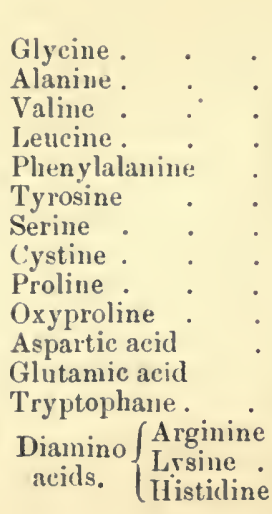 & $\begin{array}{c}\text { Per Cent. } \\
0 \\
2 \cdot 1 \\
- \\
6 \cdot 1 \\
4 \cdot 4 \\
1 \cdot 1 \\
- \\
0 \cdot 3 \\
2 \cdot 3 \\
- \\
1 \cdot 5 \\
8 \cdot 0 \\
+ \\
2 \cdot 15 \\
2 \cdot 14 \\
-\end{array}$ & $\begin{array}{c}\text { Per Cent. } \\
<0.5 \\
<0.5 \\
1.5 \\
6.8 \\
0.7 \\
2.0 \\
<0.5 \\
- \\
<0.5 \\
- \\
0.7 \\
1.0 \\
- \\
1.0 \\
1.2 \\
2.1\end{array}$ & $\begin{array}{c}\text { Per Cent. } \\
3 \cdot 9 \\
3 \cdot 5 \\
1 \cdot 1 \\
7 \cdot 4 \\
- \\
- \\
- \\
7 \cdot 6 \\
4 \cdot 0 \\
- \\
1 \cdot 1 \\
8 \cdot 1 \\
- \\
- \\
- \\
-\end{array}$ \\
\hline Total & $30 \cdot 1$ & $19 \cdot 0$ & $36 \cdot 7$ \\
\hline
\end{tabular}

With regard to the question of the presence of ferments and their significance we are on very difficult ground. We must here clearly distinguish between endo-enzymes and secreted enzymes. The endo-enzymes comprise all those enzymes which are so closely bound up with the protoplasm that they can be isolated only after the cell has been destroyed. Their sphere of activity is therefore limited to the inside of the cell. Such endo-enzymes are present in every organ, and have also been found in the egg, ${ }^{1}$ producing proteolysis and lipolysis. But since such endo-enzymes are present in many, if not in all cells, no special significance can be attached to their presence in the eggs.

The presence in the egg of secreted ferments analogous to the ferments which can be obtained by simple extraction from the digestive glands of the adult animal, would allow of more definite conclusions. The presence of such ferments

"Wohlgemuth, "Über das Vorkommen von Fermenten im Hühnerei," Festschrift für Salkowski, 1904. 
has as yet not been proved with certainty, although the diastatic action of egg yolk observed by Miiller and Masuyama ${ }^{1}$ points to the presence of a diastase analogous to the ptyalin of the saliva.

\section{Lower Vertebrates}

The covering of the eggs of the lower Vertebrates is either of the nature of a keratin, a scleroprotein rich in sulphur, similar to the membrane of birds' eggs, or it is a mucoid substance. In reptiles, like Calotes jubatus and Crocodilus biporcatus, and in Elasmobranchs, like Raja and Scyllium, the membrane is stated to consist of a keratin. ${ }^{2}$ In the membrane of the eggs of Tropidonotus, ${ }^{3}$ the British grass snake, a substance has been found which is free from sulphur and resembles the elastin which constitutes the elastic fibres of mammalian connective tissue. A similar substance is stated to occur in the egg-membrane of Mustelus lavis. ${ }^{4}$ But these data are very scanty and hardly convincing. In Amphibians like the frog the membrane has been found to consist of pure mucin. ${ }^{5}$ In Teleostean fishes it has been investigated in the case of the perch, ${ }^{6}$ and found to be of the nature of a mucin.

It would be interesting to find out by systematic investigations, such as those of $\operatorname{Pregl}^{7}$ and Buchtala, ${ }^{8}$ whether the chemical nature of the substances protecting the egg varies with the different zoological classes, or whether it is dependent upon external circumstances representing perhaps a case of chemical adaptation.

1 Müller and Masuyama, "Über ein diastatisches Ferment im Hühnerei," Zeitschr. f. Biologie, vol. xxxix., 1900.

2 Krukenberg, Vergleichende Physiolugische Studien: II. Reihe, 1 Abteilung, 1882. Neumeister, "Über die Eischalenhäute von Echidna und der Wirbeltiere im allgemeinen," Zeitschr. f. Biologie, vol. xiii., 1895.

${ }^{3}$ Hilger, "Ueber die Chemischen Bestandteile des Reptilieneis" ; Bcrichte der deutschen chem. Gesellschaft, vol. vi., 1873.

- Krukenberg, loc. cit., 2 Abteíung, 1882.

5 Giacosa, "Études sur la Composition chimique de l'EEuf et de ses Enveloppes chez la Grenouille commune," Zeitschr. f. phys. Chemie, vol. vii., 1883.

6 Hammarsten, "Chemie des Fischeies," Skandinav. Arch. f. Physiologıe, vol. xvii., 1905 .

"Pregl, "Über die Eihäute von Scyllium stellare und ihre Abbauprodukte," Zeitschr. f. phys. Chemie, vol. lvi., 1908.

- Buchtala, ibid. 
The investigations of Hammarsten brought to light the interesting fact that a chemical change takes place in the cover of the eggs during ripening. The immature eggs swell with water, and a mucilaginous solution of mucus is formed, from which the mucin may b s precipitated by the addition of acetic acid. If mature eggs are treated with water they do not swell. The water dissolves out the contents of the egg and the empty covers of the eggs remain, and can be transformed into mucin by weak alkali. During the ripening of the eggs there is therefore a change from mucin to mucinogen.

The composition of the eggs of fishes is essentially the same as that of birds' eggs.

The organic constituents consist chiefly of protein, fats, and phosphorised fats, with some cholesterin.

The following analysis of the ash of caviar ${ }^{1}$ gives an idea of the composition of the ash of the eggs of fishes :-

$\begin{array}{ccccccc}\text { Total Ash . . } & \mathrm{K}_{2} \mathrm{O} . & \mathrm{Na}_{2} \mathrm{O} . & \mathrm{CaO} . & \mathrm{Fe}_{2} \mathrm{O}_{3} & \mathrm{P}_{2} \mathrm{O}_{5} \cdot & \mathrm{Cl} . \\ 7 \cdot 70 \text { per cent. } & 3 \cdot 33 & 30 \cdot 77 & 5 \cdot 02 & 0 \cdot 22 & 10 \cdot 55 & 47 \cdot 44\end{array}$

In the egg the protein is present in the form of a phosphoprotein. Valenciennes and Frémy, who were the first to isolate this substance, called it Ichthulin. Later Walther showed that this substance very closely resembles the vitellin present in birds' eggs. On peptic digestion it yields an iron containing pseudonuclein. A similar substance containing phosphorus and jron was isolated from the eggs of the salmon by Noel Paton, from cods' eggs by Levene, and from perches' eggs by Hammarsten. ${ }^{2}$ The statement by Walther that ichthulin, on boiling with mineral acids, splits off a reducing sugar and differs in this respect from vitellin has not been confirmed by the later workers.

Ichthulin is probably identical with the crystalline material observed in the eggs of the tortoise, the frog, the shark, and other fishes, which is known morphologically under the name of yolk-spherules or "Dotterplättchen." The unripe eggs of the perch are embedded in a fluid from which a protein of the nature of a globulin has been isolated. This protein received

1 Albu and Neuberg, Mineralstoffwechsel, p. 241.

2 Hammarsten, "Chemie des Fischeies," Skandinav. Arch. f. Physiologie, vol. xvii., 1905. This paper contains a detailed review of previous work done on this subject. 
the name "percaglobulin." 1 It is rich in sulphur, and is precipitated by weak hydrochloric acid. It has an astringent taste, and possesses the remarkable property of forming precipitates with some glucoproteins such as ovomucoid, and with polysaccharides such as glycogen and starch. This substance could not be found when the eggs were mature, and does not appear to be present in the ovaries of other fishes.

Very important and interesting results have been obtained by systematic chemical examinations of the muscles and ovaries of the salmon ${ }^{2}$ and of the herring ${ }^{3}$ at different seasons. Extensive chemical changes take place in these animals during the period of their reproductive activity. The reproductive organs develop at the expense of the muscles, which diminish in weight. This is best seen in the case of the salmon, since this animal does not take any nourishment during its passage up the rivers. In the case of the herring the conditions are not quite so simple, because the herring feeds until spawning occurs, although less food is taken in the later months.

In the case of the salmon, then, the ovaries are built up from material contained in the muscle. The most marked change in the muscle during that period is a loss of fat, with which the muscles are loaded when the salmon leaves the sea. The protein constituents of the muscle also diminish, but not to the same extent as the fat. There is, further, a disappearance of the inorganic phosphates of the muscle. From these substances the ovaries build up their essential constituents - the phosphoprotein ichthulin and the phosphorised fats. The source of the choline which is contained in the phosphorised fats is not yet clear. This formation by the ovaries of phosphorised fats out of fats and inorganic phosphates points to the important function which these organic phosphorus compounds have to fulfil in the developing organism (see above).

Not all the fat which disappears from the muscles reappears

1 Mörner, "Percaglobulin ein charakteristischer Eiweisskörper aus dem Ovarium des Barsches," Zeitschrift für physiolog. Chemie, vol. xl.

${ }^{2}$ Miescher, Histochemische und physiologische Arbeiten. Noel Paton and others, "Report of Investigations on the Life-History of the Salmon in Fresh Water," Report to the Fishery Board for Scotland, 1898.

"Milroy, "Changes in the Chemical Composition of the Herring during the Reproductive Period," Biochemical Journal, vol. iii., 1908, p. 366. 
in the ovaries as phosphorised fats. $\Lambda$ portion of it serves as a source of energy for the animal. The same applies to part of the protein of the muscle.

The iron contained in organic combination in the ichthulin of the ova is derived partly from the muscle and partly also from the blood.

Together with the accumulation of fat in the muscles there is a storing of a lipochrome, the characteristic pink pigment of the flesh of the salmon. During its sojourn in the river this pigment disappears in part from the muscles and is transferred with the fat to the ova. This pink pigment is probably formed from another yellow pigment, which is also present in the salmon, and which is widely distributed in the animal kingdom, always closely associated with fat. ' It is possible that the ingestion and deposition of fat containing this yellow pigment are responsible for the formation of the pink pigment.

\section{Invertebrates}

The chemical composition of the eggs of Invertebrates does not appear to be essentially different from that of the Vertebrate eggs. The covering of the egg, which is often stated to be chitin, has been investigated by 'Tichomiroff ${ }^{1}$ in the egg of Bombyx mori. He found it to be a protein body rich in sulphur, and similar to the keratin substances of which the membrane of the hen's egg is composed. The covering of the eggs of a cephalopod - the cuttlefish — was investigated by von Fürth. ${ }^{2}$

These eggs are united by their capsules, which are often coloured black by pigment, and form what are popularly known as "sea-grapes." The covering or capsule is secreted by two " nidamental glands," which open into the oviduct, and it is interesting to note that the substance secreted by these sexual glands is a mucoid substance very similar to the pseudomucin found in cysts of the human ovary (see Mammals, p. 264).

The protein substances in the eggs of Invertebrates have not been closely investigated. Vitellin is said to occur.

1 Tichomiroff, "Chemische Studien über die Entwicklung der Insekteneier," Zeitschr. f. phys. Chemie, vol. ix., 1885.

2 Von Fürth, "UỦber Glycoproteide niederer 'Tiere," Hofmeister's Beiträge, vol. i., 1901. 
The eggs of insects are comparatively rich in phosphorised fats. By extraction with alcohol and ether, Dubois ${ }^{1}$ isolated from locusts' eggs a yellowish oil containing 1.92 per cent. phosphorus.

Glycogen, purine bases, and cholesterin have been found in the eggs of Bombyx. The changes which take place during incubation, in the chemical composition of these eggs, have been investigated by Tichomiroff. ${ }^{2}$

The following table shows that a considerable amount of purine bases are formed during incubation. At the same time the fat and glycogen diminish in amount, while the cholesterin remains practically unchanged and the phosphorised fats increase slightly in amount.

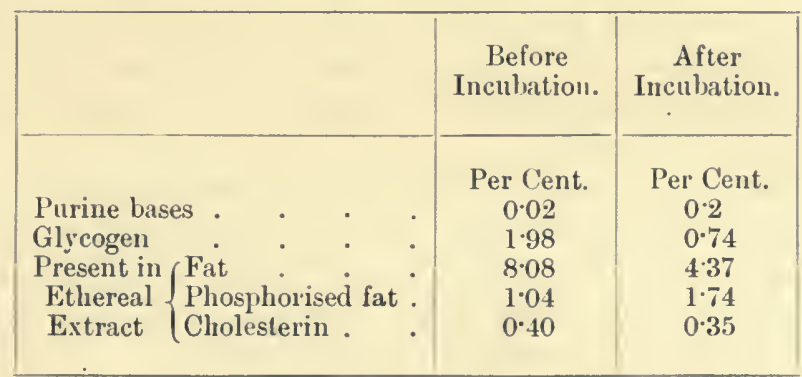

On the whole the changes are similar to those observed in hens' eggs, except that glycogen is present in considerable quantities in the egg and disappears during development as well as the fat, while the phosphorised fats are apparently not utilised as a source of chemical energy. The " energy of development" is very considerable, and, calculated as a percentage of the chemical energy contained in the whole egg, is as great as in the case of the developing hen's egg. ${ }^{3}$

The pigments have been studied especially in the eggs of Crustacea. From the eggs of Maja squinado, Maly ${ }^{4}$ isolated

1 Dubois, "Sur l'huile d'CEufs d' la Sauterelle d'Algerie (Acridium pslerinum)," Comptes Rendus, vol. cxvi., 1893.

2 Tichomiroff, loc. cit.

3 Farkas, "Ửber den Energieumsatz des Seidenspinners während der Entwicklung im Ei u. während der Metamorphose," Pfüger's Archiv, vol. xcviii., 1903. See Appendix to this Chapter, p. 302.

"Maly, “Über die Dotterpigmente," Berichte der Akademie der Wissen. schaften, in Wien, vol, Ixxxiii., 1881. 
two pigments - a red pigment, Vitellorubin, which is extremely sensitive to light, and a yellow pigment, Vitellolutein. These pigments belong to the lipochromes, which have been mentioned above. Krukenberg ${ }^{1}$ has examined the pigments of a number of other Invertebrates. All these lipochromes have characteristic absorption spectra.

The lipochromes of Maja are of special interest, because a similar pigment, Tetronerythrin, has been found in the blood of Maja and other Crustacea. The amount present in the blood shows considerable variation. According to $\mathrm{Heim}^{2}$ it is completely absent in the blood of the male, and appears in the blood of the female during ovulation. At this period also the ovaries, which usually have a yellowish or whitish colour, become first bright yellow and then red. In Heim's ${ }^{3}$ view this lipochrome is not formed in the ovary but in some other organ of the body, and passes at the period of ovulation into the blood, which carries it to the ovaries.

The same author, together with Abelous, ${ }^{4}$ has proved the existence of some ferments in watery and glycerine extracts of the eggs of various crustacea. A diastatic, a tryptic, and an inverting ferment were found. They are stated to increase in strength during the maturation of the ovum.

\section{The Male Generative Organs}

\section{The Semen}

The semen, i.e. the fluid discharged by an ejaculation, is the secretory product of the testis, epididymis, vesiculæ seminales, prostate and Littré's glands. In Man it is a thick, viscous, yellowish, opalescent fluid, which after ejaculation solidifies at first and afterwards becomes fluid again. It has a peculiar smell, which becomes even more noticeable on heating.

1 Krukenberg, Vergleichende physiologische Studien: II. Reihe, 3 Abteilung, 1882, p. 6.

2 Heim, "Sur les Pigments des CEufs des Crustacés," Comptes Rendus Soc. Biol., vol. xliv., 1892 , p. 467.

${ }^{3}$ Heim, Études sur le Sang des Crustacés, Paris, 1892.

- Abelous and Heim, "Sur les Ferments des CEufs des Crustacés," Compt. Rend. Soc. Biol., vol. xliii., 1891, p. 273. 
Its reaction is alkaline. Its specific gravity lies between 1.02 and 1.04. The amount discharged in an ejaculation is given differently by different authors, and probably varies with different individuals, and even with the same individual at different times. From the figures given in the literature 5 grammes may be taken to be the average amount. ${ }^{1}$

According to Slowtzoff, ${ }^{2}$ human semen consists roughly of 90 per cent. water and 10 per cent. solids, which, on incineration, yield about 1 per cent. of ash. The solids contain $2 \cdot 3$ per cent. of proteins, of which a nucleoprotein, traces of albumen and mucin, and an albumose-like substance have been identified.

The quantitative relation of the various solids in 100 parts of fresh semen can be seen in the following table :-

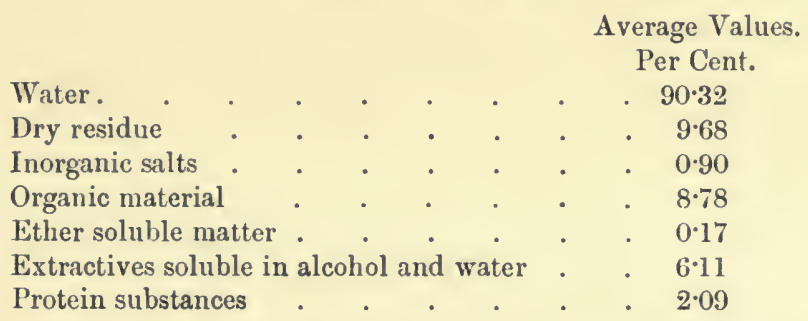

In the ash $\mathrm{K}, \mathrm{Na}, \mathrm{Ca}, \mathrm{Mg}, \mathrm{P}, \mathrm{Fe}$, and $\mathrm{S}$ have been found.

The quantitative analysis of the ash reveals a remarkably large amount of calcium and phosphoric acid-about 20 per cent. $\mathrm{Ca}$ and 30 per cent. $\mathrm{P}_{2} \mathrm{O}_{5}$. The amount of calcium excreted in one ejaculation is, therefore, about $0^{\circ} 01$ grm., and exceeds that contained in an equal quantity of lime-water. Analyses of the semen of other Mammals do not appear to have been made, but it is unlikely that there are any essential differences. Since during the breeding season about fifty sheep are served by one ram, it is evident that a profound change must take place in the metabolism of phosphorus and calcium during that period. Is it

${ }^{1}$ Acton, Functions and Disorders of the Reproductive Organs, 3rd Edition, London, 1862. Lode, "Untersuchungen über die Zahlen und Regenerations Verbältnisse der Spermatozoiden bei Hund und Mensch," Pfiuger's Archiv, vol. 1., 1891. Mantegazza, Gaz. Med. Ital., Lombardia, 1866 , quoted from Lode.

2 Slowtzoff, "Zur Chemie des menschlichen Sperma," Zeitschrift f. phys. Chemie, vol. xxxv., 1902. 
not possible that the effects which are usually ascribed to a hypothetical "internal secretion" of the testis are partly due to such a direct connection with the metabolism of the body?

The nature of the influence which the sexual glands exert upon the metabolism of the body is very complex, and has not yet been fully cleared up. Various observers have obtained very contradictory results. Since this subject will be dealt with in another chapter, we will refer to it here only in so far as it has any bearing on the calcium and phosphorus metabolism. On this point there is conclusive evidence of a morphological nature both for the male and for the female organism. Castration leads to a marked increase in the growth of the long bones. This fact, which is due to a retardation of the process of endochondral ossification taking place in these bones, accounts for the increase in stature of eunuchs and of castrated animals (see p.306).

Similar evidence, although of a more complex character, is afforded in the case of the female by the relationship which undoubtedly exists between the ovaries and osteomalacia, a disease consisting mainly in a decalcification of the bones. It is produced probably by an abnormal function of the ovaries, since removal of the ovaries markedly improves, and sometimes cures, this condition (see p. 353). In pregnancy and parturition there is what one might call a "physiological osteomalacia" of the pelvic bones; and the activity of the mammary gland during lactation must necessarily bring about an increased calcium metabolism, since milk contains a very large amount of this element.

The organic substances in the semen may be divided into two groups. If the semen is examined microscopically it is found that it contains, on the one hand, cellular elements-viz. the spermatozoa and lymphocytes, partly in a state of degeneration; on the other hand, organic material which is partly amorphous and partly crystalline.

The amorphous material consists of :-

1. Fine albuminous granules intermixed with a few fat globules and pigmented granules.

2. Small globules of about half the size of a red bloodcorpuscle consisting of a lipoid substance.

3. Oval amyloid bodies composed of concentric layers. These are, however, not invariably found. 
4. The so-called "sympexions" of Robin, oval concrements of a wax-like substance, the nature of which is not known."

The crystalline substances appear only when the semen is inspissated. They present various forms-prisms, rosettes, \&c., —and are sometimes called "Böttcher's spermine crystals." They are insoluble in alcohol, ether, and chloroform, soluble in hot water, in formol, dilute alkalies and alkali carbonates, and in dilute acids. They are coloured black by a solution of iodine in potassium iodide (Florence's reagent). Like many ammonium-bases spermine gives a characteristic colour reaction with alloxan. ${ }^{2}$ On evaporating a solution of spermine to which a saturated solution of alloxan has been added, a red colour appears, which changes into violet on the addition of alkali. The spermine crystals are not identical, as was formerly believed, with the crystals found in the blood of leucæmic patients ("Zenker's crystals"), or with the "CharcotLeyden crystals" which occur in the sputum of asthmatic persons.

Their chemical nature is still a matter of doubt. According to Schreiner, they are the phosphate of an organic base spermine, $\mathrm{C}_{2} \mathrm{H}_{5} \mathrm{~N}$, which Ladenburg and Abel ${ }^{3}$ believed to be Aethylenimin $\mathrm{C}_{2} \mathrm{H}_{4} \mathrm{NH}$. This is disputed, however, by Majert and Schmidt, who ascribe to the base the formula $\mathrm{C}_{5} \mathrm{H}_{14} \mathrm{~N}_{2}$, and by Poehl, ${ }^{4}$ who has attributed very remarkable properties to this substance.

According to Poehl, spermine is possessed of marked pharmacological properties, and has a powerful influence on the metabolism. It is recommended by Poehl as a valuable therapeutic agent. His statements have not been confirmed by other observers-for example Dixon ${ }^{5}$-and his views are now not generally accepted.

1 Cohen, "Die krystallinischen Bildungen des männlichen Genitaltraktus," Centralblatt f. allg. Pathologie u. pathol. Anatomie, vol. x., 1899. (This paper gives a very complete bibliography.)

2 Poehl, "Weitere Mitteilungen über Spermin," Berliner klin. Wochenschrift, 1891.

3 Ladenburg and Abel, "Über das Aethylenimin," Ber. der deutschen chem. Gesellschaft, vol. xxi., 1888.

- Poehl, Die Physiologisch-Chemischen Grundlagen der Spermintherapie, Petersburg, 1898.

"Dixon, "The Composition and Action of Orchitic Extracts," Journal of Physiology, vol. xxvi., 1901. 
Choline, which gives the same reactions as spermine with iodine and alloxan, has also been stated to occur in the semen.

The various glands of the genital tract contribute to the formation of the semen in the following way :-

The spermatozoa are formed in the testis, which secretes an albuminous fluid as the medium in which the spermatozoa move about. Crystals smaller than the crystals of sperminephosphate have been observed by Lubarsch ${ }^{1}$ in the tubules of the testis. They are insoluble in formol and 50 per cent. acetic acid, and swell up under the action of alkali. Other crystalloid rod-like formations in the interstitial cells have been described by Reinke ${ }^{2}$ and von Bardeleben. ${ }^{3}$ The nature of these crystals, which have been found so far only in human testes, is unknown. Amyloid bodies, which are coloured blue with difficulty by iodine, have been observed by Dareste.

The secretion of the epididymis has not been chemically investigated. The vesiculæ seminales secrete a substance of a protein nature. Both these secretions have a faintly alkaline reaction.

In the guinea-pig the protein substance secreted by the vesiculæ seminales clots if brought in contact with blood. This property is perhaps a means whereby fertilisation is ensured, since in the guinea-pig coitus may take place immediately after the termination of the previous pregnancy, when the uterus is still widely dilated. This unfavourable condition is compensated for by the formation of a clot brought about by the action of the sernen on the blood which is still present in the uterus. ${ }^{4}$

The prostate gland secretes an opaque fluid having a faintly acid reaction (which may become neutral or alkaline in in-

1 Lubarsch, "Über das Vorkommen Krystallinischer und Krystalloider Bildungen in den Zellen des Menschlichen Hodens," Virchow's Archiv, vol. cxlv., 1896.

2 Reinke, "Beiträge zur Histologie des Menschen," Archiv f. mikroskop. Anatomie, vol. xlvii., 1896.

3 Bardeleben, "Beiträge zur Histologie des Hodens und zur Spermatogenese beim Menschen," Archiv f. Anatomie u. Physiologie, Anatomische Abteilung, Supplement, 1897.

- Landwehr, "Über den Eiweisskörper der vesicula seminalis der Meerschweinchen," Pflüger's Archiv, vol, xxiii., 1880. 
flammatory conditions of the prostate). It contains spermine, ${ }^{1}$ which, when brought together with the phosphates secreted by other genital glands, forms the characteristic "Böttcher's crystals."

The secretion of the prostate also contains the substance which gives the characteristic smell to the ejaculated semen, the lecithin-like globules, and a protein substance. The statement that this protein is an albumose is probably not correct, since albumoses have never been found to occur in a living cell. Camus and Gley ${ }^{2}$ found in the prostatic secretion of some animals a ferment, vesiculase, which has the property of coagulating the fluid in the vesiculæ seminales. The presence of this ferment in the ejaculated semen produces the formation of a coagulum. This ferment appears to have the function of ensuring fertilisation, since it occurs only in those species where the contact between male and female is of very short duration. (See p. 233.)

Cowper's glands secrete a stringy mucinous substance.

If a solution of iodine in potassium iodide is added to semen, brown crystals are formed (Florence's reaction). This reaction is common to many substances belonging to the group of organic ammonium bases. One of the best-known members of this group is choline, which forms part of the lecithin molecule, and is, therefore, a constituent of almost every animal cell. Probably the reaction is not due to spermine, as Florence ${ }^{3}$ states, but to choline, as Bocarius ${ }^{4}$ believes, since other secretions and tissue extracts which do not contain spermine give the same reaction.

Another reaction for semen, which is much more specific, has been discovered by Barberio. By the addition of picric acid, fine rhombic or needle-shaped crystals are formed. It is doubtful which substance is responsible for this reaction. The

1 Fürbringer, "Die Störungen der Geschlechtsfunktion des Menschen"; in Nothnagel, Pathologie u. Therapie., vol. xix., Part III., 1895.

2 Camus and Gley, "Action Coagulante du Liquide Prostatique sur le Contenu des Vésicules Séminales," Comptes R€ndus, vol. cxxiii., 1896.

${ }^{3}$ Florence, "Du Sperme et des Taches du Sperme," Archives d'Anthropologie Criminale, vol. xi., 1896 ; vol. xii., 1897.

4 Bocarius, "Zur Kenntniss der Substanz welche die Bildung von Florencechen Krystallen bedingt," Zeitschrift f. physiologische Chemie,vol. xxxiv., 1902. 
observations of Littlejohn and Pirie ${ }^{1}$ show that the substance which forms the crystalline picrate is secreted by the prostate and by Cowper's glands, and, further, that this substance appears to be specific for human semen, since a negative result is obtained with the semen of monkeys, rabbits, and rats.

\section{The Chemistry of the Spermatozoön ${ }^{2}$}

Owing to the brilliant work of Miescher, ${ }^{3}$ which has been continued by Kossel ${ }^{4}$ and his pupils, our knowledge of the chemistry of the spermatozoon is more complete than that of any other cell.

Thanks to the intelligent generosity of the head of a large fishery concern in Bâle, Miescher obtained a liberal supply of the milt of the salmon, the sexual organs of which develop during the passage up the Rhine. By controlling his mechanical manipulations by means of histological observations Miescher was able to investigate separately the different morphological elements of the spermatozoa. The tails of the spermatozoa are very rich in phosphorised fats, and contain besides a typical protein, cholesterin, and fat, in the following proportions :-

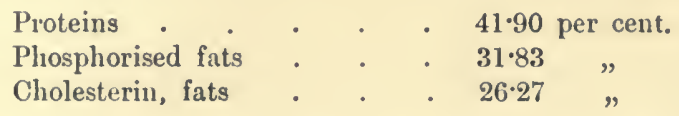

Similar conditions were found to exist in the case of other fishes and in the case of the ox. The heads were found to contain only traces of fat, lecithin and cholesterin, and to be composed almost entirely of a substance very rich in phosphorus. This on further investigation proved to be a combination of a basic substance, very rich in nitrogen, which Miescher called

1 Littlejobn and Pirie, "The Micro-Chemical Tests for Semen," Edin. Med. Jour., 1908. (This paper contains references to the literature.)

"For a detailed account of this subject and the literature see Burrian, "Chemie der Spermatozoen, I.," in Ergebnisse der Physiologie, vol. iii., 1804, and "Chemie der Spermatozoen, II.," in Ergebnisse der Physiologie, vol. v., 1906.

${ }^{3}$ Miescher, Histochemische und Physiologische Arbeiten. Gesammelt und Herausgegeben von Seinen Freunden, vol. ii., Leipzig, 1897.

"Kossel, " Über die einfacbsten Eiweisskörper," Biochemisches Centralblalt, vol. v., 1906-7, Part I. 
protamine, and a substance rich in phosphorus, having the nature of an acid and belonging to the group of substances known as nucleinic acids, which occur in the nuclei of somatic cells in combination with protein substances as the so-called nucleoproteins.

The comparative chemical investigations of Kossel showed, that while the nucleinic acid radicle present in the spermatozoa of various species of fishes shows only very little variation, the basic part is different for each species. It has, therefore, been found convenient to distinguish these basic substances by separate names, derived from the Latin names of the species of the fish in which they occur. The basic substance of the head of the spermatozoön of the salmon is salmine, that of the herring clupeine, and so on. Since they have certain general chemical and physical characters in common they have been classed together in a group, which has received the name "Protamine," which was originally used by Miescher to denote the basic substance in the spermatozoa of the salmon.

The protamines are strongly basic substances which absorb carbonic acid from the air. They are soluble in water, insoluble in alcohol and ether; not coagulable by heat; free from sulphur. They are very rich in nitrogen, the percentage amount varying from 33 per cent. to 25 per cent., while that of an albumen or globulin is about 16 per cent. They give a strong biuret reaction. Like other proteins, they are precipitated by tannic acid, phosphotungstic acid, picric acid, and ferrocyanic acid; but while the proteins are precipitated by these reagents in acid solution only, the protamines, by virtue of their basic character, form a precipitate with these reagents even in alkaline solution. They form compounds with the salts of the heavy metals (copper, mercury, silver, platinum). The protamines combine with many other protein substances in neutral or faintly alkaline solution, so that a precipitate is formed if, for example, a solution of protamine is added to a solution of caseinogen. ${ }^{1}$

If injected into an animal they have a strongly toxic action, even if small doses are given. ${ }^{2}$

1 Hunter (A.), "Über die Verbindungen der Protamine mit anderen Eiweiss-körpern," Zeitschrift f. phys. Chemie, vol. liii. 1907.

2 Thompson, "Die physiologische Wirkung der Protamine," Zeitschrift f. physiol. Chemie, vol. xxix., 1899. 
Although differing in many respects from the protein substances, the protamines have been shown by Kossel to have a constitution so similar to that of the proteins that they are now considered to represent one group of the protein substances.

The study of the products of hydrolytic decomposition shows that while in the case of the typical proteins, such as the proteins of muscle, of milk, or of the serum, the nitrogen is bound up in the form of a great many different substances, e.g. tyrosine, leucine, alanine, glycine, cystine, \&c., of which as many as fifteen have been isolated, the protamine molecule is composed of only a few constituent substances. And, further, while in the case of the typical proteins the main bulk of the substance obtained on hydrolysis belongs to the monoamino acids, the protamines are composed largely of the diamino acids: arginine, lysine, and histidine, which, from their basic nature and the fact that they contain six carbon atoms, have received the name "hexonebases."

Of these the most important one is arginine, which, on boiling with baryta, is decomposed into urea and diaminovalerianic acid (ornithin), and has the structure-

$$
\stackrel{\stackrel{\mathrm{NH}_{2}}{!}}{\mathrm{NH}=\mathrm{C}}-\mathrm{NH}-\mathrm{CH}_{2}-\mathrm{CH}_{2}-\mathrm{CH}_{2}-\stackrel{\mathrm{NH}_{2}}{\mathrm{CH}}-\mathrm{COOH}
$$

In salmine, for instance, eight-ninths of the nitrogen is bound up as arginine, while the remainder of the nitrogen is present in the form of monoamino acids, viz., serine, monoaminovalerianic acid and proline, in the following proportions : 10 molecules of arginine +2 molecules of serine +2 molecules of proline +1 molecule of aminovalerianic acid. Similar relations are found to exist in the case of scombrine and clupeine. In both these protamines eight-ninths of the total nitrogen is present in the form of arginine, which is combined with alanine and proline in the case of scombrine, and with alanine, proline, serine, and aminovalerianic acid in the case of clupeine.

Since eight-ninths of the nitrogen of these three protamines is present in the form of arginine, and since arginine contains four nitrogen atoms, while the amino acids with which it is combined contain only one nitrogen atom, it follows that in 
these three protamines the number of arginine molecules must be twice as great as the total number of monoamino acid molecules present in the protamine molecule.

The investigations of Kossel and Pringle ${ }^{1}$ have shown that substances can be obtained by partial hydrolysis of these protamines, the so-called "protones," which represent intermediate decomposition products between these protamines and the amino acid units of which the protamines are built up, and that these protones again contain eight-ninths of their total nitrogen in the form of arginine. It follows, then, that the molecules of salmine, scombrine, and clupeine have a symmetrical structure, and are built up of molecular complexes containing always twice as many arginine molecules as monoamino acid molecules.

In other protamines the amount of arginine is smaller, while lysine is found to be present. At the same time the number of monoamino acids bound up in the protamine molecule increases so that the different protamines exhibit varying degrees of complexity. Ammonia and certain monoamino acids (glycocoll, phenylalanine, glutaminic acid, aspartic acid, the sulphur-containing cystine) are never present.

In the case of some fishes-e.g. Gadus morrhua, ${ }^{2}$ Lota vulgaris ${ }^{3}$ - the basic substances isolated from the spermatozoa differ essentially from the protamines, and in character more resemble the typical proteins. Their nitrogen content varies between 16 per cent. and 18 per cent. On hydrolysis the yield of diamino acids is very much smaller than in the case of the protamines. Only 30 to 40 per cent. of diamino acids, among which arginine again preponderates, are obtained. Accordingly they are not so strongly basic as the protamines. They contain cystine. They are precipitated by ammonia, a reaction which the protamines do not give. They resemble in their behaviour substances which have been isolated from the nuclei of somatic cells, e.g. the blood corpuscles of the fowl, the

1 Kossel and Pringle, "Über Protamine und Histone," Zeitschrift f. phys. Chemie, vol. xlix., 1906.

${ }^{2}$ Kossel and Kutscher, "Beiträge zur Kenntniss der Eiweisskörper," Zeitschr.f. phys. Chemie, vol. xxxi., 1900.

${ }^{3}$ Ehrström, "Über ein neues Histon aus Fischsperma," Zeitschrift $f$. phys. Chemie, vol. xxxii., 1901. 
thymus, \&c., and which form another class of the protein substances, to which the name histone has been given. In their properties and their composition these substances, therefore, take a place between the typical proteins and the protamines.

The substance isolated from the spermatozoa of the carp, cyprinine (or rather the two cyprinines, since two slightly different substances have been isolated), is on the border-line between the protamines and the histones. The cyprinines do not contain any cystine, they are not precipitated by ammonia, and only about 35 per cent. of their total nitrogen is present in the form of diamino acids, mainly as lysine in the one of the two cyprinines. ${ }^{1}$

The chemical differences which exist between the spermatozoa of the different species and orders do not show any connection with the zoological relationship.

The significance of the presence of histones in the spermatozoa of some fishes becomes more apparent if the development of the sexual organs is considered.

It was Miescher who pointed out that in the salmon the sexual organs develop at the expense of the muscular system and that the salmine deposited in the testis during the breeding season must be derived from the proteins of the muscle, since the fish does not take any food during that period. A comparison between the amount of arginine present in salmine, and that present in the muscle of the salmon shows ${ }^{2}$ that all the arginine deposited as salmine during the breeding season can be accounted for by the arginine which becomes available by the involution of the muscular elements.

This result would suggest that the formation of salmine is not due to a profound chemical alteration of the various constituents of the muscle-proteins, transforming the divers substances into arginine, but rather to a gradual enrichment in arginine of the muscle protein by the splitting off of a number of the other constituent substances.

1 Kossel and Dakin, "Beitrag zum System der einfachsten Eiweisskörper," Zeitschrift f. phys. Chemie, vol. xl., 1904.

${ }^{2}$ Kossel, "Einige Bemerkungen über die Bildung der Protamine im Thierkörper," Zeitschrift für physiologische Chemie, vol. xliv., 1905. Weiss, "Untersuchungen ïber die Bildung des Lachs-Protamins," Zeitschrift für physiologische Chemie, vol. lii., 1907. 


\section{BIOCHEMISTRY OF THE SEXUAL ORGANS 293}

The investigation of the unripe spermatozoa of the salmon ${ }^{1}$ and of the mackerel ${ }^{2}$ has shown indeed that instead of a protamine a histone is present, i.e. a substance which represents the transition stage between the typical proteins and the protamines.

It would appear, therefore, that in the fishes the chemical processes which lead to the formation of the spermatozoa consist of a rearrangement of the constituents of the proteins of somatic tissue, so that a gradual accumulation of the basic substances rich in nitrogen takes place. This change leads at first to the formation of histones, and in some species stops here. In the majority of cases the change proceeds to the formation of substances belonging to the protamines.

In the case of some Invertebrates (Arbacia pustulosa, ${ }^{3}$ Sphorechinus granularis $\left.{ }^{4}\right)$ the spermatozoa have been investigated and histones have been found to be present.

Of the higher Vertebrates, the spermatozoa of the frog, the cock, the boar, and the bull have been examined, ${ }^{5}$ but neither protamines nor histones were found.

The acid substance isolated from the spermatozoa, the nucleic acid, does not show any great variation in the different species and classes of animals. It is, in fact, very similar to the nucleic acid present in the nuclei of somatic cells, and is probably identical with the nucleic acid prepared from the thymus. These nucleic acids do not belong to the proteins, but they exist in the cell always in combination with proteins as nucleins or as nucleoproteins, according to the amount of protein present in the combination.

The nucleic acids are dry, pulverulent, white substances of a decidedly acid character, containing 9 to 10 per cent. of

1 Miescher, "Physiologisch-Chemische Untersuchungen über die Lachsmilch," Histochemische Arbeiten, Archiv f. Experimentelle Pathologie $u$. Pharmakologie, vol. xxxvii., 1896-1897.

2 Bang (I.), "Studien über Histon," Zeitschrift f. physiolog. Chemie, vol. xxvii., 1899.

3 Mathews, "Zur Chemie der Spermatozoen," Zeitschrift f. phys. Chemie, vol. xxiii., 1897.

"Kossel, "Über die einfachsten Eiweisskörper," Biochemisches Centralblatt, vol. v., 1906-7.

5 Miescher, loc. cit., "Die Spermatozoen einiger Wirbelthiere," Histochemische Arbeiten; Mathews, loc. cit. 


\section{THE PHYSIOLOGY OF REPRODUC'ION}

phosphorus, not easily soluble in cold water, but readily dissolved by alkalies or ammonia. They are precipitated from their solutions by mineral acids and by alcohol. They form insoluble salts with the heavy metals and with barium, calcium, and strontium. If pure, they do not give the colour reactions for proteins. They rotate polarised light to the right. A solution of nucleic acid, acidified with acetic acid, gives a precipitate with protein solutions. By boiling the watery solutions the nucleic acids are partially decomposed. ${ }^{1}$ Complete hydrolysis is brought about by treatment with hot acids. The main products of hydrolysis which are thus obtained can be grouped under five headings :-

1. Phosphoric acid.

2. Lævulinic acid, a substance formed by the oxidation of carbohydrates, and indicating the presence of a hexose (some nucleic acids contain a pentose).

3. Derivatives of purine-

(1) $\mathrm{N}=\mathrm{CH}(6)$

(2) $\mathrm{HC} \quad \mathrm{l}(5)-\mathrm{NH}(7)$

(3) $\stackrel{\|}{\mathrm{N}}-\stackrel{\|}{\mathrm{C}}(4)-\mathrm{N} \quad(9)$

namely-

Adenine $=6-$ Aminopurine ; Hypoxanthine $=6-$ Oxypurine ;

Guanine $=2$ Amino -6 Oxypurine ; Xanthine $=2-6$ Dioxypurine.

Of these only adenine and guanine are present as such in the nucleic acid molecule, while hypoxanthine and xanthine are formed from them in the process of hydrolysis by a secondary reaction.

4. Derivatives of pyrimidine-

namely-

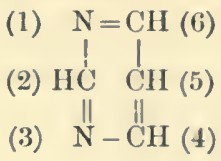

$\begin{aligned} \text { Cytosine } & =6 \text { Amino }-2 \text { Oxypyrimidine } \\ \text { Uracil } & =2-6-\text { Dioxypyrimidine } \\ \text { Thymine } & =5 \text { Methyl }-2-6 \text { Dioxypyrimidine (Methyl-Uracil). }\end{aligned}$

1 For literature for nucleic acid see Steudel, "Nucleine, Nucleinsäuren und ihre Spaltungsprodukte," Biochemisches Centralblatt, vol. vi., 1907; also Burrian, loc.cit.; Levene, Zeitschr.f. phys. Chemie, vols. xxxii. to 1., Biochem. Zeitschr., vols. iv., v., and ix. 
Of these cytosine and thymine are present as such in the nucleic acid molecule, while uracil is formed from cytosine by a secondary reaction in the process of the splitting up of the nucleic acid.

Reference has already been made to the fact that in the salmon the material for the growth of the testis is supplied by the muscle undergoing atrophy. The analogy existing between the glycophosphoric acid which forms the "skeleton" of the nucleic acid, and the glycerophosphoric acid which forms the skeleton of phosphorised fats, suggests that the glycerophosphoric acid present in the muscle as phosphorised fat furnishes the material from which the glycophosphoric acid bound up in the testis as the nucleic acid is formed. This view is supported by the fact ${ }^{1}$ that, during the period of the growth of the testis, the blood of the salmon is exceptionally rich in phosphorised fats, and that the tail of the spermatozoön is also very rich in phosphorised fats. It would appear that these substances, after having been transported to the testis, are there built up partly into the nucleus of the spermatozoön, while part remains accumulated in the tail of the spermatozoön as reserve material.

The origin of the purine and pyrimidine derivatives which form part of the nucleic acid molecule is as yet obscure. In the case of the developing ovum it has been shown (see p. 269) that the living cell has the power of synthesising these substances. But the substances which supply the material for their formation, and the reactions which lead to it, have not yet been revealed.

The substances detailed above represent all the constituent parts of the nucleic acid molecule, so that it is possible to reconstitute the nucleic acid from the products of its decomposition. According to Steudel, ${ }^{2}$ the process of hydrolysis may be expressed by the following equation :-

$$
\begin{array}{ccc}
\mathrm{C}_{43} \mathrm{H}_{57} \mathrm{~N}_{15} \mathrm{O}_{30} \mathrm{P}_{4}+4 \mathrm{H}_{2} \mathrm{O} & =\mathrm{C}_{5} \mathrm{H}_{5} \mathrm{~N}_{5} \mathrm{O}+\mathrm{C}_{5} \mathrm{H}_{5} \mathrm{~N}_{5}+\mathrm{C}_{5} \mathrm{H}_{6} \mathrm{~N}_{2} \mathrm{O}_{2} \\
\text { Nucleic acid. } & \text { Guanine. } & \mathrm{C}_{4} \mathrm{H}_{5} \mathrm{~N}_{3} \mathrm{O} \\
& +\mathrm{C}_{24} \mathrm{H}_{44} \mathrm{O}_{30} \mathrm{P}_{4} . & \text { Thymine. Cytosine. }
\end{array}
$$

1 Miescher, loc, cit.

2 Steudel, "Die Zusammensetzung der Nukleinsäuren aus Thymus u. aus Heringsperma," Zeitschr. f. phys. Chemie, vol. liii., 1907. 
The non-nitrogenous part is split up further according to the following equation :-

$$
\begin{aligned}
\mathrm{C}_{24} \mathrm{H}_{44} \mathrm{O}_{30} \mathrm{P}_{4}+4 \mathrm{H}_{2} \mathrm{O}+20= & 4 \mathrm{C}_{6} \mathrm{H}_{12} \mathrm{O}_{6}+4 \mathrm{HPO}_{3} . \\
& \begin{array}{c}
\text { Hexose Hetaphosphoric } \\
\text { sugar. acid. }
\end{array}
\end{aligned}
$$

In other words, the "skeleton" of the nucleic acid molecule is formed by four molecules of metaphosphoric acid combined with four molecules of a sugar: ${ }^{1}$ a tetraglyco-metaphosphoric acid, similar to the glycerophosphoric acid which forms the "skeleton" of phosphorised fats. In the nucleic acid molecule this glycophosphoric acid is combined with four different nitrogenous substances, of which two are pyrimidine derivatives and two are purine derivatives. ${ }^{2}$

It is an interesting fact that while nucleic acid prepared from ripe spermatozoa does not contain pentoses, these substances are stated to be present in the nucleic acid of the testis of the bull, ${ }^{3}$ which represents the acid constituent of the nuclei of the sexual element in the various stages of their development. Since the statement of the presence of a pentose in the nucleic acid from the testis of the bull is based only on the preparation of an osazone, further investigation on this point and analytical data are necessary before it can be accepted.

The observations of Miescher ${ }^{4}$ allowed of a quantitative estimation of the amount of nucleic acid and protamine present in the head of the spermatozoa of the salmon after the fat had been removed. 60.5 per cent. of nucleic acid was found to be combined with 35.5 per cent. of salmine, so that 96 per cent. of the head of the spermatozoön consists of protamine nucleate. This protamine nucleate is, however, not of the same nature in different parts of the head, the outer layer containing a basic nucleate rich in protamine, while the inner portion is composed of an acid nucleate poorer in protamine.

1 The sodium-salt of a tetraphosphoric acid can be prepared by fusing together the sodium metaphosphate and pyrophosphate (Kraut and Uelsmann, Liebig's Annalen, vol. cxviii., 1861). The organic derivatives of this base have not yet been studied.

${ }^{2}$ For a slightly different view of the constitution of nucleic acid, see Burrian in Ergebnisse der Physiologie, vol. v., loc, cit.

s Steudel, "Über die Kohlenhydratgruppe in der Nukleinsäure," Zeitschrift f. physiolog. Chemie, vol. lvi., 1908.

4 Miescher, Histochemische Arbeiten. 
The same quantitative relations have been shown to exist in the spermatozoa of the herring, ${ }^{1}$ and similar conditions may. be assumed to exist in the case of the spermatozoa of other animals, the only difference being the nature of the protein molecule which is combined with the nucleic acid. It is a protamine or a histone in the case of the fishes, but a typical protein in the case of the higher Vertebrates. ${ }^{2}$

Of the remaining 4 per cent. about one half consists of inorganic salts, mainly calcium phosphate and calcium carbonate, while the other half consists of an organic substance, the composition of which has not yet been recognised. The most important fact. known about it is that it contains 0.12 per cent. iron in organic combination. The presence of iron can be recognised only after incineration. To this iron-containing organic substance Burrian ${ }^{3}$ applies the name "Karyogen," a word originally coined by Miescher to designate the residue which he obtained after what Schmiedeberg's ${ }^{4}$ calculations showed to be an incomplete extraction of the protamine and nucleic acid from the heads of the spermatozoa of the salmon. Since Macallum ${ }^{5}$ was able to demonstrate by means of a microchemical method the presence of iron in the chromatin of the nuclei of cells, it seems possible that the "Karyogen" represents the chromatin substance of the spermatozoön.

The chemical analysis of the spermatozoön is therefore complete. It shows that the tail is very rich in phosphorised fats which are accompanied by cholesterin, fats, and a typical protein. The head consists almost entirely (96 per cent.) of a substance-a nucleoprotein-one component of which is constant for the different species and classes-the nucleic

1 Bendix and Elstein, “Über den Pentosengehalt tierischer und menschlicher Organe," Zeitschrift f. allgem. Physiologie, vol. ii., 1902.

2 Mathews, "Zur Chemie der Spermatozoen," Zeits:hrift f. phys. Chemie, vol. xxiii., 1897.

3 Burrian, Ergebnisse der Physiologie, vol. v., 1906.

4 Miescher, "Physiologisch-chemische Untersuchungen über die Lachsmilch, nach den hinterlassenen Aufzeichnungen $u$. Versuchsprotokollen des Autors bearbeitet u. herausgegeben von O. Schmiedeberg," Arch.f. Experimentelle Pathologie u. Pharmakologie, vol. xxxvii., 1896, and in Histochemische u. Physiologische Arbeiten von Miescher.

5 Macallum, "On the Demonstration of the Presence of Iron in Chromatin by Microchemical Methods," Proc. Roy. Soc., vol. 1., 1892. 
acid. The other more or less basic component varies widely for the different classes of Vertebrates, and shows minor variations for the different species in any one class. Besides this nucleoprotein, another organic substance, containing iron in organic combination, is present in very small amounts.

It is perhaps natural that attempts should have been made to associate these different substances with the functions of the spermatozoön. But such speculations are hardly justifiable until our knowledge of the nucleus of the ovum is as complete as it is in the case of the male nucleus. At present we know practically nothing of the chemical composition of the nucleus of the ovum. Nor is it likely-and Miescher himself clearly recognised this-that the intricate processes which are connected with fertilisation and heredity are directly dependent upon such crude chemical facts as the percentage of arginine or serine, or the composition of nucleic acid.

We are on safer ground when we consider the head of the spermatozoön simply as a typical nucleus, and when we draw deductions from the chemical composition of the nuclear material of the spermatozoön, as to the functions of the nucleus generally.

It is a very suggestive fact that the nucleus - that is to say, that part of the cell which is pre-eminently concerned in the new formation of living material-is distinguished by the presence of pyrimidine and purine derivatives, substances rich in nitrogen, which are arranged in a chain of alternating $\mathrm{C}$ and $\mathrm{N}$ atoms. ${ }^{1}$ In the spermatozoön, where the nuclear function finds its most pronounced expression, we find, at least in the case of the fishes, a further concentration of such groups with alternating $\mathrm{C}$ and $\mathrm{N}$ atoms. For, besides the pyrimidine and purine derivatives of the nucleic acid part, there is also present the basic protamine part. As has been explained above, this part is composed largely of arginine, which, as the formula given on p. 290 shows, contains the group-

$$
\mathrm{NH}=\stackrel{\mathrm{NH}_{2}}{\mathrm{C}}-\mathrm{NH}-\mathrm{CH}_{2}-\ldots
$$

${ }^{1}$ Kossel, "Einige Bemerkungen über die Bildung der Protamine im Thierkörper," Zeitschrift f. phys. Chemie, vol. xliv., 1905. 
These facts suggest that this special arrangement of alternating $\mathrm{C}$ and $\mathrm{N}$ atoms is the chemical expression of the specific function of the nucleus, and that this arrangement plays a special part in bringing about the chemical processes which lead to growth and to the new formation of living matter.

In the case of the other organic compound present in every nucleus, which contains iron in organic combination, the evidence that it plays an active part in the synthetic functions of the nucleus is even more suggestive. It was shown by Spitzer ${ }^{1}$ that the oxidising enzymes which are present in every cell are localised in the ircn-containing constituent of the nucleus, and Loeb concludes that the nucleus must be regarded as the essential respiratory or oxidising organ of the cell. ${ }^{2}$ Oxidation processes are generally supposed to be necessary only for the transformation of chemical energy into heat and mechanical work. But they are, according to Loeb, equally necessary for other more important and more general vital processes, i.e. growth and cell division, which come to a standstill in the absence of oxygen. As a rule, cell division follows upon the formation of nuclear material, especially chromatin material, from the protoplasm of the cell. If we accept Schmiedeberg's ${ }^{3}$ view that in the living cell synthetic processes may occur through the intervention of oxygen, we may conclude that the oxygen which is required for the process of cell division is probably needed for the synthesis of this nuclear material, and, since the iron-containing organic compound present in the nucleus has the power of bringing about oxidations, it would follow that the synthetic functions of the nucleus are dependent upon this compound. It must, however, be understood that these considerations are still very hypothetical, and that other biologists ${ }^{4}$ deny that the nucleus is the respiratory or oxidising centre of the cell.

The power possessed by the spermatozoön of bringing about segmentation of the ovum has been attributed by some authors

1 Spitzer, "Die Bedeutung gewisser Nukleoproteide für die oxydative Leistung der Zelle," Pflüger's Archiv, vol. lxvii., 1897.

2 Loeb, Dynamics of Living Matter, New York, 1906.

3 Schmiedeberg, "Über Oxydationen und Synthesen im Thierkörper," Archiv f. experimentelle Pathologie u. Pharmakologie, vol. xiv., 1881.

+ See Verworn, Allgemeine Physiologie, 1909. 
to the action of ferments present in the spermatozoön. Piéri ${ }^{1}$ claimed to have extracted from the spermatozoa of Strongylocentrotus lividus and Echinus esculentus a ferment, "ovulase," which induced segmentation of mature ova. Similar observations were made by Dubois ${ }^{2}$ on Echinus, and by Winkler ${ }^{3}$ on Spharechinus granulosis and Arbacia pustulosa. The evidence on which these authors base their conclusion is, however, not very convincing, and the searching criticism to which their observations were subjected by Gies, ${ }^{4}$. who repeated their experiments, tends to show that their results were due to other factors. Gies was unable to extract either from spermatozoa or from fertilised ova any enzyme or zymogen capable of causing development in mature ova of the same species. Similarly Cremer $^{5}$ was unable to bring about fertilisation by means of the press-juice obtained from spermatozoa (see p. 222).

Wolfgang Ostwald ${ }^{6}$ has determined the amounts of oxidising ferments present in the ovaries and testes of toads, frogs, and newts. The watery extracts of these organs had the power of decomposing hydrogen peroxide with the formation of water and oxygen, and of oxidising guaiaconic acid to guaiacum blue, so that a blue colour appeared when these extracts were added to an emulsion of guaiac resin. These reactions indicate the presence of a catalase and of a peroxidase in the extracts of the sexual glands. Such ferments are present in many, if not all, organs and tissue fluids, but a special significance is attributed by Ostwald to their presence in the ova and spermatozoa, because he found the spermatozoa to contain more catalase and more peroxidase than the ova, and because the activity

1 Piéri, "Un Nouveau Ferment soluble: l'Ovulase," Archives de Zoologie Expérimentale et Générale, vol. xxix., 1899.

"Dubois, "Sur la Spermase et l'Ovulase," Comptes Rendus de la Société de Biologie, vol. lii., 1900.

3 Winkler (H.), "Über die Furchung unbefruchteter Eier unter der Einwirkung von Extraktiostoffen a. d. Spermata," Nachrichten der kgl. Gesellschaft der Wissenschaften zu Göttingen, Mathcmat.-Phys. Klasse, 1900.

4 Gies, "Do Spermatozoa contain an Enzyme having the Power of Causing Development of Mature Ova?" American Journal of Physiology, vol. vi., 1901.

- Quoted from Loeb, Dynamics of Living Matter.

- Wolfgang Ostwald, "Über das Vorkommen von oxydativen Fermenten in den reifen Geschlechtszellen von Amphibien und über die Rolle dieser Fermente bei den Vorgängen der Entwicklungserregung," Biochemische Zeitschrift, vol, vi., 1907. 
of these ferments - especially the peroxidase-is increased when the extracts of ova are mixed with the extracts of spermatozoa.

The development of the ovum after fertilisation is, according to Ostwald, due to this activation of the oxidising ferments inducing a chemical synthesis of nuclein substances, which form a localised coagulum of a definite orientation, namely, the astrosphere. According to the view of Fischer and Ostwald, ${ }^{1}$ which is, however, not accepted by other workers, ${ }^{2}$ the formation of the astrosphere initiates cell-division, and therefore the development of the egg.

A very ingenious theory of the chemical mechanism of fertilisation has been put forward recently by Loeb, ${ }^{3}$ as the result of his work on artificial parthenogenesis. According to Loeb, the development of the mature ovum is dependent upon two processes. It is initiated by a cytolysis affecting the periphery of the cell. This process, which is accompanied by the formation of a fertilisation membrane, can be induced by any agent having a cytolyticaction, such as heat, ether, fatty acids, saponin, or the serum of an animal of a different species. If this initial cytolysis is allowed to proceed unchecked, the eggs, although they may begin to divide, eventually undergo complete cytolysis. If, on the other hand, the initial cytolysis is inhibited by suitable means, such as treatment with potassium cyanide or immersion in hypertonic sea-water containing oxygen, the eggs will develop in the same way as if they had been fertilised by a spermatozoön.

If it be admittcd that artificial parthenogenesis represents the conditions governing fertilisation by a spermatozoön, then it follows that a spermatozoön should contain two substances, namely, a cytolysin, and a substance inhibiting the initial cytolysis. The presence in the spermatozoön of a cytolysin can indeed be proved. Extracts of the testis of a cock, or the dead semen (killed by heating) of a starfish or a mollusc, will induce the initial process of cytolysis in the eggs of a sca-urchin. The dead semen of a sea-urchin, however, is quite inactive against the eggs of a sea-urchin. This is in agreement with our knowledge of

1 Fischer and Ostwald, "Zur Physikalisch-Chemischen Theorie der Befruchtung," Pfïgtr's Archiv, vol. cvi., 1905.

2 See, for instance, Burrian, loc. cit.

3 Jacques Loeb, Die chemische Entwicklungserregung des tierischen Eies, Berlin, 1909. 
the actions of cytolysins generally. The cytolysins present normally in the serum or the cells of one animal are always inactive against the cells of animals of the same species, and act only against cells of animals of a different species. The explanation of this fact is to be found, according to Loeb, in the diminished permeability of the cells of one species towards the cytolysins produced by the cells of animals of the same species, the so-called auto-cytolysins.

Similarly the ovum of an animal is not permeable to the cytolysins contained in the spermatozoön of an animal of the same species. In order to bring about the development of the mature ovum the auto-cytolysin must be carried bodily into the egg. And that is the function of the motile spermatozoön.

\section{APPENDIX $^{1}$}

More recent experiments on different insects ${ }^{2}$ have confirmed the fact that in these animals, as in birds, the main source of the energy which is used up during development is fat. No nitrogen is lost, but some of the protein material undergoes partial oxidation, to uric acid, and may thus contribute to the "energy of development." Whether the glycogen which disappears during development serves as a source of energy is doubtful. The chitin which is deposited in the cuticle of insects is a compound built up mainly of carbohydrate-groups, and it seems likely that these carbohydrate-groups are derived from the glycogen, which thus contributes to the formation of the cuticle. It is interesting to note that glycogen appears to fulfil a similar function in the developing rabbit, where it also contributes to the building up of the growing tissues. ${ }^{3}$ It appears indeed to be a general law that carbohydrate material is essential for growth.

1 See p. 281.

2 Farkas, loc. cit.; Weinland, Zeitschr. f. Biologie, vol. xlvii., 1905; vol. xlviii., 1907; vol. li., 1908; vol. lii., 1909 ; Tangl, Pfüger's Archiv, vol. cxxx., 1909.

Lochbead and Cramer, loc. cit. 


\section{CHAPTER IX \\ THE TESTICLE AND THE OVARY AS ORGANS OF INTERNAL SECRETION \\ "Da muss sich manches Räthsel lösen, \\ Doch manches Räthsel knüpft sich auch."}

-GOETHE.

THE principal evidence supporting the theory that the ovary and testicle are organs of internal secretion is derived from the experimental study of the effects produced, firstly, by removing these organs, and, secondly, by transplanting them to abnormal positions in the body. Experiments of such a kind clearly demonstrate the influence of the ovary and testicle upon the growth and development of the other generative organs, and upon many of the secondary sexual characters. They indicate, moreover, that the nature of this influence is chemical rather than nervous. Certain further evidence, which is less satisfactory in character, has been obtained from experiments on the injection of ovarian and testicular extracts.

\section{The Correlation between the Testis and the other Male Organs and Characters}

It has already been recorded (p. 239) that the removal of the testes in adult life brings about a gradual atrophy of the prostate gland. It has also been shown that this operation, if performed prior to puberty, prevents the development of the prostate, whereas division of the vas deferens and the abolition of sperm production have no arresting influence. ${ }^{1}$ One-sided castration produces no effect, the retention of a single testis being sufficient to maintain the functional activity of both

1 Wallace (C), " Prostatic Enlargement," London, 1907. It is shown also that vasotomy has no influence on the growth and activity of the prostate. 
prostate glands. Similiarly it has been stated that Cowper's glands are probably dependent upon testicular influence for their growth and activity (p. 240).

More remarkable is the close correlation that exists between the testes and the secondary sexual characters of the male-that is to say, those characters which are found only in the male sex, but are not directly connected with the organs of generation.

Thus, it is notorious that castration before puberty in man prevents the growth of hair on the face, arrests the development of the male chest and pelvis, and preserves the high-pitched voice of boyhood by hindering the growth of the larynx, while at the same time it exercises a marked influence over the mental characteristics. ${ }^{1}$ It is equally well known that at the time of puberty, when the testes begin to assume their functional activity, there is a corresponding development of the secondary sexual characters, both in Man and in a large number of animals. This correlation appears to be still closer in those animals in which the increased testicular activity that takes place in the breeding season is associated with a periodic development of other sexual characters. Thus, in the male elephant the glands on the side of the face emit a musky secretion during rut. ${ }^{2}$

Darwin, ${ }^{3}$ in elaborating his theory of sexual selection, collected together numerous examples of secondary sexual differences occurring in animals of various kinds. More recently Cunningham, in a work upon Sexual Dimorphism, has cited a number of further cases, ${ }^{4}$ in many of which the structural

1 According to Hikmet and Regnault ("Les Eunuques de Constantinople," Bull. et Mém. de la Soc. d'Anthropologie de Paris, vol. ii., 5th series, 1906), the eunuchs of Constantinople bave the following mental characteristics:They are avaricious, illogical, obstinate (i.e. cannot change their ideas), have no judgment, accept information without proof; are not cruel, but fond of children and animals; are faithful in their affections, but have no courage ; their mental activity is very slight, and they are extremely fanatical. Senility is premature, but the teeth are kept solid and white. For skeletal differences in eunuchs, see below.

${ }^{2} C f$. page 305 .

${ }^{3}$ Darwin, The Descent of Man, Popular Edition, London.

4 Cunningham (J.T.), Sexual Dimorphism in the Animal Kingdom, London, 1900 ; "The Heredity of Secondary Sexual Characters in Relation to Hornones," Arch.f. Entwick. Mech., vol. xxvi, 1908. See also Hegar, Korrelationem der Keimdrüsen und Geschlechtsbestimmung, 1893 ; and Selheim, "Zur Lehre von den sekundären Geschlechtscharakteren," Beitrïge zu Geburtsh. u. Gynäk., vol, i., 1898. 
peculiarities in question are shown to be closely correlated with the essential organs of reproduction.

The effects of castration in the stag, for example, are discussed at some length by Cunningham, Morgan, ${ }^{1}$ and other writers. If the testes are removed in quite immature animals the antlers never develop, even the knobs failing to make an appearance. If castration is performed in stags whose antlers have just commenced to develop, these remain covered by skin, forming the so-called peruke antlers, which are not shed or renewed. If the operation is carried out after the complete development of the antlers, these are shed prematurely and are replaced in the next season by incomplete antlers with a tendency towards peruke formation, and these, on being thrown off, are not renewed. Partial castration in the immature stag is said to result in a weaker horn formation ; but the effect is general, and shows no restriction to the side on which the testis is wanting. ${ }^{2}$

The results of castration in the fallow deer have been investigated by Fowler, ${ }^{3}$ who summarises his results under five headings:-(1) Complete castration at birtl limits the horn formation to the development of single dugs; (2) Castration in mature life tends to produce asymmetry in the growth of the horns; (3) The antlers of castrated deer are often shed prematurely if the operation is performed after they have lost the velvet, but antlers which have grown after castration may be retained for over two years; (4) Incomplete castration shortly after birth is followed by a weak development of the antlers, which are otherwise normal; (5) One-sided castration may result in the abnormal or incomplete development of one antler, the other antler being nearly normal. The last point would seem to require confirmation.

In the prong-buck (Antilocapra americana), which is the

1 Morgan, Experimental Zoology, New York, 1907.

2 These statements are based chiefly upon the results of Caton's experiments with Wapiti and Canadian deer (Caton, Antelope and Deer of America, 2nd Edition, New York, 1881. See also Holdich, "Exhibition of Antlers of Deer showing Arrest of Development due to Castration"), Proc. Zool. Soc, 1905. Some further examples of sexual correlation are given in Chapter I. of this work, and Morgan, loc cit. Dr. Seligmann informs me that stags which fail to grow antlers (i.e. occasional "sports") have well-developed testicles.

${ }^{3}$ Fowler, "Notes on Some Specimens of Antlers of the Fallow Deer," \&c., Proc. Zool. Soc., 1894. 
only hollow-horned Ruminant that periodically sheds its loorns, the effects of castration are also quite distinct. The horns, instead of rising vertically as in normal individuals, curve forwards from the roots, and then bend downwards and backwards so as to terminate in incurved points in the close vicinity of the eyes. The anterior tine is almost completely suppressed. The horn-sheath is never shed, and as a consequence a composite sheath is developed, and this seems to go on growing as long as new sheaths are formed from the horn-core. ${ }^{1}$

It is interesting to note that in the eland, in which both sexes possess horns, the development of these structures is not appreciably affected by castration. ${ }^{2}$ A similar statement may be made about horned cattle, in which (in common with other cattle) castration in early life produces changes in the general proportions of the body.

In the sheep, also, castration during immaturity brings about changes in the bodily conformation. Thus, in breeds in which the males only are horned, the skulls of the wethers may resembles the females rather than the males. ${ }^{1}$ Differences in the form of the body have also been noted in eunuchs and other castrated animals. Thus, the bones of the limbs tend to be longer than the normal, producing a condition of gigantism. This is due to an arrest in the ossification of the epiphyses (which is one of the effects of castration). The same phenomena have been described in castrated guinea-pigs, oxen, capons, and various animals. $^{3}$

It is well known that caponisation or the removal of the

1 Pocock, "The Effects of Castration on the Horns of the Prong-buck," Proc. Zool. Soc., 1905. It is to be noted that horns are occasionally present in the fcmale prong-buck.

2 Seligmann, "Exhibition of a Skull of a Domestic Sheep which had been Castrated when Young," Proc. Zool. Soc., 1906. Changes in conformation as a result of early castration have also been described in other animals.

${ }^{3}$ Lannois and Roy, "Des Relations qui existent entre l'État des Glandes génitales males et le Développement du Squelette"; and Poncet, "De l'Influence de la Castration sur le Développement du Squelette," $C$. R. de la Soc. de Biol., vol. lv., 1902. See also Pittard, C. R. de l'Acad. des Sciences, vol. cxxxix., 1904), who gives statistics showing that there is often an increase in size in cunuchs, especially in the legs. For accounts of other anatomical differences in eunuchoid persons, see Duckworth, Jour. of Anat. and Phys., vol. xli., 1906, and Tandler and Gross (Arch. f. Entwick.-Mech., vol. xxvii., 1909). The latter authors discuss the general effects of castration on the organism. 
testes in fowls arrests the development of the comb and spurs and other secondary male characters which are normally present in the cock. Other instances of the effects of castration are briefly referred to by Darwin. ${ }^{1}$

Secondary sexual characters, however, are not always correlated with the essential organs of reproduction. For example, castration in the horse does not arrest the development of the withers-the gelding, in this respect, resembling the stallion rather than the mare, in which the withers are lower. ${ }^{2}$

In Arthropods the correlation between the secondary sexual characters and the generative glands appears to be far less close than it is among Vertebrates. Thus, Oudemans ${ }^{3}$ showed that the removal of the testes from the male caterpillar of Ocneria dispar had no influence on the development of the secondary male characters, these being normal. Kellogg ${ }^{4}$ performed a similar experiment on the caterpillar of the silkworm moth and obtained a like result. Crampton ${ }^{5}$ grafted the heads of caterpillars of one sex upon the bodies of individuals of the opposite sex, and found that the generative organs had no influence upon the development of the secondary sexual characters of the transplanted heads. Moreover, Meisenheimer ${ }^{6}$ found that in caterpillars artificially made hermaphrodite (by transplanting ovaries into males or testes into females) the original males always developed into butterflies with typical secondary male characters in spite of the fact that living ovaries were present, while the original females always developed into normal female butterflies. The sexual instincts were also unmodified by the presence of the grafted gonads.

In spider crabs attacked by Sacculina the gonads disappear,

1 Darwin, loc. cit. Selheim (Beiträge zur Geburtshülfe und Gynäk., vol. i., 1898, and vol. ii., 1899), states that there is an increase in the size of the skull, pelvis, and leg-bones in castrated cocks.

2 Wallace, Farm Live-Stock of Great Britain, 4th Edition, London, 1907.

3 Oudemans, "Falter aus Castriten Raupen," Zool. Jahrbücher, vol. xii., 1899.

${ }^{4}$ Kellogg, "Influence of the Primary Reproductive Organs on the Secondary Sexual Characters," Jour. of Exper. Zool., vol. i., 1904.

5 Crampton, "An Experimental Study upon Lepidoptera," Arch. f. Enturick.-Mechanik, vol. vii., 1898.

- Meisenheimer, Experimentelle Studien zur Soma- und GeschlechtsDifferenzierung, Part I., Jena, 1909. 


\section{8}

THE PHYSIOLOGY OF REPRODUC'ION

and in the total absence of the testis secondary sexual characters of the female type are found in a large percentage of cases; but this change in the direction of the opposite sex may set in prior to the complete disappearance of the testes. The change is manifested in the appearance of the egg-bearing abdominal sac appendages, which have no representatives in the male. ${ }^{1}$ Potts states that in the hermit crab infected by a similar Pelto. gaster, the modifications of the male which occur are of the same type, and are maintained after the atrophy of the testis, and cannot be necessarily consequent on the presence of a secretion of the testis. ${ }^{2}$

In both these cases it is suggested that the modifications which take place are brought about independently by changes in the general metabolism.

In the male common shore crab it was found that the testis underwent very little diminution after infection by Sacculina, but that the male approximated to the female type. The change, however, was less marked than in the cases referred to above, in which parasitic castration was almost or quite complete. ${ }^{3}$

It would appear, therefore, that whereas many of the secondary sexual characters are closely associated with the presence of the genital glands, there are others which develop independently of any influence from the organs of reproduction.

Brown-Séquard ${ }^{4}$ seems to have been the first definitely to put forward the view that the testis exercises its influence upon the metabolism through an internal secretion elaborated by it. He based his conclusion to a large extent upon the beneficial effects which he believed to accrue from the administration of testicular extracts. These extracts were supposed to possess invigorating properties, and could be usefully employed in cases of deficiency of testicular substance, or in old age, when the testes lose their functional activity. It is not unlikely that

1 Smith (Geoffrey), "Rhizocephala, Fauna and Flora of the Gulf of Naples," Monograph xair., Berlin, 1906.

${ }^{2}$ Potts, "The Moditication of the Sexual Characters of the Hermit Crab, caused by the Parasite Peltogaster," Quar. Jour. Micr. Sci., vol. 1., 1906 ; and "Some Phenomena Associated with Parasitism," Parasitology, vol. ii., 1909.

3 l'otts, "Observations on the Changes in the Common Shore Crab caused by Sacculina," Proc. Camb. Phil. Soc., vol. xv., 1909.

- Brown-Séquard, “Du Rôle physiologique et thérapeutique d'un Suc extrait de Testicules," Arch. de Phys., 1889. 
some of the effects which Brown-Séquard attributed to the use of the extract were in reality due to suggestion.

Poehl ${ }^{1}$ claims to have prepared from the testis a substance having the chemical composition represented by the formula $\mathrm{C}_{5} \mathrm{H}_{14} \mathrm{~N}_{2}$. He believes this substance, which he calls spermine, to be the active principle of Brown-Séquard's testicular extract, stating that it has a beneficial influence over the metabolism of the body and acts as a physiological tonic. (See p. 285.)

Zoth, ${ }^{2}$ and also Pregel, ${ }^{3}$ state that they have obtained evidence by ergographic records of the stimulating action of testicular extracts upon the neuro-muscular apparatus in the human subject. They are of opinion that the injection of such extracts results in a decrease of nervous and muscular fatigue, and at the same time diminishes the subjective fatigue sensations.

The composition and physiological properties of testicular extract have also been investigated by Dixon, ${ }^{4}$ who found it to contain proteins, organic substances unaltered by boiling, and inorganic salts. Nucleoprotein was especially plentiful. Injection into the circulation caused a fall of blood pressure due chiefly to cardiac inhibition, but no very striking or interesting results.

Walker ${ }^{5}$ appears to be dubious about the efficacy of testicular medication, stating that the injection of fluid extract into castrated dogs had no effect in arresting the atrophy of the prostate gland ( $c f$. de Bonis, see Chapter VII., p. 239). It is possible, however, that the "active principle" of the testicular secretion was destroyed in the preparation of the extract, and

${ }^{1}$ Poehl, "Weitere Mitteilungen über Spermin," Berliner k'in. Wochen. schrift, 1891.

2 Zoth, "Zwei ergographische Versuchsreihen über die Wirkung orchitischen Extractes," Pfiuger's Archiv, vol. |xii., 1896.

${ }^{3}$ Pregel, "Zwei weitere ergographische Versuchsreihen," \&c., Pfluger's Archiv, vol. lxii., 1896.

"Dixon, "A Note on the Action of Poehl's Spermine," Jour. of Phys., vol. xxv., 1900 ; "The Composition and Action of Orchitic Extracts," Jour. of Phys., vol. xxvi., 1901. According to Hervieux, the interstitial gland of the testis contains a ferment which splits neutral fats, and converts dextrin, maltose, and glycogen into glucose but has no action on lactose $(C . R$. de la Soc. Biol, vol. 1x., 1906).

5 Walker (G.), "Experimental Injection of Testicular Fluid," \&c., Johns Hopkins Hospital Bulletin, vol. xi., 1900. 
that the constant administration of fresh testicular substance might have led to a different result.

Bouin and Ancel ${ }^{1}$ have shown in the horse and other animals that when the vasa deferentia are ligatured the spermatogenetic tissue of the testis ceases to be functional and gradually undergoes degeneration, while the interstitial cells remain unaffected. They point out, further, that those cells have a distinctly glandular appearance, and that their presence suffices for the development of the secondary sexual characters. Consequently they draw the conclusion that the testis is an organ producing an internal secretion which is elaborated by the interstitial cells and not by the spermatogenic tissue. These investigators state, further, ${ }^{2}$ as a result of a series of experiments upon guinea-pigs, that the subcutaneous injection of extract prepared from the interstitial tissue of the testis arrests the effects which castration otherwise would produce upon the rest of the generative system and upon the skeleton. ${ }^{3}$ Their results, therefore, differ from those of Walker. In another paper Bouin and Ancel ${ }^{4}$ state that the injection of similarly prepared testicular extract in guinea-pigs tends to promote growth. In the horse they found that the development of the interstitial gland substance of the adult coincided with the first occurrence of spermatogenesis; but that there was also a fotal interstitial gland, which disappeared at the end. of gestation, and a slightly developed gland composed of xanthochrome cells, which was only found in the immature animal. ${ }^{5}$

1 Bouin and Ancel, " Recherches sur les Cellules interstitielles du Testicule des Mammif̀res," Arch. de Zool. Expér., vol. i., 4th series, 1903.

2 Bouin and Ancel, "Action de l'Extrait de Glande interstitielle du Testicule," \&c., C. R. de l'Acad. des Sciences, vol. cxlii., 1906.

${ }^{3}$ Castration in early life, as already mentioned, is said to lead to a prolonged retention of the cartilaginous unions between the bones, especially in those of the limbs.

+ Bouin and Ancel, "Sur l'Effet des Injections de l'Extrait de Glande interstitielles du Testicule sur la Croissance," C. R. de la Soc. de Biol., vol. lxi., 1906.

"Bouin and Ancel, "La Glande interstitielle du Testicule chez le Cheval," Arch. de Zool. Expér., vol. iii., 1th series, 1105. According to Lécaillon the interstitial tissue in the mole's testis is functionally active during the breeding season, when the testis is sixty-four times larger than during the resting period. " Sur les Cellules interstitielles du Testicule de la Taupe considérées en dehors de la Période de Reproduction," C. R. de la Soc, de Biol., vol. lxvi., 1909). 
Shattock and Seligmann ${ }^{1}$ also have performed experiments on the results of occluding the vasa deferentia in Herdwick rams and in fowls. The animals operated upon acquired full secondary characters. The authors suppose, therefore, that the development of these characters is not brought about by metabolic changes induced by a nervous reflex arising from the function of sperm ejaculation.

Foges ${ }^{2}$ has described the effect of removing the testes of fowls and transplanting them to abnormal positions in the body cavity. In the successful experiments it was found that the presence of functional transplanted testes exercised the same influence over the development of the secondary sexual characters as testes growing in the normal position, and that the appearance of "capon" characters was averted, the comb, wattle, spurs, \&c., being developed as in uncastrated cocks. Foges concludes that the testes are organs of internal secretion, and control the development of the male characters.

Shattock and Seligmann have also described the effects of testicular transplantation and incomplete caponisation in fowls. In certain cases the testes are stated to have broken up during the operation, so that minute fragments were retained, sometimes being left in the normal position, and sometimes becoming dislocated and attached to the adjacent viscera or to the abdominal wall. Although these pieces of testicular substance continued to produce spermatozoa, they were virtually ductless glands. In such cases the secondary sexual characters of the cock developed to a varying extent which seemed to depend upon the amount of testicular'substance left behind. "One must regard the external character of maleness as a quantity which varies proportionately with the amount of gland tissue present."

1 Shattock and Seligmann, "Observations upon the Acquirement of Secondary Sexual Characters, indicating the Formation of an Internal Secretion by the Testicle," Proc. Roy. Soc., vol. Ixxiii., 1901. The same investi. gators also attempted to obtain further evidence by grafting together two cocks, one castrated and the other normal, but these experiments were unfortunately a failure, one of the birds always dying after a short time. Trans. Path. Soc., vol. xlvi., 1905.

2Foges, "Zur Lehre der secundären Geschlechtscharaktere," PAlüger's Archiv, vol. xciii., 1903. 
Aecording to Loewy, ${ }^{1}$ the injection of testicular substanee into young eapons causes the development of normal male skeletal characters, as well as a better growth of the comb, \&e. Furthermore, Walker ${ }^{2}$ states that, in two experiments in which he injeeted saline extract of eoeks' testicles into two hens daily for several months, the eombs and wattles grew in size and became more brightly eoloured, reaehing a maximum in five months. When the injections were discontinued, the combs and wattles underwent shrinkage and eventually beeame reduced almost to their original eondition. These experiments are of interest, but they would seem to require confirmation before the conelusion ean definitely be drawn that the testieular extract exerted an influence upon the sexual characters of the hens, since the eombs and wattles of fowls are normally subject to periodie growth which may vary with the individual.

It is stated that an imperfeetly descended testicle (i.e. a testicle which has failed to deseend properly from the abdominal cavity into the scrotal sac) in Man, notwithstanding the fact that it may be without any spermatogenic function, is nevertheless of the greatest benefit to its possessor in virtue of its influence over the metabolism. "The seeondary sexual characters are a far more exact measure of the value of the testicular tissues than are the presenee of spermatozoa in the external secretion. It may almost be said that a man's male plumage is in direct proportion to the weight or amount of testicular tissue present." 3

Perhaps the most eonclusive evidence so far adduced in support of the theory that the testis produces an internal secretion is that supplied by Nussbaum ${ }^{4}$ as a result of his experiments upon frogs. At the approach of the breeding season there is formed in the male frog a thiekened pad of skin on the first digit of eaeh fore limb associated with an increased muscular

1 Loewy, "Newere Untersuchungen zur Physiologic der Geschlechtsorgane," Ergebnisse der Phys., vol. ii., 1903.

2 Walker (C. E.) "The Influence of the Testis upon the Secondary Sexual Characters of Fowls," Proc. Roy. Soc. Med., vol. i., 1908.

${ }^{3}$ Corner, Diseases of the Male Generative Organs, Oxford, 1907. See also McAdam Eccles, The Imperfectly Descended Testis, London, 1903.

"Nussbaum, "Innere Sekretion und Nerveneinfluss," Merkel and Bonnet, Ergeb. der Anat. und Entwick., vol. xv., 1905. 
development in the fore arm. This modification is preparatory to the act of copulation, when the male frog uses its arms in embracing the female, and so assists in pressing out the eggs from the oviduct (see p. 22). If the male frog be castrated, the pad is not formed and the muscles fail to develop. Nussbaum found that, if pieces of testis from another frog were grafted into the dorsal lymph sac of a frog previously castrated, the secondary sexual characters of the latter developed just as in a normal frog. The transplanted testes, however, after exerting their influence in the way described, underwent a gradual absorption.

Nussbaum states, further, that when the nerves supplying the first digit were severed, the pad did not develop, this operation being performed on a normal frog. Similarly if the nerves supplying the clasping muscle of the fore arm were severed, the enlargement did not occur. He concludes, therefore, that the internal secretion formed in the testis has a specific action upon certain local groups of ganglion cells, and that the nerves passing from these to the fore arm and digit convey a stimulus which induces the growth of the muscle and that of the thickened pad. In support of the view that the testis exerts its influence upon the metabolism (at least partially) through the medium of the nervous system, Nussbaum cites an observation of Weber, according to whom an hermaphrodite finch, having an ovary on one side of the body and a testis on the other, showed the characteristic female coloration on the ovarian side and the male plumage on the side of the testis.

Nussbaum's conclusion has been controverted by Pflüger, ${ }^{1}$ who points out that in other cases the apparent effect of section of nerves is due to loss of sensibility in the parts affected, in consequence of which the tissues are not guarded from injury, and further, that the secondary sexual characters of animals are usually arranged symmetrically. The effect produced by onesided castration is general rather than local, and the operation has little or no influence in destroying the symmetry of the sexual characteristics ( $c f$., however, Fowler's statement about fallow deer, which appears to be exceptional). It is probable, therefore,

1 Pflüger, "Ob die Entwicklung der sekundären Geschlechts-charaktere vom Nervensystem abhängt?" Pflüger's Archiv, vol. cxvi., 1907. 
that Pflüger is correct in supposing that the internal secretion of the testis acts as a direct stimulus upon the cells of the frog's arm, and so induces the developinent of the sexual pad and the hypertrophy of the muscle. ${ }^{1}$

There is some evidence to show that, after one-sided castration, the remaining testis is capable of undergoing a compensating hypertrophy. ${ }^{2}$ If this is so, it affords an additional indication that the testis is an organ of internal secretion.

\section{The Correlation between the Ovary and the other Female Organs and Characters}

It has long been known that the ovary, like the testis, exerts a profound influence over the metabolism, and that the extirpation of this organ, no less than castration in the male, leads to very distinct results. In the human female double ovariotomy, if carried out before puberty, besides preventing the onset of puberty and the occurrence of menstruation, produces noticeable effects on the general form and appearance, as may be seen in adult women in semi-barbarous parts of Asia, where the natives perform this operation upon young girls. Such women are said to be devoid of many of the characteristics of their sex, and in certain cases to present resemblances to men.

In some female animals, also, the removal'or incomplete development of the ovaries has been said to lead to the appearance of male characters. For example, Rörig ${ }^{3}$ records three cases in which female deer possessed horns, and were found upon examination to show abnormalities in the ovaries. Darwin ${ }^{4}$ also states that female deer have been known to acquire horns in old age. ${ }^{5}$

1 See also Nussbaum, “Hoden und Brunstorgane," \&c., Pfïger's Arch., vol. cxxvi., 1909. For further references to the literature of testicular transplantation, see Boruttau, "Innere Sekretion," Nagel's Handbuch der Physiologie des Menschen, Braunschweig, 1906.

"Ribbert, "Beiträge zur kompensatorischen Hypertrophie," \&c., Arch. f. Entwick.-Mechanik, vol. i., 1894.

3 Rörig, "Ueber Geweihentwickelung," \&c., Arch.f. Entwick.-Mechanik, vol. $x_{.}, 1900$. 1905.

- Darwin, Variation in Animals and Plants, Popular Edition, London,

- Smith (F.) (Veterinary Physiology, 3rd Edition, London, 1907) states that female cats, whose ovaries have been removed while young, acquire a head of 
Better instances of this kind of phenomenon have been recorded from among poultry, game birds, and ducks, which, on growing senile, have been observed to acquire some of the secondary male characters. Darwin ${ }^{1}$ refers to the case of a duck which, when ten years old, assumed the plumage of the drake. He also mentions an instance of a hen which in old age acquired the secondary sexual characters of the cock. Hunter ${ }^{2}$ described a case of a hen pheasant which had male plumage correlated with an abnormal ovary, and many other such instances have been recorded. Gurney ${ }^{3}$ states that the assumption of male plumage is frequently (but not invariably) associated with barrenness in female gallinaceous birds but not as a rule in passerine birds. The phenomenon has been observed in black grouse, capercaillie, wild duck, widgeon, merganser, and various other species belonging to different orders. On the other hand, Gurney records instances of a hen chaffinch with male plumage and an unlaid egg, a hen redstart with male plumage and a number of developing eggs, as well as similar cases of hen pheasants. The male plumage may be only temporarily assumed. Further examples of the assumption of male plumage by hen birds are recorded by Shattock and Seligmann, ${ }^{4}$ who describe the phenomenon under the name of allopterotism. Some of these cases are regarded as of the nature of partial hermaphroditism. It would appear possible that the secondary male characters are normally latent in the female, and that the ovaries exert an inhibitory influence over their development. On

the male type (with well-developed tissues in the jowl, the exact converse occurring in castrated males). Herbst, who also discusses this question (Formative Reize in der Tierischen Ontogenese, Leipzig, 1901), expresses the belief that the gonads in either sex exercise a definite inhibitory influence, preventing the appearance of the secondary sexual characters of the opposite sex.

1 Darwin, loc. cit.

2 Hunter, "Account of an Extraordinary Pheasant," Phil. Trans., vol. $1 \times x$., 1780.

3 Gurney, "On the Occasional Assumption of Male Plumage by Female Birds," Ibis, vol. vi., 5th series, 1888.

"Shattock and Seligmann, "An Example of True Hermaphroditism in the Common Fowl, with Remarks on the Phenomena of Allopterotism," Trans. Path. Soc., vol. Ivii., 1906. "An Example of Incomplete Glandular Hermaphroditism in the Domestic Fowl," Proc. Roy. Soc. Med., Path. Section vol. i. (November), 1907. 
the other hand, there is no elear evidence that castration in the male animal leads to the assumption of female characters, exeepting in a negative sense (i.e. excepting in so far as it inhibits the development of male charaeters).

The operation of complete ovariotomy is impracticable in birds owing to the diffuse condition of the ovary and the close proximity of the vena eava, and in de-sexing pullets (or converting them into "poullardes") the usual praetice is to remove a portion of the oviduct or destroy in some other way its funetional relation with the ovary. ${ }^{1}$ This operation is believed to favour growth and fattening, but the result may be due simply to the faet that the albumen and the other products of ovidueal seeretion are no longer produced.

Aceording to Brandt, ${ }^{2}$ the absenee of a funetional oviduct may be correlated with male characters and a normal ovary, this being stated to be the case in Ruticilla phonicurus, but such a faet seems on the face of it unlikely exeepting on the assumption that a partial hermaphroditism existed.

Ovariotomy performed subsequently to puberty in women produees less marked results than when earried out in early life. The most notieeable effect is the cessation of menstruation, and this is sometimes aecompanied by an atrophy of the breasts and a tendeney towards obesity.

Most authorities are agreed that the uterus undergoes atrophy after the removal of the ovaries in adult life, and that castration in ehildren and young animals arrests the development of the uterus. ${ }^{3}$ These results are usually ascribed to the absence of ovarian influence, though a few authors seem disposed to dissent from this view (see below, p. 345). Thus, Hofmeir ${ }^{4}$ and Benkiser ${ }^{5}$

1 Wright, The New Book of Poultry, London, 1902. Layeock, Nervous Diseases of Women, London, 1840.

2 Brandt, "Anatomisches und Allgemeines über die sogenannte Hahnenfedrigkeit und über anderweitige Gesehlechtsanomalien bei Vögeln," Zeitschr. f. wis8. Zool, vol. xlviii., 1889.

${ }^{3}$ Kehrer, Beiträge zur Klin. und Exper. Geburtskunde, Giessen, 1877. Hegar, Die Kastration der Frauen, Leipzig, 1878. Selheim, "Die Physiologie der Weiblichen Genitalien," Nagel's Handbuch der Physiologie des Menschen, vol. ii., Braunsehweig, 1906. This article eontains further references.

"Hofmeir, "Frnährung und Rückbildungsvorgänge bei Abdominaltumoren," Zeitsch. f. Geburtsh. u. Gynäk., vol. v.

'Benkiser, Verhandl.d. Deutsch. Gesell.f. Gynäk., Fourth Congress, 1891. 
ascribe the degenerative changes to an insufficiency in the blood supply consequent upon the operation of removal, while Sokoloff ${ }^{1}$ and Buys and Vandervelte ${ }^{2}$ have supposed these changes to be due to a severance of nerves passing to the uterus.

In a series of experiments performed recently ${ }^{3}$ upon the effects of ovariotomy in rabbits, it was found that the extent to which the degenerative process was carried was roughly proportional to the time which had elapsed between the operation and the killing of the animal. After an interval of six and a half months the uterus was found to be in a condition of pronounced fibrosis and to contain no glands. The epithelium was much attenuated, and the muscle fibres were broken up. A few small capillaries, however, could still be seen in the stroma. The Fallopian tubes also underwent atrophy. In other experiments in which the ovaries were removed from very young immature rabbits, which were killed after they had grown up, it was found that the uteri, although they had undergone slight development, were quite infantile, being no larger than those of rats. The Fallopian tubes were affected similarly. In all these experiments great care was taken to avoid interference with the blood supply to the uterus, the uterine branches of the pelvic vessels and the anastomotic branch of the ovarian artery being left uninjured. Furthermore, in certain other cases in which hysterectomy was performed instead of ovariotomy, and which, therefore, may be regarded as controls to the first series of experiments, the extirpation of the uterus liad no arresting influence on the growth and nutrition of the ovaries (see p. 348).

Other and more conclusive evidence in support of the theory that the ovary is an organ of internal secretion is supplied by the results of various attempts to transplant ovaries. The cases of Morris, Glass, Dudley, and Cramer, who transplanted ovaries from one woman to another, are described below in discussing the causes of the menstrual function (p. 331).

"Sokoloff, "Ueber den Einfluss der Ovarienextirpation auf Structurveränderungen des Uterus," Arch. f. Gynäk., vol. li., 1896.

${ }^{2}$ Buys and Vandervelte, "Recherches Expérimentales sur les lésions consécutives à l'Ovariotomie Double," Arch. Ital. de Biol., vol. xxi., 1894.

${ }^{3}$ Carmichael and Marshall, "The Correlation of the Ovarian and Uterine Functions," Proc. Roy. Soc. B., vol. lxxix., 1907. 
Knauer ${ }^{1}$ has described experiments upon rabbits in which he removed the ovaries from the normal position and grafted them upon the mesometrium or between the fascia and the muscle of the abdominal wall. He found that they could be successfully implanted on both peritoneum and muscle, but that some portion of the grafted ovary invariably died. The

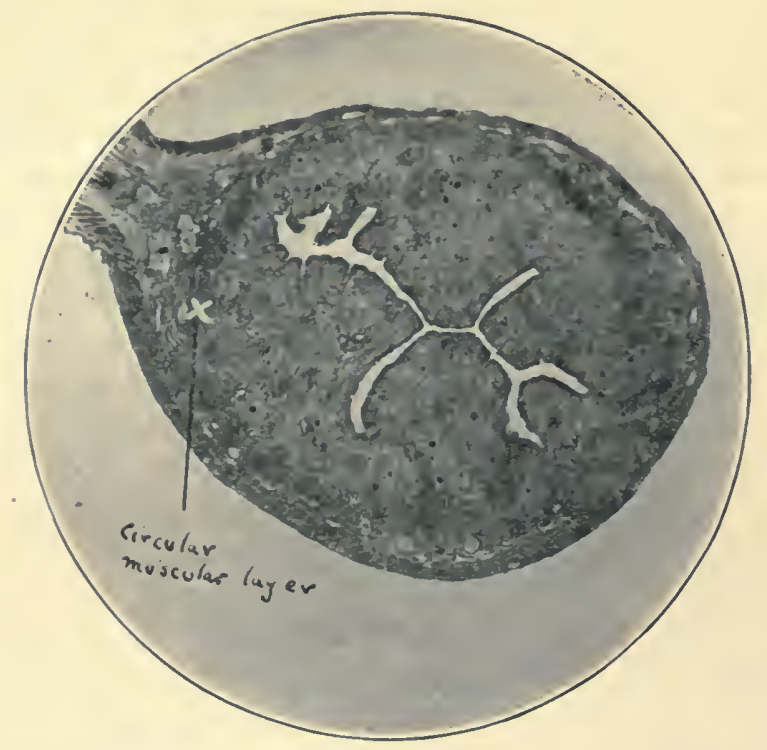

F1G. 67.-Transverse section through rabbit's uterus after ovariotomy, showing degenerative changes. (From Blair Bell, British Medical Journal and Trans. Royal Society of Medicine.)

rest, however, remained functionally active, and continued to produce ova which were capable of being fertilised. Knauer states that whereas castration in female rabbits produced a premature menopause, the uterus undergoing atrophy, this result was prevented by a successfully transplanted ovary. Knauer also experimented upon dogs and obtained similar results.

"Knauer, "Die Ovarien-Transplantation, Experimentelle, Studie," Arch. $f$. Gynäk., vol. 1x., 1900. 
Grigorieff, ${ }^{1}$ Ribbert, ${ }^{2}$ and Rubinstein ${ }^{3}$ carried out experiments upon rabbits which confirmed those of Knauer, the ovaries being transplanted in various abnormal positions. Grigorieff also records two cases in which ovaries were successfully transplanted from one individual to another (heteroplastic transplantation). Ribbert found, in his experiments, that

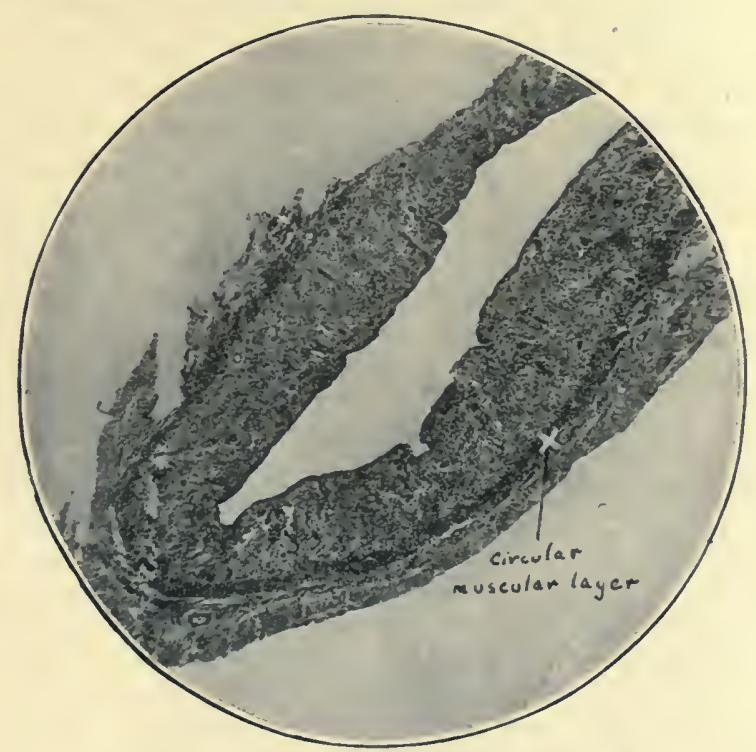

FIG. 68.-Transverse section through bitch's uterus $9 \frac{1}{2}$ months after ovariotomy. (From Blair Bell, British Medical Journal and Trans. Royal Society of Medicine.)

during the first month after transplantation the peripheral part of the grafted ovary remained unaltered, but the central part became transformed into connective tissue. At a later period, however, the central portion was again found to contain follicles. This fact is attributed to the conditions of increased nutrition which Ribbert supposed to prevail when the ovaries had been

1 Grigorieff, "Die Schwangerschaft bei Transplantation der Eierstöcke," Central. f. Gynäk., vol. xxi., 1897.

2 Ribbert, "Über Transplantation von Ovarien, Hoden, und Mamma," Arch. f. Entwich.-Mechanik, vol. vii., 1898.

"Rubinstein, "Extirpation beiden Ovarien," St. Petersburg Mediz. Wochenschr., 1899. 
transplanted for a sufficiently long period to adnit of their haviug acquired better vascular connections.

Halban ${ }^{1}$ found that the uterus and mammary glands of guinea-pigs from which the ovaries had been removed shortly after birth, remained undeveloped; but, if the ovaries were removed from the normal position and grafted underneath the skin, the other generative organs developed normally.

Limon, ${ }^{2}$ working upon rabbits, grafted ovaries beneath the muscle layers of the abdominal wall and on to the peritoneum of the same individuals. The follicles showed a tendency to degenerate, but the interstitial cells, after a short period of starvation, subsequently recuperated and acquired a condition of perfect vitality. Limon states that he found no sign of atrophy in the uterus after the transplantation of the ovaries to an abnormal position.

Carmichael $^{3}$ has recorded some success from experiments in

"Halban, "Ueber den Einfluss der Ovarien auf die Entwickelung des Genitales," Monatschr.f. Geburtsh. u. Gynük., vol. xii., 1900.

"Limon, "Observations sur l'État de la Glande Interstitielle dans les Ovaries Transplantés," Jour. de Phys. et de Path. Gén., vol. xvi., 1904.

${ }^{3}$ Carmichael, "The Possibilities of Ovarian Grafting in the Human Subject," \&c., Jour. of Obstet. and Gynac., March, 1907. Ovarian transplantation in different species of animals has also been carried out by Herlitzka ("Rechercbes sur la Transplantation des Ovaries," Arch. Ital. de Biol., vol. xxxiv., 1900), Foà (" Ia Graffe des Ovaries en Relation avec Quelques Questions de Biologie," Arch. Itxl. de Biol., vol. xxxiv., 1900), Schultz ("Transplantation der Ovarien auf Männliche Tiere," Central. f. All. Path. u. Path. Anat., vol. xi., 1900), Guthrie ("Successful Ovarian Transplantation in Fowls," Internat. Congress of Phys., Heidelberg, 1907, Abstract in Zeit. f. Phys., vol. xxi., 1907; "Further Results of Transplantation of Ovaries in Chickens," Jour. of Exp. Zool , vol. v., 1908). Schultz and other investigators, without reference to the ovarian secretion theory, grafted the ovaries of guinea-pigs on to the bodies of males and recorded some success. Herlitzka also grafted the ovaries of guinea-pigs on to other individuals (heteroplastic transplantion), some females and some males. Only one experiment was at all successful, the ovary being transplanted on to a female. Fol was successful with several beteroplastic grafts in rabbits, and even succeeded in inducing preguancy in an animal with a transplanted ovary. Guthrie's experiments were upon fowls. He states that the ova in the heteroplastically transplanted ovaries were influenced by the "foster mother" (i.e.the birds into whom they were grafted), since the offspring which resulted from fertilising these ova partook of some of the foster-mother's characters. For a few further references see Marshall and Jolly, " Results of Removal and Transplantation of Ovaries," Trans. Roy. Soc. Edin., vol. xlv., 1907, and "Heteroplastic 'Transplantation," \&c., Quar. Jour. Exp. Phys., vol. i., 1908; and Sauvé, Les Greffes Ovariennes, Paris, 1909. 
which the ovaries of rabbits were transplanted on to abnormal positions in the same individuals (homoplastic transplantation), but there is no evidence in those cases that the grafted ovaries had any influence in preventing the degeneration of the uterus.

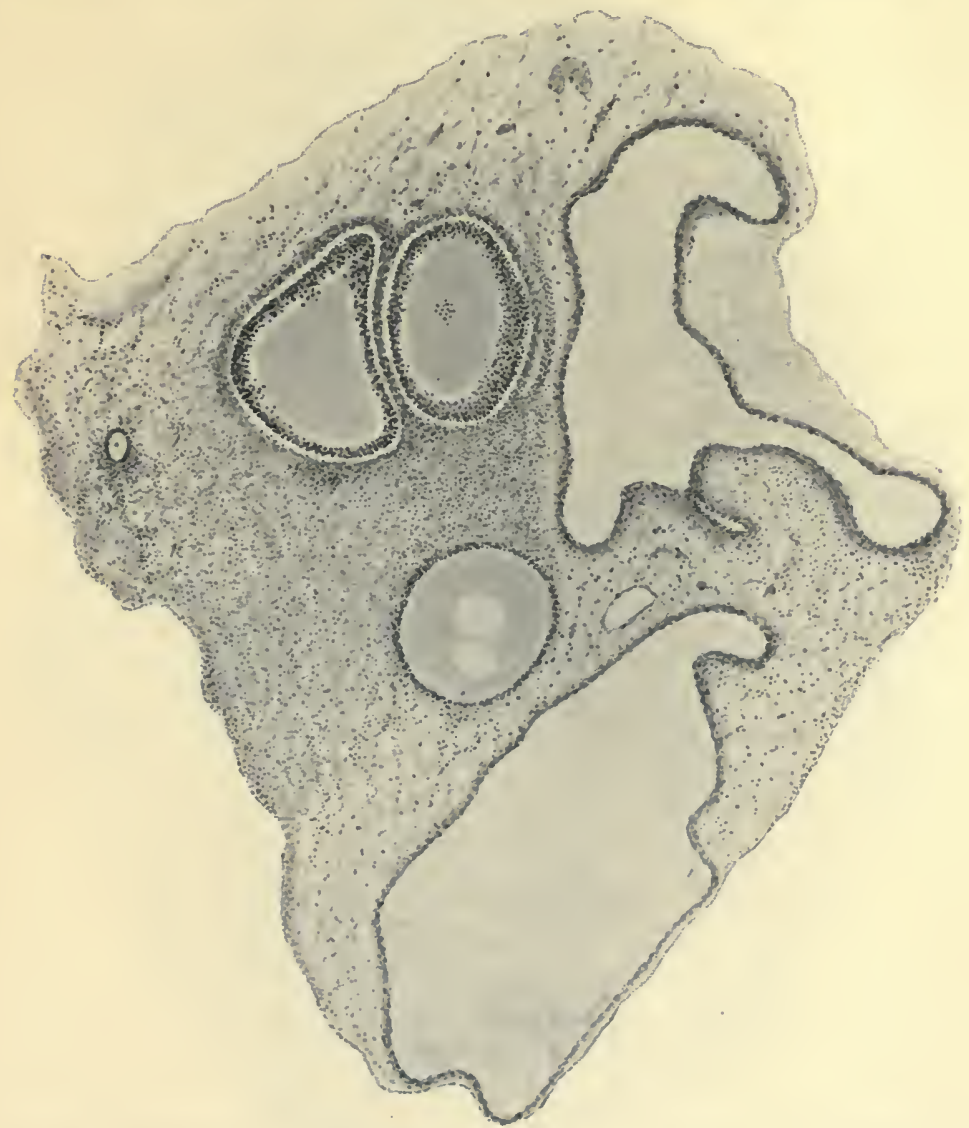

FIG. 69.-Section through ovary of rat after transplantation on to peritoneum, showing ovum, normal follicles, and follicles which have undergone cystic degeneration. (From Marshall and Jolly.)

The present writer also, working in conjunction with Dr. Jolly, ${ }^{1}$ carried out a series of experiments upon rats in order to determine whether any histological changes occurred in the

1 Marshall and Jolly, loc. cit. 
uterus after transplanting the ovaries to new situations. Other experiments were undertaken in which the ovaries were simply removed without being transplanted. The rats were killed at

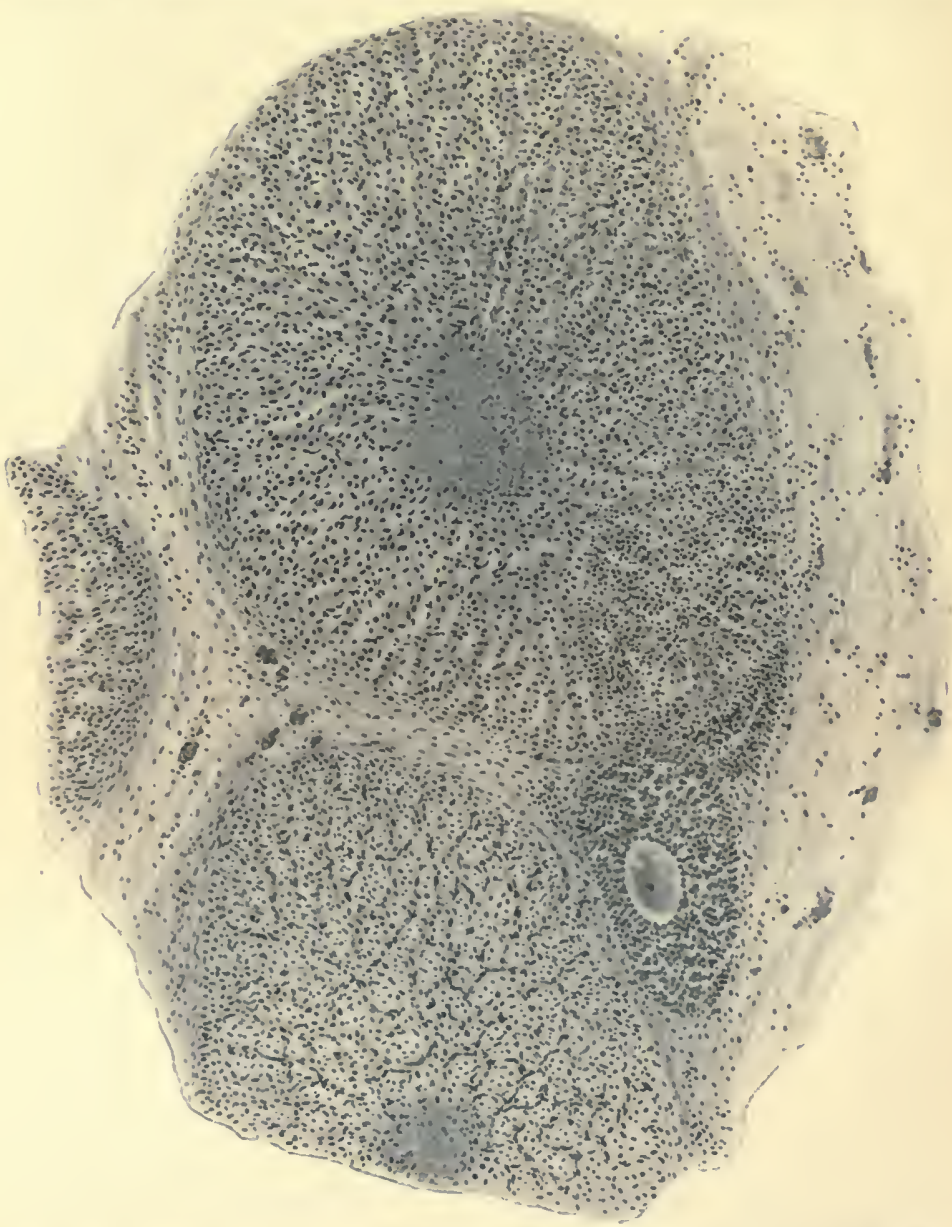

FIG. $70 .-$ Section through ovary of rat after transplantation on to peritoneum, showing corpora luteum and small follicle with ovum. (From Marshall and Jolly.)

intervals varying from one to fourteen months after the operation. In the control animals pronounced fibrosis or other atrophic appearances were always found in the uterus. On the 
other hand, in those animals in which ovaries had been successfully transplanted on to abnormal positions (such as on to the ventral peritoneum or into one of the kidneys) the uterus was found undegenerated. If, however, the ovarian graft failed to

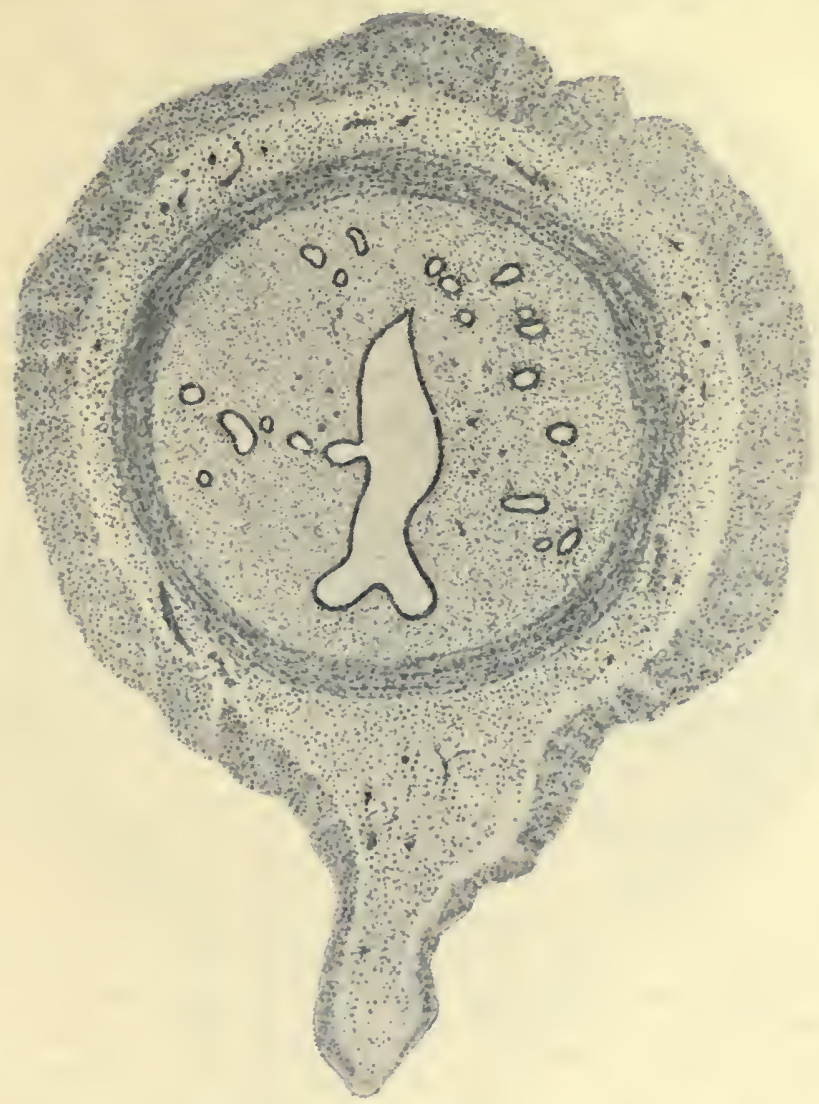

FIG. 71.-Transverse section through normal uterus of rat. (Cf. Figs. 72 and 73. From Marshall and Jolly.)

" take," or was only partially successful, the uterus presented undoubted signs of degeneration. In the cases of transplantation from rat to rat, as in homoplastic transplantation, uterine degeneration was found to be arrested by a successful ovarian graft. 


\section{4 'IHE PHYSIOLOGY OF REPRODUC'IION}

The successfully transplanted ovaries exhibited all the characteristic histological features of normal ovarian tissue, excepting that the germinal epithelium was invariably absorbed after the lapse of a short interval. In some cases a certain amount of degenerative change took place, only certain ele-

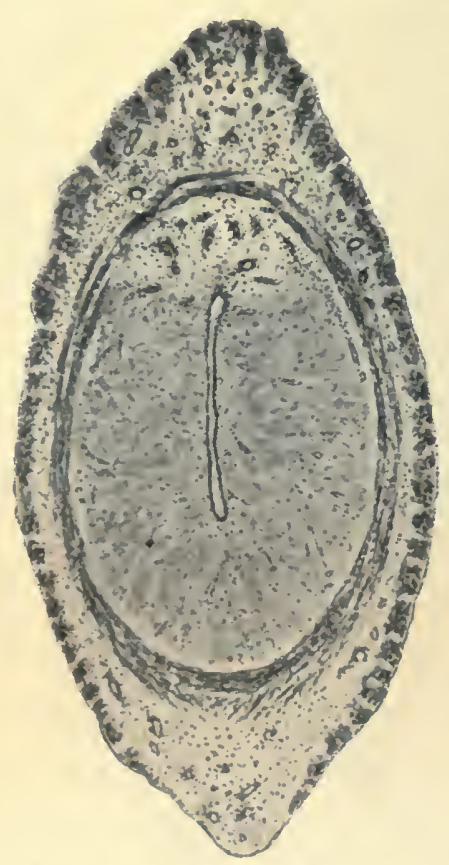

Fig. 72. - Transverse section through uterus of rat after ovariotomy, showing degenerative changes. ( $C f$. Figs. 71 and 73. From Marshall and Jolly.) ments of the tissue being recognisable after the lapse of several months ; thus, the stroma might present its normal appearance while the follicles had disappeared, or the greater part of the graft might be composed of luteal tissue alone. It was also observed that the successfully transplanted ovaries underwent the same cyclical changes as normal ovaries. Thus, in animals killed shortly before the commencement of the breeding season, large follicles were found in the grafts, while at a later period corpora lutea were present, showing that ovulation had occurred in the transplanted ovaries. In one case, a homoplastic graft was found to be normal after fourteen months, while a normal heteroplastic graft was composed entirely of healthy ovarian tissue (with follicles and ova) after six months. In these experiments the ovaries were grafted into the substance of the kidneys.

Homoplastic transplantation was found to be more easily accomplished than heteroplastic transplantation. This result could hardly be ascribed to increased difficulties in the performance of the latter operation, since the technique was identical in each case. Furthermore, our successes in heteroplastic transplantation were usually obtained in experiments 
in which two rats from the same litter were known to have been employed, so that the ovaries were grafted into whole sisters, but we were not sure of the relationship in every case.

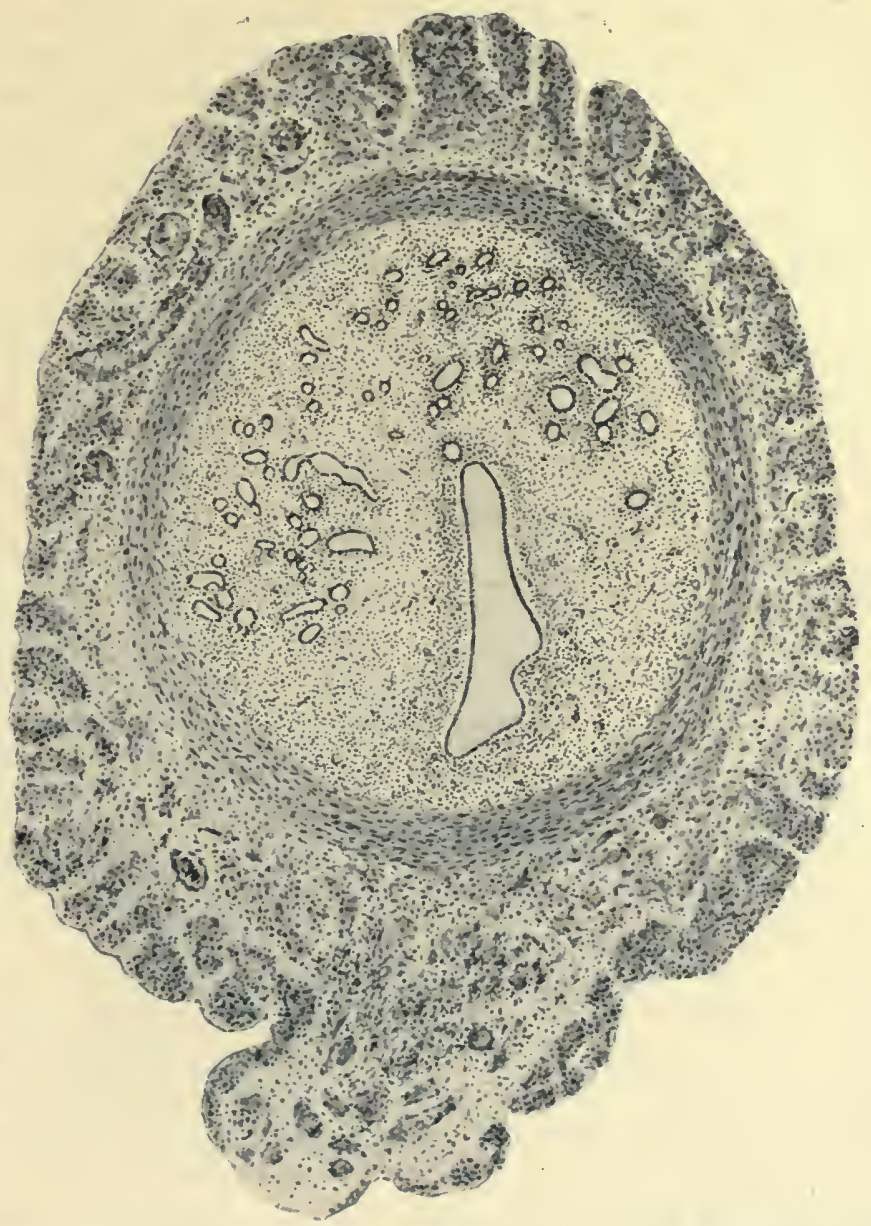

FIG. 73.-Transverse section through uterus of rat after ovarian transplantation. The uterus is normal. (See text and $c f$. Figs. 71 and 72. From Marshall and Jolly.)

These experiments clearly indicate that the nature of the ovarian influence is chemical rather than nervous, since the successfully grafted ovaries, while still maintaining their functions, 
had lost their normal nervous connections. It is probable, therefore, that the uterus depends for its proper nutrition upon substances secreted by the ovaries.

Further evidence in support of the view that the ovary produces an internal secretion is provided by the results of ovarian medication or the administration of preparations of ovarian substance for medicinal purposes. It is somewhat difficult, however, to know precisely what value to assign to this practice about which medical authorities still appear to differ. BrownSéquard ${ }^{1}$ seems to have been the first to employ ovarian extracts medicinally. He supposed them to produce similar effects to those brought about by testicular extracts, but they did not appear to be so powerful. Since Brown-Séquard's time ovarian preparations have been used medicinally in a large number of cases with more or less successful results. The fresh ovaries are themselves taken, or ovarian tissue is given in the form of fluid or powder (ovarine, oöphorine, ovigenine, \&c.). The fresh ovaries or ovarian powder are eaten, but the fluid can be administered either by the mouth, by the rectum, or by hypodermic injection. These methods of treatment are said to have met with considerable success in cases of amenorrhœea, chlorosis, and menopause troubles, both natural and postoperative. Some physicians, however, report only a very moderate or doubtful success, while a few state that the results are nearly always unsatisfactory. ${ }^{2}$ The method of administering the extract by the mouth is open to the criticism that the "active principle" of the ovarian secretion may be altered in the metabolic processes of digestion. Moreover, it is by no means certain that the "active principle" may not be destroyed in the manufacture of the preparations. Again, it is not unlikely that the effects of ovarian medication may depend, not only upon the method of preparing the extracts, but also upon the condition of the ovaries from which the extracts are made, and it would seem unreasonable to expect to obtain uniform results from the indiscriminate usage of ovaries in different stages of cyclical

1 Brown-Séquard, "Des Effets produits chez l'Homme par des Injections," \&c., C. R. de la Soc. de Biol., 1889.

2 For references to the literature of ovarian medication, see Andrews, “Internal Secretion of the Ovary," Jour. of Obstet. and Gyn., vol. v., 1904. 
activity (e.g. ovaries with prominent follicles like those from animals "on heat," or ovaries with corpora lutea like those of

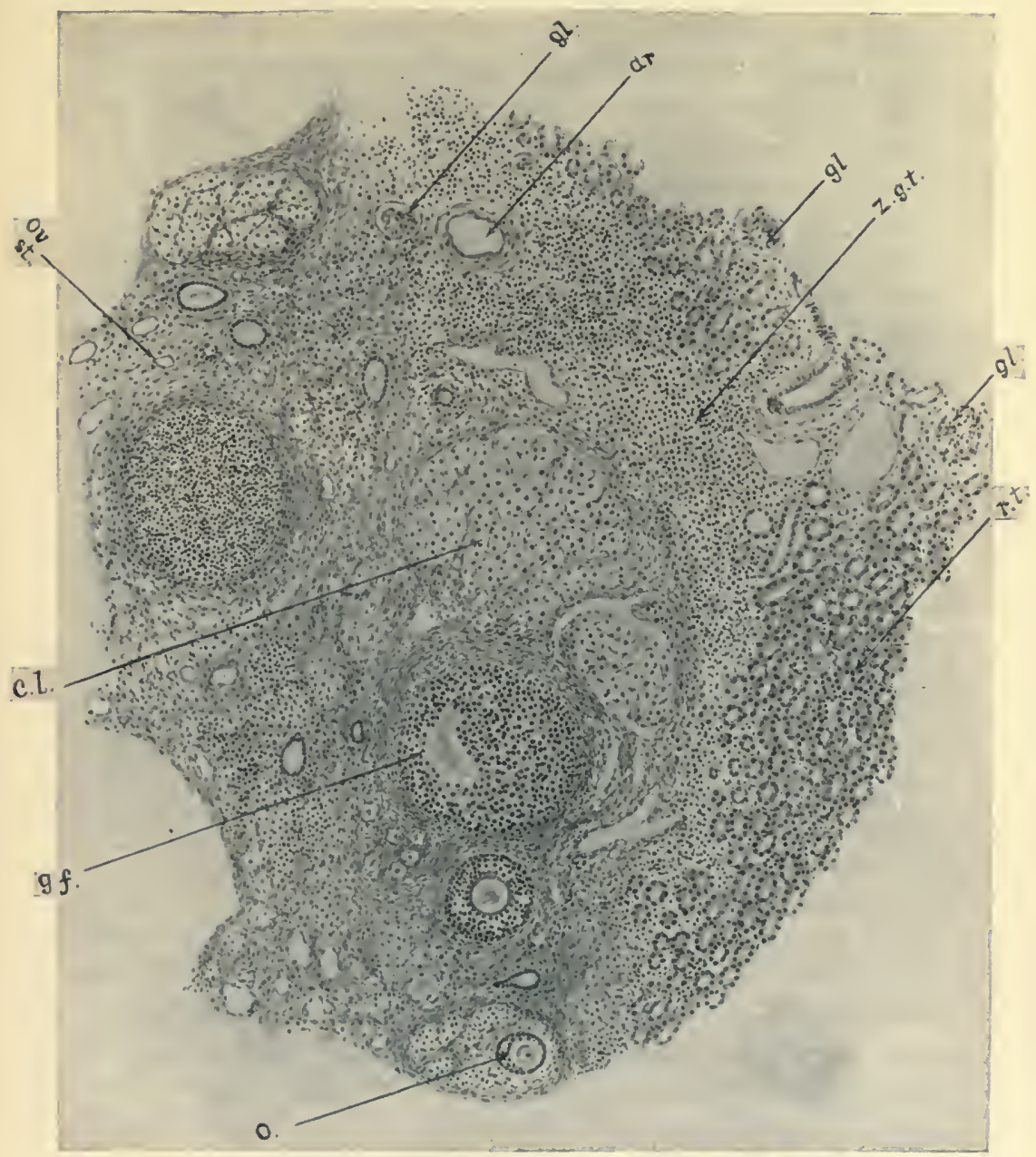

FIG. 74.- Section through rat's kidney, into the tissue of which an ovary had been transplanted. (From Marshall and Jolly, Quart. Jour. of Experimental Physiology.)

$a r$, artery; c.l., corpus luteum; $g . f .$, Graafian follicle ; $g l .$, glomerulus of kidney; ov.st., ovarian stroma; r.t., renal tubule; $z_{.}, r . t$, zone of granulation tissue between ovarian tissue and tissue of kidney. 
pregnant animals, or ovaries in a state of relative quiescence like those of anœstrous animals).

The effects of ovarian medication are discussed at some length in a memoir by Bestion de Camboulas, ${ }^{1}$ who describes a large number of experiments upon dogs, rabbits, and guileapigs, as well as a series of clinical observations. Experiments were performed on male animals as well as on female ones. The lethal injection of ovarian extract was found to be about twice as much in non-pregnant females as in males or pregnant females. With non-toxic doses the females gained weight, but the males lost weight. The lesions discovered after lethal doses were congestion of the viscera, and minute hæmorrhages in the dorsal and lumbar regions of the spinal cord. Bestion also administered ovarian extract to his patients, and states that he obtained distinctly beneficial results. Menopause troubles are described as either disappearing altogether or becoming much ameliorated, while rapid improvement was observed in cases of chlorosis and amenorrhoea. Bestion says that ovarian extract should never be administered to pregnant women, since it causes such grave results when given to pregnant animals.

Jentzner and Beuttner ${ }^{2}$ found that the subcutaneous injection of ovarian extract in castrated animals did not supply the place of living ovarian substance, and Mr. Carmichael and the present writer ${ }^{3}$ experienced a similar result after making a series of intra-peritoneal injections of commercial extract, the uterine atrophy which followed ovariotomy being in no degree diminished.

It has been shown that the ovary possesses considerable capacity for regenerating tissue after partial removal, and also that if ole ovary is extirpated the remaining one may undergo an apparent increase in size, which is probably of the nature of a compensatory hypertrophy. These facts may perhaps be regarded as supplying some further evidence that the ovary is an organ of internal secretion ${ }^{4}$ ( $c f$. the testis, p. 314).

1 Bestion de Camboulas, "Le Suc Ovarien," Paris, 1898.

2 Jentzner and Beuttner, "Experimentelle Untersuchungen zur Frage der Castratinsatrophie," Zeitschr. f. Geburtsh. u. Gynäk., vol. xlii., 1900.

3 Carmichael and Marshall, loc, cit.

- Carmichael and Marshall, "On the Occurrence of Compensatory Hypertrophy in the Ovary," Jour. of Phys., vol. xxxvi., 1908. 
According to Loisel, ${ }^{1}$ the ovary fulfils a purifying function in the organism, absorbing injurious products which are excreted with the ova or absorbed as internal secretions. This theory seems to have little experimental basis at present.

\section{The Factors which Determine the Occurrence of Heat and Menstruation}

Pfliger ${ }^{2}$ advanced the theory that menstruation is brought about by a nervous reflex, owing its origin to the pressure of the growing Graafian follicles upon the nerve endings in the ovary. This view received some support from Strassmann, ${ }^{3}$ who clained to have induced "heat" in animals by injecting gelatine into their ovaries, and so producing intra-ovarian pressure. Elizabeth Winterhalter's ${ }^{4}$ alleged discovery of a sympathetic ganglion in the ovary also tended to support this theory; but Von Herff ${ }^{5}$ discredited her description, which, so far, has received no confirmation.

Goltz ${ }^{6}$ showed that heat in animals is not brought about by a cerebral or spinal reflex. In one experiment the spinal cord of a bitch was transected in the lumbar region; normal procstrum, followed by ostrus and conception, occurred as usual, but copulation was unaccompanied by sensation, though the animal showed a marked inclination towards the dog. In another experiment the lumbar part of the spinal cord was completely removed without interfering with the cyclical

1 Loisel, "Les Poisons des Glandes génitales," C. R. de la Soc. de Biol., vol. lv., 1903 ; vol. lvi., 1904; and vol. lvii., 1904. 1865.

2 PHüger, Uber die Bedcutung und Ursache der Menstruation, Berlin'

${ }^{3}$ Strassmann, Lehrbuch der gerichtlichen Medizin, 1895.

" Winterhalter, " Ein Sympathisches Ganglion im Menschlichen Ovarium',, Arch.f. Gynäk., vol. li., 1896.

5 Von Herff, "Giebt es ein Sympathisches Ganglion im Menschlichen Ovarium," Arch.f. Gynäk., vol. li., 1896. For information upon the innervation of the ovary, see Von Herff, "Über den feineren Verlauf der Nerven im Eierstock," Zeitschr. f. Geb. u. Gynäk., vol. xxiv., 1893.

"Goltz, "Ueber den Einfluss des Nervensystems auf die Vorgänge während der Schwangerschaft und des Gebärakts," Pfüger's Archiv, vol. ix., 1874. Goltz and Ewald, "Der Hand mit verkürztem Rückenmark," Pfüger's Archiv, vol. 1xiii., 1896. 
recurrence of proøstrum and oestrus. Moreover, Sherrington, ${ }^{1}$ after transecting the spinal cord of a bitch in the cervical region, and headwards of the connection between the sympathetic system and the cord, observed that heat of normal duration and character continued to recur in the animal so operated upon. The case, described by Brachet, ${ }^{2}$ of a woman suffering from paraplegia in the lower part of the body and legs, but who conceived and became pregnant, may also be cited.

There are other facts which indicate that menstruation is not caused by a nervous reflex set up by ovulation or by the pressure of the growing follicles. Gynæcologists have pointed out that in the human subject ovulation and menstruation are not necessarily associated, and Heape ${ }^{3}$ has shown that the ovaries of menstruating monkeys do not always contain follicles in a state approaching ripeness.

But whereas the evidence is clear that heat and menstruation are not brought about by nervous reflexes arising from the ovary, it is equally obvious that these processes are dependent upon some ovarian influence. For, if the ovaries are removed, heat and menstruation no longer take place.

Some authors, however, have denied this, and cases have been cited of the occurrence of menstruation after surgical ovariotomy. For example, three cases have recently been described by Doran, ${ }^{4}$ in each of which the two ovaries were believed to have been removed, although menstruation recurred at irregular intervals after the operation. Further cases have lately been reported by Blair Bell ${ }^{5}$ and other writers. It seems probable that these exceptional cases are to be explained on the supposition that the extirpation of ovarian substance was not quite complete, and that the tissue which remained behind underwent hypertrophy subsequently to the operation. That 1906.

1 Sherrington, The Integrative Action of the Nerious Systcm, Loudon,

2 Brachet, Recherches, 2nd Edition, Paris, 1837.

"Heape, "The Menstruation and Ovulation of Macacus rhesus," Phil. Trans. B., vol. clxxxviii., 1897.

+ Doran, "Sub-total Hysterectomy for Fibroids," Lancet, Part II., November, 1905.

5 Blair Bell, "Preliminary Note on a New Theory of Female Generative Activity," Liverpool Medico.Chirurgical Journal, July 1906. 
this is the true interpretation is rendered the more probable in view of the cases referred to by Gordon, ${ }^{1}$ Doran, ${ }^{2}$ Meredith, ${ }^{3}$ and others, in which pregnancy occurred after the supposed removal of both ovaries (see also, p. 343). Doran ${ }^{4}$ also records a large series of cases in which menstruation entirely ceased after ovariotomy. ${ }^{5}$

Morris ${ }^{6}$ gives an account of a woman aged twenty, who suffered from amenorrhœea, her uterus being infantile. $\mathrm{He}$ states that he transplanted on to her fundus uteri an ovary which he obtained from another woman, aged thirty. The transplantation is said to have been successful, inducing mentruation after two months. In another case Morris ${ }^{7}$ states that he transplanted an ovary into a woman whose own ovaries had been previously removed, and that the graft was so far successful that conception, followed by a normal pregnancy, occurred as a result. It has been suggested, however, that in this case a portion of the woman's original ovary may have been left behind, and that this accounted for the pregnancy (cf. p. 343). Glasis ${ }^{8}$ describes a case of a patient who was suffering from menopause troubles due to the extirpation of the ovaries. After the transplantation of an ovary from another woman had been effected, the patient was gradually restored to health and menstruation was renewed. Dudley ${ }^{9}$ mentions a case in which a double pyosalpinx was removed, and the right

1 Gordon, "Two Pregnancies following the Removal of Both Tubes and Ovaries," Trans. Amer. Gynac. Soc., vol. xxi., 1896.

2 Doran, "Pregnancy after the Removal of Both Ovaries," Jour. Obstet. and Gynocc, vol. ii., 1902.

3 Meredith, "Pregnancy after Removal of Both Ovaries," Brit. Med. Jour., Part I., 1904.

4 Doran, "Sub-total Hysterectomy for Fibroids," Lancet, Part II., Nov. 1905.

5 The continuance of menstruation after the removal of two ovaries may be due to the presence of accessory ovaries which are occasionally known to exist.

"Morris, "The Ovarian Graft," New York Med. Jour., 1895.

" Morris, "A Case of Heteroplastic Ovarian Grafting followed by Pregnancy," \&c., New York Med. Jour., vol. lxix., 1906.

8 Glass, "An Experiment in Transplantation of the Entire Human Ovary," Medical News, 1899.

9 Dudley, “ Über Intra-uterine Implantation des Ovariums," Internat. Gyn. Congress, Amsterdam, 1899. 
ovary implanted on the fundus uteri. The patient menstruated regularly afterwards. Again, in a case recorded by Cramer of Bonn, ${ }^{1}$ the ovary of a woman suffering from osteomalacia was extirpated and transplanted into a second woman whose genital organs were much atrophied. As a result of the graft the genital organs of the woman in whom the ovary was transplanted became normal, menstruation started once more, and the breasts secreted colostrum. In none of these cases, however, is there any record of post-mortem evidence showing that the transplanted ovaries had become successfully attached.

Halban ${ }^{2}$ states that he found in monkeys that, whereas menstruation ceased after double ovariotomy, it recurred again after ovarian transplantation, even though the ovary was grafted in a position different from the normal one.

Those cases already referred to, in which atrophy of the uterus took place after the removal of the ovaries, also indicate the dependence of the menstrual and procstrous functions upon the presence of ovarian tissue, since normal heat could not occur if the uterus were in a condition of fibrotic degeneration, while certain of Knauer's experiments ${ }^{3}$ afford evidence that heat can be experienced by animals in which the ovaries are transplanted to abnormal positions.

Veterinarians are generally agreed that heat does not occur in dogs whose ovaries have been extirpated. Moreover, ovariotomy is sometimes practised on mares in order to prevent ostrus, and so suppress the vicious symptoms which are liable to render the animals periodically unworkable. ${ }^{4}$

Dr. Jolly and the author ${ }^{5}$ have shown, further, that normal procestrum, followed by oestrus, can occur in dogs which only possess transplanted ovaries, thus confirming the observations of Knauer and Halban. In the experiments in question the animals' own ovaries were removed, and a few weeks later the

${ }^{1}$ Cramer (H.), "'T'ransplantation menschlicher Ovarien," München. med. Wochenschr., 1906.

"Halban, "Über den Einfluss der Ovarien auf die Entwickelung des Genitales," Sitz.-Ber. Akad. Wissenschaft, Wien, vol. cx., 1901.

${ }^{3}$ Knauer, loc, cit.

"Hobday, "Ovariotomy of Troublesome Mares," Veterinary Jour., New Series, vol. xiii., A pril 1906.

S Marshall and Jolly, "Contributions to the Physiology of Mammalian Reproduction: Part II. The Ovary as an Organ of Internal Secretion," Phil. Trans, B., vol. cxcviii., 1905. 
ovaries obtained from other dogs were grafted in abnormal positions (e.g. between the abdominal muscular layers or on the ventral border of the peritoneal cavity). The grafts seem to have become attached, and to have survived for a sufficiently long period to exercise an influence over the generative system; but they eventually underwent considerable fibrous degeneration, as the post-mortem evidence afterwards showed.

As a result of these experiments it may probably be concluded that the enhanced activity which the ovaries exhibit during the final stages of follicular development is accompanied by metabolic changes which result in an increase in the production of the ovarian secretion, and that this phenomenon is the main factor in the periodic recurrence of heat and menstruation. ${ }^{1}$ It has been observed that, not only are the internal and external generative organs affected at these periods, but there is also a distinct hypertrophy of the breasts, and this, as Miss Lane-Claypon and Starling ${ }^{2}$ have pointed out, is probably due also to an increase in the ovarian metabolism. ${ }^{3}$

There is a certain amount of direct evidence that heat and menstruation are brought about by an internal secretion elaborated by the ovaries. It has been found that the injection of fresh ovarian extract obtained from animals which are "on heat" may produce in anœstrous animals a transient congestion of the external generative organs resembling that of the normal proœstrous condition. ${ }^{4}$ Miss Lane-Claypon and Starling also

1 As already pointed out, menstruation and ovulation are not necessarily associated. It is probable, however, that the ovarian metabolism is increased at the menstrual periods, although there may not always be any follicies present in a sufficiently mature condition to admit of ovulation occurring in the cestrous periods which normally follow them.

${ }^{2}$ Lane-Claypon and Starling, "An Experimental Inquiry into the Factors which Determine the Growth and Activity of the Mammary Glands," Proc. Roy. Soc., B., vol. Ixxvii., 1906.

${ }^{3}$ According to Pearl and Surface ("The Nature of the Stimulus which causes a Shell to be formed on a Bird's Egg," Science, New Series, vol. xxix., 1909), the stimulus which excites the activity of the shell-secreting glands in the fowl's oviduct is mechanical, being brought about by a strictly local reflex. The shape of the egg is determined by the muscular activity of the cells of the oviduct (Pearl, "Studies on the Physiology of Reproduction in the Domestic Fowl: I. Regulation in the Morphogenetic Activity of the Oviduct," Jour. of Exp. Zool., vol. vi., 1909).

4 Marshall and Jolly, loc. cit. 
have described congestion in the uterus after the injection of ovarian extract; but, in their experiments, the ovaries employed were those of pregnant animals.

Further evidence that the proœstrous and œstrous conditions are produced by substances circulating in the blood, but not necessarily elaborated in the ovaries, is supplied by certain facts recorded by Halban. ${ }^{1}$ This author affirms that the milk of suckling sows is affected during the periods of heat, in consequence of which the young are liable to develop unhealthy symptoms. In a similar way the milk of women is said to be affected during menstruation. Moreover, according to Youatt, ${ }^{2}$ cows can be brought " on heat" artificially by feeding them on milk supplied from other cows which are in that condition.

Heape ${ }^{3}$ has suggested that heat may be due to a " generative ferment" which he supposes to be periodically present in the blood. At the same time he is of opinion that a hypothetical substance called " gonadin," which is secreted by the generative glands, is also an essential factor. The precise relation in which gonadin and the generative ferment are supposed to stand to one another is not at present clear, but there is no inconsistency between a belief in their existence and the views which are adopted here.

Assuming that heat and menstruation are brought about, either directly or indirectly, through a stimulus depending upon the secretory activity of the ovary, it is still an open question as to what part of the organ is concerned in the process. Fraenkel ${ }^{4}$ has supposed that the secretion in question is supplied by the corpus luteum. This conclusion is based upon nine cases in which the corpus luteum was destroyed by the cautery, and in eight of which the next menstrual period was missed. In the remaining case it is supposed that the secretion responsible for producing menstruation had already been formed in sufficient quantity and passed into the circulation at the time of the cauterisation. Fraenkel's theory, however, is disproved by the

1 Halban, loc. cit.

2 Youatt, Cattle, London, 1835.

"Heape, "Ovulation and Degeneration of Ova in the Rabbit," Proc. Roy. Soc, $B$., vol. lxxvi., 1905.

"Fraenkel, "Die Function des Corpus Luteum," Arch. f. Gynäk., vol. Lxviii., 1903. 
fact that ovulation in most Mammals does not occur until œstrus, or, at any rate, until the end of the procstrum (see p. 135), and consequently corpora lutea are not present in the ovaries (for the corpora lutea dating from one œstrus do not always persist until the next œestrus, which may be many months afterwards). Heape's observations ${ }^{1}$ on the absence of corpora lutea in menstruating monkeys may be again cited in this connection. Moreover, Ries ${ }^{2}$ has reported a case of a woman with whom menstruation occurred normally after an operation in which an oozing corpus luteum, which was a source of hæmorrhage in the peritoneal cavity, had been peeled out. It should be mentioned that Fraenkel's views on menstruation are part of a general theory which is discussed more fully below (p. 338).

Seeing that the corpus luteum is not responsible for inducing menstruation, it becomes necessary to conclude that either the follicular epithelial cells or the interstitial cells of the ovarian stroma (or both of these) are concerned in bringing about the process (see p. 124).

It has already been shown that the breeding season, and consequently the recurrence of the ostrous cycle, are controlled to a great extent by the general environmental conditions, since these affect the physical state of the body (Chapters I. and II.). This is particularly well seen in certain of the domestic animals, in which "heat" may be caused to recur more frequently by the supply of special kinds of stimulating foods (p. 599). It would appear, therefore, that the metabolic activity of the ovaries is increased by these methods, and that the problematical internal secretion is elaborated in greater quantity.

Lastly, it must not be forgotten that, whereas it is exceedingly probable that the proœstrous changes of the uterus are brought about by a specific excitant or hormone ${ }^{3}$ arising in the ovaries,

${ }^{1}$ Heape, "The Menstruation and Ovulation of Macacus rhesus," Phil. Trans., B., clxxxviii., 1897.

2 Ries, "A Contribution to the Function of the Corpus Luteum," Amer. Jour. Obstet, vol. xlix., 1904.

${ }^{3}$ Starling has proposed the term hormone (from the Greek, o $\rho \mu \alpha \omega$, I excite or arouse) for such internal secretions or excitants of a chemical nature. Thus, secretin, or the internal secretion of the duodenum, which excites pancreatic secretion, is a hormone. See Starling, "The Chemical Correlation of the Functions of the Body," Croonian Lectures, London, 1905 ; also Lane-Claypon and Starling, loc. cit. 
little or nothing is known conccrning the source of that disturbed state of the nervous metabolism, the existence of which during œstrus is so plainly manifested in the display of sexual feeling.

\section{The Function of the Corpus Luteum}

Various theories have been put forward to explain the formation and presence of the corpus luteum. According to one vicw, which is still sometimes taught, the devclopment of this structure is merely a result of the excessive vascularisation which characterises the entire internal generative tract during the pcriod of pregnancy. Very little consideration of the actual facts is nceded to convince one of the inadequacy of this explanation. The blood supply to the generative organs is grcatest during the later stages of pregnancy, when the corpus luteum is becoming diminished in size. Moreover, the rapid liypertrophy of the luteal cells takes place independently of pregnancy during the very early stages of development at a time when therc is no appreciable congestion of the genital organs. According to another theory, the corpus luteum is of the nature of a stop-gap, whose purpose is to preserve the cortical circulation of the ovary by preventing an excessive formation of sear-tissuc. ${ }^{1}$

Prenant ${ }^{2}$ seems to have bcen the first to suggest that the corpus luteum was a ductless gland. He supposed it to produce an internal secretion which exercised an influence over the general metabolism in the manner attributed to the interial ovarian secretion. The phenomenon of chlorosis was explained as bcing due to the absence of this secretion. Prenant supposed also that the corpus luteum had the further function of preventing ovulation during pregnancy or between the oestrous periods.

This theory was supported by Regaud and Policard, ${ }^{3}$ who

1 Clark, "Ursprung, Wachstum, und Ende des Corpus Lutenm," Arch. f. Anat. u. Phys., Anat. Abth., 1898. Whitridge Williams, Olstctrics, New York, 1903.

2 Prenant, "La Valeur Morphologique du Corps Jaune," Rev. Gén. des Sciences, 1898.

3 Kegaud and Policard, "Fonction Glandulaire de l'Epitbelium Orarique chez la Chienne," C. R. de Soc. de Biol., vol. liii., 1901. 
stated that, by means of special methods of staining, droplets of a secretory substance could be detected in the cells of the corpus luteum of the hedgehog.

Beard ${ }^{1}$ independently suggested that the corpus luteum is a contrivance to suppress ovulation during pregnancy, while he supposed it to degenerate before parturition in order to admit of ovulation occurring immediately afterwards. It must be pointed out, however, that in many Mammals, if not in the majority, the breeding season does not recur until after an anœstrous period, which is often of considerable duration, and that it is extremely improbable that ovulation occurs during this period.

Beard's theory has been adopted by Sandes, ${ }^{2}$ who investigated the corpus luteum of the marsupial cat (Dasynurus vicerrinus, see p. 149). This author states that in Dasyurus, as in most other Mammals, the corpus luteum disappears towards the end of the lactation period, when the next oestrus is approaching, and the follicles are beginning to grow in preparation for the ensuing ovulation. He says, further, that as soon as the corpus luteum is formed, the ova in the surrounding follicles, which were up to that time in various stages of active development, begin to undergo atrophy. This atrophy commences in the follicles in closest proximity to the newly formed corpus luteum, and is continued in the surrounding follicles in ever-widening circles. Sandes suggests that this result is brought about by mechanical pressure, or is due to the internal secretion of the corpus luteum, if it has one. Without in any way disputing the accuracy of the facts which Sandes describes, it is difficult to understand what advantage is gained by a mechanism having a not more important object than that of securing the degeneration of the surplus ova within the ovary instead of externally to it, and it is not easy to see how, according to the usually accepted doctrines of utility and natural selection, an organ having such a purposeless function could ever have been developed at all.

Gustav Born was the first to suggest that the function of

1 Beard, The Span of Gestation and the Cause of Birth, Jena, 1897.

2 Sandes, "The Corpus Luteum of Dasyurus viverrinus," Proc. Linnean Soc., New South Wales, rol. xxviii., 1903. 
the corpus luteum might be to provide an internal secretion whiel assisted in the attachment of the embryo to the uterine mueosa. Unable to undertake the investigation himself, he persuaded Ludwig Fraenkel to put his theory to an experimental test. For this purpose a series of experiments upon rabbits was proceeded with, the ovaries being removed at intervals varying from one to six days after the oceurrenee of coition, the period of gestation in this animal being thirty days. The rabbits were afterwards killed, when it was found that the extirpation of the ovaries had prevented the fixation of the embryos, or had eaused these to be aborted. In other eases the eorpora lutea are deseribed as having been burnt out by the eleetrie eautery without destroying the rest of the ovaries, and these experiments led to a similar result. Control experiments were performed by removing one ovary while leaving the other, and by destroying some of the eorpora lutea but not all, and in the majority of these eases the animals produeed young. The experiments resulted, therefore, in supporting the view that there is an intimate eonneetion between the presence of the eorpus luteum and the oecurrence of pregnaney, and that this conneetion is in a eertain sense one of cause and effeet.

Apart from the experimental evidenee, Fraenkel adduees eertain other facts whieh tend to support the theory that the eorpus luteum is an organ of internal secretion. He points out that its general structure is eminently suggestive of its being a ductless gland, sinee it is formed mainly of large epitheloid eells surrounded by a network of eapillaries and arranged in regular rows or columns not unlike those of the eortex of the supra-renal body. Moreover, the increase in the size of the eorpus luteum, until it becomes larger than a Graafian follicle, seems inexplieable on any other view. This unusual eapaeity for growth is clearly out of all proportion to that of the rest of the ovary, and it is pointed out, further, that when the corpus luteum is most hyperæmic, the other part of the ovary is unusually anæmic, while towards the end of pregnaney, when the increase in the blood supply to the generative organs

1 Fraenkel and Cohn, "Experimentelle Untersuchungen über den Einfluss des Corpus Luteum auf die Insertion des Eies," Anat. Anz., vol. xx., 1901 ; Fraenkel. loc. cit. 
is at its height, the corpus luteum is often reduced to little more than a scar. Fraenkel also lays some stress on the discovery that the luteal cells are derived from the follicular epithelium and not from the connective tissue of the stroma. Furthermore, he observes that whereas many cases have been recorded in which double ovariotomy was performed during pregnancy without interfering with the further course of development, in none of these, so far as he is aware, was the operation conducted in the early weeks.

Fraenkel observes also that in non-placental Mammals (Marsupials and Monotremes) the corpus luteum is rudimentary or does not exist at all. Sandes, ${ }^{1}$ who has carefully described the formation of the corpus luteum in the marsupial cat, points out that this is erroneous, and says that there is a large corpus luteum in the members of both these groups. It should be remembered, however, that in Marsupials the embryo is nourished by a "yolk-sac placenta," while in at least one genus (Perameles) a definite allantoic placenta exists. In Monotremes there is a pronounced hypertrophy of the follicular epithelium following upon ovulation, but the corpus luteum is not normal in this group, since there appears to be no ingrowth of connective tissue or blood-vessels from the follicular wall (see p. 149).

$\Lambda$ similar objection, that might be raised in opposition to Fraenkel's hypothesis, is that structures resembling corpora lutea have been found in the ovaries of certain of the lower Vertebrates (see p. 151). This resemblance relates chiefly to the hypertrophy of the cells of the follicular epithelium after the discharge of the ova. Such an objection is not to be regarded as a serious one, for there is nothing improbable in the supposition that rudimentary corpora lutea, providing probably some sort of secretion, should have been developed before the acquirement of the function, which, according to Fraenkel's hypothesis, is possessed by the fully formed structure which characterises the placental Mammalia.

Fraenkel has also pointed out, as an argument in favour of his theory, that in ectopic or extra-uterine pregnancy the uterus undergoes the usual changes although there is no ovum in the uterine cavity. It is clear, therefore, that the changes do

1 Sandes, loc. cit. 
not occur simply as a consequence of the presence of the ovum. It is also pointed out that in normal pregnancy the uterine changes commence before the ovum enters the uterus.

Again, the theory that the corpus luteum is responsible for the attachment and early development of the embryo receives some support from those cases in which pathological conditions in the embryo have been found associated with pathological conditions in the corpus luteum. ${ }^{1}$ Thus lutein cysts are frequently found in apparent correlation with chorionepitheliomata.

Fraenkel's general conclusions regarding the functions of the corpus luteum may be summarised as follows: The corpus luteum is a ductless gland which is renewed every four weeks during reproductive life in the human female, and at different intervals in the various lower Mammals. Strictly speaking, there is only one corpus luteum which represents the ovarian organ of internal secretion, and is regenerated periodically in slightly different positions in the ovaries. Its function is to control the nutrition of the uterus from puberty until the menopause, to prevent it from lapsing into the infantile condition or undergoing atrophy, and to prepare its mucous membrane for the maintenance of the ovum. If the ovum be fertilised, the corpus luteum is responsible for maintaining the raised nutrition of the uterus during the first part of gestation. If the ovum be unfertilised it merely produces the hyperæmia of menstruation, and then undergoes degeneration until it is renewed in a fresh position. Since the corpus luteum is, par excellence, the ovarian gland, "lutein" or the extract of this organ, and not preparations of the entire ovary, should be employed for the purposes of ovarian medication.

Reasons have already been given for concluding that this extended theory of the meaning and function of the corpus luteum is untenable (p. 334). The fact that in a very large number of animals, heat, and presumably, therefore, ovulation, occur at infrequent intervals does not support it, while it has been shown that, in some animals at any rate, ovulation does

1 Cf. Malcolm Campbell, "Pathological Condition of the Ovaries as a Possible Factor in the Etiology of Uterine Fibroids," Scottish Med. and Surg. Jour., vol. xvi., 1905. 
not take place until œstrus, and consequently that at the time of the procestrous hyperæmia there are no corpora lutea present in the ovary. These facts, however, are in no way opposed to that part of Fraenkel's theory which assigns to the corpus luteum the function of governing the fixation of the ovum and helping to maintain its nutrition during the first stages of pregnancy.

Dr. Jolly and the author ${ }^{1}$ have carried out a series of experiments upon dogs and rats in which the ovaries were extirpated at different stages during pregnancy, as in Fraenkel's experiments upon rabbits. In the experiments on dogs, ovariotomy was performed at intervals ranging from three days to four weeks after impregnation. The pregnancy was discontinued in every case excepting one, in which a portion of the right ovary which contained the degenerate remains of two undoubted corpora lutea were found post mortem, three days after parturition, when the dog was killed. In this experiment ovariotomy was performed three days after copulation, and parturition occurred fifty days subsequently. Only a single pup was produced, and birth was premature. The pup died after being suckled normally for three days. The ovaries were also removed from a large number of rats, most of which were in early stages of pregnancy. Pregnancy was continued in no case in which ovariotomy was performed during the first six days. In other cases, in which the ovaries were removed at periods varying from the sixth day until near the end of pregnancy, the young were produced normally at full time. ${ }^{2}$ Control experiments were also carried out in which the abdominal cavity was opened up during an early stage of pregnancy and the ovaries were cauterised, or in which one ovary was removed and not the other, and in these experiments the course of pregnancy was not interfered with. ${ }^{3}$ We purposely refrained from attempting to extirpate the corpora lutea only while leaving the rest of the ovary, as it appeared to us to be practically impossible to destroy the whole of the luteal tissue

1 Marshall and Jolly, loc. cit.

2 In our paper the period of gestation in the rat was wrongly computed at twenty-eight days. It is in reality about twenty-one days.

${ }^{3}$ Cf. Carmichael and Marshall, loc. cit. 
without injuring the entire organ. The ovaries during pregnancy consist very largely of corpora lutea, and any attempt in a relatively small animal to discriminate between luteal tissue and stroma, while the ovary was lying in its normal position in the body cavity, seemed in our judgment to be impracticable.

It will be seen that our experiments on the results of ovariotomy during pregnancy fully confirm those of Fraenkel. It must be pointed out, however, that there is no evidence that the corpus luteum governs the fixation of the embryo in any other than the indirect sense implied in the supposition that the secretion elaborated by that organ acts as a stimulus which excites the uterine mucosa to undergo the necessary hypertrophy. In this general sense, also, it is probably true that the luteal secretion (or, at any rate, the secretion of the ovary) assists in nourishing the embryo during the first stages of pregnancy, since there is every reason for concluding that it helps to maintain the raised nutrition of the uterus. It has been shown that the presence of the ovaries is not essential for the continuance of pregnancy in the later stages, when the corpora lutea are in process of degeneration. It would seem not unlikely, therefore, that the atrophic changes (fibrosis) which take place in the decidua serotina, or maternal placenta, in the later part of the gestation period are directly correlated with the degeneration of the corpus luteum. ${ }^{1}$

Cases have been recorded by Essen-Möller, ${ }^{2}$ Graefe, ${ }^{3}$ and Flatau, ${ }^{4}$ in which pregnancy was not interrupted by double ovariotomy in women when performed in the early stages of pregnancy. These cases are undoubtedly very exceptional, and it seems legitimate to conclude that a small portion of an ovary, probably containing luteal tissue, was left behind acci-

1 It has been suggested that the corpus luteum contributes an essential factor in the nourishment of the embryo through the trophoblast, and that it consequently ceases to be functional in the later part of pregnancy when the trophohlast is superseded by the allantoic placenta. See Andrews, loc. cit.

2 Essen-Möller, "Doppelseitige Ovariotomie im Anfange der Schwangerschaft," Central. $f$. Gynäk, vol. xxviii., 1904.

"Graefe, "Zur Ovariotomie in der Schwangerschaft," Zeitschr. f. Geb. $u$. Gynäk., vol. lvi., 1905.

"Flatau, "Ueber Ovariotomic während der Schwangerschaft," Arch. $f$. Gynäk., vol. Ixxxii., 1907. 
dentally at the time of the operation. So able and experienced an operator as Bland Sutton ${ }^{1}$ has recently testified to the extraordinary difficulty experienced in removing the whole of the ovarian tissue in ovariotomy, and the distinguished French obstetrician, Lucas-Champonniere, ${ }^{2}$ has expressed himself in the same sense, so that there is nothing unreasonable in the assumption that the operation of removal is sometimes incomplete when performed on pregnant women.

Daels ${ }^{3}$ has recently recorded a large series of experiments upon guinea-pigs and rats in which he found that bilateral castration invariably interrupted the course of pregnancy during rather more than the first half of its duration. In control experiments portions of mesentery or other tissue, or only one ovary instead of both, were extirpated, and in these cases the pregnancy was continued. Furthermore, Kleinhaus and Schenk ${ }^{4}$ found that destruction of the corpora lutea of rabbits, after the ninth day of gestation, did not necessarily produce abortion, but that the same operation at an earlier period invariably brought the gestation to a premature end.

According to Ancel and Bouin, ${ }^{5}$ the rabbit's uterus undergoes growth, vascularisation, and muscular hypertrophy after ovulation even although the ova are not fertilised (e.g. owing to the vasa deferentia of the male having been cut). These changes are said to be followed by regression, which sets in after the thirteenth day. According to Ancel and Bouin, therefore, there is a close parallelism between the growth and regression of the corpus luteum and a series of cyclical changes which take place in the uterus. There is also said to be a parallelism.

1 Bland Sutton, "A Clinical Lecture on the Value and Fate of Belated Ovaries," Medical Press, vol. cxxxv. (July 31) 1907.

2 Lucas-Champonnière, "Sur une Observation de Graffe Ovarienne Suivie de Grossesse," Jour. de Méd. et de Chirurgie Pratiques, vol. 1xxviii. (May) 1907.

3 Daels, "On the Relations between the Ovaries and the Uterus," Surgery Gynacology and Obstetrice, vol. vi., 1908.

4 Kleinhaus and Schenk, "Fxperimentales zur Frage nach der Funktion des Corpus Luteum," Zeitschr.f. Geb. u. Gynäk., vol. lxi., 1907.

5 Ancel and Bouin, "Sur la Fonetion des Corps jaunes," C. R. de la Soc. de Biol., vol. Ixvi., 1909 ; "Le Développement de la Glande Mammaire pendant la Gestation est determiné par le Corps jaune," $C, R$, de la Soc. de Biol., vol. Ixvii., 1909. 
between the development of the corpus luteum and the growth of the mammary gland in the rabbit. ${ }^{1}$

Dubreuil and Regaud, ${ }^{2}$ however, as a result of further experiments, are very doubtful whether the corpus luteun has any influence over the non-gravid uterus. On the other hand, the observations of Niskoubina ${ }^{3}$ tend to confirm those of Ancel and Bouin.

According to Loeb, ${ }^{4}$ deciduomata (i.e., nodules having the structure of decidua) can be produced experimentally in the uterine mucosa of the guinea-pig by making a number of transverse and longitudinal cuts so as to break the continuity of the tissue. The nodules originate through a proliferation of the interglandular connective tissue. Loeb states further that this can only happen during a certain definite period after the occurrence of copulation or heat. The changes cannot be induced on the first day after heat, nor after the tenth day, but deciduomata are readily formed between the fourth and eighth days. The uterus is therefore most responsive when freshly formed corpora lutea are present in the ovaries. The changes were not excited by the presence of ova in the uterus, since they took place when the lower part of that organ was ligatured off so as to prevent the passage of the ova. On the other hand, if the ovaries were extirpated deciduomata could not be produced. If the corpora lutea were as far as possible burnt out of the ovaries by the electric cautery, deciduomata were not generally produced; but owing to the difficulty of properly performing these experiments, the results were not quite conclusive. Lastly, when pieces of uterus were transplanted into the subcutaneous tissue, deciduomata were formed in the grafted pieces. It is concluded, therefore, that the ovaries at certain periods after ovulation (and probably the corpora lutea) elaborate a predisposing substance

1 Ancel and Bouin, loc. cit.

2 Dubreuil and Regaud, "Sur les Relations fonctionelles des Corps jaunes avec l'Uterus non gravidé," I. II. III. and IV., C. R. de la Soc. de Biol., vol. lxvii., 1909. See also earlier papers in vol. lxv., 1908, and vol. lxvi., 1909.

3 Niskoubina, "Recherches expérimentales sur la Fonction des Corps jaunes," C. R. de la Soc, de Biol., vol, lxvi., 1909.

4 Loeb (L.), "The Production of Deciduomata, and the Relation between the Ovaries and the Formation of the Decidua," Jour. Amer. Med. Assoc., vol 1. (June 6), 1908. Medical Record, vol. Ixxvii. (June 25), 1910. 
in the presence of which indifferent stimuli (traumatisins), may produce deciduomata.

It has been shown that the uterine mucosa undergoes atrophy after the complete removal of the ovaries, and it seems hardly probable that this process can be arrested by the presence of a fertilised ovum in the early stages of pregnancy. On the other hand, it is scarcely conceivable that an ovum could become attached to a uterine mucous nembrane which was in process of degenerating. It would appear, however, that in the latter half or two-thirds of pregnancy, when the uterus has already undergone great hypertrophy, the presence of the ovaries may be dispensed with. ${ }^{1}$ Furthermore, it has just been mentioned that the maternal placenta undergoes a partial degeneration in the later stages of embryonic development.

Miss Lane-Claypon ${ }^{2}$ has shown that the interstitial cells of the ovarian stroma undergo an increase ill size during the period of gestation, but this increase is not so great as that of the luteal cells. Consequently, she suggests that these cells also may produce a secretion of the nature postulated for the cells of the corpus luteum. If this is so, the circumstance that the interstitial cells do not hypertrophy to the same extent as the luteal cells may perhaps be ascribed to the different conditions of mechanical pressure existing in the ovarian stroma.

\section{The Supposed Internal Secretion of the Uterus}

Although the bulk of evidence obtained clinically points to the conclusion that the uterine functions fall into abeyance after the extirpation of the ovaries, while the relatively few exceptions to this rule are probably to be explained on the supposition of incomplete removal, some surgeons and gynæcologists have adopted the view that the uterus is capable of functional activity independently of the ovaries. $\Lambda$ few writers have even gone further, and have affirmed the belief that the ovarian functions themselves are dependent upon uterine influence.

1 It has yet to be proved, however, that the further course of development is absolutely normal after ovariotomy in the later part of pregnancy.

2 Lane-Claypon, "On the Origin and Life-History of the Interstitial Cells of the Ovary of the Rabbit," Proc. Roy. Soc., B., vol. Ixxvii., 1905. 
'Zweifel and $\mathrm{Abel},{ }^{1}$ in describing the after-histories of cases of hysterectomy, stated that, in their experience, when the whole of the uterus was removed, entire atrophy of the ovaries always followed, so that menopause symptoms set in similar to those occurring after ovariotomy. In those cases, however, in which a portion of the uterine mucous membrane was conserved, menstruation continued and there were no menopause symptoms. Consequently, these surgeons have advocated the operation of sub-total hysterectomy wherever possible in preference to complete removal, believing that the functional activity of the ovary is in some way dependent on the presence of the uterus.

Doran, ${ }^{2}$ in tracing the after-histories of sixty cases of subtotal hysterectomy, is disposed to concur with Zweifel and Abel in advising that the uterus should be removed above the cervix. In support of this contention he cites two cases in which menstruation persisted after the removal of the body of the uterus, the cervix being left behind.

Mandl and Bürger, ${ }^{3}$ in a monograph dealing with the subject, express the belief that in those cases in which the ovaries are conserved after hysterectomy there is a gradual cessation of function on the part of these organs, resulting from their degeneration.

Holzbach, ${ }^{4}$ on the other hand, states that as a rule the ovaries do not atrophy after hysterectomy, and that, when such degeneration does occur, it is probably due to interference with the nervous connections consequent upon the operation of removal.

Blair Bell ${ }^{5}$ has suggested that menstruation is brought about by an internal secretion of the uterus, while he supposes ovulation to depend on the circulation of this secretion, which he calls " uterine."

1 Zweifel, "Deutsche Gesellschaft fur Gynäkologie in Berlin," Zentral. $f$. Gynïk., No. 21, 1899. Abel, “Dauererfolge der Zweifelschen Myomektomie," Arch.f. Gyniik, vol. lvii., 1899.

2 Doran, "Sub-total Hysterectomy for Fibroids," Lancet, Part II., November 1905.

${ }^{3}$ Mandl and Bürger, Die Biologische Bedeutung der Eierstöcke nach Ëntfernung der Gebärmutter, Leipzig, 1904.

" Holzbach, "Ueber die Function der nach Totalextirpation des Uterus zurückgelassen Ovarien," Arch. f. Gynäk., vol. Ixxx., 1906.

" Blair Bell, loc. cit. 
Bond ${ }^{1}$ has put forward the view that the ovarian secretion is influenced by a saline secretion from the anœstrous uterus, the two, however, acting antagonistically to one another, so that the prevention of the uterine secretion by hysterectomy favours the lypertrophy of the ovaries. Bond's view, therefore, is diametrically opposed to that of Blair Bell.

Bond records two experiments on the results of hysterectomy in rabbits. In one the entire uterus was removed and the animal killed after five months. Both ovaries were found to be normal. In the other experiment the left uterine cornua only was extirpated, and the rabbit was killed after five months. In this case also the ovaries showed no signs of degeneration. As a result of these experiments Bond affirms that the prevention of the saline secretion of the uterine mucosa by previous hysterectomy favours the overgrowth of luteal tissue in the ovary.

Stress has been laid by various writers upon the well-known fact that whereas the corpora lutea of the ovary continue to grow for a considerable period of time if pregnancy supervenes after ovulation, this hypertrophy soon ceases in the absence of pregnancy. Bond records an experiment upon a rabbit in which one of the ovaries, after transplantation in an abnormal position, was found to contain a somewhat aberrant "corpus luteum of pregnancy" in association with a gravid uterus. Such observations are regarded by him as supplying evidence of an internal uterine secretion acting on the ovaries and so exciting a growth of luteal tissue. This secretion is supposed by Bond to be quite different from the saline fluid elaborated by the annestrous uterus. ${ }^{2}$ It must be remembered, however, that pregnancy produces a profound influence over the entire organism, and not merely over the ovaries.

Certain other authors, such as Loewenthal, ${ }^{3}$ have suggested theories which imply a dependence on the part of the ovaries upon some function of the uterus; but, excepting for the two experiments of Bond referred to above, and a series of

${ }^{1}$ Bond, "Some Points in Uterine and Ovarian Physiology and Pathology in Rabbits," British Med.Jour., Part II., July 1906.

2 Bond, "Certain Undescribed Features in the Secretory Activity of the Uterus and Fallopian Tubes," Jour. Phys., vol. xxii., 1898.

3 Loewenthal, "Eine neue Deutung des Menstruationprocess," Arch. f. Gynäk., vol. xxiv., 1884. 
experiments undertaken by the author in collaboration with Mr. Carmichael, ${ }^{1}$ no systematic investigation ever appears to have been atteinpted upon the effects of hysterectomy.

In our experiments we removed the uterus, either entirely or leaving only the cervix, from a number of very young immature rabbits. The animals were killed after they had become fully grown-in some cases not until ten months after the operation. In every experiment the ovaries were found to have developed normally. In some cases also copulation was observed on the rabbits being put with the buck. Many of the ovaries contained typical corpora lutea, showing that ovulation had taken place. Also in four experiments on fully grown rats hysterectomy was performed, and the animals were killed several months subsequently. The ovaries in no instance showed any indications of atrophy. On the other hand, marked uterine degeneration was observed in rats after the removal of the ovaries for shorter periods of time. ${ }^{2}$

As a result of these experiments, it may be concluded that the growth and development of the ovaries is in no way dependent upon the presence of the uterus. Such a conclusion is no doubt opposed by some of the clinical evidence, but it is one which was to be expected on phylogenetic grounds, since the uterus is an organ which came into existence conparatively recently in the course of vertebrate evolution, whereas the ovary is common to all Metazoa. It is possible, in those surgical cases in which the ovaries underwent atrophy after the removal of the uterus, that this was due to vascular interference. ${ }^{3}$

1 Carmichael and Marshall, Proc. Roy. Soc., loc. cit.

2 Marshall and Jolly, "Results of Removal and Transplantation of Ovaries," Trans. Roy. Soc. Edin., vol. xlv., 1907.

${ }^{3}$ Boston lias recorded four cases of women where the uterus was congenitally absent, but in whom the development of the breasts and other changes relating to puberty excepting menstruation were experienced. Sentiment, sexual desire, and sexual sensation are stated to bave been normal in eacll case ("Absence of the Uterus in Three Sisters and Two Cousins," Lancet, Part I., Jan. 1907). It may also be mentioned that Sellheim found that removal of the oviducts in pheasants does not result in a shrivelling up of the ovaries and the assumption of secondary male characters as has been stated (Zcit. f. Gynük., 1904, No. 24). It has not been determined whether the generative organs (apart from the uterus) undergo the characteristic procestrous clianges after lyysterectomy, since these changes are comparatively slight and difficult to detect in rabbits. 


\section{The Correlation Between the Generative Organs AND the Ductless Glands}

Noel Paton ${ }^{1}$ and Henderson ${ }^{2}$ have shown that there is a reciprocal relation between the thymus and the testis, each checking the growth of the other. This conclusion is based on a series of observations on cattle and guinea-pigs. In the former it was found that castration delayed the onset of the atrophy of the thymus, for the average weight of that organ in bulls up to three and a quarter years old was considerably less than that in oxen. In guinea-pigs Paton found that, in those animals in which the thymus was removed at a time prior to the normal period of atrophy for that organ, there was an increase in the growth of the testis. On the other hand, Soli ${ }^{3}$ states that extirpation of the thymus, carried out in young rabbits, guinea-pigs, and fowls, caused inhibition of testicular development, and sometimes even complete arrest of growth by that organ.

Fichera ${ }^{4}$ observed a constant hypertrophy of the pituitary body (hypoplysis) in capons, oxen, buffaloes, and rabbits, castrated in early life - that is to say, an increase in weight by that organ as compared with the pituitary glands of other animals of the same kind, weight, and age. The increase in weight was associated with a rich blood supply, and an increase in the number of eosinophyl cells. These observations are confirmed for young dogs by Cimorini, ${ }^{5}$ who states that the changes in the pituitary were similar to those occurring after removal of the thyroids. According to Pepere, ${ }^{6}$ there is probably no specific hypertrophy of the hypophysis in relation to the extirpation of any particular

1 Paton, "The Relationship of the Thymus to the Sexual Organs," Jour. of Phys., vol. xxxii., 1304.

2 Henderson, "On the Relationship of the Thymus to the Sexual Organs," Jour. of Phys., vol. xxxi., 1904.

3 Soli, "Contribution a la Connaissance de la Formation du Thymus chez le Poulet et chez quelques Mammifères," Arch. Ital. de Biol., vol. Ixii., 1909.

4 Fichera, "Sulla ipertrofia della glandula Pituitaria consecutiva castrazione," Policlinico, vol. xii., 1905.

"Cimorini, "Sur l'Hypertrophie de l'Hypophyse cérébrale chez les Animaux thyréoüdectomisés," Arch. Ital. de Biol., vol. xlviii., 1907.

- Pepere, "Sur les Modifications de Structure du Tissu Parathyroidien normal et accessoire (thymique) en rapport avec sa Fonction vicariante," Arch. de Méd. Expér., vol. xx., 1908. 
ductless gland in the organism, but that the reaction of the cellular elements, though varying in response to different conditions, shows also many characters referable to a common cause.

It has been shown further that in cases of giantism and acromegaly, in which the pituitary body is enlarged, the sexual organs may be very imperfectly formed. ${ }^{1}$ Thus, the uterus is often infantile, the ovaries are rudimentary, or the penis is ill-developed. (See also final footnote, p. 356.)

It is well known that there is a correlation between the sexual organs and the thyroids. These glands undergo enlargement during menstruation and pregnancy in women, and Freund ${ }^{2}$ has shown that similar changes occur during the heat periods of many of the lower mammals. He has pointed out further, that swelling of the thyroid, at the time of puberty, often leads to goitre, and that this disease commonly begins at a period of menstruation. These facts are cited by Gaskell ${ }^{3}$ as evidence of a special connection between the thyroid and the sexual organs - the former being held to represent the uterus of the scorpion. Alquier and Thauveny ${ }^{4}$ state that after the partial or complete removal of the thyroids and parathyroids menstruation and conception are very infrequent, but this result may be due to the general metabolic disturbance arising from the absence of the glands.

There is some evidence of a correlation existing between the sexual organs and the supra-renals. Thus Gottschau ${ }^{5}$ states that in rabbits, changes occur in these organs during pregnancy, the outer zone of the cortex becoming twice its normal thickness, whereas the medulla is said to become thinner. Similarly, Stilling ${ }^{6}$ states that in frogs during the pairing time, the medulla

1 Wools Iutchinson, "The Pituitary Gland as a Factor in Acromegaly and Giantism," New York Mcd. Jour., 1900.

2 Freund, "Die Beziehungen der Schilddrise zu den weiblichen Geschlechtsorganen," Deutsche Zeitsch. f. Chir., vol. xviii., 1883.

${ }^{3}$ Gaskell, The Origin of Vertebrates, London, 1908.

4 Alquier and Thauveny, "État de l'Ovaire de Chiennes ayant l'Extirpation partielle on totale de l'A ppareil Thyro-Parathyroídien," C. R. de la Soc. de Biol., vol. lxvi., 1910.

s Gottschau, "Ueber Nebennieren der Saïgethiere," \&c., Sitz.-Ber. d. phys, med. Gesell. zu Würzburg, vol. xvii.-xviii., 1882.

"Stilling, "Zur Anatomie der Nebennieren," Arch. f. Mikr. Anat, vol. lii., 1898. 
disappears, while characteristic cells known as "summer cells" become developed. Bulloch and Sequeira ${ }^{1}$ state that in cases of children with carcinomata of the supra-renals, this is associated with premature development of the genital organs and the accessory generative glands.

\section{General Conclusions regarding the Internal Secretions OF THE OVARY AND THE TESTIS}

It will be convenient at this point to summarise the conclusions which have been tentatively arrived at concerning the nature and purpose of the internal secretions of the ovary and the testis.

The mammalian ovary, in addition to its oögenetic function, is an organ elaborating a chemical substance or substances which react on the general metabolism and control the nutrition of the uterus. The secretion is probably produced by the cells of the follicular epithelium, or by the interstitial cells of the stroma, or, perhaps, by both combined. ${ }^{2}$ It is formed in greater or less quantity at all times, but is produced in increased abundance at certain recurrent periods, when it brings about those conditions of growth and hyperæmia which characterise the procstrous processes. It is at these periods also, in typical cases, that the follicles become mature. After ovulation, which occurs during oestrus, the secretory cells of the ovary show still greater activity, and become converted by a process of simple hypertrophy into the luteal cells of the corpus luteum. If the ovum is fertilised, these cells continue to increase in size until nearly mid-pregnancy (or, in some animals, a somewhat earlier period), when they exhibit signs of degeneration. If pregnancy

1 Bulloch and Sequeira, "On the Relation of the Supra-renal Capsules to the Sexual Organs," Trans. Path. Soc., vol. 1vi., 1905.

2 Limon (loc. cit.) suggested, as a result of his experiments in grafting, that the ovarian secretion is elaborated by the interstitial cells. It should here be remembered that the follicular epithelial and interstitial cells are almost certainly identical by origin, and so probably similar potentially (p. 124), and that both of these cellular elements have been described as taking part in the formation of the corpus luteum (p. 148); and also, that those interstitial cells which do not form part of the corpus luteum have been stated to undergo an independent hypertrophy during pregnancy (p. 345). 
does not supervene, the luteal cells begin to degenerate at a much earlier period and without attaining their full development. The pronounced hypertrophy of the follicular epithelial and interstitial cells, which takes place at the beginning of pregnancy, is directly correlated with a nearly simultaneous hypertrophy on the part of the uterine wall. The corpus luteum, therefore, is to be regarded as an essential factor in maintaining the raised nutrition of the uterus during the earlier stages of the period of gestation. When the later part of this period is reached, the ovarian secretion has probably been already formed in sufficient quantity to prevent the uterus from lapsing into the normal condition until the end of pregnancy. It is to be noted, however, that fibrous degeneration has been described in the maternal placenta in the later stages of its existence.

Thus the ovaries pass through a series of cyclical changes which are directly correlated with those undergone by the uterus. Moreover, the uterus atrophies after ovariotomy.

It seems probable that this close co-ordination between the ovarian and uterine functions arose very gradually in evolutionary history, and it may be that in the aplacental mammals we have in existence at the present day an intermediate stage in the development of this relation. Starling ${ }^{1}$ has suggested that the internal secretions, or hormones generally, arose at first as products of ordinary metabolic activity in certain particular tissues, and that the evolution of the various cases of chemical correlation between different organs in the body came into existence, not by the production on the part of certain tissues of special substances acting as chemical messengers, but by the acquisition of a specific sensibility on the part of other functionally related tissues. It is no doubt possible that the chemical co-ordination of the ovarian and uterine activities arose partly in this way; but, on the other hand, the definite character of certain of the cyclical changes which take place in the ovary, and particularly those which relate to the formation of the corpus luteum, points to the conclusion that the secretory function of the ovary has been perfected, or at any rate, has undergone great development in the phylogenetic history of the

1 Starling, "The Chemical Co-ordination of the Activities of the Body," Science Progress, vol. i. (April) 1907. 
Mammalia, though it no doubt existed previously in a minor degree.

As to whether the ovary elaborates more than one specific substance acting as a chemical excitant, nothing is definitely known, but the composition of the corpus luteum (which is different from that of the rest of the ovary) indicates that the formation of this structure is accompanied by a change in the nature of the ovarian secretion. Lastly, it is possible that the influence of the ovary upon the metabolism is due partly to this organ being excretory as well as secretory in function, but there is no evidence that this is actually the case.

The fact that the testis is an organ of internal secretion seems now to be definitely proved. This secretion is probably formed throughout the entire reprodnctive period of an animal's life; but, in those animals which experience a periodic rut, it is no doubt at this season that the testicular hormone is produced in greatest abundance. The development of the prostate and the secondary sexual characters, not to mention the growth of the testes themselves, is convincing evidence that this is the case.

\section{The Effects of Castration upon the General Metabolism}

In view of the facts referred to above it is almost self-evident that castration must exercise some influence upon the general metabolism of the body since it produces such marked effects mpon the primary and secondary sexual characters. Moreover, it is commonly asserted that the removal of the reproductive glands canses a tendency towards obesity both in Man and animals, but it is not quite clear whether this occurs as a direct or an indirect consequence of castration. The deposition of fat which is sometimes seen to take place after the menopanse may be regarded as further evidence of a connection between the functional ovaries and the general metabolism.

The existence of such a functional correlation is shown more clearly by the effects of ovariotomy upon the bone disease known as osteomalacia. ${ }^{1}$ The ovaries undoubtedly exert a

${ }^{1}$ In one case of osteomalacia Krönig removed the ovaries and transplanted them on to the peritoneum. The result was immediately beneficial; 
marked influence over the phosphorus metabolism, and the improvement which sets in after the removal of these organs in cases of osteomalacia is apparently brought about by a retention of the earthy phosphates whereby the skeletal tissues acquire their normal rigidity. Unfortunately, the experimental work which has so far been done upon the phosphorus metabolism in normal and castrated animals is too contradictory to admit of the deduction of any conclusions that are calculated to throw light upon the phenomena of osteomalacia. ${ }^{1}$

The protein metabolism of castrated animals has been investigated by Lüthje, ${ }^{2}$ who records no changes as a consequence of the removal of the generative glands. Certain other investigators, as a result of shorter series of experiments, have obtained trifling effects, sometimes showing a slight increase in the nitrogenous output and sometimes a diminution. ${ }^{3}$

Experiments upon the respiratory exchange have been almost equally inconclusive, and have so far failed to show any constant alteration as a consequence of castration. This question is discussed at some length by van Noorden, ${ }^{4}$ who calls attention to the necessity for distinguishing whether the total daily metabolism, which in some cases has been shown to become diminished after castration, does so in consequence of a variation in temperament (or greater tendency towards physical repose), or whether the oxidation of the resting cell (i.e. the fundamental metabolism) is reduced. He is disposed to believe that the marked diminution in the respiratory exchange which has been observed in some animals after castration is probably due to a greater indolence, and is, therefore, an indirect result. Moreover, he points out that, in the case of

but with the return of menstruation, which followed after about two months, the symptoms of the disease are said to have reasserted themselves (Stuttgart Medical Congress, Zeit. f. Gynäk., 1996). See also Fraenkel, "Ovarialantikorper und Osteomalacia," Münch. Med. Wochenschr., No. 25, 1908.

1 Van Noorden, Metabolism and Practical Medicine, English Edition, edited by Walker Hall, vol. i., London, 1907. According to Wallart, "Ueber das Verbalten der interstiellen Eierstocksdrüse bei Osteomalacia," Zeitsch. $f$. Geb. und Gynïk., vol. 1xi., 1908, osteomalacia is correlated with an increase of the interstitial cells in the ovary.

2 Iüthje, "Ueber die Kastration und ilıre Folgen," Experim. Archiv, vol. xlviii., 1902, and vol. 1., 1903.

- Van Noorden, loc. cit.

- Ibid. 
Luithje's castrated dogs, which did not exhibit any change from their normal habits and movements, there was no diminution in the gaseous exchange as compared with control animals.

Loewy and Richter, ${ }^{1}$ however, have arrived at different conclusions, finding pronounced reduction in the respiratory metabolism of castrated dogs of both sexes. Furthermore, these investigators found that after feeding the female animals upon ovarian substances there was a great increase in the metabolism, a castrated bitch showing an increase of from 30 to 50 per cent. above the normal values observed before the operation. Testicular substance had no influence upon any of the castrated animals, while normal animals did not react at all either to ovarian or to testicular extracts. Loewy and Richter suggest that the ovaries produce a specific substance which promotes oxidation in the body.

Zuntz ${ }^{2}$ has investigated the gaseous metabolism in four castrated women, and found that it lay within the limits of the normal. It is to be noted that neither of these women showed any tendency to corpulence. These observations support the view that when castrated animals show a reduction in the respiratory exchange, this is an indirect effect resulting from greater indolence of disposition. On this view also, the tendency towards a deposition of fat on the part of many castrated animals is to be attributed to the same cause.

Dr. Cramer, ${ }^{3}$ working in conjunction with the author; has lately investigated the respiratory metabolism of a number of rats whose ovaries had been removed some time previously, and in these animals it was found that the gaseous exchange lay within the limits of the normal, tluus confirming Zuntz's experience with castrated women. It is possible, however, that the results of castration were obscured by other factors. In this investigation the apparatus employed by Haldane and Priestley was used in preference to that of Zuntz. We did not observe any marked tendency to deposition of fat in the castrated rats.

1 Loewy and Richter, "Sexual-Funktion und Stoffwechsel," Arch. f. Phys., Supplement, 1899.

2 Zuntz, "Gaswechsel bei Kastrierten Frauen," Verhandl. d. Gynäk. Gesell., Berlin, 1904. See also Deutsch. Zeitschr.f. Chir., vol. 65, 1908.

${ }^{3}$ Cramer and Marshall. MS. unpublished. 


\section{6 'THE PHYSIOLOGY OF REPRODUC'IION}

Furthermore, it is to be noted that, according to MagnusLevy and Falk, ${ }^{1}$ the period of puberty in boys and girls is not associated with any increase in the gaseous metabolism.

Certain further experiments upon the effects of administering ovarian extract may also be referred to here. Neumann and $\mathrm{Vas}^{2}$ record losses of nitrogen, phosphorus pentoxide, and calcium monoxide after injecting glycerine extract of ovary subcutaneously. Loewy ${ }^{3}$ and Neumann found no change in the nitrogen metabolism in castrated animals after administering ovarian extracts, but Neumann observed a loss of phosphorus pentoxide and calcium monoxide in the fæces. Certain other less satisfactory experiments, dealing with more or less contradictory observations, are briefly referred to by van Noorden.

The influence of castration upon the blood has formed the subject of a research by Breuer and Seiler, ${ }^{4}$ who employed bitches whose ovaries were removed shortly after puberty. They record marked diminution in the hæmoglobin and the red cells. ${ }^{5}$

In concluding this brief summary of the recorded results of castration upon the metabolism, the necessity for further investigation must be emphasised, since it is hardly possible that the totality of the effects produced is of as slight a nature as the experimental evidence at present seems to indicate. ${ }^{6}$

1 Magnus-Levy and Falk, "Lungengaswechsel des Menschen," Arch. f. Phys.; Supplement, 1899.

2 Neumann and Vas, "Einfluss der Ovariumpräparate auf den Stoffwechsel," Monatsschr.f. Geburtsh. u. Gynïk., vol. xv., 1902.

${ }^{3}$ Loewy, "Ueber den Einfluss des Oophorins," Berl. klin. Wochenschr., 1899.

4 Breuer and Seiler, "Einfluss der Kastration auf den Blutbefund weiblicher Tiere," Experim. Archiv, vol. 1., 1903.

${ }^{5}$ It has also been stated that castration may improve the quality of the milk (Oceanu and Babes, "Les Effets Physiologiques de l'Ovariotomie chez la Chèvre," C. R. de l'Acad. des Sciences, vol. cxl., 1905). For some account of the effects of disease in the ovaries and other reproductive organs upon the rest of the body, see Wilson, "The Reciprocal Relations between the Affections of the Uterus and its Appendages upon the Rest of the Body," (Lancet, Part II., Nov. 1906). Further references are given in this paper.

${ }^{6}$ For the effects of hypophysectomy sec Crowe, Cushing, and Homans, "Experimental Hypophysectomy" (Johns Hopkins Hosp. Bull., vol. xxi., May 1910). These investigators found that partial removal of the anterior lobe caused hypoplasia of the generative organs in adult dogs, but persistent infantilism if operated on before puberty. 


\section{CHAP'TER $\mathrm{X}^{1}$}

FEETAL NUTRITION : THE PLACENTA

"Birth ... is commonly considered as the point at which we begin to live. More truly it is the point at which we leave off knowing how to live. . . Not but what before birth there have been unsettled convictions (more's the pity) with not a few."-SAMUEL BUTLER.

\section{PAR'T I \\ THE PLACENTA AS AN ORGAN OF NUTRITION \\ I. Historical Survey}

THe mammalian ovum, in all except the Monotremata, is small and does not contain a sufficient supply of nutriment for the developing embryo. It is retained for a longer or shorter period in the uterus, where, by special modifications of the uterine mucosa and a part of the ovum, the placenta is formed, and a transmission of nutriment from the mother to the embryo is made possible. The changes in the maternal and embryonic tissues vary greatly in the several orders, and even in groups of the same order, but in all they are sufficiently complicated to render their explanation a matter of great difficulty. It is doubtful if any anatomical structure has given rise to keener or more prolonged controversies than the placenta.

We owe to Harvey ${ }^{2}$ the conception of the placenta as an organ elaborating from the maternal blood the aliment necessary for the growth and development of the foetus. He was the first to reject the "subtleties and fanciful conjectures" on embryonic development, and to advocate and practise direct and diligent observation. But for a century after his death the placenta received little attention. With the introduction of the microscope the attention of biologists was directed towards the origin and development of the embryo, and it was then that the ovarian vesicles and spermatozoa were first observed.

1 By James Lochhead.

2 Harvey, The Generation of Animals, London, 1651. 
In the second half of the eighteenth. century were published the researches of John and William Hunter on the human placenta, important not only in themselves, but as destined to set agoing the vast amount of work done in the first half of the nineteenth century. John Hunter ${ }^{1}$ stated that the maternal blood circulated through the placenta, and this view, which, according to Waldeyer, ${ }^{2}$ had formerly been held by Vater and Noortwyk, though the latter at least believed in the communication of the maternal and fœtal circulations, was supported by the subsequent dissection of injected placentre by John Hunter and his brother. The statement of the former that " the blood of the placenta is detached from the common circulation of the mother, moves through the placenta, and is then returned back into the circulation of the mother," gave rise later to a considerable amount of discussion. They showed that the decidua was uterine and not fœtal, and the decidua reflexa was first figured in one of William Hunter's plates. ${ }^{3}$

It is remarkable that John Hunter did not recognise the placenta as the organ of fotal respiration. A century before, Mayow ${ }^{4}$ had declared that the placenta functioned as a foetal lung, the umbilical vessels taking up the nitro-aerial gas (oxygen) and carrying it to the fotus. This view was adopted by Ray, ${ }^{5}$ who compared the villi lying in the maternal sinuses to the gills of a fish in the water. The first to take up Priestley's discovery of oxygen, and state definitely that it was oxygen that went constantly from mother to fœtus, and whose absence caused fœetal asphyxia, was Girtanner ${ }^{6}$ in 1794 . But all doubt was not removed till, in 1874, the spectroscopic bands of oxyhæmoglobin were demonstrated in the umbilical vein of a guineapig by Albert Schmidt, a pupil of Preyer. ${ }^{6}$

'The work of the brothers Hunter was carried on by Weber, Goodsir, Coste, Eschricht, Reid, and others. Of the many investigations, none had such an important influence as the

1 J. Hunter, Observations on Certain Parts of the Animal Economy, Edit. by Palmer, vol. iv.

2 Waldeyer, "Bemerkungen über den Bau der Menschen- und Affenplacenta," Arch. f. mikr. Anat., vol. xxxv., 1890.

3 W. Hunter, Anatomy of the Human Gravid Uterus, Birmingham, 1777.

4 Mayow, Tractus Tertius de Respiratione Fotus in Utero, 1674.

5 Ray, The Wisdom of God in the Creation, 12th Edit., 1754.

- See Preyer's Specielle Physiologie des Embryo, 1883. 
researches of Goodsir. ${ }^{1}$ He first studied the placental cells with regard to their function. His predecessors had spoken in the vaguest terms of the passage of nutriment from mother to fœetus, but Goodsir had definite ideas. He described the villi as having two covering layers of cells, an external system belonging to the decidua, and an internal belonging to the chorion. As to their function, he says: "The external cells separate from the blood of the mother the matter destined for the blood of the foetus, they are secreting; the internal cells absorb the matter secreted by the agency of the external cells." Thus we have the active part of placental metabolism referred for the first time to the cells of the villi.

The importance of the intervillous spaces for fœetal nutrition was first emphasised by Weber, ${ }^{2}$ and they were the subject of close attention. The Hunterian doctrine that in the human placenta they contained blood was not yet established, and their mode of development gave rise to a long-continued controversy. John Hunter considered them outwith the maternal vascular system, and his view was supported by Owen, ${ }^{3}$ Kölliker, ${ }^{4}$ and Farre. ${ }^{5}$ Weber and Reid ${ }^{6}$ held that the spaces were bounded by a thin maternal membrane, and Goodsir described two layers of maternal tissue between the blood in the sinuses and the vessels of the villi.

The investigation of the intervillous spaces and the epithelial investment of the villi was carried on by Turner, Ercolani, Langhans, and many others. Turner ${ }^{7}$ and Waldeyer looked on the intervillous spaces as dilated maternal capillaries; but while Turner held that the villi, at least in part, penetrated their endothelium, Waldeyer supposed that they pushed the endothelium before them, and so got a covering of this

1 Goodsir, Anatomical and Pathological Observations, Edinburgh, 1845.

2 See Wagner's Elcments of Physiology, translated by Willis, London, 1841.

${ }^{3}$ See Note in John Hunter's Collected Works, Edit. by Palmer, vol. if.

+ Kölliker, Entwicklungsgeschichte, 1861, 1884, \&c.

5 See Tod'\& Cyclopadix, Article "Uterus," 1858.

"Reid, "On the Anatomical Relations of the Blood-Vessels of the Mother to those of the Foetus in the Human Species," Edinburgh Medical and Surgical Journal, vol. Iv., 1841.

7 Turner, "Some General Obserrations on the Placenta," \&c., Journal of Anatomy and Physiology, vol. xi., 1877. 
maternal layer. Langhans ${ }^{1}$ regarded the spaces as formed by that part of the lumen of the uterus which lay between the surface of the mucosa and the chorion, and thought that the villi by eroding vessels came to be bathed in extravasations of maternal blood. Klebs ${ }^{2}$ considered them to be lymph-spaces, and therefore extra-vascular ; and Jassinsky ${ }^{3}$ described them as being formed by the penetration of the villi into the maternal glands, whose epithelium came to clothe the villi externally. Now it has been proved from the examination of early ova that the intervillous spaces are entirely foetal and are formed in the epiblast.

The investigations of Langhans proved to be the turningpoint in the controversy regarding the investment of the villi. He showed that it consisted in the earlier stages of pregnancy of a double covering, a deep layer of cells (Langhans' layer), and superficially a mass of "canalised fibrin." The presence of fibrin had been noted by Weber and several of his successors; Winkler ${ }^{4}$ proved it to be a constant phenomenon, and gave it the name "Schlussplatte"; but it was Langhans who first described its relations, and suggested its probable origin from the fœtal epiblast. The cellular layer, according to Langhans, was mesoblastic. Kastschenko ${ }^{5}$ first described both layers as epiblastic, and showed that the outer layer was a syncytium or mass of nucleated protoplasm without cell-boundaries. Such investigations led to the feeling that the structure of the placenta could only be understood by tracing its development from very early periods of gestation. Hence the search for and examination of young human ova were stimulated, and the study of the uterine condition in age-series of pregnant animals was begun. Up to this time the chief controversies had raged around the human placenta. Comparative placentation had engaged the

1 Langhans, "Untersuchungen über die menschliche Placenta," Arch. f. Anat. u. Physiol., anat. Abth., 1877.

"Klebs (E.). "Zur vergleichende Anatomie der Placenta," Arch. f. mikr. Anat, vol. xxxvii., 1891.

3 Jassinsky, "Zur Lehre über die Struktur der 1'lacenta," Virchow's Arch., vol. xl., 1867.

4 Winkler (F. N.), "Zur Kenntnis der menschlichen Placenta," Arch. $f$. Gynäk., vol. iv., 1872.

5 Kastschenko, "Das menschliche Chorionepithel und dessen Rolle bei der Histogenese der Placenta," Arch.f. Anat. u. Phys., anat. Abth., 1885. 
attention of few morphologists, among whom Turner, the "grand-master of placental research" (Hubrecht ${ }^{1}$ ), was fucile princeps. But within recent years investigations have been carried out on many orders of placental mammals. Of these the most important are the researches of Duval and Hubrecht, which have established that the discoid placenta is essentially " a maternal hæmorrhage encysted by fœtal elements."

\section{Structure and Functions of the Epithelial INVESTMENT OF THE VILLI}

The cellular layer of the villi is a temporary structure, and disappears to a great extent comparatively early in pregnancy. It is generally looked on as the mother zone of the outer syncytial layer. Strahl ${ }^{2}$ states, however, that in one of the new-world apes it is not present at a stage as early as that of Peters' human ovum, though a thick syncytial layer is present. Processes of it precede the mesoblastic outgrowths in the formation of the villi, and by a special proliferation of the cells at the tips of the villi, the "Zellsäulen" of Langhans, an attachment to the decidua is effected. While present, the cellular layer lies in the path by which the nutriment for the fotus is carried to the villous capillaries, but it is not known whether it exerts any metabolic influence. Peters has suggested, without any very definite evidence, that it may have a coagulating action on matemal blood, necessitating the interposition of the syncytial layer.

The syncytium is more permanent. In the earliest human ovum yet examined it already constitutes a considerable mass, and a similar thickening over the whole or part of the circumference of the blastocyst occurs early in all the Deciduata. Where a decidua reflexa exists, the early proliferation appears to be related to the excavation of the cavity in which the ovum lies. In discoid placentre the mass is vacuolated, and maternal blood is contained in the lacunx. In the later stages of pregnancy it forms an attenuated membrane over the villi, and may wholly

1 Hubrecht, "The Placentation of Erinaceus europaus," Quar. Jour. Micr. Sci., vol. xxx., 1889.

2 Strahl, "Ueber Placentarsyncytien," Anat. Anz., vol, xxix., Eryänzungsch., 1906. 
disappear at parts. The nuclei are numerous, and most of the authorities agree on the absence of mitoses, some holding that they divide directly, others that they have lost the power of division. The protoplasm has a foam-like structure, and in Man it is condensed superficially to form a layer which bears the "Bürstenbesatz" or striated border (Fig. 75). This consists, as seen in fixed specimens, of a series of fine striæ running perpendicularly to the surface, and its structure and function have been much discussed since it was first described by Minot. ${ }^{1}$

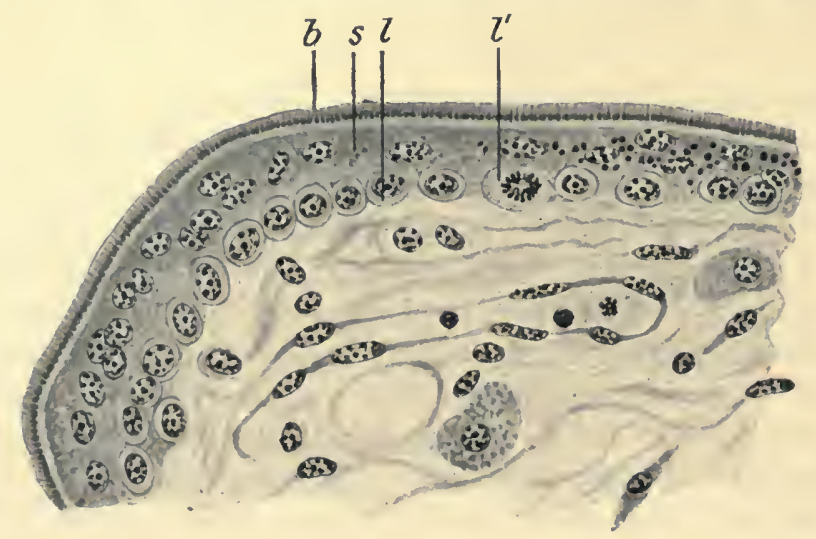

Fig. 75. - Part of an early human chorionic villus. (From Hofbauer's Biologie der menschlichen Plazenta, Braumüller.)

$b$, Bürstenbesatz with basal corpuscles ; $s$, syncytium ; l, Ianghans' layer, one cell dividing mitotically $\left(l^{\prime}\right)$.

Some have denied its existence during life, and ascribed it wholly to the method of preparation. But Hofbauer ${ }^{2}$ has shown that the fresher a specimen is when obtained, the easier it is to demonstrate the striæ by methods of staining, and, therefore, it is probably a vital structure. Kastschenko looked on the striæ as fine hairs which projected from the surface of the cells, and by their vibrations created a stream in the maternal blood of the intervillous spaces. In specimens stained with iron-hæmatoxylin, knobs may be seen at the bases-basal corpuscles or blepharoblasts-and they may constitute the

1 Minot, "Uterus and Embryo," Jour. of Morphol., vol. xi., 1889.

2 Hofbauer, Biologie der menschlichen Plazcnta, Leipzig, 1905. 
motor centre for the ciliary beats. But no movements have yet been observed, and von Lenhossék ${ }^{1}$ calls them "stereozilien," or stationary cilia, suggesting that they may help to break down vessel-walls during the burrowing of the syncytium into the serotina. Sometimes they appear not to project free on the surface but to lie in the superficial stratum; then lighter and darker striæ alternate, and it is this appearance which has led to the name "striated edge." Bonnet ${ }^{2}$ ingeniously remarks that it proves the fœtal origin of the syncytium, because, if it were uterine, the free edge would be formed by the bases of maternal cells, and they could not possess a "Bürstenbesatz." The same appearance has been noted in intestinal epithelium, but its significance is unknown. In the placenta Graf v. Spee ${ }^{3}$ attributes the appearance to the teasing out of the surface of the protoplasm, and looks on it as evidence of a strong flow of fluid through the syncytium. It has also been suggested that the thin rods may be hollow and act as pores by which nutriment may enter the syncytium, or by which a secretion of the syncytium may pour out in order to prepare the constituents of the maternal blood for their transference to the fœtus.

It is still undecided whether the syncytium possesses amœboid motility. V. Lenhossék examined a human ovum several minutes after its removal from the uterus and observed, as has already been stated, no ciliary movements; but he considered it not improbable that the syncytium underwent changes of form. Hofbauer tried unsuccessfully to demonstrate such movements in a specimen examined immediately after its removal.

The core in young villi consists of a matrix, homogeneous or delicately fibrillated. In it are placed the blood-vessels and connective-tissue corpuscles with long branching processes, which form a network in the matrix, and probably provide a series of lymph-channels. Kastschenko also described special

1 V. Lenhossék, Verhandl. d. anat. Kongresses in Halle, 1902. See Centralbl.f. Gynäk., 1904, Nr. 7.

2 Bonnet, "Über Syncytien," \&c., Monatsschr. f. Geburtsh. u. Gynäk., vol. xviii., 1903.

${ }^{3}$ Graf v. Spee, "Neue Beobachtungen iiber sehr frühe Entwickelungsstufen des menschlichen Eies," Arch.f. Anat. u. Phys., anat. Abth., 1896. 
cells, with large nuclei, which he took to be wandering cells. But Lenhossék proved that they existed before leucocytes or lymph-cells appeared, and must therefore be formed in the villi and derived from mesoblastic cells. Hofbauer has observed them also in the lumen of the fœtal vessels, and suggests a possible transformation to leucocytes.

Our ideas upon the function of syncytia are largely based on the investigations of His : " They are not really specific tissue structures, but tissue conditions requiring definite phases of protoplasmic vitality. They occur along with a high degree of activity-with increased absorption and action on materialas well as with increased motility. Favourable conditions of nutrition form the fundamental condition for the existence of syncytia, and such conditions are certainly well offered in the uterus." At the present time the syncytium is regarded as of the highest importance in foetal nutrition. Strahl ${ }^{2}$ and Heinricius, ${ }^{3}$ noting its gradual and progressive diminution as pregnancy advanced, supposed that it formed a part of the nutriment for the embryo, but this idea has not been adopted. The general theory is that it is essential in maintaining the interchange of material between mother and fotus. The substances necessary for the building up of the foetal body may be divided into two groups-diffusible and non-diffusible. The passage of the former can be explained by physical laws, but it is different with the non-diffusible or colloid substances. This is a difficulty which does not belong to the placenta alone, but to every organ of the body, and authorities are divided between two theories, the mechanical and the vital. The supporters of the mechanical theory hold that all the processes occurring in the placenta are possible by the laws of filtration and osmosis, and they have carried out numerous experiments to prove that substances in solution may pass across the placenta in both directions. Others, paying special attention to the nature of the barrier formed by the epithelial covering of the villi,

${ }^{1}$ His, "Die Umschliessung der menschl. Frucht während der frühesten "Zeit der Schwangerschaft," Arch.f. Anat. u. Phys., anat. Abth., 1897.

2 Strahl, "Der Bau der Hundeplacenta," Arch. f. Anat. u. Phys., anat. Abth., 1890.

${ }^{3}$ Heinricius, "Ueber die Entwicklung und Struktur der Placenta beim Hunde,"Arch. f. mikr. Anat., vol. xxxiii., 1889. 
deny that by such physical processes the non-diffusible substances with large molecules, e.g. hæmoglobin and other blood proteins, can be absorbed by the syncytium. They postulate a vital action on the part of the cells, by which the necessary material is selected by the syncytium, and altered to a form in which it may be transmitted to the fotal circulation. It is not yet settled whether the activity of the syncytium is due to a phagocytic power or to an enzyme action.

There is a third theory regarding the transmission of nutritive material from the mother to the fœtus, viz. by the actual passage of maternal leucocytes, charged with nutriment, from the one circulation to the other. This theory was first advocated by Rauber ${ }^{1}$ as the result of microscopic investigations, and he instanced, as further evidence in its favour, the greater number of leucocytes in the blood of the umbilical vein than in that of the artery. This view, which explained satisfactorily the passage of non-diffusible materials, subsequently received wide support. Thus Wiener ${ }^{2}$ said : "It may be held as nearly without doubt that leucocytes cross from the maternal to the fœetal blood," and Preyer ${ }^{3}$ considered the passage of leucocytes " indisputable." The first objection was raised in a paper by Paterson." In it he recorded three cases of pregnancy complicated by leucocythæmia in the mother, and stated that the infants appeared quite normal and healthy, and their blood was of the usual colour and not white like the mothers'. These results were corroborated in similar cases by Cameron ${ }^{5}$ and Sänger, ${ }^{6}$ who actually counted the fotal leucocytes and found no increase. These observations, and the inability of subsequent investigators to demonstrate healthy leucocytes in the tissues intervening between the maternal and fotal blood, have led to the abandonment of Rauber's theory.

1 Rauber, Ueber den Ursprung der Milch und die Ernährung der Frucht im allgemeinen, Leipzig, 1879. Also Zool. Anz., No. 70.

2 Wiener, "Die Ernährung des Fötus," Samml. Klin. Vorträge, No. 290.

3 Preyer, Specielle Physiologie des Embryo, 1883.

4 Paterson, "Cases of Acute Leucocythæmia in connection with Pregnancy," Edinburgh Med. Jour., 1870.

" Cameron, "The Intluence of Leucæmia upon Pregnancy," Internat. Jour. of the Med. Sc., 1888.

' Sänger, "Ueber Leukämie bei Schwangeren und angeborene Leukämie," Arch. f. Gynäk, vol. xxxiii., 1888. 
But though maternal leucocytes do not pass as such straight into the fotal blood, they may be important in another way. In Ruminants, Bonnet ${ }^{1}$ has drawn attention to the cnormous number of degenerated leucocytes in the uterine milk, and demonstrated their absorption by the ectoderm, and similar obscrvations have been recorded in Carnivores. In these orders leucocytes undoubtedly form a part of the embryonic nutriment. In the rest of the deciduate Mammals they seem to play a less important part.

\section{The Decidua}

In the uterine mucosa during pregnancy the most noticeable change occurs in the interglandular tissue of discoid placentse, in which decidual cells are formed. Various opinions have been held regarding their origin. Langhans, Hennig, ${ }^{2}$ and others held that thcy were enlarged and modified leucocytes, but they could not support their theory by direct observation. Overlach ${ }^{3}$ and Frommel ${ }^{4}$ described them as modified glandular cells, but there is no doubt that the true origin is, as Creighton ${ }^{5}$ first suggested, from the interglandular tissue of the mucosa. This consists of connective tissue of an embryonic type, which allows of a rapid transformation of its cellular elements. Masquelin and Swaen ${ }^{6}$ demonstrated this mode of origin in Rodents, and werc supported by Minot, and Hart and Gulland.? Leopold's studies of early ova showed that the same origin was most probable in Man, and Peters described in the mucosa next the ovum connective tissue cells undergoing a dccidual transformation. Their first appearance in the superficial layers

1 Bonnet, “Über Embryotrophe," Deuts. med. Woch., 1899. 1872.

${ }^{2}$ Hennig, Stulien über den Bau der menschlichen Placenta, ds., Leipzig,

3 Overlach, "Die pseudomenstruirende Mucosa Uteri nach akuter Phos. phorvergiftung," Arch. f. mikr. Anat., vol, xxxv., 1885.

4 Frommel, "Beitrag zur Frage der Wachstumsrichtung der Placenta," Zeits. f. Geburtsh.u. Gynäk., vol. xxxvi.

"Creighton, "The Formation of the Placenta in the Guinea-pig," Jour. of Anat, and Phys., vol. xii., 1878.

"Masquelin and Swaen, "Premières phases du développement du placenta chez le lapin," Bull. de l'Acad. roy. de Belg., 1879.

"Hart and Gulland, "On the Structure of the Human Placenta," \&c., Labor. Rep., Roy. Coll. of Phys., Edinburgh, vol. iv., 1892. 
of the mucosa has suggested a stimulus for their formation arising from the product of conception. ${ }^{1}$ The study of early human specimens has effectually disproved Ercolani's ${ }^{2}$ idea that the uterine mucosa was first entirely destroyed by the developing ovum, and then replaced by decidual tissue formed from the cells of the vessel walls. Such an endothelial proliferation does, however, occur in certain animals, e.g. hedgehog (Hubrecht ${ }^{3}$ ) and bat (Nolf ${ }^{4}$ ), and probably in ectopic gestation in Man.

The rapid increase in the size and number of the decidual cells, together with the dilatation of the blood-vessels, leads to a great increase in the thickness of the serotina. At a certain stage it reaches its full development, and then gradually diminishes till, at the end of gestation, it forms only a thin layer, and even disappears entirely at parts so that the villi impinge on the muscular wall.

Individual decidual cells have probably a short life-history. Even at a comparatively early period many of them are found in various stages of hyaline degeneration, giving rise in part to the layers of fibrin, and as pregnancy advances there is a gradual extension of the fibrinous change. The degeneration of the decidual tissue would seem to be due to the influence of the fotal epiblast, as in Man it occurs much earlier and more abundantly in the serotina and reflexa than in the vera $\left(\right.$ Webster ${ }^{5}$ ). Its gradual diminution during pregnancy indicates an absorption of the decidua. That maternal tissues do not play a large part in this absorption is probable from the small number of leucocytes and the absence of lymph-channels in the neighbourhood of the fibrinous masses. At the same

1 Under abnormal conditions the formation of decidual cells occurs even although no ovum is present in the uterus, e.g. in tubal pregnancy in the human female. Whether this indicates a chemical stimulus from the ovum, or perhaps from the corpus luteum, effected through the blood-stream, is not yet known (see p. 491).

${ }^{2}$ Ercolani, "Sulla unita del tipo anatomico della placenta," Mem. dell" Accad. di Bologna, 1876.

3 Hubrecht, "The Placentation of Erinaccus europceus," Quar. Jour. Micr. Science, vol. xxx., 1889.

4 Nolf, "Modifications de la muqueuse utérine pendant la gestation clıez le murin," Arch. de Biol., vol. xiv., 1896.

5 Webster, Human Placentation, Chicago, 1901. 


\section{8}

time, specialised decidual cells, which have the power of destroying the rest of the decidual tissue, have been described in the hedgehog, ${ }^{1}$ rat, and other animals. But it is now generally accepted that the fœtal ectoderm from the earliest stages of pregnancy is ablc to disintegrate the cclls with which it comes in contact, and to absorb the degenerate products. To that part of the fœetal epiblast which is thus adapted for the acquirement of embryonic nutriment the name of trophoblast has been given by Hubrecht.

Along with the gradual absorption of the degenerated parts of the decidua, and the great increase in the extent of the serotinal surface as pregnancy advances, there is probably a continued formation of new decidual elements. Pfannenstiel attributes the new formation to the peri-vascular tissue, and Webster to groups of active cells, the "Ersatz-zellen " of Klein, ${ }^{2}$ found here and there in the mucosa. Whatever their origin is, we may see, cven in the shed placenta at full time, well-formed and apparently healthy decidual elements as well as the fibrinous masses containing cellular fragments.

Within recent years there has been a tendency to belittle the importance of the connective tissue elements of the placenta. This has been largely due to the wider acceptance of the fœtal origin of the syncytium, and to the conception of the placenta as a maternal hæmorrhage circumscribed by fœtal structures. But the same idea has been encouraged by some who look on the syncytium as matcrnal, and they adduce as evidence the obvious degeneration in the decidua during the greater part of pregnancy. Pfannenstiel maintains that decidual cells are, from the beginning, degeneration forms of the connective tissue cells and are of use only as pabulum to be absorbed by the ovum. But during the whole of pregnancy, as mentioned above, there cxist in the placenta decidual cells which, in their appearance and staining properties, show no resemblance to degencrated cclls. From their abundance and great specialisation they have in all likelihood definite functions to perform. Their first formation dates

1 In a later memoir Hubrecht assigns to these cells, the deciduofracts of the hedgehog, an origin from the outer layer of the trophoblast. See foot-note, p. 470.

2 Klein, "Entwicklung und Rückbildung d. Decidua," Zeits. f. Geburtsh. u. Gynäk., vol. xxii. 
from the destruction of the surface epithelium when the blastocyst comes in contact with the connective tissue, and the earliest to appear are in the neighbourhood of the ovum. Their position and general appearance in different orders suggested to Turner a matemal reaction against the advance of the parasitic ovum, and the same idea has been forced on different observers. Fothergill ${ }^{1}$ speaks of the decidua preventing the injurious invasion of the uterine wall by the fotal elements. Chipman's ${ }^{2}$ figures on the placenta of the rabbit show that the ectoplacenta advances more rapidly where it encounters a vessel than where it lies against decidual cells. Wade and Watson ${ }^{3}$ have noted its resemblance to young granulation tissue in the mucosa of the Fallopian tube in an early ectopic pregnancy. Bryce and Teacher, ${ }^{4}$ in their description of the youngest human ovum yet examined, say: "The decidua formation is a process of a conservative nature, by which, during the early months of pregnancy, the activities of the trophoblast are limited and controlled until such time as placentation is complete." Whether or not the decidua forms the protection to the mother, there is increasing evidence that the trophoblast does not invade the decidua to the extent supposed by the older authorities. This was first emphasised by Hubrecht in the hedgehog, and has more recently been advocated by Webster, and by Bryce and Teacher, in Man.

Hoffmann ${ }^{5}$ and Ahlfeld ${ }^{6}$ considered the decidua to be of the nature of a diffuse gland whose cells secreted a nutritive juice for the wants of the fotus. They stated that they could demonstrate such a secretion in the "intervillous" spaces formed by the separation of the decidual cells; but their observations have been discounted by the investigations of Werth, ${ }^{7}$

1 Fothergill, “Decidual Cells," Edinb. Med. Jour., vol. v., 1899.

"Chipman, "Observations on the Placenta of the Rabbit," \&c., Edinb. Roy. Coll. of Physic. Labor. Rep., vol. viii., 1903.

3 Wade and Watson (B. P.), "The Anatomy and Histology of an Early Tubal Gestation," Jour. of Obstet. and Gynec. of the Brit. Emp., 1908.

4 Bryce and Teacher, Contributions to the Study of the Early Development and Imbedding of the Human Ovum, Glasgow, 1908.

5 Hoffmann, "Sicherer Nachweis der sogennanten Uterinmilch beim Menschen," Zeits. f. Geburtsh. u. Gynäk., vol. viii., 1882.

${ }^{B}$ Ahlfeld, Berichte $u$. Arbeiten aus der geburtsh. Klinik zu Giessen, Leipzig, 1883.

7 Werth, "Beiträge zur Anatomie, Physiologie, und Pathologie der menschlichen Schwangerschaft," Arch.f. Gynäk., vol. xxii. 
who showed that the spherical globules described by Hoffmann were never present in the fresh placenta, but appeared only after its separation, and probably consisted of droplets exuded by the dying chorionic epithelium. It may be mentioned here that the "boules," described by Nattan-Larrier ${ }^{1}$ as an internal secretion of the syncytium, have been thought by many to be a post-mortem appearance.

In Rodents the decidual cells have an important and definite part to play in synthesising and storing glycogen as a supply of carbohydrate for the foetus. In Man also the decidual cells contain glycogen at an early period. Fat globules infiltrate the decidual cells of various animals at a stage when there is no question of a fatty degeneration taking place in the cells. Finally, the cells appear to have the power of ingesting and decomposing erythrocytes, but their relations to the ironmetabolism of the fotus require further study.

\section{PART II}

\section{THE FIRST STAGES OF PREGNANCY: PLACENTAL CLASSIFICATION}

\section{The Ovarian Ovum}

WHILE still in the ovary, the ovum obtains the necessary nutriment by means not yet discovered. In the Graafian follicle it is surrounded by the zona pellucida and externally the corona radiata. The origin of the zona pellucida has been variously described. According to some authorities it is the thickened outer edge of the ovum itself, a true vitelline membrane, but it is more probably a deposit from the cells of the corona radiata. ${ }^{2}$ Its structure is almost homogeneous, but with the highest powers of the microscope fine striæ are seen running from without inwards. Their appearance indicates the possibility that they are pores or delicate canals by which protoplasmic processes of the cells of the corona radiata, or a secretion of

${ }^{1}$ Nattan-Larrier, "Fonction sécrétoire du placenta," Comp. Rend. de l'Acad. de Sc., vol. lii., 1900.

${ }^{2}$ I.c., the discus proligerus, or innermost layer of follicular epithelium. 
these cells, may reach the ovum and nourish it (see p. 127). Whatever the source of the food-supply of the ovum is, it not only increases in size until it is ripe for deliverance, but stores in its protoplasm yolk granules, the deutoplasm of Beneden, which increase in number as the ovum approaches maturity. The granules vary in size and number in different species, and also in their position. They may be mingled uniformly through the cytoplasm, or be collected at the marginal zone (sheep), or at the periphery of the central zone (Man). During the earliest stages of segmentation, when perhaps food is not readily accessible, or a specialised form of nutriment is required, the granules are used up.

\section{The Fertilised Ovum and its Coverings}

When the ovum leaves the ovary it carries with it the zona pellucida and cells of the corona radiata. After fertilisation, which most probably occurs in all animals at the outer end of the oviduct or Fallopian tube, the cells disappear and are replaced in some species by a homogeneous sticky layer of albuminous material. According to Robinson, ${ }^{1}$ it is derived in part from the disintegrated cells of the corona radiata, but most of it seems to be obtained from the secretion of the tubal and later of the uterine glands. ${ }^{2}$ It is covered by villous tufts, which led to its designation as prochorion by Hensen. But the tufts are merely casts of the gland-ducts, due to the coagulation of the secretion by the use of reagents.

The investment formed by the two layers around the ovum is very thick in Marsupials. In Ungulates it forms a thin coat, which disappears at a comparatively early stage in the pig, slieep, and deer. In the last named, according to Bisclioff, there is no albumen layer. In Carnivores there is invariably a firm coat of zona pellucida or albumen layer, or both, which persists, in the dog and ferret at least, till the appearance of the primitive streak and the commencement of the formation of the mesoderm

1 Robinson, "On the Early Stages of Development of Mammalian Ova, and on the Formation of the Placenta," Hunterian Lectures, Jour. of Anat. and Physiol., vol. xxxviii., 1904.

2 Bonnet, "Ueber das Prochorion der Hundekeimblase," Anat. Anz. vol. xiii., 1897. 
(Robinson). In Rodents there are differences. In the rabbit (Fig. 76) the albuminous layer is well-marked while the fertilised ovum is still in the Fallopian tube; on the fourth day, when the uterus is reached, it rapidly thins but remains up to the eighth day (Assheton ${ }^{1}$ ). In the rat the covering disappears early-usually about the eight-cell stage. In the mole the

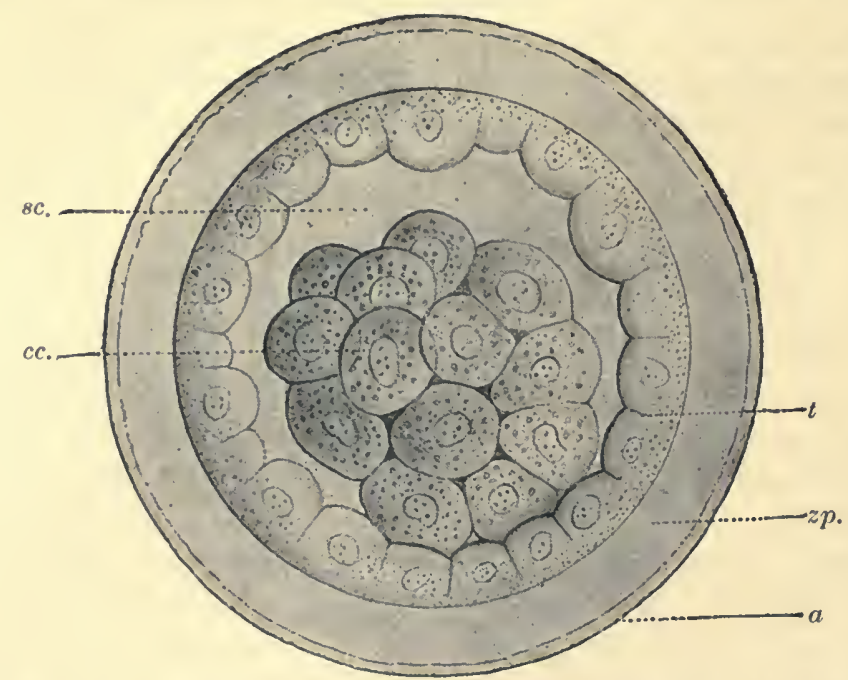

FIG. 76.- Early blastocyst of the rabbit. (From Hertwig's Entwicklungsgeschichte des Menschen und der Wirbelthiere: by permission of Gustav Fischer.)

$a$, albumen layer; $z p$, zona pellucida ; $t$, trophoblast ; $8 c$, segmentation cavity; ec, mass of embryo cells.

covering is thick, and, according to Heape, ${ }^{2}$ the albumen layer is applied in the uterus and not in the Fallopian tube. It persists, as in the shrew, till the embryonic ectoderm appears on the surface of the ovum. In the hedgehog and bat it disappears before the blastocyst is formed, and in Tipaia javanica it may be already absent in the two-cell stage. Little is known of it in the Primates; in the earliest ovum investigated,

1 Assheton, "The Attachment of the Mammalian Embryo to the Walls of the Uterus," Quar. Jour. Micr. Sci., vol. xxxvii., 1895.

"Heape, "The Development of the Mole (Talpa europaa)," \&c., Quar. Jour. Micr. Sci., vol. xxiii., 1883. 
the four-cell stage of Macacus nemestrinus, it had already disappeared.

With regard to its functions, there is little doubt that the degenerating cells of the corona radiata, and later the albumen layer, serve as food for the growing mass of the ovum in the Fallopian tube and uterus. In the investment in the mouse, Jenkinson ${ }^{1}$ found nutritive substances-fat, and probably also protein matter. In addition, Bonnet has adduced strong evidence to show that it is absorbed by the ectoderm of the blastodermic vesicle. In the rabbit the albumen layer forms a tough, strong membrane enclosing at the end of the third day the solid morula. Within the mass of cells a cavity develops and rapidly increases by diffusion inwards of fluid. "It is hardly conceivable that the delicate cells could cause expansion of the tough albuminous wall. Rather the osmotic current is more inwards than outwards, either simple or more probably assisted by the vital activity of the cells" (Assheton). Heape had previously pointed out that the increasing fluid must be secreted into the interior of the blastocyst under considerable pressure, as the vesicle remains spherical and extends the uterine walls before it. Once inside, the fluid exerts a greater or less hydrostatic pressure, which is counteracted by the albumen layer, and the rupture of the vesicle is prevented. At the beginning of the cavity formation in the morula, the cells are not yet pressed on by the investment. Later the vesicle increases in size, and the outer cells are pressed and flattened. At the same time the albumen layer is thinned, and is soon hardly perceptible. Finally it ruptures, and immediately afterwards the blastodermic vesicle is flaccid, apparently from injury to its wall.

Besides its nutritive and protective function, the investing layer may prevent the contact of the external cells of the blastodermic vesicle with the cells of the uterus. Only when it has disappeared is fusion of the maternal and foetal elements possible. Robinson has followed out this idea in different Mammals. He suggests that in those animals (Carnivores, rabbit) in which the embryonic ectoderm reaches the surface,

1 Jenkinson, "Observations on the Physiology and Histology of the Placenta of the Mouse," Tijd. Nederl. Dierk., Ver. ii., Dl. 7. 
the albumen layer prevents contact with the uterine wall till differentiation of the ectodermal cells has taken place to such an extent that they are no longer disposed to fuse with the uterine tissues. In those in which the embryonic ectoderm never reaches the surface (mouse, guinea-pig, hedgehog, bat, probably Primates), the investment disappears before the blastula is attained.

With the disappearance of the zona, the developing ovum lies naked in the Fallopian tube or the uterus. It takes some time to complete the journey along the tube-about eighty hours in the rabbit, and a little longer in the sheep. For a further period it remains unattached in the uterine cavity, and then, by processes which vary in different orders, it obtains attachment-loose in Marsupials and firmer in the other orders.

At first each blastomere is nourished separately; but when the blastocyst is formed, the greater part of its outer layer is set aside to look after the nutrition of the whole, and takes no share in the formation of the embryo or amnion. To that part Hubrecht gave the name of trophoblast, and the term has been generally accepted. Already, before the embryo is elaborated, provision is in this way made for its maintenance.

\section{The Uterine Mucosa}

While the ovum is still in the oviduct, no obvious changes occur in the uterus itself. In the sheep, Assheton ${ }^{1}$ detected no difference except an increase in the number of the leucocytes. There was no sign of activity in the uterine glands or bloodvessels. When the ovum reaches the uterus changes begindilatation of blood-vessels and lymphatics, widening and increased tortuosity of glands, disappearance of cilia from the surface epithelium. The whole mucosa is soft and odematous, and there may even be a transudation of lymph into the uterine cavity, which is mingled with the glandular secretion to form a supply of nutriment for the ovum before attachment. Great

1 Assheton, "The Morphology of the Ungulate Placenta," \&c., Phil. Trans. Roy. Soc., London, Ser. B., vol. cxcviii., 1906. 
differences, however, occur, and it is more convenient to describe the changes in the uterine mucosa in each order.

\section{Placental Classification}

At the outset we are beset with the difficulty of grouping Mammals in such a way as to show how the variations in the anatomy and physiology of the placenta have been evolved. Well-marked differences, such as occur in other organs and serve to differentiate Mammals into certain orders, are not always to be observed in their placentæ. In widely diverging groups there may be striking similarities in placentation, while great differences may exist in closely related types. On this account the most satisfactory, and indeed the only possible, classification of Mammals for our purpose is one based on their placental characters. Such a classification was introduced by Huxley ${ }^{1}$ in 1864 . He divided Mammals into two great sections according as their placentæ were non-deciduate or deciduate. ${ }^{2}$ In Deciduates the substance of the mucosa undergoes rapid growth and textural modification to form decidual tissue, and the maternal and fotal parts of the placenta become firmly united. In Non-deciduates there is no formation of decidual tissue, and at parturition the fotal villi are simply drawn out like the fingers from a glove, no vascular substance from the mother being thrown off.

In a later publication ${ }^{3}$ Huxley attempted to arrange all Mammals in one or other division. The Deciduata are classed in two groups according to the external appearance of the placenta, which is either zonary, as in Carnivora, Amplibia, and Proboscidea ; or discoid, as in Rodentia, Insectivora, Cheiroptera, Lemuridæ, Simiadæ, and Primates. The Non-deciduata are the Ungulata and Cetacea. The Sirenia and Edentata offer difficulties. Of the latter, Manis has a diffuse placenta, Bradypus a poly-cotyledonary, and Orycteropus a discoid and deciduate

1 Huxley, The Elements of Comparative Anatomy, London.

2 Thirty years earlier Weber had suggested a similar division into caducous and non-caducous; but his terms, although accepted by von Baer and Eschricht, were displaced by those of Huxley.

${ }^{3}$ Huxley, Introduction to the Classification of Mammals, London, 1869. 
placenta. One of the Sirenia, the dugong, which possesses a zonary but not deciduate placenta, illustrates a type not represented at all in Huxley's classification. No maternal tissue is lost at birth ; but, in addition, part of the fotal tissue remains attached to the uterus and is absorbed (Turner ${ }^{1}$ ). The placenta of the mole is not shed at birth, but becomes gradually absorbed by the mother. For such Hubrecht ${ }^{2}$ suggested the term contra-deciduate.

The classification of Strahl ${ }^{3}$ does not promise to be any more satisfactory. He divides Mammals into two groups, one having a "Halbplacenta" and the other a "Vollplacenta." In the former no maternal vessels are opened and the connection is less intimate, while in the latter hæmorrhages occur during pregnancy. But in a physiological sense, the half placenta is certainly as efficient an organ of nutrition as the whole placenta.

In view of the recent work on the placenta, it is obvious that Huxley's classification fails in taking no account of the trophoblast, the most active constituent of the placenta, and in laying too much stress on the differences at birth, i.e. on the shedding of an organ which is of no more use, and may be considered as physiologically dead. Moreover, it would appear that in many of the deciduate Mammals almost no maternal tissue except blood is lost at birth, and maternal blood is also lost in the non-deciduate sheep. A perfect classification must take account of the structure and behaviour of the trophoblast during the whole course, or at least the earlier part, of pregnancy. Without it a clear insight into the processes which regulate foetal nutrition cannot be obtained. Robinson ${ }^{4}$ and Assheton ${ }^{5}$ have recently made efforts in this direction, the former emphasising the methods of attachment of the trophoblast to the uterus, and the latter the anatomical condition of the tropho-

1 Turner, "On the Placentation of Halicore Dugong," Trans. Roy. Soc. Edin., vol. $\mathrm{xxxv.,} 1889$.

2 Hubrecht, "Spolia Nemoris," Quar. Jour. Micr. Sci., vol. xxxvi., 1894.

${ }^{3}$ See Hertwig, Entwicklungsgeschichtedes Menschen und der Wirbelthiere, 1906.

4 Robinson, "Hunterian Lectures," loc. cit.

s Assheton, "The Morphology of the Ungulate Placenta," Phil. Trans. Roy. Soc., London, Ser. B., vol. cxeviii., 1906. 
blast at the time of its first attachment. Hubrecht, on the basis of Huxley's statement that Insectivora are among the most archaic of Mammals, has investigated several members of this order as showing probably the most ancient type of placenta, and thus affording a starting-point for a classification. According to Huxley, the least differentiated types, the hedgehogs and Gymnura, occupy a central position, while shrews show resemblances to Rodents, and Tupaice to lemurs; moles and Galeopitheci vary in other directions, while the whole order shows more general relationships to Carnivores and Ungulates. But at present these relationships are not understood. It seems impossible to trace any connection between the placenta of the sheep, in which there is no circulation of maternal blood in the fœetal parts of the placenta but the fœtus is nourished by uterine milk, and that of the hedgehog, in which maternal blood circulates in the trophoblastic lacunæ and forms the main source of nutriment.

At present, we must be content with a review of the processes occurring in several Mammals which have been more particularly investigated, without straining to find how such processes have arisen in the course of placental evolution. ${ }^{1}$

\section{PART III}

\section{THE FETAL MEMBRANES, THE YOLK-SAC,} AND THE PLACENTA

\section{General Anatomy of the Fetal Membranes}

So far no reference has been made to the part played by the mesoblast in the nutrition of the embryo. The placenta has been described as an organ cousisting of maternal and fœtal elements - of modified uterine mucosa, and trophoblast which

1 Throughout this chapter, the arrangement of the mammalian orders is more in accordance with the older views of placental classification, but an attempt has been made to emphasise the trophoblastic characteristics. Since it was written, an important memoir has been published by Hubrecht ("Early Ontogenetic Phenomena in Mammals," Quar. Jour. Micr. Sci., 1908), in which he follows out, in more detail than previously, his ideas regarding the phylogeny of the placenta. 
absorbs nutritive material from the mucosa and from the maternal blood. The nutriment serves in part for the nutrition of the trophoblast itself, and in part for the growth and development of the embryo. In the earliest stages there are as yet no embryonic vessels, and the nutriment is transmitted from cell to cell. But as the embryo increases in size and its requirements grow in proportion, such a path becomes inadequate, and a vascular channel is developed in connection with the two fotal membranes-the yolk-sac or umbilical vesicle, and the allantois.

The mammalian yolk-sac has only a secondary importance for the nutrition of the embryo. The blastodermic vesicle at an early stage of development is divided into an embryonic and a non-embryonic area. The latter is the yolk-sac which gradually becomes folded off from the embryo. Its relations are the same as those of the yolk-sac in Sauropsida, but the contents are an albuminous fluid instead of yolk. It is commonly believed that the placental Mammals are descended from ancestors in which the ovum had a large supply of yolk, but that, when the fertilised ovum found a new supply of food in the uterus, the yolk was reduced and ultimately disappeared. At the same time the envelopes, which were developed under the influence of the vitelline contents, have been preserved and modified in different ways to aid uterine nutrition. ${ }^{1}$

In the early stages the development proceeds, as in birds and reptiles, with the gradual extension of the hypoblast round the wall of the blastocyst, which thus becomes didermic. The mesoblast grows out between the epiblast and hypoblast, starting at the embryonic area and gradually extending for a variable distance round the wall of the blastocyst. Near the embryo appears the area vasculosa, in which blood-vessels and blood are developed from the cells of the mesoblast, while at the same time the embryo begins to be folded off from the yolk-sac by anterior and posterior folds. The area gradually extends further and further round. Its outer boundary is marked by the sinus terminalis which communicates with the vitelline veins. The blood is brought from the dorsal aortæ by a

1 According to Hubrecht's views, the mammalian ovum is not desccnded from the ovum of Sauropsida. 
series of lateral vitelline branches. These arteries break up into a deeper arterial network, from which the blood is collected into the sinus terminalis and the superficial venous network, and in this way reaches the vitelline veins and so passes to the heart.

During the spread of the mesoblast, it splits into an external layer or somatopleur, and an internal layer or splanchnopleur. The former is non-vascular and adheres to the inner aspect of the trophoblast, forming with it the diplo-trophoblast, and the splanchnopleur is applied externally to the hypoblastic wall of the yolk-sac. By the splitting a space is formed between the two layers. This is the extra-embryonic colom, which thus intervenes over a larger or smaller area between the diplo-trophoblast and the yolk-sac.

While the above changes are taking place, the allantois grows out (on the tenth day in the rabbit) from the hind-gut as a vesicle lined by hypoblast, and covered externally by a layer of splanchnopleur. In some Mammals the cavity of the allantois is not continued beyond the body-wall of the embryo, the extra-embryonic portion consisting of a solid rod of mesoblast. In all orders below the Primates, however, it projects free for a time into the cœlom, and later fuses, except in the Marsupials, with the whole or part of the outer wall of the blastocyst. In the allantoic mesoblast many vessels are developed, and branches extend into the projections which form the cores of the villi. The blood is brought by two allantoic arteries continued from the terminal bifurcation of the dorsal aorta, and returned by one, or more rarely two, allantoic veins. "While the placenta is being developed, the folding off of the embryo from the yolk-sac becomes more complete, and the yolk-sac remains connected with the ileal region of the intestine by a narrow stalk, the vitelline duct. While the true splanchnic stalk of the yolk-sac is becoming narrow, a somatic stalk connecting the amnion with the walls of the embryo is also formed, and closely envelops the stalk both of the allantois and yolk-sac. The somatic stalk, together with its contents, is known as the umbilical cord" (Balfour ${ }^{1}$ ). The yolk-sac atrophies completely in some, but in others it is only removed at birth.

1 Balfour, Comparative Embryology, London, 1881. 


\section{The Nutritive Importance of the Yolk-SaC}

When the blastodermic vesicle becomes adherent to, or sinks into, the uterine mucosa, the wall of the yolk-sac in some orders becomes intimately related to the uterine mucosa and is nourished by it. Even in the non-mammalian Vertebrata the latter condition has been observed. In the Lacertilia the yolk-sac absorbs nutriment from the uterus through the porous shell. In Mustelus lavis the embryos lie in a fluid derived from the surface secretion and a lymphoid transudate of the uterine mucosa. It passes through the porous shell to reach the yolk-sac (Brinkmann ${ }^{1}$ ). In Seps chalcides, a reptile, the insufficient supply of yolk is added to by a uterine secretion containing degenerated cells and blood derivatives, the outer layer of the blastocyst being distinctly phagocytic (Giacomini ${ }^{2}$ ). But in the Sauropsida no union takes place between the maternal tissues and the fotal membranes, and so in one order of Mammals, the Ornithodelphia, ${ }^{3}$ where the young develop outside the body. In all the other orders the wall of the yolk-sac comes into relation with the uterine wall over a greater or less area, depending on the extent to which the mesoblast, spreading round the wall of the blastocyst, splits into two layers. In the non-mammalian Vertebrates, the mesoblast and the cœlom extend completely round and the yolk-sac is entirely separated from the surface layer; so in the sheep and Man. In others (e.g. the rabbit) the colom does not spread so far.

It still remains to consider the path by which the nutriment is conveyed to the embryo. In partial extension of the area vasculosa, the wall of the yolk-sac consists of three parts, each with different relations (see Fig. 77) :-(1) The non-vascular part, with a two-layered wall of epiblast and hypoblast; (2) the vascular part, where the mesoblast is unsplit, e.g. in the opossum - the mesoblast splits in its entire extent in the rabbit; (3) the part opposite the colom. In all three parts the trophoblast is

1 Brinkmann, "Histologie, Histogenese und Bedeutung der Mucosa Uteri einiger Viviparer Haie und Rochen," Mitt. a. d. Zool. Stat. z. Neapel., vol. xvi., 1903.

" Giacomini, "Ueber die Entwicklung von Seps Chalcides," Anat. Anz., vol. vi., 1891.

3 Or Monotremata. 
bathed by the uterine secretion after the disappearance of the prochorion. In the non-vascular part it is probably transmitted through the hypoblast cells to the yolk-sac, whence, in turn, it reaches the embryo either by the vitelline vessels or the developing alimentary canal. In the vascular part the same may occur, or the nutriment may be conveyed to the embryo directly by the vessels of the area vasculosa. It is in this region that the foetal circulation is brought close to the maternal, and gaseous exchanges may be effected. Opposite the cœlom

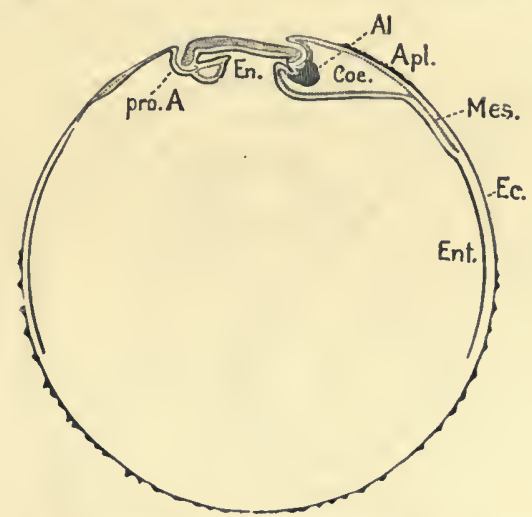

FIG. 77.-Diagram to illustrate the three parts of the wall of the yolk-sac in the rabbit. (From Minot's Human Embryology, by permission of William Wood \& Co.)

$A l$., allantois ; $A p l$., area placentalis; $E c .$, ectoderm; Mes., mesoderm; Ent., extra-embryonic entoderm; Cœ., cœlom; En., entodermic cavity of the embryo; Pro.A, proamnion.

the trophoblast is lined by a thin layer of non-vascular somatopleur, through which transference of material to the colomic cavity is possible. This part is subsequently connected with the embryo by the allantoic vessels. When the yolk-sac is entirely separated from the outer wall, nutritive substances may also be transmitted to the coelomic cavity and then to the embryo or yolk-sac.

The nutritive importance of the yolk-sac may now be considered in greater detail in several orders of Mammals.

Marsupials. - In the opossum the mesoblast spreads about half-way round the wall of the blastocyst, but it does not split 
over its whole extent. Hence the cuelom is sinall, and correspondingly the separation of the yolk-sac and trophoblast is insignificant (Fig. 78). The allantois grows out into the colom only to impinge on and invaginate the wall of the yolksac. It never comes in contact with the outer wall of the blastocyst. The part of the wall where the mesoblast is unsplit is thrown into folds which fit into corresponding furrows of the mucosa. Hence an avillous yolk-sac placenta is formed (Selenka ${ }^{1}$ ). The nutrition in the uterus is very primitive.

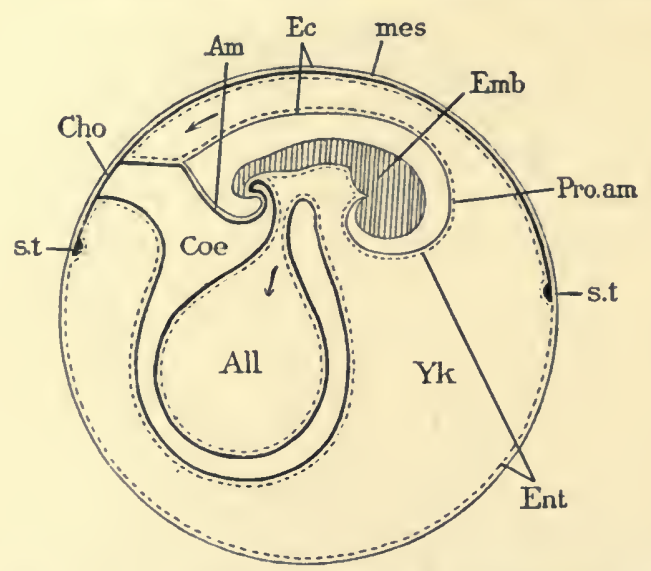

FiG. 78.-Diagram of an opossum embryo and its appendages. (From Minot.)

$A l l$, allantois ; $Y k$, cavity of yolk-sac ; $C \propto$, colom; $A m$, amnion; Pro.am, pro-amnion; Emb, embryo; Ec, ectoderm; Ent, entoderm; mes, mesoderm ; $8 . t$, sinus terminalis ; Cho, chorion (diplo-trophoblast).

The ova contain a comparatively large supply of yolk granules for the initial stages of development. $\Lambda$ s they travel along the oviduct and into the uterus, they are invested with a thick nutritive layer, derived from the secretion of the tubal and uterine glands. Later the embryos are allso nourished by the primitive placental structures for a period short in duration, but long enough to allow of the differentiation of their main organs and systems. In the mucosa the surface epithelium remains intact. The only change is an cedema of the layers, and the sole nutritive material is a watery fluid, composed of

1 Selenka, Studien über die Entwicklungsgeschichte der Thiere, Wiesbaden. 
glandular secretion and a lymph transudate almost devoid of cells. It is absorbed by the trophoblast cells, which here and there enlarge to enormous "Nährzellen" and so increase the absorbing surface. After eight days the food supply becomes inadequate for the developing embryos, and they are transferred to the pouch and nourished by the mammary secretion.

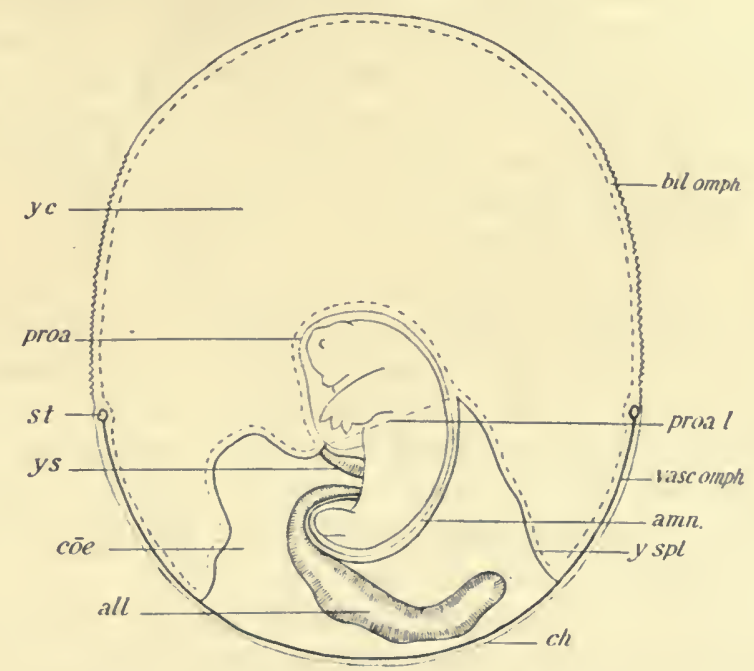

FIG. 79.-Diagram showing the arrangement of the foetal membranes in Dasyurus. (From Hill, "On the Fotal Membranes, Placentation and Parturition of the Native Cat (Dasyurus viverrinus)," Anat. Anzeig., vol. xviii., 1900.

amn., trunk amnion; all, allantois; bil.omph, bilaminar omphalopleur; ch, chorion (diplo-trophoblast); cōe, extra-embryonic splanchnocele; pron, proamnion; prox.l, posterior limit of proamnion; s.t, sinus terminalis ; vasc.omph. vascular omphalopleur ; y.c, cavity of yolk-sac; $y .8$, yolk-stalk; $y \mathrm{spl}$, invaginated yolk-sac splanchnopleur : the ectoderm is represented by a thin line, the entoderm by a dotted line, and the mesoderm by a thick line.

In Dasyurus the allantois is vascular over a small area and comes in contact with the diplo-trophoblast (Fig. 79). But the allantoic vessels degenerate rapidly and completely, and the allantois again lies free in the cœlom. In the region of the area vasculosa the wall of the yolk-sac adheres to the uterine epithelium, and, as in the opossum, forms a simple yolk-sac 
placenta. The superficial capillaries of the mucosa, which are slightly dilated, are separated from the vitelline vessels by the uterine epithelium and a thin layer of fœtal ectoderm. Through the two layers the gaseous exchange probably takes place. Beyond the sinus terminalis, the non-vascular part of the wall unites over an annular zone with the uterine epithelium by enlarged ectodermal cells. These syncytial "Nährzellen" are phagocytic, and enclose fragments of epithelium and superficial capillaries. Maternal blood is effused and lies in a space between the ectoderm and entoderm, whence it is transmitted to the cavity of the yolk-sac and serves for nutriment (Hill ${ }^{1}$ ). The gestation period is about eight days, as in the opossum.

In Perameles the placental structures are better developed $\left(\right.$ Hill $\left.^{2}\right)$. Before the attachment of the blastocyst, the uterine mucosa undergoes preliminary changes. The capillaries increase in size and new vessels are formed; the interglandular tissue is composed of a loose network of anastomosing cells and the inter-spaces are filled with lymph, the glands increase in length and diameter, and the cells of the surface epithelium lose their boundaries, and fuse to form a syncytium analogous to the symplasma of higher forms (see p. 414).

Opposite the cœlom, the blastocyst becomes attached to a discoidal area of the uterine symplasma by means of enlarged ectodermal cells, and later its wall is vascularised by the allantois. Outside the disc, the part corresponding to the area vasculosa is also attached by an annular zone, and a yolk-sac placenta is formed. The non-vascular part of the wall is bathed by the uterine fluid as in the opossum (Fig. 80).

In the discoid area a functional allantoic placenta is developed. The ectodermal giant-cells, like the early trophoblastic proliferation in Man, disappear, and the allantoic vessels become firmly attached to the symplasma into which the maternal vessels penetrate. A regular interlocking of maternal and foetal tissues is produced, and the two systems of bloodvessels are separated at the most by a thin layer of symplasma.

1 Hill, "On the Fotal Membranes, \&c., of the Native Cat (Dasyurus viverrinus)," Anat. Anz., vol. xviii., 1900. 1898.

2 Hill, "The Placentation of Perameles," Quar. Jour. Micr. Sci., vol. xl., 
It is not yet determined whether the yolk-sac placenta is functional till birth. According to Hill the wall probably breaks up before the end of pregnancy. The allantoic placenta, on the other hand, remains active, and at the time of birth some

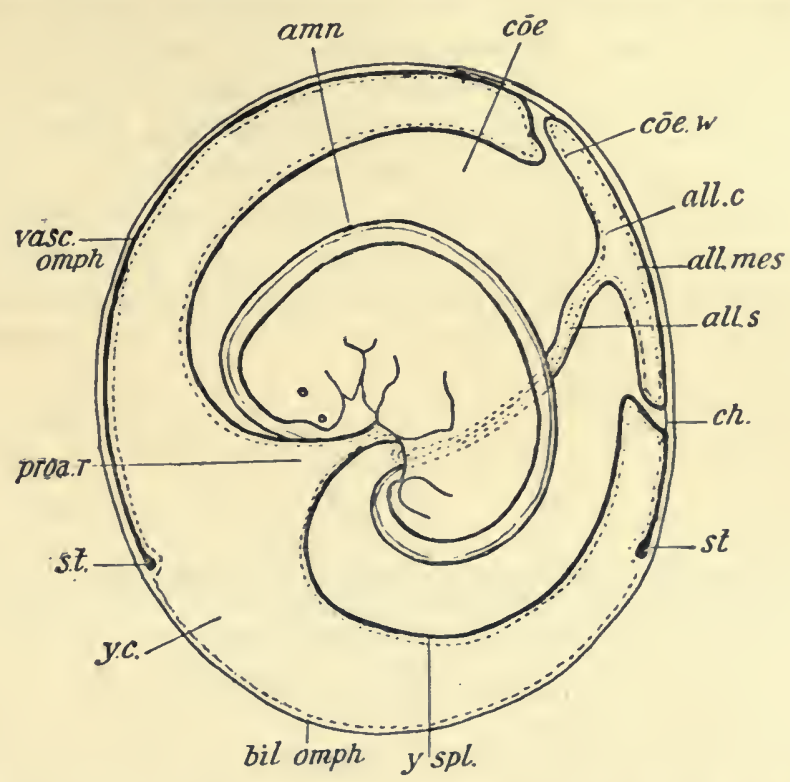

FIG. 80.-Diagram showing arrangement of fœetal membranes in Perameles. (From Hill, "The Placentation of Perameles," Quar. Jour. Micr. Sci., vol. xl., 1897.)

amn, amnion ; all.c, allantoic cavity ; all.mes, allanto-chorionic mesenchyme ; all.s, allantoic stalk; bil.omph, bilaminar omphalopleur; ch., marginal zone of true cliorion around the allanto-chorionic area; cöe, extra. embryonic cœlom; cōe.w, inner or chorionic wall of allantois; proa.r, persistent remnant of proamnion; st, sinus terminalis; vasc.omph, vascular omphalopleur; y.c, yolk-sac cavity; $y . s p l$., invaginated yolksac splanchnopleur; ectoderm represented by thin line, mesoderm by dotted line, entoderm by thick line.

maternal tissue is shed, while part of the fotal tissue is left behind. The gestation period is about eight days.

The allantois in Perameles is of greater importance than in the opossum or Dasyurus; but, relatively to the yolk-sac, it plays a small part in the nutrition of the embryo, as evidenced 
by the fact that the vitelline vein is thrice as large as the allantoic vein.

UnGULATA.- In the sheep the blastocyst elongates early, and contains at one part the thickened embryonic area or shield (Fig. 81). From it the mesoderm reaches out on all sides. As it spreads between the epiblast and hypoblast, the colom is developed in it. By the thirteenth day one-third of the circumference is surrounded by colom, and in this area the yolk-sac is separated from the outer wall. At the seventeenth day the separation of the yolk-sac is complete all round (Bonnet ${ }^{1}$ ). It continues, however, to grow pari passu with the blastodermic vesicle, and is gradually pushed to one side by the enlargement

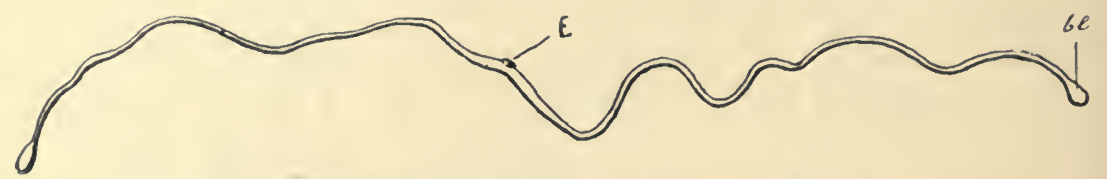

FIG. 81.-Elongated blastocyst of sheep at thirteenth day of pregnancy. (From Hertwig's Entwicklungsgeschichte des Menschen und der Wirbelthiere, by permission of Gustav Fischer.)

$$
b l \text {, blastocyst; E, embryonic shield. }
$$

of the cœlon. At the twenty-fifth day it is reduced to a solid rod of cells with a few blood-vessels on its outer surface (Fig. 82), and it disappears before the end of pregnancy $\left(\right.$ Assheton $\left.{ }^{2}\right)$. The allantois grows out into the cœlom very early and expands with extraordinary rapidity, occupying most of the cavity of the blastodermic vesicle. Its further developments are described later (p. 397). Hence in the sheep, and in the pig and cow, in which the conditions are similar, the yolk-sac is functional only from the first appearance of the vessels in the area vasculosa till about the twentieth day of pregnancy.

Carnivora. - The mesoblast and colom extend completely round the blastocyst, and the vitelline circulation is active

1 Bonnet, "Beiträge zur Embryologie der Wiederkäuer," Arch. f. Anat. u. Physiol., 1889.

${ }^{2}$ Assheton, "The Morphology of the Ungulate Placenta," Phil. Trans. Roy. Soc., London, Ser. B., vol, cxcviii., 1906. 
only in the early stages. In the dog the yolk-sac is large and extends at first to the end of the citron-shaped ovum (Fig. 97). According to Bischoff ${ }^{1}$ it persists till birth, but this is denied by Duval. ${ }^{2}$ The allantois grows out on the dorsal side of the embryo, and fuses with the diplo-trophoblast over a small discoidal area. Later, as the cavity of the allantois enlarges, it adheres to the whole of the blastocyst wall except the poles. Subsequently the zone of adhesion is reduced in extent (see p. 413).

\section{Proboscidea and Hyrax.-} The elephant and the aberrant genus Hyrax have at full-time, like the Carnivores, a zonary placenta, but little is known regarding the development of the fœtal membranes. Assheton ${ }^{3}$ has recently given an account of two early embryos of Hyrax. In the younger, the yolk-sac occupied about threequarters of the surface of the blastocyst, and the allantois the remaining quarter, the ovim possibly being wholly embedded in the uterine mucosa. The yolk-sac was covered with a network of vessels, and the head of the embryo dipped into it. It was

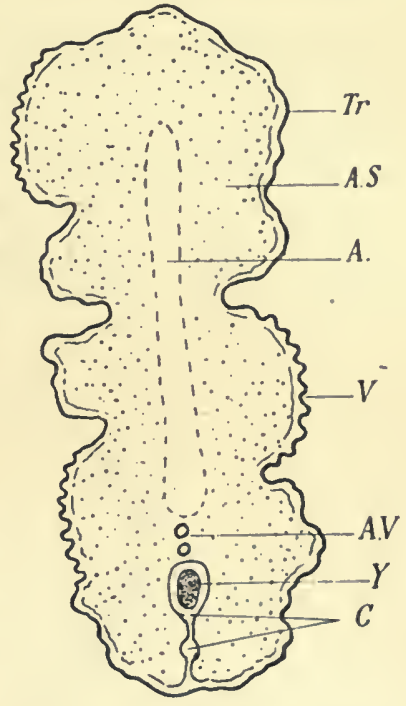

FIG. 82 -Transverse section through the blastocyst of the sheep at the twenty-fifth day. (From Assheton, "The Morphology of the Ungulate Placenta," Phil. Truns. Roy. Soc., London, Ser. B., vol. cxcviii., 1906.)

A., allantois ; A S, splanchnopleur of allantois; A.V, allantoic blood-vessel; C, coelom; $\mathrm{V}$, commencing folds from which villi spring; $Y$, solid yolk-sac. invested externally with a mass of trophoblastic cells, honeycombed with spaces and filled with maternal blood, but no villi were developed. In the second embryo the yolk-sac was 1842.

${ }^{1}$ Bischoff, Entwickelungsgeschichte der Säugethiere und des Menschen, 1893.

Duval, "Le Placenta des Carnassiers," Jour. de l'Anat. et de la Phys., .

3 Assheton, Phil. Trans. Roy. Soc., London, loc. cit. 


\section{8}

\section{THE PHYSIOLOGY OF REPRODUCTION}

much reduced, and was "presumably enveloped by the allantois." It had previously been shown by Turner that the yolk-sac disappeared at an early period.

RoDentia.-In Rodents the conditions are entirely different. The mesoblast never extends, in the rabbit, rat, or mouse, completely round the ovum, and the yolk-sac hypoblast remains long in contact with the trophoblast, and carries on the nutrition of the embryo till the tardily formed allantoic placenta is developed. Regarding the partial extension of the mesoblast, Minot ${ }^{1}$ says: "That it represents a modified condition is

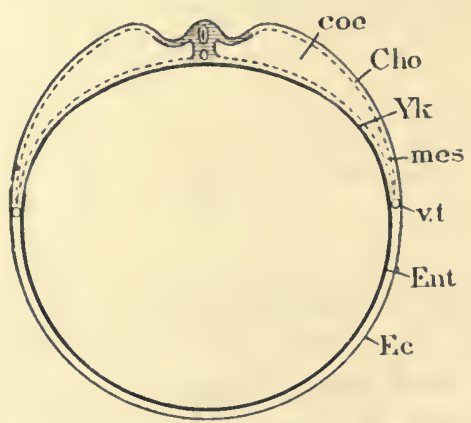

FIG. 83.-Blastodermic vesicle of the rabbit. (Minot.)

cœ, cœlom ; Cho, chorion (diplo-trophoblast); $Y k$, yolk-sac; mes, mesoderm ; $v t$, vena terminalis ; Ent, entoderm; Ec, ectoderm.

evident, since in all non-mammalian Vertebrates both mesoderm and cœlom extend completely round the yolk. Hence the complete separation of the yolk-sac in Man and the sheep is nearer the ancestral type than the relations of the extra-embryonic germ-layers to one another in the rabbit and opossum."

In the rabbit, the mesoblast begins to spread out from the embryonic region about the end of the first week of gestation, and it gradually reaches half-way round the circumference of the blastocyst. It splits into two layers over its whole extent, and it is limited below by the sinus terminalis (Fig. 83). The lower half of the yolk-sac is non-vascular, and its wall of hypoblast is closely invested by trophoblast. Later the yolk-sac begins to

1 Minot, Human Embryology, Boston, 1892. 
shrink, taking a mushroom shape, and its vascular half comes against the non-vascular half (Fig. 84). The specially large colomic space, thus left by the shrinking of the vesicle, is filled with fluid through which the allantois extends to reach the part of the wall not covered by the yolk-sac. Hence at this stage the whole wall of the blastocyst is vascularised, one half by the vitelline and the other half by the allantoic vessels. ${ }^{1}$

From an investigation of the early stages in the mouse and

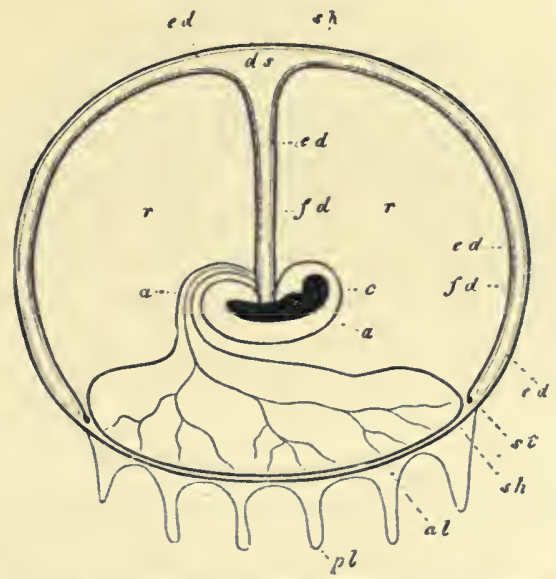

FIG. 84-Diagram of the blastodermic vesicle of the rabbit in longitudinal section. (From Hertwig's Entwicklungsgeschichte des Menschen und der Wirbelthiere.)

$e$, embryo ; $a$, amnion; $a l$, allantois with blood-vessels; $f d$, vascular layer of mushroom-shaped yolk-sac; $d .8$, cavity of yolk-sac; $8 . t$, sinus terminalis ; $r$, large space filled with fluid.

rat, Robinson ${ }^{2}$ attaches much importance to the yolk-sac in providing for the nutrition of the embryo. On the seventh day the yolk-sac is large, and becomes invaginated with the inversion of the germinal layers (see p. 438). Outside its thin wall lies extravasated maternal blood, which is absorbed into the cavity. Over a large area, the wall of the yolk-sac becomes villous with a covering of columnar hypoblast. Over a small

1 Hertwig, Entwicklungsgeschichte des Menschen und der Wirbelthiere, 1906.

2 Robinson, "The Nutritive Importance of the Yolk-Sac," Jour. of Anat. and Phys., vol. xxvi., 1892. 
area the trophoblast is thickened and maternal blood circulates in its spaces. But the allantois has not yet come in contact with it, and the blood " must serve only for the nutriment of the trophoblast itself." At the eleventh day the trophoblast is vascularised by the allantoic vessels, by which the nutriment is now transmitted as well as by the vitelline vessels in the yolkvilli. Then the yolk-sac becomes less important. The circulation in the decidua reflexa, which surrounds it, decreases and ceases altogether on the sixteenth day, and the wall of the yolk-sac becomes thin and bloodless. "At the same time numerous diverticula grow out from the entodermal sinus into the hilum of the allantoic placenta, and these may still absorb nutriment though they are more probably excretory." Later the outer wall of the invaginated yolk-sac undergoes atrophy and completely disappears. The remains of the yolk-sac cavity are in this way bathed in the uterine fluids. At the same time the villi of the inner wall increase in size and complexity, but whether they absorb the fluids or are entirely excretory is uncertain.

In the spiny mouse (Acomys caharinus), Assheton ${ }^{1}$ found in a well-advanced pregnancy that the yolk-sac was still extremely vascular, and covered with a columnar-celled epithelium which was much folded. The blood-vessels lay in the folds, and so approached closely to the placenta. The yolk-sac was firmly attached to the placenta over the peripheral area, but not so closely as described above for the rat and common mouse. In the spiny mouse the folds do not become involved in the placental tissues.

InSECTIVORA.- In the hedgehog, the yolk-sac forms a placenta which nourishes the embryo until the mesoblast splits into two layers and the allantoic placenta is formed. At a very early stage the epiblastic wall of the blastocyst has spaces in which maternal blood appears. As the mesoblast spreads out in a single layer, the area vasculosa develops, and its branches, contained in mesoblastic warts and ridges, interlock with the adjacent trophoblast to form yolk-villi (Fig. 85). The yolk-

1 Assheton, "On the Fretus and Placenta of the Spiny Mouse," Proc. Zool. Soc., London, 1905, vol. ii. 
sac or omphaloidean placenta reaches its full development at the time when the allantois comes in contact with the trophoblast (see p. 451). Then the yolk-sac is gradually separated from the wall, more and more of its villi being peeled out from the trophoblast as the separation increases. The vitelline circulation at the same time diminishes, though it never ceases entirely (Hubrecht ${ }^{1}$ ).

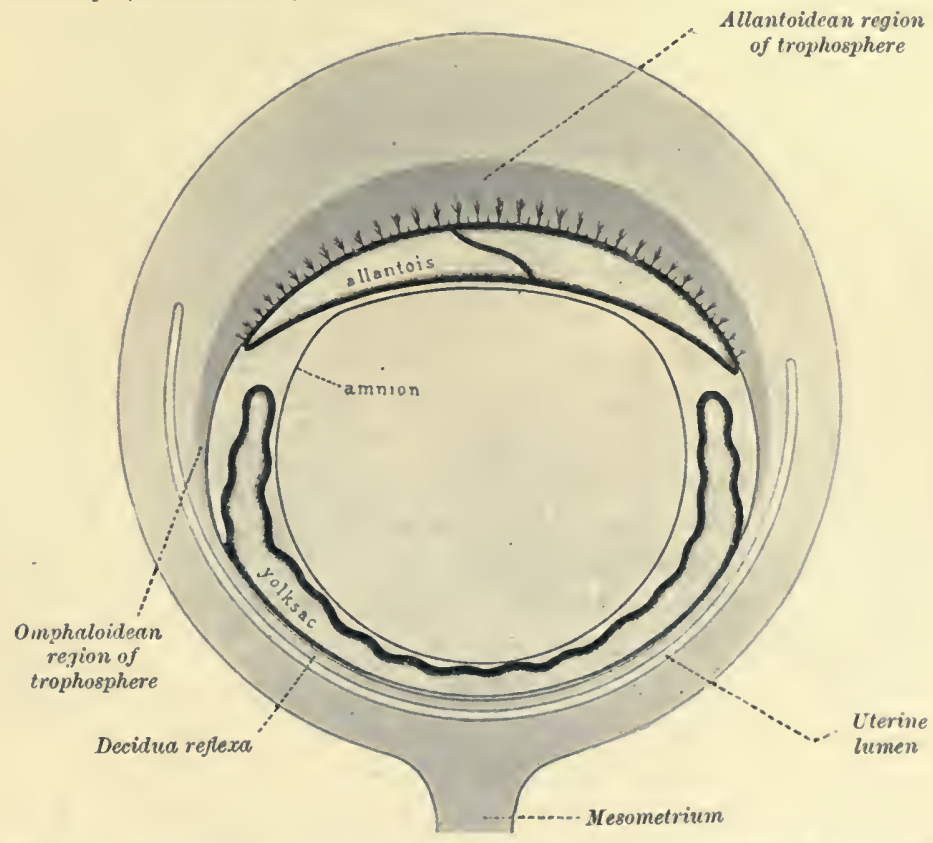

FIG. 85.-Diagram to illustrate the fotal membranes of Erinaceus. (From Hubrecht's "The Placentation of Erinaceus europacus," Quar. Jour. Micr. Sci., vol. xxx., 1889.)

In the shrew, the yolk-sac adheres by a zonary strip to lateral cushions of proliferated mucosa, but the resulting yolksac placenta is avillous (Hubrecht ${ }^{2}$ ). The trophoblast is again thickened, and in its spaces maternal blood appears, but at a later date than in the hedgehog. The maternal blood is bodily

1 Hubrecht, "The Placentation of Erinaceus europacus," Quar. Jour. Micr. Sci., vol. $\mathrm{xxx}_{\text {., }} 1889$.

2 Hubrecht, "The Placentation of the Shrew," Quar. Jour. Micr. Sci., vol. $\times x \times v ., 1894$. 
absorbed, and at the same time the yolk-sac contains a characteristic yellowish-green, glassy coagulum with granules in it. Later the mucosal cushions disappear and the adjacent trophoblast thins (see p. 454).

In the mole a simple yolk-sac placenta persists throughout pregnancy (Robinson ${ }^{1}$ ). Unlike the hedgehog and the slrew, in which the gland lumina are plugged by the trophoblastic syncytium, there is in the mole a copious glandular secretion containing degenerated cells, which is absorbed by the trophoblast (see p. 456).

Tupaia javanica differs from the other Insectivora in having a temporary yolk-sac placenta formed in the same situation as the allantoic placenta subsequently occupies (see p. 458). The same occurs in the bat (p. 462).

Primates.-In monkeys, old- and new-world, there is no decidua reflexa, and a portion of the trophoblast is in contact with the uterine fluids. But even in Selenka's earliest specimens of monkeys and apes, the yolk-sac is a small, closed sac attached to the ventral surface of the embryonic area, and is entirely separated from the trophoblast. The embryonic area is connected with the inner surface of the chorion by a short stalk of mesoderm, in which the vessels run.

In the youngest human ovum yet examined, the yolk-sac is also a small, closed vesicle, separated from the trophoblast by a single thick layer of mesoblast (Fig. 86). The splitting of the mesoblast occurs very early, even before the appearance of the primitive streak, and the colom spreads round the whole circumference of the ovum. The earliest vessels appear on the under surface of the sac, and gradually extend over its upper pole, until the whole sphere is covered by a vascular network. The vessels are in direct continuity with vessels which develop in the connecting-stalk (see p. 463), and through them with the vessels of the chorion by a vascular loop, the sinus ensiformis of Eternod (Bryce ${ }^{2}$ ). This communication appears to exist before any vessels appear in the embryo itself. From the third week onwards, saccular dilatations of the entodermal lining of

1 Robinson, Hunterian Lect., loc. cit.

2 See Quain's Anat., vol. i., Part I., 1908. 
the yolk-sac are produced, and from their walls solid masses of cells are budded off, resembling liver-tissue in its simplest form and perhaps functioning as such (von Spee ${ }^{1}$ ). The sac grows up to the end of the fourth week. It is then pear-shaped, and

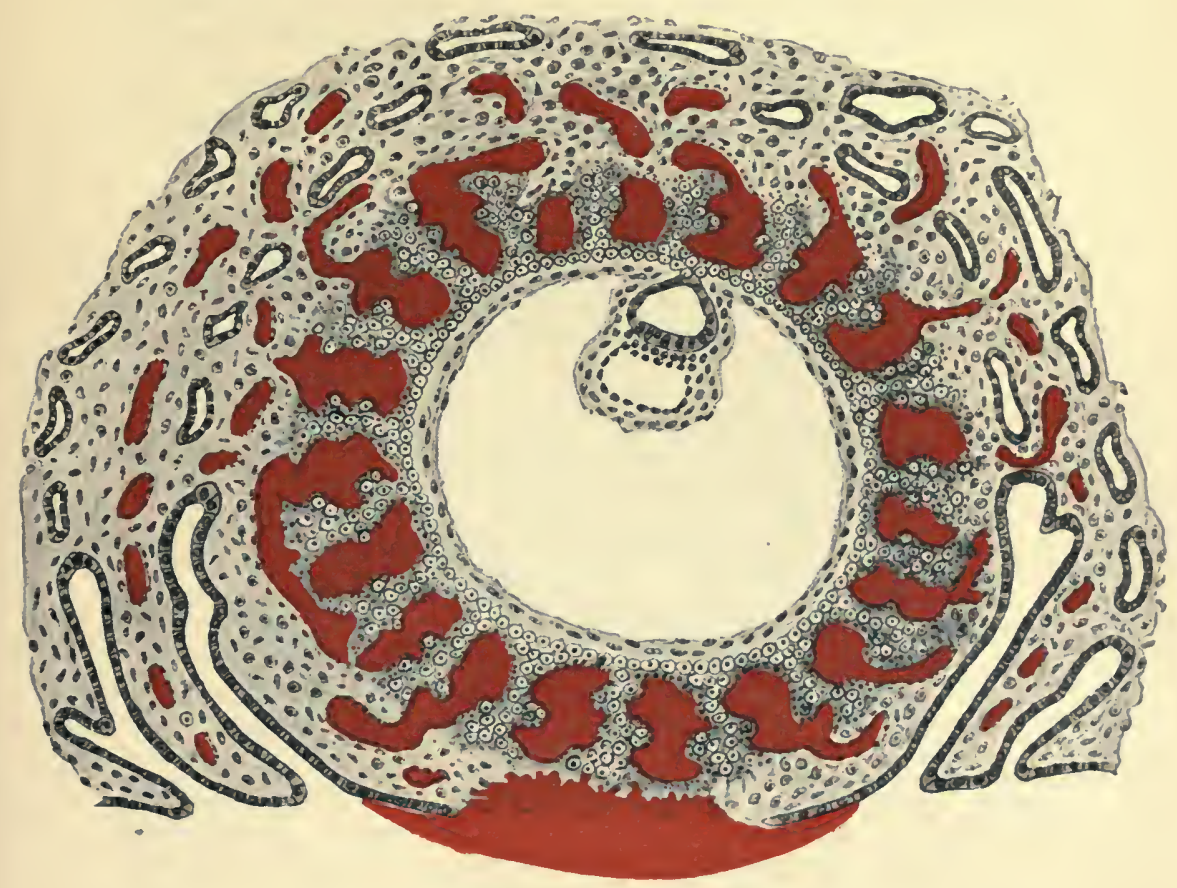

FIG. 86. - Hy pothetical section of the human ovum embedded in the decidua, somewhat younger than Peters' ovum. The trophoblast is greatly thickened, and lined with mesoderm, which surrounds also the embryonic rudiment, with its yolk-sac and amnio-embryonic cavity ('T. H. Bryce in Quain's Anatomy). The embryonic rudiment is proportionally on too large a scale.

is united to the intestine by a long neck in which the cavity is obliterated. The vesicle persists throughout pregnancy. Little is known of its contents; at the end of pregnancy it contains variable quantities of fatty substances and carbonates $\left(\right.$ Schultze ${ }^{2}$ ).

1 See Quain's Anatomy, vol. i., Part I., 1908.

2 Schultze, "Ueber die Embryonalbüllen und die Placenta der Säugethiere und des Menschen," Sitzungsb. d. Würzburger physik.-med. Gescll., 1896. 


\section{The Placenta in Indecinuata}

In the placental Mammals, an attachment takes place between maternal and foetal tissues in the uterus, and the trophoblast is vascularised, except in the Primates, by the allantois. The method of attachment varies in different orders, and sometimes in different groups of an order. In the Indeciduata,

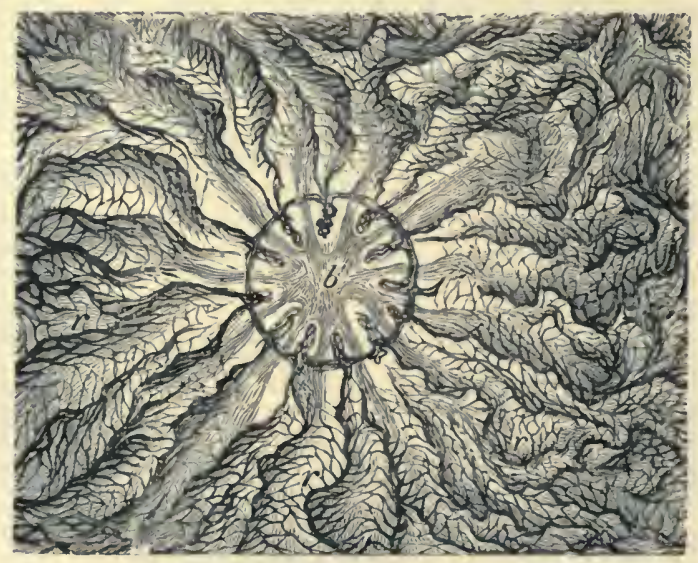

FIG. 87.-Portion of the injected chorion of the pig. The figure shows a minute circular spot, $b$, enclosed by a vascular ring from which villous ridges $(r, r)$ radiate (Turner). (From Balfour's Comparative Embryology, vol. ii. By permission of Messrs. Macmillan \& Co., Ltd.)

however, the first attachment is always obtained by an apposition of the trophoblast to the surface of the mucosa.

Ungulata : Pig.-In the pig the blastocysts are spherical till the tenth day. Then they rapidly elongate, and by the fourteenth day they fill the whole length of the uterus. Subsequently they obtain a greater surface of contact by a series of concertina-like foldings (Assheton ${ }^{1}$ ), which fit between ridges of the uterine mucosa. The ridges are inter-glandular in position

1 Assheton, Phil. Trans., loc. cit. 
(Fig. 87), radiating from small circular spots, twenty or thirty to the square inch, which represent the gland-mouths (Turner ${ }^{1}$ ). It is usually stated that the uterine surface epithelium remains intact; but Assheton has recently proved that it shows signs of degeneration as early as the eighth day, and at the eighteenth day is reduced to a thin layer. Three days later, however, it again appears normal and is formed of long columnar cells, to the ends of which the trophoblast fits closely, sending proto-

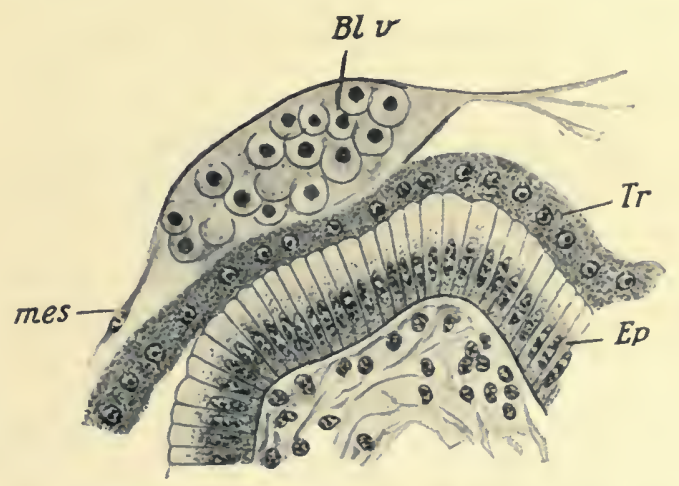

FIG. 88.-Section through the wall of the uterus and the blastocyst of the pig at the twentieth day of pregnancy (Assheton).

$m e s$, mesoblast ; $B l . v$, fœtal vessel ; $T r$, trophoblast ; $E p$, long columnar epithelium of uterine surface.

plasmic processes between the cells (Fig. 88). These processes may even reach past the epithelium to the underlying layer of dilated capillaries (Robinson), and absorb nutritive material or effect gaseous exchanges.

The trophoblast is single-layered throughout, and, after the first three weeks, forms a syncytium. Internally to it lies the mesoblast, which in the main follows its ridges and furrows, but occasionally bridges across a fold. It is vascularised by the vessels of the allantois, which completely surrounds the embryo. The gland-mouths lie along the course of the vessels (Assheton). No formation of villi takes place, and the attachment never

1 'Turner, Lectures on the Comparative Anatomy of the Placenta, Edinburgh, 1876. 
goes beyond the stage of apposition except for the protoplasmic extensions of the trophoblast (Fig. 89).

The uterine mucosa contains no special cotyledonary areas such as are found in the sheep and cow. The surface epithelium, though it shows the degenerative changes already referred to, is apparently never completely destroyed. The glandular epithelium does not at any time show signs of degeneration. It secretes actively during the early stages, and probably during the whole of pregnancy. As in the sheep and one of the lemurs (Galago agisymbanus), the glandular orifices

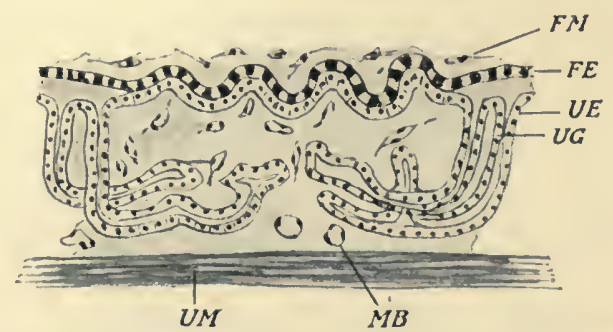

FIG. 89.-Diagram representing a stage in the formation of the placenta of the pig. (From Robinson, "Hunterian Lectures," Jour. Anat. and Phys., vol. xxxviii., 1904.)

UM, uterine muscle; MB, maternal blool-vessel; UG, uterine glands; UE, uterine epithelium; FE, fotal ectoderm ; FM, fotal mesoderm.

are covered by domes of trophoblastic cells, which absorb the secretion and transmit it as nutriment for the developing embryo by the allantoic vessels. The sub-epithelial tissue is gelatinous, and early in pregnancy it begins to increase in thickness by a widening of the lymphatics and blood-vessels and a new formation of capillaries. The constituents of the nutriment provided for the embryos are referred to later (see p. 400).

Mare.-In the mare the details of placental development are not yet known. In the early stages the blastodermic vesicle is attached to the uterine mucosa by the trophoblast covering the lower pole of the ovum, and the attachment is aided by the formation of delicate, nearly parallel ridges (Ewart ${ }^{1}$ ). Villi are

1 Ewart, Critical Period in the Development of the Horse, London, 1897. 
formed in the allantoic region, and they fit into crypts which are probably lined with maternal epithelium. Between the foetal and maternal tissues in the crypt is a space filled with secretion. The lymphatic system of the mucosa is enormously developed (Kolster ${ }^{\mathbf{1}}$ ).

Sheep.-In the sheep and cow the poly-cotyledonary type of placenta is found. The form is determined by the presence from an early period, and independently of pregnancy, of numerous prominences or cotyledonary burrs, which project as thickened knobs of the sub-epithelial tissue into the uterine lumen. During pregnancy they form connections with localised proliferations of the trophoblast. The burrs vary in number from fifty or sixty in the sheep to five or six in the roe-deer.

The ova of the sheep reach the uterus four or five days after coitus, and the blastodermic vesicles remain free till the seventeenth day. Then the attachment to the mucosal surface begins, and it is completed by the thirtieth day (Assheton). After the ninth day, when the prochorion ruptures, the trophoblast comes in contact with the uterine epithelium. Apparently, as the result of this, the absorption of nutriment is easier, and the blastodermic vesicle increases rapidly in size so as to fill the uterine horn, or both horns if only one embryo is present.

Certain changes occur in the mucosa before attachment. The leucocytes, which in the non-pregnant uterus are situated at the base of the lining epithelium, increase in number and penetrate between the epithelial cells. The glandular sacs, situated at the junction of the branches with the main ducts, expand greatly and actively secrete. It is generally held that the surface epithelium is not destroyed, but Assheton has shown that on the cotyledonary burrs it is distinctly degenerated by the seventeenth day, and he has also brought forward strong evidence that it is not subsequently regenerated, but is replaced by binucleate cells of the fotal ectoderm.

In the cotyledonary areas of the trophoblast, villi are developed as buds of epiblast, which afterwards contain cores of mesoblast with branches of the allantoic vessels (Fig. 90). They

1 Kolster, "Die Embryotrophe placentarer Säuger, mit besonderer Berücksichtigung der Stute," Anat. Hefte, vol. xviii., 1902. 
fit into depressions or crypts on the surface of the cotyledons, increase in length, and branch in different directions. Whether they literally grow into the maternal tissues either mechanically or by a phagocytic action is uncertain. ${ }^{1}$ It seems more likely that very little, if any, further penetration occurs, but that the sub-epithelial tissue swells and keeps pace with the villi as they increase in length. The crypts, if their lining cells really belong to the fœtal ectoderm, are not secretory, and there is no free space, such as is described in the mare, between them and the villi. The sub-epithelial tissue is represented in the non-

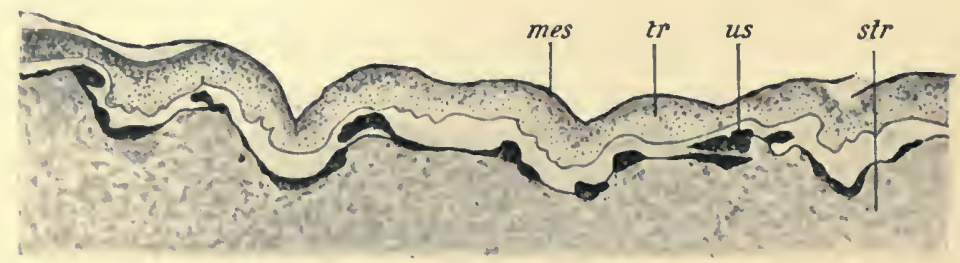

FIG. 90.- Section through the uterine and embryonic parts of a cotyledon of the sheep at the twentieth day of pregnancy. Folds in the trophoblast fitting into sulci of the cotyledonary burr. (Assheton.)

mes, mesoblast ; $t r$, trophoblast ; $u$, degenerated uterine epithelium; $s t r$, uterine stroma.

pregnant uterus by a thin layer of dense connective tissue, with localised thickenings in the burrs. With the onset of pregnancy occur an infiltration of lymph between the more superficial cells of the sub-epithelial layer, and an increase in the number and size of the blood-capillaries and lymphatics. Thus the layer becomes spongy and swells up around the fœtal villi, producing the cotyledonary interdigitation. At the fundus of the crypts the lining cells become syncytial. At the apices of the inter-crypt columns lacunæ of maternal blood are formed by repeated small hæmorrhages from the superficial capillaries (Fig. 91).

1 At this stage Assheton did not observe any actual engulfment of cells, but considered that nutriment might be transmitted by fine processes of the binucleate cells which united with similar processes of the connective tissue cells of the mucosa. 
In the inter-cotyledonary area, the epithelium, whether or not it degenerates over large areas in the early stages as Assheton supposes, is later healthy and vigorous. There is no formation of a spongy layer in the sub-epithelial tissue as in the burrs. But a great change occurs in the glands, which are wholly inter-cotyledonary in position. They increase in length and complexity, and secrete actively. Towards the end of

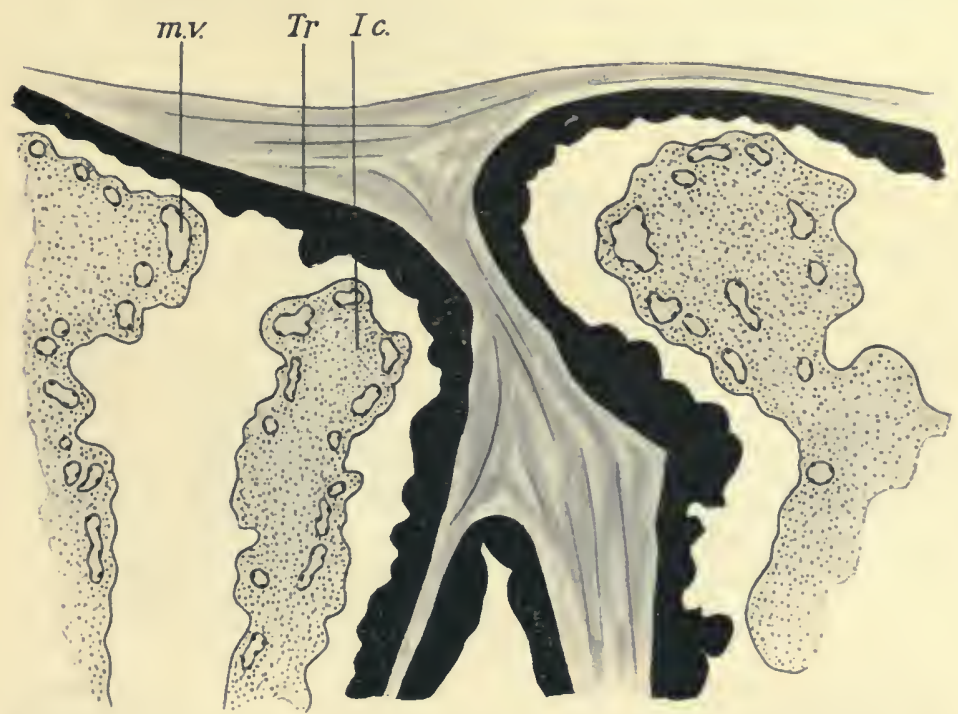

FIG. 91.- Section through the base of a fotal villus and the apices of two inter-crypt columns. Sheep. The surfaces of the columns are traversed by large blood-vessels which later rupture and form the blood-extravasations. (Assheton.)

$T r$, trophoblast dipping into crypt ; Ic, inter-crypt column; $m . v$, maternal blood-vessel.

pregnancy, however, the greater part of the uterine glands is destroyed, but the surface epithelium still secretes. At the upper end of each horn the wall of the blastocyst forms a crumpled structureless membrane with no trace of nuclei, while the uterine mucosa in this region is thrown into folds and covered with a high columnar epithelium which is very active. The secretion is apparently transmitted by transfusion through the membranous wall, and is found inside the sac. At full- 
time this part of the mucosa shows signs of great degeneration, resembling the pulpe diffluente of Duval in the guinea-pig (Assheton). The inter-glandular cells also hypertrophy like the connective tissue cells of Rodents.

The inter-cotyledonary trophoblast is avillous in the sheep and cow. In the giraffe, however, there are rows and clusters of villi in addition to the cotyledonary villi.

The development and structure of the placenta of the sheep have been described at some length because the formation of the special nutriment for the fotus has received close attention in that animal. ${ }^{1}$

Cow. - In the cow (Fig. 92) the placenta has essentially the same form as in the sheep, but the interlocking is not so firm. On separation of the maternal and foetal parts of the cotyledons, the former are found to comprise the larger part. In the fully developed sheep's placenta the fotal parts constitute the main mass of the cotyledon. The various stages of development have not been completely investigated, but one other difference has been noted, viz. the absence of lacunx of maternal blood at the bases of the villi (Ledermann ${ }^{2}$ ).

\section{The Uterine Milk}

The existence of a nutritive juice in the uterus of Ruminants during pregnancy has been recognised since the days of Harvey. He spoke of an albuminous fluid, which might be squeezed out from the cotyledons of the placenta, as a source of nutriment for the fotus. As to its origin, he says in one of his Letters : "It might be transported by the uterine arteries and distilled into the uterus." The fluid was first called uterine milk by Needham in 1667. Haller described it as a secretion of the utricular glands, and this view was supported by Bischoff, Sharpey, and others, who considered it the immediate store of

1 For the above account of the development and structure of the sheep's placenta, we are largely indebted to the important memoir of Assheton. Differing in many respects from previous descriptions, it alone brings forward evidence that the Ungulate placenta may be "secondarily simplified" in Hubrecht's sense (see Quar. Jour. Micr. Sci., 1908).

2 Ledermann, "Ueber den Bau der Cotyledonen im Uterus von Bos," \&c. Inaug.-Diss., Berlin, 1903. 
fœetal nutriment. It was analysed by Gamgee, ${ }^{1}$ who showed that the fluid contained a large amount of protein and fat and some salts, and was thus well adapted for nutrition.

But Haller's view of its origin was not accepted by Turner ${ }^{2}$ and Ercolani. ${ }^{3}$ Turner showed that during pregnancy new crypts were formed in the cotyledons, and he supposed that

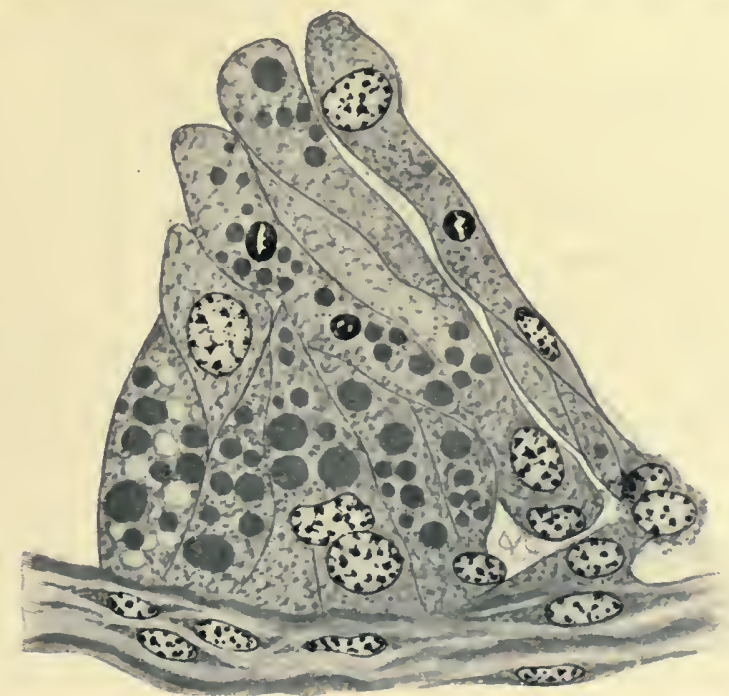

FIG. 92.-Columnar troplroblast-cells from the base of a fetal villus of the placenta of the cow at the third month of pregnancy, to show phagocytosis. (From Jenkinson's "Notes on the Histology and Physiology of the Placenta in Ungulata," Proc. Zool. Soc., London, vol. i., 1906.)

the uterine milk represented the secretion of these crypts. Ercolani went even further and stated that such a secretion existed in all placentæ, but Turner was strongly opposed to this: "That such a fluid (uterine milk) is produced in all placentæ, where utricular glands or follicles continue to secrete during the whole period of placental formation, is very probable.

1 Gamgee, "On the Chemistry and Physiology of the Milky Fluid found in the Placental Cotyledons of Ruminants," Brit. and For. Med.-Chir. Review, 1864.

2 Turner, "The Placentation of the Sloths," Jour. of Anat. and Phys., vol. viii., 1874 .

3 Ercolani, "Sull' unita del tipo anatomico della placenta," Mem. dell" Accad. di Bologna, 1876. 
But in the placentx of the sloth, the apes, and the human female, where an unusual development of the maternal bloodvessels into larger sinuses takes place, a modification in the anatomical structure is produced which seems to render the presence of such a secretion unnecessary. The nutritive changes in all probability take place directly between the maternal and foetal blood."

More recent investigations have thrown fresh light on the origin, composition, and absorption of uterine milk. It must be recognised that, even bcfore the onset of pregnancy, changes occur in the uterus which are important for the nourishment of an embryo developing later. Shortly before the first œstrous period, the mucosa " matures" by the formation of the richly cellular sub-epithelial layer of connective tissue already referred to (see p. 398). Among Indeciduates it is spccially well marked in the cotyledonary types. With the first procstrum the mucous membrane becomes œedematous, and the superficial capillaries are dilated. Many of them rupture and give rise to miliary hsemorrhages, which later undergo changes such as occur in hæmorrhages elsewhere. Whether the changes arc caused by an enzyme action on the part of the leucocytes is uncertain; but in any case the white corpuscles take up the pigmented products of disintegration, and then arrange themselves in a row, or in groups, close under the surface epithelium in the manner described in an earlier chapter (Chap. III. p. 109). Some of the leucocytes contain unaltered hæmoglobin, as is shown by the characteristic reaction with eosin ; others contain derivatives of it, in which iron may often be demonstrated. With the onset of pregnancy these cells wander out between the epithelial cells, and mingle with the secretion lying in the utcrine cavity. This secretion is poured out by the superficial and glandular cpithelium, which becomes more active at the beginning of pregnancy with the increased flow of blood and lymph through the mucosa. It forms the more fluid part of the uterine milk in which the formed constituents lie. It is neccssarily found only in the extracotyledonary regions since no glands exist in the burrs.

Besides the intracellular pigments, there is another source of iron, though in widely varying amounts. In all placental 
Mammals a greater or less amount of maternal blood is in direct contact with the trophoblast. In the pig and mare it is restricted to individual red blood corpuscles, which find their way to the surface and mingle with the gland secretion. In the ass Strahl $^{1}$ has found blood in greater amount, forming small effusions. In the sheep its presence has often been noted by Tafani, ${ }^{2}$ Bonnet, ${ }^{3}$ and others. The position of the extravasations in the placenta has been already referred to (see p. 398). In the cow they are apparently not a constant phenomenon, the supply being often restricted, as in the mare, to a few single erythrocytes. In the deer, blood is effused into the glands, but no extravasations take place in the cotyledons. Here the whole of the maternal part of the burr appears to be digested and absorbed by the trophoblast. The greater activity of the foetal ectoderm in the deer is also shown by the destruction of the epithelium over the whole surface of the uterus (Strahl ${ }^{4}$ ).

In addition to blood, the uterine milk contains fat in large quantities. Before pregnancy it may be demonstrated in the sub-epithelial leucocytes which later migrate to the surface. Fat globules are also contained in large amount in the epithelial cells of the surface and glands. According to Bonnet, it cannot be considered as a fatty degeneration because the cells are otherwise healthy ; it is rather a fatty infiltration, the epithelium secreting it from the lymph or blood-plasma, storing it and later giving it off to the uterine milk.

Kolster ${ }^{5}$ has described a process by means of which cellular elements are added to the "Embryotrophe." 6 The gland

${ }^{1}$ Strahl, see Hertwig's Handb. d. vergl. $u$. exp. Entwickelungsg. $d$. Wirbelthiere, 1902.

2 Tafani, "Sulle Condizioni utero-placentari della Vita Fetale," Arch. della Scuola d'Anat.-Path., Firenze, 1886.

${ }^{3}$ Bonnet, “Ueber Embryotrophe," Deut. Med. Woch., 1899.

"Strahl, "Ueber die Semiplacenta multiplex von Cervus elaphus "Anat. Hefte, H. xciii., 1906.

5 Kolster, "Die Embryotrophe placentarer Säuger," \&c., Anat. Hefte, vols. xviii. and xix., 1902 and 1903.

" Objections have been raised to the term " nterine milk" because the fluid contains cellular elements, pigment granules, \&c., which are not present in the mammary secretion. Bonnet and his followers have employed the convenient term "Embryotrophe," but it must be noted that in the sheep it forms the nutriment long after the embryonic stage of the developing ovum is past. The two terms are used indiscriminately in this chapter. 
epithelium proliferates so strongly that the cells cannot find room in the wall, and tracts of them are invaginated into the lumen. Later the cellular projections, sometines along with some of the underlying connective tissue as in the mare, are cut off and added to the embryotrophe (Fig. 93).

Traces of glycogen may be extracted from both the maternal and foetal parts of the cotyledons, but it is too small in amount to be demonstrated histologically. It is also present in small amounts in the extra-cotyledonary areas-in the uterine epithelium both superficial and glandular in the cow, in the sub-epithelial connective tissue in the sheep, and in the uterine milk (Jenkinson ${ }^{1}$ ). Large quantities of glycogen are stored in the plaques amniotiques, localised masses of cells on the internal surface of the amnion, and later on the umbilical cord. In the calf embryo the plaques reach their full development about the sixth month, and then gradually atrophy.

It is obvious that the uterine milk must contain many elements which have not been mentioned individually. The product of conception requires numerous other substances for its development besides protein, fat, carbohydrate, and iron. Organic phosphorus compounds are furnished by the nuclei of cells, and these may also contain iron. In general the fixation of mineral elements is slight at the beginning of pregnancy, but becomes active towards the end. But the requirements vary at different periods of pregnancy. For example, sodium decreases and calcium increases with the replacement of cartilage by bone, and potassium increases with the increased manufacture of red blood corpuscles. These and many other substances are present in uterine milk though not demonstrated histologically. Either they have been dissolved by the fixative, or have remained unstained by the methods hitherto employed.

One other constituent has been described by various observers, but its composition and significance are unknown. Besides the leucocytes that contain pigment granules and fat, others are filled with rod-like bodies, the "Uterinstäbchen " of Bonnet. ' Later they appear in the uterine milk. Rods have

"Jenkinson, "Notes on the Histology and Physiology of the Placenta in Vertebrata," Proc. Zool. Soc., London, 1906, vol. i.

2 Bonnet, "Beiträge zur Embryologie der Wiederkāuer gewonnen am Schafe," Arch. f. anat. u. Phys., anat. Abth., 1884. 
FOETAL NU'TRITION: THE PLACENTA 405

also been described in the trophoblast of the rabbit by Beneden, and in the uterine mucosa by Schmidt, ${ }^{1}$ who stated

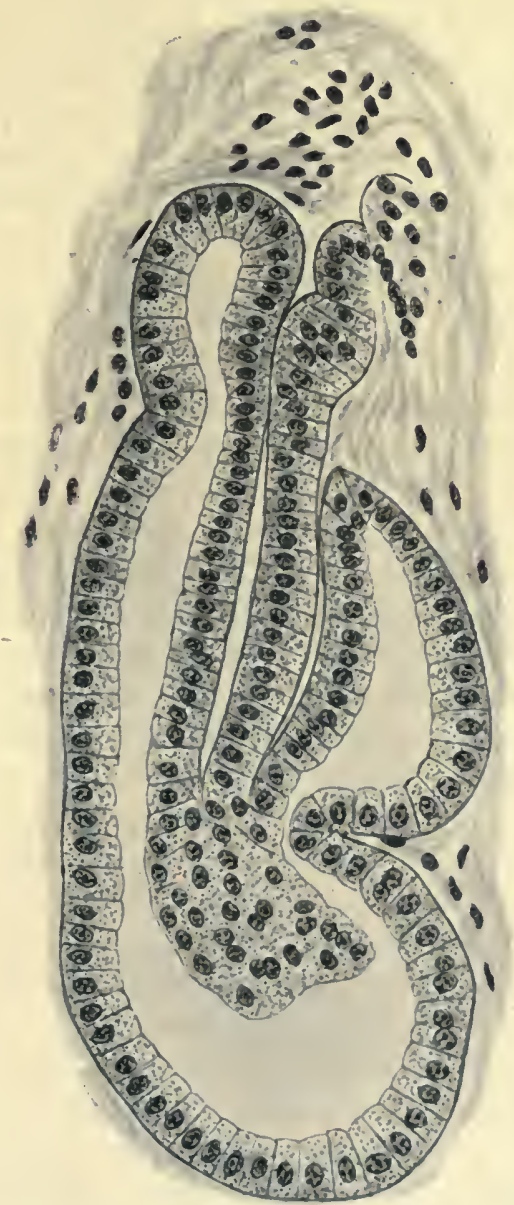

FIG. 93.-First stage of cellular secretion in the placenta of the cow. Invagination of glandular epithelium and some of the underlying connective tissue. (From Kolster, "Die Embryotrophe placentarer Säuger," Anat. Hefte, vols. xviii. and xix., 1902-3.)

that they were composed of calcium oxalate. In Ruminants they are found in enormous numbers, but whether they form

1 Quoted by Bonnet, "Ueber Embryotrophe," Münch. med. Woch., 1899. 
a supply of calcium for the foetus is not known (Fig. 95). There is at present no evidence that they are "protein crystals," a name sometimes applied to them.

The uterine milk has thus the following constituents-the secretion of the superficial and glandular epithelium, perhaps mingled with lymph transuded from the odematous mucosa; leucocytes containing hæmoglobin derivatives, fat globules, and "Stäbchen "; glycogen ; tracts of glandular epithelium set free by a process of "cellular secretion"; red blood corpuscles and their derivatives; connective-tissue elements ; salts, \&c., which are in solution and not recognisable by ordinary histological methods.

While lying free in the uterine cavity, the uterine milk undergoes changes which consist largely in a disintegration of its cellular elements. The leucocytes degenerate and their cytoplasm, with the pigment granules, fat globules, and "Stäbchen," is set free. The tracts of glandular epithelium are also transformed into a mass of débris, and their contents lie free in the embryotrophe. The red blood corpuscles may be ingested almost unaltered by the trophoblast, or they may first be laked, and the hæmoglobin may be absorbed as such, or undergo changes before absorption. According to Jenkinson, hxmoglobin is broken up into an iron-containing and an iron-free part. The former is carried away by the foctal blood-vessels and stored in large quantities, principally in the fotal liver, as a reserve for use during lactation. The iron-free part is deposited in the cells as a pigment, occurring in such amount as to give, especially in the later stages of pregnancy, a deep brown colour to the fortal cotyledons. It collects at the apices of the villi, and its presence suggests that the cotyledons are actively engaged in excretion (Assheton). The histological changes in the red blood corpuscles absorbed by the trophoblast have been described by Jenkinson. They are engulfed by amoboid processes of the cells, and gradually become paler in colour and irregular in outline; often they clump together. Gradually yellowish-brown granules are deposited on the surface of the included cells, and this process continues till the whole is converted into a dark brown mass. Bonnet called the granules hæmatoidin crystals, but Jenkinson was unable to demonstrate 
this pigment in alcoholic extracts of the placenta. He found two other pigments, one absorbing a small part of the violet end of the spectrum, and the other showing two absorption bands, which differed slightly from those of oxyhæmoglobin in neutral solution and of hæmatoporphyrin in acid solution. This pigment is obviously a hæmoglobin derivative, and from it bilirubin may be formed. It is present in the sheep and cow during pregnancy, but not in the virgin uterus of the sheep. A similar yellowish-brown pigment occurs in the crypts and the tissues outside them, and also, according to Assheton, in the maternal blood-stream. It is not yet possible to explain the exact significance of these changes. The iron-free pigment is apparently a waste product, and the iron-containing part is stored in the fœtal organs. Whether the fœtus subsequently synthesises part of the organic iron compound into hæmoglobin, or absorbs minute quantities of hæmoglobin as such, according to its requirements, is unknown.

The cotyledonary and inter-cotyledonary parts of the placenta present differences both anatomically and physiologically. In the inter-cotyledonary region are the glands, and here only are found the gland-secretion and the "cellular" secretion. In the cotyledonary parts the glands are absent. Here the villi are formed, and they effect an attachment to the mucosa by the greater activity of the trophoblast. Assheton has suggested that this hyper-activity may be stimulated by the absence of glands and consequently of uterine milk in the cotyledons, the fotal ectoderm attacking the mucous membrane more vigorously in order to obtain food. The blood effusions are also cotyledonary, and the eosin and iron reactions are obtainable in the adjacent trophoblast, and not at other places. Finally, it is probable that the exchange of oxygen and carbonic dioxide is carried out in the cotyledons. Here the maternal capillaries are more dilated than outside the burrs, and they come close up to the surface, some of them even impinging on the lining membrane of the crypts. Between them and the allantoic vessels in the villi intervene only a small amount of mesoblast, the cellular trophoblast, and the lining of the crypts which, according to Assheton, corresponds to the plasmodiblast of the bat. In the inter-cotyledonary regions, on the other hand, the 
foetal vessels are related to the orifices of the glands, and appear to be concerned principally with the absorption of their secretion. As already mentioned, the villi may also be concerned with the excretion of waste products of hæmoglobin.

Bonnet was the first to show that the trophoblast in Ruminants was actively phagocytic and absorbed the constituents of the uterine milk (Fig. 94). He demonstrated the presence of fat-globules, hæmoglobin and its derivatives, de-

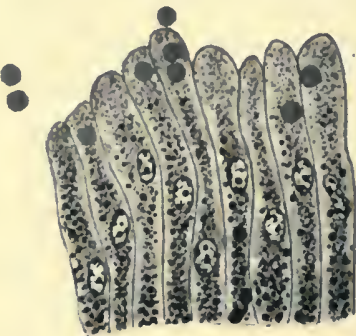

FIG. 94.-Ingestion and disintegration of red blood corpuscles by the trophoblast of the sheep. (From Jenkinson's "Notes on the Histology and Physiology of the Placenta in Ungulata," Proc. Zool. Soc., London, vol. i., 1906.) generated leucocytes and "Stäbchen" (Fig. 95)-in short, all the histologically demonstrable constituents of the embryotrophe - in the trophoblast. Many, if not all, of the cellular elements are partially degenerated before absorption. The appearances suggest an enzyme action on the part of the trophoblast, and perhaps also the leucocytes, but no proteolytic or lipolytic enzyme is contained in glycerin extracts of the maternal or foetal part of the cotyledon.

After their absorption, the disintegration of the cellular constituents is completed in the trophoblast, and they are no longer recognisable as individual elements. Their products are transmitted to the foctal vessels, though they may first be elaborated in the trophoblast into a form or forms suitable for the use of the embryo in the development of its various organs.

Lemuroidea.-Many of the lemurs have a simple avillous diffuse placenta, as Turner ${ }^{1}$ first pointed out in specimens from Madagascar. Hubrecht has investigated two others found in the East Indies-Tarsius ${ }^{2}$ and Nycticebus. ${ }^{3}$ The latter has also a diffuse placenta. Villi develop over the whole of the

1 Turner, "On the Placentation of the Lemurs," Phil. Trans. Roy. Soc., London, vol. clxvi., 1876.

"Hubrecht, "Ueber die Entwicklung des Placenta von Tarsius," \&c., Internat. Congr. of Zool., Cambridge, 1898.

${ }^{3}$ Hubrecht, "Spolia Nemoris," Quar. Jour. Micr. Sci., vol. xxxvi., 1895. 
chorion, and fit into vascular crypts in the uterine mucosa from which they are easily retracted at birth. The epithelium

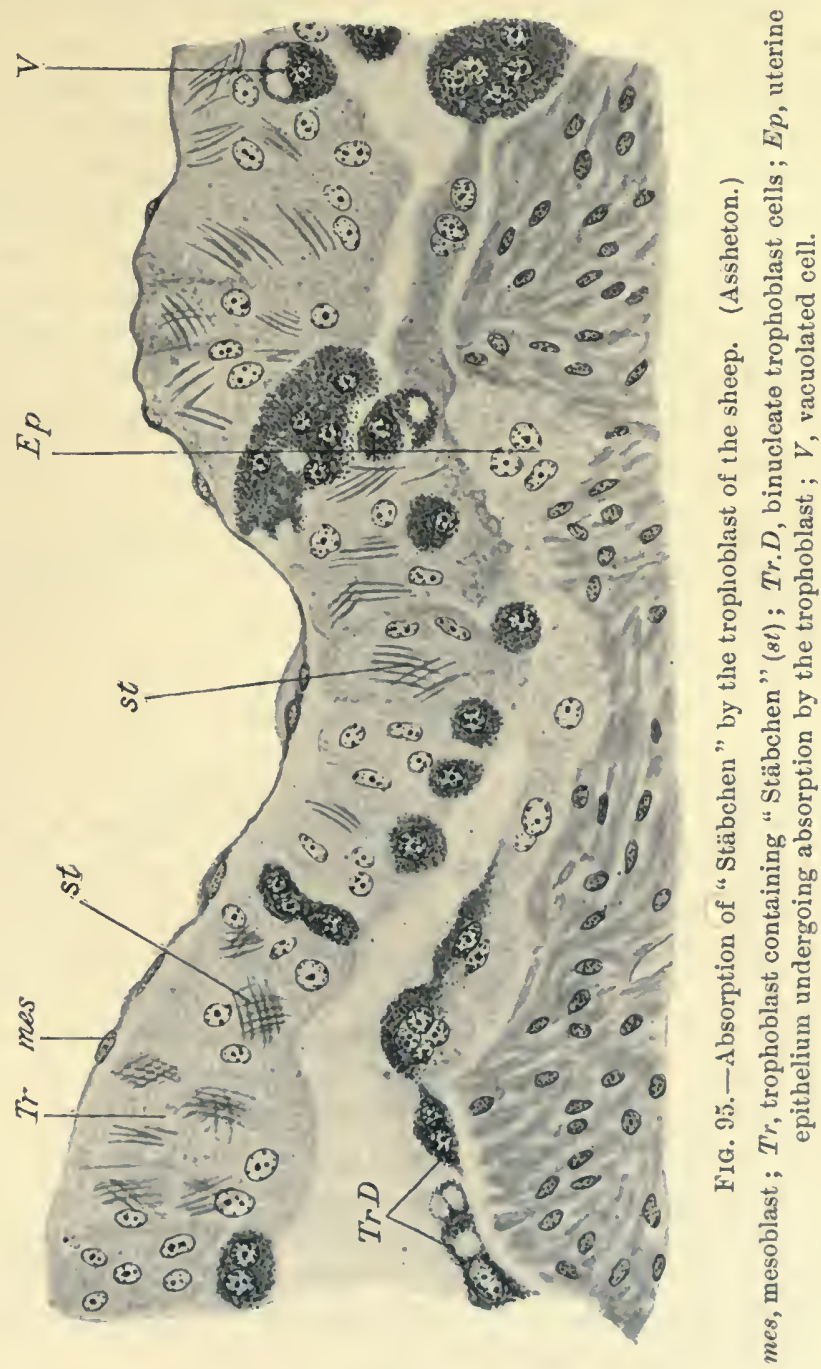

of the crypts persists as in the cow, and the "osmotic interchange takes place through two cell-layers of different origin, and of different physiological significance (phylogenetically). 
Tarsius approaches more closely to the Insectivora and Primates. The trophoblast proliferates and penetrates into the mucosa, and maternal blood circulates in its spaces. The mesoblast grows profusely, and forms with the trophoblast a true chorion in Hubrecht's restricted sense. The placenta is discoid. In Galago agisymbanus, Strahl ${ }^{1}$ has shown that a layer of secretion lies between the uterus and the ovum from the beginning of pregnancy. It is absorbed by the ectoderm, the cells of which are vesiculated over the gland orifices. Many blood extravasations occur in the connective tissue of the mucosa, and the red blood corpuscles undergo changes as in the sheep, the glandular cells and embryotrophe containing granules which give an iron reaction. Turner ${ }^{2}$ had previously noted in lemurs the intense brown staining of the glands from effused blood.

Cetacea, Edentata, and Sirenia.-The details of placental development and the constitution of the embryotrophe are unknown.

\section{The Placenta in Decindita}

In the Deciduata three modes of attachment between embryo and mother are found: Centric, in which the blastocyst rests in the cavity of the uterus, attains a large size, and comes in contact with the wall over its whole circumference; Excentric, in which the blastocyst remains small and lodges in a furrow of the uterine mucosa, and later a decidua reflexa is formed; Interstitial, in which the small blastocyst attacks the mucosa at one point and reaches the connective tissue. In this form also a decidua reflexa is formed.

In the neighbourhood of the attachment the mucosa degenerates, but the connective tissue cells usually enlarge to form decidual cells before degeneration sets in. The capillaries dilate and come in contact with the trophoblast. The mucosa interlocks so closely with the fotal villi that the two tissues cannot be separated without injury.

1 Strahl, "Die Verarbeitung von Blutextravasaten durch Uterindrüsen," Anat. Anzeig., vol. xvi., 1899.

2 Turner, "The Placentation of Lemurs," Jour. of Anat. and Phys., vol. xii., 1878. 
Carnivora.-The Carnivora are characterised by a zonary form of deciduate placenta. The following account of its development refers particularly to the dog and cat, which have been most frequently investigated. The gestation period in the cat is about sixty-three days, and in the dog fifty-eight to sixty-two days. In both the ovum takes a comparatively long time to traverse the oviduct. On reaching the uterus the blastocyst is covered by a thick prochorion which prevents adhesion for a considerable period.

The mucosa is matured, as in Ungulates, at the first proœstrum by the development of a well-differentiated subepithelial cellular layer, and of the glands and crypts (see p. 398). The crypts provide an increase of superficies and of secreting epithelium, and are later concerned in the attachment of the ovum. They have been recognised by all the authorities with the exception of Robinson, ${ }^{1}$ who states that he can find no evidence that any of the crypts are other than the ducts of the uterine glands. At the first and each succeeding procstrum there is a marked hyperæmia of the mucosa, and from the rupture of some of the superficial capillaries miliary hæmorrhages occur (see Chap. III.).

At the beginning of pregnancy, blood effusions are found close under the surface of the mucous membrane, but bleeding into the uterine cavity, which took place during the proœstrum, has entirely ceased. The epithelium of the surface glands and crypts is swollen and pervaded with minute fat-globules in the $\operatorname{dog}\left(\right.$ Bonnet $^{2}$ ) and cat (Melissenos ${ }^{3}$ ). The glands widen quickly into "chambers," and tracts of their proliferated epithelium are invaginated, and often obliterate the lumen. The widening of the glands and crypts makes the deep layer spongy. The capillaries increase and form practically the whole of the sub-epithelial layer. Immediately below it lies the layer of glandular ducts which are obliterated by débris

1 Robinson, Hunterian Lectures, Jour. of Anat. and Phys., vol. xxxviii., 1904.

2 Bonnet, "Beiträge zur Embryologie des Hundes," Anat. Hefte, vol. xx., 1902.

3 Melissenos, "Ueber die Fettkörnchen und ihre Bedeutung in der Placenta bei den Nagern und der Katze," Arch.f. mikr. Anat., vol. Ixvii., 1906. 


\section{THE PHYSIOLOGY OF REPRODUC'IION}

resulting from the degeneration of the proliferated epithelial cells. Between it and the spongy layer is the compact layer, also formed from the sub-epithelial layer. In it the glands are

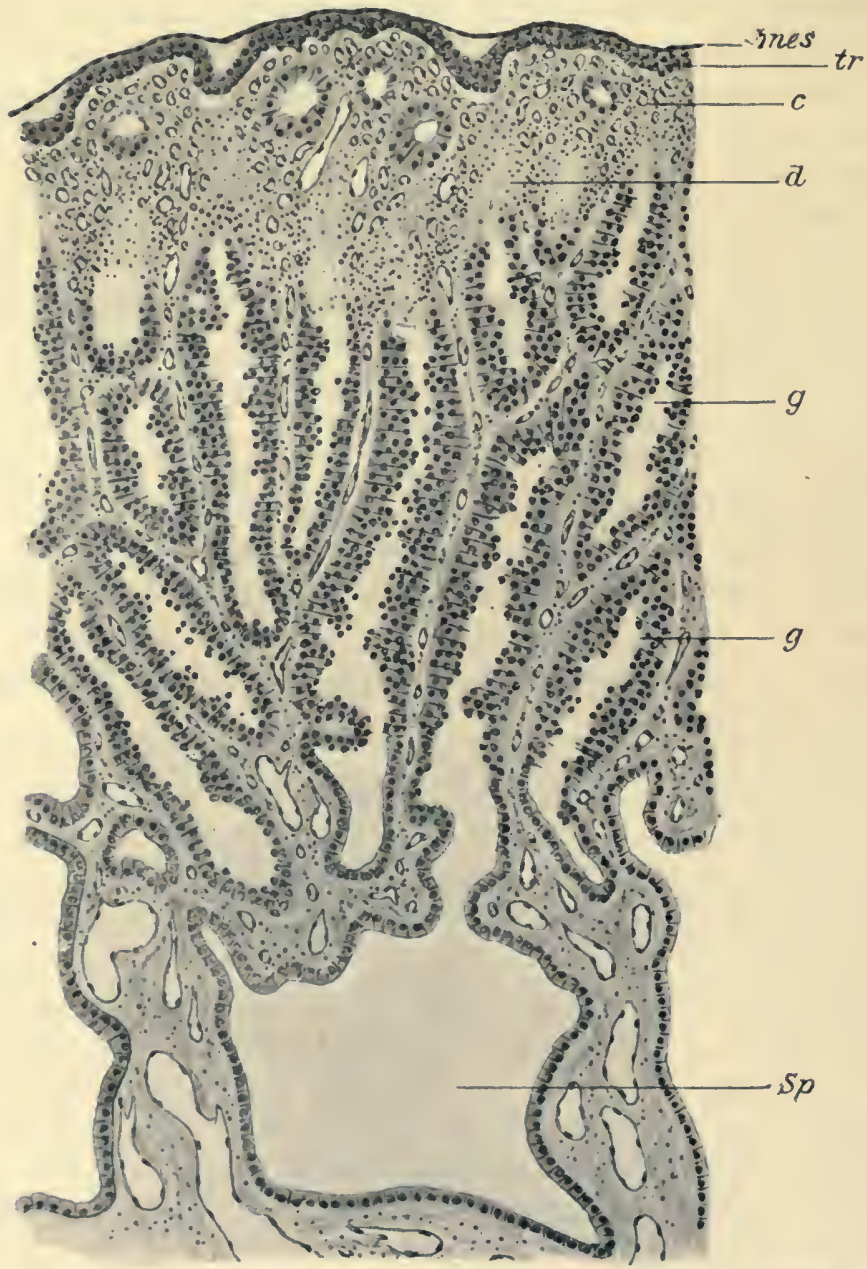

Fig. 96.-The uterine mucosa of the dog about the twenty-third day of pregnancy. (From Duval's "Le Placenta des Carnassiers," Journ. de l Anat. et de la Phys., 1893.)

mes, mesoblast; $t r$, trophoblast; $c$, capillary layer; $d$, layer of glandular detritus; $g$, glands of compact layer; $S p$, dilated glands of spongy layer. 
not so widely dilated and the connective tissue is more abundant (Fig. 96).

The embryotrophe at this stage differs from that in Ungulates. The glandular secretion is less fluid, perhaps because the lymph transudate is less abundant (Kolster ${ }^{1}$ ). It surrounds the ovum to form the prochorion or "Gallertschicht," and is, according to Bonnet, ${ }^{2}$ absorbed by the trophoblast.

When the prochorion disappears, the fœetal ectoderm already has proliferated over a broad zone of the citron-shaped ovum (Fig. 97), to form villosities which attack the surface of the mucosa, and obtain an attachment to it-about the twentieth

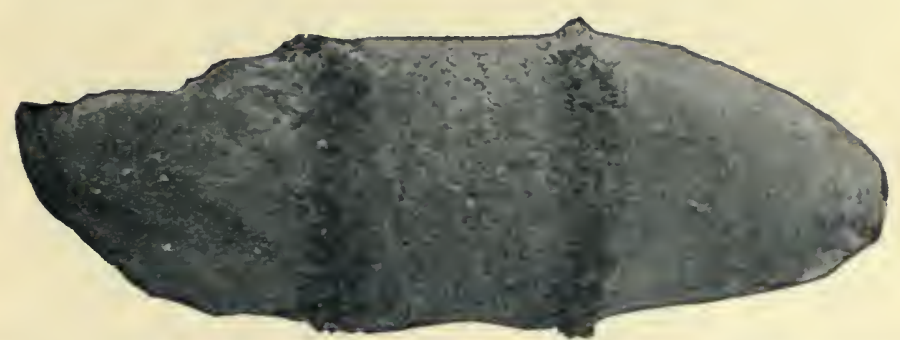

FIG. 97.-Ovum with zonary band of villi. (From Hertwig's Entwicklungsgeschichte des Menschen und der Wirbelthiere, by permission of Gustav Fischer.)

day in the dog (Duval ${ }^{3}$ ) and the twelfth day in the cat (Robinson). Vascular processes of the allantois grow into the centre of the trophoblastic villi, first over a limited discoid area, and later over the whole zone as the allantois spreads round the wall. Hence the rudimentary placenta is discoid, and the completed placenta zonary.

In procuring attachment to the uterus many of the villi project into glands and crypts. According to Strahl, ${ }^{4}$ the epithelium lining the ducts and the surface of the uterine cavity

1 Kolster, "Ueber die Zusammensetzung der Embryotrophe der Wirbelthiere," Ergebn. d. Anat., vol. xvi., 1906.

2 Bonnet, "Ueber das 'Prochorion' des Hundekeimblase," Anat. Anzeig., vol. xiii., 1897.

3 Duval, "Le Placenta des Carnassiers," Journ. de l'Anat. et de la Phys., 1893.

- Strahl, "Die histologischen Veränderungen d. Uterusepithel. in d. Raubthierplacenta," Arch.f. Anat. u. Phys., Supplement, 1890. 


\section{4 'THE PHYSIOLOGY OF REPROI)UCIION}

is then transformed into a syncytium and invests the villi externally. Heinricius ${ }^{1}$ is of opinion that the epithclium disappears, and the syncytium is formed by the utcrine connective tissue. But it is now gencrally recognised that the syncytium is trophoblastic. It has been proved by Strahl himself, and by Duval, that many of the villi obtain attachment at parts of the surface where there are no gland openings or crypts, and penetrate into the substance of the mucosa. Before the disappearance of the epithelium, the cells lose their outlines and form a homogeneous mass of protoplasm with fragmented nuclei. This degenerated tissue ought not, as Bonnet ${ }^{2}$ emphasised, to be known as syncytium, which represents an active protoplasmic condition (see p. 364). The name which he suggested, symplasma, is very convenient and is used here. It is not only the surface epithelium which forms a symplasma. The glandular epithelium, the connective tissue cells, and extravasated blood may also give rise to a symplasma which may be designated glandular, connective tissue, and homatogenous respectively. All are formed to a large extent in the placenta of Carnivores, and their rescmblance to the trophoblastic syncytium has led to much confusion.

After the destruction of the epithelium, the villi penetrate into the deeper tissues of the mucosa by gradually absorbing the symplasmata, and branch to form secondary and tertiary villi. When the ectoderm reaches the capillary layer, it sends out protoplasmic processes which encircle the dilated vessels. The trophoblast on the sides of the villi becomes syncytial, but retains its cellular character at the tips. Internally the villi contain vascular cores of mesoblast. Hence is formed the angioplasmode of Duval-a continuous layer of fotal vascular villi, clad with syncytium, penetrating everywhere into the capillary layer, and leading to a disappearance of all the matcrnal tissues except the vessels (Fig. 98). By the epithelial arcades at the tips, the layer of villi rests on the sheet of glandular detritus and the compact layer, which in turn form a symplasma and undergo absorption. Thus the fœtal structures reach the

1 Heinricius, "Ueber die Entwicklung und Struktur dèr Placenta beim Hunde," Arch. f. mikr. Anat., vol. xxxiii., 1889.

2 Bonnet, "Ueber Syncytien, Plasmodien und Symplasma," \&c., Monatsschr. f. Geburtsh. u. Gynäk., vol. xviii., 1903. 
spongy layer, in which the glandular culs-de-sac have expanded to form large cavities separated by partitions, the mesenteriform lamellæ. Gradually the roof of this layer is also absorbed by

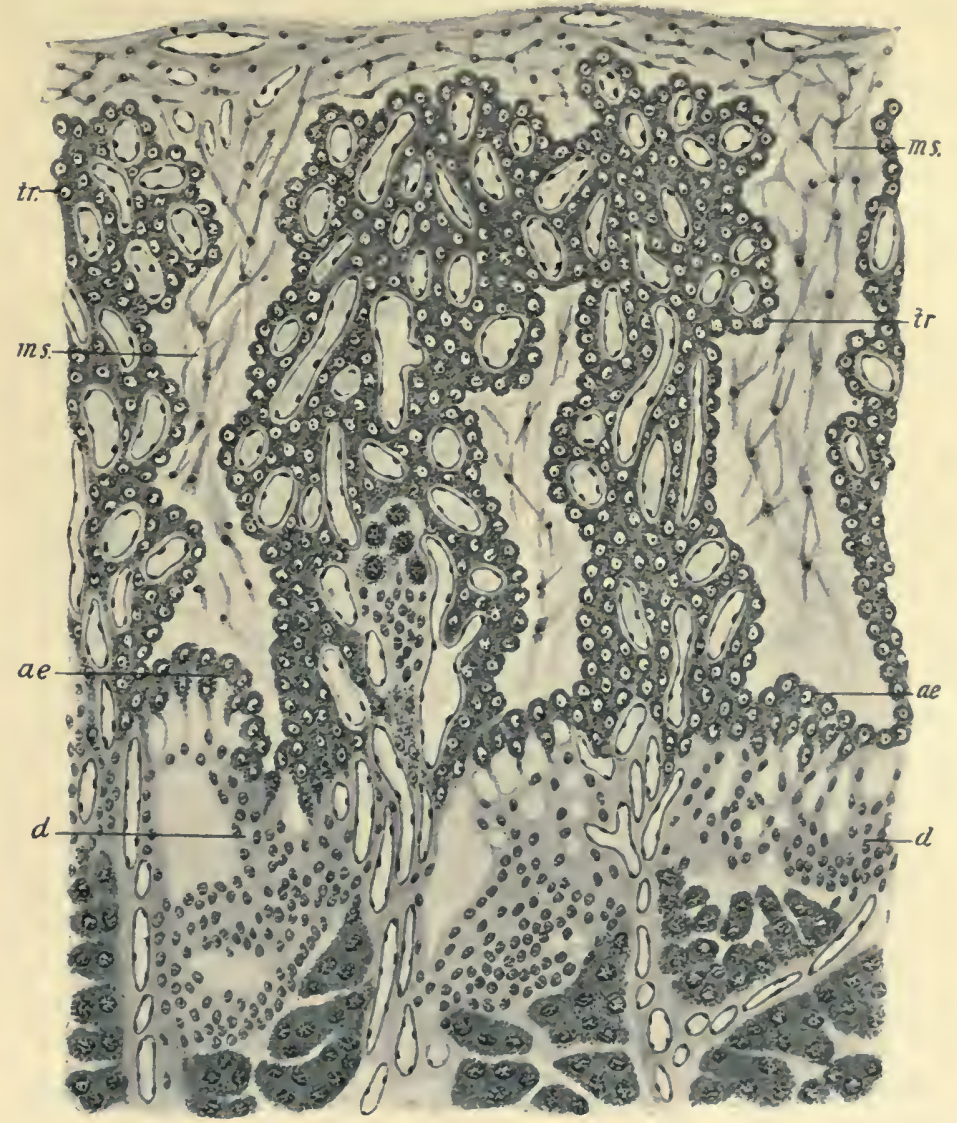

FIG. 98.-The angioplasmode of the dog at the thirtieth day of pregnancy. (From Duval's "Le Placenta des Carnassiers," Journ de l'Anat. ct de la Phys., 1893.)

$m s$, mesoblast ; $t r$, trophoblast ; ae, ectodermic arcades; $d$, layer of glandular detritus.

the trophoblast, and the ectodermal arcades at the tips of the villi gain a permanent attachment to the mesenteriform lamellx. At the same time, by the further branching and penetration 
of the fotal mesoderm in the angioplasmode, the tissue is broken up into a series of labyrinthine lamellæ, which consist of a network of maternal vessels clothed on each side by syncytial trophoblast. The meshes of the network are penetrated by the vessels of the villi. In this way, according to Duval, the labyrinth is formed. In it the maternal and the fotal blood are separated by the endothelium of the uterine capillaries, a cellular layer (considered fœetal by Duval and maternal by Heinricius) which later disappears, the syncytium, mesoblast, and fotal capillary walls.

At places, however, the villi come directly in contact with maternal blood, especially at the "green border" of the placenta, which forms a characteristic appearance in some of the Carnivora. In all the members of the order, larger or smaller maternal hæmorrhages occur at an early period after the attachment of the blastodermic vesicle. The effusions vary in size and position. In the dog they occur regularly along the margins of the placental zone, and form the bordure verte; in addition smaller hæmorrhages take place into the substance of the placenta, and form the "green pockets," which may be isolated or joined to the green border by bridges (Fig. 99). In the cat, the hæmorrhages occur in irregular positions and do not assume the green colour typical of the dog. Indications of a green border are present in the earlier stages, but not in the completed placenta. In the otter and badger, the effusion takes the form of a large bloodpouch, filled with a great variety of blood derivatives. In the ferret the conditions are similar; the main effusion occurs at the anti-mesometrial border of the uterus, and divides the zone into two lateral discs. According to Robinson, it lifts the trophoblast from the decidua, and forces it in the form of irregular pouches towards the intcrior of the ovum. Strahl and Bonnet also state that the blood is effused between the mucosa and the blastodermic vesicle, and thus is contained in spaces whose walls are maternal on the one side and fotal on the other. According to Duval the blood-spaces are entirely lined by trophoblast, and with the advance of the villi other and larger hæmorrhages occur, coalescing to form the green border and islands. In either case the trophoblast is in direct contact with maternal blood. There the wall of the blastodermic 
vesicle is avillous but strongly folded, the ends of the ectodermal cells are expanded like clubs, and their protoplasm becomes coarsely reticular. Into the meshes the constituents of the green pulpy mass, unaltered erythrocytes and hæmoglobin or its derivatives, are absorbed by phagocytosis.

From the preceding account, it is clear that certain re-

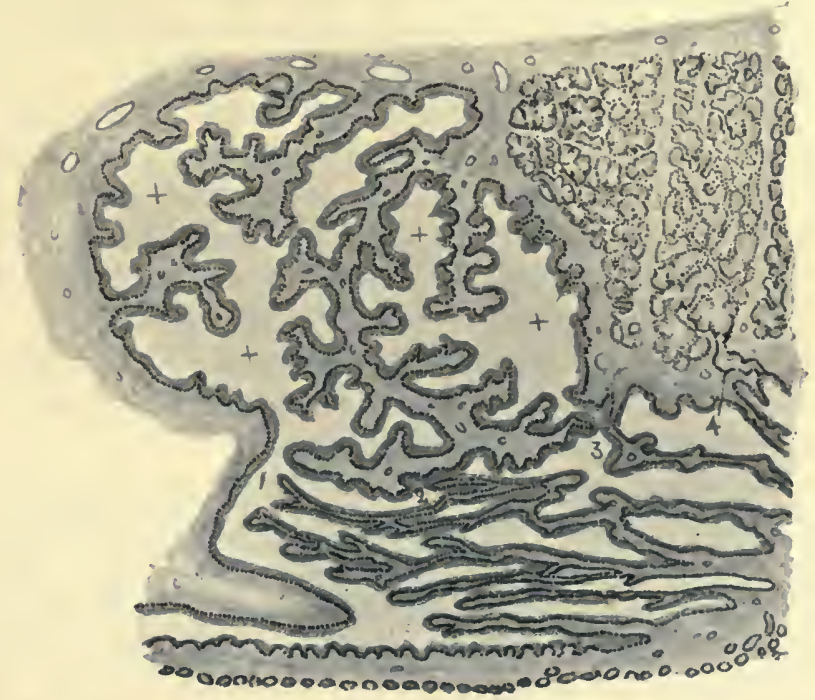

FIG. 99. - The labyrinth and the green border of the placenta of the dog at the fortieth day of pregnancy. To the right are two lobules of the angioplasmode which have reached the stage of complexity of the labyrinthine lamella: to the left is the green border, the cavities of which, normally filled with blood, are indicated by a cross. (From Duval's “Le Placenta des Carnassiers," Journ. de l'Anat. et de la Phys., 1893.)

1,2 , and 3 , basal lamelle of the green border; 4, basal lamella of lobule of labyrintl.

semblances and certain differences exist between Carnivora and Ungulata in the composition of the embryotrophe. The most notable difference in the zonary placenta is the absence of the large amount of milky fluid which arises in the sheep from the glandular secretion and the transudation of lymph. In Carnivora the gland secretion is less important. Though the deep parts of the glands which lie in the glandular layer may 
secrete, the epithelium of the more superficial parts proliferates, and then degenerates and loses its secretory function; finally it forms a symplasma which plugs up the lumen of the glands.

On the other hand, the amount of nutriment furnished directly from the maternal blood is increased. It is found in the extravasations already described, and as individual blood corpuscles and droplets of hæmoglobin or its derivatives in the lumina of glands. Leucocytes are found during the whole of pregnancy, but in less abundance than in the sheep. They do not act to the same extent as store-houses of fat, but some of them, the siderophores, contain granules which give an iron reaction. In the course of pregnancy they disappear comparatively early, with the exception of a few in the deep glandular layer. Fat is found in the intact epithelium of the glands, and in the lumen after desquamation of the cells. It appears in the epithelium partly as an infiltration and partly as a degeneration product of the protoplasm.

In the Carnivora, the foetal ectoderm of the zonular band of attachment attacks the uterine mucosa more strongly than in the Ungulata. As a result, the maternal tissues, with the exception of the septa containing the placental vessels, disappear down to the middle of the spongy layer, and the tissue which is destroyed serves as pabulum for the developing embryo. Van der Brock ${ }^{1}$ suggests that the general œdema of the uterine mucosa may lead, as elsewhere, to its malnutrition and degeneration, and thus it may fall an easy prey to the trophoblast. Others maintain that the degeneration is brought about by a trophoblastic influence, perhaps of the nature of an enzyme action. The result is a transformation of all the elements to a symplasma. In the cat the connective tissue cells may form large decidual cells before their final destruction.

As in the Indeciduates, there is strong histological evidence that the trophoblast is actively phagocytic, and takes up, as it meets them, the constituents of the prochorion, and later the degenerated tissues and extravasated blood. In the neighbourhood of the extravasations active absorption is indicated by the

1 Van der Brock, "Die Eihüllen und die Placenta von Phoca vitulina," Petrus Camper, D. ii. Quoted by Kolster (Ergebn. d. Anat., vol. xvi., 1906). 
change in shape of the trophoblast cells and by their pigmentation. In the mesoblast of the villi and its vessels no trace is found of any of the formed elements of the embryotrophe, a proof that they undergo further transformation in the trophoblast after absorption.

The interchange of oxygen and carbonic dioxide apparently occurs in the labyrinth, as in the cotyledons of the sheep. Here only is the fotal circulation brought into close proximity with circulating maternal blood. Other fœtal waste products are probably also got rid of in the labyrinth. Nolf ${ }^{1}$ suggests that the excretory products may be responsible for the degeneration of the maternal tissues into a symplasma.

In how far the other substances necessary for the growth of the embryo are taken up respectively from the circulating blood by purely physical or physiologically selective processes, and from the extravasated blood effusions by direct phagocytosis, is not known.

Probosciden.-In the elephant, the allantois is large and vesicular. Short villi are developed over a large area of the blastodermic vesicle. They lodge in pre-existing depressions in the uterine wall, but the trophoblast is inactive and does not attack the maternal tissues (Assheton ${ }^{2}$ ). Over a zonary area, however, the villi are much longer, and, penetrating deeply into the maternal tissues, they form a large mass of tissue in the meshes of which maternal blood circulates. Hence the zonary placenta differs from that of Carnivores and resembles that of Insectivores, in which, however, the maternal blood circulates in trophoblastic spaces before the advent of fotal capillaries.

Though no red blood corpuscles appear to be absorbed as such by the trophoblast, there is evidence of an active absorption of hæmoglobin derivatives, the presence of iron compounds being easily demonstrated, especially in the cores of the villi

1 Nolf, "Etude des modifications de la muqueuse utérine pendant la gestation chez le murin," Arch. de Biol., vol. xiv., 1896.

2 Assheton, "The Morphology of the Ungulate Placenta, with Remarks on the Elephant and Hyrax," Phil. Trans. Roy. Soc., London, Ser. B., vol. cxcriii., 1906. 
and the walls of the fotal capillaries. In the syncytial trophoblast, however, the Prussian-blue test is negative (see p. 486).

At birth the long villi are left in situ and absorbed by the maternal tissues.

Hyrax.-As in the elephant, the placenta of Hyrax has been studied only in isolated specimens, and its development is not known. According to Assheton, ${ }^{1}$ the trophoblast is probably thickened all round the wall of the blastocyst, as in the hedgehog and Man, but there is no appearance of a decidua reflexa. Maternal blood is carried directly to the foetal side of the trophoblast, where it is close to the fotal vessels, and so may provide nutriment. It then trickles back through a complicated system of lacunæ in the trophoblast.

The placenta is at first diffuse and later zonary. In the mucosa of the placental area the glands disappear early, and a great increase in the inter-glandular stroma occurs, as in Rodents. $^{2}$

Rodentia.-Among the Rodents there are variations in the mode of attachment. It is centric in the rabbit, excentric in the mouse and rat, and interstitial in the guinea-pig. In all the ultimate form of the placenta is discoid.

It was in Rodents that the proliferation and vascularisation of the trophoblast were first deseribed by. Selenka. ${ }^{3}$ Later Duval ${ }^{4}$ gave a fuller account of the earlier stages, and Hubrecht discovered the same conditions in other orders.

Rabbit.-The fertilised ovum of the rabbit, clothed by the prochorion, reaches the uterus at the beginning of the fourth day after coitus. At first it has no fixed position; but by the

1 Assheton, loc. cit.

2 Hubrecht (Quar. Jour. of Micr. Scicnce, 1908) draws attention to the peculiar position of Hyrax. It has many archaic peculiarities, and has been placed near Rodents, elephants, and Ungulates by different authors. Yet its placental characters resemble those of the hedgehog and Man. This he takes as strong evidence that the type of placenta found in Hyrax, the hedgehog, and Man, diverges less widely from the primitive type than the placenta of Ungulates and Rodents.

${ }^{3}$ Selenka, Keimblatter und Primitivorgane der Maus, 1883.

"Duval, "Le Placenta des Rongeurs," Journ. de l'Anat. et de la Phys., 1889-92. 
seventh day, when the blastocyst is about five millimetres in diameter, the prochorion lies so closely on the surface of the uterus that it fixes the ovum. At the end of the eighth day the prochorion ruptures, and the blastodermic vesicle probably collapses at the same time by injury to its wall. ${ }^{1}$

The "mature" uterine mucous membrane of the nonpregnant rabbit already shows specialised structures, which are of importance for the attachment and nutrition of a future embryo. These consist of symmetrical pairs of longitudinal folds, first described by Hollard, ${ }^{2}$ and subsequently named by Minot: ${ }^{3}$

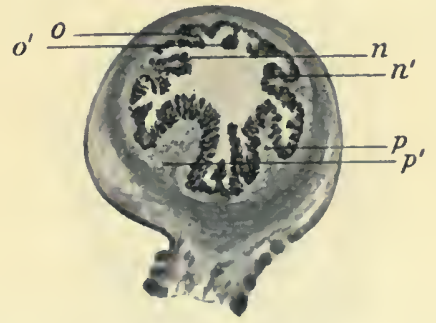

FIG. 100.-Transverse section of a four days' gestation sac of the rabbit. The mucosa is differentiated into six definite folds. The two folds nearest the mesometrium are the largest and mark the site of placental attachment. (From Chipman's "The Placenta of the Rabbit," Labor. Rep., Roy. Coll. Physic., Edinburgh, vol. viii., 1903.)

$p, p^{\prime}$, placental folds ; $n, n^{\prime}$, peri-placental folds ; $o, o^{\prime}$, ob-placental folds.

placental folds, the largest, situated one on each side of the groove corresponding to the insertion of the mesometrium; ob-placental folds, the smallest, opposite the mesometrium; peri-placental folds, intermediate in position and size (Fig. 100). Each fold is divided by transverse fissures into rectangular areas, the coussinets of Hollard. At the onset of pregnancy two of these areas on the placental folds, placed one on either side of the mesometrial groove, hypertrophy and form the maternal part of the future discoid placenta (Bischoff ${ }^{4}$ ), which is thus

1 See Hertwig's Entwicklungsgeschichte des Menschen und der Wirbelthiere, 1906.

2 Hollard, "Recherche sur le Placenta des Rongeurs," Annales des Sciences Naturelles, 1863.

3 Minot, "Die Placenta des Kaninchens," Biol. Centralbl., vol. x., 1890.

${ }^{4}$ Bischoff, Entwickelung des Kaninchen-Eies, Braunschweig, 1842. 
bi-lobed (Fig. 101). The folds of the mucosa are essentially increased areas of the mucosal connective tissue, but they differ from the cotyledons of Ruminants in having glands.

On the entrance of a fertilised ovum into the uterus, the folds, especially the ob-placental, become shortened, and a localised actual cavity appears which is occupied by the blastocyst. At the same time there is a marked hyperplasia of the cellular connective tissue of the placental and peri-placental folds, leading to a thickening of their bases (Chipman ${ }^{1}$ ). By the

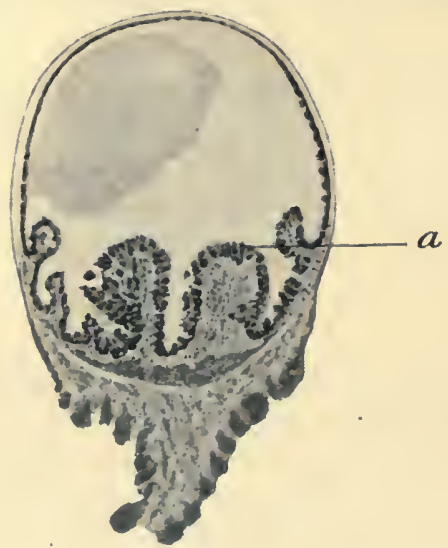

FIG. 101.-Transverse section of a seven days' gestation sac of the rabbit (Chipman). The placental folds (coussinets) are large $(a)$; the muscular walls of the sac are thin.

sixth day, the capillaries are also increased in these regions. In the ob-placental folds appear enormous giant-cells, derived by a process of "degenerative hypertrophy" from the epithelium of the surface and glands. They persist till the fourteenth day, and are probably absorbed by the trophoblast overlying the yolk-sac. In the placental lobes the epithelial

1 Chipman, "Observations on the Placenta of the Rabbit, with Special Reference to the Presence of Glycogen, Fat and Iron," Laboratory Reports, Roy. Coll. Phys., Edinburgh, vol. viii., 1903. The development of the placenta is carefully traced in a complete age-series of pregnant rabbits and admirably figured by many photo-micrographs. The account as given here is based mainly on Chipman's monograph, but the phraseology is sometimes changed. 
cells proliferate and fill up the superficial culs-de-sac of the mucous membrane. The glands are as yet unchanged, and the increased blood supply leads to a free secretion which is usually considered to be added to the albumen-layer, and then to be absorbed by the trophoblast. There is no appreciable transudation of lymph such as occurs in Ruminants.

As the blastodermic vesicle grows, it presses against the folds and levels them. Hence at the time of attachment the surfaces of the placental lobes are nearly regular. The covering epithelium again returns to normal, but the active proliferation of the connective tissue cells is continued to form the placental cotyledons. At the same time the trophoblast proliferates in concentric areas on either side of the embryonic rudiment, which is placed opposite the groove between the placental cushions. Here the ovum is generally said to gain its first attachment, the ob-placental lobes having by this time disappeared. ${ }^{1}$

Where the maternal and fotal tissues are in contact, the surface epithelium shows a form of degeneration similar to the epithelial symplasma of the zonary placenta-fusion of cells and fragmentation of nuclei. It is attacked by the thickened, horseshoe-shaped trophoblast, the ectoplacenta of Duval, and its edge presents microscopically a "bitten or corroded appearance." This phagocytic or chemical action leads later to the complete disappearance of the epithelium, so that the trophoblast comes in contact with the connective tissue of the uterus. The glands are dilated, and their proliferated endothelium forms a symplasma which blocks the lumina. At these places the trophoblast advances more quickly, as if the resistance was weaker, and the line of attachment is undulating (Fig. 102). The dips thus correspond to the gland orifices and represent the beginnings of the future villi. The blood-vessels are large and numerous and have no adventitia, i.e. they are wholly capillaries. But the more deeply placed of them acquire an adventitia, the perivascular sheath (Masquelin and

1 Assheton (Quar. Jour. Micr. Sci., vol. xxxvii., 1895) states that the trophoblast shows papillary thickenings over the ob-placental and periplacental lobes, and that by them the ovum obtains the first attachment over its lower pole. 


\section{THE PHYSIOLOGY OF REPRODUC'IION}

Swaen ${ }^{1}$ ). It is formed of one or two layers of large connective tissue cells which represent the first appearance of the decidual cells. After the destruction of the superficial and glandular epithelium, the trophoblast advances into the interglandular tissue, the cells of which degenerate in turn and are absorbed. The advance is most rapid where a capillary is met with.

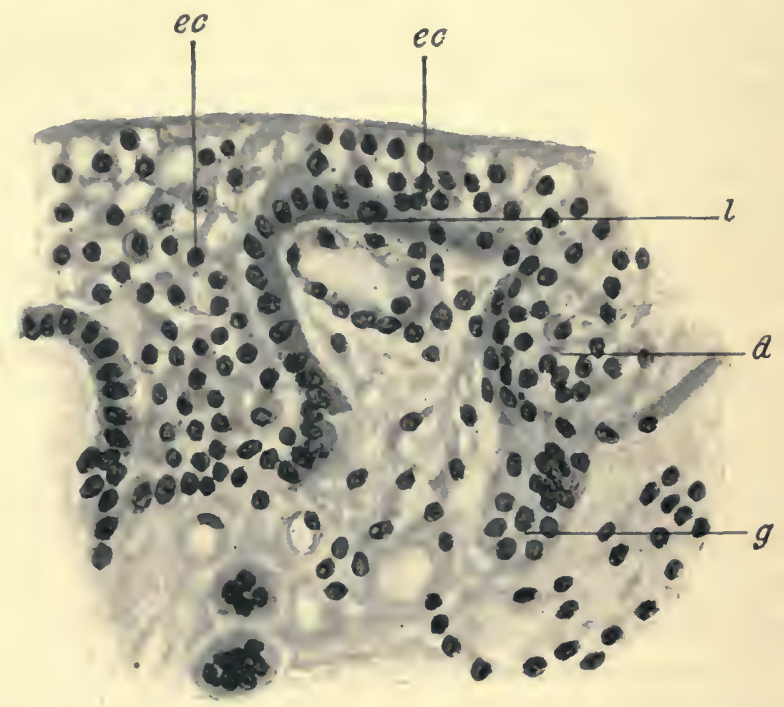

FIG. 102.-Thickened ectoderm (ectoplacenta) in the rabbit, attached to placental lobe and dipping more deeply at the position of the glands. (Chipman)

ec, fotal ectoderm; l, line of attachment of ectoderm; $d$, fotal ectoderm dipping into placental gland; $g$, terminal cul-de-sac of placental gland.

The mucous membrane is now differentiated into two zones, the intermediary region and the region of the uterine sinuses (Duval). The intermediary region lies superficially. It is closely packed with fusiform stroma cells and capillaries with thin perivascular sheaths of uninucleate decidual cells. "It suggests a reaction of the maternal placenta to the 'parasitic'

'Masquelin and Swaen, "Développement du placenta maternel cliez le lapin," Bull. de l'Acad. Roy. de Belg., 1879. 
fœetal placenta" (Chipman; see also p. 369). By the influence of the trophoblast the decidual cells increase in size and become multinucleate $\left(\right.$ Maximow $^{2}$ ). They lose their perivascular position and pervade the whole of the region. In their formation all traces of the gland ducts are lost, the cells of the latter appearing to serve as pabulum for the decidual cells. In the region of the uterine sinuses the blood-vessels dilate to form large spaces, and the decidual cells remain uninucleate till a considerably later period. The junction between the two zones is marked by the blind ends of the glands, which are filled with degenerated epithelium. In section each appears as an island of glandular symplasma.

At the tenth day the allantois joins the outer wall of the blastocyst over the site of the future placenta. The trophoblast of this region is differentiated into two layers, the plasmodiblast and the underlying cytoblast. The latter disappears before the end of pregnancy. Processes of vascular mesoblast invade the trophoblast at intervals, and break it up into columns. At the same time the fotal tissues continue to advance and surround maternal capillaries, the endothelium of which they replace. In the zonary placenta of Carnivora the trophoblast surrounds the vessels without destroying the endothelium. In the rabbit the ectodermal processes are hollow tubes which surround the vessels; they are closed on the fotal side and open on the maternal side. Their cavity is filled with maternal blood, and externally lies the cytoblast and vascular mesoblast. Such are the "villi." Subsequently the arrangement becomes more complex, each hollow column being divided up into a series of hollow tubes parallel to the original column, and each tube in turn forming a series of hollow tubules. At each division the thickness of foetal tissue between the maternal blood in the axis and the fotal vessels decreases, till finally there is only a film of trophoblast and the vascular wall. At places the trophoblast even is wanting, and the fotal endothelium alone intervenes between the two blood-streams.

The endothelium of the maternal capillaries frequently ruptures just before it is overtaken by the ectoderm, and irre-

1 Maximow, "Zur Kenntnis des feineren Baues der Kaninchen-Placenta," Arch.f. mikr. Anat., vol. li., 1897. See also ibid., vol. Ivi., 1900. 
gular blood extravasations are formed, and later surrounded by trophoblast: In the deeper layers of the intermediary region, according to Chipman, capillary hæmorrhages occur more slowly, and give rise to a fibrinous tissue with red and white blood corpuscles scattered through it. This is similar to the hæmatogenous symplasma of Bonnet. It gradually increases in amount, and extends to the region of the uterine sinuses.

While the fotal ectoderm advances along the vessels, it remains stationary at the non-vascular parts. Hence there is an interlocking of maternal and fœetal tissues, and peninsulæ of multinucleate cells come to lie between the projections of the trophoblast. At the same time the intermediary region decreases in thickness, and the ectoderm reaches the superficial sinuses of the deeper zone. Here the uninucleate decidual cells again become multinucleate, apparently at the expense of the blood symplasma, in the same manner as formerly at the expense of the glandular symplasma. The sinuses enlarge, and their walls proliferate into several layers of degenerated cells, which after mid-term are gradually replaced by lamina of fibrin.

At a later period the intermediary zone still further decreases in thickness, and the multinucleate cells gradually " melt to form a granular detritus" (Duval). At the end of pregnancy the maternal placenta consists almost entirely of blood and blood symplasma, except for a thin rim of tissue containing blood-sinuses at the zone of separation. The gestation period is thirty days.

As compared with the placenta of Carnivora, it is obvious that the dilatation of maternal vessels is much more marked in the rabbit, and throughout the placenta the maternal blood is in direct contact with the trophoblast, and not only at the border or round a blood-pouch. The blood is not degenerated to a sufficient extent to exhibit the varieties of pigmentation found in the zonary placenta. Chipman does not state whether the maternal blood circulates in the trophoblastic tubes, but Maximow ${ }^{1}$ says that it does. Similarly Duval says: "The maternal blood circulates from the fotal extremity towards the

1 Maximow, “Die ersten Entwicklungsstadien der Kaninchenplacenta," Arch. f. mikr. Anat., vol. Ivi., 1900. 
maternal extremity of a lobule" (i.e. the series of tubules derived from one tube). According to Masius, " ${ }^{1}$ "the maternal blood circulates in an ectodermal mass of fotal origin." Herein lies a great difference between the placentæ of Rodents and Carnivores or Ungulates. In the sheep the main nutriment is furnished by the glands; the maternal blood which is in contact with fœtal ectoderm is stationary and small in amount, and serves chiefly as a supply of iron; the exchange of gases takes place through fotal and maternal tissues. In the dog the gland secretion is less important; the blood is again stationary and restricted to certain situations, and it shows markedly degenerative appearances, but it is greater in amount, and probably furnishes other substances besides iron for the fœtus; in the angioplasmode the maternal blood circulates and here the exchange of gases is effected, but again both maternal and fotal tissues intervene between the two blood-systems. In the rabbit the glandular secretion is still less important after attachment, and even the blind ends do not secrete; throughout the placenta there is normal circulating maternal blood in direct contact with fotal tissues, and it serves both as nutriment and for the exchange of gases. In addition, there are stationary blood extravasations which are engulfed by the trophoblast, but they are subsidiary. Both in the dog and the rabbit there is a marked formation of symplasma which may be connected, as Bonnet suggested for the dog and Maximow for the rabbit, with the slowing of the circulation in the placenta, or may be the result of a trophoblastic influence.

In the placenta of the rabbit there is one other difference which marks it off from the placenta of Carnivores and links it with Insectivores and Man-the connective tissue cells of the mucosa form decidual cells. They assist to an important degree in the preparation of nutriment for the embryo. They exercise a phagocytic action on the neighbouring degenerated maternal tissues, glandular remnants and fibrin, and so attain their greatest development, while at the same time they become store-houses of fotal nutriment. At a later period they degenerate and are absorbed by the trophoblast. Their possible

1 Masius, "De la Genèse du Placenta chez le Lapin," Arch. de. Biol., 1889. 
function as a protection against the attack of the fotal ectoderm has already been mentioned. At the end of pregnancy their defence is no longer required, as the trophoblast has also lost its activity.

Iron Metabolism. - The decidual cells are concerned in the metabolism of iron, fat, and glycogen for the fœtus. In the rabbit, as contrasted with Ruminants, the ingestion of healthy or degenerated erythrocytes probably does not occur. Though Maximow states that they are "present in the plasmodium," they appear to be in the plasmodium only as the isolated peninsulæ of decidual cells are in it, i.e. they lie in spaces surrounded by trophoblast. Whether hæmoglobin as such, or its more immediate derivatives in the form of organic iron compounds are absorbed has not been investigated, but Chipman has shown that inorganic iron compounds are present, and their distribution speaks for their absorption by the trophoblast. The compounds appear as blue-black granules in sections stained with a weak watery solution of hæmatoxylin. At the fourteenth day they are present in the fotal mesoblast, especially where it approaches the decidua. They increase in size and number for a few days and then diminish, but some are still seen at the end of pregnancy. A few granules appear in the trophoblast between the sixteenth and twentieth days (Fig. 103). From the sixteenth day they are also found in an increasing number of the decidual cells which lie close to the foetal placenta; after the twentyfourth day, when the cells degenerate, the granules are no longer discrete, but there are irregular blue-black patches up to the end of pregnancy.

Such isolated data cannot be accurately interpreted. The fact that the deposits in the three tissues are always situated in apposition to each other speaks for their absorption by the fntal tissues; on the other hand, a very small number of granules are present in the trophoblast, and only for a few days. It is possible that oryanic iron compounds, not shown by the hæmatoxylin stain, are absorbed and broken up, and later appear as granules in the mesoderm. Their further course to the fotal liver, in which they are stored, has not been traced. It is to be noted that the iron compounds are not only derived from hæmoglobin. They may also represent degeneration products of the nucleoproteins. 
FOE'TAL, NU'TRITION: THE PLACEN'A 499

Hubrecht ${ }^{1}$ has suggested that erythrocytes may be manufactured in the decidual cells, and their iron-containing granules may thus be utilised (see p. 494).

Fat Metabolism.-Regarding the presence of fat in the

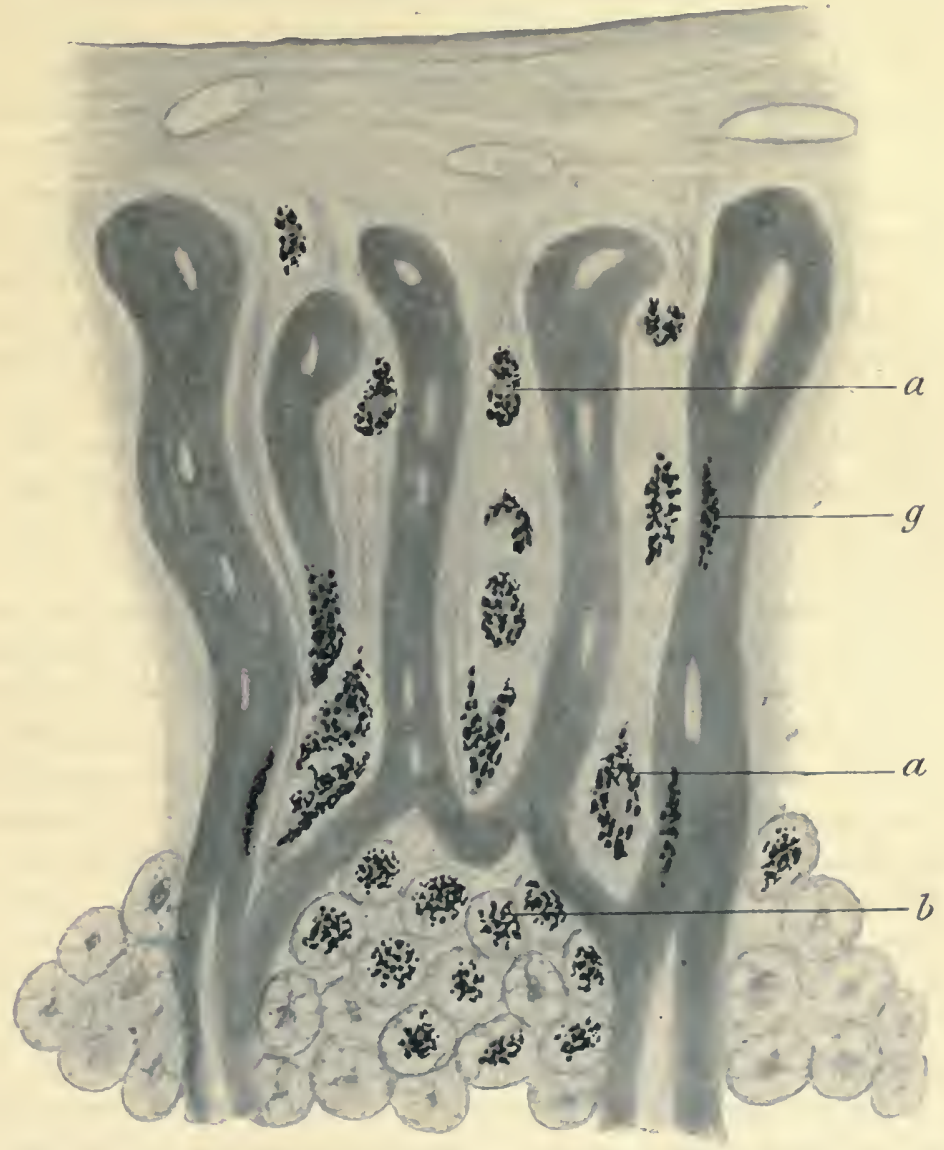

FIG. 103.--Iron granules in the placenta of the rabbit at the eighteenth day of pregnancy. (Chipman.)

$a$, iron granules in mesoblast; $b$, iron granules in multinucleate decidual cells; $g$, iron granules in ectorlermal tubules.

I Hubrecht, "Ueber die Entwicklung der Placenta von Tarsius und Tupaja," Internat. Congr. of Zool., Cambridge, 1898. 
placenta of the rabbit, a few observations have been made by Eden, ${ }^{1}$ Maximow, and Masius. Chipman has investigated the subject in greater detail, but he draws no conclusions from the histological data. In reality, the study of fat in the placenta is rendered difficult by its occurrence both as an infiltration and in the degeneration of cells.

Fat is found in the foetal viscera, liver, heart, and mid-gut, before the allantoic circulation is established. At this time, the tenth day, the vitelline circulation is at its height, and the fat probably reaches the embryo by its vessels, as it is also found in the hypoblast of the area vasculosa. It may be derived from the absorption by the trophoblast of fat-droplets contained in the giant-cells of the peri-placental folds. As the vitelline circulation diminishes, the fat disappears from the embryonic viscera, and does not reappear till four or five days after the establishment of the allantoic circulation. During this interval fat is present in the extra-placental wall of the blastocyst, but it probably arises by a degeneration of its cellular protoplasm.

In the fotal placenta, fat is never found in the mesoblast or capillary walls, but it occurs in the trophoblast, especially where it is in contact with maternal blood or decidua. It increases from the twelfth to the sixteenth day, then it decreases, and a week later disappears altogether. In the maternal placenta fat first appears in the decidual cells which are nearest the trophoblast. They show no sign of degeneration at this time, and they probably secrete the fat globules. After increasing for a few days, it diminishes with the atrophy of the decidual cells, and finally appears as fatty débris. Fat is also present in the proliferating endothelium, and later in the fibrin laminæ of the uterine sinuses.

In the new-born fotus the main store of fat is contained in the subcutaneous tissue. It is remarkable that it does not appear in this situation till the greater part of the fat has disappeared from the placenta. It is either transmitted to the fotus in a form which does not reduce osmic acid, or formed in the fœetus itself from other substances. At birth the fœetal

1 Eden, "The Occurrence of Nutritive Fat in the Human Placenta," Proc. Roy. Soc., London, vol. Ix., 1896. 
viscera, especially the liver, have a considerable store of fat which increases during suckling.

Glycogen Metabolism.-The presence of glycogen in the placenta of the rabbit was discovered by Claude Bernard ${ }^{1}$ in 1859. He showed its increase and subsequent decrease during pregnancy, and concluded from his observations that the placenta carried out for the fœetus, in the first half of intrauterine life, the glycogenic function subsequently assumed by the fœtal liver. Godet ${ }^{2}$ described two areas of glycogen-containing cells, one immediately underlying the fœtal villi, the other in the deeper part of the placenta. Maximow investigated these cells at different stages of pregnancy; he found glycogen in the decidual cells of the vascular sheaths at the eighth day, gradually increasing in amount and playing an important part in the nourishment of the trophoblast. In the later stages glycogen disappeared and the decidual tissue was transformed into polygonal multinucleate cells rich in fat. Chipman recorded detailed observations in a more complete age-series from the eighth day to the end of gestation. He showed that glycogen was always present in the maternal part of the placenta, but never in the fotal. Occurring in the decidual cells of both zones, it increased and reached a maximum between the twelfth and sixteenth days (Fig. 104); then it steadily diminished, and in the last week only a few granules were found scattered in the conglomerate masses of decidual cells. At the zone of separation, however, glycogen granules were still contained in decidual cells. Chipman also examined the fœtal liver. In it he found that glycogen appeared at the twenty-second day, and increased rapidly and steadily in amount till the end of pregnancy.

These results have for the most part been corroborated by chemical analyses carried out by the writer, working in collaboration with Dr. W. Cramer. ${ }^{3}$ They determined quantitatively the glycogen of the maternal placenta, fotal liver, and remainder

1 Bernard, "Sur une nouvelle fonction du placenta," Comp. Rend. Acad. Sci., Paris, 1859.

"Godet, "Recherches sur la structure intime du placenta du lapin," Dissert. Inaug. à la Fac. de Méd. de Berne, Neuveville, 1877.

${ }^{3}$ Lochhead and Cramer, "The Glycogenic Changes in the Placenta and the Fœtus of the Pregnant Rabbit," Proc. Roy. Soc., London, B, vol. 1xxx., 1908. 


\section{2 'THE PHYSIOLOGY OF REPROIUC'IION}

of the foetal body in an age-series of pregnant rabbits from the fourteenth day to the end of pregnancy. The maternal placenta

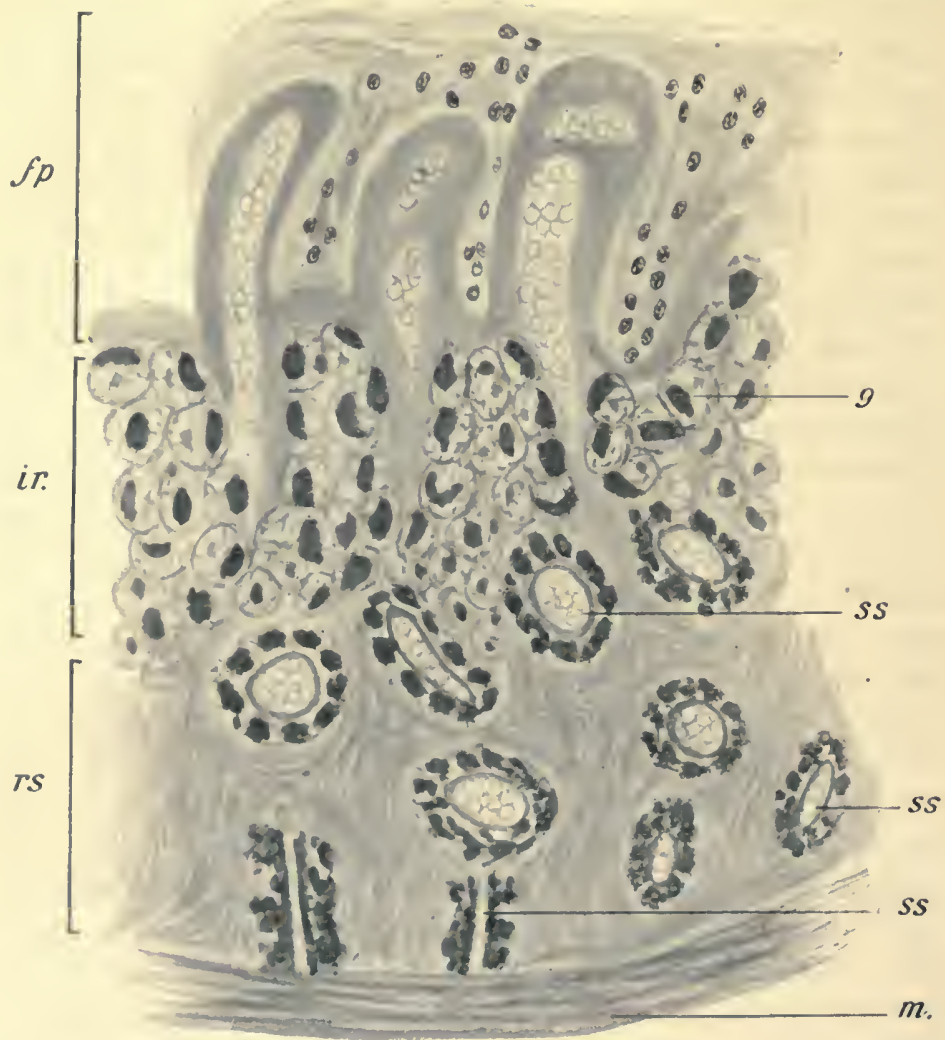

Fig. 104.-Glycogenic areas of the rabbit's pacenta at the twelfth day of pregnancy. (Chipman.)

$f p$, fustal placenta, containing no glycogeu; ir, intermediary region; $r \varepsilon$, region of uterine sinuses; 88 , uterine sinuses with peri ascular sheaths of uninucleate cells rich in glycogen; $g$, glycogen granules in multinucleate cells; $m$, muscular wall immediately above which, at a later date, the zone of separation, containing glycogenic decidual cells, is differentiated.

was separated mechanically from the fotal placenta, and each was investigated separately. The maternal part includes the two glycogenic areas, the region of the uterine sinuses and the 
zone of separation. The fotal part includes the peninsula of decidual tissue which form the intermediary zone; the glycogen contained in it belongs wholly to these peninsulæ and represents the fraction most intimately related to the trophoblast. It may on that account be termed the proximal glycogen, while that of the maternal part is the distal glycogen. On the fourteenth day the distal glycogen forms over 4 per cent. of the weight of the maternal part, and it gradually increases till the eighteenth day, when it forms 5.5 per cent.; it remains nearly constant till the twenty-second day, and then there is a continuous decrease each day till the end of pregnancy. On the day before labour it amounts to slightly over 1 per cent., and practically the whole of it is situated at the zone of separation. This last is probably not destined for the fœetus.

The variations in the proximal glycogen are similar. At the twenty-ninth day there is no glycogen left in the intermediary region.

In the foetal liver traces of glycogen are present at the eighteenth day, though none can be demonstrated histologically till four days later. Up to the twenty-fourth day the percentage gradually increases, but is still very small. Next day it rises for the first time above the glycogen percentage in the rest of the fœetal body, and then there is a rapid increase till, on the twenty-ninth day, half of the fotal glycogen is stored in the liver. Hence it may be concluded that, although the liver contains glycogen in the earlier stages, a change occurs at the twenty-fifth day of pregnancy. Only then does it store more than its proportion of glycogen by weight, and thus may be said to be capable of carrying on the glycogenic function for the foetus. Before that date the only store of glycogen available is contained in the maternal placenta. "The glycogen metabolism of the placenta and fotus shows a regular succession of changes which proceed almost regardless of external conditions, and which are independent to a great extent of the glycogen metabolism of the mother" (Lochhead and Cramer).

There can be little doubt that the glycogen stored in the decidual cells is absorbed by the trophoblast. It is situated in the maternal peninsulæ which are surrounded by fotal tissue, and it gradually decreases in amount while it increases in the 


\section{THE PHYSIOLOGY OF REPRODUCTION}

fotus. That none can be demonstrated in the trophoblast may be due to a transformation into sugar before it is absorbed. Glycerine extracts of both the maternal and the fœtal part of the placenta possess an enzyme which has a powerful hydrolytic action on glycogen. On the other hand, the enzyme action is markedly weaker, or absent altogether, in the placentæ of Ruminants, in which the glycogenic changes are known to be insignificant.

It is not easy to determine why such a complex mechanism is necessary if, as is stated by Cohnstein and Zuntz, ${ }^{1}$ glucose passes from the maternal to the fotal circulation by diffusion. But these investigators have only proved that it diffuses when a hyperglycæmia exists in the mother. Under similar conditions glucose passes into the urine and liquor amnii in Man, but it does not pass normally. ${ }^{2}$ Hence it has not been proved that the sugar of the maternal blood is diffused unchanged through the trophoblast. It is more probable that the transference of sugar is not effected by a purely physical process, since the serum of the fotal rabbit contains lævulose, while the serum of the mother has none (Paton, Kerr, and Watson ${ }^{3}$ ).

Between the glycogen metabolism and the growth of the fotus there is a distinct relationship, which probably depends directly on the uses to which glycogen is put. Part of it is accounted for by the intense carbohydrate metabolism which proceeds in the fotus (Bohr ${ }^{4}$ ). The glycogen, which is thus katabolised, furnishes thereby the energy necessary for the formation of new tissues, the "Entwicklungsarbeit" of Tangl. The question arises whether glycogen also performs anabolic

1 Cohnstein and Zuntz, "Weitere Untersuchungen zur Physiologie der Säugetierfötus," Pflüger's Arch., vol. xlii., 1888.

2 Even in the hyperglycæmia of diabetes the figures do not support the theory of the mere diffusion of glucose. Offergeld found 0.8 per cent. of sugar in the maternal blood, and $2 \cdot 2$ per cent. in the foetal blood in diabetic coma ("Ueber das Vorkommen von Kohlehydraten im Fruchtwasser bei Diabetes," Zeit.f. Geb. u. Gynäk., vol. li.).

3 Paton, Kerr, and Watson (B. P.), "On the Source of the Amniotic and Allantoic Fluids in Mammals," Trans. Roy. Soc. Edinburgh, vol. xlvi., 1907.

" Bohr, "Die respiratorische Stoff wechsel des Säugetierembryos," Skand. Arch. f. Phys., vol. x., 1900. See also vol. xv., 1904.

"Tangl, "Beiträge zur Energetik der Ontogenese," Pfüger's Arch., vol. xciii., 1903. 
functions in the development of the fœtus. "The absence of glycogen from some of the growing fotal tissues, and the fact that many of the tissues in which it is present do not contain even as much as the adult ones, leave little doubt that a definite formative power cannot be attributed to glycogen as such. On the other hand, the scarcity of glycogen in embryonic tissues does not necessarily justify the conclusion that glycogen does not take part in the building up of the tissues. It is well known that embryonic tissues are rich in mucin, which contains a large amount of a carbohydrate group in its molecule. Although glycogen as such has no formative power, it may yield one of the "Bausteine" for the building up of the main protein body of fœtal tissues. In this connection it is interesting to consider the conditions in the hen's egg, which contains in itself the material of which the embryo is built up. ${ }^{1}$ In the ovum carbohydrate as such is practically absent. At the same time all the protein substances of the white of egg are distinguished by the presence of a large amount of glucosamine in their molecule. Here the carbohydrate group has entered into the protein molecule, and correspondingly there is a scarcity of free carbohydrate." 2

Protein Metabolism.-In so far as the influence of the trophoblast on proteins has been investigated in the placenta of the rabbit, it may be considered here. It is generally accepted that colloid substances with large molecules, which are not adapted for diffusion, require a preliminary transformation, by which the size of the molecules is decreased before they can be taken up by the fœtal ectoderm. But the actual observations are against such a general statement. In the sheep the trophoblast can absorb not only hæmoglobin, a colloid, without any preliminary transformation, but even enormously larger masses of protoplasm in the form of cells. On the other hand, such hydrolysed products of albumen as albumoses and peptone are not present in the fresh placenta, nor can any extra-cellular proteolytic enzyme be extracted. ${ }^{3}$ Hence there is no evidence of a placental

1 Compare Emrys-Roberts, "A Further Note on the Nutrition of the Early Embryo, with Special Reference to the Chick," Proc. Roy. Soc., London, B., vol. lxxx., 1908.

2 Lochhead and Cramer, loc. cit.

3 Lochhead, "On the Transmission of Nitrogenous Compounds from Mother to Fœtus," Trans. Obstet. Soc., Edinburgh, vol. xxxiii., 1907-8. 
digestion of proteins before their absorption by the trophoblast. Further it has been shown, by means of the precipitin reaction, that if egg-albumen is injected into the mother some of it passes unchanged to the foetus $\left(A\right.$ scoli $^{1}$ ). On the other hand, the proteins of ox-serum cannot be recognised in the foetal blood, even when a considerable quantity is injected. ${ }^{2}$ The reason appears to be that the proteins of ox-serum resemble more closely the normal serum proteins of the rabbit and are metabolised by the trophoblast, while egg-albumen cannot be utilised, and is passed on to the foetal circulation unchanged. Hence it is probable that the normal proteins of the serum are also transformed by the trophoblast into a form suitable for the fotus. The exact nature of the transformation is unknown, but it is not comparable with the hydrolytic processes which occur in the intestine.

Respiration.-According to Bohr, ${ }^{3}$ the fotal rabbit absorbs slightly more oxygen and gives off slightly more carbonic acid per kilogram per hour than the mother. Hence the intensity of the metabolic reactions is slightly greater in fotal life. This is directly opposed to the views held by Pflüger on theoretical grounds, and by Cohnstein and Zuntz ${ }^{4}$ from their experimental results. The second result of Bohr's experiments has been already mentioned, viz. that in that part of the metabolism which is evidenced by the respiratory exchange, the encrgy arises from carbohydrates. He supposes that the energy liberated by the combustions, which in the adult is dissipated largely under the form of heat radiated and water evaporated from the surface of the body, is in the fotus used for the increase and maintenance of the newly formed tissues; in other words, "the reactions of synthesis, which are so numerous during development, are endothermic or heat-absorbing, and they borrow the heat from other simultaneous exothermic actions," ${ }^{5}$ in this case the oxidation of carbohydrates.

1 Ascoli, "Passiert Eiweiss die placentare Scheidewand?" Zeit.f. phys. Chem., vol, xxxvi., 1902. This has been confirmed by the writer and Dr. W. Cramer (see reference, note ${ }^{3}$, p. 435 ).

2 Lochliead, loc. cit.

3 Bohr, loc. cit.

- Cohnstein and Zuntz, "Untersuchungen über das Blut, den Kreislauf und die Atmung der Säugetierfötus," Pfïger's Arch., vol. xxxiv., 1884.

"See Richet's Dictionnaire de Physiologie, vol. vi., Article "Fœus." 
Mouse.-The fertilised ova of the mouse reach the uterine cavity on the third day, and segmentation is completed one day later. The zona pellucida has by this time disappeared, and fixation of the ovum to the uterus can be quickly attained. Each blastocyst comes to rest in an anti-mesometrial groove. At first spherical, it becomes ovoid on the sixth day, with the long axis perpendicular to the long axis of the uterus. One pole is turned towards the mesometrium and is composed of several layers of cells, while the opposite pole is single-layered. It is nourished by the glandular secretion, and perhaps also by a transudate, in which, however, leucocytes are not present.

The connective tissue of the mucosa shows a thickening at the point where a blastocyst rests. The epithelium degenerates as the result of contact with the fœtal ectoderm (Duval ${ }^{\mathbf{1}}$ ), or of pressure by the proliferated connective tissue cells which interferes with the nutrition of the epithelium (Burckhard ${ }^{2}$ ). More probably it is not mechanical, as the change begins first at the mouth of the groove, i.e. at the point of first contact with the ovum (Kolster $\left.{ }^{3}\right)$. In the cells the chromatin clumps on the inner surface of the nuclear membrane, the cell boundaries disappear, and a symplasma is formed which later becomes broken up into nuclear and cellular fragments. Fat globules, which are present in the epithelium of the non-pregnant uterus, are found in the detritus and also in the fœtal ectoderm.

With the destruction of the epithelium appears the first sign of decidual formation. The connective tissue cells increase in size and displace the glands; the capillaries ${ }^{\overline{2}}$ dilate irregularly, and at places form sinuses.

On the sixth day, the ectoplacental cone is formed by a proliferation of the ectoderm at the mesometrial pole of the blastocyst. It plugs the opening between the crypt and the lumen of the uterus. At the same time the lips of the crypt are gradually brought nearer to each other by the swelling of the tissues, and at the end of the seventh day they fuse and cover

1 Duval, "Le Placenta des Rongeurs," Journ. de l'Anat. et de la Phys., 1891.

" Burckbard, "Die Implantation des Eies der Maus in die Uterinschleimhaut," Arch. f. mikr. Anat., vol. lvii., 1901.

${ }^{3}$ Kolster, "Zur Kenntnis der Embryotrophe beim Vorhandensein einer Decidua Capsularis," Anat. Hefte, vol, xxii. 


\section{THE PHYSIOLOGY OF REPRODUCIION}

the ectoplacenta. In this way the ovum is completely shut off in a decidual cavity, the "Eikammer," from the uterine lumen. The roof of the chamber forms the primary decidua reflexa, and it is gradually thickened by a decidual deposit. In it new blood-vessels are developed, and they form a specially rich vascular network.

By this time the blastocyst has become tubular in shape,

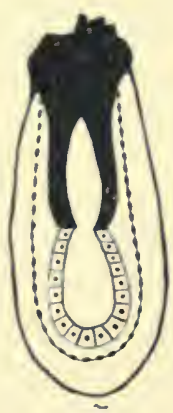

FIG. 105.-Inversion of the germinal layers in the blastodermic vesicle of the mouse. The trophoblast becomes greatly thickened and invaginated, pushing the formative epiblast before it. The whole blastocyst assumes a tubular shape, and the hypoblast appears to be external to the epiblast. Trophoblast represented by continuous black lines or masses: entoderm by interrupted lines: embryonic ectoderm by epithelial cells. (T. H. Bryce, in Quain's Anatomy, Longmans.) and it shows an inversion of the germinal layers (Fig. 105). In the earlier stage a cavity appears in the inner mass of cells. The roof of the cavity becomes thickened to form the "Träger" or ecto-placental cone, which is at first cylindrical and later conical, with its base resting on the mesometrial pole of the ovum. By its inward growth, it shoves before it the floor of the inner mass consisting of epiblast and hypoblast. In this way an invagination is produced in the tube with the epiblast internal to the hypoblast. Hence the germinal layers are said to be inverted.

Blood is regularly found in the implantation cavity. It completely surrounds the ovum, and reaches irregular spaces in the ectoplacenta which communicate with the surface. At this time, however, there are no foctal vessels near the cone, and the blood in its meshes may be of use only for its own nutrition. On the other hand, the thin trophoblast of the wall of the invaginated yolk-sac is partly vascularised by vitelline vessels, by means of which the nutriment absorbed from the blood effusion may reach the embryo, or be stored in the yolk-sac. In the trophoblast itself the hæmoglobin of laked corpuscles and its derivatives are 
present (Jenkinson ${ }^{1}$ ), and the contents of the umbilical vesicle are " not yolk, but another nutritive substance which the ovum, in the absence of yolk, takes from the maternal tissues, viz. hæmoglobin" (Sobotta ${ }^{2}$ ).

The decidual cavity is at first small and ovoid, and has a thick wall. As it grows, the lumen of the uterus is obliterated, and at its point of contact with the mesometrial wall the epithelium of the latter disappears. Thereafter the two layers fuse, and at the point of fusion the placenta is developed. The lumen of the uterus is later re-established, as in the guinea-pig (see Fig. 110), at the floor of the decidual cavity. Hence the primary decidua reflexa forms the serotina, and a secondary reflexa is formed, which is recognisable till the twentieth day of pregnancy.

The increase in size of the implantation cavity is accompanied by a thinning of its wall. According to Duval this is a mechanical process, since the cells do not increase in number, but it is probably more complicated. On the inner surface of the decidua giant-cells appear around the ovum, and they are phagocytic (Fig. 106). Duval stated that each was derived from a cell of the fotal ectodermal wall of the yolk-sac, and later from a cell of the ectoplacental cone. As they increase in number, they form a distinct layer, two to five cells in depth, between the yolk-sac and the wall of the implantation cavity, and some wander into the decidua and lie singly or in groups. In their interior degenerating leucocytes are frequently seen. Sobotta also stated that they were foetal in origin, and helped to fix the ovum and erode maternal capillaries. More recently Kolster has brought forward evidence from their histological appearance that they are transformed decidual cells, and this is strongly supported by Disse's investigations on the field-mouse, ${ }^{3}$ in which the giant-cells are found before the ovum has become embedded, and the first to appear are at an appreciable distance beneath the surface epithelium. A second series of

1 Jenkinson, "Observations on the Histology and Physiology of the Placenta of the Mouse," Tijd. Nederl. Dierk., Ver. ii., Dl. vii. 1903.

"Sobotta, "Die Entwicklung der Maus," Arch. f. mikr. Anat., vol. Ixi.,

${ }^{3}$ Disse, "Die Vergrösserung der Eikammer bei der Feldmaus," Arch.f. mikr. Anat., vol. lxviii., 1906. 
smaller size appears later in the lumen and wall of the implantation cavity. Jenkinson also recognised two groups, but assigned

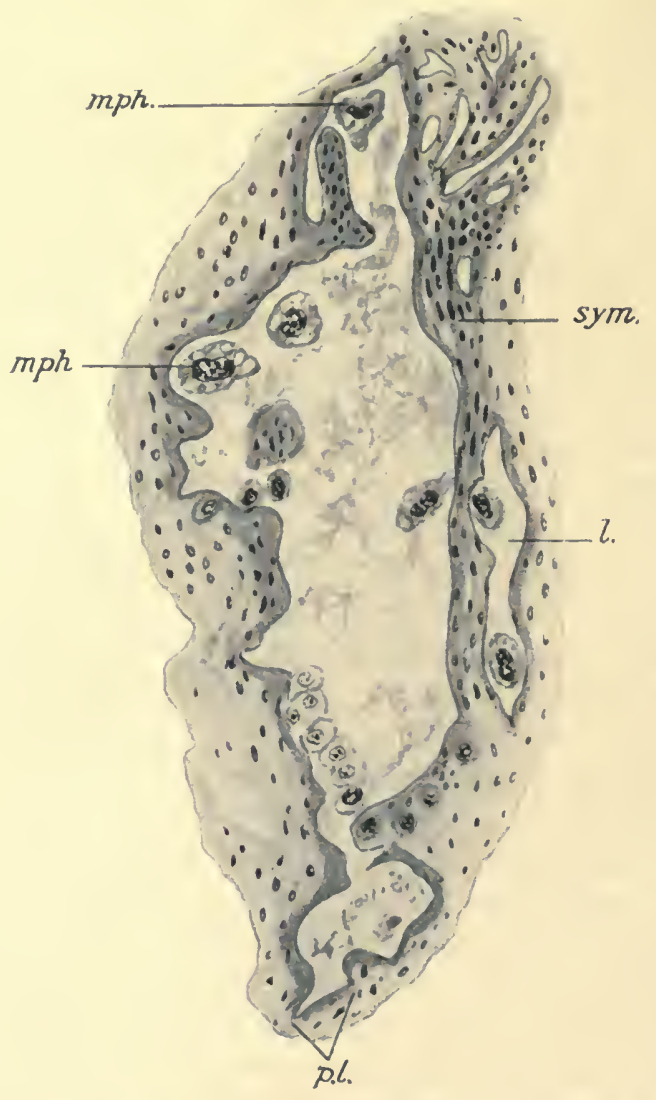

FIG. 106.-Longitudinal section of the implantation cavity of the fieldmouse about the eighth day of pregnancy. (From Disse's "Die Vergrösserung der Fikammer bei der Feldmaus (Arvicola arvalis)," Arch. f. mikr. Anat, vol. Ixviii., 1906.)

$p . l .$, placental pole; $m p h$, macrophages or giant-cells ; sym, uterine symplasma; $l$, blood lacuna.

to them different origins, foetal in the "Eikammer" and maternal in the decidua.

All authorities agree that they are phagocytic. The tissue 
around them undergoes fatty degeneration, and in their interior may be seen remnants of connective tissue and endothehial cells and fat-globules. Many capillaries are ruptured, and red and white blood corpuscles are also absorbed. Such an absorption of maternal tissue by the giant-cells leads to an increase in the size of the implantation cavity and a thimning of its wall (Disse). In spite of their abundant supply of nutriment, their life-history is short. No celldivisions occur, and soon they degenerate. Their contents are absorbed by the trophoblast, and their protoplasm shrinks to form a rim around the nucleus. Later still their remnants are also absorbed.

The allantois in the mouse is a solid mass of mesoderm with no entodermal cavity. Growing out from the posterior end of the embryo, it projects into the extra-embryonic cœlom, and on the eleventh day fuses with the mesoblast of the ectoplacental cone. After this the ovum again becomes spherical. The circulation in the decidua reflexa diminishes, and gradually more and more of the nutriment is conveyed to the embryo by the allantoic vessels. At the same time the allantoic trophoblast increases in thickness, and its lacunæ become more numerous and complicated. Into its mass, in which the circulation of maternal blood is now established, the vascular mesoblast projects at intervals, and breaks it up into segments. The glands take no part in the formation of the placenta. Their ducts do not even act as guides to the advancing edge of the trophoblast, as in the rabbit. They are completely displaced by the rapid formation of decidual tissue, and their remnants are absorbed by the giant-cells. Hence the embryotrophe contains no glandular secretion.

At this time the nutritional conditions are essentially the same as in the rabbit. The trophoblast shows two layers, plasmodiblast and cytoblast, which intervene, along with mesoblastic cells and the walls of the villous capillaries, between the two blood-streams. The subsequent changes are all in the way of producing an increased surface of contact with maternal blood, and lessening the thickness of tissue between it and the fœetal circulation.

In the mouse the decidual cells contain glycogen. According 


\section{THE PHYSIOLOGY OF REPRODUCTION}

to Driessen, ${ }^{1}$ its distribution in the placenta of the white mouse before mid-term is the same as in the rabbit. It is in great abundance in the decidual cells, especially in the boundary layer between the maternal and fotal tissues. No glycogen is found in the maternal endothelium, or in the fotal placenta. Jenkinson ${ }^{2}$ has studied the distribution of glycogen throughout the whole period of gestation in the mouse. It appears first in the cells which overlie the ectoplacenta, and increases in amount till the twelfth day, when the mesoblastic processes are just beginning to project into the trophoblast. Then the decidual cells are disintegrated and the glycogen granules are mixed with the detritus. Hence the life-history of the maternal glycogenic tissue is shorter than in the rabbit. But in the mouse glycogen again makes its appearance in the trophoblast which is most directly in contact with the maternal blood, i.e. the part not penetrated by the allantoic capillaries. It lies in oblong ectodermal cells, which gradually encroach on and occupy the space previously occupied by the maternal glycogenic cells down to the muscularis. Here the glycogen remains till the end of gestation. ${ }^{3}$

According to Kolster, a considerable amount of fat appears in the decidua, in which the connective tissue and endothelial cells undergo a fatty degeneration in the proximity of the giant cells. No observations have been made regarding the metabolism of iron-containing substances.

Guinea-Pig.-In the guinea-pig the ovum is again completely surrounded by decidua. Reichert ${ }^{4}$ was the first to notice that the ovum lay in a special cavity, "a little nest." Bischoff ${ }^{5}$ stated that the nest was only temporary, and the ovum again appeared in the uterine cavity, only that part of the 1907.

1 Driessen, "Ueber Glykogen in der Placenta," Arch.f. Gynäk., vol. lxxxii.,

2 Jenkinson, loc. cit. See also Brit. Med. Jour., 1904.

${ }^{3}$ Whether the differences in the distribution of the placental glycogen in the rabbit and the mouse during the later stages of pregnancy exist in reality, or depend only on differences of interpretation, requires further investigation.

" Reichert, "Ueber die Bildung der hinfälligen Häute der Gebärmutter," Müller's Arch., 1848.

Bischoff, Entwicklung des Meerschweinchens, 1852. 
nest remaining which formed the placenta. After a long interval this was proved to be wrong by Reichert ${ }^{1}$ and Hensen. ${ }^{2}$

The fertilised ovum reaches the uterus as a morula or early blastocyst, surrounded by the zona radiata. On the seventh day the zona disappears and embedding begins, but even before this, according to von Spee, ${ }^{3}$ the ovum is fixed by processes which extend from the cells of the implantation pole through the zona and come into direct metabolic relationship with the epithelial cells. As in the mouse, the blastocyst remains small,

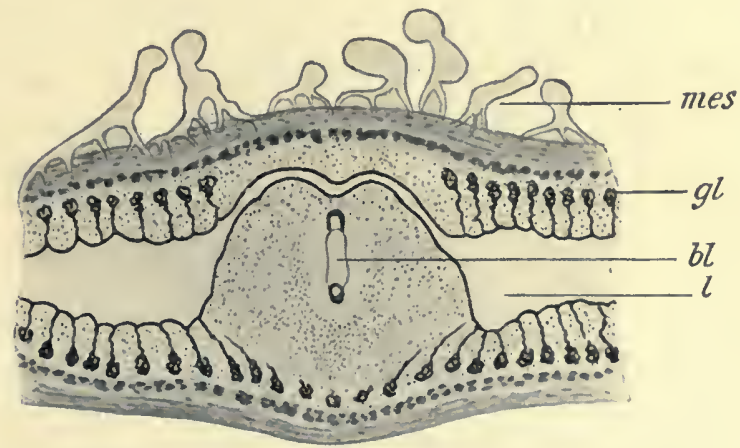

FIG. 107.-Longitudinal section of the uterus and implantation cavity of the guinea-pig. (From Duval's "Le Placenta des Rongeurs," Journ, de l'Anat. et de la Phys., 1892.)

$m e s$, mesometrial border ; $g l$, uterine glands ; $l$, uterine lumen ; $b l$, blastodermic vesicle.

about one-tenth of a millimetre in diameter. At its point of contact with the mucosa, the epithelium is rapidly eroded, and absorbed along with its fat globules by the fotal ectoderm. At the same time changes occur in the deeper layers. In the nonpregnant uterus two layers are present, a sub-epithelial layer of embryonic connective tissue cells interrupted only by capillaries and glands, and a deeper, more reticulate layer. Before the ninth day of pregnancy, no very marked changes occur in the

1 Reichert, "Beiträge zur Entwicklungsgeschichte des Meersch weinchens," Abhandl. d. Akad. d. Wissensch. zu Berlin, 1861.

2 Hensen, "Beobachtungen über die Befruchtung und Entwicklung des Kaninchens und Meerschweinchens," Zeit. f. Anat. u. Entwick., vol, i., 1866.

${ }^{3}$ Von Spee, "Die Implantation des Meerscliweincheneies in die Uterus. wand," Zeit. f. Morphol. u. Anthropol., vol. iii., 1901. 
mucosa. Some of the cells show mitoses, the blood-vessels are full, and a few red blood corpuscles may lie between the cells, and also in the fnetal ectoderm. During the penetration of the epithelium by the trophoblast, some of the superficial connective tissue cells enlarge. Their nuclei stain more deeply, and the protoplasm of adjacent cells fuses to form a symplasma. The degenerated tissue in its immediate neighbourhood is absorbed

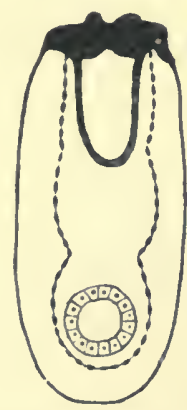

FIG. 108.-Blastodermic vesicle of the guinea-pig, showing inversion of the germinal layers. The blastocyst is tubular, and the formative cell-mass is invaginated as in the mouse, but the thickened trophoblast is not invaginated to so great an extent as in Fig. 105, and the conuection between them is lost. Hence the roof of the amnio-embryonic cavity is independent of the trophoblast. ('T. H. Bryce in Quain's Anatomy, Longmans.)

by the ectoderm, and the blastocyst thus comes to lie in the substance of the mucosa (Fig. 107). According to von Spee, the destruction of uterine tissue is effected entirely by a biochemical process; there is no evidence of absorption of formed elements by phagocytosis.

Round the periphery of the necrotic zone lies a thick layer of large foetal cells, the two together forming the "Implantationshof." Later the symplasma degenerates further. The nuclei shrink and lose their chromatin, and the protoplasn becomes fibrillated and granular. Vacuolations appear in the mass, and coalesce to form a space round the ovum filled with clear fluid. In this way the implantation cavity is excavated till it is limited externally by the large cells. Outside it the decidual cells around the vessels survive, while the rest are transformed to a symplasma and absorbed. Hence the wall is sinuous. The dips are, however, filled up in part by newly formed tissue resembling granulation tissue. It encapsules the necrotic zone, and may be looked on, as in the rabbit, as a defence against the advancing ectoderm (see p. 369).

By this time the ovum has become tubular, with its long axis perpendicular to the long axis of the uterus. It exhibits, 
as in the mouse, an inversion of the germinal layers, but in the guinea-pig the amnio-embryonic vesicle is closed and separates the thickened trophoblast from the embryonic ectoderm (Fig. 108). With the growth of the blastodermic vesicle, the roof of the implantation cavity projects into the lumen of the uterus, and in time obliterates it by coming in contact and fusing, at the tenth day, with the mesometrial mucosa (Fig. 109). Here also the cellular tissue has developed at the expense of the glands, and the surface epithelium disappears. At the fifteenth

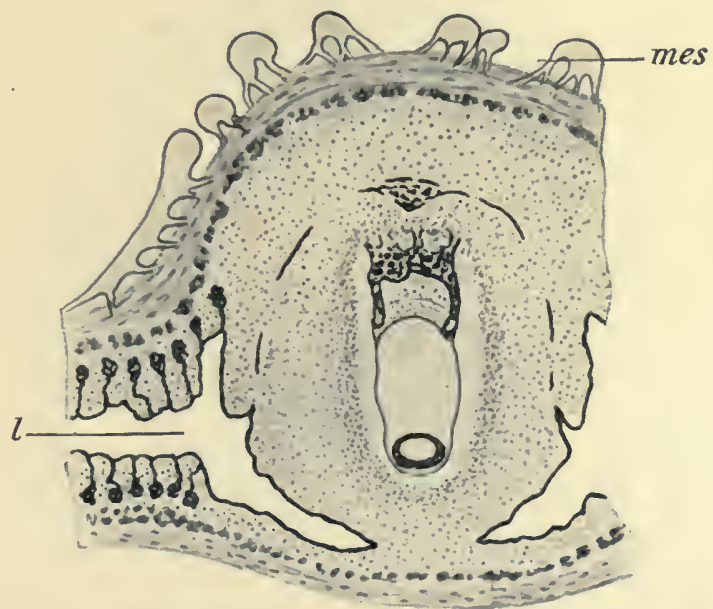

FIG. 109.-Implantation cavity of the guinea-pig. (Duval.) mes, mesometrial border; $l$, nterine lumen.

day the lumen reappears anti-mesometrially (Fig. 110). Thus a secondary decidua reflexa arises which rapidly thins and becomes vacuolated in its inner half by a loss of tissue. The cause of the tissue excavation is uncertain; it may be brought about by the large cells which, according to von Spee, are fœetal and form a third layer of the trophoblast outside the plasmodiblast, and the disintegrated products are probably absorbed by the ovum. At the same time the vessels which penetrate the necrotic zone are opened, and blood is effused into the implantation cavity.

The placenta develops, as in the mouse, mesometrially. The 
allantois consists of a tubular passage in the body wall and a solid extra-embryonic stalk of mesoderm. It projects into the cœlom and gradually extends, and becomes applied to the mesoblast underlying the thickened part of the trophoblast, in the spaces of which a circulation of maternal blood is established. The trophoblast continues to attack and absorb maternal tissue and blood, and to advance more deeply into the decidua, while at the same time it is penetrated on the embryonic side by out-

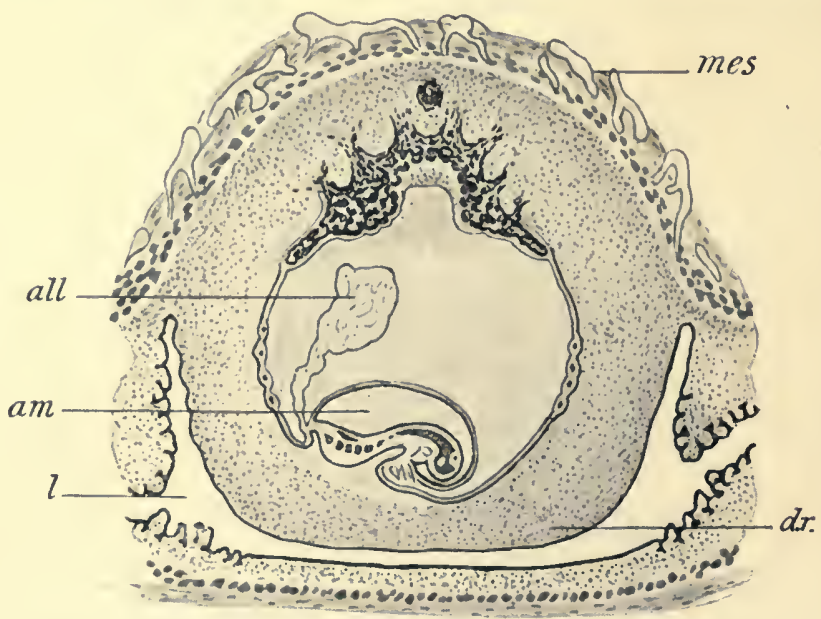

FIG. 110.--Implantation cavity of the guinea-pig. (Duval.)

mes, mesometrial (placental) border ; $l$, lumen of uterus, re-established antimesometrially ; d.r., decidua reflexa ; all, allantois : am, amnion.

growths of mesoblast containing branches of the allantoic vessels. The tissues intervening between the maternal and fœtal blood-streams are entirely fœtal; they gradually thin with the progress of gestation and the continued branching of the mesodermal villi.

Glycogen is contained in the decidual cells, but its variations have not yet been investigated. It is of interest historically that oxyhæmoglobin was demonstrated first in the umbilical vein of a foetal guinea-pig by Schmidt. ${ }^{1}$ The amounts of oxygen

'Schmidt, "Sauerstoffhämoglobin in Fötusherzblut," Cent. f. d. med. Wis8., 1874, No. xlvi. 
absorbed and carbonic dioxide excreted are the same, weight for weight, as in the foetal rabbit (Bohr).

INSECTIVORA.-The importance ascribed to the placentation in Insectivora has already been referred to (see p. 377). The hedgehog, shrew, mole, and Tupaia have been most fully investigated.

Hedgehog.-In the hedgehog (Erinaceus europaus), the zona pellucida disappears early, before the expansion of the hypoblast, which, as in Man, forms a closed vesicle. The chronology of embedding is not yet known. In the earliest stage examined by Hubrecht, ${ }^{1}$ the blastocyst was 0.22 of a millimetre in diameter. The outer wall was several layers thick all round its circumference, and spaces were already present in it. At a slightly later stage, the blastocyst grows rapidly and the epiblast is reduced to a single layer, with numerous villiform processes at intervals, except for a thickened knob which represents the future germinal area. Even now the name trophoblast may be given to the single layer of epiblast with its projections, excluding the thickened knob which is formative and gives rise to the embryonic ectoderm and the lining of the amniotic cavity. The mesoblast, as yet one-layered, which extends between the trophoblast and hypoblast, consists of an attenuated somatic part which forms with the trophoblast the diplo-trophoblast, ${ }^{2}$ and a splanchnic part which forms blood-vessels and blood.

The early blastocyst comes to rest, as in the mouse, in an anti-mesometrial furrow of the mucosa. It is not yet determined whether any changes occur previously in the uterus; but at least, soon after the blastocyst has taken up its position, there is a great cell-proliferation in the stroma of the floor and walls of the furrow, not perivascular as in the rabbit, but subepithelial. Along with this decidual formation, the lumina of the glands are closed, and their epithelium gradually disappears, perhaps by the influence of the trophoblast. The capillaries are distended and new vessels are formed. This distension is at

I Hubrecht, "The Placentation of Erinaceus europceus," Quar. Jour. Micr. Sci., vol. xxx., 1889.

${ }^{2}$ Hubrecht restricts the term chorion to Tarsius (a lemur), monkeys, apes, and Man. 


\section{THE PHYSIOLOGY OF REPRODUCTION}

first most marked in the lips and sides of the groove, and small superficial hæmorrhages occur, which detach the epithelium at places. The tissue fluids also exude, and, along with the blood and desquamated epithelium, form a coagulum around the ovum. Part of it shuts off the entrance of the furrow from the uterine cavity.

The epithelium of the crypt, after a preliminary proliferation such as Robinson describes in the mouse and rat, degenerates

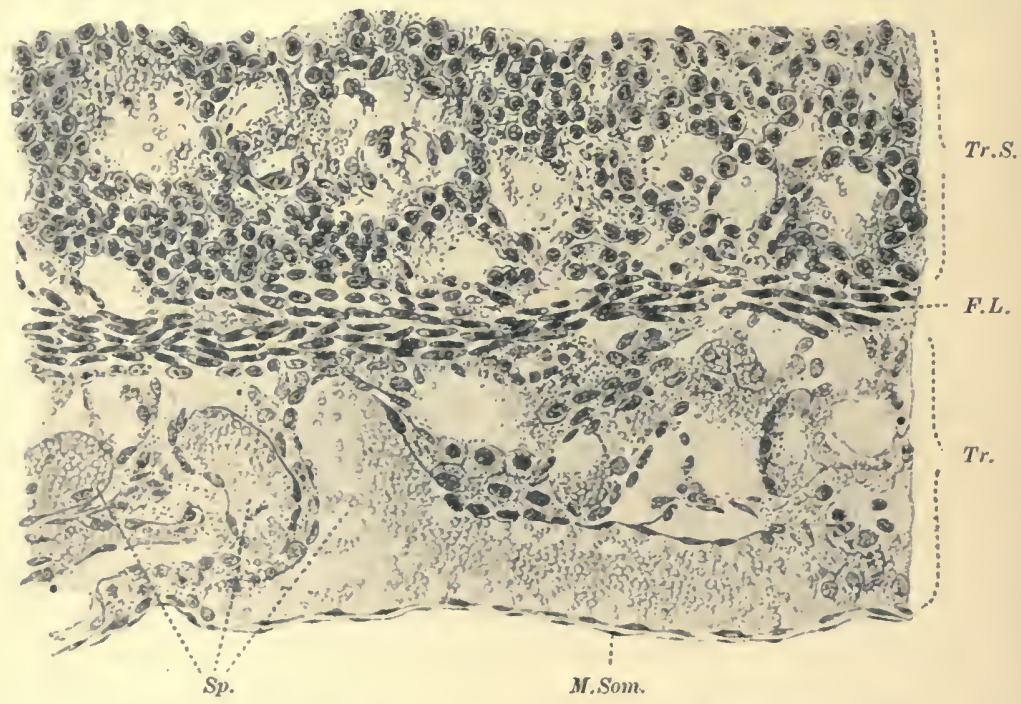

FiG. 111.-The allantoidean diplo-trophoblast of Erinaceus. (From Hubrecht's "The Placentation of Erinaceus europaus," Quar. Jour. Micr. Sci, vol. xxx., 1889.)

Tr.S., trophospongia; $T r$. , trophoblast; $F . L$. , layer of fusiform cells ; Sp., spaces in trophoblast; M.Som., thin layer of somatic mesoblast.

entirely, part being stripped off by extravasated blood and part yielding to the influence of the foetal ectoderm. Its remnants and the other constituents of the coagulum probably furnish pabulum for the ovum. The development of the decidua proceeds rapidly, and the swollen lips of the groove fuse together to complete the implantation cavity. The trophoblast is now in contact with decidual tissue, of which the innermost zone consists of a stratified layer of fusiform cells, best marked in the 
allantoic region (Fig. 111). Whether they are maternal or fœetal in origin is not yet determined. They persist for a time, but disappear when the endothelial proliferation occurs. Around the groove, the tissue becomes looser by an increase in the size of the newly formed blood-spaces. The endothelium lining them is swollen and deep, and the cells bulge into the lumen. Near the ovum the endothelium proliferates and forms an enormous cell-mass, the trophospongia, ${ }^{1}$ interposed between the blastocyst and the unaltered decidua. The trophoblast with its lacunæ, and the trophospongia with large blood-sinuses together form the trophosphere, which, along with the maternal blood, represents an effective nutritional arrangement for the embryo before the vitelline or allantoic circulation is established (Fig. 112). Many of the blood-spaces are ruptured, and the blood pours out into the lacunæ of the trophoblast, and circulates through them before returning into the maternal veins. At this stage the trophospongia is separated from the external decidua by rows of fusiform cells.

As in the mouse, in which, however, the trophospongia is derived from connective tissue cells instead of endothelium, giant-cells appear. They lie between the trophospongia and the fusiform cells, and they are first seen at the time of the appearance of the embryonic mesoblast. In their interior are contained fragments of red blood corpuscles and decidual cells. Hence they are called deciduofracts by Hubrecht (Fig. 113). Externally the circular layers of fusiform cells form sheaths round some of the endothelium-lined vessels. The line of union between the giant-cells and the external decidua is irregular, and the decidual tissue is fibrillar and reticulate. These appearances indicate an erosion and absorption of the maternal tissue. The deciduofracts are probably derived from the maternal trophospongia (Hubrecht ${ }^{2}$ ). After a short life-history they dwindle and are themselves absorbed.

1 "The trophospongia is a maternal cell-proliferation specially intended for the fixation of the blastocyst. It shows a different histological evolution in different genera" (Hubrecht).

2 Hubrecht now considers that the deciduofracts are of fotal origin, and represent the outermost layer of the trophoblast. See p. 470, footnote. Also compare Graf v. Spee's description of the trophoblast of the guinea-pig (see p. 444), and Bryce and Teacher's of that of Man (see p. 469). 
With the changes in the mucosa, changes also take place in the trophoblast. After the thinning already mentioned, its cells increase in number. They grow in strands, leaving spaces between them like the meshes of a net, and in the spaces maternal blood circulates. In this respect the hedgehog differs

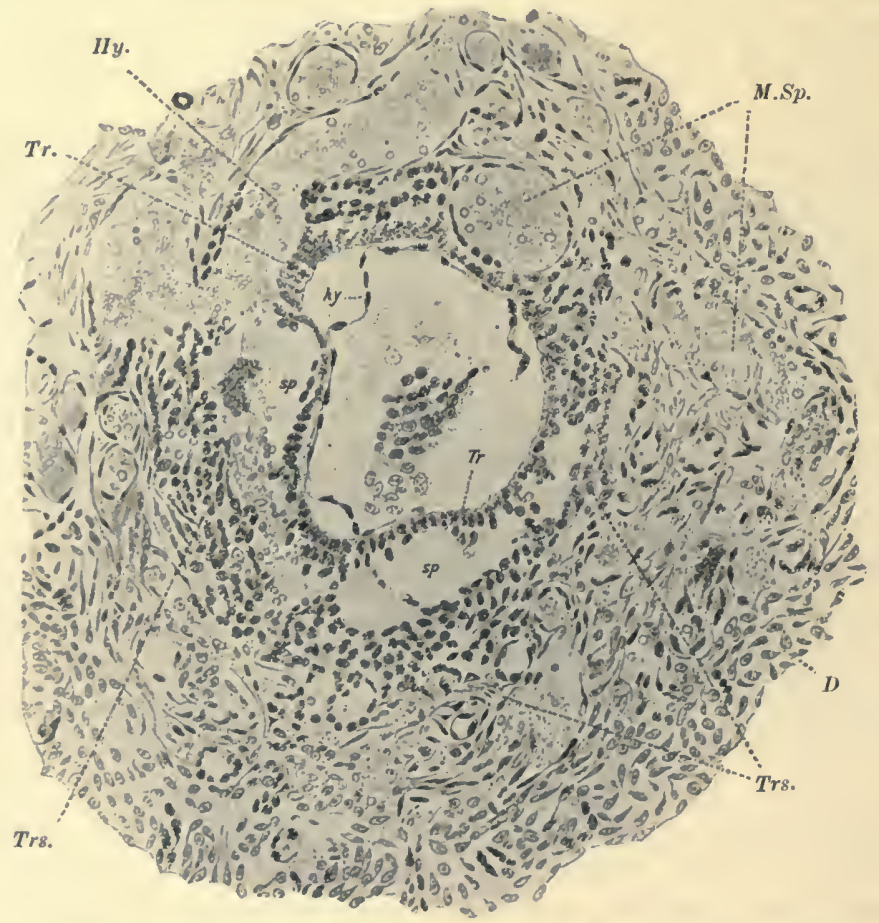

FIG. 112.-Section in situ of the ovum of Erinaceus (Hubrecht).

$H y$., hypoblast; $T r$., trophoblast ; $s p$., spaces in the trophoblast, communicating with the maternal blood-spaces $(M . S p$. $) ; D$., decidua ; Trs., trophospongia.

from the Rodents, in which the proliferation of the trophoblast is confined to the allantoic region. In the hedgehog the proliferation occurs even in the omphaloidean region, which is vascularised by the area vasculosa. Here the vacuolated trophoblast is gradually interlocked with vascular processes of the mesoblast, and yolk-villi, containing branches of the vitelline vessels, are developed. The omphaloidean placenta thus 


\section{THE PHYSIOLOGY OF REPIROUCTION}

it retains its thickness later in pregnancy. The deciduofracts remain distinct to the end, though they partly degenerate. Hence it is probable that during the whole, or nearly the whole, of pregnancy they exercise a phagocytic action on the maternal

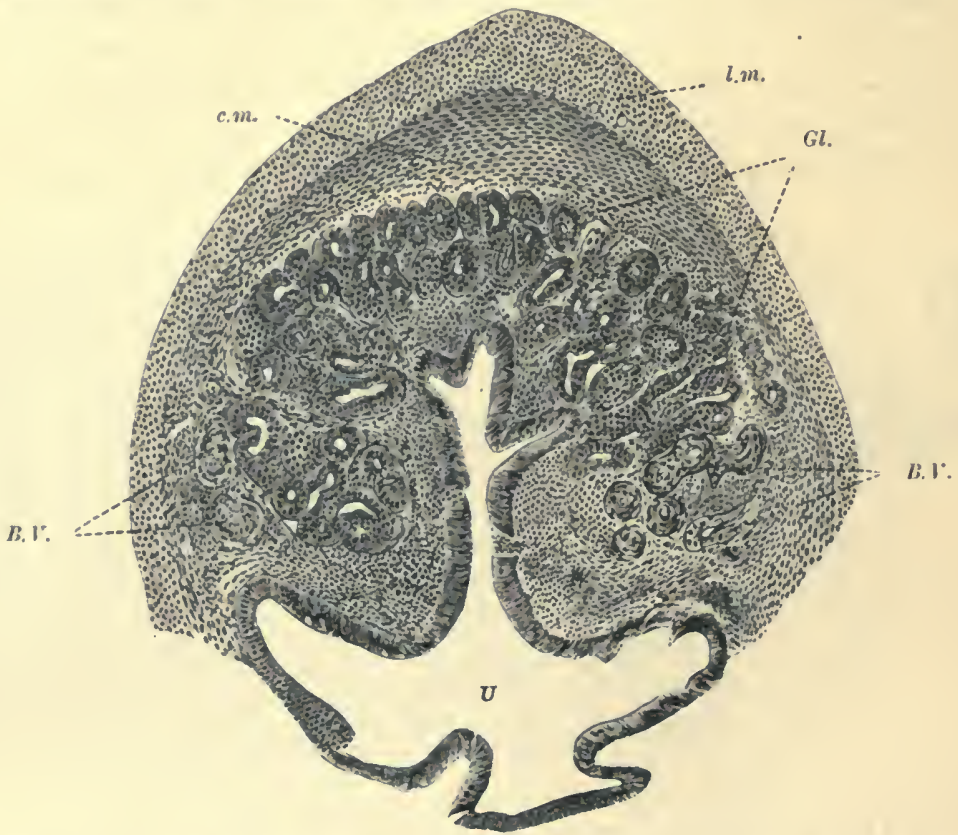

FIG. 114.-Transverse section through the uterus of Sorex at a stage when the blastocysts are still in the oviducts. The coiled uterine glands ( $G l$.) are massed together in the anti-mesometrial regions. The uterine lumen $(U)$ is more or less $\mathcal{\perp}$-shaped. (From Hubrecht's "The Placentation of the Shrew," Quar. Jour. Micr. Sci., vol. xxxv., 1894.)

B.V., blood-vessels; c.m., circular muscle; l.m., longitndinal muscle.

tissues, and store nutriment which they give up to the embryo in a way as yet unknown.

Shrew.-In the shrew (Hubrecht ${ }^{1}$ ) the method of embedding is centric, and no decidua reflexa is formed. The yolk-sac placenta is not so well developed as in the hedgehog.

The attachment of the blastocyst is modified, as in Ruminants,

'Hubrecht, "The Placentation of the Sturew," Quar. Jour. Micr. Sci., vol. $x \times x v$., 1894 . 
by special characteristics of the uterine mucosa. 'They differ from the cotyledonary burrs, however, in being proliferations of the surface epithelium. Before the fertilised ova reach the uterus, there are variations in thickness in the mucosa. It is thin at the mesometrial and anti-mesometrial sections, but thickened over the sides to form two cushions, in which the blood-vessels are more numerous. No glands are present near the mesometrium. They are collected on the opposite surface and open into a longitudinal anti-mesometrial groove (Fig. 114).

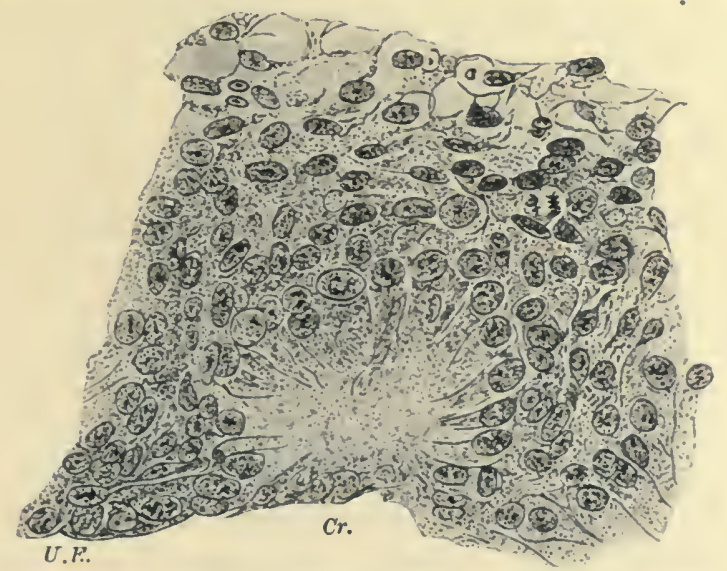

FIG. 115. - Part of the anti-mesometrial wall of the uterus of Sorex (Hubrecht). The proliferated epithelium is arranged in a radial fashion, and later it forms a secondary crypt $(\mathrm{Cr}$.), when the uterine epithelium (U.E.) gives way over it.

When the blastocysts reach the uterus, further changes take place. Both the lateral regions increase in thickness by the proliferation of connective tissue cells and the formation of new vessels, while the anti-mesometrial part is widened out into a concave bell-shaped surface into which the glands open. Then the epithelium proliferates, first in the lateral cushions and later in the concave area. In the former the proliferation reaches a thickness of twelve to eighteen cells, and the new elements pass in among the cells and vessels of the deeper layers. In the allantoidean region, the bell-shaped area, the proliferation also leads to a thick epithelial layer with vascular channels between the cells. At intervals, however, the cells are 
arranged radially like a fan, and later the internal parts of the eells break away and leave a crypt. No crypts are formed in the lateral eushions (Fig. 115).

Over the speeial areas of the mucosa the trophoblast thiekens. It comes in contaet first with the lateral eushions by a zonary strip against whieh the vessels of the area vaseulosa spread out. The eell-outlines in the epithelium of the cushions are lost, and a symplasma is formed. At the same time the trophoblast becomes syncytial, is fused to the uterine symplasma, and absorbs part of it. Some of the intercellular channels are opened, and the maternal blood thus begins to circulate in the syncytial laeunæ. At the same time a deeper eell layer, corresponding to the eytoblast of the bat, appears in the trophoblast, but it is never so well marked as in the allantoidean region. In this way the avillous yolk-sae placenta is formed (see also p. 391), and it funetions for a time. Soon retrogressive ehanges appear, resulting in the absorption of the omphaloidean syncytium and epithelial thiekenings (Fig. 116). The disappearanee is apparently brought about by a newly formed annular proliferation of the trophoblast above the non-placental part, and the degenerated produets of the thiekened uterine epithelium and of a blood extravasate, whieh eonstantly exists between the annulus and the epithelium, are absorbed and transmitted through the hypoblast to the yolk-sac. From it the vessels of the area vaseulosa, whieh at this time reach their full development, carry the nutriment to the developing embryo.

The allantoidean trophoblast is applied against the bellshaped proliferation on the anti-mesometrial side of the uterus, and is fixed by projeetions whieh sink into the newly formed crypts. After destroying their epithelial lining, the projeetions erode capillaries, and the maternal blood cireulates in the syneytial lacunæ as in the omphaloidean trophoblast. The cytoblast follows the plasmodial projections, and later the trophoblastic villi are vaseularised by the allantoic vessels. Subsequently the plasmodiblast thiekens to a considerable extent, and in it the mesoblastic villi continue to branch and form seeondary and tertiary villi. There is no penetration on their part into the deeidual tissue between the erypts, but the maternal part of the placenta as a whole is gradually absorbed 
FOETAL NUTRITION: THE PLACENTA 455

by the plasmodiblast, and is replaced by fotal elements. In the ripe placenta the only maternal constituent is blood, except a

$\mathrm{Cr}$.

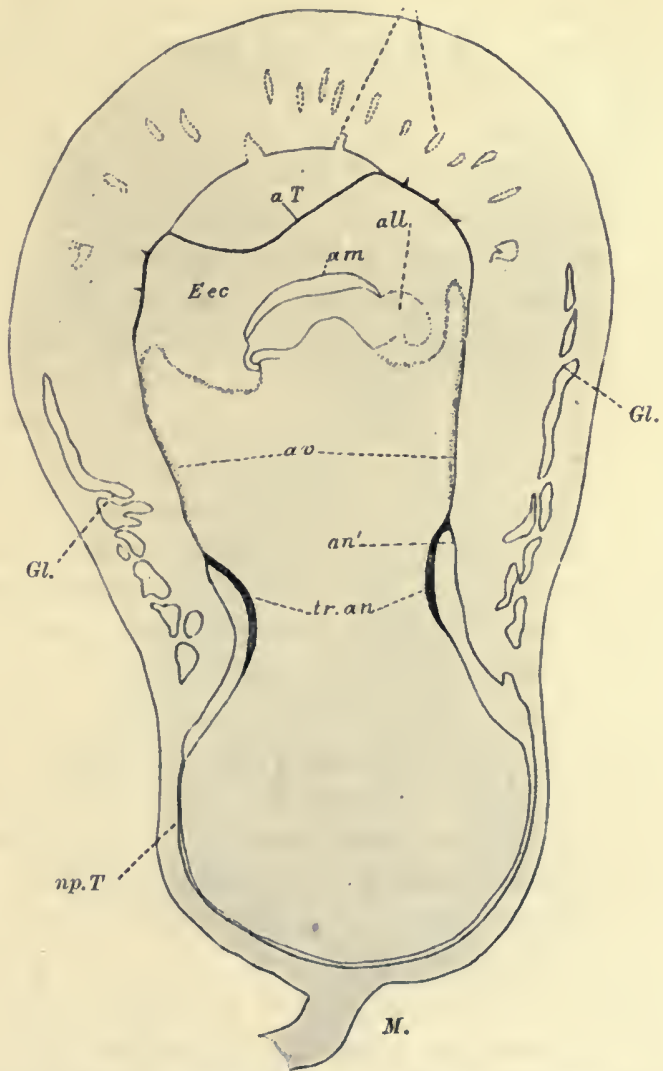

Fig. 116.-Uterus and embryo of Sorex (Hubrecht).

$a . T$., allantoidean trophoblast with knobs entering the epithelial crypts $\left(C r_{.}\right)$; am., amnion; all., free knob projecting into the extra-embryonic crelom $(E . e c$.$) ; a.v., area vasculosa ; a n^{\prime}$, embryonic cells which grow downwards from the upper rim of the trophoblastic annulus (tr.an.), and adhere against the maternal tissue; $n p . T$., non-placental troploblast; $G l$., glands ; $M$., mesometrium.

thin discoid sheet of nuclear remnants next the muscularis. The glands are not penetrated by vascular villi. In the early stages they are plugged by syncytium and later disappear. 
Mole.-The method of embedding is centric. A simple yolk-sac placenta exists for a time. The allantoic placenta is discoid and is placed anti-mesometrially. The glandular secretion is of importance for the nourishment of the developing fotus during the greater part of pregnancy (Strahl, ${ }^{1}$ Vernhout ${ }^{2}$ ).

At the beginning of pregnancy the mucosa shows variations in its different parts. Near the mesometrium, for about onethird of the circumference of the lumen, the glandular layer is thin. Anti-mesometrially the muscular layer is not so well developed, but superficially to the glands there is a proliferation of connective tissue cells, through which the ducts run to open into the lumen. The first attachment is in this region.

The uterine horns show a series of small swellings where the ova are present. The blastocysts grow to a comparatively large size, and completely fill up the lumen. By their further growth, the epithelium near the mesometrium is flattened and replaced by trophoblastic cells, which do not penetrate into the connective tissue or form villi. Hence the yolk-sac placenta is is of a simple type ; it persists throughout pregnancy.

On the opposite side the decidual formation proceeds, and the mucosa becomes thicker. In its substance a rich network of blood-capillaries is developed. The epithelial cells lose their boundaries and form a symplasma. According to Strahl this remains, and forms the syncytial covering of the future villi, but Vernhout has shown that the trophoblast proliferates and forms a layer of epithelioid cells which penetrate into the epithelium and absorb and gradually replace it. Over each gland-opening the trophoblast forms a dome as in Ruminants (Fig. 117). In the placental region the glandular epithelium is not changed, and around each opening a small area of the surrounding uterine epithelium persists. In the cavity between a gland-orifice and its trophoblastic cap lies a dark secretion, pigmented by admixture with extravasated blood, and the cap is similarly pigmented. Hence the secretion is probably absorbed by the fotal ectoderm throughout the greater part of pregnancy during which the glands remain. After the disappearance of the surface

\footnotetext{
'Strabl, "Ueber den Bau der Placenta von Talpa europea," Anat. Anz., vol. v., 1890.

2 Vernhout, "Ueber die Placenta des Maulwurfs," Anat. Hefte, vol. v.,1894.
} 
epithelium at the point of connection with the blastocyst, the plasmodiblast penetrates into the connective tissue layer which forms a symplasma. It is followed by the cytoblast and the allantoic villi. In the syncytium the circulating maternal

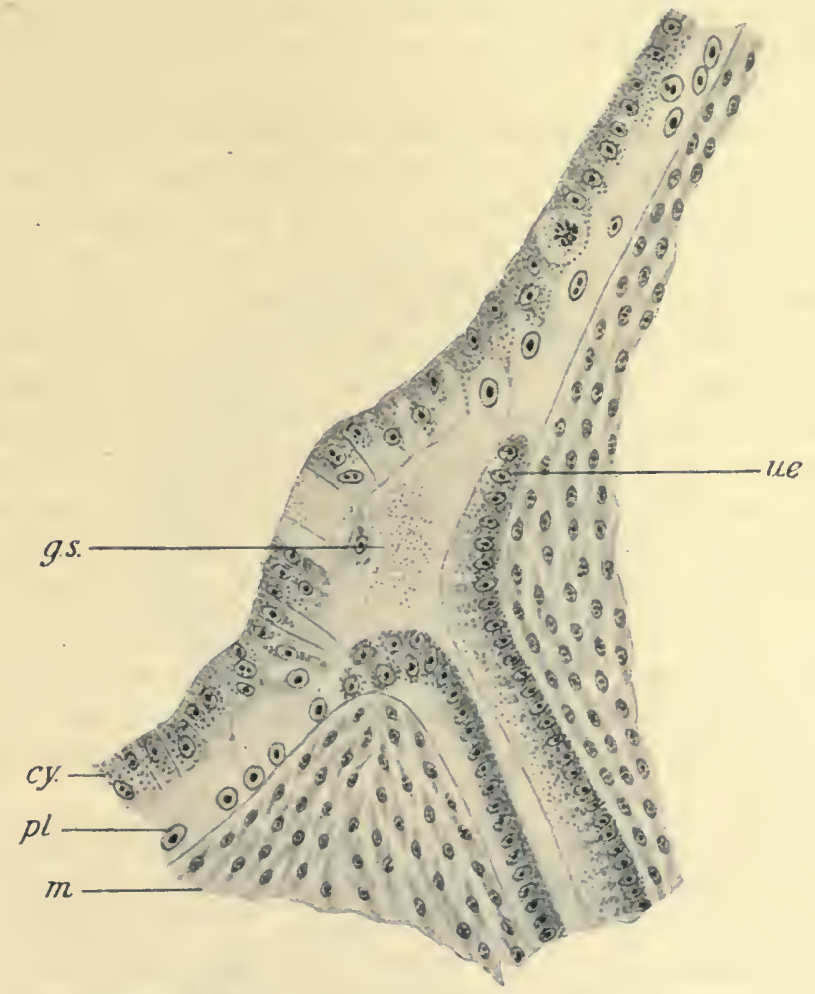

FIG. 117.-Orifice of a uterine gland of the mole with trophoblastic dome. (From Vernhout's "Ueber die Placenta des Maulwurfs," Anat. Hefte, vol. v., 1894.)

$m$. , uterine mucous membrane ; $u e_{\text {., }}$ uterine epithelium ; $p l$., plasmodiblast ; cy., cytoblast ; g.8., gland secretion.

blood provides for the exchange of gases, and supplements the nutriment supplied by the glandular secretion.

Tupaia.-In Tupaia jaranica also, the placentation is modified by the characteristics of the uterine mucosa. Hubrecht ${ }^{1}$

I Hubrecht, "Ueber die Entwicklung der Placenta von Tarsius und Tupaja," Internat. Congr. of Zool., Cambridge, 1898. 


\section{8 THE PHYSIOLOGY OF REPRODUC'IION}

has shown that two specialised areas, the "Haftflecke," exist before the attachment of the trophoblast. They lie one on each side, about midway between the mesometrial and anti-mesometrial regions, and are recognised by the absence of glandular ducts. The deeper parts of the glands persist till the end of pregnancy, but none open on the modified areas.

The uterine epithelium again disappears at the points of contact with the blastocyst over the "Haftflecke." There the trophoblast becomes thickened, and its cells enlarge and penetrate between the epithelial cells, which fuse to form a symplasma. This is quickly absorbed by the trophoblast, which continues to thicken, and now shows two layers, plasmodiblast and cytoblast. The outer layer fuses so closely with the decidual tissue as to be indistinguishable from it. The capillaries dilate and new vessels are formed, especially in the layers next the ovum. When their endothelium is destroyed, maternal blood enters the trophoblastic lacunæ and soon circulates through them. The inter-vascular connective tissue cells proliferate and form the trophospongia. The decidual layers outside it become fibrillar, and soon are extremely attenuated. The trophospongia remains longer, but finally it also thins, and at the end of pregnancy there is only a thin rim of maternal tissue left.

Over the "Haftflecke" the trophoblast is first vascularised by the vitelline vessels, and a temporary yolk-sac placenta is formed. Later the allantois displaces the yolk-sac, and its vessels vascularise the same part of the trophoblast (Fig. 118). "The permanent placenta replaces the omphalic placenta both physiologically and topographically" (Hubrecht). In this respect Tupaia differs from the hedgehog and the shrew.

Centetes.-A peculiar form of placentation has been described by Strahl ${ }^{1}$ in the tenrec (Centetes ecaudatus). A large effusion of maternal blood destroys the centre of the allantoic placenta, and leaves only a peripheral ring. Round the margin

1 Strahl, "Beitrïge zur vergleichenden Anatomie der Placenta," Abh. Senckenberg Naturf.-Ges., 1905. See also Rolleston, "On the Placental Structures of the Tenrec (Centetes ecaudatus)," \&c., Trans. Zool. Soc., London, vol. v., 1863. 
of the ring runs a deep groove which is crossed by branches of the allantoic vessels to reach an epithelial ridge of cells.

Cheiroptera.-The mode of embedding in the bat is centric, and the allantoic placenta is discoid. Before segmentation is completed, the fertilised ovum reaches the uterus and invariably enters the right cornu (Ercolani ${ }^{1}$ ). The zona pellucida is already thinned and soon disappears, the spherical blastodermic vesicle lying free in the uterine cavity.

At the beginning of gestation, according to van Beneden, ${ }^{2}$

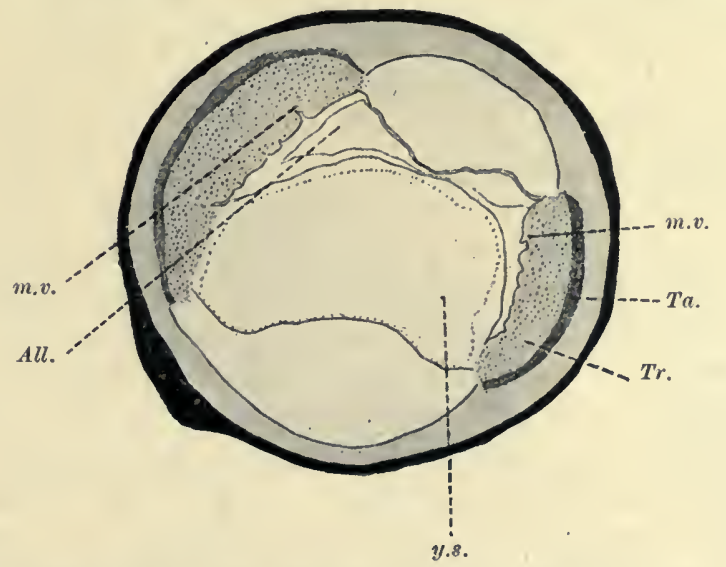

FIG. 118.-Replacement of omphaloidean by allantoidean placenta in Tupaia.

(From Hubrecht's "Ueber die Entwicklung der Placenta von Tarsius und Tupaja," Internat. Congr. of Zool., Cambridge, 1898.)

m.v., mesodermic villi ; Tr., trophoblast; $T a$, , trophospongia ; $A l l$, allantois : y.s., yolk-sac.

the mucosa is composed of a richly cellular connective tissue, covered by a non-ciliated epithelium. Of the glands some are simple tubes, and others divide dichotomously. None open on the mesometrial aspect where the blastocyst later becomes fixed. There also the cellular tissue is not so thick.

Before fixation of the blastocyst, important changes occur

1 Ercolani, "Nuove ricerche sulla placenta nei pesci cartilaginosi e nei mammiferi," Mem. dell' Accad.d. Sc.dell' Institut. di Bologna, vol. x., 1879.

2 V. Beneden, "De la formation et de la constitution du placenta chez le murin," Comp. Rend. de la Soc. de Biol., vol. v., 1888. 
in the mucosa. The sub-epithelial connective tissue cells proliferate and form a distinct compact zone. All the capillaries dilate, even before the disappearance of the zona pellucida, and give off many new branches. The tissue fluids are increased, and a serous fluid is transuded and forms, with the glandular secretion, a coagulum around the ovum (Van der Stricht ${ }^{\mathbf{1}}$ ).

On the inesometrial side, the trophoblast thickens around the formative cell mass, and absorbs the surface epithelium. At the opposite pole the cells are flattened, and they also disappear. The foetal ectoderm, which thus comes in contact with the connective tissue, is composed of two layers at the embryonic pole, the plasmodiblast, and, internally to it, the cytoblast. At the non-embryonic or anti-mesometrial pole the plasmodiblast is absent.

The decidua also differs at the two poles. Opposite the non-embryonic pole, the cells remain epithelioid and undergo little change. Where they come in contact with the trophoblast, they show a tendency to necrose. At the placental pole the deeper layers are also composed of epithelioid cells, but superficially the capillaries continue to dilate and make the layer spongy. The cells between them are in active division, but next the plasmodiblast they degenerate. This layer forms the couche paraplacentaire of $\mathrm{Nolf}^{2}$ (Fig. 119). At the placental margin it thins out and disappears. Beneath the epithelioid layer in both areas the cells are drawn out and pseudo-fibrous. The conditions for nutrition resemble those in the very early human ovum, the trophoblast lying against a non-vascular detritus-zone. But in the bat there is strong evidence of phagocytosis. The epiblastic protoplasm, where it is in contact with dead tissue, is " crammed with irregular granules, some fatty and others coloured brown with safranin" (Nolf). The mouths of the glands opening at the non-embryonic pole are filled with débris, and their epithelium is degenerated and desquamated. As previously mentioned, no gland-ducts are present in the couche paraplacentaire. The blind ends of the

1 Van der Stricht, "La fixation de l'ouf de chanve-souris à l'intérieur de l'utérus," Verh. d. anat. Gescll., 13 Vers., Tübingen, 1839.

"Nolf, "Étude des modifications de la muqueuse utérine pendant la gestation chez le murin," Arch. de Biol., vol. xiv., 1896. 
glands are, however, distended with secretion, and their epithelium is normal.

Next a change occurs such as Hubrecht described in the hedgehog (see p. 449). The endothelium of some of the vessels in the paraplacental layer proliferates irregularly round the

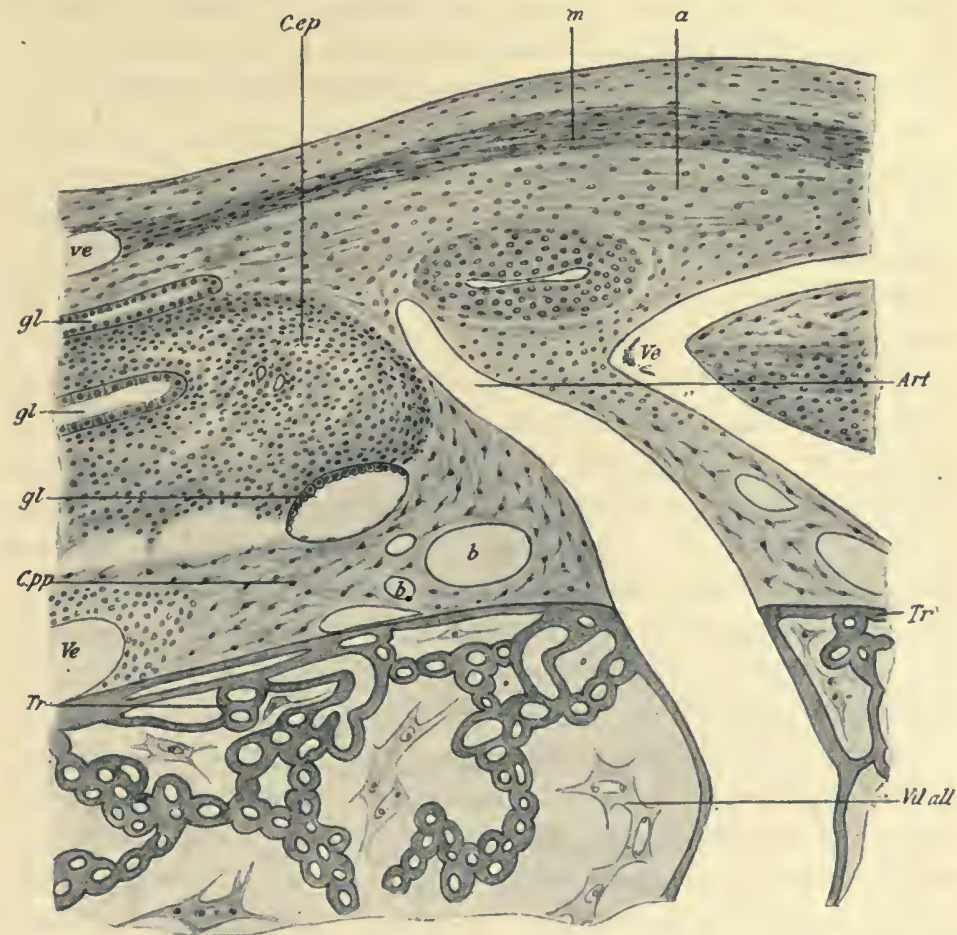

Frg. 119.-The placenta of the bat. (From Nolf's " Étude des modifications de la muqueuse utérine pendant la gestation chez le murin," Arch. de Biol., vol. xiv., 1896.)

$m$., muscularis ; $a_{\text {., }}$ unaltered mucosa ; C.ep., epithelial layer; $g l$. , glands ; C.pp., paraplacental layer with blood-spaces (b.); Art., artery running towards trophoblast; $V c$., vein; $T r$., trophoblast with lacuna ; Vil. all., allantoic villi.

lumen, and degenerates. In the bat, according to Nolf, the vessels in which the change occurs are the renous capillaries, in which the blood, returning from the placenta charged with fœtal excretory products, stagnates and produces the hyperplasia and simultaneous degeneration. Hubrecht, however, 
states that an endothelial proliferation occurs in arterial and venous capillaries alike in the hedgehog.

At the embryonic pole the plasmodiblast undergoes a marked thickening. It gradually replaces the superficial decidual cells, and surrounds the vessels as in the rabbit. Then it attacks the endothelial sheath and replaces it, so that lacunæ of maternal blood come to be surrounded by fotal tissue. At the same time the cytoblast sends out cellular buds, which project into the plasmodial mass. Under the cytoblast is the double layer of mesoblast, the thin somatopleur, and the splanchnopleur in which the area vasculosa is developed. A yolk-sac placenta is thus formed in the same region as is subsequently occupied by the allantoic placenta. Nutritive exchanges between maternal and fotal blood are now possible.

In the further development of the placenta there is very little or no penetration of maternal tissue by the trophoblast (Duval ${ }^{1}$ ). Degenerative changes occur in the cells of the epithelioid layer in the placental hemisphere. They lose their outlines, and form a symplasma which is absorbed by the adjacent cells of the couche paraplacentaire (Nolf). Superficially the paraplacental layer remains until the end of pregnancy. The blind ends of the glands are still distended, but their epithelium degenerates and is cast off into the lumen.

In the non-placental trophoblast, retrogressive changes also occur. Its cells lose their phagocytic power and contain no granules. In the placental area, as already mentioned, the allantois replaces the yolk-sac. The "villi" resemble the tubes of the rabbit. They form a series of arches whose meshes are occupied by allantoic vessels; there are no villi hanging free. As the placenta develops, the thickness of the arches surrounding maternal blood is reduced, and the two blood-streams lie close together. The cytoblast almost entirely disappears.

Pteropus edulis.-In Pteropus the placenta is attached to a large mushroom-shaped outgrowth of the uterine wall which grows nearly round the ovum to form a decidua capsularis. As pregnancy advances, the outer wall of the bell-shaped decidual

"Duval, "Étude sur l'embryologie des Cheiroptères," Journ. de l'Anat. et de la Phys., 1895-97. 
mass is pressed against the uterine surface and fuses with it. In this way the completed placenta is discoid (Göhre ${ }^{\mathbf{1}}$ ).

Primates.-The order of the Primates includes monkeys, apes, and Man. Hubrecht also includes Tarsius, a lemur (see p. 410). Owing to the difficulties of securing material for investigation, many details regarding the early stages of development of the fœtal membranes and placenta are yet unknown.

From the researches of Turner, it is known that the placentation is in general the same throughout the order, except for differences in the size and form of the villi, and in the structure of the decidua. On the other hand, the Primates are distinguished from all other placental Mammals in that they do not form an allantoic placenta. Notwithstanding the variations in the degree of its development, in all the orders previously considered the allantois projected free into the extra-embryonic cœlom before it was united with the wall of the blastodermic vesicle. In the Primates and Tarsius the embryo is attached from the beginning to the wall of the blastocyst by the "Bauchstiel " or "Haftstiel," a mesodermal connecting-stalk first observed by $\mathrm{His}^{2}$ in human embryos. The allantois appears very early as a recess of the posterior wall of the yolk-sac before the formation of the hind-gut. It never projects free into the cœlom, but is contained as a narrow tube in the "Bauchstiel" without reaching at any time the wall of the blastocyst (Fig. 120). The trophoblast is in this way vascularised directly, and a chorionic instead of an allantoic placenta is formed. For this reason Hubrecht has suggested that the term chorion should be restricted to the Primates. Minot ${ }^{3}$ strongly supported the views of His. He went even further, and stated that the placenta was also chorionic in Carnivora, Rodentia, Insectivora, and Cheiroptera, but his views have not been generally accepted. Regarding the modification in Primates, Hubrecht ${ }^{4}$ says: "Once

1 Göhre, "Dottersack und Placenta des Kalong (Pteropus edulis)," Studien über Entwicklungsgeschichte der Thiere, Selenka, vol. v., 1892.

${ }^{2}$ His, Anatomie menschlicher Embryonen, I.

3 Minot, Human Embryology, Boston, 1892.

+ See Robinson's "Iunterian Lectures," Journ. of Anat. and Phys., vol. xxxviii., 1904. 


\section{THE PHXSIOLOGY OF REPRODUCTION}

the embryonic circulation has found the shortest route towards the trophoblast by way of the 'ventral stalk,' trophoblastic lacunæ, with their profusion of maternal blood, which have been there from the very earliest periods of development, are exquisitely situated for rendering this new adaptation highly advantageous. And while in the ancestral forms of the Primates both yolk-sac and allantois largely drew upon the trophoblastic source, these embryonic organs come to be dispensed with to a very great extent in their more highly developed descendants who come to use that trophoblastic source along a more direct, a shorter, and an earlier established route."

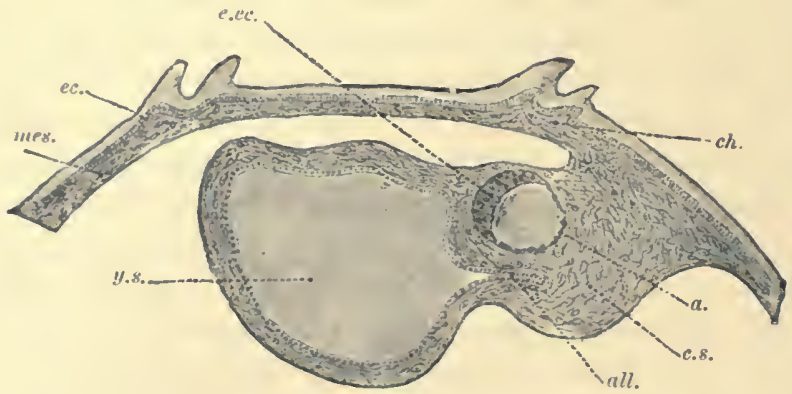

Fig. 120.-Median longitudinal section of an early human orum, $0.4 \mathrm{~mm}$. in length. (From Quain's Anatomy, Longmans.)

c.ec., embryonic ectoderm ; ch., chorion ; ec., ectoderm ; mes., mesoderm ; all., allantois ; c.8., connecting stalk ; $a$., amnion ; y.8., Jolk-sac.

In old-world monkeys there is no decidua capsularis. The trophoblast thickens over two discoid areas on the blastocyst, and the thickenings form a primary placenta on the dorsal surface, and a smaller secondary placenta on the opposite aspect. Hence two groups of chorionic villi are developed.

No unattached blastocyst has yet been obtained. In the youngest specimen of an old-world monkey, Semnopithecus nasicus, the ovum was attached to the surface of the uterus by large villous processes with mesoblastic cores at the bases. The trophoblast consisted of two layers, the cytoblast, which was much thickened at the tips of the mesoblastic cores, and, externally to it, a syncytium which was blended at the apices with maternal decidua. Over the non-villous chorion, syncytium 
was absent (Selenka). Spaces, which are in direct communication with maternal capillaries, are present in the syncytium. The most notable characteristic in the decidua is the presence of a glandular secretion in the embryotrophe. In the non-placental area the glands are dilated and open into the uterine cavity, many of them close to the peripheral villi. Hence their secretion may reach the trophoblastic lacunæ. In the placental region they are also dilated, but their superficial parts are closed and appear to degenerate early. In the decidua lie nests of epithelioid cells, the origin of which is uncertain.

The new-world monkeys, like the old-world, have no decidna capsularis, and the placenta is formed as a single disc. In the anthropoid apes, on the other hand, the ovum is lodged in an implantation cavity, and so is covered by a reflexa. The whole circumference of the trophoblast thickens and develops villi, but later they disappear except over a discoid area, the decidua serotina. In the earlier stages two main groups of villi are present, as in the old-world monkeys, while the rest of the chorion is covered with smaller villi.

In Selenka's youngest specimen, the ovum was conipletely enclosed by decidual tissue, and there was no evidence to show whether the mode of embedding was excentric or interstitial. The surface of the ovum was separated from the decidua by a series of intercommunicating spaces, the intervillous spaces, which contained lymph. In other words, Selenka looks on the intervillous space in apes as a space lying between maternal and foetal tissues, in which villi are suspended.

In Man also the villi are at first diffuse, and later restricted to a discoid area, the placenta being again developed in the decidua serotina.

The ovum probably reaches the uterus still enclosed in the zona pellucida, and lies free until the end of the first week, but this stage has never been observed. The uterine mucosa, as in other orders, is matured ahout the time of puberty (Björkenheim ${ }^{1}$ ), and then consists of embryonic connective tissne cells, separated from the sirface epithelium by a layer of flattened cells. The intercellular spaces are filled with lymph, and they

1 Björkenheim, "Zur Kenntnis der Schleimhaut im Uterovaginalkanal des Weibes in den verschiedenen Altersperioden," Anat. Hefte, H. cv., 1907. 
drain into lymphatic vessels in the outer half of the nucosa, where also the arterioles and venules lie. All the blood-vessels in the inner half are capillaries. In all probability the fertilised ovum, during its sojourn in the Fallopian tube and while it lies free in the uterine cavity, does not influence the structure of the mucosa, and may implant itself at any period during the œstrous cycle (Bryce and Teacher ${ }^{1}$ ). But under the abnormal conditions in a tubal pregnancy, the uterine mucosa undergoes a decidual change although no fertilised ovum is embedded in it.

In all the early specimens the ovum was completely enclosed in the uterine mucosa, and the actual process of embedding has not yet been observed. John Hunter considered that the ovum reached the uterus from the Fallopian tube under the mucous membrane, and so had a decidua reflexa, while at a later stage the mucosa developed underneath it; hence the term decidua serotina. Sharpey supposed that the enclosure was effected by circumvallation, i.e. by a growth round the ovum of two folds of mucosal tissue, which fused and formed the decidua capsularis. But v. Spee ${ }^{2}$ discovered a different mode of embedding in the guinea-pig, and later stated that it was the same in Man, viz. a destruction of the superficial epithelium, and the implantation of the ovum in the cellular substance of the mucous membrane. This view has received considerable support from the researches of v. Heukelom, ${ }^{3}$ Peters, ${ }^{4}$ Bryce and Teacher, and others. At the same time it must be borne in mind that His, ${ }^{5}$ in describing an early humian ovum in 1S97, stated that the implantation cavity was lined with epithelium, and thus represented a part of the uterine lumen shut off by the growth of decidual folds.

At the time of embedding, segmentation has probably

1 Bryce and Teacher, The Early Imbedding and Devclopment of the Human Ovum, Glasgow, 1908.

2 V. Spee, "Neue Beobachtungen über sehr frühe Entwicklungsstufen des menschlichen Eies," Arch. f. Anat. u. Phys., anat. Abth., 1896.

s V. Heukelom, "Ueber die menschliche Placentation," Arch. f. Anat. и. Phys., anat. Abth., 1898.

- Peters, Ueber die Einbettung des menschlichen Eies, Leipzig u. Wien, 1899.

"His, "Die Umschliessung des menschlichen Frucht während der frühesten Zeit der Scliwangerschaft," Arch. f. Anat. u. Phys., anat. Abth., 1897. 
finished and the ovum is in the condition of the early blastocyst. Its epiblastic wall disintegrates the epithelium, the subjacent cells, and a few capillaries at the point of contact. Hence the blastocyst comes to lie in the connective tissue of the mucosa, which completely surrounds it, except at the point of entrance of the ovum. Here there is a gap in the tissue, the "Gewebspilz," filled up at first by a blood-clot which afterwards becomes fibrinous (Peters), and later by decidual tissue (Kollmann ${ }^{\mathbf{1}}$ ). In Peters' ovum the gap was four-fifths of a millimetre in diameter, and in Bryce and Teacher's 'a tenth of a millimetre. The size of the ovum when it becomes embedded is probably, according to the last-named authors, a fifth of a millimetre.

When the hypoblast of the early blastocyst is differentiated, it does not apparently line the wall of the blastocyst, but forms a small vesicle. Very early, even before the appearance of the primitive streak, a marked proliferation of mesoblast occurs (Fig. 121). In the youngest ovum its cells filled the space between the wall of the blastocyst and the small amniotic and hypoblastic vesicles. In the ovum described by Leopold, ${ }^{2}$ it was already split by the "Haftstiel" into two parts, which enclosed the cœlom and were continuous with each other (Fig. 122). The outer wall of the blastocyst, the fotal ectoderm or trophoblast which anchors the ovum in the mucosa, is thickened all round its circumference, and even in the earliest specimen contained vacuoles into some of which maternal blood had penetrated. In this thick spongy layer Bryce and Teacher found no cell-outlines anywhere. Hence the transformation to syncytium is not due, as Peters supposed, to the contact with maternal blood. Under the syncytium is the cellular layer, corresponding to the cytoblast of Beneden. Its cells are in a state of active division, and they appear later to lose their outlines and merge into the syncytium. The growth of the latter from the mother-zone of cytoblast occurs, not as a solid mass, but in strands forming primitive syncytial villi (Fig. 123). Into the syncytium project outgrowths of the cytoblast, forming the cellular villi of Peters and Leopold. In the

1 Kollmann, "Die menschlichen Eier von 6 Millimeter Grösse," Arch. f. Anat. u. Phys., anat. Abth., 1879.

2 Leopold, "Demonstration eines sehr jungen menschlichen Eies," Arbeiten aus d. Königl. Frauenklinik in Dresden, Leipzig, 1906. 


\section{THE PHYSIOLOGY OF REPRODUCTION}

youngest ovium the formation of these buds was just commencing, and, according to Bryce and Teacher, they tended to grow out not so much into the strands of trophoblast as into the spaces
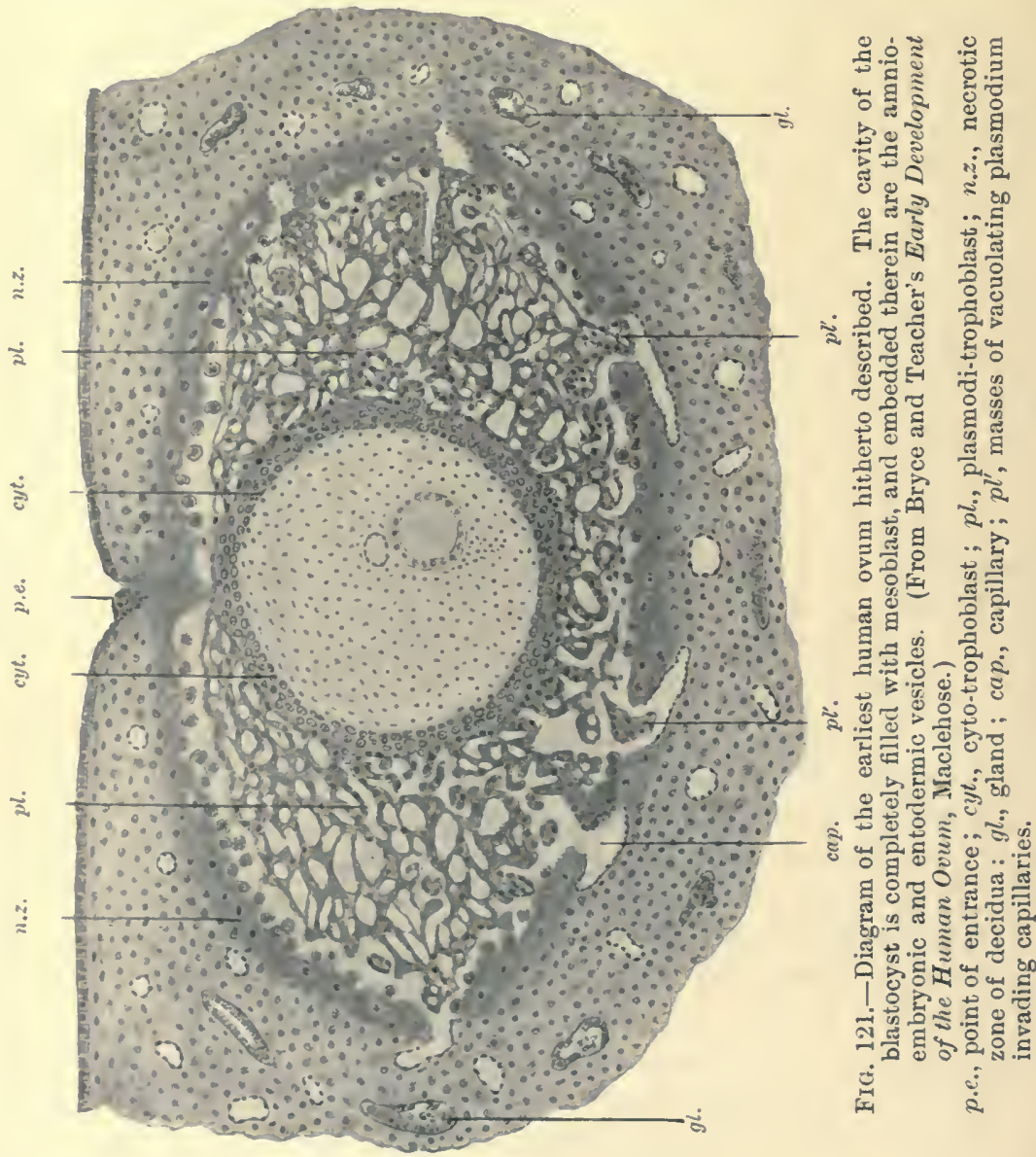

between them. Iater still, mesoblastic processes penetrate into the cellular buds and complete the vascular chorionic villi.

Round the blastodermic vesicle is a zone of degenerated tissue, the "Detrituszone" (Fig. 124). It is uncertain whether it is formed by the influence of the trophoblast or maternal elements. 
FETAL, NUTRITION: THE PLACENTA 469

At its inner edge, and within its spaces, are numerous large mononuclear cells which are "more likely maternal " (Bryce and

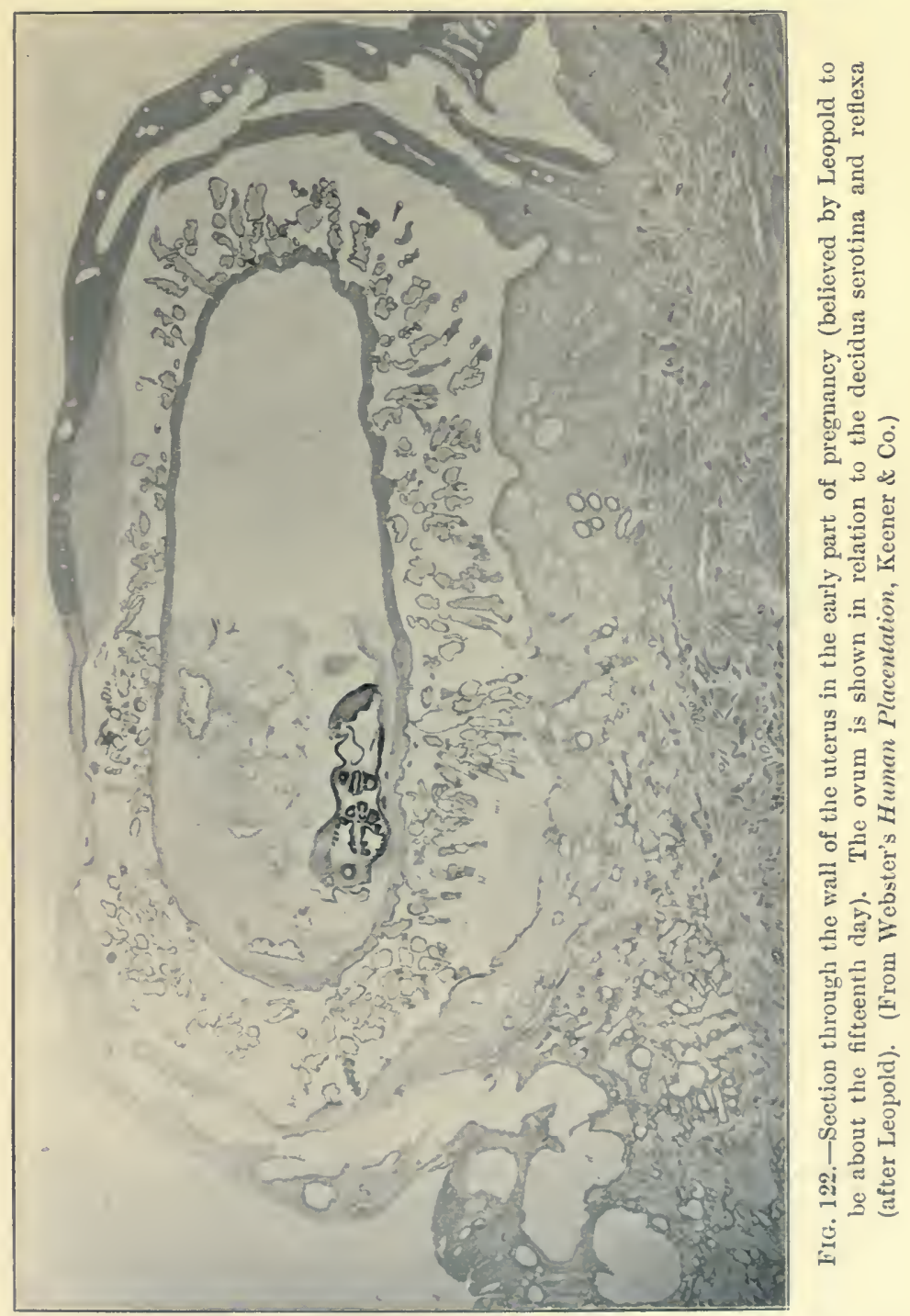

Teacher). Peters also mentioned the presence of niany large cells, and compared them to the deciduofracts of the hedgehog. 
V. Heukelom described the cellular layer outside the syncytium as foetal, and derived from Langhans' layer. ${ }^{1}$ Whatever their

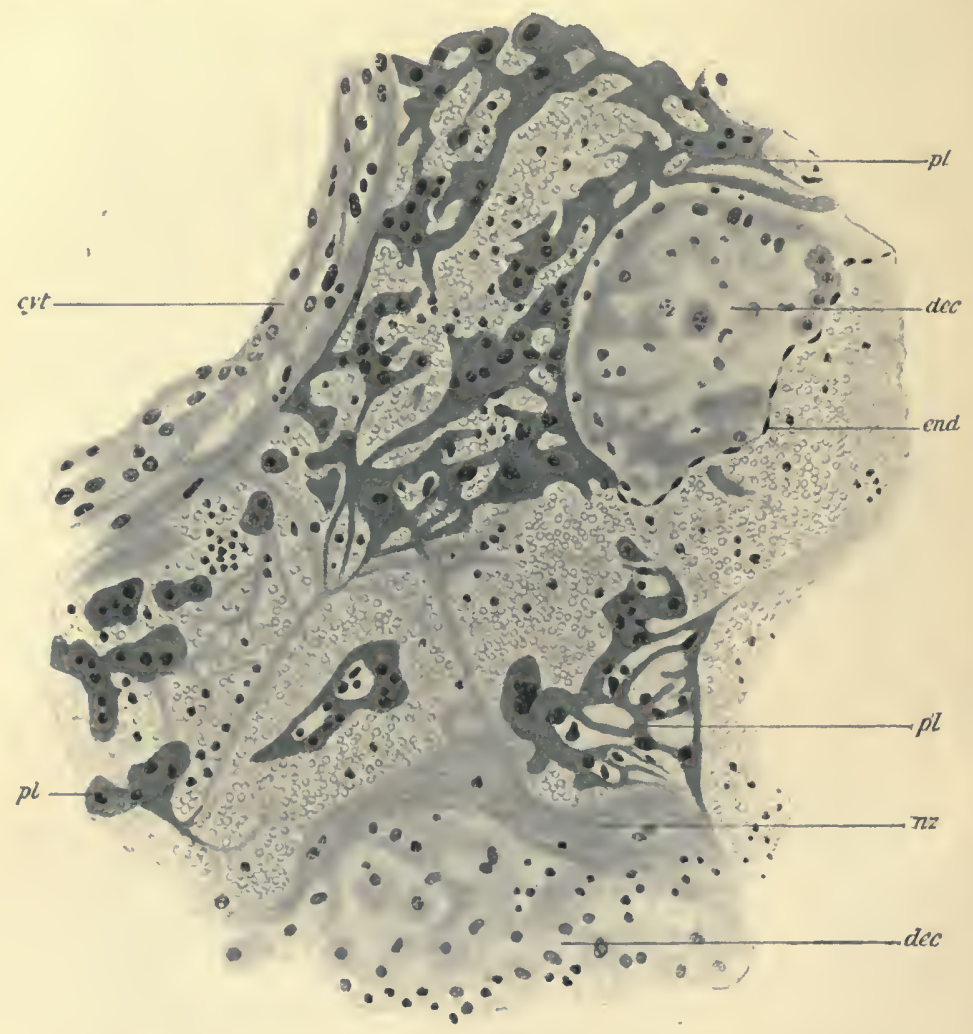

Fifi. 123.- Section of a portion of the wall of the human blastocyst.

(Bryce and Teacher.)

cyt., cyto-trophoblast ; dec., decidua ; end., endothelium of maternal capillary ; $p l .$, plasmodium; $n z .$, necrotic zone of decilua.

1 Much uncertainty still exists regarding the origin of these large cells in Man and other animals. In the mouse, Duval and Sobotta consider them futal, Kolster and Disse maternal, and Jenkinson both foetal and maternal. In the guinea-pig, v. Spee states that they are foetal. In the hedgehog they were first described by Hubrecht as maternal, and later as foctal. In Man, as stated above, the same doubt exists whether the trophoblast consists of two layers, cytoblast and plasmodiblast, or possesses a third layer composed of large cells, and forming the advance guard in attacking the uterine mucous membrane and enlarging the "Eikammer." 
origin, the mononuclear cells in Man appear to be engaged in disintegrating mucosal tissue, and producing a zone of coagulation necrosis, i.e. a symplasma, around the trophoblast. But they differ from similarly situated. cells in lower animals, e.g. the mouse, in showing no evidence of ingestion of formed tissueelements.

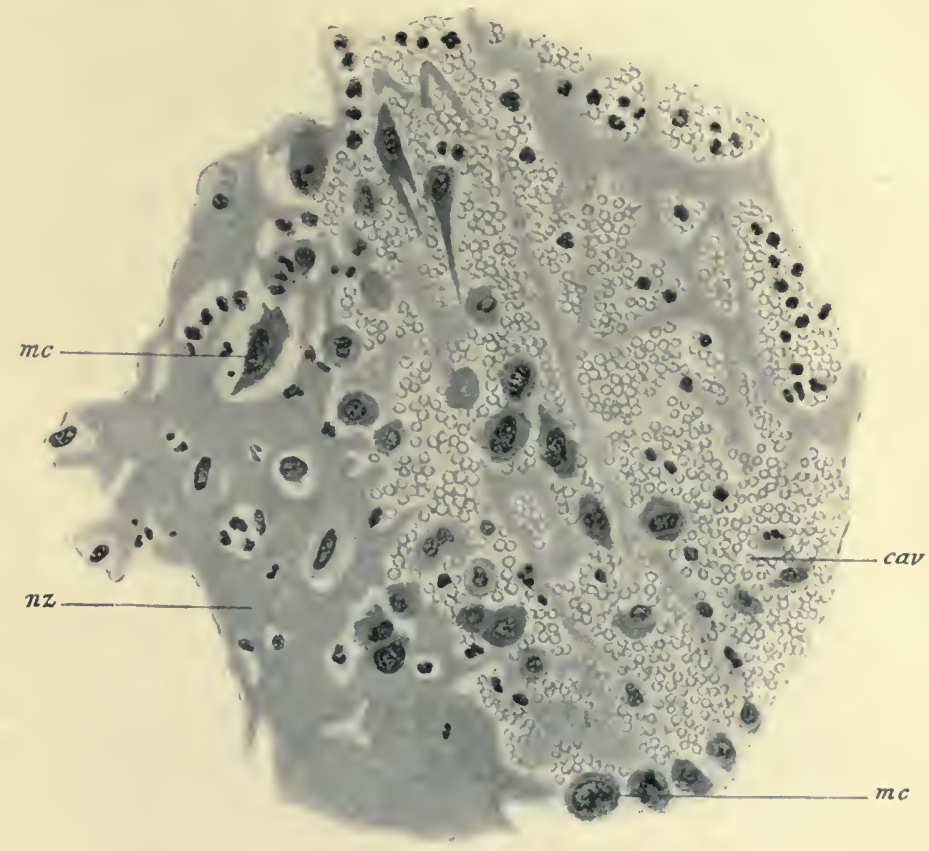

Fig. 124.-Section of a portion of the necrotic zone of the decidua, and of the layer of large cells on its inner aspect. (Bryce and Teacher.)

$n z .$, necrotic zone ; $m c$., large cells in various stages of degeneration; cav., blood-filled implantation cavity.

In the youngest ova no space exists between the trophoblast and the wall of the implantation cavity (Fig. 125). In later specimens a space is formed, apparently by the absorption of the débris of the necrotic zone. How this excavation is brought about is uncertain. According to Peters, the trophoblast may exercise a phagocytic action. Bryce and Teacher, however, found 
no evidence of such a process, and inclined to the opinion that the inaterial was dissolved by an enzyme before its absorption. In the trophoblast they found that some of the vacuoles were not yet filled with maternal blood, but contained a granular coagulum which might, when liberated, have a digestive activity. In either case, the extensive proliferation of the trophoblast

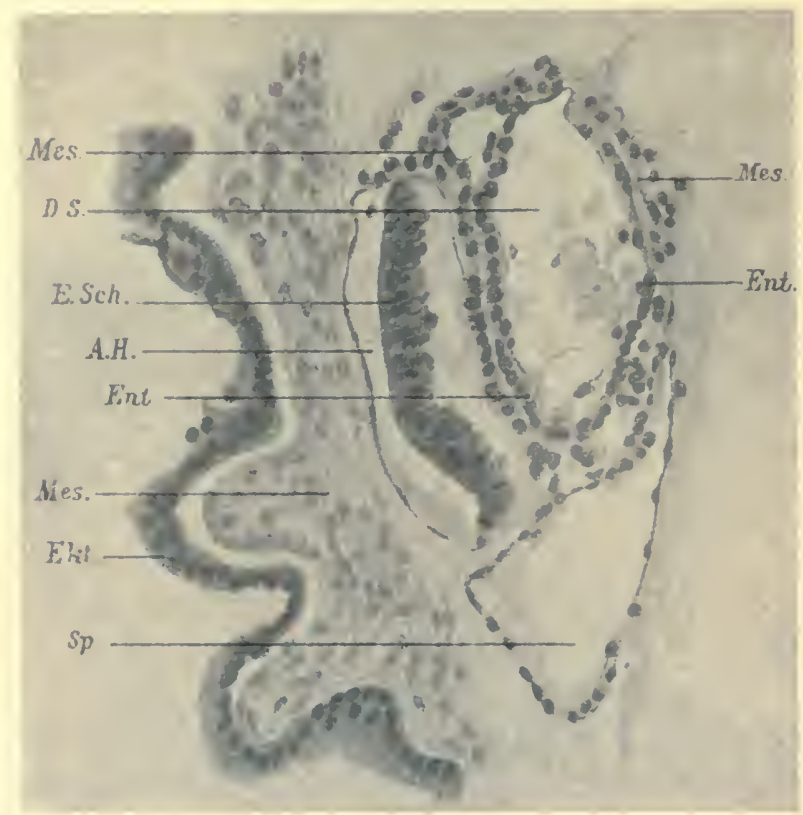

FiG. 125.-Section through embryonic region of ovum (after Peters).

(From C. Webster's Human Placentation.)

E.Sch., embryonic epiblast; Ent., embryonic hypoblast; Mes., mesoblast;

D.S., umbilical vesicle ; A.H., amniotic cavity ; Ekt., chorionic epiblast;

Sp., space.

appears to provide for the absorption of the necrosed tissue around it, as well as for the flow of maternal blood into its lacuna by the erosion of superficial capillaries. These two objects accomplished, the greater part of the trophoblastic proliferation disappears.

Immediately after the excavation of the cavity the decidual formation begins. Before this stage, the changes resemble those that take place during the menstrual period. The vessels are 
dilated, and blood extravasations occur between tha cells and into the lumen. The tissue is cedematous and spongy, and the swollen cells often appear to be floating free in a fluid (v. Heukelom). These changes are especially marked near the ovum, and they give rise to an elevation which marks the resting-place of an early blastocyst. The mucosa is differentiated into a superficial layer, the compacta, and a deeper layer, the spongiosa, in which are the enlarged middle portions of the glands, arterioles, venules, and lymphatics. In the compacta the connective tissue cells undergo active division, and they enlarge to form the decidual cells (Fig. 126). Before the excavation of the "Eikammer" they are probably not found, though Peters described the commencement of a decidual change before that stage. In Merttens' ${ }^{1}$ ovum large decidual cells were found, many of them fusiform and lying parallel to the surface. The decidual change arises first in the connective tissue cells near the ovum, and later it extends more deeply in the

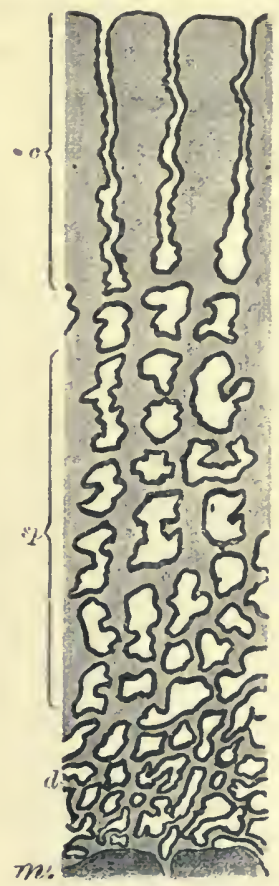

FIG. 126.-Condition of the glands at the beginning of pregnancy in Man (after Kundrat and Engelmanu). (From Quain's Anatomy, Longmans.)

$c$, compact layer near free surface of decidua: the glands are here somewhat enlarged, but not very tortuous, and the mucous membrane is rendered compact by the hypertrophy of the interglandular tissue; $s p$., spongy layer containing the middle portion of the glands greatly enlarged and tortuous, producing a spongy condition in the mucous membrane; $d$, deepest portion of glands, elongated and 1 ortuous, but not muchenlarged; $m$., muscularis. compacta. There is no special perivascular development as

1 Merttens, "Beiträge zur normalen und pathologischen Anatomie der menschlichen Placenta," Zeitschr. f. Geburtsh. u. Gynäk., vols. xxx. and xxxi., 1894-5. 
in the rabbit, and no endothelial proliferation as in the hedgehog and bat, though the latter may occasionally occur in tubal pregnancy (Webster ${ }^{1}$ ).

The capillaries dilate to sinuses, and new vessels are also formed in the compacta. Many of them are opened by the trophoblast and perhaps by the mononuclear cells, and gradually more and more blood is effused into the trophoblastic lacunæ. In them it does not clot, the syncytium acting as an endothelium, but at a certain stage the blood begins to circulate and continues to do so throughout pregnancy. The gland-ducts are destroyed in the necrotic zone. In the underlying compact zone they are found dilated in the serotina and base of the reflexa, but even in Bryce and Teacher's ovum the epithelium showed signs of degeneration and desquamation.

With the formation of the space between the ovum and the decidua, a permanent attachment of the two structures is brought about. The development of the villi has already been traced up to the stage when they consisted of simple stalks of mesoblast with a double ectodermal covering. In the core are developed capillary vessels which are continuous with the vessels of the "Haftstiel," and later with those of the umbilical cord. After the excavation of the necrotic zone, some of the stalks reach the decidual surface and attach the ovum to it. $\Lambda$ t first the attached ends of these primary villi are plasmodial, but later the cytoblast proliferates and forms thick rounded masses, the "Zellsäulen," over which the syncytium disappears. This forms the permanent attachment between the villi and the decidual surface. The spaces between the stalks form the primary interillous space, which is thus entirely in the plasmodiblast. The primary villi form buds of their three layers which develop into secondary villi. Of these some may also become attached to the decidua, while others hang free in the intervillous space. By a similar process other villi are also developed, till the whole system becomes branched like a tree (Fig. 127). $\Lambda$ t first they are equally distributed over the chorion, but the villi in relation to the reflexa do not branch so much, and even at the end of the

1 Webster, Human Placentation, Chicago, 1901. Wade and Watson (Journ. of Obstet. and Gynec. of Brit. Emp., 1908) also state that in tubal pregnancy some of the decidual cells are formed from endothelium. 
first month they are fewer in number than over the serotina (Kastschenko ${ }^{1}$ ). When the blood-supply to the reflexa is reduced, the villi in relation to it degenerate, and are compressed between the chorion and the apposed decidua reflexa and vera. Over the serotina they continue to branch and form the fœtal

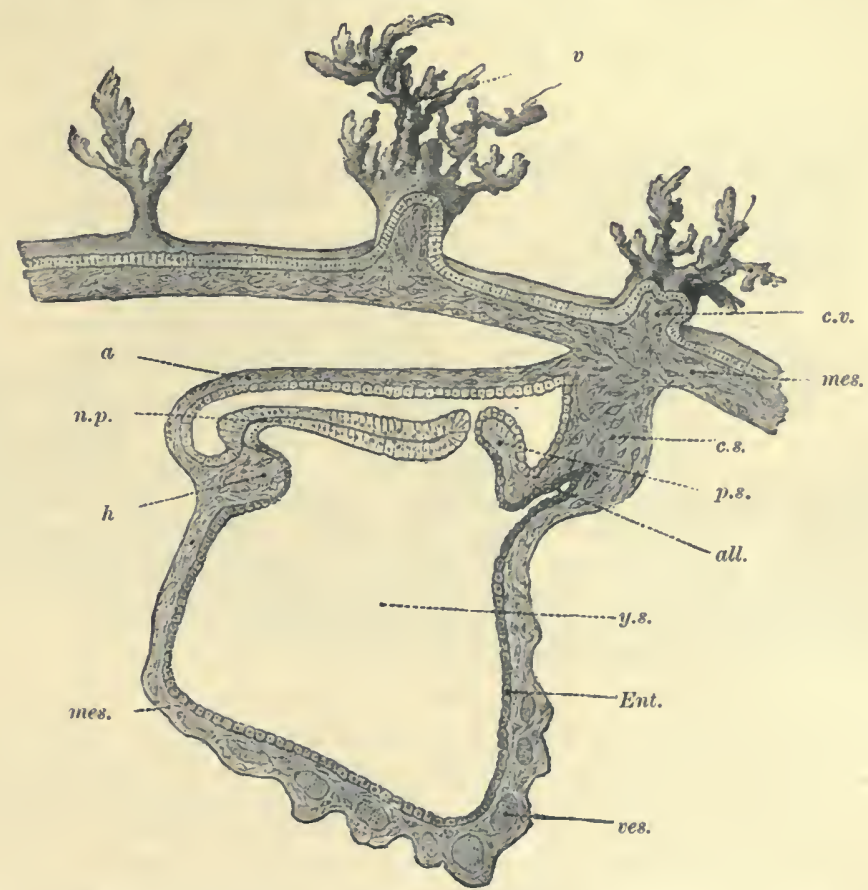

Ficr. 127.-Median longitudinal section of an embryo of $2 \mathrm{~mm}$. (von Spee). (From Quain's Anatomy, Longmans.)

$v$. , villus ; c.v., core of villus; mes., mesoderm ; c.s., connecting stalk; p.s., primitive streak; all., allantois ; y.8., yolk-sac ; Ent., entoderm ; ver., vessels; h., heart; n.p., notochordal plate; $a$., amnion.

part of the placenta, which is essentially a mass of fotal villi between which maternal blood circulates. By the "Haftzotten" the spongy mass is attached to the decidual surface. The attached ends may excavate the decidua to some extent, but there is no great degree of penetration (Fig. 128).

1 Kastschenko, "Das menschliche Chorionepithel und dessen Rolle bei der Histogenese des Placenta," Arch.f. Anat. u. Phys., anat. Abth., 1885. 
As pregnancy advances, marked degenerative changes occur in the maternal and foetal parts of the placenta. The most notable change in the villi is the gradual disappearance of the cytoblast, the mother-zone of the syncytium. Even the "Zellsäulen" tend to disappear from the tips of the villi, and their connective tissue comes in contact with the decidua. Fibrinous changes are frequent in the remnants of the cytoblast

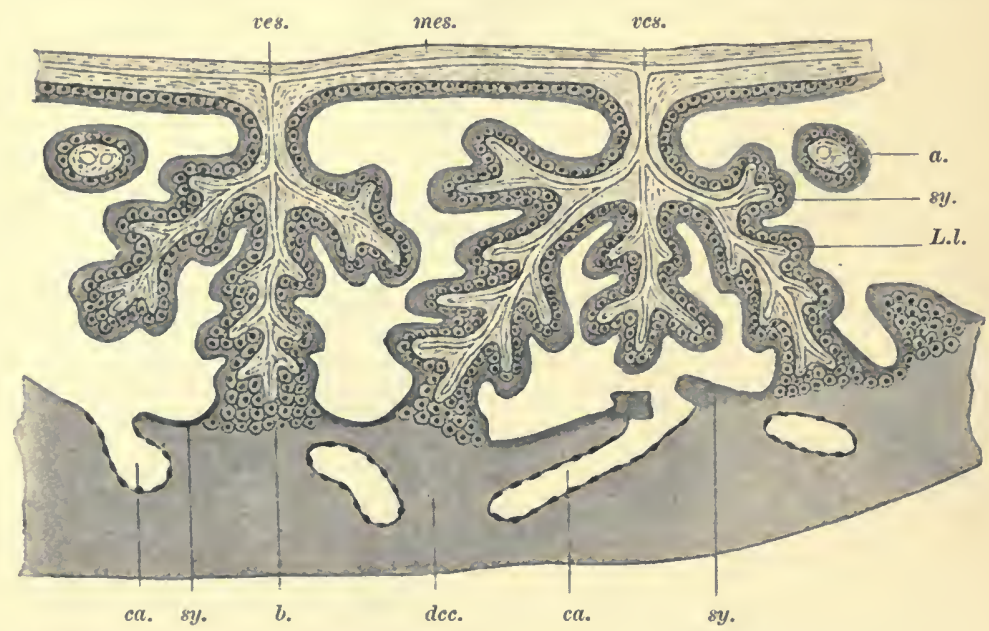

FIG. 128. - Diagram of stage in the development of the human placenta

(T. H. Bryce in Quain's Anatomy, Longmans). The "Haftzotten " are attached to the surface of the decidua. The mesodermic processes are everywhere covered by a single layer of cells (Langhans' layer) and a lamella of syncytium.

b., attachment of a villus; mes., mesoderm; ves., vessels going to villi; sy., syncytium; L.l., Langhans' layer; $a_{\text {., }}$ cross-section of a villus; dec., decidua; $c a$. , maternal capillary.

and in the mesoblast. The syncytium becomes very thin, and occasionally tracts of it are stripped off.

The decidua serotina, after reaching its full development during the third month, is gradually thinned out. This may be partly due to the stretching of the tissue by the increasing growth of the uterine contents, but it would seem also to depend on conditions of malnutrition caused by the blood-stasis (Bonnet), and the choking of the lymphatics by the decidual development (Webster). The resulting degeneration takes the form of a 
coagulation necrosis or symplasma, as shown by the "Fibrinstreifen," which are comparable to the fibrinous deposits in the rabbit's placenta. The layers of fibrin in the serotina were first described by Nitabuch. ${ }^{1}$ They may be seen as early as the sixth week, and even earlier in the reflexa (Webster). They gradually extend more deeply into the substance of the decidua, and also occur in the vessel walls. They are, however, most marked on the surface, at or near the junction of the maternal and foetal tissues. That they are due to the influence of the ovum is highly probable from their absence in the vera. Whether the symplasma is formed from the blood or the decidua, or both, is not known. It is probably absorbed by the villous ectoderm during the greater part of pregnancy.

According to Webster, there may be a new formation of decidual tissue during pregnancy, from irregularly distributed groups of active cells which are present at all periods in the maternal part of the placenta (see p. 368).

The uterine glands take no part in the formation of the placenta. By the sixth week their superficial parts are largely obliterated, and the deeper parts degenerated. At a later stage, only a few blind ends are seen next the muscular layer. Though their epithelium offers a considerable degree of resistance, and is visible for a long time, its secretory power is probably lost very early. According to Gottschalk, ${ }^{2}$ the glandular epithelium undergoes a fatty degeneration, but Bonnet ${ }^{3}$ states that the change is a hyaline one. In the vera the glands increase in size and secrete actively for a time. Their secretion is found as a milky fluid in the uterine cavity.

Glycogen.-Glycogen is present in the early stages of pregnancy. Langhans ${ }^{4}$ demonstrated it in the decidual cells, in the cellular proliferations of the trophoblast at the tips of the villi, and in the mesoblast. It was absent in the canalised fibrin and

\footnotetext{
1 Nitabuch, "Beiträge zur Kenntnis der menschlichen Placenta," Inaug.Dissert., Bonn, 1887.

${ }^{2}$ Gottschalk, "Weitere Studien über die Entwicklung der menschlichen Placenta," Arch. f. Gynäk., vol. xl., 1891.

3 Bonnet, "Ueber Syncytien," \&c., Monatsschr. f. Geburtsh. u. Gynäk., vol, xviii., 1903.

4 Langhans, "Ueber Glykogen in pathologischen Neubildungen und den menschlichen Eihïuten," Virchow's Arch., vol. cxx., 1890.
} 
Langhans' layer. Merttens ${ }^{1}$ also found it in the decidua near the ovum. Driessen ${ }^{2}$ states that it is present in the superficial and glandular epithelium of the uterus in the first month of pregnancy; around the ovum "in cells of doubtful origin," glycogen is plentiful, but absent in the deeper parts of the decidua; in the villi it is not found in the syncytium and Ianghans' layer, but is present in the cell-islands at the tips of the villi, and occasionally in the mesoblast. The total amount is, however, much smaller than in Rodents, and represents only about 0.08 per cent. by weight $\left(\right.$ Cramer $\left.^{3}\right)$.

Fat.-Fat was first described in the human placenta by Apfelstedt and Aschoff. ${ }^{4}$ They found it during the second month of pregnancy in the syncytium and Langhans' layer, and in the decidual cells near the villi. Eden ${ }^{5}$ found fat in the perinuclear protoplasm of the syncytium, and in Langhans' layer and the stroma of the villi. It is also present in the capillary walls (Dastre ${ }^{6}$ ). The appearances suggested to Eden that " the placenta appears to be a storehouse of nutritive fat just as is the liver." Minute discrete droplets were also present in the decidual cells, and by the sixth month they had increased in number. At full time the serotina still contained fat, but " it is doubtful whether now it is a physiological deposit, as the serotina shows many degenerative changes." At the same time, a fatty degeneration of the decidua is probably pathological and not a constant phenomenon (Klein ${ }^{7}$ ), and the fat globules in the early stages represent an infiltration of fat into the decidual cells from the maternal blood.

From the absence of fat in the more superficial parts of the

1 Merttens, "Beiträge zur normalen und pathologischen Anatomie der menschlichen Placenta," Zeit. f. Geb. u. Gynäk., vols. xxx. and xxxi., 1894-5.

"Driessen, "Ueber Glykogen in der Placenta," Arch. f. Gynäk., vol. 1xxxii., 1907.

"Cramer (A.), "Beitrüge zur Kenntnis des Glykogens," Zeitschr. f. Biol. vol. xxiv.

"Apfelstedt and Aschoff, "Ueber bösartige Tumoren der Chorionzotten," Arch. f. Gynäk., 1896.

s Eden, "The Occurrence of Nutritive Fat in the Human Placenta," Proc. Roy. Soc., London, vol. lx., 1896.

- See Richet's Dictionnaire de Physiologie, vol. vi., Article "Fotus."

7 Klein, "Entwicklung und Rückbildung der Decidua," Zeitschr. $f$. Geburtsh. u. Gynäk., vol. xxii. 
syncytium, Hofbauer ${ }^{1}$ suggests that it may be split up into fatty acids and glycerine before absorption, and then re-synthesised by the fotal placenta (Fig. 129). Thence it is carried by the blood in a soluble form, and is again deposited in droplets in the heart, liver, lungs, alimentary tract, and spleen of the fotus. In the later months of pregnancy there is a considerable deposit of fat in the subcutaneous tissue.

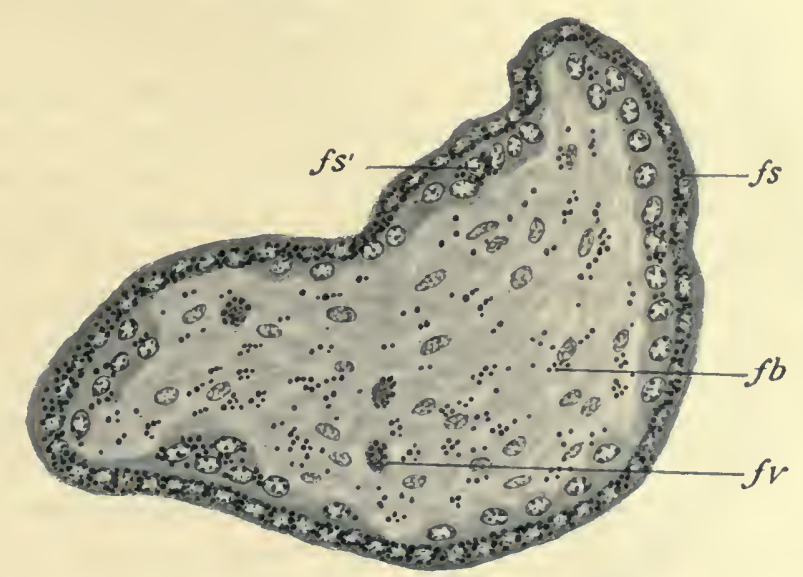

FIG. 129. - Fat in a villus of the human placenta. (From Hofbauer's Biologie der menschlichen Plazenta, Braumüller.)

$f_{s}$, fat globules in deeper layers of syncytium ; $f s^{\prime} .$, fat in syncytium between Langhans' cells ; $f b$., fat in mesoblast; $f v$., fat in vacuolated cell.

Iron.--In Man, Peters found evidence of the presence of red blood corpuscles in the trophoblast of the early ovum, and Ulesco-Stroganowa ${ }^{2}$ states that they are also present in the syncytium in later stages. This has been disputed by Kworostansky ${ }^{3}$ and Hofbauer, who maintain that the corpuscles are first dissolved. More recently Bryce and Teacher found no evidence of the ingestion of red blood corpuscles by the trophoblast, while Bonnet ${ }^{4}$ has shown that the syncytium gives the eosin-

1 Hofbauer, Grundzüge einer Biologie der menschlichen Plazenta, Leipzig, 1905.

2 Ulesco-Stroganowa, "Beiträge zur Lehre vom mikroskopischen Bau der Placenta," Monatsschr. f. Geburtsh. $u$. Gynäk., vol. iii.

${ }^{3}$ Kworostansky, "Ueber Anatomie und Pathologie der Placenta," Arch. f. Gynük., vol. ixx.

- Bonnet, quoted by Hofbauer, loc. cit. 
reaction of hæmoglobin at the points where it comes in contact with extravasated blood. It has been stated that placental extracts produce hæmolysis in vitro (Veit and Scholten ${ }^{1}$ ), but whether a similar action takes place in the body is unknown.

Iron-containing compounds are also found in the villi.

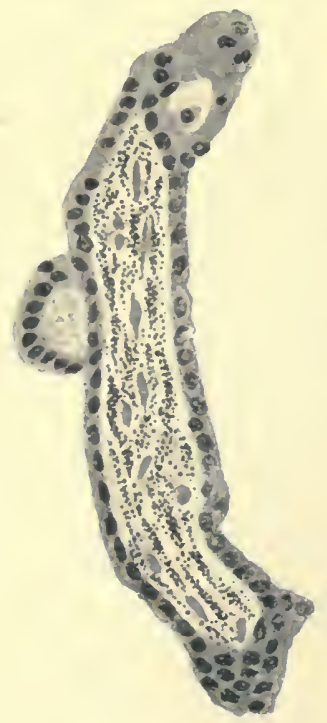

FiG. 130.-Iron granules in a villus of the placenta in Man. (From Hofbauer's Biologie der menschlichen Plazenta, Braumüller.) Using the method of Hall, which demonstrates iron in loose organic compounds, Hofbauer found none such in the superficial layers of the syncytium, but an increasing number of granules were present in the deeper parts. In the mesoblast they again decreased in number, and were altogether absent near the capillary walls (Fig. 130). He suggests that at first the hæmoglobin derivatives are in too firm combination to take on the stain, then they are further broken down and stained granules appear, and later they are again synthesised into non-stainable compounds which reach the fœetal circulation. Such changes were characteristic of the first half of pregnancy. In the second half the iron-reaction of the villi was " extraordinarily slight."

Iron is stored in the liver and other fœetal organs. According to Bunge, ${ }^{2}$ it diminishes rapidly after birth, and he supposes that it compensates for the insufficient amount of iron contained in the mammary secretion.

Albumen.-The transmission of albumen to the fotus of the rabbit has already been referred to (see p. 435). In the human placenta attention has been chiefly directed to the investigation of the decomposition products of proteins. Matthes ${ }^{3}$ and

1 Veit and Scholten, "Synzytiolyse und Hämolyse," Zeitschr. f. Geburtsh. u. Gynäk., vol. xlix., 1903.

"Bunge, "Ueber die Aufnahme des Eisens in den Organismus des Säuglings," Zeit. f. phys. Chem., vol, xvii., 1893.

3 Matthes, "Ueber Autolyse der Placenta," Centralbl. f. Gynäk, 1901. 
Hofbauer state that albumoses are present in the placenta, but this is doubtful. In watery extracts Rieländer ${ }^{1}$ demonstrated purine bases, uracil and choline, and in the autolvsed placenta leucine and tyrosine have been found (Basso ${ }^{2}$ ). It is generally held that such results prove an active metabolism of protein in the foetal placenta.

Ferments.-Various enzymes have been investigated in the placenta. They may be grouped according to the chemical nature of the actions which they produce :-

Hydrolytic Reactions. - A proteolytic enzyme was found by Ascoli, ${ }^{3}$ and subsequently by Merletti, ${ }^{4}$ Bergell and Liepmann, ${ }^{5}$ Savarè, ${ }^{6}$ and others. Bottazzi ${ }^{7}$ states that placental tissue can transform glycogen into maltose, and a similar action is strongly produced by glycerine extracts of the maternal and fœtal placenta of the rabbit (see p. 434).

Savare holds that the transformation of glycogen to sugar is due to the blood; but the fact that extracts of the ungulate placentr, which also contain blood, do not possess the same power, forces us to conclude that the enzyme activity in the rabbit and Man depends on the placental tissue. No lipolytic enzyme is present in the placenta (Charrin and Goupil ${ }^{8}$ ).

Oxidation Reactions. - The oxidation of aromatic aldehydes by the placenta has been obtained by Hofbauer and by Ferroni, ${ }^{9}$ not by Savarè or Charrin and Goupil. V. Fürth and Schneider ${ }^{10}$ state that tyrosine is oxidised by contact with the placenta,

1 Rieländer, "Ein Beitrag zur Chemie der Placenta," Centralbl. f. Gynäk., 1907.

2 Basso, "Ueber Autolyse der Placenta," Arch. f. Gynäk., vol. 1xxvi.

3 Ascoli, "Passiert Eiweiss die placentare Scheidewand?" Zeitschr. f. phys. Chemie, vol. xxxvi., 1902.

"Merletti, "Ricerche e studi intorno ai poteri selettivi del" epitelio dei villi coriali," Rass. d'Ost. e. Ginec., 1903.

5 Bergell and Liepmann, "Ueber die in der Placenta enthaltenen Fermente," Münch. med. Woch., 1905.

- Savarè, "Zur Kenntnis der Fermente der Placenta," Hofmeister's Beiträge, vol. ix., 1907.

7 Bottazzi, "Placental Activity," Boll. della R. Accad. med. Genoura, vol. xviii.

${ }^{8}$ Charrin et Goupil, "Physiologie du Placenta," Comp. Rend. de l'Acad. des Sciences; vol. cxli., 1905 ; also vol. cxlii., 1906.

9 Ferroni, "L'eterolisi utero-placentare," Ann. di Ost. e Ginec., 1905.

${ }^{10}$ V. Fürth and Schneider, "Ueber tierische Tyrosinasen und ihre Beziehungen zur Pigmentbildung," Hofmeister's Beiträge, vol. i. 
resulting in the production of a dark pigment, and they have suggested that this reaction may be related to the special pigmentation of pregnancy.

Removal of amino-groups from amino-acids.-Savarè states that the placenta transforms the $\mathrm{NH}_{2}$ group of amino-acids into ammonia by means of a special ferment, a desamidase.

Decomposition of peroxides.-This reaction may be produced by enzymes, the so-called indirect oxidases, and is sometimes regarded as the means by which oxidation changes are restricted to the appropriate parts of the body, and secluded, for instance, from the blood (Leathes ${ }^{1}$ ). The guaiacol reaction, by which a colourless solution of guaiacol becomes red, takes place, according to Charrin and Goupil, when hydrogen peroxide is present; in other words, placental tissue decomposes the peroxide, and the nascent oxygen oxidises guaiacol. Hofbauer, however, says that the presence of hydrogen peroxide is not required, i.e. that the placenta acts as a direct oxidase.

Decomposition of glucose.-No glycolytic ferment is present in the placenta. ${ }^{2}$

A few ferment actions still remain-e.g. the removal of urea from arginin, the decomposition of uric acid, and the oxidation of purine bases-which have not yet been investigated in the placenta.

\section{General Considerations of Foetal Nutrition and the Placenta}

\section{A. The Plan of Placental Formation}

The problems of foetal nutrition are not new problems. They deal with the assimilation of organic and inorganic substances, and their incorporation in the developing tissues. These phenomena are made up of a series of chemical changes which must be studied individually before we can hope to understand the final sum which constitutes foetal metabolism, or the disturbances which constitute fotal disease. Set in the path

1 Leathes, Problems in Animal Metabolism, London, 1907.

2 It cannot yet be held as proved that glycolysis by ferment action occurs at all in animals. 
traversed by the materials on their way to the new organism is the placenta, a complex organ composed of specialised maternal elements and newly developed fotal elements. Among the Monodelphia no uniform plan is observable in the formation of the placenta, nor is it possible to trace each step in its evolution. But Duval's conception of this temporary organ as a maternal hæmorrhage surrounded by fœtal elements, and Hubrecht's discovery of such a type of placenta in a mammalian order which is among the most archaic, lead to a change in the ideas of placental classification. We can no longer depend on the shape of the placenta, or the characteristics of the after-birth, for an understanding of its morphological or physiological features. Rather must' we go back to the phenomena to be observed in the uterine fixation of the blastocyst, and even earlier in the preparation for that fixation. At this stage we find two constant features, one maternal and the other foetal. The maternal change consists of an epithelial, connective tissue or endothelial proliferation, the trophospongia, which is "specially intended for the fixation of the blastocyst." According to Hubrecht, it degenerates into a symplasma when the fixation is accomplished and the foetal elements are in contact with circulating maternal blood. But its degeneration is not completed at that stage. Though individual cells may die, other cells are formed and take their place, at least in Man, throughout the greater part of pregnancy. Moreover, the cells have other functions to perform. Whether or not they act as a defence against the excessive penetration of the trophoblast, they continue in the rabbit to exercise the glycogenic function for the developing organism till the hepatic cells have attained the power, and there is reason to believe that they play a part in the iron metabolism of the foetus.

The embryonic preparation is the proliferation of the whole or part of the extra-embryonic ectoderm, the trophoblast, in the spaces of which maternal blood circulates. The outer layer is plasmodial, and thus resembles the maternal symplasma in histological appearance, but differs from it in being a live tissue while the other is dying or dead. The fusion of the trophoblast and trophospongia constitutes the placenta, which is perfected by an increase in the number and size of the trophoblastic 
lacunæ, and in the amount of maternal blood in contact with it.

The above description does not, however, fit the placenta of Ungulates, for in them the trophoblast is not permeated by maternal blood. If the Insectivore placenta represents the primitive type, or is nearer to it than any other at present existing, we must assume that the Ungulate placenta, differing more widely from the original type, has lost this characteristic. Further, the placenta of the pig must have undergone a greater degree of modification than that of the sheep. In other words, the old ideas of placental evolution, based on the researches of Turner and others, must be literally reversed. The Primates must stand with the Insectivores near the primitive type, while the sheep and pig are near the opposite end, where some of the Didelphia are placed. Such considerations as these must inevitably come up for discussion in all future investigations.

\section{B. The Nature of the Trophoblastic Activity}

During the period of gestation, the mother organism is concerned with the provision of material for the growth and development of the fertilised ovum and the new-born young. Does the material provided for the ovum, and secured for it by the trophoblast, come from the maternal tissues or from the food supply? There is no doubt that in insufficient nutrition the foetus draws on the tissues of the mother (Jägerroos ${ }^{1}$ ), and a study of comparative placentation goes far to prove that this is a normal process in some orders. It is obvious that such occurs in the earliest stages. In all orders, before fixation of the blastocyst to the uterine mucosa, the degenerating ovarian cells which surround the extruded ovum form a store of nutriment. In some animals, however, such as the opossum, in which no attachment of the blastocyst can be said to occur, and the sheep, in which the attachment is long delayed, this nutriment is added to by the secretion of the uterine glands. In the socalled Deciduate orders, fixation is effected by a phagocytic or chemical action on the part of the trophoblast, and the

'Jägerroos, "Der Eiweiss-, Phosphor-, und Salzumsatz während der Gravidität," Arch. f. Gyräk., vol. lxvii. 
destroyed maternal tissue again seems to serve as food for the blastocyst.

After fixation, differences appear in the various orders. In Ruminants a special nutritive secretion, the uterine milk, is elaborated in the inter-cotyledonary areas. This secretion contains cellular elements of maternal tissue, particularly leucocytes and glandular epithelium, which are ingested and dissolved by the trophoblast during the whole period of gestation. In addition, extravasations of maternal blood or individual corpuscles occur in all, and the erythrocytes are also taken up and dissolved. In such orders maternal tissue elements are normally used for the fœetus throughout pregnancy.

Among the Deciduata, however, with the exception of the mole, in which the glandular secretion is maintained, the maternal blood may be considered to be the only source of fotal nutriment when the allantoic or chorionic placenta is developed. ${ }^{1}$ In them the trophoblast resembles a sponge saturated with slowly circulating blood, and its large superficies is admirably adapted for the acquisition of the various materials required for the fœetus. In what form do these materials exist in the blood? Are they simply the substances absorbed from the food by way of the intestine (see also Chap. XI., p. 495), or are they more highly elaborated? In other words, in the formation of the new organism are the syntheses carried out by the fertilised ovum itself, and it must be remembered that this includes the trophoblast, or are the new tissue-elements transferred ready-made from the mother? The limitations of biological chemistry force us to approach this problem indirectly. Differential analyses of special constituents of the blood, as the proteins, in the non-pregnant and pregnant animal are not yet possible.

In the first place, a brief consideration of the development of the chick embryo is sufficient to prove the high degree of activity vested in the ovum of birds. The special proteins and other tissue-elements are not pre-formed, but are elaborated by a series of katabolic and anabolic processes which are carried

1 The Carnivora, in which the trophoblast is not in contact with circulating maternal blood, occupy a special position among the Deciduata, and are not considered above. 
out by the ovum itself. There is no reason to believe that the mammalian ovum, after aequiring the property of intra-uterine development, has lost its metabolie activity. ${ }^{1}$

In addition, we possess positive evidenee of metabolic activity in the mammalian ovum. The results of Bohr's investigations on the respiratory exchange of the fotus (see p. 436) mean nothing if they do not afford proof of this. As a large amount of energy is generated, while, at the same time, practieally none is dissipated as heat evaporated or radiated from the surfaee or lungs, the unavoidable eonclusion is that the foetus itself carries out the work of organisation, and utilises the energy for its fulfilment.

When we eome to consider individual substanees, we obtain further evidence of activity, at least in the extra-embryonie ectoderm or trophoblast. In no order of Mammals has the transmission of hæmoglobin as sueh from mother to fœtus been demonstrated. Even if it is absorbed as sueh by the trophoblast, it undergoes ehanges of sueh a nature that the ironeontaining part of the molecule is less firmly bound. In all animals in which speeial investigations have been made, such loose organic compounds of iron have been observed. In this eonneetion, reference may onee more be made to Hofbauer's statement that the histologieal appearances argue not only for a decomposition of maternal hæmoglobin in the syncytium, but also for a synthesis of its derivatives into organic compounds in whieh the iron is more firmly bound (see p. 480).

The trophoblast probably acts also on simpler proteins. If ox-serum is injected into a pregnant rabbit, its proteins cannot be detected by the biological reaction in the serum of the fœtus. It may be that the trophoblast rejects them altogether, but this is unlikely, since molecules of egg-albumen are absorbed and transferred to the foetus (see p. 436). In all probability the proteins of ox-serum are katabolised in the villi, and, as a result, the constitution of the precipitable substanee is interfered with, and the preeipitin reaetion is negative. The

'If Hubrecht's view is correct, that the mammalian ovum is older than the ovum of birds (see "Early Ontogenetic Phenomena in Mammals," Quar. Jour. Micr. Sci., 1908), the sentence ought to read: "There is no reason to believe that the fertilised ovum of birds acquired its metabolic activities only after the loss of viviparity." 
existence of an intra-cellular proteolytic enzyme ${ }^{1}$ and decomposition products of the proteins in the placenta also point to the occurrence of a trophoblastic metabolism of proteins.

The carbohydrates undergo changes which appear to be the result of trophoblastic activity. In the rabbit, the glycogen which is "swallowed" along with the decidual cells by the plasmodium (Chipman) is not found as glycogen. A hydrolytic transformation to sugar probably takes place (see p. 434). In addition the fotal serum contains lævulose, which must be formed in some part of the fertilised ovum, since it is absent in the mother. Fats may also be transformed by the trophoblast (see Chap. XI., p. 512).

It is generally supposed that many syntheses occur in the fertilised ovum, though direct evidence is difficult to obtain in Mammals. In the chick hæmoglobin is synthesised, and the same almost certainly occurs in Man and other animals, part of the synthesis being effected by the trophoblast (see p. 480). The nucleoproteins of the fotal cotyledons in the sheep appear to be formed there, since they differ in composition from the nucleoproteins of the cotyledonary burrs. The glycoprotein mucin is a characteristic constituent of the inter-cellular groundsubstance of the whole fœtal organism, and is apparently built up by the ovum. ${ }^{2}$ The chondroproteins, a special group of glycoproteins, which yield on hydrolysis proteins and the carbohydrate-containing chondroitin-sulphuric acid, are also found chiefly in the fotus as constituents of the cartilage and tendons.

A consideration of these and similar facts leads us to believe that the new organism owes its development in large part to

1 The enzyme has been found only in the human placenta. It is desirable that its presence in the trophoblast should be established, and this can only be done in such animals as the sheep and rabbit, in which the fotal placenta can be detached from the maternal, and investigated separately. As was previously mentioned, the placenta contains no extra-cellular proteolytic enzyme.

2 In the placenta of the cow, Jenkinson has described cells resembling goblet-cells in the lining of the cotyledonary crypts, and ascribes to them a maternal origin (Proc. Zool. Soc., London, vol. i., 1906). They may supply mucin to the uterine milk, and so to the trophoblast. According to Assheton, these lining cells are trophoblastic in the sheep. 
the energy generated in it and by it from the combustion of substances supplied by the mother, and to a series of active metabolic changes by means of which these substances are transformed into living protoplasm. Whether the nutritive materials are derived from the food or tissues of the mother is of secondary importance. What is essential is that the fertilised ovum obtains certain organic and inorganic compounds and a supply of oxygen to carry out its work of organisation, just as in the first period of extra-uterine life the growth and development of the new being progress by its own activities, so long as it is furnished with the proper materials.

The special organ of embryonic nutrition is the trophoblast, and evidences of its katabolic activities have been described in various orders of Mammals. But in addition to procuring fixation of the blastocyst to the uterine mucosa, and absorbing and katabolising the food for itself and the embryonic portion of the ovum, it seems also to possess anabolic functions, at least in the earlier periods of pregnancy. Already developed in the blastocyst stage, it is active and functional for a considerable time. But in the later stages, it exhibits in all orders of Mammals a degree of morphological degeneration which is incompatible with the maintenance of its early physiological activity. It is further to be noted that its condition varies inversely with the food requirements of the embryo. When the daily requirements for the new organism are almost infinitesimal, the trophoblast is well developed. But as the daily transmission of llutriment increases, the trophoblast, which is now represented by the ectodermal covering of the villi, gradually and progressively degenerates. At the end of pregnancy the cytoblast, the mother zone of the plasmodiblast, is reduced to a few scattered groups of cells, while the plasmodial layer itself is no thicker than an endothelium, and may be altogether absent over long stretches of the villi. At this stage it is impossible to believe that the syncytium has any vital functions to perform. Indeed, we know that it has none, because the foetus, if prematurely born, is able to maintain life without its aid. Hence it seems likely that in the later stages the extra-embryonic ectoderm, though allowing a greater amount of material to pass to the fotus each day, acts merely as a semi-permeable 
membrane, and has lost all, or nearly all, its physiological activity. ${ }^{1}$

What is the difference in the early stages of pregnancy, when the trophoblast is morphologically well-developed? We believe that at that time the extra-embryonic ectoderm has less to do with the quantity, and more with the quality, of the material transferred to the new organism. It does not act merely by the physical laws of diffusion and osmosis. At this stage the cells of the ovum have not yet departed widely from a general type, and the active trophoblast would seem to spare the embryonic cells much of the work of the elaboration of the food-materials, and thus conserve their energies for their own multiplication and differentiation. As the cells gradually depart further and in different directions from the original type, each cell requires to expend less energy on its own specialisation; at the same time the nutritive wants become more varied, and each cell requires to expend more energy on the synthesis of its individual protoplasm. As the duties of selection and anabolism are more and more taken up by the cells themselves, the trophoblast has a less important part to play, and it undergoes a gradual process of degeneration. ${ }^{2}$

1 Hofbauer's observations on the hæmoglobin metabolism, already quoted (see p. 480), furnish concrete evidence of such a change in the trophoblast. In the first half of pregnancy the syncytium breaks down the maternal hæmoglobin, and subsequently builds it up in part for the foetus. But in the second half, though a greater daily supply of organic iron is required for the formation of hæmoglobin and other purposes (see p. 515), the amount of loosely bound iron-compounds in the villi is "extraordinarily small." The only explanation is that the larger molecules of the more firmly combined ironcompounds are not attacked and broken down so strongly by the syncytium, but are passed on to the fotal circulation.

${ }^{2}$ A similar change occurs in the decidual cells of the rabbit. In the first periods of their existence, they synthesise and store a large quantity of glycogen. In the last week, the cells of the fotal liver assume their glycogenic function, apparently absorbing the carbohydrate from the fotal blood as it returns from the placenta, and the decidual cells degenerate with the loss of their function. 


\section{CHAPTER XI}

\section{THE CHANGES IN THE MATERNAL ORGANISM DURING PREGNANCY ${ }^{1}$}

"We cannot reason with our cells, for they know so much more than we do that they cannot understand us; but though we cannot reason with them, we can find out what they have been most accustomed to, and what therefore they are most likely to expect; we can see that they get this, as far as it is in our power to give it them, and may then generally leave the rest to them."-SAMUEL BUTLER.

\section{The Stimulus for the Maternal Changes}

THE anatomical and physiological changes which occur in the maternal organism during pregnancy are manifold. They affect not only the generative system, but the body in general. They are associated with the supply of nutriment and energy for the formation of a new organism in the uterus, and the preparation for its maintenance in the succeeding period.

What constitutes the original stimulus for the changes that occur in pregnancy remains still outside our ken. At least the influence of the cerebrum is not all-important, as is shown by the occurrence of normal pregnancy and lactation in women suffering from paraplegia (Brachet, ${ }^{2}$ Kruieger and Offergeld ${ }^{3}$ ). Similarly, transection of the spinal cord in the lumbar region has no effect on pregnancy in the $\operatorname{dog}\left(\right.$ Goltz ${ }^{4}$ ). Further, Goltz and Ewald ${ }^{5}$ have proved the absence of any spinal reflex influence in the dog by removing the entire lumbar cord without disturbing the onset and progress of pregnancy. Kruieger and Offergeld state, as the result of numerous experiments, that the central nervous system has no influence, and the

1 By James Loch head.

${ }^{2}$ Brachet, Recherches, 2nd Edition, Paris, 1837.

${ }^{3}$ Kruieger and Offergeld, "Der Vorgang von Zeugung, Schwangerschaft," \&c., Arch. f. Gynäk., vol. lxxxiii., 1908.

- Goltz, "Ueber den Einfluss des Nervensystems auf die Vorgänge während der Schwangerschaft," \&c., Pflüger's Arch., vol. ix., 1874.

s Goltz and Ewald, "Der Hund mit verkürztem Rückenmark," Pfüger's Arch., vol. lxiii., 1896. 
sympathetic system has an effect only in so far as it modifies the circulatory conditions. The only change observed, after destruction of the lumbar cord, was a prolongation of the act of parturition, due to an absence of pain and the consequent loss of the reflex contractions of the abdominal muscles. The most important nervous elements for the uterus are contained in the uterine, paracervical, and paravaginal ganglia, but their excitability for external stimuli gradually decreases during pregnancy and is lost at the end.

We are thus forced to conclude that the phenomena of pregnancy and parturition are brought about by chemical stimuli acting through the blood-stream. The hormone or hormones may arise in the corpus luteum, which is essential for the progress of pregnancy, at least in the early stages (Marshall and Jolly ${ }^{1}$ ). Evidence is also forthcoming that the mammary secretion is due to an ovarian influence in certain cases. For instance, secretion may occur in virgin women who are the subjects of ovarian tumours, and in virgin bitches. Cramer ${ }^{2}$ has recorded a case in which the transplantation of ovaries into a woman, whose genital organs were much atrophied, led to a secretion of colostrum. ${ }^{3}$ On the other hand, removal of the ovaries at the middle of pregnancy does not interfere with the second half of the period of gestation, or with labour and lactation. ${ }^{1}$

The presence of the placenta may modify the normal metabolism in various ways. It is set in the path traversed by the formative material on its way to the embryo, and by the waste products excreted by the embryo. The form in which the materials required by the product of conception reach the placenta is still obscure. The protein may be merely the "circulating protein" found in the non-pregnant condition, or more highly elaborated. The diffusion of the blood-sugar to the fœetus is disputable, ${ }^{4}$ and the form of the fats is unknown. Of the waste products carbonic acid, which, according to Bohr, ${ }^{5}$

1 Marshall and Jolly, "The Ovary as an Organ of Internal Secretion," Phil. Trans., Roy. Soc., London, B., vol. cxcriii., 1905.

2 Cramer (H.), "Transplantation menschlicher Ovarien," Münch. med. Woch., 1906.

3 With regard to the existence of an ovarian stimulus, see also Hildebrandt (Hofmeister's Beiträge, vol. v., 1904).

4 See Chap. X., p. 434.

5 Bohr, "Der respiratorische Stoff wechsel des Saugetierembryo," Skand. Arch.d. Phys., vol. x., 1900 ; also vol. xv., 1904. 
results entirely from the combustion of carbohydrates in the mammalian foetus, is excreted into the maternal circulation through the placenta. With regard to a wastage in the protein metabolism, a certain loss is bound to occur in the transformation of " circulating" or " fixed " maternal proteins into fœetal tissue proteins; and in addition, incompletely oxidised substances may possibly be transmitted to the placenta and oxidised there or in the mother $\left(B_{0 h r}{ }^{1}\right.$ ). The question of urea formation by the foetal liver or the trophoblast is still uninvestigated, and no proof exists of the excretion of urea otherwise than into the liquor amnii. Nor does its presence in the amniotic fluid necessitate an oxidation of protein; it may be split off, as in the adult, by a simple hydrolytic cleavage. At present we must be content with assuming the possibility of modifications in the maternal blood from the presence of foetal nutritive and waste materials. Hitherto the investigations have been largely confined to human pregnancies, in which individual differences are at a inaximum, and the application of the experimental method is restricted. Hence our knowledge of the chemical changes in the blood is very limited. Its composition may, in addition, be modified by the activities of the placenta itself. Several theories have been put forward in support of the view that this organ acts as an internally secreting gland. NattanLarrier ${ }^{2}$ goes so far as to state that the secretion can be demonstrated in the form of globules, lying on the surface of the villi, but these arise in the post-mortem degeneration of the tissue. Of the same nature are the products of the placenta which have a blood-pressure raising action. Extracts of the fresh organ have no pressor effects, nor do they increase uterine contractions. ${ }^{3}$ Halban ${ }^{4}$ considers that the placenta secretes a hormone which stimulates the growth of the mammary gland and the secretion of milk. Starling ${ }^{5}$ states, on the

1 Bohr, see Nagel's Handbuch der Physiologie, "Respiration," vol. i., H. i.

${ }^{2}$ Nattan-Larrier, "Fonction Sécrétoire du Placenta," Comp. Rend. Soc. Biol., vol. lii., 1900.

3 See foot-note ${ }^{2}$, p. 522.

- Halban, "Die innere Secretion von Ovarium und Placenta, und ihre Bedeutung für die Function der Milchdrüse," Arch. f. Gynäk., vol. Ixxv., 1905 .

s Starling, "Chemical Correlations of the Functions of the Body," Croonian Lect., Lancet, 1905. 
other hand, that the hormone is containcd in the tissues of the fotus. ${ }^{1}$ By its activity during pregnancy, it leads to a proliferation of the mammary tissue, while the cessation of the stimulus after parturition brings on the secretion of milk.

According to Liepmann, ${ }^{2}$ the maternal blood contains a special protein, elaborated by the placenta, which may be recognised by the biological reaction, and Freund ${ }^{3}$ states that the precipitable substance is present in the urine of pregnant women. Others have been unable to find such a substance either in the blood or urine (see Weichardt and Opitz ${ }^{4}$ ).

Veit's ${ }^{5}$ theory is also sub judice. Taking up Schmorl's ${ }^{6}$ discovery that emboli of placental cells may be found in organs of the mother in eclampsia, he extends it to normal pregnancy, and postulates that syncytial fragments and even whole villi pass regularly into the maternal circulation. There they give rise to an anti-body, a syncytiolysin; which itself dissolves the circulating syncytium. He also seeks to explain, by the activity of the lysin, the absorption of hæmoglobin and other proteins from the intervillous spacc by the villi, the pigmentation of the skin and vaginal mucous membrane from superficial emboli, and the phenomena of telegony from the circulation of elements derived in part from the paternal side.

1 It is conceivable that both vicws arc right, since the main mass of the plaecnta is as much a part of the fcrtilised ovum as the foctus itself. In future investigations, the better recognition of the composite strueture of the placenta is desirable. In many animals it is possible to separate the maternal and fotal tissues with eonsiderable accuracy, and any effect obtained from onc or other part can be definitely ascribed to the modified uterine mucous menbranc, or to the extra-embryonie part of the ovum.

2 Liepmann, "Ueber ein für nenscbliche Plazenta spezifisehes Serum," Deut. med. Woch., 1902, 1903.

"Freund, "Beiträge zur Biologie der Schwangerschaft," Vortr. auf. $d$. 76 Naturf. zu Breslau, 1904.

4 Weichardt u. Opitz, "Zur Biochemie der Sclıwangersehaft," Deutsche med. Woch., 1903.

5 Veit, "Ueber Deporlation von Chorionzotten," Zeitschr.f. Geb.u. Gynaik., vol. xliv. Also Veit u. Scholten, "Synzytiolyse und Hämolyse." Zeitschr. f. Geb. u. Gynäl., vol. xlix., 1903.

- Sehmorl, Path.-Anat. Untersuchungen über die Puerperaleklampsia, Leipzig, $1 \times 93$.

7 The discussion of the relationship between the deportation of chorionic villi and the pathology of eelampsia, pregnancy kidney, placental polypi, hyperemesis, \&c., falls outside the scope of this work. 


\section{THE PHYSIOI.OGY OF REPROIUC'IION}

At present it is only a speculation, as Veit himself is careful to explain, but its far-reaching possibilities have already given rise to many investigations. ${ }^{1}$ It must be clearly understood, however, that biologists have at present no proof of the formation of an anti-body consequent on the introduction of any protein of the same individual, or one of the same species.

From time to time evidence of hremopoiesis in the placenta has been brought forward. Mention of it was first made by Masquelin and Swaen ${ }^{2}$ in the rabbit, and later by Frommel ${ }^{3}$ in the mouse and bat. Hubrecht ${ }^{4}$ strongly upholds the occurrence of blood formation in the placentæ of Tarsius and Tupaia. The new erythrocytes arise as products of the fragmentation of nuclei of the trophoblast in Tarsius (see p. 410), and of the trophoblast, and probably also trophospongia, in Tupaia (see p. 457). They are later set free by solution of the surrounding protoplasm. Such a process is beneficial both to mother and embryo. The erythrocytes are increased at the expense of the ovum, and they in turn increase the supply of oxygen to the foetus.

\section{I1. Changes in the Metabolism of the Mother during Pregnancy}

\section{A. The Source of the Materials transferred to the New Organism}

The question is discussed in another chapter (see p. 484) whether the materials that go to the formation of the new organism are entirely elaborated in the ovum itself, or are partly

'See Kollmann, "Kreislauf der Plazenta, Chorionzotten und Telegonie," Zeitschr.f. Biol., vol. xlii., 1901.

${ }^{2}$ Masquelin and Swaen, "Développement du placenta maternel chez le lapin," Bull.de l'Acad. Roy. de Belgique, 1879.

'Frommel, Ueber die Entwicklung der Placenta von Myotus murinus, Wiesbaden, 1888.

4 Placental hæmopoiesis is denied by many authorities, including Duval, Maximow, Nasius, and Nolf. For a complete review of the subject, see Hubrecht, "Ueber die Entwicklung der Placenta von Tarsius und Tupoja, nebst Bemerkungen über deren Bedeutung als hæmatopoietische Organe," Internat. Congr. of Zool., Cambridge, 1898. 
or wholly prepared by the mother. As stated there, the histological and biological evidence leads us to believe that the materials, whatever their source and constitution, are in the early stages broken down and partly re-synthesised by the trophoblast, while later in pregnancy they are metabolised by the fotal cells themselves. Granting this, we must further suppose that the maternal duties do not extend to the formation of fœtal tissue-components, but are limited to the provision of food and oxygen for the fertilised ovum, the removal of its waste products, and the preparation of an organ of nutrition for the new-born young. Each of these duties leads to changes in metabolism, which may, in addition, be excited by special stimuli produced during pregnancy (see p. 491).

In the provision of nutriment for the embryo, does the mother deplete her own tissues, or is she content to transfer the unorganised substances, which are absorbed from the food and not yet fixed as vital constituents of the protoplasm? Probably both. In insufficient nutrition the mother certainly gives up organised tissue-products, and, even with a plentiful diet, a period is usually observed during which the mother must draw on her own tissues to account for the loss of nitrogen. On the other hand, it is probable that unorganised substances are also utilised by the trophoblast, since variations in diet are apparently capable of producing changes in the foetus. ${ }^{1}$ It was noted by the writer and Dr. W. Cramer ${ }^{2}$ that abortion occurred in three out of six pregnant rabbits fed on a diet rich in carbohydrates during the whole period of gestation. A similar observation is recorded by Cramer and Marshall. ${ }^{2}$ Wallace $^{3}$ states that cows fed on molasses prove to be uncertain breeders, and Heape ${ }^{4}$ that Lincoln sheep fed solely on turnips are specially liable to abortion.

1 Thiemich was, however, unable to discover any difference in the constitution of the fotal fat, after feeding the mother on widely different fats (see p. 512).

${ }^{2}$ See Cramer and Marshall, "A Note on Abortion as a result of a Diet rich in Carbohydrates," Journ. of Econ. Biol., vol. iii., 1908.

3 Wallace, Farm Live Stock, 1907.

4 Heape ascribes the frequency of abortion to the fouling of the turniproots by mud and excrement, a condition of things which results from overcrowding. See Journ. Roy. Agric. Soc., 1899. 


\section{6 'THE PHYSIOLOGY OF REPRODUCTION}

According to Noel Paton, ${ }^{1}$ the size of the offspring of the guinca-pig depends very directly upon the diet and nutrition of the mother during pregnancy. "To the physiologist it demonstrates the limitations in the extent to which the tissues of the mother can be utilised for the construction of the embryo. The nourishment of the maternal tissues seems to take precedence over the nutrition of the fœtus. The mother appears to pass on the surplus nourishment to the fotus. The better the nourishment of the maternal tissues, the greater the growth of the foetus." On the other hand, it has been proved in the pregnant rabbit that, when the glycogen of the body is reduced to traces by repeated injections of phloridzin, the placenta and foetus still retain considerable amounts. ${ }^{2}$ In this instance the needs of the fotus have taken precedence over the storage of a carbohydrate reserve for the mother. Like Paton, Prochownick $^{3}$ states that the size of the offspring may be markedly diminished by restricting the diet of the mother (human female); but many exceptions to this rule are found, unless the restriction of food has been severe enough to jeopardisc the life of the mother.

This opens up another question: Does the expenditure for the embryo entail loss to the mother? "If the mother must transfer a part of her own bodily substance to the germ, the loss is of little importance if she can cover this loss from her food. The setting of the question runs thus: Is the maternal body deprived of protcin, fat, and other substances during and in consequence of the formation of a new being, and is its store of these materials, after the resulting birth, or at the close of the puerperium, less than before the advent of pregnancy, or is this not the case? An unprejudiced clinical proof from human subjccts points to the possible occurrence of both conditions. Many mothers during pregnancy increase so slightly in weight that their own tissues must have suffered loss during this time, others become heavier to the extent of ten kilograms or more.

\footnotetext{
1 Noel Paton, "The Influence of Diet in Pregnancy on the Weight of the Offspring," Lancet, 1903.

${ }^{2}$ Lochhead and Cramer, "The Glycogenic Changes in the Placenta and the Fretus of the Pregnant Rabbit," Proc. Roy. Soc., London, B., vol. Ixxx., 1908.
}

${ }^{3}$ Prochownick, Therap. Monatshefte, 1901, quoted by Paton (loc. cit.). 
The investigation has not to determine whether the maternal organism suffers loss or experiences gain, but to demonstrate under which conditions of nourishment the one or the other appears. It has to investigate whether and in what amount the needs of the mother are increased, if her original condition is to remain unaltered while new tissues are being formed" (Magnus-Levy ${ }^{\mathbf{1}}$ ).

\section{B. The Body-weight during Pregnancy}

Systematic determinations of the body-weight give some idea of the effect of pregnancy on the maternal organism as a whole. Gassner ${ }^{2}$ observed a progressive increase in weight, greater than the increase in the weight of the fœetus (about 1 kilo per month) and the generative organs (about 0.125 kilo per month) together. This is due to the increase in the other parts of the maternal organism as a "result of the inactivity and good dietetic conditions during pregnancy, and the frequency with which the tissue fluids, e.g. in the lower extremities, are increased." Baumm ${ }^{3}$ confirmed these results. A diet necessary to maintain the body-weight in a woman of the same size gave an increase in weight of a pregnant woman amounting to an average of 1.777 kilo in the last month, of which $0 \cdot 650$ kilo represented increase outside the fœtus and generative organs.

Zacharjewsky ${ }^{4}$ observed an increase in weight running parallel to the increased weight of the fœtus and uterus. Some days before birth he found a decrease in primiparæ and a balance in multipare, which he referred to Ahlfeld's observations that the foetus increases only up to the thirty-ninth week, and in the last week decreases.

There are, however, limitations to the estimation of the

1 See v. Noorden, Metabolism and Practical Medicine, vol. i., section on "Metabolism of Pregnancy."

2 Gassner, "Ueber dieVeränderung des Körpergewichtes bei Schwangeren," \&c., Monatsschr.f. Geburtsh. u. Frauenkrankh., vol, xix., 1862.

3 Baumm, "Gewichtsveränderungen der Schwangeren," \&c., Inaug.Dissert., München, 1887.

- Zacharjewsky, "Ueber den Stickstoff wechsel wäbrend der letzten Tage der Schwangerschaft," \&c., Zeitschr.f. Biol., vol. xxx., 1894. 
total metabolism by the alteration in weight. Thus Bar and Daunay ${ }^{1}$ discovered no increase of weight in a pregnant dog, though it had retained $5 \cdot 24$ grammes nitrogen, equal to 170 grammes flesh. Such a discrepancy may be easily explained, for example, by a loss of water. In Man the physiological variation in the water-content is as much as 2 kilo. Hence it is necessary to obtain a more accurate measure, and for this purpose to investigate separately the metabolism of various substances, proteins, carbohydrates, fats, minerals, salts, and oxygen. The available data are as yet too meagre to demonstrate the good and the bad conditions of nutrition, but they indicate the paths along which future investigations may prove of value.

\section{The Protein Metabolism in Pregnancy}

a. The Absorption of Proteins by the Mother.-According to Kehrer, ${ }^{2}$ the gastric functions are slightly below normal in the human female during pregnancy. Free hydrochloric acid and pepsin are each decreased by a third. At the same time the intestinal functions appear to be sufficiently active for the satisfactory absorption of nutriment.

The absorption of flesh does not show any characteristic change in the dog during pregnancy. If decreased, it is due to pathological conditions, and diarrhœa and vomiting are present (Bar and Daunay). Ver Eeke ${ }^{3}$ states that the absorption of nitrogen decreases in the second half of pregnancy in the rabbit, but he ascribes the change to mechanical conditions. Maurel ${ }^{4}$ is of opinion that a gradual decrease in the nitrogen intake occurs throughout pregnancy in the guinea-pig, but at the beginning the intake is above the non-pregnant level. Zacharjewsky found that only 4 to 6 per cent. of the nitrogen was un-

1 Bar and Daunay, "Bilan des échanges azotés pendant la grossesse," Journ. de Phys. et de Path., vol. vii., 1905.

${ }^{2}$ Kehrer, Die physiologischen und pathologischen Beziehungen der weib. lichen Sexualorgane zum Tractus intestinalis, Berlin, 1905.

${ }^{3}$ Ver Eeke, Lois des échanges nutritifs pendant la gestation, Bruxelles, 1901.

- Maurel, "Des dépenses albuminoides pendant la grossesse chez le cobaye," Comp. Rend. Soc. Biol., vol. lxi., 1907. 
absorbed by the human female in the last two weeks of pregnancy, and Slemons ${ }^{1}$ found 7 per cent. and 3 per cent. in a primipara and a multipara respectively at the same period.

b. The Dxily Requirement of Protein for the Fotus.-The only measure we possess of the extra protein required in pregnancy is the amount deposited in the fotus and adnexa, the growing uterus, and mammæ. But this gives too low a figure, since one gramme of tissue-protein requires more than one gramme of food-protein for its manufacture. In addition, though we are dealing with a period when anabolic processes are at a maximum in the new organism, we are bound to assume that the cardiac, hepatic, and other activities of the fotus, and the rhythmic contractions of the uterus entail a certain loss of protein from wear and tear. What these extra requirements amount to is unknown, or whether protein substances play any part in the provision of energy for the work of organisation. ${ }^{2}$

The amount of nitrogenous material deposited in the human foetus during the last stages of pregnancy has been calculated. Michel ${ }^{3}$ estimates it at $56.69 \mathrm{grm}$. of nitrogen in two months, or slightly under $1 \mathrm{grm}$. per day. Magnus-Levy's figures are somewhat lower $-50 \mathrm{grm}$. in the last hundred days, or $0.5 \mathrm{grm}$. per day. This represents only $3 \mathrm{grm}$. of protein, and when added to the daily deposition in the placenta, uterus, and mammæ, it still remains inconsiderable.

c. The Nitrogen Balance in Pregnancy. ${ }^{4}$-According to the earlier investigators, a special economy of protein exists during pregnancy. As Repreff ${ }^{5}$ puts it, anabolic processes are in-

1 Slemons, "Metabolism during Pregnancy, Labour, and Puerperium," Johns Hopkins Hosp. Rep., vol. xii., 1904.

${ }^{2}$ In so far as the work of organisation is carried out by the mammalian fotus and not by the mother, the energy is probably supplied by the combustion of carbohydrates alone (see p. 518).

${ }^{3}$ Michel, "Sur la composition chimique de l'embryon et du foetus humain," Comp. Rend. Soc. Biol., vol. li., 1899.

4 See also v. Noorden's Metabolism and Practical Medicine, vol. i., Sect. IV. D., English Translation, 1907.

5 Repreff, "De l'influence de la gestation sur les échanges materiels," Russ. Dissert., 1888. Quoted by Slemons, loc. cit. 
creased and katabolic processes decreased in pregnancy in dogs, rabbits, and guinea-pigs.

Hagemann's 1 investigations in the dog form the first accurate observations of the nitrogen balance during the whole course of pregnancy. He set limself to solve the question whether the new organism was formed from the food, or at the expense of the maternal tissues. From the first experiment he concluded that, even on a diet rich in nitrogen, there was a loss of protein to the mother at the end of pregnancy. While $33.583 \mathrm{grm}$. nitrogen were retained, the young contained at birth $7 \cdot 445 \mathrm{grm}$. This left a balance of $26.128 \mathrm{grm}$. for the extra needs of the mother, which, he says, was nearly all required for the formation of the foctuses (calculated at $16.6 \mathrm{grm}$.$) and placentæ (8 \cdot 7 \mathrm{grm}$.$) . The additional nitrogen$ required for the growth of the uterus and mammæ must have been derived from the maternal tissues. Hence the pregnancy resulted in a loss to the mother. Similarly in lactation 34.056 grm. nitrogen were retained, and the calculated excretion in the milk was $76 \mathrm{grm}$. - a loss of $41.944 \mathrm{grm}$. nitrogen.

It is doubtful if such a conclusion is warranted, but the figures have been given in some detail to illustrate some of the difficulties to be overcome in carrying out the investigation. Many troubles have been experienced in trying to keep the animals on a constant diet, and, in addition, the increasing size of the uterus may prove a mechanical difficulty and impede the intestinal activity (Ver Eeke ${ }^{2}$ ). Hagemann failed to obtain the shed placentæ, which were eaten by the mother animal. Hence the estimate of $8.7 \mathrm{grm}$. nitrogen lost by them during pregnancy and labour is arbitrary, and is, according to Bar and Daunay, ${ }^{3}$ much too high. On these and other grounds-there is a period of thirteen days during the pregnancy for which no data are given - the calculations for pregnancy considered as a unit are open to objection.

1 Hagemann, "Ueber Eiweissumsatz während der Schwangerschaft und Laktation," Arch. f. Anat. u. Phys., phys. Abth., 1890; also Inaug. Diss., Erlangen, 1891.

2 Ver Ecke, Lois des échanges nutritifs pendant la gestation, Bruxelles, 1901.

3 Bar and Daunay, "Bilan des échanges azotés pendant la grossesse," Journ. de Phys. et de Path., vol. vii., 1905. 
On one point the results are of value. Hagemann states that the period of gestation may be divided into two parts. In the first, which lasts in his experiment for the first month of pregnancy, there is a continuous loss of nitrogen to the mother each day. In the second, there is a storage of nitrogen which is used in the growth of the product of conception.

In Ver Eeke's experiments, nineteen in all, in the rabbit, two phases were also frequently observed, but the results varied widely. In some there was a positive balance throughout, and in others a negative balance now at one time and now at another. In the greater number the same diet was administered before and after pregnancy and during its whole course. The amount of protein did not far exceed the minimal requirement for the maintenance of nitrogenous equilibrium.

Similarly variable results were obtained by Jägerroos ${ }^{1}$ in the dog. ${ }^{2}$ In his Experiment II., in which the nitrogen content of the food was high and the diet was pure flesh, there was a positive balance each week except the second, $27.9 \mathrm{grm}$. nitrogen in all being retained during pregnancy. In Experiment III., also on a diet of flesh but containing only 5.97 grm. nitrogen per day, a negative balance occurred only in the fifth and sixth weeks; but when the weight of the fœtuses and adnexa, and a serious loss of nitrogen soon after labour were deducted, there was a final loss to the mother of more than $6 \mathrm{grm}$. of protein. In the last experiment the diet consisted of $60 \mathrm{grm}$. of flesh and $100 \mathrm{grm}$. of sugar, which was just sufficient to maintain nitrogenous equilibrium. ${ }^{3}$ It was maintained for the first few days of pregnancy, and then a loss of nitrogen occurred each week throughout the whole course of gestation except the third.

In summing up the result of the three investigations, we must still leave it undecided whether an increased katabolism of protein is characteristic of pregnancy as a whole, or is entirely dependent on the diet. Hagemann's dictum that gestation entails a sacrifice of protein on the part of the maternal organism is

\footnotetext{
1 Jägerroos, "Der Eiweiss-, Phosphor-, und Salzumsatz während der Gravidität," Arch. f. Gynäk., vol. Ixvii., 1903.

2 Jägerroos and Ver Eeke failed to secure the shed placentæ.

${ }^{3}$ Calculated over two days only.
} 
still unproven. Such is undoubtedly the case on a minimal protein diet; but, with a greater allowance of nitrogen, the conclusions of Hagemann and the others are not borne out by the more recent researches of Bar and Daunay. They fed three pregnant bitches on a constant diet of bread, water, fat, beef, and salt, and estimated the nitrogen of the urine and freces at regular intervals. They took precautions to secure the young and the after-births, and were able to determine accurately their nitrogenous content. In the three animals, as in two observed by Jägerroos, the period of gestation was triphasic. There were first a period of retention of nitrogen, then a balance or very slight loss, and finally a retention increasing with the progress of gestation. Further, there was over all a gain of nitrogen in two dogs at the conclusion of labour. Hence they conclude that pregnancy in a healthy animal, with a rational and sufficient diet, does not necessitate a drain on her stock of nitrogen to satisfy the needs of the fœetus.

Jägerroos showed that, on a minimal protein diet, the nitrogenous equilibrium was disturbed by the onset of pregnancy. The loss of nitrogen began during the first week after conception, when the fertilised ova were still in the oviduct or had just reached the uterine cavity. At this stage the daily fixation of nitrogenous substances in the young blastocyst is too small in amount to affect per se the nitrogenous equilibrium. At the same time there is an appreciable daily loss of nitrogen which must be derived from the maternal tissues. It is permissible to assume a relationship between the two facts, and argue that the presence of the young blastocyst leads in some way to an increased katabolism of protein. ${ }^{1}$ The daily loss of tissue is maintained for a longer or shorter period during pregnancy, according as the nitrogenous content of the diet is near the minimum or more abundant. But, even on a comparatively rich protein diet, it is generally accepted by the investigators that a negative balance occurs for a considerable period, that it then disappears, and is replaced by a positive balance lasting

1 It must, however, be kept in mind that the corpus luteum is undergoing active changes at this period. As already stated, it is not known whether the ovum or the corpus luteum provides the stimulus for the changes referred to, or whether both of these are concerned (see p. 504). 
till the end of pregnancy. ${ }^{1}$ In other words, during the period in which the needs of the embryo are small the amount of protein katabolised is not counterbalanced by the food protein, and the maternal tissues suffer loss ; in the later period, although the daily amount of nitrogen fixed by the new organism is considerably greater, the excreted nitrogen is more than counterbalanced by the food nitrogen, and the maternal tissues gain, or at least do not lose to such an extent as formerly. In the human female, in whom investigations have been conducted only in the last few weeks of pregnancy, a retention of nitrogen has been invariably found. According to Zacharjewsky, ${ }^{2}$ it amounted to a gain of $0.873 \mathrm{grm}$. per diem in primiparæ and $5.05 \mathrm{grm}$. in multiparæ. On a diet usually containing less than 20 grm. nitrogen per day, Bar and Daunay observed an average retention of $6.54 \mathrm{grm}$. in three primiparæ for eleven days in the last month of pregnancy, a figure far exceeding that obtained in the same women on the same diet a considerable time after pregnancy. ${ }^{3}$

What is the reason for the increased katabolism of nitrogenous substances during the earlier stages of pregnancy? Hagemann says: "In the transformation of maternal proteins into the proteins of the growing uterus, embryos, and mammary glands, some of the nitrogen-containing complexes of the molecules lose their specific character, cannot be built up in the new protein molecule, and are excreted in the urine." Ver Eeke suggests that the loss of maternal blood may hasten protein katabolism, and its reconstitution entail a sacrifice of nitrogenous substances on the part of the mother. But it is not enough to say that the loss of nitrogen is due to the inability of the cells to build up protein synthetically, since no loss occurs on a sufficient diet in the later stages of pregnancy, although the synthesis of new tissue then reaches a maximum. Ver Eeke also states that the greater katabolism in proportion to weight in growing than in

${ }^{1}$ Recently corroborated in the dog by Murlin ("Protein Metabolism in Development," Amer. Journ. of Phys., vol. xxiii., 1908-9).

"Zacharjewsky, "Ueber den Stickstoftwechsel während der letzten Tage der Schwangerschaft," Zeitschr. f. Biol., vol. xxx., 1894.

${ }^{3}$ During the puerperium, the low diet administered to women entails a loss of nitrogen to the maternal organism. Very variable times have been noted in different cases before nitrogenous equilibrium was restored. 
grown animals may result in a negative nitrogen balance. But in every other instance growth is associated, not with a loss, but with a retention of nitrogen. The conditions are too complex to admit of such a simple explanation.

With the onset of pregnancy certain parts of a grown organism -uterus, mammæ, \&c.-are suddenly stimulated to growth. At the same time a new organism is to undergo development. Concurrently with these phenomena of grow: $h$, a negative nitrogen balance occurs in the first half of pregnancy; that is to say, pregnancy produces a change in the protein metabolism. In the second half of pregnancy, growth is associated with a retention of nitrogen by the mother. In other words, the conditions which come into existence at the $\mathrm{b}$ ginning of gestation, and lead to a negative nitrogen balance, alter during its course.

That growth proceeds along with a loss of nitrogen is noteworthy. It is at variance with the conditions found in all other instances of physiological growth, with which, however, the growth of certain organs in pregnancy cannot be compared, since it alone occurs in a grown mammal. It is conceivable that this phenomenon in itself is sufficient to disturb the protein metabolism. As was previously mentioned, it is not known whether the stimulus for the changes during pregnancy is derived from the fertilised ovum itself, the corpus luteum, or some other less obvious factor. It has been experimentally proved that the corpus luteum is essential in the early, but not in the later stages. ${ }^{1}$ Its development dates from the period of conception, and its activity lasts until the middle of pregnancy, after which it undergoes structural and functional degeneration. Hence the period of its activity corresponds with the period of the negative nitrogen balance in the mother. Hagemann's observation of a similar nitrogen balance at a certain phase of the ostrous cycle when corpora lutea are also developed, though no ovum is fertilised, would seem to favour the view that the loss of nitrogen is in some way connected with the changes in the ovary.

Like the corpus luteum, the trophoblast undergoes a marked change during pregnancy. In the early stages it forms the special organ of nutrition for the embryo, and in addition to

1 Marshall and Jolly, loc. cit. (see pp. 336-345, 351, and 491). 
absorbing nutriment it probably elaborates it into a form suitable for its incorporation in the new tissues. It is to this activity that we may have to lo $\mathbf{k} f \sim r$ an explanation of the negative nitrogen balance at the beginning of pregnancy. In the later stages the ectodermal covering of the villi loses its vitality, and seems to act more as a semi-permeable membrane (see p. 488). The cells of the new organism are now more fully differentiated, and are capable of carrying on their own metabolic functions.

d. The Nitrogen Fxcretion during Pregnancy.-The total nitrogen excreted during the later stages of pregnancy is decreased in amount. It again rises distinctly in the puerperium (Boni, ${ }^{1}$ Slemons ${ }^{2}$ ). The urea nitrogen was stated to be normal in amount by $v$. Winckel ${ }^{3}$ and Zacharjewsky, but more recent observations prove that it is diminished in proportion to the total nitrogen. According to Matthews, ${ }^{4}$ it may fall below 13 grm. per day without any signs of insufficiency. ${ }^{5}$ The ammonia nitrogen, which is of interest in connection with the question of acidosis in pregnancy, is relatively increased, but at present no proof is forthcoming that it is absolutely higher than in the non-pregnant state. The relative increase is due to the decrease in the total nitrogen (Slemons, Matthews). In eclampsia, Zweifel ${ }^{6}$ has frequently observed an increase of the ammonia nitrogen to 10 per cent. or more of the total, and, associated with it, the presence of an organic acid in the urine. The acidosis, at least in a certain number of the cases, is the result of the eclamptic seizures. Further investigations of the conditions when no fits have occurred are necessary before any constant association of an acidosis with the disease can be affirmed.

The uric acid excretion is within physiological limits. The

'Boni, "I corpi purinici nelle urine delle gravide e delle puerpere," Ann. di Ost. e Gin., 1906.

2 Slemons, "Metabolism during Pregnancy," \&c., Johns Hopkins Hosp. Rep., vol. xii., 1904.

${ }^{3}$ V. Winckel, Studien über den Stoffuechsel, \&c., Rostoek, 1865.

4 Matthews, "The Urine in Normal Pregnaney," Amer. Journ. Med. Sc., vol. cxxxi., 1906.

5 There are, however, wide physiological variations according to the $\mathrm{N}$-content of the diet.

"Zweifel, "Die Eklampsie," Arch.f. Gynäk, vol. lxxii., 1904. 
figures given by Zacharjewsky are $0.603 \mathrm{grm}$. per day in primiparæ, and $0.531 \mathrm{grm}$. in multiparæ. Boni states that it is almost normal in amount, but his figures are considerably lower than the average given by Magnus-Levy for a mixed diet. ${ }^{1}$ Boni observed a diminution in the purine bases which varied between $4 \cdot 7$ and $6 \cdot 8$ per cent. ${ }^{2}$

V. Leersum ${ }^{3}$ states that in 40 per cent. of pregnant women on the usual hospital diet, the amino-acid nitrogen amounts to over 10 per cent. of the total nitrogen, whereas it varies between 2.7 and 7.7 per cent. in the non-pregnant. The maximum is usually reached before birth, and there is a decrease later. Sometimes the maximum does not occur till after birth, but the acids may then be derived from the involution of the uterus. The results, according to this investigator, argue for a disturbance of the liver even in apparently normal pregnancies, its power of splitting off ammonia from and oxidising the aminoacids being impaired. ${ }^{4}$

The albuminuria of pregnancy in the human female is not strictly physiological. Regarding its frequency very varying figures have been given, ranging from 5 per cent. to 60 per cent. It appears in the second half of pregnancy, gradually increases up to the time of birth, and quickly decreases in the puerperium. In 50 per cent. of the cases it has already disappeared on the fourth day after labour. The protein is of renal origin, and in a typical case amounts to 0.01 to 0.05 per cent. That it is not due to mechanical pressure on the renal vessels or ureter, or to increased intra-abdominal pressure, seems certain. Nor has any definite proof been given of the influence of a toxin arising in the foetus, and causing degeneration of the renal epithelium. Veit ${ }^{5}$

1 As uric acid is derived in part from the nuclcins of the food, no conclusions can be drawn from its estimation on an unknown dict.

2 The average value is 8 per cont. on a mixcd dict.

3 V. Leersum, "Dic Ausschcidung von Aminosäuren währcnd der Schwangerschaft," Biochem. Zeitschr., 1908; Fest. f. Hamburger.

* It has not yet becn proved that the liver is the only organ which posscsses this function. The placenta itsclf is stated to contain a desamidase (Savarè, "Zur Kenntnis der Fermente der Placenta," Hofmeister's Beitr., vol. ix., 1907 ; sce also p. 482), hence the increase in amino-acid nitrogen may be duc to a disturbance of placental function.

"Veit, "Ucber Albuminurie in der Schwangerschaft," Berlin. klin. Woch., 1902. 
explains it by his hypothesis of the presence of placental constituents in the maternal circulation. Metabolic investigations in pregnancy complicated by albuminuria show nothing characteristic (Magnus-Levy ${ }^{1}$ ).

A special constituent of the urine may be found during the puerperium. Though called peptone (Fischel ${ }^{2}$ ), it really consists of deutero-albumuses which arise from the involution, i.e. autolysis, of the uterus (Langstein and Neubauer ${ }^{3}$ ). As with similar proteins introduced subcutaneously, the organism has not the power of splitting them up, and they are excreted unchanged. Fischel stated that peptonuria might also occur in pregnancy; but this was disproved by Thomson, ${ }^{4}$ who also showed that a puerperal peptonuria did not regularly exist. Ehrström ${ }^{5}$ regards it as a certain indication of fever and sepsis, the peptone being contained in the leucocytes of the purulent lochia.

As a result of the involution of the uterus, creatin may also appear in the urine. Murlin ${ }^{6}$ kept a dog on a creatin-free diet during the last week of pregnancy. The creatinin output was constant, but creatin appeared two days before parturition. It reached a maximum five days after labour-the period when the involution processes reach their height.

\section{The Carbohydrate Metabolism in Pregnancy}

a. The Absorption of Carbohydrates by the Mother.-The starch digestion is said to be retarded in the stomach during pregnancy (Kehrer ${ }^{7}$ ). Little is known regarding the absorption of carbohydrates, but there is evidence of a tendency to

1 Magnus-Levy, see v. Noorden, loc. cit.

2 Fischel, "Peptongehalt der Lochien," Arch.f. Gynäk., vols.xxiv. and xxvi.

${ }^{3}$ Langstein and Neubauer, "Autolyse des puerperalen Uterus," Münch. med. Woch., 1902.

4 Thomson (H.), "Ueber Peptonurie in der Schwangerschaft und im Wochenbett," Deutsche med. Woch., 1889.

5 Ehrström, "Puerperale Peptonurie," Arch. f. Gynäk., vol. Ixiii., 1901.

- Murlin, "Protein Metabolism in Development," Amer. Journ. of Phys., vol. xxiii., 1908-9.

' Kehrer, Die physiologischen und pathologischen Bezichungen der Weiblichen Sexualorgane zum Tractus Intestinalis, Berlin, 1905. 
abortion in certain animals on a diet containing them in excess (see p. 495).

b. Carbohydrates of the Maternal Organism.-Lactose may appear in the blood in pregnancy as well as during the lactation period. Lrvulose is not present in the serum of a healthy animal; but it is normally present in the allantoic fluid of the cow (Gürber and Grünbaum ${ }^{1}$ ), and in the blood-serum of the foetal rabbit, cow, and sheep (Paton ${ }^{2}$ ). Whether it is the only monosaccharide present has not yet been determined, but it is in sufficient amount to render the serum lævo-rotatory.

The glycogen store of the liver is stated to be increased in pregnancy in the dog (Burlando ${ }^{3}$ ), in the guinea-pig (Maurel ${ }^{4}$ ), and in the human female (Charrin and Guillemont ${ }^{5}$ ). There is no increase in the rabbit. The placenta contains glycogen in varying amounts. It is found only in traces in Ruminants, but in great amount in Rodents (see Chap. X., p. 431). It occurs also at the margin of the zonary placenta in Carnivores, and in the human placenta. In many species it has not yet been investigated.

In the fotus, the feature of the glycogen is not its high percentage, but its almost universal distribution in the developing tissues. ${ }^{6}$ It has been shown by Bohr that the energy in the mammalian fotus is supplied by the combustion of carbohydrates (see p. 518), and by the wide distribution of

1 Gürber and Grünbaum, "Ueber das Vorkommen von Lävulose im Fruchtwasser," Münch. med. Woch., 1904.

2 Paton, Watson (B. P.), and Kerr, "On the Source of the Amniotic and Allantoic Fluids in Mammals," Trans. Roy. Soc. Edin., vol. xlvi., 1907. The proof that the carbohydrate is lavulose rests on the lavo-rotation of the plane of polarised light and the ketone reaction. Doubts have recently been expressed regarding the sufficicncy of thesc two tests.

3 Burlando, "Behaviour of Hepatic Glycogen during Menstruation, Pregnancy, Pucrperium, and Iactation Period," Arch. Ital. di Ginec., 1906.

4 Maurel, "Des dépenses albuminoides pendant la grossesse chez lc cobaye," Comp. Rend. Soc. Biol., vol. Ixi., 1907.

"Charrin and Guillemont, "Physiologic pathologique de la Grossesse," Comp. Rend. Soc. de Biol., 1899.

- Gierke, "Glycogen in der Morphologie des Zellstoff wechsels," Habilitationsschrift, Freiburg, 1905. Sec also Lochhead and Cramer ("The Glycogenic Changes in the Placcnta and the Fotus of the Pregnant Rabbit," Proc. Roy. Soc., London, Ser. B., vol. Ixxx., 1908), from whosc memoir the Tablc is copied. 
glycogen an available supply is procured in every part of the fotal body in which the work of organisation is proceeding.

c. The Daily Requirement of Carbohydrate for the Fotus.Some idea can be obtained of the daily requirements of glycogen for the foetus of the rabbit in the second half of pregnancy. The appended table gives the amount of glycogen contained in the unborn young from the eighteenth day of gestation till the day before parturition :-

\begin{tabular}{|c|c|c|c|c|}
\hline $\begin{array}{c}\text { Day of } \\
\text { Gestation. }\end{array}$ & $\begin{array}{c}\text { Average Weight } \\
\text { of each Foetus } \\
\text { in Grammes. }\end{array}$ & $\begin{array}{c}\text { Average Amount } \\
\text { of Glycogen } \\
\text { per Foetus. }\end{array}$ & $\begin{array}{c}\text { Number of } \\
\text { Foetuses. }\end{array}$ & $\begin{array}{c}\text { Total Amount of } \\
\text { Glycogen. }\end{array}$ \\
\cline { 2 - 4 } 18 & $0 \cdot 89$ & $\cdot 0018$ & 8 & $\cdot 0144$ \\
20 & $2 \cdot 32$ & $\cdot 0050$ & 6 & $\cdot 0300$ \\
21 & $3 \cdot 28$ & $\cdot 0080$ & 5 & $\cdot 0400$ \\
22 & $4 \cdot 13$ & $\cdot 0103$ & 4 & $\cdot 0412$ \\
23 & $7 \cdot 20$ & $\cdot 0203$ & 8 & $\cdot 1624$ \\
24 & $9 \cdot 75$ & $\cdot 0346$ & 6 & $\cdot 2076$ \\
25 & $20 \cdot 23$ & $\cdot 0808$ & 7 & $\cdot 5656$ \\
26 & $11 \cdot 24$ & -0257 & 5 & $\cdot 1285$ \\
27 & $32 \cdot 84$ & $\cdot 1418$ & 3 & $\cdot 4254$ \\
28 & $32 \cdot 07$ & $\cdot 2017$ & 6 & $1 \cdot 2102$ \\
29 & $26 \cdot 67$ & $\cdot 1199$ & 9 & $1 \cdot 0791$ \\
\hline
\end{tabular}

TABLE to show the foetal weight and amount of feetal glycogen in the second half of pregnancy (rabbit). In the animal killed at the twenty-sixth day, the pregnancy was abnormal, one fotus being dead and the others badly developed. In the last also the fotuses were unusually small.

The table shows that $1.2 \mathrm{grm}$. of glycogen are deposited between the eighteenth and the twenty-eighth day, or about 0.2 grm. per fotus. Hence the average daily deposition is $0.02 \mathrm{grm}$. per fotus. In the later stages the rate of deposition increases out of proportion. This is due to the assumption of its glycogenic function by the fœtal liver.

The amount of carbohydrate oxidised each day can be calculated from Bohr's figures. The oxygen consumption for a foetus weighing $30 \mathrm{grm}$. is $0.14 \mathrm{c.cm}$. per minute. This is sufficient to oxidise $0.00017 \mathrm{grm}$. of sugar, or $0.245 \mathrm{grm}$. per day, which is equal to $0.227 \mathrm{grm}$. of glycogen. Hence for six fotuses, the average number, $1.362 \mathrm{grm}$. are required for combustion each day. In addition, an average of $0.3 \mathrm{grm}$. of glycogen is deposited 
in them daily near the end of pregnancy. Hence the total daily requirement for the unborn young at this stage is $1.662 \mathrm{grm}$. of glycogen. A small additional amount of carbohydrate is required for the daily increasing blood-serum, for the liquor amnii in the rabbit, and for the manufacture of mucin and other glycoproteins.

\section{d. Excretion of Carbohydrates in Pregnancy: Glycosuria and} Lactosuria. Blot ${ }^{1}$ was the first to postulate the occurrence of a "physiological glycosuria" in pregnancy. Kirsten ${ }^{2}$ found sugar in the urine in the majority of cases of pregnancy and labour, and regularly in the puerperium. Hofmeister ${ }^{3}$ first discussed the relationship of the glycosuria to milk secretion, and proved that the sugar excreted in the puerperium was lactose. ${ }^{4}$ The sugar is in extremely small amounts, but above the normal. Lemaire ${ }^{5}$ found 0.003 to 0.009 per cent., and Brocard ${ }^{6}$ an upper limit of 0.01 per cent. Zacharjewsky, however, observed no increase in the reducing power of the urine on an ordinary diet during the last weeks of pregnancy. The first definite increase comes with the appearance of lactose in the urine after birth, though it may also be excreted a few days before birth. It is more evident when the milk is not utilised and becomes re-absorbed, but it rarely exceeds 0.3 per cent. ${ }^{8}$ Extirpation of the mammary glands immediately stops the lactosuria, ${ }^{9}$ and, if carried out in pregnancy, prevents it. ${ }^{10}$

1 Blot, "De la glycosurie physiologique chez les femmes en couches," \&c., Comp. Rend. Soc. Biol., vol. xliii., 1856.

" Kirsten, "Ueber das Vorkommen von Zucker im Harn der Schwangeren," Monatsschr.f. Geburtsh. u. Frauenkrankh., vol. ix., 1857.

"Hofmeister, "Ueber Iaktosurie," Zeitschr.f. phys. Chem., vol. i., 1877.

"Corroborated by Kaltenbach ("Die Laktosurie der Wöchnerinnen," Zeitschr. f. Geburtsh. u. Gynäk., vol. iv.) and many others.

' Lemaire, "Ueber das Vorkommen von Milchzucker," Zeitschr. f. phys. Chem., vol. xxi., 1895.

- Brocard, "La Glycosurie de la Grossesse," These de Paris, 1898.

7 Zacharjewsky, loc. cit., Zeitschr. f. Biol., vol. xxx., 1894.

8 The inability of the organism to oxidise lactose was demonstrated by Voit ("Verhalten der Zuckerarten im menschlichen Organismus," Deut. Arch. f. klin. Med., vol. lviii., 1897).

"Sinéty, "Urine of Guinea-Pigs in Puerperium," Comp. Rend. Soc. Biol., vol. 1 .

$10 \mathrm{~V}$. Noorden, loc. cit., vol. i. (see also pp. 571-573). 
The glycosuria of pregnancy has been ascribed to a diminished glycolysis (Brocard), and to hepatic inadequacy (Cristalli ${ }^{1}$ ), without sufficient evidence. The greater tendency to alimentary glycosuria in pregnancy was upheld by Lanz. ${ }^{2} \mathrm{He}$ frequently observed it after the administration of $100 \mathrm{grm}$. of glucose. On the other hand, Payer's ${ }^{3}$ careful experiments showed an assimilation limit of 130 grm. of glucose, which is not subnormal, the excess being very rapidly excreted. Hence it must be left unsettled whether a more ready saturation of the maternal organism may be brought about in pregnancy, and whether this is related to an increased storage of carbohydrate at this time.

\section{E. The Metabolism of Fats in Pregnancy}

a. The Absorption of Fats by the Mother.-The absorption of fats from the intestine is increased during pregnancy (Ferroni ${ }^{4}$ ), the neutral fats, fatty acids, cholesterin, and soaps contained in the fæces being all decreased towards the end of the gestation period. This is the time when the subcutaneous tissues of the fœtus receive an abundant supply. They rapidly reach the normal level in the puerperium. There is a corresponding increase of fat in the maternal blood in the dog and guinea-pig, and the excess disappears after parturition (Capaldi ${ }^{5}$ ).

b. Fat of the Maternal Organism.-According to Miotti, ${ }^{6}$ the liver cells contain a continuously increasing amount of fat, first in the central parts of the lobule and later throughout. He looks on it as a fatty infiltration, and concludes that an increased fat formation takes place during pregnancy.

${ }^{1}$ Cristalli, Ricerche sulla presenza dello zuchero nelle orine delle donne gravide e puerpere, Naples, 1900.

2 Lanz, "Ueber alimentäre Glykosurie bei Graviden," Wien. med. Presse, 1895.

${ }^{3}$ Payer, "Einfluss des Zuckers auf den Stoff wechsel der Schwangeren," Monatsechr. f. Geburtsh. u. Gynäk., vol. x

"Ferroni, "I grassi neutri ... delle gravide e delle puerpere sane," Ann. di Ost. e Ginec., 1905.

5 Capaldi, "Sul contenuto di grasso del sangue nella gravidanza e nel puerperio," Ann. di Ost. e Ginec., 1905.

- Miotti, "Contributo allo studio istologico de fegato durante la gravidanza," Ann. di Ost. e Ginec., 1900. 
In the placenta there is evidence of a transmission of fat to the product of conception. Even in the early stages of pregnancy the cells of the uterine mucosa are infiltrated with fat, and the trophoblast is pervaded with fat globules. In Ungulates a large amount of fat is contained in the uterine milk (see p. 403). In those mammalian orders, in which the trophoblast is directly bathed by maternal blood, the fat dissolved in it forms a second available supply. There is no reason to doubt an active transference of fat from the mother, or to assume that a transformation from carbohydrates or proteins is necessary.

c. The Daily Requirement of Fat for the Fotus.-The daily requirement of fat varies very considerably during pregnancy, and especially towards the end, when the subcutaneous fat of the foctus is deposited. Fehling ${ }^{1}$ found 0.5 per cent. of fat in the human foetus at the fourth month, over 4 per cent. at the eighth, and 9 per cent. at the ninth month.

d. Origin of the Fotal Fat.-As to its origin, Thiemich ${ }^{2}$ states that it is not derived from the alimentary fat of the mother, since after feeding a dog in two successive pregnancies on widely different fats, palmin and linseed oil, he could determine no difference in the constitution of the foetal fat. Oshima ${ }^{3}$ comes to the same conclusion from his investigations on the number of ultra-microscopic particles in the blood of cats, rabbits, and guinea-pigs. He states that the number is dependent on the stage of development, and independent of the condition of the mother's blood-for example, when a great increase is produced by rich fat-feeding. Capaldi, on the other hand, states that the percentage of fat is the same in the maternal and fotal blood, at least at the end of pregnancy. Some feeding experiments carried out by Hofbauer ${ }^{4}$ agree with this. He administered coco-nut oil ${ }^{5}$ to three pregnant guinea-pigs, and demon-

1 Fehling, "Beiträge zur Physiologie des placentaren Stoffverkehrs," Arch.f. Gynäk., vol. xi., 1877.

${ }^{2}$ Thiemich, "Ueber die Herkunft des fötalen Fettes, Centralbl. f. Phys., vol, xii., 1898.

3 Oshima, "Ueber das Vorkommen von ultra-mikroscopischen Teilchen im fötalen Blute," Centralbl. f. Phys., vol. xxi., 1907.

- Hofbauer, Biologie der menschlichen Plazenta, Wien and Leipzig, 1905.

${ }^{5}$ It consists essentially of the triglycerides of laurinic and myristinic acids with a very small quantity of tripalmitin. 
strated laurinic acid in considerable amount in the foetuses. Hence the fat of the food, or at least one of its fatty acids, had been transmitted across the placenta. But any conclusions based on the introduction of a foreign fat must be guarded.

In the fotus, fat is present in many of the tissues in a state of fine division. Its wide-spread distribution and its amount, probably equal at least to that of glycogen, are a characteristic of fotal life; but its significance is not obvious if, as Bohr states, it is not a source of energy. Guillot ${ }^{1}$ showed that it did become a source of energy immediately after birth. He found 12 per cent. of fat in the lungs of foetuses dying during labour, and only 6 per cent. after several hours' respiration. Fat may have anabolic functions to perform in the building up of the fœtal body, e.g. in the synthesis of lecithin.

e. The Excretion of Fat Derivatives in Pregnancy.-The primary product is oxybutyric acid. This, by oxidation, is transformed to aceto-acetic acid, which in turn gives rise to acetone by the loss of carbon dioxide from the molecule. Little is known regarding the excretion of aceto-acetic acid and oxybutyric acid in apparently normal pregnancies, though in pathological cases of persistent vomiting, with a high degree of inanition, the latter may often appear (Kraus ${ }^{2}$ ). This is to be expected. In general, if the anuount of oxybutyric acid is small, acetone alone appears in the urine; if in greater amount diacetic acid mayalso be present, and, if greater still, all three may be excreted. ${ }^{3}$

That acetonuria exists in pregnancy is certain, but in the majority of cases it does not pass the physiological limit $\left(\right.$ Stolz $\left.{ }^{4}\right)$. If it is in greater abundance, some special factor must be at work. It is not enough to say that its presence is always due to the exclusion of carbohydrates in varying degrees from the metabolism, ${ }^{5}$ leading to a lowered oxidation of fats by the

1 Guillot, quoted in Richet's Dictionnaire de Physiologie, Article "Fotus."

${ }^{2}$ Kraus, quoted in v. Winckel's Handbuch der Geburtshülfe, vol. i., H. 1.

${ }^{3}$ See v. Noorden, loc. cit., vol. i.

4 Stolz, "Die Acetonurie in der Schwangerschaft," Arch. f. Gynäk., vol. lxv.

5 Wolfe ("The Chemistry of Toxamias in Pregnancy," New York Med. Journ., 1906) states that there is no connection between acetone compounds in the urine and the essential features of hyperemesis gravidarum, a condition in which there is pre-eminently a deficient absorption of carbohydrates. 
cells of the body. When no change is made in the ordinary diet, when no signs of dyspepsia are present and no glycosuria exists, we are not justified in assuming a withdrawal of carbohydrates from the metabolism. Rather is it related to the acetonuria arising after chloroform and ether narcosis (Beesly) ${ }^{1}$ or in febrile conditions - that is, it is toxic in origin. It has, however, still to be discovered whether the acetonuria of pregnancy is associated, as the acetonuria of narcosis ${ }^{2}$ and of fever (Regnard ${ }^{3}$ and Geppert ${ }^{4}$ ), with a diminished alkalinity of the blood.

\section{F. The Metabolism of Metals and Salts in Pregnancy}

Little is known regarding the metabolism of the individual metals and salts. The fixation of mineral elements is slight at the beginning, but becomes active towards the end of pregnancy. From first to last, about a hundred grammes are transferred from the mother to the human foetus. With a few exceptions, the mineral salts are approximately in the same proportion throughout pregnancy. The exceptions are sodium, potassium, and calcium, of which sodium decreases and calcium increases with the replacement of cartilage by bone, and potassium increases with the increased manufacture of red blood corpuscles (Hugounenq ${ }^{5}$ ).

a. Iron.--Part at least of the iron for the fotus is derived from the hrmoglobin of the maternal organism. ${ }^{6}$ In the poly-cotyledonary placenta of Ruminants and the zonary placenta of Carnivores, the disintegration of red blood corpuscles has been demonstrated. There is less certainty regarding the actual ingestion of the red cells by the syncytium of the discoid placenta,

1 Beesly, "Post-Anæsthetic Acetonuria," Brit. Med. Journ., 1906.

2 Beesly and Milne, unpublished paper.

3 Regnard, Combustions respiratoires, 1879.

"Geppert, "Die Gase des arteriellen Blutes im Fieber," Zeitschr. f. klin. Med., vol. ii.

5 Hugounenq, "Reclıerches sur la statique des éléments minéraux et particulièrement du fer chez le foctus humain," Comp. Rend. Soc. Biol., 11 th series, vol. i., 1889.

"It is doubtful whether haemoglobin is an "organised" protein, hence its disintegration does not, as might be supposed, afford proof of the transmission of maternal tissue protein to the fœetus. 
though it has been described by Peters in an early human ovum. ${ }^{1}$ But in all placentæ yet investigated, iron-containing granules have been observed in the trophoblast. The possible sources are hæmoglobin, which is in part absorbed as such by the trophoblast in Man (Bonnet ${ }^{2}$ ), nucleoprotein, and the reserve iron of the mother. Nuclein is the only iron-containing constituent of yolk of egg, and must serve for the manufacture of hæmoglobin in the developing chick. It is also known that in the adult organism nucleoprotein is a better source of iron for hæmoglobin than any inorganic or other organic compound hitherto administered by the mouth. ${ }^{3}$ Hence it is not difficult to conceive that the same process may occur in the fœetus. But whether it is the food nucleoproteins or the organised nuclein bodies of the maternal organism that are utilised, is unknown. With regard to the reserve iron of the mother, it is stated by Charrin ${ }^{5}$ that the store in the spleen is reduced during pregnancy.

In the fœetus iron is required for the synthesis of hæmoglobin (see p. 480) and nucleoproteins. ${ }^{6}$ Large amounts of iron are also stored in the liver and other organs. According to Bunge's ? law, this forms a reserve which is drawn on after birth to make up for the deficiency of the iron in the milk. Thus the liver of a rabbit contains $18 \mathrm{mg}$. of iron per $100 \mathrm{grm}$. body-weight at birth, and only $3.2 \mathrm{mg}$. twenty-four days later.

According to Veit and Scholten, ${ }^{8}$ the villi can dissolve intact red cells of the circulating blood, just as the solution of erythro-

See Chap. X., p. 479.

2 See Chap. X., p. 480.

3 V. Noorden, loc. cit., vol. i., p. 78.

4 As the purine bases of the urine are stated to be decreased in pregnancy (see p. 506), the maternal nucleins are probably not a source of iron for the fotus to any appreciable extent.

"Charrin, "Physiologie pathologique de la grossesse," Comp. Rend. Soc. de Biol., 1899.

6 The nucleoproteins of the foctal placenta in the sheep differ in their chemical constitution from those of the maternal placenta. They are probably synthesised in the ovum from lower complexes, in the sane way as the nucleoproteins of the chick embryo are built up though the egg contains no purine bases.

7 Bunge, "Weitere Untersuchungen über die Aufnahme des Eisens in den Organismus des Säuglings," Zeitschr. f. phys. Chem., vols. xvi. and xvii., 1892-3.

8 Veit and Scholten, "Synzytiolyse and Häemolyse," Zeitschr. f. Geburtsh. u. Gynäk., vol. xlix. 


\section{THE PHYSIOLOGY OF IREPRODUCTION}

cytes can be produced by placental extracts. As a result of this, hæmoglobinæmia may occur in pregnancy. Wychgel ${ }^{1}$ observed it in eight out of twenty-three pregnancies, and the condition occurs more frequently still in eclampsia. At present, however, it is not yet generally accepted that an erythrotoxin is formed by the syncytium, though Bonnet ${ }^{2}$ has shown histologically that a destruction of red cells probably takes place during life. He noticed on the surface of the villi " perfect and damaged erythrocytes in all stages of degeneration, clumping and solution." So Hofbauer found, by adding neutral-red to the chorionic villi of two fresh two-months' placentæe teased in saline, that many of the blood corpuscles showed red dots indicating degeneration.

b. Calcium.-The source of the fotal calcium is still unsettled. According to Drennan, ${ }^{3}$ it is derived from the circulating blood and not from the tissues of the mother, but he adduces no strong evidence. It is well known that the teeth are apt to become brittle in pregnancy from a decrease in calcium fluoride ${ }^{4}$ and a deficiency in enamel formation. Evidence of a special drain on calcium is also found in puerperal osteomalacia, which occurs in poor people who presumably have an insufficient supply of calcium in their diet.

c. Phosphates and Sulphates.-It has been generally found that the phosphoric acid excretion runs parallel to the nitrogen (V. Eeke, ${ }^{5}$ Schrader ${ }^{6}$ ). Jägerroos ${ }^{5}$ however, showed an equilibrium between intake and output in a pregnant dog which showed a distinct loss of nitrogen. According to Schrader, the excretion of sulphates is parallel to that of nitrogen.

1 Wyehgel, "Untersuchungen über das Pigment der Haut und der Urin während der Sehwangerschaft," Zeits. f. Geburtsh. u. Gynäk., vol. xlvii.

2 Bonnet, quoted by Hofbauer (Biologie der menschlichen Plazenta, Wien und Leipzig, 1905).

${ }^{3}$ Drennan, "The Abstraction of Caleium Salts from the Mother's IBlood by the Fotus," New York Medic. Journ., vol. Ixxxvii. 1899.

"Terrier, "De l'Influenee de la Grossesse sur les Dents," These de Paris,

5 V. Feke, Jiggerroos; see pp. 500 and 501 for referenees.

"Schrader, "Stoffwechsel während der'Sehwangersehaft," Arch. $f$. Gynäk., vol. x., 1900. 
d. Chlorides.-The first estimations of the chlorides of the urine in pregnancy indicated no variation from the nonpregnant level (Winckel ${ }^{\mathbf{1}}$ ). Repeated investigations have been carried out since the discovery that a retention of chlorides may occur in nephritis and lead to cedema (Widal ${ }^{2}$ ).

Biancardi ${ }^{3}$ stated that œdemas in pregnancy were sometimes due to the same cause, and might be cured by decreasing the chlorides of the food. Next Cramer ${ }^{4}$ affirmed that all cases of hydrops graviditatis without albuminuria were due to a retention of sodium chloride; and Boni, whose careful investigations of the urine in pregnancy have already been referred to, found that the chlorine excretion was decreased, and remained low during the puerperium. Along with this there is a retention of water to maintain osmotic balance. Normally 90 to 100 per cent. of the water taken in is excreted in the urine, but the percentage fell to 72 per cent. in a primipara, 53 per cent. in a multipara, and 48 per cent. in a twin pregnancy (Slemons ${ }^{5}$ ). Such a retention did not occur in a woman who was later delivered of dead twins, 93 per cent. of the water being excreted in the urine.

Birnbaum's ${ }^{6}$ results are not in agreement with the others. He states that a retention of chlorides occurs only in the nephritis of pregnancy, and not in normal pregnancy or in hydrops without albuminuria. In the blood-serum the chlorides were $0 \cdot 1740$ per cent. and $0 \cdot 1775$ per cent. in two cases, and $0 \cdot 1733$ per cent. in a non-pregnant woman.

\section{G. Respiratory Exchange during Pregnancy}

Modifications in the respiratory exchange arise from the alterations in the maternal organism, and from the requirements

1 Winckel, Studien über Stoffwechsel, \&c., Rostock, 1865.

2 Widal, "La cure de déchloruration dans le mal de Bright," Arch. Génér., vol. cxciii., 1904.

3 Biancardi, "Sulla cura declorurante nelle nefriti e nelle albuminurie nel campo ostetrico," Aun. di Ost. e Ginec., 1905.

" Cramer, "Chlornatrium-Entziehung bei Hydrops Graviditatis," Monatsschrift f. Geburtsh. u. Gynäk., vol. xxiii.

5 Slemons, "Metabolism during Pregnancy, Labour, and Puerperium," Johns Hopkins Hosp. Rep., vol. xii., 1904.

"Birnbaum, "Fxcretion of Chlorides during Pregnancy," Arch. f. Gynäk., vol. 1xxxiii., 1907. 
of the product of conception. To a certain extent diffusion of oxygen takes place from mother to foetus, as it has been proved, by experiments in asphyxia of the mother, that the direction in which oxygen goes across the placenta depends on the tension. Whether there is also a gas-secretion by the trophoblast is unknown.

With regard to the foetus, Pfliger argued on theoretical grounds that the oxidation processes were inconsiderable, and the oxygen intake small. This was confirmed experimentally by Cohnstein and Zuntz. ${ }^{1}$ More recently, however, Bohr ${ }^{2}$ has shown by more convincing experiments that in the later stages of pregnancy the foetal guinea-pig consumes at least as much oxygen as the mother. The actual figures which he obtained were $462 \mathrm{c.cm}$. for the mother and $509 \mathrm{c.cm}$. for the foetus per kilo per hour. He has also shown that the fotal respiratory quotient is unity, indicating that carbohydrates are the source of energy. The same has been found in new-born puppies before suckling (Murlin ${ }^{3}$ ). It is well to remember that Bohr's experiments refer only to the fotus in the later stages of development, and that they entirely leave out of account the placental metabolism. ${ }^{4}$

The high consumption of energy in the fotus, which differs from the adult in losing little heat by radiation from the skin surface and lungs, must be due to the intensive growth of the embryo (see Chap. X., p. 434).

1 Cohnstein and Zuntz, "Untersuchungen über das Blut, den Kreislauf, und die Atmung beim Säugetierfötus," Pfüger's Arch., vol. xxxiv., 1884.

2 Bohr, "Der Respiratorische Stoff wechsel des Säugetierembryos," Skand. Arch.f. Phys., vol. x., 1900.

3 Murlin, "Protein Metabolism in Development," Amer. Journ. of Phys., vol. xxiii., 1908-9.

4 In the later stages there is a wide distribution of glycogen throughout the tissues of the fœtus, and the fœtal liver has assumed its glycogenic function. It is scarcely justifiable to extend Bohr's results to the early stages of pregnancy, when the placenta probably takes a leading part in embryonic development. It may be that at that time also glycogen is the source of energy for the placenta in Rodents, but it cannot be so in Ruminants. In their placentx glycogen is found only in traces, while fat is in considerable amount. Hence we cannot assume that the energy is derived from the combustion of carbohydrates until experimental evidence has been obtained. 
It is possible, though not yet proved, that, in addition to carbonic acid, incompletely oxidised substances may be brought to the placenta from the foetus and oxidised there or in the mother $\left(\right.$ Bohr $\left.{ }^{1}\right)$. Such a hypothesis lies at the foundation of the theory that certain pathological conditions in pregnancy are due to the circulation of toxins manufactured in the product of conception.

With regard to the total energy exchange, the results of Magnus-Levy, ${ }^{2}$ F. Muller, ${ }^{3}$ and E. Zuntz ${ }^{4}$ tend to show that in the human pregnancy no decrease in metabolism occurs, the metabolic changes being at least as active in the fœtus as in the mother. In one experiment Levy found a progressive increase in the oxygen intake during pregnancy, but he does not lay too much stress on the figures, ${ }^{5}$ as in all the others no increase in the gaseous exchange per kilo was established. Even in the third month there was a marked increase. The weight increased from 108.4 to 111.4 kilo, and the oxygen intake from 302 to $320 \mathrm{c.cm}$. per minute, i.e. from $2 \cdot 79$ to 2.88 c.cm. per kilo per minute. With such figures we must conclude that the early stages of pregnancy have had a favourable influence on the growth of the mother animal, and at the same time have led to a more energetic metabolism. ${ }^{6}$

1 Bohr, Nagel's Handbuch der Physiologie, " Respiration."

2 Magnus-Levy, "Stoffwechsel und Nährungsbedarf in der Schwangerschaft,"Vortrag, Zeitschr. f. Geburtsh. u. Gynäk., vol. lii.; also v. Noorden, loc. cit., vol. i.

3 F. Müller, "Diskussion zum Vortrag von Magnus-Levy," see v. Noorden, loc. cit., vol. i.

" E. Zuntz, "Der Stoffaustausch zwischen Mutter und Frucht," Ergebn. $d$. Phys., 1908.

"The older investigations of Oddi and Vicarelli ("Influence de la grossesse sur l'échange respiratoire," Arch. ital. de Biol., vol. xv., 1891), showed a progressive increase in the consumption of oxygen during the last third of pregnancy in rats; but Magnus-Levy raises the objection that the movements of the animals were not restricted.

${ }^{6}$ Such a result is in conformity with those obtained in rats soon after inoculation with malignant new growths; Cramer (W.), "The Gaseous Metabolism in Rats inoculated with Malignant New Growths," 3rd Scient. Rcp., Imperial Cancer Research Fund, London, 1908). Magnus-Levy's exceptional result may, however, be due to the fact that the woman under observation had not yet completed her growth. 


\section{The Changes in the Maternal Tissues during Pregnancy}

The changes in the ovaries, the mammæ, and the mucous membrane of the uterus are dealt with elsewhere. To the changes in some of the other organs, a brief consideration is here given.

a. The Blood.-Ehrlich's ${ }^{1}$ statement that pregnancy does not appreciably alter the number of the red blood corpuscles has been more or less firmly established by Ingerslev, ${ }^{2}$ Dubner, ${ }^{3}$ Bernhard ${ }^{4}$ and others in Man, by Spiegelberg and Gscheidlen ${ }^{5}$ in the dog, and by Cohnstein ${ }^{6}$ in the sheep. Their investigations have upset the older theory of a hydræmia of pregnancy.

There is evidence of a slight increase of hæmoglobin (Payer, Fehling, ${ }^{8}$ Winckelmann, ${ }^{9}$ Wild $\left.{ }^{10}\right)$, especially towards the end of pregnancy.

The number of leucocytes increases during pregnancy, and there is a further rise during the act of parturition (Nasse, ${ }^{11}$ Lebedeff, ${ }^{12}$ Rieder ${ }^{13}$ ). The leucocytosis is referred by some to

'Ehrlich, "Die Anämien," in Nothnagel's Spezielle Pathologie.

2 Ingerslev, "Ueber die Menge der roten Blutkörperchen bei Schwangeren," Centralbl. f. Gynäk., 1879.

3 Dubner, “ Untersuchungen über den Hämoglobingehalt des Blutes," \&c., Münch. med. Woch., 1890.

4 Bernhard, "Untersuchungen ïber Hämoglobingehalt und Blutkörperchenzahl in der letzten Zeit der Schwangerschaft," Münch. med. Woch., 1892.

5 Spiegelberg and Grscheidlen, "Untersuchungen über die Blutmenge trächtiger Hunde," Arch. f. Geburtsh. u. Gynäk., vol. iv.

- Cohnstein, "Blutveränderungen während der Schwangerschaft," Pflüger's Arch., vol. xxxiv., 1884.

' Payer, vide v. Winckel's Handbuch der Geburtshülfe, vol. j., H. 1.

" Fehling, "Ueber Blutbeschaffenheit," \&c., Arch. f. Gynäk., vol. xxviii., 1886.

'Winckelmann, "Hämoglobin-Bestimmungen bei Schwangeren und Wöchnerinnen, Inaug. Diss., Heidelberg, 1888.

30 Wild, "Untersuchungen über den Hämoglobingehalt und die Anzahl der roten und weissen Blutkörperchen bei Schwangeren," Arch. f. Gynäk., vol. liii.

1 Nasse, Das Blut, Bonn, 1836.

12 Lebedeff, quoted in v. Winckel's Handbuch der Geburtshülfe., vol. i., H. 1.

${ }^{13}$ Rieder, Beiträge zur Kenninis der Leukocytose und verwandter Zustande des Blutes, Leipzig, 1892. 
the lymphoid tissue of the endometrium, and by others to an increase in the groups of lymphatic glands in the neighbourhood of the genital apparatus.

According to Spiegelberg and Gscheidlen, the total amount of blood is increased during pregnancy in the dog from 7.8 per cent. to 9 per cent. of the body-weight. There is no essential difference in the specific gravity (Nasse, Blumreich ${ }^{1}$ ). The observations on the alkalinity of the blood are few and contradictory. Lebedeff states that it is increased, and similarly Blumreich, who investigated the blood of pregnant rabbits and women. The alkalinity quickly returned to the normal level. On the other hand, Payer's estimations of the "diffusiblc" alkali, i.e. alkali not combined with protein, of defibrinated blood give values slightly below the nonpregnant level. The molecular concentration of the blood shows no change during pregnancy.

b. The Heart and Circulation.--Older authorities stated that a true hypertrophy of the heart occurred during pregnancy, and was caused by the increased length and size of the uterine vessels, the placental circulation, and the compression of the aorta by the gravid uterus. Experiments showed, however, that the uterine vessels did not offer a rcsistance which required an increasc in the work of the heart (Engström ${ }^{2}$ ), while the compression of the abdominal aorta and the introduction of large quantities of fluid into the abdominal cavity produced no change which could be detected from the pulse (Heinricius ${ }^{3}$ ). The controversy has been a long one, but it does not properly belong to this articlc. The prescnt-day opinion of the cardiac modifications in the human female may be summed up as follows : Tendency to dilatation, especially of the right heart, and to some compensatory hypertrophy. The frequent embarrassment of the right ventricle, even in the early stages of pregnancy, is marked by the occurrence of shortncss of brcath

1 Blumreich, "Der Einfluss der Gravidität auf die Blutalkalescenz," Arch. f. Aynäk., vol. lix., 1899.

2 Engström, "L'Influence de la grossesse sur la circulation," Arch. de Gyn., 1886, vol. ii.

${ }^{3}$ Heinricius, Experimentclle und klinische Untersuchungen über Circulationsverhalten der Mutter und der Frucht, Helsingfors, 1889. 
and palpitation and by changes in the rate and rhythm of the heart. An increased area of dullness to the right of the sternum can usually be made out, but it is mainly due to the abnormally transverse position of the heart, and to its greater contact with the anterior wall of the chest (v. Winckel ${ }^{1}$ ).

It has been suggested that the increased work of the heart, which leads in many cases to the dilatation of its chambers and perhaps to some compensatory hypertrophy, is due to an increased peripheral resistance from the presence of a vasoconstricting substance in the blood. ${ }^{2}$ In excess it may cause anuria and eclampsia (Nicholson ${ }^{3}$ ).

The blood-pressure is not affected in normal pregnancy, but is always raised in labour as a result of the uterine contractions. After parturition the pressure falls, but rises again on the third day of the puerperium.

Varices of the lower extremities and external genitals are frequent in human pregnancy. They are due mainly to the increased intra-abdominal pressure and the stretching of the abdominal wall. Secondary thromboses are common in the puerperium.

c. The Ductless Glands.-There is regularly a swelling of the thyroid gland in pregnancy (Tait ${ }^{4}$ ), which consists of a simple hypertrophy, and not a vascular engorgement or cystic change $\left(\right.$ Freund ${ }^{5}$ ). It has been shown experimentally in cats that a

${ }^{1}$ V. Winckel, loc. cit., vol. i., H. 1. This has been clearly established by radiograms of the thorax in pregnancy.

2 The origin of this substance, if such exists, is still unknown. The investigation of extracts of the placenta by the writer, in conjunction with Dr. W. Cramer, proved that this organ contained no blood-pressure raising substance. The substances extracted by Dixon and Taylor ("On the Physiological Action of the Placenta," Proc. Roy. Soc. of Med., London, vol. i., 1908) from the placenta and observed to have an adrenalin-like action, were subsequently shown to arise in the course of putrefaction (see Rosenheim, Journ. of Phys., 1909).

3 Nicholson, "The Maternal Heart in Pregnancy," Brit. Med. Journ., 1904, part ii.

"Tait, "Enlargement of the Thyroid Body in Pregnancy," Obstet. Journ., 1875.

"Freund, "Ueber die Bezichung der Schilddrüse," \&c., Deuts. Zeitschr. f. Chir., vol. xxxi., 1890. 
remnant of the gland, which is sufficient to maintain health in the non-pregnant state, is insufficient after the onset of pregnancy (Lange ${ }^{1}$ ).

An increased suprarenal secretion in pregnancy has also been suggested, the effect of which on the blood pressure is normally balanced by the increased thyroid secretion (Nicholson ${ }^{2}$ ). But experimental evidence seems to show that the blood-pressure raising action of the suprarenals is entirely independent of the thyroid gland (Pick and Pineles ${ }^{3}$ ).

d. The Skin.-The cause of the increased pigmentation of the skin in pregnancy is little understood. It has been looked on as a simple deposit of pigment, as the result of infection with the microsporon furfur, the cause of pityriasis versicolor which not infrequently attacks pregnant women, and as a subcutaneous hæmorrhage. ${ }^{4}$ Jeannin ${ }^{5}$ first suggested that it was derived from hæmoglobin set free by the solution of red blood corpuscles. According to Veit ${ }^{6}$ the hæmolysis may be produced by the circulation of syncytial elements in the blood. The presence of iron in the pigment, though strongly denied by Truzzi, ${ }^{7}$ has recently been demonstrated by Wychgel. ${ }^{8} \mathrm{He}$ associates its presence with the frequent occurrence of hæmoglobinuria in pregnancy. V. Fürth and Schneider's suggestion that the pigment is derived from tyrosin by the action of a placental tyrosinase is mentioned elsewhere (Chap. X., p. 481).

An abnormal development of the hair of the face and body

1 Lange, "Die Beziehungen der Schilddrüse zur Schwangerschaft," Zeitschr.f. Geburtsh. u. Gynäk., vol. xl., 1899.

2 Nicholson, "Physiological Changes in the Maternal Organism during Pregnancy," Trans. Obstet. Soc. Edinburgh, vol. xxxi., 1905-6.

${ }^{3}$ Pick and Pineles, "Beziehung der Schilddrüse zur physiol. Wirkung des Adrenalins," Biochem. Zeitschr., vol. xii., 1908.

"See v. Winckel's Handbuch der Geburtshülfe, vol. i. H. 1.

5 Jeannin, "Observations pour servir à l'histoire du masque des femmes enceintes," Gaz. Hebdom., 1868.

6Vit and Scholten, "Synzytiolyse und Hämolyse," Zeitschr. f. Gcburtsh. u. Gynäk., vol. xlix., 1903.

7 Truzzi, "Ueber die Genese der Hyperchromie der Haut in der Gravidität," Monatsschr. f. Geburtsh., vol. xi., 1898.

8 Wychgel, "Untersuchungen über das Pigment der Haut und den Ưriu während der Schwangerschaft," Zeitschr.f. Geburtsh. u. Gynäk., vol. xlvii. 


\section{THE PHYSIOLOGY OF REPRODUCTION}

is occasionally secn in pregnancy (Slocum, ${ }^{1}$ Halban ${ }^{2}$ ). Under the name of dermographismus, Freund ${ }^{3}$ describes a phenomenon, often met with in pregnancy, similar to the tache cérébrale of meningitis and other nervous affections. It may be clicited even in the early stages of gestation, and is best shown by stroking the skin over the sternum or fundus uteri.

e. The Mamma.-The growth of the mammary glands is brought about by the development of new vesicles, the widening of existing blood-channels, and the formation of new vessels. ${ }^{4}$ Even in the first half of pregnancy, and sometimes in the first weeks, the mammæ contain colostrum, a milky fluid composed of proteins, albumen, globulin, and casein, the carbohydrate lactose, fat, free fatty acids, lecithin, cholesterin, frce glycero-phosphoric acid, and urca (Wintcrstein and Stickler ${ }^{5}$ ).

1 Slocum, “Hair Development in Pregnancy," New York Med. Rec, 1875.

2 Halban, "Zur Frage der Graviditätshypertrichose," Wien. klin. Woch., 1907.

${ }^{3}$ Freund, "Die Haut bei Schwangeren," Verhandl. d. vi. deutsch. Dermatologen-Kongr. zu Strassburg.

4 See Chapter XIII.

5 Winterstein and Stickler, "Die chemische Zusammensetzung des Colostrums," Zeitschr. f. phys. Chem., vol. xlvii., 1906. 


\section{CHAP'TER XII}

THE INNERVATION OF THE FEMALE GENERATIVE ORGANS-UTERINE CONTRACTION-PARTURITION-THE PUERPERAL STATE

"Birth is the end of that time when we really knew our business, and the beginning of the days wherein we know not what we would do, or do."SAMUEL Butler.

THE innervation of the generative organs of the male was dealt with at some length in an earlier part of this work. It remains in the present chapter to describe the nerve supply to the female generative system, and more particularly to the uterus, since this is the organ which is especially concerned in the process of parturition. But before giving an account of the innervation of the internal organs, the nerve supply to the vulva and clitoris may be briefly dealt with.

\section{The Innervation of the External Generative Organs}

The external generative organs in the female are similarly innervated to those of the male (p. 254 et seq.).

Langley and Anderson ${ }^{1}$ found that stimulation of the first five lumbar nerves in the cat, or the third, fourth, and fifth lumbar nerves in the rabbit, produced the same effects as in the male excepting that they were less pronounced. The effects were (1) Pallor of the clitoris and of the mucous membrane of the vulva, accompanied by slight retraction of the clitoris, (2) Contraction of the vulva, and (3) Contraction of the muscles of the adjoining skin, drawing the vulva dorsally towards the rectum.

Langley, ${ }^{2}$ and subsequently Langley and Anderson, ${ }^{3}$ found

1 Langley and Anderson, "The Innervation of the Pelvic and Adjoining Viscera," Jour. of Phys., vol. xix., 1895.

2 Langley, "The Innervation of the Pelvic Viscera," Proc. Phys. Soc., Jour. of Phys., vol, xii., 1891.

${ }^{3}$ Langley and Anderson, loc. cit. 
that two groups of effects, which were antagonistic to one another, could be produced by stimulating the sacral set of nerves in the vertebral canal, but that, as in the male, only those fibres which exercised an inhibitory influence run from the spinal cord in the sacral nerve roots. The inhibitory effects produced were (1) Flushing of the vulva and clitoris, (2) Dilatation of the vulva, and (3) Relaxation of the skin muscles surrounding the vulva. The visceral motor effects were the same as those produced by the lumbar set of nerves as described above. Besides these effects, contraction was induced in the external sphincter of the vagina and in the striated genital muscles.

\section{The InNervation OF the Ovaries}

The ovary is innervated from the sympathetic plexus accompanying the ovarian artery and from the plexus associated with the ovarian branch of the uterine artery. It is generally supposed that the nerve fibres, which are non-medullated, are merely vascular in function. ${ }^{1}$ The fact that ovulation in some animals only occurs as a consequence of coition, and then takes place at a definite time afterwards, points to the conclusion that the follicles discharge in response to a stimulus conveyed to the ovary by its nerves (see p. 134). It has been suggested that the rupture is due to the stimulation of erectile tissue. ${ }^{2}$ Nerve fibres have been described in the tissue immediately surrounding the follicles, and have even been traced as far as the follicular epithelium.

1 Von Herff, "Ueber den feineren Verlauf der Nerven im Eierstocke des Menschens," Zeitschr. f. Geburt. u. Gynäk., vol. xxiv., 1892. Gawronsky, "Ueber Verbreitung und Endigungen der Nerven in den weiblichen Genitalien," Arch. f. G jü̈k., vol. xlvii., 1894. Kallius, "Nervendigungen in Drüsen d. Eierstöcke," Merkel and Bonnet's Ergeb. d. Anat. u. Entwick., vol. iv., 1895. Mandl, "Ueber Anordnung und Endigungsweise der Nerven im Ovarium," Arch. f. Gynäk, vol. xlviii., 1894-5. Vallet, "Nerfs d'Ovarie," \&c., Thesis. Paris, 1900. Abel and McIlroy, "Nerves of the Ovary," Phys. Soc., June 5th, 1909. See also references on p. 329.

${ }^{2}$ Rouget, "Recherches sur les Organes Érectiles de la Femme," Jour. de la Phys., vol. i., 1858. 


\section{The Innervation of the Uterus and Vagina and the Mechanism of Uterine Contraction}

It is well known that the onset of parturition is manifested by rhythmically repeated contractions of the uterus which constitute the "labour pains." But although the contractions are most pronounced at this period, observations on animals have shown that even in a virgin uterus rhythmical movements may occur.

Kehrer ${ }^{1}$ showed long ago that a uterus separated from the body is capable of undergoing contractions if kept moist, and at the normal body temperature. More recently Helme, ${ }^{2}$ Kurdinowski, ${ }^{3}$ Franz, ${ }^{4}$ and others have confirmed Kehrer's observation, thus proving that the movements are not dependent on impulses received from the central nervous system. Those investigators showed that the excised uterus may undergo regular contractions for a prolonged period if placed in a warm bath of normal saline solution or on having its vessels perfused with Locke's solution. According to Franz the excised virgin uterus exhibits no spontaneous contractions, but Helme and Kurdinowski state that they may occur, but that they are much weaker than those taking place during and after pregnancy.

The movements of the uterus have lately been more fully investigated by Cushny, ${ }^{5}$ who has carried out a large number of experiments upon rabbits and other animals. This author states that in virgins the unexcised uterus may remain motionless for a long time, but that after manipulation or exposure to air rhythmic contractions are often developed. He is disposed to believe, therefore, that the virgin uterus in the intact animal

${ }^{1}$ Kehrer, "Zusammenziehungen der glatten Genitalmuskelatur," \&c., Beiträge zur Vergl. u. Exper. Geburtskunde, 1867.

2 Helme, "Contributions to the Physiology of the Uterus and the Physiological Action of Drugs upon it," Reports of the Laboratory of the Royal College of Physicians, Edinburgh, vol. iii., 1891.

3 Kurdinowski, "Physiologische und pharmakologische Versuche an der isolirten Gebärmutter," Arch. f. Anat. $u$. Phys., phys. Abth. (supplement) 1904.

"Franz, "Studien zur Physiologie des Uterus," Zeitschr. f. Geburt. $u$. Gynäk., vol. liii., 1904.

5Cushny, "On the Movements of the Uterus," Jour. of Phys., vol. xxxv. 1906. 
undergoes no spontaneous movements. In animals in a state of " heat," and during and after pregnancy, spontaneous contractions could generally be discerned from the first, and the author is doubtful if the organ ever resumes its original inert condition after it has once been pregnant. In some cases the movements seemed to occur almost simultaneously throughout the entire organ, but in others the circular muscle fibre contracted independently of the longitudinal, and vice versa. Mechanical or electrical stimulation caused very powerful contractions, but these were elicited more easily in the pregnant than in the virgin uterus, while the increased irritability was found to persist after pregnancy was over.

Helme stated that a shutting off of the blood-supply in the excised and perfused uterus of the sheep brought about contraction. Kurdinowski, on the other hand, found that in the intact animal the opposite effect was produced. Cushny's experiments for the most part confirm those of Kurdinowski, but clamping the aorta in the cat led to conflicting results, since in two cases it was succeeded by relaxation and in three by contraction. No reason could be assigned for this divergence.

It has long been known that uterine contractions can be induced by nervous stimulation. Thus Serres ${ }^{1}$ showed that irritation of the spinal cord in the lumbar region excited the uterus to contract, and later investigators have obtained similar results. ${ }^{2}$ Röhrig ${ }^{3}$ showed that asphyxia which may bring about uterine contractions (and abortion in the pregnant condition) cannot do so if the lumbar cord is destroyed. Frankenhauser ${ }^{4}$ and Körner ${ }^{5}$ discovered that the efferent nerve fibres left the lumbar region of the spinal cord, and after traversing the sympathetic, the inferior mesenteric ganglia and

1 Serres, Anatomie Comparée du Cervea, 1824.

2 Budge, "Ueber das Centrum genitospinale des Nervus sympatheticus," Virchow's Archiv, vol. xv., 1858. Riemann, "Einige Bemerkungen über die Innervation der Gebärmutter," Arch.f. Gynäk., vol. ii., 1871.

${ }^{3}$ Röhrig, "Experimentelle Untersuchungen über die Physiologie der Uterusbewegung," Virchow'\& Archiv, vol. lxxvi., 1879.

"Frankenhauser, "Die Bewegungsnerven der Gebärnutter," Jenaische Zeitschr. f. Med., vol. i., 1864.

' Körner, Studien d. Phys. Instituts zu Breslau, 1865. 
the aortic plexus, made their way to the uterus. Langley ${ }^{1}$ found that the majority passed to this organ by way of the sympathetic in the region of the fourth, fifth, and sixth lumbar ganglia, so that they probably arise from the third, fourth, and fifth spinal nerves. Subsequently Langley and Anderson ${ }^{2}$ showed that stimulation of the second, third, fourth, and fifth lumbar nerves (in cats and rabbits) causes pallor and contraction of the Fallopian tubes, uterus, or vagina, but that stimulation of the first and sixth lumbar nerves produces no effect. They state that the efferent fibres are motor for the muscular walls and vaso-constrictor for the small arteries. The effect on the uterus and vagina was found to vary with the state of the uterus in regard to parturition. Langley and Anderson state that the sacral nerves send neither motor nor inhibitory fibres to any of the internal generative organs, thus differing from Kehrer, Körner, and others, who say that they obtained contraction of the uterus on stimulating these nerves.

Keiffer ${ }^{3}$ also independently investigated the innervation of the uterus, and the results obtained by exciting various nerves, his observations agreeing for the most part with those of Langley and Anderson.

Cushny, in the paper already referred to, has described at some length the effects of hypogastric stimulation, which produced in the rabbit powerful contraction of the whole uterus irrespective of its condition in regard to the occurrence of pregnancy. If the stimulation was prolonged for more than fifteen seconds the organ remained in a state of extreme contraction (tetanus uteri), but oscillations soon began again, and a gradual relaxation followed. Cushny shows also that the hypogastric contains inhibitory fibres, and in one exceptional case (a pregnant rabbit) stimulation of this nerve induced pure inhibition, the uterus ceasing to contract at all. Moreover, in the virgin cat the effect of hypogastric stimulation was inhibitory, the organ undergoing relaxation. On the other hand, in the cat during pregnancy, or as a general rule after pregnancy, hypogastric stimulation led to strong and immediate contraction

1 Langley, loc. cit.

${ }^{2}$ Langley and Anderson, loc. cit.

${ }^{3}$ Keiffer, Recherches sur la Physiologie de l' Utérus, Bruxelles, 1896. 
just as in the rabbit. It is supposed, therefore, that the inhibitory fibres prevail in the virgin, but that during and after pregnancy the action of the motor fibres conceals their presence. ${ }^{1}$

Fellner 2 states that the "nervi erigentes" are motor for the longitudinal muscles of the uterus and for the circular muscles of the cervix, but are inhibitory for the circular muscles of the uterus and the longitudinal muscles of the cervix. According to the same author the hypogastric nerves are motor for the circular muscles of the corpus uteri and for the longitudinal muscles of the cervix, but are inhibitory for the longitudinal muscles of the uterus and for the circular muscles of the cervix.

Dembo ${ }^{3}$ has described a peripheral nerve centre for the uterus in the upper part of the anterior wall of the vagina in the rabbit. Stimulation of this centre produced a very distinct contraction of both uterine cornua.

According to Jacob ${ }^{4}$ there is an inhibitory centre for uterine contraction situated in the medulla oblongata. This assertion is based on experiments upon rabbits, in which it was found

${ }^{1}$ Cushny deals also with the action of various drugs on the uterus, and for an account of this subject the reader is referred to his paper (loc. cit.). See also Dale, "On Some Physiological Actions of Ergot," Jour. of Phys., vol. xxxiv., 1906. The effects of temperature upon uterine contraction were first described by Runge (M.) ("Die Wirkung holer und neidriger Temperaturen auf den Uterus," Arch.f. Gynäk., vol. xiii., 1878), who found that hot water caused increased contraction followed by paralysis, while cold water produced tetanus. Helme (loc. cit.) obtained results which were mostly similar. Kurdinowski also found that cold excited contraction to tetanus, and that long-continued mechanical stimulation produced exhaustion. Asphyxia did not cause contraction, and experimental anæmia had no effect.

2 Fellner, "Ueber die Bewegungen und Hemmungsnerven des Uterus," Arch.f. Gynäk., vol. 1xxx., 1906. Labhardt ("Das Verhalten der Nerven in der Substanz des Uterus," Arch.f. Gynaik., vol. lxxx., 1906) describes an extensive system of nerves in the uterus of Man and of the rabbit, the main trunks lying between the middle layer of muscles and giving off intrafascicular bundles. Keiffer (Bull. Soc. d'Obstét, Paris, 1908, Nos. 2 and 3) describes sympathetic ganglia in the uterine and vaginal walls in the course of the large nerves coming from the hypogastric plexus.

${ }^{3}$ Dembo, "Zur Frage über die Unabhängigkeit der Kontraktinen der Gebärmutter von dem Cerebrospinalnervensystem," Abstract in Biol. Centralbl., vol. iv., 1885. (The original is in Russian.)

4 Jacob, "Ueber die Rhythmischen Bewegungen des Kaninchenuterus," T'erhandl. der Phys. Gesell. zu Berlin, Anat. f. Anat. u. Phys., phys. Abth., 1884. 
that stimulation of the medulla caused the movements of the uterus to cease. Moreover, it is to some extent borne out by the fact that the "pains" of labour can often be inhibited by emotions and other contemporary actions of the central nervous system (see below, p. 539).

It is well known that uterine contraction can be induced by the presence of a foreign body in the uterus, by injections into the rectum, by the application of the child to the breast, and by various other means. According to Kurdinowski ${ }^{1}$ the sensation of any violent pain may cause uterine contraction in animals, and the organ may respond to remote stimulation (e.g. in the ears). These observations alone are sufficient to show that the contraction is often a reflex act. The experimental evidence cited above shows no less clearly that the controlling centre is in the lumbar portion of the spinal cord. Nevertheless there are many indications, as just mentioned, that the novements of the uterus can be brought under the influence of a higher centre situated in the brain. On the other hand, the fact that rhythmical contractions can continue to occur in the absence of all nervous connections is a certain proof that they are primarily independent of the nervous system, although normally they are to a large extent influenced by it. It must be concluded, therefore, that the power to contract and relax rhythmically is an inherent property of the muscular tissue of the uterus.

The question as to the nature of the mechanism involved in uterine contraction is inseparably connected with the further problém concerning the part played by nervous influence in controlling the course of parturition. This subject is dealt with below (p. 537).

\section{The Normal Course of Parturition in the Human Female}

The increased size of the fœtus, together with the accumulation of the amniotic fluid, causes the uterus towards the end of pregnancy to become considerably distended. The enlarge-

1 Kurdinowski, "Ueber die Reflectorische Wechsel beziehung zwischen der Brüstdrüsen und dem Uterus," Arch.f. Gynäk., vol. lxxxi., 1907. 
ment is still further increased by the growth of the uterine wall itself. Partly as a consequence of this enlargement the waves of contraction which were present at the beginning of pregnancy, or cven previously, as above described, become much more marked, but are still unaccompanied by painful sensation. With the onset of labour, however, these unconscious painless contractions are replaced by others of increasing intensity, and in the human subject distinctly affecting consciousness and giving rise to severe suffering. These are the "labour pains" which bring about the dilatation of the cervix uteri and lead to the expulsion of the child followed by the placenta.

At the commencement of labour the contractions do not occur oftener than once every half or quarter of an hour, but they soon become more frequent, and recur eventually at intervals of two or three minutes. Their average duration is about a minute, though actual pain is experienced for a shorter time. ${ }^{1}$ Polaillon ${ }^{2}$ and Schutz ${ }^{3}$ have shown from tracings that the period of increase occupies the main portion of the "pain," its acme being of short duration. In animals possessing bicornuate utcri the contractions are said to be peristaltic in nature, but this is not so evident in the case of the human subject.

Williams ${ }^{4}$ lias discussed the question as to the amount of force exerted at each "pain" in a woman during delivery. He states that the expenditure of energy necessary to restrain the liead of the child as it emerges from the vulva is represented by not more than fifty pounds, although the obstetrician sometimes finds it impossible to hold it back at the acme of the pain. Schutz ${ }^{5}$ made an attempt to arrive at a more exact estimation by inserting into the nterus a rubber bag connected with a mercury manometer. He found that whereas the intra-uterinc pressure between the contractions was represented by a column

1 Williams, Obstetrics, London, 1904.

${ }^{2}$ Polaillon, Recherches sur la Physiologie'de l'Utérus Gravide, Paris, 1880.

${ }^{3}$ Schutz, "Ueber die Formen der Wehenerven und über die Peristaltik des Menschlichen Uterus," Arch. f. Gynük., vol. xxvii., 1886.

4 Williams, loc, cit.

- Schutz, "Ueber die Entwickelung der Kraft des Uterus in Verlaufe der Geburt," Verhandl.d. Deutsch. Gesell. für Gynäik., 1895. 
of mercury of twenty millimetres, during the pains it rose to a height of from eighty to two hundred and fifty millimetres. This difference is calculated to represent a force of from eight and a half to twenty-seven and a half pounds.

The clinical course of labour and the muscular forces concerned in the process are fully dealt with in the text-books on Midwifery, ${ }^{1}$ and it is not proposed in the present work to devote more than a very brief space to the consideration of this subject. It is customary to divide the period of labour into three stages.

The first stage is characterised by the dilatation of the cervix and os uteri. Galabin gives the following account of the mechanical processes which take place in the uterus during this stage of labour:- "There are three elements in the mechanism of dilatation of the cervix and os; first, the mechanical stretching by the bag of membranes; secondly, the contraction of the longitudinal fibres of the uterus, which draw the cervix open; and thirdly, the physiological relaxation of the circular fibres, which [is always associated] with the contraction of the body of the uterus. It follows from the principles of mechanics that the effect of any given pressure within the bag of membranes in producing a tension of the edge, either of the internal or external os, is directly proportional to the diameter of the os, and therefore vanishes when the os is very small. Hence, if the os is closed to begin with, some dilatation by the stretching influence of the longitudinal fibres must have taken place before the mechanism of dilatation by the bag of membranes or parts of the fœtus can come into play. The mechanical action of the dilating part, as it is pressed into the cervix, is that of a wedge; a fluid and uniform wedge, in the case of the bag of membranes; a solid and irregular wedge, in the case of the head or other part of the foetus. It follows that the effect produced by the wedge varies according to the acuteness of its angle at the points where it is in contact with the edge of the os. . . . It follows that the dilating force vanishes when there is no projection, and becomes greater the more complete

${ }^{1}$ Sce Williams, loc. cit. Galabin, Manual of Midwifery, 6th Edition, London, 1904, and the other text-books on the subject. See also Sellheim, "Die Physiologie der Weiblichen Geschlechtsorgane," Nagel's Handbuch der Physiologie des. Menschen, vol. ii., Braunschweig, 1906. 
is the projection. It follows also that it becomes progressively more and more effective in proportion to the degree of dilatation which has already been produced." 1

The second stage, which has been called the expulsive stage, may be said to include the period from the complete dilatation of the os uteri to the delivery of the fotus. When the os has become fully expanded, and the membranes have ruptured, there is generally a short lull in the pains of labour. At the end of the lull the contractions of the uterus begin to recur with increasing vigour and frequency, while the abdominal muscles which are brought into play for the first time exert on the uterus an additional extrinsic force similar to that exerted on the rectum during defæcation. These abdominal contractions are synchronous with those of the uterus, and therefore, like them, tend to occur rhythmically. At the commencement of the process the patient is able to some extent to control the contractions by an effort of the will, but later on they are quite involuntary. The combined effect of the contractions is to drive the child, usually head foremost, through the vagina and then out through the vulva, these however playing a purely passive part in the act of expulsion. Sometimes the membranes do not rupture before birth, and the child is born surrounded by a " caul."

The third stage of labour comprises the expulsion of the placenta. After the delivery of the child the uterus ceases to contract for a longer or shorter period, at the end of which its activity is renewed once more. At this time the placenta becomes completely separated from the wall of the uterus, and passes into the upper part of the vagina. It is expelled thence through the action of the muscles of the abdomen. During this stage there is almost invariably a certain amount of hæmorrhage, which is represented in normal cases by from three to four hundred cubic centimetres of blood.

The duration of labour shows considerable variation, but is generally longer in primiparous women (i.e., those who have never borne children before) than in multiparous ones. The average for the former is rather more than eighteen hours, the three stages respectively occupying sixteen, two, and from a

${ }^{1}$ Galabin, loc. cit. 
quarter to half-an-hour. The average for multiparous women is twelve hours, eleven of which are occupied by the first, and one by the second stage. The duration of labour in primiparous women depends also upon age, being usually more prolonged in elderly subjects.

\section{Parturition in other Mammalia}

In animals the process of delivery varies somewhat in the different animals. In the horse the foetus, which has been lying on its back during intra-uterine life, preparatory to birth

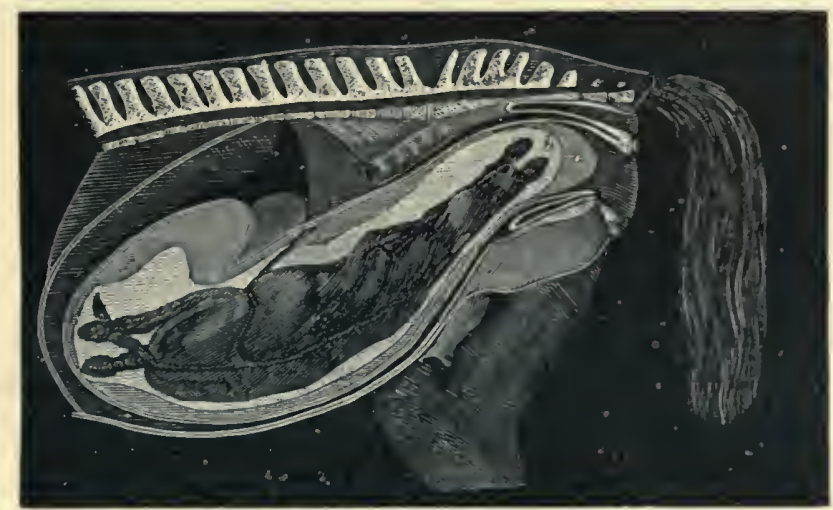

FIG. 131. - The first stage in the revolution of the equine fotus. The os is dilated by the membranes, which bave not yet ruptured. (After Franck. From Smith's Veterinary Physiology, Baillière, Tindall \& Cox.)

changes on to its side and afterwards assumes the upright position, with its muzzle and forelegs in the direction of the pelvis. Dilatation of the passage follows, and the foal is delivered head first. In the cow and sheep the movements which occur are essentially similar. It is stated that the alteration in the position of the foetus is not brought about by its own movements but by the uterine contractions. The revolution of the foetus prior to birth in the mare and cow is apparently responsible for the torsion of the neck of the uterus and vagina which often occurs in these animals.

Parturition in the mare is accompanied by a complete separation of the chorion from the uterine wall. Is a conse- 
quence of this fact any difficulty experienced in delivery usually causes the death of the foal. In Ruminants, on the other hand, the separation of the cotyledons takes place very gradually, so that the connection between the maternal and fotal circulation is maintained to some extent until the last. In these animals the process of parturition may last for hours. In the mare, on the contrary, delivery is usually effected very rapidly. ${ }^{1}$ 'The foetal membranes may be expelled with the young or be

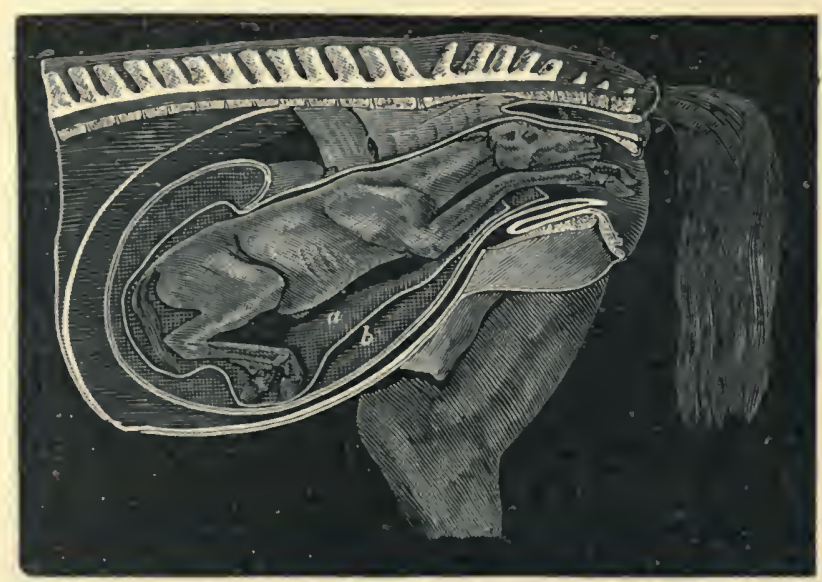

FIG. 132.-The Foal in the normal position for delivery, the revolution being completed and the membranes ruptured. (After Franck. From Smith's Veterinary Physiolcgy, Baillière, Tindall \& Cox.)

retained until a little later, when the uterus recovers its power and then expels them.

In animals such as the rat, in which multiple conception is the rule, the "presentation" of the young at birth may be either "breech" or " head." The fotuses tend to be expelled irregularly, some being discharged along with the placenta, while others are born separately. ${ }^{2}$

1 Smith, Veterinary Physiology, 3rd Edition, London, 1907. Fleming, Veterinary Obstetric8, London, 1878. See also Wortley Axe, "The Mare and Foal," Jour. Royal Agric. Soc., 3rd Series, vol. ix., 1898, and Leeney, "The Lambing Pen," Jour. Royal Agric. Soc., 3rd Series, vol. vii., 1896.

"Brumpt, "Parturition chez le Rat blanc," Bull. Soc. Zool, France, vol. xxxii., 1907. The loosening of the placenta and other changes in Tupaia are described by van Herwerden, "Die puerperalen Vorgänge in der Mucosa uteri von Tupaia javanica," Anat. Hefte, vol. xxxii., 1907. 


\section{The Nervous Mechantsm of Parturition}

Parturition may be considered as being normally a reflex act, the centre of which is situated in the lumbar region of the spinal cord. On the other hand, it has been shown from experiments upon animals that the transmission of impulses through the cord is not absolutely essential to the occurrence of parturition.

Simpson (Sir James) ${ }^{1}$ removed the spinal cord from the first dorsal vertebra downwards from a number of sows a few days before parturition was due. Some of the animals died as a result of the operation, but in others parturition proceeded normally, excepting that in each case the last foetus of the series was not born. "The uterine contractions proceeding from fundus to cervix were sufficient to expel the fotuses from the uterus; and each fotus as it came into the vagina was thence extruded by the force transmitted from the foetus behind it; but when the last fœetus came into the vagina it remained there, because there was nothing to transmit the uterine expulsive force, while the vaginal and abdominal muscles, being under the influence of the spinal nerves, had been rendered powerless by the removal of the spinal cord."

Riemann ${ }^{2}$ states that after the destruction of the cord of a cat from the third dorsal vertebra downwards the animal gave birth to a kitten two days subsequently, shortly before its death.

Rein $^{3}$ describes experiments upon rabbits in which he severed the uterus from all nervous connection with the cerebrospinal system, and found afterwards that the mechanism of labour was not destroyed.

Furthermore, Oser and Schlesinger, ${ }^{4}$ as a result of experimental evidence, state that parturition can occur in animals after the severance of the sympathetic nerves which pass to the uterus, but it is difficult to understand how this operation

1 Simpson, Selected Obstetric Works, edited by W. H. Black, Edinburgh, 1871.

2 Riemann, "Einige Bemerkungen ïber die Innervation der Gebiir. mutter," Arch. f. Gynäk., vol. ii., 1871.

3 Rein, "Beitrag zur Lebre von der Innervation des Uterus," Pflïger's Archiv, vol. xxiii.

4 Oser and Schlesinger, "Experimentelle Untersuclıungen über Uterusbewegungen," Stricker's Med. Jahrbiicher, 1872. 
could have been made complete without interfering with the blood supply to that organ.

More recently, Goltz and Ewald ${ }^{1}$ have described an experiment in which they completely exsected the spinal cord of a bitch from the mid-dorsal region downwards, and found that after the operation the animal experienced normal "heat," became pregnant, and in due course produced a litter of pups. Kruiger and Offergeld ${ }^{2}$ have also shown that parturition is possible after destruction of the cord. Goltz had already shown ${ }^{3}$ that parturition could occur after the transection of the spinal cord in the dorsal region, and consequently after all connection with the higher centres had been cut off. (See pp. 490-491.)

The last-mentioned fact is also demonstrated in the various cases in which parturition has proceeded normally in women suffering from paraplegia from the level of the mid-dorsal part of the spinal cord downwards. Routh ${ }^{4}$ has recorded several such cases, and in all of them labour set in and proceeded regularly (or almost regularly), but without sensation. In Routh's own patient the injury was in the dorsal region of the cord, which was completely disorganised at the seat of the fracture of the spine, as the post-mortem evidence showed. In the lumbosacral region, however, there were a large number of cells which were normal in appearance, so that it could not be contended that the centre for parturition had been destroyed. Routh also refers to Brachet's case ${ }^{5}$ which he states is the only one recorded in which the spinal lesion was apparently in the lumbar region of the cord. In this case the uterus failed to make the normal contractions, and the child was eventually extracted with forceps. The placenta also had to be removed by hand.

1 Goltz and Ewald, "Der Hund mit verkürztem Rückenmark," Pfüger's Archiv, vol. Ixiii., 1896.

2 Kruiger and Offergeld, "Der Vorgang von Zeugung, Schwangerschaft, Geburt, und Wochenbett an der ausgeschalteten Gebärmutter," Arch. $f$. Gynäk, vol. 1xxxiii., 1908.

${ }^{3}$ Goltz, "Ueber den Einfluss des Nervensystems auf die Vorgange während der Schwangerschaft und des Gebärakts," Pfüger's Archiv, vol. ix., 1874.

+ Routh, "Parturition during Paraplegia," Trans. Obstet. Soc., Lond., vol. xxxix., 1898.

s Brachet, Recherches, 2nd Edition, Paris, 1837. 
It is clear, therefore, that a spinal lesion in the lumbar region may result in materially weakening the action of the uterus, and so may hinder the normal course of labour. On the other hand, in those cases in which the lesion was in the dorsal part of the cord, the possibility of spinal reflexes in the lumbar region could not be excluded. ${ }^{i}$

The following general conclusions regarding the nervous mechanism of parturition are based largely on those of Routh. (1) The act of parturition is partly automatic and partly reflex, these actions corresponding in the main to the first and second stages of labour respectively, the spinal reflexes usually commencing as soon as the membranes have ruptured. (2) Direct communication with the brain is not essential for the proper co-ordination of uterine action, but the brain appears to exercise a controlling influence of some kind. Thus, emotions often become a hindrance to the progress of parturition. It would seem possible that this inhibition of uterine contractions is brought about by an inhibition of a centre in the brain (see above, p. 530). (3) Direct communication between the uterus and the lumbar region of the cord, is generally essential for the occurrence of those rhythmical contractions which take place during the progress of normal labour. There is experimental evidence upon animals, however, that the uterus is sometimes able automatically to expel its contents, at least as far as the relaxed portion of the genital cord, even when entirely deprived of all spinal influence. ${ }^{2}$

\section{Changes in the Maternal Organism}

The influence of parturition upon the metabolism of the maternal organism is dealt with by Sellheim." There is a

1 Routh also discusses post-mortem parturition, but points out that in most of those cases wherc it occurred, the expulsion of the fotus was caused by increased abdominal pressure due to putrefactive gaseous distension during a condition of muscular relaxation. There are some facts which go to prove that uterine contractility and retraction may continue or even commence after death, possibly resulting from the movements of the imprisoned child.

2 For further references to the literature of the nervous mechanism of parturition, see Bechterew, Die Funktionen der Nervencentra, Weinberg's German translation, vol. i., Jena, $190 \%$.

${ }^{3}$ Sellheim, loc, cit. 
slight rise of temperature during the process, and the pulse rate is also affected, being much quicker during the pains, but slower between them, the difference amounting to as much as thirtysix beats a minute. The blood shows a marked leucocytosis, and the blood pressure is higher. Urine is secreted in smaller quantities, and is liable to contain traces of renal epithelium, red and white blood corpuscles, and albumen.

\section{The Cause of Birth}

Foster in his Teet-book of Physiology ${ }^{1}$ has written as follows: "We may be said to be in the dark as to why the uterus, after remaining for months subject only to futile contractions, is suddenly thrown into powerful and efficient action, and within it may be a few hours, or even less, gets rid of the burden which it has borne with such tolerance for so long a time. None of the various liypotheses which have been put forward can be considered as satisfactory. We can only say that labour is the culminating point of a series of events, and must come sooner or later, though its immediate advent may sometimes be decided by accident." What Foster wrote about this question is still true to-day, for no real progress has been made towards the solution of the physiological problem as to the immediate cause of parturition.

Williams ${ }^{2}$ has classified the various theories which have been formulated under eleven heads. These may now be briefly considered in the order adopted by him.

(1) The increasing irritability of the uterus, as manifested by its greater tendency to respond to stimulation in the later stages of gestation, is probably a factor in determining the time of birth. As already described, the uterine contractions towards the close of pregnancy are not only more frequent, but they are also much more intense. This growing irritalility is no doubt to be directly associated with the increase in the size of the fotus.

(2) It is suggested that the mere distension of the uterus must, after a certain point, lead to a reaction, when the organ

I Foster, Text-Book of Physiology, 5th edition, vol. iv., London, 1891.

2 Williams, loc. cit. 
attempts to reduce itself to its former size, and so expels its contents. This idea receives some support from the fact that twin pregnancies and hydramnios (or the presence of an excessive quantity of liquor amnii) often result in premature labour.

(3) It has been supposed from early times onwards that parturition might be brought about through the pressure of the fœtus producing a gradual dilatation of the cervix. Williams, however, has pointed out that this condition of the cervix cannot be the sole factor, since in a certain number of cases, especially in twin pregnancies, a pronounced dilatation has been known to occur for a considerable period prior to the onset of labour.

(4) Keilmann, ${ }^{1}$ working upon the bat, came to the conclusion that the onset of labour was caused by the increasing pressure set up by the lower distended portion of the pregnant uterus (the lower uterine segment) upon the surrounding nerve ganglia. Supposing this conclusion to be correct as applied to the bat, it is not quite clear that it is equally applicable to the human female and to other animals.

(5) Simpson 2 and others were of opinion that the "pains" of labour were the indirect result of a partial separation of fœetus and decidua, brought about by the fatty degeneration of the latter in the last stages of pregnancy, so that the fotus became virtually converted into a foreign body, which caused the uterus to respond accordingly. It is no doubt true that part of the maternal placenta undergoes degenerative changes towards the end of pregnancy, but there is no evidence that this by itself is sufficient to cause a separation of the fotus from the uterine wall.

(6) There is no evidence in support of the theory that the exciting cause of parturition is an accumulation of carbon dioxide in the blood, beyond the fact demonstrated by BrownSéquard, ${ }^{3}$ Keiffer, ${ }^{4}$ and others, that uterine contractions can be induced experimentally by this means.

1 Keilmann, "Zur Klärung der Cervixfrage," Zeitschr. f. Geb. u. Gynük., vol. xxii., 1891.

2 Simpson, loc, cit.

${ }^{3}$ Brown-Séquard, Experimental Researches, English translation, London, 1853.

- Keiffer, loc. cit. 


\section{THE PHYSIOLOGY OF REPRODUCTION}

(7) Spiegelberg ${ }^{1}$ put forward the theory that parturition was brought about through the action of substances secreted by the fotus and passed into the maternal blood. These hypothetical substances, which appear to have been comparable to Starling's hormones, were supposed to act on the uterine centre in the spinal cord. Spiegelberg suggested, further, that the exciting substances were elaborated as a result of an insufficiency of nutrition, and were an indication that the mature fœetus required other sustenance than that supplied to it through the placenta. This theory appears to be devoid of all experimental basis, but it is not opposed by any of the known facts.

(8) Tyler Smith, ${ }^{2}$ Minot, ${ }^{3}$ Beard ${ }^{4}$ and others have held the view that there is a connection between parturition and menstruation, the two processes being physiologically homologous. According to this theory, there is an increased tendency towards uterine contractions at the periods at which menstruation would occur if the condition were not one of pregnancy. Thus Tyler Smith says that there is in all women a greater tendency to abort at the times represented by the catamenial periods. According to Minot, the menstrual and gravitidal changes follow the same cycle of events, the pregnant uterus passing through a prolonged and intensified " menstrual cycle." Consequently, it is probable that there is a common cause for the ending of the series (the casting off of the superficial part of the mucosa in both cases). This theory has been further elaborated by Beard, who has arrived at the conclusion that parturition takes place at the time it does in order that a new ovulation may be carried into effect. This author lays great stress upon the rhythmical character of the sexual processes, and points out in support of his theory that "heat" and ovulation frequently ensue shortly after parturition. That this does not happen in many animals has been already shown in the second chapter of 1891.

1 Spiegelberg, "Die Dauer der Geburt," Lehrbuch der Geburtshülfe, vol. ii.

2 Tyler Smith, Parturition and the Principles and Practice of Obstetrics, London, 1849.

${ }^{3}$ Minot, "Uterus and Embryo," Jour. of Morph., vol. ii., 1889. "Human Embryology."

- Beard, The Span of Gestation and the Cause of Birth, Jena, 1897. 
this work.1 Moreover, Beard's theory makes no attempt to explain why parturition should occur in some animals at the close of one particular ovulation interval (e.q. in the human species at the close of the tenth), and in other animals at the termination of a different one (that is to say, no explanation is given of the variation in the number of ovulation intervals which are comprised in the period of gestation in different animals). It cannot be said, therefore, that Beard's hypothesis as to the time occupied by gestation and the cause of birth is an adequate one.

(9) Various writers, such as Geyl, ${ }^{2}$ have laid some stress upon the belief that parturition occurs in women at a tims which has proved, after long ages, to be the most suitable for the perpetuation of the race. A similar statement might of course be made about any other existing species of mammal, for it is only another way of stating the generally accepted belief that parturition, like all other natural phenomena in the animal world, is under the control of natural selection. In support of this contention, as applied to the human species, it has been pointed out that when labour takes place after an abnormally prolonged gestation, it frequently results in dead children, while, on the other hand, premature labour results in puny, ill-developed children, who often perish in early life.

(10) Eden, ${ }^{3}$ and also Williams, have pointed out "that the frequent occurrence of infarct formation [i.e. a certain kind of degenerative change] in the placenta at term must be regarded as evidence of its senility, and that this change is analogous to the obliteration and atrophy of the chorion læve at an earlier period. Where these changes are marked the nutrition of the fotus must be interfered with, and it is possible that certain of its metabolic products may result in stimulation of the uterine centre." " This theory should be compared with that advanced by Spiegelberg (see above).

1 Beard holds that ovulation takes place shortly after parturition in all Mammals. This is not the case in any monœstrous animals which have a prolonged anœstrous period.

2 Geyl, "Ueber die Ursache des Geburtseintrittes," Arch. f. Gynäk:, vol. xvii., 1881.

3 Eden, "A Study of the Human Placenta," Jour. of Path. and Bacteriol., vol. iv., 1897 .

1 Williams, loc. cit. 


\section{$5+4$}

\section{'IHE PHYSIOLOGY OF REPRODUC'IION}

(11) Lastly, Williams calls attention to the fact that excessive physical fatigue, sudden jars or violence, mental emotion, fright, \&c., may lead to the termination of gestation in women. Similarly, it is well known that circumstances of a like nature may induce abortion in animals.

Williams remarks that in all probability the onset of labour in most cases is due to a combination of a number of the above-mentioned causes. The main objection to all the theories which have so far been advanced is that they take no account of the complexity of the problem. An hypothesis may be fairly adequate as a general explanation of the duration of gestation, while at the same time taking no account of the immediate cause of birth. Thus, it is no doubt true that the time of parturition is determined largely by the necessities of the offspring, but this conclusion provides no sort of explanation as to why it is that the pains of labour in any one particular species generally commence at a certain fixed stage of development, and it remains for us to assume that it is one of the inherent properties of the uterus in the species in question that they should do so. Even on this assumption it is impossible to avoid concluding that there must be some definite exciting cause, such as that postulated by Spiegelberg.

\section{Prolonged Gestation}

The duration of gestation in any one species usually varies within quite narrow limits, but under exceptional circumstances it may continue for an abnormally long period. Thus, Williams ${ }^{1}$ records a case of a woman with whom pregnancy extended for over eleven lunar months after the cessation of menstruation, instead of the usual ten lunar months (i.e. about 280 days). In this case typical labour pains were experienced at the end of the tenth month, but these subsided after a short time, and were not renewed until four weeks later, when they resulted in parturition. The same woman became pregnant a second time, when the period of pregnancy was again prolonged until the end of the eleventh month after the last menstruation. The children on each occasion were abnormally large and heavy

1 Williams, loc. cit. 
at birth. Allen ${ }^{1}$ has recently recorded a number of further cases of prolonged gestation in women, the longest time chronicled being 334 days. It is stated that inertia of the uterus (due to fatty degeneration) is frequently associated with prolonged gestation; but the occurrence of the latter is no doubt often brought about by other causes which are at present unknown.

Cases of prolonged gestation have been observed also among animals. Professor Ewart has informed the writer of a marc in his possession in which the period of gestation was extended to twelve months instead of the usual eleven. Other cases of prolonged gestation in mares, and also in cows, have been recorded by Tessier ${ }^{2}$ and Franck-Albrecht-Göring, ${ }^{3}$ and appear to be not uncommon. No satisfactory reason has been suggested to account for such cases.

According to Pinard ${ }^{4}$ prolonged gestation may occur in Rodents (Dipodillus simoni, Meriones shawi, M. longifrons, Mus musculus, \&c.), as a result of suckling a large litter produced just previously to a second gestation, the development of the young during the latter being arrested by a relative insufficiency of nourishment. In some cases the period of gestation was half as long again as the normal duration.

\section{The Puerperium}

In multiparous women the uterus continues to contract and relax at more or less regular intervals after the cxpulsion of the placenta which marks the termination of the third stage of labour. The contractions which occur at this period give rise to the scnsations commonly known as the "after-pains." These may last several days, but are not gencrally very severe after the first day. They are particularly liable to occur when the child

1 Allen (L. M.), "Prolonged Gestation," Amer. Jour. of Obstet., vol. Iv., 1907.

${ }^{2}$ T'essier, "Recherches sur la Durée de la Gestation," \&c., Mim. de l'Acad. des Sciences, Paris, 1817.

${ }^{3}$ Franck-Albrecht-Göring, "Die Trächtigkeitsdauer," Thierärzlliche Geburtshiilfe, vol. iv., 1901.

4 Pinard, Article "Gestation," Richet's Dictionnaire de Physiologie, vol. vii., Paris, 1905. 


\section{6 'IHE PHYSIOLOGY OF REPRODUC'IION}

is put to the breast, a fact which seems to indicate a nervous connection between the uterus and the mammary glands. In primiparous women the tonicity of the puerperal uterus is usually greater than in multiparous ones, so that the uterus is capable of remaining during this period in a state of almost uninterrupted retraction unless blood clots or other foreign bodies are present in the cavity, in which case the organ undergoes movements in attempting to expel them.

This tonic retraction of the uterus is an important factor in closing the blood sinuses, and so preventing bleeding. If, owing to any circumstance, the normal contraction and retraction of the uterus are interfered with, post-partum hæmorrhage is liable to occur. This is not infrequently the case with white women who have migrated to the tropics, or with ill-nourished women in the slums, in whom, owing apparently to an inefficiency in the uterine nerve supply, the organ tends to become inert. ${ }^{1}$ It follows from what has been said that multiparous women are more liable to post-partum hæmorrhage than primiparous ones. $^{2}$

According to Longridge the anæmic condition of-the normal puerperal uterus is due partly to the effacement of the ovarian and uterine arteries which occurs when the uterus contracts. "The reality of this occurrence is supported by an observation which can be made in many cases of Cæsarian section; in this operation it is noticed that as long as the uterus remains outside the abdomen it tends to bleed, but that as soon as it is dropped back bleeding ceases. It is not the warmth of the abdominal cavity that checks the bleeding, since it may continue when the uterus is wrapped in warm towels outside the abdomen. But the mere fact of pulling up the uterus opens out the concertina, as it were, and allows blood to flow through the arteries. If the bladder is full at the end of labour, the uterus is pushed

1 Longridge, The Puerperium, London, 1906.

2 Longridge has pointed out, however, that the amount of post-partum discharge in multipare is not as a rule in proportion to the severity of the "after-pains," and consequently that the latter cannot be ascribed simply to defective retraction on the part of the uterus. He suggests, therefore, that the "after-pains" in multipara are largely due to the uterus suffering from cramp resulting from the excessive exertion involved in discharging the child. 
upwards, and slight loss may continue until the water is drawn off. As soon as the uterus is allowed to nestle down into its normal position the bleeding stops." 1

The puerperal vaginal discharge is known technically as the lochia. It varies considerably in amount in different individuals, and changes in character as the puerperium proceeds, ceasing altogether about the middle of the third week. For the first few days it consists almost entirely of blood, which makes its way from the raw surface of the uterus and from lacerations caused during delivery. This is the lochia rubra. After three or four days it becomes paler, owing to the dilution of the sanguineous discharge by mucous secretion. This is called the lochia serosa. During the next three days the normal colour of the lochia is brown. This change (from pale pink to brown) is due to the fact that the normal acidity of the vaginal secretion has by this time become re-established. Longridge suggests that the brown colour is probably the result of the formation of some such compound as acid hæmatin. After about the tenth day the lochia assumes a whitish or yellowish-white colour, owing to the admixture of leucocytes and the cessation of the blood flow. It is then known as the lochia alba. In many cases, however, traces of blood may be observed for weeks, but the lochia alba consists mainly of secretions from the vagina and cervix, together with leucocytes, a few epithelial cells, fragments of decidual tissue, and crystals of cholesterin. Micro-organisms are also present in the discharge, but recent investigations liave shown that the lochia obtained directly from the uterine cavity does not contain bacteria, excepting in cases where the uterus is the seat of infectious processes. ${ }^{2}$

The average quantity of the discharge has been computed by Gassner ${ }^{3}$ at 1485 cubic centimetres, or about 50 ounces. Giles ${ }^{4}$ estimated it as $10 \frac{1}{2}$ ounces (or considerably less than Gassner's

1 Brock ('Pactitioner, January 1908) has recently expressed the opinion that puerperal bleeding is chiefly venous, pointing out that the discharge is usually very dark in colour.

${ }^{2}$ Krönig, Bakteriologie des Genitalkanales, \&c.. Leipzig, 1907.

${ }^{3}$ Gassner, "Ueber die Veränderungen des Körpergewichtes bei Schwangeren, Gebärenden, und Wöchnerinnen," Monatsschr. f. Geburtskunde, vol. xv., 1862.

"Giles, "On the Lochia," Trans. Obstet. Soc., vol. xxxv., 1897. 
estimation), and found further that in women who were accustomed to bleed freely at the menstrual periods the amount of the lochial discharge was beyond the average. According to Gassner, the discharge is generally less in women who suckle.

The uterus after delivery becomes rapidly reduced in size. This process is known as the involution of the uterus; it is completely effected in from five to eight weeks, the greatest reduction taking place in the first few days. Thus the freshly delivered uterus weighs on an average 1000 grams (or about 2 pounds), a week later it weighs only half that amount, at the close of the second week 375 grammes, and at the end of the puerperal period as little as 60 grammes (or about 2 ounces). Its decrease in size is such that by the tenth day after parturition the organ is once more confined to the cavity of the pelvis proper, and cannot be felt above the symphysis.

The process of uterine involution is the result chiefly of changes occurring in the muscle walls. ${ }^{1}$ The size of the individual cells becomes very markedly diminished, but there is little or no reduction in their number. Fatty degeneration does not take place in the muscular tissue. It is stated that the retraction of the muscle fibres produces a compression of the vessels, and that the comparatively anæmic condition of the puerperal uterus, especially in the earlier stages, is due to this cause. Subsequently the uterus becomes more vascular again.

The remains of the decidua which are not expelled at parturition undergo degeneration and are discharged in the lochia, leaving only the fundi of the glands and a certain amount of connective tissue from which the uterine stroma is renewed. The epithelium is re-formed from that of the glands, as shown by Friedländer, ${ }^{2}$ Kundrat and Engelmann, ${ }^{3}$ Leopold, ${ }^{4}$ Krönig, ${ }^{5}$

1 The account given of the changes in the uterus during the puerperium is bascd largely on that given by Williams (Obstetrics, New York, 1904). See also Sellheim, "Das Wochenbett," in Nagel's Handbuch der Physiologie des Menschen, vol, ii., Braunschweig, 1906, where further references are given.

${ }^{2}$ Fricdländer, Physiologische und Anatomische Untersuchungen über den Uterus, Leipzig, 1870.

${ }^{3}$ Kundrat and Engelmann, "Untersuchungen über die Uterusschleimlaut," Stricker's Med. Jahrbuch, 1873.

4 Leopold, Studien über die Uterusschleimhaut, \&c., Bcrlin, 1878.

s Krönig, "Beitrag zum anatomischen Verhalten der Schleimbaut der Cervix und des Uterus," \&c., Arch.f. Gynäk., vol. Ixiii., 1901. 
and others. ${ }^{1}$ Excepting in the position of the placenta, the new epithelium is completely regenerated by the end of the sixth week after delivery.

The placental area at the end of parturition is marked by the presence of thrombosed vessels. It is raised above the general surface of the uterine wall, and is irregular in shape. It very soon diminishes in size, its diameter being not more than two centimetres long at the end of the puerperal period, although its former position may be detected as an area slightly. stained by blood pigment for several months after delivery.

Williams states that in the last month of pregnancy some of the sinuses at the placental area undergo thrombosis, but that this process becomes much more marked after the completion of labour, although many of the sinuses are simply compressed by the contracting uterine muscles without ever becoming thrombosed. ${ }^{2}$ The thrombi are eventually converted into ordinary connective tissue by a cellular proliferation from the lining membrane of the vessels. While this change is in progress the lining membrane presents a folded appearance somewhat resembling a typical developing corpus luteum. This is especially well seen about the fourth week after parturition, but even up to the end of a year the convoluted appearance is still sometimes discernible. ${ }^{3}$

The lumina of the arteries become reduced in size, but the thickening of their walls, which takes place during pregnancy, is an alteration of a more permanent character. This histological change affords a means of discriminating between a virgin and a parous uterus.

The cervix uteri remains for some time after delivery as a soft, flaccid structure with lacerated edges, but it gradually undergoes involution, the lumen becoming narrower. The vagina takes about the same time to recover as the uterus.

1 Leusden, assuming the syncytial tissue of the deciduum to be of maternal origin, has suggested that it may assist in giving rise to the new epithelium ("Ueber die Serotinalen Riesenzellen," \&c., Zeitschr. f. Geb. und Gynük., vol. xxxvi., 1897).

2 According to Longridge (see below in the text), thrombosis is of little or no importance in assisting the hamostasis of normal labour.

3 Williams (Sir J.), "Changes in the Uterus," \&c., Trans. Obstet. Soc., vol. xx., 1878. See also Helme, "Histological Observations," \&c., Trans. Roy. Soc. Edin., vol. xxxv., 1890. 
After a first delivery its outlet remains permanently wider than before. The rugæ reappear about the third week. The place of the hymen is taken by numerous small tags of tissue which become transformed into the carunculæ myrtiformes. The

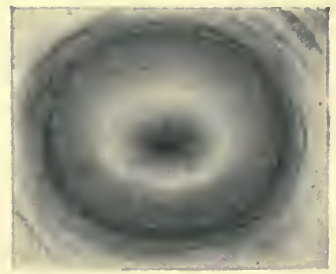

Fia. 133. - Virginal external os (human). (From Williams' Obstetrics, Appleton \& Co.) condition of the labia majora and labia minora is generally flabby and atrophic as contrasted with that existing in virgin women.

The characteristic changes which occur in the breasts in connection with the secretion of milk are described in the next chapter.

The quantity of urine passed during the first two days of the puerperium is generally above the average. The urine frequently contains sugar, which may be either glucose or lactose. In the latter case it is generally believed that the sugar has been absorbed into the circulation from the changed mammary glands. When glycosuria occurs, it is probably comparable to post-operative glycosuria (see p. 510 and pp. 571-573). Albumen may also be present in the urine in the first days of the puerperium. It is stated further that there is an increase in the amount of acetone ${ }^{1}$ (see also p. 507).

As mentioned above, a marked leucocytosis occurs during labour. According to Hofbauer, ${ }^{2}$ this becomes still more pronounced during the first twelve hours of the puerperium, after which the number of leucocytes in the blood falls again and in a short time becomes normal. Henderson ${ }^{3}$ states that on the

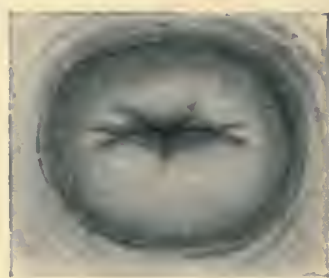

Fig. 134.-Parous external os (human). (From Williams' Obstetrics, Appleton \& Co.) fifth day the average number of leucocytes per cubic millimetre is 12,000 , whereas immediately after parturition it is 21,000 , as

'Scholten, “Ueber Puerperale Acetonurie," Hegar's Beiträge zur Gcb. und Ayniik., vol. iii., 1900.

2 Hofbauer, "Zur Physiologie des Puerperiums," Monatsschr. f. Geburt. und Gynüik., vol. v., 1897.

${ }^{3}$ Henderson, "Observations on the Maternal Blood at Term and during the Puerperium," Jour. of Obstet. and Aynocc., vol. i., 1902. 
compared with about 8000 in a normal woinan. It is stated that there is a diminution in the number of red corpuscles during the first days of the puerperium, a circumstance which is commonly ascribed to the loss of blood at delivery and the lochial discharge. It is also said that the amount of hæmoglobin is reduced, and that there is a relative increase in the quantity of fibrin and serum. Experiments show, however, that there is no appreciable shortening in the coagulation-time of the blood, such as has been supposed to account for the thrombosis of the sinuses. ${ }^{1}$

The pulse rate during the early days of the puerperium is usually stated to be somewhat below the normal, but according to Longridge such cases are unusual. Williams ${ }^{2}$ says that the pulse is slowest on the second or third day, after which it becomes quicker, resuming its normal rate after about ten days.

The temperature is ordinarily normal during the puerperium, the old idea that the commencement of milk secretion was associated with a rise of temperature having apparently no basis in fact, excepting in cases of infection.

Little attention has been paid to the changes which occur during the puerperal period in animals. Strahl has shown ${ }^{3}$ that the Mammalia with so-called full placenta (commonly called Deciduata) can be arranged under three groups according to the process of puerperal involution of the uterus. In the first group, to which Man and monkeys belong the epithelium is absent from the mucosa, and requires, therefore, to be re-formed in the manner described above. In the second group the placenta is spread out over the inside of the uterus as in the first group, but in addition to this the inside of the organ is covered by a layer of epithelium. This arrangement is found in Carnivores. In the Rodents we often meet with the third form; here, towards the end of gestation, not only is the womb covered with celltissue, but this epithelium also runs from the firbrix right underneath the placenta, undermining it till it is finally only adhering to the walls of the uterus by a slender cord carrying

- Longridge, loc. cit.

2 Williams (Whitridge), loc. cit.

${ }^{3}$ Strahl, "The Process of Involution of the Mucous Membrane of the Uterus of Tarsius spcctrum after Parturition," Proc. Section of Scicnces, Koninklijke Akademie van Wctenschappen te Amsterdam, vol, vi., 1904. 


\section{THE PHYSIOLOGY OF REPRODUC'IION}

the vessels. It is evident, therefore, that the uteri of the second and third groups -will resume relatively quickly their nonpuerperal appearance. The principal changes that occur are the reduction of the surface epithelium, both by the casting off of superfluous parts and by the changing of larger cells into smaller ones, the advance of new epithelium to cover places that were bare, ${ }^{1}$ and the reduction and consolidation of the connective tissue. The latter process is effected by the cells becoming more compact, as in the bitch, or by a reduction in the amount of inter-cellular substance, as in the hedgehog. ${ }^{2}$ The puerperal changes in Tarsius are said to resemble those of Rodents. ${ }^{3}$ Excepting in those animals which belong to the first group mentioned the lochial discharge is either very slight or absent altogether.

The changes which take place in connection with the formation of milk in animals are described in the next chapter.

1 Duval, "De la Régénération de l'Épithélium des Corne utérine après la Parturition," C. R. de la Soc. de Biol., vol. ii., Series 9, 1890.

2 Strahl, "The Uterus of Erinaceus europaus after Parturition," Proc. Sect. Sciences, Kon. Akad. Wet. Amsterdam, vol. viii., 1906.

${ }^{3}$ For the puerperal changes in Tupaia see von Herwerden, loc. cit. 


\section{CHAPTER XIII}

\section{LACTATION}

"Nunc femina quæque, Cum peperit, dulci repletur lacte, quod omnis Impetus in mammas convertitur ille alimenti."

-Lucretius.

THE possession of mammary glands is an essentially mammalian character. Their function is to provide nourishment for the newly born young. They are present in both sexes, but are usually functional in the female only. Their number and position vary considerably in different species. There may be only a single pair (Man), or as many as eleven pairs (Centetes). The number in any particular species usually bears a relation to the normal size of the litter, or to the requirements of the newly born offspring. Thus in the guinea-pig, in which the young are born in an advanced state of development, and can feed without being suckled, there are only two mammary glands, while in the rabbit, in which the newly born young are naked and helpless and the gestation period is far shorter, there are seven or eight mammæ. In animals which possess a number of mammary glands, these are usually arranged in two nearly parallel rows along the ventral side of the thorax and abdomen. In other cases they are restricted to the thorax (Primates, excepting some lemurs, Cheiroptera, Sirenia, elephants, sloths); while in others again they are confined to the inguinal region (Ungulates, Cetaceans).

In the cow and other Ungulates the nammæ are contained within a definite milk-bag or udder, which is surrounded by a fibrous envelope and is suspended below the abdomen. The udder is provided with milk cisterns or galactophorous sinuses into which the ducts of the gland open and convey the milk from the secretory acini. Each sinus communicates with the exterior by a teat, there being four teats in a cow, corresponding 
to the four mammary glands (and sinuses) commonly called the four "quarters." One quarter may run dry without the others. There is a fibrous di ision consisting of yellow elastic tissue between the two lateral halves of the cow's udder, but not between the anterior and posterior parts. In the sheep there are only two glands (lateral halves), sinuses, and teats (occasionally four), and the mare is similar excepting that there may be two or even four sinuses opening into one teat.

In Monotremes the mammary glands are stated to be modified sweat glands, whereas in other mammalian orders they are commonly regarded as representing sebaceous glands. ${ }^{1}$ In Monotremes alone there are no teats, the orifices of the glands being mere scattered pores in the skin, the exuding milk probably passing along the hairs, which in this region are arranged in bunches. In Echidna the orifices open into two depressions which have been called the mammary pockets. ${ }^{2}$ Teats, which are present in all other orders of Mammals, are of two kinds. In one kind the skin in the region of the gland becomes raised up in a circular rim, and in this way gives rise to a tubular teat or nipple, into the base of which the ducts of the gland open. This form of teat occurs in Carnivora and Ungulata. In the other kind of teat the gland itself is raised into a papilla, as in Man and other Primates, in Rodents and in Marsupials. The use of the teats is to facilitate the process of sucking. In the Cetacea, however, where the action of sucking is incompatible with the subaqueous life of these animals, the ducts of the mammary glands are enlarged into reservoirs (somewhat similar to the galactophorous sinuses of Ungulates), from which the milk is ejected into the mouths of the young by means of a compressor muscle. ${ }^{3}$

1 Brouha and certain otler authorities regard the mammary glands in all the Mammalia as modified sweat glands ("Recherches sur les Diverses Phases du Développement et de l'Activité de la Mamelle," Arch. de Biol., vol. xxi., 1905. This paper contains many references). Eggelung regards the mammary glands either as homologous with sweat glands, or else as organs which are $s u i$ generis being derived independently from the primitive merocrine skin-gland (" Ueber den wicktiges Stadium in der Entwickelung der menschlichen Milchdrüse," Anat. Anz., vol. xxiv., 1904).

2 Wiedersheim, Comparative Anatomy of Vertebrates, Parker's translation, 2nd Edition, London, 1897.

${ }^{3}$ Flower and Lydekker, An Introduction to the Study of Mammals. London, 1891. 
In the male mammal, as just mentioned, the mammæ do not usually function, though milk is occasionally produced in Man at birth and at puberty, and more rarely at other times. Male goats and sheep have been known to yield milk exceptionally, and the same is also said to be the case with male rats ${ }^{1}$ (see p. 584).

\section{Structure of the Mammary Glands}

The mammary glands are composed typically of a number of lobes, which are themselves divisible into lobules. Each lobule consists of connective tissue in which the convoluted ducts of the gland are bound together. If these ducts are traced backwards they are seen to arise from groups of secretory alveoli. If they are traced forwards they are found to unite together to form the lactiferous ducts, which in the human subject are from fifteen to twenty in number, and open to the exterior by minute apertures through the teat. The lactiferous ducts at their point of origin from the lobular ducts are provided with reservoirs in which the milk collects during the periods of glandular activity (i.e. during lactation). These reservoirs in some animals are of a very considerable size (e.g. whales, as described above). The duct walls consist of areolar tissue containing some unstriated muscle fibres. They are lined internally by short columnar epithelial cells which become flattened in the proximity of the nipple. A quantity of fat generally covers the surface of the gland, excepting the nipple. This fat is connected both with the skin in front and with the glandular tissue behind. Like the latter it is lobulated by processes of areolar tissue. The nipple also is formed of areolar tissue with unstriated muscle fibres. It is richly supplied witl vessels which give it an erectile structure. The glandular tissue also is plentifully supplied with vessels, which vary in size according to the condition of the gland. The glands in Man are innervated by branches from the anterior and lateral intercostal cutaneous nerves. Sensitive papillæ are present on the surface of the nipple, and around it there is a small area of skin, on which the ducts of little secretory glands open to the exterior.

1 Wiedersheim, loc. cit. 


\section{6 'THE PHYSIOLOGY OF' REPRODUC'TION}

In the secretory cells of the lactating mammary gland an active and a resting condition can be distinguished. In the latter the lumina of the alveoli are wide, and the cells of the lining epithelium form a single flat layer with centrally situated nuclei. In the active condition the epithelial cells are long and columnar, and project into the lumina, and some of them have two nuclei.

In these cells numbers of granules and globules accumulate,

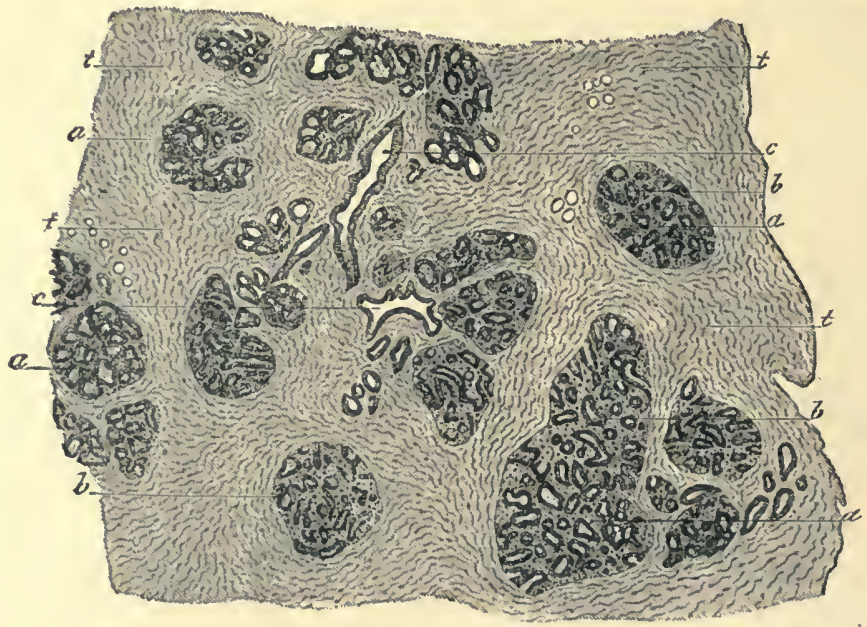

FJG. 135.-Section of mammary gland of woman. (From Schäfer, after de Sinéty.)

$a$, lobule of gland; $b$, acini lined by cubical epithelium ; $c$, duct;

$t$, connective tissue.

the former being probably of a protein nature, and the latter of a fatty composition. Gradually the alveoli become charged with a fluid containing detached cells and fatty globules. The detached cells are usually filled with granules, staining with osmic acid and seemingly identical with the colostrum corpuscles which have been observed to occur in millk in the first few days after parturition, and occasionally also at other times. These colostrum corpuscles have been seen to exhibit amœboid movements, and so are probably leucocytes which have wandered into the lumina of the alveoli. ${ }^{1}$ The secretory fluid also con-

1 Schäfer, "The Mechanism of the Secretion of Milk," Text-book of Physiology, vol. i., Edinburgh, 1898. 
tains cells which are supposed to have been detached from the epithelium, but, as will be seen presently, there is some doubt regarding this point.

The alveoli secrete milk during lactation, not merely while suckling is going on, but also at other times, so that milk tends to collect in the ducts and especially in the reservoirs. It has

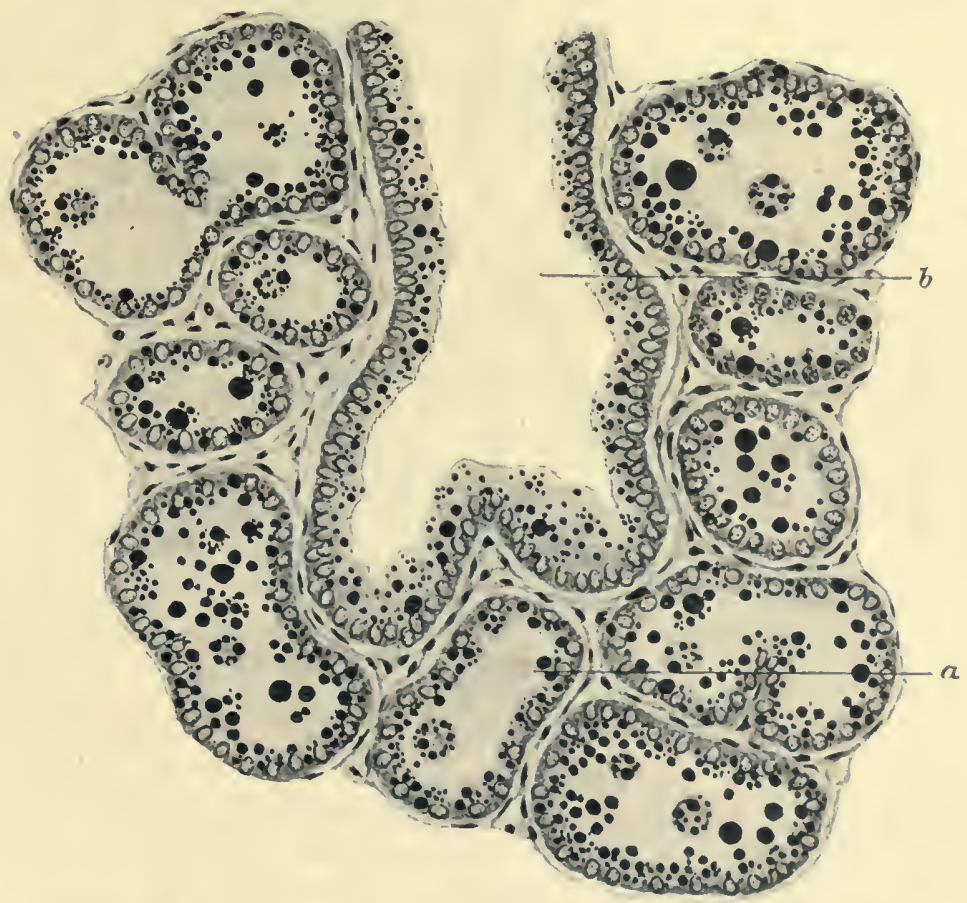

FIG. 136.- Section of mammary gland (human) during lactation (highly magnified). $a$, acini ; $b$, duct.

been calculated that the udders of a cow could not contain the quantity of milk which can be obtained from them at one milking, so that in such cases at least it seems certain that the process of secretion must be carried on during the time that the milk is being drawn. Furthermore, the milk which is drawn latest has been shown to have a different composition from that which is first obtained, the proportion of solids to liquids undergoing an increase as the process of milking is continued. This, how- 
ever, is believed to be due partly to the larger globules of fat meeting with greater resistance in passing through the ducts and so being retained until the end of milking. Lehmann ${ }^{1}$ has recorded an experiment in which a solution of sulphindigotate of sodium was injected into a vein of a goat which

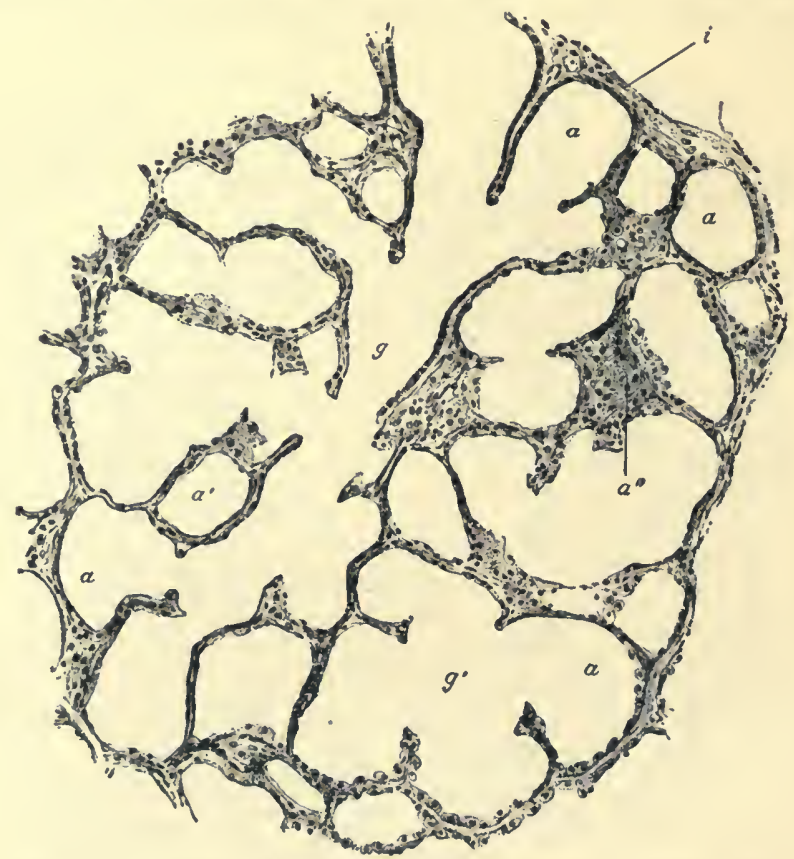

Fig. 137. - Section of mammary gland (human) in full activity. (From Schäfer, after von Eloner.)

$a, a^{\prime}, a^{\prime \prime}$, alveoli variously cut and distended by secretion; $g, g^{\prime}$, commencing ducts; $i$, connective tissue.

was immediately afterwards milked. By the time the udders had been almost completely emptied, a blue tinge appeared in the milk. After an interval of about an hour and a half the animal was again milked, when it was found that the injected sulphindigotate had penetrated in sufficient quantity to render the milk quite blue.

Three different hypotheses have been put forward regarding

'Lehmann, "Beiträge zur Physiologie der Milchbildung," Die landwirthschoftlichen Versuchs-Stationen, vol. xxxiii., 1887. 
the manner in which the substances of which the milk is formed pass out from the secretory" cells. According to one view, the cells themselves break loose and become disintegrated, setting free their contents in the alveoli of the gland, just as in the case of the sebaceous glands.

Another theory states that the cells simply excrete the substances into the alveolar lumina without becoming detached or destroyed themselves, as with the submaxillary mucous gland. According to the third hypothesis the mammary gland in its mode of activity occupies a position midway between the

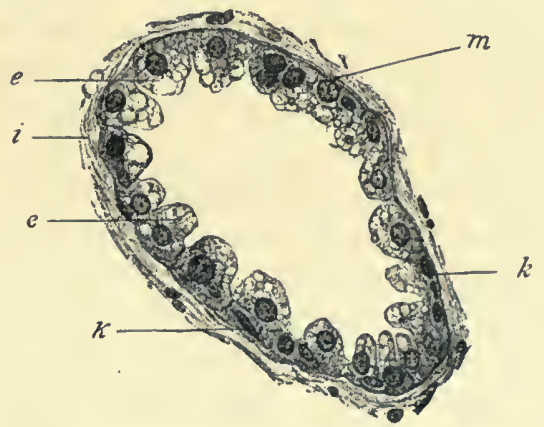

FIG. 138. - Section through an alveolus with fat drops in cells. (From Schäfer, after von Ebner.)

$e$, cells of alveolus; $k$, cells of basement membrane $(m) ; i$, connective tissue.

sebaceous and submaxillary glands; some of the cells simply discharging their contents into the lumina, while with others, the central part of the cell, containing a degenerate daughter nucleus, breaks away and becomes disintegrated, leaving the basal portion still in position.

It has already been mentioned that the mammary glands of all Mammals, with the exception of the Monotremes, are usually regarded as being of the nature of modified sebaceous glands. It was partly on account of this belief that certain of the older writers held the view that the secretion of milk was the result of a fatty degeneration leading to a complete disintegration of the secretory cells of the mammary gland. ${ }^{1}$ According to this

1 Virchow, Die Cellular-Pathologie, Berlin, 1871. 
theory the colostrum corpuscles were the detached epithelial cells. In opposition to this theory, it has been pointed out that therc is no evidence of the extensive cell multiplication, such as would be required in order to supply the large number of cells which, according to this hypothesis, would necessarily become detached. Heidenhain ${ }^{1}$ has shown that if this theory is correct, the cells of the gland must be completely renewed as often as five times in one day in order to provide the solid constituents of the secretion.

The second of the above-mentioned theories receives considerable support from the circumstance that it has the analogy of the great majority of secretory glands. ${ }^{2}$ Moreover, the recent investigation of Bertkau ${ }^{3}$ points strongly to the conchusion that any appearances of disintegration which the secretory cells possess is due to imperfect fixation. This author states that he found no necrobiosis of any kind in these cells, and he believes that milk formation is a purely sccretory process. The colostrum corpuscles, according to those who hold this view, are of the nature of wandering leucocytes.

The third theory was first suggested by Langer, and has since been adopted, with various slight modifications, by Heidenhain, ${ }^{4}$ Steinhaus, ${ }^{5}$ and Brouha ${ }^{6}$ and others. According to their view the cells of the gland lengthen out, so that their ends come to project freely into the lumina of the alveoli. The projecting portions then undergo a process of disintegration before or after becoming detached, and the cell substance passes into solution to form the albuminous and carbohydrate constituents of the milk. The fat droplets which collect in the disintegrating part of the cell give rise to the milk fat. The basal portions of the cell remain in position without being detached, and subsequently develop fresh processes, which in their turn become

'Heidenhain, " Die Milchabsonderung," Hermann's Handbuch der Physiologie, vol. iv., 1883.

2 Schäfer, loc, cit.

3 Bertkau, "Ein Beitrag zur Anatomie und Physiologie der Milchdrüse," Anat. Anz., vol. xxx., 1907.

'Heiden bain, loc. cit.

B Steinhaus, "Die Morphologie der Milchabsonderung," Arch. f. Anat. u. Phys., Phys. Abth., Suppl., 1892.

${ }^{6}$ Brouha's paper (loc, cit.) contains a full account of the literature. 
disintegrated. It is believed, however, that some cells simply discharge their fat droplets and other contents into the lumina, while otherwise remaining intact. ${ }^{1}$

Steinhaus states that mitotic division of the cell nuclei in the actively secreting mammary glands is of frequent occurrence, and that the daughter nuclei which lie in the outer portions of the cells degenerate and share in the general process of dissociation. Szabó ${ }^{2}$ also records the occurrence of two or more nuclei in the same cell during lactation, and similar evidence of nuclear division has been observed by others. Moreover, it is argued that this view is in no way inconsistent with the generally accepted homology between the mammary and sebaceous glands, since it is easy to understand how, in the course of evolutionary development, the mode of secretion in the glands in question might have undergone an alteration, whereby the process of disintegration in the actively secreting cells became gradually lessened as the character of the secretion changed. On the other hand, if we suppose that the cells of the mammary gland merely extrude their secreted materials without undergoing any histological disintegration, it is more difficult to uphold the homology in question. Iastly, it should be mentioned that those who, like Steinhaus, support the theory of partial disintegration, do not regard the colostrum corpuscles as detached epithelial cells, as Heidenhain did, but agree with those who uphold the purely secretory theory in supposing the corpuscles to be of the nature of "mast cells," or basophil leucocytes which have wandered inward from the connective tissue of the gland, as already described, and have made their way into the lumina of the alveoli. ${ }^{3}$

"Brouha, loc. cit.; also "Les Phénomenés histologiques de la Sécrétion lactée," Anat. Anz., vol. xxvii.

2 Szabó, "Die Milchdrüse im Ruhezustande und während ihrer Thătigkeit," Arch. f. Anat. u. Phys., anat. Abth., 1896.

${ }^{3}$ For references to further literature upon the physiology of milk formation see Basch, "Die Physiologie der Milchabsonderung," Ergeb. des Phys., 1903, Jahrg. See also the following for references to the histology:Bizzorzero and Ottolanghi, "Histologie der Milchdrüse," Merkel and Bonnet's Ergeb. d. Anat. u. Entwick., vol. ix., 1900, and von Ebner, "Von der Geschlechtsorganen," Kölliker's Handbuch der Gewebelehre des Menschen, vol. iii., 1902. 


\section{The Composition and Properties of Milk}

Milk is essentially an emulsion, its white appearance being caused by the reflection of the innumerable fat globules which it contains in suspension. These globules, which are from 0015 to 005 millimetres in diameter, tend to float chiefly at the top, where they help to form the cream, or that part of the fluid which is richest in fatty constituents. The specific gravity of both human and cow's milk is from about 1.028 to $1 \cdot 034 .^{1}$ When the cream is skimmed off the specific gravity of course rises.

It is not proposed in the present work to deal more than very briefly with the composition and properties of milk in different animals. ${ }^{2}$ Human milk and cow's milk have been most fully investigated, and it will suffice in this place to give a short account of their respective constituents.

The average composition of cow's milk as compared with liuman milk is as follows :-

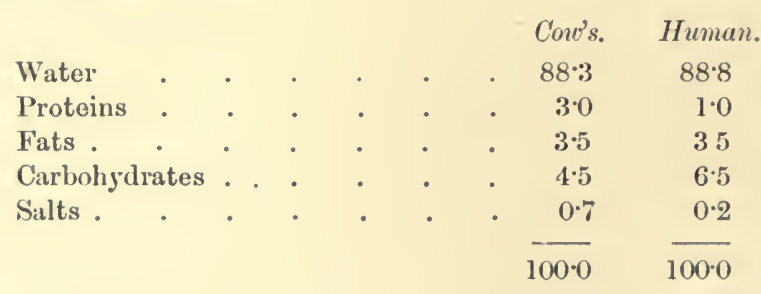

The proteins of milk are caseinogen, lactalbumen, and lactoglobulin. Of these caseinogen is the most important. This is the substance which is acted on by the ferment of rennet, producing the well-known clotting or curding of milk, when the caseinogen is converted into whey albumen and insoluble casein. Lactoglobulin and lactalbumen are only present in small quantities.

The fats of milk, which occur in small globules as just described, are olein, palmatin, and stearin, with small quantities of butyrin, capronin, and other fats of lower composition. Iecithin and cholesterin are also present in small amounts, at

"Halliburton, "The Chemical Constituents of the Body and Food," Schïfer's Text-book of Physiology, vol. i., Edinburgh, 1898.

${ }^{2}$ See Halliburton, loc. cit., and Schäfer. 
any rate in cow's milk. The percentage of volatile fatty acids is less in human than in cow's milk.

Lactose or milk-sugar is the carbohydrate of milk, but other carbohydrates (animal gum, dextrin, \&c.), have also been stated to occur. Lactose under the influence of certain micro-organisms becomes converted into lactic acid, which causes the souring of milk.

Milk is rich in calcium and potassium salts (especially in calcium phosphate), but magnesium, sodium, and other salts (chiefly chlorides) are also present in small quantities. The amount of iron in human milk is very slight, while in cow's milk it is practically absent altogether.

Bunge ${ }^{1}$ has pointed out that whereas the inorganic salts in milk are present in different proportions from those found in the blood plasma, these proportions are almost identical with those occurring in the young animal. He supposes this similarity to indicate an adaptation to the needs of the young. This point is illustrated in the following table, which gives the respective amounts of mineral constituents present in a hundred parts of ash of (1) the young pup ; (2) dog's milk, and (3) dog's serum.

\begin{tabular}{|c|c|c|c|c|c|c|}
\hline & & & & $\begin{array}{l}\text { (1) Young } \\
\text { Pup. }\end{array}$ & $\begin{array}{l}\text { (2) Dog's } \\
\text { Milk. }\end{array}$ & $\begin{array}{l}\text { (3) Doy's } \\
\text { Serum. }\end{array}$ \\
\hline $\mathrm{K}_{2} \mathrm{O}$ & . & . & - & . $\quad 8.5$ & 10.7 & 2.4 \\
\hline $\mathrm{Na}_{2} \mathrm{O}$ & - & . & • & $8 \cdot 2$ & $6 \cdot 1$ & $52 \cdot 1$ \\
\hline $\mathrm{CaO}$ & . & . & . & $35 \cdot 8$ & $34 \cdot 4$ & $2 \cdot 1$ \\
\hline MgO & . & - & - & $1 \cdot 6$ & $1 \cdot 5$ & 0.5 \\
\hline - $\mathrm{Fe}_{2} \mathrm{O}_{3}$ & . & . & . & 0.34 & $0 \cdot 14$ & $0 \cdot 12$ \\
\hline $\mathrm{P}_{2} \mathrm{O}_{5}$ & . & . & • & $39 \cdot 8$ & $37 \div 5$ & $5 \cdot 9$ \\
\hline Cl & . & . & . & $7 \cdot 3$ & $12 \cdot 4$ & $47 \cdot 6$ \\
\hline
\end{tabular}

Small quantities of oxygen, nitrogen, and carbon dioxide gases have been found in solution both in human and in cow's milk.

1 Bunge, Lehrbuch der Physiologische und Pathologische Chemie, Leipzig, 1887 , and various original papers. Cf. Abderhalden, "Die Beziehungen der Wachsthumsgeschwindigkeit der Säuglinge zur Zusammensetzung der Milch," '\&c., Zeitschr. f. Phys. Chem., vol. xxvi,, 1899, and other papers by the same author in the same journal (vols. xxvi. and xxvii.). For further references see Lusk, The Science of Nutrition, Philadelphia, 1906. It is stated also that the rennin of the stomach is specifically adapted for the coagulation of the casein produced by the female of the same race. 


\section{THE PHYSIOLOGY OF REPRODUCTION}

The chief difference in the composition of cow's milk as compared with human milk is the relatively high percentage of proteins, fats, and salts, and the correspondingly low percentage of lactose present in cow's milk.

Colostrum is the milk which is secreted during the first two or three days after parturition. It contains less caseinogen than ordinary milk, but considerable quantities of albumen and globulin enter into its composition. It coagulates on boiling. The characteristic colostrum corpuscles have already been described.

The mammary glands of newly born animals sometimes secrete small quantities of what is popularly called "witches' milk." This secretion contains most of the constituents of normal milk, but the solid substances are usually less in amount. It has an alkaline reaction. ${ }^{1}$

\section{The Influence of Diet and other Factors on the Composition and Yieli) of MitK}

The composition of the milk in any one species is subject to some amount of variation, which is due to various causes. Thus, the differences in the composition of cow's milk are said to depend on the following factors: (1) The breed, (2) The advance in the period of lactation, (3) The season of the year, (4) The length of the interval between the times of milking, (5) The occurrence of sexual excitement, (6) Situation and climate, (7) Meteorological changes, and (8) The character of the food. ${ }^{2}$ These factors may now be briefly discussed.

1 For fuller information about the constituents and properties of milk, with tables of composition for different animals, and numerous references to the literature, see Halliburton, loc. cit. See also Raudnitz, "Bestandteile, Eigenschaften und Veränderungen der Milch," Ergeb. der Phys., 1903, Jahrg. 2, where certain later papers are referred to ; and Abderhalden, loc. cit.

"Crowther, Milk Investigations at Garford, Leeds, 1904. Droop Richmond, "The Composition of Milk," Analyst, vol. xxxi., 1906. Lauder, "The Variation in the Composition of Milk," Bulletin XI. issued by the Edinburgh and East of Scotland College of Agriculture, 1906. Crowther, "The Chemical Composition of Butter," Trans. Highland and Agric. Soc., vol. xix., 1907. Gilchrist and Jones, "Dairy Investigations in the North-East of England," Trans. Highland and Agric. Soc., vol. xviii., 1906, and vol. xix., 1907 . 
That the yield and composition of the milk varies in the different breeds is generally admitted. Thus Jersey cows yield a larger proportion of butter fat than Ayrshires. But of all the factors enumerated above, diet is perhaps the most important. The richest and also the most abundant supply of milk is usually yielded when the food supply is liberal. As a result of giving food rich in protein substances, the milk supply tends to contain a larger quantity of protein, sugar, and fat (especially the latter). Schäfer has pointed out, however, that because an excess of a particular organic principle in the food causes an increase of certain constituents in the milk, it must not be supposed that these constituents are necessarily formed directly from such material, "for the effect may be produced indirectly by the functions of the gland-cells becoming modified, according to the nature of the pabulum they are receiving. Looked at in this light, certain substances may be said to stimulate the cells of the glands to increased activity in all directions, tending to the production of a larger quantity of milk rich in all kinds of sol d constituents; whilst other substances may be looked upon as stimulating the cells in a special manner, tending to the increased production of certain only of the constituents of the milk." 1

According to Crowther's researches on cows, change from a highly nitrogenous diet to one relatively poor in nitrogen causes secretion of a greater quantity of milk, but there is a decrease in the fat content, this being more pronounced in the morning than in the evening milk. A change in the reverse direction effected an improvement in the quality of the milk. Concentrated food given either in the morning or evening tended to increase the fat content of the morning milk, but had little or no effect upon the evening milk. These alterations were found to persist without appreciable diminution for fully five weeks after the change of treatment.

There are a number of preparations in the market, known as galactagogues, which are said to increase the flow of milk in women, but, according to Williams, any virtue which they possess is due largely to the quantity of fluid which is taken

1 Schäfer, loc. cit. There is evidence also that an abnormal diet during and previous to pregnancy may arrest the normal mammary development. See Watson (B. P.), "The Effect of a Meat Diet on Fertility and Lactation," Proc. Roy. Soc. Edin., vol, xxvii., 1907. 
with them. ${ }^{1}$ It is stated also that certain particular foodstuffs have a very appreciable effect upon the quantity and quality of milk in cows. Thus bean-meal is said to increase the flow of really good milk, unless it is given in immoderate quantities. Brewers' and distillers' grains are likewise described as having a beneficial influence upon the milk supply, but if given too freely they tend to injure the breeding capacity, and in consequence are most used in town dairies where the cows are not bred from. ${ }^{2}$ Many substances ingested by the mother pass unaltered into the milk. It is well known that certain foods (e.g. turnips) cause an unpleasant taste or smell in the milk of cows to which they are supplied. Lehmann's experiment, in which sodium sulphindigotate was injected into the veins of a goat, and shortly afterwards made its appearance in the milk, has been already referred to (p. 558). So also it has been found that immunity from disease may be acquired by young animals being suckled by a female which had previously become immune, the antibody to the disease being absorbed in the ingested milk.

It is generally recognised that the nature of the surroundings has an influence over the nammary secretion. For example, the composition of the fat in the milk of cows varies with the condition of the animals. Circumstances tending to cause discomfort usually lower the proportion of volatile acids present in the butter-fat, but the variation in the composition is very irregular, and appears to depend partly upon the nervous temperament of the cow. Extremes of heat and cold are said to produce a decrease in the percentage of volatile acids, a fact which has been put forward as an explanation of the general poorness in these compounds of butters from Siberia and other cold climates. Unseasonable and inclement weather is believed to have a similar influence. ${ }^{3}$

In women exercise in the open air may not infrequently increase the flow of milk. Nervous and mental influences or any cause which affects the general metabolism may so change the character of the secretion in women as to make it no longer fit

1 Williams, Obstetrics, London, 1904.

2 Wallace (R.), Farm Live Stock of Great Britain, 4th Edition, Edinburgh, 1907.

${ }^{3}$ Crowther, loc. cit. 
for the child. Violent emotion or shock have been known to lead to the complete suppression of the mammary secretion. ${ }^{1}$ The employment of certain drugs also influences it. Thus atropine, if given in sufficient quantities, stops the secretion altogether, or if supplied in smaller amounts causes the milk to become more concentrated.

The occurrence of menstruation in women, or of heat in certain animals, may have a deleterious influence upon the milk, and so upon the offspring (see p. 334). In the case of cows, œstrus generally has a marked effect on the milk-yield, which as a rule shows at first a perceptible diminution, followed usually at the next milking by a yield well above the average. The fat content is generally at first considerably reduced, but at the following milking is sometimes abnormally high, or may be still abnormally low. On the two or three days preceding the outward manifestations of heat, the fat content tends to be decidedly above the average.

Castration is stated to have a beneficial effect upon goat's milk, relieving it of the charactsristic hircine odour, increasing the quantity of butter, casein, and phosphoric acid (though decreasing the lactose present), and producing a greater and more long-continued secretion." The removal of the ovaries in cows may also tend to improve the quality of the milk, rendering it richer than when the animals have been some months pregnant. ${ }^{3}$

The advance of lactation may be accompanied by changes both in the amount and in the composition of the mammary secretion, but the changes vary greatly in different individuals. In cows, the milk fat secreted in the first few days after parturition is poor in volatile acids, but it tends to improve rapidly during the first few months, the improvement being maintained until near the close of the lactation period, i.e. in most cases near the approach of the next parturition. ${ }^{4}$

1 Williams, loc. cit.

2 Oceanu and Babes, "Les Effets Physiologiques de l'Ovariotomie," C. R. de l'Acad. des Scicnces, vol. cxl., 1905.

3 Wallace, loc, cit.

+ In cows which are "drying off," the percentage of volatile acids in the butter fat is very low. See Crowther, loc. cit. 
The duration of the lactation or nursing period in the different species of animals is governed mainly by the needs of the young. In such animals as the guinea-pig, in which the young are born in a sufficiently advanced state of development that they are able to fend for themselves, the length of the lactation period is relatively short and inconstant, while in other animals, belonging to the same order of Mammals, the young are born helpless, and are dependent for some weeks upon their mother's milk. In the larger animals the period of nursing is of course longer, but in them also its average duration appears to depend largely upon the necessities of the offspring.

The natural period of lactation in the cow is between nine and ten months, allowing for an interval of from two to three months to prepare for the next milking period. The duration of the period in any given animal depends to some extent upon such factors as diet and general treatment as described above, but there is much individual variation. Some cows continue to give milk until the next calving, but without a rest they are liable to yield a less abundant supply in the succeeding year. ${ }^{1}$

It follows that a new gestation period in the cow has no arresting influence over the mammary secretion. Cows which have been castrated during lactation may yield milk for years without any cessation, and thus give on the aggregate a larger supply than cows which calve annually in the ordinary way. It is well known that constant milking acts as a stimulus to the secretory activity, and that cows which are not milked soon " run dry."

In the human female a year may be regarded as the normal period of nursing, any longer time involving what is known as lyperlactation. The practice of hyperlactation is said to be common, but it is to be deprecated in the interests of the infant. ${ }^{2}$ It would appear that if continuous suckling is encouraged, the

1 Wallace, loc. cit.

2 Dingwall Fordyce, "An Investigation into the Complications and Disabilities of Prolonged Lactation," \&c., an extension of papers published in the Lancet, the British Medical Journal, and the British Journal of Children's Diseases, 1906. 
supply of milk in strong, healthy women may last almost indefinitely. As already mentioned, menstruation not infrequently commences to recur during the lactation period, and the latter may overlap gestation until within a short time of delivery.

\section{The Discharge of MilK}

The discharge of the milk from the lactiferous ducts which occurs during sucking is due partly to the direct mechanical pressure, and partly to the action of the muscular tissue which is present in the walls of the ducts and in the nipple. The muscular mechanism appears to be stimulated reflexly by the action of sucking. The contraction of the muscles in the nipple causes this structure to stiffen, and it is suggested that this action has the effect of keeping open the orifices of the ducts, and thus permitting the free outflow of milk. ${ }^{1}$

It is probable also that the discharge of the secretion is assisted in some degree by the swelling of the entire mammary gland resulting from a reflex dilatation of the vessels; but if the secretory process is very active, and the ducts are heavily charged, the flow of milk may take place almost automatically, and with hardly any external stimulus.

\section{The Formation of the Organic Constituents of Milk}

The principal organic constituents of milk are peculiar to the secretion, a fact which shows that they are elaborated in the mammary glands theniselves, and not elsewhere in the body. It is stated, however, that a relatively small amount of caseinogen is present in the secretion of the sebaceous glands, from which, as already remarked, it is commonly supposed that the manmary glands ${ }^{2}$ have been derived in the course of evolution. Nothing appears to be definitely known regarding the method of formation of the caseinogen of milk, ${ }^{3}$ but it has been suggested that it is derived from the degenerate nuclei of the gland cells.

1 Schäfer, loc. cit.

2 Neumeister, Lehrbuch der physiologischen Chemie, vol. ii., Jena, 1895.

3 Thierfelder, "Zur Physiologie der Milchbildung," Pfïger's Archiv, vol. xxxii., 1883. 
The precise method by which the milk fat is formed is likewise unknown. It may be derived from protein material, the change being effected in the cells of the gland, or some of it inay possibly have its source in fat which has already been formed elsewhere, and carried to the mammary glands in the blood or lymph. There is no reason for supposing that the cells of the glands do not possess, in common with most other tissues, the power to elaborate fat. On the other hand, there is definite histological evidence that they have this capacity (see above, p. 560). Moreover, the special composition of the milk fat seems to be by itself conclusive evidence that it is constructed within the mammary glands.

The suggestion has been made that the leucocytes which migrate through the epithelium and make their way into the secretory fluid may help to bring fatty globules into it, ${ }^{1}$ but there seems no necessity for assuming that this is the case.

The fat formation which takes place in the cells of the lacteal glands in the process of milk manufacture has been compared with the fatty degeneration which occurs in other tissues, milk being nothing more than an emulsion of the fat of butter in a solution of salts, proteins, and sugar. "What occurs as a normal process in the cells of the lacteal glands occurs under pathological conditions in much greater extent in very various tissues, and leads almost always to incurable and fatal losses, since as a rule no reparation is made by the younger cells." 2 "The production of milk," says Virchow, " "in the brain instead of in the lacteal glands, constitutes a form of brain softening. The same process that in the one place affords the happiest and sweetest results, in another induces a painful and bitter wound." It has already been mentioned, however, that the fat of milk has a special composition of its own, so that too much stress must not be laid upon a resemblance between the secretion of milk and the pathological formation of other fluid substances in different parts of the body.

The mode of formation of the sugar of milk has been the

1 Michaclis, "Beitrïge zur Kenntniss der Milchsecretion," Arch. f. Mikr. Anat, vol. xxi., 1898.

2 Verworn, General Physiology, Lee's Translation from the second German edition, London, 1899.

${ }^{3}$ Virchow, loc. cit. 
subject of some controversy. Bert ${ }^{1}$ supposed that it was formed from glucose which was absorbed by the cells of the mammary gland from the circulating blood. The glucose, according to this view, was manufactured in the liver, or, at any rate, elsewhere than in the mammary gland. Bert based his hypothesis upon two experiments in which the glands were removed from goats which afterwards became pregnant. The urine of each animal was tested during pregnancy to see if any reducing agent was present, but no such substance could be found prior to the birth of the kid. On the other hand, for several days after parturition a substance which reduced cupric sulphate was discovered in each case. Bert concluded that this was glucose. He supposed further that the reducing body present in the urine of the two goats represented glucose which in normal animals would have been converted into lactose in the mammary glands. The experiments were afterwards repeated by Moore and Parker, ${ }^{2}$ who operated likewise upon two goats, and obtained results which were the direct opposite of those of Bert. These authors consequently concluded that the complete process of lactose formation takes place in the cells of the mammary glands.

The question was subsequently reopened by Porcher, ${ }^{3}$ who also repeated Bert's original experiment on a goat. After parturition in the operated animal, an intense glycosuria is said to have occurred, the phenylhydrazine test showing that the substance present in the urine was glucose, and not lactose or some other reducing body. Porcher also removed the mammary glands from four goats and one cow during lactation, and for a few hours after the operation obtained marked glycosuria. As a result of those experiments, taken in conjunction with those of Bert, he concluded that the truth of the latter's theory was established beyond all doubt.

More recently the writer, working in conjunction with Dr.

1 Bert, "Sur l'Origine du Sucre du Lait," C. R. de l'Acad. des Scicnces, vol. Ixxxviii., 1884.

2 Moore and Parker, "A Study of the Effects of Complete Removal of the Mammary Glands in Relationship to Lactose Formation," Amer. Jour. of Phys., vol. iv., 1900.

3 Porcher, "Sur l'Origine du Lactose," C. R. de l'Acad. des Sciences, vol. cxxxviii., 1904. "De la Lactosurie," Monographies Cliniques, Paris, 1906. 
Kirkness, ${ }^{1}$ carried out a series of experiments upon guinea-pigs. The mammary glands were removed prior to pregnancy (four cases) or during pregnancy (one case). The urine was tested for sugar both before and after parturition, but none was found in any of the experiments. Other experiments showed that glycosuria may occur after parturition in normal unoperated animals, but that it does not do so invariably. ${ }^{2}$ When glycosuria does so take place, its occurrence is probably comparable to post-operative glycosuria, the cause of which is not understood. The glycosuria observed by Porcher after the removal of the mammary glands during lactation may perhaps be explained as an ordinary post-operative effect, and cannot be cited as proof of Bert's hypothesis.

According to Thierfelder ${ }^{3}$ and Landwehr, ${ }^{4}$ a formation of lactose may take place if pieces of fresh mammary tissue are kept in normal salt solution at body temperature. The lactose is said to be formed from a precursor which Landwehr identified as " animal gum " or carbohydrate of low reducing power.

According to Foa, there is a diminution of glucose in the venous blood coming from the mammary glands, but the amount of glucose and other carbohydrates present in the blood during lactation is no greater than in normal blood. ${ }^{5}$

Muntz $^{6}$ has put forward the view that the lactose of the mammary secretion is formed by the union of glucose, the normal sugar of the organism, with galactose, which is

1 Marshall and Kirkness, "On the Formation of Lactose," Biochem. Jour., vol. ii., 1906.

2 Puerperal glyeosuria and lactosuria have been described in women in a number of eases. Lactosuria is also stated to occur not infrequently in the late stages of pregnancy both in women and animals, the lactose in sueh eases being presumably derived from the mammary glands by a process of absorp. tion. Sec Hofmeister, "Ueber Laktosurie," Zeitsch.f. Phys. Chemie, vol. i., 1877 ; Poreher, De la Lactssurie, 1906 ; and "L'Origine du Lactose," Arch. Internat. de Phys., vol. viii., 1909. See also p. 510.

3 Thierfelder, "Zur Physiologie der Milchbildung," Pfüger's Archiv, vol. xxxii., 1883.

"Landwehr, "Ueber die Bedeutung des tierisehen Gummis," Pfl̈ger's Archiv, vol. xl., 1887.

- Foà, "Sull" Origine del Lattosio del Latte," Arch. die Fis., vol. v., 1908.

- Muntz, “Sur l'Existence des Éléments du Suere de Lait dans les Plantes," Annales de Chim. et de Phys., vol. x. 
supposed to be derived directly by hydrolysis from certain polysaccharide substances introduced in the food. It is pointed out further, that such substances are present in plants which form the normal diet of certain animals. It would appear, however, that there is no direct evidence that lactose is actually formed in this way. Moreover, this theory can scarcely be applied to carnivorous animals, as Porcher ${ }^{1}$ has pointed out.

There is, therefore, but little evidence that lactose is elaborated in the mammary glands from any closely related carbohydrate precursor carried thither from elsewhere in the body. It is of course obvious that this sugar must be derived ultimately from compounds contained in the food, and it would seem not improbable that it is manufactured partly from protein substances, and not merely from other carbohydrates.

\section{The Normal Growth of the Mammary Glands}

The growth of the mammary glands in the rabbit has been described by Miss Lane-Claypon and Starling, from whose paper the following account is taken. ${ }^{2}$

In the virgin animal of about eight to twelve months old mammary tissue cannot ordinarily be detected with the naked eye, but in stained preparations of the connective tissue surrounding the nipple, it is possible to see the ducts which comprise the gland. These are generally restricted to an area of not more than one centimetre broad. Sections show that the gland at this stage consists entirely of ducts which are lined with a single layer of flattened epithelium, and end blindly. No traces of alveoli are to be seen in the gland.

By the fifth day after conception a marked change has taken place in the gland, which now appears, on reflecting the skin from the abdomen, as a clearly differentiated pink area, circular in shape, and surrounding the position of each nipple. The diameter of this area is from about two to three centimetres.

1 Porcher, "Sur la Physiologie de la Mamelle," Jour. de Méd. Vet. de l'Ecole de Lyon, Sept. 30, 1905.

2 Lane-Claypon and Starling, "An Experimental Inquiry into the Factors which Determine the Growth and Activity of the Mammary Glands," Proc. Roy. Soc., B., vol. lxxvii., 1906. See also Brouha, loc. cit. 
Sections through the gland show that it still consists entirely of ducts, but that these are in a state of active proliferation. The epithelial lining no longer consists of a single cellular layer, but is two or three cells deep, while the individual cells are more swollen than those of the virgin gland, and mitotic figures are commonly seen.

The mammary gland now grows rapidly, so that on about

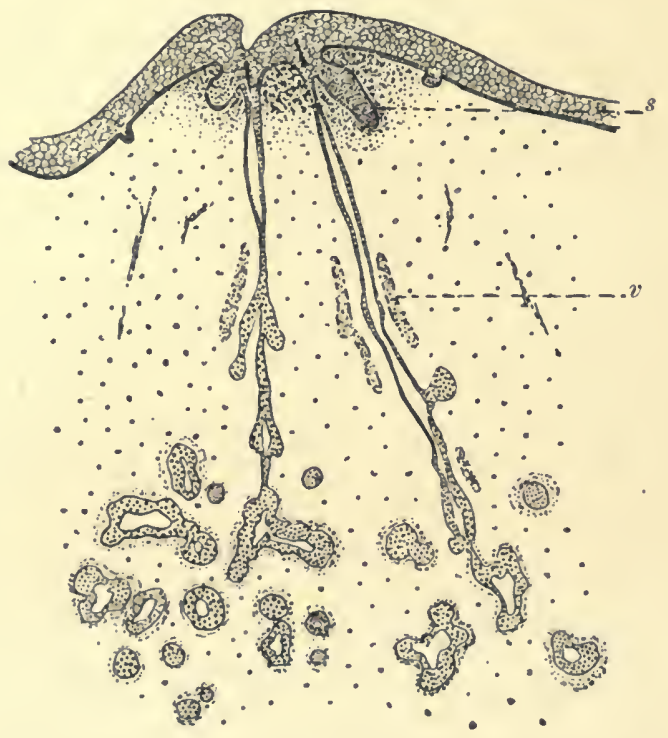

FIG. 139.-Section of developing mammary gland of horse. (From Schäfer, after Hamburger.)

8 , sebaceous glands; $v$, blood-vessels.

the ninth day after conception, on reflecting the skin from the abdomen, the entire surface is found to be covered with a layer of glandular tissue, the margins of the individual glands being practically contiguous, each of them having a diameter of from five to eight centimetres. Sections show that the formation of alveoli (i.e. definite secretory structures) has begun at this period, especially at the periphery, where the gland is generally somewhat thicker than in other parts.

From this stage onwards the growth of the ducts and the 
formation of alveoli proceed rapidly, so that by the twentyfifth day of pregnancy the whole surface of the abdomen has become covered by mammary gland tissue, which may be half a centimetre thick. This tissue is seen in sections to consist for the most part of alveoli, in the cells of which fat globules are in process of formation.

From about the ninth day onwards to the twenty-fifth it

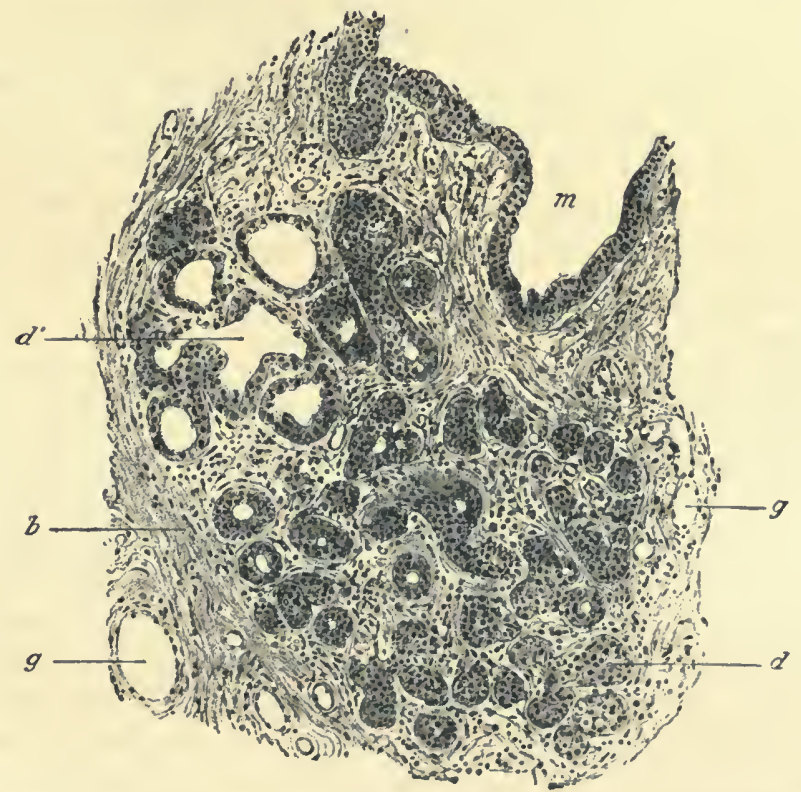

FIG. 140.-Section of mammary gland (human) showing developing alveoli. (From Schäfer, after von Ebner.)

$b$, connective tissue ; $d$, undeveloped alveoli ; $d^{\prime}$, partially developed alveoli ; $g$, blood-vessel ; $m$, portion of duct.

is usually possible to squeeze a watery fluid from the nipples. During the last days of pregnancy this fluid assumes the characteristics of normal milk, so that by the time of parturition, which occurs in the rabbit on the thirtieth day after conception, the glands are full of mill.

The multiparons rabbit differs from the virgin in possessing ready-formed alveoli at the beginning of pregnancy. 
Consequently the amount of mammary growth during the gestation period of the multiparous animal is relatively less.

The changes which take place in the human female and in other animals during pregnancy are in a general way similar to those occurring in the rabbit. In women after the second month the breasts are said to offer a nodular sensation on palpation, this being due to the hypertrophy of the mammary alveoli. The nipples also enlarge, and at the same time become more erectile and pigmented, while the areola surmounting the nipple becomes broader and pigmented also, in dark individuals being often almost black. The hypertrophy of the sebaceous glands in the areola results in the formation of the so-called glands of Montgomery, which appear as small round elevations. As already mentioned, during the later months of pregnancy the thin yellowish fluid known as colostrum can generally be expressed from the nipples.

The mammary glands are said to undergo growth at puberty, and there can be no doubt that a slight hypertrophy generally takes place in connection with each period of proœstrum and cestrus. These changes must be ascribed to ovarian influence, which, as has already been shown, is probably responsible for the changes which occur at such times in the other generative organs. Professor J. P. Hill informs me that in certain Marsupials the amount of mammary growth occurring at each ovulation period is so marked as to render it difficult to distinguish such animals from pregnant ones. Gellhorn ${ }^{1}$ refers to a case of a woman who had abnormal mammary glands with seven nipples in the neighbourhood of the mons veneris, and who yielded milk at each menstrual period. Other similar cases have been recorded. This phenomenon is, of course, contrary to the more usual tendency for menstruation to be in abeyance during lactation.

\section{The Factors which are concerned in the Process} of Mammary Growth

It has just been mentioned that the mammary glands in the female begin to undergo enlargement at the period of puberty in correlation with the increase in ovarian activity. In Man

1 Gellhorn, "Abnormal Mammary Secretion," Jour. Amer. Med. Assoc., Nov. 21, 1908. 
the difference between the glands in the two sexes is first manifested at this time. The slight hypertrophy which occurs in connection with each procstrous period has been referred to, while the great growth which the glands undergo during pregnancy has also been described. It would appear, therefore, that the stimulus to mammary growth, which arises originally in the ovary, is afterwards derived from the developing embryo. This view is supported by the fact, which has been established experimentally, that mammary development succeeded by lactation after parturition can occur in animals whose ovaries have been extirpated at about mid-pregnancy or even at a slightly earlier period.

It was formerly supposed that the connection between the growth of the mammary glands and that of the embryo in the uterus was a nervous one-that is to say, that the hypertrophy of the glands was determined reflexly through the central nervous system. There is now, however, abundant evidence that such is not the case. This is shown, for example, by the experiment performed by Goltz and Ewald, ${ }^{1}$ which has already been referred to in considering the factors concerned in parturition. The lumbo-sacral part of the spinal cord was completely exsected in a pregnant bitch, so that all possible connection between the mammary glands and pelvic organs through the nervous system was destroyed. Pregnancy was accompanied as usual by mammary development, and after parturition, lactation occurred normally. Routh's case, ${ }^{2}$ in which normal lactation took place in a woman with complete paraplegia below the level of the sixth dorsal vertebra, has also been referred to (p. 538). Moreover, it has been shown by Eckhard ${ }^{3}$ that after complete severance of the nerves (branches of the external spermatic) passing to the mammary gland, the activity of the latter, and consequently the supply of $\cdot \mathrm{milk}$, are in no way affected.4

1 See pages 490 and 538.

2 Routh, "Parturition during Paraplegia, with Cases," Trans. Obstet. Soc. vol. xxxix., 1897.

3 Eckhard, Beiträge zur Anat. u. Phys., vol. i., Giessen, 1855.

4 Eckhard's experiments have been repeated by others with somewhat contradictory results (see Basch, loc. cit.); Röhrig ("Fxperimentelle Unter. suchungen über die Physiologie der Milchabsonderung," Virchow's Archiv, vol. Ixvii., 1876) found that the external spermatic nerve contained 
Further evidence in support of the conclusion that the connection between mammary and fotal growth is not nervous in character is supplied by those experiments in which portions of gland were successfully transplanted to abnormal positions in the body. Thus in an experiment on a guinea-pig Ribbert ${ }^{1}$ grafted mammary tissue from the normal position to the neighbourhood of one of the ears. Notwithstanding the fact that the transplanted gland had lost its normal nervous connections, it underwent enlargement during a subsequent pregnancy, and afterwards secreted milk. Pfister ${ }^{2}$ states that he performed a similar experiment on a rabbit, and obtained a similar result.

The inference is, therefore, that the relation between the growth of the mammary glands and the development of the foetus in the uterus is chemical in nature.

As Miss Lane-Claypon and Starling have pointed out, the phenomenon of fertilisation succeeded by fœtal growth involves the occurrence of changes in the ovaries and in the uterus (both in the muscle and in the mucous membrane), as well as the forma-

vasomotor fibres for the vessels of the mammary gland, and that these affected its secretory activity by controlling the blood supply. Mironow ("De l'Influence du Système Nerveux des Glandes Mammaires," Arch. des Sciences Biol. de St. Petersbourg, vol. iii., 1894) states that artificial stimulation causes a reduction in the quantity of secretion. He states further that whereas section of the external spermatic on one side has no effect on the secretion, section on both sides diminishes it, but that the diminution only comes on gradually after a number of days. After completc severance of all the nerves in pregnant animals the glands may continue to grow'and yield milk after parturition. Basch (loc. cit.) states that extirpation of the creliac ganglion or transection of the spermatic nerve does not inhibit the secretory process, but increases the number of colostrum corpuscles. There is abundant evidence of a general kind that the central nervous system in some way exerts an influence on the mammary gland. Thus the effeets of nervous shock in altering or inhibiting milk secretion in women are well known. Moreover, the occurrence of uterine contractions on putting the child to the breast, and so stimulating the nipples, is cvidence of a nervous eonncetion. It would secm probable, therefore, that though the mammary gland is essentially an automatic organ, the connection of which with the generative organs is through the vascular rather than the nervous system, yet it is under the regulating control of the latter by means of secretory or vasomotor fibres.

1 Ribbert, "Ueber Transplantation von Ovarium, Hoden und Mamma," Arch. f. Entwick.-Mechanik, vol. vii., 1898.

2 Pfister, "Ueber die reficktorischen Beziehungen zwischen Mammæ und Genitalia muliebria," Beiträge zur Geb. und Gynäk., vol. v., 1901. 
tion of an organ of complicated structure-the placenta-the function of which is to nourish the developing young. The question arose, therefore, as to whether the fotus or either of the above-mentioned organs was not the direct source of formation of a hormone or chemical excitant which, after circulating in the blood stream, acted as a stimulus to mammary growth.

It has been shown that the ovaries of rats can be removed at any time during the second half of pregnancy (or somewhat earlier) without interfering with the course of fotal development or mammary growth, and, moreover, that lactation may take place normally after the ovaries have been thus extirpated. ${ }^{1}$ It is evident, therefore, that though the ovaries may represent the original source of the stimulus necessary for mammary hypertrophy, they are not essential for the continuance of the process, and exercise no sort of control over the final stages which precede the secretion of milk. ${ }^{2}$

Furthermore, it has been shown that the mammary glands undergo normal development in cases of extra-uterine fœtation in which the growth of the uterus is relatively small. This observation clearly indicates that the source of the stimulus in question is not to be sought in the hypertrophied uterus. A consideration of these and other facts led Miss Lane-Claypon and Starling to the conclusion that one or other of the products of conception (i.e. either the fuetus or placenta), or possibly both, were the seats of origin of the specific chemical stimulus which brought about mammary growth.

Halban ${ }^{3}$ had already formed the opinion, chiefly on clinical grounds, that the specific stimulus arose mainly in the chorionic villi and placenta.

More recently Ancel and Bo. in have laid stress on the close parallelism between the development and regression of the corpora lutea and mammary glands respectively in the rabbit.

1 Marshall and Jolly, "Contributions," \&c., Phil. Trans., B., rol. cxcviii., 1905.

${ }^{2}$ Cf. Foges, "Beiträge zu der Beziehung von Mamma und Genitale," Wien. klin. Woch., 1908, No. 5. Grünbaum (Deut. med. Wochenschr., 1907 , No. 20) has shown that mammary secretion may also occur after hysterectomy.

3 Halban, "Die innere Sekretion von Ovarium und Placenta und ihre Bedeutung für die Éunction der Milchdrüse," Arch. f. Gync̈k., vol. 1xxv., 1905. 


\section{THE PHYSIOLOGY OF REPRODUCTION}

This parallelism is said to exist even in the absence of pregnancy. ${ }^{1}$

Miss Lane-Claypon and Starling appear to have been the first to deal with the problem experimentally. In an initial series of experiments they injected extracts or emulsions of ovaries obtained from pregnant rabbits into other rabbits either subcutaneously or intraperitoneally. In two further series of experiments rabbits were injected with uterine and placental emulsions or extracts. In no case, however, did the injections produce any effect on the mammary glands, although in certain of the experiments in which ovarian or uterine substance was employed, marked swelling and congestion of the uterus were afterwards observed.

The effect of injecting fœetal extract was next tried, and this led to definite positive results. When repeatedly injected into female rabbits the extract was found to produce a genuine development of the mammary glands which simulated the normal growth which occurs during pregnancy. In one case a virgin rabbit received fifteen injections of extract made from many embryos of the same species. The injections were spread over a fortnight, at the end of which the rabbit was killed. It was found that a secretory fluid could be expressed from the nipples, and that on reflecting the abdominal skin all the mammary glands had grown to the size which is ordinarily reached in a rabbit about eight days pregnant. In another rabbit which received twenty-four injections, spread over five and a half weeks, the effects produced were still more marked. Further experiments showed that boiled extract was as effective as unboiled, and the conclusion is therefore drawn that in all probability the specific secretion or hormone is capable of withstanding boiling. It was shown also that the substance in question could be obtained equally well from different parts of the fœtus, that it passes through a Berkefeld filter, and that it is not retained to any appreciable extent by the kieselgur in Buchner's method for extracting cell juices.

Foi states that extract of ox foetus, when injected into rabbits, produced development of the mammary glands. He concludes, therefore, that the stimulating substance which cuuses mammary

1 See page 343. 
growth is not specific-i.e. not peculiar to any one kind of mammal. Foi says also that if the extract is heated to $110^{\circ}$ the active substance is destroyed, and no result is produced by

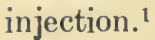

\section{The Factors which are concerned in the Commence- ment of Mammary Secretion}

Since the growth of the mammary glands was apparently due to a specific chemical stimulus arising in the fœtus, it was natural to suppose that the beginning of the actual secretory process which marks the cessation of growth was caused by the removal of this stimulus-in other words, by the expulsion of the fœetus. In this connection it is interesting to note that abortion or premature labour is often followed by the appearance of milk in the breasts.

The idea that lactation is due to the removal of an inhibition appears to have been entertained first by Hildebrandt, ${ }^{2}$ who put forward the suggestion that the developing embryo exerts an influence whereby the cells of the mammary gland are protected from those autolytic disintegrative processes which are supposed to occur during active secretion. That the act of secretion is to be ascribed to autolytic processes of the gland, is, according to Miss Lane-Claypon and Starling, highly improbable, and there is no evidence that the autolysis of the gland cells would give rise to the specific constituents which characterise milk.

Halban ${ }^{3}$ has put forward the view that the specific stimulus for mammary development arises in the placenta, while the active secretion of the mammary glands is determined by the expulsion or death of the placenta. ${ }^{4}$ Keiffer, ${ }^{5}$ on the other hand, has entertained the contrary conception, that the secretion of milk is due to a ferment elaborated in the placenta and trans-

1 Foì, "Sui Fattori che determinano l'Accrescimento e la Funzione della Ghiandola Mammaria," Arch. di Fis., vol. v., 1908.

" Hildebrandt, "Die Lehre von der Milchbildung," Hofmeistor's Beitrüje, vol. v., 1904.

3 Halban, loc. cit.

- He points out that in cases of abortion the secretion of milk may not begin until some days after the death of the child. This he believes to be due to the circumstance that the placenta remained alive during the interval.

5 Keiffer, "Recherches sur l'Anatomie et la P'hysiologie de la Mamelle," Bull. de la Soc. Belge de Gyn. et d'Obstét., 1901-2. 
ferred to the maternal circulation at the time of birth. These theories are based mainly on clinical evidence of a somewhat questionable value.

Miss Lane-Claypon and Starling have shown that after multiparous rabbits are injected with foetal extract milk is secreted by the glands. This result is explained as follows: "The multiparous rabbit differs from a virgin rabbit in possessing readyformed alveoli, i.e. secretory structures. On the theory which we have adopted, the circulation of the nammary hormone should diminish ally secretion in these alveoli, and should cause growth. In all our experiments at least twenty-four hours elapsed between each two injections. It is probable that the hormone was rapidly absorbed from the injection, and was therefore present in the blood of the animal only for a certain fraction, say a few hours, out of the twenty-four. While it was circulating it should cause building up of the secreting cells. Directly, however, it ceased to circulate, the cells would enter into dissimulative activity resulting in secretion. By our injections, therefore, we are not able to initate the continuous stimulus of pregnancy. We are rather producing each day a pregnancy of a few hours followed by a parturition. These factors should therefore result in the production of milk in any animals possessing the structures (i.e. the alveoli) which are capable of secreting milk, and would therefore account for the secretion of milk observed by us in all the cases where multiparous rabbits were the objects of our experiment."

It has been shown that in the fœtus itself there is an increased growth of the mammary glands during the last part of pregnancy, while it is well known that a secretion is often formed in the glands of the newly born. Halban has explained this secretion as the result of removal of the inhibitory influencethat is to say, it is due to the same circumstance as the secretion in the mother. Miss Lane-Claypon and Starling point out that the complete change which occurs in the environment of the newly born animal must induce equally profound changes in the metabolism, and there is consequently no difficulty about the conclusion that the formation of the mammary hormone ceases with the commencement of extra-uterine life.

The general conclusions reached by these authors may be 
summarised as follows: The anabolic changes associated with the growth of the mammary glands are due to the assimilatory effects of a hormone elaborated in the fotus and carricd thence through the placenta by the fotal and maternal circulation. The removal of this stimulus produces those katabolic changes which are involved in the breaking down of the built-up tissues and the consequent formation of milk. ${ }^{1}$

\section{Criticisms}

There are certain objections to be urged against these conclusions, which, however, are not claimed by the authors to bc as yet firmly established. Thus in certain animals the period of lactation may continue for an almost indefinitely long time, so that it would appear as if the katabolic processes involved in milk-sccretion were out of all proportion to the anabolic processes concerned in the building up of the gland tissue. For example, it is stated that in castrated cows the mammary glands may remain perpetually active for years and years so long as milking is regularly continued (see p. 568). Moreover, in some animals (e.g. mares) a secretion of milk may be induced artificially as a result of a mechanical stimulus set up by repeated attempts at milking. In onc instance known to the writer, a mare which had never had a foal could be made to yield milk at any time for years. It would seem probable, however, that in such cases there must have been an original tendency to secrete, and that this tendency was merely augmented by the emptying of the galactophorous ducts. This is in accordance with the view that the emptying of the ducts during normal suckling constitutes a physiological stimulus which acts on the gland cells, eitlicr directly or by means of a reflex.

Heape ${ }^{2}$ has pointed out as an objection to Starling's thicory of the fotal hormonc that virgin bitches are frequently known to produce milk, and that the quantity secreted may even be sufficient to admit of their rearing pups. He also refers to a statement by

1 According to Fod (loc. cit.) f(etal extract has no inhibitory influence on mammary secretion.

2 Heape, "The Source of the Stimulus which causes the Development of the Mammary Gland and the Secretion of Milk," Proc. Phys. Soc., Jour. of Phy8., vol. xxxiv., 1906. 
Tegetmeier and Sutherland ${ }^{1}$ that mules may yield milk in sufficient abundance to rear a foal. He concludes, therefore, that the source of the stimulus which excites the development of the mammary glands is to be sought in the ovary rather than in the foetus.

Instances have also been recorded by Knott ${ }^{2}$ and others, in which males have secreted milk, thus showing that mammary development is not necessarily even a female function; but such cases are at all events exceedingly rare. ${ }^{3}$ Knott mentions cases in which suckling occurred in a bull, a male goat, a wether, and in men. He also cites instances of virgin girls who were nurses secreting copious supplies of milk as a consequence of allowing infants to suck their nipples; and thus he supports Heape's objection to the fotal hormone theory. Gellhorn ${ }^{4}$ cites similar cases, including one of a virgin monkey (Cercopithecus). Another case is mentioned of a woman who suckled children uninterruptedly for forty-seven years, and in her eighty-first year had a moderate but regular supply of milk, ${ }^{5}$ thus showing that mammary secretion may continue exceptionally for long after the menopause, and presumably, therefore, in the absence of any sort of stimulus from the generative organs. This observation further supports the idea referred to above, that normal suckling acts by itself as a physiological stimulus for mammary secretion.

A more forcible objection to the theory of the fœtal hormone is supplied by the Monotremata, which are the lowest order of Mammalia. These animals are oviparous, the developing embryo being contained in an egg, which does not enter into any sort of connection with the uterine wall. Halban, ${ }^{6}$ however, has made the suggestion, which is quoted by Miss Lane-Claypon and Starling, that since the embryo goes on increasing in size during its passage down the female generative tract, and since the shell of the egg is porous, it is not impossible that substances may diffuse outward from the embryo and be absorbed by the uterine mucous membrane, and so be carried into the maternal circulation.

1 Tegetmeier and Sutherland, Horses, Asses, Zebras, Mules, and Mule Breeding, London, 1895.

" Knott, "Abnormal Lactation," \&c., American Medicine, vol. ii. (new series, June), 1907. Cf. Wiedersheim (see p. 555).

3 The occasional occurrence of milk secretion in the newly born, both males and females, is well known.

- Gellhorn, loc. cit. $\quad$ Knot, loc. cit.

- Halban, loc. cit. 
Miss Lane-Claypon and Starling, however, do not 'contend that the foetus is the sole source of the stimulus for mammary development. On the other hand, they specially mention that the growth of the mammary glands which occurs at puberty, for instance, can only be attributed to ovarian influence, since it does not take place if the ovaries have been previously removed. It is not improbable, therefore, that an ovarian stimulus is also responsible for initiating the growth of the glands in Monotremes, while Hill's observations on certain Marsupials afford a clear indication that such is the case in these animals (see p. 576).

\section{APPENDIX}

Lombroso and Bolaffio ${ }^{1}$ have described an experiment in which two female rats were grafted together so that their respective circulatory systems were presumably united. Subsequently to their union they each became pregnant, but at different times. They afterwards produced young, one prematurely, and the other at full term. The mammary glands of each underwent the characteristic changes, but they occurred independently and not synchronously. The authors cite this result as evidence against the fotal hormone theory. Moreover, as a result of this and another similar experiment, they conclude that parturition is not induced by a chemical excitant circulating in the blood (see p. 542).

On the other hand, in the case of the Bohemian pygopagous twins, Rosa-Josepha, the mammary glands of both are described as having been similarly and simultaneously affected by the pregnancy of Rosa, who bore a healthy boy on April 17, 1910 . Milk was afterwards secreted by the breasts of Josepha as well as of Rosa, although Josepha had never conceived. ${ }^{2}$

1 Lombroso and Bolaffio, "La Parabiosi e la Questione dei Fattori che determinano la Fuz Funzione mammaria e l'Insorgenza del travaglio di jarto," Atti della Soc. Ital. di Obstet. e Gin., vol. xv., 1909.

2 British Med.Jour., Part II., May 28, 1910. The twins are described as being united posteriorly by a common sacrum, but the iliac bones are separate. There is a common anus, perineum, clitoris, and meatus urinarius, but the labia majora are double. The urethra is single for an inch above the meatus, but then it bifurcates. The ureters are normal. T'he desire to micturate is said to be distinct, but not the desire to defaccate. 


\section{CHAP'TER XIV}

\section{FERTILITY}

"Nam multum harmonia veneris diferre videntur.

Atque alias alii complent magis ex aliisque,

Succipiunt alia pondus magis inque gravescunt.

Atque in eo refert quo victu vita colatur."-LUCretius.

THE rate of propagation in any species of animal depends not only upon the average number of young born in each litter, but also upon the frequency of recurrence of the sexual season and the duration of the reproductive period in the animal's life. The frequency of recurrence of the sexual season - that is to say, the astrous cycle-in different species of Mammals has been discussed at some length in an early chapter of this work. In the present chapter it remains to consider a little more closely some of the causes which control this periodicity and the factors which affect fertility.

The duration of the reproductive period of ananimal's existence extends in most cases from a time when that animal has almost reached its full size until the beginning of senescence, so that the normal period of generative activity in the individuals of any given species bears a definite relation to their average length of life. In the male the sexual maturity is usually reached later than in the female. Moreover, in the male there is no definite ending of the reproductive period, since in Man, for example, the power of producing spermatozoa continues in a gradually diminishing degree even in extreme old age, whereas in the female, on the other hand, the climacteric marks the cessation of generative activity (see below, p. 672).

Broadly speaking, the average number of young produced in a litter in any species of Mammal is inversely proportional to the average size of the animals belonging to that species. Thus, in most species of Ungulates twins are the exception rather than the rule; and there are seldom more than two young produced at a time even in sheep and goats, which show a greater degree of fertility than most Ungulates. The sow, however, is 
exceptional in having very large litters, as many as seventeen young being sometimes born. On the other hand, in small Mammals such as Rodents large litters are the rule; the rat, for example, being known occasionally to bear as many as sixteen or even twenty young; but the Cheiroptera, or bats, are remarkable for their relative infertility, only one young one ordinarily being produced at a time, although the common bat is no larger than the mouse.

Generally speaking, only one young one is produced in those animals in which the period of gestation exceeds six months. The number of teats characteristic of the species also affords an approximate indication of the average size of the litter.

"Among women, the birth of twins occurs once in about eighty deliveries. Triplets, quadruplets, quintuplets, and even higher figures, are occasionally observed; they are very uncommon, and the rarity is progressive with the number. The normal or ordinary rule in woman is to bear one child at a time ; and the next most frequent condition is temporary or persistent sterility-two points in which she signally differs from what is generally believed [of animals]." 1 Veit's statistics ${ }^{2}$ for 13,000,000 births in Prussia showed that twins were produced once in 89 cases, triplets once in 7910, and quadruplets only once in 371,125 cases. There is some evidence also that the frequency of occurrence of multiple pregnancy in women depends upon the race or climate, and that it is commoner in cold than in warm countries. ${ }^{3}$

Herbert Spencer ${ }^{4}$ elaborated a theory whereby he explained the relative degrees of fertility in the different races of men and animals. According to this theory the power to sustain individual life and the power to produce new individuals are inversely proportional, a conclusion which is summarised in the generalisation that Individuation and Genesis vary inversely. When there is an abundant food supply and a favourable environment,

1 Matthews Duncan, Fecundity, Ferility, Storility, and Allied Topics, Edinburgh, 1866.

2 Veit, "Beitrïge zur geburtshülflichen Statistik," Monatsschr. f. Geb., vol. vi., 1855 .

3 For further statistics and references see Williams, Obstetrics, New York, 1904.

4 Spencer, Principles of Biology, revised edition, vol. ii., London, 1899. 
and the necessary expenditure of energy is relatively slight, the cost of Individuation is much reduced, and the rate of Genesis is correspondingly increased; in other words, there is a high degree of fertility. Spencer cited the Boers, the Kaffirs, and the French Canadians as examples of fertile races in which the rate of increase is associated with a nutrition that is greatly in excess of the expenditure. Conversely, he concluded that a relative increase of expenditure leaving a diminished surplus reduces the degree of fertility, and in support of this statement adduced evidence that bodily labour tends to make women less prolific, since the reproductive age is said to be reached a year later by women of the labouring class than by middle-class women.

Spencer applied his generalisation to animals as well as to Man, and attempted to explain thereby the average contrast between the fertility of birds and Mammals. "Comparing the large with the large and the small with the small, we see that creatures which continually go through the muscular exertion of sustaining themselves in the air and propelling themselves rapidly through it, are less prolific than creatures of equal weights which go through the smaller exertion of moving about over solid surfaces. Predatory birds have fewer young ones than predatory Mammals of approximately the same sizes. If we compare rooks with rats, or finches with mice, we find like differences. And these differences are greater than at first appears. For whereas among Mammals a mother is able, unaided, to bear and suckle and rear half-way to maturity a brood that probably weighs more in proportion than does the brood of a bird; a bird, or at least a bird that flies much, is unable to do this. Both parents have to help; and this indicates that the margin for reproduction in each adult individual is smaller."

Spencer cites numerous instances from among both birds and Manmals illustrating the effects of different degrees of activity upon fertility. The hare and the rabbit, for example, are closely allied species, " similar in their diet, but unlike in their expenditures for locomotion. The relatively inert rabbit has six young ones in a litter, and four litters a year; while the relatively active hare has but two to five in a litter. That is not all. The rabbit begins to breed at six months old; but a 
year elapses before the hare begins to breed. These two factors compounded result in a difference of fertility far greater than can be ascribed to unlikeness of the two creatures in size."

Furthermore, Spencer refers to the case of the bat, which has been already mentioned as being abnormally unprolific in proportion to its size. The relatively low rate of multiplication is of course ascribed to a relatively high rate of expenditure resulting from the habit of flying.

In a similar way Spencer explains such well-known facts as that hens cease to lay when they begin to moult. "While they are expending so much in producing new clothing, they have nothing to expend for producing eggs."

There can be little doubt that Spencer's generalisation is in the main true, but it is equally certain that it cannot be applied indiscriminately to explain the relative degrees of fertility in all animals, and consequently it must not be pressed too far. Some of the more special factors which control fertility are referred to below, and it is evident that many (though not all) of these fall within the scope of Spencer's generalisation.

The rate of increase as distinguished from the rate of reproduction (in any given species) depends upon a large number of factors, of which the rate of reproduction is only one.

\section{EFFECT OF AGE}

Matthews Duncan ${ }^{1}$ has discussed at some length the variation which occurs in the fertility of women according to their age. He adduces statistical evidence showing that the fertility of the female population increases gradually from the commencement of the child-bearing period of life until about the age of thirty, and then it gradually declines. He shows also that the fertility is much greater before the climax is reached (at thirty years) than after it is passed. These conclusions, however, apply merely to the actual productiveness (i.e. the number of births), as opposed to the capability of bearing children, which Duncan designates the fecundity. By eliminating from his calculations all women not living in married life, Duncan arrives at the following conclusions, which are based on statistics showing the

$$
1 \text { Duncan, loc. cit. }
$$


productiveness of wives: ${ }^{1}$

(1) "That the initial fecundity of women gradually waxes to a climax, and then gradually wanes "; (2) "That initial fecundity is very high from twenty to thirtyfour years of age" ; and (3) "That the climax of initial fecundity is probably about the age of twenty-five years." The fecundity of the average individual woman may be described, therefore, as forming a wave which, starting from sterility, rises somewhat rapidly to its highest point, and then gradually falls again to sterility.

There can be no doubt that animals as a general rule tend to follow a similar law. A dog generally has fewer puppies in its first litters than afterwards, while in its declining years there is a diminution until sterility is reached once more. The same is said to be the case with the bear, the elk, and other animals, ${ }^{2}$ but there are obviously many individual exceptions. Geyelin ${ }^{3}$ gives the following table showing the fertility of the domestic fowl at different ages :-

First year after hatehing 15 to 20 Second " " . 100,120 Third " " . . 120,135 Fourth " " " . 100,115 Fifth " " $" 60 " 80$

Sixth year after hatching 50 to 60 Seventh " ". 35,40 Eighth " " . 15,20 Ninth ",$\quad$. 1,10

Furthermore Minot ${ }^{4}$ observed that in guinea-pigs the size of the litters increased with age during the first sixteen months of their lives.

\section{Effects of Environment and Nutrition}

That the generative system in animals is peculiarly susceptible to changed conditions of existence has been recognised from early days. Thus Aristotle ${ }^{5}$ commented on the increased fertility of sheep in a favourable environment. In more recent

${ }^{1}$ It is, of course, obvious that it is impossible to determine statistically the real "feeundity" (using the term as defined by Duncan) in view especially of the practice of volitional interference with coneeption (see below, p. 621).

2 Duncan, loc. cit. 1865.

${ }^{3}$ Geyelin, Poultry-Breeding in a Commercial Point of View, London,

"Minot, "Senescenee and Rejuvenation," Amer. Jour. of Phys., vol. xii., 1891.

${ }^{5}$ Aristotle, History of Animals, Bohn's Library, London. 
times Buffon, ${ }^{1}$ among others, remarked on the fact that domestic animals breed oftener and produce larger litters of young than wild animals belonging to the same species; and Darwin, who made the same observation, attributed the increased fertility of the former to a long habituation to a regular and copious food supply without the labour of seeking for it. "It is notorious how frequently eats and dogs breed, and how many young they prodnce at birth. The wild rabbit is said to breed four times yearly, and to produce each time at most six young; the tame rabbit breeds six or seven times yearly, producing each time from four to eleven young. . . . The ferret, though so closely confined, is more prolific than its supposed wild prototype [the polecat]. The wild sow is remarkably prolific; she often breeds twice in the year, and bears from four to eight, and sometimes even twelve, young; but the domestic sow regularly breeds twice a year, and would breed oftener if permitted; and a sow that produces less than eight at birth 'is worth little, and the sooner she is fattened for the butcher the better.' The amount of food affects the fertility of the same individual; thus sheep which on mountains never produce more than one lamb at birth, when brought down to lowland pastures frequently bear twins. The difference apparently is not due to the cold of the higher land, for sheep and other domestic animals are said to be extremely prolific in Lapland." 2

Darwin remarks that birds afford still better evidence of increased fertility resulting from domestication. Thus, in its natural state the female of Gallus bankiva, the wild representative of the common fowl, lays only from six to ten eggs; the wild duck lays from five to ten eggs, as compared with eighty or a hundred produced by the domestic duck in the course of the year. Similarly, the turkey, the goose, and the pigeon are more fertile in the domestic state, though this is not the case with the pea-fowl. Among plants also there are countless instances of increased fertility as a consequence of cultivation. ${ }^{3}$

1 Buffon, Histoire Naturelle, Paris, 1802.

${ }^{2}$ Darwin, The Variation of Animals and Plants under Domestication, Popular Edition, vol. ii., London, 1905.

${ }^{3} C f$. also Spencer (loc. cit.), who discusses this question at some length in connection with his generalisation that Individuation and Genesis vary inversely. See above, p. 587. 
On the other hand, it is well known that wild animals, when removed from their natural conditions and brought into captivity, often become partly or completely sterile. Darwin discusses this phenomenon at some length, and cites numerous cases from different groups of animals and birds.

The Indian elephant, for example, seldom breeds in captivity, although kept in a perfectly healthy condition and in its native country. On the other hand, most members of the Suidæ are known to breed in menageries and zoological gardens, while many Ruminants breed readily in climates widely different from their own. Carnivorous animals breed somewhat less freely in confinement, and show considerable variation in different places. The Canidæ tend to be more fertile than the Felidæ, while the members of the bear group breed less easily. Rodents as a general rule fail to breed after being brought into captivity, but there are several exceptions. Monkeys also when kept in confinement only rarely have young ones. Many of these animals, however, although failing to conceive, are known to copulate freely. This is especially the case with captive bears and monkeys, in which the typical phenomena of proøstrum and oestrus occur. It would seem probable that the sterility under these circumstances results from a failure to ovulate, due possibly to an absence of ripe follicles in the ovaries.

Among birds, members of the hawk group very seldon breed in captivity. The graminivorous birds show considerable variation, some, like the canary, breeding freely in aviaries (although it was some time before it became fully fertile), while others, like the finches, only occasionally reproduce their kind when kept in confinement. Gallinaceous birds, on the other hand, show an unusual capacity to breed in captivity, and the same is the case with pigeons, ducks, and geese. Certain kinds of gulls also are known to breed readily when kept in open spaces in zoological gardens.

As pointed out by Darwin, there is other evidence that changed conditions of life may induce a disturbance of the sexual functions. Thus when conception does occur under confinement, the offspring are sometimes born dead or ill-formed, or otherwise show signs of insufficiency of nourishment. The mother's milk may fail, indicating an interference with those 
factors which control the mammary metabolism. Moreover, in animals which are characterised by a periodic growth of the secondary sexual characters, these sometimes fail to make their appearance. The male linnet in captivity does not assume its characteristic crimson breast, or the male bunting (Emberiza passerina) the black colour on its head. Other birds, such as a pyrrhula and an oriole, may acquire the appearance of the hen, while a falcon (Falco albidus) has been observed to lose its adult plumage. ${ }^{1}$ These facts seem to show that the generative metabolism may be so altered by changed conditions of existence as to induce not merely a state of sterility, but also an interference with the secretory activity of the essential organs of reproduction. ${ }^{2}$

Darwin says: "We feel at first naturally inclined to attribute [such results] to loss of health, or at least to loss of vigour; but this view can hardly be admitted when we reflect how healthy, long-lived, and vigorous many animals are under captivity, such as parrots, and hawks when used for hawking, chetahs when used for hunting, and elephants. The reproductive organs themselves are not diseased ${ }^{3}$ and the diseases from which animals in menageries usually perish are not those which in any way affect their fertility. The failure of animals to breed under confinement has been sometimes attributed exclusively to a failure in their sexual instincts. This may occasionally come into play, but there is no obvious reason why this instinct should be especially liable to be affected with perfectly tamed animals, except, indeed, indirectly through the reproductive system itself being disturbed. Moreover, numerous cases have been given of animals which couple freely under confinement, but never conceive; or, if they conceive and produce young, these are fewer in number than is natural to the species.... Change of climate cannot be the cause of the loss of fertility, for whilst

Darwin, loc, cit.

2 The relation between the gonads and the secondary sexual cliaracters, and the apparent dependence of the latter upon the secretory activity of the former, are discussed in Chapter IX.

3 Few observations have been made upon the condition of the gonads in animals in captivity, but Branca ("Recherches sur le Testicule et les Voies spermatiques dans Lémuriens en captivité," Jour. de l'Anat. et la Phys., vol. xl., 1904) states that in captive lemurs he could find no spermatozoa in the testicles. 


\section{4 'IHE PHYSIOLOGY OF REPRODUC'IION}

many animals imported into Europe from extremely different climates breed freely, many others when confined in their native land are sterile. Change of food cannot be the chief cause; for ostriches, ducks, and many other animals, which must have undergone a great change in this respect, breed freely. Carnivorous birds when confined are extremely sterile, whilst most carnivorous Mammals, except plantigrades, are moderately fertile. Nor can the amount of food be the cause; for a sufficient supply will certainly be given to valuable animals; and there is no reason to suppose that much more food would be given to them than to our choice domestic productions which retain their full fertility. Lastly, we may infer from the case of the elephant, chetah, various hawks, and of many animals which are allowed to lead an almost free life in their native land, that want of exercise is not the sole cause." Darwin shows also that close confinement by itself does not necessarily cause sterility, since such animals as the rabbit and ferret breed freely in cramped hutches. The general conclusion reached is that " any change in the habits of life, whatever these habits may be, if great enough, tends to affect in an inexplicable manner the powers of reproduction. The result depends more on the constitution of the species than on the nature of the change; for certain whole groups are affected more than others; but exceptions always occur, for some species in the most fertile groups refuse to breed, and some in the most sterile groups breed freely."

In support of these conclusions Darwin shows further that domesticated animals also under new conditions occasionally show signs of lessened fertility, and that animals such as the canary, which now breed readily in a state of captivity, were formerly often sterile.

Bles' observations, ${ }^{1}$ to which reference has already been made (p. 20), seem to have a bearing on this question. This observer, who has kept various kinds of Amphibia in captivity, has shown that axolotls can only be induced to breed under certain special environmental conditions. By feeding them copiously in summer and allowing them to hibernate in winter,

'Bles, "The Life-History of Xenopus lavis," Trans. Roy. Soc. Edinburgh, vol. xli., 1906. 
and then suddenly transferring them to an aquarium stocked with growing plants and provided with running water, these animals could be induced to spawn within a few days. (Cf. also Annandale's observations referred to on p. 22.) Bles draws the conclusion that the difficulty so often experienced in inducing Amphibians to breed in a state of captivity is not due to toxic influence on the gonads resulting from the confinement, but must rather be ascribed to the absence of the necessary external stimuli without which the generative organs of animals are incapable of properly discharging their functions. Bles suggests that this view may help to explain why some animals (e.g. insects) make their appearance in great numbers in one year, and are comparatively scarce in another.

In animals which as a general rule breed freely in a state of domestication or under confinement, it is probable that nutrition plays the chief part (though by no means the sole part) in regulating the capacity to produce offspring. That an insufficient or markedly abnormal diet must affect this power is alınost self-evident, and Chalmers Watson ${ }^{1}$ has shown that sterility is a common condition among caged rats when fed exclusively upon meat. It is also certain that an excessive quantity of nutriment is likewise prejudicial to the proper discharge of the reproductive functions. No better example could be given of the way in which overfeeding results in a condition of sterility than that of the barren Shire mares, which in recent years have been a striking feature at agricultural shows in England. Some foods are said to induce sterility more easily than others. Sugar, molasses, and linseed are noted for having this effect when given to cattle, but they are often used to prepare beasts for show or sale, since they produce a good coat of hair and cause a deposit of fat. Very fat animals do not come in season so often, and consequently cattle "settle better and feed faster as they become what the butchers designate "fat ripe." 1 In such animals there can be no doubt that the ovarian metabolism is abnormal, for the author has often found large quantities of bright orange-coloured lipochrome in the interstitial tissue

1 Campbell and Watson, "The Minute Structure of the Uterus of the Rat," \&c., Proc. Phys. Soc., Jour. of Phys., vol. xxxiv., 1906. 


\section{THE PHYSIOLOGY OF REPRODUCTION}

of the ovaries of fat cows and heifers. A low condition, especially if associated with exposure to wet and cold, as. in the case of cattle wintered in the open air, or of cows which have suckled a large calf or more than one calf, is also a common cause of temporary barrenness. ${ }^{1}$ Certain other more special causes of sterility are referred to briefly below (p. 606).

A few years ago the Royal Agricultural Society of England instituted an inquiry into the subject of fertility in sheep. The investigation was conducted by Heape, at whose instigation it was carried out. In the report ${ }^{2}$ which was subsequently published a comparative account is given of the fertility of various breeds of sheep chiefly in the south of England in the season 1899. The most fertile breed was the Wensleydale, in which six flocks, consisting of a total of 319 ewes, produced a percentage of $177 \cdot 43$ lambs. The effects of locality are discussed, and there is an accumulation of evidence indicating that the character of the district is not without influence on the fertility of the breed. Thus, Lincoln sheep run on the wolds, Shropshire sheep on a subsoil of new red sandstone, and Hampshire sheep, which are not run upon chalk downs, are shown to be associated statistically with a relatively high percentage of infertility. The report shows further that the fertility of a flock depends greatly upon its management, that the quality and quantity of the food supplied affect the condition of the sheep, and so influence their power to breed, that some seasons are more favourable to fertility than others, and that sheep-stained pasture (or pasture on which sheep have run for some considerable time previously) is detrimental to breeding stock.

The present writer has shown ${ }^{3}$ that in Scotch Blackfaced, Cheviot, and other Scottish sheep the normal percentage of ova discharged at any single ostrous period is not appreciably in excess of the usual percentage of births at the lambing season.

1 Wallace (R.), Farm Live Stock of Great Britain, 4th Edition, Edinburgh, 1907.

2 Heape, "Abortion, Barrenness, and Fertility in Sheep," Jour. Roy. Agric. Soc., vol. x., 1899. See also Heape, "Note on the Fertility of Different Breeds of Sheep," \&c., Proc. Roy. Soc., vol. lxiv., 1899.

${ }^{3}$ Marshall, "The Estrous Cycle and the Formation of the Corpus Luteum in the Sheep," Phil. Trans., B., vol. cxcvi., 1903. 
It would seem probable, therefore, that a scarcity of twin births at lambing time is the direct consequence of an abnormally low number of ripe follicles in the ovary at tupping time (i.e. during the sexual season). A low percentage of twins is generally associated with barrenness, a fact which is recognised by flockmasters, and which is proved very clearly by Heape's statistics. And since ewes which are constitutionally barren are a rarity, there can be little doubt that infertility among sheep is due ordinarily to an absence or great scarcity of follicles available for ovulation at tupping time.

Scarcity of mature follicles must itself result either from a retardation in follicular development or from an unusual tendency towards follicular degeneration whether occurring shortly before the sexual season or at some previous period in the animal's lifetime. Atretic or degenerate follicles are by no means uncommon in sheeps' ovaries, the process of atresia appearing to set in most commonly in follicles which have reached a size varying from about one-eighth to one-half the dimensions of the mature follicle. It may set in, however, at practically any stage of development and probably in the so-called primordial follicle (see p. 156). There can be little doubt that an excessive follicular degeneration results usually from an insufficiency of stimulating power at the disposal of the ewe.

That a relative scarcity of ripe follicles in sheeps' ovaries at the sexual season is due to retardation of development is a conclusion which is based on inference rather than observation, for little is known regarding the actual rate of growth of the Graafian follicle. Nevertheless, there is every reason for supposing that the processes of growth and nuaturation can be very largely influenced both by insufficiency of food supply on the one hand and by artificial stimulation on the other. This fact has been recognised for years past by certain individual flockmasters who have consistently practised the methods of "flushing" or artificially stimulating their ewes by meaus of an extra supply of special food at the approach of the tupping season, but no precise records of the effects of this process had been published until lately, when the Highland and Agricultural Society of Scotland undertook an investigation upon this subject. 
In the report which has since been issued, ${ }^{1}$ and which contains the lambing statistics for various flocks of Scottish sheep for the years 1905,1906 , and 1907 , it is shown that the percentage of lambs born was, as a general rule, highest among sheep which had been subjected to a process of artificial stimulation. The method adopted was to feed the ewes upon turnips, oats, maize, dried grains, or other additional food at the tupping time and for about three weeks previously, while maintaining them upon grass only during the greater part of the year. Some flocks, however, received a limited supply of extra food (generally turnips) during gestation, and especially during the later part of this period. The additional supply of turnips, which are specially rich in carbohydrate material, was found to be in no way detrimental to fertility, but rather the reverse, when accompanied by other food (pasture), and so not taken in excess. The statisties show that in the flocks treated in the way described, the percentage of lambs per ewes ${ }^{2}$ was almost invariably in excess of the average percentage for flocks which received no special treatment, while the percentage of barren ewes was usually also less in the specially fed flocks. In some cases the number of lambs per ewes in the flushed flocks was nearly 200 per cent. Among flocks belonging to the same breeds (Border Leicester or half-bred Border Leicester) which received no sort of special treatment, the average proportion of lambs per ewes was between 150 and 160 per cent., while flocks which were run upon superior pasture at the approach of the sexual season, without being otherwise specially fed, generally produced a slightly larger percentage of lambs. The twins appear almost invariably to have been born early during lambing, thus showing that the generative activity of the ewes tends to be greatest at the commencement of the sexual season.

It has proved more difficult to obtain definite information concerning the effects of flushing in one year upon the fertility of the ewes in subsequent seasons. The more usual experience of flockmasters seems to be that flushing is not in any way prejudicial to breeding stock unless it is overdone, the object

\footnotetext{
1 Marshall, "Fertility in Scottish Sheep," Trans. Highland and Agric. Soc., vol. xx., 1908. See also Proc. Roy. Soc., B., vol. lxxvii., 1905.

2 That is to say, the number of lambs per 100 ewes.
} 
of the process being to get the animals in an improving condition without permitting them to put on too much fat. If the artificial feeding is excessive and the sheep are forced to depend for the remainder of the year upon a mere sustenance diet, it is easy to understand that they would tend to deteriorate, and their subsequent fertility become impaired, owing probably to a higher frequency of follicular degeneration. It is seemingly for such a reason that some flockmasters regard the practice of flushing as one altogether to be deprecated. There is some evidence, however, that if sheep are specially fed in one season, the process must be repeated in the next, and that if this is omitted the sheep tend to be less fertile than if they had never been subjected to flushing.

It has already been mentioned (p. 335) that the practice of flushing tends to hasten the sexual season, the sheep coming " on heat" sooner than they would otherwise. The result must be ascribed to a general increase in the ovarian metabolism consequent upon the stimulating power of the special food supply. Conversely, it has been shown that in ewes which are poorly fed the sexual season is often retarded, and the fertility of the flock reduced. So also the occurrence of a snowstorm, or other unfavourable climatic condition, occurring during tupping time will cause a corresponding scarcity of twin births in the following lambing season. There can be little doubt, therefore, that the conditions which exist during tupping time are largely responsible for controlling the fertility of the flock, and that favourable conditions tend to promote the more rapid growth and maturation of the follicles in the ovary, and cause a greater number to discharge their ova during the ostrous periods.

It would appear also that the condition of the ewe is a far more important factor in determining the number of twin births than that of the ram; but it is obvious that the number of ewes which one ram can serve successfully must depend upon the degree of vigour possessed by the latter. Sixty ewes to one rain is about the usual proportion allowed. ${ }^{1}$

1 It is said that a good stallion should be able to serve eighty mares in one season, and get on an average forty to fifty foals. See Wallace, loc. cil. The reproductive capacity of the male animal is almost invariably far greater than that of the female. 


\section{Effect of Prolonged Lactation}

It has been recorded that the continuance of lactation commonly exerts an inhibitory influence on menstruation in women and on heat in animals, though this is very far from being invariable (see p. 74). There can be no doubt that in the case of sows, for example, early weaning is conducive to a more frequent recurrence of œstrus and an increased number of litters (see p. 50). In a similar way long-continued lactation is believed to reduce the fecundity of women, who sometimes refrain from weaning their babies in the belief that by so doing they are less liable to become pregnant again. Moreover, Haddon's observations ${ }^{1}$ upon the Eastern Islanders of the Torres Straits show that with these people also prolonged nursing tends to reduce the size of the families, and that a single lactation may be continued for three years.

\section{EFFECT of Drugs}

There is little evidence as to the effects of drugs upon eggor sperm-production, but innumerable substances have been recommended as cures for impotence. ${ }^{2}$ Cantharides and various other drugs are said to produce sexual excitement, but this result is probably due simply to the increased flow of blood to the generative organs which these substances induce. ${ }^{3}$ Wallace says that the practice adopted by some grooms of giving cantharides to stallions is strongly to be deprecated. Bloch is disposed to recommend the use of phosphorus and strychnine in the treatment of impotence in men, but the most favourable results have been obtained by yohimbine, an alkaloid prepared from the bark of a West African tree. Bloch mentions several cases where, in his own experience, treatment by yohimbine has been entirely successful, and there are numerous others on record. Many

1 Haddon, Reports of the Cambridge Anthropological Expedition to Torres Straits, vol. vi., Cambridge, 1908.

2 For the distinction between sterility and impotence see below (p. 606). 1908.

${ }^{3}$ Bloch, The Sexual Life of our Time, English Translation, London, 
veterinarians also have testified to the powerful aphrodisiac action of yohimbine, stating further that it is capable of inducing a condition of heat in domestic animals and acting as an effective remedy for certain kinds of sterility.

Daels ${ }^{1}$. found that yohimbine when administered to dogs produced hyperæmia of the generative organs, followed by mucous and sanguineous discharge, but not true heat. Dr. Cramer and the present writer ${ }^{2}$ have made similar observations. We first administered 0.005 grams of yohimbine twice daily for nearly a fortnight to each of two anœestrous bitches, the drug being swallowed in the form of tablets. Marked congestion of the generative organs followed. On treating rabbits with yohimbine the vulva and the uterine mucosa became excessively hyperæmic, the entire generative tract being affected to some extent. The ovaries were much overgrown by luteal tissue, and degenerate follicles which are generally so common in rabbits' ovaries, were relatively scarce. "It seems extremely probable, therefore, that yohimbine, by preserving a constant and rich supply of blood, and consequently of nutriment, to the ovaries, may arrest the normal process of follicular degeneration, and so be the means of bringing a larger number of follicles to maturity than would otherwise be the case, thereby tending to increase the fertility." 2 There was some evidence also that yohimbine may promote mammary development and the secretion of milk.

\section{Effects of In-Breeding and Cross-Brendinct}

The fact that in-breeding may result in a reduced fertility has been already discussed in dealing with the significance of the fertilisation process (pp. 207-214). It was then pointed out that a tendency towards sterility is often associated with a constitutional loss of vigour. In the same place it was mentioned further that cross fertilisation between organisms which are allied but belong to different strains often results in an increased

1 Daels, "On the Relation between the Ovaries and the Uterus," Surgery Gynacology and Obstetrics, vol. vi. (Feb.), 1908.

2 Cramer and Marshall, "Preliminary Note on the Action of Yohimbine on the Generative System," Jour. Econ. Biol., vol. iii., 1908. 
fertility, ${ }^{1}$ but that cross fertilisation between different species is frequently difficult to accomplish while there is every graduation between a mere disinclination towards gametic union and complete cross sterility.

The differences in fertility between varieties and species when crossed are discussed at sQme length by Darwin, ${ }^{2}$ who summarises his general conclusions under seven heads. Firstly, the laws governing hybridisation in plants and animals are practically identical. Secondly, there are all degrees of cross infertility. "Thirdly, the degree of sterility of a first cross between two species does not always run strictly parallel with that of their hybrid offspring. Many cases are known of species which can be crossed with ease, but yield hybrids excessively sterile; and conversely some which can be crossed with great difficulty, but produce fairly fertile hybrids. This is an inexplicable fact on the view that species have been specially endowed with mutual sterility in order to keep them distinct." Fourthly, the degree of sterility is often different in the two sorts of reciprocal crosses between the same species, and hybrids produced from reciprocal crosses sometimes differ in their degree of sterility. "Fifthly, the degree of sterility of first crosses and of hybrids runs, to a certain extent, parallel with the general or systematic affinity of the forms which are united. For species belonging to distinct genera can rarely, and those belonging to distinct families can never, be crossed. The parallelism is, however, far from complete; for a multitude of closely allied species will not unite, or unite with extreme difficulty, whilst other species, widely different from one another, can be crossed with perfect facility. Nor does the difficulty depend on ordinary constitutional differences, for amnual and perennial plants, deciduous and evergreen trees, plants flowering at different seasons, inhabiting different stations, and naturally living under the most opposite climates, can often be crossed with ease. The difficulty or facility depends exclusively on the

1 Frazer has shown that this fact is probably the biological basis for the practice of exogamic marriages originally adopted by primitive races of mankind and perpetuated under the influence of natural selection (Totemism and Exogany, London, 1910).

2 Darwin, loc. cit. See also Origin of Species, 6th Edition, London, 1872. 
sexual constitution of the species which are crossed; or on their elective affinity." Sixthly, cross sterility between species may depend possibly in certain cases upon distinct causes, such as deterioration due to unnatural conditions to which the hybrid embryo may be exposed in the uterus, egg, or seed of the mother. "Seventhly, hybrids and mongrels present, with the one great exception of fertility, the most striking accordance in all other respects; namely, in the laws of their resemblance to their two parents, in their tendency to reversion, in their variability, and in being absorbed through repeated crosses by either parent form." It is obvious, however, that this last conclusion requires some modification in the light of recent Mendelian research.

Darwin maintains further that the cross fertility which exists between the different varieties of various species of domesticated animals, in spite of their great divergence in external appearance, is the direct effect of domestication which eliminates the tendency towards mutual sterility. In this way " the domesticated descendants of species, which in their natural state would have been in some degree sterile when crossed, become perfectly fertile together." Both Darwin and Wallace lay stress upon the apparent existence of a parallelism between crossing and change of conditions in so far as these affect the power to reproduce. "Slight changes of conditions and a slight amount of crossing, are beneficial; while extreme changes, and crosses between individuals too far removed in structure or constitution, are injurious." 1 Furthermorc, domestic animals are less susceptible to the influences of changed conditions of existence than wild animals, a fact which finds a parallel in the absence of sterility between domesticated varicties of the same species.

Wallace has cited several cases in which it has been shown that hybrids between distinct species are fertile inter se. Such cases are the hybrids between the domestic and Chinese geese, those between the Indian humped and common cattle, and the various hybrids between the different species of the genus Canis. A recently recorded case of a fertile hybrid between a lion and a jaguar may also be cited. These and other observations

Wallace (A. R.), Darwinism, London, 1897. 


\section{THE PHYSIOLOGY OF REPRODUC'IION}

show that sterility among hybrids between closely allied species, although usual, is very far from being universal. ${ }^{1}$ Similar cases have been recorded from among plants.

The cause of sterility in hybrid organisms is still to a large extent an open question. In some cases the generative organs are atrophied or imperfectly developed, while in most, if not all sterile hybrids, the gametes are not developed. For example, Iwanoff ${ }^{2}$ states that hybrids between the horse and the zebra do not possess spermatozoa.

It has been suggested that the sterility is due to irregularities in the mechanics of division in the germ cells. "When we recall that at one stage in the development of the germ cells there may be a pairing and subsequent fusion of the maternal and paternal chromosomes, we can readily imagine that any differences in their behaviour at this time might lead to disastrous results." 3

\section{Inheritance of Fertility}

That fertility is a racial characteristic, and consequently is capable of hereditary transmission, is a fact that is generally accepted. Among sheep, for example, some breeds, like the Dorset Horns, the Hampshire Downs, and the Limestones, are notoriously prolific, while other varieties, like the Scotch Blackfaced, are relatively infertile. ${ }^{4}$ Furthermore, there is a considerable amount of evidence that in each breed there are particular strains of related individuals which have a higher degree of fertility than the average, and that flockmasters, by breeding from twin ewes and employing the services of twin rams, have been able permanently to increase the fertility of their stock. ${ }^{5}$

1 See Suchetet, "Problèmes Hybridologiques," Jour. de l'Anat. et la Phys., vol. xxxiii., 1897 ; Dewar and Finn, The Making of Species, London, 1909.

" Iwanoff, "Untersuchungen über die Unfruchtbarkeit von Zebröiden," Biol. Cent., vol. xxv., 1905. "De la Fécondation Artificielle chez les Mammifères," Arch. des Sciences Biologiques, vol. xii., 1907.

3 Morgan, Experimental Zoology, New York, 1907.

4 The Leicester breed of sheep is characterised by a relatively low fertility, and this is said to be due to the preference that was shown to large single lambs at the time when high prices ruled, and the consequent discarding of ewes which bore twins. See Wallace (R.), loc, cit.

"Marshall, "Fertility in Scottish Sheep," Trans. Highland and Agric. Soc., vol. xx., 1908. 
The inheritance of fertility in Man and also in thoroughbred horses has been investigated statistically by Karl Pearson and his biometrical collaborators, ${ }^{1}$ to whose memoir the reader is referred for a full discussion of the mathematical details and the conclusions which are arrived at. It is there shown, among other facts, that the woman inherits fertility equally through the male and female lines. Among thoroughbred race-horses the fecundity was first ascertained (i.e. the ratio of foals surviving to be yearlings to the total number of foals possible under the given conditions), and the following general conclusions were afterwards reached :-(1) Fecundity is inherited between dam and daughter, and (2) Fecundity is also inherited through the male line, i.e. the sire hands down to his daughter a portion of the fertility of his dam. Thus fecundity, which is, of course, a latent character in the male, was measured for a horse and for his sire, and was found to be strongly inherited.

More recently Rommel and Phillips ${ }^{2}$ have shown mathematically that there is an actual correlation between the size of the litter in two successive generations of Poland China sows, the productiveness being a character which is transmitted from mother and daughter.

On the other hand Pearson ${ }^{3}$ from studying Weldon's records of mice-breeding experiments, failed to find a sensible parental correlation in regard to the size of the litters. Furthermore, Pearl and Surface, ${ }^{4}$ as a result of a statistical investigation on egg-production in Barred Plymouth Rock fowls, carried on over nine years, found no evidence of the inheritance of fecundity. For this particular breed at any rate the capacity for egg-producing could not be increased by selective breeding, but tended

1 Pearson, Lee, and Bramley-Moore, "Mathematical Contributions to the Theory of Evolution: VI., Genetic (Reproductive) Selection, Inheritance of Fertility," \&c., Phil. Trans., A., vol. cxcii., 1899.

2 Rommel and Phillips, "Inheritance in the Female Line of Size of Litter in Poland China Sows," Proc. Amer. Phil. Soc., vol. xlv., 1907.

3 Pearson, "On Heredity in Mice, from the Records of the late W. F. R. Weldon," Biometrika, vol. v., 1907.

" Pearl and Surface, "Data on the Inheritance of Fecundity obtained from the Records of Egg Production," \&c., Maine Ayric. Exp. Station, Bulletin No. 166 ; Maine, 1909. P'earl, "A Biometrical Study of Figg Production in the Domestic Fowl," U. S. Dep. of Agric, Burcau of Animal Industry, Bulletin No. 110; Washington, 1909. 


\section{6 'I'HE PHYSIOLOGY OF REPRODUC'IION}

rather to diminish, though the last result may have been due to slight environmental changes. It is possible that fertility, like other characteristics, cannot be increased indefinitely by selective breeding, but that when once the limit existing in the strain has been reached, artificial selection is powerless to effect an improvement.

\section{Certain Causes of Sterility}

A detailed account of the various pathological conditions which are capable of inducing sterility is outside the scope of this work. The medical publications dealing with the subject form a very considerable literature, ${ }^{1}$ while the causes of sterility in animals are discussed, though somewhat unsatisfactorily, in many of the veterinary text-books. It may not be out of place, however, to refer briefly to certain of the conditions which are known to induce sterility in Man and also in animals.

In the case of the male an incapacity to procreate is due either to impotence (i.e. inability to perform the sexual act), or to sterility (using the term in the more restricted sense, implying an absence of spermatozoa). Impotence may result from (1) absence of sexual desire, (2) absence of the power of erection and consequent intromission, (3) absence of the power of ejaculating the seminal fluid into the vagina, and (4) absence of the ability to experience pleasure during the act of coition, and at the time of the emission of the semen. ${ }^{2}$ Or, according to another classification, the causation of impotence may be either anatomical, physiological, pathological, or psychological. Among the anatomical causes may be mentioned defects and deformities in the penis. The physiological and pathological causes include incomplete erections, premature ejaculations, diseases of the brain and spinal cord (and more particularly of the centres for the performance of the sexual act), besides such diseases as albuminuria or prolonged diabetes. The psychological causes include fear, repugnance, want of confidence, \&c. ${ }^{3}$

1 Müller (P.), Die Unfruchtbarkeit der Ehe, Stuttgart, 1885. This work contains a bibliography.

2 Hammond, Sexual Impotence in the Male, New York, 1883.

3 Corner, Diseases of the Male Generative Organs, London, 1907. 
Complete sterility, i.e. inability to procreate owing to the absence of fertile semen, is due to various causes, and may be either congenital or acquired. Congenital sterility occurs when the testicles are never developed, or are so imperfectly developed that they fail to produce ripe spermatozoa. In cases of incomplete descent of the testicles fertility is rare, but it may exist for a short time as in young men from twenty to twentythree years of age. Acquired sterility results from the various diseases to which the generative organs are subject, such as tubercle, syphilis, attacks of inflammation, urethral stricture, epididymitis, prostatic enlargement or diminution, \&c. ${ }^{1}$

A more special cause of sterility in men is one which operates in the case of workers with radium or the Röntgen rays. Several years ago Albers-Schönberg ${ }^{2}$ noticed that the $\mathrm{X}$-rays induced sterility in guinea-pigs and rabbits, but without interfering with the sexual potency. These observations have been confirmed by other investigators, ${ }^{3}$ who have shown, further, that the azoöspermia is due to the degeneration of the cells lining the seminal canals. In men it has been proved that mere presence in an X-ray atmosphere incidental to radiography sooner or later causes a condition of complete sterility, but without any apparent diminution of sexual potency. ${ }^{4}$ As Gordon observes, for those working in an $\mathrm{X}$-ray atmosphere adequate protection for all parts of the body not directly exposed for examination or treatment is indispensable, but, on the other hand, the X-rays afford a convenient, painless, and harmless method of inducing sterility, in cases in which it is desirable to effect this result. ${ }^{5}$

1 Corner, loc, cit.

2 Albers-Schönberg, "Ueber eine bisher unbekannte Wirkung der Röntgen. stralılen auf den Organismus der Tiere," Münchener med. Wochenschr., No. 43, 1903.

${ }^{3}$ See Gordon, "Diseases caused by Physical Agents," Osler's System of Medicine, vol. i., London, 1907. See also Regaud and Dubreuil, "Action des Rayons de Röntgen sur la Testicule de la Lapin," C. R. de la Soc, de Biol., vol. lxiii., 1907.

"Brown and Osgood, "X-Rays and Sterility," Amer. Jour. of Surgery, vol. xviii. (April), 1905.

5 Gordon, loc. cit. It has been shown also that the Röntgen rays may induce degeneration of the follicles, corpora lutea, and interstitial cells in the ovaries and cause sterility in the female. See Bouin, Ancel, and Villemin (C. R. de la Soc. de Biol., vol. Ixi., 1906), Bergomié and Trabondeau (C. R. de la Soc. de Biol., vol. lxii., 1907), and Specht (Arch. f. Gynïk., vol. lxxviii. 1907). 
The various causes of sterility in women are discussed at considerable length by Kelly, ${ }^{1}$ as well as by other writers ${ }^{2}$ on gynæcology. Kelly mentions the following conditions as likely to be found associated with sterility: Gonorrhœal infection of Skene's or Bartholin's gland, stricture of the vagina or cervix, the presence of a uterine polyp, a uterine fibroid tumour, a parovarian cyst, or a nodular salpingitis (from gonorrhœea or tuberculosis), atresia of the uterine tube (from inflammation), and the existence of ovarian adhesions. These, and other causes of sterility, and the methods of treatment to be adopted, are fully dealt with by Kelly.

Sterility in animals, as in Man, is brought about by a variety of causes, ${ }^{3}$ some of which are incurable, but others, such as constriction of the os uteri, are capable of treatment. In the case of cattle great difficulty is often experienced in getting the cows to breed after attacks of contagious abortion, and this is said to be due to an acid condition of the vaginal mucous membrane. In order to remedy this, injections of dilute solutions of bicarbonate of soda are employed and are found to be effective. Others recommend that the uterus should be injected with solutions of perchloride of mercury. ${ }^{4}$

Sterility in mares and cows and other animals is often due to structural or functional defects in the vagina, os uteri, or cervix. These may sometimes be overcome by resorting to artificial insemination, the methods of which are described below. ${ }^{5}$

Furthermore, sterility among cows may be contagious owing to the disease known as infectious granular vaginitis, which is primarily an acute inflammation of the vulva and vagina. It is

1 Kelly, Medical Gynecology, London, 1908.

2 See especially Duncan, Sterility in Women, London, 1884, and Miiller, loc. cit. Duncan states his opinion that probably ten per cent. of the marriages in Great Britain are sterile.

${ }^{3}$ Fleming, Text-book of Veterinary Obstetrics, London, 1878.

"Wallace (R.), loc. cit. According to Knowles ("Sterility of Mares and Cows," Amer. Veterinary Review), "sub-acute and chronic cervical hyperremia are probably the most frequent and fruitful causes of temporary sterility, due in an astonishingly large number of instances to continually recurring abortions."

${ }^{5}$ Constriction of the os uteri in cows may often be remedied by the employment of a large probe followed by the finger, or better still by a specially devised instrument known as a dilator. See Wallace (R.), loc. cit. 
commonly communicated by a contaminated bull in which the penis and sheath are affected. Similarly a bull may become diseased by serving an infected cow, and in this way vaginitis may spread through an entire herd. During recent years contagious sterility has been very common in Switzerland and Germany, and there is evidence of its existence in England. Antiseptic disinfection is useful, but experience has shown that even when treated infectious vagin tis often runs a prolonged course. Nevertheless, a complete cure usually takes place after some months, this recovery being indicated by the cessation of the muco-p rulent discharge and the recurrence at normal intervals of the cestrous periods. ${ }^{1}$

Deficient, excessive, or unfavourable nutrition, change of environment, in-breeding, \&c., as sources of infertility, have been already discussed.

\section{-Artifictal Insemination as a Means of Over- COMING STERILITy}

Artificial insemination as a means of overcoming certain forms of sterility has been employed by various medical men from Hunter's time downwards. In the case treated by Hunter himself, ${ }^{2}$ the husband of the woman experimented upon was affected with hypospadias. The semen was injected into the vagina, conception followed, and a child was afterwards born. Sims ${ }^{3}$ recorded a case of a woman who suffered from dysmenorrhwea and a deformed uterus, and who had been married for nine years without having children. Artificial insemination was resorted to, pregnancy ensued, and a child was born in due time. Numerous other cases are cited by Heape ${ }^{4}$ and Iwanoff, ${ }^{5}$ to whose papers the reader is referred for bibliographies of the subject. 1909.

1 McFadyean, "Sterility in Cows," Jour. Royal Agric. Soc., rol. Ixx.,

${ }^{2}$ This case is described by Home, Phil. Trans, 1799. (See p. 189, Chapter V.)

${ }^{3}$ Sims, Notes Cliniques sur la Chirurgie Utérine, Paris, 1866.

" Heape, "The Artificial Insemination of Mammals," \&c., Proc. Roy. Soc, vol. $1 x i ., 1897$.

5 Iwanoff, "De la Fécondation artificielle chez les Mammifères," Arch. des Sciences Biologiques, vol. xii., 1907. 
The method adopted by gynæcologists who have practised artificial insemination is to inject seminal fluid into the uterus by means of a syringe, the fluid in most cases being obtained from the vagina of the same individual shortly after coitus. In this way it has been found possible to overcome such structural defects as constriction or undue rigidity of the cervix or hypertrophy of the lips of the external os uteri. By modifying the method by which the semen is obtained, it has proved possible to induce pregnancy in cases of abnormal vaginal secretion where the spermatozoa are ordinarily killed before they can effect an entrance into the uterus, and in other cases where there is an inability on the part of the vagina to retain the semen after coitus.

Artificial insemination has frequently been practised on mares with a view to overcoming certain forms of sterility, and considerable success has been attained. "Such defects as flexion or constriction of the canal of the cervix; rigidity of the cervix; hypertrophy of the lips of the external os, and the formation of false menibranes which may effectually close the orifice; inability to retain spermatozoa in the vagina, owing to abnormal shortness of the organ or to violent muscular contraction after coitus; a want of sufficient muscular power; abnormal structure or size of the cervix or os uteri, which prevent the free action of the functions of the cervix; occlusion of the os owing to spasmodic contraction of the muscles of the cervix during coitus; abnormal or excessive vaginal secretions, which may kill or deleteriously affect the spermatozoa, \&c., may be overcome by artificial insemination." 1 Heape, and more recently Iwanoff, ${ }^{2}$ have cited numerous cases in which mares have been got in foal successfully by artificial insemination.

The actual methods employed are described by these writers. ${ }^{3}$ The most usual plan is to allow the stallion to serve the mare in the ordinary way, and then, immediately afterwards, to insert

1 Heape, "The Artificial Insemination of Mares," Veterinarian, 1898.

2 Iwanoff, loc. cit. This important memoir, besides containing descriptions of the author's own experiments, gives a very full account of the literature of artificial insemination.

${ }^{3}$ See also a booklet edited and published by Huish, The Cause and Remedy for Sterility in Mare, Cows, and Bitches, London. 
a syringe into the vagina, and draw up into it some of the seminal fluid which is caused to collect in a depression or pocket made in the vaginal floor by the pressure of the finger tips. The same mare can then be inscminated by injecting the fluid so obtained into the uterine cavity, or the semen can be utilised for impregnating other mares. Another method is to collect the semen in gelatine capsules which are placed in the vagina before coitus, and then, when they have been filled, to close their lids and insert them in the interior of the uterus, where the heat of the body gradually melts the gelatine and sets free the spermatozoa. By such means as this several mares may be impregnated as a result of one service by a stallion. In some cases pieces of sponge have been employed instead of gelatine capsules. In transferring semen from one animal to another it is of considerable importance to preserve a moderate degree of warmth; otherwise the spermatozoa are liablc to die as a result of exposure before injection has been effected.

Artificial insemination has been of considerable usc also in remedying sterility in cows as well as in dogs. ${ }^{1}$

Several investigators by employing artificial insemination have been successful in getting crosses between animals belonging to varieties in which the disparity in size is so great that coitus between them is difficult or impossiblc. Thus, Plönnis ${ }^{2}$ in 1876 successfully inseminated a lap-dog with the semen of a settcr, and obtaincd a pup which in most of its points resembled its father. Allbrecht ${ }^{3}$ performed a similar cxperiment and obtained a similar result. More recently Heape ${ }^{4}$ has described some experiments carried out by Millais, in which bloodhounds were inseminated with spermatozoa obtained from Basset hounds (a muclı smaller breed), litters of cross-bred pups being produced.

Iwanoff ${ }^{5}$ has recorded an experiment in which he successfully inseminated a white mouse with the spermatozoa of a white rat.

1 See Huish, loc. cit.

2 Plönnis, "Künstliche Befruchtung einer Hünden," \&c., Inaug.- Dissert., Rostock, 1876.

${ }^{3}$ Allbrecht, "Künstliche Befruchtung," Wochenschr. f. Thierheilkunde und Viehzucht, Jahrg. xxxix.

"Heape, "The Artificial Insemination of Mammals," Proc Roy. Soc., vol. lxi., 1897.

s. Iwanoff, loc. cit. 
Two hybrid young ones were produced after a pregnancy lasting twenty-seven days. They were intermediate in size between rats and mice. This is the first record of a cross being obtained between two species so different in size as the rat and the mouse, coitus between them being practically impossible. Furthermore, Iwanoff has successfully employed artificial insemination to obtain liybrids between horses and zebras (a cross which is often difficult to get by the normal method owing to the liability of the animals to refuse service).

\section{ABortion}

Abortion is often an important factor in determining a low fertility, but its frequency of occurrence shows a considerable range of variation.

With women the frequency of abortion to birth at full term is said to be from one in five to one in ten. ${ }^{1}$ According to the records of Franz ${ }^{2}$ for the maternity hospital at Halle, the percentage of cases in which abortion occurred was $15 \cdot 4$. Williams ${ }^{3}$ expresses the opinion that in ordinary private practice every fifth or sixth pregnancy usually ends in abortion, and that the percentage would be considerably increased if one reckoned the early cases in which there is a profuse loss of blood following a retardation of the menstrual period, the actual fact of abortion being often obscured.

Excepting in the case of sheep, there are no satisfactory data on which to estimate the frequency of abortion among the different kinds of domestic animals, but there can be no doubt that it is of common occurrence, and that it occasions much loss to breeders. For various varieties of English sheep Heape ${ }^{4}$ found that the percentage of abortion experienced by 300 flockmasters varied from nothing to $23 \cdot 75$, while the percentage for 85,878 ewes was $2 \cdot 39$. The statistics showed that Dorset Horn and Lincoln breeds suffered most from abortion, the losses from

1 Kelly, loc. cit.

2 Franz, “'Zur Lehre des Aborts," Hegar's Beiträge, vol. i., 1898.

3 Williams, loc. cit.

4 Heape, "Abortion, Barrenness, and Fertility in Sheep," Jour. Royal Agric. Soc., vol. x., 1899. 
this cause being respectively $4 \cdot 11$ per cent. and 4 per cent. The Southdown breed were found to occupy an intermediate position (the percentage of abortion being $2 \cdot 86$ per cent.), while the other breeds investigated showed a smaller percentage of abortion. Among Scottish breeds the percentage of aborting ewes does not generally exceed 2 per cent., as far as could be ascertained; but with Blackfaced ewes it may be as much as five, or even a considerably higher number, as a consequence of any special adverse circumstance. ${ }^{1}$ It is possible, however, that the percentages of abortion are actually somewhat higher than they appear, since its occurrence during the early stages of pregnancy is not readily detected, and consequently some of the ewes which were entered in the statistical returns as barren may in reality have aborted.

Among cattle in Great Britain the frequency of abortion, according to Heape, ${ }^{2}$ is not less than ten per cent. of the total number of animals selected for breeding, and there can be no doubt that in certain districts it is often very much higher, especially where contagious or epidemic abortion occurs. Heape states further that from ten to twelve per cent. of abortion is not unusual in herds in which no contagious abortion is proved to exist.

There are no data available on which to compute the frequency of occurrence of abortion among horses, but the experience of breeders shows that the losses arising from this cause are very considerable, and that they are greatest amongst the better-bred animals. One of the earlier reports of the Royal Commission on Horse-Breeding stated that in this country in any given year no less than forty per cent. of the mares chosen for breeding fail to produce foals, but to what extent this result is due to sterility or how far it may be ascribed to abortion does not appear to have been ascertained.

The causes of abortion are diverse, and may be mechanical, psychological, physiological, or pathological. Deliberate abortion among civilised European nations is a criminal offence punishable by law, but nevertheless is not infrequently carried

1 Marshall, "Fertility in Scottish Sheep," Trans. Highland and Agric. Soc., vol. xx., 1908.

2 Heape, The Breeding Industry, Cambridge, 1906. 


\section{THE PHYSIOLOGY OF REPRODUCI'ION}

out. In Oriental countries and among savages abortion is practised more openly. The more usual means are drugs (ergot, ethereal oil of juniper, yew, turpentine, camph r, cantharides, aloes, \&c.),' but none of these are infallible, and owing to their toxie properties their use is often accompanied by danger. Haddon " says that among the Eastern I landers of the Torres Straits abortion is procured by the leaves of the shore convolvulus and certain other plants. Also the old women give the younger women young leaves of the argerarger (Callicarpa $s p$.), a large tree with inedible fruit, and bok, a large shrub. When a woman's body is saturated with the $\mathrm{j}$ ice from the leaves, she is believed to be proof against fecundity, and can indulge in sexual intereourse without fear of becoming pregnant. Probably the toxic substances introduced cause abortion at very early stages of pregnancy, or even inhibit pregnancy at the rery outset. Abortion is sometimes procured by purely mechanical means-e.g. blows, massage, hot injeetions, ${ }^{3}$ earrying heavy loads, ${ }^{\prime}$ \&e. But although mechanical and psyehologieal influences, both voluntary and involuntary, play a part in bringing about abortion, they are probably less frequently coneerned in the process than pathological conditions existing either -in the embryo or in the maternal organism.

Among the eauses of abortion in women Kelly ${ }^{5}$ mentions hæmorrhage of the chorion, imperfect vascularisation of the amnion, hydatiform degeneration of the chorion, cireulatory disturbances caused by heart lesions in the mother, various infections of the mother (notably syphilis), psyehic disturbanees, and exeessive cohabitation, acute poisoning (by alcohol, phosphorus, lead, \&c.), and various diseases of the generative organs, sueh as endometritis, decidual inflammation, polypoid thickening, \&c. It is stated that the excitability of the nerve eentres which eontrol the movements of the uterus and the tendency to uterine congestion are greatest at the epoehs which would have been menstrual periods if pregnancy had not oceurred, and consequently that abortion is especially common at these

1 Bloch, loc cit.

3 Bloch, loc. cit.

2 Haddon, loc, cit.

${ }^{4}$ Haddon, loc. cit.

5 Kelly, loc. cit. Sec also Oliver, "The Determinants of Abortion," Brit. Med. Jour., November 30, 1907. 
dates. $^{1}$ The membranes are usually cast off with the fœtus, but the decidua is said in some cases to remain, and to regenerate a normal uterine mucosa. The expulsion of the fœtus and membranes is accompanied by "pains" comparable to those occurring in normal parturition, the two processes having a general similarity, which is closer if abortion takes place in the later part of pregnancy. There is generally also a considerable loss of blood. After the expulsion the hemorrhage and pains cease, and a process of puerperal involution sets in.

In horses abortion is probably most frequent during the period from the sixth to the ninth week of pregnancy. This is explained by Ewart ${ }^{2}$ as being due to the fact that about this time the embryo loses its primitive attachment to the uterus before acquiring its more permanent connection by means of the allantoic villi, which are only beginning to be numerous. The yolk sac, which in the marsupial is the organ of foetal nourishment throughout the whole of pregnancy, in the case of the horse ceases to provide a sufficient supply at about the end of the seventh week; but the horse embryo, instead of being born at this period, like the marsupial, acquires new and more efficient structures in the allantoic villi. "At the end of the third week of gestation, when the reproductive system passes through one of its periods of general excitement, about onefourth of the embryonic sac probably adheres to the uterus; but at the end of the sixth week, when another wave of disturbance arrives, all the grappling structures are at one pole. Hence there is probably more chance of the embryo 'slipping' at the end of the sixth than at the end of the third week. About the end of the seventh week the supply of nourishment by means of the yolk sac is coming to an end, and there is perhaps still about this time an hereditary tendency for the embryo to escape. Unless the new and more permanent nutritive apparatus is provided, unless a countless number of villi rapidly sprout out from the allantois, the embryo will die from starvation during the eighth week, and in a few days be discharged. It may therefore be taken for granted that there is a certain amount

1 Galabin, Manual of Midwifery, 6th Edition, London, 1904.

2 Ewart, A Critical Period in the Development of the Horse, London, 1897. 
of danger at the end of the third and sixth weeks, but that the most critical period is about the end of the seventh or beginning of the eighth week; for unless the villi appear in time, and succeed in coming into sufficiently intimate relation with the uterine vessels, the developmental process is of necessity for ever arrested." 1

Ewart discusses briefly the external conditions and circumstances which are likely to lead to abortion, and provides some useful practical hints as to the best way to treat mares in order to prevent them from "slipping foal." He remarks that the horse is a peculiarly high-strung, nervous animal, and is easily affected by sudden changes in its surroundings, especially during the breeding season. Such changes are, no doubt, often responsible for setting up disturbances in the nervous system, and so inducing abortion, more particularly at that period of development at which the fixation of the embryo to the uterine wall is relatively insecure.

Abortion in cows is said to be commonest during the first month of pregnancy. According to Wallace $^{2}$ the usual causes are the following: (1) Eating ergotised grass; (2) injury due to horning by other cattle, hunting by dogs, or shaking and bruising in travelling, \&c.; (3) physical strain, resulting from walking over too soft land, \&c.; (4) very cold or foul water, or frozen turnips, \&c.; (5) superpurgation, whether occurring naturally or as a consequence of dosing by physic; (6) contagion from other cows affected by epidemic abortion. This is said to be the commonest and at the same time the most dangerous cause of abortion.

Bang ${ }^{3}$ has shown that contagious, epidemic, or epizo ̈̈tic abortion in cattle is due to a specific bacillus which he has been able to isolate and cultivate in oxygenated glycerine-bouillon or serum-gelatine agar. The germ causes the formation of a brownish-yellow exudate between the chorion and the mucous

1 Ewart, loc. cit.

3 Wallace (R.), loc. cit. Wallace states that after abortion in cattle the placenta adheres to the cotyledons, and should be removed artificially; otherwise it is liable to undergo a process of rotting, sometimes resulting in septicæmia and death.

" Bang (B.), "Infectious Abortion in Cattle," Nat. Vet. Soc., Liverpool, July 25,1906 . 
membrane of the uterus, and more particularly around the cotyledons, but the affected area may be considerably greater. ${ }^{1}$ The chief mode of entrance is the vagina (especially during copulation, when the contagion is introduced by the bull's penis ${ }^{2}$ ), but Bang has shown experimentally that the germs may be carried to the seat of the disease by the blood after intravascular injection, and furthermore, that they can be absorbed through the alimentary canal. Thus, after administering some bouillon culture to a cow, the placenta was found covered with typical exudate rich in bacilli. There is some experimental evidence that cows may acquire immunity to the disease, at least temporarily. Investigations show also that mares, sheep, goats, dogs, and guinea-pigs may be infected with the bacillus experimentally, but in all probability the disease is ordinarily confined to cattle. The abortion microbe is stated to be oval or rod-shaped, between one and two microns in length, and non-motile. It sometimes occurs singly, but in many places the bacilli are collected in dense groups or colonies. The microbe associated with atortion outbreaks in sheep is said to be a vibrio and therefore totally different. It has been isolated and used experimentally to infect pregnant ewes. Pregnant cows, however, cannot be infected by it.

The external use of antiseptics is said to prevent the spread of contagious abortion by means of disinfection, and this is the treatment prescribed by the Board of Agriculture. ${ }^{3}$

The causes of abortion in sheep are dealt with at some length by Heape in the paper already referred to. ${ }^{4}$ Statistical evidence shows that an excessive proportion of shearling ewes in a flock is associated with a relatively high percentage of abortion, and that ewes of particular breeds in certain districts, or run on certain subsoils, are more liable to abortion than the average for the breed in question. Thus Lincoln sheep run on the Wolds suffer much more from abortion than sheep of the same breed in other districts. The Southdown and Hampshire Down

1 Report of the Departmental Committee appointed by the Board of Agriculture and Fisheries to inquire into Epizoötic Abortion, London, 1909.

3 According to the Report referred to above, nothing more than a quite subsidiary role in the spread of the disease can now be referred to the bull.

3 Board of Agriculture Leaflet, No. 108, 1904.

"Heape, "Abortion, Barrenness, and Fertility in Sheep," Jour. Royal Agric. Soc., vol. x., 1899. 


\section{8 'THF PHYSIOLOGY OF' REPRODUC'TION}

statistics show that a heavy rainfall during gestation is associated with a high degree of abortion. Over-exertion (as from jumping ditches), fright (from strange dogs or shooting), are usually credited with producing abortion in sheep, but Heape remarks that such causes are not truly responsible unless the ewes are in a susceptible condition. The main conclusion reached is that the food and the resulting condition of the ewes are the principal factors which influence the percentage of abortion. Unsuitable food, causing indigestion or other ailments, and poor food, resulting in bad nutrition, are held to be mainly responsible. Heape states, however, that it is not the kind of food so much as the condition of the food which is most liable to be at fault, while the schedules show clearly that a poor condition of ewes during gestation is associated with a relatively high percentage of abortion. "Sheep-stained" pasture (i.e. pasture grown with the aid of sheep manure or on which sheep have been run for a considerable time previously) is credited with causing abortion, and there is strong evidence in support of this view in cases where rank or over-stimulated growth results. ${ }^{1}$

As already noted, the Dorset Horn and Lincoln breeds of sheep suffer most from abortion. ${ }^{2}$ In the case of the former this may result partly from inbreeding, since Dorset Horn ewes served by Hampshire Down rams are less liable to "slip lamb" than those served by rams of their own breed. It is possible, therefore, that the abortion may be due to a want of vitality on the part of the developing embryo, the cross-bred young possessing a superior vigour. Abortion among Lincoln sheep has been known to reach thirty, forty, or even fifty per cent., and so to assume an epidemic form. Wortley Axe, ${ }^{3}$ who reported on an outbreak of abortion among the Lincolnshire flocks in the season of 1882-83, was disposed to attribute it to debility, arising largely from foot-rot and exposure to cold winds and

1 Abortion in sheep may result from more exceptional causes. Thus it is recorded that a large proportion of a certain flock of Cheviot ewes slipped lamb after a gale which blew down a number of Scotch fir-trees, the abortion resulting, in the owner's opinion, from the animals eating the branches and bark. See Marshall, loc. cit.

${ }^{2}$ Heape, loc. cit.

${ }^{3}$ Wortley Axe, "Outbreak of Abortion and Premature Birth in the Ewe Flocks of Lincolnshire during the Winter and Spring of 1882-83," Jour. Royal Agric. Soc., vol. xxi., 1885. 
heavy continuous rains, as well as to the feeding of the cwes on unripc watery roots and unwholesome, filth-laden shells. Hcape has suggested that abortion on the Wolds ariscs partly from the practice of unduly crowding the ewes on turnip fields. As already mentioned, a bacillus has been isolated from outbreaks of abortion in ewes, and has been used to infect other ewes for experimental purposes in the laboratory.

\section{The Increase of Fertility, a Problem of Practical BREEDing}

Heape ${ }^{1}$ has shown from statistical evidence that the amount of money invested in live stock in this country cannot be computed at very much less than $£ 450,000,000$, and this sum does not include the enormous capital spent on buildings, land, vehicles, and various accessories. The annual cxport of live stock from Great Britain in recent years has been tending steadily to increase, until it has reached a total value of $£ 1,750,000$. It is clear, therefore, that in this country the breeding industry occupies a position of no inconsiderable importance, and that the scientific study of the problems of breeding possesses a great national interest. Foremost among these problems is that which concerns itsclf with the factors that control fertility.

Despite its comparative prosperity, it is evident that the breeding industry suffers annually from no inappreciable loss. Allusion has been made to the losses sustained by brecders owing to the occurrence of abortion in domestic animals. Sterility, whether persistent or temporary, is responsible for a greater reduction of profit. The prevalent barrenness among the better class of Shire mares has been already referred to, while incapacity to brced is perhaps still commoner among thoroughbreds. As already mentioned, the Royal Commission on Horse-Breeding found that no less than forty per ccnt. of the mares chosen for breeding in any given year failed to producc offspring. ${ }^{2}$ Moreover, there is evidence that in certain districts

1 Heape, The Breeding Industry, Cambridge, 1906.

2 Owing probably to a combination of circumstances, the number of foals dropped in this country in recent years has shown a tendency to decrease. This fact has called forth serious comment in many quarters, and attention 
of India this percentage is still higher. ${ }^{1}$ Among cattle the average loss from sterility and abortion (together with mortality of calves) is estimated by Heape ${ }^{2}$ to be at least fifteen per cent., while it is shown in the report (already referred to) issued by the Royal Agricultural Society on fertility in English sheep for the year 1899 , that the proportion of sterile ewes was $4 \cdot 71$ per cent. out of a total number of 96,520 , and this percentage does not include the ewes which aborted (see p. 612). In view of these facts, it is obvious, as Heape has pointed out, that any means by which sterility in domestic animals can be checked and their capacity to bear young increased, must be possessed of great commercial value.

\section{The Birth-Rate in MaN}

It is now more than a century ago since Malthus ${ }^{3}$ advanced his famous proposition that whereas population tends to increase in geometrical ratio, the means of subsistence increase only in arithmetical proportion. As a consequence of the acceptance of that doctrine, the political economists of the early Victorian period tended to see in over-population the most fruitful source of pauperism, disease, and crime, and the cause of increasing congestion in the future. That Malthus' predictions have not been verified is a matter of common knowledge, and the problem before the modern economist is not how to place a check on population generally, but rather how to secure that future generations shall be sufficiently recruited from that section of the population which is industrially capable.

There is abundant evidence that in most civilised countries at the present time the birth-rate (that is, the proportion of the children born to the population) is tending to decrease, while in some countries the actual population is diminishing. This decline in the birth-rate has been made the subject of

has been drawn to the urgent need for practical proposals on the subject with a view to maintaining the horse supply of the country and arresting a state of things which, if it continues, must be a source of danger.

1 Ewart, loc. cit.

${ }^{2}$ Heape, loc. cit.

${ }^{3}$ Malthus, An Essay on the Principles of Population, 7th edition, London, 1872. 
statistical inquiries by Newsholme and Stevenson, ${ }^{1}$ and Udny Yule. ${ }^{2}$ These writers have shown that the observed fall is not simply a consequence of changes in the ages of the people, or in the proportion of married to single women, for allowing for such alterations as have occurred, the number of births per 100,000 of the population in England and Wales, for example, has dropped from 3236 in 1861 to 2729 in 1901.

The decline in the birth-rate (so far as England and Wales are concerned) is not appreciably greater in the towns than in the rural districts. It is, however, especially marked in places inhabited by the servant-keeping class. ${ }^{3}$ It appears to be greatest in those sections of the population which give evidence of the exercise of thrift and foresight, for Heron ${ }^{4}$ has shown that the more cultured, prosperous, and healthy classes are producing fewer children than those belonging to a lower social status.

There is no evidence that this decline in the birtll-rate is due to an increase of sterility, for congenital unavoidable sterility in either sex is rare. ${ }^{5}$ The inference is, therefore, that the decline is principally, if not entirely, the result of deliberate volition in the regulation of the married state. Direct evidence that this inference is correct is provided by the Fabian Society, whose report ${ }^{6}$ indicates that the practice of limitation prevails with at least one-half, if not three-fourths, of all the married people of Great Britain. The statistics collected from other countries point in a similar direction.? This is noticeably the case for New South Wales, Victoria, and New Zealand among the British Colonies, and for France among Continental nations. Indications pointing unmistakably in the same direction are to be observed in the United States, Germany (especially Saxony, and certain of the big cities) as well as in Belgiun and Italy.

1 Newsholme and Stevenson, "The Decline of Human Fertility in the United Kingdom," \&c., Jour. Royal Statis. Soc., 1906.

${ }^{2}$ Yule, "On the Changes in the Marriage and Birth-Rates," \&c., Jour. Roy. Statis. Soc, 1906.

3 Sidney Webb, "The Decline in the Birth-Rate," Fabian Socicty Tract, London, 1907.

"Heron, "On the Relation of Fertility in Man to Social Status," \&c., Drapers' Company Memoir, London, 1906.

5 Kelly, loc. cit.

Sidney Webb, loc. cit.

7 Newsholme and Stevenson, loc. cit. 
The German rural population are apparently still unaffected, while the British and Irish Catholics are almost so, since any regulation of the married state is forbidden by their religion, but in.other Catholic countries this prohibition does not appear to be so strongly insisted on, and is often altogether ignored.

To the political economist of sixty years ago this decline in the production of children would have been regarded as the fulfilment of an aspiration, but the modern economist takes a different view. He believes that a mere limitation of numbers cannot be a factor in the improvement of social conditions, and the student of Eugenics never tires of urging that the real danger before society is not over-multiplication, but multiplication of the unfit. As Sidney Webb has said: "Modern civilisation is faced by two awkward facts; the production of children is rapidly declining, and this decline is not uniform, but characteristic of the more prudent, foreseeing, and restrained members of the community. . . The question is whether we shall be able to turn round with sufficient sharpness and in time. For we have unconsciously based so much of our social policy-so many of our habits, traditions, prejudices, and beliefs-on the assumption that the growth of population is always to be reckoned with, and even feared, that a genuine realisation of the contrary position will involve great changes. There are thousands of men thinking themselves educated citizens to-day to whose whole system of social and economic beliefs the discovery will be as subversive as was that announced by Copernicus. We may at last understand what the modern economist means when he tells us that the most valuable of the year's crops, as it is the most costly, is not the wheat harvest or the lambing, but the year's quota of adolescent young men and women enlisted in the productive service of the community; and that the due proportion and best possible care of this particular product is of far greater consequence to the nation, than any other of its occupations." 1

${ }^{1}$ Sidney Webb, loc. cit. Cf. also Whetham, The Family and the Nation, London, 1909. 


\section{CHAP'TER XV}

\section{THE FACTORS WHICH DETERMINE SEX}

"What was a question once is a question still."-BAcos.

A wORK upon the Physiology of Reproduction would be incomplete without some reference to the problem of sex-determination, and some account of the more recent attempts which have been made towards its solution. A résumé of some of the more important papers and memoirs is given by Morgan in his work on Experimental Zoology, ${ }^{1}$ and the reader is referred to this volume for further references and fuller information in regard to certain of the points discussed. It is hoped, however, that the present summary may prove useful if only as a supplement to Morgan's discussion, since certain important papers dealing with sex-determination and containing an account of experimental investigations have been published since the appearance of Morgan's volume, and these papers I have endeavoured to summarise here. Moreover, some of the more recent observations, and more particularly those relating to "parasitic castration," have necessitated a further revision of the conclusions previously arrived at.

Reproduction in organisms may occur by simple fission or budding, in which case it is said to be asexual, or it may involve the union of two conjugating cells, which in Metazoa and Metaphyta are specially differentiated for the purpose, and are known as ova and spermatozoa. In some animals these two types of cell are produced by the same individual, which is then said to be hermaphrodite or monøecious, but such a condition is rare or absent altogether among the highest forms of life. In the vast majority of animals there are two sexes-that is to say, two kinds of sexual individuals, the male and the female, whose

1 Morgan, Experimental Zoology, New York, 1907. See also Gerldes and Thomson, The Evolution of Sex, Revised Edition, Londor, 1904, and Thomson, Heredity, London, 1908. 


\section{THE PHYSIOLOGY OF REPRODUCIION}

respective functions are to produce spermatozoa and ova. This condition is described as diœecious. Again, in a relatively small number of animals, of which the bee is a familiar example, there are three kinds of individuals, perfect females, imperfect females, and males. In a few insects there are even more than three kinds. Lastly, in certain of the lower animals the females can reproduce ova which are capable of developing into adult individuals without conjugating with spermatozoa. This method of reproduction is described as parthenogenetic (see p. 216).

Among diœcious animals the two sexual individuals are generally produced in approximately equal numbers. Thus, in Man the number of male births is only slightly in excess of the number of female births, the proportion varying very slightly in different countries, ${ }^{1}$ while in those races in which the numerical proportion of the two sexes among the adult population is very unequal, inequality is due to a higher death-rate of children belonging to one sex. Thus among the Todas the pronounced preponderance of males over females results from the practice of female infanticide. ${ }^{2}$

Theories of sex determination may be conveniently arranged under three headings :-(1) Those in which it is assumed that the sexual condition of the individual is determined subsequently to fertilisation and during embryonic or larval life; (2) those which assume that sex is established either at the moment of fertilisation or prior to fertilisation; and (3) those which limit sex-determination to no particular period, or which definitely assert that sex may be established at different periods of development in different animals.

(1) Theories which assume that Sex-Determination takes PLACE SUBSEquentLy to Fertilisation

In tadpoles sex is apparently indeterminate until a relatively late stage of development, but it is said to be established at the time of metamorphosis. Born, ${ }^{3}$ and subsequently

1 Bodio, "Movimento della Populazione," Confronti Internazionali, 1895.

2 Punnett, "On the Proportion of the Sexes among the Todas," Proc. Camb. Phil. Soc., vol. xii., 1904.

3 Born, "Experimentelle Untersuchungen ueber die Entstehung der Geschlechtsunterschiede," Breslauer ̈̈rztliche Zeit., 1881. 
Yung ${ }^{1}$ and eertain other investigators, have adduced evidence in support of the view that the sex is determined by the quantity and quality of the food supply. Thus they claimed that they eould produce an excess of females by feeding the tadpoles upon a meat or fish diet. The conclusions of these authors, however, are hardly borne out by more recent researches, for Cuénot's experiments, ${ }^{2}$ condueted on similar lines to those of Born and Yung, show a preponderance of males among tadpoles which were fed upon animal food, and an approximate numerical equality among those which reeeived an exelusively vegetable diet. Moreover, the method adopted by Born for ascertaining the sex of the individual tadpoles during the period of metamorphosis seems to have been unsatisfaetory, since it was based on the assumption that the ovary is always larger than the testiele, whereas this is not invariably the ease. It is stated also that frogs' eggs from certain loealities yield a higher percentage of females than those from other localities, and eonsequently that a disproportion of the sexes may exist under normal conditions, but this faet in itself does not show that sex is not determined by nutritive or other environmental influences, but may point to a direetly opposite conelusion. But, as Morgan points out, if the natural disproportion between the two sexes is great, errors may easily creep into the experimental results. ${ }^{3}$ Lastly, King's observations relating to sex-determination in Amphibians provide no evidence that either food or temperature are faetors in this process. ${ }^{4}$

The experiments of Treat $^{5}$ and other observers who attempted to show that the sex of eaterpillars could be determined artificially by regulating the supply of food may be disregarded, since it has since been shown that the sex in those animals is already established at the time of hatehing, while it is

1 Yung, "De l'Influence de la Nature des Aliments sur la Sexualité," $C . R$. de l'Acad.des Sciences., vol. xciii., 1881.

2 Cuénot, "Sur la Détermination du Sexe chez les Animaux," Bull. Sci. de France et Belg., vol. xxxii., 1899.

${ }^{3}$ Morgan, loc, cit.

" King, "Food as a Factor in the Determination of Sex in Amphibians," Biol. Bull., vol. xvi., 1909. "Temperature as a Factor," \&c., Biol. Bull., vol, xviii., 1910.

5 'Treat, "Controlling Sex in Butterflies," American Naturalist, vol. vii., 1873. 


\section{THE PHYSIOLOGY OF REPRODUC'ION}

improbable in the cases described that it could have been reversed after having been differentiated. Furthermore, experiments by Briggs ${ }^{1}$ and other investigators have failed to support the hypothesis that the proportion of the sexes can be altered by modifying the diet, while Kellogg ${ }^{2}$ has shown that in the case of the silkworm moth, sex is definitely determined as early as immediately after the first larval moulting, this conclusion being based on an examination of the rudimentary reproductive glands.

According to Cuénot $^{3}$ the essential organs of reproduction in the maggots of flies are not differentiated into ovaries or testicles until a late period of larval development. There was a possibility, therefore, that in these animals the sex could be modified by the conditions of nutriment or other external factors. Cuénot found, however, that the proportion of the sexes was not materially affected by the supply of nourishment, although the maggots were fed upon different kinds of food, some being given brain, suet, and a little meat, some a large supply of putrefying flesh, while others were relatively starved.

Among bees and other hymenopterous insects the nutriment appears to be the main factor determining the difference between the two kinds of females (workers and queens). A worker larva can be made to develop into a queen by supplying "royal food," that is, food which is given to young queens. In the worker the female generative organs never fully develop, but royal diet stimulates these organs to grow so that the larvæ become queens. A partially developed worker may be made partially fertile by supplying it with some of the jelly obtained from a royal cell. The following table shows the relative composition of the solid food given to workers and queens : ${ }^{4}--$

\begin{tabular}{|c|c|c|c|}
\hline \multicolumn{2}{|c|}{ Solid Food. } & Workers. & Queens. \\
\hline Nitrogenous & . & $51 \cdot 21$ & $45 \cdot 14$ \\
\hline Fatty & . & $6 \cdot 84$ & 13.55 \\
\hline Glucose . & . & $27 \cdot 65$ & $20 \cdot 39$ \\
\hline
\end{tabular}

This table shows that the quantity of fatty material supplied

1 Briggs, "Notes on the Influence of Food in Determining the Sexes of Insects," Trans. Entom. Soc., London, vol. i., 1871.

${ }^{2}$ Kellogg, "Notes on Insect Bionomics," Jour. of Exper. Zool., vol. i., 1904.

${ }^{3}$ Cuénot, loc. cit.

"Geddes and Thomson, loc. cit. 
to the developing queens is very nearly double that given to the workers.

There is no evidence that drone larvæ can be converted into females by a supply of royal or other food, so that the case of bees can scarcely be regarded as affording a real instance of sex being determined by conditions of nutrition, since workers are true females whose reproductive organs and other sexual characteristics have failed to develop owing to an insufficiency of stimulating food.

The case of white ants or termites is probably comparable, though considerably more complicated, since the different kinds of sexual individuals are more numerous. The young may develop into workers, soldiers, or royal substitutes, and the latter may be further transformed into fully fertile or " royal" individuals, while both sexes (i.e. males and females) are represented in each of these forms. Grassi's observations ${ }^{1}$ point strongly to the conclusion that these different kinds of individuals are developed from similar eggs under different conditions of nutrition which is supplied to the young by the older members of the community; but here again there is no evidence that males can be converted into females or females into males.

Rolph ${ }^{2}$ has described a series of observations on the production of males and females in Nematus ventricosus, a species of wasp. These observations show that the percentage of females in broods of larvæ reared from fertilised ova steadily increased from June to August and then proceeded to diminish. "We may conclude without scruple, that the production of females from fertilised ova increases with the temperature and with the food supply (Assimilationsleistung), and decreases as these diminish." 3 Certain further experiments with unfertilised ova of the same species seem to show that "the more abundant the metabolism (Stofiwechsel) and the nutrition, the greater the tendency to the production of females." In the normal condition males only were produced as a result of

1 Grassi and Sandias, "The Condition and Development of the Society of Termites," Quar. Jour. Micr. Science, vols, xxxix. and xl., 1896-97.

2 Rolph, Biologische Probleme, Leipzig, 1884.

3 Translated by Geddes and Thomson. 
parthenogenetic development, but the superior nutrition is believed to have led to the production of females.

The fact that in certain Crustacea a condition of hermaphroditism can be induced by an external cause acting on a sexually differentiated individual is discussed below in dealing with latent characters.

(2) Theories which assume that Sex-Determination takes PLACE AT THE TIME OF Fertilisation OR PREviously to Fertilisation

Effect of Fertilisation.-While it seems certain that queen and worker bees are developed from fertilised eggs under different conditions of nutrition, the conclusion is now fairly established that drones or male bees arise parthenogenetically from unfertilised eggs. If this view is correct, it clearly follows that in bees the differentiation into female and male individuals is brought about by the occurrence or non-occurrence of fertilisation. This theory of sex-determination in the bee was first formulated by Dzierzon, ${ }^{1}$ and has since been accepted by Weismann ${ }^{2}$ and many other biologists, although some writers, such as Beard, ${ }^{3}$ deny the conclusion that fertilisation is capable of exercising any such influence.

In support of his contention Beard quotes an observation by Weismann and Petrunkewitsch, showing that a drone egg may occasionally undergo fertilisation. He also refers to the results obtained by "bastardising" hives of bees through the introduction of Italian queens into colonies of German workers and drones, or of German queens into Italian swarms. ${ }^{4}$ In such a bastard hive Dzierzon found a drone which appeared to be a cross between a German and an Italian bee, and which consequently afforded evidence of a drone egg having been fertilised. This result led Dzierzon temporarily to doubt the truth of his

1 Dzierzon, "Über die Befruchtung der Königin," Eichstadt BienenZeitung, vol. i., 1845.

2 Weismann, "Ueber die Parthenogenese der Bienen," Anat. Anz., vol. v. 1900.

${ }^{3}$ Beard, "The Determination of Sex in Animal Development," Zool. Jahrb., vol. xvi., 1902.

- Von Siebold, Wahre Parthenogenesis bei Schmetterlingen und Bienen, Leipzig, 1856. 
hypothesis, but he subsequently accepted the interpretation of von Siebold, who suggested that the queen which had given rise to the apparently bastard drone was herself of impure descent, and that in reality the egg had not been fertilised. A further exceptional case has been recorded by Perez, ${ }^{1}$ who found that a considerable number of male bees produced by an Italian queen which had been fertilised by a French drone appeared to be of mixed blood. 'This result, which is admittedly unusual, has been explained by Sanson ${ }^{2}$ as due to " reversion," while it has also been pointed out that the hybrid drones may conceivably have arisen from hybrid workers which sometimes lay eggs, and further that male bees are often very variable in their characters. ${ }^{3}$ Either of these explanations would appear to be possible.

Moreover, the later observations of Petrunkewitsch, ${ }^{4}$ showing that sperm nuclei are not found in drone eggs whereas they are commonly met with in worker eggs, supply an important confirmation of Dzierzon's hypothesis.

Attempts to extend this hypothesis to other hymenopterous insects have not been so satisfactory, though it seems, as a general rule, to hold good for ants. There are instances on record, however, in which worker ants have developed from parthenogenetic ova, and other exceptional cases have been stated to occur. ${ }^{5}$

Among the Tenthredinidæ or sawflies also the unfertilised eggs commonly develop into males, but this is by no means invariable. Thus in some forms fertile parthenogenetic females only have been known to arise for many generations in succession without the appearance of males. ${ }^{6}$

1 Perez, "Ménoire sur la Ponte de l'Abeille reine et la Théorie de Dzierzon," Annales des Sciences Nat., vol. v., 1878.

2 Sanson, "Note sur la Parthénogènése chez les Abeilles," Annales des Sciences Nat., vol. v., 1878.

3 Morgan, loc. cit.

4 Petrunkewitsch, "Die Richtungskörper und ihr Sclicksal im befruchteten und unbefruchteten Bienenei," Zool. Jahrb, vol. xiv., 1901. "Das Schicksal der Richtungskörper im Drohnenei," Zool. Jahrb., vol. xvii., 1902.

5 Wheeler, "The Origin of Female and Worker Ants from the Eggs of Parthenogenetic Workers," Science, vol. xviii., 1903.

"Doncaster, "On the Maturation of the Unfertilised Egg and the Fate of the Polar Bodies in the Tenthredinita," Quar. Jour. Micr. Science, vol. xlix., 1906. 
In the parthenogenetic Rotifer, Hydatina, Maupas ${ }^{1}$ has adduced strong evidence that if the parthenogenetic male eggs are fertilised they are thereby converted into "winter" eggs which give rise solely to females. If this is so (and Maupas's conclusions are now generally accepted), it is a clear instance of fertilisation altering the sex of the individual. It is stated, however, that impregnation has no effect unless it is performed during the first few hours after hatching.

Certain writers have adopted the view that sex in animals generally is regulated by the time at which fertilisation takes place, that is to say, by the condition of the germ cells. Thus, Thury ${ }^{2}$ and subsequently Diising ${ }^{3}$ expressed the opinion that an egg which is fertilised shortly after ovulation usually develops into a female, and that an older egg tends to produce a male. Thury claimed that he could regulate the sexes in cattle by allowing coitus only at the beginning or at the end of the ostrous periods, an early coitus being supposed to result in the birth of a female, and a late coitus in the production of a male, but other investigators have failed to establish Thury's conclusions.

Infuence of Nutrition.-Schenk ${ }^{4}$ also has elaborated a highly speculative theory which supposes sex to be determined by the relative degree of "ripeness" or " unripeness" of the ovum; but the term "unripeness" is here used to imply a condition consequent upon incompleteness of nutrition, while " ripeness" is held to result from a more favourable state of nutrition. "Ripe" ova are supposed to develop into males, and " unripe" ones into females. The presence of sugar in the urine is evidence of an incomplete metabolism, and hence is regarded by Schenk as implying a condition likely to result in the birth of females. By supplying women with a highly nitrogenous diet, which

1 Maupas, “Sur la Multiplication et la Fécondation de l'Hydatina senta," C. R. de l'Acad. des Sci., vol. cxi., 18c0. "Sur la Fécondation de l'Hydatina senta," C. R. de l'Acad. des Sci., vol, cxi., 1890. "Sur la Déterminisme de la Sexualité chez Hydatina senta," $C$. $R$. de l'Acad. des Sci., vol. cxiii., 1891.

'Thury, Ueber das Gesetz der Erzeugung der Geschlechter, Leipzig, 1863.

3 Dïsing, " Die Regulierung des Geschlechtsverhültnisses bei der Vermehrung," \&c., Jenaische Zeitschr., vol. xvii., 1884.

' Schenk, The Determination of Sex, English Translation, London, 1898. 
prevented the elimination of sugar in the urine and made the metabolism more complete, Schenk claimed that he could ripen the ova, and so increase the chances of male offspring.

Influence of Environment.-It has long been known that parthenogenesis is the normal method of reproduction among plant-lice or Aphides during the months of summer, successive generations of individuals arising in this way, but that with the approach of autumı males make their appearance and reproduction then becomes sexual. If, however, the Aphides be kept in an environment of artificial warmth, and at the same time are supplied with abundant food, the succession of parthenogenetic females may be caused to continue for years without the appearance of the sexual form. It is to be noted that the sexual and parthenogenetic females are not identical, and also that the same female may give rise to parthenogenetic and sexual offspring, or to males and females, or to only one sex. Moreover, Stevens has shown that male and female embryos may be produced practically simultaneously by the same individual. It is maintained therefore by this writer that "the changes in sex usually attributed to changes in external conditions are really a change from the parthenogenetic to the sexual mode of reproduction. The life cycle is often very complicated, and in some species of $A$ phides there is evidence that the environment (e.g. the trees on which they live) rather than the temperature is responsible for the development of the sexual forms. ${ }^{1}$

Many of the lower Crustacea undergo a somewhat similar alternation of generations. For example, the water-flea (Daphnia), after reproducing parthenogenetically during the summer time, deposits eggs which give rise to sexual forms at the commencement of autumn, and the female after inpregnation lays the winter eggs from which the new brood arises. This result is generally supposed to be brought about by the conditions of temperature or nutrition; but Weismann, ${ }^{2}$ as a consequence of numerous experiments and observations, has

1 Balbiani, "Le Phylloxera du Chêne et le Phylloxera de la Vigne," \&c., Mém. à l'Acad. des Sci., vol. xxviii., 1884. Sterens, "Studies on the Germ Cells of Aphids," Carnegie Institution Publications, Washington, 1906.

2 Weismann, "Beiträge zur Naturgeschichte den Daplıniden," Zcitsch. f. wiss. Zoologie, vols. xxvii., xxviii., $\mathrm{xxx}$., and $\mathrm{x} \times \mathrm{xiii}$., 1876-79. 
cast doubts upon this view, believing rather that the animal has been so constituted by natural selection that it tends spontaneously to reproduce sexually in the appropriate season, and that it does so to a large degree irrespectively of the actually existing conditions. More recently Issakowitsch ${ }^{1}$ has carried out an investigation upon another daphnid, Simocephalus, from which he has been able to show that differences in temperature may determine the mode of reproduction, but that this result is effected indirectly by the change of temperature altering the conditions of nutrition. Unfavourable conditions tend to the production of sexual forms, and favourable ones to the parthenogenetic method of generation. The same individual female may give rise either to sexual or parthenogenetic offspring, the conditions which exist in the ovary appearing to determine what kind of egg will develop.

In the Rotifer Hydatina senta there are at least two kinds of females, which are distinguished by the kinds of eggs that they lay-(1) thelytokous females, which produce other females parthenogenetically, and (2) arrenotokous females, which produce males parthenogenetically. The second kind of female may also produce fertilised eggs. Furthermore, the thelytokous females may give rise either to arrenotokous females or to more thelytokous females, and the proportion of arrenotokous females so produced is liable to considerable variation. Maupas ${ }^{2}$ has sought to connect this variation with differences in temperature, and Nussbaum ${ }^{3}$ with differences in nutrition, but neither conclusion has been satisfactorily established. The question has been reinvestigated by Punnett, ${ }^{4}$ who has carried out a number of further experiments. In one of these a strain which had hitherto appeared to be purely thelytokous was subjected to considerable fluctuations of temperature. The rate of reproduction was much retarded, but in the subsequent generations which were produced no arrenotokous females could

1 Issakowitsch, "Geschlechtsbestimmende Ursachen bei den Daphiden," Biol. Centralbl., vol. xxv., 1905.

2 Maupas, loc. cit.

${ }^{3}$ Nussbaum, "Die Entstehung des!Geschlechtes bei Hydatina senta," Arch.f. Mikr. Anat., vol. xlix., 1897.

"Punnett, "Sex-determination in Hydatina," Proc. Roy. Soc., B., vol. lxxviii., 1906 . 
be found. Starvation experiments were undertaken, and in these also thelytokous females which had hitherto "bred true" continued to do so. Punnett concludes that neither temperature nor nutrition has any influence in determining the production of arrenotokous females. On the contrary, it is the property of certain females to produce arrenotokous females in a definite ratio, and the property of others to produce none.

Theories which assume that the Gametes are themselves Sexual. -Many biologists have entertained the conception that the gametes are themselves sexual, and a number of facts have been adduced which give very strong support to this idea. Some of these have already been mentioned, but probably the strongest evidence in favour of this generalisation is that relating to the existence of sexually differentiated spermatozoa.

It has been known for a long time that two kinds of sperm exist in the snail Paludina, a hair-like form and a worm-like form, but it is commonly believed that only the former is functional. Dimorphic spermatozoa have also been discovered in various other animals, but the differences between the two kinds vary greatly. ${ }^{1}$

Henking ${ }^{2}$ made the discovery that in the bug, Pyrrhocoris, half of the spermatozoa differ from the other half in possessing an additional chromosome. McClung ${ }^{3}$ was the first to suggest that the difference between the two sorts of spermatozoa in this insect was connected with sex-determination, and that those which contained the accessory chromosome produced males and that those without it produced females. The last assumption has, however, proved to be incorrect, since Wilson ${ }^{4}$ found that

1 A list of species in which dimorphic forms of spermatozoa have been recorded (down to 1902) is given by Beard, loc. cit.

2 Henking, "Untersuchungen ueber die ersten Entwicklungsvorgänge in den Eien der Insekten," Zeitschr. f. wiss. Zool., vol. xlix., 1890, and vol. li., 1891.

${ }^{3}$ McClung, "The Accessory Chromosome Sex Determinant," Biol. Bull., vol. iii., 1902.

4 Wilson, "Studies on Chromosomes," Jour. of Exp. Zool., vols. ii. and iii., 1905-6; vol. vi., 1909. "Note on the Chromosome Groups of Metapodius and Banusa," Biol. Bull., vol. xii., 1907 ; "'The Supernumerary Chromosomes of Hemiptera," Science, vol. xxvi., 1907; see also Stevens, "Studies in Spermatogenesis," Part I., 1905, and Part 1I., 1906, Carnegie Institution 
in this and other forms the female and not the male contains an additional chromosome in its somatic cells. It is almost certain also that the ova have one more chromosome than one half of the sperms have, and the same number as that possessed by the sperms which contain the additional chromosome. Consequently the latter are supposed to produce females and the former males.

For example, in Anasa tristis the somatic cells of the male contain twenty-one chromosomes, whereas those of the female contain twenty-two. Half of the spermatozoa are supposed to contain eleven chromosomes, the other half having only ten. The ova are believed to all resemble one another in containing eleven chromosomes. It is concluded, therefore, that the spermatozoa possessing the smaller number give rise to males, while those with eleven chromosomes produce females. ${ }^{1}$

Payne $^{2}$ has recently shown that in Galgulus oculatus there are two sorts of spermatozoa possessing respectively sixteen and nineteen chromosomes, whereas the eggs are uniform in containing nineteen chromosomes. Furthermore, the females are believed to have three more chromosomes than the males (i.e. thirty-eight as compared with thirty-five). It is evident therefore that the sexual differences of the chromosomes, even in the same order of animals, do not conform to a single numerical rule, but at present it would appear that where there is a difference in the number it is always the female which has more chromosomes than the male.

That two sorts of spermatozoa (one with an additional chromosome) may exist in other animals besides insects has

Publications, Washington. In these papers dimorphic spermatozoa (one kind containing one smaller chromosome or lacking one chromosome) are described for various species of Orthoptera, Coleoptera, Hemiptera and Lepidoptera.

1 Miss Foote and Strobell "A Study of Chromosomes in the Spermatogenesis of Anasa tristis," Amer. Jour. of Anat., vol. vii., 1907), as a result of an investigation with smear preparations instead of sections, find no evidence of a persisting accessory chromosome in Anasa tristis, and believe that the body described as such by Wilson is a plasmosome and not a chromosome.

2 Payne, "On the Sexual Differences in the Chromosome Groups in Galgulus oculatus," Biol. Bull., vol. xiv., 1908. Correns also has shown that in some plants there are two classes of male germ cells, and that these are produced in equal numbers (Die Bestimmung und Vererbung des Geschlechtes nach neuen Versuchen mit höheren Pflanzen, Berlin, 1907). 
been shown by Guyer, ${ }^{1}$ who has investigated the matter for the chicken and guinea-fowl. ${ }^{2}$ (See footnote ${ }^{2}$, p. 657.)

The inanner in which the spermatozoön with the accessory chromosome (or chromosomes) produces a female is still an open question. It is often supposed that the accessories are themselves the carriers of those hereditary characters which distinguish the female sex, but it may be that the result is due simply to the greater amount of chromatin carried into the egg in the process of fertilisation. "The result," as Morgan renıarks, " is similar to that of the bee, in the sense that the fertilised egg contains more chromosomes than the unfertilised, and produces in consequence the female. ${ }^{3}$ In the absence of all knowledge as to how the greater quantity of chromatin produces a female, one is tempted to assume that the result is reached through assimilative changes that take place in the early cells, and there is some evidence in favour of the view that one of the main functions of the chromatin is tocarry on the assimilative processes in the cells."

Morgan has shown further that in Phylloxera, in which all the fertilised ova become females, the "male" spermatozoa are rudimentary. ${ }^{4}$

The theory that there are two kinds of sexually differentiated ova has also been advanced. In support of this contention it has been pointed out that in Hydatina senta, Phylloxera, and Dinophilus apatris, there are two sizes of eggs, and that in each case the large eggs produce females and the small ones males. It is not clear, however, whether the size determines the sex, or the sex controls the size, but Beard says: "As the size of the egg will naturally be attained during the oögenesis, it would seem to follow, that here the destination of the ooggonium must

1 Guyer, "The Spermatogenesis of the Domestic Chicken," Anat. Anz., vol. xxxiv., 1909; "Guinea-fowl," Anat. Anz,, vol. xxxiv., 1909.

2 So also in the Nematode Heterahis and probably also in Ascur is (see Boveri and Gulick, Arch. f. Zellforsch, vol. iv., 1909).

${ }^{3}$ It is said that in the process of spermatogenesis in the drone one of the maturation divisions is suppressed, a fact which suggests that only half the normal number of chromosomes is present in the cells (Meves, Arch.f. Mikr. Anat., vol. lxx., 1907).

4 Morgan, "The Production of two Kinds of Spermatozoa in Phylloxerus," \&c., Proc. Soc. Exp. Biol. and Med., vol. v., 1908; "Sex Determination and Parthenogenesis in Phylloxera and Aphids," Science, vol. xxix., 1909. 
be determined prior to the final phenomena of the reduction and of the ripening, for these latter would not appear to possess any influence on the size of the egg itself." 1 Beard states that the eggs of the skate, Raja batis, are likewise of two kinds. It is also pointed out in support of Beard's view that according to von Ihering ${ }^{2}$ embryos which are found in one chorion (and which are supposed, therefore, to have arisen from one ovum) in the Edentate Praopus hybridus, are invariably of one sex, and that "double monsters" in Man are of the same sex, while Marchal ${ }^{3}$ states that in the chalcid fly (Ageniaspis fuscicollis) in which a chain of embryos takes origin from a single egg, these embryos are all of one sex. (See footnote ${ }^{2}$, p. 657.)

Beard asserts that sex is determined solely in the egg, and that in those animals in which there are two kinds of spermatozoa one kind is always functionless. This theory is clearly opposed by the facts discovered by Wilson regarding the spermatozoa of many insects, and by the case of the bee and other forms in which sex is determined by fertilisation. It must be pointed out, however, that, according to Morgan, in the parthenogenetic Phylloxera, the egg has the power of determining sex by regulating the number of its chromosomes in the same kind of way as has been shown in the case of other insects for the spermatozoön. ${ }^{4}$

The view has also been entertained that there is a relation between the position of the ovary and the sex of the ova. Thus, according to Rumley Dawson, ${ }^{\mathbf{5}}$ the ova produced by the right ovary become males, and those produced by the left become females. This theory is believed to be applicable especially to Man, and is based on clinical evidence and on a supposed alternation of the sexes of the eggs discharged at the ovulation periods. It clearly cannot apply to birds, in which the left ovary only is functional, and King ${ }^{6}$ has shown experimentally that it is

1 Beard, loc. cit.

2 Von Ihering, "Ueber Generations-wechsel bei Säugethieren," Biol. Centralbl., vol. vi., 1886.

3 Marchal, "Recherches sur la Biologie et le Développement des Hymenoptères parasites," Arch. de la Zool. Expér. et Gén., vol. ii., 1904.

- Morgan, Proc. Soc. Exp. Biol. and Med., loc. cit.

s Dawson, The Causation of Sex, London, 1909.

- King, "Studies on Sex Determination in Amphibians," Biol. Bull., vol. xvi., 1909. 
inapplicable to Amphibians. The alternative theory that sex depends on the position of the testis from which the fertilising spermatozoön was derived has been negatived by Copeman ${ }^{1}$ as a result of an experimental investigation upon rats.

Castle's Theory.-Bateson ${ }^{2}$ was the first to suggest that the Mendelian laws are applicable to sex-heredity. This suggestion has been elaborated by Castle ${ }^{3}$ into a theory which is based on the idea that sex is determined during the process of maturation, when the male and female gametes are believed to undergo differentiation. Thus, in the case of the ovum, the male or female element is supposed to be ejected in one of the polar bodies, while a similar process is thought to occur in spermatogenesis, excepting that in the latter case all the products of division become functional gametes. According to this hypothesis the ordinary sexual individual is regarded as comparable to a Mendelian hybrid. It is clear, however, that the ordinary Mendelian interpretation requires modification if it is to be applied to the phenomena of sex, since hermaphrodite individuals do not occur in accordance with the usual formula which assumes a gametic segregation and three kinds of conjugation according to the law of probabilities :-

Spermatozoa . 50 per cent. male +50 per cent. female.

Ova . $\quad 50$ per cent. male +50 per cent. female.

$\left.\begin{array}{l}\text { Result after } \\ \text { conjugation }\end{array}\right\} 25$ per cent. mm. +50 per cent. mf. +25 per cent. ff.

If this result actually happened, lermaphrodite individuals (mf.) would be twice as common as individuals belonging to either sex. Castle assumes, therefore, that male spermatozoa are capable of conjugating with female ova only, and that female spermatozoa can conjugate with male ova only. The actual determination of sex in the zygote is supposed to depend upon whether the male or female character is dominant.

Dominance, according to this theory, in dicecious forms, is

1 Copeman, "Sex Determination," Phys. Soc., May, 1908.

2 Bateson, Report to the Evolution Committee of the Royal Society, I., 1902.

3 Castle, "The Heredity of Sex," Bulletin of the Museum of Comparative Zoology, Harvard, vol. xl., 1903. 
possessed sometimes by the male character and sometimes by the female. No zygotic individual is of either sex purely, for the characters of the recessive sex (whether it be male or female) are latent, as has been shown both anatomically and experimentally. ${ }^{1}$ In parthenogenetic animals, however, the female character always dominates over the male whenever the characters of both sexes are present together. In such species, all the fertilised ova are female, those unfertilised ova which are formed without the segregation of the sex characters are also female, while male individuals only develop from unfertilised ova from which the female character has been eliminated.

"The segregation of sex characters takes place in most parthenogenetic animals, and doubtless in diceious animals also, at the second maturation division (the 'reduction division ') of the egg, and probably at a corresponding stage in spermatogenesis. For (1) eggs which develop without fertilisation and without undergoing a second maturation division contain both the male and female characters, the former recessive, the latter dominant; but (2) in normally parthenogenetic species, eggs which, after undergoing a second maturation division, develop without fertilisation, are always male (except in the gall-wasp, Rhodites). In such species the female character regularly passes into the second polar cell, the male character remaining in the egg. In diœcious animals, on the other hand, either sex character may remain in the egg after maturation."

In Hydatina senta only a single division occurs in the maturation of the male eggs, and this is held to be comparable to the second maturation division of other parthenogenetic forms, and in it a segregation of sex characters is believed to take place. In the case of the female parthenogenetic ovum no maturation division occurs. The parthenogenetic egg of the gall-wasp (Rhodites ros $\alpha$ ) undergoes two maturation divisions, but apparently without segregation taking place in either of them, for no reduction occurs (at least normally), the nucleus of the ovarian egg, the three polar nuclei, and the nuclei of the mature egg being alike in each containing nine chromosomes.

\footnotetext{
1 Evidence that this is so is given below (p. 652 et seq.).
} 
The offspring are almost invariably females. Castle concludes that in those rare instances in which males are produced a reduction of chromosomes probably takes place, the dominant female character being then eliminated.

Experiments by Doncaster and Others.-Important evidence has lately been obtained by Doncaster ${ }^{1}$ as a result of breeding experiments with certain Lepidoptera. He has shown that in the moth Abraxas grossulariata, there is a rare variety, which generally occurs only in the female sex. This variety, which is called A. grossulariata lacticolor, is a Mendelian recessive, so that when crossed with an ordinary grossulariata male, the offspring are all typical, the lacticolor variety disappearing. Experimental crossings yielded the following results :-

(1) Lact. $+\times$ gross. of gave males and females all gross.

(2) Heterozygous ${ }^{2} q \times$ heterozygous of gave gross. of, gross. $\uparrow$, and lact. $\$$.

(3) Lact. $q \times$ heterozygous $\delta$ gave all four possible forms (gross. $\delta$, lact. $\delta$, gross. $q$, and lact. $q$ ), the lacticolor males being the first ever seen.

(4) Heterozygous $q \times$ lact. $\delta$ gave gross. of and lact. $q$.

(5) Lact. $q \times$ lact. $\delta$ gave lact. $\delta$ and lact. $q$.

(6) Wild gross. $q \times$ lact. $\delta$ gave gross. of and lact. $q$.

It is shown, therefore, that males of the lacticolor variety can be produced by mating lacticolor females with heterozygous males (i.e. with males obtained by crossing the two original varieties, and so presumably bearing two sorts of gametes), but that the converse mating (4) results in offspring which are either grossulariata males or lacticolor females. Furthermore, whereas lacticolor females, mated with wild grossulariata

1 Doncaster, "Recent Work on Determination of Sex," Britiah Associa. tion Report, Dublin Meeting, 1908. See also Punnett and Bateson, "The Heredity of Sex," Science, vol. xxvii., 1908.

2 The term heterozygote has been given by Bateson to offspring resulting from the union of dissimilar gametes. Such organisms, according to the Mendelian theory, produce more than one sort of gamete (see p. 194). Homozygotes are formed by the union of similar gametes, and produce gametes of one kind. Thus, homozygotes, as regards sex, are believed to produce gametes bearing one sex character only (either male or female); whereas heterozygotes, as regards sex, are supposed to give rise to both male-bearing and female-bearing gametes. 
males (1) produce offspring which are of both sexes, but all of the grossulariata variety, the converse cross (6) yields grossulariata males and lacticolor females. It is concluded, therefore, that the wild and presumably pure grossulariata females are heterozygous for sex, femaleness being dominant and maleness a homozygous recessive character. All the fenales are believed to produce male-bearing and female-bearing gametes in equal numbers, whereas all the males appear to produce only male-bearing spermatozoa. According to this view, in gametogenesis there is a repulsion between the female determinant and the grossulariata determinant, so that each gamete can be the bearer of one or other of these two characters, but not of both.

The results obtained by Miss Durham in her experiments on cinnamon canaries are explicable on a similar hypothesis. When a cinnamon male was mated with a green female, the female offspring were cinnamon and the males green; but when a cinnamon female was paired with a green male, all the offspring of both sexes were green. ${ }^{\text {' }}$ Where, however, a green cock of the second generation (the $\mathrm{F}_{1}$ generation produced by crossing) was mated with a cinnamon hen, both green and cinnamon birds of both sexes were produced; but when a green cock of the second $\left(F_{1}\right)$ generation was crossed with a green hen the resulting male birds were all green, but the females were of both types. A more complex case of a like kind has been brought to light by Bateson and Punnett in their investigation on the heredity of the black pigmentation of the silky fowl in its crosses with brown Leghorns and other fowls with light shanks. Here two allelomorphic characters, in addition to the two sex determinants, are concerned, but Bateson and Punnett state that the facts point very clearly to some such solution as that indicated by Doncaster's experiments with Abraxas. They suggest further that whereas in Vertebrates it is probable that the female is heterozygous as regards sex (the production of secondary male characters in castrated females supporting this view), the work of Potts and Smith (see p. 308) on parasitic castration in Crustacea points to the converse conclusion that in these animals the male is heterozygous, assuming definite

1 Durham, Report to the Evolution Committee of the Royal Socioty, IV., London, 1908. Cf. p. 637 . 
female characters after the destruction of the testicles, while in the female, castration merely arrests development. ${ }^{1}$

Ziegler's Theory.-Ziegler ${ }^{2}$ has put forward a theory which assumes that the chromosomes which are derived from a grandparental female tend to produce a female, and that those derived from a grandparental male tend to give rise to a male. Ziegler points out that the parental chromosomes as such cannot determine the sex, since these are equal in number. He therefore assumes that the grandparental chromosomes are the directing factor, and consequently that sex is a matter of chance depending on the result of the reduction division during maturation-that is to say, upon which member of a pair of homologous chromosomes goes to one pole of the spindle and which to the other. If the number of chromosomes derived from the male grandparent is greatest, the sex will be male, and if the chromosomes from the female grandparent are most numerous the offspring will be a female. Ziegler's theory has been adversely criticised by Morgan, who writes as follows:-- "On Ziegler's theory of sex it is evident that whenever the reduced number of chromosomes is even; there may occur an exact balance of grandmother and grandfather chromosomes, hence the child can have no sex at all. . . . It seems improbable that the equal balance of the maternal and paternal chromosomes could be counterbalanced by the presence of chromosomes derived from the grandparents, especially since these have also been contained in one or the other parent whose sex, on the theory, should have influenced them to acquire the character of that parent. These and other difficulties make Ziegler's hypothesis very improbable." 3

Heape's Vieus.--Heape ${ }^{4}$ has recently expressed the belief " that while each ovum and spermatozoön in the generative glands contains within itself sex, which is probably determined by the laws of heredity, the proportion of those male and female ova and spermatozoa which are developed and set free

1 For further discussion see Bateson, Mendel's Principles, Cambridge, 1909.

2 Ziegler, Der Vererbungslehre in der Biologie, Jena, 1905.

3 Morgan, loc. cit. See also "Ziegler's Theory of Sex Determination and an Alternative Point of View," Science, vol. xxii., 1905.

4 Heape, "Note on the Proportion of the Sexes in Dogs," Proc. Camb. Phil. Soc., vol. xiv., 1907. 


\section{THE PHYSIOLOGY OF REPRODUC'IION}

from the generative glands may be regulated by selective action, exerted in accordance with the resultant of a variety of extraneous forces. If this be true, the proportion of living male and female ova and spermatozoa which are freed from the generative glands, and the proportion of the sexes of the offspring which result therefrom, will thus be influenced." A similar suggestion had been made by Schultze ${ }^{1}$ and also by Morgan. ${ }^{2}$

Heape is of opinion, however, that just as there is evidence that adult animals are never purely male or female, ${ }^{3}$ so it is probable that the sexual products (i.e. the gametes) are themselves similarly constituted. According to this view, an ovum or a spermatozoön may possess dominant male or female characters as the case may be, and recessive characters of the opposite sex. "In such cases the possibility of infinite gradations of sexual differentiation in an individual would be vastly increased, and from the point of view of heredity, such complex conditions carry with them factors of the highest importance."

Ova and spermatozoa in which the characters of one sex are dominant are referred to as being male and female, and Castle's conclusion is accepted, that an ovum of one sex must always be fertilised by a spermatozoön of the opposite sex, but whether the sex of the adult is determined by the ovum or by the spermatozoön is a question which is left open, as it may admit of a different answer for different species of animals, or even for different individuals. Heape says, however, that even if that be so, the sex of the ovum must be regarded as bearing a regular relation to the sex of the embryo as surely as if it conferred its own sex.

"On this assumption a female parent producing ova of one sex only will give birth to embryos of one sex, unless the male parent possesses no spermatozoa of the opposite sex wherewith to fertilise it, in which case the union will be barren. Düsing ${ }^{4}$ claimed that the statistical results he obtained from a study of

1 See below (p. 652 et seq.).

2 Morgan, loc. cit.

$3 C f$. Castle (see above, p. 638). Evidence on this point, including some of that adduced by Heape, is cited below in dealing with hermaphroditism and the latency of sexual characters.

- Düsing, loc. cit. 
the mating of thoroughbred horses indicated the dominant influence of the male parent on the sex of the offspring. Any sire that usually produces spermatozoa of one sex only can be fertile, as a rule, only with mares which produce ova of the other sex, and to such an extent he determines the proportion of the sexes of the offspring for which he is responsible; but where the sperm of both sexes is uniformly produced, the sire must be fertile with all mares producing ova, and as only one ovum is produced by each mare, the responsibility for the sex of the offspring then lies solely with the female parent."

The opinion is expressed that much of the evidence cited to show the dominating influence of the male parent on the offspring produced may be explained on this view; "while statistically the father might be shown to be responsible, physiologically the mother controls the governing influence."

It is assumed that in normal cases both sexes of ova and spermatozoa are probably produced in the gonads in equal quantities, and that in those females which shed all their ova the proportion of the sexes in the offspring is, in all likelihood, determined by Mendelian laws. But it is pointed out that in many animals-only a small proportion of the ova formed in the ovary ever reach maturity, the remainder undergoing degeneration and ultimately absorption (see p. 156). It is inferred, therefore, that the proportion of the sexes among the ova which survive and are discharged must depend directly upon the causes which lead to the degeneration of some ovarian ova and the continued development of others. On this view it is held that the ova are subject to the same law of natural selection as other organisms, and that in some cases the male ova are best fitted to survive, and in other cases the female ones.

Heape ${ }^{1}$ has shown further that in the ovary of the rabbit two kinds of degeneration prevail, and that in one kind it is the follicle which first begins to undergo atretic changes, and that in the other kind it is the ovum that is earliest affected. The former condition is regarded as evidence that the available supply of nutriment is insufficient for the maintenance of all the ova in the ovary, while the latter is interpreted to mean that

1 Heape, "Ovulation and Degeneration of Ova in the Rabbit," Proc. Roy. Soc., B., vol. Ixxvi., 1905. 


\section{4 'IHE PHYSIOLOGY OF REPRODUCTION}

the ovum, for one reason or another, is unable to assimilate the nutriment provided for it. It is possible, therefore, that nutrition may in this way exercise a selective action as regards sex. In this connection it is interesting to note that, according to Issakowitsch, ${ }^{1}$ the nutritive conditions prevailing in the ovary of the daphnid Simocephalus are determinative as to the kind of egg which will develop (i.e. whether it will be a parthenogenetic or a "winter" egg), and that the two kinds of eggs are stated to arise in different parts of the ovary. Moreover, Heape suggests that the marked difference between the death-rate of men and women during famines, ${ }^{2}$ for example, may be reproduced among male and female ova in the ovary when that organ is subjected to conditions of a homologous kind.

Heape's general conclusions are summarised as follows :-

"(1) That through the medium of nutrition supplied to the ovary, either by the quantity or by the quality of that nutrition, either by its direct effect upon the ovarian ova or by its indirect effect, a variation in the proportion of the sexes of the ova produced, and therefore of the young born, is effected in all animals in which the ripening of the ovarian ova is subject to selective action ;

"(2) That when no selective action occurs in the ovary the proportion of the sexes of ovarian ova produced is governed by laws of heredity."

Having arrived at these conclusions, Heape next adduces evidence that certain external forces may affect the proportion of the sexes in dogs. It is shown that amongst greyhounds conception during the period from August to November is most favourable to the production of males under the conditions of breeding at present practised, and this result is attributed to a selective action on the ova produced at this time. There is evidence also that among dachshunds and Basset hounds the seasons affect the proportions of the males and females born. The bloodhound returns seem to show that an excessive production of males is associated with inbreeding. Further, there is statistical evidence that a higher proportion of males is produced in the larger litters, that the larger dogs produce the

Issakowitsch, loc. cit.

${ }^{2}$ MeIvor, Madras Census Reports, 1883. 
larger litters, and consequently that the larger breeds have a racial tendency to produce an excess of dog pups. Lastly, the schedule returns strongly support the popular belief that there is a tendency to prolonged gestation when the embryo is of the male sex.

In a further paper ${ }^{1}$ Heape discusses the apparent influence of extraneous forces on the proportion of the sexes in two aviaries of canaries, kept under different conditions. One aviary was kept at a regular temperature during the breeding season; it was comparatively well lighted, and the sun had access to it. On the other hand, the birds did not receive specially rich nutrition. The other aviary was kept in a room facing north and east, and the temperature was allowed to vary considerably during the breeding time, but the birds were always fed with a plentiful supply of rich food. In the former of the two cases nesting, hatching, and moulting took place earlier, only about half the percentage of loss was experienced, and from the nests in which all the eggs were hatched, the percentage of males produced was more than three times that which was obtained from the other aviary, in which the environmental conditions were less favourable. The results obtained in each case could not be ascribed to the particular strains of canaries, since an interchange of birds between the aviaries was not followed by any material alteration in the proportion of the sexes in the two environments. It is concluded, therefore, that the ova were subject to a selective action on which depended the proportional differences produced.

"As a rule in nature the climatic forces which stimulate the activity of the generative functions are also associated with a plentiful supply of food; the conditions which excite the one ensure the supply of the other. Among domesticated animals living in the open air, on the other hand, any forcing of the breeding time is brought about by special feeding. In neither case are the results obtained comparable to those we have now before us, where both the quality and the quantity of the food supplied is regulated entirely independently of the other causes

1 Heape, "Note on the Influence of Extraneous Forces upon the Proportion of the Sexes Produced by Canaries." Proc. Camb. Phil. Soc., vol. xiv., 1907. 
which stimulate the activity of the generative system. It is to this peculiar combination I attribute the regularity of the remarkable differences shown in these aviaries."

In a still later paper ${ }^{1}$ Heape shows that there is evidence of the influence of extraneous forces upon the proportion of the sexes produced by the white and coloured peoples of Cuba. Illegitimate unions were found to give rise to a larger proportion of females, and it is concluded that in this class of union there is an exceptionally active metabolism of the mother which favourably affects the development of those ovarian ova which give rise to female offspring.

Heape suggests further that much of the evidence that has been collected in regard to the influence of nutrition and other environmental causes upon the proportions of the sexes, although it may be disregarded from the point of view from which it was put forward (since it is commonly assumed that the conditions directly determine the sex of the embryo), may yet be well worthy of attention from the standpoint adopted by him. Some of this evidence is briefly referred to below.

(3) Theories which Limit Sex-Determination to No particular Period of Development, or which assert that Sex may be established at Different Periods.

Influence of Age of Parent.-Hofacker ${ }^{2}$ and Sadler ${ }^{3}$ arrived independently at the conclusion that the sex of the offspring depends on the relative ages of the parents-that when the father is the oldest more male births occur, and similarly when the mother is the oldest there tends to be a preponderance of females. This hypothesis, which is known as Hofacker and Sadler's Law, has been both confirmed and contradicted, ${ }^{4}$ but the most recent statistical investigation ${ }^{5}$ on the causes con-

${ }^{1}$ Heape, "The Proportion of the Sexes Prorluced by Whites and Coloured Peoples in Cuba," Phil. Trans., B., vol. cc., 1909.

"Hofacker, Ueber die Eigenschafen welche sich bei Menschen und Thieren auf die Nachkommen vererben, Tübingen, 1828.

3 Sadler, The Law of Population, London, 1830.

- Geddes and Thomson, loc. cit.

"Newcomb, "A Statistical Inquiry into the Probability of Causes of the Production of Sex in Human Offspring," Carnegie Institution Publications, 
trolling sex in Man lends no support to it. Moreover, Schultze's experimental investigation ${ }^{1}$ on the sexes produced by mice of different ages has led likewise to a negative result. ${ }^{2}$

Influence of Parental Vigour or Superiority.-Considerable importance has been attached by breeders and others, and notably by Starkweather, ${ }^{3}$ to the comparative vigour or condition of the parents as a factor in sex determination. According to Starkweather, the superior parent tends to produce the opposite sex. This theory has been accepted by Allison, ${ }^{4}$ who believes it to be applicable to thoroughbred horses. It is obvious, however, that in attempting to apply Starkweather's hypothesis much depends on the signification to be attached to the term "superiority," and for this, if for no other reason, the theory is unsatisfactory. Furthermore, Schultze ${ }^{5}$ has shown that long-continued or strained reproduction in female mice has no effect on the proportion of the sexes produced. The results of experiments on the effects of inbreeding were also indefinite or contradictory.

Influence of Nourishment.-Of the various external factors which have been supposed to have direct influence in determiling sex, nourishment seems to have found more favour than any other. In some cases this factor is supposed to act upon the developing embryo or larva (see p. 624), and so to determine its sex, while in other cases it is concluded that sex is established at an earlier period.

Geddes and Thomson have elaborated the idea that favourable nutritive conditions tend towards the production of females, and unfavourable ones towards the development of males, and certain of the evidence referred to above (p. 624) has been cited

Washington, 1904. Newcomb states that the first-born child of any mother is more likely to be a boy in the proportion of about eight to seven.

1 Schultze, "Zur Frage von den geschlechts-bildenden Ursachen," Arch. f. Mikr. Anat., vol. Ixiii., 1903.

2 This theory, and that which follows, slould possibly be included among those which assume that sex is settled at fertilisation ; for if sex is determinerl by the age of the parents, it seems to follow that no event occurring during embryonic life can alter it. This point, however, does not appear to have been raised by the authors of the theory.

3 Starkweather, The Law of Sex, London, 1883.

4 Allison, The British Thoroughbred Horse, Loudon, 1901.

5 Schultze, loc. cit. 
by them in support of this hypothesis. The normal female metabolism is said to be relatively anabolic, while the greater activity of the male is held to indicate a preponderance of katabolic conditions. Consequently the generalisation is reached that abundant or rich nutrition (or any other favourable circumstance) tends to induce an anabolic habit, and so favours the development of females; and conversely, that deficiency of the necessary food supply (or any adverse circumstance) leads to a katabolic condition of life, and so causes the production of males. According to this idea, the organism is at first "sexually indifferent," the sex becoming established at varying periods of development in different animals according to the circumstances. Thomson has recently admitted that some of the evidence which was formerly adduced in support of this view has since been invalidated, and that it seems being proved more and more that sex is fixed in the fertilised ovum or earlier, and consequently that subsequent conditions of nutrition can play no part in determining the relative proportion of males and females. But Thomson is still disposed to lay stress on the connection between sex and metabolism, believing that the determinants for each of the sexual characteristics (both male and female) are present in all ova and in all sperms, and that their liberation or latency depends on a bias towards eggproduction or sperm-production. The so-called contrasted peculiarities of the two sexes are due in certain cases " to internal physiological conditions which give the same primordium two different expressions, much less different than they seem." 1

Statistics of human births have been brought forward in support of the view that the proportion of the sexes varies with the conditions of nutrition. It has been pointed out that in France the proportion of births of boys and girls is 104.5 to 100 for the upper classes (which are presumably best nourished) and 115 to 100 for the lower classes (who are more poorly fed). In the Almanack of Gotha the proportion recorded is 105 boys to 100 girls, while for Russian peasants this proportion is 114 to 100. Among the nobility of Sweden statistics show a proportion of 98 male to 100 female births, but that given for the Swedish clergy is 108.6 boys to 100 girls. $^{2}$ There is therefore some

' Thomson, Heredity, London, 1908.

${ }^{2}$ See Morgan, loc. cit. 
slight evidence that the percentage of female births is a little higher among those classes which are best nourished or subject to more favourable circumstances, but the differences are very small.

Punnett ${ }^{1}$ has examined the statistics collected in the official census of the county of London for the year 1901, with a view to determining the relative proportions of the sexes amongst different classes of society. The following is his summary and conclusion :-

"If the population of London be divided into three portions exhibiting graduated poverty, it is found that the proportion of male to female infants produced [or rather which have survived] is lowest in the poorest portion, highest in the wealthiest portion, and intermediate in the intermediate portion. The proportion of males is highest of all in a number of births taken from Burke's Peerage, where the nutrition may be supposed to be of the best. From this alternative conclusions may be drawn: that either more favourable conditions of nutrition (1) may result in a large proportion of male births [a conclusion which is contrary to that indicated in the returns mentioned above, but which nevertheless appears to be warranted at first sight], or (2) may have no effect on the proportion of the sexes, or (3) may even result in a relative preponderance of female births, but that in the last two cases the effect is masked by other factors which affect unequally the different strata of society. Such factors are shown to exist in a differential infant mortality, a differential birth-rate, and probably also in a differential marriage-age. These factors all tend to diminish the proportion of males in the poorer portions of the population, and consequently render the first of the above alternative conclusions improbable. Whether the second or third of the other possible conclusions is to be accepted must remain doubtful so long as we are not in a position to estimate the quantitative effect of the factors given above. From the necessarily rough estimate which he has been able to form, the writer's opinion is that their combined effect would not be sufficiently great to mask a preponderance of female births due to better nutrition,

1 Punnett, "On Nutrition and Sex-Determination in Man," Proc. Cainb. Phil. Soc, vol. xii., 1903. 
and consequently he is inclined to believe that in man, at any rate, the determination of sex is independent of parental nutrition. In any case its influence can be but small."

Cuénot's experiments ${ }^{1}$ upon rats, in which some were fed mainly on bread and others were fed upon an abundant supply of different kinds of food, yièlded no evidence of a preponderance of one sex among the better-nourished individuals.

Lastly, in Schultze's experiments ${ }^{2}$ on mice, in which one lot was starved and other lots were variously nourished upon different kinds of foods, there is no evidence that sex-determination is regulated by nutrition.

Schultze and Morgan conclude that if nutrition really influences the proportion of the sexes, it is probable that it does so indirectly by eliminating one or the other kind of egg. This suggestion has been further elaborated by Heape, as described above (p. 641).

Neucomb's Statistical Investigation.-Newcomb, ${ }^{3}$ as a result of an investigation into the statistics of multiple births, has come to the conclusion that sex is established at different periods of development in different cases. He shows that there is a tendency among human offspring for twins to be of the same sex, a fact which he regards as supplying a "practically conclusive negation of the theory of completely determined sex in the original germs." His conclusion appears to be that sex is established by "accidental causes," the nature of which is at present unknown, and that in the case of twins the sexdetermining factors act similarly on both children, and so tend towards a uniformity of sex. But he omits to mention the probability that some twin embryos arise from a single ovum, a fact which would account for their sexual identity on the assumption that sex is already determined in the germ cell.

\section{Hekmaphroditism and Sexual Latency}

Organisms which combine within themselves the essential characters of both sexes are said to be hermaphrodite. True hermaphrodites produce both ova and spermatozoa, but there

1 Cuénot, loc. cit.

3 Newcomb, loc. cit.

2 Schultze, loc. cit. 
are all gradations between true and partial hermaphroditism (in which the essential organs of reproduction are not involved), and between the latter and the completely unisexual condition, in which the characters of the other sex are either latent or absent altogether.

Complete hermaphroditism is the normal state in many groups of invertebrate animals (many sponges, cœlenterates, and worms, and some molluses and crustaceans). In some forms the male and female sexual elements do not exist contemporaneously, but are called forth separately by different environmental conditions or are associated with particular phases in the reproductive cycle (see Chapter I.). In such cases the fact that the animal is hermaphrodite is liable to be obscured.

Among vertebrate animals true hermaphroditism is rare, though its casual occurrence has been recorded even in Mammalia, and is said to be comparatively frequent in certain species of Amphibia. ${ }^{1}$

According to Castle ${ }^{2}$ the true hermaphrodite is a sex mosaic, the alternative sexual characters existing side by side without dominance of either, and passing (without segregation) into the gametes. Diœcious individuals are supposed to result ordinarily from a union of gametes in which one sex is dominant and the other recessive, so that no one individual is purely either male or female. The occurrence of partial hermaphroditism may be held to be an expression of an incomplete dominance of the characters of one sex.

Partial hermaphroditism is usually said to occur when only one kind of gonad is developed (either testis or ovary) in conjunction with accessory generative organs characteristic of

1 See Geddes and Thomson, loc. cit. Curtis, "Studies on the Physiology of Reproduction in the Domestic Fowl " (Biol. Bull., vol. xvii., 1909). Pearl and Surface have described a case of an hermaphrodite fowl which had a testis on one side and an ovary on the other. The accessory organs were likewise unilaterally arranged. Externally it was an antero-posterior gynandromorph, having male characters in front but female body characters. Cf. Weber's finch (p. 313), which was a lateral gynandromorph. Such gynandromorphs are not uncommon among some insects (Hymenoptera). See also Shattock and Seligmann's papers quoted on p. 315 . For an exhaustive account of the question of hermaphroditism in Man, with a full discussion of the evidence, see von Neugebaur, Hermaphroditismus beim Menschen, Leipzig, 1908.

2 Castle, loc. cit. 
both sexes. Such cases are by no means uncommon even among the higher animals. The so-called "Free-Martins" among cattle have been held to be examples of incomplete hermaphroditism. According to Berry Hart, however, the FreeMartin is in reality a sterile bull which is co-twin of a normal fertile bull. ${ }^{1}$

Among animals which are usually regarded as purely diœcious there are many instances of vestigial or even of functional sexual organs characteristic of one sex being present normally in individuals of the opposite sex. The mammary glands and teats of the male mammal, and the clitoris of the female are examples of such organs. $\Lambda$ more striking case is that of the pipe fish (Siphostoma florida), in which the male possesses a marsupium which acts functionally as a placenta. ${ }^{2}$

Such cases as these have led Castle, Heape, and others to conclude that all animals and plants are potentially hermaphrodite, inasmuch as they contain the characters of both sexes, although ordinarily the characters of one sex only are developed, while those of the other are either latent or imperfectly developed.

Castle has cited cases from among plants in which the characters of one sex can be induced to appear by the artificial destruction of those of the other. Examples of the same kind of

1 Berry Hart, "I'le Structure of the Reproductive Organs of the FreeMartin, with a Theory of the Significance of the Abnormality," Proc. Roy. Soc. Edin., vol. xxx., 1910. The Free-Martin has also been regarded as a sterile cow born co-twin with a potent bull. In most cases a vagina and rudimentary uterus have been described, but vesicula seminales and other male organs are also stated commonly to occur. Berry Hart bases his explanation of the occurrence of Free-Martins upon his recently elaborated theory of sex. (Mendelian Action on Differentixted Sex, Edinburgh, 1909.) According to this theory, sex is determined by a "sex-gamete" which may be either male or female. There are also male and female "nonsex gametes," which unite with the "sex-gametes" but are non-potent in determining sex. A female sex-gamete uniting with a male non-sex gamete gives rise to a female zygote, and conversely. Moreover, according to Hart, a Free-Martin with a potent bull twin is the result of a division of a male zygote, so that the somatic determinants are equally divided, but the gametic determinants unequally divided, the potent going to the one twin, the potent bull, and the non-potent to the Free-Martin.

${ }^{2}$ Gudger, "The Breeding Habits and the Segmentation of the Egg of the Pipe-Fish, Siphostoma Florida," Proc. U. S. Nat. Mus., vol. xxix., 1905. 
phenomenon are supplied by certain animals. Thus Potts ${ }^{1}$ has shown that in the male Hermit Crab ova make their appearance in the testes, and the secondary sexual characters become modified in the direction of the female as a consequence of the animal being affected by the parasite Peltogaster. Similar changes occur in a number of other animals belonging to widely different groups, but they are especially common in the Crustacea. Smith, who has paid considerable attention to this subject, ${ }^{2}$ explains the phenomenon by assuming that the inales, in order to cope with the drain on the system caused by the parasites, have to increase their vegetative activity, and that they do this by suppressing their male organisations and calling into play the female ones, which they possess in a latent condition. In further support of this view, Orton has shown that in the molluse Crepidula fornisata also the males under certain conditions may change into females, thus showing that they have the potentialities of both sexes. ${ }^{3}$

Further evidence in support of the view that each sex is latent in the other is afforded by the well-known fact that the characters of one sex can be transmitted through the other. For example, Darwin states that the gamecock can transmit his superiority in courage and vigour through his female offspring to his male grandchildren, while with Man it is believed that diseases such as hydrocele, which are necessarily restricted to the male sex, can be handed on through female children to a future generation. ${ }^{4}$ Again, it is well known to cattle-breeders that a bull which is descended from a good milking stock can transmit this guality to his female offspring.

Smith has laid much stress on the relation between sex and metabolism, inasmuch as changes in the latter are capable under certain circumstances of calling forth the cliaracters of the

1 Potts, "The Modification of the Sexual Characters of the Hermit Crab caused by the Parasite Peltogaster," Quar. Jour. Micr. Science, vol. I. 1906. (See p. 308, Chapter IX.)

"Smith (G.), "Sex in the Crustacea," \&c., British Association Report, Leicester Meeting, 1907 ; "Studies in the Experimental Analysis of Sex," Quar. Jour. Micr. Science, vols. liv, and lv., 1910. (See p.658.)

${ }^{3}$ Orton, "On the Occurrence of Protandric Hermaphrorlitism in the Molluse Crepidula fornicata," Proc. Roy. Soc., B., vol. Ixxxi., 1909.

"Darwin, The Varixtion of Animals and Plants, vol. ii., Popular Edition, London, 1905. 
opposite sex. In this connection it is important to note that the removal of the testes in the male is believed in certain instances to lead to the development of the secondary female characters, and that conversely the extirpation of the ovaries in the female is said sometimes to cause the assumption of the male characters (see p. 314). Moreover, Darwin and others have shown that female birds (e.g. poultry, pheasants, ducks) in old agc, when the ovaries are no longer functional, or in cases where these organs are diseased or have been injured by shot, sometimes acquire the secondary sexual characters of the male. So also Wallace ${ }^{1}$ states that aged mares tend to assume the arched neck characteristic of the stallion. Conversely, cases are recorded in which characters and habits ordinarily confined to the female are assumed by the castrated male. Thus Darwin states that capons have been known to incubate eggs and bring up chickens, and that sterile malc hybrids betwcen the pheasant and the fowl may act in a similar manner. Such cases as these are cvidence of the latency of characters bclonging to the recessive sex in individuals of the other sex. Furthermore, in studying the sexual pathology of youth and old age, there are a number of well-ascertained facts that point in a similar direction.

Weininger ${ }^{2}$ has elaborated the idea that just as there may be an "Idioplasm" that is the bearer of the spccific characters and exists in all the cells of a multicellular animal, so also there may be two sexual modes in which this idioplasm can appear, namely an "Arrhenoplasm" or male plasm, and a "Thelyplasm" or female plasm. He maintains further that every metazoön cell (and not merely every reproductive cell) has a sexuality lying somewhere betwcen arrhenoplasm and thelyplasm, but that the actual degree of maleness or femaleness varies in the different groups of cells of which the animal is built up. Moreover, the different parts of the organism are supposed to possess their own sexual determinants, which are believed to be stable from their earliest embryonic foundation. Weininger makes no suggestion as to what it is that determines 1907.

1 Wallace, Farm Live-Stock of Great Britain, 4th Edition, Edinburgh

${ }^{2}$ Weininger, Sex and Character, English Translation, London, 1906. 
the differentiation of the original protoplasm into arrhenoplasm and thelyplasm, but his idea, though somewhat too morphologically conceived, is useful if only because it emphasises the fact that male and female characters coexist (though they are very unequally represented) in most if not in all dicecious individuals - that is to say, that such individuals are rarely, if ever, wholly male or wholly female. "There may be conceived," he tells us, "for every cell all conditions, from complete masculinity through stages of diminishing masculinity to its complete absence and the consequent presence of uniform femininity."

Weininger draws special attention to the gradations in sexual characters which exist among men and women. There are many men, he remarks, with a poor growth of beard and a weak muscular development, who are otherwise typically males; and so also there are women with ill-developed breasts who in other respects are typical females. There exist all transitional forms from the most masculine male to the most effeminate male, and on the other side, from the Sapphist and the virago to the most feminine female; but in Man the characters of one sex are always dominant, though the degree of dominance varies through considerable limits. On this view, the phenomena of so-called sexual inversion and lomosexuality, which are ordinarily regarded as purely pathological, are in reality psychological manifestations of special characters belonging to the recessive sex. ${ }^{1}$

It is usual to regard the sex of an animal as being contributed by the essential reproductive organs, while the effect of removing these organs points to the conclusion that they exercise by means of their internal secretions a very powerful influence over the entire organism and more particularly over those characters the development of which is ordinarily correlated with

1 For further information see Krafft-Ebing, Psychopathix Sexualis, Stuttgart, 1882; Havelock Ellis, Studiog in the Psychology of Sex: Sexual Inversion, Philadelphia, 1901 ; Forel, The Sexual Question, English Translation, London, 1908; and Bloch, The Sexual Life of our Tim", English Translation, London, 1908. For a discussion on the distinctions between men and women, see Manouvrier, "Conclusions générales sur l'Anthropologie des Sexes et Applications sociales," Rev. de l'École d'Anthropologie de Paris, 1909. 
sexual potency. But it has been shown that castration, while tending in certain cases to favour the development of characters belonging to the opposite sex, results frequently in a distinctive sexual type, as the experiments of Sellheim and others have shown. Moreover, in certain forms of life (e.g. insects) the secondary sexual characters are developed independently of the essential organs of reproduction (see p. 307), the sexual characteristics of the different tissues, although clearly correlated to a large extent in most individuals, being independent of one another when once they have been laid down in embryonic life. This fact is demonstrated by Crampton's experiment in grafting the heads of caterpillars from individuals of one sex on to those of the other sex.

It would appear possible, therefore, that in exceptional individuals, whose sex has been assigned to them on account of the presence of testicles or ovaries, the sexual complement is to be found actually on their own side of the sexual line-that is to say, on the side on which they are reckoned, although in reality they may belong to the other. ${ }^{1}$ In the terms of Weininger's hypothesis, such individuals would be regarded as possessing more arrhenoplasm than thelyplasm (or conversely), although the particular kind of plasma that predominates in the soma is unrepresented in the organs of generation.

Lastly, Weininger's theory helps to explain why it is that transplantation of gonads on animals of the opposite sex is usually attended by failure, a fact which has been noted by Ribbert and others, including the present writer. The internal secretions of the ovaries or testicles, on this view, are operative only in an appropriate environment of thelyplasm or arrhenoplasm, or, to speak physiologically, in the existence of a responsive metabolism, and without this their influence on the organism is ineffective, even though they succeed in becoming attached.

In criticism of Weininger's morphological hypothesis, it must be pointed out again that there is no real evidence that any sort of character, whether sexual or otherwise, is at any time definitely located in a special kind of material or plasma (not even in the accessory chromosome, since this probably

${ }^{1}$ Weininger, loc. cit. 
is merely one factor in a complex system of causes), and that the physiological mode of thought requires one to associate the characters of an organism with its particular metabolism and not with any special sort of cell substance. ${ }^{1}$

\section{Genfral Conclusions}

If it be true that all individuals are potentially bisexual (one of the two sexes being recessive or latent excepting in hermaphrodites), and that changed circumstances, leading to a changed metabolism, may, in exceptional cases, even in adult life, cause the development of the recessive characteristics (as in the case of the Crustaceans mentioned above), it would seem extremely probable that the dominance of one set of sexual characters over the other may be determined in some cases at an early stage of development in response to a stimulus which may be either internal or external. The observations which Smith and others have made upon certain Crustaceans point even to the possibility that sex may be reversed after it has once been established.

It seems certain that sex is not determined by the same factors in all cases, neither is it determined at the same period of development. . It may well be that some gametes have an initial tendency to give rise to males and others to give rise to females, and to this extent it is probably legitimate to speak of male and female ova or male and female spermatozoa. ${ }^{2}$ Moreover, the conclusion is probably correct that these are developed (at least generally) in simple Mendelian ratios. But it is also probable that no gamete is either purely male or purely female, and it is possible that in some the two kinds of sexual determinants or tendencies are about equally represented.

1 The presence of a certain kind of cell substance must of course influence the metabolism, but the extent of its influence will depend upon other factors, and may vary with different external conditions.

2 Bateson and Punnett suggest that in some forms of life (e.g. Verte. brates) the ova are the sexually differentiated gametes, and that in other organisms (e.g. Crustaceans) the sexual differentiation occurs among the spermatozoa. Guyer's cytological observations, however (p. 635), seem to show that male Vertebrates may be sexually heterozygous. Moreover, Raltzer's cytological observations seem to show that among sea-urchins there may be two kinds of eggs (Arch. f. Zellforsch., vol. iv., 1909). 
When once, we admit the existence of latent (i.e. recessive) sexual characters in individuals in which the characters of one sex are dominant, and that under certain circumstances those of the latent sex can develop at the expense of the dominant ones, in response to appropriate physiological stimuli, we are compelled to acknowledge also that the sex of the future individual is not always predetermined in the gametes or even in the fertilised ovum, but may be called into being at a later stage of life.

Such an admission is of course opposed to some extent to the modern tendency to believe that sex is fixed irrevocably in the fertilised ovum or in the gametes before fertilisation; but while there is evidence amounting to proof that this is the case in some forms of life, it does not necessarily follow that it is true of all metazoön animals, or even that it is uniformly so of the particular species which have been investigated. On the other hand, many of the facts enumerated above point to the conclusion that the sex of the future organism is determined in different cases by different factors and at different stages of development-either in the unfertilised gamete, or at the moment of fertilisation, or in the early embryo, while the effects of castration indicate that an alteration in the metabolism, even in comparatively late life, may initiate changes in the direction of the opposite sex. ${ }^{1}$

\section{APPENDIX}

Braem ${ }^{2}$ has described an experiment in which he divided in half a mature female of the annelid, Ophryotrocha puerilis. The head portion after some weeks regenerated and produced spermatozoa, but the ova almost disappeared. There was no sign of hermaphroditism at the outset, and Braem regards the case as one of change of sex resulting from altered conditions.

In a recent paper Potts $^{3}$ has adduced evidence that in certain hermaphrodite Nematodes, in Rlabdocoel Turbellarians and in Rhizocepplale the monœcious condition has arisen through the sperms developing in the ovaries in gradually increasing numbers in successive generations.

Smith states that in the male of Inachus affected by Sacculina the assumption of adult female characters is due to the formation of a yolk substance (or female generative substance) similar to that normally elaborated in the ovaries.

${ }^{1}$ Such changes are notoriously more difficult to effect after puberty than before it.

2 Braem, Anat. Anz., vol. xxxiii., 1908.

3 Potts, Quar. Jour. Micr. Science, vol. lv., 1910.

4 Sinith, Quar. Jour. Micr. Science, vol. lv., 1910. 


\section{CHAP'TER XVI}

PHASES IN THE LIFE OF THE INDIVIDUAL-THE DURATION OF LIFE AND THE CAUSE OF DEATH

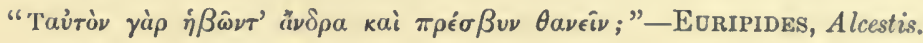

THE physiological life of the metazoön individual begins with the union of sperm and ovum, and the organism thus formed thenceforth proceeds to grow. As has been said by Verworn, ${ }^{1}$ there is an essential similarity between reproduction and growth, both processes consisting of an increase of living substance. "The difference between that which is usually termed growth in the narrow sense and the phenomenon of reproduction consists only in the fact that in the former case the newly-formed living substance remains in constant connection with the original organism and helps to increase its volume; while in the latter case a part of the substance separates itself from the original organism, either, as in most cases, being set entirely free, or, as in the increase of tissue-cells, being separated merely by a partition-wall and remaining in place." Among the more highly organised Protozoa there are various transitional stages between these two conditions.

Growth, like reproduction, involves cell division. As the mass of living substance increases, the cells must multiply, for every cell has assigned to it a limit in size beyond which it cannot pass. Cell division goes on, though with gradually decreasing frequency throughout practically the whole of life; tissue formation continues, but from an early period of development onwards there is a progressive diminution in the power of growth. Increase in the number of cells is, however, specially characteristic of the embryonic period. In the later stages of development growth occurs largely through cell enlargement and the deposition of intercellular substance.

1 Verworn, General Physiology, Lee's Translation, London, 1899. 
Minot has compared the growth of the body to a man building a wall. " "He begins at first with great energy, full of vigour; the wall goes up rapidly; and as the labour continues, fatigue comes into play. Moreover, the wall grows higher, and it takes more effort and time to carry the material up to the top of the wall, and to continue to raise its height, and so, as the wall grows higher and higher, it grows more slowly and ever more slowly, because the obstacles to be overcome have increased with the very height of the wall itself. So it seems with the increase of the organism, and with the increase of our development, the obstacles to our growth increase." According to Minot, the explanation of this phenomenon must be sought in the differentiation of the protoplasm, which goes on growing with an ever-increasing complexity as the cells of the body multiply.

It has just beell mentioned that every cell has assigned to it a definite limit in size beyond which it cannot go. Boveri ${ }^{2}$ has enunciated the general law that the process of cell division is regulated by the proportion of chromatin material to cytoplasm, and that it comes to a standstill when the ratio of the mass of chromosomes to that of the cells in any given tissue or organ reaches a certain definite point. Furthermore, it is stated that the size of the cells in any given tissue after active cell multiplication has ceased, bears a definite relation to the original mass of chromatin contained in the fertilised egg. ${ }^{3}$ Thus it is pointed out that the mesenchyme cells of the embryo developed from the artificially fertilised sea-urchin's egg are only half the size of those of the embryo which has been produced by normal fertilisation, for although the parthenogenetic and normally fertilised eggs are equal in size at the commencement of segmentation, the latter possess initially twice as much nuclear substance as the former. ${ }^{4}$

The fact that cell division ceases when the ratio of the mass

"Minot, "The Problem of Age, Growth, and Death," Popular Science Monthly, vol. Ixxi., 1907 ; reprinted London, 1908.

2 Boveri, Zellen-Studien, Part V., Jena, 1905.

a Robertson, "On the Normal Rate of Growth of an Individual and its Biochemical Significance," Arch.f. Entwick.-Mech., vols, xxv. and xxvi., 1908.

- Driesch, "Ü̉ber das Mesenchym von unharmonisch zusammengesetzten Keimen der Echiniden," Arch.f. Entwick.-Mech., vol. xix., 1905. 
of chromosomes in the nuclei of an egg (or of a tissue or organ) to that of the surrounding protoplasm reaches a certain definite limit, is regarded by Loeb ${ }^{1}$ as evidence that this ratio is determined by the laws of mass action and chemical equilibrium. He says further that if this conclusion is correct the synthesis of nuclein compounds, from their protoplasmic constituents, must be a reversible process.

The fertilisation of an ovum is immediately succeeded by an enormous synthesis of nuclear material. In the cellular division which follows, each new nucleus is of the same size as the parent nucleus. From this fact Loeb ${ }^{2}$ concludes that the nucleus itself, or one of its constituents, acts as a catalyser in the synthesis of nuclein in the fertilised ovum. Robertson, ${ }^{3}$ quoting partly from Loeb, writes as follows :- " If the mass of the original fertilisation-nucleus be $m$, the mass of nuclear material increases during the first segmentation period to $2 m$, during the next to $4 m$, and so on in geometrical progression. The duration of the various periods of segmentation, however, matters very little. Hence in the first unit of time after the beginning of cell division, a mass $m$ of nuclear material is formed, in the second a mass $2 m$, in the third a mass $4 m$, and so on; thus the velocity of the synthesis increases with lapse of time and with the mass of nuclear material already formed. This is a characteristic of that class of reactions known as autocatalytic, in which one of the products of the reaction, or, in this case, one of the constituents of the nucleus, accelerates the reaction. During the process outlined above, an emphatic disproportion between nuclear and protoplasmic material has been established. As the nuclear synthesis becomes slower, however, the disproportion tends to adjust itself until, finally, the growth of the organism consists almost entirely of the growth of protoplasmic material and in the final re-establishment of the equilibrium between cytoplasm and nuclear material."

Robertson has investigated mathematically the quantitative

1 Loeb, The Dynamics of Living Matter, New York, 1906.

2 Loeb, "Weitere Beobachtungen iber den Einfluss der Befruchtung," \&c., Bio. Chem. Zeitsch., vol. ii., 1906. "The Chemical Character of the Process of Fertilisation and its Bearing on the Theory of Life Phenomena," Seventh Internat. Congress, Boston, Univ. of California Publications, vol. iii., 1907.

3 Robertson, loc. cit. 
relations which exist between the amount of growth and the time of growth. He concludes that there are two or more growth cycles representing autocatalytic processes which make up the total growth of an individual. In Man there are three maxima of rate of growth, representing three phases or growth cycles. One of these is intra-uterine, but it is probable that this is not quite complete at birth. The second growth cycle seems to attain its maximum annual increment at about the fifth year, since the increment in weight at that age, as deduced from an investigation on growth in English boys, considerably exceeds the annual increments for the years immediately following. A third maximum in yearly increments occurs in males at about the sixteenth year, that is, at about the time of puberty. In the rat, according to Donaldson, ${ }^{1}$ there are two intra-uterine growth cycles, while there is only a single well-defined extrauterine cycle. Robertson suggests that the first growth cycle in Mammals represents the course of the autocatalytic synthesis of the nuclear substance, that the third cycle represents the period during which cytoplasmic material is built ıp, while the second growth cycle is intermediate, representing a time when both synthetic processes go on contemporaneously.

\section{Growth of the Body Before Birth}

Minot ${ }^{2}$ has recorded the results of weighing embryo rabbits at different stages of development with a view to determining their rate of growth. The results showed that in the period from the ninth to the fifteenth day the young rabbit adds on an average 704 per cent. to its weight daily, and that in the period from the fifteenth to the twentieth day, the average daily addition is only 212 per cent. It may be assumed, therefore, that in younger embryos (before the ninth day) there is an increase of over a thousand per day. Minot estimates that over 98 per cent. of the original power of growth of the rabbit or the chick has been lost at the time of birth or hatching, and that a similar fact is equally true of Man. "We start out at birth certainly with

1 Donaldson, "A Comparison of the White Rat with Man in respect to the Growth of the Entire Body," Boas Anniversary Volume, Anthropological Papers, New York, 1906.

2 Minot, loc. cit. 
less than two per cent. of the original growth power with which we were endowed. Over 98 per cent. of the loss is accomplished before birth-less than two per cent. after birth." The accom-

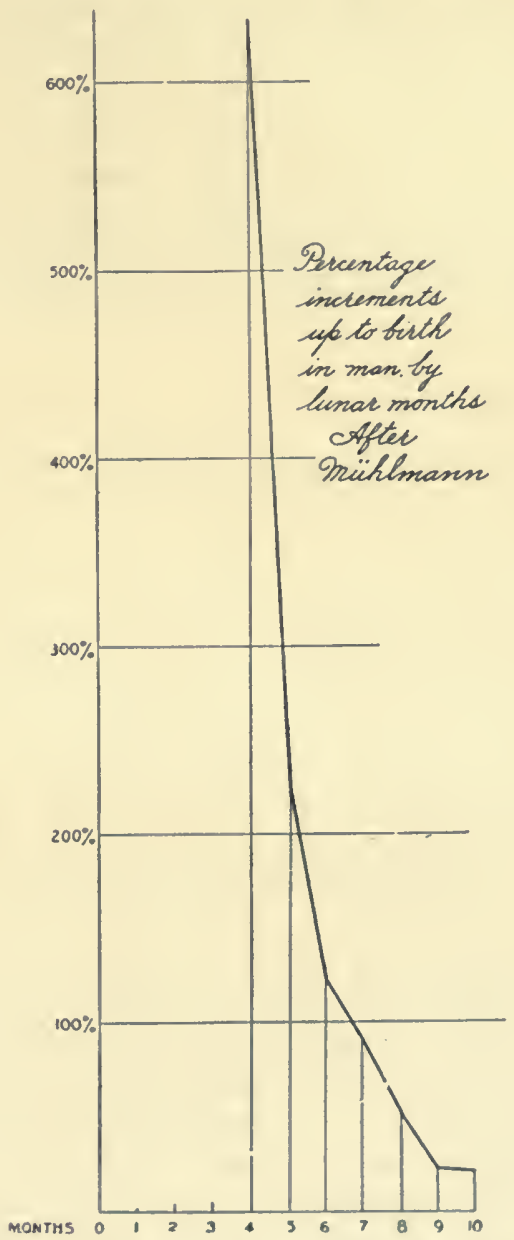

FIG. 141.-(From C. S. Minot's Problem of Age, Grouth, and Death, G. S. Putnam \& Sons, and John Murray.)

panying diagram represents roughly the rate of growth in Man before birth. The time intervals correspond to the ten lunar months of gestation. The rate of increase in the first three 
months is not indicated, since there are no statistical data on which to found any knowledge, but from the third month onwards there are a few records available. The diagram shows that from the third to the fourth month the increase in growth is 600 per cent., after which it quickly drops until, during the last month of pregnancy, it is barely twenty per cent.

\section{Growth of the Body after Birth}

The rate of growth from birth to maturity has been investigated most fully by Minot ${ }^{1}$ in the case of the guinea-pig.

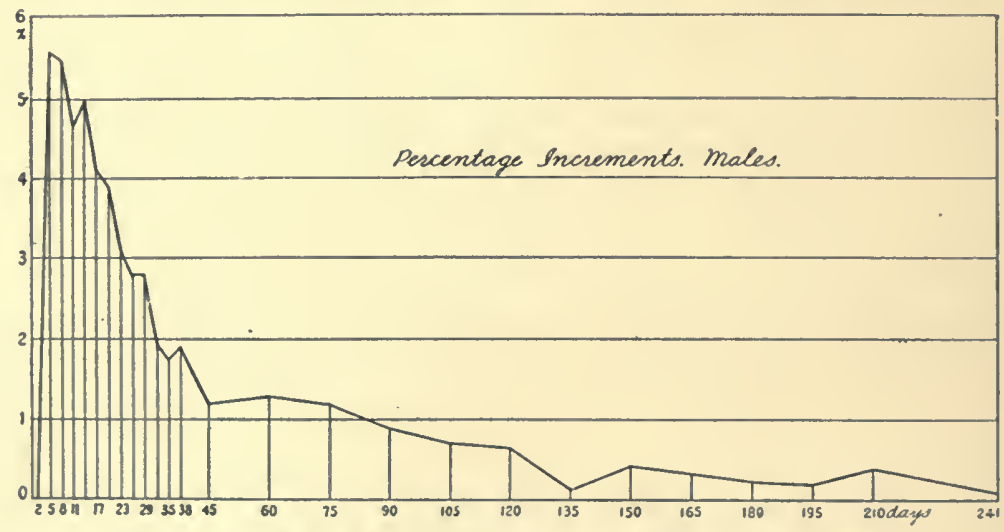

FIG. 142.-(From Minot's Problem of Age, Growth, and Death, G. S. Putnam \& Sons, and John Murray.)

When this animal is born it is far advanced in development, the period of gestation being unusually long. Immediately after birth there is a lessening in the power of growth, a fact which Minot ascribes to the physiological shock from which the organism suffers as a consequence of being born. After two or three days, however, the young are fully recovered, and are capable of adding over five per cent. to their weight in a single day. By the time they are seventeen days old they are only able to add four per cent. to their weight, and by the time they are twenty-four days old, less than two per cent. When they have been born forty-five days, they can add only a little

1 Minot, "Growth and Senescence," Jour. of Phys., vol. xii., 1891. " Age, Growtb, and Death," Popular Science Monthly, vol. 1xxi., 1907. 


\section{PHASES IN THE LIFE OF THE INDIVIDUAL 665}

over one per cent. to their weight; when ninety days old, less than one per cent., and still less as they grow older, until when about a year old they attain their full size. The curves in the accompanying diagrams show the daily percentage increments in weight in male and female guinea-pigs respectively, as ascertained by Minot. It is seen that the curve for the females is very similar to that for the males. Both show an early period of rapid decline in which the rate of growth is quickly diminishing, followed by a period of slight decline in which the curve is still falling, but very much more gradually. (Figs. 142 and 143.)

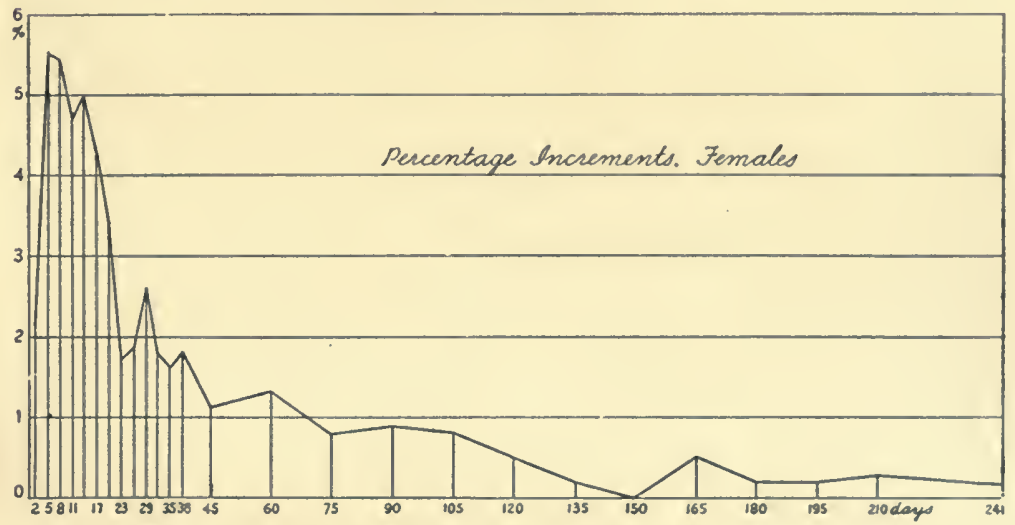

Fig. 143.-(From Minot's Problem of Age, Growth, and Death, G. S. Putnam \& Sons, and John Murray.)

Minot has also investigated the rate of growth in the rabbit and in the chicken. The young rabbit, as is well known, is born in a very immature state of development after a relatively short gestation period. Correlated with this fact, it was found that the male rabbit four days after birth is capable of adding over seventeen per cent. to its weight in a single day. From that time the percentage increment drops very rapidly, so that at an age of twenty-three days the rabbit can only add a little over six per cent. After about the fifty-fifth day the decline in the growth rate, which has hitherto been rapid, becomes more gradual. In the case of the chicken, Minot's results were in a general way similar, but the rate of growth on the first day it could be measured was a nine per cent. addition to the weight, 


\section{6}

THE PHYSIOLOGY OF REPRODUC'IION

while the change from the initial rapid decline to the subsequent slow decline was more gradual than in the other two animals.

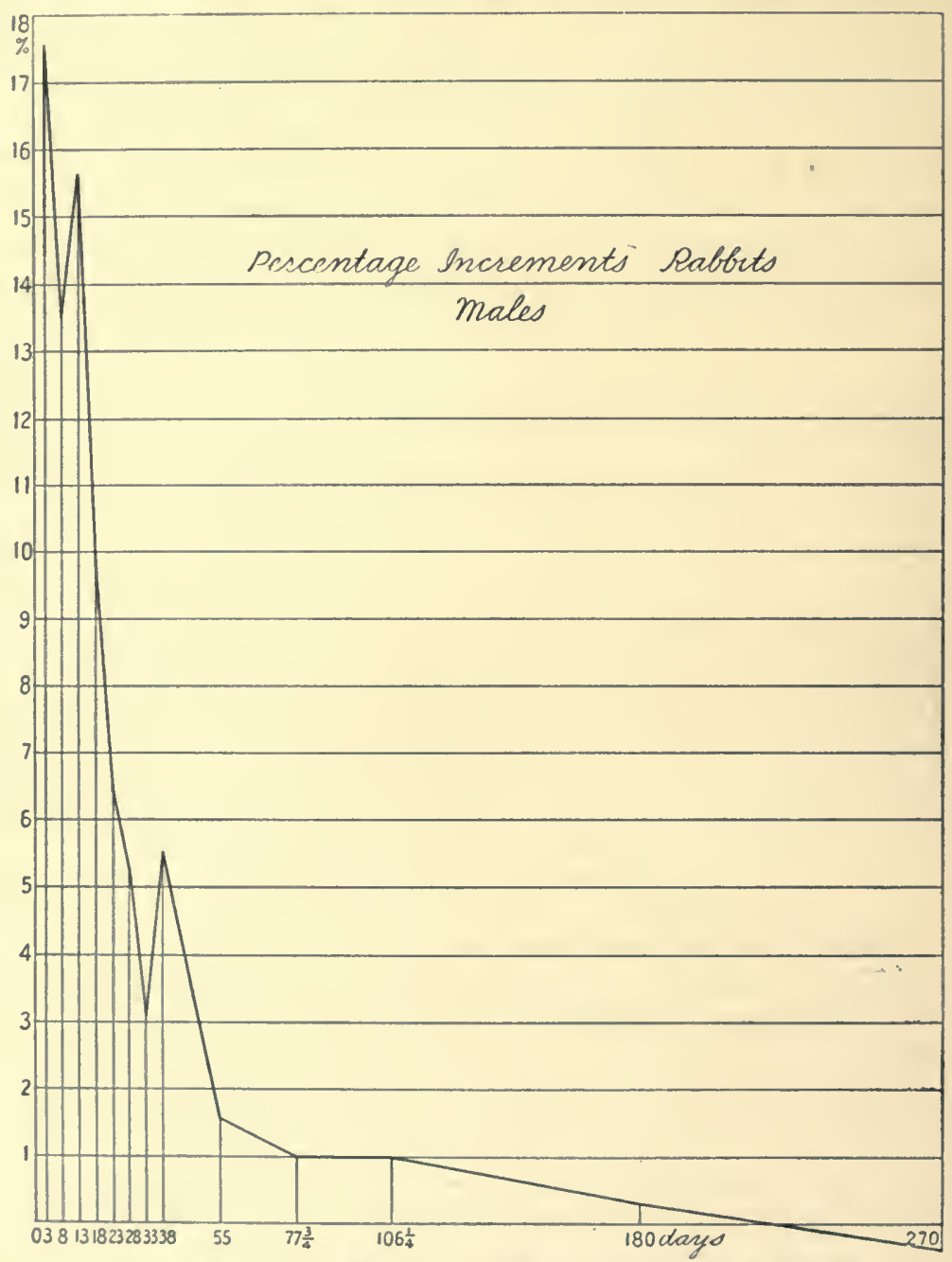

Fir. 144.-(From Minot's Problem of Age, Growth, and Death, G. S. Putnam \& Sons, and John Murray.)

The mean weight of the foal at birth is said to be 112 pounds. During the first three months the average daily increase is 
PHASES IN THE LIFE OF THE INDIVIDUAL $66 \%$

2.2 pounds ; from three up to six months it is 1.3 pounds; and from six months up to three years 0.7 pound. It is said that

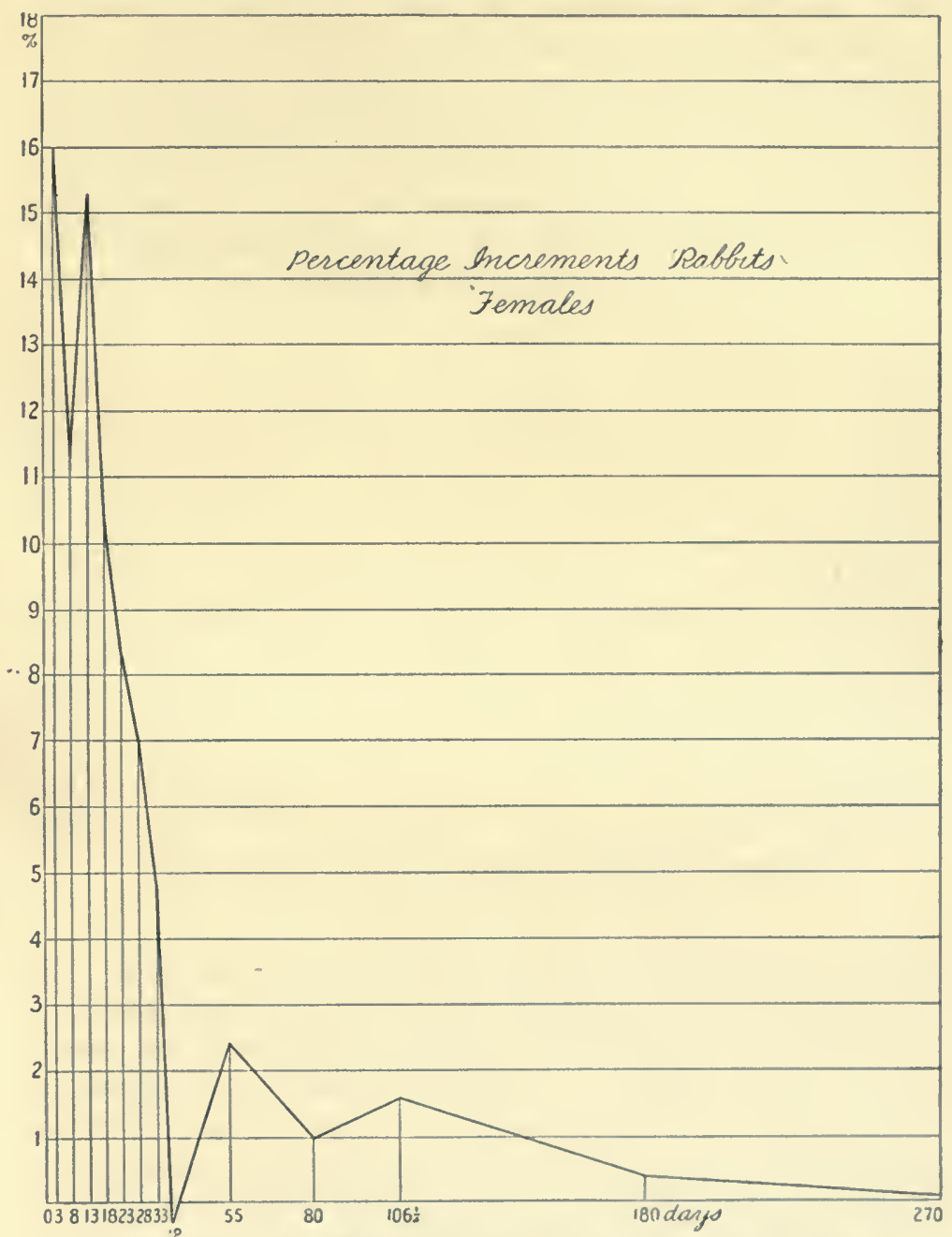

Fig. 145.-(From Minot's Problem of Age, Growth, and Death,

G. S. Putnam \& Sons, and John Murray.)

probably many horses continue to grow until they are six years old. ${ }^{1}$

1 Smith (F.), Veterinary Physiology, 3rd Edition, London, 1907. 


\section{8}

\section{THE PHYSIOLOGY OF REPRODUC'IION}

The calf at birth weighs about 77 pounds, and the average daily increase during the first two years is 1.5 pounds. With the sheep the increase is greater, for a young lamb in ten days can add fifty per cent. to its original weight, and can double it at the end of the first month, and treble it at the end of the second. In pigs, however, the increase is even more rapid, for a young pig can add twenty per cent. to its original weight by the end of the first week, and up to the end of the first year can add an average daily increase of 0.44 pound.

In Man growth is most rapid during the first year of life,

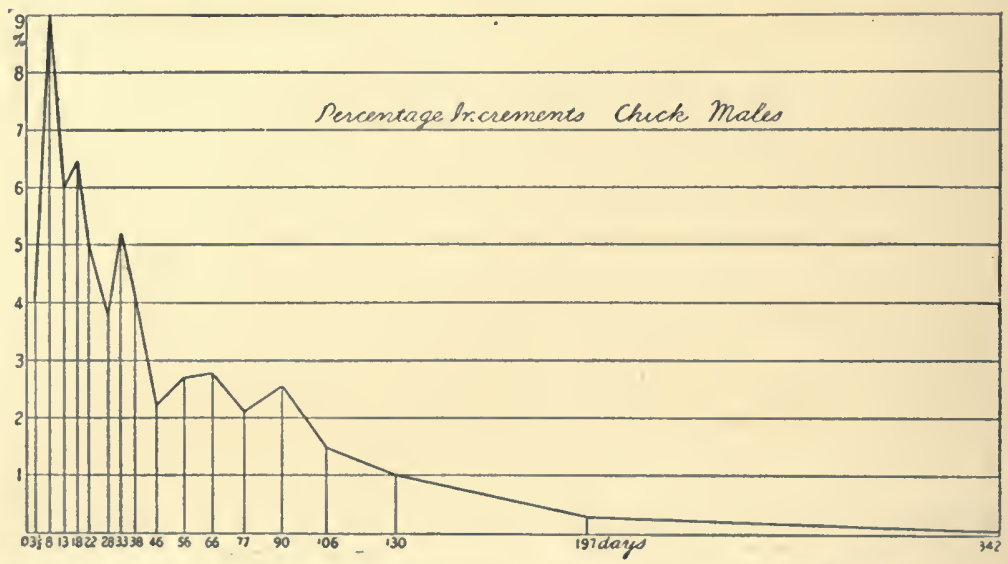

Fia. 146.-(From Minot's Problem of Age, Growth, and Death, G. S. Putnam \& Sons, and John Murray.)

when a child is able to increase its weight by 200 per cent. For the second year this percentage drops to twenty, and for subsequent year's up to about the age of thirteen, it fluctuates around ten, showing a gradual tendency to decrease (but $c f$. Robertson, quoted on p. 662). After this there is a distinct increase in the percentage increment representing the prepubertal and pubertal growth. Then there is a further decline in the power of growth, which gradually diminishes. The prepubertal growth of girls usually precedes that of boys, so that between the ages of twelve and fifteen girls are often heavier and taller than boys. Boys grow most rapidly at sixteen, girls at thirteen or fourteen. Boys attain their full height at from twenty-three to twenty- 


\section{PHASES IN THE LIFE OF THE INDIVIDUAL 669}

five years of age ; girls at twenty or twenty-one. In both sexes the weight of the body tends to increase until about the fiftieth year or somewhat later, owing to an accumulation of fat, but there are of course very many exceptions. ${ }^{1}$

That good nourishment and a healthy environment favour growth is a fact recognised by all. So also systematic exercise has been found to increase both the weight and the height, ${ }^{2}$ and it has been shown further that well-developed children are more efficient mentally and take better places at school than ill-developed and badly-nourished ones. ${ }^{3}$

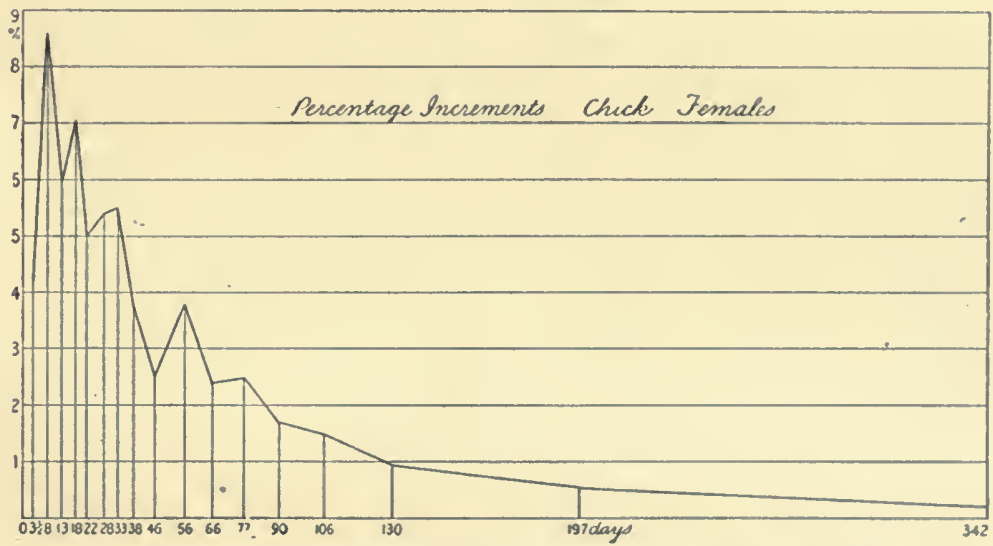

Fig. 147.-(From Minot's Problem of Age, Growth, and Death, G. S. Putnam \& Sons, and John Murray.)

In horses and other domestic animals the effects of feeding on growth and general development are remarkable. Thus it is said that a highly-fed thoroughbred at two years old is "furnished" and looks as old as an ordinary horse at four years old. ${ }^{4}$

1 See Minot, Popular Science Monthly, vol. Ixxi., 1907. Minot states that his calculations are based on data supplied by Professor Donaldson. See also Lee, Article "Reproduction," in Howell's American Tcxt-Book of Physiology, 2nd Edition, London, 1900.

2 Beyer, "The Influence of Exercise upon Growth," Jour. of Exper. Medicine, vol. i., 1896.

3 Porter, "The Physical Basis of Precocity and Dulness," Trans. Acad. of Science, St. Louis, vol, vi., 1893.

Smitb, loc. cit. 
The various other external factors that influence growth in animals of different kinds are discussed by Morgan in his recent work on Experimental Zoology, ${ }^{1}$ to which the reader is referred for an account of the literature of the subject.

\section{Puberty}

Puberty, or the period at which the organism becomes sexually mature, is marked by the occurrence of those constitutional changes whereby the two sexes become fully differentiated. It is at this period that the secondary sexual characters first become conspicuous, and the essential organs of reproduction undergo a great increase in size, ${ }^{2}$ while in those animals in which during immaturity the testicles remain within the body cavity, it is at puberty that these organs first descend into the scrotal sacs. The puberty acceleration in growth which takes place in Man has been already referred to. This change is accompanied, as is well known, by alterations in the general proportions, associated with an increase of strength, a deepening of the voice and a growth of hair on the face and other parts of the body. In temperate climates puberty begins in boys at about the fourteenth or fifteenth year; in tropical countries it is usually a few years earlier. It is at this period that ripe spermatozoa first make their appearance in the seminal fluid, which is henceforward secreted in considerable quantity.

In women puberty occurs at a slightly earlier age than in the male sex. The constitutional changes characterising this period take place more suddenly in the female, the girl almost at once becoming a woman, whereas the boy is several years before he develops into a man. Moreover, the onset of puberty in the girl is marked more precisely by the coming of menstruation, which may make its appearance in temperate climates in the thirteenth year. At about the same time the pelvis widens, and the other characteristic anatomical changes take place; the subcutaneous layer of fat, the development of which assists so largely in giving the body its graceful contour, is deposited;

I Morgan, Experimental Zoology, New York, 1907.

2 Disselhorst, "Gewichts- und Volumszunahme der männlichen Keimdriisen," \&c., Anat. Anz., vol. xxxii., 1908. 
while the internal generative organs enlarge and ripe ova are produced by the ovary. ${ }^{1}$

In both sexes the purely physical changes of puberty are accompanied by psychical ones which are no less pronounced. Both kinds of change are dependent largely, if not entirely, upon the functional development of the generative glands.

In animals the general nature of the change which sets in at puberty is similar to that occurring in the human species, and the secondary sexual characters often appear for the first time at this phase of life. Excepting in the case of the domestic animals, little is definitely known concerning the respective ages at which the different species become mature. Most fillies come in use when two years old, and all by the time they are three. Cows may come on heat when a year old, but it is best to postpone service until three months later. A good deal depends on nutrition, but even starved and backward cows will receive the bull when fifteen months old. Sows will receive the boar when eight months old, and sometimes two months earlier. Sheep will breed at the age of six months (that is to say, lambs born in the spring will breed in the following autumn), but the practice is to be deprecated in the interests both of the ewes themselves and of their lambs. Dogs will breed when about ten months old or even earlier (sometimes seven), but the larger kinds do not breed so soon. Cats are similar. Rodents may breed when still younger, but whether they do so or not depends upon the season of the year and other conditions of environment and nutrition.

1 Runge (E.), however ("Beitrag zur Anatomie der Ovarien Neugeborener und Kinder von der Pubertätzeit," Arch. f. Gynäk., vol. lxxx., 1906), states that growing follicles are by no means uncommon in ovaries of young children. In the first year of life he found follicles of considerable size, and in the second year still larger ones, some having a diameter of $135 \mu$. In the third year degenerate follicles were also found. During this and the following years there was a progressive increase in the size of certain of the follicles until the ovaries became scarcely distinguishable from those of adults excepting for their smaller size. Runge states further that in one instance be found a corpus luteum in an ovary of a recently born child, but this must be regarded as very exceptional. As a result of his observations, Runge concludes that follicular maturation sets in during infancy and not at puberty. Ovaries of human embryos showed growing follicles only in very rare instances. 


\section{The Menopause}

In the male sex (as already mentioned) there is no definite age at which the reproductive functions cease. In the female, on the other hand, the close of the reproductive period is far more definite, and it is this change in the human female which constitutes the menopause or climacteric. The essential phenomenon of the menopause, therefore, is the permanent arrest of all the functions connected with reproduction. It is the inversion of the developmental process of puberty, and marks the termination of active sexual life. In temperate climates it almost always takes place between the ages of forty and fifty, and most usually at about the age of forty-five. ${ }^{1}$ In warm countries it has a tendency to be earlier, and in colder ones later. It is usually earlier among the labouring classes, and also in cases in which puberty was early. The actual duration of the period when menopause symptoms occur varies from about three to five years.

The symptoms of the menopause may be referred to two stages-(1) a stage of menstrual irregularity, and (2) a postcessation stage, during which various systemic disturbances are wont to occur. During the latter period especially the organic functions are irregular. Palpitation, dyspepsia, sweating, and vasomotor changes are not infrequent, and hysteria and other psychic disturbances sometimes occur, accompanied by neuralgia, rheumatism, and various disorders. The changes which take place in the lower Mammals have not been studied, but they can hardly be so great as those which occur in women.

The anatomical and physiological basis of the menopause is, as already indicated, the atrophy of the reproductive organs. The following are the changes which take place in women :-

(1) Senile changes in the ovary: (a) Atrophy, induration, and shrinkage to the size of the rudimentary ovary; $(b)$ disappearance of Graafian follicles and cessation of ovarian functions.

(2) Senile changes in the Fallopian tubes: $(a)$ shortening and narrowing, often accompanied by obliteration of the lumen ; (b) destruction of the epithelial cells.

1 For further details see Kelly, Medical Gynecology, London, 1908. 
(3) Senile changes in the uterus : (a) Atrophy of the entire organ, which may be reduced to a hard, wedge-shaped body, one quarter the size of the functional organ; $(b)$ in many cases closure of the internal os, or of the external os, or complete obliteration of the canal; $(c)$ consequent secretions producing

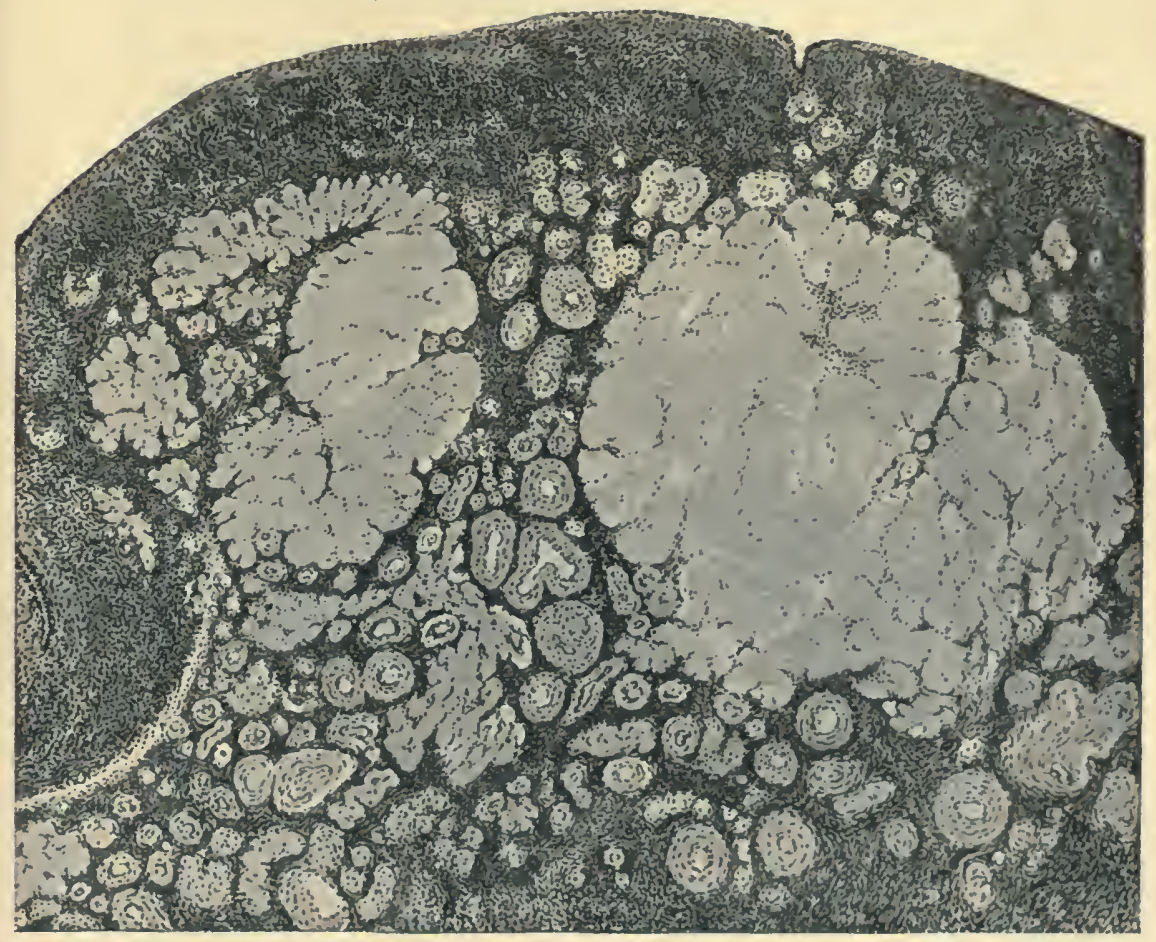

Fia. 148.-Section throngh orary of woman of fifty-six, showing degeneration of follicles and sclerosis of connective tissues. (From Sellheim.)

pyometra or hydrometra, due to the locking up of the secretions; $(d)$ in some cases the disappearance of the vaginal portion, making the upper part of the vagina continuous with the uterine canal ; $(e)$ degeneration of the muscular and glandular elements; and $(f)$ cessation of menstruation.

(4) Senile changes in the vagina: (a) shortening, narrowing, and loss of elasticity; (b) loss of pavement epithelium, and 
substitution of a hard surface containing cicatricial tissue; and (c) contraction of the entrance to the vagina.

(5) Senile changes in the vulva: $(a)$ great contraction and loss of elasticity, $(b)$ destruction of glands and follicles, and $(c)$ cutaneous surface becoming dry and scaly.

(6) Senile changes in the mammary glands: (a) loss of

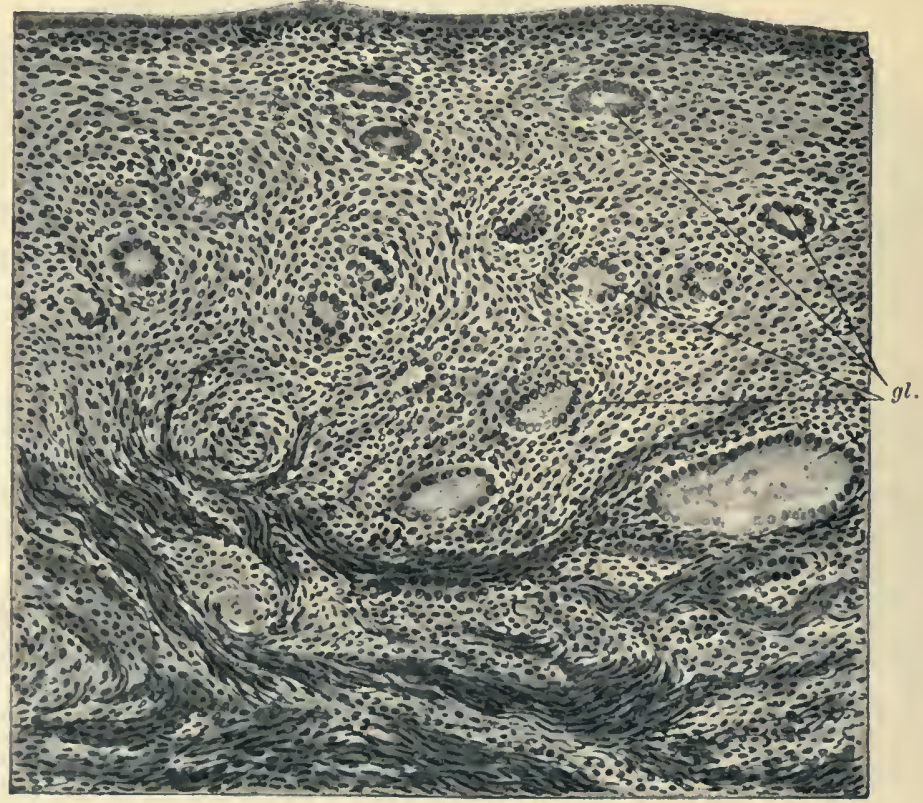

FIG. 149.-Section through uterine mucous membrane of woman of sixty. (From Sellheim.) gl. glands.

glandular elements and cessation of function ; and (b) shrinkage due to atrophic loss, which, however, is sometimes compensated for by a deposition of fat. ${ }^{1}$

Other changes, depending probably on the degeneration of the ovaries, are the assumption of certain of the secondary male characters. These are apparently more marked in some animals

' Dudley, The Principles and Practice of Gyncecology, 4th Edition, London, 1905. For a further account of the atrophic changes in the uterus and other generative organs, see Sellheim. 


\section{PHASES IN THE LIFE OF 'THE INDIVIDUAL 675}

than they are in the human species, and have already been mentioned in dealing with the internal ovarian secretions (p. 314).

\section{Senescence}

As age advances, in addition to the menopause changes which relate more especially to the cessation of the female generative functions, atrophic changes of one sort or another take place in both sexes throughout practically the entire system. The internal spongy structure of the bones is dissolved away, so that they are left with only a hard external shell and consequently become brittle. The teeth decay and drop out. The

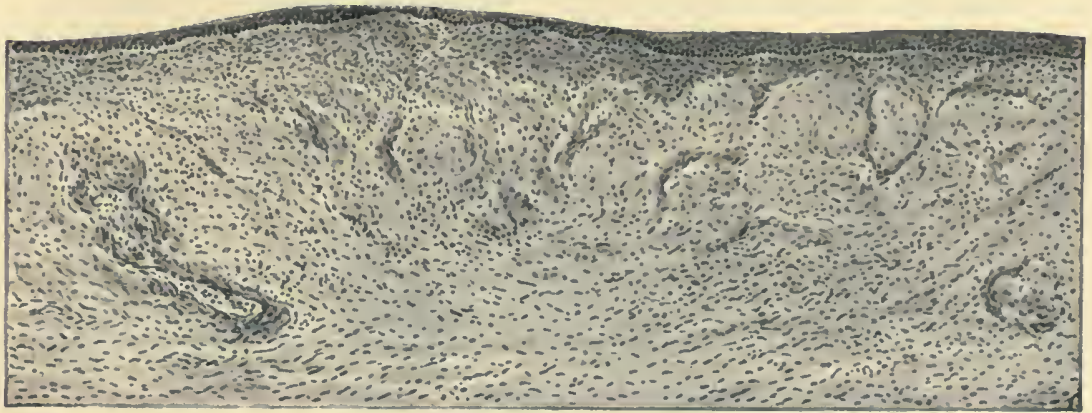

FIG. 150.- Section through vaginal mucous membrane of woman of sixty-one. (From Sellheim.)

muscles shrink in volume, the actual fibres of which they are composed becoming smaller in size and fewer in number. The arterial walls lose their elasticity and undergo sclerosis, a characteristic which is so constant that it has given rise to the well-known dictum that " a man is as old as his arteries." The tendons and ligaments also become calcified, and there is a consequent shrinkage of stature. The size of the liver and other viscera undergoes diminution, but the kidney and heart retain their size; in fact the heart is usually slightly enlarged in old age, but this apparent hypertrophy is not associated with an accession of power but with an increased feebleness, and the pulse, in order to compensate for the weakness of the enlarged heart, beats more quickly, the normal rate of seventy- 
two beats per minute rising to seventy-nine or eighty. The rate of respiration also rises slightly, and the vital capacity of the lungs diminishes. Moreover, the amount of carbon dioxide and urine which are excreted becomes less. The pigment in the hair undergoes absorption, the hair turning grey or white. The adipose tissue beneath the skin disappears, especially in advanced old age, but fatty degeneration of muscle or glandular tissue is not infrequent. In the male sex the prostate gland undergoes atrophy, or in some cases a pathological hypertrophy, which is said to be the cause of frequent penile erections.

It has been shown also that the brain decreases in size in old age. The shrinkage begins soon after maturity, and then continues almost steadily to the very end of life. ${ }^{1}$ Handmann ${ }^{2}$ has published the following statistical results, which are based on measurements carried out at the Pathological Institute at Leipzig :-

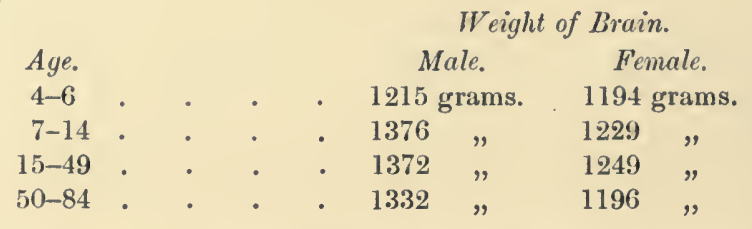

The decrease in brain weight is accompanied by a diminution in the thickness of the cortex and in the number of tangential fibres present in it. These changes are associated on the psychical side with a gradual mental failure-loss of memory, decrease in the power of original thought and in the assimilation of new ideas, and general decline of mental activity. Moreover, the reaction time is lengthened, the sense organs lose their delicacy, and in the eye the power of accommodation is largely lost.

The minute cellular changes in the tissues are no less pronounced. These also are in the direction of atrophy. There is a general shrinkage in the protoplasm of the cells, but especially in the nuclei, so that the relative amount of cytoplasmic to nuclear substance becomes increased in old age. The nucleoli

1 Minot, loc, cit.

${ }^{2}$ Handmann, "Über das Hirngewicht des Menschen," Arch. f. Anat, u. Phys., anat., Abth., 1906. 
also tend to disappear. Hodge ${ }^{1}$ has made a comparison of the changes in the cells of the first cervical ganglion with the following result :-

$$
\begin{aligned}
& \begin{array}{lcc} 
& \text { Volume of Nucleus. } & \text { in Nucleus. } \\
\text { At birth } & \text {. } 100 \text { per cent. } & \text { In } 53 \text { per cent. } \\
\text { At } 92 \text { years } & . & 64.2
\end{array} \\
& \text { In } 53 \text { per cent. }
\end{aligned}
$$

\section{Nucleoli observable}

(2)

Thus the nucleoli are often apparently quite absent in extreme old age. The nuclei, besides becoming smaller, grow irregular

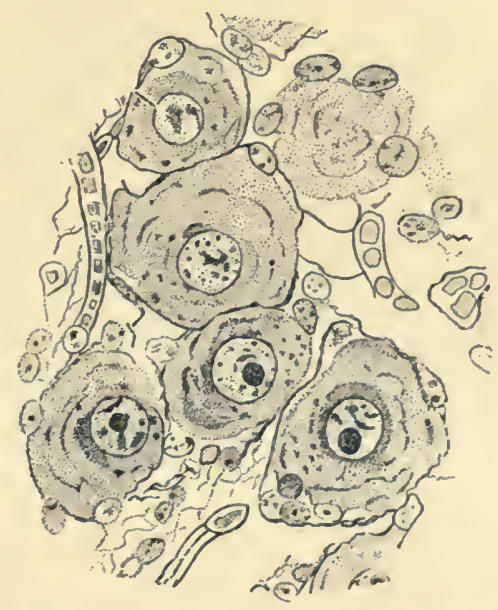

FIG. 151.-Group of nerve cells from the first cervical ganglion of a child at birth. (After Hodge, from Minot's Age, Growth, and Death, G. S. Putnam \& Sons, and John Murray.)

in shape, and in the cytoplasm there is a deposition of pigment granules.

Senescence in men is said to commence at about the age of fifty, ${ }^{2}$ but it is obvious that no definite limit can be assigned to the period, since in some of the organs changes which are in their nature degenerative begin quite early in life.

Spermatozoa continue to be produced even in quite advanced old age, and instances have been recorded of men of

1 Hodge, "Dic Nervenzelle bei der Geburt und beim Tode an Alterschwäche," Anat. Anz., vol. ix., 1894.

2 Lee, loc. cit. 


\section{8}

\section{THE PHYSIOLOGY OF REPRODUC'TION}

94,96 , and even 103 in whose semen aetive sperms were found. ${ }^{1}$ There can be no doubt, however, that the spermatozoa are produced in far less abundance in old age.

In women the period of senescence is usually reekoned from the menopause.

It is difficult to form any accurate eomparison between the phases of life of men and those of animals, partly beeause so

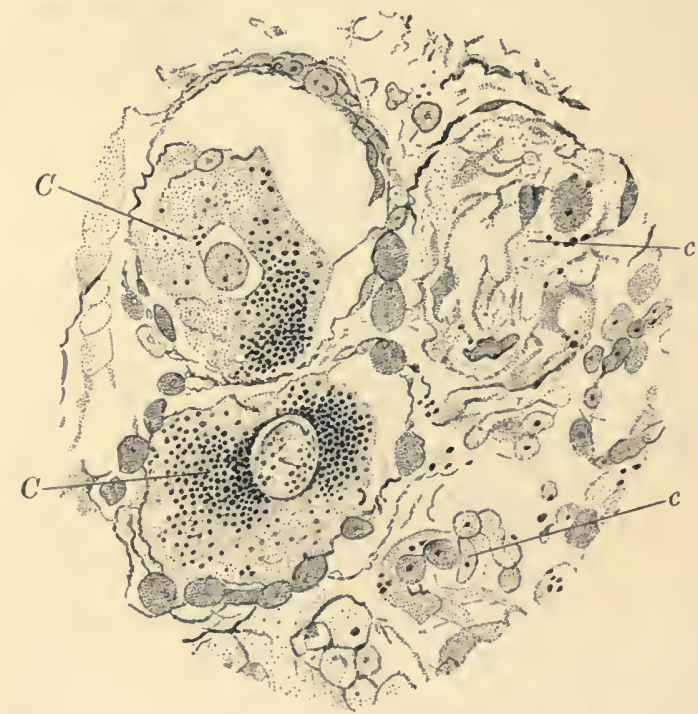

FIG. 152.-Group of nerve cells from the first cervical ganglion of a man of ninety-two. (After Hodge, from Minot's Age, Growth, and Death, G. S. Putnam \& Sons, and John Murray.)

$\mathrm{C}, \mathrm{C}$, cells still intact, but shrunken and loaded with pigment; $c, c$, cells which have disintegrated.

little is known regarding the conditions of natural seneseenee and death in animals. Smith ${ }^{2}$ remarks that few horses live long enough to show much sign of arterial degeneration; the work they perform is the ehief cause of their rapid deeay, for their legs wear out before their bodies: but, apart from this, degenerative ehanges in the teeth, and more particularly the wearing away of the molars, prevent many horses from reaching

1 Cooper, The Sexual Disabiliti s of Man, \&c., London, 1908.

2 Smith, loc, cit. 
a real old age. Blaine ${ }^{1}$ has drawn the following comparison between the age of a horse and that of a man :- "The first five years of a horse may be considered as equivalent to the first twenty years of a man ; thus, a horse of five years may be comparatively considered as old as a man of twenty; a horse of ten years as a man of forty ; a horse of fifteen as a man of fifty ; a horse of twenty as a man of sixty ; of twenty-five as a man of seventy ; 'of thirty as a man of eighty ; and of thirtyfive as a man of ninety."

\section{The Duration of Life and the Cause of Deati}

Weismann, in a famous essay on the duration of life, ${ }^{2}$ and Metchnikoff in his book of optimistic studies, ${ }^{3}$ have dealt at some length, but from different standpoints, with the factors which determine longevity in the animal kingdom. That the duration of life in the various races of animals is very variable, and that, whereas some species are remarkably long-lived, others die after a relatively brief existence, are facts that are known to all. Both Weismann and Metchnikoff cite numerous instances of longevity among animals, some of the more extreme of which may be mentioned here.

A sea-anemone belonging to the species Actinia mesembryanthemum is known to have lived for sixty-six years, and to have produced young, though in smaller numbers than formerly, at the age of fifty-eight. Another sea-anemone of the species Sagartia troglodytes, lived to be fifty years old. ${ }^{4}$ Certain marine Mollusca are said to live for as many as a hundred years. Among insects there is an extraordinary variability in the duration of life, some living in a condition of maturity for only a few days or even hours, while others (certain Hemiptera) are believed to survive for as many as seventeen years. Moreover, the duration of life is sometimes very different in the two sexes,

1 Blaine, Encyclopadix of Rural Sports, London, 1858.

2 Weismann, "The Duration of Life," English Translation, in Essays upon Heredity, \&c., 2nd Edition, Oxford, 1891.

3 Metchnikoff, The Prolongation of Lif, English Translation, London, 1907.

"Ashworth and Annandale, "On Some Aged Specimens of Sagartia," Proc. Roy. Soc., Edin., vol. xxv., 1904. 
the queen ant being known to live for several years (in one case for fifteen years), whereas the male ant survives for only a few weeks.

Among fish, pike and carp are usually said to attain to great ages and even to live for centuries, but there are few accurate data.

Among reptiles, crocodiles and tortoises are known to have long lives, a tortoise from the Galapagos Islands being stated to have lived for 175 years.

The length of life in birds has been discussed by Gurney, ${ }^{1}$

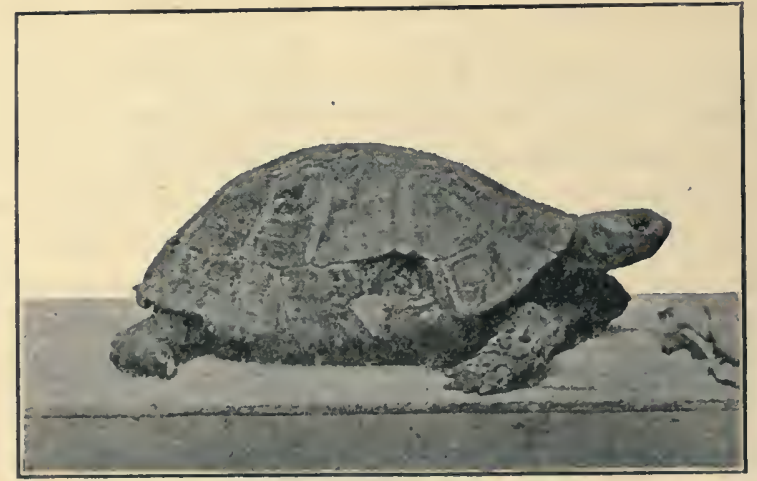

Fig. 153.-Land tortoise (Testudo mauritanico), aged at least eighty-six, belonging to M. Élie Metchnikoff.

(From Metchnikoff's "The Prolongation of Life," by permission of Mr W. Heinemann.)

who cites several examples of great longevity, but the more usual duration of life is from fifteen to twenty years. Canaries are stated to have attained to twenty years of age, a herring gull to forty-four, an imperial eagle to fifty-six, a heron to sixty, an eagle owl to sixty-eight, a raven to sixty-nine, a swan to seventy, and a goose to eighty. Metchnikoff records a case of a parrot which lived for eighty-two years.

Mammals on the average appear to have considerably shorter lives than birds. According to Weismann, whales live for some hundreds of years, but it is difficult to see how this can be 1899.

1 Gurney, "On the Comparative Ages to which Birds Live," Ibis, vol. v., 


\section{PHASES IN 'THE LIFE OF 'THE INDIVIDUAL 681}

more than an assumption. There can be little doubt that the great age assigned by some of the older writers to elephants is mythical, and probably 150 years is almost the maximum ever attained. Horses in rare cases have reached forty years, cattle somewhat over thirty, and sheep over twenty years. A dog is said to have lived for thirty-four years, but twenty is usually regarded as a great age for this animal. Cats have been

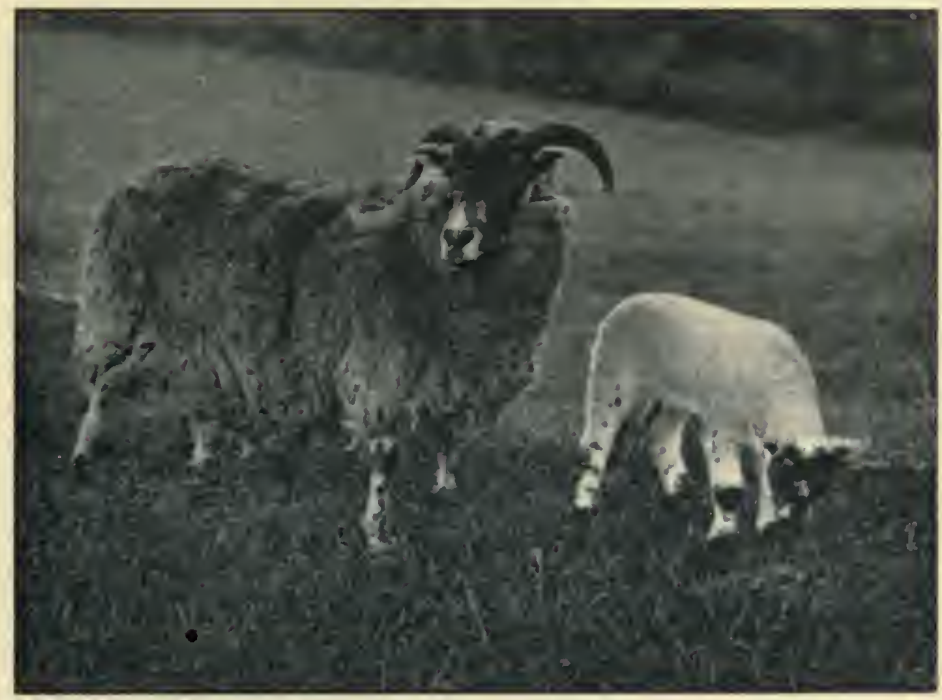

FIG. 154.-Lonk sheep, aged eighteen years, with her last lamb. 'This sheep, which belonged to Mr. William Peel of Knowlemere Manor, Clitheroe, lived to be twenty-one years. It had thirty-five lambs, nine of which were triplets. ${ }^{1}$

known to live to be twenty-one and even twenty-three, but no greater ages appear to have been recorded.

Many instances are on record of extraordinary longevity among men and women, but perhaps the most trustworthy is the famous case of Thomas Parr, described by Harvey in the Philosophical Transactions of the Royal Society. ${ }^{2}$ His death is

1 I am indebted to my friend Mr. W. Ralph Peel, of Trinity College, Cambridge, for this photograph (taken by his sister, Miss Peel), and for the information which accompanied it.

" Harvey, "Anatomical Account of Thomas Parr," Phil. Trans., vol. iii., 1700. A portrait of Parr painted by van Dyck may be seen in the Royal Gallery at Dresden. 
said to have been due to the change in his mode of life, resulting from his migration from Shropshire to London, "where he fed high and drunk plentifully of the best wines." "He died after he had outlived nine princes, in the tenth year of the tenth of them, at the age of one hundred and fifty-two years and nine months."

As to what factors determine the average duration of life in different species is a problem about which there has been much speculation. Weismann has elaborated a theory which asserts that living matter was originally immortal, mortality first arising in correlation with cellular differentiation. On this view the Protozoa are potentially immortal, ${ }^{1}$ natural death occurring only among multicellular organisms. The protoplasm of the latter is shown to be of two kinds-germplasm, which is capable of propagating itself indefinitely under suitable conditions like the protoplasm of unicellular organisms, and somatoplasm, which composes the rest of the body and is subject to natural death. The life of the somatic cells was at first limited to one generation, but afterwards in the higher Metazoa was extended to many generations, and the life of the organism was lengthened to a corresponding degree. Such a restriction went on hand in hand with a differentiation of the parts of the organism into somatic and reproductive cells, in accordance with the principle of the physiological division of labour, and this process of differentiation was controlled by natural selection. "Death itself," says Weismann, " "and the longer or shorter duration of life both depend entirely on adaptation. Death is not an essential attribute of living matter; it is neither necessarily associated with reproduction, nor a necessary consequence of it." According to this theory, therefore, the phenomena of senescence and death, as exhibited by all the cells of the body with the exception of the germ cells, are secondary properties which have been preserved in multicellular organisms by natural selection, because they are of direct advantage in the propagation of the species. An indefinite prolongation of the life of the organism after the age of reproduction had been passed would

1 This question, about which there has been much controversy, is referred to in Chapter VI. (pp. 212-14).

2 Weismann, "Life and Death," Essays, vol. i., 2nd Edition, Oxford, 1891. 
be of no value or utility to the race, but rather a disadvantage, since it would tend to retard the evolution of more perfectly adapted forms of life. Furthermore, according to Weismann, longevity, although depending ultimately upon the physiological properties of the cells, is capable of adaptation to the conditions of existence, and consequently is influenced by natural selection just in the same way as other specific characters are.

Perhaps the most cogent criticism of Weismann's doctrine of immortality is that of Verworn, who writes as follows:- "The conception of living substance as immortal will be accepted by scarcely any one who bears in mind the characteristic peculiarity of living substance, viz., that it continually decomposes, or, in other words, dies. There is no living substance that, so long as it is living at all, is not continually decomposing in some parts, while being regenerated in others. No living molecule is spared this decomposition: the latter, however, does not seize upon all molecules at the same time; while one is decomposing, another is being constructed, and so on. Onc living particle affords the conditions for the origin of another or scveral others, but itself dies. The particles newly formed in turn give rise to others, and, likewise, die. In this manner living substance is continually dying, without life itself becoming cxtinct." 1 From this standpoint, therefore, there can be no qucstion of any kind of living substance being truly immortal. The whole conception of a possible immortality arises from a confusion of ideas.

Minot, ${ }^{2}$ on the other hand, has elaborated a theory of senescence which may be regarded as an cxtension of that of Weismann. Like the latter, he seems to assume that death is not a universal accompaniment of life, and that natural death has been acquired in the course of evolutionary development. He proceeds to define senescence as an increasc in the differentiation of the protoplasm. During the early periods of life the young material is produced, and the protoplasm is undifferentiated. During the later stages of cxistence cell differentiation goes on, and the organism gradually becomes old. When the cells acquirc the faculty of passing beyond the

1 Verworn, General Physiology, Lee's Translation from the second German Edition, London, 1899.

2 Minot, loc. cit. 


\section{THE PHYSIOLOGY OF REPRODUCIION}

simple stage to the more complete organisation, they lose something of their vitality, of their power of growth, and of their possibilities of perpetuation. Just as senescence depends upon the increase and differentiation of the cytoplasm, so, conversely, rejuvenation depends upon the increase of the nuclear material; and consequently the alternation of the two phases of the life cycle (the early brief one when the young material is formed, and the later prolonged one when the process of differentiation is going on) is due to an alternation in the proportions of nucleus and protoplasm. In criticism of this theory, it may be urged that it is in reality nothing more than a descriptive account of a general type of cellular change, and that it provides no sort of explanation as to why this type of change occurs, nor how it is that differentiation is apparently correlated with a reduction of vitality leading eventually to death.

Metchnikoff has laid great stress on the idea that natural death is a rare phenomenon, at least among the higher animals. That death with Man is frequently, if not generally, caused by disease or accident is a fact about which there can be no disagreement, and Karl Pearson ${ }^{1}$ has worked out statistically the chances of death occurring in the different phases of human life. "We have five ages of man," he says, "corresponding to the periods of infancy, childhood, youth, maturity or middle age, and senility or old age. In each of these periods we see a perfectly chance distribution of mortality centring at a given age and tacking off on either side according to a perfectly clear mathematical law." It was found also that the curve of mortality, as deduced from a study of the deaths per annum of a thousand persons born in the same year, "starts very high in infancy, falls to its least value at thirteen or fourteen years with only 236 deaths. It then slowly increases till it reaches a maximum in the seventy-second year of life, and falls more rapidly than it rose, till scarcely two isolated stragglers of the thousand reach ninety-one." It is clear, therefore, that death from old age is far from being the rule in the human species, but according to Metchnikoff it seldom occurs at all. ${ }^{2}$

' Pearson, The Chances of Death, \&c., vol. i., London, 1897.

2 Metchnikoff, loc. cit.; and The Nature of Man, Mitchell's Translation, London, 1903. 
This biologist finds it impossible to accept the view that the high mortality observable between the ages of seventy and seventy-five indicates a natural limit to human life at about this period. Centenarians, he points out, are not really very rare, and he cites many cases of extreme old age, including that of Thomas Parr referred to above. Real old age, we are told, is associated with an instinct for death which is as natural as is the instinct for sleep. Metchnikoff therefore answers in an emphatic negative the question asked by Admetus in Euripides' Alcestis, "Is it the same thing for an old man as for a young man to die?" The fact that the instinct for death seems so rarely to exist is regarded as evidence that true senility is a comparatively infrequent phenomenon.

According to Metchnikoff, senescence is not brought about simply as the result of arrest of the reproductive powers of the cells. The whitening of hair in old age is due to the destructive action of phagocytes which remove the pigment. Moreover, hairs become old and white without ceasing to grow. Metchnikoff believes also that atrophy of the brain is due to the destruction of the higher nerve cells by neuronophags, and that there are many other devouring cells which are adrift in the tissues of aged men and animals and cause the destruction of other cells of the higher type. The testes, however, appear to have the power to resist these phagocytes, and with this power is correlated the fact that spermatozoa are often produced even in advanced old age. Metchnikoff's theory as to the cause of death is that it is due to the poisoning of the tissues and to the damage done by phagocytes to those parts of the body affected by the toxic action. He believed further that in Man and certain of the animals this process of poisoning is brought about by fermentation set up by microbial action in the large intestine. The toxic substances produced by the intestinal fermentation are supposed to enter the system and poison it, the result being that the vitality of the tissues is lowered, so that they are less able to resist the action of devouring phagocytes. The presence of lactic acid in the intestine is believed to arrest the process of fermentation. Metchnikoff recommends, therefore, the regular drinking of sour milk as a means of destroying the microbes in the intestine in the hope of prolonging life. 
The term "Death" is employed in two separate senses; it may mean the death of the whole body, i.e. somatic death (this being the sense in which it is ordinarily used), or it may be applied to the death of the individual tissues, some of which remain alive for many hours after the body as a whole is said to be dead. The death of the body as a whole usually occurs suddenly. As Michael Foster says :- "Were the animal frame not the complicated machine we have seen it to be, death might come as a simple and gradual dissolution, the 'sans everything' being the last stage of the successive loss of fundamental powers. As it is, however, death is always more or less violent; the machine comes to an end by reason of the disorder caused by the breaking down of one of its parts. Life ceases not because the molecular powers of the whole body slacken and are lost, but because a weakness in one or other part of the machinery throws its whole working out of gear." 1

The synchronous disturbance of two or more of the bodily functions, such as is wont to occur in old age, may destroy that co-ordination of the various vital activities, without which life cannot continue. The stoppage of the heart's beat is the ordinary criterion of death, and this is a true conception, because the cessation of the heart's movements implies the arrest of the circulation of the blood and the consequent starvation of the tissues of the body.

The tissues do not die simultaneously, for as already described, some cells of the body are in process of disintegration through the whole of life. After somatic death, the cells which make up the nervous system usually die very rapidly. The same is true of the gland cells; but the muscles may remain sensitive to external influences for many hours. In animals it has been shown that the heart itself after removal from the body, if kept under suitable conditions and perfused with an artificial fluid resembling blood serum, may continue to live and undergo rhythmical contractions for a considerable time. In the process of death-stiffening, or rigor mortis, the muscles once more contract spontaneously, and not till this has happened is their life utterly extinguished. Rigor mortis is brought about by the coagulation of the muscle plasma within the cells. It begins

'Foster, Textbook of Physiology, Part IV., 5th Edition, London, 1891. 


\section{PHASES IN 'THE LIFE OF THE INDIVIDUAL 687}

at periods varying from half-an-hour to thirty hours after somatic death, and it continues for an average of about thirty hours. Certain cells may even live for some time after rigor mortis has passed. This is notably the case with the ciliated epithelial cells of the inner surface of the respiratory passages, and with the white corpuscles of the blood. Sooner or later, however, every part of the organism perishes, putrefactive changes set in, and the entire substance of the body passes once more to that " dust" out of which its vital activities enabled it to build itself up in the progress of individual life. 



\section{N D E X}

[Names of authors are printed in Clarendon type, specific names in Italics.]

A

Abderhalden, 563 sq.

Abel and Mcllroy, 526

Abelous, 282

Abortion, 612 sqq.

Abraxas grossulariata, 639

Acmœa, 221

Acomys caharinus, 390

Actinia mesembryanthemum, 8 sq., 679

Acton, 283

Adolphi, 177

Agassiz, 17

Ageniaspis fuscicollis, 636

Ahlfeld, 369, 497

Akutsu, 233, 259

Albatross, 27

Albers-Schönberg, 607

Albertoni, 22

Albu and Neuberg, 266, 278

Alcyonium digitatum, 9

Allbrecht, 182, 611

Allen, B. M., 124, 153, 168

L. M., 545

Allison, 214, 647

Alquier and Thauveny, 350

Amia, 17

Amphibia, breeding season of, $19 \mathrm{sqq}$.; insemination in, 184; fertilisation in, 190 ; fertility of, $5948 q$.; sex-determination in, $625,637,651$

Amphioxus lanceolatus, 16

Anasa tristis, 634

Ancel and Bouin, 154, 343, 579

Anderson. See Langley and Anderson Anguis, 151

Annandale, 7, 22, 44

Annandale and Robinson, 70

Annelida, breeding season ot, 10 sq. : $133,205,221$

Ancestrum defined, 36

Anopheles, 13

Ant, sex-determination in, 629 ; age of, 680

Antelope, 48, 241, 247

Antilocapra americana, 28, 305
Ape, ostrous cycle in, 63 sqq. : foetal nutrition in, 392,463 sqq.

Apfelstedt and Aschoff, 478

Aphidæ, $11 s q ., 216,631$

Arbacia, 179, 218

Arbacia pustulosa, 293, 300

Aristotle, 590

Arthropoda, breeding season of, 11 ; spermatozoa of, $174 ; 307$

Arvicola, 250

Arvicola agrestis, 40

Arvicola glareolus, 40

Ascaris, 128

Ascidians, fertilisation of, 207

Ascoli, 436, 481

Ashworth, $8 \mathrm{sq}$.

Ash worth and Annandale, 679

Ass, 403

Assheton, 110, foetal nutrition, 372 sqq., 376, 386 sq., 390, $3948 q$., 397 sqq., 406 sq., 419 sq., 423, 487

Astacus fluviatilis, 11

Asterias, 134 n., 204, 220 sq., 223 sqq.

Asterias forbesii, 218

Asterina, 223

Atretic follicle, $1548 q q$.

Aves, breeding season of, 23 sqq. See also Birds

Axe, Wortley, 51, 536, 618

Axis, œstrous cycle in, 49

Axolotl, 22, 189 sq., 594

\section{B}

Backhouse, 159

Badger, gestation of, $59 n$. ; 416

Baer, von, $143,145 s q ., 375$

Balbiani, 631

Balenoptera musculus, 52

Balfour, $1168 q ., 124,160,379$

Ballowitz, 172, 175, 178, 179 \&q.

Bang, B., $6168 q$.

- I., 293

Bar and Daunay, 498, 500, 502 8q.

Barasingha, $47 \mathrm{gq}$. 
Barberlo, 287

Bardeleben, von, 286

Barrett-Hamliton, 29

Barrows, 208

Barry, D. T., 165

M., 165,187

Basch, 561, 577, 578

Basso, 481

Bat, breeding season of, 32 ; œestrous cycle in, 61 sq. : maturation in, 132 ; ovulation in, 135,$185 ; 367$, $374,392,407,494$; parturition in, 541; fertility of, 587,589

Bataillon, 203, 221

Bateson, 194, 198, 637, 639 sqq., 657

Baumm, 497

Bear, breeding season of, 58 ; fertility of, 590,592

Beard, 110, $162 \mathrm{sq} ., 337,542 \mathrm{sq} ., 628$, $633,6358 q$.

Bechtere w, 262, 539

Beck, 180

Beddard, 42

Bee, 186 ; sex-determination in, 626 sqq.

Beebe, 30

Beesiy, 514

Beesiy and Milne, 514

Bell, Biair, 69, 87, 142, 330, 346

Bende, 169

Bendl $X$ and Elsteln, 297

Beneden, van, Cheiroptera, 62, 118 ; maturation, 128, 131, 136, 165, $187 ; 371,405,459$ sq., 467

Beneke, 62, 136

Benkiser, 316

Bergell and Liepmann, 481

Bergomié and Trabondeau, 607

Bernard, 431

Bernhard, 520

Bert, 571

Bertkau, 560

Bestion de Camboulas, 328

Beyer, 669

Blancardi, 517

Birds, female generative organs in, 264 sqq. ; 315 sq. ; fotal nutrition in, 485 ; breeding of, in captivity, 592 sqq. ; hermaphroditism in, 654 ; age of, 680

Birnbaum, 517

Blrnbaum and Osten, 69

Birth-rate, 620 sqq.

BIschoff, 47, 55 ; corpus luteum, $143,147,1498 q . ; 177$; placenta, $371,387,400,421,442$

Bison, 47 sqq.

Blzzorzero and Ottolanghl, 561

Björkenhelm, 465
Biackman, 213

Blaine, 679

Blandford, 65

Bles, 5, 20, 22, $5948 q$.

Bloch, $600,614,655$

Blood, changes in, during pregnancy, $520 \mathrm{sq}$.

Blot, 510

Blumreich, 521

Bocarius, 287

Bodio, 624

Bohr, $272 s q ., 434,436,486,491 s q$. , 508, 512, 518 8q.

Bohr and Hasselbalch, $2718 q$.

Bolaffio, 585

Bombyx mori. See Silkworm moth

Bond, $347 \mathrm{sq}$.

Bondzinski and Zoja, 275

Boni, $505 s q$.

Bonnet, 100, 108 sqq., 184 ; placenta, $363,366,371,373,386,403$ sqq., 411,413 sqq., 426 sq., 476 sq., 480 ; $5158 q$. See also Merkel and Bonnet

Born, $624 \mathrm{sq}$.

- Gustav, 337

Boruttau, 314

Bos, 208

Bossi, 185

Boston, 348

Bottazzi, 481

Bouin and Ancel, 154, 310, 343

Bouin, Ancel, and Villemin, 607

Bourne, 10

Boveri, 129, 187 sqq., 199, 660

Brachet, 253, 262, 330, 490, 538

Bradypus, 375

Braem, 658

Branca, 593

Brandt, 316

Breeding season, 4-35

Breschet, 65

Breuer and Selier, 356

Bridge, 16

Briggs, 626

Brill, 205

Brinkmann, 380

Brocard, $510 \mathrm{sq}$.

Brock, 547

Brock, van der, 418

Brooks, 192

Brouha, 554, 560 sq., 573

Brown, 169

Brown and Osgood, 607

Brown-Séquard, 308 sq., 326, 541

Brumpt, 536

"Brunst," 36

Bryce, 138, 392

Bryce and Teacher, $369,449,466$ $8 q q ., 471,474,479$ 
Buccinum undatum, 14

Budge, $2548 q ., 259$ \&q., 528

Budgett, 17, 28

Buffalo, 349

Buffon, 591

Bufo, 203

Bühler, 145,151

Buller, 178 sqq., 215

Bulloch and Sequeira, 351

Bullot, 221

Bunge, 265, 270, 480, 515, 563

Burchell's zebra, 202

Burckhard, 437

Burlando, 508

Burrian, 288, 296, 297

Bustard, 30

Buys and Vandervelte, 317

\section{C}

Calf, growth of, 668

Calkins, 6, 7, 213

Callionymus lyra, 29

Calotes jubatus, 277

Camel, rut in, 26, 49

Cameron, 48, 365

Campbell, Malcolm, 340, 595

Camus and Gley, 233, 237, 287

Canary, breeding of, in captivity, $592 ; 640,680$

Canis azaro, 55

CapaldI, $5118 q$.

Capercaillie, 315

Capon, 306, 312, 349, 654

Capybara, 250

Carmichael, 320

Carmlchael and Marshall, 317, 328, 341,348

Carnegie, 58

Carnivora, œstrous cycle in, 53 sqq. ; uterine cycle in, 99 sqq. ; foetal nutrition in, $3868 q ., 411$ $8 q q ., 485$; puerperium in, 551 ; lactation in, 554; fertility of, 592 : 594

Carnot and Deflandre, 68

Carp, 292

Carpenter, 208

Castle, $2078 q ., 637,639,642,651 s q$.

Castration, chap. ix. passim, in Man, 303 ; stag, 305 ; sheop, \&c., 306 ; arthropods, 307 ; fowl, $3118 q$. : frog, 313 ; effect of, on general metabolism, 353 sqq., 656

Cat, œstrous cycle in, 56 sq. ; superfotation in, 159 ; acces. sory reproductive organs in, 229 , 232, 247, 252, 255 sq., 260, 262; foetal nutrition in, 411, 413, 416, 418; pregnancy in, 512, 523;
525 ; female generative organs in, $525,5288 q ., 537$; fertility of, 591; growth in, 671; age attained by, 681

Caterpillar, 307,625

Catlin, 48 8q.

Caton, 305

Cattle, œstrous cycle in, $468 q$., 334; effects oi castration on, 306,349 ; abortion in, 613 ; hermaphroditism in, 652 ; hered. ity in, 653 ; age in, 681

Cavia, 150

Cavia porcellus, 41

Caviar, 278

Centetes, 553

Centetes ecaudatus, 458

Cephalochordata, breeding season of, 16

Ceratocephale os tu ai, 11

Ceratodus, 17

Cercocebus, 63, 96 sq.

Cercocebus cynomolgus, 89, 96

Cercopithecus, 63, 74 n., 584

Cercopithecus cynosurus, 65

C'ervus alces, 233

Cervus elaphus, 27

Cesa-Bianchi, 161

Cotacea, œestrous cycle in, 5289 .; $141,246,375$; lactation in, 553 sqq.

Chad wick, 15

Chatopterus, 217, 221

Chaffinch, 315

Champneys, 85

Charrin, 515

Charrin and Goupil, $4818 q$.

Charrin and Gulllemont, 508

Cheiroptera, cestrous cycle in, 61 $8 q$. ; fotal nutrition in, 459-463 ; lactation in, 553 ; fortility in, 587

Chelchowski, 185

Chermes, 12

Chicken, growth in, 665

Child, 10

Chimpanzee, œstrous cycle in, 63

Chlpman, 369, 422, 425 sq., 428, 430 sq., 487

Christ, 85

Chrysochloris, $61 n$.

Clmorini, 349

Ciona intestina'is, 207

Clark, 118, 139, 145 sq., 208, 336

Clarke, Eagle, 24, 26

Cock-of-the-rock, 27

Cocks, 56, 57, 59

Cod, 278

Coelenterata, breeding season of, 7 ; $125 \mathrm{n}$.; spermatozoa of, 174,190 ; 200 
Cohen, 285

Cohn, 149

Cohnstein, 520

Cohnstein and Zuntz, 434, 436, 518

Cole, 246

Collocalia, 30

Colpoda steini, 7, 214

Cook, 14

Cooper, 678

Copeman, 637

Copulatory organ, 242 sqq.

Corner, 312, $6068 q$.

Corpus luteum, formation of, 142 sqq. ; false, 154 ; $3348 q$.; function of, $336 s q ., 491,502 n$.

Correns, 193, 634

Coste, 358

Courant, 242

Cow, ovulation in, $136 ; 183$; fœtal nutrition in, 386, $396 s q ., 400,403$ $8 q ., 407$; pregnancy in, 487,495 , 508 ; parturition in, 535 ; lactation in, $5538 q ., 557,568,571$, 583 ; composition of milk of, 562 $8 q q$. : fertility of, $596,608 s q$. ; artificial insemination of, 611 ; abortion in, $616 \mathrm{sq}$.; growth of, 668, 671. See also Cattlo

Cowper's glands, 239 sqq.

Crab, 307 sq., 653

Cramer, A., 478

\section{H., $332,491,517$}

W., chap. viii., 355, 431, 436, 519. See also Lochhead and Cramer and Marshail and Cramer

W., and Marshall, 601

Crampton, 307, 656

Creighton, 366

Cremer, 300

Crepidula fornicata, 653

Cristalii, 511

Crocodile, 31

Crocodilus biporcatus, 277

Croom, Haliiday, 65

Cross-breeding, 202-11 passim; effects of, $6018 q q$.

Crowe, Cushing, and Homans, 356

Crowther, 564 sqq.

Crustacea, ovulation in, $137 n$.; $2818 q$. ; parasitic castration in, $640 ; 653$

Cryptorhynchus gravis, 13

Ctenophora, 9

Cuckoo, 24

Cuénot, $6258 q ., 650$

Culicidæ, 13

Cull, 213

Cunningham, D. J., 55
Cunningham J. T., 28, 29, 151, $3048 q$.

Curtis, 651

Cushing, 356

Cushny, 527 sqq.

Cuttlefish, 280

Cyclopterus lumpus, 29

Cynthia partita, 207

\section{D}

Daels, 343, 601

Daie, 530

Dandie Dinmont, 183, 209 sq.

Daphnia, 631

Darbishire, 195

Dareste, 286

Darwin, 5, 28, 29, 201, 206, 208, $304,307,314$ sq., 591 sqq.. 602 $8 q ., 653 s q$.

Dastre, 478

Dasyurus, 150, 158 sq., 383, 385

Dasyurus viverrinus, 149,337

Dawson, 636

Dean, Bashford, 17

Death, 682 sqq.

Death's-Head hawk moths, 13

De Bonis, 236, 239

Decidua, and fnetal nutrition, 366 $s q q$.

Deer, 32, $478 q ., 241$; effects of castration on, 305,313 ; fœtal nutrition in, $371,397,403$

De Graal, 251

Delage, $223 s q q$.

Dembo, 530

De Sinéty, 85

De Vries, 193

Dewar and Finn, 604

Dewitz, $178 s q$.

Dinophilus apatris, 635

Diœstrous cycle, defined, 37

Diœstrum, defined, 37

Diplozoön paradoxum, 10

Dipodillus campestris, 40

Dipodillus simoni, 40, 41, 545

Discoglos8us, 22

Disse, 439, 441

Disselhorst, 24, 228, 232, 241, 244, 670

Dixon, 285, 309

Doering, $1458 q$.

Dog, gestation of, 32 ; œestrous cycio in, 37, 53 sqq., 99 sqq., 329 ; ovulation in, 135,141 ; artificial insemination of, $1828 q$., 203, 611; in-brecding in, 208 $8 q q$. ; accessory reproductive organs in, 229, 232, 236, $238 s q$., 252 sqq., 256, 260 ; castration of, 
309,$355 ; 349$; influence of ovary in, $318,328 s q ., 332 s q ., 341$; ovum of, 371 ; fœtal nutrition in, $387,411,413,416,427$; pregnancy in, 490, 498, $500 s q q$., 507 sq., 511 sq., 520 ; parturition in, 538 ; 552 ; lactation in, 563, 583 ; fertility of, $5908 q ., 601$; sex in, $644 s q . ; 671$

Dolphin, breeding period of, 53

Donaldson, 662

Doncaster, 131, 204, 210 sq., 629, $639 \mathrm{sq}$.

Donkey, ovulation in, $136 ; 183$

Doran, $330 s q ., 346$

Drennan, 516

Driesch, 190, 660

Driessen, 442, 478

Droop-Ríchmond, 564

Drosophila ampelophila, 208

Dubner, 520

Dubois, 281, 300

Dubreuil and Regaud, 159, 344

Dubuisson, 157

Duck, 315; fertility of, $591 s q$.

Duck worth, 306

Ductless glands, 336 ; correlation between generative organs and, 349 sq. ; during pregnancy, $5228 q$.

Dudley, 331,674

Duesberg, 131

Dugong, 376

Dührssen, 185

Dumas, 184

Duncan, Matthe ws, 66, 587, $5898 q$., 608

Dungern, 179, 216

Durham, 640

Düsing, 630,642

Duval, 62, 361, 387, 400, 413 sq., $416,420,423$ sq., 426, 437, 439, $462,483,552$

Dzierzon, $628 s q$.

E

Eurthworm, 186, 190

Ebner, von, 561

Echidna, œstrous cycle in, 38 sq.; lactation in, $\mathbf{5 5 4}$

Echinodermata, breeding season of, $15 s q$. : spermatozoa of, 174,178 , sqq., 190 ; cross-fertilisation of, 203 sqq., 210 sq.; parthenogenesis in, 216-226 passim

Echilloidea, 178

Echinus, 179, 300

Echinus acutus, 16

Echinus esculentus, 15, 300
Echinus microtuberculatus, 16

Eckhard, 251, $254 s q q ., 577$

Eden, $430,478,543$

Eel, 18, 23

Eggelung, 554

Ehrlich, 520

Ehrström, 291, 507

Eimer, 62

Ejaculation, mechanism of, $251 s q q$.

Eland, cestrous cycle in, 49 ; 306

I lasmobranchs, 16, 190, 277

Elephant, œstrous cycle in, 52 ; 242 , 304 ; fotal nutrition in, $419 \mathrm{sq}$. : lactation in, 553; fertility of, 592 ; age attained by, 681

Eliomys quercinus, 40

Ellenberger, $45-6,47,50$

Ellis, Havelock, $63,65,70,71$, 655

Emberiza passerina, 593

Embryotrophe, defined, $403 n$.

Empidæ, 13

Emrys-Roberts, 47, 163, 435

Engelmann, 80, 83. See also Kundrat and Engelmann

Engström, 521

Enriques, 192, 214

Equus prjewalskii, 51

Ercolani, 359, 367, 401, 459

Erection, mechanism of, $251 \mathrm{sqq}$.

Erlandsen, 267

Eschricht, 358, 375

Essen-Möller, 342

Eunice fucata, 11

Eunice viridis, 11

Eutheria, 149

Ewart, 51, 108, 136, 159, 201 sq., $210,396,545,615$ sq., 620

Exner, 234

\section{F}

Falco albidus, 593

Farkas, 281, 302. See also Tangl and Farkas

Farmer, 191, 201

Farre, 359

Fehling, 512, 520

Fellner, 530

Ferret, 57; breeding period of, 58 $s q$. ; cestrous cycle of, $99 s q q$. ; ovulation in, 136, 141, 154; ovum in, 371 ; 416 ; fertility of, 591,594

Ferroni, 481, 511

Fertilisation, chap. vi., 371 ; and sex-determination, 628 sqq.

Fertility, chap. xiv., 586

Fichera, 349

Fick, 200, 260

Finch, breeding of, in captivity, 592 
Findley, $84 s q$.

Finn, 604

Fischel, 507

Fischer, 275

Fischer and Ostwald, 301

Fish, 184; biochemistry of eggs of, 277 sqq. : age attained by, 680

Flatau, 342

Fleming, 536, 608

Flemming, $156 \mathrm{sqq}$.

Fletcher, 253

Flies, sex-determination in maggots of, 626

Florence, 287

Flower, 43

Flower and Lydekker, 554

Foà, 320, 572, 580 sq., 583

Fœtal membranes, 377 sqq.

Foges, 311, 579

Fogge, 258

Foote and Strobell, 634

Fordyce, Ding wall, 74, 568

Forel, 655

Foster, 540, 686

Fothergill, 369

Foulis, 118

Fowl, oviduct of, 24, 333 ; ovulation in, 139 n. ; 184 ; Andalusian, $194 s q . ;$ biochemistry of the sexual organs of, 264 sqq. ; 311 sq., 315,320 n., 349 ; fœtal nutrition in, $435,485,487$; fertility of, $589,590,605$; heredity in, 640 ; hermaphroditism in, 651 n., 654

Fowler, 305

Fox, breeding season of, 55

Fraenkel, 118, 161, 334, 338 sqq., 353

Fraenkel and Cohn, 338

Franck-Albrecht-Göring, 545

Françols-Franck, 251, 255

Frankenhauser, 528

Franz, 527, 612

Frazer, 70, 602

Freo-Martin, 652

Freund, 350, 493, 522, 524

Friedländer, 548

Fries, $59 n$.

Frog, breeding season of, 20 sqq. ; maturation in, 133 ; oviposition in, 140, 141; insemination in, 184; fertilisation in, 187, 216, $221 ; 234,277,278,300$; experiments on testes of, 312 sqq., 350 . See also under Rana

Frommel, 366, 494

Fürbringer, 236, 287

Fürth, von, 280

Fürth, von, and Schneider, 481
Gadow, 20, 23, 24

Gadus morrhua, 291

Galabln, 66, 83, 86, 139, 160, 533 sq., 615

Galago agisymbanus, 396, 410

Galeopithecus, 377

Galeopithecus volans, 98

Galgulus oculatus, 634

Gallus bankiva, 591

Gramecock, 653

Gametic selection, $202 s q q$.

Gamgee, 267, 401

Garner, 63

Garrod, 247

Gaskell, 254, 350

Gassner, 497, $547 s q$.

Gasteropods, 133

Gautier, $181 s q$.

Gawronsky, 526 !

Gayal, nestrous cycle in, 49

Gazella dorcas, 49

Gazelle, 247

Gebhard, $84 s q ., 87 s q ., 89$

Geddes and Thomson, 30, 164, 165, $175,191,623,626$ sq., 646 sq., 651

Gellhorn, 74, 576, 584

Geppert, 514

Gerbillus hertipes, 40

Gerhardt, 141, 244

Gerlach, 132

Gestation in Mammalia, 32 ; guinoapig, 42 ; sheep, 46 ; cattlo, 47 ; camel, 49 ; sow, 50 ; mare, 51 ; elephant, 52 ; dog, 54 ; wolf, 55 ; fox, $i b$.; Cape hunting dog, $i b$. ; domestic cat, 56 ; wild cat, 57 ; lioness, 58 ; tigress, $i b$. ; puma, ib. ; bear, $i b$. ; badger, $59 n$. ; walrus, 60 ; hedgehog, 61 ; apes and monkeys, 65 ; duration of, 73 sq., $544 s q$.

Geyelin, 590

Geyl, 543

Glacominl, 151, 380

Glacosa, 277

Glerke, 508

Gies, 222, 300

Gllbert, 247

Gilchrist and Jones, 564

Giles, 68, 547

Giraffe, œstrous cycle in, 49, 247. 400

Girtanner, 358

Glass, 331

Gley, 240. See also Camus and Gley

Gnu, œestrous cycle of, 49 
Goat, œstrous cycle in, 64 ; inbreeding in, 214; 231; lactation in, $555,558,567,571 s q ., 584$

Godet, 431

Godle wsky, 199

Godman, 67

Gofton, 142

Göhre, 463

Goltz, 22, 253, 329, 490, 538

Goltz and Ewaid, 329, 490, 538, 577

Goodslr, 358 8q.

Goose, fertility of, $591 \mathrm{sq}$.

Gordon, 331, 607

Gorilla, ostrous cyclo in, 63

Gottschalk, 477

Gottschau, 350

Graele, von, 342

Grassi, 627

Grassi and Sandlas, 627

Grifliths, 238, 240

Grlgorleff, 319

Grohmann, 48

Gross, 306

Grouse, 315

Gruber, 235

Gruenhagen, 253

Grünbaum, 579. See also Gürber and Grünbaum

Guaita, von, 208

Gudger, 652

Guillot, 513

Guinea-fowl, 635

Guinea-pig, maturation in, 132 ; ovulation in, 135 ; 150,156 ; artificial insemination of, 183,234 ; male accessory reproductive organs in, $232,234,236 ; 273$, 286; castration in, 306, 310 , 349 ; ovariotomy in, 320,343 ; 328,349 ; foetal nutrition in, $374,400,439,442-7,466$; lactation in, 568, 578 ; fertility of, 590,607 ; growth in, $664 \mathrm{sq}$.

Guldberg and Nansen, 53

Gull, breeding of, in captivity, 592

Günther, 184, 251

Gürber and Grünbaum, 508

Gurney, 315,680

Gusterosteus spinachia, 30

Guthrle, 320

Guyer, 635,657

Gymnura, 61, 377

\section{H}

Haddon, 600, 614

Hage mann, 54, 500 sqq., 504

Halban, $320,332,334,492,524$, $579,5818 q$.
Haldane, 52

Haller, $400 \mathrm{sq}$.

Halli burton, 562, 564

Hamm, 165

Hammarsten, 264, 277, 278

Hammond, 606

Hamster, 241

Hand mann, 676

Hare, 588

Harper, 139 sqq.

Harrington, 17

Hart, Berry, 652

Hart and Gulfand, 366

Hartung, 266

Harvey, 187, 357, 400, 681

Hasselbalch, 274. See also Bohr and Hasselbaich

Hausmann, 135

Haycraft, 71

Heape, 26, 32 sq.; the oestrous cycle, chap. ii., passim, 79, 85 sqq., 89-97 passim : the ovary, $127,133-9,154,158,163$; in. semination, 180-5 passim, 609 $s q q$. ; 209, 330, $334 s q$. ; placenta, 372 sq.; 495, 583 sq., 596 sq., 617 sqq.; sex-determination, 641-6

"Heat," 26, chap. ii., passim ; and menstruation, 110,329 sqq.; and ovulation, 135 ; cause of, 329

Hedgehog, breeding season of, 60 sq., 238; 240, 252, 337 ; fœtal nutrition in, 367 sqq., 374,377 , 390 sqq., 420, 447-452, 469; 552

Hegar, 304

Heldenhain, $560 \mathrm{sq}$.

Heil, 74

Heim, 282

Heinriclus, 364, 414, 416, 521

Helme, 527 sq., 530, 549

Hemitragus jerulaicus, 47, 48

Henders on, 349, 550

Henking, 633

Henneguy, 156

Hennlg, 366

Henriques and Hansen, 270

Hensen, 371, 443

Herbst, 220, 315

Herdman, 17

Herff, von, 329,526

Hergesell, 138

Herlitzka, 320

Hermaphroditisın, 650 sqq.

Heron, 621

Herring, 279, 297

Hertwig, 187, 191, 217, 219, 376, 389

Herwerden, van, 60, 62, 63, 89, 96 sqq., 137, 536 
Heukelom, von, 466, 470, 473

He wltt, 13, 131, 226

Hlckson, $1998 q$.

Hikmet and Regnault, 304

Hildebrandt, 491, 581

Hllger, 277

Hill, $149,3848 q ., 576,585$

Hls, $143,146,162,364,463,466$

Hobday, 332

Hodge, 677

Hofacker, 646

Hofbauer, 362 sqq., 479 sqq., 486, $489,512,516,550$

Hoffmann, $3698 q$.

Hofmelr, 316

Hofmelster, 274, 510, 572

Hogue, 226

Holdich, 305

Hollard, 421

Holophytum, 9

Holzbach, 346

Homans, 356

Home, 189, 609

Honoré, 126 sq., 144

Hopkins and Pinkus, 274

Horse, 229, 234, 252 ; effect of castration on, 307,310 ; fortility of, 599 n., 604 sq. ; 612 ; sexdetermination in, 643 ; growth in, 666 sq., 669,671 ; age attained by, 681. See also Maro

Howlett, 13

Hubrecht, placenta, 361, 367 sqq., 376 sqq., 391-486 passim, 494

Hugounenq, 514

Hulsh, 183, $6108 q$.

Hunter, A., 289 609 John, 184, 315, 358 sq., 466,

Willam, 358

Hurst, 194

Hutchinson, Woods, 350

Huth, 214

Huxley, $3758 q q$.

Hybrids, fertility of, $6038 q . ; 612$

Hydatina, 630

Hydatina senta, 632, 635, 638

Hydra orientalis, 7

Hydromedusæ, 190

Hyena, 250

Hylomys, 61

Hyrax, 387, 420

Ibex, $478 q$.

Ihering, von, 636

In-breeding, $2088 q$. ; effects of, $6018 q q$.

Infusoria, 6, 200

\section{Ingerslev, 520}

Insecta, spermatozoa of, 178, 190

Insectivora, œstrous cycle in, 60 8q. ; fotal nutrition in, 390 sqq., 447-459

Insemination, artificial, $1818 q q$. , $609,8 q q$.

Issako witsch, 632,644

I wanoff, $1358 q ., 183,234,237,604$, $6098 q ., 612$

Izuka, 11, 134

\section{J}

Jacob, 530

Jacobi, 18, 184

Jägerroos, 484, 501, 516

Janko wski, $1498 q$.

Janoslk, 156 \&q., 217

Jassinsky, 360

Jeannln, 523

Jenkinson, 188 sqq., 220, 373, 404, 406,439 sq., 442, 487

Jenner, 24

Jennings, 215

Jentzner and Beuthner, 328

Jouko wsky, 212

Julin, 118

K

Kahlden, von, 85

Kallius, 526

Kaltenbach, 510

Kangaroo, 39

Kastschenko, 360, $3628 q ., 475$

Kazzander, 108, 110

Kehrer, 140, 316, 498, 507, 527

Kelffer, 100, 529 8q., 541, 581

Kellmann, 541

Kellogg, 307, 626

Kelly, 608, 614, 621, 672

Kennedy, 66

Kerr, 18, 28

King, 625,636

Kirkham, 132

Klrsten, 510

Klebs, E., 360

G., 8

Klein, 368, 478

Kleinhaus and Schenk, 343

Knauer, 318 8q., 332

Knott, 584

Kobelt, 251

Kölliker, 118, 143, 146, 156, 158, $165,236,252,359,561$

Kollmann, 467, 494

Kolster, 108, 233, 397, 403, 413, 437, 439,442

Körner, 528 
Kossel, 269, 275, 288 sq., 292, 293, 298

Kossel and Dakin, 292

Kossel and Kutscher, 291

Kossel and Pringle, 291

Kostanecki, 224

Krafft-Ebing, 655

Kraft, 180

Kraus, 513

Krōnig, 353, 548

Kruleger and Offergeld, 490, 538

Krukenberg, 265, 277, 282

Kühne and Ayres, 243

Kundrat and Engelmann, 163, 548

Kupel welser, 205

Kurdinowski, $5278 q ., 530$ 8q.

$\mathrm{K}$ worostansky, 479

L

Lacertilia, 380

Lactation, and the ostrous cycle, 74 ; and pregnancy, $138 \mathrm{n}$., chap. xiii. ; and fertility, 600

Laden burg and Abel, 285

Lamprey, 190, 221

Land wehr, $233,286,572$

Lane-Claypon, 118, 122 sqq., 148, $150,1608 q ., 168,344$

Lane-Clay pon and Starling, 333,573 , 578 8qq.

Lang, 186

Lange, 523

Langer, 560

Langhans, 359 sqq., 366, 477

Langiey, $255,259,525,529$

Langley and Anderson, $2528 q$., $255 \mathrm{sq}$. ., 259, $260 \mathrm{sq.}$., 525, 529

Langstein and Neubauer, 507

Lannois and Roy, 306

Lanz, 511

Lark, 27

Lataste, 41, 106, 233

Lauder, 564

La Valette St. George, 173

Laycock, $31,65,66,316$

Leathes, 482

Lebedeff, $520 \mathrm{sq}$.

Lécallion, 310

Ledermann, 400

Lee, 669,677

Leeney, 536

Leersum, 506

Leeu wenhoek, 165, 184

Lefevre, 224

Lefroy, 13

Lehmann, 558, 566

Lemaire, 510

Lemur, oestrous cyclo in, 62, $978 q$.: ovulation in, 137; fœtal nutrition in, $377,396,410$; fertility of, in captivity, $593 \mathrm{n}$.

Lemuroidea, foetal nutrition in, 408 sqq.

Lenhossék, von, $3638 q$.

Leopold, 83 sq., $366,467,548$

Lepidoptera, 13, 639

Lepidosiren, 18, 28

Lepidosteus, 17

Lepus, 150

Lepus cuniculus. See Rabbit

Lepus variabilis, 41

Leslie, 21

Leuckart, 233

Leusden, 549

Levene, 278, 294

Leydig, 240

Llebermann, 271, 274

Llepmann, 493

Lillie, 52, 221

Limnaa, 14

Limon, 320, 351

Linnet, 593

Linton, 241

Lion, 247

Lioness, œstrous cyclo in, 58

Llpes, 80, 82, $858 q$.

Littlejohn and Plrle, 288

Littorina, 14, 15

Lo Blanco, 14, 16

Lochhead, chap. x., $4358 q$.

Lochhead and Cramer, 269, 273, $302,431,433,435,496,508$

Lock, 191, 196

Lode, 176, 232, 234, 283

Loeb, A., 258 299 sq., 301 sq., 661

L., $150,156,344$

Loe wenthal, 162,347

Loewy, 312, 356

Loe wy and Richter, 355

Loisel, 170, 329

Lombroso and Bolafllo, 585

Longrldge, 546 sq., 549, 551

Lota vulgaris, 291

Lott, 177

Lottia, 221, 224

Lovén, 251

Low, 46, 208

Lubarsch, 286

Lucas-Champonnière, 343

Luclen, 151

Lusk, 563

Luthje, $3548 q$.

Lycaon pictus, 55 sq.

Lydekker, 42, 43, 46. See also Flower and Lydekker

Lyre-bird, 30 


\section{M}

Macacus cynomolgus, 64

Macacus fascicularis, 64

Macacus nemestrinus, $63,65,373$

Macacus rhesus, 63 sq., 89 sqq., 96, 259

Macacus sinicus, 64

Macallum, 297

Macbrlde, 204

McClung, 130, 633

McFadyean, 609

Macgregor, 89

M'Intosh and Masterman, 205

McIlroy, 526

MeIvor, 644

Mackerel, 293

MacLean, 23

Maerdervort, 85

Magnus-Levy, 497, 499, 506 sq., 519

Magnus-Levy and Falk, 356

Maja, 282

Maja squinado, 281

Majert and Schmldt, 285

Malthus, 620

Maly, 281

Mammalia, breeding season of, $268 q q$.; œstrous cycle in, chap. ii. ; spermatozoa of, 174 ; fertilisation in, $190 s q ., 203$; female generative organs in, $2638 q ., 273$; placental classification of, $3758 q q$.

Man, œstrous cyclo in, 65 sqq.; menstrual cycle in, 75 sqq., $1618 q q ., 334$; ovulation in, 137 sqq.; spermatozoa in, 172 sqq.; artificial insemination in, 184 , 609 ; accessory reproductive organs in, chap. vii. ; castration in, 304 ; ovariotomy in, $314,3168 q$., $330 \mathrm{sqq}$. ; fotal nutrition in, 371 , $380,384,388,392,402,463-483$ passim, 487; changes in the maternal organism during preg. nancy in, chap. xi. passim; innervation of female generative organs in, 525 sqq.; parturition in, $5318 q q$. ; prolonged gestation in, 544 sq. ; puerperium in, $5458 q q$. ; lactation in, 553, 562, 566 8qq.; fertility in, chap. xiv. passim; sox-dotermination in, 636 sqq. ; 653, 655 ; growth in, 662 $8 q q ., 6688 q$. ; puberty in, $6708 q$. ; menopause in, 672 sqq. ; sene*. cence in, $675 \mathrm{sqq}$. ; age attained by, $6818 q$.

Mandl, 85, 88, 526

Mandl and Bürger, 346

Manis, 375
Manouvrier, 655

Mansfeld, 268

Marchal, 636

Mare, œestrous cycle of, $50 \mathrm{sq}$. ; ovulation in, 136 ; 159 ; artificial insemination of, $183,185,6108 q$. ; telegony in, $2018 q$.; in-breeding in, 208, 214; ovariotomy in, 332 ; fœtal nutrition in, $3968 q ., 403$ sq. ; parturition in, $5358 q$. ; ges. tation in, 545; lactation in, 554,583 ; fertility of, 595,605 ; abortion in, 613,615 sqq., 619,654

Markhor, $478 q$.

Marmot, œestrous cycle in, $1058 q$. ; corpus luteum in, 149, 247

Marshall, F. H. A., the cestrous cycle, $35,42,99,136$; the corpus luteum, 147, 148, 152 ; $154,202,247,268$; fotal nutrition, 431, 436 ; fertility, 595 sq., 598, 604, 613, 618. See also Carmlchael and Marshall ; Cramer and Marshall ; and Slmpson and Marshall.

Marshall, F H. A., and Cramer, 495

Marshall, F. H. A., and Jolly, 35, $53,56,58,99,135,184,320$, $321,332,341,348,491,504$, 579

Marshall, F. H. A., and Klrkness, 572

Milnes, 78

Marsupialia, ostrous cycle in, 39 ; $141,149,246$; corpus luteum in, 339 ; fœtal nutrition in, $3818 q q$. ; lactation in, 554; mammary glands in, 576

Martin, 69, 86

Maslus, 427, 430

Masquelin and Swaen, 366, 423-4, 494

Mast, 208

Masterman,16,205. See also M'Intosh and Masterman

Matthes, 480

Matthews, 134, 224, 293, 297, 505

Maturation, 125 8qq.; rabbit, 131 ; mouse, 132; guinea-pig, ib. ; bat, ib. ; mole, 133 ; pigeon, ib. ; frog, ib. ; Invertebratos, 133-4

Maupas, 212 8q., 630, 632

Maurel, 498, 508

Maxlmow, 425 sqq., 430 sq.

Mayo-Smith, 71

Mayow, 358

Mead, 217

Meade-Woldo, 59

Meckel, 232

Melsenhelmer, 307 
Mendel, 193 sqq.

Mendel and Leaven worth, 269

Menopause, 353, $672 \mathrm{sqq}$.

Menstruation, in Primates, 62 sqq. ; in Man, 65 sqq., 75 sqq., 161 sqq.; and lactation, $74,334,569$; and "heat," 329 sqq. ; 346,350

Merconitskl, 268

Meredith, 331

Merganser, 315

Meriones longifrons, 40, 545

Meriones shaui, 40, 41, 545

Merkel, 169

Merkel and Bonnet, 526, 561

Merlettl, 481

Merttens, 473,478

Metaphyta, 7

Metazoa breeding season of, 7

Metchnik off, 78, 111, 163, 679 sq., $684 \mathrm{sq}$.

Metœstrum, defined, 37

Mlchaelis, 570

Michel, 499

Mlescher, 18, 279, 288 sq., 292 sq. $2958 q q$.

Milk, uterine, 400 sqq. ; composition and properties of human and cow's, $562 s q q$.; influence of diet, \&c., on yield of, 564 sqq. ; discharge of, 569 ; formation of organic constituents of, $569 \mathrm{sqq}$.

Millais, 48, 52, 53, 55 sq., 59 sqq., 183

Mliroy, 19, 279

Mingazzini, 151

Minot, $79,86,202$; foetal nutrition, $362,366,388,421,463 ; 542$, 590 ; growth, $660,662,6648 q q$. , 676,683

Mlotti, 511

Mlronow, 578

Mlsuraca, 232

Mislawsky and Bormann, 258

Möbius, 30

Mohrike, 63

Mole, breeding season of, 61 ; maturation in, 133; accessory reproductive organs in, 232,238 , 240 ; ovum in, 372 ; fœtal nutrition in, $3768 q . ; 392,456-7$, 485

Mollusca, broeding season of, 13 sqq., 205

Monkeys, œestrous cycle in, $62 s q$. ; menstrual cycle in, 89,335 ; ovulation in, 137,330 ; 255 ; fotal nutrition in, 392, 463 sqq. ; for. tility of, 592

Moncestrous, definition of, 38

Monotremata, œstrous cyclo in, 38
$8 q ., 141$; 244 ; corpus luteum in, 339 ; 357 ; lactation in, 554, 584

Montgomery, 129

Moore and Parker, 571

Morat, 254

Morgan, 8, 12, 140, 199 ; fertilisation, 207, 208, $2168 q$; 305, 604; sex-dotermination, $623,625,635$ sq., 64l sq., 648, 670

Möricke, 84 sq.

Mörner, 274, 279

Morrls, 331

Mosher, 68

Mouse, 40 ; ovulation in, $135 ; 156$; artificial insemination of, 183 ; $3738 q ., 389$; fœtal nutrition in, $420,437-442,449,494 ; 545,605$, 611 ; sex in, 647,650

Mule, 203, 584

Müller, A., 253 F., 519

Fritz, 207

P., 606

Müller and Masuyama, 277

Muntz, 572

Murlin, 503, 507, 518

II $u s, 150$

Mus decumanus. See Rat

Mus minutus, 40

Mus musculus. See Mouso

Mus rattus, 40

Mus sylvaticus, 40

Musk doer, 241

Musk ox, 49, 249

Musk rat, 241

Mustelus lovis, 277, 380

Myliobatis, 151

Mytilus, 205

$\mathrm{N}$

Nagel, 117, 145, 177, 240, 260, 533

Nasse, $5208 q$.

Nathuslus, 46

Nattan-Larrier, 370, 492

Needham, 400

Nematodes, 133, 174

Nematus ventricosus, 627

Nemertea, breeding season of, 10

Neugebaur, 651

Neumann and Vas, 356

Neumelster, 277, 569

Ne wbigin, 29

Ne wcomb, 646, 650

Ne wport, 187

Newsholme and Stevenson, 621

Newt, 23, 184, 300

Nicholson, $5228 q$.

Nlcolas, 247

Nightingale, 25 
Nikolskl, 255

Nlskoubina, 344

Nitabuch, 477

Nolf, $367,419,4608 q q$.

Noorden, von, $68,354,356,497,510$, 513,515

Nudibranchs, 14

Nussbaum, 141, 312 8q., 632

Nycticebus, 408

Nylghau, ostrous cycle in, 49

\section{O}

Oceanu and Babes, 356, 567

Ocneria dispar, 307

Oddi and vicarelll, 519

Gstrus or Gistrum, dofined, 36

Estrous cycle, chap. ii., 335

Offergeld. Sec Kruleger and Offergeld

Ollver, $83,85,138,614$

Onchorhynchus, $30 \mathrm{n}$.

Onuf, 253

Ö̈genesis, chap. iv.

Ophelia, 221

Ophiothrix fragilis, $204 n$.

Opossum, 385, 484

Orang-utan, restrous cycle in, 63

Ornithodelphia, 380

Ornithorhynchus paradoxus, 149

Orton, 653

Orycteropus, 375

Osborne and Campbell, 275

Oser and Schlesinger, 537

Oshlma, 512

Ostwald, $3008 q$.

Ott, 67, 68

Otter, brooding soason of, $59 ; 416$

Oudemans, 239, 307

Ovariotomy, 314, 316 sqq.; and menstruation, $330 \mathrm{sqq}$. ; and pregnancy, $3418 q q$.

Ovary, changes in, during the œestrous cycle, chap. iv.; in. fluence of, 314 sqq. ; Man, 314, 316 sq., 330 sqq.; doer, 314; poultry, $3158 q$. ; rabbit, $3178 q q$. ; guinea-pig, 320 ; rat, 321 sqq. ; internal secretions of, chap. ix. passim ; innervation of, 526

Overlach, 366

Ovis, 150

Ovis ammon, 43

Ovis argali, 43

Ovis burrhel, $428 q$.

Ovis canadensis, 43

Ovis musimon, 42

Ovis poli, 43

Ovis tragelaphus, 42

Ovis vignei, 43
Ovulation, 125 sqq.; rabbit, 134 ; mouse, 135 ; rat, $i b$. ; guinea-pig, $i b$. ; dog, $i b$. ; sow, $i b$. ; ferret, 136, mare, $i b$. ; donkey, $i b$. ; cow, $i b$. ; sheep, $i b$.; bat, 136 sq. ; Primates, 137; Man, 137 sqq. ; Invertebrata, $137 \mathrm{n}$. ; and menstruation, 330,333 n., 335

Ovum, formation of, $160 s q$. chap. x., part ii., passim ; the ovarian, $370 \mathrm{sq}$. ; the fertilised, $3718 q q$.

Owen, $31,42,61,247,359$

$\mathrm{Ox}, 288,296,306,349,486$

\section{$\mathrm{P}$}

Pachyuromys duprasi, 41

Paladino, 146

Palolo worms, 10 sq., 134

Paludina, 175, 633

Papio, 63

Papio porcarius, 64

Paramocium, 6, 212 sqq.

Paramacium caudatum, 211

Parthenogonesis, 216 sqq.

Parturition, 527 sqq.; human, 531 sqq., 538 ; other Mammalia, 535 sqq. ; nervous mechanism of, 537 sqq.

Patella, 14, 216, $224 n$.

Paterson, 143, 365

Paton, Noel, 18, 19, 278 sq., 349, 496,508

Paton, Kerr, and Watson, 434, 508

Payer, 511, 520 8q.

Payne, 634

Pearl, 211

Pearl and Surface, 333, 605, 651

Pearson, Karl, 202, 605, 684

Pearson, Lee, and Bramley-Moore, 605

Peel, 681

Pelican, 30

Pelikann, 235

Pelodytes, 203

Pembrey, 272

Pepere, 349

Perameles, 39, 339, 384 8q.

Perch, $2778 q$.

Perez, 158, 176, 217, 629

Peripatus, 11

Perry-Coste, 72

Peters, 361, 366, 466 sq., 469, 471, $473,479,515$

Petrel, stormy, 26

Petrunkewltsch, $628 \mathrm{sq}$.

Pfannenstlel, 264, 368

Pfeffer, 215 
Pfister, 578

Pflüger, 114, 116, 124, 143, 203, 313 sq., 329, 436, 518

Pflüger and Smith, 203

Phalarope, 30

Phascolarctus cinereus, 39

Pheasant, 315

Phylloxera, 635 sq.

Plecolo and Lieben, 263

Pick and Pineles, 523

Piérl, 299

Pig, 208, 371, 668. See also Sow

Pigeon, maturation in, 133 ; ovula tion in, 139 sqq.; fertility of $5918 q$.

\section{Pinard, 545}

Pine-marten, breeding season of, 59

Pisces, breeding season in, $168 q q$. ; spermatozoa in, 174 ; fertilisation in, 190

Pittard, 306

Plzon, 222

Placonta, as an organ of nutrition, chap. x., 491 sqq.

Placotus, 148

Plaice, 17

Plimmer, 270, 275

Plimmer and Scott, 268

Plönnis, 183, 611

Ploss, 70

Plover, golden, 25

Pocock, 63 sqq., 96, 137, 306

Poehl, 236, 285, 309

\section{Polaillon, 532}

Polecat, breeding season of, 59

Polynoe, 224

Polyoestrous, definition of, 38

Polyphemus, 174

Polypterus, 17, 28

Polypterus bichea, 17

Polypterus laprodei, 17

Polypterus senegalis, 17

Polyspermy, 190

Poncet, 306

Porcher, $571 \mathrm{sqq}$.

Porpoise, breeding period of, 53

Porter, 669

Potthast, 54

Potts, 308, 640, 653, 658

Praopus hybridus, 636

\section{Pratt, 0}

Pregel, 309

Pregnancy, 138 n., chap. x. passim; changes in tho maternal organism during, chap. xi. ; body-woight during, $4978 q$.; protein metabolism in, 498 sqq. ; carbohydrate motabolism in, 507 sqq. ; metabolism of fats in, 511 8qq. ; metabolism of metals and salts in, 514 sqq.; respiratory exchange during, 517 sqq. ; changes in matornal tissue during, 520 sqq.

Prenant, 336

Prepotency, defined, $206 n$.

Prévost, 184

Preyer, 358, 365

Primates, œestrous cyclo in, $62 \mathrm{sqq}$.; ovulation in, 137 ; 374 ; foetal nutrition in, 392 sqq., 402, 463482,484 ; lactation in, 553

Prje walsky, 43

Proboscidia, fœtal nutrition in, 387 8q., 419 8q.

Prochownick, 496

Proœstrum, defined, 36 ; significance of changes during, $1618 q q$.

Prostate gland, 235 8qq.

Protopterus, 18

Protozoa, brceding season of, $68 q$. ; 200 ; conjugation in, 211 8qq. ; immortality of, 682

Przibram, 134, 190

Pteropus, 62

Pteropus edulis, 462

Puberty, 670 sq.

Pucrperium, 545 sqq.

Puma, œstrous cycle of, 58

Punnett, 194, 624, $6328 q ., 6398 q$. , 649,657

Punnett and Bateson, 639

Purpura lapillus, 14

Pussep, 254

Pyrrhocoris, 633

Q

Quagga, Lord Morton's, 201

$\mathbf{R}$

Rabbit, astrous cycle in, 37,41 , $10589 q$. ; changes in the ovary of, $123,128,131,1348 q ., 139,144$, $149,154,156,158$ sq., 160 ; spermatozoa of, 177, 180; artificial insemination of, 183 sq., 234; fortilisation in, 187; in-breoding in, 214 ; accessory reproductive organs in, 232, 252, 254 sqq., 260 ; 269,273 ; ovariotomy in, 317 sqg., 338 ; 328, 343 sq. ; liystercetomy in, $3478 q$.; 349 ; fotal nutrition in, $369,3728 q q ., 380,388$ sqq., $405,420-436,481,483,486$ sq., 489 n. ; pregnancy in, 494 sqq., 498,500 sq., 508, 512, 515; fomalo generativo organs in, 525 , 527 sqq.; parturition in, 537; lactation in, 553; growth of 
mammary glands in, $573 s q q$. , $5788 q q$.; fertility of, 588, 591, 594, 601, 607: sex in, 643; growth in, 662,665

Raciborsky, 47, 138

Raja, 277

Raja batis, 636

Rana arvalis, 203

Rana fusca, $202 s q$.

Rana limnocharis, 22

Rat, œestrous cycle in, 37, 40, $1058 q q$. ; changes in the ovary in, 123 ; ovulation in, $126 ; 135$, $183,234,236$; influence of ovary in, $3218 q q ., 341,343$; hysterectomy in, 348 ; 355,368 ; ovum in 372 ; 389,420 ; parturition in. 536 ; lactation in, 555, 579: fertility in, 587,595 ; 637 ; sex in, 650 ; growth in, 662

Rauber, 365

Raudnitz, 564

Rauther, $2338 q$.

Raven, 26

Ray, 358

Réaumur, 12

Redstart, 315

Regaud and Dubreuil, 607

Regaud and Policard, 336

Regnard, 514

Rehfisch, 231

Reichert, $4428 q$.

Reid, 358 8q.

Rein, 537

Reinke, 286

Reinl, 67, 68

Rémy, 259

Rengger, 55

Repreff, 499

Reptilia, breeding season of, 23 ; fertilisation in, $190 ; 273$

Retraction, mechanism of, $2518 q q$.

Retterer, 100, 251, 254

Retzius, 175

Rhacophorus leucomystax, 22

Rhinoceros, 247

Rhodites, 638

Ribbert, 314, 319, 578, 656

Rieder, 520

Rieländer, 481

Riemann, 528, 537

Ries, 335

Rink, 54

Robertson, $6608 q q$.

Robinson, 371 sqq., 376, 389, 395 $411,413,416$

Rodentia, cestrous cycle in, $40 \mathrm{sqq}$. 232 n., 241 ; accessory reproduc. tive organs in, 244, $2468 q$. ; foetal nutrition in, $388 s q q ., 420 s q q$, ; gestation in, 545; puerperium in, 551 ; lactation in, 554 ; fortility in, 587,$592 ; 671$

Röhrig, 528, 577

Rolleston, 458

Rollinat, 186

Rolph, 627

Romanes, 206

Rommel and Phillips, 605

Rörig, 314

Ross, $13 n$.

Rossi, Pierro, oxperiment by, 182

Roth, 180

Rouget, 140 , 526

Routh, 538 \&7., 577

Roux, 216

Rubaschkin, 132, 135

Rubinstein, 319

Runge, E., 671 - M., 530

Ruticilla phœnicurus, 316

Rutting season, defined, $358 q$.

\section{S}

Sadier, 646

Sagartia troglodytes, 8 sq., 679

Sainmont, 121

Salamander, 23, 177

Salamander maculosa, 186

Salmon, 18 sq., 28, 31, 278 sqq., 288, $2928 q ., 295$

Salvi, 62

Sanderling, 24

Sandes. 149, 158, 337, 339

Sänger, 365

Sanson, 629

Sányál, 63

Sarcophytum, 9

Saunders, 194

Sauropsida, 378, 380

Sau vé, 320

Savarè, $4818 q$.

Sawflies, $131 n ., 629$

Schäfer, 24 sq., 116 sq., 153, 556, 562, 565,569

Scharf, 55

Schenk, 630. See also Kieinhaus and Schenk

Schmidt, Albert, 358, 405, 446 H., 47

Schmiedeberg, 297, 299

Schmorl, 493

Schneide mühi, 240

Schörndorff, 54

Schottiänder, $156 \mathrm{gqq}$.

Schrader, 516

Schreiner, 28;

Schröder, 68 
Schrön, 118

Schulin, $1568 q$.

Schultz, 320

Schultza, 393, 642, 647, 650

Schutz, 532

Sch welgger-Seldel, 173

Sciumes vulgaris, 41

Sclater, 65

Sclerophytum, 9

Scorpion, 350

Scyllium, 277

Seal, gestation of, 32 ; broeding season of, $59 \mathrm{sq}$.

Sea-urchin, 199, 225, 301. See also under generic names

Sedg wick, $6,73,186$

Seeliger, 199

Seltz, 149, 156, 158

Selenka, 382, 392, 420, 465

Seligmann, 305, 306. See also Shattock and Seligmann

Semen, chemistry of, $2828 q q$.

Seminal fluid, 176

Semnopithecus entellus, 63, 89 sqq., 97

Semnopithecus nasicus, 464

Semon, 18, 38, 39

Semper, 10, 12, 14, 15, 22, 31

Senesccnce, $6758 q q$.

Sep8, 151

Seps chalcides, 380

Serralach and Parès, 238

Serres, 528

Sertoli, 253

Seubert, 232

Sex, determination of, chap. xv.

Sfameni, 68

Shad, 18

Sharpey, 400, 466

Shattock and Sellgmann, 311, 315

Sheep, 26 ; dicestrous cycle in, 37 ; œestrous cyclo in, 42 sqq., 107 sqq. ; ovulation in, 136 ; corpus luteum in, $147 \mathrm{sq.,} 152$; 183 ; Mondelian experiments on, 198 ; in-breeding in, 209 ; accessory reproductive organs in, 229, $2478 q$. ; castra. tion in, 306 ; fœtal nutrition in, $371,376,380,386,3968 q ., 400$; $403 s q ., 407,417,127,435,484$, 487 ; pregnancy in, 495, 508, 520 ; parturition in, 535 ; lactation in, $5548 q$. ; fertility in, 590 sq., 596 sqq., 604; abortion in, $6128 q ., 617$ sqq. ; growth of, 668 ; age attained by, 681

Sherrington, 255, 259, 330

Shortt, 44, 47

Shrew, breeding season of, 60 ; fœtal nutrition in, 372,377 , $3918 q ., 452-5$
Siebold, von, 186, $628 \mathrm{sq}$.

Sigismund, 162

Silkworm moth, 184, 217, 280 8q., 307,626

Simocephalus, 632, 644

Simpson, Sir James, 537, Е41

J. Y., 213

Simpson (Sutherland) and Marshall, 262

Sims, 609

Sinéty, 510. Spe also De Sinéty

Siphostoma florida, 652

Sipunculids, 224

Sirenia, 376 8q., 553

Sixta, $38 n$.

Skin, changes in, during prognancy, 523

Slemons, $499,505,517$

Slocum, 524

Sloth, 402, 553

Slo wtzoff, 283

Smith, F., 314, 536, 667, 669, 678

Geofirey, 308, 640, 653, 658 Tyler, 542

Smyth, 126

Snail, 186

Snakes, scent-glands of, 31

Snipe, 27

Sobotta, 42, 132, $1438 q q ., 150,156$, 233,439

Sokoloff, 317

Soli, 349

Somerset, 58

Sow, œstrous cycle in, 50, 334; ovulation in, 135 ; 145 ; in-breed. ing in, 208; fœetal nutrition in, 386,394 sqq., 403, 484; parturition in, 537 ; fertility of, 586 , $591,600,605,671$

Spallanzani, 4, $198 q ., 22,23,56$, $140,165,181$ sqq.. 203

Sparrow, 24, 26, 157

Specht, 607

Spee, von, 363, 393, 443 sqq., 449, 466

Spencer, Herbert, 587 sqq.

Spermatogenesis, chap. v.

Spermatozoa, structure of, 172 sqq. ; movements of, 176 sqq.; chemo. tactic propertics of, $214 \mathrm{sqq}$.; chemistry of, 288 sqq.

Spermophilus, 150

Sphxrechinus, 179, 300

Spharechinus granulosus, 293, 300

Spider crab, 307

Splegelberg, $5428 q$.

Spiegelberg and Gscheldlen, $5208 q$.

Spina, 254

Spinax, 151 
Spitzer, 299

Sorex, 144, 150

Stag, breeding season of, $27 s q$.; effects of castration on, 305

Starfish. Seo Asterias

Stark weather, 647

Starling, 26

Starling, 335, 352, 492. See also Lane-Claypon and Starling

Steinach, 234, $2368 q$.

Steinhaus, $89,5608 q$.

Stenops, 250

Sterility, $6068 q q$.

Steudel, 294, 295, 296

Stevens, 12, 631, 633

Stevenson, $678 q$. See also Newsholme and Stevenson

Stllling, 232, 240, 350

Stoat, breeding season of, 59

Stöckel, 146

Stolz, 512

Stonehenge, $538 q$.

Strahl, 361, 364, 376, 403, 410, 413 sq., 416, 456, 458, 551 sq.

Strasburger, 187, 215

Strassmann, 85, 185, 329

Stratz, 61, 62, 97, 113

Stricht, van der, 122, 132, 137, 148, $150,156,460$

Strongylocentrotus, $2048 q$.

Strongylocentrotus lividus, 300

Strongylocentrotus purpuratus, 219

Sturgeon, 18

Stychostemma asensoriatum, 10

Stylonychia, 212

Stylonychia pustulata, 6

Suchetet, 604

Superfœtation, 159 sqq.

Sutton, 130 Bland, 89, 95, 97, 343

Swan, 26

Swayne, 49

Swifts, 25

Symplasma, defined, 414

Szabó, 561

\section{$\mathrm{T}$}

Tadpole, $6248 q$.

Tafanl, 135, 403

Tait, 163, 522

Talpa, 250

Tandler and Gross, 306

Tangl, 272, 434

Tangl and Farkas, 273, 302

Tapir, 247

Tarchanoff, 22, 234, 275

Tarsius, 144, 150; fotal nutrition in, $408,410,463,494 ; 552$

Tarsius spectrum, 62, 97 sq., 137, $551 n$.
Tchermak, 193

Teacher, 138. See also Bryce and Teacher

Tegetmeler and Sutherland, 584

Telegony, $2018 q$.

Teleosts, 16, 151, 277

Tennent, 226

Tenrec, 458

Tergipes, 15

Termite, 627

Terrler, 516

Tessler, 545

Testis, influence of, $303 \mathrm{sqq.}$; in Man, $2 b$. ; stag, 305 ; fallow deer, ib. ; sheep, 306 ; horse, 307,310 ; arthropods, 307 ; fowl, 311 8q. ; frog, $3128 q q$. ; relation between thymus and, $349 ; 353$

Thle mlch, 495,512

Thierfelder, 569,572

Thierfelder and Stern, 267

Thompson, 289

Thomson, J. A., 165, 201, 623, 648. See also Geddes and Thomson H., 507

Thudichum, 264, 267

Thury, 630

Thymus, relation between testis and, 349

Tichomiroff, $217,2808 q$.

Tiedemann, 241

Tiger, 247

Timofee w, 258

Toad, breeding season in, 20 ; ovulation in, $140 ; 300$

Torelle, 216

Tortoise, 22, 31, 278, 680

Tread well, 224

Treat, 625

Trematode, 10

Trevlranus, 192

Triton, 174

Triton alpestris, 202 sq.

Triton ualtlii, 22

Tropidonotus, 277

Tropidonotus viperinus, 186

Truzzi, 523

Tupaia, 144, 150, 250, 377, $4578 q$. , $494,552 n$.

Tupaia javanica, 61, 98 sq., 372, $392,4578 q$.

Turbot, 205

Turner, 60, 359, 361, 369, 376, 388, $395,401,408,410,463$

Twins, pygopagous, 585

U

Ulesco-Strogano wa, 479

Ungulata, œstrous cycle in, 42 ; 
fœtal nutrition in, 375,386 , $394 s q q ., 417 s q ., 484$; lactation in, $5538 q$. ; fertility in, 586

Uterus, structure of, 75 sqq. ; changes in, during oestrous cycle, chap. iii.; significance of provestrous changes in, 161 sqq. ; supposed internal secretion of, 345 sqq. ; innervation of, 527 sqq.

\section{V}

Surnames with van and von are in. dexed under name following.

Valenciennes and Frémy, 278

Vaientin, 114, 252

Vallet, 526

Vaughan, 264

Veit, $493 s q ., 506,523,587$

Veit and Scholten, $480,493,515$

Ver Eeke, 498, 500 sq., 503, 516

Vernhout, 456

Vernon, $203 s q$.

Verworn, 178 sq., 197, 200, 299, $570,659,683$

Vesiculr seminales, 231 sqq.

Vesperigo, 148, 150, 156

Vesperugo noctula, 132

Vespertilia, 148

Vicarelli, 68. See also Oddi and Vicareili

Virchow, 559, 570

Voit, 510

Völker, 149

W

Wade and Watson (B. P.), 369, 474

Waideyer, $1148 q q ., 143,184,271$, 358 sq.

Walker, C. E., 312

Walker, G., 237, 239, 309 sq.

Wailace, A. R., 27, 603

Cuth bert, 239, 303

R., 17 ; astrous cycle, 45,47 , 50,$51 ; 151,214,248,307,495$; lactation, 566 sqq.; fertility, $596,599,600,604,608 ; 616$; 654

Wailart, 354

Walrus, breeding season of, 49, 60 ; 246

Walther, 278

Wapiti deer, cestrous cycle in, 49 ; $305 n$.

Water-buck, œstrous cycle in, 49

Watson, M., 250

B. P., 565. See also Paton, Kerr, and Watson

Chalmers, 595
Weasel, breeding season of, 59

Webb, Sidney, $621 s q$.

Weber, 313,358 sqq., 375

Webster, $80,138,164,367,474$, $476 s q$.

Welchardt and Opitz, 493

Weil, 135

Weininger, $654 s q q$.

Weinland, 302

Weismann, 172, 191, 192 sqq., 628, $631,6798 q ., 6828 q$.

Weiss, 292

"Wellenbewegung" hypothesis, 67, 164

Wendeier, 118, 145

Westermarck, $70 \mathrm{sq}$.

Westphalen, 82 sq., $85,87,89$

Werth, 369

Whales, breeding period of, $528 q$. ; age of, 680

Wheeier, 629

Whetham, 622

Whitney, 7

Widal, 517

Widgeon, 315

Wiedershelm, $554 \mathrm{sq}$.

Wiener, 365

Wild, 520

Wilicock and Hardy, 275

Willey, 16

Wiiliams, Whitridge, utorus, 85, 88 ; $149,180,336$; female generative organs, 532 sq., 540 sq., 543 sq., 548 sq., 551; 565 sqq., 587,632

- Sir J., 83, 549

Wilson, E. B., changes in the ovary, $113,122,130,131$; spermatogenesis, $172,174,175 ; 190,216$, 226,356 ; sex-determination, 633 , 636

S. M., 48

Wiitshíre, $19,25,39,50,62,66$

Winckel, 505, 517, 522

Winckelmann, 520

Wini water, van, 117 sq., 131

Winkier, H., 300

- F. N., 360

Winterhaiter, 329

Winterstein and Stickler, 524

Win wood Reade, 63

Wohigemuth, 276

Wolf, breeding season of, 55

Woile, 513

Wood, 198

Woodruff, 214

Worth mann, 250

Wright, 23, 316

Wychgei, 516, 523

Wyder, 88 


X
Xenia hicksoni, 9
Xenopus lavis, 20 sqq.
Y
Yak, 49 478 ; nutritive import-
Yolk-sac, 37.
ance of, 380 sqq.
Yule, 621
Youatt, 334
Yung, 625

Z

Zacharjewsky, 497 sq., 503, $5058 q$. , 510

Ziegler, 641

Zoarces, 151

Zoth, 309

Zuntz, L., 68, 355

- E., 519

Zweifel, 50J

$\mathrm{Z}$ weifel and $\mathrm{Abel}, 346$ 


\section{A LIST OF WORKS ON MEDICINE，SURGERY AND GENERAL SCIENCE}

\section{CONTENTS}

ANATONY

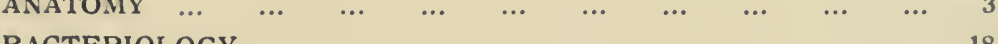

$\begin{array}{lllllllllll}\text { BACTERIOLOGY } & \ldots & \ldots & \ldots & \ldots & \ldots & \ldots & \ldots & \ldots & \ldots & 18\end{array}$

$\begin{array}{llllllllllll}\text { BIOLOGY } & \ldots & \ldots & \ldots & \ldots & \ldots & \ldots & \ldots & \ldots & \ldots & \ldots & 13\end{array}$

$\begin{array}{lllllllllll}\text { CHEMISTRY } & \ldots & \ldots & \ldots & \ldots & \ldots & \ldots & \ldots & \ldots & \ldots & 20\end{array}$

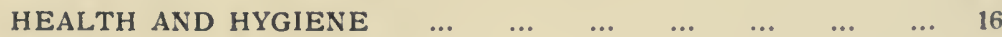

INDEX

$\begin{array}{llllllllllll}\text { MIEDICINE } & \ldots & \ldots & \ldots & \ldots & \ldots & \ldots & \ldots & \ldots & \ldots & \ldots & 3\end{array}$

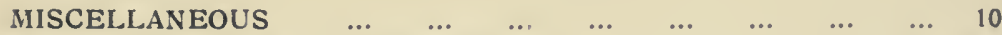

$\begin{array}{llllllll}\text { MONOGRAPHS ON BIOCHEMISTRY } & \ldots & \ldots & \ldots & \ldots & \ldots & 24\end{array}$

OPTICS

$\begin{array}{lllllllllll}\text { PHOTOGRAPHY } & \ldots & \ldots & \ldots & \ldots & \ldots & \ldots & \ldots & \ldots & \ldots & 19\end{array}$

$\begin{array}{lllllllllll}\text { PHYSIOLOGY } & \ldots & \ldots & \ldots & \ldots & \ldots & \ldots & \ldots & \ldots & \ldots & 13\end{array}$

$\begin{array}{lllll}\text { PROCEEDINGS OF THE ROYAL SOCIETY OF MEDICINE } & \ldots & 12\end{array}$

$\begin{array}{llllllllllll}\text { SURGERY } & \ldots & \ldots & \ldots & \ldots & \ldots & \ldots & \ldots & \ldots & \ldots & \ldots & 3\end{array}$

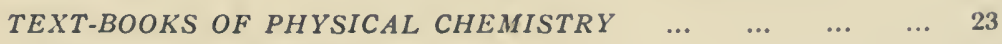

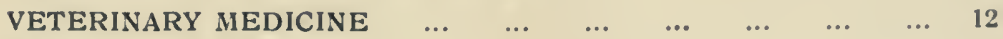

$\begin{array}{llllllllllll}\text { ZOOLOGY } & \ldots & \ldots & \ldots & \ldots & \ldots & \ldots & \ldots & \ldots & \ldots & \ldots & 13\end{array}$

\section{LONGMANS GREEN \& CO.}

39 PATERNOSTER ROW LONDON EC.

FOURTH AVE. \& THIRTIETH ST. NEW YORK

8 HORNBY ROAD BOMBAY

$3 \circ 3$ BOWBAZAR STREET CALCUTTA 


\section{INDEX.}

Abney's Photography

Armitage's A History of Chemistry

Armstrong's Simple Carbohydrates and the Glucosides

Arrhenius's Text-book of Electro-Chemistry Theories of Chemistry ...

Ashby's Healti in the Nursery Notes on Physiology and Wright's The Diseases of C̈hildren

Bain and Edgecombe's Harrogate Waters...

Baly's Spectroscopy

Barnett's Making of the Body....

Bayliss' Nature of Enzyme Action

Beddard's Elementary Practical Zoology

Bell's Principles of Gynæcology

Bennett's Abjominal Hernia - On the Use of Massage

On Varix: Its Causes and Treatment

Recurrent Effusion into the Knee-

Joint after Injury Treatment of Simple Fractures

_ Varicose Veins

Bidgood's Practical Elementary Biology

Bose's Comparative Electro-Physiology

Plont Response

Response in Living and Non-Living

Brodie's Essentials of Physiology

Buckton's Health in the House

Bull's Hints to Mothers...

Maternal Management of Children

Bunge's Organic Chemistry for Medical Students

Butterworth's Manual of Household Work

Cabot's Clinical Examination of the Blood..

Chapman's The Foraminifera ...

Charities Register and Digest ..

Cheyne and Burghard's Manual of Surgical Treatment

Coats' Manual of Pathology

Cooke's Aphorisms in Applied Anatomy Tablets of Anatomy

Corfield's Laws of Health

Creighton's Economics of the Household

Crookes' Methods in Chemical Analysis

Curtis' Practical Bacteriology ...

Dakin's Handbook of Miduifery

Desch's Metallography

Dickson's The Bone Marrow ....

Donnan's Thermodynamics

Drude's Theory of Optics

Ellis' Outlines of Bacteriology...

Findlay's Phase Rule and its Application Physical Chemistry

- Practical Physical Chemistry ...

Fit zwygram's Horses and Stables

Fowler and Godlee's Diseases of the Lungs

Frankland's Bacteria in Daily Life

Friend's Theory of Valency

Furneaux's Human Physiology Practical Hygiene

Gaskell's The Origin of the Vertebrates

Glazebrook's Physical Optics

Goadby's Mycology of the Mouth

Godfrey's Elementary Chemistry

Goodsall and Miles' Diseases of the Anus and Rectum

Gray's Anatomy, Descriptive and Applied ...

Halliburton's The Essentials of Chemical Physiology

Hanson's and "Dodgson's ' Intermediate

Course of Laboratory Work in Chemistry

Harden's Alcoholic Fermentation

Hardy's Colloids

Hare's The Food Factor in Disease ...

Hayes' Training and Horse Management

Hobart's Medical Language of St. Luke

Hopf's Human Species

Hopkins Development and Present Position of Biological Chemistry

Hudson and iosse's The Rotifera

Influence of Heredity on Disease

Inquiry into the Phenomena attending Death by Drowning

James's Ball Games and Breathing F. xercises King's College Hospital Cooking Recipes Klöcker's Fermentation Organisms

Leathes' The Fats

Lehfeldt's Electro-Chemistry ...

Ling's The Polysaccharides

Lloyd and Bigelow's Teaching of Biology ... Luff's Text-book of Forensic Medicine

Macalister's Systematic Zoology of the Vertebrate Animals

.

20

Macalister's Zoology of the Invertebrate Animals Macdougall's Elementary Plant Physiology I4 Text-book of Plant Physiology ... I4 Iees' Atlas of Absorption Spectra ... $\quad$... 19 Mellor's Chemical Statics and Dynamics ... 23 Iendeléeff's Principles of Chemistry $\quad . . .20$ Ieyer's Outlines of Theoretical Chemistry 20 Monographs on Bi -chemistry ... ... ... 24 Ioon's Relation of Medicine to Philosophy II Moore's Elementary Physiology ... ... 15

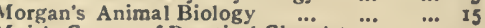
Muir's Course of Practical Chemistry ... 2 ... Newth's Chemical Lecture Experiments ... 21 - Elementary Practical Chemistry ... 2 I _- Manual of Chemical Analysis... $\quad . . .2$ 2I - Smaller Chemical Analysis ... ... - Text-book of Inorganic Chemistry... 2I Notter and Firth's Hygiene ... - Practical Domestic Hygiene ... $\quad \ldots . . \quad$ I7 Osborne's Vegetable Proteins... $\quad . .2 \quad \ldots .24$ Ostwald's Principles of Chemistry $\ldots . \quad \ldots .21$ Paget's Memoirs and Letters ... $\quad . . . \quad$... Perkin's Methods of Electro-Chemistry ... 2 I Qualitative Chemical Analysis ... 2 I Pettigrew's Design in Nature ... ... ... II Plimmer's Constitution of the Proteins $\ldots .24$ Pollok's Practical Spectographic Analysis I9, 23 Poole's Cookery for the Diabetic ... ... II Poore's Colonial and Camp Sanitation $\quad \ldots .17$ $\begin{array}{lllll}\text { - Essays on Rural Hygiene } \quad . . & \ldots & \text { I7 }\end{array}$

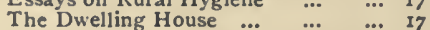
The Earth in Relation to Contagia ...

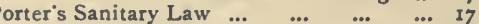
… 17

Price and 'T wiss' Organic Chemistry ... $\quad \ldots . .21$ Probyn-Williams' The Administration of

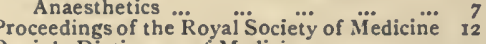
Quain's Dictionary of Medicine (Ith Edition)... Radclifle and Sinnatt's Practical Organic

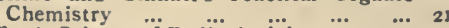

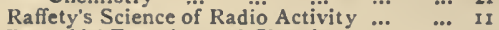
Reynolds' Experimental Chemistry ... ... 2I Robinson's Health of our Children in the
Colonies $\ldots . . .$.

Schäfer's Essentialis of $\ddot{H}$ istology $\ldots \begin{array}{lllr}\ldots & \ldots & \ldots & 17 \\ & \ldots & 9\end{array}$

- Practical Physiology ... $\ldots . . . . \quad$ I5

Schryver's Characters of the Proteins $\ldots .24$

Sheppard and Mees' Photographic Process... I9

Sheppard's Actinochemistry ... $\quad \ldots \ldots \ldots c 23$ male and Colyer's Diseases and Injuries
of the Teeth ... ... ...

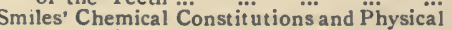

Properties ...
Smith and Hall's Teaching of Chemistry and Physics in Secondary School ... 21

\begin{tabular}{llllr}
\hline Handbook for Midwives & $\ldots$ & $\ldots$ & 9 \\
Steel's Diseases of the Ox & $\ldots$ & $\ldots$ & $\ldots$ & I2
\end{tabular}

Stevenson's Wound $\begin{array}{llll}\text { Sheep } & \ldots & \ldots & 12 \\ \end{array}$

Stewart's Physical and Inorganic Chemistry 22 Chemistry Advances in Organic

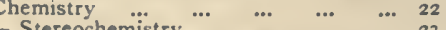

Sutherland-Gower's Cleanliness versus Cor- $\quad \ldots 23$ ruption.. Symington and Rankin's Atlas of Skiagrams Io Text-Books of Physical Chemistry $\quad . . \quad \quad \ldots \quad 23$

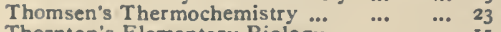
Thornton's Elementary Biology $\quad \ldots . \quad \ldots$. Is

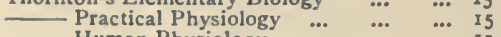
\begin{tabular}{lllll} 
Human Physiology & $\ldots$ & $\ldots$ & $\ldots$ & ... \\
\hline Thorpe & $\ldots$ & I5
\end{tabular} Thorpe's Dictionary of Applied Chemistry... 22 Tilden's Chemical Philosophy ... $\quad \ldots \quad \ldots \quad \ldots 22$

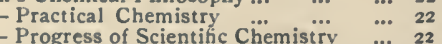
$\begin{array}{lll}\text { Progress of Scientific Chemistry } & \ldots & 22 \\ \text { Vanderpoel's Colour Problems } & \ldots & \text {... }\end{array}$ Waller's Introduction to Human Physiology $\begin{array}{llll}\text { Watt's Dictionary of Chemistry } & \ldots & \ldots & 22\end{array}$ West's How to Nurse Sick Children... .... $\quad$ I7 Weston's Detection of Carbon Compounds.... 22 Whiteley's Chemical Calculations ... $\quad$... 22 $\begin{array}{lllll}\text { Organic Chemistry } & \ldots & \ldots & \ldots & 22\end{array}$

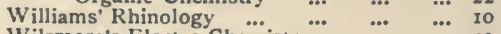
Wilsmore's Electro-Chemistry $\quad \ldots . \quad \ldots .23$

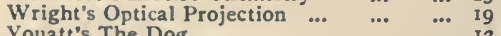
$\begin{array}{llllll}\text { Youatt's The Dog } & \ldots & \ldots & \ldots & \ldots & \text { I2 }\end{array}$

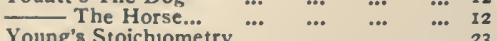




\section{MEDICINE, SURGERY, ANATOMY, ETC.}

ASHBY AND WRIGHT. THE DISEASES OF CHILDREN, MEDICAL AND SURGICAL. By HENRY ASHBY, M.D. Lond., F.R.C.P., late Physician to the Manchester Children's Hospital ; and G. A. WRIGHT, B.A., M.B. Oxon., F.R.C.S. Eng., Surgeon to the Manchester Royal Infirmary; Consulting Surgeon to the Manchester Children's Hospital. With 15 Plates (1 Coloured) and 241 Illustrations in the Text. Fifth Edition. Thoroughly Revised, 1905. 8vo, 21s. net.

BAIN AND EDGECOMBE. THE PHYSIOLOGY AND THERAPEUTICS OF THE HARROGATE WATERS, BATHS, AND CLIMATE APPLIED TO THE TREATMENT OF CHRONIC DISEASE. By WiLLIAM BaIN, M.D., M.R.C.P., and Wilfrid Edgecombe, M.D. 8vo, 7s.6d. net.

BENNETT.-IVORKS by Sir WILLIAM H. BENNETT, K.C.V.O., F.R.C.S., Surgeon to St. George's Hospital.

RECURRENT EFFUSION INTO THE KNEE-JOINT AFTER INJURY, WITH ESPECIAL REFERENCE TO INTERNAL DERANGEMENT, COMMONLY CALLED SLIPPED CARTILAGE : an Analysis of 750 Cases. A Clinical Lecture delivered at St. George's Hospital. With 13 Illustrations. 8vo, 3s. 6d.

CLINICAL LECTURES ON VARICOSE VEINS OF THE LOWER EXTREMITIES. With 3 Plates. 8vo, 6 s.

CLINICAL LECTURES ON ABDOMINAL HERNIA: chiefly in relation to Treatment, including the Radical Cure. With 12 Diagrams in the Text. 8 vo, 8s. $6 d$.

ON VARIX, ITS CAUSES AND TREATMENT, WITH ESPECIAL REFERENCE TO THROMBOSIS. 8vo, 3s. $6 d$.

LECTURE ON THE USE OF MASSAGE AND EARLY MOVEMENTS IN RECENT FRACTURES AND OTHER COMMON SURGICAL INJURIES : SPRAINS AND THEIR CONSEQUENCES : RIGIDITY OF THE SPINE, AND THE MANAGEMENT OF STIFF JOINTS GENERALLY. With 23 Illustrations. $8 \mathrm{vo}, 6$.

THE PRESENT POSITION OF THE TREATMENT OF SIMPLE FRACTURES OF THE LIMBS : an Address delivered to the British Medical Association. To which is appended a Summary of the Opinions and Practice of about 300 Surgeons. 8 vo, $2 s .6 d$. 


\section{MEDICINE, SURGERY, ANATOMY, ETC.-continued.}

\section{BELL. THE PRINCIPLES OF GYN AECOLOGY. By W. BLAIR} BELL, B.S., M.D., Assistant Gynæcological Surgeon, Royal Infirmary, Liverpool. With Illustrations. 8vo.

A concise, yet complete account of the development, anatomy and physiology of the female genital organs. The methods of physical examination are fully described. The diseases of the special organs and the allied morbid conditions are discussed, special attention being paid to the pathology which is illustrated by numerous photomicrographs and drawings of actual specimens, each of which is carefully described.

CABOT. A GUIDE TO THE CLINICAL EXAMINATION OF THE BLOOD FOR DIAGNOSTIC PURPOSES. By RICHARD C. CABOT, M.D., Physician to Out-Patients, Massachusetts General Hospital. With 3 Coloured Plates and 28 Illus. in Text. 8vo, 16s.

\section{CHEYNE AND BURGHARD. A MANUAL OF SURGICAL} TREATMENT. By Sir W. WATSON CHEYNE, Bart., C.B., M.B., F.R.C.S., F.R.S., D.Sc., Professor of Clinical Surgery in King's College, London; Surgeon to King's College Hospital, and the Children's Hospital, Paddington Green, etc.; and F. F. BURGHARD, M.D. and M.S. Lond., F.R.C.S., Teacher of Practical Surgery in King's College, London; Surgeon to King's College Hospital, and the Children's Hospital, Paddington Green, etc.

PART I. The treatment of General Surgical Diseases, including inflammation, suppuration, ulceration, gangrene, wounds and their complications, infective diseases and tumours; the administration of anæsthetics. With 66 Illustrations. Royal $8 \mathrm{vo}, 9 s$. net.

PART II. The treatment of the Surgical Affections of the Tissues, incliding the skin and subcutaneous tissues, the nails, the lymphatic vessels and glands, the fasciæ, bursæ, muscles, tendonsand tendon-sheaths, nerves, arteries and veins; deformities. With 141 Illustrations. Royal 8vo, 12s. net.

PART III. The treatment of the Surgical Affections of the Bones. Amputations. With 100 Illustrations. Royal 8 vo, $10 s .6 d$. net.

PART IV. The treatment of the Surgical Affections of the Joints (including excisions) and the spine. With 138 Illustrations. Royal 8vo, 12s. net.
PART V. The treatment of the Surgical Affections of the head, face, jaws, lips, larynx and traches; and the Intrinsic Diseases of the nose, ear and larynz, by H. LAMBrRT LACK, M.D. (Lond.), F.R.C.S., Surgeon to the Hospital for Diseases of the Throat, Golden Square, and to the Throat and Ear Department, the Children's Hospital, Paddington Green. With 145 Illustrations. Royal 8vo, 15s. net.

Part VI.-Section 1. The Surgical Affections of the tongue and floor of the mouth, the pharynx, neck, cesophagus, stomach and intestines. With an Appendix on the Examination of the Blood in Surgical Condition. By W. Este Esery, M.D., D.Sc. (Lond.). With 124 Illustrations. Royal 8vo, 15s. net.

Section 2. The Surgical Affections of the rectum, the liver, pancreas and spleen, and genito-urinary organs, the breast and the thorax. With 113 Illustrations. Royal 8vo, 18s, net. 


\section{MEDICINE, SURGERY, ANATOMY, ETC.-continued.}

COATS. A MANUAL OF PATHOLOGY. By JOSEPH COATS,

I.D., late Professor of Pathology in the University of Glasgow. Fifth Edition, 1903. Revised throughout and Edited by LEWIS R. SUTHERLAND, M.D., Professor of Pathology, University of St. Andrews. With 729 Illustrations and 2 Coloured Plates. 8vo, 28s. net.

COOKE.-WORKS by THOMAS COOKE, F.R.C.S. Eng., B.A., B.Sc., M.D. Paris, late Senior Assistant Surgeon to the Westminster Hospital.

TABLETS OF ANATOMY. Being a Synopsis of demonstrations given in the Westminster Hospital Medical School. Eleventh Edition in three Parts, thoroughly brought up to date, and with over 700 Illustrations from all the best sources, British and Foreign. Post 4 to. Part I. The Bones, 7s. 6d. net; Part II. Limbs, Abdomen, Pelvis, 10s. 6d. net; Part III. Head and Neck, Thorax, Brain, 10s. 6d. net.

APHORISMS IN APPLIED ANATOMY AND OPERATIVE SURGERY. Including 100 Typical viva voce Questions on Surface Marking, etc. Crown $8 v 0,3 s .6 d$.

DAKIN. A HANDBOOK OF MIDWIFERY. By WILLIAM RAD. FORD DAKIN, M.D., F.R.C.P., Obstetric Physician and Lecturer on Nid wifery at St. George's Hospital, Examiner in Midwifery and Diseases of Women on the Conjoint Board of the Royal Colleges of Physicians and Surgeons in England, etc. With 400 Illustrations. Large crown 8vo, $18 s$.

DICKSON. THE BONE-MARROW: a Cytological Study. Forming an Introduction to the Normal and Pathological Histology of the Tissue, more especially with regard to Blood Formation, Blood Destruction, etc. Together with a short account of the Reactions and Degenerations of the Tissue in Disease. By W. E. CARNEGIE DICKSON, M.D., B.Sc. Edin., F.R.C.P. Edin., Lecturer on Pathological Bacteriology and Senior Assistant to the Professor of Pathology in the University of Edinburgh; Assistant Pathologist to the Edinburgh Koyal Infirmary. With 12 Coloured Plates and 51 MicroPhotographs by Richard Muir. Medium 4 to, $£ 22 s$. net. 
MEDICINE, SURGERY, ANATOMY, ETC.-continued.

FOWLER AND GODLEE. THE DISEASES OF THE LUNGS. By JAMES KINGSTON FOWLER, M.A., M.D., F.R.C.P., Physician to the Middlesex Hospital and to the Hospital for Consumption and Diseases of the Chest, Brompton, etc.; and RICKMAN JOHN GODLEE, M.S., F.R.C.S., Honorary Surgeon-in-Ordinary to His Majesty, Fellow and Professor of Clinical Surgery, University College, London, etc. With 160 Illustrations. $8 \mathrm{vo}, 25$ s.

GOODSALL AND MILES. DISEASES OF THE ANUS AND RECTUM. By D. H. GOODSALL, F.R.C.S., late Senior Surgeon Metropolitan Hospital, Senior Surgeon St. Mark's Hospital; and W. ERNEST MILES, F.R.C.S., Assistant Surgeon to the Cancer Hospital, Surgeon (out-patients) to the Gordon Hospital, etc. (In Two Parts).

PART I.-Anatomy of the Ano-rectal Region-General Diagnosis-AbscessAno-rectal Fistula - Recto-urethral, Recto-vesical and Recto-vaginal Fistulæ-Sinus over the Sacro-coccygeal Articulation-Fissure-Hæmorrhoids (External and Internal). With 91 Illustrations. 8vo, 7s. 6d. net.

PART II.-Prolapse of the Rectum-Invagination of the Rectum-Ulceration - Stricture of the Anus and of the Rectum-Nalignant Growths of the Anus and Rectum-Benign Tumours of the Anus and Rectum-Foreign Bodies in the Rectum-Pruritus Ani-Syphilis of the Anus and Rectum. With 44 Illustrations. 8vo, 6s. net.

GRAY. ANATOMY, DESCRIPTIVE AND APPLIED. By HENRY GRAY, F.R.S., late Lecturer on Anatomy at St. George's Hospital Medical School. Seventeenth Edition. Edited by ROBERT HOWDEN, M.A., M.B., C.M., Professor of Anatomy in the University of Durham. Notes on Applied Anatomy, revised by A. J. JEX-BLAKE, M.A., M.B., M.R.C.P., Assistant Physician to St. George's Hospital; and W. FEDDE FEDDEN, M.S., F.R.C.S., Assistanc Surgeon and Lecturer on Surgical Anatomy, St. George's Hospital. With 1,032 Illustrations. Royal 8vo, 32s. net.

HARE. THE FOOD FACTOR IN DISEASE : Being an investigation into the humoral causation, meaning, mechanism and rational treatment, preventive and curative, of the Paroxysmal Neuroses (migraine, asthma, angina pectoris, epilepsy, etc.), bilious attacks, gout, catarrhal and other affections, high blood-pressure, circulatory, renal and other degenerations. By FRANCIS HARE, M.D., late Consulting Physician to the Brisbane General Hospital; Visiting Physician at the Diamantina Hospital for Chronic Diseases, Brisbane; Inspector-General of Hospitals for Queensland. 2 vols. Medium 8vo, 30s. net. 
MEDICINE, SURGERY, ANATOMY, ETC.—continued.

INFLUENCE OF HEREDITY ON DISEASE (THE), WITH SPECIAL REFERENCE TO TUBERCULOSIS, CANCER, AND DISEASES OF THE NERVOUS SYSTEM. A Discussion opened by Sir WILLIAM S. CHURCH, Bt., K.C.B., M.D., Sir WILLIAM R. GOWERS, M.D., F.R.S. (Diseases of the Nervous System), ARTHUR LATHAM, M.D. (Tuberculosis), and E. F. BASHFORD, M.D. (Cancer). [From the Proceedings of the Royal Society of Medicine, 1909, Vol. II., No. 3.] 4to, 4s. 6d. net.

LUFF. TEXT-BOOK OF FORENSIC MEDICINE AND TOXICOLOGY. By ARTHUR P. LUFF, M.D., B.Sc. Lond., Physician in Charge of Out-Patients and Lecturer on Medical Jurisprudence and Toxicology in St. Mary's Hospital ; Examiner in Forensic Medicine in the University of London; External Examiner in Forensic Medicine in the Victoria University; Official Analyst to the Home Office. With 13 full. page Plates ( 1 in colours) and 33 Illustrations in the Text. 2 vols., Crown $8 \mathrm{vo}, 24 s$.

PROBYN-WILLIAMS. A PRACTICAL GUIDE TO THE ADMINISTRATION OF ANAESTHETICS. By R. J. PROBYN-WILLIAMS, M.D., Senior Anaesthetist and Instructor in Anaesthetics at the London Hospital, etc. With 44 Illustrations. Crown 8vo, 4s. 6d. net.

QUAIN. QUAIN'S (Sir RICHARD) DICTIONARY OF MEDICINE. By Various Writers. Edited by H. MONTAGUE MURRAY, M.D., F.R.C.P., Joint Lecturer on Medicine, Charing Cross Medical School, and Physician to Charing Cross Hospital, and to the Victoria Hospital for Children, Chelsea; Examiner in Medicine to the University of London. Assisted by JOHN HAROLD, M.B., B.CH., B.A.O., Physician to St. John's and St. Elizabeth's Hospital, and Demonstrator of Medicine at Charing Cross Medical School, and W. CECIL BOSANQUET, M.A., M.D., F.R.C.P., Assistant Physician, Charing Cross Hospital, etc. Third and Cheaper Edition, largely Rewritten, and Revised throughout. With 21 Plates (14 in Colour) and numerous Illustrations in the Text. 8vo, 21s. net., buckram. 


\section{MEDICINE, SURGERY, ANATOMY, ETC.-continued.}

QUAIN. QUAIN'S (JONES) ELEMENTS OF ANATOMY. The Tenth Edition. Edited by EDWARD ALBERT SCHÄFER, F.R.S., Professor of Physiology in the University of Edinburgh; and GEORGE DANCER THANE, Professor of Anatomy in University College, London. ** The several parts of this work form complete TEXT-Books of Their RESPECTIVE SUBJECTS. They can be obtained separately as follows:-

Vol. I., PARt I. EMBRYOLOGY. By E. A. SCHÄFER, F.R.S. With 200 Illustrations. Royal 8vo, 9s.

Vol. I., PART II. GENERAL ANATOMY OR HISTOLOGY. By E. A. SCHAFER, F.R.S. With 491 Illustrations. Royal 8vo.

[Out of print.

Vol. II., Part I. OSTEOLOGY-ARTHROLOGY. By G. D. THANE. With 224 Illustrations. Royal 8vo, 11s.

Vol. II., PART II. MYOLOGY-ANGEIOLOGY. By G. D. THANE. With 199 Illustrations. Royal 8vo, $16 s$.

Vor. III., Part I. THE SPINAL CORD AND BRAIN. By E. A. SCHÄFER, F.R.S. With 139 Illustrations. Koyal 8vo, 12s. 6d.

Vol. III., PArt II. THE NERVES. By G. D. THANE. With 102 Illustrations. Royal 8 vo, $9 s$.

Vol. III., PART III. THE ORGANS OF THE SENSES. By E. A. SCHÄFER, F.R.S. With 178 Illustrations. Royal 8vo, $9 s$.

Vol. III., PART IV. SPLANCHNOLOGY. By E. A. SCHÄFER, F.R.S., and JOHNSON SYMINGTON, M.D. With 337 Illustrations. Royal 8vo, $16 s$.

APPENDIx. SUPERFICIAL AND SURGICAL ANATOMY. By Professor G. D. THANE and Professor R. J. GODLEE, M.S. With 29 Illustrations. Royal Svo, 6s. $6 d$. 


\section{MEDICINE, SURGERY, ANATOMY, ETC.—continued.}

QUAIN. QUAIN'S ELEMENTS OF ANATOMY. The Eleventh EDIrion. Edited by EDWARD ALBERT SCHÄFER, F.R.S., Professor of Physiology and Histology in the University of Edinburgh ; JOHNSON SYMINGTON, M.D., F.R.S., Professor of Anatomy in Queen's College, Belfast; and THOMAS HASTIE BRYCE, M.A., M.D., Regius Professor of Anatomy in the University of Glasgow.

IN FOUR VOLUMES. Royal 8vo.

Vol. I. EMBRYOLOGY. By T. H. BRYCE, M.A., M.D. Illustrated by more than 300 Engravings, many of which are coloured. 10s. $6 d$. net.

Vos. III. NEUROLOGY. By E. A. SCHÄFER and J. SYMINGTON. Part I. Containing the General Structure of the Nervous System and the Structure of the Brain and Spinal Cord. With 361 Illustrations, many of which are coloured. 15s. net.

Part II. Containing the Descriptive Anatomy of the Peripheral Nerves and of the Organs of Special Sense. With 321 Illustrations, many of which are coloured. 15s, net.

\section{* * The other Volumes are in preparation.}

This work has been completely re-edited and brought up to date. The volumes will comprise respectively Embryology; General and Visceral Anatomy; the Nervous System and Sense Organs; and the Bones, Ligaments, Muscles, and Blood-vessels. Each volume will be complete in itself, and will serve as a text-book for the particular subject or subjects with which it deals. Thus the first volume is intended to form a complete text-book of Human Embryology, the second a text-book of Histology and Visceral Anatomy, the third a text-book of Neurology, the fourth dealing with the systems which are not included in the second and third volumes.

SCHÄFER. THE ESSENTIALS OF HISTOLOGY: Descriptive and Practical. For the Use of Students. By E. A. SCHÄFER, F.R.S., Professor of Physiology in the University of Edinburgh. With 553 Illustrations some of which are Coloured. Seventh Edition, 1907. 8vo, 10s. 6d. net.

SMALE AND COLYER. DISEASES AND INJURIES OF THE TEETH, including Pathology and Treatment. By MORTON SMALE, M.R.C.S., L.S.A., L.D.S., Dental Surgeon to St. Mary's Hospital, Consulting Dental Surgeon, Dental Hospital of London, etc.; and J. F. COLYER, L.R.C.P., M.R.C.S., L.D.S., Dental Surgeon to Charing Cross Hospital and to the Dental Hospital of London, Dean of the School, Dental Hospital of London. Second Edition Revised and Enlarged by J. F. COLYER. With 645 Illustrations. Large Crown 8vo, 21s, net.

SMITH. THE HANDBOOK FOR MIDIVIVES. By HENRY FLY SMITH, 'B.A., M.B., Oxon., M.R.C.S. Second Edition. With 41 Woodcuts. Crown 8 vo, $5 s$. 


\section{MEDICINE, SURGERY, ANATOMY, ETC.-continued.}

STEVENSON. WOUNDS IN WAR : the Mcchanism of their Production and their Treatment. By Surgeon-Gencral W. F. STEVENSON, C.B. (Army Medical Staff), B.A., M.B., M.Ch. Dublin University; Profcssor of Military Surgery, Royal Army Medical College, London. With 127 Illustrations. 8vo, 15s. net.

SYMINGTON AND RANKIN. AN ATLAS OF SKIAGRAMS, ILLUSTRATING THE DEVELOPMENT OF THE TEETH. With Explanatory Text. By JOHNS JN SYMINGTON, M.D., F.R.S., Professor of Anatomy, Queen's College, Belfast; and J. C. RANKIN, M.D., Physician in charge of the Electrical Department, Royal Victoria Hospital, Belfast. With 12 Plates. Demy 4to. 10s. 6d. net.

WILLIAMS. RHINOLOGY : a Text-book of Diseases of the Nose and the Nasal Accessory Sinuses. By PATRICK WATSON WILLIAMS, M.D. (London). With 3 Coloured Plates and 44 Black and White Plates (of which 26 arc Stercoscopic) and 140 Illustrations in the Text. 8vo, 12s. $6 d$. net. With Stereoscope, 15s. net.

\section{MISCELLANEOUS.}

ANNUAL CHARITIES REGISTER AND DIGEST: being a Classified Register of Charities in or available for the Metropolis, together with a Digest of Information respecting the Legal, Voluntary, and other Mcans for the Prevention and Relief of Distress and the Improvement of the Condition of the Poor. With an elaborate Index, and an Introduction, "How to Help Cases of Distress". By C. S. LOCH, Secretary to the Council of the Charity Organisation Society, London. 8vo, 5s. net.

GASKELL. THE ORIGIN OF VERTEBRATES. By WALTER H. GASKELL, M.A., M.D. (Camb.), LL.D. (Edinburgh and McGill Univ., Montreal), F.R.S., Fellow of Trinity Hall and University Lecturer in Physiology, Cambridge. With 168 Illustrations. 8vo, 21s. nct.

HOBART. THE MEDICAL LANGUAGE OF ST. LUKE. By the Rev. WILLIAM KIRK HOBART, LL.D. 8vo, 16.

HOPF.- THE HUMAN SPECIES : CONSIDERED FROM THE STANDPOINTS OF COMPARATIVE ANATOMY, PHYSIOLOGY, PATHOLOGY AND BACTERIOLOGY. By Dr. LUDWIG HOPF. Authorised English Translation. With 7 Plates and 217 Illustrations in the Text. $8 \mathrm{vo}, 10 \mathrm{~s}$. $6 d$. net. 
MISCELLANEOUS-continued.

INQUIRY (AN) INTO THE PHENOMENA ATTENDING DEATH BY DROWNING AND THE MEANS OF PROMOTING RESUSCITATION IN THE APPARENTLY DROWNED. Report of a Committee appointed by the Royal Medical and Chirurgical Society. With 2 Diagrams and 26 Plates. 8vo, 5s. net.

KING'S COLLEGE HOSPITAL BOOK OF COOKING RECIPES : being a Collection of Recipes contributed by Fricnds of the Hospital and Published in aid of the Fund for the Removal of King's College Hospital to South London. Crown 8vo, 1s, net.

MOON. THE RELATION OF MEDICINE TO PHILOSOPHY. By R. O. MOON, M.A., M.D. (Oxon.), F..R.C.P., Pliysician to the National Hospital for Diseases of the Heart, etc. Crown $8 v 0,4 s .6 d$. net.

PAGET. MEMOIRS AND LETTERS OF SIR JAMES PAGET, Bart., F.R.S., Sergeant-Surgeon to Her late Majesty Queen Victoria. Edited by STEPHEN PAGET, F.R.C.S. With Portrait. 8vo, 6s. nct.

PETTIGREW. DESIGN IN NATURE: Illustrated by Spiral and other Arrangements in the Inorganic and Organic Kingdoms as excmplificd in Matter, Force, Life, Growth, Rhythms, etc., especially in Crystals, Plants, and Animals. With Examples selected from the Reproductivc, Alimentary, Respiratory, Circulatory, Nervous, Mruscular, Osseous, Loco motory, and other Systems of Animals. By J. BELL PETTIGREW, M.D., LL.D., F.R.S., F.R.C.P.; Laureate of the Institute of France; latc Chandos Professor of Anatomy and Medicine in the University, St. Andrews; Fellow of the Royal Botanical, Medico-Chirurgical, Royal Medical, Literary and Philosophical, Harveian and other Societics. Illustrated by nearly 2,000 Figures, largely original and from naturc. In 3 vols. 4 to. 63 s. net.

POOLE. COOKERY FOR THE DIABETIC. By W. H. and Mrs. POOLE. With Preface by Dr. PAVY. Feap. 8vo, 2s. $6 d$.

RAFFETY, AN INTRODUCTION TO THE SCIENCE OF RADIO-ACTIVITY. By CHARLES W. RAFFETY. With 27 Illustrations. Crown 8vo. 4s. 6d. net.

SUTHERLAND-GOWER. CLEANLINESS VERSUS CORRUPTION. By Lord RONALD SUTHERLAND-GOWER. With 11 Illustrations. Crown 8vo, paper covers, $6 d$. A plea for the more general adoption of cremation for human bodies. 


\section{THE PROCEEDINGS OF THE ROYAL SOCIETY OF MEDICINE.}

The Royal Society of Medicine was formed in June, 1907, by the amalgamation of the following London Medical Societies :-

The Royal Medical and Chirurgical The Neurological Society.

Society.

The Pathological Society.

The Epidemiological Society.

The Odontological Society of Great

Britain.

The Obstetrical Society.

The Clinical Society.

The Dermatological Society.

The British Gynæcological Society.

The British Laryngological, Rhinological, and Otological Association.

The Laryngological Society.

The Dermatological Society of Great Britain and Ireland.

The Otological Society of the United Kingdom.

The British Electro-therapeutic Society.

The Therapeutical Society.

The "Proceedings" of the Royal Society of Medicine are published monthly from November to July inclusive. The numbers contain the papers of, and the discussions read at each of the Sections during the previous month, and are so arranged that each Section can, if desired, be detached and bound separately at the end of the year.

The Annual Subscription is £3 3s. net, which may be paid through any bookseller.

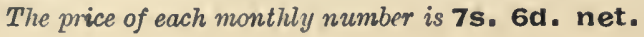

\section{VETERINARY MEDICINE, ETC.}

FITZWYGRAM. HORSES AND STABLES. By Lieutenant. General Sir F. FITZWYGRAM, Bart. With 56 pages of Illustrations. $8 \mathrm{vo}, 3 s$. net.

HAYES. TRAINING AND HORSE MANAGEMENT IN INDIA. With Hindustanee Vocabulary. By M. HORACE HAYES, F.R.C.V.S. (late Captain, "The Buffe"). With Portrait. Crown 8vo, 8s. net.

STEEL. -WORKS by JOHN HENRY STEEL, F.R.C.V.S., F.Z.S., A.V.D., late Professor of Veterinary Science and Principal of Bombay Veterinary College.

A TREATISE ON THE DISEASES OF THE OX; being a Manual of Bovine Pathology. Especially adapted for the use of Veterinary Practitioners and Students. With 2 Plates and 117 Woodcuts. 8vo, 15 s.

A TREATISE ON THE DISEASES OF THE SHEEP; being a Manual of Ovine Pathology for the use of Veterinary Practitioners and Students. With Coloured Plate and 99 Woodcuts. 8vo, 12 s.

YOUATT.-WORKS by WILLIAM YOUATT.

THE HORSE. Revised and Enlarged by W. WATSON, M.R.C.V.S. With 52 Wood Engravings. 8vo, 7s. $6 d$.

THE DOG. Revised and Enlarged. With 33 Wood Engravings. 8vo, 6s. 


\section{PHYSIOLOGY, BIOLOGY, ZOOLOGY, ETC.}

ASHBY. NOTES ON PHYSIOLOGY FOR THE USE OF STUDENTS PREPARING FOR EXAMINATION. By HENRY ASHBY, M.D. (Lond.), F.R.C.P., late Physician to the General Hospital for Sick Children, Manchester; Lecturer and Examiner in Diseases of Children in the Victoria University. Revised by HUGH T. ASHBY, B.A., M.B., B.C. (Camb.), M.R.C.P. (Lond.). With 148 Illustrations. $18 \mathrm{mo}, 5 s$.

BARNETT. THE MAKING OF THE BODY : a Children's Book on Anatomy and Physiology. By Mrs. S. A. BARNETT. With 113 Illustrations. Crown 8vo, 1s. $9 d$.

BEDDARD. ELEMENTARY PRACTICAL ZOOLOGY. By FRANK E. BEDDARD, M.A. (Oxon.). With 93 Illustrations. Crown 8 vo, 2s. $6 d$.

BIDGOOD. A COURSE OF PRACTICAL ELEMENTARY BIOLOGY. By JOHN BIDGOOD, B.Sc., F.L.S. With 226 Illustrations. Crown 8 vo, 4s. $6 d$.

BOSE. -WORKS by JAGADIS CHUNDER BOSE, M.A. (Cuntab.), D.Sc. (Lond.), Professor, Presidency College, Calcutta.

RESPONSE IN THE LIVING AND NON-LIVING. With 117 Illustrations. 8vo, 10s. $6 d$.

PLANT RESPONSE AS A MEANS OF PHYSIOLOGICAL INVESTIGATION. With 278 Illustrations. $8 \mathrm{vo}, 21 s$.

COMPARATIVE ELECTRO-PHYSIOLOGY: A PHYSICOPHYSIOLOGICAL STUDY. With 406 Illustrations and Classified List of 321 new Experiments. 8vo, 15s. net.

BRODIE. THE ESSENTIALS OF EXPERIMENTAL PHY. SIOLOGY. For the use of Students. By T. G. BRODIE, M.D., Lecturer on Physiology, St. Thomas's Hospital Medical School. With 2 Plates and 177 Illustrations in the Text. Crown 8vo, 6s. 6d.

CHAPMAN, THE FORAMINIFERA : an Introduction to the Study of the Protozoa. By FREDERICK CHAPMAN, A.L.S., F.R.MI.S. With 14 Plates and 42 Illustrations in the Text. $8 \mathrm{vo}, 9 s$. net. 
PHYSIOLOGY, BIOLOGY, ZOOLOGY, ETC.-continued.

FURNEAUX, HUMAN PHYSIOLOGY. By W. FURNEAUX, F.R.G.S. With 223 Illustrations. Crown 8 vo, 2s. $6 d$.

HALLIBURTON. THE ESSENTIALS OF CHEMICAL PHYSIOLOGY. For the Use of Students. By W. D. HALLIBURTON, LL.D., M.D., F.R.S., F.R.C.P., Professor of Physiology in King's College, London. With 71 Illustrations. $8 \mathrm{vo}, 4 s .6 d$. net.

HUDSON AND GOSSE. THE ROTIFERA OR "WHEEL ANIMALCULES". By C. T. HUDSON, LL.D., and P. H. GOSSE, F.R.S. With 30 Coloured and 4 Uncoloured Plates. In 6 Parts. 4to, price 10s. 6d. each; Supplement, 12s. 6d. Complete in Two Volumes, with Supplement, 4to, £4 $4 s$.

* * The Plates in the Supplement contain figures of almost all the Foreign Species, as well as of the British Species, that have been discovered since the original publication of Vols. I. and II.

LLOYD AND BIGELOW. THE TEACHING OF BIOLOGY IN THE SECONDARY SCHOOL. By FRANCIS E. LLOYD, A.M., and MAURICE A. BIGELOW, Ph.D., Professors in Teachers' College, Columbia University. Crown 8vo, 6s. net.

MACALISTER.-WORKS by AI.EXANIER MACALISTER, M.D.

AN INTRODUCTION TO THE SYSTEMATIC ZOOLOGY AND MORPHOLOGY OF VERTEBRATE ANIMALS. With 41 Diagrams. 8 vo, 10s. $6 d$.

ZOOLOGY OF THE INVERTEBRATE ANIMALS. With 77 Diagrams. Fcp. 8vo, 1s. 6d.

ZOOLOGY OF THE VERTEBRATE ANIMALS. With 59 Diagrams. Fep. 8vo, 1s. 6 .

MACDOUGALL.-WORKS by IIANIEL TREMBLY MACDOUGALL,

TEXT-BOOK OF PLANT PHYSIOLOGY. With 159 Illustrations. $8 v 0,7$ s. $6 d$. net.

ELEMENTARY PLANT PHYSIOLOGY. With 108 Illustrations. Crown 8 vo, 3 s. 
PHYSIOLOGY, BIOLOGY, ZOOLOGY, ETC.-continued.

MOORE. ELEMENTARY PHYSIOLOGY AND ANATOMY. By BENJAMIN MOORE, D.Sc., Professor of Bio-Chcmistry in the University of Liverpool. With 125 Illustrations. Crown 8vo, 3s. 6d.

MORGAN. ANIMAL BIOLOGY. An Elementary Text-Book. By C. LLOYD MORGAN, F.R.S., Principal of University College, Bristol. With numerous Illustrations. Crown 8 vo, $8 s .6 d$.

SCHÄFER. DIRECTIONS FOR CLASS WORK IN PRACTICAL PHYSIOLOGY : Elcmentary Physiology of Muscle and Nerve and of the Vascular and Nervous Systems. By E. A. SCHÄFER, LL.D., F.R.S., Professor of Physiology in the University of Edinburgh. With 48 Diagrams. $8 \mathrm{vo}, 3 s$. net.

THORNTON.-WORKS by JOHN THORNTUN, M.A.

HUMAN PHYSIOLOGY. With 284 Illustrations, some of which are Coloured. Crown 8vo, $6 s$.

ELEMENTARY BIOLOGY, Descriptive and Experimental. With numerous Illustrations. Crown 8vo, 3s. 6d.

ELEMENTARY PRACTICAL PHYSIOLOGY. With 178 Illustrations ( 6 of which are Coloured). Crown $8 \mathrm{vo}, 3 s$. $6 d$.

WALLER. AN INTRODUCTION TO HUMAN PHYSIOLOGY. By AUGUSTUS D. WALLER, M.D., F.R.S., Hon. LL.D. Edin., Lecturer on Physiology at St. Mary's Hospital Medical School, London ; late External Examiner at the Victorian Univcrsity. With 314 Illustrations. $8 \mathrm{vo}, 18 \mathrm{~s}$. 


\section{HEALTH AND HYGIENE, ETC.}

ASHBY. HEALTH IN THE NURSERY. By HENRY ASHBY, M.D., F.R.C.P., Physician to the General Hospital for Sick Children, Manchester; Lecturer and Examiner in Diseases of Children in the Victoria University. With 25 Illustrations. Crown $8 \mathrm{vo}, 3 s$. net.

BUCKTON. HEALTH IN THE HOUSE. By Mrs. C. M. BUCKTON. With 41 Woodcuts and Diagrams. Crown 8vo, 2s.

BULL.-WORKS by THOMAS BULL, M.D. Thoroughly Revised by ROBERT W. PARKER, M.R.C.S. Eng.

HINTS TO MOTHERS ON THE MANAGEMENT OF THEIR HEALTH DURING THE PERIOD OF PREGNANCY, AND HINTS ON NURSING. Fcp. 8vo, sewcd, 1s. $6 d$; ; cloth, gilt edges, 2s. net.

THE MATERNAL MANAGEMENT OF CHILDREN IN HEALTH AND DISEASE. Fcp. 8vo, sewed, 1s. 6d.; cloth, gilt edges, $2 s$. net.

BUTTERWORTH. MANUAL OF HOUSEHOLD WORK AND MANAGEMENT. By ANNIE BUTTERWORTH. Crown 8vo, $2 s .6 d$.

CORFIELD. THE LAWS OF HEALTH. By W. H. CORFIELD, M.A., M.D. Fcp. $8 \mathrm{vo}, 1 s$. $6 d$.

CREIGHTON. THE ECONOMICS OF THE HOUSEHOLD. Six Lectures given at the London School of Economics during the Winter of 1906 . By LOUISE CREIGHTON. Crown 8 vo, $1 s .4 d$.

FURNEAUX. ELEMENTARY PRACTICAL HYGIENE. Section I. By WILLIAM S. FURNEAUX. With 146 Illustrations. Crown $8 \mathrm{vo}, 2 s$. $6 d$.

JAMES. BALL GAMES AND BREATHING EXERCISES. By ALICE R. JAMIES. With Preface by HARRY CAMPBELL, M.D., B.S. (London), F.R.C.P. With 17 Illustrations. Crown $8 \mathrm{vo}, 1 \mathrm{~s} .6 \ddot{d}$. 
HEALTH AND HYGIENE, ETC.-continued. NOTTER AND FIRTH.-WORKS by J. LANE NOTTER, M:A., M.D.,
and R. H. FIRTII, F.R.C.S.

HYGIENE. With 99 Illustrations. Crown 8vo, 4s. $6 d$.

PRACTICAL DOMESTIC HYGIENE. With 84 Illustrations Crown 8vo, 2s. $6 d$.

POORE.-WORKS by GEORGE VIVIAN POORE, M.D., F.R.C.P

THE EARTH IN RELATION TO THE PRESERVATION AND DESTRUCTION OF CONTAGIA : being the Milroy Lectures delivered at the Royal College of Physicians in 1899, together with other Papers on Sanitation. 13 Illustrations. Crown 8vo, $5 \mathrm{~s}$.

ESSAYS ON RURAL HYGIENE. With 12 Illustrations. Crown 8 vo, 6s. $6 d$.

THE DIVELLING HOUSE. With 36 Illustrations. Crown 8vo, $3 s .6 d$. COLONIAL AND CAMP SANITATION. With 11 Illustrations. Crown 8vo, 2s. net.

PORTER.-WORKS by CHARLES PORTER, M.D., E.SC., M.R.C.P. (Eilin.).

SCHOOL HYGIENE AND THE LAWS OF HEALTH : a TextBook for Teachers and Students in Training. With 121 Illustrations. Crown 8vo, 3s. $6 d$.

SANITARY LAW IN QUESTION AND ANSWER. Crown 8 ro.

This book is primarily intended to assist candidates for Diplomas in Public Health and the certificates of the various examining bodies granting qualifications to Sanitary Inspectors, in their study of the Sanitary Laws of England and Wales. As many of the queries in the book are such as have to be dealt with almost daily in practice, the volume should prove of value also to those already in the Public Health Service, as a reference book and guide to Sanitary Legislation.

ROBINSON. THE HEALTH OF OUR CHILDREN IN THE COLONIES : a Book for Mothers. By LILIAN AUSTEN ROBINSON, M.D. Crown 8vo, $2 s .6 d$. net.

WEST, HOW TO NURSE SICK CHILDREN. By CHARLES WEST, M.D., Founder of and late Physician to the Hospital for Sick Children, Great Ormond Street, London. With Preface by GEORGE F. STILL, MI.D., Physician to the Hospital for Sick Children, Grcat Ormond Street. Crown 8 vo, $1 s$, net. 


\section{BACTERIOLOGY, ETC.}

CURTIS. THE ESSENTIALS OF PRACTICAL BACTERIOLOGY : an Elementary Laboratory Work for Students and Practitioners. By H. J. CURTIS, B.S. and M.D. Lond., F.R.C.S., formerly Surgeon to the North-Eastern Hospital for Children ; Assistant Surgeon, Royal Hospital for Children and Women, Waterloo Road; Surgical Registrar and Assistant to the Professor of Pathology, University College, London. With 133 Illustrations. $8 \mathrm{vo}, 9 s$.

ELLIS. OUTLINES OF BACTERIOLOGY (Technical and Agricultural). By DAVID ELLIS, Ph.D. (Marburg), D.Sc. (London), F.R.S.E., Lecturer in Bacteriology and Botany to the Glasgow and West of Scotland Technical College, Glasgow. With 134 Illustrations. 8 vo, 7s. $6 d$. net.

FRANKLAND. BACTERIA IN DAILY LIFE. By Mrs. PERCY FRANKLAND, F.R.M.S. Crown 8 vo, 5s. net.

GOADBY. THE MYCOLOGY OF THE MOUTH: A TEXTBOOK OF ORAL BACTERIA. BY KENNETH W. GOADBY, L.D.S. Eng., D.P.H. Camb., L.R.C.P., II.R.C.S., Bacteriologist and Lecturer on Bacteriology, National Dental Hospital, etc. With 82 Illustrations. $8 \mathrm{vo}, 8 \mathrm{~s}$. $6 d$. net.

KLÖCKER. FERMENTATION ORGANISMS. A Laboratory Handbook. By ALB. KLÖCKER, Assistant in the Carlsberg Laboratory, Copenhagen. Translated from the German by G. E. ALLAN, B.Sc., Lecturer in the University of Birmingham, and J. H. MILLAR, F.I.C., formerly Lecturer in the British School of MIalting and Brewing, and revised by the Author. With 146 Illustrations. 8vo, 12s. net. 


\section{OPTICS, PHOTOGRAPHY, ETC.}

ABNEY, A TREATISE ON PHOTOGRAPHY. By Sir WILLIAM DE WIVELESLIE ABNEY, K.C.B., F.R.S. With 134 Illustrations. Crown 8ro, $5 s$.

BALY.-SPECTROSCOPY. By E. C. C. BALY, F.I.C., Lecturer on Spectroscopy and Assistant Professor of Chemistry, University College, London. With 163 Illustrations. Urown 8vo, 10s. 6d.

DRUDE. THE THEORY OF OPTICS. By PAUL DRUDE, Professor of Physics at the University of Giessen. Translated from the German by C. RIBORG MANN and ROBERT A. MILLIKAN, Professors of Physics at the University of Chicago. With 110 Diagrams. 8vo, 15s. net.

GLAZEBROOK. PHYSICAL OPTICS. By R. T. GLAZEBROOK, M.A., F.R.S. With 183 Woodcuts of Apparatus, etc. Crown 8ro, 6s.

MEES. AN ATLAS OF ABSORPTION SPECTRA. By C. E. KENNETH MEES, D.Sc. Crown 8vo, 6s. net.

POLLOK. PRACTICAL SPECTROGRAPHIC ANALYSIS. By J. H. POLLOK, D.Sc. Crown 8vo.

SHEPPARD AND MEES. INVESTIGATION ON THE THEORY OF THE PHOTOGRAPHIC PROCESS. By S. E. SHEPPARD, D.Sc. (Lond.), 1851 Exhibition Scholar of University College, London, and C. E. KENNETH MEES, D.Sc. (Lond.). With 65 Illustrations and Diagrams. Crown 8ro, 6s. 6d. net.

VANDERPOEL. COLOUR PROBLEMS: A Practical Manual for the Lay Student of Colour. By EMILY NOYES VANDERPOEL. With 117 Plates in Colour. Square 8vo, 21s. net.

WRIGHT. OPTICAL PROJECTION: A Treatise on the Use of the Lantern in Exhibition and Scientific Demonstration. By LEWIS WRIGHT, Author of "Light: a Course of Experimental Optics". With 243 Illustrations. Crown 8vo, $6 s$. 


\section{CHEMISTRY, ETC.}

ARMITAGE, A HISTORY OF CHEMISTRY.

By F. P. ARIIITAGE, M.A., F.C.S. Crown 8 ro, $6 s$.

ARRHENIUS.-WORKS by SVANTE ARRHENIUS, Director of the Nobel Institute, Stockholm.

THEORIES OF CHEMISTRY: being Lectures delivered at the University of California, in Berkeley. Edited by T. SLATER PRICE, D.Sc., Ph.D., F.I.C. 8 vo, $5 s$. $6 d$. net.

A TEXT-BOOK OF ELECTRO-CHEMISTRY. Translated from the German Edition by JOHN McCRAE, Ph.D. With 58 Illustrations. $8 \mathrm{vo}, 9 s .6 d$. net.

BUNGE. TEXT-BOOK OF ORGANIC CHEMISTRY FOR MEDICAL STUDENTS. By Dr. G. VON BUNGE, Professor of Physiology in the University of Basel. Translated by R. H. ADERS PLIMMER, D.Sc. 8vo, 6s. net.

CROOKES. SELECT METHODS IN CHEMICAL ANALYSIS (chiefly inorganic). By Sir W. CROOKES, F.R.S. With 68 Illustrations. 8 vo, 21s. net.

FINDLAY.-WORKS by ALEX. FINDLAY, M.A., Ph.D., D.Sc.

PHYSICAL CHEMISTRY AND ITS APPLICATIONS IN MEDICAL AND BIOLOGICAL SCIENCE. Being a Course of Seven Lectures delivered in the University of Birmingham. Royal 8vo, 2s. net.

PRACTICAL PHYSICAL CHEMISTRY With 92 Illustrations. Crown 8 vo, 4 s. $6 d$.

GODFREY, ELEMENTARY CHEMISTRY. By HOLLIS GODFREY, Head of the Department of Science, Girls' High School of Practical Arts, Boston, Mass. With numerous Illustrations. Crown 8vo, 4s. $6 d$. net.

HANSON AND DODGSON. AN INTERMEDIATE COURSE OF LABORATORY WORK IN CHEMISTRY. BY EDWARD KENNETH HANSON, M.A. (Cant.), F.I.C., Teachers' Diploma (Lond.); Lecturer in Chemistry. University College, Reading; Lecturer to the Cambridge University Local Lecture Syndicate, and JOHN WALLIS DODGSON, B.Sc. (Lond.); Director of Evening Classes and Lecturer in Chemistry, University College, Reading. With Illustrations. 8vo, 3s. $6 d$.

MENDELEEFF. THE PRINCIPLES OF CHEMISTRY. By D. MENDELEEFF. Translated from the Russian (Seventh Edition) by GEORGE KAMENSKY, A.R.S.M., and Edited by THOMAS H. POPE, B.Sc., F.I.C. With 110 Illustrations. 2 vols. 8 vo, $32 s$. net.

MEYER. OUTLINES OF THEORETICAL CHEMISTRY. By LOTHAR MEYER. Translated by Professors P. PHILLIPS BEDSON, D.Sc., and W. CARLETON WILLIAMS, B.Sc. 8 vo, $9 s$. 


\section{CHEMISTRY, ETC.-continued.}

MUIR. A COURSE OF PRACTICAL CHEMISTRY.

By M. M. P. MUIR, M.A.

Part I. Elementary. Cr. 8vo, 4s. 6d. Part II. Intermediate. Cr. 8 vo, $4 s .6 d$.

NEWTH.-WORKS by G.S. NEWTH, F.I.C., F.C.S.

CHEMICAL LECTURE EXPERIMENTS. With 230 Illustrations. Crown 8vo, 6s.

MANUAL OF CHEMICAL ANALYSIS, QUALITATIVE AND QUANTITATIVE. With 102 Illustrations. Crown 8vo, 6s. 6d.

SMALLER CHEMICAL ANALYSIS. Crown 8vo, 2s.

A TEXT-BOOK OF INORGANIC CHEMISTRY. With 15 Illustrations. Crown 8vo, 6s. 6 d.

ELEMENTARY PRACTICAL CHEMISTRY. With 108 Illustrations and 254 Experiments. Crown 8vo, 2s. $6 d$.

OSTWALD, THE FUNDAMENTAL PRINCIPLES OF CHEMISTRY. An Introduction to all Text-Books of Chemistry. By WILHELM OSTWALD. Authorised Translation by HARRY W. MORSE. 8vo, 7s. $6 d$. net.

PERKIN.-WORKS by F. MOLLWO PERKIN, Ph.D.

QUALITATIVE CHEMICAL ANALYSIS (ORGANIC AND

INORGANIC). With 15 Illustrations and Spectrum Plate. 8ro, 4s.

PRACTICAL METHODS OF ELECTRO-CHEMISTRY. 8vo, 6s. net.

PRICE AND TWISS. A COURSE OF PRACTICAL ORGANIC CHEMISTRY. By T. SLATER PRICE, D.Sc., Ph.D., F.I.C., Head of the Chemical Department of the Birmingham Municipal Technical School, and D. F. TWISS, M.Sc., A.I.C., Lecturer in Chemistry at the Birmingham Municipal Technical School. 8vo, 3s. $6 d$.

RADCLIFFE AND SINNATT. A SYSTEMATIC COURSE OF PRACTICAL ORGANIC CHEMISTRY. By LIONEL GUY RAD. CLIFFE, F.C.S. With the assistance of FRANK STURDY SINNATT, F.C.S. 8 vo, $4 s .6 d$.

REYNOLDS. EXPERIMENTAL CHEMISTRY for Junior Students. By J. EMERSON REYNOLDS, M.D., F.R.S. Fcap. 8vo, with numerous Illustrations.

Part I.-Introductory, 1s. 6d. PART III.-Metals and Allied Bodies, 3s. 6d. PART II.-Non-Metals, 2s. 6d. PART IV.-Chemistry of Carbon Componends, 4 s.

SMITH AND HALL, THE TEACHING OF CHEMISTRY AND PHYSICS IN THE SECONDARY SCHOOL. By ALEXANDER SMITH, B.Sc., Ph.D., Associate Professor of Chemistry in the University of Chicago, and EDWIN H. HALL, Ph.D., Professor of Physics in Harvard University. With 21 Woodcuts, Bibliographies, and Index. Crown 8ro, 6s. net. 


\section{CHEMISTRY, ETC.-continued.}

STEWART.-IVORKS by A. W. STEWART, D.SC.

RECENT ADVANCES IN ORGANIC CHEMISTRY. With an Introduction by J. NORMAN COLLIE, Ph.D., LL.D., F.R.S., Professor of Organic Chemistry in University College, London. 8vo, 7s.6d.

RECENT ADVANCES IN PHYSICAL AND INORGANIC CHEMISTRY. With an Introduction by Sir WILLIAM RAMSAY, K.C.B., F.R.S. 8 vo, 7s. $6 d$. net.

THORPE. A DICTIONARY OF APPLIED CHEMISTRY. By Sir T. E. THORPE, C.B., D.Sc. Vict., Ph.D., F.R.S., Principal of Government Laboratory, London. Assisted by Eminent Contributors. 3 vols. 8 vo. Vols. I. and II., £2 2s. each (Postage, 3s. 4d.); Vol. III., £3 3 s.

TILDEN.-Works by Sir WILLIAM A. TILDEN, D.Sc. London, F.R.S.

A SHORT HISTORY OF THE PROGRESS OF SCIENTIFIC CHEMISTRY IN OUR OWN TIMES. Crown 8vo, 5 s. net.

INTRODUCTION TO THE STUDY OF CHEMICAL PHILO. SOPHY. The Principles of Theoretical and Systematic Chemistry. With 5 Illustrations. Crown 8vo, 5s. With ANSWERS to Problems. Crown $8 \mathrm{vo}, 5 s .6 d$.

PRACTICAL CHEMISTRY. The Principles of Qualitative Analysis. Fep. 8vo, 1s. $6 d$.

WATTS' DICTIONARY OF CHEMISTRY. Revised and entirely Re-written by H. FORSTER MORLEY, M.A., D.Sc., Fellow of, and lately Assistant-Professor of Chemistry in, University College, London; and M. M. PATTISON MIUIR, M.A., F.R.S.E., Fellow and Prælector in Chemistry of Gonville and Caius College, Cambridge. Assisted by Eminent Contributors. 4 vols. 8vo, £5 net.

WESTON. A SCHEME FOR THE DETECTION OF THE MORE COMMON CLASSES OF CARBON COMPOUNDS. By FRANK E. WESTON, B.Sc., London (First Class Honours), F.C.S., Lecturer in Chemistry at the Polytechnic, Regent Street, W. 8vo, $2 s$.

-WHITELEY. -WORKS by R. L. Whiteley, F.I.C., Principal of the Municipal Science School, West Bromwich.

CHEMICAL CALCULATIONS. With Explanatory Notes, Problems, and Answers, specially adapted for use in Colleges and Science Schools. With a Preface by Professor F. CLOWES, D.Sc. (Lond.), F.I.C. Crown 8 ro, $2 s$.

ORGANIC CHEMISTRY : the Fatty Compounds. With 45 Illustrations. Crown 8vo, 3s. $6 d$. 


\section{TEXT.BOOKS OF PHYSICAL CHEMISTRY.}

Edited by Sir WILLIAJI RAISAY, K.C.B., F.R.S., D.Sc.

Crown 8vo.

STOICHIOMETRY. By SYDNEY YOUNG, D.Sc., F.R.S., Professor o Chemistry in the University of Dublin; together with AN INTRODUCTION TO THE STUDY OF PHYSICAL CHEMISTRY, by SIr WILLIAM RAMSAY, K.C.B., F.R.S., Editor of the Series. 7s.6d.

CHEMICAL STATICS AND DYNAMICS, INCLUDING THE THEORIES OF CHEMICAL CHANGE, CATALYSIS, AND EXPLOSIONS. By J. W. MELLOR, D.Sc., B.Sc. 7s. 6d.

THE PHASE RULE AND ITS APPLICATIONS. By ALEX. FINDLAY, M.A., Ph.D., D.Sc., Lecturer and Demonstrator in Chemistry, University of Birmingham. With 134 Figures in the Text. 5 s.

SPECTROSCOPY. By E. C. C. BALY, F.I.C., Lecturer on Spectroscopy and Assistant Professor of Chemistry, University College, London. With 163 Illustrations. 10 s. $6 d$.

THERMOCHEMISTRY. By JULIUS THOMSEN, Emeritus Professor of Chemistry in the University of Copenhagen. Translated by KATHARINE A. BURKE, B.Sc. (Lond.), Assistant in the Department of Chemistry, University College, London. $9 s$.

ELECTRO-CHEMISTRY. PART I.-GENERAL THEORY. By R. A. LEHFELDT, D.Sc., Transvaal University College, Johannesburg. Including a Chapter on the Relation of Chemical Constitution to Conductivity, by T. S. MOORE, B.A., B.Sc., Lecturer in the University of Birmingham. $5 s$.

ELECTRO-CHEMISTRY. PART II.-APPLICATIONS TO ELECTROLYSIS, PRIMARY AND SECONDARY BATTERIES, ETC. By N. T. M. WILSMORE, D.Sc. [In preparation.

STEREOCHEMISTRY. By A. W. STEIVART, D.Sc., Carnegie Research Fellow. With 87 Illustrations. 10s. $6 d$.

THE THEORY OF VALENCY. By J. NEWTON FRIEND, Ph.D. (Würz), M.Sc. (Birmingham). 5s.

METALLOGRAPHY. By CECIL H. DESCH, D.Sc. (Lond.), Ph.D. (Wurzb.); Graham Young Lecturer in Metallurgical Chemistry in the University of Glasgow. With 14 Plates and 108 Diagrams in the Text. 9s.

THE RELATIONS BETWEEN CHEMICAL CONSTITUTION AND SOME PHYSICAL PROPERTIES. BY SAMUEL SMILES, D.Sc., Fellow of University College, and Assistant Professor of Organic Chemistry at University College, London University.

THERMODYNAMICS. By F. G. DONNAN, II.A., Ph.D. [In 1reparation. ACTINOCHEMISTRY. By S. E. SHEPPARD, D.Sc. [In preparation. PRACTICAL SPECTROGRAPHIC ANALYSIS. By J. H. POLLOK, D.Sc. [In preparation. 


\section{MONOGRAPHS ON BIOCHEMISTRY.}

Edited by R. H. ADERS PLIMIER, D.Sc., and F. GOWLAND HOPKINS, D.Sc., F.R.S.

Royal 8vo.

In these volumes an attempt is being made to make the subject of Biochemistry more accessible by issuing a series of monographs upon the various chapters of the subject, each independent of and jet dependent upon the others, so that from time to time, as new material and the demand therefor necessitate, a new edition of each monograph can be issued without reissuing the whole series. The expenses of publication and the expense to the purchaser will thus be diminished, and by a moderate outlay it will be possible to obtain a full account of any particular subject as nearly current as possible.

THE DEVELOPMENT AND PRESENT POSITION OF BIOLOGICAL CHEMISTRY. By F. GOWLAND HOPKINS, M.A., M.B., D.Sc., F.R.S.

[In preparation.

THE NATURE OF ENZYME ACTION. By W. M. BAYLISS, D.Sc., F.R.S., Assistant Professor of Physiology, University College, London. 3s. net.

THE CHEMICAL CONSTITUTION OF THE PROTEINS. By R. H. ADERS PLIMMER, D.Sc., Assistant Professor of Physiological Chemistry, University College, London. In 2 Parts. Part 1, 3s. net; Part 2, 2s. 6d. net.

THE GENERAL CHARACTERS OF THE PROTEINS. By S. B. SCHRYVER, D.Sc., Ph.D., Lecturer on Physiological Chemistry, University College, London. 2s. 6d. net.

THE VEGETABLE PROTEINS. By THOMAS B. OSBORNE, Ph.D., Research Chemist in the Connecticut Agricultural Experiment Station, New Haven, Connecticut ; Research Associate of the Carnegie Institution of Washington, D.C. $3 s .6 d$. net.

THE SIMPLE CARBOHYDRATES AND THE GLUCOSIDES. By E. FRANKLAND ARMSTRONG, D.Sc., Ph.D., Associate of the City and Guilds of London Institute. 3s. $6 d$. net.

THE FATS. By J. B. LEATHES, D.Sc.

[n the press.

THE POLYSACCHARIDES. By ARTHUR R. LING, F.I.C.

[In preparation.

COLLOIDS. By W. B. HARDY, M.A., F.R.S.

[In preparation.

ALCOHOLIC FERMENTATION. By H. HARDEN, D.Sc., F.R.S.

[In preparation.

II. $-5,000-$ A. v. P. $-\mathrm{iv} / 1910$. 






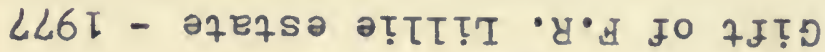

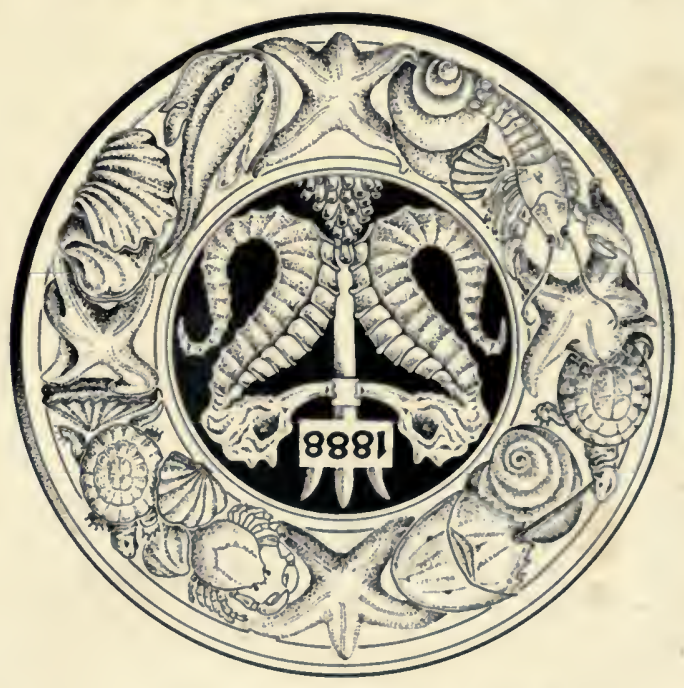

S772SกYJOSSOW "วоН SPOOM

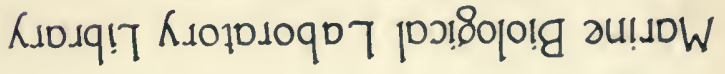


